\title{
Dictionnaire de politique sociale suisse
}

Jean-Michel Bonvin, Valérie Hugentobler,

Carlo Knöpfel, Pascal Maeder,

Ueli Tecklenburg (dir.)
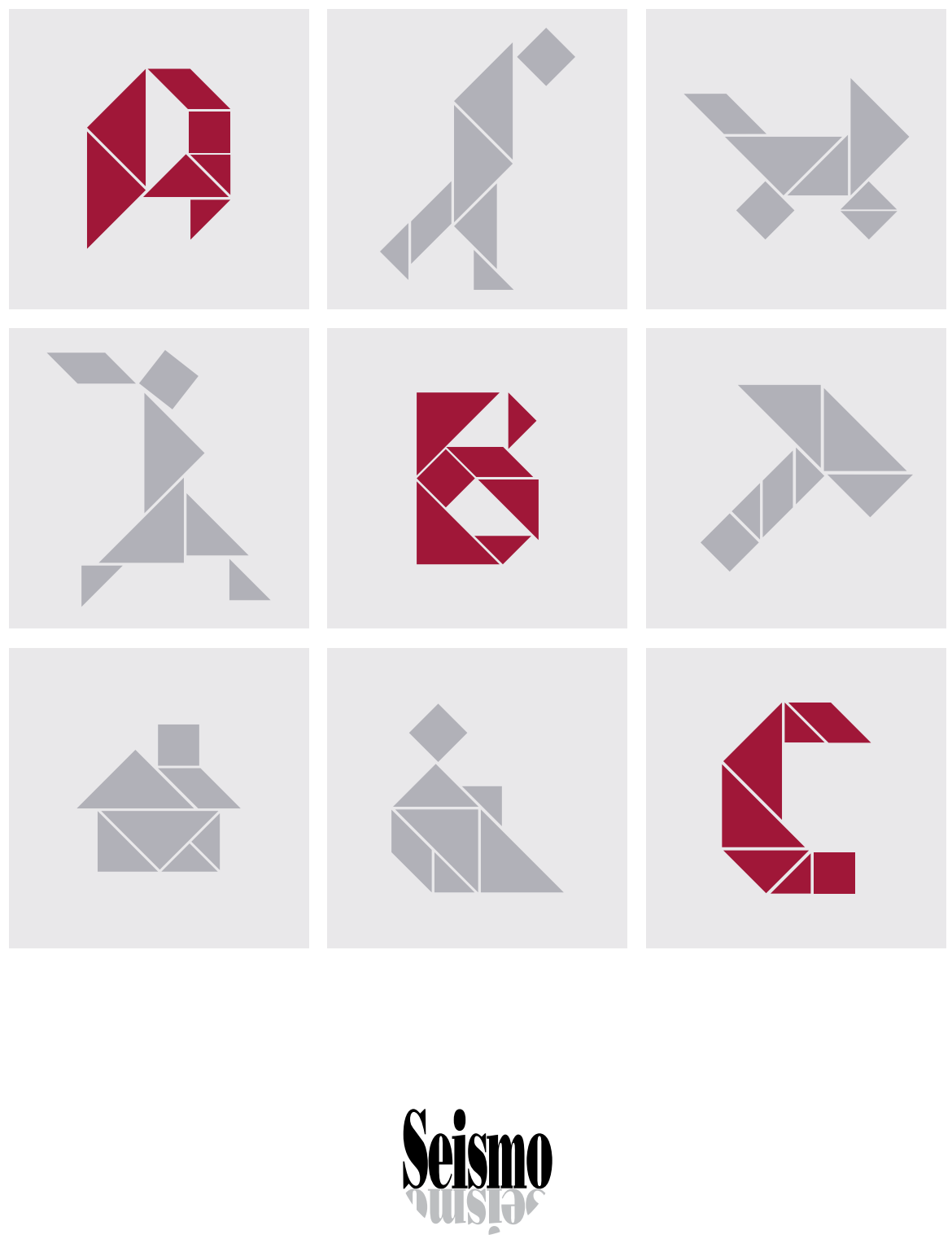
Dictionnaire de politique sociale suisse Jean-Michel Bonvin, Valérie Hugentobler, Carlo Knöpfel, Pascal Maeder et Ueli Tecklenburg (dir.) 



\section{Dictionnaire de politique sociale suisse}

Jean-Michel Bonvin, Valérie Hugentobler,

Carlo Knöpfel, Pascal Maeder et Ueli Tecklenburg (dir.) 
Publié avec le soutien des organisations suivantes : Académie suisse des sciences humaines et sociales; Association suisse de politique sociale; Domaine du travail social de la Haute école spécialisée de Suisse occidentale; Fonds de la loterie suisse des cantons d'Argovie, Bâle-Campagne, Bâle-Ville et Soleure; fondation anonyme à Genève; Haute école de travail social de la Haute école spécialisée du nord-ouest de la Suisse; Loterie romande ; Pôle de recherche national LIVES/Centre LIVES ; Société suisse d'utilité publique; VPS Verlag Personalvorsorge \& Sozialversicherung. Nous remercions le Fonds national suisse de la recherche scientifique pour le soutien de cette publication.

Titre de l'édition allemande

Wörterbuch der Schweizer Sozialpolitik

Publié par

Éditions Seismo, Sciences sociales et questions de société SA, Zurich et Genève www.editions-seismo.ch

info@editions-seismo.ch

Texte (c) les auteur·e.s 2020

ISBN 978-2-88351-088-3 (Print)

ISBN 978-2-88351-729-5 (PDF)

https://doi.org/10.33058/seismo.20729

Couverture: Vincent Freccia, COBRA Communication \& Branding, Lausanne

Cet ouvrage est couvert par une licence Creative Commons Attribution - Pas d'Utilisation Commerciale - Pas de Modification 4.0 International (CC BY-NC-ND 4.0) 


\section{Table des matières}

$\begin{array}{ll}\text { Préface } & 7\end{array}$

En guise d'introduction 9

$\begin{array}{ll}\text { Liste des concepts } & 13\end{array}$

Thèmes et responsables de rubriques 571

$\begin{array}{ll}\text { Liste des auteur·e·s } & 575\end{array}$

Liste d'institutions en lien avec les politiques sociales $\quad 589$ (sélection) 



\section{Préface}

Dans une société ayant atteint une rare complexité, les politiques sociales courent un risque sournois, celui de la méconnaissance, voire plus franchement de l'ignorance. Malgré leur importance cruciale pour les différentes catégories de la population et leur contribution indéniable à la cohésion sociale et à la prospérité, elles ne sont désormais qu'une préoccupation, qu'un enjeu, qu'un espace de revendications ou de rapports de force parmi d'autres. L'individualisme, la haute technicité juridique et financière des régimes sociaux ou les critiques récurrentes discréditant les institutions et politiques garantes de la solidarité ou de la redistribution expliquent, en partie du moins, l'émergence d'une forme de désintérêt pour la question sociale.

C'est que tout semble aller de soi! Pourtant, les politiques sociales n'ont de sens et ne continueront d'en faire que si l'on a conscience qu'elles s'inscrivent dans une histoire et se fondent sur des références conceptuelles fondamentales. Cette histoire est faite de revendications, de conflits, mais aussi de pragmatisme consensuel pour trouver une issue positive à des souffrances devenues insoutenables. Elle a porté et légitimé des principes, des modes d'organisation et des types et niveaux de prestations. Ces références, on ne saurait les balayer d'un revers de main ou les ignorer, car elles constituent le socle qui ancre les innombrables déclinaisons de la solidarité.

Certes, l'ensemble ainsi construit est imparfait, mais il a le mérite fondamental d'exister. Au gré des transformations des modes de vie, des mutations économiques et des rapports de force, les politiques sociales évoluent. Ce mouvement est inéluctable, quand bien même son sens peut être remis en cause. C'est pour cela qu'il nous faut disposer de repères. Repères destinés à rassembler les acteur.trice-s impli-

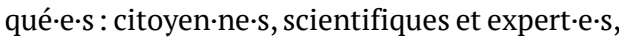
autorités politiques et administratives, par-

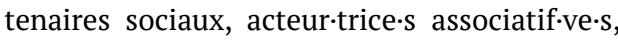
personnes protégées et bénéficiaires de prestations. Repères ayant pour ambition de rendre compte de la richesse de ce vaste domaine, des principes qui le sous-tendent, de ses effets, des enjeux qui le caractérisent et des défis à relever. Telle est l'essence du Dictionnaire de politique sociale suisse.

L’ambition affirmée de disposer d'un outil scientifique destiné à la fois au grand public et à des publics spécialisés, y compris les étudiant·e-s appeléee-s à se former dans ce domaine, est noble. Elle s'inscrit dans la nécessité de rapprocher science et société et dans la volonté de bâtir des ponts. La richesse du contenu, la diversité des thèmes et des approches et sa publication en français et en allemand constituent un formidable vecteur de partage des connaissances et de rapprochement des cultures, des champs d'activité, des catégories de la population.

Le dictionnaire s'avère un formidable vecteur de communication. On s'immerge dans une diversité conceptuelle et institutionnelle parfois peu connue ou simplement ignorée. On découvre les contenus et les déclinaisons de l'interdisciplinarité. On décortique l'ancrage de ces domaines au sein des politiques publiques. On perçoit la somme d'engagements individuels et collectifs, publics et privés qui portent la solidarité. On rend intelligible et accessible ce qui souvent rebute.

Et puis, cette nouvelle édition du Dictionnaire de politique sociale suisse s'inscrit dans la continuité des démarches pionnières des éditions précédentes, à savoir: une base scientifique rigoureuse, une mise en contexte et en perspective des concepts, un solide ancrage institutionnel des auteur.e-s et une structure uniforme. Par la pluralité des thèmes et des concepts de référence ou par leur mise en perspective, l'ouvrage constitue ainsi un véritable support de connaissances et un outil de travail précieux. 
Le Dictionnaire de politique sociale suisse parvient donc, au-delà de la technicité des concepts qui le composent, à créer un espace de compréhension, d'échange ou de rencontre mis à disposition de publics différents, avisés ou simplement curieux. L'ouvrage explore un univers de connaissances plurielles, spécialisées et étroitement reliées les unes aux autres. Il facilite le dépassement des frontières qui sous-tendent la construction des savoirs et contribue à la compréhension d'un certain nombre de mécanismes de fonctionnement de notre société. Il stimule le partage nécessaire à la pérennisation des conditions du Vivre ensemble et d'accomplissement de la solidarité.

Que les initiant.e.s et les auteur.e.s soient sincèrement remercié·e-s pour cette précieuse réalisation.

Stéphane Rossini, Directeur de l'Office fédéral des assurances sociales 


\section{En guise d'introduction}

La politique sociale représente un pan important des États sociaux modernes. Elle promeut la cohésion sociale, protège les personnes contre les risques sociaux et veille à ce que des ressources adéquates soient mises à disposition des personnes vulnérables afin de prévenir, contrer ou surmonter les situations de vie et de nécessité les plus difficiles. Elle touche à des domaines politiques aussi variés que les finances, le logement, la famille, la santé, le travail ou la formation, en même temps elle est enracinée dans des conceptions normatives qui imprègnent et «normalisent» les parcours de vie. La politique sociale est ainsi multidimensionnelle et a des implications ambivalentes pour les personnes concernées: d'un côté source d'émancipation et d'empowerment, de l'autre facteur de subordination et de standardisation.

Cette édition du Dictionnaire de politique sociale suisse vise à mieux comprendre les mécanismes sous-jacents de cette complexité et à les rendre accessibles à un large public. À cette fin, elle privilégie des articles courts, qui présentent de manière synthétique les aspects essentiels et les défis pour la pratique quotidienne, l'étude, l'enseignement et la recherche.

Deux éditions précédentes du Dictionnaire de politique sociale suisse sont parues en 1998 et 2002 en français et une en allemand en 2003'. De même que la présente édition, elles émanaient de personnes pionnières, membres de l'Association suisse de politique sociale, ayant mené une réflexion approfondie et contribué à développer la politique sociale dans ses soubassements normatifs et ses contenus substantiels. Le monde a profondément changé depuis ce temps-là. Les banques de données électroniques, mobilisables depuis des tablettes, des

1 Editées par Jean-Pierre Fragnière et Roger Girod pour les versions en langue française et par Erwin Carigiet, Ueli Mäder et Jean-Michel Bonvin pour la version en langue allemande. ordinateurs ou des téléphones mobiles, ont remplacé dans une large mesure les manuels de référence, dont les entrées classées par ordre alphabétique permettaient au lectorat d'obtenir, de manière concise, les contenus et points de référence importants sur la notion ou le thème recherché. L'index prolongeait souvent les dernières pages du manuel de référence avec une liste de concepts-clés et une table des matières.

Pourquoi aurions-nous encore besoin d'un dictionnaire à l'époque de Wikipedia et des plateformes digitales? Par rapport à ces sources d'information digitales, qu'elles soient accessibles de façon payante ou gratuite, le Dictionnaire de politique sociale suisse se distingue sur plusieurs points. Tout d'abord, il fait le lien entre une connaissance scientifiquement expertisée et validée et une expertise professionnelle dans les champs pertinents de la politique sociale. Pas moins de 245 expertes et experts de la Suisse et au-delà ont été impliquée.e-s comme auteur.e.s dans la rédaction du dictionnaire. Ils et elles ont été approché·e·s par 21 responsables thématiques, en lien avec l'équipe éditoriale, et accompagné·e-s sur le long chemin vers la publication du dictionnaire. Un peu plus des deux tiers d'entre elles et eux sont actif.ive-s dans des établissements académiques dans différentes disciplines (sciences humaines, droit, sciences sociales et économiques), environ un tiers émanent d'organisations non gouvernementales, d'administrations, d'entreprises privées et d'autres organisations. Les responsables thématiques reflètent également cette variété de perspectives, même si les représentants du monde académique sont majoritaires parmi eux. En collaboration avec l'équipe éditoriale, toutes et tous se sont impliqué·e-s dans la déclinaison du thème général en 8 à 15 concepts plus spécifiques, ainsi que dans l'évaluation minutieuse des versions rendues par les auteur·e-s.

La collaboration avec le Pôle de recherche national «LIVES - surmonter la vulnérabilité 
dans les parcours de vie» (PRN LIVES) a également été cruciale pour la réalisation du dictionnaire, notamment son pôle «transfert de connaissances » porté par la Haute école spécialisée de Suisse occidentale (HES-SO). La composition de l'équipe éditoriale atteste de ce lien entre monde scientifique et recherche appliquée, car à l'exception d'une personne au bénéfice d'une reconnaissance nationale dans les associations et administrations du champ de la politique sociale, tous les membres de l'équipe éditoriale sont actifs à la fois dans l'Association suisse de politique sociale et dans le champ académique, en particulier à l'Université de Genève, qui assume le co-leadership du Pôle LIVES financé par le Fonds national de la recherche suisse (FNS) avec l'Université de Lausanne, la Fachhochschule Nordwestschweiz (FHNW) et la HES-SO.

D'autre part, le nouveau Dictionnaire de politique sociale suisse se démarque, car il inclut les thèmes de la politique sociale au sens le plus large et éclaire les enjeux de politique sociale liés aux domaines de vie les plus variés, de la petite enfance au plus grand âge. Ainsi se côtoient dans le dictionnaire des concepts relatifs à l'action sociale et la sécurité sociale, au logement, à la santé ou encore la sexualité. En partant de notions générales comme la formation, le travail ou le handicap, les différentes entrées sont rassemblées en 20 thématiques générales, qui sont déclinées suivant les cas en fonction de leurs aspects spécifiques (p.ex. l'entrée dans la vie professionnelle, l'inclusion, le chômage, etc.) ou de leurs mesures, structures ou manifestations propres (p.ex. l'école obligatoire, l'assurance-chômage, les effets de seuil, etc.).

En comparaison avec les ouvrages de référence existants, le nouveau Dictionnaire de politique sociale suisse est en outre structuré de façon à ce que chacune de ses entrées place la focale principale sur les liens entre les champs politiques les plus divers, afin d'englober tous les aspects pertinents pour les politiques sociales et de les expliquer de manière compréhensible pour un large public. Les 251 concepts réunis dans ce dictionnaire s'étendent tous sur une page et demie à deux pages et demie et sont structurés de la même façon, même si les points essentiels sont mis en lumière différemment suivant le thème concerné. Après une brève définition et description de l'objet $\mathrm{du}$ concept, suivent les aspects historiques, économiques, sociaux et juridiques. Ensuite, le lectorat se familiarise dans la plupart des cas avec les spécificités de la politique sociale suisse en comparaison internationale, pour conclure sur une appréciation critique sur les enjeux actuels et futurs de la politique sociale en Suisse et au-delà. Jusqu' à trois références bibliographiques accompagnent chacun des concepts.

Ce n'est pas le moindre mérite de cette nouvelle édition de paraître simultanément dans deux langues nationales, cela pour la première fois dans le champ de la politique sociale en général et pour le dictionnaire en particulier. Cela contribue à surmonter les obstacles liés aux différences linguistiques et culturelles, qui imprègnent aussi le champ de la politique sociale. Ainsi, le concept Selbsthilfe n'a pas d'équivalent français et sa traduction par le terme «entraide» peut être décrite comme imparfaite. La même remarque vaut pour des termes comme participation ou inclusion, qui en allemand ont un sens et une compréhension différents ${ }^{2}$. Cela illustre bien les efforts de traduction qui ont dû être déployés pour ce dictionnaire, lequel est donc aussi un instrument de communication interculturelle et inter-régionale sur les questions de politique sociale.

L'édition de ce dictionnaire a demandé un travail considérable qui s'est étendu sur plusieurs années. Nous tenons ici à adresser notre

2 À noter que le titre d'un concept suivi d'un ou plusieurs astérisques indique qu'il s'agit d'un concept traduit: un astérisque (*) pour un concept dont la version originale a été rédigée en allemand, deux astérisques $\left.{ }^{* * *}\right)$ pour l'italien. 
gratitude et nos remerciements à plusieurs personnes et organisations dont la contribution et le soutien ont été indispensables. En premier lieu, les auteur·e.s et les expert·e.s, qui ont mis tout leur savoir et leur énergie au service de cette entreprise de longue haleine. Ensuite, cette nouvelle édition n'aurait pu voir le jour sans le soutien généreux d'un certain nombre de fondations, associations et autres instances, parmi lesquelles la Loterie romande, l'Académie suisse des sciences humaines, la Société suisse d'utilité publique, les Loteries des cantons d'Argovie, Bâle-Campagne, Bâle-Ville et Soleure, une fondation genevoise anonyme, la VPS Verlag Personalvorsorge und Sozialversicherung $A G$, le PRN LIVES, la FHNW et la HES-SO. Nos remerciements vont aussi au FNS pour le financement de la version open access de ce dictionnaire. Sans l'appui et le soutien de toutes ces personnes et organisations, cette nouvelle édition du Dictionnaire de politique sociale suisse n'aurait pas pu être publiée. Nous espérons qu'elle trouvera le public très large qu'elle mérite auprès des spécialistes de politiques sociales, des étudiant·e.s, des acteurs et actrices de la politique sociale suisse et des autres milieux intéressés. Compte tenu de la pandémie du coronavirus qui s'étend actuellement à l'échelle globale, il est d'autant plus important de comprendre et de situer la contribution des politiques sociales au traitement des questions sociales et des problèmes sociaux.

Les éditeur·e·s, octobre 2020 



\section{Liste des concepts}



Abus

Accords bilatéraux

Accueil extrafamilial et extrascolaire des enfants

Action sociale (système d')

Activation

Activité professionnelle personnes en situation handicapées

Addiction

Âge

Âgisme

Aide à l'enfance et à la jeunesse

Aide au logement

Aide aux victimes d'infractions

Aide en matière d'addictions

Aide sociale

Aide sociale dans le domaine de l'asile

Aide sociale et genre

Aide sociale (groupes à risque)

Aide sociale pour les Suisses et les

Suissesses de l'étranger

Aides à l'éducation

Allocation familiale

Amour du prochain

Animation socioculturelle avec des enfants et des jeunes

Asile

Assurance-accidents

Assurance-chômage

Assurance-invalidité

Assurance-invalidité (révisions législatives) 77

Assurance-maladie

Assurances sociales

Assurances sociales et genre

Assurance-vieillesse et survivants

Austérité

Bien-être

Biens communs

Calcul des risques et science actuarielle

Capabilités

Capital social

Case management

Changement social

Chômage
19 Chômage de longue durée 107

20 Citoyenneté 109

Collaboration interinstitutionnelle $\quad 112$

23 Configurations familiales 114

25 Conservatisme 116

27 Contrat de prestations 118

29 Contrat de travail 120

Contribution d'assistance (vie autonome 122

32 avec assistance personnelle)

34 Convention collective de travail 124

36 Convention de l'ONU relative aux droits 127

38 des personnes en situation de handicap

41 Corporatisme 129

43 Délinquance et politique criminelle 131

45 Délinquance des femmes 133

48 Délinquance juvénile 135

50 Démocratie directe 138

52 Démographie sociale 140

55 Dépenses de santé 142

57 Dépenses publiques 144

Développement urbain $\quad 147$

59 Dignité humaine 149

61 Diversité 151

63 Divorce 153

66 Droit de l'aide sociale 155

Droit de la famille $\quad 158$

68 Droit des assurances sociales 160

70 Droit du bail 162

73 Droit du travail 164

75 Droit pénal des mineur·e·s 166

77 Droit social 169

79 Droits de l'enfant 171

81 Droits des patient.e.s 173

84 Droits humains 175

86 Droits LGBT (évolution des) 178

88 Droits procéduraux 180

90 Durabilité sociale 182

93 École inclusive (élèves en situation de 184

95 handicap)

97 École obligatoire 187

99 Écologie 189

101 Économie solidaire 191

103 Éducation 193

105 Éducation de la petite enfance 195 
Péréquation

Placement à des fins d'assistance

Planification sociale

Politique budgétaire

Politiques de la dépendance

Politique de la famille

Politique de la reproduction

Politique de la santé

Politique de la vieillesse

Politique de l'éducation

Politique de l'égalité

Politique de l'emploi

Politique des addictions

Politique du handicap

Politique du logement

Politique économique

Politique financière

Politique monétaire

Politiques et pratiques policières

Politique sociale

Précarité*

Prestations complémentaires à l'AVS et à l'AI

Prestations complémentaires pour familles 416

Prestations sociales sous condition de ressources

Prévention de la criminalité

Prévention des addictions

Prévention et promotion de la santé

Prévoyance professionnelle

Prix

Procédure pénale

Processus décisionnels en politique sociale 435

Professions de la santé

Prostitution

Protection contre la discrimination

Protection de l'adulte

Protection des consommateurs et des consommatrices

Protection des mineur.e.s

Protection des travailleur.euse-s

Rationnement dans le secteur de la santé

Réadaptation

Recherche en politique sociale
367 Redistribution

459

370 Réforme de la sécurité sociale 461

372 Régime fiscal 464

374 Régimes d'État-providence 466

376 (de protection sociale)

379 Regroupement familial 468

381 Relations de travail (atypiques) 470

383 Relations de travail 472

385 Répartition de la fortune 474

387 Répartition du revenu 476

390 Resocialisation 478

392 Responsabilité 480

394 Responsabilité sociale des entreprises 483

396 Retraite 485

398 Risques sociaux 487

400 Salaire 489

403 Sanctions pénales 491

405 Sans-abrisme 493

407 Santé 495

409 Santé des personnes âgées 497

412 Santé mentale 499

414 Santé sexuelle 502

Sécurité sociale 504

Sécurité sociale des enfants et des jeunes 506

419 Sécurité sociale (financement) 508

Sécurité sociale (propositions $\quad 510$

421 d'alternatives)

423 Sexualité(s) 512

426 Socialisme 514

428 Soins de longue durée 516

430 Soins de santé aux personnes âgées $\quad 519$

433 Soins médicaux 521

435 Solidarité 523

437 Statistique sociale 525

439 Statut d'étranger et aide sociale 528

441 Subsidiarité 530

444 Surendettement 532

446 Temps de travail 534

Travail 536

448 Travail «au noir» 539

450 Travail de care (care work) 540

453 Travail domestique 543

455 Travail frontalier 545

457 Travail social 547 
Travail social (histoire)

549

Travail social en milieu scolaire

551

Travailleur-euse pauvre

554

Trois piliers (principe des)

556

Vieillissement de la population

558

Vieillissement des publics vulnérables

560

Violences de genre

562

Vulnérabilité

564

Xénophobie

566 


\section{Abus $^{*}$}

Utilisé de multiples manières dans le domaine de la sécurité sociale, le terme d'abus n'est toutefois pas clair. D'un point de vue juridique, la notion d'abus peut être interprétée selon cinq approches différentes. Une première interprétation possible de l'abus social serait l'obtention préméditée et illicite de prestations d'une assurance sociale ou de l'aide sociale. Une deuxième interprétation, plus étroite, est mobilisée lorsque le terme d'abus est employé pour qualifier une situation où, en plus de la préméditation, l'intention de s'enrichir motive le comportement de l'auteur.e.

Troisièmement, une interprétation encore plus étroite est possible en analogie avec le concept d'abus de droit, généralement rencontré dans la jurisprudence: il y a abus de droit lorsqu'une institution juridique, telle que l'aide sociale ou les assurances sociales, est utilisée de manière contraire au but prévu pour servir des intérêts que cette institution ne souhaite pas protéger. L'interdiction de l'abus de droit est étroitement liée au principe de bonne foi et constitue un principe juridique général pour l'ensemble du système juridique. Dans ce sens étroit, il ne pourrait être question d'abus que si, par exemple, quelqu'un provoquait ou maintenait délibérément une situation de détresse ou une condition d'octroi afin d'obtenir des prestations du système de sécurité sociale. Selon un arrêt du Tribunal fédéral, l'abus doit être incontestable et évident. L'aspect spécifique réside ici dans le fait que le cas d'assurance ou la condition d'octroi de prestations sont délibérément visés avec une intention directe et que cela semble évident et sans ambiguïté.

Une quatrième interprétation beaucoup plus large de l'abus dans le domaine des prestations sociales est possible lorsque l'on classifie comme abusives des prestations obtenues en dehors des règles du régime social, non seulement de manière intentionnelle ou délibérée mais aussi par négligence voire négli- gence grave. Une telle interprétation de l'abus est inhérente, par exemple, à la suspension du droit aux indemnités journalières de chômage lorsqu'une personne se retrouve au chômage par sa propre faute. Dans le domaine de l'assurance-accidents également, une réduction des indemnités journalières est possible en cas de négligence grave dans la cause de l'accident, sans que cela ne soit toutefois explicitement qualifié d'abus par la loi.

Cinquièmement, on parle également d'abus dans la pratique lorsque des personnes perçoivent des prestations de la sécurité sociale de manière légitime mais les utilisent ensuite délibérément de manière illégitime, c'està-dire d'une manière inappropriée. Dans ce contexte, l'obtention des prestations n'est certes pas illicite, mais leur utilisation n'est pas conforme à leur but.

La législation suisse mentionne explicitement et sanctionne l'abus de prestations sociales à divers endroits, comme dans la Constitution fédérale telle qu'amendée sur la base d'une initiative populaire: selon l'article 121 de la Constitution fédérale, les étranger-ère·s sont privé·e·s de leur titre de séjour, indépendamment de leur statut, et de tous leurs droits à séjourner en Suisse si, entre autres, ils·elles ont perçu abusivement des prestations des assurances sociales ou de l'aide sociale. Dans ce contexte, le $1^{\text {er }}$ octobre 2016, le Code pénal (CP) a été complété par une disposition qui prévoit que quiconque, par des déclarations fausses ou incomplètes, en passant des faits sous silence ou de toute autre façon, induit une personne en erreur ou la conforte dans son erreur, et obtient de la sorte pour luimême ou pour elle-même ou pour un tiers des prestations indues d'une assurance sociale ou de l'aide sociale, est puni d'une peine privative de liberté d'un an au plus ou d'une peine pécuniaire. Dans les cas de peu de gravité, la peine est une amende. En application de l'article 121 de la Constitution fédérale, la conséquence juridique d'un tel acte est l'expulsion. 
En outre, la loi fédérale sur la partie générale du droit des assurances sociales (LPGA) prévoit que les abus résultant de la provocation intentionnelle de la réalisation d'un risque assuré peuvent entraîner une réduction des prestations ou leur suspension (article 21). Il en va de même pour l'aide sociale dans de nombreuses lois cantonales sur l'aide sociale ainsi que dans les normes de l'aide sociale de la Conférence suisse des institutions d'action sociale (CSIAS), sans que la notion d'abus ne se retrouve généralement dans ces normes. De plus, dans le domaine des assurances sociales (article 25 LPGA) ou de l'aide sociale (voir les règles spéciales de remboursement correspondantes dans les lois cantonales sur l'aide sociale), il existe des clauses spéciales de remboursement en cas de prestations indûment touchées.

Enfin, l'extension du droit pénal à compter du $1^{\text {er }}$ octobre 2016 prévoit des sanctions pénales pour certains cas d'abus liés à une obtention illicite intentionnelle. Bien entendu, des sanctions peuvent également s'appliquer dans le cas d'autres comportements relevant du droit pénal, tels que la falsification de documents ou la fraude. Les lois sur la sécurité sociale et certaines lois cantonales sur l'aide sociale prévoient des contraventions en complément.

Dans le discours public, comme on le voit dans les médias et en politique, le concept d'abus est utilisé de manière non spécifique et imprécise, souvent en relation avec la dénonciation et la scandalisation vis-à-vis des dysfonctionnements du système social. De la même manière, la notion d'abus est également utilisée dans d'autres discours politiques, tels que la scandalisation vis-à-vis des infractions liées à l'obligation fiscale. Dans le domaine social, la notion d'abus s'applique à diverses formes d'obtention non conformes, réelles ou alléguées, de prestations. Dans ce contexte, un comportement inapproprié des demandeur.euse-s de prestations est également parfois qualifié d'abus social (p.ex. le non-respect des rendez-vous), alors même qu'il n'a rien à voir avec un déroulement non conforme aux règles des prestations sociales. En outre, le discours politique qualifie ou traite même parfois d'abusif le simple exercice du droit de percevoir des prestations de l'État social. Toutefois, une telle utilisation du terme est par définition et juridiquement inadmissible. Dans l'ensemble, l'utilisation du terme «abus» dans le discours public tend à individualiser de manière simpliste les problèmes sociaux de la pauvreté et du chômage ou à les attribuer de façon excessive à certains groupes.

\section{Peter Mösch Payot}

\section{Références}

Bonvin, J.-M. \& Nadai, E. (Éd.) (2013). La question de l'abus dans le travail social et les politiques sociales. Schweizerische Zeitschrift für Soziale Arbeit - Revue suisse de travail social, 13.

Mösch Payot, P. (2008). ,,Sozialhilfemissbrauch?!“ Sozialhilfemissbrauch, unrechtmässiger Leistungsbezug und sozialhilferechtliche Pflichtverletzung: Begriffsklärung, Rechtsgrundlagen und Sanktionen. In C. Häfeli (Hrsg.), Das Schweizerische Sozialhilferecht: Rechtsgrundlagen und Rechtsprechung (S. 279-321). Luzern : Interact.

Schleicher, J. (2016). Sozialhilferecht. In P. Mösch Payot, J. Schleicher \& M. Schwander (Hrsg.), Recht für die Soziale Arbeit: Grundlagen und ausgewählte Aspekte (4., akt. Aufl., S. 263-289). Bern : Haupt.

\section{Accords bilatéraux}

Les accords bilatéraux entre la Suisse et l'Union européenne (UE) sont une série d'accords qui règlent les relations entre la Suisse et les pays de l'UE dans de nombreux domaines, comme la libre circulation des personnes, la circulation routière, la fiscalité de l'épargne ou le transport aérien. Dans le domaine des politiques sociales, l'enjeu le plus important concerne la libre circulation des personnes, qui a entraîné le renforcement de la coordination des sys- 
tèmes nationaux de protection sociale, ainsi que le développement de mesures pour protéger le marché du travail contre la sous-enchère salariale.

Le processus de négociation des accords bilatéraux a commencé au lendemain du rejet par le peuple de l'accord sur l'Espace économique européen en 1992. La première série d'accords (agriculture; libre circulation des personnes; marchés publics; obstacles techniques au commerce; recherche; transport aérien ; transports terrestres) a été acceptée par $67,2 \%$ du peuple le 21 mai 2000 . Le deuxième volet (entre autres: Schengen-Dublin; environnement; fiscalité de l'épargne) a été conclu en 2004 et l'arrêté fédéral sur les accords de Schengen et Dublin a été accepté à $54,8 \%$ en juin 2005. Suite à l'élargissement de l'UE à 10 nouveaux pays membres en 2004, puis à la Roumanie et la Bulgarie en 2007 et la Croatie en 2013, les accords de libre circulation ont été étendus à ces pays, avec des durées transitoires.

Le volet le plus controversé de ces accords a sans doute été celui de la libre circulation des personnes, dans la mesure où il a progressivement ouvert le marché du travail suisse aux travailleurs et travailleuses de l'UE, et mis fin au système de quotas d'immigration qui prévalait depuis les années 1960. Puisque les ressortissant-e.s de l'UE peuvent désormais venir travailler en Suisse sans restrictions, cela a créé un besoin de coordination entre les systèmes de protection sociale. Cette coordination repose sur 5 principes de base.

Le premier est que les cotisations sociales sont versées dans le pays du lieu de travail. Une personne n'est en principe soumise aux dispositions que d'un seul pays en matière de législation sociale. Ce principe est facile à comprendre dans le cas des travailleur-euse-s étranger·ère-s résidant en Suisse, mais il est plus compliqué pour ce qui concerne les travailleur-euse-s frontalier-ère-s ou détaché·e-s de manière temporaire en Suisse. Dans ce der- nier cas, les cotisations peuvent être acquittées dans le pays de résidence.

Le second principe est celui de l'égalité de traitement, c'est-à-dire qu'une personne a en principe les mêmes droits et obligations que les ressortissant.e.s du pays dans lequel elle est assurée. Si ce principe semble aller de soi, il n'a pas toujours été la règle pour les personnes étrangères employées en Suisse, par exemple les titulaires de permis saisonniers ne résidant pas toute l'année en Suisse, dont l'accès aux programmes sociaux était limité.

Le troisième est la possibilité d'exporter les prestations à l'étranger. Par exemple, les rentes assurance-vieillesse et survivants (AVS) peuvent être versées à l'étranger si la personne a contribué à cette assurance en Suisse durant au moins une année. Il y a toutefois des exceptions concernant certaines politiques, comme l'assurance-chômage où les prestations ne peuvent être perçues qu'au maximum trois mois durant une recherche d'emploi à l'étranger. Les prestations du deuxième pilier peuvent également être perçues à l'étranger ; par le passé, le capital du deuxième pilier pouvait être perçu en espèces par les personnes qui quittaient la Suisse.

Le quatrième principe est celui de la totalisation, c'est-à-dire que la durée des cotisations effectuées à l'étranger est prise en compte dans le calcul des conditions d'octroi des indemnités sociales. Dans la perspective d'un marché du travail européen, cela évite que les personnes qui changent de pays soient désavantagées dans les programmes sociaux dont les prestations requièrent une durée minimale de cotisation (ce qui est le cas de l'assurance-chômage, p.ex.).

Le cinquième et dernier principe est l'obligation de coopération entre les États membres, notamment dans l'échange d'informations et le versement des prestations. Il faut noter que les révisions récentes de la loi sur l'assurance-chômage et de la loi sur les étrangers ont rendu plus difficile l'accès aux prestations sociales 
en Suisse pour les personnes étrangères afin de prévenir le «tourisme social», notamment en étendant la période de cotisation requise, et en permettant de retirer le permis de séjour aux personnes qui dépendent de l'aide sociale.

La deuxième implication importante des accords bilatéraux pour les politiques sociales concerne le système des relations de travail et la protection contre la sous-enchère salariale. Dans la mesure où l'on a mis fin au contrôle préalable des conditions d'emploi dans l'octroi des permis de travail, et où la Suisse ne possède pas de salaire minimum légal, les syndicats ont demandé des mesures d'accompagnement pour protéger le marché du travail contre la sous-enchère salariale. Ces mesures ont été acceptées à contrecœur par les associations patronales et les partis de droite, mais étaient une condition posée par la gauche pour soutenir les accords bilatéraux. Ces mesures ont consisté dans l'adoption d'une loi sur les travailleur·euse-s détaché·e·s, l'extension facilitée des conventions collectives de travail (CCT), la possibilité d'introduire des contrats-types de travail fixant des salaires minimaux, et le renforcement des contrôles par l'engagement d'inspecteur-trice-s des conditions de travail.

La loi sur les travailleur·euse-s détaché·e-s oblige, d'une part, les entreprises étrangères qui détachent des employé·e·s en Suisse à offrir les conditions de rémunération et de travail minimales en vigueur en Suisse. Ainsi, ce sont les standards du pays où la prestation est offerte qui prévalent. D’autre part, en cas de sous-enchère «abusive et répétée» (un terme laissé délibérément vague par le législateur, laissant une marge de manœuvre aux autorités de surveillance du marché du travail), les dispositions des conventions collectives peuvent être plus facilement étendues et rendues contraignantes dans une branche, un secteur ou une région déterminée. Dans les secteurs sans convention collective, les autorités publiques ont la possibilité d'établir des contrats-types de travail fixant des standards minimaux contraignants.
Lors de l'extension de l'accord sur la libre circulation aux nouveaux pays membres, les partenaires sociaux ont par ailleurs négocié un système renforcé de mise en œuvre impliquant des commissions tripartites cantonales chargées de contrôler le marché du travail, ainsi que l'engagement de personnel d'inspection chargé de vérifier le respect des conventions collectives et des standards minimaux.

Notons qu'indépendamment des dispositions additionnelles pour lutter contre la sous-enchère, le nombre de conventions collectives étendues et rendues contraignantes a augmenté depuis l'introduction de la libre circulation. Un nombre important de petites entreprises dans des secteurs comme la sécurité ont cherché à obtenir l'extension des conventions collectives pour se protéger contre la concurrence d'entreprises étrangères qui pourraient pratiquer des salaires plus bas en l'absence de normes salariales contraignantes. Néanmoins, si l'on peut considérer que les accords bilatéraux ont entraîné un mouvement de re-régulation du marché du travail, l'efficacité de la mise en œuvre et la protection effective des conditions de travail dans un marché ouvert restent incertaines.

\section{Alexandre Afonso}

\section{Références}

Afonso, A. (2012). Employer strategies, cross-class coalitions and the free movement of labour in the enlarged European Union. Socio-Economic Review, 10(4), 705-730.

Church, C.H. (Ed.) (2005). Switzerland and the European Union: a close, contradictory and misunderstood relationship. London: Routledge.

Kahil-Wolff, B. (2016). La coordination européenne des systèmes nationaux de sécurité sociale. In U. Meyer (Hrsg.), Soziale Sicherheit / Sécurité sociale (3. Aufl., S. 161-211). Basel : Helbing Lichtenhahn. 


\section{Accueil extrafamilial et extrascolaire des enfants}

En Suisse, l'accueil extrafamilial et extrascolaire des enfants se voit à tous les niveaux, politiques, économiques, privés, prioritairement posé autour de la conciliation entre vie professionnelle et vie familiale, et ce dans un contexte de pénurie de l'offre, en dépit d'efforts considérables consentis en la matière. En effet, le nombre de mères qui doivent ou qui souhaitent se maintenir sur le marché de l'emploi après la naissance de leur enfant est en constante progression.

L'établissement d'une typologie des modes d'accueil constitue un exercice délicat, tant ceux-ci présentent des dénominations et des contours variables. Globalement, outre la prise en charge informelle assurée par l'entourage des parents, on distingue trois types d'offres réglementées, parfois privées, le plus souvent subventionnées, voire publiques. Il s'agit d'une part de l'accueil familial de jour, d'autre part de l'accueil en collectivité, lequel comprend les équipements parascolaires (avant et après l'école, repas de midi) et les institutions préscolaires. Ces dernières se différencient selon leurs prestations : celles qui ont un horaire d'ouverture restreint (jardins d'enfants, groupes de jeux), celles dont l'horaire d'ouverture élargi, sur la journée, sur la semaine, sur l'année, correspond, en théorie, à l'horaire de travail des parents (crèches-garderies).

L'accroissement du nombre de familles d'accueil reconnues est indéniable. Comme toute offre publique d'accueil, cette prise en charge est régie par une ordonnance fédérale, dont les modalités d'octroi d'agrément varient selon les cantons. Ces dernières années ont été mis en place dans certains cantons plusieurs réseaux de coordination, afin d'encourager l'amélioration des conditions de placement.

Le développement du secteur parascolaire s'inscrit au sein d'un programme plus vaste, l'accord intercantonal sur l'harmonisation de la scolarité obligatoire, incluant notamment l'idée d'école à journée continue, accepté par votation en 2006, et qui a donné lieu à un concordat (HarmoS). Pour qu'il soit mis en œuvre, dix cantons au moins devaient l'approuver, ce qui fut le cas. En termes de prestations, ce concordat n'oblige cependant pas à l'adoption d'un modèle unique pour toute la Suisse. Il existe par exemple une forte variabilité des horaires, des tarifs et de leurs formes de calcul (liées au revenu familial, à la situation financière de la commune, etc.).

Sans que des données à l'échelon national soient précisément documentées, mais avec des variations sensibles entre cantons, ces deux dernières décennies ont vu une forte augmentation du nombre de crèches-garderies. La Confédération n'est pas étrangère à cette augmentation. Entrée en vigueur en 2003 pour une durée initialement limitée, régulièrement reconduite, une loi fédérale vise à encourager le développement de places d'accueil. En complément de ce programme d'impulsion, afin de soutenir le maintien des femmes qualifiées dans le marché du travail, les Chambres fédérales ont débloqué, en 2017, une aide substantielle destinée aux familles avec, également en perspective, un relèvement de la déduction fiscale pour frais de garde.

Il n'en demeure pas moins un décalage important entre l'offre et les demandes de placement. Outre une pénurie éprouvée directement par les familles, en particulier pour ce qui touche à la réception des tout-petits, qui demande un ratio adulte/enfants plus exigeant, subsiste la question, négligée, de l'intensification des horaires de travail atypiques.

Accueillir un petit enfant en de bonnes conditions présente un coût certain, qui donne lieu à des débats vivaces. Le financement et, partant, le coût direct pour les usager-ère-s de crèches-garderies font l'objet d'une grande diversité en Suisse. Le principe confédéral de subsidiarité trouve ici sa pleine expression. Depuis quelques années, en particulier en 
Suisse romande, un nouveau modèle de financement, dit tripartite, est mis en œuvre. Plusieurs cantons expérimentent un engagement des entreprises, qui participent à un fonds commun en complément de la participation du canton et/ou de la commune ainsi que de celle des parents, pour lesquels les tarifs appliqués dépendent, le plus souvent, de la capacité contributive du ménage.

Tous les cantons se sont dotés de lois qui définissent les conditions nécessaires pour l'accueil de jour des enfants. Les instances compétentes en la matière sont tenues d'élaborer un certain nombre de recommandations et de normes afin de garantir la sécurité, l'hygiène et la bonne tenue de la prise en charge des enfants au sein des structures collectives. Ainsi, la qualification du personnel, le nombre d'enfants accueillis au sein de l'institution en fonction du nombre de professionnel-le-s, l'espace à disposition, font l'objet d'un octroi d'autorisation puis d'une surveillance impliquant les services concernés.

En comparaison internationale, par exemple à l'examen des données produites par l'OCDE, l'effort consenti par les politiques publiques en Suisse demeure insatisfaisant quant à l'accueil extrafamilial et extrascolaire. À quoi s'ajoute le fait qu'il n'existe guère, sur le plan national, de directives relatives à la formation des personnes en charge de cet accueil (familial, parascolaire, mais aussi en crèche-garderie), ni davantage de directives permettant d'établir ce que seraient des standards de qualité. Concernant les crèches-garderies, plusieurs niveaux de formation du personnel coexistent, hiérarchisés, reconnus pour la plupart par la Confédération. Le recrutement selon le niveau de formation est contrasté, au gré des cantons, des communes, voire des institutions. De surcroît, ce qui favorise certes une marge de liberté mais ne garantit guère l'universalité des principes éducatifs et des moyens engagés à cet effet, ce sont le plus souvent les institutions ellesmêmes qui définissent leur ligne pédagogique.
Il est une autre spécificité, qui ne tient pas au caractère plurilingue du pays. Les noms donnés aux différentes formes d'accueil recouvrant une même modalité de prestation ne sont pas sanctuarisés par une terminologie uniforme qui permettrait, notamment aux usagers et usagères, d'y voir un peu plus clair. La difficulté d'adopter une dénomination consensuelle des lieux d'accueil ne contribue pas à leur reconnaissance, qui demeure fragile dans le discours social.

L'accueil extrafamilial et extrascolaire figure désormais à l'agenda politique, en maints aspects. De multiples défis se profilent. Parmi eux figurent la tension entre l'offre et la demande, les coûts tant pour les collectivités que pour les usager.ère-s, la formation du personnel éducatif. Concernant les crèches-garderies, quand bien même prévaut l'objectif de conciliation entre vie professionnelle et vie familiale, la question de l'universalité de l'accès est aujourd'hui posée. Le recours à ces institutions ne serait-il pas un droit, pour tous les enfants et pour toutes les familles, notamment à des fins de meilleure intégration sociale des plus vulnérables?

La thématique de la qualité de l'accueil est également à l'ordre du jour. Il n'est pas insignifiant à ce propos de relever que la Commission suisse pour l'UNESCO se soit penchée sur le sujet. Elle a contribué à l'élaboration d'un Cadre d'orientation actuellement débattu avec les multiples protagonistes intervenant dans le champ de la petite enfance. Un «changement de paradigme» émerge: il est impératif de reconnaître qu'au-delà de leur traditionnelle fonction de garde, ces structures remplissent une fonction d'éducation, capitale, tant pour les enfants que pour leurs parents. Elles constituent un microcosme reflétant la diversité des situations familiales. Leur mission socioéducative se voit affirmée. La qualification profes- 
sionnelle du personnel éducatif constitue ici un enjeu majeur.

\section{Annelyse Spack \& Gil Meyer}

\author{
Références \\ Meyer, G., Spack, A., Perrenoud, D. \& Dumont, P. \\ (2009). Familles singulières, accueil collectif. Lau- \\ sanne: Éditions ÉÉSP. \\ Stamm, M. (2009). Éducation de la petite enfance en \\ Suisse. Étude de base élaborée à la demande de \\ la Commission suisse pour l'UNESCO. Fribourg : \\ Université de Fribourg. \\ Wustmann Seiler, C. \& Simoni, H. (2016). Cadre \\ d'orientation pour la formation, l'accueil et l'édu- \\ cation de la petite enfance en Suisse (3e éd. rev. \\ et augm.). Berne: Commission suisse pour \\ l'UNESCO.
}

\section{Action sociale (système d')*}

Le système d'action sociale englobe l'ensemble des institutions, établissements et organisations qui fournissent des prestations matérielles et des prestations de service sociale. C'est aussi le lieu du travail social et de l'innovation sociale. Il est façonné par la politique sociale et est essentiellement régi par le droit social. De là découlent les valeurs telles que la solidarité ou le sentiment d'appartenance, mais aussi le principe de responsabilité personnelle et d'entraide, qui caractérisent encore aujourd'hui le système d'action sociale. Les points de contact avec d'autres sphères sociales, telles que l'éducation et la santé, sont nombreux. Le système d'action sociale peut être décrit et analysé par organismes responsables, types de prestations, groupes cibles et critères régionaux.

Il est ici compris comme un lieu organisé de l'État social. De là résulte une démarcation avec l'aide informelle, que ce soit dans le cadre de la solidarité familiale, des cercles d'ami-e.s ou de l'aide entre voisin·e-s. Néanmoins, ce sont précisément ces prestations sociales qui contribuent de manière significative à la sécu- rité sociale et à la bonne prise en charge des citoyen'ne.s.

Suivant le concept du welfare mix, trois secteurs peuvent être distingués dans le système d'action sociale: l'État, l'économie privée et un «tiers secteur». Ce tiers secteur, souvent appelé société civile, réunit un groupe extrêmement hétérogène d'acteur-trice-s sociaux-ales comme les œuvres d'entraide, les fondations philanthropiques à vocation sociale, les groupes d'entraide ou les organisations d'intervention bénévole. Par conséquent, vu les attentes des citoyen-ne-s d'un pays visà-vis du système d'action sociale, on peut distinguer entre les droits vis-à-vis de l'État social, les offres d'entreprises sociales organisées selon les principes de l'économie privée et les demandes à des organisations caritatives à vocation sociale. Cette distinction conduit également à la poursuite d'objectifs différents. Les droits résultent du droit social, les offres des entreprises sociales découlent de la demande axée sur le pouvoir d'achat, les appels aux organismes caritatifs dérivent de leur orientation sur les situations sociales problématiques qui ne sont pas couvertes par des droits utilisables ni par des offres abordables. Les fondations, elles, jouent un rôle particulier dans le sens de l'engagement philanthropique. Elles font parfois pression sur l'État social lorsqu'elles se mettent à disposition pour des financements d'impulsion et s'attendent par conséquent à ce que l'État social reprenne ultérieurement les innovations sociales réussies.

Le système d'action sociale moderne est né en Europe lors du passage du XIX ${ }^{\mathrm{e}}$ au $\mathrm{XX}^{\mathrm{e}}$ siècle. Dans un premier temps, les organisations caritatives dominent le système d'action sociale, comme la diaconie des églises ou les sociétés de secours privées de citoyen-ne·s aisé·e·s, mais dès le début du XX $\mathrm{XX}^{\mathrm{e}}$ siècle, l'État-providence se développe et le système d'action sociale est de plus en plus façonné par le secteur public. Les organismes de bienfaisance qui, comme par exemple en Allemagne, ne se transforment pas 
en organisations exploitant des jardins d'enfants, des écoles, des hôpitaux ou des homes pour personnes âgées perdent en importance. L'idée de l'État social façonne le système d'action sociale pendant plusieurs décennies, même si le «principe de solidarité» de l'entraide syndicale continue à concurrencer pendant un certain temps encore le «principe d'État» de la bourgeoisie. Petit à petit et de manière peu coordonnée, les risques sociaux majeurs sont couverts par les assurances sociales (souvent déclarées obligatoires pour toutes ou tous ou, au moins, pour toutes les personnes actives).

De plus, ce qui est souvent passé sous silence, l'économie privée a joué dès le début un rôle important dans le système d'action sociale. Par exemple, les entreprises gèrent leurs propres assurances-maladie, d'abord sous la pression des syndicats puis en coopération avec eux, elles proposent une prévoyance vieillesse à leurs employés, participent à la construction de logements sociaux et s'engagent dans le domaine des loisirs. Aujourd'hui, elles s'engagent en plus dans le cadre de la corporate social responsability. Toutefois, les accords de partenariat social sont et restent une force motrice dans l'élaboration et le développement du système d'action sociale.

Une nouvelle évolution peut être observée lors du passage du XX $\mathrm{XX}^{\mathrm{e}}$ au XI ${ }^{\mathrm{e}}$ siècle. Le système d'action sociale devient un secteur lucratif pour les entreprises privées, d'une part, en raison de la privatisation des tâches incombant à l'État-providence. Dans le cadre de contrats de prestations, non seulement des œuvres d'entraide mais aussi des entreprises privées à but lucratif travaillent pour l'État social, par exemple dans l'accueil et le logement des demandeur.euse-s d'asile ou au service de recouvrement des services sociaux communaux. L'État social devient un État garant technocratique et se replie de plus en plus sur son rôle de financeur et de contrôleur, notamment dans le domaine des prestations de service sociale, dans la logique du new public manage- ment. D'autre part, des entreprises de services privées et indépendantes apparaissent de plus en plus dans le secteur social, attirées par les opportunités de faire des «affaires lucratives avec le social». Par exemple, elles exploitent des homes et des crèches privés sur des marchés initiés, régulés et contrôlés par l'État social, offrent des conseils, une assistance et un suivi dans le domaine des services d'aide et de soins à domicile ou encouragent la construction de logements sociaux.

Le système d'action sociale suisse présente un certain nombre de particularités quant à ses origines et à ses caractéristiques. Les luttes pour la conception des assurances sociales sont par exemple marquées par les droits populaires de la démocratie directe et plus particulièrement par le droit de référendum, et font de la Suisse un pays en retard en matière d'État social. Il faut souvent plusieurs tentatives de vote pour voir se dessiner des majorités en faveur de nouveaux systèmes de sécurité régulés par la loi. La structure fédérale de l'État se reflète également dans le système d'action sociale. C'est ainsi que les premières assurances sociales publiques ont vu le jour dans de grandes villes comme Berne ou Zurich. Aujourd'hui, l'État social suisse est structuré par des assurances sociales nationales, des prestations cantonales sous condition de ressources et par l'aide sociale organisée majoritairement au niveau communal. Les prestations de service sociale sont principalement prises en charge aux niveaux cantonal et communal, bien qu'il existe des organismes nationaux tels que la Croix-Rouge suisse ou Pro Senectute Suisse. Ces prestations de service sociale incluent le conseil en matière d'endettement pour les personnes en situation de pauvreté, l'accompagnement des personnes dans le besoin, les mesures d'insertion professionnelle pour les chômeur.euse-s de longue durée et les offres de prise en charge pour les personnes âgées. Une autre particularité de la Suisse est le sens spécifique donné à la subsidiarité dans l'État social. Les princi- 
pales sources de la sécurité sociale sont l'emploi rémunéré et la famille. Le système d'action sociale n'entre en jeu de manière subsidiaire que dans un second temps. Cette conception est illustrée par le premier alinéa de l'article 41 de la Constitution fédérale, qui traite des buts sociaux. Celui-ci stipule que la Confédération et les cantons s'engagent en faveur de ces buts sociaux en complément de la responsabilité individuelle et de l'initiative privée.

Le système d'action sociale suisse est confronté à de nombreux défis. La concurrence nationale et mondiale entre places économiques n'épargne pas le système d'action sociale. On se demande de plus en plus si l'État social doit être considéré comme un facteur de compétitivité positif parce qu'il contribue de manière décisive à la paix sociale, au bien-être général et à la stabilité politique, ou comme un facteur de coût en ce qu'il réduit la compétitivité des entreprises, auquel cas son influence doit être amenuisée. L'évolution démographique ne fait pas seulement peser une charge croissante sur le financement de la prévoyance vieillesse, mais pose également la question $\mathrm{du}$ travail de care non rémunéré au vu de l'évolution des modes de vie familiaux. Enfin, les modifications des rapports de force dans le champ politique imposent de réaliser des économies également dans le secteur social et d'étendre les possibilités de sanction. Au-delà de ces tendances, des discussions sont également en cours en Suisse quant à la nécessité de remanier profondément le système d'action sociale. Certains prônent un revenu de base garanti, d'autres des systèmes automatiques dans les assurances sociales suivant la logique du frein à l'endettement dans la politique budgétaire.

\section{Carlo Knöpfel}

\section{Références}

Castel, R. (1995). Les métamorphoses de la question sociale: une chronique du salariat. Paris : Fayard.
Epple, R. \& Schär, E. (2010). Stifter Städte Staaten: Zur Geschichte der Armut, Selbsthilfe und Unterstützung in der Schweiz 1200-1900. Zürich : Seismo.

Riedi, A. M., Zwilling, M., Meier Kressig, M., Benz Bartoletta, P. \& Aebi Zindel, D. (2015). Handbuch Sozialwesen Schweiz (2., überarb. und erg. Aufl.). Bern : Haupt.

\section{Activation}

La période des Trente Glorieuses coïncide avec un développement important des politiques sociales visant à verser des prestations financières aux personnes en incapacité de subvenir à leurs besoins par leurs propres moyens. Dès le départ, ces politiques sont souvent assorties d'obligations de contre-prestations, sous forme de participation à des programmes de travail ou à des mesures de réadaptation professionnelle. Depuis le début des années 1980, émergent des critiques qui exigent la réforme de ces politiques dans le sens d'un renforcement et d'une systématisation de l'activation des dépenses et des bénéficiaires. La protection sociale est désormais appelée à mettre en son cœur l'objectif de remarchandisation, c'est-àdire de retour en emploi de ses bénéficiaires. L'État social d'indemnisation financière est alors vu comme un pis-aller temporaire, dont il convient de s'affranchir au plus vite. Trois ordres de critiques sont sous-jacents à cette évolution de l'État social vers l'activation des prestations.

D’abord, le coût de l'État social est présenté comme excessif. Ce «constat» coïncide avec la fin du plein emploi et l'augmentation des taux de chômage dans la majorité des pays de l'OCDE. L'action de l'État en matière d'emploi tend dès lors à se concentrer sur le volet de l'offre via des politiques d'amélioration de l'employabilité et à délaisser les politiques keynésiennes de soutien à la demande. On observe ici un paradoxe: les bénéficiaires 
des politiques sociales sont en effet appelés à s'activer au moment même où le plein emploi n'est plus garanti. Ensuite, l'État social est dénoncé comme un facteur de dépendance pour ses bénéficiaires. Gilder, dans Richesse et pauvreté (1981), y voit un facteur d'étouffement du dynamisme des personnes, qui empêcherait leur autonomie et favoriserait leur dépendance. Dans le langage des économistes, on parle d'un préjudice moral (moral hazard) qui entraînerait des comportements d'irresponsabilité individuelle: les personnes assurées contre les risques sociaux ne feraient plus tous les efforts nécessaires pour prévenir leur apparition (on n'hésiterait ainsi plus à démissionner de son poste à la moindre contrariété, à adopter des comportements hygiéniques ou sanitaires contestables, etc. vu que les conséquences de ces comportements sont assumées par la collectivité au travers de l'État social).

La troisième critique porte sur l'inadéquation des interventions standardisées de l'État social redistributeur et l'exigence d'individualisation de ces prestations. Cette exigence se traduit par la montée en force du paradigme de contractualisation au sein des politiques sociales: au droit inconditionnel et standardisé, qui donne à l'ensemble des bénéficiaires l'accès aux mêmes prestations, devrait se substituer le contrat, qui permet d'ajuster le contenu des interventions aux circonstances des personnes concernées. Avec ce glissement du droit au contrat émerge une nouvelle forme d'échange entre l'État social et les citoyennes et citoyens: au droit de recevoir des prestations correspond, en plus du devoir de cotisation, le devoir de collaboration, celui de tout faire pour sortir de la dépendance de l'État et revenir à meilleure fortune. La tendance vers l'activation des prestations s'accompagne donc d'un accent exacerbé sur les devoirs des bénéficiaires.

Sous la pression de ces critiques, deux modèles principaux d'activation se mettent en place. Le premier met l'accent sur l'incitation financière à reprendre un emploi qui peut prendre une tournure positive (la carotte) ou négative (le bâton). Dans le premier cas, il s'agit de valoriser financièrement la reprise d'emploi en accordant par exemple des dégrèvements fiscaux ou des compléments de revenu à celles et ceux qui reprennent un emploi. Dans le deuxième, les prestations financières de l'État social sont envisagées comme un obstacle à la reprise d'emploi. Il s'agit donc de réduire ces prestations pour diminuer leur effet désincitatif sur les bénéficiaires. C'est une version négative de l'activation qui est ici promulguée: la prestation sociale doit être conçue de telle manière qu'elle agisse comme un «repoussoir» et incite à s'en éloigner pour reprendre un emploi le plus vite possible. Ce modèle négatif d'activation peut passer par la réduction des prestations ou de leur durée de versement, ou encore par un durcissement des conditions d'éligibilité. Mais il peut aussi soumettre les bénéficiaires à des conditions plus restrictives, ce qui se traduit par l'introduction de normes comportementales, notamment en termes de devoir de collaborer et de recherche active d'emploi, dont le non-respect entraîne des sanctions. Dans les deux cas, il s'agit de faire en sorte que le travail soit toujours l'option la plus lucrative.

Le deuxième modèle d'activation met l'accent sur le développement de l'employabilité des récipiendaires de prestations sociales. Il s'agit ici de doter les individus des compétences nécessaires à leur intégration professionnelle. On vise à établir un cercle vertueux entre les politiques sociales et la compétitivité économique: en développant les compétences des personnes, on fournit à l'économie une main-d'œuvre mieux à même de contribuer à sa compétitivité. La prospérité économique qui en résulte permettra de créer des emplois et de financer l'État social. La caractéristique d'investissement des dépenses sociales est ainsi affirmée, dans une logique qui exige le développement des dépenses dites actives (la formation, les stages professionnels, etc.) et la 
maîtrise des dépenses dites passives, envisagées avant tout comme des coûts. Cette deuxième version de l'activation coïncide avec une augmentation, parfois considérable, des dépenses sociales en vue de financer les nouvelles interventions «activantes». Certaines mesures se caractérisent par leur longue durée et leur ambition de qualification clairement affichée. En Suisse, nous trouvons des exemples de telles mesures dans l'assurance-chômage, avec l'allocation de formation qui permet à ses bénéficiaires de suivre un apprentissage en les soutenant financièrement tout au long du cursus, mais aussi et surtout dans l'assurance-invalidité, où les mesures de reclassement visent à requalifier les personnes en vue de restaurer une capacité de gain équivalente à celle qu'elles avaient avant leur invalidité. Mais il existe aussi d'autres mesures d'activation qui reposent davantage sur la valorisation des compétences existantes que sur le développement de nouvelles qualifications, tels que les programmes visant à inculquer des «techniques de recherche d'emploi » que l'on trouve par exemple dans le cadre de l'assurance-chômage suisse. De telles mesures, de durée limitée, mettent l'accent sur le marketing de soi sans doter les personnes de nouvelles compétences certifiées. On ne peut pas vraiment parler d'investissement social à leur propos, dans la mesure où leur ambition limitée ne suffit pas à déclencher un cercle vertueux de prospérité économique et de justice sociale.

Suivant le modèle retenu - (dés-)incitation financière ou développement de l'employabilité - l'activation peut avoir des impacts très différents sur les personnes concernées: alors que le premier modèle voit dans les politiques sociales un coût qu'il faut réduire, le développement de programmes de formation les envisage comme des investissements éducatifs ou formateurs dont la rentabilité se manifestera à plus ou moins long terme. Quel que soit le modèle retenu, on envisage la reprise de l'emploi ou de la formation comme une contrainte.
L'activation n'est en effet pas conçue comme une affaire de choix des personnes, mais comme une obligation de ne plus dépendre de l'État et de retrouver une autonomie financière. De plus, les deux stratégies relèvent de politiques de l'offre et font confiance à la capacité des acteur-trice-s du marché du travail de créer des emplois en quantité suffisante et de qualité adéquate. Les statistiques disponibles montrent cependant la difficulté du marché à insérer chacune et chacun dans un emploi de qualité.

$\mathrm{Au}$ final, l'activation des bénéficiaires des politiques sociales, sous ses diverses formes, apparaît comme une stratégie à l'efficacité discutable. Il semble ainsi que pour relever les défis qui l'attendent, l'activation devra être accompagnée d'autres mesures portant sur la stimulation de la demande de travail, la qualité des emplois et le développement et la reconnaissance des activités non marchandes. À défaut, elle risque fort de se résumer à une contrainte de travailler, déconnectée du droit au travail décent pour toutes et tous.

Jean-Michel Bonvin

\section{Références}

Bonvin, J.-M. \& Moachon, E. (2005). L'activation et son potentiel de subversion de l'État social. In P. Vielle, P. Pochet \& I. Cassiers (Éd.), L'État social actif: vers un changement de paradigme? (pp. 62-92). Bruxelles: Peter Lang.

Esping-Andersen, G. (1999). The social foundations of postindustrial economies. Oxford : Oxford University Press.

Gilbert, N. (2002). Transformation of the welfare state: the silent surrender of public responsibility. Oxford: Oxford University Press.

\section{Activité professionnelle personnes en situation handicapées*}

Lactivité professionnelle désigne un travail productif effectué contre rémunération. Elle 
permet non seulement d'assurer sa subsistance, mais aussi de s'affirmer et de faire l'expérience de ses compétences. Gage de normalité et d'appartenance, elle joue un rôle important dans la formation de la personnalité. L'activité professionnelle est donc, de toute évidence, un facteur clé d'intégration sociale et professionnelle, et cela pour toute personne, avec ou sans handicap. Les chances d'obtenir un emploi sont toutefois nettement moindres pour les personnes handicapées que pour les autres. Au sens de la loi fédérale sur l'élimination des inégalités frappant les personnes handicapées (LHand, article 2), une personne handicapée est une personne dont la déficience corporelle, mentale ou psychique l'empêche d'exercer une activité professionnelle, ou la gêne dans l'accomplissement d'une telle activité. Un handicap peut ainsi avoir pour conséquence une capacité de gain réduite ou une incapacité de gain. En cas d'incapacité de gain réelle ou potentielle, les personnes handicapées ont droit à des prestations de l'assurance-invalidité (AI). Selon l'article 7 de la loi fédérale sur la partie générale du droit des assurances sociales, l'incapacité de gain est une perte due à une atteinte à la santé physique, mentale ou psychique - de l'ensemble ou d'une partie des possibilités de gain de la personne assurée dans son domaine d'activité sur un marché du travail équilibré, c'est-à-dire un marché équilibré en termes d'offre et de demande de main d'œuvre.

Les personnes handicapées allocataires d'une rente AI, qui ne peuvent pas remplir les exigences en termes de compétences et d'employabilité sur le marché de l'emploi ordinaire (premier marché) ou n’y trouvent pas de travail, peuvent trouver un emploi sur le marché complémentaire (second marché), dans des «ateliers». Il s'agit d'entreprises organisées selon des critères économiques, mais qui se distinguent des entreprises du premier marché par le fait qu'elles donnent à des personnes handicapées la possibilité d'exercer un tra- vail productif correspondant à leurs capacités, rémunéré à hauteur de leur productivité, et qui favorise leur intégration socioprofessionnelle. L'origine de ces ateliers remonte à l'entredeux-guerres. Auparavant, au cours de l'industrialisation, les personnes handicapées étaient souvent exploitées comme main d'œuvre dans des institutions (p.ex. établissements pénitenciers) ou alors, a fortiori en cas de handicap cognitif ou psychique lourd, étaient considérées comme incapables de travailler et d'apprendre. En 1930, onze ateliers se réunirent pour former l'Union suisse des institutions pour handicapés (USIH). La loi fédérale sur l'assurance-invalidité de 1959 déclencha la création de nombreuses nouvelles institutions dans le marché du travail complémentaire, dont une grande majorité est rattachée à INSOS Suisse (l'ancienne USIH), la faîtière des institutions pour personnes handicapées. INSOS compte aujourd'hui près de 300 ateliers, qui réalisent un revenu annuel de quelque 300 millions de francs et couvrent environ $40 \%$ de leurs coûts. Ces ateliers offrent plus de 23000 places de travail (février 2017). En 2008, suite à la réforme de la péréquation et de la répartition des tâches entre la Confédération et les cantons, les cantons ont pris le relais de l'Office fédéral des assurances sociales et financent désormais ces institutions. La loi fédérale sur les institutions destinées à promouvoir l'intégration des personnes invalides en est la base légale.

L'insertion professionnelle des personnes handicapées dans le marché du travail ordinaire est devenue un objectif sociopolitique qui vise le développement de formes de travail plus intégrées. De nombreuses institutions du marché complémentaire offrent aujourd'hui des possibilités de places de travail externes intégrées dans une entreprise ordinaire. Depuis la 5 e réforme de l'AI, «l'intégration avant la rente » est également l'idée force de cette assurance. Entre 2009 et 2014, ce nouveau concept s'est soldé par une diminution de $10 \%$ du nombre de rentes AI. Cependant, selon les organisations 
d'entraide, ce recul s'explique plus par le durcissement des critères pour déterminer le degré d'invalidité que par le nombre de (ré)insertions réussies dans le marché du travail ordinaire.

Bien que la plupart des personnes handicapées travaillent, leur taux d'activité est inférieur d'environ $20 \%$ d'après les chiffres de l'Office fédéral de la statistique. En outre, près d'une personne handicapée sur deux travaille à temps partiel, alors que le rapport est d'une personne sur trois pour les personnes non handicapées. Les personnes handicapées se heurtent souvent à des limitations et des obstacles (p.ex. taux d'occupation, type de travail, accessibilité du lieu de travail). Sans compter les stigmatisations et autres préjugés dont elles sont la cible, au travail et ailleurs.

En ratifiant la Convention de l'ONU relative aux droits des personnes handicapées, la Suisse s'est engagée à éliminer les facteurs de discrimination au travail et à assurer un marché du travail ouvert et accessible. Toutefois, le cadre légal actuel - la LHand, la loi fédérale sur l'assurance-invalidité et la loi fédérale sur les institutions destinées à promouvoir l'intégration des personnes invalides - s'avère insuffisant pour atteindre cet objectif. Parmi les points problématiques, mentionnons la protection contre les discriminations de la part des employeur·euse-s du secteur privé, ou la liberté de choisir, en particulier pour les personnes avec une déficience plus lourde, de travailler sur le marché complémentaire ou ordinaire. S'il est dans l'intérêt de l'AI qu'un maximum de personnes handicapées disposent d'un travail rémunéré - ce qui conduit à une diminution de la rente - l'accès au travail et l'intégration durable dans le marché du travail demeurent difficiles pour elles.

Le changement de paradigme dans le domaine de l'aide aux personnes handicapées a eu pour effet une focalisation sur le soutien à l'intégration, avec des modèles de quotas, des outils anti-discrimination (p.ex. diversity management, disability management), des modèles incitatifs ou d'emploi assisté (supported employment). Ce dernier modèle a prouvé son efficacité pour aider les personnes handicapées à trouver et à garder un emploi rémunéré sur le marché du travail ordinaire, mais il est difficile à financer et donc à mettre en œuvre en Suisse dans les conditions-cadre légales actuelles.

On note une contradiction entre la définition médicale du handicap et la notion de handicap telle qu'elle est comprise dans les milieux spécialisés. La première, ancrée dans la législation, est axée sur l'idée de déficit et se traduit par la prise de mesures d'intégration professionnelle des personnes handicapées au niveau de l'individu. La deuxième part de l'idée que le handicap n'est pas un déficit individuel, mais la résultante de conditions sociétales excluantes. En suivant cette logique, les mesures à prendre devraient l'être avant tout là où elles ont un impact sur les conditions sociétales. Il reste des efforts à faire du côté des employeur-euse-s; ils doivent être non seulement informé.e-s et sensibilisé·e·s, mais aussi soutenu·e-s et conseillé·e.s concrètement, par exemple pour l'aménagement de places de travail adaptées, afin qu'une personne handicapée puisse faire valoir pleinement ses compétences. On pourrait également envisager d'élargir le champ d'application de la LHand aux conditions d'emploi du secteur privé, toujours dans le but de réduire la discrimination des personnes en situation de handicap.

\section{Susanne Aeschbach \& Annina Studer}

\section{Références}

Egger, T., Stutz, H., Jäggi, J., Bannwart, L., Oesch, T., Naguib, T. \& Pärli, K. (2015). Evaluation des Bundesgesetzes über die Beseitigung von Benachteiligungen von Menschen mit Behinderung - BehiG. Bern: Büro für arbeits- und sozialpolitische Studien BASS.

Office fédéral de la statistique (Éd.) (2012). Handicap et travail: restrictions et facilitateurs de l'activité professionnelle des personnes handicapées. Neuchâtel: Office fédéral de la statistique. 
Organisation für Wirtschaftliche Zusammenarbeit und Entwicklung (Hrsg.) (2003). Behindertenpolitik zwischen Beschäftigung und Versorgung. Frankfurt a.M. : Campus.

\section{Addiction*}

Dans le jargon spécialisé, l'usage du terme d'addiction gagne à nouveau du terrain sur celui de dépendance. L'usage du terme «dépendance» a été étendu par l'Organisation mondiale de la santé (OMS) afin de lutter contre la stigmatisation des toxicomanes. On distingue généralement les comportements sans risque, les comportements à risque et l'addiction.

Dans l'ouvrage de référence Manuel diagnostique et statistique des troubles mentaux (DSM-5) l'abus et la dépendance sont réunis sous l'appellation générique de «consommation abusive de substances» (alcool, tabac, cannabis, opiacés, stimulants). La distinction entre catégories qui existait jusqu'ici est donc remplacée par un modèle dimensionnel aux différents degrés de manifestation. Outre la consommation abusive de substances, le DSM-5 traite aussi de l'addiction aux jeux de hasard. D'autres addictions comportementales telles que la dépendance à Internet ou les achats compulsifs ne sont pas couvertes, les preuves scientifiques manquant pour l'instant. À noter néanmoins que l'annexe du DSM-5 introduit la catégorie de diagnostic internet gaming disorder (trouble du jeu sur internet).

L'addiction fait intervenir des changements temporaires et durables dans la perception, dans le vécu et dans le comportement de la personne. La dépendance implique des processus biologiques, psychologiques et sociaux. Par conséquent, un traitement purement médical ne suffit pas. L'addiction est un état aux facteurs multiples qui nécessite une action interdisciplinaire (médecine, sciences infirmières, psychologie, travail social).
Suite aux scènes de drogue ouvertes dans les années 1980 et 1990, la politique alors en vigueur des trois piliers (prévention, thérapie, répression) s'est enrichie d'un quatrième pilier, la réduction des dommages. Cette approche de harm reduction a entraîné un changement de paradigme dans les relations avec les dépendant·e.s. Dès lors il est devenu possible politiquement de distribuer des seringues stériles, de prescrire de l'héroïne et, dans un cadre plus large, de la méthadone et d'aménager des lieux de consommation avec point d'accueil et de contact. La Confédération a mis en œuvre des stratégies pour les addictions: le Programme national alcool, le Programme national tabac et trois trains de mesures destinés à réduire les problèmes de toxicomanie.

Depuis le début des années 2000, les spécialistes ont commencé à comprendre qu'il fallait remplacer les trois politiques séparées (lutte contre l'alcoolisme, la toxicomanie et le tabagisme) par une politique anti-addiction globale, cohérente et couvrant toutes les substances et comportements d'addiction.

Actuellement, il existe deux stratégies au niveau fédéral: la Stratégie nationale Prévention des maladies non transmissibles (stratégie MNT) et la Stratégie nationale Addictions (2017-2024). La Stratégie Addictions a pour objectif d'intensifier la promotion de la santé et la prévention des maladies et vise à coordonner les différentes politiques de lutte contre les addictions.

Les coûts directs et indirects de la toxicomanie pour la société sont énormes. Outre les dépenses en soins de santé et les poursuites pénales, la perte de productivité dans l'économie contribue à engendrer des coûts économiques. La toxicomanie a également des coûts indirects liés, par exemple, à la baisse de la qualité de vie, à la morbidité et à la mortalité. D’un point de vue de santé publique, le tabagisme et l'alcoolisme nécessiteraient des investissements beaucoup plus importants 
qu'aujourd'hui pour la promotion de la santé et la prévention.

Les addictions engendrent énormément de souffrance humaine. Elles limitent la qualité de vie non seulement pour les personnes concernées, mais aussi pour leur entourage et en particulier pour les enfants, les partenaires et autres membres de la famille. Ces personnes, mais aussi les ami·e·s, les collègues et même les groupes d'entraide doivent être impliqués davantage dans le champ professionnel du traitement de l'addiction. Pour les employeur-euse-s, il est recommandé de reconnaître suffisamment tôt les problèmes d'addiction de leurs collaborateur.trice-s. Le fait de les ignorer n'est pas un bon calcul. En revanche, la collaboration étroite entre services sociaux, médecins traitant·e·s et supérieur·e·s hiérarchiques a fait ses preuves.

La Confédération fixe les objectifs de la politique anti-addiction et ce sont les cantons et les communes qui la mettent en œuvre. Cela explique la diversité des processus et des modèles d'organisation qui existent en Suisse. Ceux-ci permettent de mener des projets pilotes qui améliorent la compréhension du problème.

Dans le domaine de l'alcoolisme, les caisses maladie prennent en charge les coûts des désintoxications et des sevrages. Pour les problèmes de drogue, elles ne remboursent que les frais de désintoxication, mais pas les traitements stationnaires de sevrage. Pour ces derniers, la personne ou la commune de résidence et donc, bien souvent, l'aide sociale, doivent mettre la main à la poche. Cela entraîne des disparités locales qui ont pour conséquence des inégalités de traitement.

Depuis la décision du Tribunal fédéral en juillet 2019, les maladies de dépendance donnent en principe droit aux mêmes prestations que les autres maladies mentales. Il reste à voir comment cette nouvelle réglementation sera mise en œuvre dans la pratique.
La Suisse a fait figure de pionnière avec la politique des quatre piliers. Le thème de la décriminalisation et/ou de la libéralisation (partielle) est aujourd'hui à l'ordre du jour dans la politique au niveau international. En Suisse, des projets de libéralisation partielle de la consommation de cannabis comprenant un suivi scientifique sont initiés dans les grandes villes (protection des jeunes, enregistrement des consommateur.trice-s, contrôle des quantités et de la qualité des substances distribuées, etc.). Toutefois, il n'existe pas encore de base juridique pour l'autorisation de ce type de projet par l'Office fédéral de la santé publique (OFSP). Quant à la délivrance thérapeutique de cannabis, elle est en règle générale accordée, par exemple en cas de troubles du sommeil ou de douleurs ou comme stimulateur d'appétit dans les cas de cancer.

Cependant, l'intégration des toxicomanes sur le marché du travail continue de poser problème. Qui plus est, le vieillissement croissant des dépendant.e.s exige de nouvelles offres. On teste donc divers modèles : maisons de retraite spécialisées, placement dans des foyers pour handicapés et personnes âgées, aide à domicile, etc.

La loi suisse fait une distinction entre substances légales et substances illégales. Les spécialistes de l'addiction plaident pour une politique cohérente, orientée sur les dommages effectifs liés à la consommation d'une substance. L'alcool et le tabac, substances légales, ne sont pas traités de la même façon que les substances illégales par le droit pénal et les politiques de santé. Pour ces deux produits, la législation applicable à la publicité et à la commercialisation a par exemple été récemment libéralisée par le Parlement suisse.

La Suisse dispose d'un système de protection sociale bien développé, mais mal coordonné. Chaque composante du système applique en effet ses propres règles en matière de compétences. Les travailleur-euse-s sociaux-ales défendent les intérêts de leur 
clientèle vis-à-vis du système de protection sociale. Ils n'ont pas reçu de mandat officiel au sens de case management. Les spécialistes des diverses institutions telles que la médecine, la justice, les assurances sociales, la thérapie et le monde du travail ne travaillent souvent pas de manière coordonnée. Cette collaboration peut être largement améliorée. Pour améliorer cette mise en réseau et cette coordination, il serait judicieux d'offrir des formations interprofessionnelles de médecine, sciences infirmières, psychologie et travail social.

Le souci de réduction des coûts pèse aussi sur le financement de l'aide aux toxicomanes. En essayant de médicaliser les traitements, on cherche à transférer les dépenses engagées par le canton aux caisses d'assurance-maladie. La question de savoir à quoi doit ressembler le financement d'une aide interdisciplinaire aux toxicomanes, pertinente d'un point de vue professionnel, reste ouverte.

\section{Urs Gerber \& Marcel Krebs}

\section{Références}

Commission fédérale pour les questions liées aux addictions (Éd.) (2012). La politique drogue en tant que politique de société: un rétrospectif sur trente ans de politique suisse en matière de drogues, 19812011. Zurich: Seismo.

Conseil fédéral (2015). Stratégie nationale et plan de mesures addictions 2017-2024. Berne: Office fédéral de la santé publique.

Infoset - Le portail suisse d'information en ligne dans le domaine des addictions. https://www. infoset.ch

\section{Âge*}

Le terme «âge » se réfère d'une part aux années de vie vécues (l'âge civil) et d'autre part à une phase tardive de la vie (la vieillesse, par opposition à la jeunesse, p.ex.). Sur le plan social et sociopolitique, l'âge (civil) d'une personne est utilisé comme un critère pour déterminer les rôles sociaux et les droits civils, tels que l'âge d'entrée à l'école, l'âge de protection concernant les actes d'ordre sexuel, l'âge du droit de vote, les limites d'âge pour certaines fonctions professionnelles, politiques ou militaires, l'âge pour percevoir une rente de vieillesse et l'âge de l'examen de l'aptitude à la conduite automobile, de 70 ans actuellement en Suisse. En tant que phase de la vie, la vieillesse est associée à des défis spécifiques tels que l'organisation de la vie quotidienne sans activité professionnelle, la gestion des limitations physiques et mentales ou encore la perte des liens sociaux (comme le veuvage). Tant l'assignation sociale des droits et des obligations en fonction de l'âge que la perception et l'organisation de la phase de la vieillesse sont soumises à des changements sociaux liés à des règles sociopolitiques et à des normes de performance.

Dans l'histoire culturelle européenne, la vieillesse a toujours été associée à des idées de deux ordres: d'un côté, la vieillesse a été, et reste, rattachée au déclin physique et intellectuel, à la faiblesse et à la proximité de la mort. De l'autre, on met en avant, aujourd'hui comme hier, certaines évolutions positives telles que la sagesse et la sérénité des personnes âgées ou encore, la vieillesse en tant qu'accomplissement de la vie. Dans les définitions sociales s'attachant à fixer le moment où l'on est considéré comme vieux, deux aspects différents sont pris en compte: premièrement, on définit la vieillesse en s'appuyant sur des symptômes physiques visibles. Une posture voûtée ou l'utilisation d'une canne sont traditionnellement considérées comme des signes extérieurs de déclin lié à l'âge. Dans la culture européenne, qui depuis la Renaissance a pour modèle esthétique les corps jeunes tels que représentés dans la Grèce antique, les corps vieillissants faisaient, et font, l'objet d'un jugement négatif, en particulier chez les femmes. Deuxièmement, on utilise des limites d'âge chronologique pour déterminer le début de la vieillesse. Historiquement, l'âge de 60 ans 
a souvent été défini comme le seuil de cette phase de la vie. Dans l'ancienne Confédération helvétique, par exemple, le $60^{\mathrm{e}}$ anniversaire était considéré comme l'âge à partir duquel les hommes étaient libérés de leurs obligations communales.

La première loi du Reich allemand sur l'assurance-invalidité et l'assurance-vieillesse des travailleur.e.s, datant de 1889, fixait un seuil d'âge de 70 ans. En 1912, ce seuil a été abaissé à 65 ans pour les pensions d'État. Le même seuil réglementaire a été adopté par la Suisse en 1948 pour les hommes dans le cadre de l'assurance-vieillesse et survivants (AVS). Le seuil d'âge formel de 65 ans est encore utilisé aujourd'hui pour mesurer le vieillissement démographique. D'un point de vue sociopolitique et démographique, la vieillesse, en tant que phase de la vie associée à la retraite, commence à 65 ans, bien que la sortie effective de la vie active s'effectue souvent plus tôt, et parfois plus tard. En Suisse aussi, le vieillissement de la population suscite de nombreuses discussions politiques sur le relèvement de l'âge de référence pour la retraite; de nombreuses interventions visent à flexibiliser cet âge.

$\mathrm{Au}$ cours des dernières décennies, les concepts scientifiques, la perception sociale de la vieillesse ainsi que la situation des hommes et des femmes âgé-e·s ont changé de façon spectaculaire. Premièrement, dans une société moderne et diversifiée, l'âge chronologique n'est un indicateur adéquat ni pour déterminer la phase de la vie correspondant à la vieillesse, ni pour définir le vieillissement démographique. La grande hétérogénéité des processus de vieillissement ainsi que les inégalités socioéconomiques importantes dans la situation des personnes âgées contribuent au fait que l'âge civil, en tant que variable statistique, soit relégué au second plan par rapport aux variables sociales, économiques et biographiques (au moins jusqu'au groupe des personnes de plus de 80 ans). Parallèlement, on constate que l'écart se creuse, dans les sociétés d'aujourd'hui, entre l'âge réel et l'âge subjectif ou ressenti. Les personnes âgées se perçoivent souvent comme plus jeunes que leur âge réel et, depuis quelques années, les personnes âgées de 65 à 74 ans en Suisse se perçoivent comme tout aussi créatives et innovantes que des personnes bien plus jeunes.

Deuxièmement, parallèlement à la construction de nouvelles idées fortes sur l'âge et à la suite de l'allongement du temps passé à la retraite, on en vient à différencier diverses phases de vieillesse et à distinguer notamment un «troisième âge» et un «quatrième âge». Les premières universités «du troisième âge» ont été fondées à Lyon et à Genève dès 1975 . Cette différenciation est entrée dans le langage courant par des expressions telles que «les jeunes vieux» ou «les vieillards ». Par la suite, les débats sur le vieillissement actif se sont fortement concentrés sur la situation des femmes et des hommes retraité·e-s en bonne santé. La retraite est toujours considérée comme un moment de transition important, mais elle est davantage associée à une forme de liberté active tardive qu'à une retraite (Ruhestand en allemand, pour: repos) passive. Le quatrième âge, en revanche, est davantage lié aux notions de fragilité, de vulnérabilité et de dépendance (avec les coûts sociaux et de santé qui y sont associés).

Troisièmement, à partir des années 1970 et du début des années 1980, les théories de la vieillesse axées sur le déficit ont été remplacées, progressivement, par des théories axées sur les compétences correspondant à un vieillissement actif, réussi et en bonne santé. Des études longitudinales montrent que toutes les dimensions de la performance cognitive ne diminuent pas avec l'âge ou, autrement dit, que certaines dimensions cognitives ont une grande constance par rapport à l'âge. D'autre part, des recherches-actions montrent que des facteurs qui maintiennent la performance et la santé peuvent être renforcés ou améliorés même à un âge avancé. Le grand âge, considéré 
auparavant comme une fatalité, s'est de plus en plus révélé être un champ d'action (professionnel) propice aux interventions destinées à améliorer les compétences. Dans sa version radicale, cette approche a contribué à l'émergence des concepts du mouvement anti-ageing. La redéfinition de la vieillesse s'est vue renforcée par le fait qu'un nombre croissant de personnes âgées s'est tourné vers des activités auparavant considérées comme l'apanage exclusif des jeunes - voyager, faire du sport, suivre une formation, s'habiller à la mode. Grâce au développement de ses infrastructures sociales et sanitaires, la Suisse fait partie des pays européens dans lesquels la phase de la vie post-professionnelle sans handicaps a connu une expansion particulièrement forte. À l'heure actuelle, et compte tenu des déficits publics, on voit apparaître toujours davantage de modèles promouvant un vieillissement productif. L'idée centrale est que les personnes âgées et retraitées pourraient - ou devraient fournir des prestations utiles à la société. Dans les faits, bon nombre de femmes et d'hommes âgé·e·s sont déjà très engagé.e-s dans des activités sociales (bénévolat, aide de voisinage, garde des petits-enfants, etc.). Depuis quelques années, la proportion de personnes âgées de plus de 65 ans qui continuent à travailler augmente également, bien qu'elles le fassent, le plus souvent, à temps partiel.

\section{François Höpflinger}

\section{Références}

Becker, S. \& Brandenburg, H. (Hrsg.) (2014). Lehrbuch Gerontologie: Gerontologisches Fachwissen für Pflege- und Sozialberufe. Bern: Huber.

Lalive d'Epinay, C. \& Spini, D. (Éd.) (2008). Les années fragiles: la vie au-delà de quatre-vingts ans. Québec: Les Presses de l'Université Laval.

Samochowiec, J., Kühne, M. \& Frick, K. (2015). Digital ageing: unterwegs in die alterslose Gesellschaft. Rüschlikon: Gottlieb Duttweiler Institute.

\section{Âgisme}

Le terme d'âgisme a été proposé pour la première fois par Robert Butler en 1969 pour indiquer les préjugés envers un groupe d'âge. Si l'âgisme peut concerner les jeunes, au fil du temps l'attention s'est cependant centrée progressivement sur les personnes âgées qui semblent en être les principales victimes. En 1975, le même Butler définit l'âgisme en lien avec les stéréotypes et les attitudes discriminatoires envers des personnes simplement parce qu'elles sont âgées, de la même manière que le sexisme et le racisme le font en lien avec le sexe et la couleur de peau. Plus récemment, Iversen, Larsen et Solem définissent l'âgisme comme les stéréotypes, les préjugés et les discriminations (qui peuvent être tant positifs que négatifs) envers les personnes considérées comme âgées sur la base de leur âge chronologique ou qui sont perçues comme étant vieilles.

L'âgisme peut se manifester aux différents niveaux du fonctionnement social. En effet, il peut apparaître au niveau de l'individu, du réseau et du fonctionnement institutionnel, ainsi que de la société et de la culture. L’âgisme peut être conscient ou inconscient (donc volontaire ou involontaire) et se concrétiser à travers des manifestations explicites (comme des mauvais traitements, des injures ou le refus de fournir un service) ou implicites (p.ex. des attitudes condescendantes ou le fait d'ignorer la personne).

Dans les pays occidentaux, la personne âgée est fréquemment perçue comme un fardeau pour la société et un risque pour l'équilibre économique, et les stéréotypes négatifs relatifs à la vieillesse sont bien plus fréquents et nombreux que ceux qui sont positifs. Cette perception restreinte et négative de la vieillesse peut amener à des attitudes de dévalorisation des besoins, des capacités, des préoccupations ou encore des ressentis de la personne âgée. Elle peut aussi avoir des répercussions importantes sur l'identité et l'estime de soi de la personne 
âgée ainsi que sur la perception, et donc l'utilisation, de ses propres compétences (p.ex. en termes de communication et de mobilité). Ces éléments influencent à leur tour l'établissement et le maintien des relations avec autrui, qui sont étroitement associées au bien-être de l'individu. Depuis les années 1990, plusieurs études en laboratoire ont montré que l'âgisme a un effet négatif, par exemple sur la santé générale autoévaluée, les sentiments d'autoefficacité et d'indépendance, les performances cognitives ainsi que sur les capacités motrices et l'acceptation hypothétique de traitements médicaux pouvant prolonger la vie.

Parmi les modèles théoriques avancés pour rendre compte de l'impact de l'âgisme sur le bien-être, un des plus utilisés est le stereotype embodiment theory de Becca Levy. Selon cette théorie, les stéréotypes présents dans le contexte socioculturel sont élaborés, intériorisés et exprimés par l'individu dès l'enfance et, avec l'avancement en âge, ils sont perçus comme étant toujours plus pertinents pour soimême. L'individu les intègre alors progressivement à l'image et à la définition de soi, devenant ainsi des self-stereotypes et influençant son fonctionnement et son bien-être.

En Suisse, au niveau légal, l'article 8.2 de la Constitution fédérale stipule que «Nul ne doit subir de discrimination du fait de son origine, de sa race, de son sexe, de son âge, de sa langue, de sa situation sociale, de son mode de vie, de ses convictions religieuses, philosophiques ou politiques [...]». Par contre, si dans le droit fédéral on retrouve la loi fédérale sur l'égalité entre les sexes, l'ordonnance relative aux droits humains et la lutte contre le racisme ou encore la loi fédérale contre les inégalités vis-à-vis des personnes handicapées, la question des inégalités relatives à l'âge n'est pas considérée au niveau des droits fondamentaux. Enfin, dans le Code pénal suisse, on retrouve uniquement un article portant sur la discrimination relative à la race, l'ethnie et la religion (article 261).
Même si les données peuvent varier d'une étude à l'autre, dans l'ensemble les travaux récents s'accordent sur le fait que l'âgisme est très présent dans la société occidentale actuelle. Selon la quatrième vague de l'enquête European Social Survey, menée en 2008 dans 28 pays européens dont la Suisse, l'âgisme est même plus fréquent que le racisme et le sexisme. Au niveau européen, chez les 65 ans et plus, environ $34 \%$ a déjà été victime de discrimination à cause de l'âge, alors qu'environ $19 \%$ ont été victimes de sexisme et $14 \%$ de racisme. En Suisse, les chiffres suivent la même tendance, mais sont légèrement inférieurs. En effet, parmi les 65 ans et plus, $23 \%$ rapporte de l'âgisme, $12 \%$ du sexisme et $8 \%$ du racisme. Parmi les situations d'âgisme les plus mentionnées on retrouve un manque de respect de la part d'autrui ainsi que des traitements injustes à cause de l'âge. À noter encore qu'environ $40 \%$ de la population générale considère l'âgisme comme un problème sérieux dans notre pays, alors qu'environ $3 \%$ des interviewé.e-s indiquent que le problème n'existe pas. Si ces données sont appelées à évoluer dans le temps, elles donnent néanmoins une indication pertinente par rapport à l'état actuel de la problématique.

Tant en Suisse que dans les autres pays occidentaux, l'âgisme représente une réalité très répandue mais qui est encore trop souvent ignorée et mal connue. Il est donc essentiel de poursuivre et renforcer les efforts de compréhension relatifs à l'âgisme et ses mécanismes sous-jacents. Si d'une part, la recherche scientifique a un rôle central à jouer, d'autre part il est nécessaire de mettre davantage cette problématique au centre du débat social actuel et sensibiliser les différents groupes de la population, des enfants aux personnes âgées elles-mêmes. Cette sensibilisation doit également passer par une meilleure compréhension de la réalité de la personne âgée. En effet, la méconnaissance de la vieillesse est considérée comme une des principales causes de l'âgisme. Un autre enjeu 
majeur est représenté par la présence d'attitudes âgistes chez les professionnel-le-s du domaine social et de la santé, qui peuvent être préjudiciables tant pour l'accès aux services sociosanitaires que pour le choix et la qualité des prestations fournies. À titre d'exemple, le Rapport social 2012 souligne que dans notre pays environ un tiers des personnes âgées de 70 ans et plus a déjà vécu des situations de discrimination dans le milieu de la santé, telles que la banalisation par les soignant·e.s du problème de santé à cause de leur âge. La formation des professionnel-le-s - actuel.le-s et futur.e.s - travaillant auprès et pour les personnes âgées est donc un élément essentiel pour lutter contre l'âgisme. Celle-ci doit permettre l'acquisition de méthodes et d'outils adaptés à ce groupe de la population, afin aussi de limiter les possibles sentiments de frustration ou d'irritation perçus face à des situations pour lesquelles les professionnel-le-s pourraient être mal préparé·e-s. Enfin, un autre enjeu qui doit être mis en exergue est représenté par l'âgisme auprès des groupes sociaux déjà exposés à des formes de discrimination, tels que les femmes et les minorités ethniques, et qui risquent donc d'être confrontés de manière plus importante et prolongée à plusieurs formes d'injustices.

Ces différentes considérations et enjeux sont d'autant plus importants lorsqu'on considère l'évolution démographique dans notre pays, qui pourrait engendrer des craintes concernant l'impact de l'adulte âgé sur la stabilité économique de notre société et ainsi conduire à une exacerbation des attitudes discriminatoires vis-à-vis des ainé·e·s.

\section{Christian Maggiori}

\section{Références}

Abrams, D., Russell, P., Vauclair, M. \& Swift, H. (2011). Ageism in Europe: Findings from the European Social Survey. London: AgeUK.

Iversen, T. N., Larsen, L. \& Solem, P. E. (2012). A conceptual analysis of ageism. Nordic Psychology, 61, 4-22.
Lagacé, M. (Éd.) (2010). L’Âgisme. Comprendre et changer le regard social sur le vieillissement. Sainte-Foy: Presses de l’Université Laval.

\section{Aide à l'enfance et à la jeunesse*}

L'aide à l'enfance et à la jeunesse désigne le domaine d'action créé par les États-providence modernes afin d'intervenir sur les conditions sociales du développement des enfants et des jeunes en dehors de l'école (et d'autres institutions de l'éducation formelle et de la formation professionnelle) et des prestations privées fournies par les familles et les systèmes de parenté. Depuis le rapport du Conseil fédéral de 2012 Violence et négligence envers les enfants et les jeunes au sein de la famille: aide à l'enfance et à la jeunesse et sanctions des pouvoirs publics, une vision moderne de l'aide à l'enfance et à la jeunesse s'impose en Suisse. Cette vision considère comme complémentaires les interventions visant à protéger les enfants contre des mises en danger manifestes de leur bienêtre d'une part et les aides aux enfants, aux jeunes et aux familles d'autre part.

Dans cette logique, l'aide à l'enfance et à la jeunesse couvre tout l'éventail de prestations, de services et d'offres qui soutiennent les parents dans l'accomplissement de leur tâche éducative, qui offrent aux enfants et aux jeunes des possibilités d'apprentissage et de formation en dehors de l'école et qui, globalement, créent des conditions favorables à leur protection et à leur épanouissement. L'aide à l'enfance et à la jeunesse n'intervient pas seulement dans les situations particulièrement graves ou s'écartant de la norme ou lorsque des services spécialisés recommandent un placement extrafamilial pour des mineur.e-s. Elle s'adresse de plus en plus souvent à l'ensemble des enfants, des jeunes et des familles quels que soient leurs besoins de soutien et d'assistance. 
Si l'on suit cette logique à la lettre, l'aide à l'enfance et à la jeunesse implique également des prestations, des services et des offres pour mineur.e.s en situation de handicap. Pourtant, bien que les arguments ne manquent pas pour justifier une telle conception inclusive de l'aide à l'enfance et à la jeunesse, celle-ci n'est pas encore très répandue en Suisse. Concevoir l'aide à l'enfance et à la jeunesse comme une infrastructure publique disponible pour les enfants, les jeunes et les familles exprime deux principes: d'une part, la reconnaissance des droits sociaux des enfants et des jeunes en tant que membres de la société impliquant leur participation et leur droit à la protection, au soutien et à l'aide (voir la Convention des Nations Unies relative aux droits de l'enfant; les articles 11 et 41 de la Constitution fédérale; diverses constitutions cantonales). D'autre part, cette conception exprime la reconnaissance des exigences et des enjeux actuels liés à la parentalité. Cette reconnaissance repose sur le fait empiriquement établi que les relations intergénérationnelles et les processus d'éducation et de développement sont fondamentalement susceptibles de traverser des crises, qu'ils peuvent être considérablement contrariés et mis en danger par des structures et événements internes et externes, et qu'il existe aussi peu de garantie de réussir dans son rôle de parent que de réussir la transition vers une vie adulte indépendante et responsable.

Sur la base du rapport du Conseil fédéral susmentionné, on peut distinguer cinq types de prestations d'aide à l'enfance et à la jeunesse :

a) l'encouragement de l'enfance, de la jeunesse et de la famille, l'animation socioculturelle avec des enfants et des jeunes, l'accueil extrafamilial et parascolaire, la formation des parents ;

b) le conseil et le soutien dans la vie quotidienne et lors de difficultés: conseil et soutiens aux enfants et aux jeunes, du travail social en milieu scolaire, des aides et soutiens aux parents ; c) des aides complémentaires à l'éducation: le placement en institution ou en famille d'accueil, les aides à l'éducation en milieu ouvert, par exemple l'accompagnement éducatif au domicile des familles ou des structures éducatives de jour; ainsi que des prestations de médiation;

d) l'analyse de situation et

e) la gestion par cas.

Dans le système suisse d'aide à l'enfance et à la jeunesse, il existe trois voies d'accès aux prestations. Tout d'abord un accès général: toutes les personnes appartenant à un groupe cible ont accès aux prestations et peuvent les solliciter librement. Ensuite un accès découlant de la décision d'un organe autorisé (p.ex. un service d'aide à l'enfance et à la jeunesse, un service social): cet organe décide, en vertu du droit cantonal, si une personne (ou une famille) doit pouvoir bénéficier d'une prestation (prestation volontaire ou consensuelle). Cette décision est généralement précédée d'une évaluation professionnelle du besoin (indication); la prestation est fournie en accord avec les personnes exerçant l'autorité parentale ou avec l'enfant ou l'adolescent capable de discernement. Enfin une décision d'une autorité de protection de l'enfant et de l'adulte (prestation ordonnée): quand le bien d'un enfant est menacé et que les parents ne sont pas disposés ou ne sont pas en mesure d'écarter le danger, l'autorité de protection de l'enfant et de l'adulte peut ordonner des prestations pour assurer le bien de l'enfant. En principe, toutes les prestations d'aide à l'enfance et à la jeunesse entrent en ligne de compte. L'application de l'article 310 du Code civil (CC) aboutit généralement à un placement en institution ou en famille d'accueil.

Comme dans d'autres secteurs du système de protection sociale, on observe une juxtaposition d'initiatives privées et d'actions des églises et de l'État. Ces trois types d'interventions constituent aujourd'hui la trame d'un réseau d'organisations et d'institutions privées (d'utilité publique) et publiques (wel- 
fare mix). La première phase de création de ces structures correspond aux années 1890 à 1930 (p.ex. création du premier office de tutelle de Suisse dans la Ville de Zurich en 1908). Dans sa version de 1978, le Code civil utilise le terme générique d'aide à la jeunesse pour désigner les prestations destinées aux enfants, aux jeunes et aux parents en dehors de l'école, ainsi que les autorités et services responsables de ces prestations - sans, bien sûr, définir le contenu de ce domaine.

Dans le système fédéral suisse, l'aide à l'enfance et à la jeunesse relève de la compétence des cantons. Cependant, seuls 11 des 26 cantons ont adopté des lois spécifiques sur l'aide à l'enfance et à la jeunesse (BS, FR, GE, JU, NE, OW, SZ, TI, VD, VS, ZH); certains cantons ont réglementé des aspects de l'aide à l'enfance et à la jeunesse dans le cadre de leur législation sociale (p.ex. BE, BL, SO). Depuis les années 2000 , on observe une augmentation du nombre de lois cantonales élaborées ou révisées dans le domaine de l'aide à l'enfance et à la jeunesse. Dans la mesure où il existe une législation cantonale, elle définit les groupes cibles, les domaines de prestation ainsi que les services responsables et elle clarifie les responsabilités en matière de financement. Elle légitime les dépenses publiques consacrées aux offres et prestations d'aide à l'enfance et à la jeunesse, mais ne constitue pas un droit individuel à ces prestations. En règle générale, les législations cantonales ne fournissent que de vagues indications quant aux conditions d'octroi des prestations. La question relative à l'accès aux prestations est donc laissée à la discrétion des services locaux concernés (services sociaux, services d'aide à l'enfance et à la jeunesse, etc.) et de leurs employé-e·s spécialistes. Les offres disponibles et leur qualité varient considérablement d'un canton ou d'une région à l'autre. La plupart du temps, elles sont le résultat d'un développement non planifié. Ce n'est que dans de rares cas que des organes administratifs cantonaux chargés de planifier l'offre et de définir des exigences minimales de qualité ont vu le jour.

Dans le domaine de l'aide à l'enfance et à la jeunesse, la Suisse se caractérise par le fait qu'elle ne dispose d'aucune loi fédérale régissant les droits aux prestations, comme c'est le cas en Allemagne (KJHG - loi sur l'aide à l'enfance et à la jeunesse, livre VIII du code social) ou en Autriche (B-KJHG - loi fédérale sur l'aide à l'enfance et à la jeunesse). En outre, seuls quelques cantons collectent systématiquement des informations statistiques sur les offres, sur le recours à celles-ci ainsi que sur les effets et les coûts qui en résultent. Tandis que l'accès aux prestations ordonnées par une autorité de protection de l'enfant et de l'adulte est réglementé de manière uniforme dans toute la Suisse, l'accès volontaire (consensuel) aux prestations reste particulièrement opaque, alors qu'il permettrait de recourir à des prestations à un stade précoce avant qu'une grave mise en danger du bien de l'enfant ne soit identifiée et avec l'accord des personnes exerçant l'autorité parentale.

Relevant de la compétence des cantons, l'octroi de prestations volontaires suit principalement des règles informelles échappant au radar des lois et ordonnances, il est opaque et dépend dans une large mesure du lieu de résidence de l'enfant, du ou de la jeune et de la famille et des services avec lesquels les personnes entrent en contact. Les caractéristiques structurelles favorisent une tendance à fournir des prestations tardives, à seuil d'accès élevé et coûteuses.

\section{Stefan Schnurr}

\section{Références}

Conseil fédéral (2012). Violence et négligence envers les enfants et les jeunes au sein de la famille. Aide à l'enfance et à la jeunesse et sanctions des pouvoirs publics : rapport du Conseil fédéral en réponse au postulat Fehr (07.3725) du 5 octobre 2007. Berne: Office fédéral des assurances sociales. 
Piller, E. M. \& Schnurr, S. (2013). Kinder- und Jugendhilfe in der Schweiz: Forschung und Diskurse. Wiesbaden : Springer VS.

Schnurr, S. (2016). Child removal proceedings in Switzerland. In K. Burns, T. Pösö \& M. Skivenes (Eds.), Child welfare removals by the state: $a$ cross-country analysis of decision-making systems (pp. 117-145). Oxford: Oxford University Press.

\section{Aide au logement*}

La Suisse fait partie des pays qui disposent d'une très bonne offre de logements. Elle est principalement gérée par le secteur privé. Le secteur public s'assure par diverses mesures complémentaires que toutes les catégories de la population ont accès à des logements appropriés. En Suisse, l'aide au logement d'utilité publique repose sur le principe de subsidiarité. Elle est proposée aux niveaux fédéral, cantonal et communal. La première loi fédérale sur le logement est entrée en vigueur en 1965 sur la base de l'article sur la famille. La répartition des tâches entre la Confédération et les cantons, résultat d'un processus historique, est définie dans les buts sociaux énoncés à l'article 41 de la Constitution fédérale: la Confédération et les cantons s'engagent, en complément de la responsabilité individuelle et de l'initiative privée, à ce que toute personne en quête d'un logement puisse trouver, pour ellemême et sa famille, un logement approprié à des conditions supportables. Ces dispositions découlent de l'ancienne loi fédérale encourageant la construction et l'accession à la propriété de logements (LCAP) de 1974, remplacée en 2003 par la loi fédérale encourageant le logement à loyer ou à prix modérés (loi sur le logement, LOG).

En principe, l'administration publique a recours à deux approches pour encourager le logement à loyer ou à prix modérés: l'aide à la pierre et l'aide à la personne. L'objectif de l'aide à la pierre est d'aider des promo- teur-trice-s immobilier·ère-s d'utilité publique à offrir plus de logements à loyer ou à prix modérés. L'aide à la pierre est liée à un bien nouvellement construit, rénové ou acquis par un·e promoteur-trice immobilier-ère d'utilité publique. Les instruments d'encouragement actuels comprennent, par exemple, la cession de terrains en droit de superficie, des cautionnements, des prêts à taux préférentiel ainsi que des contributions aux coûts de construction, au paiement des intérêts ou à l'amortissement. La participation aux fonds propres de promoteur·trice-s immobilier·ère-s d'utilité publique est un autre instrument encore. Depuis 2007, le Conseil fédéral renonce toutefois aux prêts directs de la Confédération. Indirectement, il contribue de deux manières : premièrement, il accorde des prêts en cautionnant les emprunts par obligations de la Centrale d'émission pour la construction de logements (CCL). De cette façon, les coopératives d'habitation peuvent obtenir un financement partiel à long terme plus avantageux, habituellement sous la forme d'une hypothèque de deuxième rang. Cette pratique permet notamment de réduire les risques des variations du taux hypothécaire pour les nouvelles constructions. Deuxièmement, la Confédération accorde au secteur de la construction de logements d'utilité publique des prêts remboursables à faible taux d'intérêt jusqu'à une limite de $90 \%$ du fonds de roulement. De la sorte, de nombreux projets de promoteur.trice-s immobilier-ère-s plus petits et plus jeunes et disposant de fonds propres réduits sont soutenus; ils ne pourraient pas se réaliser sans de tels prêts.

Dans le cas de l'aide à la personne, l'État verse une allocation de logement directement aux ménages à faible revenu afin que ceux-ci puissent trouver, sur le marché, un logement approprié à un loyer abordable. Citons comme autre forme d'aide à la personne les contributions aux coûts du logement versées dans le cadre des prestations complémentaires de l'assurance-vieillesse et survivants (AVS) et de 
l'assurance-invalidité (AI). L'aide sociale peut aussi prendre en charge le loyer.

Les deux formes d'encouragement peuvent se combiner en n'accordant des allocations au logement que pour les biens immobiliers au bénéfice d'une aide à la pierre. Quand des limites de revenus et des normes d'occupation sont appliquées lors de l'attribution de logements au bénéfice d'une aide à la pierre, il s'agit également d'une aide à la personne liée à l'aide à la pierre.

Au niveau cantonal, il n'existe pas de base juridique uniforme et seuls quelques cantons encouragent activement le logement à loyer modéré, ceci par le biais de contributions initiales au financement ou d'aides à l'acquisition de terrains. Les cantons sont responsables des conditions-cadres légales. Ils peuvent encourager la construction de logements à loyer ou à prix modérés par le truchement de l'aménagement du territoire. Ils ont pour mission de se prononcer, dans le cadre des plans directeurs, sur la garantie d'une offre de logement répondant à tous les besoins et notamment sur la promotion de logements à loyer ou à prix modérés adaptés aux familles et aux personnes âgées. Le canton de Zurich, par exemple, sur la base de la loi du 7 juin 2004 sur l'encouragement de la construction de logements et de l'accession à la propriété, octroie des prêts sans intérêt ou à faible taux d'intérêt aux promoteur-trice-s immobilier·ère-s d'utilité publique, pour autant que la commune contribue avec un montant équivalent. Ces prestations sont liées à diverses conditions, entre autres des limites de revenu pour les locataires ainsi qu'une limite des coûts de construction. D'autres formes d'aide à la personne se pratiquent dans le canton de Bâle-Ville qui accorde des contributions aux frais de loyers des familles ou encore le canton de Genève qui octroie des allocations de logement.

$\mathrm{Au}$ niveau communal, il existe davantage d'instruments d'encouragement concrets qu'au niveau des cantons, mais en réalité, ils ne sont utilisés que dans quelques communes suisses. Certains exécutifs communaux avisés analysent la situation du logement et pratiquent une politique foncière active en vendant des terrains ou en cédant temporairement des terrains en droit de superficie à des promoteur·trice-s immobilier·ère·s d'utilité publique. Une politique du logement active comprend l'octroi d'aides financières, initiales ou liées à un projet, la mise à disposition d'une assistance technique ainsi que la construction de logements communaux. Certaines communes des cantons de Bâle-Campagne et de Vaud accordent des contributions au loyer, soit des aides à la personne.

En comparant de manière pragmatique les avantages et les inconvénients ainsi que les coûts prévisibles (notamment une économie annuelle de 22 millions de francs réalisée sur les prestations complémentaires de l'AVS/AI et les prestations d'aide sociale, selon une étude de l'Office des statistiques du canton de Zurich de 2001), la Confédération ainsi que la plupart des cantons et des communes ont jusqu'à présent axé leur politique du logement principalement sur l'aide à la pierre. Le choix de cette approche se justifie notamment par le maintien à long terme d'une offre de logements à loyer ou à prix modérés et la possibilité d'influencer la qualité des logements (via des concours) et leur quantité. La possible diminution des loyers est un autre effet important dans un marché du logement déséquilibré.

Le traitement favorisant les promoteur-trice-s immobilier-ère-s d'utilité publique est donc parfaitement justifié, car ils offrent et sauvegardent des logements abordables dans l'intérêt de la collectivité. Ce type de logement échappe durablement à la spéculation. Avec ses loyers basés sur les coûts réels et la renonciation à la recherche de profits, ces logements sont beaucoup moins chers à long terme que l'offre locative standard du marché. L'écart entre les types de ménages se creuse en fonction de leur pouvoir d'achat, en particulier 
dans un contexte où la vie urbaine continue de gagner en attractivité en raison des stratégies délibérées de développement urbain et des effets du marché. Dans le débat sur la gentrification, la distinction entre les acteur-trice-s est décisive: lors de la construction de nouveaux bâtiments, les promoteur-trice-s immobilier`ère-s d'utilité publique, dont le parc immobilier est souvent situé en centre-ville et qui ont recours aux encouragements à la construction de logement, sont en mesure de proposer des logements de remplacement abordables aux habitant.e-s d'anciens logements. Ces dernier-ère-s sont souvent copropriétaires via des parts sociales.

L'aide à la personne ne freine pas les prix excessifs sur le marché du logement. Au contraire, si les allocations de logement attribuées se généralisent sur un marché tendu, le risque d'une hausse générale des prix augmente. Dans ce cas toutefois, les aides à la personne permettent d'amortir, au moins partiellement, des loyers excessifs. Des effets secondaires indésirables sont néanmoins à craindre, notamment une augmentation des profits et une redistribution de l'argent des contribuables aux propriétaires.

L'encouragement au moyen de l'aide à la pierre peut viser l'augmentation générale de l'offre de logements à loyer et à prix modérés, comme le montre l'exemple de l'aide fédérale actuelle. Toutefois, l'aide à la pierre peut également être conçue de manière à permettre une réduction ciblée des prix des logements. La pratique des cantons de Zurich et de Zoug va dans ce sens : dans ces cantons, les logements subventionnés sont réservés aux ménages qui en ont le plus besoin. L'attribution en fonction des besoins est garantie au moyen de limites de revenu et de fortune ainsi que par le biais de normes d'occupation, régulièrement contrôlées pour prévenir tout abus.

\section{Références}

Hauri, E. (2009). Quelle politique pour le logement social? Dans L. Pattaroni, V. Kaufmann \& A. Rabinovich (Éd.), Habitat en devenir : enjeux territoriaux, politiques et sociaux du logement en Suisse (pp. 299-321). Lausanne: Presses polytechniques et universitaires romandes.

Sfar, D. (2014). Eine zukunftsgerichtete Wohnraumpolitik für eine Zehn-Millionen-Schweiz. Sozialalmanach, 152-167.

Wohnbaugenossenschaften Schweiz (Hrsg.) (2015). Bezahlbarer Wohnraum - welche Förderung ist sinnvoll? Die Vor- und Nachteile der Objekt- und der Subjekthilfe. Zürich: WBG.

\section{Aide aux victimes d'infractions*}

Depuis le $1^{\text {er }}$ janvier 1993, les droits des personnes victimes d'infractions sont réglés dans la loi sur les victimes d'infractions (LAVI). Toute personne qui, du fait d'une infraction, a subi une atteinte directe à son intégrité physique, psychique ou sexuelle, a droit au soutien prévu par cette loi. Par atteinte directe, on veut dire que les préjudices subis par la personne sont en lien direct avec l'infraction. Les personnes indirectement touchées, par example les témoins d'une infraction, ne sont pas concernées par la LAVI. Les proches des victimes en revanche ont droit à l'aide aux victimes. Il n'existe pas de restriction d'âge et le statut de séjour de la personne concernée ne joue pas de rôle pour autant que l'infraction ait été commise en Suisse. Si l'infraction a été commise à l'étranger, la victime a droit à une aide si elle était domiciliée en Suisse au moment des faits et du dépôt de sa demande.

La loi sur l'aide aux victimes a été acceptée à une majorité de plus de $80 \%$ en 1984 , suite à une initiative lancée par le magazine Beobachter. De nombreux cantons ont délégué l'organisation de centres de consultation LAVI à des fondations et associations privées, d'autres assument eux-mêmes cette tâche. Même si de tels centres de consultation relèvent des admi- 
nistrations cantonales, la loi dispose qu'ils doivent fonctionner de manière autonome sur le plan professionnel. Afin de promouvoir l'application efficace et uniforme de la LAVI et d'encourager la collaboration entre les cantons, la Conférences des directrices et directeurs cantonaux des affaires sociales (CDAS) a institué la Conférence l'aide aux victimes (CSOLLAVI). La CSOL-LAVI publie notamment des recommandations sur l'application de la LAVI. Les cantons n'ont malheureusement pas pu s'accorder sur une forme plus contraignante de norme. Il serait souhaitable qu'ils appliquent lesdites recommandations de manière contraignante. C'est le seul moyen d'empêcher des inégalités de traitement des victimes d'infractions entre cantons.

Dès les premières années suivant l'introduction de la LAVI, une modification de la loi s'est avérée nécessaire pour assurer une meilleure protection aux victimes mineures. Chose faite en 2001, avec une première révision partielle qui renforça leurs droits. Les craintes politiques que la LAVI coûte trop cher en raison des indemnisations financières prévues ont conduit, en 2009, à une révision complète de la loi. Depuis, les prétentions financières pour les infractions commises à l'étranger ont été fortement réduites, mais les prestations de conseil sont demeurées les mêmes. Il convient de relever ici que les coûts de l'aide aux victimes sont proportionnellement modestes comparés aux coûts afférents aux personnes accusées et condamnées.

La force de la loi suisse sur l'aide aux victimes par rapport aux dispositifs correspondants d'autres pays réside dans le fait qu'elle règle non seulement le dédommagement financier des victimes mais qu'elle met l'accent sur le conseil. En Allemagne, par exemple, l'aide aux victimes est fournie sur une base volontaire, en partie par des bénévoles, et les victimes ne bénéficient d'aucun dédommagement financier de l’État. En Suisse, les coûts générés par l'aide aux victimes ne sont pas entièrement couverts par la LAVI, mais les aides importantes et nécessaires, comme les frais d'avocat, l'aide psychothérapeutique et, le cas échéant, une réparation morale, peuvent être prises en charge.

Les centres de consultation LAVI apportent un soutien juridique, psychologique, social, matériel et médical. Lors d'un premier contact téléphonique ou personnel, la conseillère ou le conseiller dresse un bilan de la situation avec la victime, incluant les aspects les plus importants comme la sécurité, l'état psychique, les effets juridiques et financiers, etc. Hormis un travail de service d'intermédiaire vers d'autres professionnel-le-s, la principale mission des centres LAVI est l'accompagnement psychosocial des victimes. La durée de la consultation dépend des besoins de la personne touchée et son objectif est de stabiliser l'état psychique, social et les autres éléments constitutifs de sa situation. Il est essentiel que la consultation soit axée sur les ressources de la victime. Celle-ci ne pourra dépasser son rôle de victime que lorsqu'elle aura repris conscience de ses forces. Les centres de consultation LAVI peuvent offrir une aide financière immédiate. Généralement, le besoin d'une telle aide se manifeste directement après les faits, mais il arrive aussi que la victime se retrouve plus tard dans une situation matérielle difficile et soit tributaire d'une aide pécuniaire urgente. Hormis l'aide financière immédiate, les victimes d'infractions peuvent bénéficier d'un soutien financier supplémentaire, par exemple pour un appui juridique ou une thérapie. Cette aide à plus long terme est fournie sur la base d'une demande. Elle est fonction du revenu, les limites de revenu étant assez généreuses. Les centres LAVI aident à formuler la demande.

La victime et ses proches ont droit, à certaines conditions, à une indemnisation pour les dommages ayant résulté de l'infraction (perte de salaire, frais de traitement, frais funéraires, etc.), à l'exception des dommages matériels. L'indemnisation est calculée en fonction du 
revenu. Lorsque la gravité de l'atteinte le justifie, la victime ou ses proches peuvent en outre bénéficier d'une réparation morale. Les montants accordés en Suisse à ce titre ne sont pas très élevés et donc controversés. Il faut cependant noter qu'il ne s'agit pas d'une assurance qui verse une réparation, mais d'un geste de solidarité de l'État qui reconnaît par là la situation difficile de la victime.

Les demandes d'indemnisation et de réparation doivent être introduites au plus tard cinq ans suivant la date de l'infraction. La personne qui a subi une atteinte grave en tant qu'enfant peut introduire une telle demande jusqu'au jour de ses 25 ans.

Dans le cadre d'une procédure pénale, la victime jouit de droits particuliers. Parmi les plus importants, mentionnons le droit de se faire accompagner par une personne de confiance à toutes les auditions, le droit de refuser la confrontation avec le-la prévenu·e, d'être interrogé-e par une personne du même sexe, le droit au huis-clos dans des circonstances particulières, ainsi que le droit d'obtenir des informations sur la détention, la fuite et la mise en liberté de l'auteur-e. La victime peut participer activement à la procédure pénale en déposant une plainte pénale ou une plainte privée, exiger la condamnation de la personne accusée et faire valoir des prétentions financières.

D'après les centres de consultation LAVI, l'introduction du nouveau Code de procédure pénale a eu pour effet d'affaiblir ce dernier point. Ainsi, de nombreux délits aboutissent à une ordonnance pénale dans laquelle les prétentions financières de la victime ne sont pas prises en compte. Les auteur.e-s d'une évaluation de la LAVI mandatée par la Confédération, publiée en 2015, préconisent le renforcement de la position des victimes. À l'avenir, les prétentions pécuniaires de la victime devraient être réglées directement dans la procédure de l’ordonnance pénale, pour éviter que la victime ne doive les faire valoir dans un procès civil qui peut s'avérer coûteux. Avec la pratique actuelle, la victime n'obtient pas de compensation financière de la personne condamnée et doit recourir à l'aide aux victimes.

Globalement, les auteur·e·s de l'évaluation constatent qu'il n'existe pas de besoin urgent d'agir dans le domaine de l'aide aux victimes. Leur avis rejoint celui des actrices et acteurs du domaine : le dispositif LAVI fonctionne bien en Suisse et les prestations destinées aux victimes sont efficaces.

\section{Susanne Nielen Gangwisch}

\section{Références}

Berset-Hemmer, V. (2015). Les prestations financières fondées sur la loi sur l'aide aux victimes d'infractions. Lugano: Commissione ticinese per la formazione permanente dei giuristi.

Gomm, P. \& Zehntner, D. (Hrsg.) (2009). Kommentar zum Opferhilfegesetz: Bundesgesetz vom 23. März 2007 über die Hilfe an Opfer von Straftaten (3., überarb. Aufl.). Bern : Stämpfli.

Weber, J., Hilf, M. J., Hostettler, U., Sager, F., Geth, C., Leu, N., ... \& J., Scheidegger, N. S. (2015). Evaluation des Opferhilfegesetzes. Bern: Universität Bern.

\section{Aide en matière d'addictions*}

L'aide en matière d'addictions (ou de dépendances) comprend l'ensemble des offres ambulatoires et résidentielles de conseil, sevrage, traitement, thérapie et réduction des risques, qui visent à aider les personnes concernées à sortir de la dépendance ou à réduire la consommation de substances, améliorer leur santé et s'intégrer dans la société. La prescription d'héroïne aux personnes fortement dépendantes d'opiacés et les traitements de substitution, principalement à la méthadone, font partie des mesures thérapeutiques. Parmi les offres de réduction des risques, mentionnons les centres de contact et de consultation, les locaux de consommation, les soupes populaires, l'accueil de nuit, les logements protégés, les programmes d'occupation et le travail social de 
proximité. Des offres ciblées sur la vie festive nocturne - information et conseil sur les substances et leurs risques, drug checking mobile et travail social «hors murs» - s'adressent au groupe-cible, bien intégré socialement, des fêtard·ess.

La Suisse dispose d'un dispositif diversifié et bien développé d'aide en matière d'addictions. Mis en place à la fin du XIX siècle pour lutter contre l'alcoolisme, il s'est recentré quelque cent ans plus tard sur les problématiques de la consommation d'héroïne et des scènes ouvertes dans les grandes villes. Les offres sont du ressort des cantons ou des communes, qui créent des services nécessaires ou soutiennent des institutions privées.

L'aide en matière d'addictions était initialement axée sur l'abstinence. Cependant, même avec le renforcement de la répression et le durcissement de la loi sur les stupéfiants, en 1975, cette approche s'avéra inopérante pour lutter efficacement contre la hausse du nombre de décès dus à la drogue, la précarisation des personnes dépendantes, la rapide augmentation des infections VIH dans le groupe des personnes s'injectant des drogues et les risques pour la santé publique. Seules la mise en place d'offres à bas seuil de réduction des risques et la prescription d'héroïne et traitements de substitution parvinrent à dissoudre les scènes ouvertes et à intégrer les personnes touchées dans des projets de prise en charge. Afin de réduire l'attrait des grandes villes, les personnes dépendantes de substances furent renvoyées dans leurs communes de domicile, et les cantons et les communes confrontés au défi de mettre à disposition une offre de soutien à leur intention. Il s'ensuivit la création en Suisse de nombreux centres de traitement stationnaire. Très différents au départ en termes de qualité de leurs prestations, ces centres se professionnalisèrent progressivement. En 2001, l'Office fédéral de la santé publique développa une norme de qualité pour le domaine des addictions (QuaThéDA) en étroite collaboration avec des spécialistes. Les institutions de la première heure ne passèrent pas toutes le cap de cette consolidation. Au tournant du millénaire, une vague de fermetures frappa les centres d'aide sociothérapeutique aux personnes toxicodépendantes. Parmi les raisons invoquées, deux méritent mention: une offre pléthorique et des défaillances au niveau du management. Mais parallèlement à l'augmentation du nombre de traitements basés sur la méthadone et l'héroïne, les options et les objectifs thérapeutiques s'élargissaient eux aussi. Le paradigme de l'abstinence absolue céda le pas aux objectifs plus réalistes de la stabilisation et de la (ré)intégration sociale. Le concept de la consommation contrôlée fut repris plus tard dans la lutte contre l'alcoolisme. Des centres de traitement résidentiel s'ouvrirent bientôt au traitement de substitution avec prescription médicale de méthadone, non seulement pour des motifs médicaux, mais également à cause de difficultés financières et d'effectifs. L'imbrication de plusieurs sources de financement - assurance-invalidité, assurance-maladie, aide sociale, cantons et communes - et la pression au niveau des coûts eurent pour effet de réduire la durée de traitement et de renforcer la médicalisation de l'aide en matière d'addictions. L'inscription du principe de «l'ambulatoire avant le stationnaire» dans la loi sur l'assurance-maladie incita en outre les cliniques spécialisées à mettre en place des services ambulatoires. Il reste à savoir si le bilan global de la tendance à la réduction de la durée et des coûts des traitements est positif. La dépendance ne se résume pas à l'aspect médical, mais inclut des problèmes sociaux qui demandent un traitement et un encadrement sur la durée. L’optimisation des coûts conjuguée à une coopération et coordination non optimales entre système de santé et système social ont pour effet in fine que les personnes touchées doivent attendre plus longtemps la décision de prise en charge des coûts et que l'accès à un traitement et un accompagnement adéquat est restreint. 
Les offres d'aide aux personnes dépendantes de substance ont été développées avec un haut degré de spécialisation en fonction de la substance (alcool, drogue, tabac) et des groupes cibles, et - dans un premier temps - avec l'abstinence comme unique but thérapeutique. Un lien entre les institutions, plus anciennes, de lutte contre l'alcoolisme (cliniques spécialisées, services de consultation) et l'aide dans le domaine des drogues s'est établi relativement tard. Des considérations d'ordre professionnel et économique ont finalement conduit au regroupement des deux types d'offres en des centres de conseil qui proposent une offre intégrée d'aide en matière d'addictions, y compris celles qui ne sont pas liées à la consommation de substances, comme l'addiction au jeu ou à Internet.

Ces dernières années, des institutions pour groupes cibles spécifiques n'ont pu survivre que lorsqu'elles dépassaient le cadre régional (p.ex. thérapie stationnaire pour femmes avec enfants) ou qu'elles s'adressaient à un groupe de population suffisamment grand dans la région (p.ex. migrant.e.s et dépendant·e.s de substance) et en élargissant en même temps le groupe cible au-delà du domaine de l'addiction. Des programmes thérapeutiques individualisés ont remplacé les concepts de traitement rigides, et les offres destinées à des groupes cibles spécifiques ont fait place à un travail global axé sur la diversité. Un travail qui tient compte de manière différenciée des caractéristiques, problématiques et ressources des personnes dépendantes et qui vise à exploiter au mieux leur potentiel d'insertion sociale et de santé. $\mathrm{Vu}$ le vieillissement de la population, le thème «addiction et vieillesse» gagne en actualité, la question se posant de savoir comment traiter et prendre en charge les personnes d'un certain âge ayant un problème d'addiction.

Pour le dépistage précoce, le traitement et le suivi, l'accent est mis aujourd'hui sur le développement de coopérations concrètes entre le domaine des addictions et des domaines connexes (aide sociale, santé publique, justice et police, monde du travail, migration, etc.). Le travail professionnel en matière d'addictions s'adresse non plus seulement aux personnes directement concernées, mais aussi aux proches, aux employeur-euse-s et à d'autres professionnels. La collaboration entre aide professionnelle et entraide pour les personnes dépendantes, les proches et les parents s'est beaucoup intensifiée et jouit d'une reconnaissance mutuelle.

Avec son modèle des quatre piliers et l'introduction du traitement avec prescription d'héroïne, la Suisse a été pionnière en comparaison internationale. Dans le domaine de la réduction des risques surtout, les centres suisses d'accueil et de consultation avec possibilités de consommer ont capté l'attention du monde entier. La plupart de ces centres se trouvent en Suisse alémanique, car en Suisse romande, l'objectif de la réduction des risques a longtemps peiné à rallier une majorité. Ce n'est que récemment que certaines villes romandes ont développé des offres correspondantes. Parallèlement, la discussion qui à l'origine était focalisée sur la consommation d'héroïne, se poursuit en Suisse alémanique sur l'avenir et le développement de la réduction des risques, dans un contexte marqué par la transformation des modèles de consommation et la pression sur les coûts.

Le développement technologique et le changement de comportement de la population en matière de recherche d'information ont aussi des conséquences pour le domaine des addictions. À côté d'offres de conseil et de traitement sur place, l'aide en ligne revêt une importance grandissante. L'accès se fait de plus en plus souvent virtuellement, indépendamment du lieu et à toute heure, par le biais de sites Internet, d'outils sur mesure pour le soutien thérapeutique et la réduction de la consommation, de tests à faire soi-même ou via le portail professionnel national SafeZone.ch. L'établissement du lien entre l'aide en matière d'addic- 
tions «online» et celle en «face à face» est un des défis de l'heure.

\section{Franziska Eckmann}

\section{Références}

Commission fédérale pour les questions liées aux addictions (Éd.) (2012). La politique drogue en tant que politique de société: un rétrospectif sur trente ans de politique suisse en matière de drogues, 19812011. Zurich: Seismo.

Offre d'aide en matière d'addictions en Suisse. Base de données, Infodrog. https://www.infodrog.ch

Office fédéral de la santé publique (2012). Le Référentiel modulaire QuaThéDA: la norme qualité pour le domaine des dépendances, de la prévention et de la promotion de la santé. Berne: Office fédéral de la santé publique.

\section{Aide sociale*}

Selon la disposition constitutionnelle, l'aide sociale apporte de l'aide dans des situations de détresse. Ses buts sont la couverture des besoins matériels de base des allocataires et le soutien à leur intégration sociale et professionnelle. Conformément au principe de subsidiarité, elle n'intervient que lorsque toutes les autres sources de revenu sont épuisées, insuffisantes ou ne peuvent être obtenues à temps. En vertu de l'article 115 de la Constitution fédérale, l'aide sociale est du ressort des cantons qui peuvent en déléguer la compétence aux communes. Du fait que l'article 12 de la Constitution fédérale stipule un droit à l'aide dans des situations de détresse, les cantons sont obligés d'accorder l'aide sociale. Celle-ci obéit au principe de finalité, c'est-à-dire qu'elle est accordée indépendamment des raisons qui ont conduit à la situation de détresse, à la différence des assurances sociales qui sont, elles, versées selon le principe de causalité. Toujours à la différence de ces dernières, financées en premier lieu au travers de contributions salariales, les versements de l'aide sociale le sont par le produit des impôts cantonaux et communaux. Laide sociale est une "prestation sous condition de ressources", ce qui veut dire que la situation économique de l'ensemble du ménage est prise en considération pour établir le droit à l'aide et les revenus déterminants. Ce n'est pas le cas non plus dans la plupart des assurances sociales.

En raison de la compétence cantonale en la matière, il n'existe pas de législation fédérale sur l'aide sociale (voir plus bas), si l'on excepte la loi fédérale sur la compétence en matière d'assistance des personnes dans le besoin (LAS) qui, comme son nom l'indique, règle cependant uniquement les compétences cantonales dans le cas particulier. En l'absence d'une réglementation à l'échelle nationale et afin d'assurer une harmonisation minimale entre les cantons, la Conférence suisse des institutions d'action sociale (CSIAS) publie des normes pour la conception et le calcul de l'aide sociale. Ces normes formulent des règles pour la détermination du besoin de base matériel, pour les mesures d'intégration sociale et professionnelle, ainsi que pour d'autres aspects liés à l'aide sociale. Cependant, s'agissant uniquement de recommandations à l'attention des cantons, seule leur inscription dans les lois cantonales sur l'aide sociale leur confère force de loi. Et même si ces normes sont valables à l'échelle suisse, leur application diffère grandement d'un canton à un autre, qu'il s'agisse de l'organisation et du financement de l'aide sociale, des droits et devoirs des bénéficiaires ou encore du montant des prestations notamment. Certains cantons connaissent également des prestations sociales en amont de l'aide sociale ayant pour but de faire sortir certains groupes de bénéficiaires de l'aide sociale. On observe des différences parfois si importantes qu'elles mettent en cause les principes constitutionnels de l'égalité de traitement et de la sécurité du droit. Par ailleurs, la péréquation financière intracantonale entre le canton et les communes, qui tient compte du fait que 
les communes financièrement plus faibles sont davantage touchées par les coûts de l'aide sociale, est également réglée différemment d'un canton à un autre, allant de la cantonalisation intégrale des coûts de l'aide sociale à leur communalisation complète.

En 1963, la CSIAS publie pour la première fois des normes chiffrées en francs pour le calcul des prestations d'aide, en soulignant que ces prestations devaient être considérées comme un minimum vital social, qu'elles devaient être adaptées au renchérissement et qu'il y avait lieu de faire participer leurs bénéficiaires dans une juste mesure à la croissance du revenu réel. Dans les révisions consécutives, dont certaines se sont succédé rapidement, le forfait censé couvrir le besoin de base fut ainsi relevé jusqu'en 2003. En 2005, sous le signe de la nouvelle notion de l'État social actif, une nouvelle révision des normes a lieu qui peut être considérée comme un véritable changement de paradigme, en mettant dorénavant l'orientation vers l'effort des bénéficiaire au premier plan au lieu de l'orientation vers les besoins qui prédominait jusqu'alors. Pour preuve, la réduction de près de $7 \%$ du forfait pour l'entretien, une première dans l'histoire de la CSIAS. Afin de compenser cette réduction, en partie du moins, on introduisit un système de suppléments pour honorer les efforts des bénéficiaires : une franchise sur le revenu provenant d'une activité lucrative, un supplément d'intégration pour les bénéficiaires sans activité lucrative mais participant à un programme d'intégration, ainsi qu'un supplément minimal d'intégration pour les personnes qui, pour des raisons de santé, ne peuvent participer à un tel programme. Ce changement de système s'inscrivait dans la nouvelle logique du fördern und fordern (encourager et exiger). Par la suite et en maints endroits, l'accent fut cependant mis sur le deuxième élément. La logique d'activation est également interprétée comme obligation contraignante pour les allocataires de l'aide sociale de prendre un emploi ou de participer à une mesure d'intégration, ce que le Tribunal fédéral a d'ailleurs confirmé. Dix ans plus tard, suite à de vives critiques (voir plus bas), les normes CSIAS furent une nouvelle fois révisées, avec une réduction des allocations de soutien pour les jeunes adultes et les grandes familles et une augmentation massive des possibilités de sanction.

En comparaison avec les pays limitrophes, l'aide sociale suisse présente différentes particularités. Ainsi, les versements de l'aide sociale sont en principe remboursables. Autrement dit, les personnes qui sollicitent l'aide sociale s'apprêtent à contracter une dette qu'ils devront rembourser si, une fois sortis de l'aide sociale, ils se trouvent dans une meilleure situation économique. Relevons qu'en 1999 déjà, l'OCDE avait taxé cette obligation de rembourser d'«archaïque». Toujours est-il que les pratiques relatives au remboursement de l'aide sociale sont fort différentes d'un canton à un autre. Elles vont de l'abolition presque complète de cette réglementation à l'exigence d'un remboursement «tolérable» en cas d'amélioration de la situation financière. Un autre principe valable dans le domaine de l'aide sociale est celui de l'obligation d'entretien en vertu du droit de la famille: les parents en ligne directe ascendante et descendante qui vivent dans des conditions aisées sont censés soutenir financièrement le membre de la famille en situation de détresse. Cette disposition du Code civil a elle aussi été qualifiée d' "archaïque» par l'OCDE. Et ici encore, l'application varie d'un canton à un autre.

En raison des particularités cantonales évoquées plus haut, des voix se sont élevées pratiquement dès la première heure pour réclamer une solution fédérale. En 1905 déjà, la Armenpflegerkonferenz (Conférence de l'assistance aux pauvres), aujourd'hui CSIAS, plaidait pour une législation suisse sur l'aide aux indigent·e.s. Depuis les années 1990, les interpellations réclamant une compétence fédérale en matière d'assistance sociale ont été nom- 
breuses. En 2015, en réponse à un postulat du Conseil national, le Conseil fédéral a présenté un rapport sur l'aménagement de l'aide sociale et des prestations cantonales sous condition de ressources. La position de la majorité des cantons a néanmoins incité le Conseil fédéral à rejeter une loi-cadre fédérale sur l'aide sociale, aussi parce que la Confédération n'entend pas participer au financement de ce filet de sécurité. Autrement dit, une harmonisation de l'aide sociale par le biais d'une réglementation fédérale n'est pas en vue.

Depuis le début du XXI ${ }^{\text {e }}$ siècle, l'aide sociale est la cible de critiques toujours plus nombreuses. On parle d'abus massifs, d'explosion des coûts, d'une «industrie sociale» en expansion, de fainéant·e-s qui se complairaient dans leur situation, etc. Les prestations d'aide seraient trop généreuses et dissuaderaient les bénéficiaires de prendre un emploi. Ce concert de voix indignées couvre le fait que les coûts de l'aide sociale en Suisse se chiffrent à moins de $3 \%$ du total des dépenses de la sécurité sociale. On exige une baisse des prestations et une plus grande autonomie des communes dans le domaine de l'aide sociale. Comme conséquence de ces critiques, les mécanismes de contrôle ont été renforcés, entre autres par l'engagement d'inspecteur·trice-s sociaux·ales.

\section{Ueli Tecklenburg}

\section{Références}

Conférence suisse des institutions d'action sociale (différentes éditions 1963 à 2015). Concepts et normes de calcul de l'aide sociale. Berne: Conférence suisse des institutions d'action sociale.

Conseil fédéral (2013). Aménagement de l'aide sociale et des prestations cantonales sous condition de ressources: rapport du Conseil fédéral donnant suite au postulat 13.4010 de la CSSS-N «Loi-cadre relative à l'aide sociale» du 6 novembre 2013. Berne: Office fédéral des assurances sociales.

Hänzi, C. (2011). Die Richtlinien der schweizerischen Konferenz für Sozialhilfe: Entwicklung, Bedeutung und Umsetzung der Richtlinien in den deutschsprachigen Kantonen der Schweiz. Basel : Helbing Lichtenhahn.

\section{Aide sociale dans le domaine de l'asile}

Dans le cadre du domaine de l'asile, l'aide sociale est souvent conçue de manière dissuasive. La décision de retirer l'aide sociale aux refusé·e·s de l'asile représente ainsi un exemple abouti d'une telle politique de dissuasion consistant à agir sur la subjectivité des personnes tenues de quitter le territoire afin qu'elles se résolvent d'elles-mêmes à partir. Cette mesure figurait dans le plan d'allègement budgétaire de la Confédération de 2003 (PAB2003) qui prévoyait de réduire de 10000 personnes l'effectif de l'asile et de réaliser une économie de 137 millions en trois ans. Une de ses dispositions transférait les personnes frappées par une décision de non-entrée en matière (NEM), de la législation sur l'asile à la législation ordinaire sur les étranger-ère-s, permettant de les exclure de l'aide sociale encore prévue par le droit d'asile. Cette modification, adoptée le 24 mars 2004 par le Conseil fédéral, est entrée en vigueur le $1^{\mathrm{er}}$ avril 2004, date à partir de laquelle l'aide sociale n'est plus octroyée aux migrant·e·s frappé·e·s de NEM, avant même la révision de la loi sur l'asile. La proposition du Conseil fédéral d'élargir la suppression de l'aide sociale à l'ensemble des requérant·e·s d'asile débouté·e·s a été plébiscitée le 24 septembre 2006, date à laquelle le peuple a approuvé à une majorité de $67,8 \%$ la $7^{\mathrm{e}}$ révision de la loi sur l'asile (LAsi), entrée en vigueur le $1^{\mathrm{er}}$ janvier 2008.

Dès lors, l'aide financière des requérant·e.s sans droit de rester s'est articulée autour de l'article 12 de la Constitution fédérale, qui stipule un droit à une aide pour toute personne dans une situation de détresse. À partir de cette base légale, un véritable système, une administration et un monitoring de cette aide d'urgence vont être établis et concrétisés par les cantons. Couvrant spécifiquement le soutien destiné aux personnes n'ayant pas le droit de rester en Suisse, le système d'aide d'urgence va être plus nettement différencié de celui de l'aide sociale 
applicable aux personnes faisant partie de la population résidente régulière. Depuis 2017, la révision des normes CSIAS attribue clairement l'aide d'urgence au domaine de l'asile et la réserve aux requérant·e-s ayant reçu une décision de non-entrée en matière et dont la décision de renvoi est entrée en force (y compris les «cas Dublin»), à ceux et celles dont l'admission provisoire a été révoquée et à ceux et celles qui ont perdu le droit de rester en vertu de la loi sur les étrangers et l'intégration (LEI).

En matière de prestations, l'octroi de l'aide d'urgence relève de la compétence cantonale. Les cantons peuvent déléguer cette tâche aux communes ou à des œuvres d'entraide et reçoivent des indemnités de la Confédération pour leurs frais d'assistance. Ce transfert des charges de la Confédération vers les cantons et les communes a ouvert la voie à un traitement différencié et inégal. Les prestations sont en principe octroyées en nature et comprennent nourriture, vêtements de deuxième main et articles d'hygiène, lesquels sont souvent délivrés selon un système de bons qui tend à accroître la dépendance des personnes. Elles incluent également l'hébergement dans des centres collectifs souvent isolés des centres urbains et dont la gestion connaît aussi d'importantes disparités cantonales: certains centres ont des régimes stricts avec contrôles à l'entrée, obligation de présence et interdiction de visites, d'autres ferment pendant la journée, même en hiver. Depuis 2011, les requérant·ess en régime d'aide d'urgence sont obligatoirement affilié·ess à une assurance-maladie. Pour renouveler l'aide reçue, les requérant·e-s doivent en outre se présenter régulièrement au service cantonal des migrations (tous les 5 à 15 jours selon les cantons) où ces personnes subissent en général des pressions pour quitter le territoire ou collaborer à leur départ.

Par le jeu combiné de l'obligation constitutionnelle d'aider les personnes en détresse et de l'impossibilité de renvoyer une partie d'entre elles, l'octroi en principe ponctuel de l'aide d'urgence va donner lieu à la gestion de situations se prolongeant dans le temps. Si l'entrée en régime d'aide d'urgence place les migrant·e-s dans une zone intermédiaire d'illégalité tolérée et contrôlée, l'entrée dans la clandestinité qui peut lui succéder les livre à leur sort. La personne prolonge dans ce cas son séjour illégal en recourant à des stratégies de survie, ou, parfois, à des services officiels non destinés aux requérant.e.s. C'est ainsi que lorsque l'existence sous aide d'urgence n'est plus possible et que le renvoi ne peut avoir lieu, les personnes disparaissent sur le plan administratif et social, sans pour autant avoir quitté le territoire. Nous avons là une forme identifiable des processus d'invisibilisation des personnes qui semblent se développer dans les sociétés d'aujourd'hui jusqu'à ce que des situations de détresse telles qu'elles ont été engendrées par la pandémie de coronavirus en 2020 forcent ces personnes à rejoindre les files d'attentes pour obtenir quelques aliments.

En matière d'aide sociale, seul-e.s les réfugié·e-s reconnu·e-s ont droit aux mêmes prestations que les nationaux, en vertu de l'égalité de traitement stipulée par la Convention de Genève de 1951 relative au statut des réfugiés. Relevant depuis 1999 de la compétence cantonale, l'octroi d'une aide sociale aux requérant·ess d'asile en procédure, aux personnes admises provisoirement sur le territoire suisse et aux personnes à protéger, varie selon les cantons et le statut juridique des personnes, tout en demeurant inscrit, comme l'aide d'urgence, dans l'objectif de réduire l'attractivité de la Suisse. Cela se traduit dans le montant des prestations qui sont de 40 à $60 \%$ inférieures à celles de l'aide sociale «standard» et par une tendance à réduire l'aide sociale au niveau de l'aide d'urgence, comme il ressort des nouvelles dispositions légales visant à accélérer les procédures d'asile, acceptées par votation populaire le 5 juin 2016, qui prévoient de fournir l'aide sociale, dans la mesure du possible, sous la forme de prestations en nature. Au-delà de 
la péjoration des conditions de vie des demandeurs et demandeuses d'asile qu'entraînent ces dispositions, l'évolution de l'aide sociale dans le cadre de l'asile doit être regardée à la lumière d'une politique dissuasive postulant a priori l'interdiction de travailler. Contrairement à l'aide sociale dont bénéficient les nationaux et les réfugié·e-s reconnu·e-s, qui vise à favoriser la réintégration sociale et professionnelle des bénéficiaires, l'aide destinée aux requérant·e·s d'asile revêt avant tout une dimension de contrôle et d'incitation au départ. En outre, la situation de dépendance et de passivité dans laquelle se retrouvent des personnes potentiellement capables de subvenir à leurs besoins risque de les rendre incapables de se projeter dans l'avenir. Ceci peut entraîner des effets paradoxaux sur l'incitation au départ, notamment sur la demande de l'aide au retour assurée par les services et les œuvres d'entraide cantonaux, sous l'égide du Secrétariat d'État aux migrations.

Avec l'accroissement du nombre de migrant·e.s empruntant la voie de l'asile, la question de l'aide sociale aux requérant-e-s est devenue centrale dans de nombreux pays européens. Elle s'inscrit dans une orientation des politiques d'asile actuelles qui vise à limiter l'assistance étatique à partir de l'idée selon laquelle des prestations trop généreuses rendraient les États trop attractifs. Bien que marqué par un durcissement général dans l'Union européenne, le traitement des requérant.e.s d'asile et des réfugié·e·s demeure fort inégal d'un État membre à un autre. Une allocation temporaire et l'hébergement en centre collectif sont en général assortis d'une interdiction de travailler (p. ex. France et Allemagne), bien que l'on trouve des systèmes plus flexibles (Suède). On observe un manque d'installations et un système débordé par l'explosion des demandes d'asile de ces dernières années dans les pays du sud de l'Europe (Grèce, Italie, Espagne) tandis qu'en Hongrie les requérant·e-s d'asile débou-

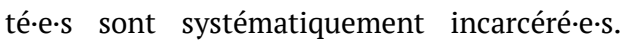

Malgré l'obligation commune de protéger les requérant·e·s, l'expérience de l'Union européenne suggère que la menace de dénuement serait devenue instrumentale pour contrer la demande d'asile. La Suisse ne fait pas exception à cet égard.

\section{Margarita Sanchez-Mazas}

\section{Références}

Bolzman, C. (2001). Politiques d'asile et trajectoires sociales des réfugiés : une exclusion programmée. Le cas de la Suisse. Sociologie et sociétés, 33(2), 133-158.

Lomba (da), S. (2006). The threat of destitution as a deterrent against asylum seeking in the European Union. Refuge, 23(1), 78-93.

Sanchez-Mazas, M., Effionayi-Mäder, D., Maggi, J., Achermann, C., Schaer, M., Roca i Escoda, M., Coumou-Stants, F. (2011). La construction de l'invisibilité: suppression de l'aide sociale dans le domaine de l'asile. Genève: ies.

\section{Aide sociale et genre*}

Selon une formule consacrée par la recherche en politique sociale, les femmes seraient «pauvres sans mari», surtout lorsqu'elles ont des enfants. Parce que, d'une part, les salaires habituellement versés aux femmes ne leur permettraient pas de nourrir une famille, et d'autre part parce qu'elles seraient désavantagées par la sécurité sociale, encore organisée sur le modèle masculin de l'activité permanente à plein temps. Dans ces conditions, l'aide sociale non contributive prendrait une dimension existentielle. Dans les faits, même en Suisse les femmes sont davantage touchées par la pauvreté que les hommes. Les aides sociales sont versées à peu près autant aux deux sexes, mais les familles monoparentales présentent le risque de dépendance à l'aide sociale le plus élevé. Mais pour les femmes, et en particulier pour celles qui élèvent seules leurs enfants, l'aide sociale a plus souvent que pour les 
hommes la fonction de couverture des besoins de base à long terme : elles sont clairement surreprésentées parmi les bénéficiaires de longue durée ou permanent.e.s.

Depuis le tournant des mesures d'activation prises à la fin des années 1990, on attend des bénéficiaires de l'aide sociale en capacité et en âge de travailler qu'ils-elles recherchent et acceptent toute activité professionnelle raisonnable ou qu'ils-elles soient prêts à participer à des programmes d'intégration. Dans les normes CSIAS, les mesures d'intégration professionnelle et sociale sont considérées comme des investissements censés apporter un bénéfice à la société ainsi que des avantages aux personnes concernées. Le travail de care non rémunéré traditionnellement accompli par les femmes pour leur famille (les soins aux enfants et aux personnes dépendantes et les tâches ménagères) ne justifie pas en soi une exonération du devoir d'intégration. Du point de vue du genre, la réorientation de l'aide sociale pose deux questions fondamentales. Premièrement, si l'aide sociale se focalise tellement sur l'intégration professionnelle, quelle valeur accordet-elle au travail de care non rémunéré au sein de la famille? Deuxièmement, on peut se demander si les deux sexes profitent dans une même mesure de cet encouragement propagé par les mesures d'intégration.

Dans l'aide sociale, l'ensemble du foyer représente l'unité économique de référence. Les revenus de tous les membres de la famille sont inclus dans le budget; les deux sexes sont donc en principe considérés comme des pourvoyeurs potentiels. Du point de vue de la couverture des besoins de base, le travail de care représente surtout un obstacle professionnel: celui ou celle qui assume les responsabilités familiales perd en flexibilité pour le marché du travail. Le modèle du double revenu est aussi à la base du paradigme sociopolitique des investissements sociaux auxquels font référence les normes CSIAS (voir ci-dessus). Ici, la promotion du capital humain par la société joue un rôle prépondérant. C'est pourquoi, outre l'incitation à l'«employabilité» des adultes, on insiste tant pour créer les conditions favorables au développement des enfants, qui constituent le futur potentiel de main d'œuvre. Selon cette logique, il faudrait donc trouver en permanence le bon équilibre entre potentiel de revenu et potentiel de care dans le ménage : les parents doivent-ils travailler davantage à l'extérieur de la maison et gagner plus d'argent, ou rester à la maison pour s'occuper de l'éducation des enfants? Dans leur dernière version de 2017, les normes de la CSIAS donnent clairement la priorité au travail rémunéré: une activité lucrative ou la participation à des mesures d'intégration est à prévoir au plus tard à la fin de la première année de vie du plus jeune enfant (section C.1.3). Alors qu'auparavant, elles fixaient cette échéance aux trois ans du plus jeune enfant pour les familles monoparentales, il n'y a plus de règle spéciale aujourd'hui pour ces dernières. Dans la même section, il est stipulé que les coûts de garde extrafamiliale des enfants doivent être pris en charge si les parents ont une activité lucrative, cherchent activement un emploi ou participent à une mesure d'intégration. Mais le travail de care lui-même n'ouvre pas droit à des prestations financières supplémentaires. Par conséquent, le supplément d'intégration introduit en 2005 pour les personnes élevant seules leurs enfants et qui ne peuvent exercer d'activité à l'extérieur du foyer en raison de leurs responsabilités familiales a été supprimé dès 2016 dans les normes CSIAS, en même temps qu'un supplément pour le soin aux proches.

Des études empiriques ont montré que dans le cadre de leurs consultations, les travailleur·eus·s sociaux·ales traitent la répartition du travail professionnel et du travail de care entre les sexes de manière ambivalente. En vue de la sortie du ménage de l'aide sociale par l'activité professionnelle, ils·elles préconisent théoriquement le travail des deux conjoints. Cependant, ils·elles ne vont pas jusqu'à remettre en 
question la traditionnelle répartition du travail afin d'optimiser les revenus du ménage, en visant par exemple l'emploi à plein temps des deux parents ou en inversant les rôles dans le cas où la femme aurait de meilleures opportunités professionnelles ou de revenu. On privilégie plus souvent le modèle modernisé constitué d'un pourvoyeur masculin et d'une femme au foyer, dans lequel l'homme travaille à temps plein et la femme travaille à temps partiel et assume l'éducation des enfants. Car comme toujours, le travail de care est en principe dévolu aux femmes. Par conséquent, le fait de concilier travail professionnel et vie de famille n'est considéré comme un problème que pour les femmes. Lorsqu'une femme (élevant seule ses enfants) souhaite rechercher rapidement un emploi ou participer à une mesure d'intégration, elle est plutôt freinée qu'encouragée au nom du bien-être des enfants. On y voit également un certain pragmatisme: étant donné l'inégalité des sexes au niveau des salaires, il est fort probable que l'homme pourra gagner plus que la femme, et au vu du niveau élevé des frais d'accueil extrafamilial des enfants, il n'est pas forcément rentable que les deux parents partent travailler, surtout si leurs salaires sont peu importants. Dans la mesure où les femmes sont d'abord considérées comme des mères et ensuite seulement comme des personnes professionnellement actives, elles semblent aussi moins encouragées. Les données relatives aux mesures d'intégration de l'aide sociale sont peu nombreuses et peu différenciées. Mais il apparaît que les femmes, et particulièrement les femmes étrangères, sont clairement sous-représentées dans les programmes recensés par les statistiques de l'aide sociale.

L'aide sociale en tant que dernier maillon de la sécurité sociale soutient et conseille les personnes particulièrement vulnérables en situation de précarité et intervient directement dans leur mode de vie. Elle doit par conséquent exercer son pouvoir de manière réfléchie et avec retenue. Pour que l'aide sociale garantisse une égalité entre les sexes, il faut donc éliminer les obstacles à un modèle familial égalitaire, sans imposer aux bénéficiaires un quelconque modèle familial et de répartition des rôles. L'activité professionnelle et le travail de care doivent être reconnus comme des contributions de même valeur au bien-être de la famille et de la société. Le fait d'assumer le travail de care ne doit donc pas être pénalisant. D'un point de vue financier, le manque à gagner lié aux opportunités professionnelles perdues doit être compensé par un supplément substantiel, et des incitations à l'activité lucrative des deux conjoints doivent être mises en place grâce à des franchises sur le revenu. Il convient en outre de s'assurer que les bénéficiaires des prestations d'aide sociale devant assumer un travail de care ne soient pas exclu.e.s de la promotion professionnelle, mais en même temps, que les femmes et les hommes puissent choisir d'assumer eux·elles-mêmes le soin aux enfants et aux proches sans avoir à en pâtir.

\section{Eva Nadai}

\section{Références}

Modak, M., Messant, F. \& Keller, V. (2013). Les normes d'une famille «juste» dans les interventions des assistantes et assistants sociaux de l'aide sociale publique. Nouvelles questions féministes: revue internationale francophone, 32(2), 57-72.

Nadai, E., Canonica, A. \& Hauss, G. (2013). Investieren, Aktivieren, Profitieren: Berufliche Eingliederung als Frauenförderung? Olten: Hochschule für Soziale Arbeit.

Stutz, H. \& Knupfer, C. (2012). Sozialhilfe. In H. Stutz \& C. Knupfer (Hrsg.), Absicherung unbezahlter Care-Arbeit von Frauen und Männern. Anpassungsbedarf des Sozialstaats in Zeiten sich ändernder Arbeitsteilung (S. 99-111). Bern: Eidgenössisches Büro für die Gleichstellung. 


\section{Aide sociale (groupes à risque)}

Des groupes sociaux peuvent être déclarés «à risque» d'aide sociale en fonction du nombre absolu de personnes qu'ils concernent, du taux ou de la durée de l'aide et d'une augmentation y relative, ou encore si l'aide est perçue comme peu légitime. Les caractéristiques des groupes et le nombre de personnes devant recourir à l'aide sociale sont déterminés par des paramètres dynamiques sociaux, politiques et administratifs propres à chaque époque et à chaque lieu.

Le marché de l'emploi et les salaires, l'organisation des familles et la division sexuée du travail, la démographie et le marché du logement sont des facteurs décisifs, tout comme les comportements des individus et les conditions d'accès à l'aide sociale. Aujourd'hui, de par le caractère subsidiaire de l'aide sociale suisse, les groupes de bénéficiaires sont fonction de l'étendue des dispositifs en amont de l'aide sociale. Toute modification dans les assurances-chômage, vieillesse et invalidité modifie la composition des groupes et le nombre de personnes assistées. De même, les prestations pour familles, y compris la disponibilité ou l'absence de structures d'accueil extrafamilial pour enfants et les conditions d'accès aux formations et aux bourses sont d'autres facteurs de risque, respectivement de protection contre le besoin de recourir à l'aide sociale. Enfin, les normes sociales dominantes rendent plus ou moins légitime le recours à l'aide sociale qui sera dès lors plus ou moins visibilisé voire scandalisé.

Contrairement à une affirmation répandue, le risque de devoir un jour recourir à l'aide sociale ne touche pas tout le monde de manière identique. Aujourd'hui, en Suisse, quatre groupes sont régulièrement mis en avant comme des groupes à risque: les jeunes adultes, les personnes de nationalité étrangère, les personnes avec un faible niveau de scolarité et les familles monoparentales. Ce risque est essentiellement défini comme une surreprésentation par rapport à la population résidente, mais pas seulement. Qu'en est-il pour les quatre groupes? La Statistique suisse de l'aide sociale renseigne à ce propos depuis 2005 .

Premier groupe, les jeunes adultes. Ce groupe - les personnes entre 18 et 25 , parfois 35 ans - figure comme catégorie problématique dans un grand nombre de publications sur l'aide sociale. Il relève d'un traitement spécifique dans les normes de la CSIAS et dans de nombreuses lois cantonales. Les jeunes adultes sont légèrement surreprésentés à l'aide sociale. Leur taux d'aide - la proportion par rapport à la population résidente - est toutefois en légère diminution depuis plusieurs années, même si leur nombre absolu augmente. Cependant, l'augmentation du nombre absolu s'observe dans tous les groupes aidés car, en dehors de tout autre phénomène, la population résidente s'accroît.

Le groupe des jeunes adultes n'est pas le groupe d'âge le plus surreprésenté à l'aide sociale. Cette première place revient aux enfants. En Suisse, un enfant sur vingt est bénéficiaire de l'aide sociale, et près d'un tiers des personnes aidées sont des enfants. La pauvreté des enfants est pourtant rarement pointée - une pauvreté silencieuse ? Pourquoi alors la construction du groupe des jeunes adultes et son traitement spécifique? Les jeunes adultes d'aujourd'hui font partie de ces mauvais pauvres que l'Histoire a toujours connus: soupçonnés de mauvaise volonté et mauvaise vie dont l'inactivité est perçue comme illégitime. Sans doute l'antique crainte d'une aide «à vie» ou de «dynasties d'assisté·e-s » opèret-elle. Elle est omniprésente dans les discours des responsables de l'aide sociale. Cette crainte n'est toutefois pas fondée: les jeunes adultes sont parmi les groupes qui ont besoin de l'aide sociale le moins longtemps de manière ininterrompue.

Deuxième groupe, les personnes de nationalité étrangère. Elles reçoivent l'aide sociale 
près de trois fois plus souvent que les Suisses. Ce ne sont toutefois pas tous les étrangers et toutes les étrangères qui sont surreprésenté·e·s à l'aide sociale. Les titulaires d'un passeport de l'Union européenne ne s'y retrouvent guère plus souvent que les Suisses. La surreprésentation est le fait de ressortissant.e-s extra-européen-ne-s. Elle est due à des qualifications professionnelles souvent faibles, à la non-maitrise de la langue et au manque de liens avec le marché du travail. À noter aussi que les personnes de nationalités extra-européennes travaillent, pour beaucoup d'entre elles, plus souvent dans des secteurs à bas salaires et peu protégés. Le risque de devoir s'adresser à l'aide sociale est alors accru. Ce risque touche en particulier les réfugié.e-s reconnu.e.s parmi lesquel-le-s une large majorité doit recourir à l'aide sociale.

Troisième groupe, les personnes sans formation professionnelle certifiée. Leur proportion est bien plus élevée (plus de deux fois) que dans la population résidente. L'absence de formation professionnelle constitue un facteur de risque de se retrouver à l'aide sociale. Toutefois, le fait de disposer d'une formation professionnelle n'exclut pas ce risque puisque plus de $40 \%$ des bénéficiaires possèdent un diplôme professionnel. Le niveau de formation n'est pas une simple question de volonté, de motivation et de persévérance. Il dépend de l'origine sociale. Dans les classes moyennes et supérieures, les jeunes se forment plus souvent et plus longtemps. Plus tard dans la vie adulte, plus on est diplômé·e, plus on continue à se former. Le niveau de formation dépend par ailleurs du genre et de la nationalité. Le groupe le moins qualifié est constitué des jeunes femmes de nationalité étrangère.

Quatrième groupe, les «familles monoparentales». Elles sont fortement surreprésentées à l'aide sociale. Près d'un ménage monoparental sur cinq en Suisse est bénéficiaire de l'aide sociale. De tous les groupes à l'aide sociale, la durée de l'aide est la plus longue pour ces ménages - le temps que les enfants deviennent autonomes. La notion de monoparentalité, neutre en termes de genre, masque le fait que la quasi-totalité (env. 95\%) des familles monoparentales à l'aide sociale sont des femmes qui élèvent seules leurs enfants. Cette neutralisation occulte le fait que les effets d'une séparation touchent les femmes bien plus que les hommes. D'une part en raison d'inégalités financières précédant la séparation. D'autre part en raison de la garde des enfants attribuée aux mères dans la très grande majorité des situations. Et enfin, en raison d'une discrimination des femmes lors du calcul de la pension alimentaire. La jurisprudence actuelle protège le revenu d'existence de la personne qui doit verser une pension - l'homme en règle générale. L’autre ex-partenaire - la femme en règle générale - n'a droit à une pension qu'une fois les besoins de l'homme couverts. Elle devra donc s'adresser à l'aide sociale. La pauvreté suite à une séparation est conséquence d'inégalités de genre. Elle est aussi conséquence d'inégalités de classe. Les effets matériels d'une séparation ne projettent pas les femmes de milieux aisés dans la pauvreté.

Les personnes de 50 ans et plus constituent un groupe à part. Leur taux d'aide sociale n'est certes pas supérieur à la moyenne ; il est toutefois en augmentation depuis quelques années. Ces personnes sont surreprésentées dans le groupe des bénéficiaires de longue durée. Les difficultés de retrouver un travail à cet âge en sont la principale cause.

En synthèse, les caractéristiques sociodémographiques des quatre groupes présentés démontrent que ce n'est pas la malchance arrivant dans un ciel bleu qui conduit à l'aide sociale, mais l'appartenance aux classes populaires pauvres et précarisées qui constitue le principal facteur de risque d'aide sociale. En ce sens, l'aide sociale d'aujourd'hui s'inscrit dans la continuité des logiques d'assistance antérieures : elle s'adresse, tout en cherchant à les normaliser, à des groupes sociaux disposant 
de ressources inférieures. Aujourd'hui, elles et ils sont peu formé·e·s, peu payé·e·s et peu protégé·e·s, davantage exposé·e·s aux risques de maladie, d'accident et de chômage et davantage touché·e-s par les effets d'une séparation. Si les frontières de ces groupes sont floues, les effets des rapports sociaux inégalitaires de genre, de classe et d'origine nationale se cumulent et font système. Aujourd'hui comme hier.

\section{Véréna Keller}

\section{Références}

Peugny, C. (2013). Le destin au berceau: inégalités et reproduction sociale. Paris : Seuil.

Salzgeber, R., Fritschi, T., von Gunten, L., Hümbelin, O., Koch, K. (2016). Verläufe in der Sozialhilfe (2006-2011). Neuchâtel: Bundesamt für Statistik.

Tabin, J.-P., Frauenfelder, A., Togni, C. \& Keller, V. (2010). Temps d'assistance: le gouvernement des pauvres en Suisse romande depuis la fin du XIX ${ }^{e}$ siècle ( $2^{\mathrm{e}}$ éd. rev.). Lausanne: Antipodes.

\section{Aide sociale pour les Suisses et les Suissesses de l'étranger*}

Lorsque des ressortissant.e.s suisses se trouvent dans une situation financière difficile à l'étranger, ils et elles peuvent demander l'aide de la représentation suisse. Les Suisses et les Suissesses de l'étranger bénéficient de l'aide sociale de la Confédération. En cas de besoin lors d'un séjour temporaire à l'étranger, un prêt d'urgence peut leur être accordé.

$\mathrm{Au}$ cours des 50 dernières années, les dispositions relatives à l'assistance aux Suisses et aux Suissesses de l'étranger ont été modifiées et clarifiées à plusieurs reprises. Jusqu'à l'entrée en vigueur de la loi fédérale sur l'assistance des Suisses de l'étranger du 21 mars 1973 (LASE), l'assistance à ces personnes relevait, en principe, de leur canton d'origine. Cette réglementation conduisait régulièrement à des inégalités de traitement entre des personnes dans des circonstances comparables mais dont les droits civils divergeaient. Avec la LASE, la responsabilité et le financement de l'assistance aux ressortissant·e·s suisses résidant ou séjournant plus de trois mois à l'étranger ont été transférés à la Confédération. Lorsque ces personnes rentraient en Suisse, elles étaient aidées par les cantons dès leur arrivée en Suisse. Cette responsabilité était réglée par la loi fédérale sur la compétence en matière d'assistance des personnes dans le besoin du 24 juin 1977 (LAS). Quant à l'aide aux ressortissant.e-s suisses se trouvant dans une situation de besoin lors d'un séjour temporaire à l'étranger, elle était réglementée par le Conseil fédéral dans des ordonnances limitées dans le temps fondées sur la Constitution fédérale. La révision partielle de la LASE du $1^{\text {er }}$ janvier 2010 a changé cette règle. La LASE a changé de nom pour devenir loi fédérale sur l'aide sociale et les prêts alloués aux ressortissants suisses à l'étranger (LAPE). Un nouveau chapitre sur les prêts accordés aux ressortissant·e-s suisses en difficulté séjournant temporairement à l'étranger a été introduit. La LAPE est restée en vigueur jusqu'au 31 octobre 2015. Elle a été remplacée par la loi sur les Suisses de l'étranger du 26 septembre 2014 (LSEtr). Cette loi regroupe plusieurs actes législatifs; elle permet de meilleures relations entre la Confédération et la communauté des Suisses et Suissesses de l'étranger. Pour la première fois, elle attribue les tâches de manière centralisée à un seul département: le Département fédéral des affaires étrangères.

La LSEtr, toujours en vigueur, règle toutes les questions concernant les Suisses et les Suissesses de l'étranger. Cette loi définit ces personnes comme des ressortissant·e-s suisses sans domicile en Suisse inscrit.e-s au registre des Suisses de l'étranger. En principe, seules les personnes inscrites dans ce registre peuvent bénéficier de l'aide sociale selon la LSEtr. Son financement est assuré par la Confédération. En cas de nationalités multiples, l'aide sociale n'est, en principe, pas accordée si la nationalité 
étrangère prévaut. Plusieurs facteurs sont pris en compte, comme les circonstances qui ont conduit à l'acquisition de la nationalité étrangère, le lieu où la personne a passé son enfance, la durée de résidence dans le pays où elle séjourne actuellement ainsi que les relations qu'elle entretient avec la Suisse. Dans le cas de mineur.e.s ou d'adultes très gravement handicapé·e-s et sans capacité d'exercer leurs droits civils, des prestations d'assistance peuvent être accordées même si la nationalité étrangère prédomine pour autant que la nationalité suisse prévale chez l'un des parents. En cas de doute, la décision est prise en faveur des personnes concernées lors d'événements de guerre ou de catastrophes naturelles. L'octroi de l'aide sociale selon la LSEtr présuppose que la personne ne peut subvenir dans une mesure suffisante à son entretien par ses propres moyens, par une aide privée ou de l'État de résidence. Le principe de subsidiarité s'applique. La nature et l'étendue de l'aide sociale se déterminent selon les conditions de l'État de résidence. En vertu de la LSEtr, l'aide sociale doit permettre à la personne concernée de mener une existence décente et de participer à la vie sociale dans l'État de résidence dans le but de maintenir ou de recouvrer son indépendance économique. Cette aide ne couvre pas les risques entrepreneuriaux ni une activité de développement économique. La LSEtr distingue entre prestations uniques et récurrentes. Les prestations récurrentes sont versées pendant un an et peuvent être prolongées. Les frais pour l'entretien sont calculés sur une base forfaitaire en tenant compte de la taille du ménage. Le droit à des prestations récurrentes est accordé pour autant que l'ensemble des circonstances justifie un séjour dans l'État de résidence. Tel est le cas si la personne y vit depuis de longues années, s'il est probable qu'elle retrouvera rapidement son indépendance économique ou si le retour en Suisse n'est pas exigible en raison de liens familiaux étroits. La question de savoir s'il est plus coûteux pour les pouvoirs publics d'as- sister une personne en Suisse ou à l'étranger n'est pas déterminante. Quant aux prestations uniques, elles seront accordées, par exemple, pour un traitement médical. Lorsqu'une personne reçoit une aide pour rentrer en Suisse, la Confédération prend contact avec le canton de destination. Outre les frais de rapatriement et les prestations éventuelles jusqu'au départ, la Confédération prend en charge les frais lors de l'arrivée en Suisse et ceci jusqu'au premier contact avec le service social compétent du canton de destination. Par la suite, toutes les prestations d'assistance sont versées par le canton de résidence conformément à la LAS. L'aide sociale versée au titre de la LSEtr doit être remboursée en totalité ou en partie si la situation économique de la personne s'est stabilisée et améliorée.

Si un.e ressortissant.e suisse se trouve dans une situation de détresse lors d'un séjour temporaire à l'étranger, la représentation suisse peut lui accorder un prêt d'urgence. Dans les cas d'extrême urgence, la représentation suisse apporte immédiatement l'aide nécessaire. Cette «assistance des touristes» couvre également les réfugiéee-s reconnu·e·s et les apatrides résidant en Suisse, car il existe une obligation internationale de traiter ces groupes de personnes de la même manière que les ressortissant.e-s suisses. Les Suisses et les Suissesses de l'étranger qui se trouvent dans une situation de détresse dans un pays tiers - ni en Suisse ni dans l'État de résidence où ils·elles sont enregistré·e·s - peuvent également recevoir un prêt d'urgence. Si une situation d'urgence, souvent d'ordre médical, se produit en Suisse, le canton de domicile compétent selon la LAS est tenu d'apporter son aide. La Confédération rembourse l'aide d'urgence au canton si la personne concernée est jugée dans le besoin conformément à la LSEtr. Si, en vertu de la LSEtr, elle n'est pas dans le besoin, mais qu'elle n'est néanmoins pas en mesure de payer les frais d'urgence en temps utile, les frais non 
couverts sont à la charge du canton d'assistance.

Contrairement à la plupart des autres États, la Suisse accorde donc une aide sociale à ses ressortissant.e.s aussi lorsqu'ils et elles résident à l'étranger. En 2017, ils et elles étaient au nombre de 751800 à vivre dans près de 200 pays du monde entier. Il n'existe pourtant aucune obligation internationale de le faire. La Suisse fournit une aide sociale à ses ressortissant·e.s à l'étranger de son plein gré. Dans le débat politique, les avantages l'emportent sur les inconvénients. En effet, les Suisses et les Suissesses aidé·e-s à l'étranger ne sont ainsi pas obligéee-s de quitter leur environnement social en cas de besoin et, même s'il ne s'agit pas d'un critère d'octroi de l'aide sociale au titre de la LSEtr, le retour en Suisse des personnes avec un faible potentiel de réinsertion professionnelle et sociale serait souvent bien plus coûteux que la résidence à l'étranger. Le nombre de personnes aidées à l'étranger a baissé, passant de 540 en 2009 à 336 en 2017, et ceci avec un budget de 1,1 million de francs en 2018. La plupart de ces personnes vivent en Amérique centrale et du Sud, en Thaïlande et aux États-Unis. De même, des Suisses et des Suissesses en situation de précarité vivant en Italie et en Espagne reçoivent également une aide sociale parce que les systèmes nationaux de sécurité sociale dans ces pays sont lacunaires. Pour l'octroi des prestations financières, les autorités fédérales suivent les directives de la Conférence suisse des institutions d'action sociale (CSIAS).

Nadine Zimmermann

\section{Références}

Conseil fédéral (1972). Message du Conseil fédéral à l'Assemblée fédérale concernant un projet de loi fédérale sur l'assistance des Suisses de l'étranger (du 6 septembre 1972). Feuille fédérale, 2(39), 540. Conseil fédéral (2008). Message relatif à la loi fédérale sur la création de bases légales pour l'assistance financière des ressortissants suisses à l'étranger (du 23 avril 2008). Feuille fédérale, 20, 3165-3178.
Direction consulaire (2016). Aide sociale aux Suisses et Suissesses de l'étranger (ASE): prêt d'urgence à des personnes séjournant temporairement à l'étranger. Directives d'application, entrée en vigueur $1^{\text {er }}$ janvier 2016. Berne: Département fédéral des affaires étrangères.

\section{Aides à l'éducation*}

Les «aides à l'éducation» ou «aides complémentaires à l'éducation» désignent un ensemble de prestations, ambulatoires et stationnaires, d'aide à l'enfance et à la jeunesse destinées aux enfants, aux jeunes et (à des degrés divers) aux personnes exerçant sur eux l'autorité parentale ou le droit de garde. Ces aides sont activées lorsque, de façon temporaire ou permanente, le bien de l'enfant, son éducation et son développement sont compromis. En Suisse, les aides classiques à l'éducation sont le placement en institution ou en famille d'accueil (placement familial, parents nourriciers) et l'accompagnement éducatif des familles.

Les premières pratiques de placement en institution remontent loin en Suisse (comme dans d'autres pays européens). Au Moyen-Âge déjà, les orphelins et orphelines trouvaient refuge dans les hôpitaux, aux côtés des nécessiteux et des malades. Depuis le XVII ${ }^{\mathrm{e}}$ siècle, l'hébergement d'enfants dans les hospices de pauvres, les établissements pénitentiaires et les orphelinats est allé croissant. À partir des années 1830, des institutions d'assistance, de secours et d'éducation des pauvres ont été mises en place dans les zones rurales. Sous un angle sociohistorique, le contexte suisse montre que les orphelin·e-s, les enfants de familles pauvres et les enfants de «vagabond·e.s» ont été placé·e-s notamment à des fins d'assistance et ceci jusqu'à une période avancée du $\mathrm{XX}^{\mathrm{e}}$ siècle. L' «Guvre des enfants de la grand-route» était plus particulièrement chargée de placer les 
enfants de «vagabond.e.s». Les réflexions critiques de la Heimkampagne (campagne sur les institutions éducatives), dans les années 1968, ont permis de centrer l'attention sur le bien de l'enfant placé·e. Aujourd'hui, le paysage des institutions d'accueil suisses se caractérise par un large éventail d'offres, d'autorités responsables et de groupes cibles. Sur le plan politique, l'époque des enfants placé·e·s, en institution ou dans des familles paysannes, est abordée au travers d'une reconnaissance des souffrances des personnes concernées et d'une réparation. Dans ce but, le Conseil fédéral a mis sur pied, en 2014, une Commission indépendante d'expert·e-s (CIE) sur les internements administratifs chargée d'enquêter et de documenter leur histoire en Suisse jusqu'en 1981. En outre, le programme national de recherche (PNR) 76 "Assistance et coercition» a été mis en place en 2017 dans le but de mieux comprendre les causes et les mécanismes des mesures d'assistance ainsi que leur impact, constructif ou destructeur, sur l'intégrité des personnes concernées.

Les débuts des services de placement familial en Suisse remontent à l'époque où des enfants étaient placés comme domestiques (Kostkinderwesen). En raison d'indications de négligence et d'exploitation des enfants placé.e-s, ces services ont perdu en importance dans un premier temps, avant d'être à nouveau mieux perçus (notamment suite à la Heimkampagne dans les années 1968) en tant qu'alternative au placement en institution. Depuis lors, en Suisse, l'action éducative en milieu ouvert (AEMO) - une aide ambulatoire - s'est développée et largement répandue en complément aux prestations stationnaires d'aide à l'éducation. Les aides à l'éducation ambulatoires comprennent, de plus, des offres telles que des structures éducatives de jour, l'accompagnement des visites et des remises de l'enfant après une séparation ou encore l'accompagnement éducatif individuel de jeunes.
Pour la Suisse, les aides complémentaires à l'éducation (allemand: ergänzende Hilfen zur Erziehung; italien: aiuti complementari all'educazione) ont été répertoriées, systématisées et décrites, pour la première fois, dans le catalogue Prestations de base de l'aide à l'enfance et à la jeunesse en s'appuyant sur les termes de la législation allemande (SGB VIII) et autrichienne (B-KJHG) sur l'aide à l'enfance et à la jeunesse. Bien que le terme «aides (complémentaires) à l'éducation» ne soit pas encore utilisé uniformément en Suisse, il est de plus en plus répandu. En Suisse romande et en Suisse italienne, on a fréquemment recours aux termes «soutien à la parentalité» et «attività di sostegno alla genitorialità» pour décrire les prestations d'aide à l'éducation, les mesures de protection de l'enfance ou d'autres services de prévention.

Contrairement à l'Allemagne et à l'Autriche, la Suisse ne dispose ni d'une loi nationale sur l'aide à la jeunesse ni d'un droit légal aux prestations d'aide à l'éducation. Au lieu de cela, les bases juridiques pour leur fourniture, octroi et accès sont façonnées par les structures fédéralistes et subsidiaires de la politique et de la législation. Seules existent, au niveau national, des normes minimales pour la surveillance du placement d'enfants dans des familles nourricières, ceci dans l'ordonnance sur le placement d'enfants (OPE). D'autres dispositions se trouvent parfois dans les lois et ordonnances cantonales qui, cependant, ne régissent généralement que les prestations stationnaires d'aide à l'enfance et à la jeunesse (foyers, familles d'accueil), et guère les prestations ambulatoires.

En principe, les aides à l'éducation peuvent être soit convenues volontairement, soit ordonnées par les autorités de protection de l'enfant et de l'adulte (APEA) sur la base du Code civil (CC) et par les autorités pénales des mineurs sur la base du Droit pénal des mineurs (DPMin), si nécessaire contre la volonté des personnes ayant la garde de l'enfant. Contrai- 
rement aux prestations ordonnées, l'accès aux prestations convenues volontairement est encore peu réglementé par la loi. En outre, il n'existe souvent pas de règles contraignantes sur leur financement, ce qui peut avoir un effet préjudiciable sur leur utilisation.

Bien qu'en Suisse (comme dans d'autres pays européens), de nombreux enfants, jeunes et personnes responsables de leur garde aient recours à des prestations ambulatoires et stationnaires d'aide à l'éducation, peu de connaissances systématiques sont disponibles quant à l'éventail des prestations, leur utilisation et leur coût, puisqu'il n'existe pas de statistiques nationales à ce sujet. Toutefois, l'Office fédéral de la justice construit actuellement une statistique nationale sur le placement en institution et l'aide aux enfants placés dans le cadre du projet «Base de données planification des foyers Suisse/Casadata». Les lacunes dans les connaissances relatives aux aides ambulatoires s'avèrent, en comparaison, plus graves encore, notamment en ce qui concerne le type, l'ampleur, l'accès, la réglementation des coûts, la qualité des prestations offertes et leur efficacité. Pour la fourniture de ces prestations ambulatoires, il n'existe pas de normes uniformes et contraignantes. Cette situation se reflète dans la coordination insuffisante de l'éventail et de la qualité des offres. Bref, des questions fondamentales se posent en matière de professionnalisation et de développement de concepts.

Les défis actuels dans le domaine des aides à l'éducation sont donc multiples. Avant tout, il manque des données fiables permettant d'évaluer précisément la situation présente. En raison de l'ancrage juridique insuffisant des aides ambulatoires et des aides convenues volontairement, une inégalité de traitement des personnes ayant besoin d'aide est inévitable. Cette situation a pour conséquence de favoriser une culture d'interventions éducatives intrusives, tandis que les formes de soutien préventif, précoce et à bas seuil sont désavan- tagées. Face aux problématiques éducatives de plus en plus complexes et à la demande sans cesse croissante de formes d'aide réellement adaptées aux problèmes telles qu'elles existent depuis longtemps en Allemagne et en Autriche, il devient urgent de mettre sur pied, en Suisse, un éventail national uniforme d'offres d'aide à l'éducation fondé sur des normes contrôlées de qualité et d'efficacité.

\section{Marina Wetzel, Heinz Messmer \& Lukas Fellmann}

\section{Références}

Conseil fédéral (2012). Violence et négligence envers les enfants et les jeunes au sein de la famille. Aide à l'enfance et à la jeunesse et sanctions des pouvoirs publics: rapport du Conseil fédéral en réponse au postulat Fehr (07.3725) du 5 octobre 2007. Berne : Office fédéral des assurances sociales.

Macsenaere, M., Esser, K., Knab, E., Hiller, S. (Hrsg.) (2014). Handbuch der Hilfen zur Erziehung. Freiburg i.B.: Lambertus.

Savourey-Alezra, M., Brisson, P. (2013). Re-créer les liens familiaux: médiation familiale et soutien à la parentalité ( $3^{\mathrm{e}}$ éd.). Lyon: Chronique sociale.

\section{Allocation familiale}

Les aides dispensées aux familles revêtent des formes multiples: prestations monétaires visant à compenser une charge financière (allocations familiales et bourses d'études) ou à diminuer certains coûts (subsides de l'assurance-maladie et allocations au logement); mise sur pied d'infrastructures pour les familles (crèches, accueil parascolaire). Dans ce tableau, les allocations familiales occupent une place particulière. Étroitement liée à la Première Guerre mondiale, leur histoire débute par la reconnaissance, et l'indemnisation partielle, de la charge financière générée par la naissance d'un enfant, sous forme d'une allocation de renchérissement versée aux personnes employées par la Confédération. Les premières 
législations cantonales ont été adoptées après la Seconde Guerre mondiale. L'ancrage des allocations familiales dans la Constitution fédérale, en 1945, a permis l'adoption d'un régime fédéral en 1952, limité au seul secteur agricole (salarié.e-s et paysan-ne·s de montagne). La Confédération n'ayant pas utilisé pleinement sa compétence, les cantons ont eu toute latitude de développer leur propre législation, en fonction de leurs choix politiques, sociaux et économiques. Alors que les personnes exerçant une activité salariée ont, progressivement, été couvertes par les régimes cantonaux, il n'en est pas allé de même pour les personnes de condition indépendante, et encore moins pour les personnes sans activité lucrative. Les critiques adressées au système helvétique ont été nombreuses et récurrentes: opacité, complexité, inégalités, pour ne citer que les principales.

Quelques décennies séparent les premières allocations versées par la Confédération (1916) des allocations inscrites dans la loi fédérale sur les allocations familiales (2006). Au cours de cette période, les inégalités de traitement générées par les régimes existants ont été importantes, souvent choquantes. Elles ont concerné prioritairement les femmes.

Une première source d'inégalité doit être recherchée dans les modalités de travail. En effet, plusieurs législations cantonales reconnaissaient le droit à une allocation familiale entière aux seules personnes travaillant à plein temps. L'exercice d'un travail à temps partiel donnait alors lieu à une allocation proportionnelle au taux d'activité. Quelques législations cantonales prévoyaient une exception pour les femmes divorcées ayant obtenu l'autorité parentale. Une allocation entière pouvait alors être versée, à condition que leur activité atteigne au moins un certain taux (généralement $50 \%$ ). Dans tous les cas où une telle exception n'était pas prévue, la femme divorcée touchait une allocation partielle, et le père était alors empêché de faire valoir son droit à une allocation entière. Ces situations pro- fondément inégalitaires étaient encore largement répandues en 2004, ainsi que l'atteste le rapport de cette année de la Commission de la sécurité sociale et de la santé publique du Conseil national: sur 26 cantons, seuls deux cantons prévoyaient le versement d'allocations complètes indépendamment du taux d'occupation, et 14 cantons avaient abaissé le taux d'occupation exigé pour le versement d'une allocation complète aux personnes élevant seules un enfant.

Une deuxième source de discrimination sans doute la plus importante - tient à la titularité du droit, dans les situations où tant la mère que le père peut faire valoir un droit à l'allocation familiale. Dans les premières législations, notamment celle que la Confédération a adoptée pour son personnel, le droit à l'allocation de renchérissement a été reconnu au seul père salarié, dans une première étape "sous condition de ressources» (salaire inférieur à une limite fixée), puis de manière inconditionnelle dès 1927. Indépendamment de l'allocation pour charge d'enfant, la Confédération a introduit une «allocation de mariage» pour son personnel en 1927, puis une «allocation de ménage» pour les ouvriers agricoles entrant dans le champ d'application de la loi fédérale de 1952. L'allocation de mariage ou de ménage était versée au chef de l'union conjugale et détenteur de l'autorité domestique, au sens du Code civil alors en vigueur. L'influence des normes régissant le mariage était alors prépondérante. Elle le restera longtemps encore, essentiellement dans les normes régissant l'interdiction de cumul des prestations. Dans la plupart des cantons, en effet, la priorité était donnée au père, l'activité de la mère, et le revenu qui en était tiré, étant considérés comme accessoires. Cette inégalité de traitement flagrante n'a toutefois pas été immédiatement corrigée par le Tribunal fédéral. En 1985, ce dernier a considéré que l'article 4 al. 2 de la Constitution fédérale (adopté le 14 juin 1981) ne s'appliquait pas à une législation cantonale (en l'occurrence ber- 
noise) qui réservait le droit à l'allocation familiale aux seuls fonctionnaires mariés de sexe masculin, les femmes pouvant le faire valoir dans la seule mesure où elles contribuaient de manière prépondérante aux coûts de l'entretien de la famille. La position du Tribunal fédéral a été fermement critiquée par une large partie de la doctrine. D'autres auteur·e-s, cependant, considéraient qu'une telle règle - par ailleurs contenue dans plusieurs législations - était une simple règle «d'attribution à une caisse de compensation » qui ne fondait aucune inégalité de traitement entre père et mère. En 2002, le Tribunal fédéral, appelé à statuer sur un cas de conflit intercantonal, a dû se prononcer sur la priorité donnée au père par une législation cantonale (en l'occurrence, fribourgeoise). Il a tout d'abord écarté l'argument du tribunal cantonal de première instance, qui s'était fondé sur la prévalence du travail masculin exercé à temps plein, comme une réalité sociale toujours prégnante. Il s'est ensuite appuyé sur la révision du droit matrimonial entrée en vigueur le $1^{\text {er }}$ janvier 1988, et sur une partie de la doctrine, pour déclarer que la norme cantonale qui donnait la priorité au père était clairement contraire au principe de l'égalité des droits entre hommes et femmes, contenu à l'article 8 al. 3 de la Constitution fédérale (ATF 129 I 265, consid. 3.4).

La loi fédérale sur les allocations familiales, entrée en vigueur le $1^{\text {er }}$ janvier 2009, a permis d'inclure, dans le champ d'application, l'ensemble des personnes professionnellement actives (salariées et indépendantes) et, dans une certaine mesure, les personnes sans activité lucrative. Elle a par ailleurs permis de régler quelques points litigieux. Une allocation familiale entière est ainsi versée indépendamment du taux d'activité, et les règles concernant la priorité du parent dans l'ouverture du droit à l'allocation familiale sont établies, non pas sur un critère de sexe, mais en regard de l'exercice du salaire réalisé (avec une priorité donnée à l'activité salariée), ou de facteurs concernant la situation de l'enfant après la séparation des parents. Cependant, dans la mesure où les compétences cantonales ne sont pas abolies, les inégalités de traitement demeurent en fonction du lieu de vie. Et le rattachement du droit à l'exercice d'une activité rémunérée est assorti de difficultés - parfois importantes - lorsque le parcours professionnel est interrompu par la maladie, l'accident, le chômage ou par choix de vie familiale. À ce titre, les femmes sont - et resteront encore - victimes de discrimination.

Béatrice Despland

\section{Références \\ Caisse de compensation des banques suisses (2019). Manuel allocations familiales ( $11^{\mathrm{e}}$ éd. rev. et compl.). https://www.ak-banken.ch/Formulare/ Fr-Handbuch.pdf \\ Matthey, F. \& Mahon, P. (2016). Les allocations familiales. In U. Meyer (Hrsg.), Soziale Sicherheit - Sécurité sociale (3. Aufl., S. 1985-2028). Basel : Helbing Lichtenhahn.}

\section{Amour du prochain*}

La vertu chrétienne de l'amour du prochain trouve son origine dans ce que l'on appelle le double commandement, exprimé, par exemple, dans l'Évangile de Luc $(10,25-37)$ : «Tu aimeras le Seigneur ton Dieu de tout ton cœur, de toute ton âme, de toute ta force et de tout ton esprit, et ton prochain comme toi-même.» Ce lien entre l'amour de Dieu et l'amour du prochain, selon lequel l'amour de Dieu se manifeste dans l'amour du prochain, est souvent considéré comme le propre du christianisme. Cependant, dans la tradition juive, ce lien est tout aussi central puisqu'il constitue le noyau de la Torah, la loi mosaïque.

Le commandement de l'amour du prochain est basé sur une logique de décloisonnement : il est obligatoire à l'égard de toutes les personnes humaines, en particulier envers les étrangers et les étrangères, les ennemi-e·s (en renonçant à 
riposter par la violence) et les personnes considérées comme pécheresses, déclassées et discriminées (publicains, lépreux, etc.). La compréhension biblique de l'amour du prochain (agapè en grec, caritas en latin) doit être distinguée de la philanthropie qui se définit comme l'attitude de magnanimité et de renoncement à la violence exigée des rois et des dirigeants de l'Antiquité. La philanthropie est un «idéal de la classe supérieure», l'agapè une «éthique de la classe inférieure» qui doit être mise en pratique à la fois au-delà des frontières de sa propre société et au-delà de l'exclusion sociale. Dans le même temps, la pratique de l'agapè a sans cesse libéré un potentiel de critique des institutions au sein de l'Église. Au nom de l'unité de l'amour de Dieu et de l'amour du prochain, leurs protagonistes se sont opposés aux stratégies ecclésiastiques d'exclusion placées sous le signe du dogmatisme et de l'intolérance. Ils prônaient la primauté de l'orthopraxie («action juste») plutôt que la primauté de l'orthodoxie («foi juste»).

Le lien entre la pratique religieuse et l'aide aux pauvres et aux faibles caractérise l'éthique sociale de toutes les religions du monde. Dans l'histoire du christianisme, cette éthique n'est pas tant connue sous le nom de l'amour du prochain que sous les mots-clés de la miséricorde et de la charité. Les «sept œuvres de miséricorde corporelles» constituent une référence. Leur ordre est basé sur le discours du Jugement dernier dans l'Évangile de Matthieu (25, 31-46) : donner à manger aux affamé·e-s, donner à boire à ceux et celles qui ont soif, accueillir les étrangers et les étrangères, vêtir ceux et celles qui sont nu·e·s, assister les malades, visiter les prisonnier-ère-s du cachot et ensevelir les morts. Même si les œuvres de miséricorde vont plus loin que l'aide aux pauvres, nourrir les pauvres a toujours été l'une des principales tâches sociales des monastères, des fondations ecclésiastiques, des ordres religieux et des confréries. Jusqu'au milieu du XIX ${ }^{\mathrm{e}}$ siècle, les églises chrétiennes en Europe continuent à jouer un rôle important dans la mise en place des aides sociales. Cela ne changera que lorsque les processus de paupérisation et de prolétarisation associés à l'industrialisation appelleront de nouveaux acteur-trice-s sociaux-ales et des solutions nouvelles. Les aides sociales des églises chrétiennes sont alors remplacées par des systèmes publics d'assurances et de prestations sociales. C'est désormais l'État qui assure l'assistance aux pauvres. Les églises et leurs institutions remplissent dorénavant une fonction subordonnée et subsidiaire au profit des personnes qui passent au travers des mailles du filet social. En conséquence, en politique sociale, le discours n'est plus fondé sur des normes chrétiennes mais sur le droit naturel et les droits humains.

Des sociologues des religions comme Franz-Xaver Kaufmann ou Karl Gabriel reconnaissent que les églises et les mouvements chrétiens sociaux, malgré leurs contradictions, ont été décisifs dans le développement de la solidarité moderne organisée par l'État social. Le christianisme a développé très tôt une éthique intégrative exigeant l'inclusion sociale contre l'exclusion sociale, c'est-à-dire la participation de toutes et tous aux domaines fondamentaux de la société que sont la famille, l'éducation et le travail. Il en a résulté une éthique qui, de par son caractère universaliste, concerne tous les groupes et toutes les classes, par exemple sous la forme de l'amour du prochain. Cette éthique s'applique avant tout à la solidarité de l'État social et ses droits de participation pour toute personne.

Pour leur part, les églises chrétiennes ont réagi aux conséquences négatives de l'industrialisation en créant des organisations sociales et des associations spécialisées telles que la Mission intérieure, la Conférence de Saint-Vincent-de-Paul ou Caritas. Dans une perspective à long terme, cependant, leurs structures d'aide ont perdu de leur importance dans la société. En revanche, la culture de l'aide représentée par les églises a gagné en impor- 
tance. Elle s'exprime par des actions de soutien de donateurs et donatrices, de membres actifs et de bénévoles de la société civile. La culture de l'aide dépasse vraisemblablement le cercle des églises et se pratique dans toutes les organisations privées d'utilité publique. Comme le souligne Wolfgang Huber, ancien président du Conseil de l'Église protestante d'Allemagne, l'attitude de miséricorde concrétisée dans la culture de l'aide permet de mieux percevoir la situation sociale dans son ensemble: «Elle attire l'attention là où la justice fait défaut.» Les églises et leurs institutions ne doivent donc pas être considérées comme de simples institutions de miséricorde compensatoires face au démantèlement de l'État social. Leur fonction de sensibilisation prévient les pratiques d'éviction et d'exclusion sociales. Dans le meilleur des cas, elles interviennent dans l'agenda politique en imposant des thèmes d'actualité.

Bien que les organes religieux et ecclésiastiques soit réglementés au niveau cantonal en Suisse, le modèle général dominant en matière de rapports entre l'Église et l'État est celui qui accorde aux organes ecclésiastiques une reconnaissance publique au niveau communal et cantonal. L'État reconnaît ainsi les prestations éducatives, culturelles et sociales fournies par les églises. La reconnaissance publique s'accompagne de l'octroi de droits souverains tels que le droit de percevoir des impôts et un accès facilité aux institutions publiques (écoles, hôpitaux, prisons). Mais des critiques sont aussi formulées à l'encontre du statut public des églises chrétiennes. De fait, certaines voix (chrétiennes aussi) réclament l'extension de la reconnaissance de l'État aux communautés religieuses non chrétiennes. D'autres voix postulent la séparation complète de l'Église et de l'État. Les églises n'auraient alors plus que le statut d'associations privées. Même si l'effort de légitimation des églises pour maintenir le statu quo ne cesse de croître, il est peu probable que les rapports traditionnels entre l'État et l'Église changent prochainement en Suisse.
Une conclusion similaire semble s'imposer en ce qui concerne les institutions sociales proches des églises ou religieuses. En Suisse, les pouvoirs publics concluent des partenariats avec de telles organisations en leur attribuant des mandats de prestations. Ces partenariats apportent aux églises une reconnaissance et un ancrage supplémentaires au sein de la société. Dans le même temps, ils leur donnent l'opportunité ou, le cas échéant, la nécessité de développer leur engagement en faveur des «personnes dans le besoin» et de clarifier leur identité d'organisations d'utilité publique.

Dans les églises chrétiennes et leurs organisations sociales d'aujourd'hui, c'est plus précisément le concept de solidarité qui exprime le principe de l'amour du prochain. La pratique de la solidarité est, dans une certaine mesure, une interprétation politique et sociale du commandement de l'amour du prochain. La critique séculière de la société dans la tradition du marxisme a certainement contribué à ce développement. Elle a qualifié l'amour du prochain de principe apolitique et illusoire qui mène finalement à la réconciliation avec un statu quo injuste. Dans le même temps, dans l'Église catholique en particulier, on peut observer l'influence de la «théologie de la libération» latino-américaine. Elle comprend le commandement de l'amour du prochain comme un principe impératif pour défendre la justice. L'exigence de l'«option préférentielle pour les pauvres» est une mise à jour historique et sociale du commandement de l'amour du prochain. Dans ce contexte, les églises et leurs organisations sociales exercent, d'une part, un mandat politique renforcé en faveur des personnes défavorisées et marginalisées. D’autre part, elles estiment que leur action relève d'une responsabilité globale et mondiale. C'est pourquoi il n'est pas rare qu'elles soient confrontées à des pressions des forces politiques néolibérales et de droite.

Odilo Noti 


\section{Références}

Collinet, M. (Hrsg.) (2014). Caritas - Barmherzigkeit - Diakonie: Studien zu Begriffen und Konzepten des Helfens in der Geschichte des Christentums vom Neuen Testament bis ins späte 20. Jahrhundert. Berlin : LIT.

Kaufmann, F.-X. (1989). Religion und Modernität: Sozialwissenschaftliche Perspektiven. Tübingen: Mohr.

Pankoke, E. (1994). Diakonie/Caritas Wohlfahrtsverbände. In S.R. Dunde (Hrsg.), Wörterbuch der Religionssoziologie (S. 51-64). Gütersloh: Gütersloher Verl.-Haus.

\section{Animation socioculturelle avec des enfants et des jeunes*}

L'animation socioculturelle avec des enfants et des jeunes fournit aux jeunes en dehors de l'école et de la famille des lieux et des opportunités pour des expériences diverses, des aventures et des activités largement autogérées. L'animation socioculturelle avec des enfants et des jeunes est un domaine de l'aide à l'enfance et à la jeunesse qui se caractérise par le travail bénévole et la participation et qui comprend à la fois l'animation socioculturelle avec des enfants et des jeunes en milieu ouvert ainsi que le travail des associations pour l'enfance et la jeunesse. Tandis que le travail des associations pour l'enfance et la jeunesse est caractérisé par l'auto-organisation, le travail bénévole et l'obligation d'adhésion pour les membres et qu'il est principalement réalisé par les associations pour l'enfance et la jeunesse (p.ex. Jungwacht/Blauring, Unions chrétiennes, Mouvement Scout), l'animation socioculturelle avec des enfants et des jeunes en milieu ouvert est un domaine professionnalisé du travail social qui est ouvert et accessible sans adhésion à tous les enfants et les jeunes pendant leur temps libre et qui est principalement financé par le secteur public (communes).

Le travail des associations pour l'enfance et la jeunesse a une longue tradition en Suisse et s'appuie sur les mouvements de jeunesse de différents milieux dans la seconde moitié du $\mathrm{XIX}^{\mathrm{e}}$ et la première moitié du $\mathrm{XX}^{\mathrm{e}}$ siècle. Les associations autrefois très confessionnelles comme les Unions chrétiennes, le Mouvement Scout et Jungwacht/Blauring sont devenues au cours du siècle dernier les associations pour l'enfance et la jeunesse les plus importantes de Suisse. Par rapport aux années fondatrices, le caractère religieux de leurs offres (à des degrés divers selon les associations et les régions) est passé à l'arrière-plan au profit d'un idéal de loisirs qualifiés. Fondée en 1944, l'organisation faîtière nationale, le Conseil suisse des activités de jeunesse (CSAJ), est aujourd'hui l'organisation de lobbying la plus significative pour les associations pour l'enfance et la jeunesse en Suisse. Outre le niveau national, ces associations sont organisées en associations cantonales et en départements et groupes locaux. En règle générale, les offres représentatives (cours collectifs, activités pour le week-end ou les vacances) sont proposées dans les départements ou groupes locaux souvent différenciés par tranches d'âge. Les préférences respectives en matière de contenu et d'idéologie ainsi que les valeurs de chaque association sont déterminantes pour les offres. Il n'y a pas de différences majeures entre les régions linguistiques dans le travail des associations pour l'enfance et la jeunesse en Suisse. Une comparaison du travail des associations pour l'enfance et la jeunesse en Suisse et dans les pays limitrophes ne permet pas de dégager des différences importantes au niveau des structures et des développements.

En revanche, l'animation socioculturelle avec des enfants et des jeunes en milieu ouvert en Suisse est plus hétérogène que dans d'autres pays. Cela s'explique notamment par les structures fédéralistes et les influences et caractéristiques qui prévalent dans les différentes régions linguistiques. Tandis que la plupart des pratiques en Suisse alémanique sont orientées vers les développements de l'espace 
germanophone, la conception de l'animation socioculturelle avec des enfants et des jeunes en milieu ouvert en Suisse romande et au Tessin a été fortement influencée par les développements dans les pays latins. Cependant, on constate qu'il n'y a pratiquement aucune animation socioculturelle avec des enfants et des jeunes en milieu ouvert au Tessin. En Suisse romande et en Suisse alémanique, il existe d'autres concepts de relations avec les jeunes et d'autres orientations scientifiques. L'animation socioculturelle avec des enfants et des jeunes en milieu ouvert en Suisse alémanique est considérée comme un champ d'action indépendant avec ses propres concepts et méthodes, alors qu'en Suisse romande, elle est comprise comme faisant partie du champ professionnel de l'animation socioculturelle, qui est souvent mis en œuvre dans des centres de loisirs ou maisons de quartier intergénérationnels. Bien que ces différences socioculturelles continuent de façonner le champ d'action, des influences mutuelles sont perceptibles. Par exemple, le concept d'animation socioculturelle est également relativement bien connu en Suisse alémanique aujourd'hui et est pris en compte dans les concepts pratiques. En outre, les deux conceptions peuvent être attribuées à l'encouragement de l'enfance et de la jeunesse au sens de la loi sur l'encouragement de l'enfance et de la jeunesse (LEEJ).

À l'origine, l'animation socioculturelle avec des enfants et des jeunes en milieu ouvert en Suisse est née du mouvement de la jeunesse des années 1960 et, au cours des dernières décennies, elles s'est implantée et différenciée de plus en plus dans les régions et cantons ruraux, à partir de villes plus grandes, telles que Zurich, Bâle, Berne, Bienne, etc. Selon la définition de l'Association faîtière pour l'animation enfance et jeunesse en milieu ouvert (AFAJ), l'animation socioculturelle avec des enfants et des jeunes en milieu ouvert est liée à un espace social, a une mission sociopolitique, pédagogique et socioculturelle et s'oriente vers les principes de base constitutifs de l'ouverture, du volontariat et de la participation. En raison des structures fédéralistes, les offres et les structures de l'animation socioculturelle avec des enfants et des jeunes en milieu ouvert varient encore beaucoup selon les conditions locales (p.ex. il existe des terrains de jeux d'aventure, des centres de loisirs, des centres de jeunesse ouverts, des approches mobiles, des offres spécifiques à certains groupes cibles ou des formes d'utilisation autogérées). La grande majorité des offres pour le groupe d'âge des enfants n'est apparue qu'au cours des 15 à 20 dernières années. Depuis la création de l'AFAJ en 2002, il existe une importante association pour l'animation socioculturelle avec des enfants et des jeunes en milieu ouvert au niveau national, qui, en collaboration avec le CSAJ, exerce du lobbying, réalise des projets et participe notamment à des consultations sur l'élaboration de la politique nationale de l'enfance et jeunesse. Depuis lors, il existe dans tout le pays des associations cantonales d'animation socioculturelle avec des enfants et des jeunes en milieu ouvert qui constituent les organisations membres de l'AFAJ.

En Suisse, il n'existe aucune base juridique obligeant les communes et les cantons à proposer de l'animation socioculturelle avec des enfants et des jeunes. Un cadre juridique important est toutefois la loi sur l'encouragement de l'enfance et de la jeunesse, qui est en vigueur depuis début 2013 et a remplacé la loi fédérale sur les activités de jeunesse qui était en vigueur depuis la fin des années 1980. Elle s'efforce d'assurer la cohérence de la politique de l'enfance et de la jeunesse dans la mesure où la Confédération apporte à l'animation socioculturelle avec des enfants et des jeunes un soutien financier pour les structures et activités, les projets pilotes novateurs d'importance nationale, les projets de participation, ainsi que la formation et le perfectionnement des tâches de gestion et de conseil.

L'une des principales caractéristiques de l'animation socioculturelle avec des enfants 
et des jeunes est qu'elle doit s'adapter en permanence à l'évolution constante des milieux de vie, des thèmes et des besoins des adolescent.e.s. Dans le travail des associations pour l'enfance et la jeunesse, les défis actuels à relever comprennent la baisse du nombre de membres, le soutien financier aux associations pour l'enfance et la jeunesse, les questions d'ouverture (interculturelle), mais aussi la coopération avec l'animation socioculturelle avec des enfants et des jeunes en milieu ouvert.

L'animation socioculturelle avec des enfants et des jeunes en Suisse connait un processus dynamique d'expansion, de structuration et de professionnalisation. L'un des défis, cependant, est qu'elle est simultanément exposée à une attention accrue du public et qu'il est de plus en plus nécessaire de démontrer et de rendre visibles publiquement la qualité, les avantages et les effets de ses services et de ses offres. Cela nécessite, entre autres, de nouvelles structures organisationnelles et de nouveaux modèles de financement appropriés, ainsi que la promotion des compétences du personnel en ce qui concerne les tâches de conception.

Enfin, il faudrait générer des données empiriques de base sur le champ d'action, lesquelles fourniraient par exemple des informations sur les enfants et les jeunes qui utilisent les services et sur la couverture de l'offre, ainsi que sur les développements et besoins actuels.

\section{Julia Gerodetti \& Manuel Fuchs}

\section{Références}

Gerodetti, J. \& Schnurr, S. (2013). Offene Kinder- und Jugendarbeit in der Schweiz. In U. Deinet \& B. Sturzenhecker (Hrsg.), Handbuch Offene Kinderund Jugendarbeit (S. 827-839). Wiesbaden: Springer Fachmedien.

Gretler Heusser, S. \& Stade, P. (2014). Verbandsjugendarbeit in der Schweiz: Herausforderungen und Entwicklungen gestern, heute und morgen. Luzern : Interact.

Tironi, Y. (2015). Participation et citoyenneté des jeunes: la démocratie en jeu (préface de Stéphane Rossini). Lausanne: Haute école de travail social et de la santé ÉÉSP.

\section{Asile*}

Dans l'Antiquité, l'asile (de l'ancien grec asylon) désignait un lieu sacré où toute personne menacée pouvait trouver refuge. Aujourd'hui, le terme «asile» renvoie à la protection accordée par un pays à des personnes venues d'ailleurs qui peuvent faire valoir de manière crédible qu'elles sont persécutées individuellement dans leur pays. La personne qui demande l'asile dans un autre État est un·e «requérant.e d'asile». Pendant la procédure d'asile, les autorités décident si la personne est reconnue comme «réfugiée». Conformément à l'article premier de la Convention de 1951 relative au statut des réfugié.e-s (dite Convention de Genève), ratifiée par la Suisse en 1955, le terme de «réfugié·e» s'applique à toute personne qui «craignant avec raison d'être persécutée du fait de sa race, de sa religion, de sa nationalité, de son appartenance à un certain groupe social ou de ses opinions politiques, se trouve hors du pays dont elle a la nationalité et qui ne peut ou, $\mathrm{du}$ fait de cette crainte, ne veut se réclamer de la protection de ce pays ».

Depuis des siècles, des personnes persécutées cherchent refuge en Suisse (p.ex. des Huguenots au XVII ${ }^{\mathrm{e}}$ siècle, des révolutionnaires de différents États européens et des soldats de l'armée de Bourbaki au XIX ${ }^{\text {e }}$ siècle). Si la Suisse a aussi de tout temps refoulé des réfugié.e.s jugéee.s indésirables, sa tradition humanitaire demeure une composante centrale de l'identité nationale. Depuis 1925, l'octroi de l'asile est du ressort de la Confédération. Pendant longtemps, cette compétence a été réglée à l'article 21 de la loi fédérale du 26 mars 1931 sur le séjour et l'établissement des étranger-ère-s. Lorsque, pendant la Seconde Guerre mondiale, des centaines de milliers de personnes menacées souhaitèrent se réfugier en Suisse, une interprétation restrictive du critère déterminant de la «persécution politique » eut pour effet le refoulement de milliers de Juifs et Juives à la frontière, la persécution «au 
seul motif de la race» n'étant pas reconnue. $\mathrm{La}$ politique suisse à l'égard des réfugié·e-s pendant la Seconde Guerre mondiale donnera lieu à des débats controversés pendant les décennies suivantes.

À l'époque de la guerre froide et de la reprise économique, la Suisse se montra généralement bien disposée envers les réfugié-e·s des États communistes, souvent bien formé·e-s. Par l'entremise du Haut Commissariat des Nations Unies pour les Réfugiés (HCR), un grand nombre d'entre elles et eux - arrivant de Hongrie en 1956, du Tibet en 1963, de Tchécoslovaquie en 1968 - furent accueilli.e.s sans grandes formalités. Dès les années 1970 et jusqu'en 1995, la Suisse accueillait des réfugié.e-s dit.e.s de «contingent» provenant de différentes régions en conflit (p.ex. Uganda, Vietnam, Bosnie-Herzégovine). En 1973, confrontées à des réfugié·e·s chilien·ne·s, les autorités se montrèrent pour la première fois plus frileuses; les Chilien-ne-s ne fuyaient pas un régime communiste, eux. En réaction, la société civile se mobilisa pour un accueil plus généreux.

La première loi suisse sur l'asile est entrée en vigueur en 1981. Concrétisant la pratique suivie jusqu'alors et fondée sur la définition du statut de réfugié.e de la Convention de Genève, elle était caractérisée par l'ouverture aux personnes cherchant protection et par la grande marge de manœuvre accordée aux autorités compétentes. Parallèlement, on assista à la bureaucratisation, l'institutionnalisation et la judiciarisation de la procédure d'asile. L'année 1986 vit l'engagement de la première personne déléguée aux réfugié·e·s, relayée en 1989 par l’Office fédéral des réfugiés, intégré en 2015 dans le Secrétariat d'État aux migrations (SEM). Depuis l'entrée en vigueur de la loi sur l'asile, le domaine n'a cessé de se développer, avec une politisation du thème de l'asile et des révisions continuelles de la loi, souvent adoptées en procédure d'urgence. Sous l'influence de la hausse du nombre de requérant·ess d'asile à partir des années 1980 partout en Europe occidentale, la loi fut durcie. La peur de l'arrivée d'un grand nombre de requérant·e-s susceptible de menacer la «capacité de réception» de la Suisse est une constante. Mentionnons, comme autres thèmes récurrents, l'accélération de la procédure d'asile, la réduction de l'attractivité de la Suisse comme pays de destination, les renvois non exécutés de requérant·e.s d'asile débouté·e-s, ainsi que l'exclusion rapide de la procédure des personnes n'ayant aucune chance d'obtenir l'asile en Suisse.

Le nombre de requérant.e.s d'asile varie en fonction de la fréquence des conflits armés et de leur proximité géographique avec la Suisse. Entre 1981 et 1991, il décupla pour grimper à près de 42000 . Le nombre record de demandes (47 500) fut enregistré en 1999, dans le contexte de la guerre du Kosovo. Après un recul marqué au début du XXI ${ }^{\text {e }}$ siècle, le nombre de demandes a atteint, dans le contexte des grands mouvements de réfugié·e's vers l'Europe en 20152016, temporairement un niveau élevé (39500 en 2015). En 2017, ce nombre s'est à nouveau réduit de moitié (18088).

Depuis fin 2012, les requérant·e·s ne peuvent plus déposer leur demande dans une représentation suisse à l'étranger, mais doivent le faire en Suisse. L'exécution de la procédure d'asile, divisée en deux phases, est du ressort du SEM. La phase préparatoire a lieu dans un centre d'enregistrement et de procédure où la personne est enregistrée et auditionnée sommairement sur son identité et les motifs de sa fuite. S'il s'avère que la Suisse n'est pas compétente pour le traitement de la demande ou si l'on n'entre pas en matière pour d'autres motifs, les autorités prononcent la décision correspondante. La deuxième phase est celle de l'enquête, qui se déroule dans le centre (durée de séjour de 90 jours au maximum) ou dans un canton (les requérant·e·s sont attribué·e·s aux cantons d'après une clé de répartition selon le nombre d'habitant.e.s). Pendant cette phase, ces personnes sont auditionnées plus en détail 
sur les motifs de leur demande d'asile. Des règles spéciales s'appliquent pour les requérant·e.s mineur.e.s non accompagné·e.s. La personne qui peut faire valoir de manière vraisemblable qu'elle est une réfugiée, reçoit une décision d'asile positive (permis de séjour B). Si sa demande est rejetée, elle peut faire recours au Tribunal administratif fédéral. Après une décision négative exécutoire, la personne doit quitter la Suisse dans un délai donné. La personne qui n'obtient pas l'asile en Suisse mais qui ne peut être renvoyée parce que ce renvoi serait illicite, inexigible ou impossible est admise provisoirement (permis $\mathrm{F}$ ).

Le système suisse de l'asile correspond dans une large mesure à celui des autres États européens. Cette uniformité s'explique par le cadre général donné par la Convention de Genève et par des effets de mimétisme. Pour donner un exemple: en 1990, la Suisse a été le premier pays à introduire le concept aujourd'hui largement répandu de «pays d'origine sûr». On part de l'idée que les personnes provenant de ces pays ne sont pas persécutées. Suite aux accords d'association à Dublin et à Schengen, la Suisse met en œuvre, depuis décembre 2008, les règlements de Dublin, qui déterminent l'État membre responsable de traiter une demande. La Suisse n'est toutefois pas entièrement partie prenante au système d'asile de l'UE et n'est donc pas soumise aux directives correspondantes. En Suisse, les compétences en matière d'asile sont partagées entre la Confédération (procédure) et les cantons (prise en charge, exécution du renvoi). Ainsi, selon le canton de séjour, les requérant-e.s d'asile se voient confrontés à des structures, des prestations d'aide et des priorités politiques différentes. Les instruments de la démocratie directe ont pour effet, en outre, une politisation spécifique du thème de l'asile.

Les débats politiques actuels sur l'asile ressemblent à ceux du passé. En juin 2016, le peuple a dit oui à une accélération de la procédure en acceptant la «restructuration du domaine de l'asile» qui est entrée en vigueur en 2019. L'objectif est de trancher $60 \%$ des demandes d'asile dans les centres de la Confédération; la présence sur place de tous les protagonistes devrait permettre un traitement plus rapide. Les modifications législatives proposées prévoient que la majorité des procédures d'asile aboutissent dans un délai de 140 jours à une décision exécutoire et à l'exécution du renvoi, le cas échéant. Une représentation juridique gratuite doit garantir le respect des droits des requérant·e-s dans la procédure accélérée. Les autres requérant·e.s d'asile (40\%), dont la demande nécessite des clarifications, sont attribuéerss aux cantons. Des «centres de départ» devraient permettre d'exécuter plus rapidement et en nombre plus élevé les renvois de requérant·e.s débouté.e.s. Comme par le passé, les deux grands thèmes du débat politique actuel sur l'asile sont, d'une part les principes de l'octroi de protection inscrits dans les droits humains et le droit international, et d'autre part, l'objectif de garder le contrôle souverain sur l'accès au territoire national.

Christin Achermann

\section{Références}

Organisation suisse d'aide aux réfugiés (Éd.). (2016). Manuel de la procédure d'asile et de renvoi ( $2^{\mathrm{e}}$ éd. entièrement révisée). Berne: Haupt.

Secrétariat d'État aux migrations. (1 ${ }^{\text {er }}$ mars 2019). Manuel asile et retour. https://www.sem.admin. $\mathrm{ch} / \mathrm{sem} / \mathrm{fr} /$ home/asyl/asylverfahren/nationaleverfahren/handbuch-asyl-rueckkehr.html

\section{Assurance-accidents*}

L'assurance-accidents est une assurance sociale qui offre une protection sociale contre les suites d'accidents survenus au travail ou pendant les loisirs. Les personnes employées au moins huit heures par semaine par la même entreprise sont soumises à l'obligation de s'as- 
surer. L'employeur-euse verse les cotisations d'assurance pour le risque d'accident professionnel et l'employéee verse celles pour le risque d'accident non professionnel. Les prestations de l'assurance-accidents comprennent les indemnités journalières en cas de perte de gain, les frais de traitement, les rentes pour les personnes lésées à long terme et le soutien financier pour les survivant·e-s. Ces prestations entrent également en vigueur en cas de maladie professionnelle. La prévention contre les accidents et la réadaptation des victimes d'accidents font également partie de la protection sociale garantie par l'assurance-accidents. Elle est gérée par la Caisse nationale suisse d'assurance en cas d'accident (Suva), qui détient un monopole partiel, et des sociétés d'assurance privées. La loi sur l'assurance-accidents (LAA) en constitue la base légale.

L'assurance-accidents est la plus ancienne forme d'assurance sociale complète en Suisse. Elle a été créée pour répondre au double risque de dépendance du revenu et des dangers liés à la santé, qui faisaient partie inhérente du travail en usine. La personne qui se blessait au travail touchait une indemnité journalière de l'assurance pour la période non rémunérée. À compter des années 1880, la loi fédérale sur le travail dans les fabriques a régulé les conditions de travail, et la loi sur la responsabilité civile a imposé par principe la responsabilité en cas d'accident professionnel à l'employeur-euse. Puisque les employeur-euse-s étaient souvent dans l'incapacité d'assumer leurs obligations financières envers les employé·e-s victimes d'accidents, le Parlement a créé en 1890 une base constitutionnelle pour une assurance-maladie et accidents. La première loi sur l'assurance-maladie et accidents (LAMA) a été rejetée par référendum en 1900. La nouvelle version de 1911 est finalement entrée en vigueur en 1918. La LAMA de 1911 ne limitait pas la protection sociale aux accidents professionnels, mais l'étendait aussi aux accidents survenant durant les loisirs, ainsi qu'à un certain nombre de maladies professionnelles. Sous l'influence de la recherche médicale, la liste des maladies professionnelles a été peu à peu complétée, notamment avec la silicose en 1937. Depuis l'entre-deux-guerres, l'assurance-accidents investit aussi dans la prévention et la réhabilitation des victimes d'accidents. Conformément aux statistiques de la Confédération, depuis les années 1980 , le nombre d'accidents non professionnels dépasse celui des accidents professionnels, en particulier parce que les métiers de l'industrie sont devenus plus sûrs et que la part des ouvrier-ière-s industriel-le·s a diminué. Le montant des prestations d'assurance montre également que les accidents non professionnels ont pris le dessus sur les accidents professionnels.

L'assurance-accidents obligatoire s'est longtemps limitée aux métiers de l'artisanat et de l'industrie, qui étaient exposés à des risques plus importants dus à l'utilisation de machines. Les employé·e-s qui n'étaient pas soumis·es à l'obligation de s'assurer pouvaient le faire volontairement auprès de la Suva ou d'une société d'assurance privée. La révision de la loi sur l'assurance-accidents (désormais LAA) de 1981 a élargi l'obligation de s'assurer aux employé-e-s de tous les groupes professionnels. Après l'entrée en vigueur de la loi en 1984, la part de la population active assurée est passée d'environ $50 \%$ à $90 \%$.

$\mathrm{Au} \mathrm{XIX}^{\mathrm{e}}$ siècle, les assurances accidents étaient conclues auprès des sociétés d'assurance privées. La LAMA a étatisé ce marché et créé en 1918 la Suva comme monopole de droit public. La Suva est en grande partie autonome, mais reste soumise à la surveillance des autorités. Son conseil d'administration est constitué de représentant.e-s des employeur·euse-s, des employé·e-s et de la Confédération. La révision de la loi de 1981 a ouvert le marché de l'assurance-accidents obligatoire aux sociétés d'assurance privées tout en préservant le monopole partiel de la Suva pour les métiers de l'artisanat 
et de l'industrie ainsi que pour les entreprises de la Confédération.

L’assurance-accidents réglementée par la loi suisse s'est d'abord basée sur le modèle des assurances sociales allemandes, qui offraient depuis 1884 déjà une protection sociale contre les accidents. Jusqu'à l'entrée en vigueur de l'assurance-vieillesse et survivants (AVS) en 1948, elle était la principale institution d'assurance sociale. Jusqu'en 1945, la France disposait uniquement d'une loi de responsabilité civile en cas d'accidents professionnels et avait confié l'exécution aux assureurs privés.

Aujourd'hui, les pratiques d'indemnisation des assurances accidents sont très similaires dans les pays industrialisés, même si le niveau d'indemnisation varie d'un pays à l'autre. Les structures organisationnelles de l'assurance-accidents peuvent se diviser en trois catégories : le modèle d'assistance financé par les impôts en Grande-Bretagne et en Irlande, le modèle d'assurance géré par des organismes de droit public et financé par des cotisations sociales existant notamment en Allemagne, en Autriche ou au Luxembourg, et le modèle du système exploité par des entreprises privées comme en Belgique, au Portugal et en Finlande. En Suisse, il existe depuis 1984 une forme mixte entre modèle étatique et modèle privé de l'assurance-accidents.

Contrairement à d'autres assurances sociales, l'assurance-accidents étatique n'a pas à craindre de problèmes de financement à moyen terme. C'est pourquoi, dans les débats qui entourent la révision de la loi sur l'assurance-accidents depuis 2006, d'autres questions ont la priorité, comme la question de la répartition exacte du marché de l'assurance-accidents entre le marché monopolisé par l'État et le marché libre. Alors que les assureurs privés exigent l'ouverture totale du marché de l'assurance-accidents, la Suva souhaite étendre ses activités aux assurances complémentaires dans le domaine des accidents.
La question de savoir quelles maladies sont causées par une activité professionnelle et doivent être couvertes par l'assurance-accidents est toujours d'actualité. Il s'agit, par exemple, de déterminer si des troubles de la santé avec une étiologie complexe, tels que les conséquences du stress et de l'épuisement professionnel (burnout), tombent dans cette catégorie.

Différentes parties de la population profitent de l'assurance-accidents à des degrés différents. Depuis son introduction, les accidents sur le lieu de travail sont indemnisés de manière plus conséquente que toute autre forme de dommage causé. Cela a pour effet que les hommes sont indemnisés plus souvent par l'assurance-accidents que les femmes, car ils sont bien plus souvent victimes d'accidents du travail. Les femmes, par contre, travaillent plus souvent dans le ménage ou sont employées à moins de $20 \%$ auprès du·de la même employeur.euse et doivent donc recourir à leur assurance-maladie en cas d'accidents, dont l'indemnisation est plus limitée. De plus, les femmes montrent plus souvent des signes d'usure du corps que des séquelles d'accidents, qui sont moins documentés et indemnisés par l'assurance-accidents.

Les personnes étrangères forment un groupe à risque particulier en matière d'accidents professionnels. Elles sont exposées à un risque d'accident plus élevé parce que, d'une part, elles sont plus nombreuses à exercer des métiers à risque d'accident élevé et, d'autre part, en raison de leur plus jeune âge, de leur niveau de formation inférieur ainsi que leurs conditions d'emploi moins stables, elles sont en moyenne moins expérimentées face aux dangers que la main d'œuvre de nationalité suisse.

Beat Stüdli 


\section{Références}

Bonvin, J.-M., Gobet, P., Rossini, S. \& Tabin, J.-P. (2015). Manuel de politique sociale ( $2^{\mathrm{e}}$ éd.). Lausanne: Éditions ÉÉSP.

Lengwiler, M. (2006). Risikopolitik im Sozialstaat: Die schweizerische Unfallversicherung 1870-1970. Köln : Böhlau.

Tabin, J.-P., Probst, I. \& Waardenburg, G. (2008). Accidents du travail : la régularité de l'improbable. Interrogations, revue pluridisciplinaire des sciences de l'homme et de la société, 6, 131-149.

\section{Assurance-chômage}

La protection des salarié·e-s en cas de perte d'un emploi est réglementée par la loi fédérale sur l'assurance-chômage obligatoire et l'indemnité en cas d'insolvabilité (LACI) adoptée en 1982 et profondément révisée quatre fois depuis. Cette législation repose sur des principes qui se sont imposés au début du $\mathrm{XX}^{\mathrm{e}}$ siècle.

Les premières caisses de chômage créées à la fin du XIX ${ }^{\mathrm{e}}$ et au début du XX $\mathrm{XX}^{\mathrm{e}}$ siècle sont essentiellement l'œuvre des organisations syndicales naissantes, qui prônent un projet mutualiste de prise en charge des risques sociaux. Ces caisses sont considérées par les dirigeant·e.s syndicaux-ales comme un moyen de propagande et de fidélisation de leurs membres. Elles rencontrent toutefois des difficultés financières qui amènent les syndicats à revendiquer des subventions publiques. La loi fédérale sur l'assurance-chômage de 1924 leur accorde des subventions (ainsi qu'aux caisses de chômage publiques et patronales), tout en imposant des conditions qui visent à préserver l'intérêt des employeur.euse-s à disposer d'une maind'œuvre stable, disponible et disciplinée. Une de ces conditions est l'exclusion des personnes considérées comme responsables de leur chômage (p.ex. ayant quitté volontairement l'emploi, ou licenciées à cause d'inconduite ou de faute professionnelle). La loi de 1924 exige également des caisses de vérifier la disponibi- lité et l'aptitude à l'emploi des assuré·e.s. Ces exigences ne suscitent pas de véritable débat, encore moins celle d'avoir exercé une activité salariée régulière qui pénalise tout particulièrement les femmes ayant des parcours professionnels discontinus. D'autres principes s'imposent également lors de cette première loi, notamment celui d'une indemnité limitée dans le temps et inférieure au salaire assuré, ce qui participe à définir le chômage comme situation temporaire et subalterne à l'emploi. La priorité est donnée à l'indemnisation des hommes suisses, en particulier des «chefs de familles», ce qui participe à promouvoir un modèle familial traditionnel. Enfin, les diverses forces en présence s'accordent autour d'une assurance facultative, faiblement étatisée et fortement décentralisée.

Ces consensus expliquent le succès du système adopté en 1924 qui reste en vigueur jusqu'au milieu des années 1970. Malgré l'initiative de plusieurs cantons qui rendent l'assurance obligatoire pour certaines catégories de salarié.e-s, le taux d'affiliation reste faible en comparaison européenne: lorsque la crise économique éclate au milieu des années 1970 un actif sur cinq et une active sur dix est assuré.e auprès d'une caisse. Le taux de couverture de l'assurance est particulièrement faible au sein de la main d'œuvre migrante, notamment en raison des conditions d'affiliation plus restrictives imposées aux personnes avec un permis de séjour annuel et l'exclusion du droit à s'assurer pour celles avec un permis saisonnier. Malgré un taux de chômage relativement faible - en raison de la faible étendue de l'assurance, de sa définition limitée (voir aussi le concept «chômage») et de la politique de non-renouvellement des permis de séjour - la question d'une réforme du dispositif d'assurance-chômage s'impose à l'agenda politique.

En 1976, un arrêté fédéral introduit l'obligation d'assurance et la LACI est adoptée en 1982. Malgré les réticences d'une partie des employeur.euse-s à se voir imposer une nou- 
velle cotisation, le patronat soutient l'adoption de la LACI afin de garantir le maintien d'une législation du travail très libérale et d'éviter notamment des mesures de protection contre les licenciements. Les caisses de chômage existantes sont maintenues, mais leur rôle se limite au calcul et au versement des indemnités sur la base de critères définis par la LACI. Les cantons sont responsables du contrôle et du service de placement des personnes au chômage, organisés depuis les années 1990 par les Offices régionaux de placement (ORP). La Confédération exerce une surveillance à travers le Secrétariat d'État à l'économie (SECO). La LACI a connu quatre révisions $(1990,1995,2002,2010)$ qui ont porté essentiellement sur la durée des prestations, les conditions d'accès aux indemnités, la mise en place de mesures de contrôle et d'insertion, le montant des cotisations. Le financement de l'assurance par des prélèvements sur les salaires représente une socialisation du coût du chômage entre les employeur-euse-s. Le plafonnement des salaires soumis à cotisation limite l'effet distributif de l'assurance.

La LACI prévoit une indemnisation en cas de perte d'emploi, de perte de revenu en raison de réduction de l'horaire de travail, d'intempérie ou d'insolvabilité de l'employeur.euse. Des personnes en emploi, subissant des réductions temporaires de gain, sont ainsi considérées comme chômeuses au sens de la LACI, contrairement aux personnes sans emploi mais qui ne remplissent pas les conditions d'accès aux prestations. Les indépendant·e.s restent exclu.e.s du dispositif. Pour bénéficier d'une indemnité de chômage il faut avoir subi une perte de salaire suffisante, être domicilié.e en Suisse, avoir achevé sa scolarité obligatoire, n'être pas encore en âge de retraite et avoir cotisé un nombre minimum de mois (12 en 2017) durant les deux dernières années («délai-cadre de cotisation»). Certaines catégories, notamment les personnes ayant achevé une formation ou devant reprendre une activité suite à une séparation, sont dites «libérées de l'obligation de cotiser» et peuvent bénéficier de prestations (réduites). L'exigence d'une certaine régularité de l'emploi est maintenue, mais assouplie par l'introduction du «délai-cadre de cotisation » qui permet de tenir partiellement compte de certains parcours discontinus. La LACI améliore la protection en cas de chômage des salariées travaillant à temps partiel, enceintes ou ayant interrompu leur emploi pour cause de maternité. Les formes d'emplois dites «atypiques» (sur appel, intermittent, irrégulier, horaires très réduits, etc.), dans lesquelles les femmes sont surreprésentées, restent toutefois pas ou peu protégées par l'assurance-chômage. La «période éducative» introduite en 1996 et révisée en 2002, permet de tenir compte d'une interruption de l'activité professionnelle pour s'occuper d'un enfant, sans toutefois que ce travail soit assimilé à du travail salarié.

Parmi les obligations des personnes au chômage, figure celle de se montrer apte et disponible au placement et de se soumettre aux contrôles de la part des ORP, notamment en ayant des entretiens réguliers avec les fonctionnaires, en présentant des preuves de recherche d'emploi et en participant à des mesures du marché du travail (stages, cours, emplois subventionnés, etc.). Ces mesures se développent à partir du milieu des années 1990, en lien avec le succès du principe d'activation. La personne au chômage doit également accepter un «travail convenable», à savoir tout emploi à l'exception de ceux qui ne respectent pas les conventions collectives de travail ou les conditions usuelles dans la profession, qui ne tiennent «pas raisonnablement compte des aptitudes et de l'activité exercée précédemment» (depuis 2011 cette condition n'est plus valable pour les moins de 30 ans), qui ne sont pas adaptés à l'âge, à l'état de santé ou à la situation familiale de l'assuré·e, ou encore qui nécessitent un déplacement de plus de 4 heures par jour. Une personne au chômage est également tenue d'accepter un salaire jusqu'à $30 \%$ inférieur à son gain assuré, ce qui peut entrainer plusieurs réductions suc- 
cessives de salaire en cas de chômage répété. Les indemnités sont calculées en pourcentage du gain assuré $(70 \%$ ou $80 \%$ en cas d'enfants à charge ou de bas salaire). La durée des prestations varie de 200 indemnités journalières (environ 9 mois) à 520 (environ 2 ans) en fonction de l'âge et du nombre de mois de cotisation. La révision de 2010 a renforcé un principe déjà bien inscrit au niveau de l'assurance: la protection augmente avec l'âge et les mois de cotisations. Au contraire, la légitimité des jeunes salariée-e·s et des étudiant·e-s à recevoir une indemnité est remise en cause.

\section{Carola Togni}

\section{Références}

Tabin, J.-P. \& Togni, C. (2013). L'assurance chômage en Suisse: une sociohistoire (1924-1982). Lausanne: Antipodes.

Togni, C. (2015). Le genre du chômage: assurance chômage et division sexuée du travail en Suisse (1924-1982). Lausanne: Antipodes.

Togni, C. (2015). Arbeit und Geschlechterordnung zur Normalisierung der Lohnarbeit in der Arbeitslosenversicherung des 20. Jahrhunderts. In B. Bernet \& J. Tanner (Hrsg.), Ausser Betrieb: Metamorphosen der Arbeit in der Schweiz (S. 91-108). Zürich : Limmat-Verlag.

\section{Assurance-invalidité}

À l'image de la plupart des assurances sociales suisses, l'assurance-invalidité (AI) voit le jour relativement tardivement, en 1960, à l'issue de 15 années de controverses politiques. Des désaccords sur les modalités de financement de cette nouvelle assurance, la crainte d'une gestion étatique de l'invalidité et aussi des effets d'aubaine qu'elle pourrait susciter, ont longuement pesé sur les débats autour de la création de l'AI. Finalement conçue comme «la sœur jumelle de l'AVS", l'AI fait partie du premier pilier du système de protection sociale helvétique. Toute personne résidant ou exerçant une activité lucrative en Suisse y est obligatoirement affiliée et ce jusqu'à l'âge de la retraite. Chaque année, environ $5 \%$ de la population suisse bénéficie de prestations de l'AI. Placée sous la supervision de l'Office fédéral des assurances sociales, l'AI est mise en œuvre au niveau cantonal par deux entités : d'une part, les Offices AI (OAI) qui ont la responsabilité d'instruire les demandes et de suivre les bénéficiaires de prestations AI pour chaque canton; d'autre part, les caisses de compensation, chargées de prélever les cotisations et de délivrer les prestations financières du premier pilier. Le financement de l'AI est organisé autour d'un système de cotisation paritaire entre employeur·euse-s et employé·e·s, complété d'une contribution de la Confédération.

La mission de l'AI est de prévenir, réduire ou compenser l'invalidité résultant d'une maladie, d'un accident ou d'une infirmité congénitale. Cependant, il importe de relever que l'AI s'est dotée d'une définition essentiellement économique de l'invalidité. Si l'on s'en réfère à la loi fédérale sur la partie générale du droit des assurances sociales, l'invalidité est conçue comme une «incapacité de gain totale ou partielle qui est présumée permanente ou de longue durée». Ainsi, c'est la différence entre le revenu qui aurait pu être réalisé en l'absence d'invalidité et ce que l'on appelle le revenu d'invalide qui sert à calculer le taux d'invalidité. Dans ce contexte, l'invalidité est reconnue si et seulement si une altération de l'état de santé engendre directement une diminution de la capacité de gain. De plus, le but de l'AI n'est pas de maximiser la capacité de gain de ses assuré·e·s, mais plutôt de les rapprocher d'un niveau de gain ou de formation équivalent à celui antérieur à l'invalidité. Dès lors, les personnes sans qualification et avec un faible revenu connaissent une prise en charge plus limitée. On retiendra alors que cette approche économique de l'invalidité oriente l'action de l'AI vers une reproduction des inégalités sociales existant sur le marché du travail. Ceci tend à maintenir la dépendance 
à l'égard du marché du travail des individus atteints dans leur santé, tout particulièrement parmi les plus vulnérables.

Ce lien étroit entre invalidité et travail existe depuis la création de l'AI et caractérise également ses prestations, parmi lesquelles on distingue généralement deux grandes catégories, mutuellement exclusives : la réadaptation professionnelle et la rente. La première inclut des mesures médicales pour les assuré·e·s jusqu'à l'âge de 20 ans, la remise de moyens auxiliaires ou encore des mesures d'ordre professionnel comprenant le financement de formations, le versement d'indemnités journalières, des mesures d'orientation professionnelle, voire une aide au placement. Tous ces outils visent à restaurer la capacité de gain des assuré-e-s et à faciliter leur retour sur le marché du travail. La rente, quant à elle, a pour but de compenser les effets économiques de l'invalidité lorsque la réadaptation professionnelle n'est pas envisageable. Depuis la création de l'AI, la voie de la réadaptation a toujours été privilégiée, comme le signale le célèbre mot d'ordre «la réadaptation prime la rente». Ainsi, la rente ne peut être envisagée qu'après l'examen des possibilités de réadaptation professionnelle. L’AI délivre alors des rentes, entières ou partielles en fonction du taux d'invalidité de l'assuré·e, pouvant être complétées par des prestations complémentaires, des rentes pour enfant, voire par une allocation pour impotent.e.

Pendant longtemps, le fonctionnement de l'AI n'a pas été remis en question et n'a connu que des adaptations techniques ou organisationnelles. Cependant, à partir du milieu des années 1990 et en l'espace de 10 ans, le nombre de bénéficiaires de prestations AI (et de rentier·ère-s tout particulièrement) a augmenté d'un tiers. Si la crise du chômage participe de ce phénomène, on en voit surtout la cause dans l'accroissement de la part des rentes octroyées pour des raisons psychiques, notamment parmi les plus jeunes assuré-e.s. Pour parer à cette tendance et freiner l'endettement de l'AI, celle-ci est entrée dans une phase de réformes quasi continues visant l'activation des assuré-e-s. Ainsi, les $4^{\mathrm{e}}, 5^{\mathrm{e}}$ et $6^{\mathrm{e}}$ révisions de l'AI ont eu pour but de limiter le nombre de rentes versées par une accélération de la prise en charge et par le développement des possibilités de réadaptation professionnelle et de placement, voire de maintien des assuré·ess sur le marché du travail. De nouvelles mesures ont été créées comme le développement de services de placement au sein des OAI, l'introduction d'un volet de détection et d'intervention précoce, ou encore l'adoption de mesures transitoires visant à faciliter le passage de la rente vers des mesures de nouvelle réadaptation. Parallèlement à cet élargissement des possibilités de réadaptation professionnelle, l'accès à la rente a été quant à lui restreint. Que ce soit en limitant l'octroi de nouvelles rentes, ou par la révision et la suppression de rentes existantes, on observe un durcissement des conditions d'accès ou de maintien du droit à la rente, raison pour laquelle les organisations de défense des personnes handicapées ont marqué une forte opposition à l'égard de ces réformes. À titre d'exemple, on peut mentionner l'augmentation de la durée minimale de cotisation (d'un à trois ans), la suppression de la rétroactivité de la rente, ou encore le durcissement de l'obligation de collaborer et de réduire le dommage à laquelle sont soumis les assuré-e.s. Mais la restriction de l'accès à la rente est aussi le fait d'une évaluation plus stricte de la capacité de travail des assuré·e.s. Sur ce plan, la création des Services médicaux régionaux en 2004, dédiés à l'évaluation systématique des demandes adressées à l'AI du point de vue médical, a joué un rôle important, tout comme le Tribunal fédéral des assurances aociales dont la jurisprudence a une forte influence sur l'AI et sur la manière d'appréhender certaines pathologies.

Les statistiques montrent que si l'objectif de réduire l'octroi de nouvelles rentes a été largement atteint, le potentiel de suppression de rentes par la révision ou la réadaptation pro- 
fessionnelle reste limité. Ainsi, parmi les principaux défis qui marquent l'avenir de l'AI, on retiendra la question de l'intégration professionnelle des bénéficiaires. En l'absence d'outil permettant de lutter contre la discrimination des personnes handicapées sur le marché du travail, l'AI a déployé des stratégies incitatives à l'égard des employeur-euse-s. La collaboration avec les employeur.euse-s reste cependant un exercice complexe. La prise en charge des personnes atteintes psychiquement est également un enjeu majeur pour l'AI. Cette thématique, méconnue lors de la création de l'AI, a pris une importance croissante jusqu'à devenir la première cause d'invalidité en Suisse. En dépit de mesures de réinsertion spécialement mises en place pour ce public depuis 2008, la question de la santé mentale reste un défi pour l'AI et oblige à repenser le principe même de la réadaptation qui en l'état, est souvent inaccessible à cette catégorie d'assuré.e.s. Ces deux enjeux constituent des défis majeurs pour l'avenir de l'AI, et sont d'ailleurs au cœur du projet de $7^{\mathrm{e}}$ révision de l'AI actuellement en cours de discussion.

\section{Emilie Rosenstein}

\section{Références}

Ferreira, C. (2015). Invalides psychiques, experts et litiges. Lausanne: Antipodes.

Fracheboud, V. (2014). L'introduction de l'assurance invalidité en Suisse (1944-1960): tensions au cœur de l'État social. Lausanne: Antipodes.

Rosenstein, E. (2018). Activer les publics vulnérables? Le cas de l'assurance-invalidité (thèse de doctorat). Université de Genève, Genève.

\section{Assurance-invalidité (révisions législatives)}

Entrée en vigueur le $1^{\text {er }}$ janvier 1960, la loi fédérale sur l'assurance-invalidité (LAI) a fait l'objet de révisions successives dont les plus récentes datent de 2004, 2008 et 2012. Outre l'assainissement financier de l'assurance, le principal fer de lance de ces réformes est de réaffirmer la primauté de la réadaptation sur le versement de rentes. Ce principe a été introduit explicitement pour la première fois dans le texte de loi avec la $4^{\mathrm{e}}$ révision LAI du 21 mars 2003. Depuis, pour atteindre cet objectif, à chacun de ces moments législatifs des prestations sociales ont été abrogées et de nouvelles mesures ont été introduites.

Avec la $4^{\text {e }}$ révision de la LAI (2004) ont été supprimées les rentes complémentaires pour conjoint·e.s et les rentes pour cas pénible qui concernaient les personnes au bénéfice d'un quart de rente mais qui percevaient l'équivalent d'une demi-rente. Dans le même mouvement, a été introduit le trois-quarts de rente pour les taux d'invalidité d'au moins $60 \%$; en conséquence, le taux d'invalidité pour obtenir une rente entière a été fixé à $70 \%$ au moins. Initialement prévue dans le projet de loi, la proposition de supprimer le quart de rente a été refusée en votation populaire en 1999. L'allocation pour impotent·e a été uniformisée de manière à supprimer les inégalités de traitement existantes entre les mineur.e.s atteint.e.s d'une maladie congénitale et celles et ceux qui souffraient d'une maladie survenue après la naissance. Jusqu'alors seul le premier groupe avait le droit à bénéficier de contributions aux frais spéciaux et aux frais de soins à domicile. Sur le plan de la réadaptation, le nouvel article 18 LAI a inscrit le droit d'être activement soutenu.e dans la recherche d'un emploi approprié, ou à être suivi·e pour préserver le poste de travail. Enfin, parmi les mesures importantes introduites par la $4^{\mathrm{e}}$ révision, figure la création des Services médicaux régionaux (SMR) qui consacre la volonté du législateur d'adopter des critères plus stricts dans l'évaluation médicale de l'incapacité de travail.

C'est avec la $5^{\mathrm{e}}$ révision de la LAI en 2008 que la volonté de redéfinir l'invalidité dans des termes plus restrictifs s'affirme pleine- 
ment. Les rentes complémentaires versées aux conjoint·e-s ont été supprimées au motif qu'elles reposaient sur un modèle marital stable, dominant par le passé, mais qui ne correspondait plus aux dynamiques conjugales actuelles. Dans le même ordre d'idées, ont aussi été supprimés des "suppléments de carrière » versés aux personnes qui devenaient invalides avant l'âge de 45 ans. Ces suppléments étaient calculés sur la base d'un revenu qui aurait pu être obtenu si la personne avait poursuivi sa carrière professionnelle. Calqué sur le modèle d'une carrière linéaire et prévisible, ce droit a été jugé obsolète. Simultanément, la $5^{\mathrm{e}}$ révision a renforcé les obligations individuelles de réduire le dommage et d'entreprendre tout ce qui peut être raisonnablement exigible pour réduire la durée et l'étendue de l'incapacité de travail. Au surplus, pour se donner les bases légales permettant une extension de l'action de l'assurance des mesures inédites ont été introduites : la détection et l'intervention précoces sur les lieux de travail auprès de personnes signalées en raison de période d'arrêt de travail et dont il s'agit de conserver le poste ou d'envisager une reconversion. Enfin, les personnes qui sont «en menace d'invalidité» peuvent, après examen, bénéficier de nouvelles mesures comme le réentraînement progressif à l'endurance, l'accoutumance au travail et l'aide à la formation. L'ampleur de ces réformes a alimenté le débat public au cours d'une campagne référendaire qui a abouti à une votation populaire le 17 juin 2007 et à l'acceptation de la $5^{\mathrm{e}}$ révision. Parmi les objets âprement discutés s'est trouvé le refus du gouvernement d'instituer des obligations légales pour les employeur.euse-s sous la forme d'un système de quotas de places de travail réservées aux personnes en situation de handicap. L'alternative adoptée a été la sensibilisation des entreprises à cette problématique au moyen de campagnes et d'incitations financières.

Le premier volet de la $6^{\mathrm{e}}$ révision de la LAI de 2012 s'inscrit expressément dans cette phi- losophie. Prenant acte du succès relatif des instruments de réadaptation introduits par la $5^{\mathrm{e}}$ révision, le législateur a voulu offrir davantage de garanties aux employeur.euse-s. L'assurance-invalidité réduit les risques que représente le recrutement d'une personne dont un rendement plus faible est présumé en raison d'un handicap et/ou d'une maladie. À cette fin, des allocations d'initiation au travail sont versées qui compensent financièrement les performances réduites de la personne pendant la période d'initiation. Cette révision a également introduit les placements à l'essai pendant plusieurs mois permettant aux employeur-euse-s de tester une personne sans être astreints à une obligation d'engagement. En parallèle, les instruments d'un «accompagnement actif» ont été renforcés pour mieux explorer le potentiel de réadaptation de ceux et de celles qui perçoivent de nouvelles rentes. Dans un autre registre, une contribution d'assistance destinée aux bénéficiaires d'une allocation pour impotent vivant à domicile a été instaurée. Le droit à cette contribution a été étendu aux mineur.e-s mais à condition qu'elle leur permette de suivre la scolarité ordinaire.

Ces processus législatifs s'inscrivent dans un contexte historique et idéologique plus large qui place l'activation des bénéficiaires de prestations au cœur de l'action publique. Préconisée par l'Organisation de coopération et de développement économiques (OCDE), cette politique de l'activation - d'abord mise en œuvre dans l'assurance-chômage et l'aide sociale - s'étend dorénavant aux régimes de l'assurance-invalidité. Dans le paysage européen, la Suisse fait partie des pays engagés sur cette voie économique libérale - comme les Pays-Bas et le Royaume-Uni - qui consiste à subordonner les interventions des assurances sociales aux exigences sélectives imposées par le marché du travail. C'est sans doute la raison pour laquelle les révisions de la LAI ne font pas l'objet d'un consensus politique. À chaque processus législatif ont eu lieu des oppositions 
vives de la part de la société civile et qui ont abouti à des référendums ( $4^{\mathrm{e}}$ et $5^{\mathrm{e}}$ révisions). En substance, les critiques formulées ces dernières années dénoncent la fragilisation des droits sociaux acquis et les effets de précarisation qui en résultent. Selon cet argumentaire critique, bien que la philosophie de l'activation promeuve l'autonomisation des individus, elle peut aussi comporter des exigences de performance auxquelles certaines personnes ne sont pas aptes à satisfaire en raison d'une santé fragile et/ou d'un niveau insuffisant de qualifications. À ces contradictions, viennent s'ajouter les rapports de force entre les partis politiques comme ce fut le cas avec le deuxième volet de la $6^{\mathrm{e}}$ révision de la LAI rejeté par le Parlement en juin 2013. Les parlementaires se sont montré·e.s divisé.e-s autour de ce deuxième train de mesures dont l'un des principaux points d'achoppement a été l'introduction d'un système linéaire de rentes ayant pour effet une réduction des montants perçus par les rentier.ère $\cdot s$.

Toujours est-il que ces révisions législatives tendent à redéfinir les rapports qui lient les personnes à la puissance publique selon des modalités plus exigeantes en termes d'efforts individuels. L'un des indices les plus révélateurs est le renforcement de l'obligation faite à l'assuré-e de réduire les risques de bénéficier des prestations de l'assurance. Comme le fait remarquer Béatrice Despland en 2012, l'appel à la responsabilité individuelle, qui sous-tend ces obligations, tend à se substituer à la garantie par l'État d'assurer la sécurité matérielle en toutes circonstances. Compte tenu de la restriction instituée dans l'accès aux rentes, l'un des enjeux à venir réside dans les transferts potentiellement massifs vers l'aide sociale de personnes jugées aptes à se réadapter par leurs propres moyens.

\section{Références}

Despland, B. (2012). L'obligation de diminuer le dommage en cas d'atteinte à la santé. Son application aux prestations en espèces dans l'assurance-maladie et l'assurance-invalidité: analyse sous l'angle du droit d'être entendu. Genève: Schulthess.

Organisation de coopération et de développement économiques (2010). Maladie, invalidité et travail - surmonter les obstacles: synthèse des résultats dans les pays de l'OCDE. Paris: OECD Publishing.

\section{Assurance-maladie*}

L'assurance-maladie comprend l'assurance de base et des assurances complémentaires privées. Toutes les personnes domiciliées en Suisse sont obligatoirement assurées à l'assurance de base (assurance-maladie sociale). Cette dernière prévoit des prestations en cas de maladie, d'accident et de maternité. Les primes d'assurance sont facturées per capita et varient en fonction de la compagnie d'assurance, de la franchise choisie, du modèle d'assurance et de la région de résidence. Dans l'assurance-maladie sociale, le risque de maladie et les prestations sollicitées n'exercent aucune influence sur le montant des primes, pas plus que le revenu du ménage ou la fortune. Les assuréee·s se trouvant dans une situation économique modeste ont droit à des réductions de primes. Pour les prestations non couvertes par l'assurance-maladie sociale, des assurances complémentaires peuvent être souscrites. Pour ces dernières, il n'existe pas d'obligation d'admission du côté des compagnies d'assurance.

La loi sur l'assurance-maladie (LAMal), en vigueur depuis 1996, constitue la base légale de l'assurance-maladie sociale. La LAMal est le fruit d'un compromis entre les partisan-e-s d'une assurance publique financée solidairement et les partisan-e-s des principes de la concurrence et de la responsabilité individuelle. L'assurance-maladie sociale est ainsi fondée sur une «concurrence régulée» réu- 
nissant plusieurs principes: obligation de s'assurer, obligation pour les assureur.e.s d'admettre toute personne, règle de non-profit et catalogue uniforme des prestations. Des compagnies d'assurance privées gèrent l'assurance-maladie sociale; elles sont en situation de concurrence et déterminent leurs primes en fonction des coûts.

Avec la LAMal, la Confédération s'est vue attribuer une série de nouvelles compétences allant de la mise en œuvre de l'obligation d'assurance jusqu'au contrôle de l'efficience et de la qualité des prestations. Bien que l'assurance-maladie sociale ne couvre qu'un peu plus d'un tiers des dépenses totales de santé, elle constitue le noyau dur des soins de santé en Suisse. De son organisation dépendent non seulement la sécurité sanitaire de la population mais aussi les revenus d'un grand nombre de prestataires et de fournisseur.euse-s de soins de santé. Les révisions de la LAMal s'accompagnent toujours de luttes politiques acharnées, ceci en raison des vastes compétences de la Confédération et de l'incidence économique du système de santé. Différents groupes d'intérêts plus ou moins puissants interviennent dans ces débats.

Les prestations couvertes par l'assurance-maladie sociale sont énumérées dans la LAMal et précisées dans l'ordonnance sur les prestations. Le catalogue de prestations comprend, en plus des prestations médicales et de soins, les listes exhaustives des médicaments (liste des spécialités), des analyses (liste des analyses) et des moyens médicaux (liste des moyens et appareils) ainsi que les montants maximaux remboursés. La LAMal régit également la reconnaissance des prestataires de services. Quant aux coûts des soins dentaires, ils sont presque complètement exclus de la liste des prestations.

La LAMal attribue à la Confédération des compétences en matière de fixation des primes et des tarifs, d'assurance qualité et de maîtrise des coûts. Une condition préalable aux pres- tations de l'assurance de base est le «principe $E A E »$ : les prestations doivent être efficaces, appropriées et économiques. Les assureur·e·s maladie peuvent refuser d'indemniser des prestations qui ne respectent pas ces principes.

Les cantons sont responsables de l'octroi et $\mathrm{du}$ financement des réductions de primes aux assuréee-s de conditions économiques modestes. La Confédération contribue aux réductions des primes.

Le système de primes per capita pour financer l'assurance-maladie sociale est unique en Europe. Dans la plupart des pays, les soins de base sont financés en grande partie par des cotisations salariales et/ou des impôts directs. En Suisse, les primes par tête, indépendantes $\mathrm{du}$ revenu, conduisent à un financement de la santé fortement régressif, impliquant une contribution disproportionnée des personnes à faible et moyen revenu. Dans certains cantons, les charges peuvent s'élever à plus de $20 \%$ du revenu disponible des ménages à revenus modestes. Les initiatives politiques visant à introduire un financement de la santé en fonction du revenu sont restées jusqu'à présent sans suite.

Le système de franchises à option permet aux assuré·e.s de réduire leurs primes d'assurance en assumant eux- et elles-mêmes un montant annuel pouvant s'élever jusqu'à 2500 francs. Ce système réduit la solidarité entre les personnes en bonne santé et les malades, car le choix d'une franchise élevée est payant pour les assuré-e·s avec un faible besoin en prestations, tandis que les personnes atteintes de maladies chroniques, par exemple, paient des primes plus élevées. Depuis quelques années, les personnes à faible revenu ont tendance à opter pour des franchises élevées afin d'économiser sur les primes d'assurance-maladie. Cela les conduit à renoncer à des visites médicales ou à les reporter pour des raisons financières. La non-prise en charge des frais dentaires par l'assurance-maladie sociale entraîne d'autres situations sociales difficiles. Entre 2010 et 
2016, la proportion d'adultes en Suisse qui ont renoncé à des prestations médicales pour des raisons financières a augmenté, passant de 10,3 à $22,5 \%$. Ce taux est très élevé comparé à d'autres pays industrialisés.

La LAMal autorise des formes d'assurance particulières, par exemple une restriction du libre choix du médecin en échange d'une réduction des primes. Les modèles du médecin de famille et les cabinets de groupe HMO avec une coresponsabilité budgétaire coordonnent le déroulement du traitement et exercent en même temps une fonction de contrôle d'accès aux médecins spécialistes.

Les primes par tête élevées et en augmentation constante ainsi que les participations élevées des patient·e.s aux prestations de santé représentent un défi majeur pour la sécurité sociale en Suisse. Le système de réductions des primes n'est que ponctuellement en mesure de soulager efficacement les ménages à faibles et moyens revenus. Le montant des réductions, les seuils de revenus y donnant accès et les modalités administratives varient d'un canton à l'autre. Au cours des dernières années, de nombreux cantons ont réduit leurs contributions aux réductions de primes dans le cadre de programmes d'austérité.

L'absence de protection complète contre la perte de gain due à la maladie est l'une des dernières lacunes majeures de la protection sociale suisse. Cette protection dépend du type d'emploi, de l'employeur.euse, du lieu de résidence ou encore de l'état de santé préalable. La plupart des employeur-euse-s - mais pas la totalité - souscrivent à titre privé une assurance d'indemnités journalières pour leurs employéres.s. Les personnes sans emploi qui tombent malades peuvent perdre leurs indemnités de l'assurance-chômage. Souvent, ce n'est qu'après la survenue d'une maladie que les personnes se rendent compte qu'elles sont insuffisamment assurées contre la perte de gain. Certes, la LAMal inclut la possibilité de souscrire, sur une base volontaire, une assurance collective ou individuelle d'indemnités journalières. Cependant, comme la loi ne prescrit pas de montant minimal, la plupart des compagnies d'assurance ne couvrent que des indemnités entre 6 et 40 francs. L'assurance d'indemnités journalières selon la LAMal n'offre donc pas de véritable compensation du salaire ; elle est dès lors devenue pour ainsi dire insignifiante.

\section{Anna Sax}

\section{Références}

Indra, P., Januth, R. \& Cueni, S. (2016). Krankenversicherung. In W. Oggier (Hrsg.), Gesundheitswesen Schweiz 2015-2017 : eine aktuelle Übersicht (5.,vollst. überarb. Aufl., S. 217-241). Bern : H. Huber.

Merçay, C. (2016). Expérience de la population âgée de 18 ans et plus avec le système de santé, situation en Suisse et comparaison internationale. Neuchâtel: Observatoire suisse de la santé.

\section{Assurances sociales}

Les assurances sociales se définissent comme un ensemble de mesures destinées à couvrir des cercles définis de personnes contre les conséquences de la survenance de différentes éventualités (maladie, invalidité, p.ex.). Elles octroient des prestations en nature (soins médicaux, p.ex.) et en espèces (rentes de vieillesse, d'invalidité ou de survivants, p.ex.) et fonctionnent selon le principe de l'assurance, lequel permet l'octroi d'une protection par le biais d'une répartition des risques sur une communauté de personnes plus ou moins large («les assuré·e-s») et moyennant le paiement de primes ou de cotisations.

Les premières assurances sociales sont apparues en Allemagne à la fin du XIX ${ }^{\mathrm{e}}$ siècle. Introduites sous l'égide du chancelier impérial Otto von Bismarck, elles visent alors le double objectif d'assistance publique («paix sociale») 
et de répression politique («lois antisocialistes»). En Suisse, les premières initiatives remontent aux années 1890, mais seule l'assurance militaire passe le cap en 1901. En 1912, le Parlement approuve la création de l'Office fédéral des assurances sociales (OFAS), qui depuis veille au fonctionnement et au développement successif des assurances sociales, lesquelles relèvent de la compétence de la Confédération (articles 111-114 et 116-117 de la Constitution).

Conformément à la conception traditionnelle de la Convention 102 de l'Organisation internationale du travail (OIT), adoptée en 1952, les assurances sociales garantissent une prévoyance vieillesse, survivants et invalidité (qui, en Suisse, est réalisée selon le système dit des trois piliers; article 111 de la Constitution) et prennent en charge les conséquences économiques de la maladie et de l'accident (professionnels ou non), de la maternité, du chômage, ainsi que les charges familiales. S'ajoute encore l'assurance militaire, qui accorde une large gamme de prestations (prestations en cas de maladie, d'accident, d'invalidité et de décès, notamment). Bien que portant le nom d'assurance, ce régime n'est pas une assurance au sens strict du terme, étant donné, notamment, qu'il n'est pas financé par le biais de cotisations et qu'il n'y a pas de calcul des risques.

Depuis le $1^{\text {er }}$ janvier 2003, les différents régimes sont coordonnés par la loi fédérale sur la partie générale du droit des assurances sociales (LPGA), qui, en particulier, définit les éventualités couvertes (maladie, accident, maternité, etc.), établit des règles de procédure uniformes et prévoit des règles de coordination lorsque des prestations sont versées par plus d'une assurance sociale. La prévoyance professionnelle (LPP) n'entre toutefois pas dans le champ d'application de la LPGA.

Développé sur une période de plus de cent ans et basé sur onze lois fédérales, l'ensemble des assurances sociales présente plusieurs caractéristiques communes. Tout d'abord, les différents régimes partagent une finalité sociale. Les assurances sociales interviennent en présence d'un événement reconnu par l'État comme nécessitant un besoin de protection (maladie, naissance d'un enfant, perte de l'emploi, p.ex.). Les institutions d'assurance sociale accomplissent une tâche publique et ne poursuivent aucun but lucratif.

Deuxièmement, l'affiliation est obligatoire sur la base de la loi. Le cercle des assuré.e-s est défini dans les différentes lois, de sorte qu'il suffit qu'une personne remplisse les conditions légales pour être soumise à l'obligation d'assurance. Certains régimes confèrent une protection qualifiée d'universelle (l'AVS/AI, p.ex.), alors que d'autres restreignent leur champ d'application aux personnes professionnellement actives. L'assurance-accidents et la prévoyance professionnelle sont ainsi des régimes obligatoires pour les personnes salariées et facultatifs pour les personnes indépendantes; l'assurance-chômage est quant à elle réservée aux salarié.e-s. Par ailleurs, en ce qu'il impose aux assurances sociales le devoir d'accepter toute personne tenue de s'assurer, le principe de l'affiliation obligatoire est incompatible avec la sélection des risques qui a cours dans l'assurance privée.

Le principe de la légalité est une troisième caractéristique. Chaque loi d'assurance sociale définit les personnes et éventualités couvertes, les prestations allouées et leurs conditions et modalités d'octroi, ainsi que l'organisation et le financement du régime. Le principe de la légalité s'oppose au principe de l'autonomie, ce qui signifie qu'une institution d'assurance sociale ne peut fixer des règles propres (droit autonome) que dans les domaines où la loi l'y autorise expressément. La liberté contractuelle qui prévaut dans l'assurance privée ne s'applique donc pas, puisque les organes d'exécution (caisses maladie, p.ex.) sont tenus de respecter le cadre légal. Le principe de la légalité garantit la sécurité du droit et l'égalité de traitement. 
Une quatrième particularité concerne l'organisation autonome des assurances sociales. Celles-ci sont gérées par des institutions publiques (caisses cantonales de compensation, caisses de chômage, etc.) ou privées (caisses maladie et caisses de compensation professionnelles, p.ex.) sous la surveillance de l'État, par l'intermédiaire de l'OFSP (assurance-maladie et assurance-accidents), de l'OFAS (AVS/AI, notamment) ou du SECO (assurance-chômage). Ces différentes entités appliquent le droit public et rendent des décisions, dont le bien-fondé peut être contesté par la personne assurée.

Enfin, les assurances sociales se distinguent aussi par leur mode de financement solidaire. Elles sont financées par le prélèvement de primes ou de cotisations auprès des assuré·e.s, et en principe, également auprès des employeur-euse-s (AVS/AI, assurance-accidents, assurance-chômage, notamment). Les subventions des pouvoirs publics peuvent aussi constituer une source de financement, de même que les impôts généraux (TVA, taxes sur l'alcool, les maisons de jeu ou le tabac, p.ex.). Les primes et cotisations ne sont généralement pas fixées en fonction de la catégorie de risque à laquelle appartient l'assuré.e, d'où une solidarité horizontale entre les jeunes et les personnes âgées, respectivement entre les individus en bonne santé et les personnes malades (primes d'assurance-maladie, p.ex.). Une solidarité entre les revenus (solidarité verticale) existe également dans certains régimes (AVS/ AI, notamment), puisque les cotisations sont calculées en proportion du revenu de l'activité lucrative ou selon la condition sociale de l'assuré (lorsque celui-ci n'exerce pas d'activité lucrative). Dans l'AVS/AI, la solidarité verticale est très forte, car si les prestations sont plafonnées, tel n'est pas le cas du revenu soumis à cotisations.

Parmi les problèmes connus concernant les assurances sociales, relevons qu'il n'existe pas de couverture obligatoire de la perte de gain consécutive à la maladie non professionnelle et que les personnes indépendantes ne sont pas soumises à titre obligatoire à l'ensemble des assurances sociales. Par ailleurs, il convient également de tenir compte du fait que certaines assurances sociales sont susceptibles de défavoriser les personnes qui interrompent, momentanément ou définitivement, leur activité professionnelle. En particulier, la personne qui cesse de travailler afin de se consacrer aux tâches familiales s'expose au risque de ne pas disposer d'une prévoyance professionnelle suffisante au moment de la retraite ou en cas d'invalidité. Afin de prendre en considération cette réalité, la législation pose le principe du partage, en cas de divorce, des expectatives de la prévoyance professionnelle acquises durant le mariage depuis le $1^{\text {er }}$ janvier 2000 (articles 122 ss du Code civil). Une révision entrée en vigueur le $1^{\text {er }}$ janvier 2017 a amélioré le système puisqu'elle prévoit que le partage des avoirs doit également avoir lieu lorsque l'un des membres du couple perçoit déjà des prestations du $2^{\mathrm{e}}$ pilier au moment de l'introduction de la procédure de divorce. Dans le $1^{\text {er }}$ pilier, un système similaire prévaut depuis le $1^{\text {er }}$ janvier 1997, puisque les revenus acquis pendant les années civiles de mariage doivent être répartis et attribués pour moitié à chaque membre du couple (splitting) au moment du calcul des rentes ou d'un éventuel divorce.

\section{Stéphanie Perrenoud}

\section{Références}

Gnaegi, P. (2017). Histoire et structure des assurances sociales en Suisse (4 éd. revue et augmentée). Genève: Schulthess.

Greber, P.-Y., Kahil-Wolff, B., Frésard-Fellay, G., Molo, R. \& Perrenoud, S. (Éd.) (2010/2015). Droit suisse de la sécurité sociale (2 vols). Berne : Stämpfli.

Steiger-Sackmann, S. \& Mosimann, H.-J. (Hrsg.) (2014). Recht der Sozialen Sicherheit: Sozialversicherungen, Opferhilfe, Sozialhilfe, Beraten und Prozessieren. Basel : Helbing Lichtenhahn. 


\section{Assurances sociales et genre}

Les assurances sociales ne sont jamais neutres d'un point de vue du genre. Les choix des dispositifs mis en place, des conditions d'octroi et de calcul des prestations ont des conséquences en termes de gestion des inégalités entre les femmes et les hommes.

Les premières assurances sociales adoptées au début du $20^{\mathrm{e}}$ siècle visaient essentiellement une protection des hommes en tant que soldats (assurance militaire fédérale, 1901) ou travailleurs (assurance fédérale en cas de maladie et d'accidents, 1911; assurance-chômage fédérale, 1924). Calqués sur le modèle familial de l'«homme gagne-pain» et de la «femme au foyer», les critères d'accès aux assurances sociales ont été construits sur la base des normes d'emploi masculines (régulier, à plein temps) et la non-prise en compte du travail domestique réalisé essentiellement par les femmes dans le cadre familial. De plus, des formes féminines d'emploi, telles que le travail dans des entreprises familiales (agricoles ou autres), le travail à domicile ou dans des secteurs fortement féminisés (dont le service de maison) ont souvent été exclues d'une protection sociale. Les femmes mariées ont été particulièrement pénalisées dans l'accès aux prestations sociales. L'assurance-vieillesse et survivants (AVS) adoptée en 1947 n'octroyait pas de rente à la femme mariée mais une rente supérieure à son mari. À la même période (de 1942 à 1951), les femmes mariées sont également exclues de l'assurance-chômage. Ces exclusions ou ces droits dérivés, ainsi que le très faible développement de la politique familiale, ont contribué à situer la Suisse parmi les pays à forte adhésion au modèle familial traditionnel de l'épouse au foyer et de l'homme gagne-pain.

À partir des années 1980-1990, suite à un renouveau des mobilisations féministes et de leur institutionnalisation dans des politiques d'égalité, ainsi qu'à d'importantes transforma- tions de l'emploi féminin (salarisation, généralisation du temps partiel), le modèle familial sur lequel se basent les dispositifs assurantiels change : les deux conjoints travaillent, l'homme à plein temps et la femme à temps partiel. Des révisions des assurances sociales reflètent ce changement de modèle familial tout en participant à renforcer cette nouvelle norme d'activité féminine. Au niveau de l'assurance-chômage, la loi de 1982 assouplit l'exigence de régularité de l'emploi, améliore la protection en cas d'emploi à temps partiel et de maternité. Au niveau des retraites, la 10 révision de l'AVS (1997) instaure un système de rente individuelle moins dépendante de l'état civil, des bonifications pour tâches éducatives, une amélioration des rentes en cas de veuvage et le splitting (calcul de la rente sur la base d'un partage des revenus que les deux époux ont acquis pendant leurs années de mariage). Des féministes ont toutefois critiqué l'élévation de l'âge de la retraite de 62 à 64 ans. Le nouveau droit du divorce entré en vigueur en 2000 a amélioré le partage des prestations de la prévoyance professionnelle (LPP) entre époux. Enfin, l'introduction de la loi sur l'assurance-maladie en 1994 supprime la possibilité d'exiger des femmes des primes plus élevées (jusqu'ici justifiées par les coûts inhérents à la maternité).

Ces changements intervenus au cours des années 1980-1990 ainsi que l'adoption d'un congé maternité fédéral en 2004 constituent des progrès en matière de protection des salariées et de réduction des inégalités. Les dispositifs actuels restent toutefois basés sur des critères et des normes d'emploi qui continuent à prétériter les femmes, qui se retrouvent surreprésentées dans les emplois à temps partiel, les contrats à durée déterminée, le travail sur appel et autres formes d'emploi dites «atypiques ». La 4 e révision de l'assurance-chômage de 2010, en augmentant de 12 à 18 le nombre de mois de cotisation nécessaires pour bénéficier de 400 indemnités de chômage (environ 18 mois) renforce l'exigence de régularité et de 
stabilité de l'emploi qui pénalise particulièrement les femmes. Au niveau des retraites, les bas salaires, majoritairement féminins, n'ont pas accès à la prévoyance professionnelle (LPP) et ont encore moins la possibilité de cotiser à la prévoyance privée. Si l'AVS est le pilier le moins discriminant, les propositions récurrentes d'élévation de l'âge de la retraite des femmes vont dans le sens de limiter son caractère favorable aux femmes et à l'égalité.

L'emploi, en particulier le salariat, reste au centre du dispositif assurantiel. Les mesures prises concernant la prise en compte du travail domestique reflètent plus des réajustements dans la gestion de la division sexuée du travail qu'une remise en cause de celle-ci. La disposition concernant la "période éducative» au niveau de l'assurance-chômage est un bon exemple. Introduite en 1996, cette disposition permet de considérer le temps consacré à l'éducation de ses propres enfants comme du temps de cotisation pouvant ouvrir un droit à une indemnité en cas de chômage. Elle est toutefois soumise à une condition de ressource, ce qui reflète plus une volonté d'assister les familles pauvres que de reconnaitre le travail domestique. En 2002, la disposition est révisée : d'une part le critère du besoin économique est supprimé, d'autre part la «période éducative » n'est plus considérée comme du temps de cotisation, mais prolonge la période pendant laquelle il faut prouver un nombre suffisant de mois de cotisation. Il ne s'agit plus de protéger les familles pauvres, mais d'encourager le retour relativement rapide des mères sur le marché de l'emploi. La reconnaissance du travail domestique reste fort limitée, car c'est uniquement le travail rémunéré qui compte pour l'ouverture d'un droit aux indemnités. C'est le cas également au niveau du congé maternité fédéral, qui ne s'adresse qu'aux salariées et indépendantes qui peuvent prouver avoir travaillé durant au moins cinq mois pendant la période précédant l'accouchement. La mère doit également être en emploi ou inscrite au chômage au moment de l'accouchement. Ce n'est donc pas la maternité qui est assurée et indemnisée, mais l'interruption (supposée momentanée) d'un emploi rémunéré. Parmi les derniers pays européens à avoir introduit un congé maternité (2004), la Suisse n'accorde des prestations qu'aux mères, alors que plusieurs États prévoient des congés parentaux plus ou moins longs (de 6 mois aux Pays-Bas, jusqu'à 3 ans en Suède). D'un point de vue des assurances sociales suisses, l'éducation des enfants reste une prérogative féminine, ce qui est confirmé par les fortes réticences vis-à-vis de l'établissement d'un congé paternité au niveau fédéral. Depuis 2005, le dispositif de l'allocation perte de gain (APG), initialement prévue pour les militaires, finance une allocation maternité de 14 semaines, déchargeant ainsi financièrement la majorité des employeur.euse-s qui offrait déjà des prestations similaires, voire supérieures. Cela s'est traduit par un élargissement du cercle des assurées, mais pas nécessairement par une amélioration des prestations pour les mères qui étaient déjà assurées. Les modalités de calcul des prestations de l'allocation maternité, $80 \%$ du revenu plafonné, sont les mêmes que celles de «l'allocation de base » de l'APG pour les militaires. Cependant, contrairement aux mères, les militaires avec enfants à charge peuvent compter sur une «allocation pour enfant» qui se rajoute à l'allocation de base. De plus, l'APG militaire prévoit une allocation minimale (qui n'existe pas dans l'APG maternité) qui est octroyée également aux militaires non actifs professionnellement. Cette comparaison montre bien que la sécurité sociale suisse n'accorde pas la même reconnaissance sociale à la maternité qu'au service militaire. De plus, la charge domestique qui découle de la maternité est utilisée pour remettre en cause le droit des mères à des prestations en cas de chômage. Un rapport du SECO de 2006 constate des pratiques discriminantes de la part des Offices régionaux de placement, qui consistent à exiger des chômeuses des preuves de solutions de 
garde pour leurs enfants, alors que rien n'est demandé aux pères au chômage. Les dispositifs et les pratiques sur lesquels reposent les assurances sociales ne sont donc pas neutres d'un point de vue du genre.

\section{Carola Togni}

\section{Références}

Studer, B. (2014). Genre et protection sociale. Dans A. Brodiez-Dolino \& B. Dumos (Éd.), La protection sociale en Europe au $X X^{e}$ siècle (pp. 101-120). Rennes: Presses universitaires de Rennes.

Togni, C. (2015). Le genre du chômage: assurance chômage et division sexuée du travail en Suisse (1924-1982). Lausanne: Antipodes.

Wecker, R. (2009). Ungleiche Sicherheiten: Das Ringen um Gleichstellung in den Sozialversicherungen. In Schweizerischer Verband für Frauenrechte (Hrsg.), Der Kampf um gleiche Rechte (S. 185-194). Basel: Schwabe.

\section{Assurance-vieillesse et survivants (AVS)*}

L'assurance-vieillesse et survivants (AVS) est au cœur du système de prévoyance vieillesse en Suisse. Elle verse principalement deux formes de rentes: l'une pour les retraité·e-s, l'autre pour les survivant·e.s. La rente de vieillesse est destinée à permettre une sortie financièrement sûre de la vie active. La rente de survivant.e vise à éviter que des difficultés financières s'ajoutent aux souffrances causées par le décès d'un·e parent·e ou d'un·e conjoint·e.

Les premières revendications visant à instaurer une assurance-vieillesse obligatoire ont été formulées par les syndicats dans les années 1880. L'article constitutionnel relatif à la création de l'AVS a été adopté en 1925 suite à une motion déposée en 1912 déjà, demandant l'introduction d'une assurance-vieillesse et invalidité fédérale. Cette motion n'a été prise en considération qu'en 1918, après la fin de la guerre et la grève générale. La loi d'application de l'AVS a été adoptée à la deuxième tentative après un rejet dans les urnes en 1931: lors d'une votation populaire, elle a reçu l'appui d'une majorité de près de $80 \%$ de l'électorat. La loi est entrée en vigueur en 1948. Les rentes versées à cette époque étaient comprises entre 40 et 125 francs par mois.

Depuis, dix révisions ont permis d'étendre le système AVS et d'améliorer les prestations de rente de manière significative à certains égards. L'âge de la retraite des hommes est resté inchangé à 65 ans depuis 1948. En revanche, l'âge de la retraite des femmes a été relevé à plusieurs reprises. Avec la $10^{\mathrm{e}}$ révision de l'AVS, il a été porté à 63 ans en 2001 et à 64 ans en 2005. Lors de cette même révision, un système de rentes individuelles indépendantes de l'état civil a été introduit en 1997.

L'AVS et l'assurance-invalidité (AI) constituent le premier pilier du système dit des trois piliers. Selon le mandat de la Constitution fédérale, l'AVS doit couvrir les besoins vitaux de manière appropriée pendant la vieillesse. Les personnes pour lesquelles ce n'est pas le cas ont droit à des prestations complémentaires (PC). Les rentes AVS et les prestations du deuxième pilier (prévoyance professionnelle vieillesse, survivants et invalidité, LPP) doivent, conformément à la Constitution fédérale, permettre de «maintenir de manière appropriée le niveau de vie antérieur ». Cela signifie la garantie d'un revenu, sous forme d'une rente, qui couvre au moins $60 \%$ du dernier salaire perçu. En règle générale, les rentes AVS sont adaptées tous les deux ans à l'évolution des salaires et des prix à l'aide de l'indice mixte. Un tel mécanisme d'adaptation n'est pas prévu par la loi dans le cas des rentes de la prévoyance professionnelle.

L'AVS est obligatoire pour toutes les personnes domiciliées en Suisse. L'obligation générale de cotiser commence à l'âge de 20 ans révolus, et à l'âge de 17 ans révolus pour les personnes actives. Les cotisations salariales pour l'AVS se montent à 8,7\% depuis 2020 . L'AVS repose sur le principe de solidarité 
entre les générations que l'on appelle communément le «contrat des générations». Le financement se fonde sur un système dit de répartition. Les cotisations perçues durant une certaine période servent directement à financer les prestations versées durant cette même période : les cotisations sont « réparties ». L'AVS contribue, de plus, à la redistribution entre les riches et les moins riches: les cotisations sont perçues sur la totalité du salaire, alors que seuls les salaires jusqu'à une certaine limite influencent le montant des rentes. Les cotisations versées sur les salaires dépassant cette limite sont donc purement solidaires. Environ $80 \%$ des recettes de l'AVS proviennent des cotisations versées par les personnes assurées et leurs employeur-euse-s, et plus de $20 \%$ proviennent des recettes fiscales fédérales. À cela s'ajoute un point de pourcentage supplémentaire de TVA introduit en 1999, dont le montant va entièrement dans les caisses de l'AVS depuis 2020 et l'acceptation du paquet RFFA (réforme fiscale et financement de l'AVS).

Le Conseil fédéral et en particulier l'Office fédéral des assurances sociales (OFAS) surveillent l'AVS. Les caisses de compensation de l'AVS en sont les organes d'exécution. Elles sont responsables de la perception des cotisations et du versement des prestations d'assurance. La centaine de caisses de compensation existant en Suisse est gérée par des associations, les cantons et la Confédération. La participation des entreprises, notamment en matière de prélèvement des cotisations salariales, est exigée par la loi. La Centrale de compensation à Genève fait le lien entre les caisses AVS. Elle tient un registre central des assuré.e.s et des rentes ainsi que la comptabilité du fonds de compensation de l'AVS. Le placement de l'argent de ce fonds relève de la responsabilité de son conseil d'administration.

Les controverses sur l'avenir de la prévoyance vieillesse dominent depuis longtemps le débat sociopolitique en Suisse. Leur principal objet est de savoir comment stabiliser ce système à long terme. Une des questions centrales est la relation entre le premier et le deuxième pilier. Les deux formes de financement (par répartition ou par capitalisation) présentent des avantages et des inconvénients. L'augmentation de la productivité économique et la hausse de la masse salariale ont un effet positif sur l'AVS, tandis que le vieillissement démographique de la société a tendance à l'influencer de manière négative. Dans le cas de la prévoyance professionnelle, c'est l'évolution des produits des capitaux qui est le facteur le plus important. La réforme "Prévoyance vieillesse 2020 », que le peuple a rejetée de justesse en 2017, aurait constitué une approche complète comprenant à la fois le premier et le deuxième pilier.

Il existe différentes possibilités de stabiliser le système de la prévoyance vieillesse, et en particulier l'AVS. Citons notamment un relèvement général de l'âge de la retraite et/ou une augmentation des recettes. Cette dernière option pourrait passer par une hausse des cotisations salariales ou par un financement accru à partir de recettes fiscales. L'augmentation de la taxe sur la valeur ajoutée n'est pas la seule solution possible. La proposition de créer un impôt national sur les successions et les donations, dont une partie aurait profité à l'AVS, a été clairement rejetée lors d'une votation populaire en 2015. Toutefois, la question de savoir si non seulement les revenus du travail, mais aussi les revenus de la fortune devraient être utilisés pour financer la prévoyance vieillesse n'a pas encore été tranchée.

Compte tenu du mandat de la Constitution fédérale, une réduction du niveau des rentes semble exclue.

Les discussions sur l'avenir de la prévoyance vieillesse se sont intensifiées dans de nombreux pays industrialisés depuis le début du millénaire. En Allemagne notamment, le débat s'est, entre autres, inspiré de l'expérience de la Suisse (et de son système des trois piliers). De nombreux pays ont opté pour un relèvement de 
l'âge de la retraite et une réduction du niveau de la rente de vieillesse légale afin de stimuler la prévoyance privée. Cependant, les résultats d'une telle restructuration de la prévoyance vieillesse sont parfois très problématiques.

\section{Kurt Seifert}

\section{Références}

Bowald, B. \& Bürgstein, W. (2009). Brennpunkt Altersvorsorge: Gerechtigkeit angesichts demografischer Herausforderungen. Zürich : Rüegger.

Conseil fédéral (2015). Message du Conseil fédéral relatif à la réforme Prévoyance vieillesse $2020 \mathrm{du}$ 19 novembre 2014. Feuille fédérale, 1-242.

Dossier : réforme Prévoyance vieillesse 2020. (2015). Sécurité sociale CHSS, 2, 63-88.

\section{Austérité**}

Le terme d'austérité définit la politique budgétaire restrictive de l'État. À savoir une politique de rigueur prévoyant une réduction des dépenses publiques en vue d'assurer la stabilité financière et l'assainissement du budget public nécessaire pour l'atteindre. Les politiques d'austérité s'inscrivent normalement dans la politique fiscale (selon la terminologie anglo-saxonne) qui vise à atteindre l'équilibre - ou la parité - du budget public. Pour certaines personnes, l'équilibre budgétaire visé par les politiques d'austérité est la condition de la viabilité financière des politiques sociales; d'autres estiment au contraire que ces politiques sont marquées par une vision du monde néolibérale, selon laquelle les gouvernements, les États et les citoyen·ne·s doivent être régi-e·s par les marchés, financiers en particulier, et dénoncent les implications négatives de ces instruments pour les politiques sociales et la mise en œuvre des droits sociaux en général.

Ce qu'on appelle les «mesures d'austérité» prévoit l'«examen des dépenses publiques» (spending review) pour «optimiser» les services publics, une réduction des dépenses sociales, comme celles de retraite, de santé et d'assistance et l'augmentation de la pression fiscale sur les contribuables. Des conséquences fréquentes des politiques d'austérité sont l'augmentation du chômage, la récession ou encore la baisse de la consommation. En provoquant un ralentissement de la croissance économique, ou sa stagnation, les mesures d'austérité peuvent entraîner une réduction des recettes fiscales et donc, par un curieux paradoxe, une augmentation de la dette publique au lieu de sa réduction, qui est pourtant la raison d'être des politiques d'austérité.

Les politiques d'austérité s'inscrivent le plus souvent dans le cadre des politiques économiques et fiscales néolibérales qui se sont affirmées dès le début des années 1980 avec l'élection de Margaret Thatcher en Grande-Bretagne et Ronald Reagan aux États-Unis. Ce tournant néolibéral s'accompagnait de la volonté de créer les conditions nécessaires à un profond remaniement de l'État social au profit de la primauté du marché, en s'appuyant sur le principe de la capacité des marchés à s'autoréguler. Pour ce faire, la stratégie mise en œuvre a été celle des caisses vides ou de l'État pauvre, résumée par David Stockman, conseiller économique de Ronald Reagan, dans la formule starving the beast, à savoir vider les caisses de l'État par des mesures de défiscalisation des revenus élevés et des profits, de manière à contraindre les politicien.ne-s à adopter des mesures de réduction des dépenses. Selon cette théorie, les disponibilités libérées par la réduction de la pression fiscale devaient se traduire par une augmentation des investissements, de l'emploi et de la consommation. En réalité, cette stratégie a contribué à alimenter la financiarisation naissante, à savoir le détournement de l'épargne vers les marchés financiers et non pas vers les activités de production. Dès les années 1990, la Suisse au même titre que d'autres États européens a été influencée par ces politiques 
néolibérales, comme l'ont par exemple montré les travaux de Sébastien Guex.

Pour se déployer pleinement, selon les intentions de leurs partisan-e.s théorico-politicien·ne·s, les mesures d'austérité nécessitent la création d'un contexte d'urgence susceptible de contourner le processus démocratique normal et le consensus nécessaire pour les mettre en pratique. En Suisse, l'instrument du frein à l'endettement peut être interprété de cette façon. Au-delà du cas de la Suisse, la crise de 2008, qui a vu le jour aux États-Unis et s'est propagée en Europe, a été l'occasion de transformer les mesures d'austérité en véritables interventions (voir Troika ci-dessous), rendues inévitables en raison de l'état d'urgence créé par la crise et soutenues par des traités internationaux comme le fiscal compact. Durant cette crise, les États ont porté secours au système bancaire par des aides massives. En augmentant ainsi fortement la dette publique, ils se sont exposés aux marchés financiers et à leur discipline par la vente de leur dette aux investisseur.e.s privé·e.s, créant une raison supplémentaire de réduire les dépenses publiques, sociales en particulier. Ces circonstances ont fait émerger les conditions pour la réalisation de ce que Naomi Klein a appelé la stratégie du choc, une situation d'urgence qui autorise l'adoption de mesures sociales de réduction des droits démocratiques et sociaux qui, autrement, ne seraient pas réalisables politiquement. "Nous avons tous vécu au-dessus de nos moyens », «l'État est au bord de la faillite», «les retraites et le système de santé ont atteint des sommets insoutenables», «nous ne devons pas faire peser sur nos petits-enfants la dette publique que nous avons créée»: tels sont les arguments avancés pour justifier les mesures d'austérité, alors même qu'elles ne sont ni scientifiquement étayées ni légitimées par des procédures démocratiques.

N'appartenant pas à l'Union européenne et à la zone euro, la Suisse subit les effets des mesures d'austérité européennes à travers une forte pression sur le franc, considéré comme une monnaie refuge. En effet, les mesures d'austérité appliquées dans les pays membres de l'UE ont contribué à la persistance de la récession qui a suivi la crise de 2008. Avec la diminution de la demande et de la consommation, les dettes publiques des États membres n'ont pas diminué, amorçant dans certains cas un cercle vicieux de réduction des dépenses publiques pour satisfaire les directives de la Troïka (Commission européenne, Banque centrale européenne et Fonds monétaire international). Le climat d'incertitude planant sur la tenue de l'euro a maintenu à un niveau élevé la tension sur les marchés monétaires et sur le franc en particulier. Cela en contraignant, dans un premier temps, la Banque nationale suisse (BNS) à défendre un taux de change minimum entre le franc et l'euro puis, dans un deuxième temps en 2014, à l'abandonner, afin d'éviter l'injection excessive de francs visant à défendre cette parité. L'augmentation de la quantité de francs en circulation, d'une part, et la réévaluation du franc, d'autre part, sont à l'origine d'une pression sur les conditions salariales et de l'emploi dans l'industrie d'exportation. Ainsi, les mesures d'austérité mises en œuvre en Europe à partir de 2010 ont été importées en Suisse. Elles ont toutefois été précédées par des mesures visant à assainir les bilans des assurances sociales, très sollicitées au terme de la crise des années 1990, au cours desquelles la Suisse a connu un taux de chômage élevé et le recours à l'assurance-invalidité (AI) a joué le rôle d'amortisseur social. Les révisions de l'AI et de l'assurance-chômage (AC) peuvent être interprétées comme les équivalents des mesures d'austérité inscrites dans les politiques libérales du «moins d’État». Les réductions de budget des assurances sociales se sont, à leur tour, répercutées à l'échelle cantonale avec l'augmentation des dépenses d'aide sociale.

Pour sortir de la grande récession sans remettre en cause la pertinence des politiques 
budgétaires restrictives, la Banque centrale européenne $(\mathrm{BCE})$ a eu recours à des politiques monétaires expansives. Le quantitative easing (assouplissement quantitatif monétaire), dans le cadre duquel la BCE acquiert des titres publics et privés avec une injection mensuelle massive de liquidités, a pour objectif de relancer le crédit aux entreprises et aux familles et, par conséquent, de favoriser la reprise de l'économie et de l'emploi. Aux yeux de ses détracteur.trice-s, cette stratégie de politique monétaire a surtout servi à alimenter les marchés financiers sans avoir de retombées positives sur l'économie réelle, ni atteindre les objectifs souhaités. Pour la Suisse, le quantitative easing a contraint la BNS à continuer de défendre discrètement le franc par l'injection de liquidités destinées à l'achat d'euros et à engager une politique de taux d'intérêt négatifs pour contrecarrer la pression sur le franc. Compte tenu de la configuration du système des assurances sociales qui, au cours de la dernière décennie, ont investi une grande partie de leurs réserves dans les marchés financiers, les taux d'intérêt négatifs ont d'importantes conséquences sur leur capacité d'assumer leurs engagements, notamment en ce qui concerne les trois piliers du système de retraite. Par contraste, les politiques monétaires restrictives que certaines banques centrales, dont en tout premier lieu la Federal Reserve, ont adoptées à partir de 2016, laissent entrevoir une augmentation généralisée des taux d'intérêt. On parle du passage du quantitative easing au quantitative tightening. Cette nouvelle dynamique, après des années de taux d'intérêt négatifs, peut entraîner une dévaluation des obligations détenues par de grands investisseurs comme les fonds de pension et le Fonds de compensation de l'AVS. Avec des taux d'intérêt en hausse et, par suite, la réduction de la valeur des titres, les liquidités du système de prévoyance vont diminuer, mettant en danger la capacité de verser les rentes. Pour juguler ce risque, le défi consiste à intervenir sur les entrées, en créant des emplois et en augmentant l'assiette des cotisations, et par conséquent les revenus. Cela signifie toutefois qu'il faut identifier de nouvelles sources de financement dans une économie de plus en plus numérisée, en envisageant, par exemple, une taxe sur les robots ou la fiscalisation de la part de profit résultant de la masse d'informations produites par les utilisatrices et utilisateurs des plateformes numériques.

\section{Christian Marazzi}

\section{Références}

Gallino, L. (2015). Il denaro, il debito e la doppia crisi. Torino: Einaudi.

Guex, S. (1998). L'argent de l'État: parcours des finances publiques au $X X^{e}$ siècle. Lausanne : Réalités sociales.

Varoufakis, Y. (2017). Et les faibles subissent ce qu'ils doivent? Comment l'Europe de l'austérité menace la stabilité du monde. Paris : Babel.

\section{Bien-être}

Selon l'Office fédéral de la statistique, «le bien-être est le fait pour une personne de disposer de moyens suffisants et de conditions favorables lui permettant de mener sa vie de manière aussi libre et autonome que possible». Le bien-être est un concept multidimensionnel, qui peut être mesuré au niveau individuel ou collectif. L'Organisation de coopération et de développement économiques (OCDE) propose de le mesurer autour de onze dimensions réparties en deux piliers, le premier porte sur les conditions matérielles (revenus et patrimoine, emplois et salaires, logement), le second est associé à la qualité de vie (état de santé, équilibre vie professionnelle-vie privée, éducation et compétences, liens sociaux, engagement civique et gouvernance, qualité de l'environnement, sécurité personnelle et bienêtre subjectif). Le bien-être objectif renvoie aux indicateurs sociaux (p.ex. les conditions 
de logement, la qualité de l'environnement) alors que le bien-être subjectif s'appuie sur le ressenti des individus, généralement évalué sous forme de ce qui fait que des expériences ou la vie sont plaisantes ou déplaisantes (vision hédoniste) ou de la réalisation de son vrai potentiel (vision eudémonique). On distingue ainsi en psychologie deux grandes traditions et visions du bien-être (pas forcément antagonistes), qui ont toutes deux un ancrage dans la philosophie grecque ancienne (Aristippe de Cyrène, Épicure d'un côté, Platon et Aristote de l'autre). La vision hédoniste du bonheur est définie comme la recherche du plaisir et l'évitement de la douleur ou de la souffrance. Le bonheur eudémonique lui est défini comme la réalisation de ce qui a du sens et de la valeur pour soi. Il est lié au développement de la personne et à la découverte de son vrai potentiel.

Les recherches en sciences sociales sur le thème du bien-être ont pris un réel essor dans les années 1960, soit lors d'une période marquée par une importante prospérité économique. Dès lors qu'il a été perçu que les besoins primaires des individus dans les sociétés développées étaient a priori satisfaits, les gouvernements ont souhaité dépasser les mesures relatives à l'ampleur des ressources disponibles et disposer de mesures évaluant la qualité de la vie des citoyen·ne.s. On a alors vu émerger une volonté d'aller plus loin que les évaluations du progrès économique en mesurant le progrès social, qui s'est traduite par le développement d'indicateurs sociaux. Cette période est par ailleurs caractérisée par une transformation des systèmes de valeurs avec l'émergence de valeurs postmatérialistes, comprenant désormais des revendications des citoyen-ne-s quant à leur autonomie, la réalisation de soi et l'épanouissement individuel. Les indicateurs relatifs au bien-être ont été développés en vue d'informer l'opinion publique mais aussi de mettre en place des politiques sociales promouvant des conditions de vie aussi bonnes que possible pour chacunee.
La mesure du bien-être a suscité un regain d'intérêt à la fin du $20^{\mathrm{e}}$ siècle, autour de nouvelles préoccupations liées à l'écologie et au développement durable. Dans ce contexte, il est apparu que le progrès économique peut avoir des conséquences néfastes sur l'environnement et qu'il est particulièrement important de prendre en compte des dimensions autres à la base du bien-être, comme par exemple le bénévolat ou les activités non marchandes. La mesure du bien-être a donc été vue comme un moyen de donner plus d'importance au point de vue des citoyen-ne-s sur leur cadre de vie. Par ailleurs, le bien-être est envisagé dans une perspective orientée vers le futur, exprimant le souhait d'assurer des conditions de vie favorables aux générations futures.

Aujourd'hui, sous l'impulsion des Nations Unies et de l'OCDE, les pays disposent de données statistiques permettant d'évaluer le bien-être de leur population, mais aussi de documenter les évolutions au fil du temps et les inégalités entre groupes sociaux. Ces informations sont importantes dans la définition des politiques publiques se déclinant autour des différentes dimensions du bien-être (éducation, emploi, logement, etc.). Notons qu'au niveau d'un pays il y a une forte corrélation positive entre niveau de richesse et niveau de bien-être subjectif. Les différences entre les personnes les plus pauvres et les plus riches à l'intérieur d'un pays existent (voir ci-dessous), mais elles expliquent une part bien moindre des variations de bonheur que les différences de richesse (et d'autres variables liées) entre pays. Ainsi, les différences de bien-être moyen entre pays riches et pauvres se révèlent tout aussi importantes, voire plus importantes que les différences de bien-être liées à des écarts sociaux à l'intérieur des pays.

À l'échelle internationale, le niveau de bienêtre est élevé en Suisse. Selon l'Indicateur du vivre mieux développé par l'OCDE, la Suisse présente des valeurs supérieures à la moyenne dans la plupart des dimensions associées au 
bien-être, incluant la satisfaction à l'égard de la vie, les liens sociaux, le revenu et le patrimoine, l'état de santé, l'emploi et les salaires, l'éducation et les compétences, la qualité de l'environnement et la sécurité. Concernant le niveau de bien-être subjectif, mesuré par la satisfaction dans la vie, le score suisse moyen de 7,6 (sur une échelle entre 0 et 10) est parmi les plus élevés de ceux mesurés dans les pays de l'OCDE. Derrière ces niveaux élevés, des différences s'observent en fonction de plusieurs facteurs sociaux: la satisfaction dans la vie est la plus faible entre 25 et 49 ans, elle augmente avec le niveau d'éducation et le niveau de revenu; elle est plus faible chez les personnes de nationalité étrangère que celles de nationalité suisse. On constate un gradient social, c'est-à-dire une amélioration du bien-être pour chaque échelon gagné dans la hiérarchie sociale pour tout un ensemble de variables dont l'éducation, le revenu du ménage, le taux d'emploi. Une condition particulièrement critique est celle des travailleurs et travailleuses pauvres.

Selon les disciplines et les secteurs concernés, plusieurs termes concurrents renvoient à l'idée de bien-être et soulignent différentes dimensions ou valeurs que ces termes peuvent recouvrir. Ainsi on trouve fréquemment des références à la qualité de vie, au bonheur, à la satisfaction dans la vie ou la réalisation de soi, sans que les frontières et différences entre les termes soient clairement établies ou que l'on ait des mesures toujours valides. La préférence pour l'un ou l'autre terme est a priori associée à des traditions disciplinaires, mais elle est aussi associée à différents niveaux d'appréhension de la notion, qu'ils soient théoriques ou empiriques.

Pour certaines personnes, la notion de bienêtre viendrait supplanter une approche des politiques sociales longtemps centrées sur la résolution des problèmes sociaux et présentant le risque de créer une dépendance des citoyen·ne-s vulnérables envers les institutions publiques. Toutefois, la vision du bien-être, devenue centrale dans la définition des politiques sociales, promeut une vision de l'individu entrepreneur et responsable de son propre bonheur. Une perspective critique dénonce le risque d'individualisation et de responsabilisation des acteur-trice-s, censé·e-s atteindre le bien-être par eux·elles-mêmes (ou à l'autre extrême être responsables de leur malheur) en mettant en retrait le rôle de l'État et de la société à assurer des conditions de vie favorables pour tou-te.s. Par exemple des travaux récents montrent que la confiance en l'avenir est liée au nombre de personnes ayant des symptômes dépressifs dans l'entourage et au niveau de chômage local. Par conséquent, une perspective trop individuelle prend le risque de ne permettre qu'un changement limité ou peu durable car le bien-être d'un individu est intimement lié à son environnement. C'est ainsi que pour la santé psychique globale, on trouve de plus en plus de modèles concentriques des facteurs qui influencent le bien-être incluant: 1) l'âge, le sexe et les facteurs héréditaires; 2) les styles de vie individuels ; 3 ) les influences sociales et de la communauté; 4) les conditions générales socioéconomiques, culturelles et environnementales. Ces modèles soulignent bien le rôle crucial que peuvent jouer les politiques sociales sur le bien-être des personnes.

\section{Claudine Burton-Jeangros \& Dario Spini}

\section{Références}

Kahn, R. L. \& Juster, T.F. (2002). Well-being : concepts and measures. Journal of Social Issues, 58(4), 627-644.

Organisation for Economic Cooperation and Development. (2016). How's life? 2017. Measuring well-being. Paris : OECD Publishing.

Spini, D., Pin le Corre, S. \& Klaas, H. (2016). Santé psychique et inégalités sociales. Dans M. Blaser \& F.T. Amstad (Éd.), La santé psychique au cours de la vie: rapport de base (pp. 31-41). Berne: Promotion Santé Suisse. 


\section{Biens communs*}

Les biens communs sont des biens accessibles à toutes personnes, gratuitement ou à un prix nettement inférieur à leur coût effectif. Certains biens communs sont disponibles naturellement, comme l'air et l'eau, d'autres sont fournis par différents acteur-trice-s. Ces acteur.trice-s sont généralement des institutions étatiques, mais il peut aussi s'agir d'organisations de la société civile et de collectivités locales. La mise à disposition de biens communs suit une logique de l'intérêt général par opposition à celle de la poursuite d'intérêts économiques ou d'autres intérêts particuliers. Dans une société qui érige le droit à la propriété privée et la maximisation des gains économiques au rang de normes légitimes ou prioritaires, les biens communs apparaissent comme l'exception qui confirme la règle et sont souvent menacés dans leur existence même. La fourniture gratuite ou à bas prix d'eau potable, par exemple, est aujourd'hui remise en question en maints endroits à cause de la pollution de l'eau ou de la privatisation des sources.

En sciences économiques, on distingue plusieurs types de biens communs en fonction des critères de la (non-)exclusion et de la (non-) rivalité de leur consommation. La non-exclusion veut dire que personne ne peut être empêché d'utiliser un bien, la non-rivalité, que l'utilisation d'un bien par une personne $\mathrm{X}$ n'entrave en rien son utilisation par une personne Y. Les biens communs qui répondent à ces deux critères sont appelés biens publics. L'air, par exemple, est un bien public : personne ne peut être empêché de le respirer et la respiration d'une personne n'empêche pas une autre personne de respirer. L'éclairage public est un autre exemple. Il est accessible à toute personne, librement, sans restriction liée au critère de non-rivalité. Par contre, l'utilisation d'une route a des limites: si beaucoup de voitures l'empruntent en même temps, on arrive à un embouteillage. Pour la télévision, le cri- tère de la non-rivalité de la consommation est donné, mais pas celui de la non-exclusion, car il est possible d'exclure des téléspectateur-trice-s (p.ex. en faisant payer certaines chaînes).

Les propriétés des différents biens ne sont pas simplement données; elles dépendent de normes culturelles et de décisions politiques. Dans le système suisse de l'éducation, par exemple, la formation scolaire obligatoire est un bien commun, car elle est accessible gratuitement à tous les groupes de la population. Pour les formations plus avancées en revanche, l'État n'assume qu'une responsabilité partielle. La formation professionnelle dépend de l'offre d'acteur-trice-s privé·e-s, et l'accès à la formation tertiaire est hautement sélectif, même si les étudiant·e-s des hautes écoles publiques ne doivent payer qu'une partie des coûts.

La théorie économique de la différenciation des biens communs s'avère aujourd'hui une grille d'analyse importante dans les discussions et décisions politiques. La définition restrictive des biens publics (non-exclusion et non-rivalité) offre un champ très large à la recherche de solutions de marché pour la mise à disposition de bien communs. La dite tragédie des biens communs est un exemple édifiant de ce rapport entre théorie et politique. Présenté pour la première fois par l'économiste anglais W. F. Lloyd (1794-1852), l'exemple a été repris en 1968 par l'écologiste et philosophe américain G. Hardin (1915-2003). Si - telle est l'argumentation tou·te-s les berger-ére·s font paître leurs bêtes dans le pré communal, celui-ci se trouvera surexploité et ne fera au final que des perdant·e.s. La tragédie des biens communs a été et est encore souvent utilisée comme argument en faveur de la privatisation des ressources naturelles ou de la restriction des prestations sociales. Cette manière de voir les choses présuppose que les individus tendent tout naturellement à placer leurs intérêts privés au-dessus de ceux de la communauté et qu'ils ne sont pas capables de régler l'usage des biens dans l'intérêt général. Or ce théorème est de plus en plus 
critiqué, aussi par les économistes. Ainsi, E. Ostrom, prix Nobel d'économie en 2009, plaide pour des solutions communes en tant que voie médiane entre le marché et l'État. À son avis, des communautés locales sont souvent en mesure de trouver des mécanismes de coopération et de contrôle sociaux, qui garantissent une gestion durable des ressources.

Les biens communs revêtent une grande importance en politique sociale. Ils peuvent être fondateurs de cohésion sociale et d'identité. L’offre de tels biens joue également un rôle essentiel dans la définition des seuils de pauvreté et des prestations sociales sous condition de ressources. Pour prendre l'exemple de l'approvisionnement en soins médicaux: en Grande-Bretagne grâce au National Health Service, l'État paie la totalité des coûts alors qu'en Suisse, ce sont les patient.e.s qui en paient une très large partie, nonobstant l'existence d'une assurance-maladie obligatoire. L'aide sociale prend en charge les primes des caisses-maladie et les dépenses de santé, et de nombreuses familles ont droit à une réduction des primes. Le modèle d'assurance-maladie, qui repose sur des assureur.e.s privé.e.s et la responsabilité individuelle, conduit ainsi à des dépenses sociales plus élevées. Dans d'autres domaines de politique sociale, l'État développe ses offres parce que les acteur.trice-s privé·e·s ou de la société civile se retirent de la fourniture de biens communs. C'est le cas aujourd'hui notamment pour l'accueil extrafamilial et les soins aux personnes âgées (dans le champ de l'économie du care).

Des pays comme la Suisse, avec une tradition d'État social libéral, tendent depuis toujours à promouvoir les acteur-trice-s privé·e-s comme fournisseur.euse-s de biens communs. Dans le contexte du néolibéralisme, des «marchés providence» se sont développés aussi ailleurs. L'assertion souvent entendue qu'il importe peu que les biens communs soient fournis par des acteur-trice-s privé.e.s ou publics est cependant controversée. D. Hevenstone atteste ainsi que l'orientation de la politique sociale vers le marché, aux États-Unis, a régulièrement pour effet de passer à côté de l'objectif politique visé. En Suisse, les caisses maladie et les caisses de pension sont des acteurs privés centraux de la politique sociale. Ici aussi, les contradictions entre les intérêts particuliers des acteur·e·s et l'orientation vers l'intérêt général donnent lieu à maintes controverses. La transformation des anciennes régies fédérales de la poste, des télécommunications et des chemins de fer en entreprises de marché, à partir des années 1990, a généré des débats parfois virulents sur le «service public». La notion de «service universel» fut introduite dans ce contexte pour faire la distinction entre l'approvisionnement de base, orienté vers l'intérêt général, et l'approvisionnement allant au-delà, à but lucratif.

Les prestations sociales publiques ne doivent pas être considérées per se comme des biens communs. En effet, leur octroi est souvent assorti de conditions d'éligibilité restrictives, de contre-prestations et de sanctions. À l'ère de la politique d'activation, l'image de l'homo oeconomicus s'impose, que seul un mélange d'incitations et de sanctions économiques peut faire avancer dans la bonne direction. Sous l'angle des sciences sociales et culturelles, il existe toutefois de bonnes raisons d'être plus optimiste quant à la capacité des individus à agir pour le bien commun. Si l'être humain est, par nature, un être social, la mise en place de conditions-cadre sociales qui favorisent un comportement orienté vers l'intérêt général doit être une des tâches premières d'une bonne politique sociale. Le sociologue P. Bourdieu (1930-2002) a nommé cette perspective la «Realpolitik de la raison».

Peter Streckeisen

\section{Références}

Helfrich, S. \& Heinrich-Böll-Stiftung (Hrsg.) (2014). Commons : Für eine neue Politik jenseits von Markt und Staat (2. Aufl.). Bielefeld : transcript. 
Hevenstone, D. (2015). The American myth of markets in social policy: ideological roots of inequality. Basingstoke: Palgrave Macmillan.

Petrella, R. (1999). Le manifeste de l'eau: pour un contrat mondial. Lausanne: Éd. Page deux.

\section{Calcul des risques et science actuarielle*}

Les procédures formalisées de calcul des risques jouent un rôle important dans de nombreux domaines du système social, par exemple pour la gestion, le contrôle et la planification des assurances sociales. Les institutions de sécurité sociale sont généralement des systèmes d'indemnisation collective très complexes dont le budget financier dépend souvent de facteurs à long terme tels que l'évolution économique, démographique ou sanitaire. Comme l'État assume une responsabilité réglementaire ou financière en matière sociale, le pouvoir de calculer les risques est souvent entre ses mains ou entre les mains d'acteur.e.s de droit public. Les connaissances spécialisées et les positions politiques sont imbriquées de multiples façons. Les calculs scientifiques sont considérés comme étant objectifs et réduisent la marge de manœuvre politique. Dans le même temps, les différents camps politiques se réfèrent à des opinions d'expert·e-s divergentes afin de donner une plus grande légitimité à leur propre position.

Les calculs statistiques et mathématiques des risques sont appliqués en particulier dans la prévoyance vieillesse (AVS et prévoyance professionnelle), l'assurance-accidents et l'assurance-invalidité, ainsi que de plus en plus dans l'assurance-maladie. Ils servent à calculer les risques assurés, les primes, les réserves et les dépenses, et permettent également souvent d'établir des prévisions à long terme. Diverses disciplines sont utilisées, comme la science actuarielle, l'économie de l'assurance, la démographie ou l'épidémiologie.

L'essor des calculs statistiques et mathématiques des risques remonte au milieu du XIX siècle. Avec le développement de la statistique mathématique - le précurseur de la science actuarielle - ce type de calculs a été employé depuis les années 1860, d'abord dans l'assurance-vie commerciale, puis dans les assurances sociales. Dans l'entre-deux-guerres, les débats ont porté sur le calcul du risque de chômage, des systèmes de financement (par répartition ou par capitalisation) et du risque d'inflation. Après la Seconde Guerre mondiale, le problème de l'indexation des rentes ainsi que de la planification et de la sécurisation des dépenses de l'État-providence à long terme s'est ajouté aux débats, en particulier depuis les années 1970 dans un environnement économique difficile. Les prévisions démographiques et les questions relatives au calcul des tarifs et des primes ont occupé une place importante tout au long de cette période.

De nombreux scientifiques et organisations scientifiques ont contribué au développement des calculs des risques liés à la politique sociale. Citons notamment l'Association Suisse des Actuaires (ASA) fondée en 1905. Jusqu'aux années 1970, la science actuarielle était la discipline reine incontestée des sciences liées à l'assurance. Parmi les hautes écoles, celles de Berne, Saint-Gall, Zurich, Lausanne et Genève ont été particulièrement actives. En 1901, l'Université de Berne a été la première à créer une chaire d'assurance et un séminaire sur les sciences actuarielles. De nombreux-euses et éminent.e-s expert·e.s en assurances sociales y ont étudié dont notamment Arnold Bohren (1875-1957) qui, en plus d'être mathématicien et social-démocrate, était considéré comme la conscience de la Caisse nationale suisse d'assurance en cas d'accidents (Suva) en matière de science actuarielle. Sa carrière l'a conduit à la tête de la Suva, qu'il a dirigée de 1936 à 1942, durant les années difficiles qui 
ont suivi la Grande Dépression et pendant la Seconde Guerre mondiale. Même à la retraite, son expertise était très demandée. En 1942, le Conseil fédéral l'a chargé d'examiner dans quelle mesure le plan Beveridge était transposable à la Suisse. Le rapport Beveridge, paru en Grande-Bretagne et très remarqué, demandait la centralisation de l'action sociale britannique dans le but d'offrir à l'ensemble de la population une protection d'assurance globale et des prestations de base garantissant le minimum vital. Arnold Bohren a rejeté le modèle britannique, qu'il trouvait trop étatique et incompatible avec les traditions fédéralistes de la Suisse. Le Conseil fédéral a adopté cette recommandation et limité la réforme de la protection sociale après 1945 à la création d'une prévoyance vieillesse publique (l'AVS).

En Suisse romande, les centres des sciences de l'assurance sont situés à Lausanne (avec l'ancienne École des hautes études commerciales, aujourd'hui intégrée à l'université) et à Genève, au sein de son université. À Genève, le centre de science actuarielle a toujours été en contact étroit avec les organisations internationales, en particulier l'Organisation internationale du travail. Ernst Kaiser (1907-1978), par exemple, était issu de ce milieu et a été actuaire au sein de l'administration fédérale pendant de nombreuses années après 1942. Connu comme le «père mathématicien» de l'AVS dans le pays, Kaiser était un expert très demandé au sein de l'Organisation internationale du travail et d'autres réseaux internationaux. Non seulement, il a été responsable de la construction technique de l'AVS, mais également de celle de l'assurance-invalidité (introduite en 1960). $\mathrm{Au}$ niveau international, il était également considéré comme un spécialiste de l'adaptation automatique des rentes à l'évolution des salaires et des prix (dynamisation des rentes, indexation selon un indice mixte) - un savoir qu'il a mis à profit au niveau national dans le cadre de la révision de l’AVS de 1979.
Aujourd'hui, les calculs statistiques et actuariels sont présents dans divers débats de politique sociale, lors des scénarios démographiques de la prévoyance vieillesse, des calculs des primes et des tarifs de l'assurance-maladie ou du calcul des futurs droits à une rente dans la prévoyance professionnelle. Le taux de conversion qui, dans la prévoyance professionnelle, permet de convertir l'avoir de vieillesse épargné en une rente au moment de la retraite, a pris beaucoup d'importance au niveau politique. Le taux de conversion est une valeur technique qui dépend du vieillissement démographique et du rendement attendu du capital épargné. Il a été abaissé pour la première fois en 2003, en raison de l'allongement de l'espérance de vie et de la baisse des taux directeurs. Une deuxième réduction, critiquée dans les cercles de gauche, a été proposée mais rejetée lors d'une votation populaire en 2010 .

L'histoire des calculs du risque dans le domaine de la sécurité sociale est riche en exemples de prévisions erronées. La croissance démographique a été sous-estimée à plusieurs reprises, par exemple dans la planification de la première loi sur l'AVS (1931), rejetée lors de la votation populaire. Depuis l'an 2000 également, les autorités ont à plusieurs reprises été trop prudentes dans leurs prévisions quant au développement économique et à la croissance de la population, notamment en raison de la migration, et elles en ont déduit des scénarios trop pessimistes pour le financement de l'AVS. Récemment, la science actuarielle a également mal évalué les risques dans le domaine des assurances commerciales. De fait, les actuaires et les économistes d'entreprise ont participé à la conception et à la diffusion de produits financiers structurés depuis les années 1980. Rétrospectivement, ces produits ont été un facteur clé dans l'éclatement et la propagation rapide de la crise financière de 2007-2008.

Martin Lengwiler 


\section{Références}

Bühlmann, H. \& Lengwiler, M. (2016). Calculating the unpredictable: history of actuarial theories and practices in reinsurance. In G. Jones \& N.-V. Haueter (Eds.), Managing risk in reinsurance: from city fires to global warming (pp. 118-143). Oxford : Oxford University Press.

Leimgruber, M. (2008). Solidarity without the state? Business and the shaping of the Swiss welfare state, 1890-2000. Cambridge: Cambridge University Press.

Lengwiler, M. (2006). Risikopolitik im Sozialstaat: Die schweizerische Unfallversicherung 1870-1970. Köln : Böhlau.

\section{Capabilités}

L’approche par les capabilités a été développée par l'économiste et philosophe indien Amartya Sen, qui a reçu le Prix Nobel d'économie en 1998. Cette approche propose une manière différente de mesurer le degré de développement d'un pays : il ne s'agit en effet pas de comparer le niveau des PIB respectifs pour indiquer quels pays sont les plus développés, mais de prendre en compte les capabilités de leurs citoyen·ne·s ou résident·e-s de mener une vie de valeur. Cette approche a notamment inspiré la création de l'indice de développement humain (IDH) qui calcule le degré de développement d'un pays à l'aune de trois indicateurs portant sur la prospérité économique, l'éducation et la santé. En posant le développement des capabilités comme objectif de l'action publique, l'approche par les capabilités représente un défi qui concerne également les politiques sociales dans les pays de l'OCDE.

Les capabilités sont définies comme «les libertés réelles d'une personne de mener une vie qu'elle a des raisons de valoriser ». Cette définition complexe repose sur la combinaison de deux dimensions. La première - la «liberté réelle» - se rapporte au pouvoir d'agir des personnes, aux moyens qui doivent leur être donnés pour qu'elles puissent réellement mener une vie qui a de la valeur à leurs yeux. Il s'agit ici non pas d'une liberté formelle, sur le papier, dont le principe serait par exemple inscrit dans la Constitution, mais d'une liberté réelle, ancrée dans la vie concrète des personnes. La concrétisation de cette liberté réelle requiert qu'un certain nombre de conditions soient réunies. Tout d'abord, l'accès à un niveau adéquat de ressources financières doit être garanti. À défaut, la personne se retrouvera contrainte d'accepter un emploi qui n'aurait aucune valeur à ses yeux, mais qui serait une nécessité pour subvenir à ses besoins. La redistribution financière, qui constitue le cœur des politiques sociales mises en place pendant les Trente Glorieuses, est donc indispensable au développement des capabilités de leurs bénéficiaires. Mais elle ne suffit pas. Il importe aussi d'accroître leur pouvoir d'agir et leur employabilité, par exemple à travers des formations visant l'acquisition d'habiletés et compétences qui les équiperont pour les métiers auxquels elles et ils aspirent. Et il convient également d'agir sur l'environnement socioéconomique et de veiller à ce que les bénéficiaires de prestations sociales puissent trouver une place de valeur sur le marché du travail et plus généralement dans la société. À défaut, nous serions en présence de personnes dont l'employabilité aurait été améliorée, mais que personne ne voudrait embaucher. Si l'on prend l'exemple des personnes en situation de handicap, il s'agit de lever à la fois les barrières matérielles et symboliques à leur pleine participation au marché du travail et à la société en général. Ainsi l'accessibilité du bâti ou l'adaptation du poste de travail, notamment en termes d'horaire et de charge de travail, apparaissent comme des conditions nécessaires au développement de leurs capabilités. Mais il faut aussi lever les obstacles symboliques découlant des préjugés ou comportements discriminants des employeur-euse-s vis-à-vis de ces personnes. À cet égard, la Convention de l'ONU relative aux droits des personnes handicapées, créée en 2006 et entrée en vigueur en Suisse en 2014, 
s'inscrit dans la perspective des capabilités. Au total, sur ce versant de la «liberté réelle», l'approche par les capabilités requiert une action sur le triple plan des ressources (pour donner la possibilité de refuser un emploi de mauvaise qualité), des compétences des individus (pour les équiper en qualifications) et des environnements socioéconomiques (pour veiller à la présence d'opportunités d'intégration sociale et professionnelle en quantité et qualité suffisantes, qui soient accessibles à tous les membres de la collectivité). Si un de ces trois plans fait défaut, le développement des capabilités sera entravé. L’approche par les capabilités suggère ainsi une alternative aux politiques sociales centrées sur le développement de l'employabilité ou du capital humain, en mettant l'accent sur la nécessité d'une approche globale. Elle représente à ce titre un défi pour les politiques sociales suisses, notamment dans les champs du chômage, de l'invalidité et de l'assistance sociale.

La deuxième dimension, liée à la «raison de valoriser », insiste sur la centralité du choix libre et raisonnable dans le développement des capabilités: les bénéficiaires des politiques sociales sont ici envisagéee-s comme des acteur-trice-s susceptibles d'exprimer des opinions et jugements de valeur qui doivent être pris en compte dans les actions ou politiques sociales. Leurs préférences et aspirations doivent donc être prises au sérieux, lorsqu'il s'agit de définir le contenu d'une intervention sociale ou de proposer un emploi. Cette perspective se situe à l'opposé des formes de paternalisme qui voient les concepteur.trice-s de la politique sociale ou celles et ceux qui la mettent en œuvre décider à la place des bénéficiaires, souvent au nom de très bonnes intentions. Dans l'approche par les capabilités, la personne est partie prenante des politiques sociales, elle co-construit, au moins dans une certaine mesure, le contenu des interventions sociales, le rythme auquel elles se déploient, les objectifs qu'elles poursuivent, etc. Aux yeux de ses détracteur-trice-s, une telle conception semble ouvrir la porte à des formes d'individualisme libertaire: toutes les préférences individuelles seraient-elles alors légitimes et devraient-elles être également soutenues par les politiques sociales? Amartya Sen se garde bien d'une telle conclusion, il prend soin de préciser que le développement des capabilités ne coïncide pas avec la reconnaissance et le soutien de toutes les préférences, mais uniquement de celles que la personne a «des raisons» de valoriser. Chez Sen, le critère de la rationalité, ou plutôt de la raisonnabilité, découle de la confrontation des arguments entre les diverses parties prenantes: de fait, ni l'intervenant-e sociosanitaire, ni le-la bénéficiaire ne peuvent décider seul.e.s de la raisonnabilité d'une préférence ou d'une aspiration. En d'autres termes, ce ne sont que les préférences qui passent le test de cette confrontation d'arguments, qui seront soutenues par les politiques sociales. Certaines préférences trop coûteuses ou d'autres trop peu ambitieuses (qui reflètent p.ex. une résignation des personnes aux conditions de vie insatisfaisantes auxquelles elles se trouvent réduites) pourront ainsi être remises en question en raison de leur caractère déraisonnable: la politique sociale ne va par exemple pas soutenir le désir d'une personne de devenir astronaute ou chanteur d'opéra, mais elle ne va pas non plus accepter qu'une personne douée se résigne à exercer un métier qu'elle ne valorise pas ou à ne pas poursuivre des études supérieures, en raison de circonstances familiales défavorables par exemple. La voie proposée par Sen n'est donc pas libertaire, elle invite plutôt à une démocratisation des politiques sociales qui reconnaît une place effective à l'ensemble des acteur.trice-s directement concerné.e.s. À ce titre, elle représente un défi pour la plupart des politiques sociales contemporaines, en Suisse et au-delà, dont les objectifs et contenus sont très largement définis par les responsables institutionnel-le·s sans prendre en compte le point de vue des bénéficiaires. 
L'approche par les capabilités ouvre une voie originale pour repenser les politiques sociales dans les pays de l'OCDE. Au-delà des approches strictement redistributives de l'État social (critiquées pour leur côté passif) ou de celles insistant sur le développement du capital humain (au détriment d'interventions plus globales portant aussi sur le contexte socioéconomique), mais aussi au-delà des perspectives dites workfaristes visant à imposer aux bénéficiaires des manières d'être ou d'agir conformes aux attentes institutionnelles, l'approche par les capabilités appelle à une rénovation des politiques sociales orientées sur le développement des capabilités ou libertés réelles de chacune et chacun de mener une vie qu'il ou elle a des raisons de valoriser. Elle suggère ainsi l'instauration d'un nouvel âge de l'État social, qui ne soit pas simplement redistributeur ou activant, mais qui se donne comme objectif central l'accroissement des capabilités de ses bénéficiaires.

\section{Jean-Michel Bonvin}

\section{Références}

Bonvin, J.-M. \& Farvaque, N. (2008). Amartya Sen: une politique de la liberté. Paris : Michalon.

Bonvin, J.-M. \& Rosenstein, E. (2015). Contractualising social policies: a way towards more active social citizenship and enhanced capabilities? In R. Ervik, N. Kildal \& E. Nilssen (Eds.), New contractualism in European welfare policies (pp. 47-72). Farnham: Ashgate.

Sen, A. (2000). Un nouveau modèle économique: développement, justice, liberté. Paris: O. Jacob.

\section{Capital social}

La notion de capital social revêt un grand nombre de définitions et peut être comprise de deux manières, selon que ce capital est attaché à un individu ou à un groupe. Le capital social d'un individu fait référence aux avan- tages socioéconomiques que lui procurent ses relations sociales. Quant au capital social d'un groupe, il est abordé à travers divers indicateurs de son fonctionnement, par exemple la densité des relations entre ses membres, la confiance qu' elles ou ils se portent les uns aux autres, ou encore le taux d'engagement dans des associations et la participation politique.

La perspective individuelle est marquée par les apports de James Coleman, Mark Granovetter et Pierre Bourdieu. Ils s'intéressent au réseau social des individus et à la manière dont ils-elles peuvent en tirer divers avantages (surtout économiques). Pour Bourdieu, cette forme de capital contribue à la cohésion des classes sociales, puisqu'à travers lui les classes dominantes s'arrogent des ressources et en privent ainsi les classes dominées. Chez Coleman et Granovetter, au contraire, un individu peut mobiliser son capital social pour compenser d'autres formes d'inégalités. Par contraste, la perspective collective attribue une valeur intrinsèquement positive au capital social dont sont dotés des groupes, des quartiers, voire des pays. Les travaux d'Arnaldo Bagnasco et de Robert Putnam sont ici centraux. Pour eux, le capital social permet aux individus de coopérer. Il s'agit d'un cercle vertueux, où la confiance réciproque, les normes partagées et les relations sociales se renforcent mutuellement.

Les débats autour du capital social font écho à des questions qui occupaient déjà les fondateurs des sciences sociales. L'anomie par exemple, terme introduit par Durkheim à la fin du XIX ${ }^{e}$ siècle pour qualifier une situation où les normes n'assurent plus l'ordre social, correspond à ce qui est appelé dans la sociologie contemporaine un manque de capital social. Avant lui, Tocqueville, dans ses travaux sur la démocratie en Amérique, avait pointé les risques d'un individualisme croissant et l'importance de l'engagement civique, élément clé du concept de capital social dans sa dimension collective. Plus tôt encore, Adam Smith avait montré, dans sa théorie des senti- 
ments moraux, la nécessité d'une société basée sur la confiance pour pouvoir y développer un marché concurrentiel respectueux des règles $\mathrm{du}$ jeu. La notion de capital social est ainsi polysémique et vague, ce qui lui vaut des critiques, mais aussi une grande popularité dès les années 1990. Désormais, des organismes tels que l'ONU, la Banque Mondiale ou l'OCDE utilisent le terme de capital social dans leurs programmes.

En comparaison internationale, la Suisse témoigne de scores élevés pour plusieurs indicateurs du capital social dans sa version collective. L'engagement associatif y est particulièrement élevé, reflétant le rôle subsidiaire accordé à l'État. Markus Freitag montre que la Suisse alémanique se distingue sur ce point de la Suisse latine, qui accorderait une place relativement plus importante à l'État, au détriment de la société civile. En outre, certains indicateurs montrent un déclin qui concerne le pays dans son entier, particulièrement en ce qui concerne l'adhésion aux partis politiques et aux syndicats. Simone Baglioni souligne, quant à lui, des différences entre villes et campagnes, les premières comptant plus d'associations à but social. Il montre aussi que les difficultés économiques affaiblissent le capital social.

$\mathrm{Au}$ niveau individuel, Giuliano Bonoli et Nicolas Turtschi ont enquêté auprès d'un échantillon de personnes en recherche d'emploi dans le canton de Vaud. Ils observent que si le capital social facilite la recherche d'emploi, les personnes qui en ont le moins - c'est-à-dire celles qui disposent du carnet d'adresses le plus mince - cumulent par ailleurs d'autres formes de désavantages (faible niveau de formation, origine étrangère, etc.). Leurs travaux montrent encore que certaines relations sont plus utiles que d'autres: c'est le cas des ancien-ne-s collègues de travail et des connaissances ayant elles-mêmes un emploi. Ainsi, mobiliser ses «liens faibles »-comme les avait appelés Mark Granovetter - peut favoriser le retour à l'emploi, mais encore faut-il disposer de tels liens.
La notion de capital social continue d'être développée en sciences sociales et de nouvelles définitions tentent de pallier les critiques dont elle a fait l'objet. Parmi ces critiques figure la dimension tautologique de cette notion: difficile d'en distinguer les causes et les conséquences. Les normes partagées sont par exemple à la fois une source et un produit du capital social. De plus, une attention soutenue a été portée aux conséquences du capital social, alors que les mécanismes et ressources nécessaires à sa création et à son renforcement sont moins étudiés. Ainsi, en tant qu'objectif de politiques publiques, le capital social - dans sa dimension collective - peut être conçu à la fois comme un moyen et une fin, et il se heurte à la difficulté de son opérationnalisation et de sa mesure à travers des indicateurs. Par exemple, le taux d'adhésion aux partis politiques et aux syndicats est-il encore un indicateur pertinent pour mesurer l'engagement civique?

Dans sa dimension individuelle, le capital social peut être accusé de mettre la faute sur les victimes (blaming the victims). Son utilisation dans le cadre des politiques sociales peut ainsi tendre à suggérer que tout ce qui manque aux personnes en situation de précarité est un bon réseau social. Or, le problème tient plutôt dans le fait que les ressources qui permettent de développer du capital social sont inégalement distribuées. Enfin, la notion de capital social a aussi le défaut d'attacher une valeur intrinsèquement positive aux relations sociales et aux groupes cohésifs, apportant peu d'attention aux possibles conséquences négatives de telles relations. Or, les réseaux ont différents déterminants sociaux et différentes conséquences. Bourdieu reconnaissait ainsi que «le capital social divise et unit». Par exemple, les sectes et les groupes mafieux ont un fort capital social. De plus, tous les liens ne se valent pas et tous ne représentent pas des ressources. Certains peuvent même être des fardeaux. Cependant, même si le concept est controversé et polysémique, il a le mérite d'avoir lancé un débat et 
un effort de conceptualisation sur la création et la reproduction des liens sociaux et leurs effets sur la cohésion et le fonctionnement des sociétés.

\section{Maxime Felder}

\section{Références}

Baglioni, S. (2004). Société civile et capital social en Suisse: une enquête sur la participation et l'engagement associatif. Paris : L'Harmattan.

Bonoli, G. \& Turtschi, N. (2015). Inequality in social capital and labour market re-entry among unemployed people. Research in Social Stratification and Mobility, 42, 87-95.

Freitag, M. (Hrsg.) (2014). Das soziale Kapital der Schweiz. Zürich: NZZ Libro.

\section{Case management}

Le case management est un dispositif de prise en charge couramment utilisé dans le champ des politiques sociales et sanitaires. Il vise un accompagnement personnalisé, cohérent et continu, coordonné par une personne unique, appelé à renforcer l'autonomie de l'usager·ère par une participation active de celui/celle-ci ainsi que par la mobilisation de ses ressources. Il n'y a pas de consensus dans la littérature sur les origines du case management. Le secteur psychiatrique, qui s'en est saisi pour étayer le mouvement de désinstitutionalisation de la prise en charge des années 1970, a sans doute contribué à lui donner la forme qu'il connaît aujourd'hui.

Défini comme dispositif d'accompagnement, le case management est plus qu'un outil d'intervention ou une simple méthode de suivi. Il est considéré comme un véritable modèle de prestations et de soins intégrés. Le réseau d'intervention que le ou la case manager monte, pilote et évalue, en est l'agent d'intégration essentiel. Il fédère les intervenant·e-s par la mise en place d'objectifs partagés. Le réseau d'intervention est configuré de manière originale dans chaque situation, permettant ainsi la personnalisation de l'accompagnement, à l'encontre de toute forme de normalisation $\mathrm{du}$ processus d'intervention par l'imposition de guidelines ou la définition d'algorithmes de traitement.

Le case management repose sur la conviction que la-le bénéficiaire de soins ou de prestations a un rôle actif à jouer dans l'intervention sociale et sanitaire. Il souligne que sa contribution est essentielle au traitement de sa situation. C'est pourquoi, la·le bénéficiaire est envisagé.e comme un·e partenaire des membres $\mathrm{du}$ réseau d'intervention avant d'être un·e patient $\cdot e$, un·e client $\cdot e$ ou un·e usager.ère. Avec ses proches, elle ou il est membre à part entière du réseau de prise en charge. Dans le sillage de l'approche dite salutogénique, le case management assume que toute personne, même dans les situations les plus précaires et désespérées, dispose de ressources et de potentiels sur lesquels l'accompagnement peut s'appuyer et qu'il ou elle peut mettre en valeur. C'est pourquoi les case managers mettent davantage l'accent sur les moyens que sur les déficits des personnes qu'elle ou ils accompagnent. Le case management préconise ainsi une forme particulière d'accompagnement social, qui a par exemple inspiré des projets de collaboration interinstitutionnelle comme le projet CII-MAMAC.

Le dispositif de case management combine plusieurs niveaux: il associe un programme, un modèle et une méthode de suivi. Le programme chapeaute le dispositif. Il exprime la volonté collective d'entreprendre une action pour un groupe de personnes spécifique. Cette volonté peut être formulée à différents niveaux et dans les domaines les plus divers. La Stratégie nationale en matière de soins palliatifs est par exemple l'expression d'une telle volonté collective au plan fédéral dans le domaine sanitaire. Les sept programmes vaudois dédiés aux soins palliatifs, à Alzheimer, à la santé mentale, 
à la petite enfance, à la prévention des infections, au diabète et aux problèmes de santé liés au viellissement relaient au plan cantonal l'intention fédérale, voire l'anticipent avec des initiatives originales. Mais un programme peut également émaner d'une démarche bottom up n'impliquant pas les autorités publiques. Il peut ainsi découler du secteur associatif et s'adresser à un public restreint.

En satisfaisant les besoins individuels d'un groupe de population spécifique, le programme vise un objectif explicite d'intérêt général, tel que le maintien à domicile, l'intégration professionnelle, l'amélioration de la qualité de la prise en charge, mais aussi la réduction des coûts du système de la sécurité sociale. À travers la mise en place d'un suivi personnalisé, le case management poursuit ainsi des objectifs de nature supra-individuelle. Le programme indique également les ressources matérielles, organisationnelles, financières et humaines à disposition et établit le catalogue des mesures et des prestations offertes en vue de sa réalisation. Tous les projets d'accompagnements individuels destinés à un même public cible et orientés sur un même objectif d'intérêt général relèvent du même programme.

Le programme ainsi adopté est ensuite concrétisé par un modèle, qui donne la structure du dispositif de case management. C'est à ce niveau que l'on décidera par exemple à quel groupe professionnel la fonction de case manager sera confiée ou encore, comment le programme sera porté à la connaissance de son public cible. La configuration du modèle dépend des caractéristiques spécifiques du contexte dans lequel le programme est établi. Ainsi, un même programme peut être modélisé de différentes façons.

Alors que le programme et le modèle définissent les niveaux macro et meso du dispositif de case management, la méthode de suivi se situe au niveau micro, où se déploient les rapports entre membres du réseau d'intervention. La méthode s'articule le plus souvent en 6 phases successives. Tout d'abord, l'intake vise à examiner si le candidat ou la candidate a droit à la prestation et si celle-ci fait sens pour lui, c'est par exemple à ce moment qu'on va décider si un e bénéficiaire de l'aide sociale a droit à telle ou telle mesure. On distingue deux formes d'intake: le triage quand il s'agit de sélectionner les bénéficiaires dans un groupe de candidat·e·s connu·e-s; et le recrutement lorsque les bénéficiaires potentiel-le·s doivent être identifié·ess et gagné·e·s à la démarche, qui, a priori, ne les intéresse pas. Ensuite, l'assessment consiste à analyser la situation de la.du patient.e afin de mettre en évidence ses problèmes, de même que les moyens qu'elle-il peut mobiliser. L'orientation salutogénique de la démarche est particulièrement importante dans le cadre de la maladie chronique, avec laquelle l'usager-ère doit apprendre à composer en s'appuyant sur les ressources qui lui sont accessibles. Les objectifs sont co-construits par la-le patient.e, ses proches et la-le case manager dans la troisième phase, celle de la planification. Les mesures nécessaires pour atteindre les objectifs ainsi que les intervenant.e.s susceptibles de fournir les prestations requises sont également identifié·e.s. Sur la base de ces éléments, la·le case manager construit le réseau d'intervention, qu'elle-il ou elle peut convoquer tout ou partie pour en assurer la cohérence. Contrairement aux réseaux d'interventions habituels, dans lesquels chaque intervenant.e définit et poursuit ses propres buts, les membres du réseau de case management travaillent tous ou toutes aux mêmes objectifs, qui sont ainsi de nature contraignante pour eux ou elles. Dans la phase suivante, la mise en œuvre, la·le case manager supervise la réalisation des mesures. Les résultats de l'accompagnement sont appréciés dans la phase d'évaluation. Si les objectifs sont atteints, le suivi case management peut prendre fin, ce qui constitue alors la dernière étape du processus, celle de la sortie. Dans le cas contraire, la situation fera l'objet d'une nouvelle analyse et la démarche sera répétée, 
en principe autant de fois qu'il sera nécessaire à l'accomplissement de l'objectif général du programme.

Composée d'un nombre prédéfini d'étapes agencées logiquement et orientée sur un objectif posé en début d'intervention, cette méthode «en cascade» est sous-tendue par une vision linéaire de la prise en charge. C'est pourquoi, elle est peu à même de composer avec l'inattendu, l'incertain ou la surprise qui sont généralement perçus comme des facteurs perturbateurs ou dysfonctionnels. Cette limitation pourrait être une invitation à pourvoir le case management d'une méthode plus «agile» qui reste encore à développer.

\section{Pierre Gobet}

\section{Références}

Gobet, P., Galster, D., Repetti, M., Scherer, F. \& Constantin, E. (2016). Le case management en contexte: bases conceptuelles et applications d'un dispositif de prise en charge intégratif. Lausanne: Éditions ÉÉSP.

Lindström, B. \& Ericksson, M. (2012). La salutogenèse: petit guide pour promouvoir la santé. Québec: Presses de l'Université Laval.

\section{Changement social*}

Les formes prémodernes de cohabitation humaine étaient, elles aussi, soumises à des changements permanents. Pourtant, les termes «société» et «changement», qui sont historiquement étroitement liés, n'ont pris leur sens actuel qu'à la fin du XVIII ${ }^{e}$ siècle. Avant le siècle des Lumières, le cosmos politico-religieux du «droit divin» dominait et contraignait les personnes pieuses à s'insérer dans un ordre social immuable. Les souverains luttaient contre la mobilité sociale au moyen de commandements et d'interdictions aussi multiples que variés, et la répression draconienne des hérésies ou des infractions devait garantir l'obéissance des sujets. À l'inverse, les protestations et les soulèvements du début des temps modernes ne visaient pas un renversement radical, mais accusaient les puissant.e-s de violer la loi divine avec leurs impôts abusifs et l'oppression de la population rurale.

À la fin du XVIII ${ }^{\mathrm{e}}$ siècle, avec le mouvement d'indépendance américain et la Révolution française, de nouvelles formes de mobilisation sociale et politique ont non seulement vu le jour, mais pour la première fois, il a semblé concevable que les personnes n'aient pas à se soumettre à un destin ordonné par Dieu, mais puissent se gouverner elles-même sur la base de décisions sensées. La démocratie fondée sur les trois valeurs que sont la liberté, l'égalité et la fraternité autorisait les changements sociaux et était ouverte sur l'avenir. Cependant, la mutation socioéconomique provoquée par le début simultané de l'industrialisation capitaliste est entrée en collision avec l'idéal d'égalité de la souveraineté populaire. Aux XIXe et $\mathrm{XX}^{\mathrm{e}}$ siècles, les trois grands courants idéaux du conservatisme, du libéralisme et du socialisme se sont opposés sur la manière dont la politique devait traiter l'inégalité et les aspects incontrôlables, incalculables d'une société de plus en plus complexe et donc opaque. Alors que les conservateurs se rebellaient souvent contre le changement social, les libéraux gardaient une grande confiance dans le marché et rejetaient toute intervention poussée de l'État. De son côté, le socialisme préconisait une conception politico-étatique du développement économique et des rapports sociaux.

Au tournant du siècle (de 1890 à 1914 environ), le terme politique de «question sociale» est apparu pour évoquer les inégalités croissantes. C'est alors qu'est née la sociologie, qui voulait faire du changement social l'objet d'une observation systématique et permettre ainsi une compréhension adéquate de la société moderne. Tous les pays européens ont mis sur pied des appareils statistiques et, à l'aide de nouvelles méthodes quantitatives, la science 
sociologique a prouvé que l'impression de perte de contrôle causée par la mobilité sociale et géographique, l'urbanisation rapide, les nouveaux médias de masse et modes de vie était un leurre. Elle a montré comment des modèles stables se reproduisaient en dépit des expériences irritantes de cette modernité industrielle, vécue comme chaotique à divers égards. Cette confiance dans les chiffres a également renforcé l'ordre social ainsi rendu transparent.

Parallèlement, la situation entre la recherche scientifique sur le changement social et la dynamique des conflits sociaux s'est tendue. À l'instar de la société en pleine division, les parties en conflit ont perçu différemment les problèmes sociaux et les ont associés à des notions de justice souvent diamétralement opposées. Le mouvement ouvrier et le mouvement féministe (qui se battaient également pour leurs droits politiques fondamentaux) critiquaient l'exploitation capitaliste. Ils exigeaient la sécurité sociale, un droit au travail ainsi que l'égalité des chances et dénonçaient le scandale des conditions de travail, de logement et d'alimentation précaires des «classes ouvrières ». De leur côté, les forces bourgeoises et conservatrices revendiquaient la responsabilité individuelle et l'adaptation au système. Aujourd'hui encore, les désaccords subsistent quant à la nature des problèmes d'une société et à la manière de les résoudre.

Dans la période de l'après-guerre, les théories du changement social ont bénéficié d'une souveraineté d'interprétation scientifique et politique d'une grande portée. La sociologie prétendait alors observer «l'ensemble des changements intervenus dans la structure d'une société pendant un laps de temps déterminé» (selon Peter Heintz dans les années 1960). Le lien avec le concept de structure a permis de distinguer les dynamiques de changement endogène et exogène, évolutionnaire et révolutionnaire, linéaire et cyclique. À cela étaient associées une croyance dans le progrès et une volonté de planifier. Les gouverne- ments attendaient des recherches scientifiques qu'elles permettent au changement social d'apporter l'égalité des chances et la sécurité sociale.

Dans un contexte de prospérité économique persistante (les Trente Glorieuse entre 1945 et 1975), le pouvoir d'achat financier et le niveau de vie matériel de larges couches de la population des pays industrialisés occidentaux ont augmenté, ce qui a atténué les confrontations entre les classes. Face à l'expérience de l'accélération, qui a sensiblement réduit la durée de vie des qualifications et des connaissances, les politicien-ne-s ont réagi avec des approches technocratiques pour résoudre les problèmes. Des systèmes d'éducation, de santé, de transport et de communication ont été systématiquement mis en place partout. Dans la compétition globale entre les systèmes de l'«économie sociale de marché» et du «socialisme réel existant», ce dernier a pris de plus en plus de retard. Les économies du bloc de l'Est, gérées de manière centralisée, semblaient être submergées par des changements sociaux rapides, tandis que dans les pays industrialisés occidentaux, les mesures de politique sociale promettaient une solution efficace aux problèmes sociaux. Malgré les aspirations théoriques du «système mondial», la mise en œuvre politique est restée fortement ancrée dans les États nationaux qui soutenaient certes un processus d'intégration européenne, tout en voulant cependant préserver leurs droits souverains.

Dans l'ensemble, les changements sociaux survenus pendant la guerre froide ont été fortement perçus sous l'angle du structuro-fonctionnalisme ou du fonctionnalisme systémique sociologique et, à partir des années 1960, de la cybernétique. Ces approches ont été condensées dans les théories de la modernisation rapidement devenues à la mode, qui reposaient sur un ensemble normalisé de paradigmes (différenciation, mobilisation, participation, sécularisation, institutionnalisation des conflits). 
Depuis les années 1970 cependant, des voix critiques se sont fait entendre, rejetant à la fois l'inévitabilité et la linéarité supposées des élans de modernisation et le déséquilibre eurocentrique de toute cette construction théorique.

Avec la fin de la guerre froide, les théories établies ont connu une période de crise. Depuis plusieurs décennies, il est évident que l'analyse $\mathrm{du}$ changement social exige une perspective transnationale et globale afin de tenir compte des multiples interdépendances, interactions, dépendances et processus de transculturation. Cela a stimulé la réflexion sur l'évolution des formes et le fonctionnement des régimes réglementaires transnationaux, européens et mondiaux. Et avec le débat sur la «disparition du social», divers facteurs sous-exposés dans les théories traditionnelles du changement social - les inégalités sociales et l'impact des religions et des fantasmes nationalistes racistes - sont entrés dans le champ de mire. De plus, le concept de l'Anthropocène reflète d'une nouvelle manière la dimension historique profonde de la dynamique du changement dans les sociétés modernes. Alors que les théories du changement climatique anthropique impliquent le changement social des sociétés modernes dans le cadre d'enjeux écologiques à plus long terme, la théorisation du changement social est aujourd'hui confrontée à de nouveaux problèmes.

\section{Jakob Tanner}

\section{Références}

Jäger, W. \& Weinzierl, U. (2011). Moderne soziologische Theorien und sozialer Wandel. Wiesbaden : VS.

Müller, H.-P. \& Schmid, M. (1995). Sozialer Wandel. Modellbildung und theoretische Ansätze. Frankfurt a.M.: Suhrkamp.

Zapf, W. (Hrsg.) (1969). Theorien des Sozialen Wandels. Köln: Kiepenheuer \& Witsch.

\section{Chômage*}

Le chômage arrive régulièrement en tête dans les sondages sur les préoccupations de la population suisse. En Suisse, il est perçu comme un problème social urgent malgré un taux de chômage bas en comparaison internationale. Dans la moyenne des deux dernières décennies (1991-2011), il oscillait entre 3 et $4 \%$ selon la définition utilisée.

Une première définition officielle du chômage considère comme chômeuses les personnes inscrites auprès d'un Office régional de placement (ORP), sans emploi mais employables immédiatement, qu'elles aient ou non droit à des indemnités de chômage. Communiqué tous les mois à l'attention de la Confédération et des cantons par le Secrétariat d'État à l'économie (SECO), c'est cet indicateur qui a cours dans le quotidien politique en Suisse.

Un second indicateur du chômage est basé sur la définition du Bureau international du travail (BIT). Un·e chômeur.euse au sens du BIT est une personne sans emploi pendant la semaine de référence, ayant cherché un travail au cours des quatre semaines précédentes et disponible pour travailler. Calculé chaque année par l'Office fédéral de la statistique à l'aide de l'Enquête suisse sur la population active (ESPA), cet indicateur est utilisé pour les comparaisons internationales de l'OCDE.

Par rapport à la définition du BIT, le taux de chômage officiel du SECO présente l'avantage de se fonder sur des données de registre et non pas sur un échantillon. En outre, il est décisif pour la situation financière de l'assurance-chômage. Par contre, l'indicateur du BIT inclut également les jeunes ayant terminé l'école, les chômeur-euse-s en fin de droits et les sans-emploi bénéficiant de l'aide sociale qui n'ont pas droit aux indemnités de chômage, et qui par conséquent s'inscrivent rarement auprès d'un ORP. Il en résulte que le taux de chômage établi 
selon la définition du BIT est supérieur d'environ un point au taux officiel de la Suisse.

Pendant des décennies, le chômage a été presque inexistant en Suisse. Entre 1950 et 1990, la haute conjoncture conjuguée à l'absence d'une assurance-chômage obligatoire et à une politique où les étranger·ère-s servaient de «tampons» a permis de maintenir le taux de chômage officiel sous la barre de $1 \%$. La récession du début des années 1990 a mis fin à cet état d'exception. Depuis le milieu des années 1990, le taux de chômage en Suisse fluctue entre 2 et $4 \%$ (définition SECO) ou entre 3 et $5 \%$ (définition BIT). Dans la moyenne des deux dernières décennies, le taux de chômage des cantons romands de Genève, Neuchâtel et Vaud dépassait de un à deux points de pourcentage la moyenne nationale, alors que dans les cantons de Suisse centrale et orientale il se situait un point en dessous.

En comparaison internationale, la Suisse fait partie des pays affichant le taux de chômage le plus bas. En Europe, seuls quelques pays comme l'Autriche, le Danemark, le Luxembourg, la Norvège ou les Pays-Bas présentaient pendant un certain temps des taux de chômage comparables. Cependant, si l'on compare la Suisse aux régions limitrophes comme le Bade-Wurtemberg, la Bavière ou le Vorarlberg, les différences sont faibles.

Les médias relaient régulièrement la crainte que le progrès technologique ne conduise à la suppression d'emplois dans les pays industrialisés. Un coup d'œil à l'évolution de la population active révèle que le contraire est vrai. En 1900, la Suisse comptait 1,55 millions de personnes actives. En dépit du développement technologique fulgurant, ce chiffre a doublé jusqu'en 1970 (3,15 millions) et triplé jusqu'en 2015 (5 millions). De toute évidence, malgré la prolifération d'automates, d'ordinateurs et de robots, le nombre de personnes qui trouvent du travail en Suisse a considérablement augmenté du début du $\mathrm{XX}^{\mathrm{e}}$ siècle jusqu'à nos jours. Mais elles le font évidemment dans d'autres domaines: en 1900, $31 \%$ de toutes les personnes actives l'étaient dans l'agriculture, une proportion qui a chuté à $3 \%$ en 2015. C'est surtout le taux d'activité professionnelle des femmes qui a connu une forte progression.

Dans la théorie du marché du travail, on distingue plusieurs types de chômage, notamment frictionnel, saisonnier, conjoncturel et structurel. Le chômage frictionnel, qui se produit lors d'un changement d'emploi et se limite à de brèves périodes de transition, est peu problématique. Le chômage saisonnier est une conséquence des fluctuations de la demande au gré des saisons et est typique de secteurs tels que la construction, l'hôtellerie ou l'agriculture. Quant au chômage conjoncturel, il est dû à une demande insuffisante en biens et services et est étroitement lié aux récessions. En période de récession, il revient à la Confédération et aux cantons de stimuler la demande globale avec des investissements publics anticipés et ainsi de stabiliser le marché de l'emploi. Parallèlement, la politique monétaire de la Banque nationale peut encourager les investissements privés en abaissant les taux d'intérêt et contribuer ainsi à la politique de l'emploi.

Par chômage structurel, on entend l'inadéquation (mismatch) entre le profil des personnes demandeuses d'emploi et les exigences des postes vacants. Cette inadéquation peut concerner la formation, la région ou le secteur. On parle de chômage structurel lorsque le taux de chômage se maintient à un niveau élevé malgré une croissance économique soutenue et prolongée. Les mesures pouvant servir à le combattre sont l'orientation professionnelle individuelle, les allocations d'initiation au travail, les formations continues ou encore les reconversions professionnelles. Les ORP, qui proposent de telles mesures dans les cantons, sont ici les principaux acteurs politiques.

En Suisse, quelque 150000 personnes sont inscrites auprès d'un ORP en moyenne annuelle. Ce chiffre n'est constant qu'en apparence car il cache des flux marqués. En effet, 
près de $20 \%$ des chômeur-euse-s se désinscrivent de l'ORP (sorties) chaque mois et environ $20 \%$ nouveaux.elles chômeur.euse-s s'y inscrivent (entrées). Ces sorties et entrées continuelles se reflètent dans la durée du chômage : en Suisse, la valeur médiane de la durée du chômage est inférieure à quatre mois (111 jours calendaires).

La durée du chômage varie selon les tranches d'âge. Si les jeunes présentent un risque plus élevé d'être sans emploi, leur durée de chômage est inférieure à la moyenne. À l'inverse, les employéee-s plus âgé·e-s sont moins touché·e.s par le chômage, mais présentent un risque plus élevé de devenir des chômeur-euse-s de longue durée. La réinsertion des sans-emploi plus âgé·e·s représente ainsi un défi majeur pour la politique du marché de l'emploi.

Malgré le dynamisme du marché du travail, 10 à $15 \%$ des sans-emploi ne trouvent pas d'emploi pendant les 18 à 24 mois où ils peuvent percevoir des indemnités de chômage et arrivent alors en fin de droits. Près de la moitié d'entre eux.elles trouve un travail dans un délai d'une année, environ un cinquième se retrouve à l'aide sociale, les autres vivent d'économies ou du revenu de leur partenaire.

\section{Daniel Oesch}

\section{Références}

Bonoli, G. \& Champion, C. (2013). La réinsertion professionnelle des bénéficiaires de l'aide sociale en Suisse et en Allemagne. Lausanne: IDHEAP.

Flückiger, Y. (2002). Le chômage en Suisse : causes, évolution et efficacité des mesures actives. Aspects de la Sécurité Sociale, 4, 11-21.

\section{Chômage de longue durée**}

Le terme «chômage de longue durée» désigne le fait de se retrouver au chômage pour une période d'au moins un an. Selon la définition administrative, conforme aux dispositions de la loi sur l'assurance-chômage (LACI) et aux données du Secrétariat d'État à l'économie (SECO), le chômage de longue durée concerne toutes personnes sans emploi annoncées auprès d'un Office régional de placement (ORP) depuis au moins 12 mois (indépendamment du fait qu'elles perçoivent ou non une indemnité de chômage) et immédiatement disponibles au placement. Si l'on adopte en revanche les standards internationaux, notamment ceux de l'Organisation internationale du travail (OIT), sont considéré·e·s chômeur·euse·s de longue durée toutes celles et tous ceux qui, depuis au moins une année au moment du relevé statistique, sont sans emploi, disponibles au placement et à la recherche d'un emploi (indépendamment de leur enregistrement auprès d'un ORP).

Les chômeur·euse-s de longue durée constituent un sous-groupe de l'ensemble de la population des chômeur-euse-s. La distinction avec les chômeur·euse-s de courte durée se justifie en raison des importantes conséquences économiques et sociales liées à la persistance de la condition de chômeur.se, notamment à partir du moment où le-la chômeur.se de longue durée a épuisé son droit aux indemnités journalières. En effet, dans une société où le travail constitue une norme sociale centrale, ces personnes sont exposées non seulement à une perte de revenu, mais aussi à une profonde marginalisation personnelle et sociale qui aboutit souvent à des troubles de santé psychiques et physiques.

Dans le système politique suisse, la LACI fixe le cadre de référence en matière de chômage. Cette assurance vise à couvrir temporairement le risque lié à la perte de gain et à garantir aux personnes au chômage un retour rapide et durable dans le marché du travail à travers un soutien au placement, la promotion de la requalification et de la réinsertion professionnelle par le biais de mesures actives spécifiques. À cet égard, la LACI constitue un élément central du système de sécurité sociale 
suisse qui, s'il se révèle efficace, permet de limiter la probabilité de se retrouver dans une situation de chômage de longue durée, d'arriver en fin de droit et de devoir recourir à l'aide sociale. Dans certains cas, la mission de (ré-) insertion professionnelle des personnes sans emploi est partagée avec d'autres institutions et instruments de la politique sociale tels que les structures de l'aide sociale et de l'assurance-invalidité pour les demandeur-euse-s d'emploi qui risquent de connaître un chômage de longue durée, ou les institutions de formation et de la politique de l'emploi pour les étranger·ère-s ayant des qualifications ou des connaissances linguistiques insuffisantes, ou encore les jeunes qui rencontrent des difficultés avec leur cursus de formation et risquent de décrocher.

Du point de vue de ses conséquences (souvent désignées par la notion de scarring effects), on constate que le chômage de longue durée a un impact sur la possibilité de retrouver un emploi, notamment un emploi stable et bien rémunéré. L'insécurisation et la précarisation croissantes des trajectoires professionnelles, le passage à l'aide sociale représentent des situations courantes pour un nombre non négligeable de chômeur-euse-s de longue durée; parmi ceux.celles-ci les groupes particulièrement à risque sont les personnes âgées, les personnes sans formation, les étranger-ère-s - en particulier en provenance des pays hors UE - les personnes divorcées, etc. Pour les classes d'âge plus avancé, la LACI prévoit un nombre plus élevé d'indemnités journalières. Ce nombre n'a pas été diminué à l'occasion des réformes restrictives de la quatrième révision de la LACI, entrée en vigueur en 2011, dans le but de ne pas entraîner un risque accru de chômage de longue durée.

Du point de vue de l'appréciation statistique du chômage de longue durée, les données de l'Enquête suisse sur la population active (ESPA) de l'Office fédéral de la statistique (OFS), correspondant aux standards internationaux, doivent être préférées aux données administratives produites par le SECO. En effet, ces données ne se limitent pas aux chômeur·euse·s inscrit.e.s et intègrent les personnes ayant épuisé leurs droits aux indemnités de chômage et celles qui ne remplissent pas les conditions d'éligibilité à de tels droits. Elles permettent de mieux quantifier le phénomène sous toutes ses facettes et facilitent la comparaison internationale.

En comparaison internationale (sur la base des données ESPA), la Suisse se place parmi les quelques pays qui peuvent afficher des taux de chômage relativement bas, mais en termes de chômage de longue durée elle occupe une position intermédiaire entre les pays où le taux est bas et les valeurs centrales de la distribution. Avec un taux de chômage de 4,5\% (données Eurostat, 2015), elle occupe la troisième place derrière l'Islande et la Norvège et se situe au-dessous de la moyenne des 28 pays de l'Union européenne (9,4\%), bien loin des records négatifs de l'Espagne, la Grèce et la Macédoine (respectivement 22,1\%, 24,1\% et $26,1 \%)$. Cependant, avec une proportion de chômeur-euse-s de longue durée qui atteint $35,8 \%$ du total des chômeur.euse-s, elle se place au dixième rang d'un classement qui voit en tête l'Islande (12,4\%) et à la dernière place la Macédoine $(81,6 \%)$ et où la moyenne des 28 pays de l'UE atteint $48,3 \%$.

Les causes du chômage doivent être recherchées dans la conjoncture économique, le fonctionnement du marché du travail et le comportement de ses acteur-trice-s (personnes, entreprises, intermédiaires), et le progrès technologique, dont les effets structurels impliquent une automatisation accrue des activités manuelles et une inadéquation entre les profils recherchés par les entreprises et les compétences de la main-d'œuvre disponible. À cela s'ajoutent des arguments relatifs à la flexibilité des salaires, la générosité de l'assurance-chômage, la mobilité géographique des chercheur-euse-s d'emploi, la propension des 
entreprises à assurer la formation continue en interne, etc. Cela étant, le risque de rester longtemps dans une situation de chômage augmente fortement avec le temps passé hors emploi, en raison d'une part de la perte de compétences des chercheur-euse-s d'emploi et, d'autre part, de l'influence du phénomène persistant de stigmatisation sociale sur les comportements d'embauche des entreprises.

En Suisse, l'agenda politique se focalise sur l'ensemble des chômeur-euse plutôt que sur la catégorie spécifique des chômeur-euse-s de longue durée. Le débat autour des solutions pour combattre la pénurie d'emploi se polarise autour de ceux qui, d'une part, réclament davantage de dérèglementation du marché du travail, de flexibilité dans les rapports de travail et un durcissement accru de l'accès aux indemnités de chômage et ceux qui, d'autre part, insistent sur les réformes du système de formation et de perfectionnement professionnel, sur un accompagnement ciblé des catégories particulièrement vulnérables et une meilleure collaboration entre les ORP et les autres branches de la protection sociale, notamment l'aide sociale. En raison du vieillissement de la population et de la force de travail et en lien avec la vulnérabilité des personnes âgées par rapport au chômage de longue durée, le thème des travailleur·euse-s âgé·e·s fait l'objet d'une attention particulière dans le débat public. Les prestations transitoires récemment introduites pourraient ici apporter une amélioration.

Fabio B. Losa

\section{Références}

Losa, F. B., Bigotta, M., Stephani, E. \& Ritschard, G. (2014). D'où venons-nous? Que sommes-nous? Où allons-nous? Analyse des parcours professionnels des chômeurs de longue durée en Suisse. Giubiasco: Ufficio di statistica.

Sheldon, G. (1999). Die Langzeitarbeitslosigkeit in der Schweiz: Diagnose und Therapie. Bern: Haupt.

Wegmüller, J. S. \& Keller, D. (2016). L'importance de l'assurance-chômage face au risque de chômage de longue durée. Sécurité sociale CHSS, 1, 11-17.

\section{Citoyenneté}

Le concept de citoyenneté remonte à la Grèce antique, où être citoyen signifie être homme la femme étant exclue - membre de la polis, la cité. Dans les temps modernes, c'est surtout la Révolution française qui a donné au concept sa force émancipatrice, en instituant l'égalité morale et de droits de toutes et tous. Ce qui l'a rendu constitutif de toute réflexion postérieure sur la démocratie, la république, l'État ou la justice. Au sens strict, au sein des États démocratiques, la citoyenneté représente l'expression de l'identité politique. En ce sens, elle exprime l'appartenance statutaire à la communauté politique, donc la possibilité formelle de participer à l'exercice de la souveraineté politique et de bénéficier, directement ou indirectement, des prestations matérielles et opportunités formelles découlant des politiques publiques. En Suisse, l'acquisition de la citoyenneté pour les ressortissant.e.s étranger·ère-s est restrictive en comparaison internationale, dans la mesure où elle implique, depuis le $1^{\text {er }}$ janvier 2018, d'avoir résidé 10 ans au moins dans le pays (avec un permis C), ainsi qu'un processus de décision qui s'échelonne sur le plan fédéral, cantonal et communal.

La citoyenneté est un concept qui a à la fois une dimension empirique et une dimension morale, ce qui le rend par nature politiquement controversé. La citoyenneté incarne en effet des idéaux d'émancipation, d'égalité et de liberté qui, ultimement, déterminent les principes de légitimation des institutions, des politiques publiques et des réformes sociales. Ces idéaux sont thématisés par différentes philosophies politiques de la citoyenneté (p.ex. républicaine ou libérale). Celles-ci donnent un sens aux représentations et aux lois concernant la façon dont les citoyen-ne-·s devraient être et fonctionner dans l'espace public. Ces philosophies permettent de penser les incarnations concrètes de la citoyenneté, notamment les ressources légales, politiques, symboliques et 
matérielles auxquelles la citoyenneté donne accès. De ce point de vue, elle peut être définie comme le statut unissant un individu à un État et à une communauté politique ou nationale, avec la palette de droits et de devoirs s'y rattachant. Cette palette peut être très différente en fonction des modèles philosophiques de citoyenneté qui s'imposent dans un contexte politique particulier (p.ex. le modèle solidariste français en opposition au modèle libéral des États-Unis).

Selon la typologie canonique proposée par Thomas $\mathrm{H}$. Marshall quelques années après la Seconde Guerre mondiale, la citoyenneté se compose de trois ensembles de droits. À savoir : les droits civils, les droits politiques et les droits sociaux. Les premiers concernent les libertés des individus, comme la liberté de croyance, d'expression et de religion, et leur protection contre l'ingérence de l'État. Les deuxièmes permettent la participation à l'exercice de la souveraineté politique et sanctionnent l'égalité des citoyennes et citoyens en ce qui concerne leur expression de la volonté politique (par un vote ou une élection). Enfin, les droits sociaux concernent les protections dont jouissent les individus face au chômage, la maladie, la vieillesse ou la détresse économique. Institués surtout au $\mathrm{XX}^{\mathrm{e}}$ siècle, ces trois ensembles de droits forment le socle de l'État social et des politiques redistributives qui s'y réfèrent. Pour certains, une quatrième dimension s'est désormais ajoutée lors des trois dernières décades, à savoir les droits culturels, visant la protection de groupes culturels et de leurs pratiques. Par la mise en place de politiques multiculturelles, des pays tels que le Canada ont en effet mis en place des droits des minorités sur base culturelle.

Aux droits correspondent aussi des obligations. Traditionnellement, en Suisse, pour les hommes le service militaire était vu comme une obligation (inspirée du citoyen soldat envisagé par Jean-Jacques Rousseau). Le paiement des impôts est aussi une forme d'obligation, stipu- lant la nécessité que les citoyennes et citoyens participent au financement des biens publics, comme l'est le fait de respecter la loi. Au-delà de ces obligations formelles, il est important de préciser que les obligations de citoyenneté déploient particulièrement leur rôle dans le processus de naturalisation ou d'obtention du permis de résidence. Les résident-e-s étranger-ère-s doivent en effet respecter la loi, ne pas être à la charge de l'assistance ou encore faire preuve de leur volonté d'intégration. En ce sens, l'acquisition de la citoyenneté implique de fortes obligations, laissant souvent un pouvoir discrétionnaire aux autorités pour évaluer les attitudes des personnes.

Pour Marshall, la citoyenneté se révèle être un statut intimement égalitaire, en mesure de réduire les inégalités socioéconomiques et politiques injustes inhérentes à une communauté donnée. En ce sens, la citoyenneté représente une catégorie fondamentale pour réaliser l'idéal d'une communauté nationale stable, démocratique et juste. Les droits civils, politiques et sociaux de citoyenneté jouent un rôle crucial pour promouvoir l'intégration sociale et politique. Ils permettent le fonctionnement de la démocratie et l'exercice de la souveraineté politique. Car l'exercice de la citoyenneté politique implique aussi bien les libertés protégées par les droits civils que les ressources provenant des droits sociaux. Les ressources de citoyenneté sociale constituent en effet des préconditions importantes pour que l'exercice des droits civils ou une participation effective des citoyen-ne-s puissent s'accomplir.

Dans une perspective diachronique, la palette de droits et d'opportunités rattachés à la citoyenneté n'est pas fixe, mais elle fait l'objet d'élargissements ou de reculs en fonction des contingences politiques, sociales ou économiques. Contrairement à la vision de Marshall, en effet, les droits de citoyenneté en Suisse ne suivent pas un développement nécessairement linéaire et acquis une fois pour toutes. Par exemple, malgré une tradi- 
tion de démocratie directe (au niveau fédéral, avec le droit de référendum en 1874 et le droit d'initiative populaire en 1891) qui fait de la Suisse un cas pratiquement unique au monde, le suffrage universel incluant le droit de vote des femmes au niveau fédéral n'est introduit qu'en 1971 par votation populaire. Par le biais de l'exercice des droits démocratiques, les citoyennes et citoyens suisses peuvent modifier la Constitution fédérale (sauf le droit impératif), ce qui peut entraîner des restrictions de certains droits civils (comme l'interdiction de construire des minarets en 2009) ou sociaux (p.ex. la révision de l'assurance-chômage votée en 2010). C'est particulièrement le cas en ce qui concerne la citoyenneté sociale. Les droits sociaux et les prestations qui en découlent, en portant souvent sur des situations particulières qui n'affectent pas nécessairement l'ensemble des citoyen'ne-s, se démarquent du caractère formel et à prétention universelle des droits civils et politiques. Cela rend les prestations sociales sujettes aux aléas des rapports de force politiques ou de la conjoncture économique. Il en découle que, dans les démocraties occidentales, le risque de dégradation de ce que Robert Castel nomme la citoyenneté sociale, prônée par des forces politiques néolibérales ou imposée par des contraintes économiques, budgétaires ou de compétitivité, constitue une menace pour la citoyenneté dans son ensemble et pour sa fonction de légitimation des décisions collectives.

La définition des ressources et des modalités matérielles et symboliques permettant de préserver la dignité individuelle et sociale est fortement débattue en Suisse. Elle cristallise ainsi les oppositions entre les forces politiques de droite prônant, d'une part, la réduction de l'intervention de l'État dans la distribution de prestations sociales, et, d'autre part, celles de gauche qui estiment que l'État doit jouer un rôle fondamental dans la protection des droits et des prestations sociales. En vertu des droits populaires, par ailleurs, plusieurs enjeux relatifs à la citoyenneté sociale font l'objet de votations populaires, et donc, de débats publics étendus. Les analyses des résultats de ces scrutins montrent des différences entre Suisse romande et Suisse alémanique concernant le soutien de la population aux prestations sociales (les Romand.e.s étant plus enclin.e.s à considérer le rôle de l'État dans la solidarité collective, tandis que les Alémaniques ont une vision plus axée sur la responsabilité individuelle).

La question de la réduction ou de la préservation des droits de citoyenneté touche l'ensemble des démocraties occidentales contemporaines. En ce qui concerne les droits sociaux, des dispositifs mis en place lors des Trente Glorieuses, comme les systèmes de retraites, font l'objet de remises en question pour des raisons politiques, économiques ou démographiques. En ce qui concerne les droits civils, les tensions produites par la globalisation et les flux migratoires font émerger des forces politiques nationalistes, dont le programme est fondé sur la réduction des droits civils offerts aux membres de groupes religieux ou culturels minoritaires. Sans oublier la restriction des droits civils à la suite du tournant sécuritaire introduit à partir des attaques terroristes aux États-Unis en 2001. Finalement, les droits politiques sont menacés par la qualité effective de l'offre politique et des conditions de production de la volonté politique. Par exemple, fausses informations, médiatisation à outrance de faits divers, mobilisation de registres émotionnels constituent des facteurs qui ont une incidence sur la qualité et la propension des citoyen·ne-s à se déterminer politiquement. En conclusion, la palette de droits, opportunités et ressources offertes par la citoyenneté n'est pas donnée une fois pour toutes. Elle est perpétuellement négociée, amendée ou élargie. Seule une compréhension plus philosophique de la citoyenneté permettra de dire si ces modifications vont dans le sens des idéaux contenus dans la notion de citoyen- 
neté, notamment de liberté, égalité, dignité et détermination de la volonté collective.

\section{Matteo Gianni}

\section{Références}

Castel, R. (2008). La citoyenneté sociale menacée. Cités, 35, 133-141.

Kymlicka, W. (2001). La citoyenneté multiculturelle: une théorie libérale du droit des minorités. Paris: La Découverte.

Marshall, T. H. (1950). Citizenship and social class. In T.H. Marshall \& T. Bottomore (Eds.), Citizenship and Social Class (pp. 1-51). London: Pluto Press, 1992.

\section{Collaboration interinstitutionnelle}

De manière générale, la collaboration interinstitutionnelle (CII) désigne la collaboration entre les domaines de la sécurité sociale, de la formation et de l'intégration avec pour but de trouver des solutions centrées sur les personnes, de faciliter leur intégration rapide et durable dans le monde professionnel, et de mieux harmoniser les différents systèmes. La CII vise donc aussi bien une meilleure collaboration au niveau individuel que structurel.

La mise sur pied de projets concrets de CII est avant tout du ressort des cantons et des communes. Dans la pratique, la CII prend donc des formes diverses et multiples. Sous cette dénomination sont ainsi recouverts divers modèles de coopération formelle et informelle, bilatérale ou multilatérale, allant du simple échange d'informations à la mise en place conjointe de mesures d'intégration et à la définition de stratégies communes. Les principales institutions partenaires sont l'assurance-chômage (AC), l'assurance-invalidité (AI), l'aide sociale, ainsi que les institutions de la formation professionnelle et de la migration/intégration. Toutefois, d'autres institutions actives dans la (ré-)intégration de personnes, comme les assureur·e.s indemnités journalières en cas de maladie et les assureur.e.s accidents, constituent également des partenaires important·e.s (CII-plus, cf. ci-dessous).

Le besoin d'une plus grande coordination du système de sécurité sociale a émergé dès la fin des années 1990, en réponse à la crise économique et à la réorientation des régimes sociaux vers l'activation. Mais c'est dans les années 2000 que la CII a réellement pris son essor, notamment suite à une recommandation commune entre la Conférence des chefs des départements cantonaux de l'économie publique (CDEP) et la Conférence des directrices et directeurs cantonaux des affaires sociales (CDAS) en 2001. Depuis, chaque canton a initié et formalisé au moins une forme de CII bilatérale ou multilatérale pour le suivi des personnes.

$\mathrm{Au}$ niveau fédéral, plusieurs projets ont participé à l'essor de la CII. Parmi ces projets, on peut citer la publication, en 2004, d'un manuel pour la collaboration interinstitutionnelle par un comité national composé des principales institutions impliquées au niveau fédéral et cantonal. On peut également mentionner le projet-pilote CII-MAMAC (Medizinisch-arbeitsmarktliche Assessments mit Case Management, soit «Bilan médical, appréciation du potentiel professionnel par rapport au marché du travail et gestion par cas») qui s'est déroulé de 2005 à 2010. Ciblant les personnes présentant une problématique complexe mais ayant une chance de réinsertion, le projet se caractérisait par une procédure précise de prise en charge et une stratégie d'intégration commune et contraignante pour les institutions partenaires, à savoir les Offices régionaux de placement (ORP), les services sociaux et les Offices AI. Malgré des résultats mitigés, le projet CII-MAMAC a constitué une étape décisive dans le développement de la CII. Il a contribué à l'initiation de nouveaux projets CII dans les cantons, a permis un meilleur dialogue entre institutions partenaires, et a conféré à la CII 
un caractère plus contraignant. Finalement, on peut également citer le projet CII-plus, initié dès 2008 , et visant à encourager une collaboration axée sur la réadaptation entre les Offices AI et les institutions d'assurance opérant en amont. Sont ici concerné·e·s les assureur·e·s indemnités journalières en cas de maladie, les assureur·e-s accidents et - du fait de la libération du paiement des primes et de la force obligatoire de la décision prise dans le domaine de la LACI - les institutions de prévoyance.

Depuis 2011, la CII dispose d'une organisation nationale spécifique. Celle-ci regroupe l'ensemble des partenaires fédéraux, cantonaux et communaux impliqués dans la CII. Elle a pour objectif de promouvoir la CII au niveau fédéral, de favoriser les échanges d'expériences entre les cantons et de les soutenir dans leurs efforts de développement.

Finalement, au niveau de la législation fédérale, l'encouragement de la CII est ancré, depuis 2002, dans l'article $85 \mathrm{f}$ de la LACI et, suite aux $4^{\mathrm{e}}$ et $5^{\mathrm{e}}$ révisions de la loi sur l'AI, dans l'article 68bis de ladite loi ainsi que dans la loi sur le contrat d'assurance.

Alors que d'autres pays se sont tournés vers des restructurations organisationnelles pour assurer une meilleure coordination de leurs systèmes sociaux, la Suisse a privilégié, avec la CII, une forme de coordination légère et pragmatique. Ce choix reflète la très grande fragmentation du système suisse de sécurité sociale, de formation et d'intégration. Ainsi, la CII a jusqu'ici été guidée par le principe que la coordination devait être atteinte à travers une meilleure collaboration à l'intérieur des structures existantes, et qu'aucune nouvelle institution ou structure parallèle ne devait être créée. Ce choix est aussi influencé par les particularités de l'aide sociale en Suisse. Le fait que l'aide sociale relève de la compétence des cantons et des communes complique les efforts de collaboration sur le terrain, et restreint les possibilités d'une coordination plus contraignante au niveau fédéral.
Si la CII est aujourd'hui bien implantée dans les cantons et ses bénéfices reconnus par les professionnel-le-s du terrain et les personnes qui y recourent, elle subit toujours de nombreuses critiques pointant ses limites. Ainsi, le fait que la CII reste dépendante des personnes et le manque d'incitations structurelles à collaborer dans un système très cloisonné reviennent régulièrement. Ensuite, la difficulté à mesurer les effets de la CII constitue une autre limite, qui se traduit par des résultats d'évaluations mitigés quant à l'impact de la CII sur le retour à l'emploi et sur les coûts du système. En partie, cela tient au fait que la CII concerne souvent un public éloigné du marché du travail cumulant des problèmes de chômage, de santé et des difficultés sociales. Mais cela tient aussi à la difficulté à isoler les effets de la collaboration de ceux d'autres mesures d'intégration sociale et professionnelle.

À cause de ou grâce à ses limites, la CII est en constant développement. Depuis la fin du projet CII-MAMAC, on assiste à un regain d'innovations dans ce domaine au niveau des cantons. Ainsi, en plus des projets «traditionnels» de CII de type bilatéral ou multilatéral (cf. CII-MAMAC), plusieurs cantons testent des formes plus intégrées de coopération entre institutions. Ces nouvelles formes de coopération consistent, par exemple, dans la prise en charge de chômeur-euse-s de longue durée en tandem par des professionnel-le·s des ORP et de l'aide sociale, ou dans la création de guichets uniques pour l'intégration. Les domaines impliqués ont également beaucoup évolué. Initialement centrée sur l'AC, l'AI et l'aide sociale, la CII s'est progressivement étendue à la formation professionnelle et à la migration. Elle s'adapte ainsi à l'émergence de nouveaux enjeux socioéconomiques.

Cyrielle Champion 


\section{Références}

Bieri, O., Itin, A., Nadai, E., Canonica, A., Flamand, E. \& Pluess, S. (2013). Formen institutioneller Zusammenarbeit in der Schweiz: Bestandsaufnahme und Typologie. Bern: Bundesamt für Sozialversicherungen.

Egger, M., Merckx, V. \& Wüthrich, A. (2010). Évaluation du projet national CII-MAMAC. Berne: Office fédéral des assurances sociales.

Membres du groupe national de coordination CII (2004). Manuel pour la collaboration interinstitutionnelle (CII). Berne : Secrétariat d'État à l'économie.

\section{Configurations familiales}

La perspective configurationnelle sur les familles s'inspire directement des travaux de Norbert Elias, qui définit les configurations comme des structures d'individus mutuellement orientés et dépendants les uns des autres. Elle postule que les différentes dyades constitutives de la famille, telles que la relation de couple, ou la relation parents-enfants, sont largement influencées par les réseaux de relations interpersonnelles plus larges dans lesquels elles s'intègrent. D’un autre côté, les modèles d'interdépendances caractérisant ces réseaux dépendent en large partie de la distribution du pouvoir, du conflit et du soutien existant dans ces dyades clés. Ainsi, plutôt que de se centrer sur les dynamiques propres à chacune des dyades familiales ou de tabler sur une distinction nette entre le domaine de la famille et celui de la parenté, la perspective configurationnelle s'intéresse à mettre en lumière les modèles complexes d'interdépendances, à la fois positives (soutien de natures multiples, proximité émotionnelle) et négatives (conflit, stress, exploitation) qui lient de multiples dyades familiales entre elles.

Une seconde caractéristique des configurations familiales tient au fait qu'elles ne peuvent être définies a priori en utilisant des critères comme l'appartenance des individus à un même ménage, ou le fait qu'ils sont liés par le mariage ou une filiation reconnue légalement. Ces critères sont considérés comme simplifiant à outrance la diversité des familles «qui comptent», qui ne suivent pas dans leurs modes de fonctionnement ces critères administratifs. Ainsi, dans les familles de seconde union, il arrive que des membres du ménage ne se considèrent pas les uns les autres comme membres de leur famille respective. Alternativement, une majorité d'individus en Suisse, quand on leur demande de définir les frontières de la famille qui compte, incluent des personnes qui ne résident pas avec eux, ou même, qui ne sont pas liées avec eux directement par des liens de sang ou de mariage. En ce sens, les configurations familiales se distinguent donc de ce que les démographes appellent les «structures familiales» en ceci qu'elles se centrent sur les interdépendances effectives existant entre des personnes qui s'identifient d'elles-mêmes comme membres d'une même famille, quels que soient leurs résidences et leurs statuts de parenté.

Centrer son attention sur les configurations familiales permet donc d'échapper à une vision étroite de la famille, qui a parfois donné lieu à des politiques familiales inefficaces voire discriminatoires. La question de la composition des configurations familiales est en effet essentielle pour les politiques sociales, mais aussi publiques: par exemple les politiques de migration et de regroupement familial tablent sur des définitions implicites de la famille proche (le-la conjoint $\cdot$ e et les enfants) qui n'ont pas jusqu'ici fait l'objet d'évaluations systématiques. Il en va de même des mesures relatives aux proches aidants qui considèrent bien souvent l'enfant adulte comme jouant par définition un rôle de proximité et de soutien actif. Suite à la pluralisation des parcours de vie, les configurations familiales se sont diversifiées au-delà de la famille nucléaire, en incluant une grande diversité de liens, allant des frères et sœurs à la famille élective, constituée de 
personnes qui ne sont pas liées par le mariage ou la parentalité. La centration sur une définition de la famille comme nucléaire fait courir le risque aux intervenant.e.s sociaux-ales de sous-évaluer les ressources familiales à disposition des individus.

La question des solidarités familiales a reçu beaucoup d'attention. L'évaluation de la portée de l'entraide produite par les configurations familiales montre clairement que les soutiens effectivement échangés sont localisés principalement dans la relation conjugale, et que le rôle des autres membres de la famille est plus ponctuel, associé à des moments de crise ou des transitions de vie. Le soutien se déclenche en raison d'une grossesse, d'une maladie, d'un ennui financier, d'un divorce, etc. La garde des petits-enfants a cependant un caractère plus régulier et structurel. Ces solidarités se fondent sur des justifications à la fois affectives et statutaires: si les relations entre parents et enfants adultes sont marquées par de fortes injonctions normatives à l'entraide, d'autres relations familiales, telles les relations entre frères et sœurs, dépendent bien davantage de la proximité affective.

C'est sans doute moins, en général, dans des échanges effectifs réguliers qu'interviennent les configurations familiales, que dans la mise à disposition d'un potentiel d'aide, une réserve relationnelle, qui peut être activé dans des situations d'urgence, et, plus encore, dans un sentiment d'appartenance familiale très important pour l'identité individuelle. Si les configurations familiales ont une grande importance dans la production de ce capital, elles l'ont aussi comme productrices de stress social et psychologique. Ainsi, divers travaux ont révélé que le capital social qu'elles mettent à disposition permet aux individus de surmonter diverses difficultés, tant du point de vue de la vie professionnelle (chômage et autres problèmes professionnels) que du point de vue de la santé (maladie ou fragilité). Ce capital social a cependant des effets souvent inattendus, par- fois pervers. Ainsi, quand la configuration familiale est constituée de liens très étroits, elle a une influence conservatrice du point de vue du genre. Nos travaux ont de ce point de vue révélé que les jeunes couples ayant une configuration constituée de membres très interconnectés les uns aux autres sont davantage susceptibles de développer une division du travail domestique et professionnel très inégale entre hommes et femmes. Le soutien produit par les configurations familiales n'est donc pas sans ambiguïté pour l'adaptation des individus aux impératifs d'employabilité et de polyvalence de la société contemporaine. Les configurations familiales sont par ailleurs productrices de conflit et de stress, du fait qu'elles placent les individus face à des demandes de soutien souvent excessives, et parfois contradictoires entre elles. Ainsi, plusieurs résultats portant sur des individus ayant atteint les troisième et quatrième âges, révèlent une large ambivalence de leurs relations familiales, entre le désir de maintenir des liens significatifs avec les générations cadettes et un sentiment de surcharge aigu. Les femmes âgées avec enfants sont surreprésentées dans ces situations caractérisées par un large déséquilibre des échanges. Les solidarités familiales génèrent donc des ambivalences, ayant parfois un impact négatif sur la santé psychique et le bien-être.

Finalement, quelques travaux ont révélé que la composition des configurations familiales et les ressources qu'elles mettent à disposition des individus sont sensibles à des facteurs contextuels, dont les politiques sociales. Les politiques sociales d'inspiration sociale-démocrate semblent favoriser une définition plus ouverte des configurations familiales et de leurs fonctions de soutien que les politiques sociales d'inspiration conservatrice ou corporatiste. Il y a, dans les premiers contextes, une spécialisation de l'intervention familiale dans le soutien émotionnel. Dans les seconds, surtout quand les ressources financières de l'État sont limitées, la famille est appelée à jouer un 
rôle de premier plan dans les solidarités intergénérationnelles sans en avoir toujours les moyens.

Dans tous les cas, il semble aujourd'hui essentiel que les acteur.trice-s sociaux-ales et politiques prennent en compte dans leurs réflexions et décisions la variabilité des compositions et des dynamiques d'interdépendances propres aux configurations familiales contemporaines au-delà du ménage.

Eric D. Widmer

\section{Références}

De Carlo, I., Aeby, G. \& Widmer, E.D. (2014). La variété des configurations familiales après une recomposition : choix et contraintes. Revue suisse de sociologie, 40(1), 9-27.

Kellerhals, J. \& Widmer, E.D. (2012). Familles en Suisse: nouveaux liens ( $3^{\mathrm{e}}$ éd.). Lausanne: Presses polytechniques et universitaires romandes.

Widmer, E. D. \& Lüscher, K. (2011). Les relations intergénérationnelles au prisme de l'ambivalence et des configurations familiales. Recherches familiales, 1, 49-60.

\section{Conservatisme}

Le conservatisme désigne un système de valeurs qui défend une conception traditionnelle de la société et le maintien du statu quo. Dans le sens philosophique, le conservatisme est constitué par une opposition a priori à la rationalité et au changement radical, favorisant à leur place l'expérience et les pratiques existantes. Par exemple, il peut se manifester dans l'idée que l'activité professionnelle des femmes est dommageable à l'éducation des enfants, et que l'État devrait promouvoir des politiques qui permettent aux femmes de rester à la maison et maintenir le modèle de famille nucléaire. Plus généralement, les idées conservatrices s'opposent au développement de programmes sociaux qui confèrent plus de compétences à l'État, arguant que ce dernier ne doit pas interférer avec la sphère familiale. Elles s'opposent également aux politiques visant à bouleverser les hiérarchies sociales existantes.

Dans le domaine des politiques sociales, le concept de conservatisme a souvent été associé au modèle Bismarckien/Conservateur d'État-providence, qui a prévalu dans un grand nombre de pays d'Europe continentale, et dont les buts étaient précisément de préserver les structures familiales traditionnelles et contenir les révoltes sociales. Alors que la création de l'État Providence est souvent associée aux forces de gauche, on tend à négliger le rôle des forces plus conservatrices, comme l'Église et les partis démocrates-chrétiens, dans la création des programmes de sécurité sociale dans des pays comme la France, l'Allemagne, l'Autriche ou la Suisse. Sous-tendue par la doctrine sociale catholique, l'action de ces forces conservatrices se basait sur l'idée de subsidiarité: la famille devait être la première source de solidarité sociale, suivie par les organisations religieuses et caritatives, l'État n'intervenant qu'en dernier recours. Créés dans l'ère industrielle, les principaux programmes de sécurité sociale en Europe continentale se fondaient sur l'idée que les destinataires principaux de la protection sociale devaient être les hommes employés dans le secteur industriel, en leur fournissant un niveau de sécurité qui leur permettrait de maintenir une famille où les femmes n'auraient pas besoin de travailler. Ainsi, l'objectif principal de ces programmes sociaux n'était pas de redistribuer la richesse, mais d'assurer que les bénéficiaires pourraient conserver leur mode et niveau de vie malgré les risques liés au travail, à l'âge ou à la santé.

En Suisse, les valeurs conservatrices ont joué un rôle particulièrement important dans le développement de l'État social. Les principaux programmes sociaux (assurances accidents, vieillesse, chômage, maladie) ont en effet été développés dans un contexte politique dominé par le «bloc bourgeois» unissant les radicaux (aujourd'hui PLR), les catholiques 
conservateurs (PDC) et les principales associations patronales. Sa manifestation politique contemporaine la plus influente, l'Union Démocratique du Centre (UDC), est l'héritière du Parti des Artisans et Bourgeois (PAB) formé en 1921. Ce rapport de force favorable aux idées conservatrices, conjugué avec un système institutionnel relativement hostile au changement (fédéralisme, démocratie directe, extension tardive du suffrage aux femmes), est l'un des principaux responsables du développement tardif des programmes de l'État-providence en Suisse en comparaison avec les pays environnants. L'importance des valeurs conservatrices s'est manifestée par exemple dans l'introduction très tardive de l'assurance-maternité (2005), sa faible durée en comparaison internationale, ou l'intervention limitée des autorités publiques pour réduire le coût de l'accueil de la petite enfance pour les familles. L’idée que l'État ne doit pas interférer dans la sphère privée et qu'il appartient aux familles - en particulier aux femmes - de s'occuper des enfants en bas âge, était une justification importante pour les opposant.e.s à ces programmes.

Depuis les années 1990, on a pu constater un éloignement progressif du modèle conservateur traditionnel dans les politiques sociales, dans un contexte où le taux de participation professionnelle des femmes a sensiblement augmenté. L'un des développements les plus importants a été l'adoption d'une assurance-maternité, acceptée par référendum en 2004. Par ailleurs, les principales villes suisses ont augmenté le montant des subventions à l'accueil de la petite enfance et plusieurs cantons ont rendu le coût des garderies déductible des impôts. Dans le domaine de l'AVS, l'adoption du splitting et du bonus éducatif dans la $10^{\mathrm{e}}$ révision de 1995 a également contribué à introduire plus d'égalité entre les genres dans le système de protection sociale, rendant les femmes mariées moins dépendantes de leur conjoint quant au versement des rentes. Ces réformes peuvent être décrites comme une «recalibra- tion» de l'État social en Suisse dans la mesure où elles ont contribué à adapter les programmes de sécurité sociale aux changements du monde du travail et de la société. Elles ont souvent été sous-tendues par une alliance entre les partis de gauche (socialistes et verts) et la droite libérale (radicaux-libéraux) dans le but de faciliter la participation professionnelle des femmes, alors que les démocrates-chrétiens et l'UDC, adeptes d'une vision plus traditionnelle de la famille, et les syndicats, dont la base est encore majoritairement masculine, ont souvent été marginalisés.

Toutefois, les succès électoraux de l'UDC, qui défend une conception résolument conservatrice de la société, ont changé les rapports de force politiques qui ont sous-tendu ce mouvement de modernisation. En 2013, le parti a par exemple lancé une initiative - refusée par le peuple mais soutenue par le PDC - qui visait à introduire des exonérations d'impôts pour les familles qui choisissent de garder leurs enfants à la maison plutôt que de les placer en crèche. On peut aussi noter l'opposition de l'UDC à d'autres mesures de modernisation des politiques sociales, notamment celles visant à donner un rôle accru à l'État dans l'activation des demandeur.euse-s d'emploi, par exemple via des mesures de formation. Ainsi, le fait que l'UDC soit devenue la première force politique au Parlement fédéral semble avoir donné un nouveau souffle aux idées conservatrices dans les politiques sociales.

\section{Alexandre Afonso}

\section{Références}

Afonso, A. \& Papadopoulos, Y. (2015). How the populist radical right transformed Swiss welfare politics : from compromises to polarization. Schweizerische Zeitschrift für Politikwissenschaft / Revue Suisse de Science Politique, 21(4), 617-635. 
Häusermann, S. (2010). Reform opportunities in a Bismarckian latecomer : restructuring the Swiss welfare state. In B. Palier \& T. Alti (Eds.), A long good-bye to Bismarck? The politics of welfare reform in continental Europe (pp. 207-232) Amsterdam: Amsterdam University Press.

Mach, A. (2006). La Suisse entre internationalisation et changements politiques internes: législation sur les cartels et relations industrielles dans les années 1990. Zürich : Rüegger.

\section{Contrat de prestations}

Dans le sillage des réformes de type «nouvelle gestion publique» de nouvelles formes d'intervention étatique sont développées. Visant à une séparation plus stricte entre activités politiques ou stratégiques et activités administratives ou opérationnelles, les principes et outils de la nouvelle gestion publique favorisent le développement de nouvelles pratiques de délivrance des services publics. Aussi, assistons-nous à une décentralisation des activités étatiques, mais également à leur délégation et externalisation progressives, voire à leur privatisation. Autrement dit, la délivrance de prestations publiques n'est plus l'apanage des administrations publiques, qu'elles soient centrales (ou fédérales) ou locales (cantonales ou municipales). Ces phénomènes accompagnent un mouvement plus général dans la gestion publique : la gouvernance à distance.

En effet, de nouveaux outils de pilotage des organisations publiques sont apparus ces dernières années. Ainsi en est-il de la «gestion par mandat de prestations et enveloppe budgétaire». De façon synthétique, cette forme de gestion permet d'administrer à distance les organisations publiques ou partenaires des autorités publiques centrales ou locales. Les autorités politiques négocient avec les organisations publiques ou partenaires un contrat. Dans celui-ci sont stipulés un certain nombre d'objectifs à atteindre ou prestations à réaliser, des délais dans le cadre desquels ils doivent être délivrés, bien souvent également des indicateurs (de qualité et de quantité) permettant d'évaluer la réalisation «adéquate» des prestations publiques. Il est accompagné par une enveloppe budgétaire qui stipule les ressources (humaines et financières) qui sont allouées à la réalisation des prestations figurant dans le contrat. Les contrats de prestations représentent donc un dispositif gestionnaire central en lien avec la tendance actuelle en matière de délivrance des prestations publiques.

En effet, la mise en œuvre des politiques publiques a subi des transformations importantes. La production et la réalisation de prestations publiques sont bien souvent déléguées à des partenaires se situant en dehors du périmètre traditionnel de l'État. Des associations, des fondations, des organisations à but non lucratif, mais également des entreprises privées sont sollicitées par les autorités politiques en vue de mettre en œuvre des politiques publiques, notamment dans le domaine des politiques sociales. Les crèches, dans les municipalités suisses, sont le plus souvent gérées et administrées par des associations. La prise en charge des personnes âgées s'effectue souvent dans des structures privées, des sociétés anonymes d'intérêt public. L'insertion professionnelle est également un secteur dont les principaux acteurs en matière de mise en œuvre des prestations font partie du secteur associatif ou du secteur privé. La prise en charge des requérant.e.s d'asile en Suisse est notamment déléguée à une entreprise privée, qui s'occupe de gérer des dizaines de centres d'hébergement, centres de transit et structures d'aide d'urgence. Le champ de la prise en charge des addictions est principalement l'œuvre d'associations. Autant d'exemples, non exhaustifs, d'externalisation de services publics en Suisse. À cet égard, le contrat de prestations, en tant que dispositif de gestion mettant en relation autorités politiques (fédérales, cantonales et communales) et prestataires de services 
publics, permet le développement de telles délégations de service et donc la privatisation de larges pans des services publics.

En Suisse, la délégation, l'externalisation, ou le contracting out ne sont pas des phénomènes totalement nouveaux dans la mesure où des relations entre public et privé ont toujours existé. La séparation entre sphères publique et privée n'est pas absolue et l'hybridation organisationnelle est bien souvent la règle. Ceci étant, ces pratiques se sont développées depuis les années 1980 à la faveur d'une idéologie politique inspirée des théories économiques dites «néoclassiques» considérant le marché et la concurrence comme les seuls mécanismes de coordination des activités humaines permettant d'obtenir une efficience productive maximale. En Suisse, les institutions propres à notre démocratie fédéraliste, fortement décentralisées, constituent un terreau particulièrement favorable à l'implication de partenaires externes à l'administration publique dans la délivrance des prestations publiques. Même si, par ailleurs, tous les pays de l'OCDE sont concernés par cette dynamique, à des degrés divers bien sûr eu égard aux caractéristiques de leurs institutions politiques et à leur tradition administrative. Aussi, le renouvellement de la manière dont les prestations publiques sont délivrées aux usager-ère-s-client·e-s est soustendu par une logique de «marchandisation» et rendu possible par des pratiques «commerciales ».

La gouvernance à distance, rendue possible par la «contractualisation», se développe également par le truchement d'autres procédés. Ainsi, les partenariats public-privé (ou PPP) correspondent à une volonté de faire participer des organisations du secteur privé au développement d'infrastructures publiques d'ampleur. Des PPP sont à l'origine de la construction de certains stades de football en Suisse (Aarau et Genève notamment). De multiples infrastructures peuvent ainsi voir le jour via des PPP, comme un centre de chirurgie ambulatoire (à
Lausanne) ou encore une auberge de jeunesse (à Saas Fee). D'autres interventions étatiques peuvent contribuer à la création d'un «marché » dans des secteurs traditionnellement étatiques. Même dans les secteurs où la concurrence est a priori faible, il est possible de la stimuler. Il est ainsi possible de créer une concurrence, par exemple dans le domaine de l'éducation, en distribuant aux parents des vouchers (ou bons donnant droit à certains services) qu'ils peuvent faire valoir dans l'école de leur choix, qu'elle soit publique ou privée, en vue de la scolarisation de leur progéniture. Pour l'instant cette logique des vouchers en est à ses balbutiements et rares sont les pays à utiliser ces nouvelles techniques commerciales (certains États américains principalement) en vue de la fourniture des services publics. Dans d'autres cas, des systèmes de tarification standardisés peuvent agir comme incitatif. Dans le domaine hospitalier, le système de tarification «SwissDRG» (Swiss Diagnosis Related Groups) est un exemple de ce type d'aiguillon concurrentiel. Il correspond au système tarifaire national de rémunération des prestations hospitalières et attribue, de manière uniforme, une indemnisation des prestations hospitalières selon les forfaits par cas. Ce mécanisme tarifaire permet aux autorités politiques de comparer les établissements hospitaliers, en fonction de leur capacité à délivrer les prestations sur la base des tarifs prévus. Un «quasi-marché» est ainsi créé et une concurrence peut donc se développer entre établissements hospitaliers.

Le contrat de prestations est un dispositif de gestion qui permet ces nouvelles formes de délivrance des prestations publiques tout en favorisant une gouvernance à distance. Les critiques envers ces dynamiques sont également nombreuses. Elles soulignent, notamment, que ces dispositifs contribuent à l'augmentation des contrôles et à une bureaucratisation des activités des salarié·e-s. Elles évoquent le risque d'apparition d'une «indicatocratie» (ou gouvernance par les indicateurs) et soulignent que 
ce système de gestion s'inscrit dans une tradition de «taylorisation» des activités publiques, supprimant du coup une partie de l'autonomie professionnelle des salarié.e.s qui se trouvent en contact avec les usager-ère-s-client·e-s. Le contrat de prestations, ainsi que la nouvelle gouvernance qu'il favorise, est un dispositif managérial probablement appelé à être remplacé, comme tous les modes managériaux. En attendant, il est une pièce maîtresse de la nouvelle gestion publique.

\section{David Giauque}

\section{Références}

Dardot, P. \& Laval, C. (2009). La nouvelle raison $d u$ monde: essai sur la société néolibérale. Paris : La Découverte.

Giauque, D. \& Emery, Y. (2008). Repenser la gestion publique: bilan et perspectives en Suisse. Lausanne: Presses polytechniques et universitaires romandes.

Linhart, D. (2015). La comédie humaine du travail: de la déshumanisation taylorienne à la sur-humanisation managériale. Toulouse : Érès.

\section{Contrat de travail*}

Le contrat de travail individuel règle les droits et les obligations de l'employeur-euse et du-de la travailleur-euse. Le contrat de travail individuel de droit privé est régi par le Code des obligations (CO). Les rapports de travail auprès de la Confédération, des cantons et des communes, ainsi que d'organismes et d'établissements de droit public (universités, hôpitaux publics, voiries, etc.) sont, eux, réglés par les lois sur le personnel correspondantes (p.ex. pour le personnel de l'administration fédérale, par la loi sur le personnel de la Confédération). Certaines lois sur le personnel renvoient toutefois directement au $\mathrm{CO}$, ou alors il faut se référer à celui-ci en l'absence de telle ou telle disposition (p.ex. concernant le certificat de travail).

Le droit du contrat de travail est fondé sur le principe de la liberté contractuelle: les parties peuvent convenir du début, du contenu et de la fin du contrat. Le droit des obligations sert de cadre. Il contient selon les termes des normes d'application dispositive et des normes d'application obligatoire. Les parties $\mathrm{au}$ contrat peuvent déroger aux premières mais pas aux deuxièmes. Mentionnons encore certaines normes d'application relativement contraignante dont il peut être dérogé, dans des conventions individuelles, uniquement en faveur des travailleur-euse-s (et non pas en faveur des employeur.euse-s).

Le contrat de travail n'est soumis à aucune prescription de forme légale, à l'exception du contrat d'apprentissage. Un contrat de travail individuel peut donc être passé oralement, pour une durée déterminée ou indéterminée. Le contrat de durée déterminée prend fin à l'expiration de la période convenue et ne doit pas être résilié. Si un tel contrat est reconduit tacitement après expiration du terme convenu, il est réputé continuer pour une durée indéterminée. Si plusieurs contrats de durée déterminée se succèdent, on parle de contrats de travail en chaîne. Dans la pratique, les contrats en chaîne sont assimilés à un contrat unique de durée indéterminée pour prévenir le contournement des dispositions de protection en fonction de la durée du rapport de travail. Un contrat de travail de durée indéterminée peut être résilié en tout temps par chacune des parties, sans autre forme de procès, à moins que le contrat ne prévoie la forme écrite. Sur demande, la partie qui résilie le contrat doit motiver sa décision par écrit.

Lors de la résiliation d'un contrat de travail des délais de congé légaux et contractuels doivent être respectés. Si, pour des motifs importants, la continuation des rapports de travail jusqu'à l'expiration du délai de congé ordinaire s'avère insupportable, une partie 
peut mettre fin à la relation de travail avec effet immédiat. Pendant des périodes définies par la loi, notamment pendant la grossesse et les seize semaines après l'accouchement, ou en cas d'incapacité de travail pour une durée limitée, le congé est réputé nul ou est ajourné.

Nonobstant le principe de la liberté de résiliation, le congé abusif est susceptible de sanction. Si, par exemple, l'employeur-euse licencie un.e collaborateur-trice parce que cette personne a fait valoir de bonne foi certaines prétentions découlant du contrat (congé donné par vengeance), le-la collaborateur-trice en question peut se défendre en invoquant un abus de droit. Mentionnons encore certaines limites matérielles au licenciement de travailleur.euse-s qui s'engagent syndicalement ou qui représentent le personnel dans l'entreprise, ainsi qu'en cas de licenciement collectif. Même s'il est abusif, le licenciement est valable, mais la partie licenciée a droit à une indemnisation financière, fixée à six salaires mensuels au maximum. De facto, en cas de litige, les tribunaux prononcent une indemnisation de deux à trois salaires mensuels seulement. En Suisse, ni les représentant.e.s des travailleur.euse.s ni les représentant·e·s des autorités ne sont impliquéee.s dans les cas de résiliation.

L'employeur-euse doit verser au-à la travailleur·euse le salaire convenu, usuel ou fixé par un contrat-type ou une convention collective. En Suisse, la fixation du salaire est affaire de négociation entre parties, à l'exception de quelques rares limites de salaires minimum. Pour rémunérer la prestation du travail, il est généralement convenu d'un salaire mensuel ou à l'heure, parfois assorti de composantes flexibles comme une participation au chiffre d'affaires ou au bénéfice, ou une prime pour l'atteinte d'objectifs donnés. Si l'employeur-euse ne paie pas entièrement le salaire, le-la travailleur.euse peut refuser de travailler et engager la poursuite. Cependant, il ou elle ne pourra démissionner avec effet immédiat qu'à certaines conditions.
Le principe général «pas de travail, pas de salaire » s'applique. L'employeur-euse doit toutefois continuer de payer le salaire si le-la travailleur-euse est empêché·e de travailler sans faute de sa part pour des causes inhérentes à sa personne (maladie, accident, accomplissement d'une obligation légale), mais pas en cas d'empêchement pour des causes externes (problèmes de transports, intempéries, etc.). L'obligation de continuation de salaire existe uniquement si les rapports de travail de durée déterminée ont été conclus pour plus de trois mois ou ont duré plus de trois mois au moment de la survenance de l'incapacité de travail. Le $\mathrm{CO}$ se borne à disposer que la continuation du salaire s'élève à trois semaines au minimum pour la première année de service. La jurisprudence a dû admettre une durée appropriée, en fonction de la fidélité à l'entreprise; elle l'a fixée à six mois, même pour plus de vingt ans de service.

Outre ses obligations financières, l'employeur-euse a aussi un devoir d'assistance envers ses employé·e·s. Il ou elle doit préserver leurs intérêts légitimes et s'abstenir de tout acte susceptible de nuire à ces intérêts. De nombreux aspects du devoir d'assistance sont mentionnés dans la loi: protection de la vie, de la santé, de la personnalité et de l'intégrité sexuelle, protection des données, égalité entre femmes et hommes, obligation d'accorder des congés, des vacances et des congés spécifiques, obligation de protéger le patrimoine, obligation de remettre un certificat de travail, obligation d'informer sur les principaux éléments du rapport de travail, etc.

Pour sa part, le-la travailleur-euse est tenu.e d'exécuter le travail dont il est chargé·e avec le soin requis et de préserver les intérêts de son employeur-euse en toute bonne foi. Plusieurs dispositions légales concrétisent ce devoir général de diligence et de fidélité du·de la travailleur-euse, comme l'obligation de garder le secret, l'obligation de rendre compte et de restituer, ainsi que l'obligation de faire des 
heures supplémentaires. Celles-ci doivent être compensées par un congé ou rémunérées avec une majoration de $25 \%$, à moins qu'il en ait été convenu autrement.

Comparé à celui d'autres pays, le droit suisse du contrat de travail a ceci de particulier que ses dispositions s'appliquent en principe à tous les contrats de travail, indépendamment du statut et du salaire des travailleur.euse-s. Il ne connaît pas de règles spécifiques pour les «faux fausse» indépendant·e.s. Les rapports de travail de ceux-ci ou de celles-ci sont considérés comme des contrats de travail s'il existe un rapport de subordination et s'ils ne sont pas attribuables à un autre type de contrat comme le mandat ou le contrat de services.

La grande liberté de résiliation dans le droit suisse du travail est régulièrement critiquée. Il est actuellement question d'améliorer la protection contre le licenciement pour les lanceur-euse-s d'alerte et les travailleur-euse-s engagéee.s syndicalement. Il est en outre prévu de relever de six à douze mois de salaires mensuels l'indemnisation à verser par l'employeur-euse en cas de licenciement abusif, afin de renforcer le caractère dissuasif de la sanction. Plusieurs interventions parlementaires plaident pour une amélioration de la situation des travailleur·euse·s plus âgé·e·s. S'ils ou elles ne sont pas touché·e·s davantage par des licenciements que les travailleur.euse-s plus jeunes, ils ou elles mettent nettement plus de temps à retrouver un nouvel emploi.

La législation sur le travail est coresponsable, en Suisse, de la difficile conciliation entre profession et famille. Elle ne prévoit notamment aucun droit à une réduction du taux d'occupation pour des raisons familiales.

\section{Sabine Steiger-Sackmann}

\section{Références}

Vischer, F. \& Müller, R. A. (2014). Der Arbeitsvertrag (4., erw. Aufl.). Basel : Helbing Lichtenhahn.
Wyler, R. \& Heinzer, B. (2014). Droit du travail

( $3^{e}$ éd.). Berne : Stämpfli.

\section{Contribution d'assistance (vie autonome avec assistance personnelle)*}

L'assistance, lorsqu'elle est suivie de l'épithète «personnelle» ou «autonome», désigne les prestations d'aide que les personnes en situation de handicap déterminent elles-mêmes, autrement dit les prestations qu'elles choisissent de demander et dont elles définissent les modalités (nature de l'aide, prestataire, lieu, durée, forme et moment). Elles deviennent ainsi des personnes agissantes, assumant la responsabilité et le contrôle de leur vie. Les personnes en situation de handicap ont besoin d'assistance pour tout ce qu'elles ne peuvent pas faire elles-mêmes en raison de leur handicap : se laver et s'habiller, faire le ménage, pour les loisirs, l'activité professionnelle, la formation et la formation continue, la garde d'enfants, etc. L'assistance peut consister à guider, exécuter et surveiller. Elle vise à compenser le handicap dans la mesure du possible et peut être envisagée pour et par toute personne en situation de handicap, indépendamment de la nature de son handicap.

L'assistance ainsi comprise se distingue fondamentalement de l'aide déterminée par des tiers prévue dans les formes d'aide et de soins classiques, où ce ne sont pas les personnes concernées elles-mêmes qui déterminent leurs besoins et la manière d'y répondre mais, du moins dans une large mesure, les personnes qui les accompagnent et les soignent.

Pour que l'on puisse parler d'assistance personnelle, la personne qui la demande doit avoir certaines compétences fondamentales (qui peuvent aussi être déléguées à une personne de référence au sein de la famille ou à 
une personne de confiance de l'équipe d'assistance): 1) compétence organisationnelle: la personne en situation de handicap planifie les engagements ; 2) compétence d'instruire: elle détermine les prestations souhaitées et instruit les prestataires en conséquence; 3) compétence en matière de gestion de personnel : elle embauche elle-même les prestataires d'aide et, si besoin, met fin aux rapports de travail ou à la relation contractuelle ; 4) compétence financière: elle dispose de moyens financiers suffisants et gère les comptes de façon indépendante avec les prestataires.

Le système de l'assistance personnelle est étroitement lié à la revendication d'une vie autonome. Inspiré par l'Independent Living Movement, fondé en 1970 aux États-Unis, le mouvement s'est d'abord développé en Allemagne avant de gagner la Suisse, qui a vu l'ouverture en 1996 à Zurich du Zentrum für Selbstbestimmtes Leben. Vivre de manière autonome signifie non pas être indépendant d'autrui, mais exercer son droit de décider librement et de garder le contrôle sur sa vie. Pour de nombreuses personnes en situation de handicap, cela n'est possible que grâce à l'assistance personnelle.

Pro Infirmis a mené les premiers projets pour une vie autonome avec assistance personnelle vers l'an 2000 dans les cantons de Vaud et de Zurich. Les représentants de la prise en charge conventionnelle réagirent d'abord avec scepticisme à cette nouvelle manière de soutenir les personnes handicapées. L'habitude de voir celles-ci comme des personnes dans le besoin et en demande, était solidement ancrée - et voilà qu'elles prenaient de l'assurance et devenaient à leur tour employeur.euse-s. En 2006, à la suite de laborieux débats parlementaires, l'Office fédéral des assurances sociales lança le projet pilote Budget d'assistance. Rebaptisée «contribution d'assistance» et revue à la baisse, cette prestation fut intégrée dans la législation ordinaire le $1^{\mathrm{er}}$ janvier 2012 dans le cadre de la $6^{\mathrm{e}}$ révision de l’AI.
Les pays européens ont connu une évolution similaire, avec des projets pilotes privés ou publics débouchant ensuite sur l'adoption de mesures. Mais chez eux, tout a commencé bien plus tôt. La Suède a mené un projet pilote d'assistance autonome en 1987 et la réforme de l'assistance suédoise entra en vigueur en 1994 déjà. Les solutions adoptées sont très différentes d'un pays européen à l'autre. On trouve ainsi des systèmes d'assistance avec ou sans prise en compte du revenu ou de la fortune, avec fixation du besoin d'assistance minimal ou maximal, avec un budget global, des limitations régionales, des plafonds et des seuils de rémunération à l'heure maxima très différents, des prestataires agréés, etc.

En Suisse, la contribution d'assistance est une prestation de l'assurance-invalidité (AI), que les personnes en situation de handicap peuvent solliciter pour financer l'aide dont elles ont besoin, à condition qu'elles aient droit à une allocation pour impotent·e.s de l'AI, et qu'elles vivent à la maison. À l'âge de la retraite, la situation acquise est maintenue. La prestation est la même dans tout le pays. Le revenu et la fortune des bénéficiaires ne sont pas pris en compte, contrairement à ce qui est le cas pour les prestations complémentaires et l'aide sociale. La contribution d'assistance n'est pas versée automatiquement, elle doit être demandée. Qui la demande doit être capable d'exercer ses droits civils. Les personnes mineures et les personnes placées sous une curatelle de portée générale ou de coopération doivent remplir encore d'autres conditions (suivre une scolarité ordinaire ou une formation, travailler sur le marché ordinaire de l'emploi, tenir le ménage ou avoir droit à un supplément pour soins intenses de l'AI). La contribution d'assistance est censée favoriser l'autonomie et la responsabilité individuelle.

Moyennant une évaluation des besoins faite par l'AI, le besoin d'assistance personnelle est calculé en heures. L'AI fixe des plafonds en fonction du montant de l'allocation pour 
impotents. Ainsi, une personne percevant une allocation pour impotence grave peut obtenir un maximum de 8 heures d'assistance par jour pour les actes ordinaires de la vie, la tenue du ménage et l'organisation des loisirs. Pour les personnes ayant besoin d'aide la nuit, un forfait supplémentaire est accordé. La contribution d'assistance doit servir uniquement à payer les prestataires qui sont employé.e-s par les bénéficiaires d'assistance avec un contrat de travail (modèle de l'employeur-euse). Elle ne peut donc pas être utilisée pour rémunérer des services fournis sur mandat. En outre, les parents en ligne directe et les partenaires (conjugaux) ne peuvent pas être employé.e-s.

La contribution d'assistance participe de manière décisive à l'application de la Convention de l'ONU relative aux droits des personnes handicapées, à laquelle la Suisse a adhéré en avril 2014 en tant que 144 état. En vertu de l'article 19 de cette convention («Autonomie de vie et inclusion dans la société»), les personnes en situation de handicap doivent pouvoir vivre en société avec la même liberté de choix et jouir de la même participation et intégration à la société que toutes les autres personnes. Il s'agit donc non pas d'un droit spécial mais du droit fondamental à l'égalité des chances. Toute personne qui veut profiter de ce droit doit pouvoir bénéficier de l'assistance si elle a besoin d'aide dans la vie quotidienne en raison de son handicap. Au-delà du fait qu'elle soit essentielle pour permettre à la personne de vivre chez soi, l'assistance favorise l'exercice d'une activité lucrative sur le premier marché du travail et promeut ainsi l'intégration dans le monde du travail.

À l'avenir, il s'agira de continuer à adapter la contribution d'assistance aux besoins des personnes en situation de handicap afin de mettre en œuvre pleinement les prescriptions de la Convention de l'ONU relative aux droits des personnes handicapées. De nombreuses personnes en situation de handicap sont aujourd'hui en effet exclues de cette prestation en raison d'obstacles administratifs majeurs (procédures de demande et de décompte complexes, limitation au modèle de l'employeur-euse) et ne peuvent donc pas mener une vie autonome. En outre, la contribution d'assistance ne permet pas toujours de couvrir l'intégralité des besoins à cause des plafonds et d'une évaluation rigide des besoins qui tient peu compte des particularités inhérentes au handicap. Les personnes concernées doivent ainsi, avec beaucoup d'efforts, trouver des financements supplémentaires, par exemple faire les démarches pour obtenir des prestations complémentaires. Le libre choix du logement et du travail est lui aussi restreint. Pour donner un exemple: la contribution d'assistance est diminuée de moitié si la personne fréquente un atelier protégé. Une autre question qui demande à être clarifiée au niveau politique concerne les proches dont la contribution à l'assistance n'est actuellement pas rétribuée.

\section{Simone Leuenberger}

\section{Références}

European Network on Independent Living (2014). Factsheet: Personal Assistance. http://enil.eu/ wp-content/uploads/2016/06/FAQ_Personal_ Assistance.pdf

Huainigg, F.-J. (2008). Auch Schildkröten brauchen Flügel : Ein herausforderndes Leben. Wien : Ueberreuter.

Pro Infirmis en collaboration avec Inclusion Handicap (Éd.). Le guide sur les questions juridiques soulevées par le handicap. Handicap - que faut-il savoir? Assistance. https://www.proinfirmis.ch/fr/ guide-juridique.html.

\section{Convention collective de travail ${ }^{*}$}

Une convention collective de travail (CCT) est un accord écrit signé entre une ou plusieurs associations de travailleur.euse-s, d'une part, et un ou plusieurs employeur-euse-s ou une ou plusieurs associations d'employeur.euse-s, 
d'autre part, ayant pour objet la réglementation des conditions de travail et des rapports entre les parties. Le terme allemand Gesamtarbeitsvertrag, issu de la révision du Code suisse des obligations de 1911, n'est utilisé qu'en Suisse alémanique. Dans un contexte international, le terme Tarifvertrag est privilégié. En Suisse, les termes accord, contrat collectif ou convention étaient également utilisés. Selon le champ d'application, une distinction est faite entre les conventions collectives d'entreprise, locales, régionales et nationales. Des conventions-cadres règlent les questions fondamentales et s'en remettent pour le reste aux conventions collectives locales ou aux contrats de travail individuels. Le champ d'application de ces derniers ne doit pas déroger aux normes de la CCT.

Constituant, avec les lois, les principaux instruments du droit du travail, les conventions collectives de travail contiennent des dispositions normatives sur les salaires, le temps de travail et d'autres conditions de travail, ainsi que des dispositions relevant du droit des obligations sur les droits et obligations réciproques des parties, comme le respect de la paix du travail. En raison de l'absence de dispositions normatives, l'accord de «paix du travail » signé en 1937 dans l'industrie de la métallurgie et des machines n'est pas une CCT. Deux courts articles de loi ajoutés à la révision du Code suisse des obligations de 1911 ont permis d'introduire une innovation fondamentale dans le droit suisse du travail. La formulation ouverte a donné aux parties contractantes une grande marge de manœuvre. Elles pouvaient, dans une large mesure, réglementer les conditions de travail au-delà d'une consécration formelle au niveau législatif, c'est-à-dire qu'elles disposaient d'un instrument de droit du travail pour formuler la politique sociale au plan privé. Pour conclure une CCT, les parties contractantes doivent être indépendantes; par conséquent, du côté des travailleur-euse-s, seul un syndicat libre est apte à négocier, une association interne à l'entreprise (commission des travailleur·euse-s, commission du personnel) n'est pas admise.

En revanche, la possibilité d'étendre le champ d'application d'une CCT à l'ensemble d'un secteur professionnel ou économique ne vint que tardivement. Elle ne reçut une base juridique qu'en 1941 par un décret fédéral urgent, qui fut prolongé jusqu'à l'adoption de la loi fédérale de 1956 permettant d'étendre le champ d'application de la convention collective de travail (LECCT). Dans la pratique, la loi fut rarement appliquée pendant longtemps, si ce n'est dans l'hôtellerie et la restauration ainsi que dans le secteur principal de la construction. Les mesures d'accompagnement autorisant la libre circulation des personnes dans l'Union européenne (UE) ont permis de simplifier l'extension du champ d'application en 2004 en vue de prévenir une sous-enchère salariale. Depuis lors, celle-ci est plus populaire que jamais et s'est étendue à de nouveaux secteurs de l'économie, tels que la location de services et l'industrie du nettoyage.

Les premières conventions collectives ont vu le jour timidement au milieu du XIX ${ }^{\mathrm{e}}$ siècle, mais leur importance est restée très limitée sur le plan économique global. C'est seulement au début du XXe siècle que le nombre des conventions collectives s'est accru, principalement à la suite d'une vague de grèves entre 1905 et 1907. Le tournant décisif dans l'industrie d'exportation s'est produit vers la fin de la Seconde Guerre mondiale, notamment après que les entreprises chimiques de la région de Bâle ont été les premières à abandonner la résistance au début de 1945. La Suisse n'a donc pas été l'un des pays pionniers de la CCT, bien que sa signification symbolique joue un rôle idéologique important. En particulier, les dispositions relatives au droit des obligations ont été développées et souvent déplacées de la fin vers le début de la CCT. Les accords de partenariat social entre travailleur.euse-s et employeur-euse-s ont largement été considérés comme la meilleure 
alternative à la législation. Le nombre de CCT a augmenté jusqu'au début des années 1960, puis a stagné avant de diminuer considérablement après 1966 en raison d'une extension du rayon d'action des accords.

Ce n'est que dans les années 1970 que les employéee-s en bénéficièrent également de plus en plus ; auparavant, les CCT concernaient presque exclusivement les ouvrières et ouvriers. Dans la seconde moitié du XXe siècle, le taux de couverture a toujours fluctué autour de $50 \%$ de la population active, plaçant la Suisse dans les derniers rangs de l'OCDE. Le contenu des CCT a été pendant longtemps enrichi et aux questions du salaire et du temps de travail vinrent s'ajouter d'autres conditions de travail telles que le maintien du salaire en cas de maladie, de maternité ou de service militaire, l'inclusion dans les caisses de pension, les congés, les jours fériés, les frais professionnels, la protection de la santé, l'assurance, les cotisations sociales des personnes n'appartenant pas à une organisation, etc. Souvent, les CCT ont précédé la législation sociale en termes de contenu ou du moins en termes quantitatifs, par exemple pour l'organisation du temps de travail depuis la deuxième moitié du XXe siècle. Malgré de nombreuses initiatives parlementaires et plusieurs initiatives populaires, la norme juridique ne fut abaissée qu'à l'occasion de la loi sur le travail de 1964, d'abord de 48 à 46 heures par semaine, puis en 1975 à 45 heures, valeur encore valable aujourd'hui. Au niveau de la CCT, les normes sont dans certains cas nettement inférieures, par exemple 40 heures dans l'industrie pharmaceutique et chimique bâloise et dans les industries horlogère et microtechnique, ou 42 heures dans la location de services, dans la branche du nettoyage en Suisse alémanique, à la poste, l'industrie graphique et dans l'hôtellerie-restauration (à l'exclusion du travail saisonnier et des petites entreprises). Cependant, certaines CCT fixent le temps de travail annuel - par exemple 2080 heures dans l'industrie des machines, des équipements électriques et des métaux ou 2112 heures dans l'industrie principale de la construction - ou introduisent des mesures de compensation de sorte que la comparaison directe est difficile. Néanmoins le temps de travail est généralement inférieur à la loi.

Une évolution contraire se dessine ensuite durant les années 1990. Avec le déploiement du néolibéralisme, les salaires et les conditions de travail ont été de plus en plus déclarés comme étant le résultat du libre jeu du marché du travail. Les CCT ont perdu de l'importance pour de nombreux-ses employeur·euse-s. La densité de la réglementation des CCT existantes a de nouveau diminué. Par exemple, les négociations salariales ont été transférées du niveau sectoriel au niveau de l'entreprise et l'indemnité pour inflation n'était plus déterminée automatiquement mais par la voie de la négociation. La non-diminution du nombre de personnes soumises à une CCT est due en grande partie au fait que les entreprises qui étaient auparavant soumises aux lois sur le personnel en tant que parties de l'administration publique ont été externalisées et disposent désormais d'accords contractuels. Depuis la fin des années 1990, mais surtout depuis le début du siècle, l'importance des CCT a de nouveau augmenté, notamment parce que les travailleur.euse-s et les employeur·euse-s voulaient se protéger des effets de la libre circulation des personnes dans l'UE.

\section{Bernard Degen}

\section{Références}

Prince, J.-C. (1994). L'impact des conventions collectives de travail en Suisse. Zurich: Schulthess. Union syndicale suisse (Éd.). (2014). Droit collectif $d u$ travail. Bâle: Helbing Lichtenhahn. 


\section{Convention de l'ONU relative aux droits des personnes en situation de handicap*}

La Convention des Nations Unies relative aux droits des personnes en situation de handicap $(\mathrm{CDPH})$ est un traité de droit international adopté le 13 décembre 2006 par l'Assemblée générale de l'ONU. Son élaboration par un comité ad hoc créé en 2001 repose sur la reconnaissance de l'insuffisance de la protection des personnes en situation de handicap par les traités existants en matière de droits humains. Les droits humains civils, politiques, économiques, sociaux et culturels généraux devraient donc être concrétisés et précisés en fonction des besoins spécifiques des personnes en situation de handicap. La mesure dans laquelle la CDPH inclura, le cas échéant, aussi de nouveaux droits humains, fait l'objet de discussions dans la littérature juridique.

Après sa ratification par la Suisse en avril 2014, la CDPH est entrée en vigueur le 15 mai 2014, devenant ainsi partie intégrante du droit suisse. Son objet est de «promouvoir, protéger et assurer la pleine et égale jouissance de tous les droits de l'homme et de toutes les libertés fondamentales par les personnes en situation de handicap et de promouvoir le respect de leur dignité intrinsèque». Les bases juridiques et les structures sociales qui désavantagent les personnes en situation de handicap devraient être systématiquement vaincues, afin qu'elles puissent participer à tous les domaines de la vie sociale sur un pied d'égalité et de manière autonome avec les non-handicapé.e.s.

L'objet de la CDPH est concrétisé par huit principes généraux qui assurent une continuité conceptuelle. Le premier de la liste est le principe d'autonomie, étroitement lié à celui du respect de la dignité humaine et incluant la liberté de faire ses propres choix. En outre, la participation tout comme l'intégration pleines et effectives à la société s'inscrivent comme des thèmes centraux.

Le terme d'«intégration» correspond au terme d'«inclusion» dans la version anglaise, qui est également un concept clé de la $\mathrm{CDPH}$. D'autres principes de la CDPH concernent la garantie de la non-discrimination, de l'égalité des chances et de l'accessibilité, ainsi que du respect de la diversité. Enfin, la CDPH doit être lue à la lumière de l'égalité entre femmes et hommes, et du respect du développement des enfants en situation de handicap et de la préservation de leur identité.

En ce qui concerne la compréhension du handicap, un véritable changement de paradigme s'opère au sein de la $\mathrm{CDPH}$ : pour la première fois, un modèle de handicap fondé sur les droits humains est codifié, remplaçant ainsi le modèle médical, qui considère le handicap comme un phénomène individuel déficitaire et propage des mesures médico-thérapeutiques ou éducatives spéciales. Dans le texte du traité, cette nouvelle notion de handicap apparaît dans le préambule ainsi que dans l'article précité définissant les buts de la convention.

Avec la ratification de la CDPH, les États signataires s'engagent à faire rapport tous les quatre ans sur l'état de sa mise en œuvre. Sur la base notamment des rapports nationaux et des rapports parallèles de la société civile concernée, le Comité onusien des droits des personnes en situation de handicap, en tant qu'organe d'experts, adresse des recommandations à l'État signataire. Si celles-ci ne constituent pas une décision de justice juridiquement contraignante, elles se distinguent aussi clairement des déclarations diplomatiques non contraignantes. Faisant partie intégrante de la jurisprudence du Comité, elles contiennent en outre une première interprétation des droits individuels. Le Protocole facultatif à la Convention des Nations Unies relative aux droits des personnes en situation de handicap, qui peut être ratifié sur une base volontaire, prévoit une procédure de plainte individuelle et d'enquête 
spéciale en tant que mécanisme de surveillance supplémentaire.

L'importance de la CDPH pour la Suisse tient d'abord au fait qu'elle établit une distinction substantielle entre l'interdiction fondamentale de la discrimination et l'obligation correspondante d'adopter des mesures positives dans la Constitution fédérale. De plus, en sa qualité de traité de droit international fondé notamment sur les droits humains, la $\mathrm{CDPH}$ prime le droit national suisse. En conséquence, la Suisse est tenue de prendre toutes les mesures législatives, administratives et autres mesures appropriées, favorisant la mise en œuvre de la $\mathrm{CDPH}$, et de modifier ou d'abroger les lois, ordonnances, habitudes et pratiques qui sont contraires à la Convention. La protection et la promotion des droits des personnes en situation de handicap comme missions transversales de l'État s'appliquent également à tous les concepts et programmes politiques. La Confédération, les cantons et les communes étant assujettis aux obligations de la $\mathrm{CDPH}$, ils ne peuvent donc se contenter de créer de nouvelles bases juridiques ou une politique en faveur des personnes en situation de handicap qui ne concerne que le droit des assurances sociales. Qui plus est, les personnes en situation de handicap et leurs organisations doivent être étroitement consultées et activement impliquées dans l'élaboration et la mise en œuvre de la législation et des politiques visant à concrétiser la $\mathrm{CDPH}$.

En théorie comme en pratique, la Suisse est tenue, en vertu de la Convention des Nations Unies relative aux droits des personnes en situation de handicap, de transposer immédiatement ses obligations d'abstention et de protection, ainsi que certains aspects de ses obligations de service concernant les droits économiques, sociaux et culturels des personnes en situation de handicap. Elle devra remplir progressivement l'intégralité des autres obligations de service, en utilisant pleinement les ressources disponibles. Par consé- quent, au moins tous les droits de la CDPH dont découle une obligation directe - à l'exception des mandats de légiférer - doivent être considérés comme directement exécutoires devant les tribunaux suisses. Indépendamment de cela, toute base juridique existante doit être interprétée à la lumière de la CDPH.

N'ayant pas encore ratifié le Protocole facultatif, la Suisse n'a à répondre devant le Comité des droits des personnes en situation de handicap que dans le cadre de la procédure d'élaboration des rapports par les États. Elle a présenté son premier rapport en juin 2016. Celui-ci se concentre clairement sur les bases juridiques fédérales et, outre les dispositions cantonales, néglige notamment la question de savoir dans quelle mesure celles-ci ont effectivement un impact sur la mise en œuvre de la CDPH. En juin 2017, les organisations suisses représentant les personnes handicapées, membres de l'organisation faitière Inclusion Handicap, ont soumis un rapport, incluant des critiques et des propositions d'action, sur l'état de la mise en œuvre de la CDPH au Comité des droits des personnes en situation de handicap. Inclusion Handicap a notamment critiqué l'absence d'une politique globale relative aux personnes en situation de handicap en Suisse et le manque de protection juridique de celles-ci contre la discrimination par des particuliers dans le cadre des relations de travail et de l'accès aux services. Sur cette base le Comité a formulé ses recommandations à la Suisse fin 2019. Il est à espérer qu'elles serviront de catalyseur pour la mise en oeuvre de la $\mathrm{CDPH}$.

\section{Caroline Hess-Klein}

\section{Références}

Degener, T. \& Diehl, E. (Hrsg.) (2015). Handbuch Behindertenrechtskonvention: Teilhabe als Menschenrecht - Inklusion als gesellschaftliche Aufgabe. Bonn: BpB Bundeszentrale für politische Bildung. 
Hess-Klein, C. (2017). Le cadre conventionnel et constitutionnel du droit de l'égalité des personnes handicapées. Dans F. Bellanger \& T. Tanquerel (Éd.), L'égalité des personnes handicapées: principes et concrétisation (pp. 9-100). Genève : Schulthess.

Schefer, M. \& Hess-Klein, C. (2013). Droit de l'égalité des personnes handicapées. Berne: Stämpfli.

\section{Corporatisme* $^{*}$}

On appelle corporatisme la collaboration entre l'État et des groupements d'intérêts fonctionnels (syndicats, organisations d'employeur·euse-s, fédérations paysannes) en vue d'élaborer et d'appliquer des politiques privées et publiques concertées. Il peut s'agir de politiques en matière de formation professionnelle, de politiques sociales ou fiscales (elles sont alors publiques) ou de politiques salariales des syndicats et de politiques en matière de prix et d'emploi développées par les organisations d'employeur-euse-s (qui sont, elles, privées). Les politiques sont coordonnées entre elles (concertées). Par exemple, les syndicats pourront se déclarer disposés à revoir leurs revendications salariales à la baisse pour autant que l'État renforce ses efforts sur le plan de la politique sociale et que les entreprises s'emploient activement à préserver, voire créer de l'emploi. Cette collaboration intervient tant au moment de l'élaboration des politiques (les acteur-trice-s concerné.e-s se consultent et participent) que de leur mise en œuvre. Un exemple connu à ce sujet est le transfert de fait des tâches d'exécution de la politique d'État lorsque les fédérations paysannes aident à constituer l'agriculture nationale. Le terme de «partenariat social» est souvent employé comme synonyme du corporatisme, soulignant tout particulièrement la paix sociale inhérente à ce dernier, qui supprime généralement la nécessité de recourir à des procédures conflictuelles (grèves, lock-outs, manifestations). Le contraire du corporatisme est le pluralisme. On parle de défense des intérêts pluraliste lorsque certains groupes d'intérêts exercent une influence unilatérale sur l'État, sans se concerter entre eux et sans assumer de missions de mise en œuvre de la politique qui allègent la charge de l'État. Le lobbyisme est quant à lui une forme d'influence qu'exercent des groupes d'intérêts sur certains acteurs politiques. Il se pratique en principe tant dans les systèmes pluralistes que corporatistes, bien que plus rarement dans ce dernier.

Le corporatisme suisse est né au XIXe siècle. À cette époque, l'État fédéral suisse avait besoin de statistiques pour bien fonctionner, mais manquait des compétences et des ressources nécessaires pour les obtenir lui-même. Il a dès lors financé le secrétariat de l'Union suisse du commerce et de l'industrie (Vorort) afin que celui-ci recueille et traite ces données pour son compte. De même, il a financé les secrétariats de l'Union des arts et métiers, des syndicats et de la fédération paysanne en échange de services. L'État a poursuivi ce fonctionnement jusqu'au lendemain de la Seconde Guerre mondiale. C'est entre la Première Guerre mondiale et la fin de la Seconde Guerre mondiale que l'intégration des groupements d'intérêts au sein de l'État suisse a pris son essor. À cet égard, la paix du travail conclue en 1937 entre les syndicats et le patronat afin de chercher une autre manière que la grève pour mener des négociations collectives est une étape importante. Ce processus d'intégration s'est vu couronner par les articles relatifs à l'économie ajoutés à la Constitution suisse en 1947. Les groupements d'intérêts avaient désormais le droit d'être consultés par l'État qui, de son côté, pouvait compter sur eux pour la mise en œuvre de ses politiques. Cette position de force des groupements d'intérêts est restée incontestée jusque dans les années 1980. Par la suite, leurs chances d'influencer les politiques ont commencé à s'amoindrir : les changements sociétaux et économiques en cours 
leur posaient des problèmes d'organisation. Les syndicats subissaient les conséquences de la désintégration des structures socioculturelles, de l'évolution de la société industrielle vers une société de services et de la tendance croissante à l'individualisme. Les travailleur-euse-s industriel-le-s traditionnel-le.s, avec leur attitude fondamentalement positive à l'égard de l'auto-organisation syndicale, ont largement disparu. Les nouveaux emplois dans le secteur des services privés ont été difficiles à organiser pour les syndicats et l'érosion de la conscience d'un destin collectif, en tant que salarié·e, a ébranlé la volonté d'adhésion aux associations. Les organisations d'employeur-euse-s ont été confrontées aux conséquences de l'internationalisation des marchés des capitaux et des biens. Les intérêts nationaux ont moins été pris en compte et la volonté de parvenir à un équilibre et à un compromis entre les secteurs économiques s'est émoussée. Les organisations d'employeur-euse-s ne pouvaient ainsi plus compter sur la même volonté de suivre le mouvement des chef-fe-s d'entreprise, qui ont davantage opté pour un lobbying spécifique à l'entreprise. La littérature fait également état du processus d'européanisation, qui a de plus en plus transféré les décisions du domaine préparlementaire au domaine parlementaire et qui a partiellement dissous un bastion de l'influence associative: les commissions préparlementaires avec une forte représentation des groupes d'intérêts. Il y a eu en outre une politique budgétaire prudente, qui a réduit la marge de manœuvre politique dans les cycles de négociations entre l'État et les associations, ainsi qu'une plus grande transparence du processus politique grâce aux critiques des médias, ce qui a entravé les négociations et compromis confidentiels entre les acteur-trice-s à huis clos. De nombreuses réalisations ont été attribuées au corporatisme suisse. Citons notamment la large absence de conflits de travail ouverts, les bons rapports des entreprises avec leur maind'œuvre et la tentative de créer le plein emploi pour les travailleur-euse-s suisses. Les critiques ont attiré l'attention sur les rigidités institutionnelles et l'hostilité aux réformes du système corporatiste.

La recherche établit une distinction entre le corporatisme libéral et le corporatisme social. L'État a un rôle important à jouer dans le corporatisme social, par exemple en compensant les associations collaborantes par des politiques fiscales et sociales. Les syndicats sont ici égaux, voire supérieurs aux organisations patronales en termes d'influence. L'Autriche est un parfait exemple de corporatisme social. Le corporatisme libéral, quant à lui, se caractérise par des associations patronales fortes et un État discret qui s'abstient largement de toute compensation sociale. Les syndicats sont pour ainsi dire des «partenaires juniors ». C'est le cas en Suisse. Le corporatisme a connu de graves crises dans de nombreux pays depuis le milieu des années 1970 et a été au moins temporairement abandonné, il est resté cependant relativement fort en Suisse, malgré une perte d'influence marquée. L'une des principales raisons en est la démocratie directe, qui garantit aux groupes d'intérêts «aptes au référendum » de grandes possibilités d'influence, même si leur base de membres diminue. Tandis que le corporatisme social était particulièrement actif dans le domaine de la gestion macroéconomique et de la politique sociale et fiscale, le corporatisme libéral suisse se concentre sur la coopération associative dans des domaines plus éloignés des questions de redistribution, tels que la formation professionnelle.

Un défi important pour le corporatisme suisse n'est pas seulement l'érosion déjà évoquée de sa base socioculturelle. Les relations étroites entre les partis politiques et les associations en matière de programmes et de liens personnels ont constitué une ressource importante du système de négociation. La social-démocratie, en tant que partenaire historique des syndicats de l'Union syndicale suisse, a assoupli ses liens avec les associations de travail- 
leur-euse-s afin d'attirer de nouveaux groupes d'électeur-tice-s au-delà du monde ouvrier classique, tandis que les classes sociales inférieures votent de manière disproportionnée pour l'Union Démocratique du Centre. Enfin, la polarisation du système de partis ébranle non seulement les coalitions entre l'économie et les partis bourgeois, mais aussi la capacité de fonctionnement du corporatisme en tant que deuxième système de négociation central de la Suisse, à côté de la concordance qui est tout autant menacée.

\section{Klaus Armingeon}

\section{Références}

Armingeon, K. (2011). A prematurely announced death? Swiss corporatism in comparative perspective. In C. Trampusch \& A. Mach (Eds.), Switzerland in Europe: continuity and change in the Swiss political economy (pp. 165 - 185). London: Routledge.

Gruner, E. (1959). Der Einbau der organisierten Interessen in den Staat. Schweizerische Zeitschrift für Volkswirtschaft und Statistik, 95, 59-79.

Sciarini, P., Fischer, M. \& Traber, D. (Eds.) (2015). Political decision-making in Switzerland: the consensus model under pressure. London: Palgrave Macmillan.

\section{Délinquance et politique criminelle*}

La notion de délinquance (de delinquere: manquer, fauter) est synonyme de criminalité. Elle décrit une infraction criminelle, indépendamment de la responsabilité concrète, contrairement à la notion empirique de déviance (comportement déviant). Cependant, contrairement à la notion d'infraction pénale, la délinquance n'est pas traitée dans une perspective normative mais considérée comme un phénomène social par les sciences sociales.

Le fait que la délinquance se caractérise par la violation pénale indique clairement qu'il n'y aurait pas de délinquance sans un code pénal (généralement national). Ce dernier a le monopole s'agissant de définir ce qui constitue la délinquance. Le lien entre le crime et la peine, traité à plusieurs reprises dans la littérature (Beccaria, Dostoïevski, etc.), souligne que la délinquance n'existe pas naturellement, mais qu'elle est déterminée par la loi et donc par la politique criminelle.

La criminologie traditionnelle, au contraire, se référait uniquement à l'acte criminel et l'isolait du contexte interactif de sa perception normative. Toutefois, le caractère intersubjectif des structures sociales impose, s'agissant de la reconstruction de la délinquance en tant que partie intégrante de la société, de prendre en compte l'interaction sociale. Car c'est dans l'interaction sociale que les actions se voient attribuer une certaine compréhension et que les mentalités relatives se constituent. Il ne s'agit pas de prendre position sur la responsabilité individuelle de l'auteur-trice pour ses actes telle que préconisée par le droit pénal, mais plutôt d'un dogme, qui ne peut pas être argumenté par les sciences sociales.

$\mathrm{Au}$ centre de cette réflexion se trouve la question des causes de la délinquance. À l'image d'une histoire infinie, des liens hétérogènes avec la criminalité sont explorés et superposés. Pour ce faire, on utilise les connaissances issues de la recherche génétique et cérébrale, de la psychiatrie, de la sociologie, de la psychologie, de l'économie, ainsi que des approches d'analyse discursive et d'anthropologie culturelle. Suivant la conclusion de Kunz et Singelnstein, toutes ces tentatives explicatives aboutissent à une image aux approches multiples et aux contours peu précis.

La question de savoir s'il existe des crimes «naturels» (génocide, crimes contre l'humanité) ubiquitaires et non codifiés est controversée : ici aussi, il faut s'attendre à ce qu'il y ait différentes conceptions culturellement spécifiques, qui se traduisent généralement par des normes criminelles liées à la culture. Considérant que le scandale ne devient scandale que 
par les réactions qu'il suscite, on peut affirmer qu'un acte sera considéré comme délictueux à condition d'être enregistré formellement et d'engager des poursuites pénales. Les actes non découverts ou non enregistrés ne seraient alors pas considérés comme relevant de la délinquance.

L’ampleur et la gravité de la délinquance connue et enregistrée par les autorités sont saisies dans les statistiques criminelles par diverses instances de justice pénale selon des critères essentiellement pénaux. De plus, on tente de déterminer la délinquance non détectée dans des études des chiffres noirs. De telles enquêtes démoscopiques s'intéressent à la perception de la délinquance par la population. Il est impossible de vérifier si les réponses reflètent avec authenticité la «véritable» charge de délinquance. Il faut toujours s'attendre à des distorsions dans la perception et dans les manières de répondre, de sorte que même les études sur les chiffres noirs ne reflètent guère la réalité du volume et du type de la délinquance.

L'idée qu'un grand nombre de délits graves soient commis par un petit nombre de multirécidivistes a inspiré des études à long terme sur la récidive (aussi pour la statistique des condamnations pénales de la Confédération). Elles s'efforcent surtout de déterminer quels types de sanctions sont le moins susceptibles d'entraîner des récidives et donc plus efficaces en termes de prévention. De telles études n'évaluent certes pas les récidives, mais les nouvelles condamnations. Celles-ci sont déterminées par des circonstances telles que l'intensité du contrôle et la visibilité sociale. Elles ne couvrent absolument pas les récidives non découvertes. Différentes circonstances, en dehors de la peine antérieure, influent sur la survenue ou l'absence de nouvelles condamnations. En cas de délinquance réitérée, il faut tenir compte des variations de durée de la période d'impunité et de la gravité du nouveau délit.
En plus de leur incrimination formelle, les actes délictueux sont stigmatisés socialement. Les effets d'un tel ostracisme peuvent dépasser la peine en tant que telle et perdurer au-delà. Plus la peine est élevée, plus la stigmatisation sociale est grande. Comme l'ostracisme ne se contrôle guère et qu'il dépasse généralement la sévérité des sanctions pénales imposée juridiquement, surtout en des périodes de punitivité accrue, la peine étatique est souvent alourdie par cet effet secondaire stigmatisant. Pour déterminer la sanction appropriée, il conviendrait donc de choisir celle qui semble tout juste équitable par rapport au crime commis mais qui impliquerait, de ce fait, un minimum de conséquences secondaires.

La délinquance en tant qu'action jugée négativement est attribuée à des individus ou à des groupes sociaux selon les mêmes règles qui prévalent pour des actes jugés positivement. La réputation, la considération et les rapports de pouvoir opèrent. Le contrôle pénal fait partie de la structure macrosociale de la société tout en la mettant en œuvre. L'intensité de la délinquance reflète la hiérarchie sociale : un nombre supérieur à la moyenne de personnes de faible statut social sont poursuivies pénalement.

Contrairement à l'intuition, des peines sévères ne réduisent ni le nombre ni la gravité des délits. Au contraire: compte tenu des graves effets de stigmatisation de peines élevées, on doit plutôt s'attendre à une spirale qui augmente la délinquance. Cela suggère de choisir la plus légère des sanctions prévues par la loi selon le cas concret.

La gestion étatique de la délinquance (politique criminelle) influe donc sur cette dernière. La politique criminelle entretient des liens directs avec les politiques sociale et sociétale. L'expression de Franz von Liszt, à savoir que la politique sociale est la meilleure politique criminelle, a été complétée par Gustav Radbruch. Selon lui, la mission, problématique, du droit pénal serait de compenser ce que la politique sociale aurait omis d'offrir au criminel. En 
opposition à ces considérations, dans la pratique, le droit pénal est parfois activé sous la pression populiste même si des mesures de politique sociale étaient tout autant, voire mieux appropriées. La répression pénale de la consommation de drogues ou de la mendicité est dans cette logique parfaitement discutable.

La politique criminelle est de plus en plus marquée par les émotions et craintes suscitées, voire suggérées par les médias. De telles craintes de la population à l'égard de multirécidivistes ou de terroristes entraînent des durcissements de la politique criminelle. La sécurité, la prévention et le contrôle revêtent beaucoup d'importance. Il n'empêche que sous les influences macro-sociales (mondialisation, néolibéralisme), les nations avec un profil d'État social présentent un taux de criminalité plus faible et moins dangereux que les nations à structure néolibérale.

La politique criminelle traditionnellement modérée de la Suisse est devenue plus sévère récemment. Les révisions du droit pénal et les initiatives populaires (internement à vie, renvoi d'étrangers criminels, imprescriptibilité des actes de pornographie enfantine, peines plus sévères à l'encontre des chauffards) complètent et durcissent l'éventail des sanctions. Cette tendance se reflète plus particulièrement dans les mesures de sécurité (internement à vie pour les délinquant·e-s jugéee-s très dangereux·euses, traitement institutionnel des délinquant·e.s souffrant de troubles psychiques graves). Pour des raisons de sécurité, les libérations anticipées deviennent plus délicates. Compte tenu des besoins accrus de la population en matière de sécurité, la volonté d'appliquer des sanctions sévères s'est développée. Quant à la communauté scientifique, elle est sceptique quant à l'efficacité de ce durcissement.

Karl-Ludwig Kunz

\section{Références}

Kunz, K.-L. (2015). Soziales Klima, Sanktionspraxis und Kriminalität. Schweizerische Zeitschrift für Kriminologie, 15(2), 18-26.

Kunz, K.-L. \& Singelnstein, T. (2016). Kriminologie: eine Grundlegung (7., grundlegend überarb. Aufl.). Bern: Haupt.

Kury, H., Brandenstein, M. \& Yoshida, T. (2009). Kriminologische Vergleichsanalyse: Kriminalpräventive Wirksamkeit härterer Sanktionen. Zur neuen Punitivität im Ausland (USA, Finnland, Japan). Zeitschrift für die gesamte Strafrechtswissenschaft, 121(1), 190-238.

\section{Délinquance des femmes}

Les femmes commettent tout l'éventail des infractions pénales. Elles sont toutefois moins nombreuses que les hommes à transgresser les lois et commettent plus fréquemment qu'eux des infractions de moindre gravité. Arrestations, condamnations, incarcérations: quelles que soient les statistiques, les femmes y sont minoritaires. En moyenne européenne, elles représentent 15 à $20 \%$ des personnes identifiées dans les statistiques policières et 4 à $6 \%$ de la population carcérale. Mais sont-elles traitées de la même manière que les hommes?

Sournoises ou instigatrices, l'on a dit des femmes qu'elles ne commettaient que des crimes cachés ou manipulaient les hommes pour les exécuter, mais surtout que, les rares fois où elles se faisaient prendre, la police et la justice les traitaient avec favoritisme. La thèse du paternalisme judiciaire, esquissée déjà dans les années 1950, postule que les femmes sont traitées de façon plus avantageuse que les hommes par les autorités. Les raisons évoquées sont multiples: favoritisme, représentations sociales biaisées, préjugés, raccourcis cognitifs, mais aussi un certain pragmatisme. Lorsqu'il s'agit de priver un enfant d'un de ses parents, le juge serait plus réticent à sanctionner la mère que le père. Toutefois, la présence d'enfants pourrait aussi se retourner contre 
l'accusée, punie alors car «mauvaise mère»; c'est la thèse de la femme diabolique qui postule que les femmes sont traitées plus sévèrement que les hommes, sanctionnées pour leurs infractions, mais aussi pour s'être comportées de façon contraire à leur rôle: un phénomène qualifié de «double déviance». Ne bénéficieraient de la clémence des juges que les femmes qui adopteraient un comportement conforme à leur genre.

La recherche s'est attelée à décortiquer les décisions judiciaires prononcées à l'encontre des femmes et des hommes, comparant arrestations, renvois en jugement, libérations sous caution et verdicts. Les résultats contradictoires traduisent, en partie, les difficultés méthodologiques inhérentes au fait de tenir compte empiriquement de la multiplicité de paramètres influant sur la décision judiciaire, mais reflètent aussi le principe d'individualisation de la peine. Dans tous les cas, il est avisé de ne pas se limiter aux seules institutions pénales. Si l'on adopte une définition plus large du contrôle social, la déviance des femmes apparaît sanctionnée différemment de celle des hommes aussi en marge de la sphère pénale. Circonstance tantôt atténuante tantôt aggravante, être une femme n'est jamais anodin en matière de justice (pénale) et renvoie toujours à des conceptions particulières du féminin et du masculin, et à leurs interrelations avec d'autres hiérarchies sociales.

Il en va de même dans l'histoire de la détention féminine. Prises sous l'aile des réformatrices pénales de la bourgeoisie qui entendaient les sauver en leur inculquant morale chrétienne et bonnes manières domestiques, condamnées à des peines indéterminées par des autorités qui voulaient s'assurer du temps nécessaire à leur resocialisation, tantôt incarcérées au milieu des hommes ou oubliées dans des établissements sous-financés, les détenues ont longtemps été discriminées. Et leur situation ne s'est que peu améliorée.
Sur le plan légal, la détention est régie par les textes garantissant les libertés fondamentales et les accords internationaux relatifs à l'exécution des peines privatives de liberté, soit les recommandations du Conseil de l'Europe et les résolutions de l'Assemblée générale des Nations Unies, parmi lesquelles les Règles de Bangkok, seul instrument juridique spécifique à la détention féminine. Cette résolution non contraignante promeut une prise en charge ciblée des besoins dits «spécifiques» des détenues. En Suisse, l'exécution des peines et des mesures est réglée par les articles 74-92 du Code pénal. Le principe d'individualisation de la sanction autorise aussi des différences de prise en charge, eu égard aux caractéristiques personnelles et besoins spécifiques des condamnés, à commencer par leur sexe. Des besoins toutefois souvent ignorés en raison d'une certaine invisibilité de la population carcérale féminine.

La prise en charge des détenues enceintes, relevant de couches et avec enfant est aussi explicitement régulée. Leurs besoins médicaux, d'hygiène et alimentaires doivent être pris en charge par des professionnels qualifiés. Les règles internationales prévoient que l'accouchement ait lieu dans un hôpital civil ou que les soins nécessaires soient disponibles. Ces règles sont intransigeantes en ce qui concerne les mesures de contrainte: il est inacceptable qu'une femme accouche entravée, une pratique inhumaine et dangereuse qui a pourtant cours notamment aux États-Unis. Après la naissance, plusieurs pays autorisent les détenues à élever leur enfant en prison, jusqu'à l'âge de 18 mois à environ 3 ans. En Suisse, l'enfant peut rester auprès de sa mère jusqu'à sa scolarisation, mais la pratique est opposée au fait de prolonger cette situation au-delà de l'âge de 2 ou 3 ans. L'intérêt supérieur de l'enfant est toujours prépondérant: il doit bénéficier d'un cadre de vie propice à son bon développement, avoir accès à des soins adéquats, pouvoir régulièrement quitter la prison et participer à des 
activités propres à son âge. Des mesures d'accompagnement de la détenue dans sa maternité doivent également être mises en place. Les arrangements disponibles pour l'enfant et la mère varient pourtant fortement d'un établissement à l'autre.

Même constat pour les mesures propices au maintien des liens affectifs et familiaux, pourtant partie intégrante du droit à la vie privée et familiale. Alors que les contacts des détenues avec leur famille, notamment leurs enfants, doivent être facilités et bénéficier des aménagements adéquats, ce sont les directions d'établissement qui choisissent les modalités de visite autorisées (ordinaire, familiale, conjugale), ouvrant la voie à des inégalités de traitement.

$\mathrm{Au}$ cœur des fonctions de la peine, la resocialisation passe aussi par une offre adaptée en matière d'éducation et de formation professionnelle. Si la réhabilitation morale des détenues n'en est plus l'objectif, l'offre disponible est restreinte comparativement à celle des établissements pour hommes. Malgré les efforts consentis, les activités sont fortement genrées et peu orientées vers l'acquisition de compétences utiles à la réinsertion.

Enfin, plusieurs études attestent de la (plus) grande vulnérabilité des femmes en milieu carcéral, tant en regard de leurs trajectoires de vie que de leurs conditions de détention. Les détenues présentent davantage de problèmes de santé que les détenus aussi bien en ce qui concerne les pathologies somatiques et les maladies chroniques que les troubles psychiatriques et les addictions. Eu égard à leur vécu et aux circonstances ayant présidé à leur incarcération, les femmes présentent aussi des besoins spécifiques en matière de réinsertion et de prévention de la récidive. Or, les interventions à visée thérapeutique répondent rarement à ces impératifs et les interventions sexospécifiques sont encore trop peu disponibles malgré leurs résultats prometteurs. La prise en charge de la «santé incarcérée» doit être une priorité sociale et politique, ce d'autant plus que, pour certaines détenues, la prison représente une possibilité unique d'accès aux soins, ce qui inscrit clairement la médecine pénitentiaire dans la santé publique.

Trop souvent oubliées par le législateur et les institutions sociales et pénales, les criminelles sont loin de présenter une unicité de trajectoires de vie. À la variété des circonstances de leur délinquance correspondent des besoins d'intervention complexes. Or, si nombre d'organismes nationaux et internationaux attestent de la vulnérabilité des femmes délinquantes et de la pertinence d'une réflexion intégrant le genre en matière de dispositifs de prise en charge, tant les politiques criminelles que les politiques sociales peinent à franchir le pas.

\section{Véronique Jaquier}

\section{Références}

Belknap, J. (2015). The invisible woman: gender, crime, and justice. Belmont: Wadsworth.

Cardi, C. (2007). Le contrôle social réservé aux femmes : entre prison, justice et travail social. Déviance et Société, 31(1), 3-23.

Jaquier, V. \& Vuille, J. (2017). Les femmes et la question criminelle: délits commis, expériences de victimisation et professions judiciaires. Zurich : Seismo.

\section{Délinquance juvénile*}

La délinquance juvénile désigne les infractions pénales commises par les jeunes. En Suisse, ce terme concerne les enfants et les jeunes de 10 à 18 ans révolus qui ont commis un acte poursuivi pénalement.

Le terme de délinquance juvénile repose sur l'idée que les jeunes délinquants n'ont pas encore achevé de construire leur personnalité et qu'ils ne peuvent donc pas être tenus responsables de leurs actes de la même façon que les adultes. D’après des recherches sur la 
criminalité cachée, les délits relevant du droit pénal sont très répandus chez les jeunes (surtout les délits mineurs). Les actes sont souvent commis spontanément, en groupe, et les dommages économiques sont la plupart du temps négligeables. À l'approche de la majorité, les comportements répréhensibles diminuent sensiblement, et sans intervention pénale. La délinquance juvénile se caractérise par trois éléments : l'ubiquité (omniprésence), le recul des délits vers la fin de la jeunesse même sans intervention et la moindre gravité. Seul un petit groupe (environ $6 \%$ des jeunes dans cette tranche d'âge) commet des délits nombreux et graves sur une période prolongée. C'est ce groupe qui est considéré comme problématique et à risque par la politique de lutte contre la criminalité (dans les pays anglo-saxons, on les appelle les chronics, high risk offenders ou persistent offenders). Ce groupe cumule souvent divers facteurs de risques sociaux, culturels, psychologiques (difficultés d'apprentissage) ou biologiques/neurologiques. La question de savoir lesquels des nombreux facteurs d'influence imaginables déterminent le comportement conforme ou déviant des jeunes ne fait pas l'unanimité.

La position particulière des enfants et des jeunes au regard du droit est un acquis récent. $\mathrm{Au}$ Moyen-Âge, le droit pénal s'appliquait encore de la même façon aux enfants et aux adultes. Parallèlement à l'humanisation du droit pénal au début du siècle des Lumières, au développement de la peine moderne de privation de liberté, au recul de la peine capitale et des châtiments corporels et à la création de pénitenciers sont apparues les premières institutions avec prétention pédagogique pour les «enfants mal élevés ». Le développement d'une juridiction moderne (destinée aux jeunes) a connu une avancée décisive lorsque Franz von Liszt a réclamé que les interventions de droit pénal s'attachent non pas aux faits et à leur répression, mais plutôt à la personnalité du coupable et aux possibilités de resocialisation éducative.

En Suisse, l'idée d'une justice des mineur·e.s est née à la fin du XIX ${ }^{\mathrm{e}}$ siècle. Dans les années 1920 et 1930, plusieurs cantons ont adapté leur législation aux réformes éducatives. Le Code pénal suisse de 1942 a finalement remplacé les législations cantonales. Les articles 82 à 99 formulent les grandes lignes d'un droit pénal axé sur la faute, mais à vocation éducative. Il exige qu'en cas de négligence ou d'atteinte (à la moralité), des mesures soient d'abord prononcées.

Depuis les années 1960 et 1970, divers programmes de réforme ont changé durablement la perception du phénomène de «criminalité juvénile» sur la scène internationale. On a commencé à remettre en question les objectifs officiels de la peine: celle-ci n'aurait qu'un effet dissuasif relatif et la probabilité de nouveaux délits ne diminuerait pas avec la sévérité de la sanction pénale, au contraire; de plus les comportements délinquants seraient abandonnés à l'entrée dans l'âge adulte, la plupart du temps sans intervention. On a donc préconisé une action plus éducative que répressive et proposé de contenir le plus possible les influences stigmatisantes de la juridiction pénale officielle. Il fallait renoncer aux poursuites pénales pour les infractions mineures ou de gravité moyenne, et s'efforcer davantage de resocialiser le délinquant. Dans le jargon juridique, on utilise le terme «diversion» pour désigner le détournement des procédures pénales officielles.

À peu près au même moment, des mouvements d'aide aux victimes exigeaient que l'on accorde davantage d'attention à l'indemnisation qu'à la peine. Plutôt que de constater la faute (en pointant du doigt le délinquant), la justice compensatrice (restorative justice) se concentre sur la constatation du dommage (en mettant l'accent sur la partie lésée). Depuis, l'idée d'indemnisation est présente dans la plupart des systèmes juridiques occidentaux, 
mais n'a souvent qu'une portée limitée dans la justice des mineur.e.s.

La «criminalité juvénile» n'existe donc pas comme un fait établi. Elle est davantage conditionnée par ce que la société définit comme normes incontournables et frontières morales, par les moyens qu'elle utilise pour réagir aux violations des normes et par la manière dont elle tient compte de la situation de chaque jeune.

Depuis 2007, la Suisse connaît un Droit pénal des mineur·e·s à part entière. Il s'articule autour de deux formes de réaction: les peines et les mesures de protection. Il applique le principe «éduquer avant de punir». Les réactions doivent être adaptées à la situation personnelle du délinquant ou la délinquante et favoriser le développement de sa personnalité de manière positive. Les peines ne sont pas vues comme des représailles, mais comme un avertissement censé déclencher des processus d'apprentissage. Les peines et mesures éducatives peuvent être formulées simultanément ou se remplacer lors de leur application (remplacement de sanctions pénales ou système dualiste vicariant respectivement). Le coût de l'application des mesures de protection est supporté par les cantons ; les parents et les jeunes ont une obligation de contribution.

Dans le droit pénal suisse des mineur·e·s, les menaces de sanction sont bien moins sévères que dans les autres pays d'Europe. Les mesures pénales de placement telles que la privation de liberté ou la détention provisoire ou de sécurité sont rarement prononcées. Qui plus est, elles ont encore diminué depuis le début des années 2010. Dans le Droit pénal des mineur·e·s, l'essentiel des mesures interventionnistes est surtout mis en œuvre dans une optique de protection (surveillance, suivi personnalisé, traitement ambulatoire, placement en milieu ouvert ou fermé), tandis que les «peines» (hors peines privatives de liberté) sont plutôt appliquées aux délits mineurs (avertissement, travail personnel, amende).
Le système suisse se distingue également par les compétences attribuées au ministère public des mineur·e·s (Suisse alémanique) ou aux juges pour mineur.e.s (Suisse romande et Tessin). Il s'agit d'autorités d'instruction, d'accusation ainsi que d'exécution et elles ont un pouvoir décisionnel sur la plupart des sanctions.

Les avantages du système pénal suisse pour mineur.e.s s'observent surtout dans sa souplesse et l'examen au cas par cas. Ses possibles inconvénients résident dans le fait qu'il manque souvent au personnel judiciaire l'expérience professionnelle pour juger des mesures d'éducation et dans la faiblesse des conditions-cadres fixées pour l'établissement et l'évaluation des sanctions. Comme le taux de récidive est plutôt faible en Suisse en comparaison internationale, le système pénal des mineurs du pays a généralement bonne presse.

Si le nombre de jeunes délinquant.e-s jugée-e·s en Suisse a augmenté entre 1999 et 2009, les chiffres ne cessent de reculer depuis 2010. Les principes de prévention et d'intervention à visée éducative semblent donc agir sur les comportements déviants. L'identification précoce des groupes à risque et le développement des réactions appropriées face aux délinquants récidivistes constituent d'autres défis de taille. Par ailleurs, avec la médiatisation croissante des sphères de vie, on voit apparaître de nouvelles formes de déviance telles que le cyberbullying (diffamation ou harcèlement par des moyens de communication numériques) ou le sexting (diffusion de photos intimes par des moyens de communication numériques), contre lesquelles il reste encore à définir des réactions appropriées.

Heinz Messmer \& Rahel Heeg 


\section{Références}

Pruin, I., Aebersold, P. \& Weber, J. (2017). Switzerland. In S.H. Decker \& N. Marteache (Eds.), International handbook of juvenile justice ( $2^{\text {nd }}$ ed., $\mathrm{pp}$. 473-494). Cham : Springer.

\section{Démocratie directe*}

On appelle démocratie directe un système où les citoyennes et citoyens participent directement à la prise de décisions politiques. À l'heure actuelle, le discours politique et scientifique ne parle pas d'une démocratie directe pure au sens d'un modèle de type idéal de souveraineté politique du peuple. Elle est plutôt considérée comme un processus décisionnel politique susceptible d'intervenir en complément de la démocratie représentative. Si les instruments de démocratie directe varient fortement d'un pays à l'autre, on distingue toutefois deux grandes familles: les initiatives qui permettent au peuple de faire des propositions de loi ou de modifications constitutionnelles à soumettre au verdict des urnes et les référendums dans le cadre desquels la population se prononce par le vote sur des propositions de loi ou constitutionnelles du gouvernement et du Parlement. Les instruments de démocratie directe peuvent par ailleurs être appliqués de manière top-down (par le gouvernement ou par la loi, comme le référendum obligatoire) ou de manière bottom-up (par la population ellemême, comme l'initiative populaire ou le référendum facultatif). La manière dont la Suisse applique la démocratie directe est une spécificité propre au pays. Dans les faits, la Suisse est le seul pays où les instruments de démocratie directe jouent un rôle majeur au niveau national. Pour la politique sociale toutefois, la participation démocratique directe n'est pas seulement déterminante à l'échelle nationale (surtout au niveau des assurances sociales ou, récemment, de la politique familiale), mais aussi dans les cantons et les communes (réduction des primes d'assurance-maladie, offres de garde des enfants, impôts).

L'impact des instruments de démocratie directe sur la politique sociale est théoriquement ambivalent. Une première approche part de l'hypothèse - étant donné une distribution des revenus qui penche vers la gauche - qu'une majorité de la population profite d'une redistribution. Si les citoyennes et citoyens définissent directement la politique sociale en passant par les urnes, on peut s'attendre à une politique de l'État-providence plus généreuse et plus redistributive que ce ne serait le cas dans une démocratie représentative pure. Ce lien est d'autant plus fort que les initiatives populaires inscrivent de nouvelles questions à l'agenda politique, impulsant et rendant ainsi possible des réformes de l'État-providence voire des innovations sociales.

Une autre perspective, privilégiée notamment par Uwe Wagschal et Herbert Obinger, voit plutôt la démocratie directe comme un outil de veto institutionnel qui entrave plus particulièrement le développement de l'État-providence. Cela s'explique surtout par le fait que l'électorat se montre généralement sceptique face à de nouvelles taxes ou dépenses et qu'en cas de doute, il tend à opter pour le statu quo plutôt que pour des réformes à l'issue incertaine. De plus, les couches sociales élevées, donc les contributeurs nets typiques d'une politique d'État-providence, ont plus couramment tendance à participer aux votations que la moyenne. Inversement, la population résidente étrangère qui perçoit des prestations sociales plus souvent que la moyenne ne peut pas participer au processus de démocratie directe. Cette réalité met en cause la préférence, mentionnée plus haut, qui s'exprimerait dans les urnes pour davantage de redistribution. Il semblerait plutôt que les groupes riches en ressources et prônant moins d'État-providence parviennent mieux que d'autres à faire valoir leurs intérêts par le biais de la démocratie directe. 
Des études internationales empiriques (menées notamment aux États-Unis) tendent à corroborer la thèse d'un effet de frein. L'évolution de la politique sociale suisse semble aussi confirmer cette approche. De fait, la démocratie directe (combinée au fédéralisme) est le principal facteur expliquant le retard de développement de l'État-providence en Suisse. L'exemple parfait de cet effet retardateur est l'assurance-maternité qui a été inscrite dans la Constitution dès 1945. Il a fallu toutefois attendre 60 ans et l'échec de nombreuses votations avant que la loi régissant son application entre en vigueur. L'introduction des assurances sociales centrales comme l'assurance-vieillesse et survivants ou bien l'assurance-maladie obligatoire a pris plusieurs décennies, notamment pour surmonter les différents obstacles constitutionnels et législatifs liés à la démocratie directe. Il faut cependant rappeler que cette évolution retardée présente aussi des avantages en termes de qualité, de soutien et de stabilité des mesures sociales adoptées. Il faut de plus noter que les propositions découlant d'initiatives populaires ont régulièrement influé sur l'évolution et le succès de projets ultérieurs, donnant ainsi maintes fois des impulsions pour des processus de réforme. Ce qui peut apparaître comme un paradoxe met en lumière la différence essentielle entre les référendums, qui ont une fonction de contrôle et d'entrave des réformes, et les initiatives, qui permettent d'introduire de nouvelles propositions dans le processus politique et peuvent donc servir de tremplin à l'innovation sociale.

Néanmoins, sous le signe du démantèlement ou de la restructuration de l'État-providence, l'effet inhibiteur de la démocratie directe est particulièrement visible aujourd'hui: dans la démocratie directe, des prestations ou des droits acquis sont bien plus difficiles à abroger que dans des systèmes purement représentatifs, puisque la population doit explicitement soutenir ce démantèlement social. Dans un contexte de participation directe, les réformes sociopolitiques sont un exercice particulièrement difficile et ne peuvent être mises en œuvre que si des mesures d'austérité peuvent être assorties d'une amélioration des prestations. Les risques de blocage induits par la démocratie directe ne relèvent cependant pas seulement de causes institutionnelles; ils dépendent aussi de manière déterminante d'autres facteurs sociétaux, économiques et politiques. Ainsi, la polarisation croissante entre les différents partis politiques depuis le début des années 2000 a accru ce risque de blocage, alors que la politique sociale n'avait cessé d'évoluer lentement mais sûrement au cours des décennies précédentes et ce, en dépit de la démocratie directe.

L'effet inhibiteur de la participation directe aux réformes sociopolitiques peut donc être considéré comme un défi passé, actuel, mais aussi futur, propre à la politique sociale suisse. Compte tenu de l'évolution démographique et de la faible marge de manœuvre financière de l'État, la nécessité de réforme du système de la sécurité sociale est incontestée dans une large mesure, mais les propositions en ce sens échouent les unes après les autres depuis le début du millénaire, notamment dans les urnes. Le débat sur la prévoyance vieillesse illustre parfaitement les particularités des processus de réforme sociopolitiques dans le cadre de la démocratie directe. Premièrement et comme évoqué plus haut, ces processus se caractérisent par des mesures d'économies assorties d'éléments de développement concrets, rendant peu probable toute réforme globale et l'allègement financier du budget de l'État reste souvent limité. Deuxièmement, les processus de réforme sont par essence des processus de longue haleine dans la mesure où des solutions globales équilibrées sont généralement le fruit d'années de négociations au sein du Parlement et du gouvernement. On peut y voir un impact indirect de la démocratie directe: afin d'éviter le référendum, on tente de trouver une solution aussi consensuelle que possible déjà au Parle- 
ment. Troisièmement, même en anticipant la «menace de référendum», les processus de réforme comprennent une part d'incertitude. Des campagnes de votation peuvent entraîner des dynamiques imprévues et mener à un Non dans les urnes. Le processus de réforme doit alors recommencer à zéro.

Isabelle Stadelmann-Steffen

\section{Références}

Bonoli, G. \& Häusermann, S. (2009). Who wants what from the welfare state? Socio-structural cleavages in distributional politics : evidence from Swiss referendum votes. European Societies, 11(2), 211-232.

Obinger, H. (1998). Politische Institutionen und Sozialpolitik in der Schweiz: der Einfluss von Nebenregierungen auf Struktur und Entwicklungsdynamik des schweizerischen Sozialstaates. Frankfurt a.M.: P. Lang.

Wagschal, U. \& Obinger, H. (2000). Der Einfluss der Direktdemokratie auf die Sozialpolitik. Politische Vierteljahresschrift, 41, 466-497.

\section{Démographie sociale}

La démographie sociale vise à expliquer les causes et les conséquences des phénomènes démographiques (natalité, mortalité et migration), en utilisant les approches explicatives de la théorie sociale et en s'appuyant essentiellement sur des matériaux le plus souvent quantitatifs (données administratives, données d'enquête), mais aussi qualitatifs. Cette discipline se distingue de la démographie formelle dont l'intérêt porte sur l'analyse de l'effectif d'une population, de sa composition par âge et par sexe, voire de sa répartition géographique, tels qu'ils découlent des phénomènes démographiques, sans que ne soit fait référence à l'insertion de cette population dans son environnement socioéconomique et culturel. La recherche en démographie sociale accorde une place importante aux individus, à leur parcours de vie et à leur agentivité (agency) en relation avec le contexte institutionnel et normatif dans lequel ils vivent en vue d'expliquer leurs comportements de reproduction, de santé ou de mobilité.

Quelle que soit la société considérée, une particularité de la démographie sociale, par rapport à un grand nombre de disciplines des sciences sociales, est que deux de ses principaux objets, la natalité et la mortalité, se situent à la frontière entre des processus biologiques - naître, donner vie, vieillir, mourir - et des processus socioculturels qui règlent les formes $\mathrm{du}$ vivre ensemble, les obligations entre individus, la sexualité, la procréation, etc. Dans le domaine de la natalité, Kingsley Davis et Judith Blake recensaient dans leur article Social Structure and Fertility publié en 1956 dans le journal Economic Development and Cultural Change un ensemble de «variables intermédiaires » au travers desquelles des facteurs socioéconomiques et culturels pouvaient exercer une influence sur le nombre d'enfants et le calendrier de la fécondité. Selon eux, ces facteurs intermédiaires se résument en trois groupes: ceux qui agissent sur la sexualité (p.ex. l'âge d'entrée dans la sexualité, les conditions qui règlent la sexualité ou l'abstinence), ceux qui agissent sur la conception (contraception) et ceux qui agissent sur la gestation et la parturition (mortalité fœtale, avortement). Ces facteurs intermédiaires peuvent aussi, pour nombre d'entre eux, servir de levier ou de cible à des politiques incitatives visant à diminuer ou à augmenter la natalité. Dans le même ordre d'idées, des variables intermédiaires ont aussi été définies dans le cadre de l'analyse de la mortalité, plus particulièrement de la mortalité infantile.

Entre les années 1850 et 1950 environ, la plupart des pays occidentaux ont connu une transformation démographique majeure en passant d'un régime démographique caractérisé par une forte mortalité et une forte natalité à un régime caractérisé par une mortalité et une natalité faible. Cette transition d'un 
régime démographique à un autre signifie l'installation d'un système démographique dans lequel les fréquences de naissances et de décès une année donnée sont moindres par rapport à l'ancien régime démographique. $\mathrm{La}$ transition démographique a été induite par les changements socioéconomiques liés à l'industrialisation et à la sécularisation des sociétés durant cette époque ainsi que par d'importants changements sanitaires en relation avec les politiques «d'hygiène» mises en place à cette époque. Elle s'est diffusée depuis la Seconde Guerre mondiale à l'ensemble des régions de la planète, en réponse à la mise en place, d'une part de politiques plus ou moins efficaces de santé publique et d'autre part, de politiques malthusiennes visant à freiner la croissance démographique par le levier de la fécondité.

Ce changement de régime démographique se traduit au niveau individuel par une transformation des parcours de vie en raison de l'allongement de l'espérance de vie et au niveau collectif par une augmentation de la part des personnes âgées dans l'ensemble d'une population. Outre le vieillissement de la population, la transition démographique a eu aussi pour conséquence une transformation des structures familiales : l'augmentation de l'espérance de vie signifie en effet que plus de générations se côtoient au sein d'une famille (trois, quatre, voire cinq générations) alors que la baisse de la natalité signifie des fratries moins grandes que par le passé.

Il est devenu couramment admis dans la recherche en démographie sociale que notre époque contemporaine connaît une deuxième transition démographique, celle-ci ayant débuté dans les pays occidentaux dans les années 1960 à 1970, le baby-boom temporaire ayant suivi la Seconde Guerre mondiale marquant la séparation entre cette nouvelle transition et la première transition démographique. Cette nouvelle transition est caractérisée par des transformations des parcours de vie familiaux (augmentation des divorces, diffusion de la cohabitation hors-mariage, des naissances hors-mariage, etc.) et serait parallèle à la montée des normes d'individualisme. Par ailleurs, la période actuelle se caractérise aussi par l'accentuation, la féminisation et la diversification des flux migratoires internationaux, les déplacements de personnes étant dus tant à des raisons économiques qu'à l'intensification des conflits entre pays ou civils. Les années les plus récentes ont en outre vu l'apparition et l'accroissement des réfugié·e.s climatiques, ce phénomène étant appelé à s'amplifier au cours du $\mathrm{XXI}^{\mathrm{e}}$ siècle en relation avec le réchauffement de la Terre et en tenant compte du fait que deux personnes sur cinq dans le monde habitent actuellement à moins de 100 kilomètres d'une côte maritime.

La Suisse n'a pas fait exception à ces différentes transformations de mortalité, de fécondité et de migration. Son régime démographique se caractérise par une faible mortalité et une faible natalité, les deux grandeurs étant devenues à partir du milieu des années 1970 presque égales. Avec une espérance de vie qui augmente chaque année de deux à trois mois et une fécondité en dessous du seuil de renouvellement des générations, la Suisse fait face à un vieillissement de population, celui-ci étant accentué par l'avancée en âge des générations du baby-boom nées après la Seconde Guerre mondiale. Ce vieillissement est globalement considéré comme une menace sur le financement des systèmes de retraite, particulièrement de l'AVS, mais dans un avenir proche il posera d'autres types de questionnements politiques, tels que celui de l'organisation du système de santé et de la place de la gérontologie dans cette organisation, celui de l'aménagement du territoire et des modalités d'habitation des personnes âgées et très âgées, ou encore celui des solidarités intergénérationnelles. La basse natalité a dans l'histoire helvétique peu souvent été une préoccupation ouverte des pouvoirs publics, les politiques visant à développer le nombre de crèches ou 
plus généralement à permettre aux femmes de concilier vie familiale et vie professionnelle n'étant pas considérées selon un point de vue nataliste. Les transformations du parcours de vie en relation avec l'augmentation de l'espérance de vie, l'augmentation des divorces et séparations posent depuis deux ou trois décennies de nouveaux questionnements en termes de politiques sociales, par exemple, concernant la pauvreté des mères seules et de leurs enfants.

Avec des niveaux de natalité et de mortalité qui s'annulent quasiment, la croissance démographique suisse est essentiellement régie par les aléas de la migration, cette dernière dépendant d'une part des crises économiques et de l'autre de l'alternance de politiques de frein ou de libération à l'immigration qui se sont succédé depuis le milieu des années soixante. L'immigration est l'objet d'une tension permanente depuis la fin du XIX ${ }^{\mathrm{e}}$ siècle, les politiques publiques se partageant entre réflexe malthusien de limitation des entrées et laisser-faire. $\mathrm{Si}$ au sortir de la Seconde Guerre mondiale, la migration était perçue à la manière d'un gigantesque turn-over et de séjours de courte durée d'une main-d'œuvre essentiellement masculine, cette perception a fait place à partir du milieu des années 1970 à une autre conception de la migration dans laquelle une part non négligeable de migrant·e.s s'installent dans leur pays d'accueil, se marient éventuellement avec un.e partenaire suisse et fondent une famille. À ce changement de perception a correspondu l'apparition de préoccupations politiques concernant l'intégration des immigrant·e.s ainsi que de leurs enfants.

\section{Jean-Marie Le Goff et Laura Bernardi}

\section{Références}

Mahning, H. (Éd.) (2005). Histoire de la politique de migration, d'asile et d'intégration en Suisse depuis 1948. Zürich: Seismo.

Office fédéral de la statistique (Éd.). Démos Newsletter (publication biannuelle depuis 2017). Neuchâtel: Office fédéral de la statistique.
Weeks, J.R. (2014). Population: an introduction to concept and issues (12 ${ }^{\text {th }}$ ed.). Boston: Cengage Learning.

\section{Dépenses de santé*}

Selon les chiffres de l'Office fédéral de la statistique (OFS) sur les coûts et le financement du système de santé, les dépenses de santé en Suisse oscillent depuis le tournant du millénaire entre 10 et $12 \%$ du produit intérieur brut. En 2017, elles s'élevaient à environ 10000 francs par personne. Le secteur hospitalier - les hôpitaux et les homes médicalisés - contribue aux dépenses de santé à hauteur de $45 \%$, alors que les prestations ambulatoires, fournies par les médecins, les services hospitaliers ambulatoires, les soignant.e.s et les thérapeutes, représentent $35 \%$. Les pharmacies et autres points de vente de produits de santé représentent $10 \%$ des dépenses, tandis que $8 \%$ sont consacrés à l'administration et d'autres services. Selon l'OFS, seuls $2 \%$ sont dédiés à la prévention. Les coûts indirects de la maladie, tels que les pertes de production ou les soins informels des proches, devraient être ajoutés aux dépenses de santé. Les coûts indirects pourraient se révéler au moins aussi élevés que les dépenses directes.

Le financement de la santé en Suisse se caractérise par une pluralité de tarifs et de modèles de remboursement. Depuis 2004, la structure tarifaire TARMED qui permet le décompte des prestations médicales est en vigueur dans les cabinets médicaux et les hôpitaux pour les prestations ambulatoires. En raison des évolutions technologiques de la médecine, TARMED relève désormais d'une surcompensation relative des prestations techniques (telles que radiographies ou interventions chirurgicales), ainsi que d'une sous-compensation des examens simples ou 
des entretiens. Une révision - qui devait être sans incidence sur les coûts et développer les soins médicaux de base - a échoué provisoirement en 2016 en raison de la résistance de groupes d'intérêts tels que les associations de médecins et les assureurs-maladie. TARMED tend à inciter au sur-traitement, chaque acte médical étant rémunéré séparément.

Dans le secteur stationnaire des hôpitaux de soins aigus, le système tarifaire forfaitaire de SwissDRG (DRG = Diagnosis Related Groups) est en vigueur depuis 2012. Pour calculer des forfaits par cas, les patient·e-s sont affecté-e·s à un groupe de cas en fonction de leur diagnostic et d'autres caractéristiques, telles que l'âge et les besoins en soins. Les hôpitaux reçoivent un montant fixe par cas, calculé à partir des coûts moyens de traitement du groupe de cas concerné (pondération des coûts) et du tarif négocié entre les hôpitaux et les organismes payeurs (prix de base). Les SwissDRG sont controversés parmi les professionnel-le·s de la santé en raison de leur incitation à agir sous un angle économique. En fait, les politicien-ne-s s'attendaient à ce que l'introduction de ce nouveau système de financement entraîne une rentabilité supérieure et une intensification de la concurrence entre les hôpitaux. Les effets sur les coûts, la qualité des soins, la satisfaction des patient.e.s et les conditions de travail $\mathrm{du}$ personnel hospitalier sont analysés dans des études concomitantes. Les premiers résultats indiquent une augmentation de la charge administrative dans les hôpitaux, une concurrence accrue pour les cas lucratifs et un glissement des prestations et des coûts vers les secteurs en aval comme celui des soins de longue durée.

Un autre élément du financement hospitalier en vigueur depuis 2012 est celui de la répartition des coûts hospitaliers pour les assuré.e-s de base entre les caisses-maladie d'un côté et les cantons de l'autre. Ces derniers supportent $55 \%$ des frais stationnaires, tandis que les caisses-maladie paient la totalité des frais en ambulatoire. En raison de ce régime de financement, les traitements ambulatoires peuvent entraîner des coûts supérieurs pour les assureurs-maladie, bien qu'ils soient, de fait, moins onéreux.

D'autres régimes de financement sont en vigueur dans les établissements médico-sociaux, la réhabilitation stationnaire et la psychiatrie. Ces prestations sont financées selon des forfaits journaliers ; elles sont échelonnées en fonction du degré de dépendance dans les EMS. Les personnes dépendantes supportent elles-mêmes $20 \%$ des frais de soins ainsi que les frais d'accompagnement et d'hôtellerie, ce qui correspond facilement à un montant mensuel entre 5000 et 10000 francs. Si le revenu propre est insuffisant et la fortune inférieure à un certain seuil, la personne a droit aux prestations complémentaires de l'AVS/AI. En ce qui concerne le financement de la réhabilitation stationnaire et de la psychiatrie, l'introduction de forfaits de cas ou, éventuellement, de combinaisons de forfaits journaliers et de cas est prévue au cours des années à venir.

En comparaison européenne, il est frappant de constater que les Suisses paient directement de leur poche une part très élevée de leurs dépenses de santé. $37 \%$ du financement de la santé provient de l'assurance sociale de base, $20 \%$ de recettes fiscales (principalement cantonales) et $28 \%$ de contributions privées des ménages (out of pocket). Ces dernières comprennent les quotes-parts et les franchises, les coûts non pris en charge par l'assurance-maladie (p.ex. les médicaments non prescrits et les soins dentaires) ainsi que la part privée des coûts des soins de longue durée.

La part de l'assurance-maladie sociale est financée par des primes individuelles indépendantes du revenu. Le financement des soins de santé très régressif qui en résulte n'est pas compensé par les contributions aux hôpitaux financées par l'impôt, les réductions de primes ou les prestations complémentaires. Cette situation est exacerbée par le transfert 
des prestations du secteur stationnaire au secteur ambulatoire, car la médecine ambulatoire (après déduction de la franchise et de la quote-part) est entièrement financée par l'assurance-maladie. Elle entraîne un développement voulu par le politique et potentiellement dans l'intérêt des patient.e-s, ce qui, par «effet boomerang », alourdit la charge financière des personnes à faible revenu.

Les différences entre les systèmes de financement des soins médicaux stationnaires d'un côté et ambulatoires de l'autre ont abouti, ces dernières années, à une augmentation disproportionnée des primes d'assurance-maladie obligatoire. Depuis l'entrée en vigueur de la loi sur l'assurance-maladie en 1996, l'augmentation des primes a été nettement supérieure à l'augmentation des coûts globaux de la santé. Ni les salaires ni les réductions de primes n'ont suivi le rythme de croissance des primes, de sorte que le poids de ces primes sur le budget des ménages s'est fortement alourdi, en particulier dans le segment des revenus inférieurs et moyens dont le revenu disponible baisse par conséquence. Cette situation se transforme en une rude épreuve de politique sociale, épreuve qui pourrait être désamorcée, du moins en partie, par l'harmonisation des régimes de financement dans les secteurs stationnaire et ambulatoire. Afin de soulager efficacement les ménages à faibles revenus, les cantons devraient, par ailleurs, étendre et uniformiser leurs systèmes de réduction des primes.

Bien que les dépenses de santé per capita soient relativement élevées par rapport aux chiffres internationaux et contrairement aux affirmations souvent entendues, les coûts de la santé au cours des 15 dernières années n’ont nullement connu une augmentation «explosive». Toutefois, la situation pourrait changer au cours des prochaines années en raison de l'évolution démographique. Malgré l'accroissement de la population, le nombre de décès en Suisse reste stable à environ 60000 par an depuis la fin des années 1970, ceci en raison de l'augmentation de l'espérance de vie. Mais le vieillissement de la génération des baby-boomers augmentera considérablement le nombre de décès jusque dans les années 2040-2050. Étant donné que les coûts de la santé sont généralement plus élevés en fin de vie, cette évolution est susceptible d'accélérer l'augmentation des coûts. L'ampleur réelle de cet effet dépend toutefois aussi de l'évolution de la médecine gériatrique et palliative.

\section{Anna Sax}

\section{Références}

Meyer, B., Rohner, B., Golder, L., Longchamp, C., (2016). Administrativer Aufwand für Ärzte steigt weiter an. Schweizerische Ärztezeitung, 97(1), 6-8.

Office fédéral de la statistique (2016). Coûts et financement du système de santé 2014: données définitives. Neuchâtel: Office fédéral de la statistique.

Wieser, S., Tomonaga, Y., Riguzzi, M., Fischer, B., Telser, H., Pletscher, M., ... Schwenkglenks, M. (2014). Die Kosten der nichtübertragbaren Krankheiten in der Schweiz: Schlussbericht. Winterthur : Winterthurer Institut für Gesundheitsökonomie ZHAW.

\section{Dépenses publiques}

On définit les dépenses publiques comme l'ensemble des dépenses réalisées par les administrations publiques. Pour assurer la comparaison au niveau international, les statistiques des administrations publiques suisses sont établies selon les directives du Fonds Monétaire International (FMI) contenues dans le modèle dit SFP (Statistiques de finances publiques). Selon ce cadre normatif, font partie des administrations publiques suisses la Confédération, les cantons, les communes et les assurances sociales obligatoires (assurance-vieillesse et survivants, assurance-invalidité, allocations pour perte de gain, assurance-chômage, allocations familiales dans l'agriculture, l'assurance-maternité du Canton de Genève). Ce 
modèle permet également de préciser la notion de dépenses des administrations publiques: il s'agit de la somme des charges et des acquisitions nettes d'actifs non financiers. Leur financement est assuré par les recettes fiscales et les cotisations obligatoires des assuré-e-s et des employeur.euse-s, ainsi que par le déficit public.

Du point de vue comptable, les dépenses publiques peuvent être classées selon leur nature économique ou selon leur destination fonctionnelle. D'après le premier critère, on peut distinguer dépenses de fonctionnement, telles que les dépenses de personnel et les transferts aux ménages, et dépenses d'investissement, dont le but est de maintenir ou d'élargir la capacité productive des administrations publiques. Suivant le deuxième critère, les dépenses publiques sont classées d'après les grands objectifs poursuivis par les administrations publiques tels que la défense, la formation, la culture, la santé, la sécurité sociale et la protection de l'environnement. La dépense publique répond fondamentalement à trois fonctions, à savoir : l'allocation des ressources, pour financer la production de biens et services considérés comme essentiels pour la collectivité ; la redistribution, pour limiter les inégalités et atteindre une distribution équitable des revenus et de la richesse; la stabilisation économique à travers des politiques budgétaires et monétaires, en vue de limiter les variations cycliques de l'activité économique.

$\mathrm{Au}$ cours de la deuxième moitié du $\mathrm{XX}^{\mathrm{e}}$ siècle, les dépenses publiques ont joué un rôle de plus en plus important suite à l'affermissement du keynésianisme. Ce courant économique, issu de la pensée de John Maynard Keynes, prônait que l'État, et donc les administrations publiques, devait jouer un rôle dans la sphère économique, notamment en matière de création d'emplois. Toutefois, cela ne suffit pas à expliquer la croissance, aussi bien en termes absolus que relatifs, des dépenses publiques depuis la fin de la Seconde
Guerre mondiale. C'est vers la fin du XIX ${ }^{\mathrm{e}}$ siècle que l'économiste allemand Adolph Wagner a énoncé pour la première fois la «loi de l'extension croissante de l'activité publique». Selon cette loi, les dépenses publiques augmentent plus rapidement que la richesse produite au fur et à mesure que l'économie se développe. Cette progression est principalement due à trois facteurs: l'urbanisation et l'augmentation de la population, qui appellent des formes plus avancées d'organisation de la vie collective; l'élévation du niveau de vie, qui induit une demande accrue de certains biens publics dits supérieurs (comme l'éducation, la santé ou la culture), leur demande augmentant plus vite que le revenu par tête; et la nécessité de financer des investissements en infrastructures, suite à l'avancement du processus d'industrialisation. Les auteurs de l'école des choix publics, un courant de pensée fondé aux ÉtatsUnis au milieu du $\mathrm{XX}^{\mathrm{e}}$ siècle, estiment que la croissance des dépenses publiques est déterminée par des facteurs politiques, car les gouvernements, en période électorale, tendent à augmenter les transferts sociaux et les investissements publics pour s'attirer les faveurs des électeur-trice-s; des facteurs sociaux, en raison de la rigidité des dépenses publiques à la baisse; des facteurs institutionnels, étant donné que lors du processus budgétaire, les administrations ont tendance à demander une augmentation des ressources afin d'améliorer leur prestige et leur position. D'autres auteurs expliquent la hausse des dépenses publiques en invoquant la tendance des coûts des services offerts par les administrations publiques à croître à des taux plus élevés que ceux du secteur privé, notamment en raison d'une faible possibilité du secteur des services de bénéficier du progrès technique.

La croissance des dépenses et des déficits publics dans l'après-guerre a suscité la réaction de la pensée libérale qui, à partir de la fin des années 1970, a imposé le retour à la primauté du marché et de ses règles. Depuis lors, 
la plupart des pays ont introduit un frein aux dépenses publiques et à l'endettement public, poussé la privatisation de certains secteurs traditionnellement liés à l'État et encouragé l'adoption de nouvelles formes d'organisation et de gestion des services publics inspirées par les principes de la nouvelle gestion publique et de la gouvernance publique.

Le rapport entre les dépenses publiques et le PIB en Suisse se situe à quelque $33 \%$ en 2014 et est l'un des plus bas parmi les pays de l'OCDE. Dans l'État fédéral suisse, les dépenses publiques sont partagées entre trois niveaux institutionnels, à savoir la Confédération, les cantons et les communes dans un cadre défini par la Constitution de 1999. Depuis 2008, il existe une nouvelle répartition des compétences entre la Confédération et les cantons ainsi qu'une solidarité verticale (de la Confédération vers les cantons) et horizontale (entre les cantons) régie par un système de péréquation. Par conséquent, les relations financières entre les cantons et leurs communes ont également été modifiées. En 2008 est aussi entrée en vigueur la Nouvelle politique régionale (NPR) qui vise à stimuler la capacité d'innovation et à renforcer la compétitivité nationale et internationale des régions de montagne, des autres régions rurales ainsi que des régions frontalières de la Suisse.

En comparaison internationale, la part de l'emploi public par rapport à l'emploi total est également faible. Il faut néanmoins constater que ces dernières décennies, c'est l'État qui a créé de l'emploi en Suisse, notamment dans le domaine de la santé, de l'éducation, du social et de la culture. La faible importance du secteur public s'explique par le fait que certains cantons, depuis les années 1990, mais aussi la Confédération, depuis 2003, sont soumis au principe du frein à l'endettement et à d'autres règles budgétaires qui, comme le relève l'OCDE, empêchent la hausse des dépenses et du déficit. L’endettement de l'État reste bas en comparai- son internationale, nettement en dessous de la barre des $60 \%$, déterminante dans la zone euro.

Aujourd'hui, le débat sur les dépenses publiques est fortement influencé par la nécessité de surmonter la crise et de stimuler l'économie. Le dilemme est entre une politique de rigueur financière - ou politique d'austérité - d'un côté et l'augmentation des dépenses publiques financées par des déficits de l'autre. Si le principe de la rigueur l'emporte, il peut être mis en œuvre à travers une réduction des dépenses, une augmentation des impôts ou un mix des deux. Dans de nombreux cas, ceux qui mettent en œuvre la rigueur ne visent pas seulement la réduction des dépenses, mais aussi celle des impôts qui souvent précède la réduction des dépenses, transformant cette dernière en une conséquence inévitable du fait du manque de ressources fiscales et obligeant ainsi à recourir à l'emprunt sur les marchés de capitaux privés (stratégie des caisses vides ou de l'État pauvre). Dans le débat actuel, on néglige souvent que s'endetter n'est pas nécessairement mauvais en soi, a fortiori dans une période de taux d'intérêt négatifs, pourvu que la dette soit utilisée pour financer les investissements (lesquels comportent normalement des rendements pour la collectivité, en permettant p.ex. de faire face aux défis de la digitalisation et de la globalisation de l'économie). Contrairement à un ménage, qui doit rembourser sa dette dans un laps de temps donné, l'État peut demeurer endetté pourvu qu'il démontre sa faculté à assurer le service de sa dette. En outre, la dette de l'État ne va pas nécessairement grever les générations futures, dans la mesure où la génération qui hérite une dette hérite également un crédit. Après tout, il n'y a qu'une seule façon pour la génération présente de s'endetter au détriment des générations futures: c'est en leur laissant le soin de payer la facture, en contractant avec l'étranger plus de dettes que de crédits, par exemple en important plus de biens et de services qu'on en exporte. Ce n'est pas le cas de la Suisse, dont la 
balance des transactions courantes est régulièrement excédentaire.

\section{Spartaco Greppi}

\section{Références}

Dafflon, B. (2014). Le fédéralisme financier suisse: état des lieux et réformes récentes. Dans M. Leroy \& G. Orsoni (Éd.), Le financement des politiques publiques (pp. 605-654). Bruxelles: Bruylant.

Département fédéral des finances (Éd.) (2004). $L a$ politique budgétaire de A à Z: termes essentiels de la politique budgétaire, de la politique de place financière et de la surveillance des marchés financiers. Berne : Département fédéral des finances.

Guex, S. (1998). L'argent et l'État: parcours des finances publiques au XX $X^{e}$ siècle. Lausanne : Réalités sociales.

\section{Développement urbain}

Le phénomène urbain a longtemps été contenu et limité au territoire d'une commune: la ville, qui se caractérisait par une séparation claire d'avec la campagne. Cette ville traditionnelle a peu à peu disparu et d'importantes mutations ont provoqué l'émergence de régions urbaines («agglomérations»). Selon la définition de l'Office fédéral de la statistique en vigueur depuis 2012, l'espace urbain helvétique se compose de 49 agglomérations. Celles-ci rassemblent plus d'un millier de communes et concentrent $73 \%$ de la population et $79 \%$ des places de travail. Une agglomération est constituée d'une ville-centre et de ses couronnes, soit des communes qui lui sont fortement liées selon des critères morphologiques ou fonctionnels. On distingue généralement les communes suburbaines (continuité du bâti avec le centre, forte densité, zones d'activités économiques, grands ensembles d'habitation, etc.) des communes périurbaines (paysage à dominante rurale, faible densité, prépondérance de la maison individuelle, forte proportion de pendulaires, etc.).
La dynamique territoriale la plus marquante depuis les années 1960 est l'étalement urbain, soit la croissance conséquente des couronnes suburbaines et périurbaines. Cette extension des agglomérations est le fruit de plusieurs facteurs influençant la localisation des ménages et des entreprises. Certaines activités économiques - comme l'industrie, la logistique ou les centres commerciaux - privilégient une localisation où le terrain est plus abondant et moins cher et qui bénéficie d'une grande accessibilité routière. L'habitat joue un rôle plus important dans l'étalement urbain car sa diffusion touche des communes de plus en plus éloignées des centres. Cette dynamique s'explique de différentes manières selon les périodes et les catégories de population. On peut distinguer l'influence d'aspirations résidentielles (accéder à la propriété, disposer d'un logement plus spacieux, d'une plus grande proximité avec la nature, d'un environnement plus favorable pour élever des enfants, etc.) mais aussi de contraintes économiques (pénurie du marché immobilier et prix élevé des appartements de grande taille dans les centres, etc.). Ce mouvement a été rendu possible par la diffusion de la voiture individuelle qui a permis à certaines catégories de population de vivre à plus grande distance des centres d'emplois. Il a également été encouragé par des promoteurs immobiliers ainsi que par certaines communes pour qui l'accueil de nouveaux habitants constitue une stratégie de développement.

Si l'étalement urbain demeure actuellement la tendance dominante, les villes-centres ont connu d'importantes transformations ces dernières années. Entre 1970 et 2000, la majorité d'entre elles ont perdu des habitants, sous l'effet conjoint du départ des familles vers les couronnes, du vieillissement de leur population, de la diminution de la taille moyenne des ménages et de l'augmentation de la consommation d'espace habitable. Depuis le début des années 2000 en revanche, elles enregistrent une nouvelle phase de croissance démogra- 
phique («réurbanisation») en raison essentiellement des migrations internationales et de l'installation de jeunes adultes. Autre tendance marquante, certains quartiers centraux ont fait l'objet d'un réinvestissement au profit des classes moyennes supérieures ("gentrification») sous la forme de nouvelles constructions ou d'opérations de réhabilitation du bâti. Ce dernier point soulève la problématique du risque de relégation de ménages au pouvoir d'achat peu élevé vers les communes suburbaines et leur éloignement des aménités et infrastructures urbaines.

Malgré leur regain d'attractivité, il est important de préciser que les villes continuent à enregistrer des taux d'aide sociale supérieurs à la moyenne. Ainsi, les six grandes villes (Zurich, Genève, Bâle, Lausanne, Berne et Winterthour) abritent un quart des bénéficiaires $d u$ pays contre un septième des habitants. Ce phénomène s'explique lui-même par la surreprésentation de catégories de population plus vulnérables tant en termes de capital économique que social (migrant·e·s peu qualifié·e·s, familles monoparentales, jeunes rencontrant des difficultés d'insertion professionnelle, etc.). Elles trouvent notamment en ville certaines opportunités sur le marché immobilier (en raison de la présence de logements petits et anciens). Les villes ont réagi en mettant en place un certain nombre de mesures comme l'illustre la constitution de «l'Initiative des villes pour la politique sociale». Les dynamiques résidentielles à l'œuvre rendront les questions sociales de plus en plus prégnantes dans certaines communes suburbaines. Il en est de même du vieillissement de la population qui concernera également davantage les communes qui ont connu une forte croissance démographique il y a quelques décennies et dont la population a vieilli sur place.

La «métropolisation» constitue un autre phénomène caractérisant le développement urbain en Suisse. Ce terme désigne, d'une part, le renforcement des plus grandes aggloméra- tions (avec une concentration de la population, des activités à haute valeur ajoutée, des richesses) et, d'autre part, la constitution d'un réseau des villes suisses. Ce fonctionnement en réseau est à la base de l'hypothèse de l'émergence d'une «métropole suisse». On y trouve la concrétisation du constat dressé par Rousseau au XVIII ${ }^{e}$ siècle déjà et qui considérait la Suisse comme une grande ville divisée en quartiers.

Les débats des dernières années ont porté en grande partie sur les impacts négatifs de l'étalement urbain. Le mitage du paysage et l'utilisation croissante du sol ont été particulièrement mis à l'index lors de la votation sur la révision de la loi sur l'aménagement du territoire en 2013. D'autres critiques de la «ville étalée» ont porté sur la place prépondérante de la voiture (et ses effets négatifs en termes de consommation énergétique et d'émission de polluants) et sur les coûts de l'urbanisation de faible densité. Parallèlement, la forte croissance démographique et économique enregistrée par la Suisse dans les années 2000 et les changements de mode de vie se sont heurtés à un développement plus lent du marché du logement et des infrastructures de transport. Ce décalage s'est notamment traduit par une augmentation des prix de l'immobilier et par une utilisation accrue - parfois perçue comme une saturation - des infrastructures de transport.

En réaction aux impacts négatifs de la «ville étalée» est prôné le modèle urbanistique de la «ville compacte». Il s'agit d'orienter l'urbanisation vers l'intérieur du tissu bâti, de densifier l'environnement construit (en redéveloppant d'anciennes zones industrielles p.ex.) et de planifier l'urbanisation en fonction des transports publics et des mobilités actives. Un des enjeux centraux pour le développement territorial est d'appliquer les principes de densification tout en garantissant une qualité de vie et d'habitat élevée et accessible pour l'ensemble des catégories de population notamment en termes de pouvoir d'achat. Cette nouvelle manière 
de faire la ville implique des démarches innovantes comme la prise en compte des modes de vie et des aspirations résidentielles, l'aide à des maîtres d'ouvrage d'utilité publique (tels que les coopératives) ou encore la mise en œuvre de démarches participatives visant à atteindre une qualité de vie partagée.

\section{Patrick Rérat}

\section{Références}

Bassand, M. (2004). La métropolisation de la Suisse. Lausanne: Presses polytechniques et universitaires romandes.

Office fédéral de la statistique (Éd.) (2014). L'espace à caractère urbain 2012. Neuchâtel : Office fédéral de la statistique.

Rérat, P. (2015/6). Le retour des villes : les phénomènes de déprise et de reprise démographiques dans les villes suisses. Espace, populations, sociétés, 3/1, en ligne. http://journals.openedition.org/ eps/6204.

\section{Dignité humaine*}

Le concept de dignité humaine a joué un rôle important dans les débats éthiques, juridiques et politiques de ces dernières années. C'est le cas tant au niveau international qu'en Suisse. L'article 7 de la Constitution fédérale stipule que la dignité humaine doit être respectée et protégée. Aux fins d'interprétation de cette norme, la Feuille fédérale du 14 janvier 1997, par exemple, établit que la dignité humaine revêt, premièrement, un caractère subsidiaire et peut être appliquée comme la «dernière ressource du droit au cas où la garantie de tous les autres droits fondamentaux demeurerait inefficace»; deuxièmement, elle constitue le «noyau et le point de départ» d'autres droits fondamentaux et détermine l'«interprétation et le développement» de ceux-ci ; et troisièmement, «plusieurs domaines de l'ordre juridique» lui sont liés en tant que norme «de programme» (cf. pages 140-141).
Le droit à l'aide sociale en particulier est explicitement lié à la dignité humaine dans la Constitution fédérale. Son article 12 prévoit que «quiconque est dans une situation de détresse et n'est pas en mesure de subvenir à son entretien a le droit d'être aidé et assisté et de recevoir les moyens indispensables pour mener une existence conforme à la dignité humaine». Ce rôle central de la dignité humaine dans le système juridique suisse en général et pour la légitimation de l'aide sociale en particulier soulève inévitablement des questions sur sa nature et son contenu. Clarifier ces questions est essentiel, non seulement pour déterminer avec plus de précision les moyens que l'aide sociale, par exemple, doit fournir, mais aussi pour contrer les critiques du concept de dignité humaine, critiques qui lui refusent justement cette capacité de légitimer des normes concrètes. Selon ces critiques, le terme est désespérément vague et souvent instrumentalisé à des fins idéologiques ou politiques. D'un point de vue philosophique, trois questions se posent avant tout : qu'est-ce que la dignité humaine? Qui peut en jouir? Et quels biens vise-t-elle à protéger?

La question portant sur la définition de la dignité est d'abord confrontée au problème suivant: la notion de dignité est utilisée dans différentes expressions relatives aux personnes humaines. Ainsi, on parle par exemple d'un «comportement digne» en référence aux rôles sociaux, en le refusant par exemple à un juge qui se rend ivre à un procès. Il s'agit là de ce qu'on pourrait appeler une «dignité contingente»; elle peut se perdre si le rôle social n'est pas respecté. Dans le cadre de cet article, nous nous intéresserons uniquement à la forme de la dignité qui peut être attribuée aux individus en tant qu'êtres humains.

Contrairement à la dignité contingente, cette «dignité inhérente» ne dépend pas du comportement de la personne ni de tiers. En effet, même une violation des droits légitimés par la dignité humaine ne fait pas perdre la dignité. Cette caractéristique se reflète dans 
le principe de finalité de l'aide sociale, selon lequel les circonstances dans lesquelles le besoin est apparu ne sont pas déterminantes. Que le besoin naisse par la faute de la personne ou par la faute de tiers, la dignité humaine exige que les personnes concernées soient soutenues et aidées afin de sortir de leur situation de détresse.

En outre, les droits fondés sur la dignité humaine doivent se distinguer par leur importance particulière. Quiconque porte atteinte à la dignité humaine ne commet pas simplement une faute morale, mais nuit gravement à celui ou celle qui jouit de la dignité. La forme de dignité humaine dont il est question ici n'est pas non plus quelque chose que l'on peut accorder plus ou moins complètement. Toute personne qui possède la dignité humaine, la possède au même degré et en dispose de la même manière.

Mais quels sont les groupes cibles des normes fondées sur la dignité humaine, et sur la base de quelles qualités une personne jouit-elle de la dignité humaine? On répond généralement à la deuxième question en nommant certaines capacités qui semblent «typiques» pour le cercle supposé des êtres humains comme la capacité de vivre, l'autodétermination, la rationalité ou le respect de soi. Le nombre de personnes possédant la dignité humaine varie selon la définition de ces capacités. Les théoriciens et théoriciennes de la dignité sont largement d'accord pour dire que les capacités prises en compte devraient être interprétées de telle sorte qu'au moins toutes les personnes en vie entrent dans le champ de protection de la dignité humaine. Cependant, des divergences se manifestent notamment en ce qui concerne le début et la fin de la vie humaine: la dignité humaine concerne-t-elle aussi les embryons dans un stade précoce? Les personnes disposent-elles toujours de la dignité humaine lorsqu'elles sont plongées dans un coma irréversible?
Les capacités qui fondent la dignité humaine apportent les premiers éléments d'appréciation de l'étendue de sa protection. Par exemple, si la capacité de respect de soi est au centre de l'attribution de la dignité humaine, il semble plausible de supposer que la dignité humaine protège la valeur que cette capacité a pour nous. Afin de protéger le respect de soi, la dignité humaine justifie alors l'interdiction d'humiliations et d'avilissements. Elle peut être étendue à la garantie des conditions nécessaires au respect de soi des individus.

C'est précisément à partir de ces conditions que l'on peut définir les ressources que l'aide sociale devrait fournir pour permettre une vie digne. En y regardant de plus près, ces conditions s'avèrent largement indépendantes des capacités qui fondent la dignité: le respect de soi, la rationalité ou l'autodétermination présupposent, tous trois, un minimum de bienêtre physique, émotionnel et social sans lequel ils ne peuvent se développer. Une personne qui vit dans l'extrême pauvreté ne peut décider de manière autonome; une pauvreté relative par rapport au contexte social compromet le développement et le maintien du respect de soi. Il est donc relativement aisé d'identifier les biens auxquels chaque personne devrait avoir droit: un logement doté d'un confort adéquat, les moyens de se nourrir, de se vêtir et d'assurer son hygiène corporelle, de prendre soin de sa santé et de participer à la vie publique, et plus encore. Bien sûr, cette spécification ne doit pas conduire à attribuer aux personnes, de manière paternaliste, une quantité étroitement définie de biens. Même si la majorité des théories de la dignité n’associe pas dignité humaine et respect de l'autonomie de l'individu, cette dernière constitue une norme de protection essentielle fondée sur la dignité humaine. Ainsi, l'autonomie représente un axe important de l'aide sociale et de son principe d'individualisation.

Dans une approche théorique, les normes justifiées par la dignité humaine n'apparaissent pas seulement comme le «produit final» d'une 
conception préalable de la nature et des fondements de l'attribution de la dignité humaine. Comme plusieurs auteur·e.s l'ont souligné, notre compréhension de la dignité humaine est d'abord et avant tout guidée par l'expérience de ses violations, ce qui présuppose la validité de certaines normes. Les exemples historiques de traitements dégradants ou d'asservissement de groupes ethniques entiers nous font prendre conscience des principes moraux qui interdisent, de manière quasiment absolue, certains actes et comportements envers nos semblables. De tels «exemples typiques» de violations de la dignité aident à façonner, dans le cadre d'une réflexion morale, le concept de dignité humaine qui sous-tend ces normes.

\section{Sebastian Muders \& Holger Baumann}

\section{Références}

McCrudden, C. (Ed.) (2013). Understanding human dignity. Oxford: Oxford University Press.

Rosen, M. (2011). Dignity: its history and meaning. Cambridge: Harvard University Press.

Schaber, P. (2010). Instrumentalisierung und Würde. Paderborn: Mentis-Verlag.

\section{Diversité* $^{*}$}

Le terme diversité (diversity, Diversität) décrit la variété ou l'hétérogénéité des situations et des caractéristiques personnelles et contextuelles des personnes. Il souligne le fait que les individus ne sont pas seulement différents les uns des autres, mais qu'ils sont en même temps porteurs des propriétés caractéristiques les plus diverses. Les dimensions primaires de la diversité, considérées comme des attributs assignés et en grande partie immuables, sont notamment le sexe ou l'âge, l'origine nationale et sociale, les capacités intellectuelles et physiques ou encore l'orientation sexuelle. Les dimensions secondaires de la diversité, telles que la formation, le lieu de résidence, l'état civil, le revenu, la profession ou l'expérience de vie, sont considérées comme acquises au cours de la vie. Notons que certaines caractéristiques, comme l'appartenance religieuse, sont difficiles à attribuer à l'une ou l'autre catégorie, tandis qu'il existe des interactions entre les dimensions primaires et secondaires (p.ex. entre l'origine sociale et la formation). Dans une perspective sociopolitique, la question se pose de savoir dans quelle mesure des problèmes spécifiques d'inégalité sociale et de discrimination ainsi que l'exclusion sociale d'individus ou de groupes sont liés aux dimensions ou catégories identitaires décrites ici et à leur enchevêtrement.

Les origines du concept remontent au mouvement afro-américain pour les droits civiques et au mouvement féministe en Amérique du Nord entre 1950 et 1970 . C'était la première fois que des militant.e.s des droits civiques et des organisations de femmes s'opposaient aux formes racistes et sexistes de discrimination dans la société et sur le marché du travail et appelaient à l'égalité des droits politiques pour tous les citoyens et toutes les citoyennes des États-Unis. La loi sur les droits civils (Civil Rights Act) de 1964 ainsi que les programmes Affirmative Action (AA) et Equal Employment Opportunity (EEO) ont constitué le socle d'une première obligation légale d'antidiscrimination sur le marché du travail nord-américain. Dans les années 1980, les pionniers de l'approche de la diversité, notamment Taylor $\mathrm{H}$. Cox et R. Thomas Roosevelt Jr., opposèrent aux programmes d'antidiscrimination axés sur l'équité et la justice l'affirmation provocatrice selon laquelle il ne s'agissait là que d'«interventions artificielles », dont le succès était voué à disparaître tôt ou tard. Leurs idées relatives à une «gestion de la diversité », développées dans les écoles de gestion du Michigan et de Harvard et dans le cadre du conseil aux entreprises, se fondaient sur un changement fondamental de perspective. Celui-ci mettait en évidence 
le fait qu'une approche sensible et critique de la diversité des personnes eu égard aux transformations sociales, démographiques et économiques était non seulement indispensable sur le plan social, mais aussi qu'elle recelait un grand potentiel et présentait d'immenses avantages pour les entreprises. La «perspective entrepreneuriale», qui est depuis lors fortement liée à l'approche de la diversité, conçoit l'hétérogénéité de la société et du personnel des entreprises comme une ressource. De ce point de vue, un environnement de travail non discriminatoire augmente non seulement la satisfaction et la performance des employéee-s, mais il a aussi des effets positifs sur la qualité du travail et la productivité, la capacité de résolution des problèmes et d'innovation, ainsi que sur l'accès au marché des entreprises.

Le concept de diversité, utilisé depuis les années 1990 pour de nombreuses questions pratiques relatives à la gestion et à l'organisation du travail, est aujourd'hui souvent discuté dans le contexte des problématiques liées à l'égalité des sexes ou à la politique sociale. Il met en évidence, au niveau sociétal, des structures complexes de discrimination et les risques sociaux qui en découlent, par exemple en ce qui concerne les possibilités de formation, l'accès au marché du travail ou la sécurité sociale des personnes âgées. Étant donné que le concept de diversité permet de traiter les questions sociales d'une manière beaucoup plus différenciée qu'auparavant en considérant certains groupes cibles (p.ex. les travailleur.euse-s atypiques, les parents élevant seuls leurs enfants) ou les formes cumulatives de discrimination (p.ex. les femmes peu qualifiées issues de la migration), il se révèle très pertinent dans le domaine de la politique sociale. Les aspects sociopolitiques du concept de diversité apparaissent également en l'articulant au concept d'inclusion. Ce dernier fait référence, au sens normatif, à la tâche d'intégration sociale de l'État dans une société de plus en plus diversifiée. Et lorsqu'on se penche sur la sphère poli- tique, on s'aperçoit que les réformes et stratégies de politique sociale ne peuvent répondre à la variété des conditions et des situations de vie individuelles que si elles sont abordées conjointement avec d'autres domaines politiques, tels que la politique de formation, de l'emploi ou de la migration.

L'interdiction de toute discrimination $\mathrm{du}$ fait de l'âge, du sexe, de l'origine ethnique, $\mathrm{du}$ handicap, de la race, de la religion et de l'orientation sexuelle, formulée dans le traité d'Amsterdam en 1997, constitue un socle juridique pour la diversité au sein des entreprises. Depuis le début du XXI ${ }^{\mathrm{e}}$ siècle, les violations du principe d'égalité de traitement dans et en dehors du monde du travail sont sanctionnées par diverses directives et lois européennes sur l'égalité de traitement. Par ailleurs, depuis 2004, de nombreux pays européens ont signé une Charte de la diversité, s'engageant par là à prendre des mesures de lutte contre la discrimination et pour l'égalité en tenant compte de facteurs de diversité très variés.

Le $1^{\text {er }}$ janvier 2000, la Suisse a introduit pour la première fois l'interdiction de la discrimination dans sa Constitution de manière explicite avec l'article 8, alinéa 1. Cette interdiction précise que nul ne doit subir de discrimination du fait de son origine, de sa race, de son sexe, de son âge, de sa langue, de sa situation sociale, de son mode de vie, de ses convictions religieuses, philosophiques ou politiques ni du fait d'une déficience corporelle, mentale ou psychique. Cependant, la notion ou le concept sociopolitique de diversité ne se généralise que lentement au sein de la Confédération, et ce malgré le fait que sa population se distingue, notamment en vertu de ses quatre communautés linguistiques officielles, par une grande diversité culturelle et le pluralisme de ses valeurs. De plus, en comparaison européenne, la population résidente et active inclut une proportion très élevée d'immigrant·e.s. Ce sont principalement les analyses et les débats axés sur l'égalité des sexes et la politique d'intégra- 
tion qui entraînent aujourd'hui une réflexion sur les discriminations dues à l'hétérogénéité socioculturelle en Suisse. En particulier pour la population migrante, la question se pose de savoir comment créer un cadre institutionnel qui lui garantisse les mêmes chances en termes de participation (Teilhabe) sociale.

Aujourd'hui, la notion de diversité est considérée comme insuffisamment prise en compte dans ses dimensions et sa portée sociopolitiques. L'interprétation dominante du concept dans l'espace européen, qui se détourne des inégalités socioculturelles de répartition des ressources et des chances pour ne souligner que les avantages de la diversité pour les entreprises, doit notamment être considérée d'un œil critique. Les discours et mesures relatifs à la diversité qui dominent dans le contexte économique visent avant tout l'intégration de travailleur-euse-s hautement qualifié.e.s; ils n'améliorent guère la situation des femmes peu qualifiées issues de la migration. En Suisse tout spécialement, des études récentes mettent en évidence les discriminations particulières sur le marché du travail et dans le système de sécurité sociale auxquelles sont confrontées les femmes avec des obligations de care, issues de la migration et qui occupent des emplois précaires. De plus, des recherches récentes révèlent les conséquences négatives d'une politique sociale qui, en termes de sécurité sociale et de qualité de vie des personnes âgées, prend encore et toujours comme référence un emploi stable à temps plein tout au long de la vie, ignorant ainsi la situation de nombreuses femmes ou de jeunes travailleur·euse-s. D'un point de vue sociopolitique en particulier, il est nécessaire de renouer avec les origines politico-normatives du concept qui aborde prioritairement l'inégalité sociale et les risques sociaux qui lui sont associés.

\section{Références}

Liebig, B., Gottschall, K. \& Sauer, B. (Eds.) (2016). Gender equality in context: policies and practices in Switzerland. Opladen: Barbara Budrich.

Riedmüller, B. \& Vinz, D. (2009). Diversity als Herausforderung für die Sozialpolitik. In S. Andresen, M. Koreuber \& D. Lüdke (Hrsg.), Gender und Diversity: Albtraum oder Traumpaar? Interdisziplinärer Dialog zur „Modernisierung “ von Geschlechter- und Gleichstellungspolitik (S. 65-78). Wiesbaden: VS.

Vertovec, S. (Ed.) (2015). Routledge international handbook of diversity studies. Abingdon: Routledge.

\section{Divorce}

Le divorce signe la fin légale des unions par mariages, il implique la recomposition des obligations d'entretien, d'assistance et d'éducation qui y étaient liées. Toutefois, il ne dissout pas l'alliance qui perdure notamment au travers des enfants. De plus, cette séparation juridique n'est qu'une des formes de ruptures conjugales possibles: on peut se séparer légalement sans divorcer et même sans avoir été mariés civilement.

L'imbrication du système de genre, du patriarcat et du capitalisme fait que le divorce ou la séparation, lorsqu'il y a des enfants, devient une étape risquée de la vie familiale, en termes économiques et sociaux, quel que soit le statut des personnes concernées (époux ou épouse, enfant, père, mère ou parent social). La division sexuée du travail (séparation et hiérarchisation des activités masculines et féminines, ségrégation entre la sphère productive et reproductive) et le régime de genre en vigueur (naturalisation des rôles parentaux, assignation des femmes aux soins des proches) pèsent sur les processus de séparation, la famille restant associée à la gratuité et ne donnant que peu de rétributions s'agissant des droits sociaux.

Les politiques encadrant le divorce ne prennent pas en compte les inégalités de 
genre et de statut en matière d'assistance aux enfants. De ce fait, elles ne parviennent pas à compenser la «charge mentale» et matérielle que représente l'éducation d'un enfant lorsque les parents sont séparés. Elles restent plutôt paternalistes, voire patriarcales, s'adaptent trop lentement aux mutations familiales et sont incapables d'en limiter les coûts spécifiques pour certaines populations, alors même que l'objectif de justice sociale est au cœur de leur développement.

Des changements législatifs notables sont pourtant à signaler. En 2000, la loi fédérale consacre le divorce par consentement mutuel, la possibilité d'une autorité parentale conjointe et la reconnaissance partielle du travail ménager effectué par les femmes par le partage du $2^{\mathrm{e}}$ pilier notamment. En 2014, plus tard que dans les autres pays européens, l'autorité parentale conjointe devient la modalité ordinaire du «départage de l'enfant». Les négociations ont été ardues, car des voix, notamment celles des féministes, se sont élevées, afin que soient liées la question de l'autorité parentale et celle de l'entretien de l'enfant. Elles n'ont pas été entendues et un certain nombre de questions restent ouvertes en lien avec la résidence de l'enfant.

La sous-estimation du care pénalise les personnes qui le produisent et les enfants. De ce fait, près de la moitié des enfants recevant l'aide sociale vivent dans des foyers monoparentaux. Les lois visant une meilleure répartition des charges, le partage du deuxième pilier par exemple, ne sont qu'imparfaitement appliquées. Les contributions d'entretien destinées aux enfants, payées irrégulièrement dans $20 \%$ des cas et inférieures aux coûts effectifs des enfants, créent des injustices entre les familles des classes populaires et celles des milieux aisés: il est beaucoup plus pénalisant financièrement pour un père au revenu modeste de payer une pension, si modique soitelle, que pour un père directeur de banque. Les pratiques de recouvrement et d'avance de pen- sion, dépendantes de l'action des bénéficiaires, contribuent toujours et encore à l'accroissement des inégalités entre les familles. En fait, les politiques sociales ne répondent pas au risque économique encouru parce qu'elles se confinent au registre assistanciel et à celui de la subsidiarité : l'aide sociale est accordée sous «condition de ressources» et remboursable lorsqu'on revient à meilleure fortune; l'aide au recouvrement, suivant des règles fluctuantes, n'est disponible qu'aux plus pauvres.

Si l'autorité conjointe et la garde partagée marquent symboliquement une place équivalente des deux parents, elles ne sont pas synonymes d'égalité et peuvent être le lieu d'une démonstration de puissance et un moyen de pression supplémentaire pour les parents, puisque chaque décision importante peut être négociée et refusée par la partie adverse, contrevenant ainsi à l'idéal de coparentalité souhaité par la loi. Sans garde-fous et sans contrôles, elles pourraient, d'une part, légitimer le paiement de pensions très basses par les individus bénéficiant d'un revenu supérieur grâce à leur inscription en continu et à plein temps dans le travail salarié. Et d'autre part, elles ne les empêcheraient pas de déléguer à d'autres personnes une partie des tâches éducatives qui leur échoient en tant que coresponsables de l'enfant. Les quelques interventions sociales cherchant à réduire ces tensions, telle la médiation familiale, ne sont pas pensées dans une perspective de rapports sociaux potentiellement conflictuels et peuvent apparaître comme une imposition faite aux personnes dominées. Par ailleurs, dans les cas de violences conjugales, très peu de mesures permettent de protéger l'enfant.

Une part des professionnel-le-s de l'accompagnement social mobilisent des définitions normatives de ce que devrait être une famille ainsi que des visions passablement négatives des parents séparés. Si le stigmate s'est estompé du fait de la banalisation du divorce, les foyers monoparentaux, dont plus de $80 \%$ 
ont une femme à leur tête, sont de manière générale plus soumis à l'examen. Le nombre d'enfants institutionnalisé.e-s issu·e-s de ce type de ménage, environ $70 \%$ de la population accueillie, en témoigne. De plus, les structures de garde censées soulager les parents sont insuffisantes, chères et peu flexibles face aux situations de l'après-divorce: il est compliqué de changer le jour où l'enfant est accueilli; un foyer monoparental ou une garde partagée n'octroient pas de priorité pour l'obtention d'une place en garderie. Cette quasi absence de politiques substitutives orientées vers un traitement égalitaire entre les enfants, un dépassement des codes de genre et une interchangeabilité des rôles des parents complexifie l'organisation quotidienne des mères et des pères, même s'ils sont coopérants, et engendre une forme de fragilisation parentale, doublée d'une discrimination potentielle principalement pour les familles en difficulté.

Considérer le divorce comme un risque social requiert d'imaginer un mode collectif et réellement égalitaire de traiter cet événement probable pour une grande partie de la population. Le traitement devrait alors s'émanciper des pièges de genre. Il chercherait à diminuer les inégalités structurelles en élevant globalement les salaires dans les branches féminisées de l'économie et en offrant une juste rémunération du care effectué par les personnes qui sont pourvoyeuses de soin et productrices de travail domestique. Il pourrait comprendre une assurance-divorce, avec retenue automatique sur le salaire du débiteur, inspirée de l'assurance-vieillesse et survivants (AVS). Un revenu minimum de base pour chaque enfant serait aussi à envisager. Il tendrait à redistribuer les responsabilités «du faire famille» et à contrer la réification des rôles familiaux en fonction du sexe par la mise en place de divers soutiens sociaux (formation des professionnel·le·s, garderie, activités culturelles, etc.).

\section{Clothilde Palazzo-Crettol}

\section{Références}

Freivogel, E. (2007). Contribution d'entretien après le divorce: soutien financier par des proches parents. Aide sociale. Questions au féminin, 1, 25-38.

Palazzo-Crettol, C. (2014). Du bien-être des enfants et des politiques sociales: des enjeux contradictoires. Dans P. Jaffé (Éd.), Enfants, familles, État: les droits de l'enfant en péril (pp. 60-68). Sion: Institut universitaire Kurt Bösch.

Stutz, H., Knupfer, C. \& Thomet, U. (2012). La protection sociale du travail de care non rémunéré: les besoins d'adaptation de l'État social liés à l'évolution du partage du travail entre femmes et hommes. Berne: Bureau fédéral de l'égalité entre femmes et hommes.

\section{Droit de l'aide sociale*}

On entend par droit de l'aide sociale le corps de droit public qui se consacre aux prestations d'aide sociale aux personnes dans le besoin. Il est désormais d'usage de distinguer entre un droit de l'aide sociale au sens strict et un droit de l'aide sociale au sens large. Au sens strict, il s'agit des normes juridiques qui se fondent sur une loi formelle en matière d'aide sociale. Au sens large, on entend par aide sociale toutes les prestations sous condition de ressources, cantonales et communales, se trouvant en aval des prestations d'assurance sociale. Par conséquent, outre l'aide sociale au sens strict, elle inclut aussi des bourses d'étude, des allocations au logement ou aux parents, etc.

Les actes juridiques pouvant être imputés au droit de l'aide sociale sont ainsi tout aussi variés. Au sens strict, le droit de l'aide sociale est généralement restreint à la législation cantonale en matière d'aide sociale qui régit les prestations de droit public accordées aux personnes n'étant pas en mesure d'assurer leur subsistance par leurs propres moyens et étant donc considérées dans le besoin. Il s'agit aussi des dispositions nationales et internationales qui traitent de l'assistance aux personnes dans le besoin. 
Il y a quelques décennies encore, le droit de l'aide sociale ne retenait que très peu l'attention. Les publications à ce sujet étaient peu nombreuses. La jurisprudence, peu étendue, n'avait pratiquement pas été analysée scientifiquement. La situation a changé ces dernières années. L'augmentation du nombre de cas, mais aussi des coûts de l'aide sociale, a mis les autorités communales et cantonales face à des défis bien particuliers. Qui plus est, l'étendue et les concepts de l'aide sociale ont fait l'objet de divergences idéologiques, ce qui a suscité un regain d'intérêt du public pour ce sujet. Tout ceci a contribué à placer l'aide sociale sous le feu des projecteurs. Les lois en matière d'aide sociale ont été révisées les unes après les autres. La jurisprudence s'est également étoffée; le Tribunal fédéral mais aussi les tribunaux administratifs cantonaux ont fixé un cadre pour certaines questions fondamentales.

L'aide sociale est en premier lieu une compétence cantonale. Par conséquent, ce sont les lois cantonales sur l'aide sociale qui marquent le droit de l'aide sociale. Il en existe 26, soit autant que de cantons. En dépit de leur diversité et de certaines différences, elles sont concordantes sur les maximes fondamentales de l'aide sociale. Elles ont toutes en commun le réel objectif de l'aide sociale, à savoir assurer l'existence des personnes dans le besoin. Quelles que soient les raisons de cet état de besoin, les lois stipulent que ces personnes ont droit à des prestations économiques et financières. Le principe de finalité est reconnu. Toutes les lois se fondent sur le principe de subsidiarité selon lequel les moyens propres, les prestations d'assurances sociales et les apports tiers prévalent sur l'aide de l'État. Pour ce qui est de l'ampleur des prestations, la plupart des lois renvoient d'une manière ou d'une autre aux recommandations de la Conférence suisse des institutions d'action sociale (normes CSIAS). Cette institution, à laquelle appartiennent les cantons, ainsi que des villes et des communes, élabore depuis 50 ans les standards à l'intention de la pratique, adoptés ensuite par la Conférence des directrices et directeurs des affaires sociales, puis repris par la majorité des cantons. Toutes les lois soulignent en outre l'importance de l'intégration économique et sociale comme aspect fondamental de l'aide sociale et décrivent de manière plus ou moins détaillée comment y parvenir. Les lois sur l'aide sociale portent enfin sur l'organisation et le financement de l'aide sociale au sein de chaque canton, la palette allant de la communalisation à la cantonalisation complète, avec de nombreuses formes mixtes. En tant que lois spécifiques du droit administratif public, elles comprennent aussi des règles de procédure divergeant d'un canton à l'autre. Elles décrivent de plus les voies judiciaires qui aboutissent aujourd'hui en dernière instance aux tribunaux administratifs cantonaux. Sur le plan formel, il existe des différences importantes entre les lois. Si elles régissent parfois exclusivement l'aide sociale, elles comprennent dans d'autres cas des tâches complémentaires réglant la prévention, l'aide à la jeunesse ou aux personnes handicapées.

Bien que le droit de l'aide sociale relève principalement des compétences des cantons, certains actes juridiques de la Confédération influent à plusieurs égards sur le droit de l'aide sociale. Tout d'abord la Constitution fédérale. D’une part, elle prévoit une disposition régissant les conflits de loi et établissant les compétences dans son article 115 . Cet article pose les bases constitutionnelles de la loi fédérale sur la compétence en matière d'assistance des personnes dans le besoin (LAS). D'autre part, les dispositions afférant aux droits fondamentaux ont une signification particulière pour l'aide sociale. Dans son application, le droit de l'aide sociale a souvent affaire à des atteintes aux droits fondamentaux. À cet égard, les limites constitutionnelles sont importantes. Ces dernières années, des questions sur la proportionnalité de certaines dispositions prises par les autorités, sur les obligations et les conditions, 
sur la légalité de refuser, voire de supprimer l'octroi des prestations ou sur l'admissibilité des sanctions ont donné lieu à de nombreuses controverses publiques autour de l'aide sociale. La jurisprudence et la littérature contribuent depuis quelques années à faire évoluer le droit. Régulièrement, il a été nécessaire de rappeler le principe du droit d'être entendu et d'autres droits de procédure prévus dans la Constitution car ce principe juridique était, jusque récemment, encore peu pris en compte dans la pratique administrative.

L'article 12 de la Constitution fédérale sur «le droit d'obtenir de l'aide dans des situations de détresse» occupe une position particulière parmi les droits fondamentaux. Dans une certaine mesure, il renferme l'idée centrale de l'aide sociale car il garantit à quiconque se trouve dans une situation de détresse et n'est pas en mesure de subvenir à son entretien le droit d'être aidé.e et assisté.e et de recevoir les moyens indispensables pour mener une existence conforme à la dignité humaine. Il renvoie ainsi au cœur de tous les droits fondamentaux, à savoir la dignité humaine. Cette disposition clé garantit aux personnes en situation de détresse des prestations minimales, qui doivent impérativement être assurées. Elle limite également de manière très stricte les conditions de suppression ou de refus du droit à ces prestations. Elle revêt une importance particulière au vu des débats politiques virulents portant sur des soi-disant abus de l'aide sociale ou l'attitude récalcitrante de certains bénéficiaires de prestations.

L'aide sociale, qui puise ses origines dans l'aide aux indigents d'autrefois, est assurément l'instrument de politique sociale de droit public le plus ancien. Elle se base donc sur une multiplicité de dispositions juridiques qui, dans leur ensemble, font partie du corpus du droit de l'aide sociale. En font notamment aussi partie des dispositions issues du Code civil réglementant les devoirs d'assistance entre époux et l'obligation d'entretien en vertu du droit de la famille. On y trouve également l'aide au recouvrement et les avances alimentaires qui sont importantes pour la pratique. Historiquement parlant, le droit de l'aide sociale a surtout évolué suite à des concordats, c'est à dire des conventions intercantonales, qui jouent encore un rôle aujourd'hui. Ainsi, la convention intercantonale relative aux institutions sociales réglemente le placement des enfants, des adolescent.e.s et des adultes.

On trouve par ailleurs aussi dans ce tableau d'autres dispositions juridiques fédérales qui organisent l'aide sociale destinée à des groupes de personnes spécifiques, à l'instar de la loi fédérale sur les personnes et les institutions suisses à l'étranger ou de la loi sur l'asile. Cette dernière a acquis, ces trente dernières années, une importance considérable en raison du nombre croissant de bénéficiaires de prestations et de la charge financière qu'elle représente - ce qui n'est pas sans influence sur le développement de l'aide sociale. Les réalités internationales étant de plus en plus imbriquées, les principes fondamentaux du droit international en matière d'assistance aux personnes dans le besoin (et notamment par rapport à la libre circulation des personnes) gagnent aussi en visibilité. Malgré de nombreuses lois fédérales, le droit de l'aide sociale reste fortement teinté de fédéralisme. Le fait que, jusqu'à présent, ni le législateur ni les tribunaux n'aient encore défini le montant du minimum vital appliqué à l'échelle nationale et juridiquement contraignant peut de surcroît être considéré comme une spécificité suisse.

\section{Walter Schmid}

\section{Références}

Häfeli, C. (Hrsg.). (2008). Das Schweizerische Sozialhilferecht: Rechtsgrundlagen und Rechtsprechung. Luzern: Interact.

Hänzi, C. (2011). Die Richtlinien der schweizerischen Konferenz für Sozialhilfe: Entwicklung, Bedeutung und Umsetzung der Richtlinien in den deutsch- 
sprachigen Kantonen der Schweiz. Basel : Helbing Lichtenhahn.

Wizent, G. (2014). Die sozialhilferechtliche Bedürftigkeit: Ein Handbuch. Zürich : Dike.

\section{Droit de la famille*}

Le droit de la famille constitue une branche du droit privé ou civil. Il définit les normes régissant l'établissement, la modification, la cessation et le contenu des relations juridiques entre les personnes liées par le mariage, le partenariat enregistré, la famille et la parenté. En Suisse, il s'agit du deuxième livre du Code civil (CC) intitulé «Droit de la famille». Celui-ci réglemente le droit matrimonial en première partie, la parenté (y compris le droit de la filiation et la protection de l'enfant) en deuxième partie et le droit de la protection de l'adulte en troisième partie. Les définitions classiques du droit de la famille diffèrent d'un système institutionnel à l'autre; en comparaison internationale, le droit suisse de la famille se caractérise par le fondement sur le critère formel du mariage entre un homme et une femme (binarité de genre; fondé sur le statut). En revanche, la réglementation de la communauté de vie hors mariage des couples hétérosexuels et de leurs enfants est rudimentaire, alors que la question du partenariat entre personnes de même sexe est reléguée dans la loi sur le partenariat enregistré. Ainsi, le droit suisse de la famille associe encore aujourd'hui la notion de famille légitime à la binarité de genre. Il ignore donc le changement social, ce qui est problématique pour les nouvelles formes de vie commune qui sont juridiquement inexistantes.

Le droit de la famille est influencé par des facteurs non juridiques en constante mutation - et vice versa. Les possibilités de la biotechnologie (tests génétiques, procréation médicalement assistée), l'évolution des pratiques éducatives, l'économie (pénurie de travailleur·euse-s qualifiéee-s), les mouvements migratoires et les nouvelles constellations familiales telles que les familles recomposées, sont à l'origine des tendances observées à la pluralisation. De plus, de nombreux domaines juridiques traitent de questions familiales : le droit privé, et plus particulièrement le droit de succession et le droit des personnes, mais également la loi sur la procréation médicalement assistée, le droit du travail, le droit fiscal, le droit de l'aide sociale, le droit des assurances sociales et le droit des migrations. Ainsi, les facteurs d'influence interdépendants se multiplient et créent un champ de tension qui oppose les réalités familiales vécues et une compréhension juridique fondée sur le statut.

Dans ce contexte, une série d'aspects posent problème: les reliquats de règles directement discriminatoires, les normes à l'origine d'inégalités de fait, les concepts de normes ancrés dans des stéréotypes de genre, la négligence des rapports interculturels, des pratiques façonnées par des clichés ou ne prenant pas suffisamment en compte les faits, mais également la faiblesse des infrastructures pour les familles («la famille est privée»). Ces éléments sont l'expression et la conséquence de l'idéal de la famille conjugale unique.

Sur le plan sociopolitique, le droit suisse de la famille prévoit, dans le seul cas de la famille conjugale, une indemnisation complète pour prestations effectuées au sein de sa famille et entraînant une perte (partielle) de l'autonomie économique. Trois législations revêtent à ce propos une importance particulière: le droit de l'entretien (après le mariage; séparation ou divorce), le régime matrimonial ainsi que le partage de l'avoir de prévoyance professionnelle. La notion d'entretien englobe l'ensemble des besoins vitaux d'une famille et de ses membres. On distingue les obligations et les contributions d'entretien, l'entretien sous forme de prestations en espèces (pension alimentaire en liquide) et en nature (prise en charge et tenue du ménage), l'entretien pen- 
dant et après le mariage ainsi que l'entretien de l'enfant. Le droit de l'entretien est régi par divers principes et la pension alimentaire est calculée à l'aide de diverses méthodes. Quant au régime matrimonial, il règle les effets $d u$ mariage sur les biens des époux et leurs prétentions respectives concernant les biens préexistants ou acquis pendant le mariage. Le partage de l'avoir de prévoyance professionnelle, enfin, garantit un droit individuel à l'épargne du deuxième pilier.

Toutefois, on doit noter des déficits dans les domaines couverts par la loi. Ainsi, aucun montant minimum pour une pension alimentaire adéquate pour enfants n'est fixé (p.ex. à hauteur du maximum de la rente simple d'orphelin) et les arguments relatifs à l'entretien sont souvent avancés de manière incongrue. La notion d' «entretien» désigne le plus souvent le seul entretien en espèces, alors que trop peu d'attention est accordée à l'entretien en nature. D’autre part, la répartition unilatérale du déficit est fondamentalement intenable. Le déficit désigne la différence entre les ressources disponibles et les besoins de l'ensemble des membres de la famille. Selon le principe de la répartition unilatérale, le déficit est supporté par la personne ayant droit à la pension alimentaire en espèces (en règle générale la personne ayant la garde de l'enfant, très majoritairement la femme). Cette personne sera alors plongée dans une situation de pauvreté et devra dans ce cas solliciter l'aide sociale, tandis que la personne tenue de verser la pension alimentaire en espèces (généralement la personne qui exerce une activité rémunérée, très majoritairement l'homme) conserve son minimum vital. Le partage du déficit est désormais revendiqué. D’autres aspects sont problématiques dans une logique de protection sociale, comme la dérogation au principe du partage par moitié des fonds de prévoyance ou encore l'importance centrale accordée à la mère dans le droit de la filiation.
Un droit de la famille fondé sur un modèle familial exclusif risque d'ignorer les principes directeurs (en particulier le bien de l'enfant, la liberté de choix, l'égalité) et les réalités. En effet, les responsabilités familiales sont, aujourd'hui, assumées dans une diversité d'arrangements. En se concentrant sur l'état civil, le travail de care effectué et les responsabilités familiales réelles ne sont pas suffisamment pris en compte, que ce soit dans le cadre ou en dehors du droit de la famille. Cette situation est particulièrement problématique en raison de l'absence de réglementation de la communauté non maritale.

Certes, le modèle de la famille conjugale unique s'érode aussi juridiquement, comme l'illustrent ces exemples: l'autorité parentale conjointe s'applique désormais de manière générale après le divorce, mais pas en cas de concubinage. Depuis le $1^{\text {er }}$ janvier 2017, le Code civil prévoit une contribution pour la prise en charge de l'enfant en cas de concubinage: l'enfant a ainsi droit à des prestations d'entretien qui comprennent les coûts de sa prise en charge par l'un des parents. Pour le bien de l'enfant, la possibilité de la garde alternée (résidence alternée) doit être examinée dans le but de stabiliser la relation de l'enfant avec ses deux parents après une séparation. L'échange d'informations (en particulier concernant la filiation génétique; nouveau système d'information dans le triangle de l'adoption) gagne en importance car la présence de différents systèmes familiaux est admise. L'adoption de l'enfant du ou de la partenaire devient possible aussi dans les partenariats entre personnes de même sexe. Et enfin, les libertés de choix sont élargies (p.ex. révision du droit du nom).

Ainsi, les évolutions des formes de famille concrètes impactent le droit formel, bien qu'uniquement de manière ponctuelle. La dynamique des relations et des phases de la vie devrait mieux être prise en compte par les procédures administratives et les institutions (en particulier, via la mise en place de tribunaux 
de la famille et de la médiation linguistique et culturelle), mais aussi grâce au développement de conditions-cadres structurelles.

En ne protégeant plus seulement la famille conjugale (protection institutionnelle), les sphères économique et familiale ne sont plus strictement séparées. Les prestations familiales ne sont ni purement privées ni purement immatérielles, mais représentent un garant de la solidarité et une base de l'efficience économique. Elles sont indispensables pour l'ensemble de la société. Les prestations familiales sont fournies dans un vaste éventail d'arrangements, les relations familiales étant en constante évolution. Par conséquent, une approche relationnelle peut être judicieuse pour définir (le droit de) la famille: le droit de la famille vise à protéger la relation en tant que telle (alors que d'autres relations juridiques visent la réalisation d'autres objectifs). L'objet du droit de la famille est la réglementation de relations interpersonnelles spécifiques incluant des obligations de soin et des responsabilités particulières.

\section{Monika Pfaffinger}

\section{Références}

Contributions du symposium Avenir Familles du 24 juin 2014 à l'Université de Fribourg (2014). FAMPRA.ch. La pratique du droit de la famille, 4 , 779-1008.

Pfaffinger, M. \& Hofstetter, D. (2015). Umsetzung von Art. 16 in der Schweiz. In E. Schläppi, S. Ulrich \& J. Wyttenbach (Hrsg.), CEDAW: Kommentar zum UNO-Übereinkommen über die Beseitigung jeder Form der Diskriminierung der Frau (S. 1211-1250). Bern: Stämpfli.

Schwenzer, I. (1987). Vom Status zur Realbeziehung: Familienrecht im Wandel. Baden-Baden: Nomos.

\section{Droit des assurances sociales*}

En Suisse, l'idée de protéger la population contre les effets économiques de risques sociaux tels que la maladie, le chômage, l'âge ou l'invalidité fait son chemin dans la conscience politique depuis le XIX siècle, période marquée par les problèmes sociaux liés à l'industrialisation, sous l'impulsion notamment du voisin allemand. Le droit des assurances sociales, cet élément clé de l’État social, est donc un domaine juridique relativement récent. La loi fédérale sur l'assurance militaire (LAM), en vigueur depuis 1901, est le premier acte législatif en matière d'assurance sociale. À partir du milieu du XXe siècle, onze lois fédérales ont été promulguées, qui forment la base légale des différentes branches des assurances sociales :

> loi fédérale du 6 octobre 2000 sur la partie générale du droit des assurances sociales (LPGA);

> loi fédérale du 20 décembre 1946 sur l'assurance-vieillesse et survivants (LAVS);

> loi fédérale du 19 juin 1959 sur l'assurance-invalidité (LAI) ;

, loi fédérale du 6 octobre 2006 sur les prestations complémentaires à l'assurance-vieillesse et survivants et à l'assurance-invalidité (LPC) ;

> loi fédérale du 25 juin 1982 sur la prévoyance professionnelle vieillesse, survivants et invalidité (LPP);

> loi fédérale du 18 mars 1994 sur l'assurance-maladie (LAMal);

> loi fédérale du 20 mars 1981 sur l'assurance-accidents (LAA);

> loi fédérale du 25 septembre 1952 sur le régime des allocations pour perte de gain en faveur des personnes servant dans l'armée, dans le service civil ou dans la protection civile; depuis le $1^{\text {er }}$ juillet 2005 : loi fédérale sur les allocations pour perte de gain en cas de service et de maternité (LAPG);

> loi fédérale du 20 juin 1952 sur les allocations familiales dans l'agriculture (LFA); , loi fédérale du 24 mars 2006 sur les allocations familiales (LAFam); 
> loi fédérale du 25 juin 1982 sur l'assurance-chômage obligatoire et l'indemnité en cas d'insolvabilité (LACI).

Ces lois règlent la couverture d'assurance de groupes d'assurée-e-s définis avec des prestations différentes (prestations en nature, indemnités journalières, rentes, indemnisations, prestations sous condition de ressources, prestations mensuelles) en cas de survenance d'un des risques sociaux suivants: maladie, accident, chômage, charge de famille, maternité, perte de gain pour cause de service militaire, de service de protection civile ou de service civil, âge, décès du soutien de famille, invalidité et défaut de moyens d'existence. Certains risques sont couverts par plusieurs assurances sociales.

Les branches d'assurance sont organisées et financées différemment et présentent des spécificités propres en matière de prestations, dues souvent à des causes historiques.

Il s'ensuit que le droit suisse des assurances sociales n'est pas un domaine juridique d'un seul tenant, cohérent, construit sur un concept uniforme. Les différentes branches ont évolué chacune de leur côté, parfois sur plusieurs années ou décennies, sous l'influence des réalités politiques, économiques et sociales du moment. Le développement et la révision de domaines partiels de ce droit suivent ces mêmes mécanismes et reflètent l'esprit du temps.

Dans la pratique, la fragmentation du droit des assurances sociales est un défi de taille pour qui doit s'y référer. Pour les assureur·e·s et les autorités, la difficulté réside dans l'application des lois, alors que pour les demandeur·euse-s de prestations, il n'est pas aisé de savoir si elles ou ils ont droit à des prestations, et si oui auxquelles, et quels sont leurs devoirs correspondants.

Prenons l'exemple d'une personne qui, ressentant des douleurs au genou en pratiquant le jogging dans la forêt, se rend chez le médecin. Qui devra prendre en charge les coûts de ce dommage? La réponse dépend de plusieurs paramètres. Si la personne exerce une activité rémunérée et est donc assurée obligatoirement contre les accidents (AA) et si, juridiquement parlant, on est en présence d'un accident couvert par l'assurance, c'est l'AA qui paie les frais médicaux et qui, en cas d'incapacité de gain, verse des indemnités journalières. Sinon, c'est l'assurance-maladie de la personne blessée qui prend en charge les frais médicaux, en tenant compte de la franchise et de la quote-part. Il n'existe pas, en Suisse, d'assurance indemnités journalières obligatoire en cas de maladie. Le cas échéant, l'employeur-euse a l'obligation de continuer à verser le salaire, ou des contributions sont versées au titre d'une assurance indemnités journalières conclue sur une base volontaire. La situation se complique si l'assuré subit un préjudice de santé tel qu'il ou elle ne peut plus travailler ou ne peut plus tenir son ménage et doit alors solliciter l'assurance-invalidité. Selon sa couverture d'assurance, il ou elle aura droit à une rente d'invalidité de l'assurance-invalidité (AI), de la prévoyance professionnelle obligatoire (PP), de l'assurance-accident (AA) ou même de l'assurance militaire (AM). L'AI est responsable au premier chef de la (ré)insertion professionnelle de la personne invalide, même si l'AA et l'AM connaissent elles aussi des mesures d'insertion. D'autres questions doivent en outre être clarifiées, par exemple si la difficulté de l'assuré-e de réaliser un revenu garantissant le minimum vital est due non seulement à son état de santé mais aussi à des problèmes sociaux (p.ex. manque de compétences linguistiques et professionnelles) ou, le cas échéant, s’il faut aussi recourir à des prestations de l'aide sociale.

La pluralité des compétences et la diversité des prestations, qui sont réglées dans des lois spécifiques mais qui ont des points de contact avec d'autres institutions de la sécurité sociale, exigent un énorme travail de coordination dans la pratique. Dans le but de coordonner et d'harmoniser dans la mesure du possible le droit complexe des assurances sociales, une loi a été 
promulguée: la loi fédérale sur la partie générale du droit des assurances sociales (LPGA) est entrée en vigueur le $1^{\text {er }}$ janvier 2003. La LPGA définit les principes, notions et institutions du droit des assurances sociales (sous réserve d'exceptions), fixe les normes d'une procédure uniforme, règle l'organisation judiciaire, harmonise les prestations et règle les prétentions financières des assurances sociales envers des tiers. Elle s'applique à toutes les assurances sociales, à l'exception de la prévoyance professionnelle obligatoire. Par ailleurs, il est précisé dans chaque loi individuelle si des domaines entiers de celle-ci sont exclus du champ d'application de la LPGA ou si certaines de ses dispositions y dérogent expressément.

Pour trouver des réponses aux questions afférentes aux assurances sociales, on consultera, hormis les lois fédérales, les ordonnances d'exécution correspondantes du Conseil fédéral, ainsi que les nombreuses directives administratives. S'agissant de questions en rapport avec la migration de main d'œuvre, notamment dans les domaines de l'AVS, AI et AA, on tiendra compte en outre des accords bilatéraux de sécurité sociale que la Suisse a conclus avec les pays membres de l'UE et de l'AELE, ainsi qu'avec d'autres États.

L'assuréee qui veut demander une prestation doit s'adresser à l'organe responsable de l'assurance compétente (p.ex. caisse maladie, Office AI, caisse de chômage, etc.), qui lui signifiera par voie de décision s'il ou elle a droit ou non à la prestation demandée. La décision peut être attaquée par voie de recours auprès du tribunal cantonal des assurances sociales compétent. La procédure est réglée de manière uniforme dans la LPGA pour pratiquement toutes les branches et est en principe gratuite. Une obligation de supporter les frais existe uniquement dans le cadre de l'AI. En dernière instance, l'assuré.e peut former recours contre une décision cantonale auprès du Tribunal fédéral.

\section{Références}

Greber, P.-Y., Kahil-Wolff, B., Frésard-Fellay, G., Molo, R. \& Perrenoud, S. (2010/2015). Droit suisse de la sécurité sociale (2 vols). Berne: Stämpfli.

Locher, T. \& Gächter, T. (2014). Grundriss des Sozialversicherungsrechts (4., vollst. überarb. Aufl.). Bern : Stämpfli.

Scartazzini, G. \& Hürzeler, M. (2012). Bundessozialversicherungsrecht (4., vollst. überarb. und erw. Aufl.). Basel: Helbing Lichtenhahn.

\section{Droit du bail}

Le bail est le contrat par lequel une bailleresse ou un bailleur s'oblige à céder l'usage d'une chose à une personne locataire; celle-ci s'oblige à verser à la bailleresse ou au bailleur un loyer, la plupart du temps en espèces. Le droit du bail est constitué par l'ensemble des règles régissant cette relation contractuelle.

Dans sa conception traditionnelle, le bail est soumis à l'autonomie des parties. L'État met à disposition des parties des règles qui trouvent application à moins que les parties conviennent d'y déroger. L'État met également à disposition des tribunaux dont la tâche est la constatation de l'existence et de l'étendue des relations juridiques entre les parties, en fonction des éléments présentés et des conclusions prises par elles. Ce concept est conforme à la garantie de la propriété de la bailleresse ou du bailleur et assure la liberté contractuelle ainsi que la liberté économique des parties, éléments fondamentaux d'un système libéral.

Toutefois, l'application sans restriction de ce concept mène à des résultats insatisfaisants sur le marché des baux d'habitation et de locaux commerciaux. Le logement est un besoin élémentaire, chaque individu doit disposer d'un toit pour se protéger contre les forces naturelles et assurer le respect de sa sphère privée; les activités commerciales supposent elles aussi un lieu pour les exercer. Les locataires se trouvent de facto dans une 
situation d'obligation de contracter. En cas de demande croissante pour des logements, l'offre peut uniquement être augmentée dans un cadre restreint, étant donné le caractère limité de l'un des facteurs de production, à savoir le sol. De plus, même s'il est possible d'augmenter l'offre, le processus de planification et de réalisation de nouveaux locaux d'habitation prend un certain temps. Il existe donc un déséquilibre sur le marché locatif entre locataires et bailleresses/bailleurs qui disposent d'une position plus forte dont ils peuvent potentiellement abuser au détriment des locataires, notamment par des loyers exorbitants, d'autres conditions défavorables aux locataires ou des résiliations chicanières. Un tel comportement abusif pourrait entraîner, pour des parties importantes de la population, la privation d'un logement décent, situation mettant en danger la paix sociale. En outre, le logement ne satisfait pas seulement à un besoin élémentaire, mais constitue également le centre des relations familiales et sociales des locataires qui disposent d'un intérêt digne de protection à une certaine stabilité de leur situation.

Compte tenu de ces éléments, le législateur suisse est depuis longtemps intervenu sur la relation entre locataires et propriétaires. Après des régimes provisoires successifs, une base constitutionnelle autorisant la Confédération à légiférer afin de lutter contre les abus, notamment les loyers abusifs, ainsi que sur l'annulabilité des congés abusifs et la prolongation du bail pour une durée déterminée, a été créée en 1982 et de nouvelles dispositions réglant le droit du bail dans le Code des obligations sont entrées en vigueur le $1^{\text {er }}$ juillet 1990 (nouveau droit du bail).

Le droit du bail à loyer en vigueur est le résultat d'un combat politique entre les propriétaires immobiliers et leurs représentant·e.s d'un côté, et les locataires et leurs associations de l'autre. Il est le fruit d'un compromis permettant de maintenir l'attractivité d'investissements dans l'immobilier tout en atténuant les conséquences du déséquilibre de forces entre propriétaires et locataires.

Le régime de protection mis en place permet aux locataires de :

> contester, dès la conclusion du bail, un loyer jugé abusif. Le loyer est en principe abusif s'il permet à la bailleresse/au bailleur de réaliser un rendement qui dépasse de plus de $0,5 \%$ le taux hypothécaire de référence ; , exiger une baisse de loyer et contester une hausse selon l'évolution des critères relatifs en cours de bail ;

> remettre en l'état la chose louée si elle est défectueuse ainsi que de consigner le loyer si la bailleresse/le bailleur ne procède pas à la remise en l'état;

> prétendre à l'annulation du congé en cas d'abus : la résiliation est abusive lorsqu'elle a été donnée de manière contraire à la bonne foi. La loi mentionne un certain nombre d'hypothèses dans lesquelles le congé doit être considéré comme étant contraire à la bonne foi, notamment la résiliation suite à une contestation de l'augmentation du loyer, une demande de baisse de loyer ou de réparation d'un défaut, à moins que celle-ci soit abusive;

> demander une prolongation du contrat (4 ans maximum pour les habitations, 6 ans maximum pour les locaux commerciaux) : la prolongation du bail est accordée aux locataires si le congé est valable, mais que la fin du contrat aurait des conséquences pénibles sans que les intérêts de la bailleresse et du bailleur le justifient.

Pour permettre aux locataires la mise en œuvre de leurs droits, le législateur a également introduit des facilitations au niveau de la procédure. Ainsi, les parties peuvent saisir, en cas de litige, gratuitement une autorité paritaire de conciliation, composée d'un·e président·e ainsi que d'un·e représentant·e des locataires et d'un·e représentant.e des bailleresses et bailleurs. Celle-ci tente d'amener les parties à un accord dans une procédure peu formaliste; si les par- 
ties ne trouvent pas d'accord, elle peut rendre une proposition de jugement qui entre en force si aucune des parties ne l'attaque. Si l'autorité estime inopportun de rendre une telle proposition ou que celle-ci est attaquée, elle délivre une autorisation de procéder à l'une des parties, qui saisira le tribunal ordinaire. Celui-ci tranche généralement dans une procédure simplifiée qui lui accorde la possibilité d'intervenir dans une certaine mesure pour contrebalancer le rapport de force inégal entre les parties («maxime inquisitoire sociale»).

Le marché immobilier suisse se caractérise par un taux élevé de locataires. Ce taux, d'environ $65 \%$, est plus élevé que dans la plupart des États d'Europe de l'Ouest; le droit du bail se révèle donc particulièrement important pour notre pays.

Le système mis en place par le Code des obligations est un compromis et se trouve dans le champ de tension entre les intérêts des milieux concernés. Les locataires et leurs défenseur·euse-s demandent une législation plus protectrice, les propriétaires immobiliers une législation plus libérale. Les deux milieux ont tenté ces dernières années d'influencer la législation dans leur sens, mais aucune de leurs propositions n'a abouti.

Le système est complexe et peu accessible dans ses subtilités pour des non-juristes, en particulier en matière de fixation du loyer. Il opère avec passablement de notions juridiques indéterminées telles que le «besoin urgent» ou les «conséquences pénibles» qui donnent au tribunal une marge de manœuvre, ce qui permet de prendre en compte les situations du cas d'espèce mais se révèle peu favorable à la sécurité du droit. Cela étant, le système est en place, avec des modifications mineures, depuis plus d'un quart de siècle; il a été peaufiné par une abondante jurisprudence et produit des solutions largement acceptables en pratique.

François Bohnet \& Pascal Jeannin

\section{Références}

Bohnet, F. \& Dietschy, P. (2016). Introduction générale. Dans F. Bohnet, C. Carron \& M. Montini (Éds), Droit du bail à loyer, Commentaire pratique (2e éd., pp. 1-10). Bâle: Helbing Lichtenhahn.

Giger, H. (2013). Die Miete, Art. 253-273c OR: Grundsatzanalyse, Vorbemerkungen und Art. 253-255 OR. Bern : Stämpfli.

Lachat, D. (2008). Le bail à loyer. Lausanne: ASLOCA, Association suisse des locataires.

\section{Droit du travail ${ }^{*}$}

Le droit du travail est un droit dynamique, influencé par l'évolution des valeurs sociales. Les premières réglementations sur le travail remontent à des temps reculés. Au Moyen-Âge déjà, il était d'usage de rémunérer la prestation de services; les ouvrier-ère-s soumis.es à la corvée, par exemple, recevaient le manger. Avec le travail salarié sont apparus, au XIVe siècle, les premiers contrats de travail et d'apprentissage, pour les artisans notamment, qui réglaient les congés, les périodes de récolte, la nourriture, etc. Formalisés au fil du temps, ils devaient même, pour certains, être passés devant notaire. On accordait donc une grande importance aux contrats de travail à cette époque déjà. Leurs dispositions pouvaient aller très loin et bon nombre d'entre elles seraient de nos jours interdites au motif de la protection de la personnalité. Un exemple: la maisonnée était placée sous l'autorité du maître, doté du droit de punir. D'autres règles, en revanche, sont comparables aux actuels devoirs d'assistance et de loyauté exigés respectivement des employeur.euse-s et des employée-e.s.

Le droit du travail a profondément évolué sous l'influence de l'industrialisation et des conflits sociaux pour atteindre aujourd'hui un haut degré de complexité. Il règle les divers aspects du travail dépendant et accompli conformément à des directives dans le cadre d'une organisation du travail externe. Men- 
tionnons l'obligation de travailler, les heures et le temps de travail supplémentaires, le travail à temps partiel, le travail sur appel et le chômage partiel, le salaire, les primes, le maintien du salaire, les empêchements de travailler, les devoirs d'assistance et de loyauté déjà mentionnés, le licenciement, les certificats de travail, les vacances et les congés. De plus, le droit du travail prescrit le principe de non-discrimination et en particulier l'égalité de traitement entre hommes et femmes. Actuellement encore, le droit du travail se caractérise par l'importance des relations contractuelles, le législateur intervenant par des mesures correctrices en cas de déséquilibre des forces. Les particularités du droit du travail suisse sont exposées ci-après.

De nos jours, les rapports de travail sont réglés par un contrat individuel de travail (CIT), une convention collective de travail (CCT) ou, plus rarement, par un contrat-type de travail (CTT). On distingue le droit individuel du travail et le droit collectif du travail. Le premier régit les rapports de travail entre un·e employé-e et son employeur-euse dans le cadre d'un CIT, le second porte sur les modalités négociées entre les associations d'employé·e-s et d'employeur-euse-s (c'est-à-dire les partenaires sociaux) et leurs conséquences pour les travailleur.euse-s individuel-le·s. La CCT fixe les résultats de ces négociations. Les rapports de travail des employé·e·s de l'État sont quant à eux en principe réglés par les dispositions de la législation sur le personnel.

Une CCT est le reflet d'un partenariat social réussi. L'enjeu est de créer de bonnes conditions de travail sans freiner l'innovation. La CCT contient des dispositions relatives à la conclusion, à la teneur et à la résiliation des rapports de travail et confère ainsi aux employé-e-s une sécurité qu'ils ou elles n'avaient pas auparavant. Fruit d'une négociation entre les partenaires sociaux, elle permet d'atteindre des objectifs favorables aux deux parties sans fragiliser la place économique suisse. Géné- ralement, une CCT n'est valable que pour les employeur-euse-s membres d'une association professionnelle partenaire de la convention. Le Conseil fédéral ou un gouvernement cantonal peuvent toutefois, dans certains cas, lui conférer force obligatoire, de sorte que sa validité est étendue à toutes et tous les employé.e-s d'une profession ou d'une branche économique.

Lorsque l'on constate, dans une branche ou une profession pour laquelle il n'existe pas de CCT pouvant être déclarée de force obligatoire, une sous-enchère abusive et répétée par rapport aux salaires locaux usuels, une commission tripartite (composée de représentant·e-s de l'État, des employé·e·s et des employeur·euse-s) peut demander à l'autorité compétente d'édicter un contrat-type de travail de durée limitée et fixant des salaires minimaux contraignants.

Les conditions de licenciement sont un élément crucial du droit du travail. En Suisse, la réglementation en la matière est relativement libérale. Le principe de la liberté de résiliation prévaut dans les contrats de travail à durée indéterminée. La résiliation ne doit être justifiée que lorsqu'une des parties le demande. En outre, elle ne nécessite pas de forme spécifique: elle peut être communiquée par oral, à moins que les parties n'en aient convenu autrement. Une résiliation prononcée durant un délai de protection, par exemple pendant un congé maladie ou pendant la grossesse, est nulle. Dans certains cas, la résiliation hors d'une période de protection peut aussi être abusive. Une résiliation abusive est exécutoire, mais peut donner lieu à des indemnités. Des dispositions spéciales s'appliquent aux licenciements collectifs.

De nos jours, la notion de droit du travail va plus loin que la seule protection des travailleur-euse-s. Le droit du travail vise aussi à promouvoir le dialogue au sein de l'entreprise, partant, à contribuer à une bonne collaboration. Les employéee-s disposent d'un droit de participation qui implique le droit d'être informé·e·s et entendu·e.s - soit directement soit 
par l'intermédiaire de leurs représentant·e-s. Conformément à la loi, les employéee-s doivent être informé·e·s au moins une fois par année sur les conséquences de la marche des affaires sur l'emploi ainsi que sur toutes les affaires dont la connaissance leur est nécessaire pour s'acquitter de leurs tâches. De plus, des droits de participation et des droits à l'information particuliers leur sont conférés dans les domaines de la sécurité au travail et de la protection des travailleur-euse-s. Ces droits s'appliquent également en cas de restructuration de l'entreprise.

Le droit du travail ne peut plus se concevoir sur un plan national uniquement, influencé qu'il est par des accords internationaux. Ainsi, depuis l'entrée en vigueur en 2002 de l'accord sur la libre circulation des personnes entre la Suisse et l'Union européenne (ALCP), les citoyen-ne-s suisses et les ressortissant.e.s de l'UE ont le droit de choisir librement leur lieu de travail sur l'ensemble du territoire des États parties.

Des mesures d'accompagnement ont été introduites en juin 2004 pour atténuer les effets négatifs de cet accord. Elles prévoient que les travailleur·euse-s détaché·ess en Suisse soient soumis·es aux mêmes conditions de travail que les employé·e.s résidant dans le pays. Cela signifie que les dispositions relatives au salaire minimum, à la durée du repos, aux vacances, à la sécurité au travail, à la protection de la santé, à la protection durant la grossesse et durant la période suivant l'accouchement ainsi qu'à la protection des enfants et des jeunes doivent être appliquées. Tel n’a pas toujours été le cas par le passé, notamment parce que des entreprises générales qui confiaient des travaux à des sous-traitants ne vérifiaient pas l'application de ces dispositions. Désormais, à moins d'apporter une preuve à décharge, les entreprises générales répondent sur le plan civil des manquements d'un sous-traitant en matière de respect des conditions de travail convenues. Les CCT (de force contraignante générale) et les contrats-types de travail sont également des instruments efficaces de lutte contre le dumping salarial et social pouvant être mis en œuvre dans le cadre de l'ALCP. L'initiative populaire contre l'immigration de masse adoptée en février 2014 a conduit, entre autres, à la mise en œuvre de la "préférence des travailleur·euse-s en Suisse, version allégée » en juillet 2018. Celle-ci oblige les entreprises de certains secteurs d'annoncer les postes à pourvoir aux ORP avant de les annoncer publiquement.

Le droit du travail est appelé à s'adapter constamment à l'évolution des besoins de la société. Le législateur doit ainsi tenir compte des mutations du contexte sociopolitique et régler les problématiques qui en résultent. Par exemple celles de la protection insuffisante des lanceurs d'alertes contre le licenciement ou de l'application des salaires minimaux. Les développements observés au plan international doivent par ailleurs être pris en compte dans la législation. L'influence de la politique sociale sur cette dernière est d'ores et déjà perceptible.

Sara Licci \& Tanja Juelich

\section{Références}

Licci, S. (2015). Codes of Conduct im Arbeitsverhältnis mit besonderem Blick auf das Whistleblowing. Aktuelle Juristische Praxis, 1168-1184.

Portmann, W. \& Stöckli, J. F. (2013). Schweizerisches Arbeitsrecht (3., vollst. überarb. Aufl.). Zürich : Dike.

Streiff, U., von Kaenel, A. \& Rudolph, R. (2012). Arbeitsvertrag. Praxiskommentar zu Art. 319-362 OR (7., vollst. überarb. und stark erw. Aufl.). Zürich: Schulthess.

\section{Droit pénal des mineur·e.s}

En Suisse, le Droit pénal des mineur·e-s est aujourd'hui unifié et constitué de deux lois fédérales : l'une régissant leur condition pénale (Droit pénal des mineurs, DPMin) depuis 2007, et l'autre la procédure pénale (Procédure 
pénale applicable aux mineurs, PPMin) depuis 2011. Le DPMin constitue une loi spéciale par rapport au Code pénal des adultes et il régit les sanctions pénales (mesures de protection et peines) applicables aux personnes mineures âgées de 10 ans révolus à moins de 18 ans. La PPMin représente également une loi spéciale par rapport au Code de procédure pénale des adultes. En Suisse, des juridictions spécialisées pour les mineur.e.s existent au niveau cantonal depuis 1911. La PPMin a maintenu cette organisation cantonale de la justice des mineur.e.s, qui connaît deux grands modèles: celui du juge des mineur.e.s en Suisse romande, et du Jugendanwalt ou procureur des mineur.e.s en Suisse alémanique et au Tessin.

Le droit pénal suisse des mineur.e-s s'inscrit dans un cadre international, constitué en particulier du respect de la Convention européenne des droits de l'homme (ratifiée par la Suisse en 1974) et de la Convention des Nations Unies relative aux droits de l'enfant (ratifiée en 1997).

Le droit pénal suisse des mineur·e-s se caractérise par les principes essentiels suivants :

> Il ne peut y avoir d'intervention pénale que lorsqu'un.e mineur.e «commet un acte punissable entre 10 et 18 ans » (article 3 DPMin). Les actes punissables (ou infractions) sont définis par le droit pénal ordinaire (Code pénal, loi sur les stupéfiants, loi sur la circulation routière, etc.).

> Le Droit pénal des mineur·e·s est centré sur l'auteur (Täterstrafrecht), à savoir sur la situation personnelle du ou de la mineur.e délinquant·e. Le principe de l'individualisation de l'intervention pénale est ainsi une caractéristique majeure de la justice des mineur.e.s. Cependant, le DPMin pose l'exigence de la culpabilité et de la responsabilité pénale d'un·e mineur·e délinquant·e pour pouvoir lui infliger une peine.

> Le droit pénal des mineur·e.s est guidé par la philosophie de l'éducation du mineur délinquant et du soutien au développement de sa personnalité (article 2 DPMin et article 4 PPMin).

> Il en découle le principe de la primauté des mesures de protection par rapport aux peines, qui tient compte des besoins éducatifs et thérapeutiques du ou de la mineur.e. Ceci permet d'ailleurs à la justice des mineur.e-s de prononcer des mesures de protection à titre provisionnel, en cours d'instruction, ces mesures concernant près de $2 \%$ des mineur·e-s finalement jugé·e-s pour des motifs pénaux.

> Le DPMin a instauré un système dualiste facultatif, selon lequel, si le ou la mineur.e a agi de manière coupable et que l'enquête sur sa situation personnelle révèle qu'il ou la a besoin d'une mesure de protection, celle-ci peut être prononcée cumulativement à une peine. Selon Michel Lachat, le magistrat des mineur.e.s peut être qualifié de "père et maître à la fois », en raison de ce travail pédagogique d'explication, de démonstration et de persuasion.

Les mesures de protection à disposition de la justice des mineur.e-s sont, par ordre croissant d'intensité: la surveillance (qui est un droit de regard externe sur l'action éducative des parents), l'assistance personnelle (mesure la plus prononcée, qui est proche de la curatelle du droit civil), le traitement ambulatoire (socio-éducatif et/ou thérapeutique en milieu ouvert) et le placement (en famille d'accueil ou en établissement). Depuis 2015, s'y sont ajoutées les mesures (sécuritaires) d'interdiction d'exercer une activité, d'interdiction de contact et d'interdiction géographique.

En ce qui concerne les peines, le DPMin laisse d'abord une large place aux possibilités d'exemption de peine. Le magistrat des mineur.e.s peut alors exercer un pouvoir de renonciation à prononcer une peine (et de classement du dossier pénal), en particulier (article 21 DPMin): si l'acte commis est de peu de gravité, si le ou la mineur·e a lui- ou elle-même réparé le dommage causé, s'il ou 
elle a été directement atteint·e par les conséquences de son acte ou suffisamment puni.e par ses parents. Font ensuite partie des peines, également dans un ordre croissant de sévérité : la réprimande (ou réprobation officielle de l'acte commis); la prestation personnelle (peine la plus prononcée, y compris pour les adolescent·e-s), qui peut consister soit en une astreinte à un travail d'intérêt général, soit en une obligation de suivre des cours (p.ex. de prévention des addictions) et, dès l'âge de 15 ans révolus, l'amende (jusqu'à 2000 francs, si le ou la mineur.e a une source de revenu) et la privation de liberté (de un jour à un an, pouvant cependant aller jusqu'à quatre ans à l'encontre de mineur·e·s âgé·e·s de 16 ans au moins qui ont commis des actes graves). L'exécution des peines de prestation personnelle, d'amende et de privation de liberté jusqu'à 30 mois peut être suspendue au bénéfice du sursis (total ou partiel), si la justice estime qu'il n'y a pas de risque de récidive.

Il faut relever que les mesures de protection sont de durée indéterminée et pourraient se prolonger jusqu'à l'âge de 25 ans. En revanche, les peines sont prononcées avec une durée et un terme (délai d'exécution) précis. C'est pourquoi les mineur-e.s préfèrent souvent être puni·e·s (subir une peine) que protégé·e·s (être astreint·e.s à une mesure).

Dans la pratique, la justice pénale suisse des mineur.e.s prononce très majoritairement des peines (environ $95 \%$ de peines et $5 \%$ de mesures) et des jugements de condamnation qui concernent principalement des garçons (78\% en moyenne annuelle depuis 2007), des adolescent·e-s de 15 ans et plus (77\% en moyenne annuelle) et des jeunes de nationalité suisse (68\% en moyenne annuelle, $24 \%$ pour les jeunes domicilié.ère-s en Suisse, $4 \%$ pour les mineur.e.s requérants d'asile et 3,5\% pour les mineur·e·s étranger-ére·s domiciliés à l'étranger).

Le droit pénal suisse des mineur.e-s est composé d'un assemblage des modèles divers suivants de justice des mineur.e.s qui se sont développés depuis la fin du XIX ${ }^{\mathrm{e}}$ siècle :

> Le modèle d'éducation et de protection des jeunes justiciables (ou modèle de réhabilitation), qui gouverne le prononcé des mesures éducatives et thérapeutiques, mais également le choix du type de peine adéquate.

> Le modèle de garantie des droits des enfants et des jeunes, initié dans les années 1980 par les Nations Unies et qui a culminé avec l'adoption de la Convention relative aux droits de l'enfant en 1989.

> Le modèle de diversion, avec la renonciation à toute poursuite pénale lorsque les processus de conciliation (article 16 PPMin) ou de médiation (article 17 PPMin) sont couronnés de succès, ou que les conditions étendues d'exemption de peine sont réunies; mais aussi par le prononcé d'une simple peine de réprimande comme avertissement. > Le modèle de réparation, déjà présent dans les voies de conciliation, de médiation et d'exemption de peine et qui gouverne principalement le prononcé de la peine de prestation personnelle.

, Le modèle de répression, surtout avec la peine privative de liberté.

Cette agrégation successive de modèles a amené la justice des mineur.e-s à une attitude nettement moins paternaliste (sanctionner pour le bien du mineur) et bien plus légaliste (sanctionner dans le respect des droits du ou de la mineur·e).

En Allemagne, pays qui n'a pourtant pas le Droit pénal des mineur.e-s le plus punitif, les mineur·e's (dès 14 ans) qui ont commis des actes graves contre la vie, l'intégrité corporelle ou sexuelle, et au sujet desquel-le-s un pronostic de récidive élevée a été établi, peuvent être condamné·e-s à une peine privative de liberté de sept ans au moins et de dix ans au plus, ainsi que subsidiairement à un internement de sûreté (Sicherungsverwahrung). La Suisse - et c'est une chance qu'il faut absolument défendre - continue de maintenir un Droit pénal des mineur·e·s 
ouvert, accordant une attention particulière «aux conditions de vie et à l'environnement familial du mineur, ainsi qu'au développement de sa personnalité» (article 2 al. 2 DPMin). Ce qui lui a permis de résister jusqu'ici aux sirènes répressives et sécuritaires.

\section{Nicolas Queloz}

\section{Références}

Queloz, N. (Éd.) (2018). Droit pénal et justice des mineurs en Suisse: commentaire du DPMin et de la PPMin. Zurich: Schulthess.

Repond, M. (2012). Michel Lachat: le juge et les mineurs. Fribourg: Éditions La Sarine.

Riedo, C. (2013). Jugendstrafrecht und Jugendstrafprozessrecht. Basel : Helbing Lichtenhahn.

\section{Droit social $^{*}$}

Le droit social est la traduction juridique d'objectifs de politique sociale. La politique sociale sert à réaliser la sécurité et la justice sociales. Du point de vue de l'État, la redistribution et l'égalité des chances contribuent à la paix sociale et à la stabilité politique. Le droit social protège les individus des conséquences matérielles que peuvent entraîner des risques sociaux. À cette fin, il a pour objet les droits individuels à l'obtention de prestations sociales. Il garantit que la validité et les conditions d'octroi des prestations sociales soient ancrées dans le droit et ne soient pas tributaires d'opportunisme ou de décisions politiques arbitraires.

Dans un État devant offrir à chacun un cadre de liberté individuelle aussi large que possible, des inégalités naissent des différences entre les individus. Le droit social intervient là où il est nécessaire de protéger le plus faible. Il vise à assurer la justice sociale au sein d'un système économique et juridique qui privilégie et récompense les performances tout en ayant tendance à négliger celles et ceux qui ne sont pas à même de remplir ses exigences. La jus- tice sociale exige la solidarité dans le respect de la liberté, c'est-à-dire des liens réciproques et une responsabilité collective vis-à-vis des personnes qui ne peuvent subvenir seules à leurs besoins. Le droit social établit les conditions nécessaires pour que chaque individu puisse mener une existence digne, participer à la vie en société et être ainsi en mesure de développer librement sa personnalité.

Le droit social suisse découle de l'ensemble des dispositions sociales de la Constitution fédérale et des constitutions cantonales, ainsi que de leur mise en application au niveau légal et dans la jurisprudence du Tribunal fédéral. S'il fallait scinder le droit social en plusieurs catégories, on pourrait distinguer le droit des assurances sociales, le droit de l'aide sociale et la législation sociale. Cette dernière inclut certaines réglementations issues de domaines juridiques ne visant pas directement la protection des plus faibles, comme le droit du travail, de la famille, le droit pénal, fiscal ou encore procédural.

Les buts sociaux énoncés à l'article 41 de la Constitution fédérale constituent les fondements essentiels du droit social en Suisse. Ces objectifs, axés sur les besoins humains élémentaires, constituent une liste des buts de la politique sociale. Ils chargent la Confédération et les cantons de prendre des mesures en matière de sécurité sociale, de santé, d'emploi, de logement et d'éducation et ce, en complément des responsabilités individuelles et des initiatives privées. Les objectifs sociaux doivent être réalisés avec les moyens disponibles. Aucun droit subjectif à des prestations de l'État ne peut être déduit directement de ces objectifs sociaux. Ces derniers doivent en revanche être pris en compte dans le cadre de l'application des lois en vue de leur interprétation. Ils laissent une marge de manœuvre permettant de réagir de manière ouverte et souple aux défis sociopolitiques.

Plus précisément, les objectifs sociaux chargent les instances politiques de veiller à 
ce que tout individu bénéficie d'une protection juridique contre les conséquences matérielles des risques sociaux tels que la vieillesse, l'invalidité, la maladie, les accidents, le chômage, la maternité, le fait de devenir orphelin ou le veuvage. La Confédération et les cantons assurent à tous l'accès à des soins médicaux de base suffisants de grande qualité. La santé relève de la responsabilité des cantons et le droit de chacun à bénéficier des soins nécessaires doit être respecté. Toute personne active doit pouvoir subvenir à ses besoins par un travail exercé dans des conditions équitables. Ce mandat comprend une politique de plein emploi, le libre choix de la profession et du poste de travail et l'exigence que l'activité professionnelle et le salaire permettent à chacun de gagner décemment sa vie. La Confédération encourage la construction de logements et l'acquisition de propriétés immobilières; elle protège ses citoyennes et citoyens des abus dans le secteur locatif afin que chaque individu et chaque famille puissent trouver un logement décent à des conditions acceptables. Les enfants, les adolescent.e.s et les personnes en âge de travailler doivent être en mesure de se former et de se perfectionner, en fonction de leurs capacités. La Confédération et les cantons veillent ensemble à la qualité et à la perméabilité de l'espace éducatif suisse. L'éducation contribue de manière substantielle au développement de la personnalité. Elle n'est pas seulement la base d'une vie autonome, mais aussi la condition essentielle à l'exercice des droits politiques garantis par le droit constitutionnel. L'éducation poursuit aussi des fins économiques, notamment la formation d'une maind'œuvre qualifiée de bonne qualité.

Les droits sociaux fondamentaux exécutoires garantis par la Constitution comme le droit à une aide en situation de détresse, le droit à un enseignement de base, le droit à l'assistance judiciaire gratuite ainsi que le droit à la protection de l'enfance et des adolescents constituent une partie importante du droit social. Les dispositions constitutionnelles ne visant pas directement le droit à des prestations mais comportant néanmoins un volet social sont le droit à la liberté personnelle, la protection de la vie privée, le droit au mariage et à la famille, la liberté de réunion, le libre choix d'une profession et le libre exercice d'une activité professionnelle. Enfin, un refus arbitraire d'octroi de prestations viole le principe général d'égalité des droits et l'interdiction de discrimination.

Les traités internationaux sur les droits humains ratifiés par la Suisse ont eux aussi une influence sur le droit social national. La teneur de la codification du droit du travail de l'Organisation internationale du travail (OIT) et les garanties apportées par le Pacte international relatif aux droits économiques, sociaux et culturels (Pacte I) se traduisent dans les dispositions légales nationales grâce à des interprétations du droit national conformes au droit international. La Suisse n'ayant pas ratifié le protocole facultatif au Pacte I en matière de procédure individuelle de recours, il n'est pas possible de déposer auprès du comité de l'ONU compétent une plainte pour violation des obligations de l'État édictées par le Pacte I de l'ONU. La Suisse n'a pas non plus ratifié la Charte sociale européenne ni sa version révisée.

Les obligations issues des accords bilatéraux sur la libre circulation des personnes signés avec les États membres de l'UE font aussi partie du droit social. Il s'agit, d'une part, des obligations relevant du droit international et, d'autre part, du droit social de l'UE (p.ex. les dispositions relatives à l'accès non discriminatoire aux prestations de sécurité sociale ou la Charte des droits fondamentaux de l'UE).

De nombreux cantons ont adopté dans leur constitution des buts sociaux propres (Berne: favoriser la compatibilité entre vie professionnelle et familiale; Fribourg: droit des personnes âgées à la participation et à la qualité de vie) et d'autres droits fondamentaux de nature sociale (Genève: droit au logement; 
Bâle-Ville: droit à l'accueil extrafamilial pour enfants; Berne: droit des enfants et des victimes de délits graves à une protection et une assistance particulières; Vaud: droit à des soins médicaux essentiels et au soutien nécessaire pour atténuer un état de souffrance, droit des femmes à leur sécurité matérielle avant et après l'accouchement, droit à une aide de l'État pour une formation professionnelle initiale). Ces mesures reflètent davantage l'évolution des objectifs de l'État social que la Constitution fédérale. Une compétence centrale des cantons est la législation sur l'aide sociale. Elle comprend les prestations subsidiaires dans le système global de la sécurité sociale. Si des risques sociaux et leurs conséquences matérielles ne peuvent pas être couverts (ou pas suffisamment) par une autre institution étatique, alors l'aide sociale cantonale est tenue d'assurer «l'ultime filet» de sécurité permettant une vie digne. Parmi les autres compétences cantonales, retenons aussi les allocations familiales, les prestations complémentaires pour familles, les aides financières à l'accueil extrafamilial pour enfants, les indemnités journalières octroyées aux chômeur·euse·s en fin de droits, l'aide aux personnes âgées, la prise en charge en maison de retraite ou de soins, la promotion de la construction de logements sociaux, les allocations de logement ou encore les bourses d'études.

\section{Alexandra Caplazi}

\section{Références}

Bigler-Eggenberger, M. \& Schweizer, R. J. (2014). Art. 41 BV. In B. Ehrenzeller, B. Schindler, R.J. Schweizer \& K.A. Vallender (Hrsg.), Die Schweizerische Bundesverfassung: St. Galler Kommentar (3. Aufl., S. 917-940). Zürich : Dike Verlag, Schulthess.

Eichenhofer, E. (2010). Sozialrecht (7., neubearb. Aufl.). Tübingen: Mohr Siebeck.

Meyer, U. \& Siki, E. (2013). Bestand und Umsetzung der Sozialrechte in der Schweiz. In T. Gächter (Hrsg.), Ulrich Meyer. Ausgewählte Schriften (S. 3-34). Zürich : Schulthess.

\section{Droits de l'enfant}

Le terme «droits de l'enfant» désigne l'ensemble des droits contenus dans la Convention relative aux droits de l'enfant (ci-après $\mathrm{CDE}$ ), adoptée par l'Organisation des Nations Unies le 20 novembre 1989. Au sens de la CDE, un enfant s'entend de tout être humain âgé de moins de dix-huit ans, sauf si la majorité est atteinte plus tôt en vertu de la législation qui lui est applicable. Les droits dont il est titulaire portent sur des principes généraux (non-discrimination, intérêt supérieur de l'enfant, droit à la vie, à la survie et au développement, droit d'être entendu), les libertés civiles, le milieu familial et la protection sociale de remplacement, la santé et le bien-être, l'éducation, les loisirs et les activités culturelles, et enfin les mesures spéciales de protection de l'enfance.

Ancêtre de la CDE, la Déclaration de Genève (1924) comptait 10 principes non-contraignants axés sur la satisfaction des besoins essentiels de l'enfant. La Déclaration des droits de l'enfant (1959), inspirée de la Déclaration des droits de l'homme (1948), restait encore marquée par une approche protectionniste dans laquelle l'enfant est vu comme bénéficiaire de la bienveillance des adultes. Ce n'est qu'avec la CDE (1989) que les droits participatifs (libertés civiles) font de l'enfant un véritable sujet de droits.

Contrairement aux Déclarations de 1924 et de 1959, la CDE a un caractère contraignant, obligeant les États qui l'ont ratifiée à rendre compte, tous les 5 ans, de l'avancement de sa mise en œuvre dans leur juridiction. Ils soumettent leurs rapports périodiques au Comité des droits de l'enfant, qui reçoit également les rapports alternatifs (shadow reports) de la société civile, procède à une audition et rend des recommandations. La CDE est l'instrument international de droits humains qui est le plus largement ratifié. À ce jour, la ratification de la CDE est quasi universelle : tous les pays, à l'exception des États-Unis (qui l'ont uniquement 
signée), l'ont ratifiée. La Suisse a ratifié la CDE en 1997.

La CDE est complétée par le Protocole facultatif concernant l'implication d'enfants dans les conflits armés (2000), le Protocole facultatif concernant la vente d'enfants, la prostitution des enfants et la pornographie mettant en scène des enfants (2000), et le Protocole facultatif établissant une procédure de présentation de communications (2011) permettant à un enfant et ses représentants légaux de déposer une plainte individuelle (appelée "communication») devant le Comité des droits de l'enfant des Nations Unies au cas où ils n'auraient pas pu obtenir de réparation dans leur pays.

Le Comité des droits de l'enfant est composé de 18 membres dont la candidature est présentée par les États parties. Il s'agit d'experts indépendants élus pour un mandat de quatre ans, renouvelable. Le Comité examine les rapports périodiques présentés par les États parties, organise annuellement une journée de discussion générale sur un des sujets de préoccupation et adopte des observations générales.

Si la Suisse compte, en comparaison internationale, parmi les États qui respectent le mieux les droits de l'enfant, les recommandations du Comité mettent cependant en lumière la question du fédéralisme et les possibles discriminations qui peuvent en résulter. Les différences intercantonales concernant l'appui financier aux familles en situation de précarité sont importantes et engendrent donc une inégalité de traitement des enfants concernés. Il y a également une grande disparité au niveau des mesures et structures d'accueil pour les mineur·e.s non accompagné·e-s, qui sont d'abord vus comme des étranger-ère-s requérant.e.s d'asile plutôt que comme des enfants, et le droit à la formation professionnelle de cette catégorie spécifique d'enfants est inégalement reconnu suivant les cantons. Le Comité des droits de l'enfant recommande aussi à la Suisse d'uniformiser les pratiques en matière d'inclusion des enfants en situation de handi- cap dans l'enseignement ordinaire et d'allouer les ressources nécessaires en vue de passer dans tous les cantons à un système scolaire réellement inclusif. Enfin, la Suisse est sommée de fournir davantage de données statistiques (ventilées par âge, sexe, origine ethnique, zone géographique et situation socioéconomique) concernant les enfants qui vivent sur son territoire.

À l'instar de nombreux pays, la Suisse pourrait se doter d'une institution nationale des droits humains (INDH). Un tel organisme indépendant, dont les modalités sont régies par les Principes de Paris adoptés par les Nations Unies en 1993, permettrait de protéger et de promouvoir les droits humains de manière plus systématique et transversale, ce qui est d'autant plus nécessaire dans un pays comme la Suisse où le fédéralisme joue un rôle important dans l'accès concret des enfants à leurs droits.

Les droits de l'enfant provoquent parfois des réactions hostiles, basées sur la conviction qu'ils instituent la figure de «l'enfant-roi». Or la CDE souligne la primauté de la famille. La responsabilité subsidiaire de l'État-providence est un principe fondateur.

Le décalage plus ou moins important entre les droits formels de l'enfant et sa capacité réelle de les comprendre et donc de s'en saisir constitue un enjeu très important. À l'instar de ceux des adultes, la mise en application des droits de l'enfant est conditionnée par des facteurs politiques, économiques, sociaux et culturels. S'ajoute cependant ici une spécificité propre à la situation des enfants: leurs capacités évolutives, qui ne sauraient cependant être un prétexte pour les priver de la possibilité d'exercer leurs droits. Car une telle limitation ne ferait que renforcer la discrimination des enfants plus faiblement dotés en capitaux économiques, sociaux et culturels. Il y a donc nécessité absolue de soutenir tous les enfants dans l'exercice progressif de leurs droits, et cela requiert des adaptations des dispositions juridiques nationales, ainsi que des capacités ren- 
forcées de tous les acteur-tice-s œuvrant dans le champ de l'enfance. Sans cela, il restera difficile pour les enfants de faire valoir leurs droits directement.

De fait, on constate que pour l'instant le Protocole facultatif à la CDE établissant une procédure de présentation de communications (2011) a été très majoritairement saisi par des adultes et non pas directement par des enfants. Cette situation est emblématique de la position sociale des enfants à qui l'on octroie formellement l'accès à des possibilités et des procédures, ne renforçant de fait que des ONG ou des «défenseurs » des enfants qui trouvent dans ces instruments de nouvelles possibilités d'action.

Une politique de l'enfance basée sur les droits et la possibilité de les exercer effectivement induit un changement de paradigme, déjà repérable au niveau des recherches sur l'enfance (childhood studies), mais qui reste cependant encore difficile à traduire en pratiques correspondantes. Il s'agit de considérer l'enfant comme acteur-trice social.e sujet de droits et non plus comme un objet de protection. L'approche interdisciplinaire des droits de l'enfant contribue au regard critique nécessaire pour une mise en œuvre appropriée de ce nouveau statut de l'enfant sujet de droits.

\section{Daniel Stoecklin}

\section{Références}

Hanson, K. \& Nieuwenhuys, O. (Eds) (2013). Reconceptualizing children's rights in international development : living rights, social justice, translations. Cambridge: Cambridge University Press.

Nations Unies (1989). Convention relative aux droits de l'enfant. Recueil des Traités, 1577, 3.

Stoecklin, D. \& Bonvin, J.-M. (Eds) (2014). Children's rights and the capability approach: challenges and prospects. Dordrecht: Springer Netherlands.

\section{Droits des patient $\cdot e \cdot s$}

Au sens étroit, les droits des patient·e-s peuvent se définir comme l'ensemble des droits dont bénéficient les patient·e-s dans leurs relations avec le personnel soignant. Au sens large, ils désignent l'ensemble des droits des personnes en lien avec leur santé.

Dans leur première acception, il s'agit en fait de la mise en œuvre des droits de la personnalité et des droits fondamentaux dans la relation entre patient·e et médecin. D'abord consacrés dans la jurisprudence à partir des années 1970, ils se sont imposés dans les législations cantonales dès le milieu des années 1980. À partir des années 2000, ils apparaissent également en droit fédéral au travers de nombreuses lois spécifiques touchant au progrès médical, comme la loi sur la procréation médicalement assistée, la loi sur la transplantation d'organes, la loi sur l'analyse génétique humaine ou la loi sur la recherche sur les êtres humains. Ils englobent en particulier la règle du consentement éclairé, le droit à l'information, le droit d'accès à son dossier de santé, le droit à la protection de la sphère privée et à la confidentialité, le libre choix de son médecin, le droit d'accès aux soins, le droit au financement des soins essentiels.

Le droit au consentement libre, exprès et éclairé repose sur le principe que chacun dispose d'un droit à l'autodétermination et au respect de son intégrité corporelle. Afin de garantir l'un et l'autre, il est en principe interdit d'imposer un traitement médical ou un soin à une personne contre sa volonté ou simplement à son insu. En fait, juridiquement, chaque acte médical, chaque traitement ou soin implique une atteinte aux droits de la personnalité du patient ou de la patiente concerné·e. En cas d'opération, le chirurgien procède à des gestes invasifs qui sont autant d'atteintes à l'intégrité des patient·e.s. Le simple fait de procéder à une anamnèse en posant des questions sur la santé constitue aussi une brèche dans la sphère pri- 
vée. Conformément à l'article 28 du Code civil, «une atteinte [aux droits de la personnalité] est illicite, à moins qu'elle ne soit justifiée par le consentement de la victime, par un intérêt prépondérant privé ou public, ou par la loi». Le consentement du patient ou de la patiente apparait ainsi comme le motif justificatif de l'acte médical ou du soin. Il s'agit de la pierre angulaire de la relation entre patient.e et personnel soignant.

Pour être valable, le consentement doit être éclairé, autrement dit basé sur des informations claires et compréhensibles de la part des patient.e.s. Cela implique que les patient.e.s soient en mesure de les comprendre et de se prononcer en conséquence. On parle dans ce cas d'un·e patient.e capable de discernement.

La capacité de discernement se comprend comme la faculté d'agir raisonnablement, à savoir la faculté de comprendre les circonstances dans lesquelles on se trouve et celle de pouvoir se décider en conséquence en résistant raisonnablement aux pressions extérieures. En vertu de l'article 16 du Code civil, il existe une présomption de capacité de discernement pour toute personne dont la faculté d'agir raisonnablement n'est pas altérée par une cause prévue par la loi (jeune âge, déficience mentale, troubles psychiques, ivresse ou autres causes semblables). En principe, cette présomption concerne toute personne depuis son adolescence. Le Tribunal fédéral l'a admis pour des patients dès 13 ans. Elle dépend toutefois des circonstances. En l'absence de capacité de discernement, le droit exige que la décision de soins soit prise par une représentation légale ou par les parents lorsqu'il s'agit d'une personne mineure. En principe, les médecins ne sont autoriséee-s à agir sans le consentement de la personne ou l'accord de sa représentation légale que dans des situations d'urgence.

Les législations cantonales romandes ont aussi introduit depuis les années 1990 le droit des patient-e.s de rédiger des directives anticipées, à savoir la faculté pour un·e patient·e de définir par écrit le type de traitement qu'elle ou il souhaite recevoir ou non dans l'éventualité où sa capacité de discernement suite à une maladie ou un accident serait perdue. Les directives anticipées permettent aussi de désigner une personne de confiance qui sera chargée de décider en lieu et place de la personne concernée dans de telles circonstances. On parle dans ce cas de «représentant·e thérapeutique». Depuis la dernière révision du chapitre sur la protection de l'adulte dans le Code civil en 2013, les directives anticipées sont également reconnues en droit fédéral.

Pour que les patient.e-s capables de discernement donnent valablement leur consentement, il convient que ces personnes aient reçu l'ensemble des informations nécessaires afin de se forger une opinion sur les raisons de l'intervention (le diagnostic), l'existence de traitements alternatifs, y compris les conséquences en cas de non-traitement, les bénéfices et les risques associés à chaque traitement possible avec les chances de succès (le pronostic), les contraintes associées à ces traitements (durée, prise de sang, médicaments, hospitalisation, etc.) ainsi que les coûts et leur prise en charge par les assurances. De plus, selon la jurisprudence du Tribunal fédéral, la patiente ou le patient doit disposer, pour les opérations non-urgentes et électives, d'au moins 72 heures pour se décider entre le moment où l'information est reçue et celui de l'intervention. L'étendue et le degré de précision des informations auxquelles les patient·ess ont droit dépendent des circonstances. En principe, plus les risques sont élevés, plus le cercle des informations sera large. Il s'agit en fait de garantir que les patient.e-s puissent effectivement exercer leur droit à l'autodétermination et au respect de leur intégrité corporelle en toute connaissance de cause.

Depuis le serment Hippocrate, qui pendant des siècles a servi de fondement à l'éthique médicale, les médecins sont tenu·e·s de garder le secret sur toutes les informations auxquelles 
le corps médical peut avoir accès concernant les patient·e-s dans l'exercice de sa profession. Le secret médical est consacré en droit suisse à l'article 321 du Code pénal. Sa fonction est double. D'une part, il vise à protéger la sphère privée des patient·e.s en maintenant la plus stricte confidentialité sur les informations les plus intimes qu'une personne peut être amenée à partager avec son ou sa médecin. D’autre part, l'objectif est de garantir le rapport de confiance que les patient.e.s sont en droit d'attendre dans leur relation avec les médecins ou le personnel soignant. Sachant qu'une stricte confidentialité sera maintenue sur les informations confiées au personnel soignant, les patient.e.s seront en confiance pour se dévoiler, condition sine qua non pour poser le diagnostic et définir le traitement adéquat.

Avec l'informatisation de la société dès la fin des années 1980, la capacité de traiter un grand nombre d'informations et de les combiner afin d'établir des profils de personnalité s'est démultipliée. Un tel développement met en cause le fondement même de la sphère privée. C'est ainsi que la Suisse et de nombreux États, notamment en Europe, se sont dotés d'une législation sur la protection des données. Cette loi apporte une protection supplémentaire par rapport au secret médical. Elle ne se limite pas à interdire la divulgation d'informations confidentielles. Elle règle aussi la collecte de ces données qui doit répondre à un but précis avec un intérêt justifié (principe de finalité). De même, l'État ou un organisme privé, comme une assurance complémentaire, ne peut traiter des données sans être autorisé par la loi et avoir le consentement de la personne concernée, le but n'étant pas d'interdire toute utilisation de données, mais d'imposer un usage encadré de celles-ci. De plus, la législation sur la protection des données garantit que chacun puisse savoir quelles informations le ou la concernant sont conservées par qui (principe de transparence). Elle donne aussi un droit d'accès ainsi qu'un droit de demander la correction de ces données, voire leur destruction (droit à l'oubli).

En ce qui concerne le droit d'accès aux soins et à leur financement, il est reconnu par la Constitution fédérale. Sa réalisation dépend toutefois des ressources disponibles et de l'organisation du système de soins. La loi sur l'assurance-maladie (LAMal) introduit depuis 1996 une obligation à toute personne domiciliée en Suisse d'être assurée contre les aléas de la maladie afin de couvrir les frais. L'objectif est de permettre à chacun d'accéder à des soins essentiels, en principe sans devoir se préoccuper des coûts. Pour les personnes à revenu modeste, il existe un mécanisme de subvention qui permet de couvrir tout ou partie de leurs primes d'assurances. Au-delà de sa dimension sociale indéniable, l'accès aux soins en Suisse est plutôt satisfaisant en comparaison internationale, l'objectif de contrôle des coûts de la LAMal n'a toutefois pas été atteint et les primes ne cessent d'augmenter. Cela grève de manière toujours plus importante le budget des ménages, surtout de la classe moyenne.

\section{Dominique Sprumont}

\section{Références}

Manaï, D. (2013). Droits du patient face à la biomédecine ( $2^{\mathrm{e}}$ éd.). Berne : Stämpfli.

Services de la santé publique des cantons de Berne, Fribourg, Genève, Jura, Neuchâtel, Tessin, Valais et Vaud (2014). L'essentiel sur les droits des patients ( $3^{\mathrm{e}}$ éd.). [multiples lieux]: [multiples éditeurs].

\section{Droits humains*}

Les droits humains découlent de la dignité inhérente et inaliénable de chaque être humain. La dignité humaine vise la liberté d'autodétermination et la reconnaissance de chaque individu dans toutes ses spécificités et différences propres. Les droits humains com- 
portent des aspects moraux, politiques et juridiques. Les premiers se fondent sur l'éthique consistant à accorder le même respect à tout le monde. Les droits humains sont ici envisagés comme des principes moraux qui s'appliquent à chacun dans ses interactions avec autrui. En tant que concept politique, les droits humains obligent la communauté politique à faire en sorte que chaque individu soit traité de la même façon par l'ordre public en place. Sur le plan juridique, les droits humains protègent les aspects de l'existence humaine les plus vulnérables face au pouvoir étatique et social. La reconnaissance de ces droits est un système de normes et de valeurs assumé qui limite le pouvoir de l'État vis-à-vis de l'individu.

Les horreurs de la Seconde Guerre mondiale ont montré que le pouvoir de l'État face à l'individu devait être limité, ce qui a conduit à la fondation de l'ONU en 1945. La Charte des Nations Unies engage les États membres à promouvoir durablement le respect des droits humains et des libertés fondamentales. La Déclaration universelle des droits de l'homme, adoptée en 1948, concrétise cette obligation. Elle décrit la protection des droits humains comme un idéal à atteindre conjointement et stipule que la reconnaissance de la dignité inhérente à tous les êtres humains et de leurs droits égaux constitue le fondement de la liberté, de la justice et de la paix dans le monde.

La Déclaration universelle des droits de l'homme reconnaît tant les droits à la liberté que les droits sociaux. Pour en assurer le caractère contraignant sur le plan juridique, l'ONU a adopté en 1966 le Pacte international relatif aux droits économiques, sociaux et culturels (Pacte I) et le Pacte international relatif aux droits civils et politiques (Pacte II). Le Pacte I porte sur les droits sociaux tels que le droit au travail et à des conditions de travail équitables, les droits syndicaux, le droit à la sécurité sociale, le droit à un niveau de vie suffisant, à la santé, à l'éducation, mais aussi à la participation à la vie culturelle et au progrès scientifique. Les États signataires s'engagent à concrétiser ces droits sociaux avec tous les moyens adéquats et toutes les possibilités dont ils disposent. Ces droits garantissent à chacun le droit subjectif à certaines prestations de l'État. Le Pacte II garantit les droits à la liberté classiques, qui sont juridiquement et directement obligatoires. L'État est tenu de tolérer les activités déployées dans le cadre de la liberté individuelle, de s'abstenir de toute restriction de l'autonomie de l'individu et de protéger chaque personne contre l'agression de tiers. Les Pactes I et II constituent avec la Déclaration universelle des droits de l'homme l'International Bill of Rights, sur lequel s'est basée l'ONU pour adopter des conventions relatives aux droits de l'Homme réglementant la protection étendue d'un droit humain spécifique ou garantissant la protection juridique de groupes de personnes particulièrement vulnérables. En ratifiant une convention de l'ONU, le pays signataire s'engage à faire respecter les droits garantis sur son territoire et à se plier aux procédures de contrôle et de mise en application liées. Les termes des conventions de l'ONU relatives aux droits de l'homme ratifiées par la Suisse se traduisent dans l'ordre juridique suisse selon l'interprétation du droit international dans le droit interne.

À l'échelle régionale, ce sont la Convention européenne de sauvegarde des droits de l'homme et des libertés fondamentales, adoptée en 1950 par le Conseil de l'Europe, ainsi que la Charte sociale européenne de 1961 et sa version révisée de 1996 qui s'appliquent. La Convention européenne des droits de l'homme garantit les droits à la liberté, mais aucun droit social, exception faite du droit à une assistance juridique gratuite en cas de procédure juridique. Toutefois, certaines garanties peuvent produire des effets sociaux. Les droits de procédure doivent également être respectés dans le cadre d'une procédure de droit social et le droit au respect de la vie privée et familiale peut entraîner des conséquences en termes de 
droits sociaux. La Charte sociale européenne comprend 19 droits sociaux fondamentaux, dont les plus importants sont le droit au travail, le droit d'association et de coalition, le droit à la sécurité sociale, le droit à l'assistance, la protection de la famille et la protection des droits des travailleur.euse-s migrant·e-s et de leur famille. En ratifiant la Charte sociale, les signataires réaffirment leur volonté de mener, par tous les moyens utiles, une politique permettant d'assurer l'exercice effectif des droits garantis. La Charte sociale révisée tient compte du développement de la société européenne et garantit d'autres droits sociaux, notamment les dispositions fondamentales en matière de protection des enfants et de la jeunesse ou encore d'égalité des chances et de traitement dans le cadre de l'emploi et du travail sans discrimination fondée sur le sexe. Lors de la ratification, les signataires peuvent choisir toute une série de garanties auxquelles ils souhaitent souscrire. Ils sont tenus de reconnaître un nombre minimum de dispositions clés. Les garanties offertes par la Convention européenne des droits de l'homme sont en principe directement applicables en Suisse. La Charte sociale européenne de 1961 et sa révision de 1996 ne sont pas contraignantes pour la Suisse qui ne les a pas ratifiées.

La Constitution suisse comprend un catalogue de droits fondamentaux qui, au-delà de nombreux droits à la liberté, ne garantit que quelques droits sociaux fondamentaux, l'égalité devant la loi et des droits de procédure. Les droits à la liberté correspondent dans une large mesure aux garanties offertes par la Convention européenne des droits de l'homme. À la différence des droits humains reconnus au niveau international et accordés à chacun, indépendamment de sa nationalité, le catalogue des droits fondamentaux prévoit aussi la liberté d'établissement, la protection contre l'expulsion et des droits politiques qui ne s'appliquent qu'aux citoyennes et citoyens suisses. Les droits sociaux fondamentaux exé- cutoires sont le droit à une aide en situation de détresse, le droit à un enseignement de base, le droit à l'assistance judiciaire gratuite et le droit à la protection de l'enfance et de l'adolescence. Le catalogue des droits fondamentaux n'inclut pas les buts sociaux visés à l'article 41 de la Constitution fédérale, qui s'appuient sur les droits sociaux du Pacte I de l'ONU. En tant que normes cibles, ils se conçoivent comme un mandat aux autorités nationales et ne créent pas de droit justiciable de l'individu à des prestations étatiques. En tant que droit constitutionnel formel, ils sont contraignants et doivent être pris en compte en particulier par le législateur. Ils posent les bases constitutionnelles de la politique sociale et de l'État social suisse, ainsi que des dispositions sociojuridiques des constitutions cantonales. De nombreuses constitutions cantonales comportent des catalogues de droits fondamentaux détaillés qui vont ponctuellement au-delà des articles de la Constitution fédérale.

$\mathrm{Au}$ niveau international, le principe des droits humains et celui de la dignité humaine, qui y est inhérent, posent la question de la valeur universelle des droits humains. Les États ne contestent pas cette validité. Il existe toutefois des divergences par rapport à ce que recouvrent concrètement les garanties, à leurs limites et à la signification des différentes catégories de droits humains. D'un point de vue relativiste, un concept unique (occidental) ne peut pas être le seul déterminant, car le pluralisme des valeurs qui prévaut est issu de l'évolution historique de chaque société ainsi que de critères et de valeurs propres à chaque culture. Le point de départ pour obtenir l'indispensable consensus sur la teneur de chaque droit humain consiste bien plus en un processus d'apprentissage inter- et intraculturel : d'une part, identifier les besoins fondamentaux communs à tous les êtres humains et, d'autre part, se confronter à d'autres cultures et à leurs valeurs.

Alexandra Caplazi 


\section{Références}

Hertig Randall, M. \& Chatton, G. T. (2014). Les droits sociaux fondamentaux dans l'ordre juridique suisse. Dans L. Heckendorn Urscheler (Éd.), Rapports suisses présentés au XIX ${ }^{e}$ Congrès international de droit comparé. Zurich: Schulthess.

Kälin, W. \& Künzli, J. (2019). Universeller Menschenrechtsschutz: Der Schutz des Individuums auf globaler und regionaler Ebene (4., vollst. überarb. und erw. Aufl.). Basel : Helbing Lichtenhahn.

Müller, J. P. \& Schefer, M. (2008). Grundrechte in der Schweiz : Im Rahmen der Bundesverfassung, der EMRK und der UNO-Pakte (4. Aufl.). Bern : Stämpfli.

\section{Droits LGBT (évolution des)}

L'acronyme LGBT (lesbiennes, gays, bisexuels et trans) désigne le terme actuellement utilisé pour faire référence aux minorités sexuelles et à l'évolution historique du mouvement homosexuel. En Suisse, ce mouvement est né dans la première moitié du $\mathrm{XX}^{\mathrm{e}}$ siècle. Cependant l'«homosexuel» comme question sociale apparaît dès le XIXe siècle, dans le cadre de la confection du Code pénal suisse. À ce moment-là, se construit une pathologisation qui perdurera pendant presque un siècle, en opposition à une pénalisation. C'est durant cette période que l'homosexualité sera la marque d'une «dégénérescence anatomique et psychique » qui appréhende l'homosexualité comme innée. Face au refus d'une pénalisation, les sciences construiront une différence qui permettra, plus tard, de légitimer une multitude de discriminations (p.ex. l'âge du consentement aux rapports sexuels).

Les premières formes organisées de personnes s'identifiant comme homophiles ou homosexuelles se constituent, en terres helvétiques, dans les années 1930, dans le contexte de la naissance et du développement du Kreis qui, comme d'autres mouvements homophiles européens, met en avant une définition positive de l'homosexualité. Durant ces années des actions juridiques et politiques ont lieu autour de la construction du Code pénal suisse de 1942, qui donne lieu à une dépénalisation partielle de l'homosexualité. Partielle en effet, dans la mesure où les actes consentants demeurent encadrés par un article sur l'outrage aux mœurs, qui permet aux polices cantonales d'opérer des surveillances et de mener à terme un travail de fichage des personnes homosexuelles, sous forme de registres jusqu'aux années 1980.

La fin des années 1960 verra émerger un mouvement homophile, se distanciant du premier modèle proposé par le Kreis, car il s'agira de promouvoir une visibilité des homosexuel-le·s dans la société avec la finalité d'y être intégrés. Durant la même période, une association nationale, l'Organisation suisse des homophiles ( $\mathrm{SOH}$ ), est constituée dans le but de fédérer les différents groupes homosexuels suisses. Regroupant en 1976 plus de 600 membres, la SOH vise une transformation radicale de la société.

La mouvance des années 1970 se caractérise par la création de groupes plus radicaux prônant la libération homosexuelle et refusant l'assimilationnisme prêché par les mouvements homophiles précédents. Ces groupes radicaux sont créés en Suisse alémanique (la $H A Z$ à Zurich) et s'étendent ensuite en Romandie. Dans ce même contexte, en 1974, une organisation radicale nationale, la coordination homosexuelle suisse (CHOSE) voit le jour. Ces groupes vont mobiliser le droit pour dénoncer les discriminations à l'encontre de l'homosexualité. Dans ce cadre de lutte, le Groupe homosexuel de Genève (GHOG) fera un travail pionnier dans l'articulation du problème des discriminations.

Dans les années 1980, l'épidémie du VIH/ sida marque un changement radical dans l'esprit du militantisme et dans la forme des structures des associations gays, celles-ci devant tout à coup gérer une épidémie aux conséquences mortelles. L’association gene- 
voise Dialogai, créée en 1982, est exemplaire de ces transformations, puisqu'elle devient la première antenne cantonale de lutte contre le sida en Suisse. Suivent en 1983 l'Organisation suisse des enseignants et éducateurs homosexuels (OSEEH), en 1985 l'Aide suisse contre le sida (ASS). Durant ces années, plusieurs associations cantonales gays et lesbiennes seront créées, et deux associations faîtières verront le jour, Pink Cross (1993) et LOS (1989). Dans ce cadre nouveau, plusieurs victoires politiques sont remportées : même âge de consentement pour les relations homosexuelles et hétérosexuelles (1992), suppression des fichiers de police et des certificats de bonnes vies et mœurs (années 1980), reconnaissance des couples homosexuels (2005).

L'institutionnalisation des couples homosexuels, qui commence au niveau cantonal (Genève 2001, Zurich 2002 et Neuchâtel 2004), sera un processus long et controversé. La loi sur le partenariat ou LPart est entrée en vigueur en 2007, après avoir été approuvée en référendum en 2005. La loi amène une reconnaissance politique et juridique importante des couples homosexuels. Elle introduit notamment plusieurs principes stipulés dans le droit du mariage, comme le devoir d'assistance et de respect envers le partenaire et l'interdiction pour un des partenaires d'aliéner le logement commun sans le consentement de son partenaire. Le partenaire est l'héritier légal en cas de décès. Dès 2008, après un jugement du Tribunal fédéral, les personnes engagées depuis longtemps dans un partenariat enregistré peuvent bénéficier d'une rente de veuvage au même titre que les personnes mariées. Avec ces changements législatifs, le Parlement suisse estime contribuer à une meilleure acceptation des couples homosexuels par la société, mais ne met pas les couples hétérosexuels et homosexuels sur un pied d'égalité, puisque le mariage et la filiation continuent à être exclusivement hétérosexuels.
Quelques années plus tard, en 2016, grâce aux demandes des associations des familles homoparentales et du mouvement LGBT, les deux chambres et le Parlement approuvent une nouvelle loi qui permet à une personne liée par un partenariat enregistré d'adopter l'enfant de son partenaire (dans le cadre du nouveau droit de l'adoption entré en vigueur en janvier 2018). L'adoption crée une pleine parentalité juridique. En parallèle, en 2015, la Commission des affaires juridiques du Conseil national fait un pas vers l'ouverture du mariage aux couples homosexuels en donnant suite à une initiative parlementaire. Mais à ce jour, le futur est incertain car cette initiative législative devra être soumise au Parlement et sûrement au peuple suisse dans les années à venir.

Actuellement, l'égalité juridique entre couples homosexuels et couples hétérosexuels n'est pas garantie, elle n'est pas clairement inscrite dans le droit. Les discriminations basées sur l'orientation sexuelle et l'identité de genre ne forment pas un motif de discrimination de l'article 8 de la Constitution suisse. Dès les années 1980, le mouvement homosexuel a revendiqué l'interdiction des discriminations à l'encontre des personnes homosexuelles. Une petite victoire a été emportée dans les années 1990, dans le cadre de la révision du Code pénal et de la Constitution, en interdisant les discriminations basées notamment sur le «mode de vie». En 2013, une initiative parlementaire est déposée au Conseil national proposant de compléter le Code pénal, en élargissant la disposition existante luttant contre la discrimination raciale, à l'orientation sexuelle.

Si l'orientation sexuelle est une revendication importante du mouvement LGBT, l'identité de genre constitue un thème récent dans le champ social et politique, qui perçoit la transsexualité comme une pathologie et pas forcément comme une transidentité. Les personnes transgenres sont encore vues comme des individus nécessitant une intervention chirurgicale pour remettre en place l'identité de genre avec 
le «bon corps». Le mouvement transgenre en Suisse lutte précisément contre cette vision, dans l'objectif de «dépathologiser» l'identité transgenre. Plusieurs actes et décisions récents présagent cette dépathologisation. Le $1^{\text {er }}$ février 2012, l’Office fédéral de l'état civil a publié un avis de droit basé sur les recommandations du Conseil de l'Europe sur le fait que les stérilisations forcées seraient abandonnées lors d'une procédure de changement de sexe. De plus, une personne a désormais le droit de faire apparaître sur ses papiers son sexe social et non plus obligatoirement son sexe biologique. En outre, il est possible de demander un changement de nom sans changement de sexe.

\section{Marta Roca i Escoda}

\section{Références}

Delessert, T. \& Voegtli, M. (2012). Homosexualités masculines en Suisse: de l'invisibilité aux mobilisations. Lausanne: Presses polytechniques et universitaires romandes.

Roca i Escoda, M. (2010). La reconnaissance en chemin: l'institutionnalisation des couples homosexuels à Genève. Zurich: Seismo.

Ziegler, A.R., Montini, M. \& Copur, E. (Hrsg.) (2015). LGBT-Recht der Schweiz: Eingetragene Partnerschaft, faktische Lebensgemeinschaft, Rechtsfragen zur sexuellen Orientierung und Geschlechteridentität (2., völlig überarb. und stark erg. Aufl.). Basel : Helbing Lichtenhahn.

\section{Droits procéduraux*}

Les droits procéduraux individuels sont un élément central des règles d'application du droit, que ce soit dans le cadre d'un procès civil, d'une procédure ou d'un procès administratif. Les procédures en matière de droit social traitent souvent de questions ayant une importance vitale pour les personnes concernées (travail, logement, services de santé, revenu de remplacement en cas d'incapacité de travail ou de chômage, etc.). Dans ce cas, la loi facilite l'accès à la protection des droits individuels, notamment pour ce qui concerne le risque financier. Les rapports de force des parties dans une procédure de droit social sont cependant typiquement inégaux. À commencer par l'inégalité au niveau des connaissances, lorsqu'une personne se trouve confrontée à une administration spécialisée devant un tribunal. Les codes de procédure renforcent les droits de la partie plus faible afin de compenser ces inégalités. Sans justice procédurale, il ne peut y avoir de justice matérielle. L'égalité des chances dans la procédure (principe d'égalité des armes) est donc une condition préalable importante de la protection juridique. En outre, une procédure équitable a une valeur intrinsèque: elle renforce la légitimation et favorise l'acceptation du jugement, partant, garantit la paix juridique.

Les garanties générales de procédure (directement applicables) prévues aux articles 29 ss de la Constitution fédérale et à l'article 6 de la Convention européenne des droits de l'homme délimitent un cadre minimum. Les règles de procédure fédérales et cantonales concrétisent et complètent les règles constitutionnelles et les adaptent aux spécificités des domaines d'application. Moins les normes matérielles applicables sont précises, plus les garanties de procédure sont importantes. Leur portée est également influencée par les droits matériels fondamentaux. En cas de poursuite pour abus de l'aide sociale, par exemple, la protection de la sphère privée sert de jauge pour déterminer si l'utilisation d'une observation faite illégalement en tant que preuve résiste au principe d'une procédure équitable.

Dans la procédure administrative - par exemple celle concernant une institution d'assurance sociale - l'autorité agit en tant qu'organe d'exécution de la loi. En cette qualité, elle doit être neutre et objective. Si la personne privée n'est pas d'accord avec la formation du droit, elle peut introduire un recours devant le tribunal compétent. La procédure sera dès lors une procédure opposant deux parties. 
L'administration ne devient toutefois partie qu'au sens procédural; dans son action, elle demeure liée aux principes de l'État de droit. Devant le tribunal, les droits de participation sont généralement plus développés que dans la procédure administrative. Cela peut s'avérer problématique lorsque la prise de décision lors d'un procès s'appuie sur des moyens de preuve (p.ex. une expertise) qui ont été relevés selon des standards locaux dans la procédure administrative antérieure.

Les droits de procédure modèlent également l'organisation des autorités. La partie à la procédure a droit, entre autres, à un tribunal établi par la loi, indépendant et impartial. Les motifs concrets de refus et de récusation sont réglés dans les codes de procédure pertinents. De manière générale, il y a motif de refus lorsque le comportement individuel d'un membre de l'autorité ou des circonstances matérielles fondent, aussi objectivement, un soupçon de partialité. Il n'est pas nécessaire que la partialité soit effective (ce qui serait difficile à prouver au demeurant). Des règles dites d'incompatibilité empêchent d'ailleurs d'emblée que des membres du tribunal s'occupent de la même affaires à différents stades de la procédure. Dans le cas de prestations sociales qui dépendent dans une mesure déterminante d'expertises médicales, les motifs de refus ou de récusation d'un membre du tribunal s'appliquent par analogie aux experts médicaux.

Le droit d'être entendu est sans doute la principale garantie d'une procédure équitable. Ce droit est compris comme un droit de participation de la personne: la partie doit être un sujet agissant dans la procédure et non objet de celle-ci. Le droit d'être entendu est important pour la réalisation du droit matériel en ce sens qu'il permet de réunir un maximum d'éléments pour étayer la décision. La personne qui demande justice doit pouvoir participer efficacement à l'établissement des faits et à l'appréciation juridique de ces faits. Le droit d'être entendu inclut le droit de consulter les dossiers, le droit au traitement des offres de preuve importantes et le droit de collaborer à la collecte des preuves ou, du moins, de prendre position sur le résultat de l'administration des preuves. Finalement, la partie a le droit de s'exprimer globalement sur l'affaire avant le rendu du jugement. Un droit de prendre position existe en outre concernant tous les actes de la partie adverse, des instances antérieures et de surveillance. L'autorité doit examiner soigneusement les arguments et en tenir compte de manière appropriée dans sa décision. Le droit d'être entendu l'oblige aussi à motiver sa décision ou son jugement de manière probante. La «nature formelle» du droit d'être entendu met en exergue le caractère indissociable de la personne de ce droit: le non-respect de droits de participation potentiellement pertinents pour la décision conduit à l'annulation de la décision attaquée, qu'il soit ou non déterminant pour l'issue du litige. Pour des motifs d'économie de la procédure, une instance judiciaire peut «réparer» des violations (peu graves) du droit d'être entendu, pour autant qu'elle puisse examiner librement les faits et la situation juridique.

Le droit à l'assistance judiciaire gratuite est essentiel pour l'accès équitable à la justice de personnes de condition économique modeste. Ce droit inclut l'exonération des avances de frais et frais de procédure, ainsi que la représentation gratuite par un avocat sur demande. Pour bénéficier de l'assistance judiciaire gratuite, il faut que la personne qui en fait la demande ne dispose pas de ressources suffisantes et que sa cause ne paraisse pas d'emblée dépourvue de toute chance de succès. Dans les procédures judiciaires relevant du droit des assurances sociales, une assistance judiciaire gratuite est accordée si les circonstances le justifient, tandis que dans les procédures administratives, elle ne l'est généralement que si les circonstances l'exigent, ce qui n'est qu'exceptionnellement le cas. Les pouvoirs publics peuvent exiger le remboursement des frais 
s'il s'avère que la partie ayant bénéficié d'une assistance judiciaire gratuite peut, ultérieurement, s'en acquitter.

La validité et l'interprétation des droits de procédure sont fixées, même si elles dépendent en partie également de la jurisprudence dynamique de la Cour européenne des droits de l'homme. On n'observe pas de développements foncièrement nouveaux. Un besoin de réforme est parfois évoqué en ce qui concerne les obstacles financiers à la protection judiciaire. Dans des domaines socialement sensibles, comme le droit de la famille ou le droit des assurances sociales, les coûts d'une procédure - jusqu'au Tribunal fédéral - sont généralement peu élevés. La procédure est même parfois gratuite, par exemple dans la procédure de première instance en matière d'assurances sociales (à l'exception des litiges en matière de prestations d'invalidité) ou pour des litiges relevant du droit du travail jusqu'à un certain montant. Mais dans d'autres domaines de la «procédure sociale civile» (p.ex. en matière de logement), les frais dépendent en revanche du montant du litige. Ici, c'est avant tout la classe moyenne, qui ne peut faire valoir le droit à une assistance judiciaire gratuite, qui s'expose à un risque financier important.

\section{Andreas Traub}

\section{Références}

Grabenwarter, Ch. \& Struth, K. (2014). Justiz- und Verfahrensgrundrechte. In D. Ehlers (Hrsg.), Europäische Grundrechte und Grundfreiheiten (4. Aufl., S. 198-238). Berlin: De Gruyter.

Steinmann, G. (2014). Art. 29 \& Art. 30. In B. Ehrenzeller, B. Schindler, R.J. Schweizer \& K.A. Vallender (Hrsg.), Die Schweizerische Bundesverfassung: St. Galler Kommentar (3. Aufl., S. 640-676 \& 693724). Zürich: Dike Verlag, Schulthess.

Thurnherr, D. (2013). Verfahrensgrundrechte und Verwaltungshandeln: Die verfassungsrechtlichen Mindestgarantien prozeduraler Gerechtigkeit unter den Bedingungen der Diversität administrativer Handlungsmodalitäten. Zürich : Dike.

\section{Durabilité sociale}

La durabilité sociale est constitutive du troisième pilier du développement durable. Apparue au tournant des années 1700 en lien avec le souci de gestion efficace des forêts, la notion de durabilité est ensuite étendue aux enjeux sociaux. Elle met alors au cœur de son propos la transmission aux générations futures du capital humain et du capital social en leur permettant de vivre aussi bien, en termes de niveaux et de conditions de vie, que les générations actuelles. Ainsi tant la préservation du capital naturel que la croissance économique ne devraient pas se faire au détriment des équilibres sociaux. Dans le champ des politiques sociales, la politique du logement représente un enjeu particulièrement important pour la durabilité sociale, car elle permet de garantir des conditions de vie décentes et l'intégration sociale de tous. Il s'agit ainsi d'anticiper les évolutions sociétales et démographiques afin d'adapter l'offre de logement future aux besoins des différentes catégories de population. En effet, tant le vieillissement tendanciel que le renforcement des inégalités sociales ou économiques à l'œuvre dans nos sociétés contemporaines entraînent un risque de fragilisation de certains groupes.

Le concept de développement durable se définit à l'intersection de trois piliers fondamentaux: l'environnement, l'économie et la société. Il prend naissance après la Seconde Guerre mondiale, période durant laquelle les pays connurent une forte croissance et où plusieurs spécialistes s'interrogèrent sur les impacts de ce développement sur l'environnement et la société. La Banque mondiale fait évoluer le concept en proposant la notion de stock de capital vu comme une quantité de ressources définies dans l'espace et le temps dont la pérennité est essentielle pour que le développement soit réellement durable à long terme. Ce stock s'organise autour de quatre capitaux (naturel, humain, social et manufacturé) caractérisés par différentes ressources. 
Plus spécifiquement, le capital humain correspond au potentiel dont une personne dispose pour favoriser son bien-être, prendre part à la vie sociale, s’intégrer à l'économie, ainsi que la santé, la motivation, les compétences sociales, le savoir-faire et les connaissances d'une personne. Le capital social recouvre les contacts sociaux, les relations humaines, les liens et les réseaux créés entre les individus et les groupes ainsi que les institutions au sens de normes, de valeurs et d'ensembles de règles.

Plusieurs auteurs ont néanmoins constaté un déséquilibre dans la prise en compte des trois piliers ou des différents capitaux, déséquilibre qui permet d'expliquer le statut précaire du concept de durabilité sociale. En effet, le rôle central de l'influence du contexte culturel et des rapports sociaux sur les systèmes socio-écologiques est souvent peu reconnu. Ce déséquilibre repose sur le fait que les sciences sociales ont longtemps ignoré le discours sur le développement durable au contraire des sciences de l'environnement qui ont approfondi le concept de développement urbain écologique dès les premières conférences climatiques. Ces spécialistes ont par ailleurs l'habitude de travailler avec des catégories tangibles et mesurables tandis que les scientifiques sociaux travaillent avec une interprétation des normes de comportement, des symboles culturels et des configurations relationnelles, plus difficilement quantifiables. Le domaine des sciences sociales s'est attaqué à la question du développement humain durable au milieu des années 1990 mais en restant centré sur des objectifs globaux de santé publique, de stabilité sociale ou de bon développement et de bon fonctionnement de la société. Ce déséquilibre se traduit par exemple dans les systèmes de certification internationaux ou nationaux de construction qui proposent des critères écologiques ou économiques très aboutis et facilement mesurables. Au niveau social, les indicateurs restent très disparates et peu consolidés : mixité sociale des quartiers, programmation urbaine, design pour tous et accessibilité universelle, mobilité, qualité des processus et des projets. Seule la participation des habitants trouve réellement une place de choix dans la majorité des processus.

En Suisse, ces dernières décennies, le Conseil fédéral a défini une stratégie et un système de monitoring du développement durable (MONET) dans lesquels les aspects sociaux trouvent une large batterie d'indicateurs organisés autour de l'objectif de «solidarité sociale». Toutefois les différentes politiques sectorielles ont réagi différemment et la dimension sociale est souvent restée peu opérationnalisée contrairement aux dimensions écologiques et économiques. Sur la base de ce constat, l'Office fédéral du développement territorial a notamment pris des initiatives et institué un groupe en 2011 pour entreprendre un approfondissement des aspects sociaux du développement durable: sept ressources et quatorze composantes ont été définies ainsi que des indicateurs permettant l'évaluation de la mise en place de politiques publiques. À l'instar de plusieurs pays d'Europe, la Suisse a ainsi amorcé progressivement l'adaptation de ses outils réglementaires aux évolutions sociétales. Les «projets urbains » et les «projets-modèles », financés par plusieurs offices fédéraux, illustrent ce développement en soutenant des initiatives qui mettent la durabilité sociale au cœur de leur propos. L'aspect processuel se retrouve souvent au cœur de telles initiatives avec la notion de gouvernance de projet qui permet à la fois de piloter l'utilisation juste des ressources mais aussi de coordonner les différents acteur-trice-s qui gèrent la mise en œuvre des politiques publiques. Le fort engouement récent pour l'habitat coopératif et l'intégration de spécialistes des sciences sociales dans les processus de planification urbaine est aussi un autre exemple d'évolution des pratiques nationales.

Cependant, les indicateurs de «durabilité sociale» sont encore peu utilisés pour agir opé- 
rationnellement dans le cadre de projets territoriaux. Les modèles de développement durable ne parviennent par exemple pas à contrer efficacement les mécanismes de filtrage du marché immobilier qui ont tendance à exclure les plus fragilisés. Ils peinent également à sortir des travers du fonctionnalisme qui tendent par la standardisation en particulier - à nier les différences entre les catégories de la population au profit d'une homogénéisation des bons comportements. Afin de traiter pleinement la durabilité sociale dans le champ spécifique de la politique du logement, il faudrait ainsi réinterroger les modèles d' "éco-quartier» véhiculés par les élites urbaines. Ces modèles sont-ils réellement «habitables» par tous? Incluentils réellement une diversité de modes de vie? Favorisent-ils le vivre-ensemble de gens aux valeurs et aux capacités économiques diversifiées? Permettent-ils d'intégrer tantôt les familles, les seniors ou les jeunes selon le projet démographique de la commune? L'individualisation de la société et les disparités sociales se traduisent par des besoins sociaux différenciés selon le type de public auquel on s'adresse tout comme la diversité des contextes territoriaux invite à concevoir l'urbanisme et les politiques sociales au sens large différemment selon les lieux. Planifier durablement et socialement le territoire, c'est adapter et anticiper la conception des politiques sociales, ainsi que des logements et des quartiers en fonction de la diversité des besoins des ménages. Les typologies résidentielles proposées, les niveaux de loyers, la qualité et les usages des espaces publics, les types de politiques et services sociaux proposés détermineront le degré d'inclusion ou d'exclusion d'un territoire pour des groupes de population aux revenus, aux situations familiales et aux modes de vie différents. Tels seront les défis de la durabilité sociale du XXI ${ }^{\mathrm{e}}$ siècle qui invitera les acteurs du développement à proposer des mesures centrées sur la compréhension de la diversité des usages et des besoins sociaux, la planification de logements adap- tés pour chacun et une gouvernance de projet permettant de mettre en œuvre des politiques sociales proactives différenciées et contextualisées.

\section{Marie-Paule Thomas}

\section{Références}

Conseil fédéral (2016). Stratégie pour le développement durable 2016-2019. Berne: Office fédéral du développement territorial.

Drilling, M. \& Weiss, S. (2012). La durabilité sociale dans le développement urbain. Territoire et Environnement, 3, 1-23.

Lobsiger-Kägi, E., Renner, E., Kunz, M., Fricker, J. \& Suter, C. (2014). Aspects sociaux du développement durable: bases pour l'évaluation de la durabilité des projets. Berne: Office fédéral du développement territorial.

\section{École inclusive (élèves en situation de handicap) $^{* *}$}

Face à l'enfant en situation de handicap, quatre principales approches pédagogiques se sont succédé au fil du temps: 1) soigner et modifier la situation de handicap par le biais d'une intervention de portée curative (paradigme médical) ; 2) compenser le déficit en développant d'autres compétences à même de pallier les effets des déficits (paradigme compensatoire); 3) adapter l'intervention pédagogique, didactique et organisationnelle dans le but de minimiser l'impact du déficit sur l'expérience individuelle (paradigme fonctionnel); 4) développer la prise en charge de l'hétérogénéité conformément à la Déclaration universelle des droits de l'homme et au principe d'équité (paradigme des droits humains).

La première moitié du XXe siècle dénombre deux principales orientations dans le développement de l'éducation spécialisée : l'une visant à éviter ou limiter l'impact du déficit sur la personne (instituts spécialisés dans différentes «typologies de causes invalidantes», souvent 
dans une perspective médicale); l'autre, axée sur la culture de l'accueil souvent inspirée par la religion ou la philanthropie.

La formation spécialisée se développe en parallèle à l'émergence des catégories particulières de «besoins » plus ou moins identifiables quant à la spécificité et possibilité de leur faire correspondre une (ré-)éducation. La «surdité», par exemple, occupe rapidement une position émergente: l'attention à la parole comme composante typiquement humaine en fait une catégorie facilement identifiable, favorisant ainsi un développement rapide d'attentions spécifiques.

En 1964, l'entrée en vigueur de l'assurance-invalidité (AI) représente un tournant significatif. La loi qui l'accompagne, tout en assurant l'autonomie des cantons, donne aux sujets reconnus «invalides", à travers le principe du droit d'assurance, le statut de porteur d'un droit individuel au financement de prestations éducatives, de réhabilitation, médicales et sociales. Ce droit ne prévoit aucune mesure directe d'intervention. Il assure le soutien aux initiatives des cantons et des fondations en assumant l'excédent, par rapport à la norme, des dépenses relatives à la scolarisation et aux thérapies d'élèves en situation de handicap. La distinction entre l'instance qui finance ce surplus (Confédération) et celle qui exécute, engendre une dynamique vertueuse qui favorise le développement de l'innovation et de la qualité dans le respect de l'autonomie des institutions et des cantons. Le mécanisme des subsides stimule les interventions de réhabilitation ainsi que la spécialisation des compétences, il supporte et incite les formations et la réalisation de projets et de structures spécialisées.

En Suisse, l'école et la santé relèvent de la compétence des cantons. Dès lors, face à la particularité des traditions, des cultures et modèles scolaires, on observe dès le début des tendances parfois très différenciées et hétérogènes entre elles. Alors que pour les uns les attentions spécifiques (l'éducation et la pédagogie spécialisée) coïncident avec des lieux d'apprentissage différenciés de ceux de l'enseignement régulier, pour les autres la «normalité» des lieux est une des conditions de qualité des attentions spéciales (favorisant l'intégration des élèves et/ou de classes bénéficiant de mesures pédagogiques ou thérapeutiques spécialisées dans les classes et/ou les lieux de l'enseignement régulier). Parallèlement, les associations des parents, des professionnel-le·s ainsi qu'un nombre croissant de mouvements sociaux et scientifiques contribuent à l'émergence d'une attention croissante à l'intégration scolaire et sociale des personnes en situation de handicap.

À partir de la deuxième moitié des années 1970, les attentions pour la pédagogie spécialisée ne coïncident plus exclusivement avec les lieux pour l'enseignement spécialisé (différenciation structurelle). Au contraire, les attentions scolaires sont de plus en plus qualifiées et les possibilités de différenciation des attentions pédagogiques internes à l'enseignement régulier se multiplient. La pédagogie spécialisée se libère des contraintes qui la limitent à l'intérieur des lieux de l'éducation spécialisée. Sur le plan régional et cantonal, ce processus se traduit par des modalités, des temps et des actions politiques particulières et spécifiques à chaque canton mais la tendance est désormais irréversible. Sur le plan national, la moyenne des personnes en âge scolaire suivant un enseignement spécialisé en dehors de l'enseignement régulier fluctue entre $4 \%$ et $6 \%$ du total de la population au cours des années 1990 Pour la même période sur le plan cantonal, en fonction du recours plus ou moins prononcé des cantons à l'enseignement spécialisé, la moyenne oscille entre $2 \%$ et $10 \%$.

Le paradigme qui considère l'intégration d'hier et l'inclusion d'aujourd'hui comme une finalité et un outil d'éducation s'impose à la fin des années 1990 en Europe comme alternative qualifiant les attentions aux besoins éducatifs 
particuliers. L'incorporation de cette vision au sein des systèmes d'éducation au niveau cantonal, national et international relance le débat sur les formes et les lieux de l'enseignement spécialisé à l'école. En avril 2013, la Suisse signe la Convention relative aux droits des personnes handicapées, ce qui constitue un engagement officiel à la fois sur le plan politique et éthique. Cet engagement pousse à la reconnaissance et à la valorisation officielle des expériences d'enseignement inclusif qui existent depuis longtemps aussi bien sur le territoire national qu'à l'étranger. En dépit de la diversité des pratiques dans les divers cantons, au fil des années on assiste à une tendance générale consistant à intégrer les enfants avec un déficit sensoriel ou des troubles de la coordination motrice (ne compromettant pas leur autonomie) au sein des écoles régulières, tandis que les élèves avec des troubles du comportement ou des déficits intellectuels importants sont plutôt orientés vers des écoles spécialisées ou des classes spéciales. Durant l'année scolaire 2014-2015 la moyenne nationale des personnes en âge scolaire suivant un enseignement spécialisé en dehors de l'enseignement régulier est de $3,4 \%$ et les variations cantonales de plus ou moins $2 \%$.

Le modèle assurantiel sur lequel reposait l'enseignement spécialisé représentait un cadre institutionnel exceptionnel et complexe dans lequel convergeaient l'assurance fédérale, garante d'un certain type de droit individuel, et les valeurs et principes organisationnels des systèmes d'éducation et de formation des collectivités locales. Dans ce modèle, chaque mesure scolaire à caractère spécial, que ce soit au niveau de la différenciation structurelle ou de l'inclusion, impliquait la rencontre de l'exceptionnalité avec les traditions, les conventions, les habitudes, les disponibilités et les ressources de chaque institution. Ce cadre offrait des possibilités à négocier mais il n'imposait pas de devoirs. L'intégration ponctuelle, partielle ou totale d'élèves avec des «besoins pédagogiques particuliers» reposait sur les contingences spécifiques du dialogue entre l'individu et l'institution.

La perspective inclusive, voulue par les États signataires de la convention, met l'accent non pas sur le droit individuel, mais sur le droit d'accès de chacun·e à une école capable de garantir à tous et toutes l'accueil et le suivi dans un espace scolaire et d'apprentissage commun. C'est le principe des droits humains et de l'équité des attentions et des opportunités de croissance et développement au sein de cette communauté qui est au cœur de ce nouveau paradigme.

Le passage du droit individuel et causal au droit général de l'inclusion scolaire de tout élève (paradigme des droits humains) s'accompagne d'une charge idéologique qui exerce une pression nouvelle au sein des communautés de pratique et d'apprentissage. L'«école pour tous » implique la révision des bases scolaires sur le plan de la répartition des tâches éducatives et formatives, de la formulation des plans d'études, du développement de nouvelles situations et conditions didactiques, formatives et éducatives, de l'évaluation de l'apprentissage et de l'élaboration de nouveaux indicateurs scolaires de qualité.

\section{Michele Mainardi \& Mauro Martinoni}

\section{Références}

Bless, G. \& Mohr, K. (2007). Die Effekte von Sonderunterricht und gemeinsamem Unterricht auf die Entwicklung von Kindern mit Lernbehinderungen. In W. Jürgen \& F. Wember (Hrsg.), Sonderpädagogik des Lernens: Handbuch Sonderpädagogik (Bd. 2, S. 375-383). Göttingen: Hogrefe.

Mainardi, M. (2005). Scuola regolare e pedagogia speciale e specializzata: un rapporto in costante divenire? In B. Kronenberg \& A. Kummer Wyss (Hrsg.), Heilpädagogik für alle? Éducation et pédagogie spécialisées pour tous? (S. 127-146). Luzern : Édition SZH/SPC.

Rochat, L. (2009). Les conceptions et modèles principaux concernant le handicap. Berne: Bureau fédéral de l'égalité pour les personnes handicapées. 


\section{École obligatoire*}

L'école obligatoire a été inscrite dans la Constitution suisse en 1874. Les cantons ont été chargés de veiller à un enseignement primaire obligatoire suffisant, sous gestion étatique et gratuit qui, dans les écoles publiques, garantit la liberté de croyance et de conscience. Cet acquis important d'un point de vue sociopolitique est encore valable aujourd'hui. En Suisse, la majorité des enfants (jusqu'à $95 \%$ selon le niveau) fréquentent les écoles primaires et secondaires publiques. Les écoles privées ont une importance plutôt faible pour la scolarité obligatoire.

Aujourd'hui, la scolarité obligatoire dure onze ans dans la majorité des cantons. Le niveau primaire, y compris le jardin d'enfants/ cycle d'entrée comprend huit années. Il est suivi de trois ans au degré secondaire I. Les enfants commencent l'école à l'âge de 4 ans révolus. Le temps nécessaire pour passer les différents niveaux scolaires dépend du développement individuel de l'enfant (redoublement ou saut d'une ou plusieurs années scolaires). Les enfants passent les huit premières années d'école dans la même classe. Dans de nombreux cantons, au niveau secondaire I, ils reçoivent leur enseignement dans différents niveaux, selon leurs résultats scolaires. Le passage au niveau secondaire II (formation professionnelle, école de culture générale, offres transitoires) a lieu après la $11^{\mathrm{e}}$ année de scolarité. Pour les écoles de maturité gymnasiales, c'est généralement après la $10^{\mathrm{e}}$ année.

En raison de la souveraineté cantonale sur l'école obligatoire, le domaine de la scolarité obligatoire est peu réglementé au niveau fédéral. Depuis plusieurs années toutefois, des développements sont en cours. Ils visent à uniformiser davantage l'école obligatoire dans toute la Suisse afin de créer un espace éducatif suisse. À la suite d'une votation populaire, des innovations en la matière ont été introduites dans la Constitution fédérale («articles sur la formation») en 2006. Elles prévoient que la Confédération et les cantons soient conjointement responsables de la qualité élevée et de la perméabilité du système éducatif suisse dans le cadre de leurs compétences respectives et qu'ils coordonnent leurs efforts et coopèrent à cet égard. Les cantons sont tenus d'harmoniser l'âge de l'entrée à l'école et la scolarité obligatoire, la durée, les objectifs des niveaux de formation et le passage d'un niveau à un autre, ainsi que la reconnaissance mutuelle des qualifications. Ils veillent à fournir un enseignement spécialisé approprié à tous les enfants et jeunes jusqu'à l'âge de 20 ans révolus.

La Conférence suisse des directeurs cantonaux de l'instruction publique (CDIP) a posé une première pierre importante pour l'harmonisation de la scolarité obligatoire avec l'accord intercantonal, le concordat HarmoS, entré en vigueur en 2009. Chaque canton est libre d'adhérer ou non au concordat HarmoS. En 2016, la majorité des cantons y avait adhéré. Parmi les innovations clés figurent l'inclusion du jardin d'enfants dans la scolarité obligatoire, la formulation d'objectifs éducatifs nationaux, l'harmonisation des programmes d'enseignement ainsi que les paramètres principaux de l'enseignement des langues.

$\mathrm{Au}$ lieu du modèle du jardin d'enfants, les cantons peuvent aussi avoir pour le cycle d'entrée deux autres modalités: deux années préscolaires et une année d'école primaire (Grundstufe) ou deux années préscolaires et deux années d'école primaire (Basisstufe). L'idée de base est de rendre l'inscription à l'école plus souple par le biais d'un soutien individuel permettant à l'enfant de passer une année de plus ou de moins dans le cycle d'entrée. Certains cantons n'ont pas (encore) d'enseignement obligatoire de deux ans pour le cycle d'entrée, mais ils proposent l'offre de formation. Dans les faits, la quasi-totalité des enfants de ces cantons fréquentent le cycle d'entrée pendant deux ans. 
Le temps d'enseignement au niveau de l'école primaire est organisé dans la mesure du possible en horaires blocs et, dans les communes, des structures de jour sont proposées, mais leur utilisation est facultative et généralement payante. L'organisation des structures de jour implique également la politique familiale et la politique de l'égalité des sexes.

Sur la base du concordat HarmoS, des objectifs éducatifs nationaux (normes éducatives) sont définis, c'est-à-dire que des compétences de base à acquérir sont formulées pour l'école obligatoire dans la langue de l'école, en mathématiques, en sciences et en langue étrangère, et à trois moments (fin de la $4^{\mathrm{e}}, 8^{\mathrm{e}}$ et $11^{\mathrm{e}}$ années scolaires). Ils sont intégrés aux nouveaux programmes d'enseignement des trois langues régionales: Plan d'études romand, Piano di studio et Lehrplan 21 des 21 cantons germanophones et multilingues. Dans certains cantons germanophones, on observe une plus grande résistance à l'introduction du Lehrplan 21. Les objectifs de formation sont contrôlés à l'aide d'enquêtes cantonales qui font partie du monitorage de l'éducation, lequel consiste à collecter et traiter systématiquement et à long terme des informations sur le système éducatif suisse. Le monitorage de l'éducation est complété par le Rapport sur l'éducation en Suisse, publié tous les quatre ans.

En ce qui concerne l'enseignement des langues, il est précisé qu'une deuxième langue nationale ainsi que l'anglais sont enseignés à tous les élèves du degré primaire, au plus tard dès les $5^{\mathrm{e}}$ et $7^{\mathrm{e}}$ années. Pour les élèves issus de l'immigration, les cantons soutiennent, par des mesures organisationnelles, les cours organisés par les pays d'origine et les différentes communautés linguistiques dans leur langue maternelle et leur culture.

De plus, l'accord intercantonal sur la collaboration dans le domaine de la pédagogie spécialisée est entré en vigueur en 2011. Il confirme que l'instruction des enfants et des jeunes ayant des besoins spéciaux en matière d'éducation s'inscrit dans le cadre de la mission éducative publique, définit des conditions-cadres communes en matière d'offre de base, de bénéficiaires et d'instruments et régit la collaboration des cantons. En 2016, la majorité des cantons avait adhéré à ce concordat. Les cantons assument désormais l'entière responsabilité professionnelle, juridique et financière de la formation des enfants ayant des besoins éducatifs spéciaux. Jusqu'alors, une part substantielle des mesures de pédagogie spécialisée était cofinancée et réglementée par l'assurance-invalidité. L'objectif de l'accord est notamment de promouvoir l'intégration des enfants dans l'école ordinaire en préférant les solutions intégratives aux solutions séparatives. Ces dernières années, le nombre d'élèves fréquentant une classe spéciale a diminué.

L'inclusion de tous les enfants dans l'école ordinaire reste toutefois une tâche exigeante. À côté de résultats positifs, des voix critiques se font de plus en plus entendre. Celles-ci se réfèrent à la charge excessive qui pèse sur les enseignant·e.s, aux nouvelles formes cachées de ségrégation au sein des classes, à l'augmentation des mesures de soutien en matière de pédagogie spécialisée et l'extension des désavantages pour les autres enfants qui reçoivent trop peu d'aide et d'attention de la part des enseignant·ess.

Depuis le début du siècle, l'école est de plus en plus confrontée à la critique, elle ne garantirait pas l'égalité des chances, contreviendrait au principe du mérite et discriminerait certains groupes d'enfants et de jeunes. Les études sur les parcours éducatifs montrent également que la réussite de l'apprentissage, les évaluations des enseignant.e.s, la scolarisation dans des classes spéciales, les décisions de passage prises par les parents et les choix scolaires et professionnels des élèves sont influencés par les caractéristiques sociales des enfants et des jeunes - sexe, statut migratoire, nationalité, 
origine sociale, appartenance religieuse, handicap.

\section{Regula Julia Leemann}

\section{Références}

Haenni Hoti, A. (2015). Équité - discrimination et égalité des chances au sein du système éducatif: migration et origine sociale. Berne: Conférence suisse des directeurs cantonaux de l'instruction publique.

L'éducation en Suisse: rapport. (2006, 2010, 2014 \& 2018). Aarau: Centre suisse de coordination pour la recherche en éducation.

Conférence suisse des directeurs cantonaux de l'instruction publique. http://www.edk.ch

\section{Écologie}

L'écologie, entendue comme valeur politique, rappelle que les sociétés humaines font partie d'un ensemble de relations matérielles, biologiques, voire culturelles, avec le monde non-humain. Pour les écologistes, la reconnaissance de cette interdépendance entre les êtres humains et leur environnement, doit encadrer - parfois limiter - les activités humaines. De multiples traductions de l'écologie en politique existent à droite comme à gauche.

Dès les débuts de l'industrialisation, les «dégâts du progrès» affectent les populations, surtout ouvrières, et les milieux, urbains notamment. La socialisation des risques amenée par les premières politiques sociales est concomitante des mesures de police visant à réguler les «externalités» de la production économique, comme la pollution de l'air ou de l'eau. Ces régulations sont moins des limites mises à la libre initiative des acteurs capitalistes de l'économie que des mesures permettant de faire accepter aux populations les nouveaux risques industriels. Les années 1970 ne marquent dès lors pas un tournant radical qui se caractériserait par une «prise de conscience écologique» nouvelle. Par contre, les trente ou quarante dernières années voient les préoccupations écologiques se globaliser (climat, biodiversité, etc.). Au cours de cette période plus récente, trois grandes visions de l'écologie - et de ses rapports à la politique sociale - peuvent être distinguées: l'écologie néomalthusienne, l'écologie libérale et l'écologie sociale.

Très présent dans les années 1970, le néomalthusianisme américain et européen a surtout proposé des politiques sociales visant à limiter, voire à réduire, la taille de la population mondiale, à commencer par celle des pays du Sud. Craignant que la «surpopulation» mondiale, la «Bombe $\mathrm{P}$ » du biologiste Paul Ehrlich, ne vienne détruire les ressources naturelles, épuiser les sols et polluer la planète, les néomalthusiens demandent des mesures drastiques. Parfois en appui des mouvements féministes, certains encouragent le planning familial, l'avortement et la contraception. La plupart, toutefois, se montrent coercitifs, demandant que les gouvernements, notamment dans les pays du Sud, interdisent les naissances multiples par des campagnes de stérilisation, ou en amendant les familles trop nombreuses. Quelques-uns s'affichent ouvertement comme eugénistes (le biologiste Garett Hardin, théoricien de la «tragédie des communs ») et suggèrent des politiques d'amélioration génétique de la population et de limitation des migrations internationales au nom de la protection de la «qualité de vie». Cette vision de l'écologie promeut ainsi une conception de la politique sociale qui ne vise pas prioritairement l'expansion des droits sociaux et l'amélioration du niveau de vie, mais la limitation des populations susceptibles d'en bénéficier.

Pour les écologistes libéraux, le marché peut réguler parfaitement les contraintes écologiques, à condition de distribuer correctement les droits de propriétés sur les ressources et l'environnement. Basée sur le principe du pollueur-payeur, leur politique consiste, dès les années 1970, à mettre un prix sur la nature. 
Ainsi l'introduction de taxes écologiques sur la consommation vise à modifier le comportement des individus en renchérissant les comportements jugés écologiquement néfastes. Par exemple, les taxes poubelles incitent la population à trier ses déchets, tandis que les taxes sur les carburants la découragent de prendre l'avion ou la voiture et donc d'émettre des gaz à effet de serre. À l'inverse, diverses subventions aux énergies renouvelables et à l'isolation des bâtiments, profitent financièrement aux propriétaires de villas. En matière de politique sociale, les écologistes libéraux dénoncent les distorsions de marché induites par certaines politiques redistributives, notamment celles qui subventionnent les carburants (chauffage, mobilité) pour les plus pauvres. Ils plaident pour réduire les droits sociaux comme le droit à la mobilité au profit d'une tarification effective des déplacements (mobility pricing dans les transports publics), ou pour l'instauration de péages à l'entrée des villes. Cette vision libérale de l'écologie tend ainsi à renforcer les inégalités sociales, dans la mesure où les plus riches sont mieux en mesure de supporter le coût de comportements polluants (p.ex. liés à la mobilité) et sont aussi les bénéficiaires principaux de certaines mesures.

L'écologie sociale lie l'organisation de la société - le capitalisme et la croissance économique perpétuelle - à la dégradation de l'environnement; elle est formée de deux sous-tendances qui ont des implications différentes en termes de politique sociale. La première sous-tendance - celle de la décroissance - tend à se montrer critique à l'égard de l'industrie, de la technique, et plus généralement de la division du travail et de l'urbanisation. Dans sa filiation avec la tradition libertaire - mais aussi néolibérale - elle identifie la bureaucratie et l'État, comme sources des problèmes. Pour elle, le maintien d'un État social présuppose la perpétuation de la croissance économique destructrice de l'environnement. Prônant l'autogestion, elle critique les politiques sociales et l'État-providence, comme des formes de domination ou de contrôle, rendant les individus dépendants d'une «méga machine» qui restreindrait indûment leur autonomie (Ivan Illich, Lewis Mumford, etc.). Cette tendance de l'écologie est ainsi plutôt opposée aux politiques sociales, si ce n'est la création d'un revenu de base inconditionnel, censé permettre de déconnecter la protection sociale de l'emploi, d'abolir la soi-disant bureaucratie de l'État social et d'augmenter la liberté des individus sur le marché.

Une seconde tendance de l'écologie sociale se montre plus étatiste et avance que les régulations et les politiques publiques sont nécessaires pour créer une économie moins consommatrice de ressources (et plus respectueuse du développement durable), voire pour changer le mode de production (éco-socialisme). Plus proche de la défense traditionnelle de l'État social, cette tendance insiste sur la réduction du temps de travail pour réduire l'impact environnemental de la production et libérer du temps. Elle soutient que la transition écologique à une société moins gourmande en ressources et en énergie, peut créer des emplois et améliorer la qualité de vie. Elle défend l'idée d'une «transition juste» qui implique que les travailleuses et travailleurs des secteurs menacés par les régulations environnementales (mines, énergie, industrie lourde, etc.) ne doivent pas payer la disparition de leur secteur d'activité par la perte de leurs emplois et revenus. Les industriels et l'État doivent compenser les travailleur-euse-s de ces secteurs et leur fournir les moyens (notamment par la formation continue) de se requalifier et de retrouver un emploi dans d'autres secteurs. Les politiques sociales au sens traditionnel ont ainsi une place importante dans cette deuxième tendance de l'écologie sociale, alors que la première préconise leur remplacement par le revenu de base inconditionnel.

Le réchauffement climatique constitue un nouveau défi pour les politiques sociales. Il 
s'agit d'une part de « décarboniser » l'État social, en réduisant l'empreinte carbone des politiques menées (p.ex. dans les investissements publics dans le logement ou la mobilité), mais aussi de s'assurer que les mesures écologiques (p.ex. la taxation de l'énergie) n'affectent pas disproportionnellement les plus pauvres. Les politiques d'emploi doivent notamment être repensées pour favoriser la réduction collective du temps de travail et sa meilleure répartition, afin de réduire l'empreinte environnementale du mode de production.

Mais l'État social va aussi devoir répondre aux nouveaux risques amenés, ou amplifiés, par les transformations de l'environnement: intempéries, vagues de chaleur, sécheresses, inondations, etc. qui auront des effets sur les conditions de travail, la santé, la disponibilité de la nourriture et de l'eau. Par exemple, en Suisse, les vagues de chaleur de plus en plus fréquentes et longues en été changent les conditions de travail dans le secteur de la construction et nécessitent une nouvelle protection des travailleur-euse-s de ce domaine. Les emplois dans le secteur du tourisme hivernal vont devoir évoluer. Les assurances sociales et les services publics peuvent contribuer à réduire la vulnérabilité des populations aux effets du changement climatique et doivent constituer le cœur des politiques d'adaptation.

\section{Romain Felli}

\section{Références}

Fressoz, J.-B. (2012). L'Apocalypse joyeuse: une histoire du risque technologique. Paris: Seuil.

Gough, I. \& Meadowcroft, J. (2011). Decarbonizing the welfare state. In J. Dryzek, R.B. Norgaard \& D. Schlosberg (Eds.), Oxford handbook of climate change and society (pp. 490-503). Oxford: Oxford University Press.

Koch, M. \& Mont, O. (Eds.) (2016). Sustainability and the political economy of welfare. London: Routledge.

\section{Économie solidaire*}

Le terme d'économie solidaire décrit un ensemble de pratiques, initiatives, projets, organisations et discours divers qui ont pour objectif une autre forme, sociale, de l'économie. L'économie solidaire, aussi appelée «économie sociale» en Suisse, donne la priorité au développement et à l'expérimentation d'une économie basée non pas prioritairement sur le profit, mais sur des principes sociaux, de solidarité, écologiques et démocratiques. Elle est guidée en cela notamment par l'idée d'autodétermination et de cogestion ainsi que par des principes de durabilité sociale, écologique et économique. Dans ce sens, l'économie solidaire se définit toujours comme le contre-projet d'une économie capitaliste et mondialisée, principalement motivée par le profit.

Historiquement, l'économie solidaire trouve son origine dans les traditions et conceptions des mouvements sociaux du début de l'ère industrielle, et plus précisément dans les concepts des «socialistes utopiques» tels que Robert Owen (1771-1858), Charles Fourier (1772-1834) et Pierre-Joseph Proudhon (18091865). Ceux-ci avaient évoqué des modèles socioéconomiques ne reposant pas sur l'exploitation de l'homme et la destruction de la nature. Ce premier mouvement socialiste a donné naissance à un «produit» particulièrement réussi et aujourd'hui reconnu de tous : les coopératives, une forme d'organisation démocratique reposant dès le départ sur l'idée de la cogestion solidaire et de la copropriété entre travailleur·euse-s. Appliquer l'idée de coopérative à toute une région, c'est le pari qu'a réussi la Mondragón Corporación Cooperativa (MCC), maintenant active au niveau mondial et souvent citée comme modèle réussi d'économie solidaire. Cette coopérative fut fondée dans les années 1940 dans la petite ville basque de Mondragón par le prêtre José María Arizmendiarrieta (1915-1976), qui voulait lutter par l'entraide coopérative contre le chômage et la 
pauvreté qui touchaient la région. Aujourd'hui encore, le but premier de l'économie solidaire n'est pas de révolutionner le système économique capitaliste, mais de fournir à la population locale les biens et les services nécessaires, en se basant sur les besoins locaux et les ressources disponibles sur place. C'est dans ce sens que se conçoivent la plupart des projets d'économie solidaire: comme des «îles dans un océan capitaliste», selon la formule consacrée par Roland Bunzenthal en 2011, qui fonctionnent sciemment d'après une autre logique, basée sur l'ancrage local. Ceci dit, l'économie locale ne vise pas l'isolement et l'enfermement, elle tente plutôt de coopérer avec d'autres «îles» et organisations ou mouvements de la société civile, dans une sorte de réseau, afin de créer et propager de nouvelles formes d'activités économiques et au final, d'avoir un impact local toujours plus important.

Si l'on essaie d'établir un lien entre l'économie solidaire, la politique sociale et les questions sociales, ceci présuppose une compréhension pluraliste de la politique sociale. Une compréhension où les parties prenantes de la société civile sont perçues et reconnues comme des acteur-trice-s participant au bien-être de tous et toutes, même si elles fonctionnent selon leur propre logique entre l'État et le marché. Si l'on essaie d'absorber ces projets novateurs émanant de la base (grass-roots) pour les mettre au service d'objectifs qui leur sont étrangers et les soumettre à d'autres régimes, on court le risque de les démolir à terme. Les approches de la société civile, dont fait partie l'économie solidaire et qui trouvent leur origine dans les mouvements sociaux, existent parce qu'elles représentent un moment critique. Ce sont des projets d'expérimentation sociale destinés à trouver de nouvelles solutions aux problèmes sociaux, et ces projets se trouvent dans une relation tendue avec la politique sociale de l'État (qui suit une logique bureaucratique). Cette relation de tension peut toutefois être transformée par le dialogue en une coopération fructueuse où différentes logiques peuvent coexister.

Dans la perspective analytique du pluralisme social, l'économie solidaire en tant qu'approche de la société civile peut contribuer (potentiellement) à la prospérité, sans pour autant faire partie de la politique sociale d'État. Même s'il n'est guère possible de construire une économie solidaire selon une approche top-down, il est important du point de vue de la politique sociale de savoir si la politique de l'État favorise et soutient l'économie solidaire sans lui opposer d'obstacles et si elle permet à cette «contre»-économie locale de se développer aux côtés de l'économie mondiale. Ayant une culture perméable, l'économie solidaire peut, dans une optique de pluralisme social, aider les personnes et en particulier celles disposant de ressources financières limitées et/ou ne trouvant pas leur place dans l'autre économie pour diverses raisons, à participer économiquement et socialement à l'économie solidaire et trouver dans l'entraide un moyen d'assurer leur existence. Dans ce sens, les économies solidaires révèlent des potentiels (d'aide) réciproques encore non exploités et qui ne sont pas développés sur d'autres marchés ni dans les mesures de l'État social. L'économie solidaire apporte généralement des avantages directs à ses participant·e-s, mais aussi la plupart du temps une «valeur ajoutée» à la communauté, à la commune, au quartier ou à la ville, sous forme d'excédent ou en éliminant certains coûts.

La façon dont l'économie solidaire est représentée ici se base sur une perception surtout répandue en Suisse alémanique et dans l'espace germanophone en général. Comme les économies solidaires en tant qu'initiatives bottom-up sont souvent largement marquées localement ou régionalement, même dans des pays relativement petits comme la Suisse, elles peuvent se présenter sous la forme de conceptions et d'approches tout à fait différentes dans les diverses régions (linguistiques). En 
Suisse, mais également en Allemagne et en Autriche, on peut ainsi observer les activités suivantes d'économie solidaire: émission de monnaies alternatives ou locales, instauration de systèmes d'échanges de temps, création de coopératives en nom collectif, constitution de coopératives d'usagers-consommateurs dans le domaine agricole ou encore culture et gestion communes de terrains communaux (comme dans le cas de l'urban gardening). Dans certains cas, ce type de projet est animé ou soutenu par des travailleuses et travailleurs sociaux-ales issu.e.s du travail communautaire (Community Development). Dans les régions francophones et latines, en revanche, l'économie solidaire est beaucoup plus liée au marché secondaire du travail, subventionné par l'État, et aux autres «mesures d'intégration» (au marché du travail). Cette tendance n'a pas encore été observée dans la conception germanophone de l'économie solidaire qui est associée davantage à des initiatives de la société civile.

Les défis sociaux, économiques et écologiques actuels (en lien avec la société post-croissance, la nouvelle précarisation, la crise du travail et les régions perdantes) pourraient avoir pour conséquence d'intensifier la discussion autour de l'économie solidaire en Suisse dans les prochaines années. Le grand défi consiste à savoir comment concevoir et stabiliser ces projets afin de les rendre accessibles aussi aux personnes démunies et sans emploi et comment les transformer en processus d'échange réciproques, capables d'améliorer l'existence dans tous les milieux et toutes les situations sociales.

\section{Patrick Oehler}

\section{Références}

Bunzenthal, R. (2011). Solidarische Ökonomie : Inseln im kapitalistischen Meer. In Verein zur Förderung der Solidarischen Ökonomie e.V. (Hrsg.), Schritte auf dem Weg zur Solidarischen Ökonomie (S. 273-275). Kassel : Kassel Univ. Press.
Nerge, H. (2001). Auf der Suche nach der zukunftsfähigen Gesellschaft : Fundort Mondragon (unveröffentlichte Publikation). N.p.: Eigenverlag.

Wallimann, I. (2014). Social and solidarity economy for sustainable development: its premises - and the social economy Basel example of practice. International Review of Sociology, 24(1), 48-58.

\section{Éducation*}

L'éducation est une mission centrale des États-nations modernes et constitue une clé de la réussite du développement personnel et sociétal. Elle peut être considérée à la fois comme une fin en soi (mouvement de recherche, instruction) et comme un moyen pour parvenir à ses fins. La vocation du système d'éducation est d'encourager les individus à être autonomes et responsables, notamment dans le cadre de leur intégration et leur contribution à la société civile, et de garantir la formation adéquate des travailleur·euse-s qualifié·e-s pour le marché du travail. Dans cette optique, l'école doit relever le défi paradoxal de garantir l'égalité des chances de formation à tous et toutes les élèves et, dans le même temps, de les répartir selon le principe de performance entre des niveaux scolaires différents, les places étant rationnées dans les domaines de formation supérieurs.

La formation précoce, ou l'éducation de la petite enfance, qui favorise le développement de la santé et de la condition physique, le bienêtre émotionnel, l'accès à l'apprentissage, l'aptitude à communiquer ainsi que les connaissances cognitives et générales des enfants en âge préscolaire, inclut des offres institutionnelles (entre autres les structures d'accueil de jour) qui sont pour la plupart attribuées au secteur social (et non au secteur scolaire).

L'école obligatoire, qui englobe l'école enfantine/le cycle élémentaire, le degré primaire ainsi que le degré secondaire I (cycle secondaire), est la partie la plus importante du système d'éducation suisse, avec plus de $50 \%$ 
des dépenses publiques de formation. Les systèmes scolaires cantonaux qui se sont forgés au fil des ans se caractérisent par une diversité structurelle (durée de l'école enfantine et de l'école primaire; modèles scolaires du degré secondaire I), une diversité du contenu (plans d'études et moyens pédagogiques) ainsi que différentes échelles de système. Actuellement, une harmonisation des systèmes scolaires cantonaux est visée (concordat HarmoS). Les offres de l'école obligatoire sont pour la plupart publiques; seuls $5 \%$ des enfants fréquentent des écoles privées. L'accès à l'école enfantine, le passage à l'école primaire, puis au degré secondaire I réparti selon des groupes de performance varient d'un canton à l'autre (suivant l'âge, le niveau de développement, la maturité scolaire, la performance, le comportement, la participation parentale, etc.). Au sein de chaque cycle, les élèves ont la possibilité de sauter ou de répéter des classes. À l'école obligatoire, le taux de répétition atteint $2,4 \%$. Les garçons et les élèves étranger.ère-s sont plus particulièrement touché-é-s. L'efficacité du redoublement est jugée de manière critique. Quant à l'abandon scolaire, il ne survient que rarement.

Alors que les cantons assument désormais à la place de l'assurance-invalidité la responsabilité de l'enseignement spécialisé des enfants et des jeunes handicapé·e-s, ils sont aussi responsables de la pédagogie spécialisée pour les enfants et les jeunes aux besoins éducatifs particuliers. L'offre inclut, entre autres, la formation précoce spécialisée, la logopédie, la thérapie psychomotrice, les mesures pédagogiques spéciales et le suivi dans les structures d'accueil de jour. L'encouragement dans les écoles spécialisées et dans les petites classes ou les classes spécialisées est progressivement remplacé par le soutien intégratif dans les classes régulières, qui comprend également la promotion des talents.

L'une des particularités de l'école obligatoire suisse est la diversité intercantonale et parfois intracantonale des modèles de struc- tures ainsi que les différences de hiérarchisation du degré secondaire I selon les niveaux de performance ou les profils des exigences. Outre le modèle séparé (deux à quatre types d'écoles hiérarchiquement distincts avec différents plans d'études), il existe le modèle coopératif (deux types de classes de référence avec des cours de niveaux basés sur la performance) ainsi que le modèle intégré (classes de référence non sélectionnées avec cours de niveaux basés sur la performance). La part d'élèves fréquentant des écoles ou des classes de référence avec profil d'exigence bas («exigences élémentaires») varie d'ailleurs entre $5 \%$ et $40 \%$ selon les cantons.

La hiérarchisation du degré secondaire I, majoritairement motivée par l'organisation de l'école et de l'enseignement, pose problème. D'une part, il en résulte un rationnement renforcé de l'éducation dans les cantons qui présentent une part réduite de profils à exigences étendues. D’autre part, les écoles qui appliquent des «exigences élémentaires » entraînent la ségrégation sociale des élèves, provoquant une baisse des performances, ainsi que des inégalités d'apprentissage pour les enfants issu·e-s de familles défavorisées du point de vue socioéconomique, celles et ceux issu.e.s de la migration ainsi que pour les garçons.

Le degré secondaire II comprend la formation professionnelle, les écoles de culture générale et les écoles de maturité gymnasiale (gymnase, école cantonale, etc.). En Suisse, deux tiers des jeunes effectuent une formation élémentaire professionnelle après l'école obligatoire. Le taux d'abandon d'apprentissage varie entre $10 \%$ et $30 \%$ selon le métier. Les abandons d'apprentissage à un stade plus avancé (à compter de la troisième année) sont rares, par contre le risque de rester sans formation est alors très élevé. Cette formation en général duale, organisée à la fois dans les écoles professionnelles et les entreprises de formation, est très appréciée pour sa proximité avec le marché du travail. La formation élé- 
mentaire professionnelle mène très souvent à des choix de formation professionnelle inégaux entre filles et garçons (ségrégation des sexes).

La part des formations professionnelles varie fortement d'un canton à l'autre. Alors que dans les cantons de Thurgovie et de SaintGall, plus de $80 \%$ des élèves suivent une formation professionnelle, ils ne sont que $40 \%$ dans le canton de Genève. Dans les cantons où la part de formations professionnelles est inférieure, l'enseignement gymnasial et en école de culture générale est à proportion plus répandu. L'équilibre raisonnable entre formation professionnelle et formation générale est un sujet de controverse en Suisse.

L'un des points forts de la formation professionnelle élémentaire est sa capacité à intégrer également les jeunes en difficulté. Par contre, les diplômé·e-s des classes d'écoles avec «exigences élémentaires» se voient souvent refuser le passage au gymnase, à l'école de culture générale avec maturité spécialisée et aux formations élémentaires professionnelles exigeant des performances supérieures. Dans le système de formation professionnelle, ils et elles ont essentiellement le choix entre la formation élémentaire professionnelle de deux ans avec attestation fédérale de formation professionnelle (AFP) et l'apprentissage dual avec un niveau d'exigence modeste. La régulation du marché relative à l'accès à la formation recèle en outre un potentiel de discrimination parmi les employeur.euse-s, qui toucherait en particulier les jeunes étranger-ére-s. Les jeunes qui n'ont pas d'accès direct à l'école secondaire ni à la formation professionnelle disposent de solutions intermédiaires (offres de passerelle). Les apprenti·e-s ayant choisi un métier qui requiert trois ou quatre années de formation ont la possibilité d'obtenir la maturité professionnelle à la suite de la formation initiale, qui leur permettra d'entrer dans une haute école spécialisée.

Le degré tertiaire se compose des hautes écoles universitaires, des hautes écoles spécia- lisées, des hautes écoles pédagogiques, ainsi que de la formation professionnelle supérieure. Cette dernière inclut la formation dans les écoles supérieures ainsi que différents examens professionnels et techniques supérieurs. Les hautes écoles qui décernent des titres académiques (surtout des bachelors et masters) requièrent une qualification spécifique d'accès aux études supérieures (maturité gymnasiale, maturité spécialisée, maturité professionnelle). Dans le contexte du développement des hautes écoles spécialisées, le système d'enseignement supérieur s'est diversifié relativement tard au cours des vingt dernières années en comparaison internationale. Les hautes écoles s'imposent de plus en plus dans la formation continue avec des cours qui ne requièrent aucune qualification d'accès aux études supérieures (p.ex. Certificate of Advanced Studies). L'offre de formation continue inclut notamment les universités du troisième âge, qui permettent aux personnes âgées de se former tout au long de leur vie et de participer activement à la société.

Christian Imdorf

\section{Références}

Office fédéral de la statistique (Éd.) (s.d.). Éducation et sciences. https://www.bfs.admin.ch/bfs/fr/ home/statistiques/education-science.html

Schweizerische Akademie der Geistes- und Sozialwissenschaften (Hrsg.) (2016). Dossier: Das Versprechen der Bildung / La promesse de la formation. Bulletin SAGW, 16(4), 31-61.

Wolter, S. C., Cattaneo, M. A., Denzler, S., Diem, A., Hof, S., Meier, R. \& Oggenfuss, C. (2018). L'éducation en Suisse: rapport 2018. Aarau: Centre suisse de coordination pour la recherche en éducation.

\section{Éducation de la petite enfance*}

Dans les régions de langue française, «éducation de la petite enfance» traduit le terme utilisé internationalement early childhood education. L'éducation de la petite enfance couvre 
la période allant de la naissance à l'entrée à l'école et se rapporte aux dispositifs institutionnels comme les crèches, les parents de jour et les groupes de jeu. Il convient de différencier ces modes de garde du cycle élémentaire ou de l'école enfantine (Kindergarten) qui, en Suisse, accueille les enfants de 4 à 6 ans et fait partie du système scolaire. Les débats relatifs au programme de l'éducation de la petite enfance reviennent systématiquement sur la nécessité d'orienter tous les aspects ayant trait au développement sur l'objectif de la promotion et de l'apprentissage de l'enfant. Dans ce domaine, l'ambition globale est essentielle: l'éducation de la petite enfance se rapporte au développement cognitif, social, émotionnel, physique et moral de l'enfant.

Les racines historiques de la réflexion sur les potentialités de l'éducation de la petite enfance apparaissent au début de l'ère moderne, notamment dans les œuvres de Comenius, Rousseau, Pestalozzi ou encore Montessori. La création en 1840 du premier jardin d'enfants en Allemagne par Fröbel représente un exemple pratique précoce d'institution d'éducation de la petite enfance ayant retenu l'attention à l'échelle internationale. Avec pour mot d'ordre de favoriser l'épanouissement des capacités physiques et mentales de potentiellement tous les enfants en fonction de leur âge, le premier jardin d'enfants voyait déjà plus loin que la simple préparation des enfants à l'école. Le principe de base de l'éducation de la petite enfance repose sur l'idée de stimuler le développement des capacités des enfants par des expériences spatiales, matérielles, sociales et culturelles structurées et exigeantes.

$\mathrm{Du}$ point de vue sociohistorique, le sujet de l'éducation de la petite enfance est abordé en Suisse principalement de manière indirecte depuis la fin des années 1960 . Depuis le début du XXI ${ }^{\text {e }}$ siècle, sa pertinence est toutefois revenue au centre de l'attention. Cet intérêt s'explique par le changement social qui a entraîné de nouvelles perceptions des rôles au sein de la famille, ainsi qu'un nombre croissant de femmes actives et le besoin parallèle de modes de garde extrafamiliaux. Par ailleurs, les connaissances en économie de l'éducation ont depuis établi que les investissements réalisés dans l'infrastructure de l'éducation de la petite enfance se répercutaient plus tard dans des rendements économiques. En outre, les résultats d'études comparatives internationales sur la performance des systèmes d'éducation de chaque pays, comme PISA, attirent régulièrement l'attention sur l'importance des premières années de la vie pour le parcours de formation ultérieur et la compensation des désavantages liés au milieu d'origine. Enfin, l'engagement accru d'organisations supranationales comme l'OCDE, la Banque mondiale, etc. et leurs recommandations concernant la structure nationale de l'éducation de la petite enfance dans de nombreux États ont entraîné dans leur sillage des efforts d'expansion, de généralisation des curricula et de développement qualitatif de l'offre.

Bien que le développement international ait considérablement influencé les débats sur l'éducation de la petite enfance en Suisse, cela est resté largement sans effet au niveau politico-juridique. Ainsi, en Suisse, il n'existe actuellement pas d'accès généralisé aux institutions d'éducation de la petite enfance en raison du manque de places dans les structures d'accueil et de l'absence d'un droit légal à une place d'accueil. De plus, il n'existe pas de loi spécifique et contraignante au niveau fédéral qui établisse des principes pédagogiques au-delà des standards minimums. Pourtant, au niveau fédéral, l'OPE (ordonnance sur le placement d'enfants) définit les conditions légales relatives à l'autorisation et la surveillance des offres de prise en charge extrafamiliale des enfants. Mais, au-delà, la Confédération ne dispose ni de la responsabilité ni de la compétence législative. Par conséquent, les possibilités politiques de gestion des offres institutionnelles d'éducation de la petite enfance sont limitées au niveau 
national. L'absence de caractère contraignant en ce qui concerne l'orientation de fond du secteur se reflète dans l'hétérogénéité des organismes responsables. Outre les offres du secteur public, on trouve des associations à but non lucratif, des crèches d'entreprises ainsi qu'un grand nombre d'organisations commerciales.

Par rapport à d'autres pays d'Europe de l'Ouest, la Suisse est en retard en ce qui concerne le développement de la prise en charge des jeunes enfants. En outre, elle compte toujours parmi les pays de l'OCDE qui investissent le moins dans le domaine de la petite enfance (2012: 0,25\% du PIB). De plus, elle se différencie des autres pays européens par le recours aux offres d'éducation de la petite enfance formelles. Certes, avec un taux d'inscription en 2016 avoisinant $41 \%$ des enfants de 0 à 3 ans, la Suisse se situe au-dessus de la moyenne européenne, mais le temps passé par les enfants en crèche chaque semaine, qui est d'à peine 18 heures, y est largement inférieur. Les fortes disparités locales en matière de taux de fréquentation et de couverture sont frappantes. En effet, on observe un écart entre la ville et la campagne ainsi qu'entre les différentes zones linguistiques: les offres formelles d'éducation de la petite enfance sont plus nombreuses en ville et en Suisse romande, où elles sont également plus souvent sollicitées.

En Suisse, les débats relatifs à l'importance de l'éducation de la petite enfance sont souvent dominés par des considérations économiques liées au marché du travail. Les aspects liés aux politiques de migration et d'intégration jouent également un rôle, car l'éducation de la petite enfance est censée avoir un effet compensatoire sur les chances éducatives, notamment chez les enfants parlant une langue étrangère à la maison et vivant dans un milieu défavorisé. De 2003 à 2017, la Suisse a enregistré, notamment grâce aux aides financières à l'accueil extrafamilial pour enfants versées par la Confédération (RS 861; 353 millions de francs), une hausse considérable du nombre de places (31078 nouvelles places en crèche; situation au 31.12.2016), si bien que l'accueil extrafamilial des enfants est devenu un facteur de socialisation important pour les enfants d'âge préscolaire. En outre, des initiatives spécialisées ont été prises, lesquelles montrent un changement structurel de l'accueil des enfants qui voit sa fonction éducative renforcée. Mentionnons les efforts menés par les acteur-trice-s de la société civile qui visent à obtenir un nouveau développement qualitatif, comme le «cadre d'orientation pour la formation, l'éducation et l'accueil de la petite enfance en Suisse» ou le label de qualité «QualilPE». Toutefois, ces instruments n'étant ni inscrits dans la loi ni contraignants, on ignore encore dans quelle mesure ils pourront établir des critères éducatifs sur le terrain. Outre la consécration des réflexions sur la formation, le principal défi sur le plan sociopolitique consiste à assurer un accès universel aux établissements d'éducation de la petite enfance, ce qui soulève d'une part la question du coût pour les parents, lesquels sont très élevés en Suisse. En effet, dans les structures d'accueil non subventionnées, les parents doivent payer des montants allant de 120 à 150 francs par jour et par enfant. D'autre part, se pose la question de savoir dans quelle mesure la conception selon laquelle l'éducation et l'accueil de la petite enfance ne constituent pas seulement une mission familiale et privée, mais aussi un bien public auquel parents et enfants ont droit, peut s'imposer au niveau sociopolitique.

\section{Sascha Neumann \& Marina Wetzel}

\section{Références}

Burger, K., Neumann, S. \& Brandenberg, K. (2017). Études sur la formation, l'accueil et l'éducation de la petite enfance en Suisse. https://jacobsfoundation.org/ 
Kibesuisse \& Jacobs Foundation (Éd.) (2014). Critères normatifs du label de qualité pour l'éducation et l'accueil de jour de l'enfance. https://www. quali-ipe.ch

Wustmann Seiler, C. \& Simoni, H. (2012). Cadre d'orientation pour la formation, l'accueil et l'éducation de la petite enfance en Suisse. Berne : Commission suisse pour l'UNESCO.

\section{Éffets de seuil*}

Des effets de seuil peuvent se produire dans les systèmes fiscaux et de transferts sociaux, ainsi que dans les systèmes de prestations où les tarifs sont fixés en fonction du niveau de revenu. On parle d'effet de seuil lorsqu'une hausse du revenu provenant d'une activité lucrative se solde par une baisse du revenu effectivement disponible, parce qu'elle entraîne une brusque augmentation de la charge fiscale ou des tarifs ou une diminution notable des prestations sociales. Le revenu disponible d'un ménage est l'argent qui lui reste après déduction des frais fixes (loyer, primes d'assurance-maladie, éventuellement frais de garde des enfants) et des impôts. Les effets de seuil sont problématiques à deux égards. D'abord, si le fait d'augmenter son taux d'activité ou de chercher un emploi mieux rémunéré a potentiellement pour effet une diminution du revenu disponible, c'est l'incitation même à exercer une activité lucrative qui disparaît. Ensuite, un système d'imposition et/ou de prestations sociales qui présente des effets de seuil sera ressenti comme injuste tant par les bénéficiaires que par la population dans son ensemble avec, en corollaire, la remise en cause de sa légitimité.

Les impôts et les prestations sociales sous condition de ressources sont plus exposés aux effets de seuil que les assurances sociales, parce qu'ils dépendent davantage que les prestations d'assurance directement du niveau de rémunération actuel. Un effet de seuil se produit par définition lorsqu'une prestation est calculée par échelon de revenu. Dans un tel système, une légère hausse du revenu peut faire passer à un échelon de revenu supérieur, partant, induire une diminution notable des prestations. Des effets similaires s'observent dans des systèmes fiscaux à progression échelonnée. Moins un système compte de paliers et plus les paliers sont grands, plus l'effet de seuil est marqué. Par exemple, dans quelques cantons, les avances sur pensions alimentaires sont couplées à une limite de revenu fixe. Il s'ensuit que la personne dont le revenu est à peine inférieur à cette limite se voit verser l'intégralité de la prestation, tandis que celle qui gagne à peine plus n'y a pas droit du tout. Une augmentation minime du revenu peut donc générer une perte de plusieurs milliers de francs par année. Des systèmes plus nuancés (paliers de revenu plus petits et plus nombreux) ont des effets de seuil plus faibles. C'est le cas, dans de nombreux cantons, pour les réductions de primes et les tarifs de l'accueil extrafamilial, qui sont fixés en fonction des revenus. Des effets de seuil peuvent également se produire lorsque certains éléments ne sont pas pris en compte lors du calcul du droit aux prestations, mais qu'ils s'appliquent seulement ultérieurement au moment du calcul du montant de la prestation - dans l'aide sociale, par exemple, lorsque les éléments «prestations circonstancielles» ou «franchise sur le revenu» ne sont pas pris en compte dans le calcul du droit aux prestations.

L'effet de seuil n'est cependant qu'une incitation au travail négative parmi d'autres. Ainsi, une prestation qui diminue de manière linéaire (sans paliers), mais plus fortement que l'éventuelle augmentation de revenu, n'incitera personne à gagner plus. Ce cas de figure se présente notamment lorsque plusieurs réductions de prestations ou augmentations de contributions sont cumulées ou, plus concrètement, lorsqu'un revenu plus élevé conduit à la fois à une augmentation de la charge fiscale et à une diminution de la réduction des primes. 
Les effets de seuil, et plus généralement les effets négatifs sur l'incitation au travail, peuvent être supprimés en partie ou intégralement par une adaptation structurelle des systèmes de prestations sociales et d'impôts. En principe, les prestations sociales et les systèmes fiscaux qui sont conçus sans échelons et qui intègrent tous les éléments déterminants dès le calcul du droit aux prestations ne génèrent pas d'effets de seuil. L'harmonisation des prestations sociales entre elles peut également contribuer à réduire les effets négatifs.

En Suisse, la problématique des effets de seuil a été traitée sérieusement pour la première fois en 2007, avec deux études de la Conférence suisse des institutions d'action sociale (CSIAS). Elle est alors devenue partie de l'agenda politique et matière à débat tant politique que scientifique. Suite à diverses initiatives politiques, plusieurs cantons ont examiné leurs systèmes de prestations sous l'angle des effets de seuil et d'autres effets négatifs sur l'incitation au travail et mandaté des études circonstanciées sur le sujet. Ces études ont relevé l'existence d'effets de seuil et les moyens de les éliminer, certaines allant jusqu'à chiffrer le nombre de personnes concernées. Les recherches de Bütler sur les frais de crèche et sur les prestations complémentaires (les deux en 2009) et de Bieri/Gysin sur les rentes de l'assurance-invalidité (2010) ont élargi le savoir relatif aux effets de seuil et effets négatifs sur l'incitation au travail à d'autres branches du système des prestations sociales. La thématique a également fait son entrée sous la coupole fédérale, d'abord avec un postulat du Conseiller aux États socialiste Claude Hêche (09.3161), qui déboucha sur un rapport détaillé concernant les effets de seuil et les effets négatifs sur l'incitation au travail dans les systèmes fiscaux et de transferts cantonaux, y inclus des solutions de bonnes pratique. Ensuite avec une motion concernant l'imposition des prestations d'aide sociale (10.3340), qui donna lieu à un examen approfondi des répercussions d'une imposition des prestations sociales et d'une exonération fiscale du minimum vital, avec une attention particulière portée aux effets de seuil et aux incitations.

Grâce à ces résultats scientifiques et interventions politiques, presque tous les cantons ont ajouté la question des effets de seuil à leur agenda politique. Plusieurs ont réussi à éliminer ou au moins à réduire les effets de seuil et plus généralement les effets négatifs sur l'incitation au travail en adaptant les systèmes de prestations sociales relevant de leur compétence. Quelques cantons, notamment en Suisse latine, ont adopté des lois qui garantissent l'harmonisation des différentes prestations sociales, et sont parvenus ainsi à mieux gérer les injustices inhérentes au système. Tant sur le plan cantonal que fédéral, la question des effets de seuil est désormais reconnue comme une thématique transversale devant être considérée lors de chaque réforme des systèmes fiscaux et de transferts.

Malgré les efforts consentis, certains systèmes fiscaux et de transferts cantonaux et fédéraux continuent à présenter des effets de seuil. Un besoin d'action existe notamment dans les domaines de l'aide sociale et des avances sur pensions alimentaires, mais aussi dans les cas où une prestation entraîne automatiquement d'autres contributions forfaitaires élevées. Par exemple, lorsque des bénéficiaires de prestations complémentaires pour familles ou d'aide sociale se voient systématiquement accorder la réduction de prime la plus élevée, ou que des allocataires de l'aide sociale sont exonéré·e-s de l'impôt sur le revenu, ou encore que des bénéficiaires de prestations complémentaires sont libéré·e-s du paiement des redevances radio/TV. Tous ces cas peuvent déployer des effets de seuil, dans la mesure où des ménages ayant une situation financière similaire ou légèrement meilleure n'ont pas droit à ces prestations supplémentaires et à ces allègements. Comme les effets de seuil peuvent être éliminés aussi moyennant une réduction 
des prestations (p.ex. par la suppression des prestations supplémentaires citées), le risque est réel d'une instrumentalisation politique de la question pour démanteler le système de prestations sociales. Après la première vague d'efforts politiques avant 2010, le défi consiste aujourd'hui à maintenir l'attention et le soutien des politiques concernant la question des effets de seuil et à trouver des solutions socialement acceptables. La suppression des effets de seuil est une condition clé pour des systèmes fiscaux et de transferts équitables et efficients. Il est important de tenir compte de la problématique des effets de seuil également lors de futures réformes du système, pour éviter l'apparition de nouveaux effets de seuil.

\section{Franziska Ehrler, Caroline Knupfer \& Yann Bochsler}

\section{Références}

Ehrler, F., Knupfer, C. \& Bochsler, Y. (2012). Effets de seuil et effets pervers sur l'activité: une analyse des systèmes cantonaux de transferts sociaux et de prélèvements. Rapport de base en réponse au Postulat du conseiller aux États Claude Hêche (09.3161). Berne: Office fédéral des assurances sociales.

\section{Égalité}

L'égalité figure parmi les concepts de philosophie politique les plus difficiles à définir. Au IV siècle avant notre ère, Aristote écrivait déjà que ce qui est égal et inégal est source de difficultés (aporia), la question donnant du même coup matière à philosophie politique. Dans le domaine des politiques sociales, cette question ne pose pas moins problème mais elle permet de trancher entre différents modèles.

Il y a deux manières principales de considérer l'égalité, qui correspondent elles-mêmes à deux imaginaires politiques distincts. La première, moderne et libérale, postule l'égalité naturelle et demande aux institutions de la reconnaître, comme le font la Déclaration d'Indépendance américaine de 1776 ou la Déclaration des droits de l'homme et du citoyen de 1789. La seconde, démocratique, assigne aux institutions de la collectivité la tâche de former des individus égaux jouissant des mêmes libertés.

Cette incertitude sur la définition de l'égalité hante toutes les discussions à son sujet, selon que l'on tienne l'égalité pour naturelle ou instituée. Dans la modernité, c'est la première solution qui a eu les faveurs de la plupart des philosophes politiques. L'égalité est alors assimilée à l'état de nature, la société venant par la suite instituer des hiérarchies, par ailleurs justes ou injustes. Une société doit ici garantir l'égalité des droits, non une égalité substantielle de ses membres. Au XXe siècle, cet argument est réactivé par John Rawls, pour qui seules les libertés fondamentales doivent être égales pour tous les membres d'une société juste. Les inégalités sont souhaitables à la condition qu'elles améliorent le sort des plus défavorisé-e-s et que les différents postes soient ouverts à tout le monde. Bien conscient qu'il n'avançait nullement là un argument égalitaire, Rawls a défini cela comme le «principe de différence». Divers auteurs ont cherché à compléter la liste des choses qui doivent être également garanties dans une société juste, notamment Amartya Sen qui y a ajouté ce qu'il nomme les «capabilités», sans toutefois modifier essentiellement le problème. L'objectif est toujours de procurer à tous les sociétaires, dans une société qui demeure inégalitaire, une quantité équivalente de quelque chose avant que les interactions sociales ne se déploient.

La leçon athénienne nous rappelle au contraire que l'égalité n'est ni première ni purement formelle: nous pensons toujours l'égalité à partir des inégalités. L'égalité politique ne vise nullement la similitude de toutes et tous, voire leur interchangeabilité, ni une sorte de minimum exigible défini d'une manière ou 
d'une autre, mais une égale possibilité de participation aux affaires communes, qui s'accompagne d'institutions permettant de garantir l'effectivité de cette participation. On connaît les infinis raffinements de la constitution des Athéniens pour s'approcher de cet idéal. On connaît peut-être moins les avertissements des auteurs de la longue tradition républicaine, d'Aristote à Rousseau et au-delà, contre les effets délétères qu'entraînent des disparités de fortune trop importantes sur la préservation de cette égalité. En termes contemporains, cela signifie qu'une égalité politique suppose, non pas une parfaite égalité de ressources, mais des inégalités économiques limitées.

L'idée d'égalité vient subvertir d'autres notions centrales de la pensée politique, à commencer par celle de justice. Contrairement à ce qu'une partie de la philosophie politique avance, égalité et justice ne sont nullement équivalentes, et peut-être sont-elles même contradictoires sur certains aspects tout à fait fondamentaux. Depuis Platon, la justice est définie en termes de vérité et hors de toute délibération politique. Elle cherche à ordonner la société selon des critères qui lui sont transcendants. L'égalité est au contraire un concept politique de part en part, sans transcendance, comme l'a souligné Cornelius Castoriadis. C'est pourquoi elle est souvent considérée avec circonspection, sinon avec méfiance, par les philosophes, les juristes ou les spécialistes de l'éthique.

L'égalité entretient un rapport plus compliqué avec la notion de liberté. Qu'on les considère comme opposées, selon l'opinion conservatrice habituelle, ou qu'on les tienne pour intimement articulées, voire coextensives l'une à l'autre comme le fait Étienne Balibar avec son concept d'«égaliberté» dans La proposition de l'égaliberté publié en 2010, leur rapport est dans tous les cas problématique. Norberto Bobbio, dans Destra et sinistra publié en 1994, concevait d'ailleurs celui-ci comme un marqueur distinctif de la droite et de la gauche, la pre- mière opposant les deux concepts, la seconde les tenant pour complémentaires.

L'égalité se trouve toujours au cœur des théories de la démocratie. Celui qui l'a peutêtre le mieux montré est Tocqueville dans sa description de la démocratie américaine. Pour lui, l'égalisation des conditions est au fondement de la société démocratique qui émerge aux États-Unis, ce qui se traduit par une horizontalité des rapports entre individus alors inconnue en Europe. Les développements possibles d'une telle égalisation inquiètent en même temps l'aristocrate: c'est en effet chez Tocqueville que l'on trouve dans sa publication De la démocratie en Amérique l'une des premières occurrences modernes de l'équivalence entre égalité et servitude, la multitude indifférenciée se plaçant sous la protection d'un «pouvoir immense et tutélaire». Si l'auteur a souvent été embrigadé par les contempteurs de l'égalité, on a moins remarqué cependant qu'un tel développement ne constituait pas pour lui une fatalité.

Dans le domaine des politiques sociales, l'égalité a traditionnellement été associée aux politiques mises en place dans les régimes sociaux-démocrates dans l'après-guerre, fondées sur l'universalité de l'accès aux différentes assurances sociales. Dans son analyse des différents types d'État-providence, Gøsta Esping-Andersen relève par exemple que c'est le modèle social-démocrate scandinave, contrôlé par l'État et qui distribue universellement ses prestations, qui a contribué à créer les sociétés les plus égalitaires. Selon lui, les autres modèles, «corporatiste-conservateur» (ou «bismarckien») et «libéral» (ou «beveridgien»), n'atteignent pas les mêmes résultats sur ce plan-là. Quant aux politiques reposant sur la charité, à savoir le maintien des personnes les plus défavorisées au-dessus d'un seuil de pauvreté défini unilatéralement, elles ne s'inspirent évidemment pas de la notion d'égalité et lui sont même très exactement opposées. 
Dans le cas des politiques sociales suisses, l'on peut identifier différentes institutions répondant plus ou moins à l'impératif égalitaire. L'AVS s'y conforme le plus complètement, avec ses contributions proportionnelles au revenu et sans limite supérieure, alors que des prestations très similaires sont versées à chacun et chacune à partir d'un âge identique. Les outils qui s'y sont ajoutés, qu'il s'agisse de la prévoyance professionnelle (le « $2^{\mathrm{e}}$ pilier») ou des assurances privées et volontaires (le « $3^{\text {e }}$ pilier»), répondent quant à eux au principe inverse, celui du maintien des inégalités antérieures.

De toutes les valeurs censées fonder la démocratie, l'égalité est assurément la plus contentieuse, la moins uniformément admise, la plus combattue aussi. Si personne n'argumente sérieusement en faveur de l'injustice, de l'arbitraire ou de la tyrannie, on rencontre en revanche quantité d'arguments défendant le principe de l'inégalité, que celle-ci soit justifiée par la concurrence, le mérite, la performance ou l'éducation. Or, comme l'écrivait Rousseau dans le deuxième livre du Contrat social, «c'est précisément parce que la force des choses tend toujours à détruire l'égalité que la force de la législation doit toujours tendre à la maintenir ».

\section{Antoine Chollet}

\section{Références}

Castoriadis, C. (1986). Domaines de l'homme. Paris : Seuil.

Esping-Andersen, G. (1990). The three worlds of welfare capitalism. Cambridge: Polity Press.

Myers, J. (2010). The politics of equality: an introduction. London: Zed Books.

\section{Emploi « normal »}

La notion d'emploi normal (emploi typique, classique ou traditionnel) désigne un emploi salarié, de durée indéterminée, exercé à plein temps et de manière régulière pour un·e même employeur-euse vis-à-vis duquel existe un rapport de subordination. L'emploi normal implique, via le paiement de cotisations prélevées sur les salaires, l'accès aux prestations octroyées par le système d'assurances sociales qui permettent d'obtenir un revenu de remplacement en cas de chômage, invalidité, maladie, vieillesse, etc. Il s'oppose aux formes particulières d'emploi, que l'on qualifie également d'emplois atypiques et qui englobent, notamment, les emplois à temps partiel volontaire, ainsi que les emplois précaires (soit les emplois qui sont caractérisés par un élément d'insécurité temporelle, économique ou en termes de protection et qui regroupent, en particulier, les relations de travail de durée déterminée, les emplois saisonniers, les stages, le travail temporaire, le travail sur appel, la pseudo-indépendance ou encore le travail à temps partiel non choisi).

Le travail, en tant qu'activité fournie pour le compte d'autrui, existe depuis des temps très anciens. Le "contrat de louage de services» (locatio conductio operarum) est en effet une institution qui remonte à l'époque romaine. Si le droit romain a consacré les éléments essentiels du contrat de travail sur lesquels se fonde le droit actuel (articles 319-362 du Code des obligations), il a fallu attendre l'avènement à partir du XIX siècle de l'industrialisation pour que des normes soient adoptées afin de garantir une certaine protection sociale à ceux et celles qui s'engageaient à travailler dans les nouvelles usines et exploitations de production de masse. L'émergence du libéralisme et de la liberté du commerce et de l'industrie a en effet entraîné la nécessité de légiférer dans le dessein de sauvegarder les intérêts de la population ouvrière.

La plupart des pays industrialisés ont légiféré sur les relations de travail et sur les assurances sociales dès la fin du XIX $\mathrm{X}^{\mathrm{e}}$ siècle et la législation s'est développée sur un peu plus 
d'un siècle. L'emploi normal constitue la norme sur la base de laquelle le droit du travail et le droit des assurances sociales ont été conçus; ces droits ont en effet été élaborés afin de garantir une protection aux salarié-e.s occupé·e-s à plein temps. Fondées sur une conception traditionnelle du partage des tâches entre les sexes, ces législations ont protégé l'homme, en sa qualité de soutien de famille. En ce qu'il représente la source principale de revenu de l'employé·e, le travail place ce dernier ou cette dernière dans un fort rapport de dépendance économique face à son employeur-euse, d'où la nécessité d'encadrer l'emploi normal de garde-fous concernant par exemple la durée du travail, la protection contre le licenciement, le niveau de rémunération, l'accès aux protections offertes par le système d'assurances sociales, etc. en vue, en particulier, d'assurer à celui-ci sa stabilité et sa durée.

Étant donné que le droit du travail et le droit des assurances sociales ont, à l'origine, été orientés autour de l'emploi normal, la protection sociale des personnes qui occupent des emplois atypiques est susceptible de se révéler lacunaire. On en trouve de nombreuses illustrations dans le système d'assurances sociales suisses. Ainsi, les employé·e-s au bénéfice d'un contrat de durée déterminée jouissent d'une protection moindre contre le licenciement et sont prétérité-e-s par les protections qui sont fonction de la durée des relations de travail (comme il en va, par exemple, du droit au versement du salaire en cas d'incapacités non fautives de travailler, telles que la maladie ou l'accident). Les travailleur-euse-s temporaires et sur appel peuvent, pour leur part, subir des désavantages en matière d'assurance-chômage. En outre, seul·e·s les salarié·e·s qui réalisent un revenu annuel excédant un seuil minimum préalablement défini ont accès au deuxième pilier et les accidents non professionnels des personnes employées moins de huit heures par semaine ne sont pas couverts par l'assurance-accidents, mais par l'assu- rance-maladie obligatoire, c'est-à-dire par un régime qui accorde uniquement des prestations en nature (soins médicaux). L'invalidité des travailleur.euse-s à temps partiel qui accomplissent en parallèle des travaux habituels (tenue du ménage, notamment) est par ailleurs évaluée en application d'une méthode spécifique (la méthode dite «mixte»), qui est susceptible de les pénaliser par rapport aux salarié.e-s à temps plein, qui se voient appliquer la méthode ordinaire de comparaison des revenus. À cet égard, toutefois, un nouveau mode de calcul a été introduit depuis le $1^{\text {er }}$ janvier 2018, afin de garantir une meilleure prise en compte des interactions existant entre les différents domaines d'activité (activité professionnelle et travaux habituels).

Si les exemples qui précèdent démontrent que l'emploi normal bénéficie d'une meilleure protection, le travail atypique, qui a fait son apparition afin de répondre au besoin de flexibilité du marché du travail, n'est cependant pas obligatoirement une situation subie par les travailleur-euse-s concerné·e-s. En particulier, le travail à temps partiel choisi constitue une modalité de travail qui offre une certaine liberté aux salarié·ess, leur permettant, par exemple, de concilier vie professionnelle et vie familiale. Étant donné que le travail à temps partiel est l'apanage des femmes (selon les chiffres publiés par l'Office fédéral de la statistique, 6 femmes actives professionnellement sur 10 exercent un emploi à temps partiel, contre seulement 1,6 hommes sur 10), il convient de porter une attention particulière à ce que les salarié.e.s à temps partiel ne soient pas traité.e.s différemment des salarié.e-s occupé-e.s à temps plein et aient accès aux mêmes droits ; à défaut de justification objective, réserver un traitement particulier aux personnes occupées à temps partiel contrevient au principe de l'égalité entre les sexes consacré par la Constitution fédérale.

Les dernières décennies du $\mathrm{XX}^{\mathrm{e}}$ siècle ont été marquées par de profondes mutations dans le monde du travail. On assiste effectivement 
à un recul de l'emploi normal, parallèlement à l'émergence de nouvelles formes de travail flexible (forte augmentation des emplois à temps partiel et du recours à des contrats de travail de durée déterminée, émergence de la pseudo-indépendance et du freelance, «ubérisation» des rapports de travail, etc.). Ces nouvelles formes d'emplois dites atypiques sont apparues afin de permettre au marché du travail de s'adapter rapidement aux changements de l'économie (libéralisation de l'économie, mondialisation et «déréglementation » du marché du travail, augmentation de la concurrence, crise économique et détérioration du cours de l'euro, etc.) et de la société (croissance du travail féminin ou réduction volontaire du temps de travail afin de se consacrer à l'éducation des enfants, p.ex.). La tendance à la «déréglementation» des rapports de travail est particulièrement perceptible ces dernières années (introduction d'assouplissements et d'exceptions à l'obligation d'enregistrer le temps de travail, initiatives parlementaires tendant à la suppression de la durée maximale de la semaine de travail et à une réduction des temps de repos dans certains secteurs d'activité, etc.). Le défi consiste alors à faire accéder les détenteur-trice-s de ces nouveaux emplois atypiques, toujours plus nombreux-ses, aux formes et niveaux de protection jusque-là garanties à l'emploi normal.

\section{Stéphanie Perrenoud}

\section{Références}

Bosch, G. (2001). Konturen eines neuen Normalarbeitsverhältnisses. WSI Mitteilungen, 4, 219-230.

Buelens, J. \& Pearson, J. (Eds.) (2013). Standard work: an anachronism? Antwerpen: Intersentia.

\section{Encouragement de l'enfance et de la jeunesse ${ }^{*}$}

L'encouragement de l'enfance et de la jeunesse (EEJ) est l'un des piliers de la politique suisse de l'enfance et de la jeunesse, au même titre que la protection et la participation/codétermination des enfants et des jeunes. L'article 41 de la Constitution fédérale définit l'EEJ comme l'encouragement du développement des enfants et des adolescent-e.s pour devenir des personnes indépendantes et socialement responsables qui doivent être soutenues dans leur intégration sociale, culturelle et politique. La loi sur l'encouragement de l'enfance et de la jeunesse (LEEJ) spécifie la mise en œuvre des dispositions constitutionnelles et fait de l'EEJ un domaine public d'activités et de fonctions. Elle détermine l'objet, le but et les conditions préalables du soutien financier fédéral aux organismes publics (cantons, communes) et privés (non commerciaux) responsables d'activités et de services destinés à la promotion extrascolaire d'enfants, de jeunes et de jeunes adultes et définit les procédures correspondantes. La LEEJ désigne les enfants et les jeunes de l'âge de l'entrée à l'école enfantine à 25 ans révolus comme groupes cibles de l'EEJ. La LEEJ crée également une base légale pour l'aide financière à des projets modèles d'EEJ d'importance nationale. Elle ne contient pas d'obligation pour la Confédération en matière de soutien financier et ne constitue pas non plus un droit aux prestations (dispositions facultatives). Elle définit le rôle de la Confédération dans un domaine d'activité qui, selon les principes du fédéralisme et de la subsidiarité, relève en premier lieu de la compétence des communes et des cantons et qui est marqué, dans une large mesure, par des organismes responsables privés suprarégionaux (ces derniers présentant souvent de forts particularismes régionaux).

L'EEJ a été mentionné pour la première fois en Suisse en 1973. Près de vingt ans plus tard, la première loi fédérale sur l'encourage- 
ment des activités extrascolaires des enfants et des jeunes est entrée en vigueur en 1991. Elle habilite les autorités fédérales à soutenir financièrement le travail des associations de jeunesse en Suisse. En réponse à divers postulats et motions, le Conseil fédéral a adopté en 2008 un rapport intitulé Pour une politique suisse de l'enfance et de la jeunesse. Elle repose sur trois piliers : la protection, la promotion et la participation/codétermination des enfants, des jeunes et des jeunes adultes.

Contrairement à la protection des enfants et des jeunes, l'EEJ ne se préoccupe pas du traitement des situations de mise en danger et de détresse concrètes, mais plutôt de la création de conditions-cadres favorables dans lesquelles les jeunes peuvent bien vivre et se développer; en même temps, l'EEJ est orienté vers des domaines d'action en dehors de l'école et de la famille. Les conditions de vie des enfants, des adolescent.e-s et des jeunes adultes étant influencées par différents facteurs, le but déclaré de l'EEJ est d'exercer dans la Confédération, les cantons et les communes/ villes une fonction transversale et de soutenir le développement et la mise en œuvre d'offres extrascolaires efficaces et axées sur les besoins des enfants, des adolescent·e.s et des jeunes adultes.

L'EEJ a été élargi en 2013 avec l'entrée en vigueur de la loi sur l'encouragement de l'enfance et de la jeunesse (LEEJ) entièrement révisée, qui se fonde sur l'article 67 de la Constitution fédérale. Elle renforce le potentiel d'intégration et de prévention de l'EEJ, développe des formes ouvertes et innovantes de travail extrascolaire dans le cadre de l'encouragement financier et soutient la participation et la codétermination des jeunes en Suisse. Cette extension du contenu reste toutefois liée à des activités de subvention sélective dans ces domaines.

L'article 67 de la Constitution fédérale, adopté en 2006, chargeait les cantons et les communes/villes de «répondre aux besoins des enfants et des jeunes », sans toutefois avoir de caractère juridique contraignant. Il n'existe pas non plus de base légale au niveau cantonal qui oblige les communes et les villes à un EEJ actif. Au niveau intercantonal, la «Conférence des délégués cantonaux à la promotion de l'enfance et de la jeunesse» (CDEJ) est un organe important composé de responsables cantonaux de l'enfance et de la jeunesse. L'objectif de la $\mathrm{CDEJ}$ est de promouvoir les échanges intercantonaux d'expertise ainsi que l'établissement et la professionnalisation de l'EEJ aux niveaux fédéral, cantonal et communal. Un jalon important est le document de position Standards de la promotion de l'enfance et de la jeunesse en Suisse développé par la CDEJ, qui contient des recommandations sur les principes et les caractéristiques d'un équipement de base de l'EEJ.

L'EEJ a connu un développement très différent dans les cantons suisses et au sein des cantons. Au niveau cantonal, cependant, les structures se sont considérablement développées ou agrandies dans le domaine de l'EEJ au cours des vingt dernières années. En 2009, il existait des lois et des ordonnances sur l'EEJ dans un peu moins de la moitié des cantons suisses, les trois quarts d'entre eux disposaient de bureaux de coordination de l'EEJ et d'un règlement pour l'encouragement financier des activités extrascolaires. Il existe néanmoins des différences considérables entre les cantons en ce qui concerne les bases juridiques, l'extension des organes de coordination et les modèles d'encouragement financier. Les communes et les villes jouent un rôle primordial dans le développement et la mise en œuvre de l'EEJ en confiant généralement la mise en œuvre des stratégies ou la fourniture de services et d'offres à des organismes d'activités de jeunesse extrascolaires à but non lucratif ou commerciaux.

$\mathrm{Au}$ cours des dix dernières années, on a pu observer des évolutions considérables dans le domaine de l'EEJ à l'échelon communal dans de nombreuses villes et, de plus en plus, dans 
des communes de Suisse alémanique et de Suisse romande. D'une part, les processus de formation de structures et de professionnalisation se déroulent dans le cadre de l'animation socioculturelle avec des enfants et des jeunes en milieu ouvert; d'autre part, les associations d'enfants et de jeunes et les associations locales du secteur des loisirs contribuent à la diversité des activités extrascolaires. De plus en plus, des délégué·e-s à l'enfance et à la jeunesse sont déployé·e.s dans les administrations communales. Ils et elles ont pour mission de coordonner, planifier et développer des activités extrascolaires pour les enfants, les adolescent·e.s et les jeunes adultes et de soutenir la participation des enfants, des adolescent.e.s et des jeunes adultes, leur permettant ainsi de jouer un rôle clé dans la mise en place de conditions propices au développement et à l'égalité des chances.

Dans le domaine de l'EEJ, des défis cruciaux se posent actuellement en Suisse à deux niveaux. D'une part, il n'y a pas de monitoring systématique jusqu'à présent. Certes, depuis le milieu des années 2000, des relevés structurels ont été réalisés dans certains cantons ( $\mathrm{AG}, \mathrm{BE}$, $\mathrm{BL}, \mathrm{BS}, \mathrm{FR}, \mathrm{SO}, \mathrm{ZH})$ et ont parfois été utilisés pour l'élaboration de stratégies de politique de l'enfance et de la jeunesse basées sur des données. Cependant, la Suisse est bien loin d'avoir établi une base de données systématique dans le domaine de l'EEJ. Pourtant, ces informations fondamentales sont indispensables pour la conception d'un EEJ basé sur les données, orientée vers la demande et efficace.

D'autre part, un EEJ communal actif nécessite un ancrage juridique au niveau communal, une discussion des objectifs stratégiques (p.ex. sous la forme d'une ligne directrice) et la formulation de concepts de mise en œuvre et de plans d'action appropriés. En outre, il faut des structures de processus claires et des acteur-tice-s défini-e.s qui ont un œil sur le développement de l'EEJ au-delà des organisations individuelles dans le secteur extrascolaire et qui veillent à ce que les activités extrascolaires soient adaptées aux groupes cibles et aux besoins. Cette tâche clé est accomplie en partie par des commissions de l'enfance et de la jeunesse ou par des délégué·e·s spécialisé·e·s. La majorité des communes et des villes suisses doivent prendre des mesures supplémentaires pour atteindre l'image idéale qui se reflète, entre autres, dans les standards pour la promotion de l'enfance et de la jeunesse en Suisse. Il est également important que les initiatives de la population (jeune) ne soient pas entravées. Divers cantons ont fait des expériences positives en soutenant activement les communes et les villes dans le développement et la mise en œuvre de l'EEJ, que ce soit sous la forme d'un soutien financier, de conseils spécialisés ou d'aides au travail et aux processus.

\section{Manuel Fuchs \& Julia Gerodetti}

\section{Références}

Conseil fédéral (2008). Pour une politique suisse de l'enfance et de la jeunesse: rapport du Conseil fédéral en réponse aux postulats Janiak (00.3469) du 27 septembre 2000, Wyss (00.3400) du 23 juin 2000 et Wyss (01.3350) du 21 juin 2001. Berne: Office fédéral des assurances sociales.

May, A. \& Wiesli, R. (2009). Kinder- und Jugendförderung in der Schweiz: Begleitbericht zuhanden der kantonalen Fachstelle für Kinder- und Jugendförderung Freiburg. Bern : Fachstelle für Gesundheitspolitik.

Poretti, M. (2015). Politiques locales de l'enfance et de la jeunesse en Suisse romande: état des lieux et enjeux. Sion: Centre interfacultaire en droits de l'enfant.

\section{Enfance et jeunesse*}

L'enfance et la jeunesse désignent des phases de la vie définies par des critères physiques, sociaux et psychologiques. L'enfance est généralement comprise comme la période entre la naissance et le début des changements qui se produisent au niveau des organes géni- 
taux (puberté). Dans cette même perspective, la jeunesse commence avec les changements physiques des organes génitaux et se termine lorsque le corps a achevé sa maturation. Les termes enfance et jeunesse font également référence aux différences de statut établies par les institutions sociales entre les adultes, les enfants et les jeunes. En Suisse, avec l'introduction de la scolarité obligatoire en 1874 et l'interdiction du travail des enfants (loi sur les fabriques de 1877), ce sont des réformes sociales et sociopolitiques qui ont contribué, de manière décisive, à ce que les termes d'enfance et de jeunesse recouvrent des statuts sociaux spécifiques.

Sur le plan culturel, l'enfance n'a obtenu un statut de phase particulière de la vie humaine que lors de la transition vers les temps modernes. Au cours de l'industrialisation, des sphères de vie distinctes se sont développées pour tous les enfants et les jeunes (en particulier les écoles). À partir du XVIII ${ }^{\mathrm{e}}$ siècle, la pédagogie s'est penchée de manière intense sur les questions relatives au développement et à l'éducation, et à partir du XIX ${ }^{\mathrm{e}}$ siècle, la notion d'enfance s'est étendue, incluant désormais non seulement la phase de l'éducation mais également de la formation. À partir du $\mathrm{XX}^{\mathrm{e}}$ siècle, les enfants sont de plus en plus souvent perçus comme des individus. C'est ainsi que naissent des discours romantiques sur l'enfance et la jeunesse, notamment dans le sillon des mouvements de jeunesse. Ces changements de perception sont étroitement liés aux changements sociaux, tels qu'une vie de famille plus intime et la création d'institutions publiques chargées spécifiquement de s'occuper des enfants, de les éduquer et de les former (écoles, institutions à des fins d'assistance).

Le développement de l'État-providence et du système éducatif s'accompagne d'une différenciation des rôles, des droits et des devoirs de l'État, des parents (ou de la personne exerçant l'autorité parentale) et des enfants/jeunes. Les réglementations correspondantes en matière de politique sociale portent principalement sur la sécurité matérielle des enfants et des jeunes et sur leur accès au système d'éducation et de formation. Une importance croissante est accordée à leur protection et à des mesures de soutien. Outre la politique de l'enfance et de la jeunesse et la politique familiale, la politique de l'éducation, la politique de l'emploi, la politique migratoire et la création des institutions d'assurance (AVS, AI) sont particulièrement décisives quant au façonnement des conditions de vie des enfants et des jeunes. Depuis les années 2000, la Confédération joue un rôle croissant dans la politique familiale et celle de l'enfance et de la jeunesse.

Parmi les mesures de politique familiale majeures prises par la Confédération, citons le programme d'impulsion visant à encourager la création de places d'accueil pour enfants (2002), l'introduction de l'assurance-maternité (2005), l'introduction des allocations familiales (2006) ainsi que celle des subsides fédéraux destinés à la réduction des primes de l'assurance-maladie (2007). Ces mesures témoignent d'une responsabilité sociale croissante en matière de financement et de prise en charge des enfants et des jeunes. Le programme d'impulsion (prolongé à plusieurs reprises) a permis d'augmenter le nombre de places d'accueil de manière significative, mais il est encore faible en comparaison internationale. Les offres varient considérablement d'une région à l'autre et impliquent fréquemment des coûts élevés pour les parents.

Dans le rapport du Conseil fédéral Pour une politique suisse de l'enfance et de la jeunesse de 2008 , la politique de l'enfance et de la jeunesse est conçue comme une politique de protection, d'encouragement des activités et de participation. Le rapport distingue la politique de l'enfance et de la jeunesse au sens large et au sens strict. Dans son acception stricte, elle inclut les activités politiques qui façonnent directement les conditions de vie des enfants et des jeunes. La politique de l'enfance et de la jeunesse comprise dans un sens plus large a pour but de faire 
valoir les souhaits et les besoins des enfants et des jeunes dans les divers domaines politiques. La politique suisse de l'enfance et de la jeunesse se caractérise par la répartition fédéraliste des compétences entre la Confédération, les cantons et les communes. Ces politiques relèvent en premier lieu de la compétence des cantons et des communes. En conséquence, les offres et les prestations destinées aux enfants et aux jeunes ainsi que leurs possibilités de participation varient considérablement. La Confédération n'intervient qu'à titre subsidiaire.

L'accent mis sur l'encouragement des activités, sur le soutien et la participation dans la loi sur l'encouragement de l'enfance et de la jeunesse (LEEJ) exprime une nouvelle compréhension de l'enfance et de la jeunesse. Les enfants et les jeunes sont davantage considérés comme des actrices et acteurs actif.ve-s dans les processus politiques; ils et elles doivent pouvoir agir de manière autonome, responsable et démocratique.

Les mesures de protection des enfants et des jeunes visent à protéger leur intégrité physique et mentale ainsi que leur santé. Dans le cadre de la réforme du Code civil de 2013, le droit des enfants et des jeunes d'être entendu.e.s dans une procédure de protection a été renforcé. Une autorité interdisciplinaire, l'Autorité de protection de l'enfant et de l'adulte (APEA) est désormais chargée de toutes les dispositions de droit civil. La protection des enfants et des jeunes gagne ainsi en considération. Le droit d'être entendu montre qu'ils et elles sont désormais considérée.es comme des actrices et acteurs autonomes disposant d'un statut de personnes juridiques, dont le point de vue est pertinent et doit être pris en compte dans l'action de l'État.

Mentionnons en outre les particularités du droit pénal suisse des mineur·e·s, qui met l'accent sur les mesures éducatives. Ainsi, l'enfance et la jeunesse sont comprises comme des processus de développement individuel dont le bon déroulement relève d'une responsabilité sociale.

$\mathrm{Au}$ niveau fédéral, l'encouragement des activités pour enfants et jeunes a récemment gagné en importance. Il est structuré de manière hétérogène au niveau cantonal et communal. En comparaison avec d'autres démocraties occidentales et malgré l'expansion des vingt dernières années, la politique de la famille suisse est sous-développée. Dans ce domaine, une spécificité suisse de l'image de l'enfance et de la jeunesse apparaît clairement : bien que, d'un point de vue de libéralisme social, les enfants et les jeunes devraient être davantage impliqué.e dans les prises de décision politiques, à l'inverse, d'un point de vue de libéralisme économique, les familles restent largement responsables du financement et de la prise en charge de leurs enfants. D'autres caractéristiques distinguent la Suisse d'autres pays : sa faible proportion d'étudiant·e·s, le rôle dominant de la formation professionnelle de degré secondaire II ainsi qu'un régime national de transition vers l'emploi particulièrement développé, qui vise l'intégration professionnelle de $95 \%$ des jeunes avant l'âge de 25 ans. L'institutionnalisation croissante de la transition vers l'emploi rémunéré ainsi que la prolongation et la discontinuité des cursus de formation entraînent de nouveaux défis pour les jeunes, mais également pour la politique de l'enfance et de la jeunesse.

Les défis actuels de la politique de l'enfance et de la jeunesse en Suisse résultent en particulier de l'accroissement des inégalités sociales, de la pluralisation des formes de vie familiale et de l'évolution technologique. Notons en particulier que la proportion de jeunes touché·ess par la pauvreté en Suisse reste importante, avec un taux de pauvreté de $5 \%$ et un taux de risque de pauvreté de $16 \%$. La pauvreté infantile a des conséquences négatives immédiates et à long terme. Elle est considérée comme un risque majeur pour le développement. La Suisse aurait besoin d'études scientifiques qui permettraient 
de faire évoluer la politique de l'enfance et de la jeunesse aux niveaux national, cantonal et local. De plus, les enfants et les jeunes ont encore trop peu la possibilité de participer aux processus politiques.

\section{Olivier Steiner \& Rahel Heeg}

\section{Références}

Moser, J. (2008). Der schweizerische Wohlfahrtsstaat: zum Ausbau des sozialen Sicherungssystems. Frankfurt a.M.: Campus.

Office fédéral des assurances sociales (Éd.) (2014). État actuel de la politique de l'enfance et de la jeunesse en Suisse. Berne: Office fédéral des assurances sociales.

Poretti, M. (2015). Politiques locales de l'enfance et de la jeunesse en Suisse romande : état des lieux et enjeux. Sion: Centre interfacultaire en droits de l'enfant.

\section{Enseignement social catholique}

Trois termes sont utilisés pour signifier la contribution chrétienne et catholique à l'éthique sociale: pensée, enseignement et doctrine. La pensée sociale chrétienne peut être vue comme un vivier d'idées et d'analyses, alimenté par les chrétiens analystes ou acteurs de la vie sociale. L'enseignement social puise dans ce réservoir pour formuler une parole d'autorité et proposer une lecture «à chaud», à la lumière de la foi, du contexte social propre à chaque étape de l'histoire humaine. Quant à la doctrine sociale - une particularité de l'Église catholique - elle offre une synthèse articulée, mais jamais achevée, de l'enseignement social catholique.

Les trois piliers de la doctrine sociale catholique sont:

> La personne humaine créée à l'image de Dieu est la prémisse anthropologique centrale. Valeur suprême et intangible, chaque personne est unique et constitue la référence ultime de toute réalité sociale qui doit permettre son développement intégral, à la fois spirituel et matériel. De la «centralité » de la personne humaine découle directement l'accent sur la famille.

> Le bien commun - au-delà de la famille, la personne humaine est membre de la communauté humaine. En tant que telle, elle participe naturellement à la construction du bien commun dont elle est également destinataire. Le bien commun n'est point réductible à l'intérêt général des économistes ou politologues contemporains: il vise simultanément le bien de toute personne et le bien de la communauté elle-même.

> L'horizon eschatologique inscrit l'enseignement social catholique dans la perspective des fins dernières de l'homme. Il ne s'agit pas de créer un paradis sur terre, ni de nier la souffrance de l'humanité, mais bien de lui permettre d'atteindre son salut, par-delà les vicissitudes de l'histoire.

L'enseignement social se déploie dans le temps en fonction des événements dont il propose une analyse en suggérant des pistes d'action. Son élaboration mobilise aussi bien les apports de la pensée sociale chrétienne que ceux des sciences humaines et sociales. Pour ce qui est de l'Église catholique, son enseignement prend le plus souvent la forme de lettres encycliques ou de lettres des conférences épiscopales. La doctrine sociale de l’Église catholique se précise au fil des encycliques sociales consacrées aux problèmes sociaux, économiques et politiques du moment. Cinq encycliques ont laissé une empreinte particulièrement durable.

Rerum novarum (Des choses nouvelles) du pape Léon XIII (1891) est la première encyclique sociale des temps modernes. Elle aborde les défis sociaux inédits, issus de la révolution industrielle, notamment les rapports entre le capital et le travail. Le texte stigmatise l'exploitation dont la révolution industrielle est porteuse, mais il ne prône pas la confrontation et la lutte des classes que promeut le premier programme marxiste rendu public six mois après 
l'encyclique. Le pape souligne la complémentarité naturelle et l'entente nécessaire entre le capital et le travail, en appelant à la constitution de syndicats chrétiens et à la négociation collective avec le patronat, qu'il admoneste par ailleurs. Le texte met aussi en exergue l'indispensable autonomie des familles par rapport à l'État qui doit être sauvegardée par la propriété privée et un salaire décent. Rerum novarum introduit les deux principes qui seront au cœur de tous les développements futurs: le principe de solidarité et le principe de subsidiarité.

En mai 1967, cent ans après la publication de Das Kapital, Paul VI publie l'encyclique Populorum progressio, qu'il consacre aux défis que pose le développement en tant qu'héritage de la décolonisation dans un monde en voie de globalisation. Paul VI affirme: «La question sociale est devenue mondiale.» L'encyclique est traversée par la préoccupation de la justice sociale. Toutefois le problème du développement ne saurait se résumer à la seule répartition des ressources économiques. Il s'agit d'assurer les conditions du «développement humain intégral», matériel et spirituel. Le pape fait ainsi part de ses préoccupations face à la montée en puissance des considérations quantitatives (croissance) liées à l'avoir par rapport aux dimensions qualitatives liées à l'être.

En 1991, deux ans après la chute du Mur de Berlin, Jean-Paul II publie Centesimus annus, en référence explicite au centenaire de Rerum Novarum. Il s'agit d'un texte écrit alors que les décombres du totalitarisme communiste sont encore chauds. Le pape procède à un tour d'horizon des problèmes et défis qui subsistent dans un contexte de libéralisme triomphant. Il rappelle avec force le principe de la destination universelle des biens qui est synonyme de «l'hypothèque sociale». Cette dernière pèse sur toute propriété, qui doit impérativement être mise au service du bien commun. Le texte mentionne pour la première fois l'importance de la liberté d'entreprendre, mais rappelle aussi qu'il ne s'agit que d'une des dimensions de la liberté, laquelle doit être préservée dans son intégralité. Il souligne le rôle central de la famille pour le développement de la personne humaine et les dangers auxquels elle est exposée dans une société de consommation.

Une encyclique sociale de Benoît XVI était attendue pour 2007, quarantième anniversaire de Populorum progressio. La crise financière en a décidé autrement, et Caritas in Veritate paraît en 2009, avec la crise en toile de fond. Le texte insiste sur trois points. D'abord, l'accent est mis sur l'importance de fondements anthropologiques solides pour toute théorie sociale ou économique. Le rappel de la dignité imprescriptible de la personne humaine met en évidence la fragilité anthropologique du discours économiste dominant. Ensuite, il affirme que tout échange économique, pour qu'il reste humain, doit contenir un élément de gratuité. Sans don et sans réciprocité, l'économie et la finance risquent de déshumaniser leurs propres protagonistes. Enfin, le texte revient sur la question de la gouvernance mondiale déjà abordée par Paul VI et Jean-Paul II, pour souhaiter l'instauration d'une "autorité politique mondiale», seule susceptible de prendre en charge des problèmes globaux, notamment ceux induits par la crise financière.

En 2015, le pape François publie Laudato $S i$ '. Le texte est articulé autour d'un diagnostic de crise qui met la Terre - «la maison commune» - en danger de mort. Il n’y a pas deux crises séparées, écrit le pape François, «l'une environnementale, l'autre sociale, mais une et complexe crise socio-environnementale. Les possibilités de solution requièrent une approche intégrale pour combattre la pauvreté, pour rendre la dignité aux exclus et simultanément pour préserver la nature» (par. 139). La réponse doit être à la hauteur des défis sociaux et écologiques. Elle a pour nom «l'écologie intégrale». Ce programme insiste sur le soin qu'il s'agit de prendre de la création, sur la destination universelle des biens et sur l'option préférentielle pour les pauvres (un autre 
principe important de la doctrine sociale de l'Église) comme moyen de lutter contre l'exclusion et l'indifférence. Le pape critique avec force la toute-puissance du paradigme technocratique et l'emprise qu'il exerce sur la liberté et l'autonomie des personnes.

La doctrine sociale de l'Église a fortement influencé les politiques, les institutions et les comportements sociaux, notamment dans le champ des politiques familiales de nombreux pays européens comme l'Allemagne, l'Espagne, l'Italie, plus récemment la Pologne, et aussi la Suisse. Parfois, la référence à la doctrine a conduit certains pays à invoquer le principe de subsidiarité (l'autonomie des familles par rapport à l'État) pour justifier des politiques publiques allant dans une certaine mesure à l'encontre du principe de solidarité. La Suisse n’a pas échappé à cette tendance. La doctrine sociale a aussi guidé la mise en place et l'action concrète de nombreuses organisations telles que Caritas ou ATD Quart Monde. Les initiatives inspirées de l'enseignement social chrétien sont aussi nombreuses dans le domaine de l'éducation spécialisée et des soins, notamment aux personnes âgées. Mentionnons encore deux œuvres d'entraide en matière de développement: Action de Carême (émanation de l'Église catholique) et Pain pour le Prochain (émanation des églises protestantes).

\section{Paul H. Dembinski}

\section{Références}

Conseil Pontifical Justice et Paix (Éd.) (2004). Compendium de la doctrine sociale de l'Église catholique. Città del Vaticano: Libreria Editrice Vaticana, 2004.

De Laubier, P. (2011). La pensée sociale de l'Église catholique: une orientation idéale de Léon XIII à Benoît XVI. Paris : P. Téqui.

\section{Entraide*}

La notion d' "entraide» est couramment utilisée en français pour traduire les termes allemands et anglais Selbsthilfe et self-help. Le sens de ces notions n'est toutefois pas identique: si l'allemand et l'anglais renvoient à l'individu «s'aider soi-même» - le mot français renvoie à un groupe de personnes, à la mutualité.

Nous distinguons l'entraide entre personnes (parfois appelée «entraide autogérée» pour gemeinschaftliche Selbsthilfe en allemand), le self-help individuel et les groupes d'entraide sous conduite professionnelle. L'entraide peut revêtir différentes formes, comme la mise en réseau de personnes, les groupes d'entraide locaux ou virtuels, le soutien par des pairs (peer support) et les organisations d'entraide. Ce qu'elles ont toutes en commun, c'est que des personnes ayant un même problème, un objectif commun ou vivant une situation similaire s'unissent pour s'entraider. Dans un groupe d'entraide, les personnes concernées et leurs proches ne trouvent pas seulement de l'aide et de la solidarité, mais font aussi l'expérience de la responsabilité individuelle et de l'autodétermination par le biais d'une participation active. Les participant·e-s aux groupes d'entraide sont et deviennent des «expert.e.s de leur propre situation». Les membres d'un groupe d'entraide recueillent diverses informations, collectent des connaissances et des expériences et s'entraident au sein du groupe. L'aide aux personnes externes rencontrant les mêmes problèmes, la coopération avec les services publics, la sensibilisation du public et la représentation des intérêts sont également du ressort de tels groupes. En termes de sujet et de contenu, les groupes et organisations d'entraide peuvent être divisés en groupes travaillant sur les maladies somatiques, les maladies psychiques et les questions de la vie sociale. $\mathrm{Au}$ cours des dernières décennies, l'entraide (autogérée) est devenue un pilier important et 
reconnu du système de santé et d'action sociale en Suisse.

La forme des organisations d'entraide a une très longue tradition en Suisse. Les premières organisations d'entraide de personnes handicapées (association des sourds, des aveugles ou des invalides) sont apparues au début du $\mathrm{XX}^{\mathrm{e}}$ siècle. L'absence d'assurances sociales conduisait alors souvent les personnes handicapées à la misère. Le mouvement ouvrier naissant a encouragé les personnes concernées à se défendre et à lutter pour leurs droits. Actuellement, de nombreuses organisations d'entraide se sont structurées et offrent une aide professionnelle, favorisent l'entraide et initient ou accompagnent des groupes d'entraide. Les organisations d'entraide travaillent de manière ciblée dans un domaine défini par une indication médicale ou (psycho-)sociale. Les Alcooliques anonymes (AA), la Ligue contre le cancer et la Ligue contre le rhumatisme sont très connus. Les organisations d'entraide sont généralement fortement structurées et enregistrées en tant qu'associations d'intérêt public. En règle générale, elles prélèvent des cotisations de leurs membres.

Les groupes d'entraide réunissent des personnes qui traitent ensemble un thème qui leur importe. La responsabilité personnelle et le soutien mutuel sont les éléments centraux des groupes d'entraide. Dans ces groupes, les personnes partagent leurs expériences, leurs sentiments, les difficultés qu'elles rencontrent et échangent des informations et des moyens pratiques pour gérer le quotidien. L'orientation sur les ressources de chacun·e est essentielle. Ces groupes ne sont pas conduits par des professionnel-le-s. L'animation des discussions et des échanges est assurée par les membres. Les groupes qui sont ponctuellement ou durablement dirigés par un ou une professionnel-le sont considérés comme des groupes d'entraide si cette personne est également concernée individuellement par le sujet du groupe, si elle se place au même niveau que les autres dans les échanges et si elle ne reçoit pas d'honoraires. Alors que l'on comptait, en Suisse, 24 groupes d'entraide pour 100000 habitant.e.s en 2004, il y en avait déjà 32 en moyenne en 2015.

Les centres régionaux d'entraide assurent, dans leur région, la mise en réseau des groupes d'entraide actifs pour l'ensemble des thèmes des domaines de la santé et du social. Ils ont une vue d'ensemble de tous les groupes d'entraide existants ou en voie de création. Ils fonctionnent comme plate-forme d'accueil, d'information et de conseil. Leur principe central est de favoriser l'empowerment et de promouvoir l'autonomie, l'autodétermination et le développement personnel et collectif. Les collaboratrices et collaborateurs des centres se considèrent comme des facilitateur.e.s des processus de création et de développement des groupes. Il s'agit de renseigner et d'orienter les personnes intéressées à rejoindre un groupe ou à en créer un. Vingt centres d'entraide ont conclu un contrat de prestations avec Info-Entraide Suisse.

La Fondation Info-Entraide Suisse a été créée en 1996 par les centres suisses d'entraide sous la forme d'une communauté de travail dénommée KOSCH (Koordination und Förderung von Selbsthilfegruppen in der Schweiz / Coordination et promotion des groupes d'entraide en Suisse). L'objectif était de considérer le mouvement d'entraide en Suisse comme un tout et de mettre au point des stratégies de financement public. Un bureau national a été mis en place en 2000, une étape décisive pour le mouvement. Depuis 2001, un contrat de prestations existe avec l'OFAS, ce qui constitue la reconnaissance officielle longuement attendue par les centres d'entraide et qui a déclenché des contributions d'autres financeurs publics. En 2010, la fondation a été renommée Info-Entraide Suisse et un nouveau conseil d'administration a été formé pour améliorer le positionnement de l'entraide dans le secteur de la santé.

Selon une étude mandatée par la Fondation Info-Entraide Suisse et publiée en 2017, 
les participant-e.s de groupes d'entraide constatent les effets sur leur personne, sur leur situation et sur leurs relations avec les autres. En participant à un groupe, les membres se sentent mieux. Ils et elles se sentent moins coupables et isolé.e-s face à une situation difficile. Le groupe peut les aider à trouver des solutions concrètes. Pour certain'e-s, participer, c'est aussi prendre leur situation en main et ne plus simplement la subir. Les participant·e.s du groupe améliorent leurs relations avec leurs proches. De nouvelles relations se nouent entre elles et eux. Leurs rapports avec les professionnel·le·s s'améliorent grâce à des questions plus ciblées, et ils et elles prennent de plus en plus souvent leurs propres décisions. Les effets sur la vie privée ainsi que sur les relations avec autrui sont très largement confirmés par les professionnel-le·s interrogé·e.s. Des effets sur la société dans son ensemble, un bien-être général, sont également mis en évidence. Les groupes d'entraide devraient être encouragés en tant que mesure préventive dans le domaine de la santé. Dans le même temps, des avantages financiers en termes de coûts de la santé sont également mis en avant.

La reconnaissance de l'entraide (autogérée) comme complément dans les secteurs de la santé et de l'action sociale s'est accrue au cours des dernières années. Toutefois, le financement des centres d'entraide et d'Info-Entraide Suisse reste incertain, voire insuffisant. Il manque une base juridique promouvant l'entraide (autogérée) au niveau national. Comme plus de trois quarts des groupes d'entraide enregistrés traitent de sujets liés à la santé, un positionnement principal dans le système de santé serait tout naturel. L'Allemagne, par exemple, pourrait servir de modèle. Les caisses-maladie y sont légalement tenues de verser au moins un euro par assuré.e pour la promotion de l'entraide (autogérée). Un autre défi est la poursuite de la mise en réseau de l'entraide avec les autres acteur-trice-s des systèmes de l'action sociale et de la santé. Cela inclut la coopération avec d'autres organisations thématiques de patient.e.s, d'autres organisations de personnes concernées et de proches ainsi qu'avec des hôpitaux, des cliniques et services psychiatriques, des services sociaux, des organisations pour personnes handicapées, des organisations d'entraide et des ligues de santé. Intégrer le concept de l'entraide dans la formation initiale et continue des professionnel-le-s est également souhaitable. Les résultats de l'étude de 2017 montrent que certains groupes de personnes bénéficient moins que d'autres des offres de l'entraide. Il s'agit des jeunes, des hommes, des personnes issues de la migration et des personnes avec un faible niveau de formation. Élaborer des stratégies et déployer des efforts pour favoriser la participation de ces groupes de personnes représente un défi majeur.

\section{Pascal Pfister, Sarah Wyss \& Bettina Haefeli}

\section{Références}

Ben Salah, H., Knüsel, R., Lanfranconi, L.M. \& Stremlow, J. (2017). Entraide autogérée en Suisse: importance, portée socio-sanitaire et développement. Berne: Hogrefe.

Borgetto, B. (2004). Selbsthilfe und Gesundheit: Analysen. Forschungsergebnisse und Perspektiven in der Schweiz und in Deutschland. Bern : Huber.

\section{Entrée en emploi}

L’entrée en emploi est associée à ce qu'il est devenu courant d'appeler la transition de l'école vers le marché du travail. Cette transition peut s'avérer plus ou moins longue, selon les caractéristiques intrinsèques des personnes (aptitudes, compétences, personnalité), leurs caractéristiques sociodémographiques (sexe, ethnie) et bien entendu les conditions sociales et économiques qui caractérisent leur environnement. Cette transition implique dans les faits une séquence de transitions qui débute 
déjà lorsque les filières de formation commencent à diverger, pour se terminer lorsque les personnes trouvent une situation relativement stable dans l'emploi, soit entre 15 et 25 (voire 29) ans selon l'Organisation pour la coopération et le développement (OCDE).

En Suisse, dès l'âge de 14 ans il est possible d'exercer un emploi régulier, pour autant que dans le canton concerné la scolarité obligatoire s'achève avant l'âge de 15 ans révolus. Dans la majeure partie du pays toutefois, l'âge minimum requis pour exercer un emploi dans une entreprise est 15 ans. L'organisation de la formation postobligatoire en Suisse est historiquement centrée autour de la formation professionnelle. Ainsi, dès le début du secondaire II, les jeunes peuvent intégrer un emploi par la voie d'une formation professionnelle qui constitue la plus importante porte d'entrée en emploi sur le marché du travail. Actuellement plus d'une jeune personne sur deux effectue ce choix au niveau national. Toutefois, comme dans d'autres domaines, les différences intercantonales sont importantes: cette proportion est nettement plus élevée dans les cantons alémaniques que dans les cantons latins. En outre, la différence de genre dans la formation professionnelle initiale est importante: les jeunes femmes retardant davantage leur entrée sur le marché de l'emploi. La même tendance caractérise les populations d'élèves provenant de pays qui sont ethniquement différents du phénotype local. L'apprentissage n'échappe pas aux (perceptions quant aux) risques de discrimination présents sur tous les marchés du travail, y compris en Suisse.

Les voies de formation alternatives se caractérisent logiquement par une transition vers l'emploi qui s'avère généralement plus longue mais également moins linéaire que pour celles et ceux qui font un apprentissage directement après la scolarité obligatoire. Lorsqu'une jeune personne ne trouve pas immédiatement sa voie après la scolarité obligatoire, elle peut choisir une offre de formation transitoire ou opter pour un semestre de motivation (SEMO). Celui-ci fait partie intégrante des mesures actives du marché du travail de la loi sur l'assurance-chômage (AC). Ce semestre a été spécialement conçu pour les jeunes qui ne se sont pas encore forgé une idée précise de leur avenir professionnel, mais également pour celles et ceux qui sont en rupture d'apprentissage ou qui ont abandonné une des autres voies de formation du niveau secondaire supérieur. Au même titre que les stages professionnels de l'AC, généralement proposés aux jeunes qui ont terminé une formation, ou que les programmes spéciaux d'insertion professionnelle soutenus par l'aide sociale, l'objectif est l'intégration (ou la réintégration) rapide des jeunes sur le marché du travail. Cet objectif s'inscrit ainsi dans la logique des politiques d'emploi en Suisse qui, de manière générale, visent prioritairement l'insertion à court terme et expliquent, en partie, la bonne performance de la Suisse dans le taux de transition des jeunes vers l'emploi.

L'un des indicateurs importants pour évaluer dans quelle mesure les jeunes se trouvent en situation de vulnérabilité dans leur transition est la proportion de jeunes qui ne sont ni en formation, ni en emploi (NEET: not in employment, education or training). Il s'élève à $15 \%$ en moyenne pour l'ensemble des pays de l'OCDE (OCDE, 2015). Les pays caractérisés par des systèmes de formation dits «classiques", comme les États-Unis, le Royaume-Uni ou la France, sont légèrement au-dessus. Les pays dont le système de formation est fortement orienté vers l'apprentissage, comme la Suisse et ses voisins germaniques ou le Danemark, sont tous en dessous de la moyenne. En Suisse ce taux est inférieur à $10 \%$. Les mêmes tendances caractérisent les comparaisons internationales basées sur les taux d'emploi et de chômage des jeunes. Par contre, le taux de chômage des 15-29 ans reste structurellement supérieur à celui des personnes plus expérimentées en Suisse, comme dans la plupart des 
pays de l'OCDE, et est (au moins) deux fois plus élevé que pour les 30-54 ans.

Même après l'obtention de leur diplôme, les conditions d'emploi auxquelles les jeunes font face sont généralement plus défavorables que celles observées parmi les populations plus expérimentées. Que ce soit en termes de rémunération, de durée du contrat, voire d'adéquation en termes de compétences et qualifications. Pour les entreprises, averses au risque par nature, les jeunes représentent une plus grande inconnue que les personnes plus expérimentées. C'est aussi la raison pourquoi les plus jeunes se retrouvent dans le haut de la liste lorsqu'une entreprise doit réduire la taille de sa masse salariale. Les jeunes étant souvent considéré·e-s comme une variable d'ajustement entre la marche des affaires et l'emploi dans les entreprises. Ceci se reflète dans la proportion de jeunes qui entrent dans la vie active par le biais d'un emploi temporaire: en Suisse, plus d'une jeune personne sur deux en emploi âgée de 15 à 25 ans est sous contrat temporaire, deux fois plus que la moyenne de l'ensemble des pays de l'OCDE.

Les indicateurs et recherches récentes sur la transition école-marché du travail confirment l'aggravation temporelle des désavantages cumulés par les jeunes relativement aux personnes plus expérimentées: plus grand risque de chômage ou de sous-emploi et plus grande vulnérabilité face aux chocs conjoncturels et aux changements structurels qui touchent le monde du travail. Ainsi, malgré une stagnation, voire une élévation de leurs aspirations, la position des jeunes sur le marché du travail s'est progressivement détériorée. Pour les jeunes ayant acquis une formation de niveau tertiaire, cette tendance est reflétée par la multiplication de stages mal rémunérés et rarement en adéquation avec leurs compétences et aspirations. En Suisse, ce groupe est davantage concerné par l'emploi non-standard que d'autres ayant obtenu une qualification via l'apprentissage.
La multiplication des formes de travail qui diffèrent des rapports de travail dits "normaux» depuis les années 1980 dans les économies industrialisées a accentué les inégalités entre les nouveaux entrants sur le marché et les populations expérimentées. Pour les plus vulnérables, la situation est devenue très critique avec l'érosion des normes et des valeurs qui a accompagné et renforcé les transformations de l'emploi. Celles et ceux qui renoncent prématurément aux études et à toutes autres formes d'apprentissage représentent potentiellement une population à risque, dépendante à long terme de l'aide sociale. Le diplôme de fin de secondaire II est ainsi devenu une condition minimale pour réduire les risques de chômage ou de précarisation.

Quel que soit le système de formation, l'évidence empirique montre que la transition école-marché du travail s'est considérablement allongée, notamment pour les jeunes qui accumulent des désavantages et/ou qui manquent de ressources; le risque de démotivation et de marginalisation le long du chemin est grand et bien réel. La question de l'entrée en emploi se situe ainsi au croisement des politiques éducatives, de l'emploi et de l'aide sociale. Dans des sociétés de plus en plus tournées vers l'immédiateté des résultats et de l'information, les gouvernements ne sont incités ni à la patience, ni à prendre le risque d'évaluer correctement les politiques à partir desquelles une grande part de leur crédibilité est établie. Malgré le peu d'évidences empiriques quant aux impacts causaux des politiques implémentées dans les différents pays, il semble évident que seule une vision à long terme permettra de freiner l'allongement généralisé de la transition de l'école vers le marché du travail, y compris en Suisse.

\section{José V. Ramirez}

\section{Références}

Organisation de coopération et de développement économiques (Éd.) (2015). Perspectives de l'OCDE 
sur les compétences: les jeunes, les compétences et l'employabilité. Paris: Editions OCDE.

Secrétariat d'État à la formation, la recherche et l'innovation (Éd.) (2017). La formation professionnelle en Suisse. Faits et chiffres 2017. Berne: Secrétariat d'État à la formation, la recherche et l'innovation.

\section{Entreprise sociale*}

En Suisse, les organisations actives dans le domaine de l'intégration professionnelle et/ ou sociale sont nommées des «entreprises sociales». Jusqu'à présent, il n'existe pas de définition homogène du concept et du modèle ni dans la pratique, ni dans la politique ou la recherche. En règle générale, les entreprises sociales ou «entreprises d'intégration sociale et professionnelle» se caractérisent par leur caractère hybride dans la mesure où elles offrent, le plus souvent sur mandat des institutions d'assurances sociales, des emplois aux personnes défavorisées sur le marché du travail, les intègrent dans les processus de production et génèrent des revenus sur le marché en vendant des produits ou des services.

L'Italie est considérée comme le pays d'origine des entreprises sociales. Les premières d'entre elles y ont été créées dans les années 1970 en réponse à la fermeture des cliniques psychiatriques. En tant que mouvement social partant de la base, les personnes concernées se sont organisées en coopératives pour créer des emplois. Les conditions-cadres de ces coopératives sont réglementées par la loi depuis 1991. La forme originelle de l'entreprise sociale est donc étroitement liée à la logique de l'empowerment: concentration sur les potentiels - et non sur les déficits - des personnes défavorisées sur le marché du travail.

Les entreprises sociales suisses se distinguent à certains égards des modèles comparables à l'échelle internationale. Dans notre pays, par exemple, les employéee-s défavori- sé.e.s touchent plus rarement un salaire correspondant à ceux en usage dans la branche et leurs possibilités de participation sont moins étendues. L'importance des fonds publics dans le financement est plus marquée pour les entreprises sociales suisses, les rentrées d'argent sous forme de dons étant proportionnellement moins importantes. Une différence frappante est que les entreprises sociales suisses ne possèdent pas de forme juridique spécifique, comme c'est le cas en Italie, par exemple.

Sur le plan politique et médiatique, le terme «entreprises sociales » a gagné en popularité en Suisse à partir de 2000 environ. Il a été utilisé pour mettre l'accent, positivement ou négativement, sur les approches entrepreneuriales dans l'intégration sociale et professionnelle. Parfois, le terme a été étendu à d'autres organisations de l'action sociale. Dans le contexte scientifique, le terme est proche du concept de (work integration) social enterprise et, plus généralement, de social entrepreneurship. Dans les projets de recherche récents, le terme plus neutre d' «entreprises d'intégration sociale et professionnelle» (EISP) a été introduit.

Le développement des entreprises sociales doit être considéré dans sa relation étroite avec le système de protection sociale suisse. Avec la création de l'assurance-invalidité en 1960, des mécanismes de financement ont été introduits pour la première fois pour aménager des «ateliers (protégés)» qui offraient des possibilités d'emploi pour les personnes en situation de handicap. Face à l'augmentation du chômage dans les années 1990, la réforme de l'assurance-chômage a conduit à la mise en place de «programmes d'emploi temporaire» pour les chômeurs et les chômeuses. La révision de l'aide sociale en termes de politique d'activation à partir de 2000 a également conduit à une demande d'offres d'intégration et d'emploi. L'éventail des organisations qui offrent des emplois et un soutien dans le cadre de l'intégration sur le marché du travail est donc très large aujourd'hui. 
Le premier état des lieux national mené en 2015 a permis d'établir une vue d'ensemble de ces organisations. Au total, il existe en Suisse 1159 organisations qui offrent des services liés à l'intégration professionnelle ou sociale. Aujourd'hui, la Suisse compte environ 400 entreprises sociales qui proposent des emplois productifs pour des groupes cibles défavorisés et génèrent des revenus sur le marché en vendant des produits et des services. Elles ont le plus souvent une forme juridique à but non lucratif (fondation, association), seules environ $6 \%$ d'entre elles sont organisées sous forme de société anonyme ou de société à responsabilité limitée. La majorité des entreprises sociales ont été créées depuis les années 1990 (60\%). Les secteurs économiques dans lesquels elles sont actives sont divers et vont des activités agricoles aux activités administratives. Les activités dans l'industrie, la restauration et la vente sont particulièrement répandues. En tant que sous-traitantes d'entreprises industrielles régionales, les entreprises sociales contribuent souvent à ce que des activités «improductives» puissent se maintenir en Suisse. $27 \%$ des entreprises sociales proposent des emplois pour un groupe cible et $73 \%$ s'adressent à plusieurs groupes cibles. Plus de $30 \%$ des entreprises sociales versent une forme de salaire aux personnes concernées (p.ex. lié à la productivité), près de $40 \%$ une forme de complément aux prestations versées par les assurances sociales alors qu'un peu plus de $30 \%$ ne paient pas de salaire. Au total, les entreprises sociales emploient environ 43000 personnes défavorisées et 10000 salarié.e-s permanent·e.s. Leurs produits et services génèrent un chiffre d'affaires de 630 millions de francs.

Cependant, cette situation est régulièrement critiquée: les entreprises sociales bénéficieraient d'un «équipement luxueux» financé par des fonds publics, et ces fonds publics seraient privatisés par le biais de distributions de bénéfices. L'étude sur les entreprises sociales suisses montre cependant qu'elles ne réalisent pas de profits aux dépens de la collectivité. En raison de leur forme juridique, des règlements cantonaux, du but de l'organisation ou de leurs statuts, elles ne peuvent pas distribuer de bénéfices mais doivent expressément les conserver au sein de l'organisation. De même, les entreprises sociales ne se financent pas exclusivement par des contributions publiques: en moyenne, les recettes commerciales représentent la moitié des revenus d'une entreprise sociale.

D'un point de vue de politique sociale, les entreprises sociales soulèvent la question fondamentale de la position et de l'organisation d'un «second marché du travail» ou d'autres possibilités de traiter les groupes de population menacés d'exclusion. La participation volontaire, les modèles salariaux, la concurrence pour l'industrie, les questions du déplacement des emplois, les effets de lock-in et la précarisation des situations de vie font l'objet d'un débat politique particulièrement controversé. Toutefois, les aspects problématisés sont davantage liés au cadre des assurances sociales qu'à la structure des entreprises sociales (p.ex. la possibilité limitée de verser des salaires réguliers ou l'obligation de participer à une mesure du marché du travail pour les chômeur-euse-s). Des objectifs contradictoires en matière de concurrence et d'effets de lock-in peuvent survenir, en particulier lorsque des activités proches du marché sont proposées dans le but d'offrir aux personnes défavorisées des tâches réalistes tout en réduisant les coûts pour le secteur public grâce à des recettes commerciales. L'étude empirique des entreprises sociales montre que ces conflits sont généralement désamorcés par un bon ancrage local. Dans l'ensemble, en combinant un travail productif et un accompagnement social visant l'insertion, les entreprises sociales sont en mesure de produire des effets très positifs pour les personnes concernées, effets qui permettent des améliorations psychosociales ou mêmes matérielles au-delà de l'intégration sur le marché 
du travail. D'un point de vue entrepreneurial et socio-administratif, un certain nombre de défis restent à relever. La coopération entre les pouvoirs publics (qui mandatent) et les entreprises sociales doit évoluer, éventuellement pour uniformiser, à l'échelle des régions et des assurances sociales, les mécanismes de pilotage afin d'obtenir un équilibre optimal entre le mandat d'intégration et la marge de manœuvre entrepreneuriale (gestion des excédents, gestion de la concurrence, promotion de l'innovation). Il conviendrait également d'optimiser les rapports d'activité afin de permettre une évaluation efficace de l'impact économique et social et de refléter de manière adéquate les multiples avantages des entreprises sociales.

\section{Stefan Adam \& Bernadette Wüthrich}

\section{Références}

Adam, S., Amstutz, J., Avilés, G., Caimi, M., Crivelli, L., Ferrari, D., ... Zöbeli, D. (2015). Social enterprise in Switzerland: the field of work integration. ICSEM Working Papers, 19, online. http:// www.iap-socent.be/icsem-working-papers

Adam, S., Avilés, G. \& Schmitz, D. (2016). Facteurs de succès des entreprises d'intégration. Sécurité sociale CHSS, 3, 44-48.

Crivelli, L., Bracci, A. \& Avilés, G. (2012). Il modello d'impresa sociale "made in Switzerland": Risultati di un'indagine esplorativa condotta su piano nazionale. Manno: Scuola universitaria professionale della Svizzera italiana SUPSI.

\section{Équité intergénérationnelle}

Depuis quelques décennies, le concept de génération émerge et s'impose en sciences sociales, bouleversant la manière dont on analyse les phénomènes sociaux. Cette émergence met au-devant de la scène de nouvelles interrogations liées aux échanges ou relations entre les générations vivant simultanément et à l'équité qui caractérise ou non ces échanges.
Mentionnons au préalable que la notion même de génération peut prendre différentes significations. Elle peut être définie en fonction de la position dans le cycle de vie (enfant, adolescent.e, adulte, etc.), de la position dans la famille (grand-parent, parent, enfant, etc.), mais aussi en fonction des caractéristiques liées au vécu (génération silencieuse, génération du baby-boom, génération sacrifiée, etc.). Pour chacune de ces définitions, un flou subsiste quant aux seuils séparant les différentes générations, rendant encore plus complexe l'analyse de l'équité intergénérationnelle.

La sociologie de la famille s'est fréquemment penchée, ces dernières années, sur les relations entre générations, pour constater finalement que si elles sont essentielles à la famille et à la société, ces relations sont difficilement mesurables ou chiffrables. Le principe de l'équité, qui repose sur l'idée que chaque génération reçoive autant qu'elle donne aux autres générations, est pour cette raison l'objet de nombreuses spéculations et interrogations, faute d'une appréciation claire de la situation.

Les échanges intergénérationnels sont à la base du fonctionnement de la société: ils peuvent se produire autant dans le cadre de la famille (soins apportés aux parents âgés, garde des petits-enfants, etc.) qu'à l'extérieur de celle-ci (p.ex. sur le lieu de travail ou dans le cadre des loisirs). Ils peuvent prendre différentes formes (apprentissage, soutien social, aide pratique ponctuelle ou régulière, mais aussi transfert financier). Autant au sein de la famille qu'à l'extérieur, le principe d'équité est essentiel afin de ne pas briser le contrat intergénérationnel implicite. Pour l'observateur, la difficulté est cependant de chiffrer les soutiens non financiers, et par là de valider si le principe d'équité s'applique. Ce principe garantit l'absence de conflit entre générations.

L'équité intergénérationnelle couvre différents domaines, autant liés aux sciences économiques et sociales qu'aux sciences environnementales. Elle a aussi émergé dans la dis- 
cussion sur le développement durable, depuis le Sommet de Rio de 1992. Dans ce domaine, l'équité signifie ne pas laisser en héritage aux générations futures le poids de comportements environnementaux inappropriés, dans un contexte de durabilité.

L’analyse financière de l'équité entre générations a été développée au cours des années 1990 en particulier aux États-Unis. L'objectif des bilans (ou comptabilités) intergénérationnels est de mesurer le poids financier des différentes générations sur les dépenses publiques et de mettre en relation ce poids avec les apports de la génération, exprimés en termes d'impôts payés ou de cotisations versées. Ces exercices de comptabilité, qui reposent généralement sur de nombreuses hypothèses et spéculations quant à l'avenir, présentent alors le bilan comptable de chaque génération, commenté suivant l'hypothèse implicite selon laquelle un État est contraint à l'équilibre budgétaire sur le long terme et ne peut donc pas accroître continuellement sa dette. En Suisse, le premier exercice de bilan intergénérationnel effectué en 2001 a par exemple montré que la génération née en 2001 devrait recevoir au cours de sa vie 102000 francs (valeur 2001) en transferts financiers de l'État de plus que ce qu'elle versera en impôts et autres cotisations. L'exercice de bilan intergénérationnel a été reproduit en Suisse par l'UBS en 2014, en collaboration avec le Centre de recherche sur les contrats entre générations de l'Université de Fribourg-en-Brisgau. Les résultats confirment que la durabilité des finances publiques n'est pas assurée en raison du déséquilibre entre prestations versées et cotisations prélevées / impôts perçus pour les différentes générations. En particulier, le $1^{\text {er }}$ pilier produit une dette implicite croissante, correspondant aux engagements de l'État vis-à-vis des retraité·e-s futur-e.s qui vivent de plus en plus longtemps.

Dans le domaine de la protection sociale et plus largement en ce qui concerne les finances publiques, le principe de l'équité intergénéra- tionnelle fait référence à la notion de justice entre générations, d'un point de vue financier. Il y a équité dans le domaine de la protection sociale lorsque chaque génération utilise ses propres ressources et opportunités (souvent d'une manière différée comme c'est le cas pour les retraites par capitalisation des $2^{\mathrm{e}}$ et $3^{\text {e }}$ piliers), sans emprunter aux ressources du moins financières des générations suivantes. Dans le domaine des finances publiques, il y a équité lorsque les générations en vie s'abstiennent de laisser une trop importante dette aux générations à venir, qui se verraient alors forcées de rembourser les emprunts des générations qui précèdent. Selon ce principe, l'endettement des collectivités publiques pose problème puisque ses conséquences sont transmises en héritage aux générations à venir.

Ce genre d'approches comptables doit cependant être considéré avec la prudence rendue nécessaire par les nombreuses limites méthodologiques: le concept d'équité intergénérationnelle est clair, mais son application empirique reste complexe, et soumise à de nombreuses remises en question. Il n'est pas toujours aisé d'attribuer correctement les dépenses publiques aux différentes générations (certaines dépenses étant à usage collectif). Le calcul prospectif nécessite des hypothèses prospectives accroissant le niveau d'incertitude des résultats. Mais la principale limite réside dans le fait que les échanges intergénérationnels ne s'arrêtent pas aux dépenses publiques, mais impliquent énormément d'échanges privés, non mesurables. Quoi qu'il en soit, l'entrée en scène de l'équité intergénérationnelle a eu de nombreux mérites. Le premier est de fournir des éléments empiriques en vue de tendre vers un comportement répondant au principe de durabilité. Le second est de fournir aux planificateurs des indications claires sur les conséquences futures des déséquilibres que nos sociétés génèrent.

Philippe Wanner 


\section{Références}

Auerbach, A.J., Gokhale, J. \& Kotlikoff, L.J. (1994). Generational accounting: a meaningful way to evaluate fiscal policy. Journal of Economic Perspectives, 8, 95-111.

Moog, S., Weisser, V. \& Raffelhüschen, B. (2014). Altersvorsorge und die Schweizer Generationenbilanz: Lasten in die Zukunft verschoben. Zürich: UBS.

Raffelhüschen, B. \& Brogmann, C. (2001). Zur Nachhaltigkeit der Schweizerischen Fiskal- und Sozialpolitik: Eine Generationenbilanz. Bern: Staatssekretariat für Wirtschaft.

\section{État social ${ }^{*}$}

L'État social, ou État-providence, est le fondement institutionnel de l'action de l'État visant à couvrir les risques de la vie, à réduire les inégalités et la pauvreté et à promouvoir l'égalité des chances. En substance, l'État social signifie que les préoccupations fondamentales du bienêtre privé deviennent l'objet de la politique de l'État. En garantissant les droits à la couverture des besoins vitaux et d'autres droits sociaux aux niveaux constitutionnel et législatif, la société endosse formellement et explicitement la responsabilité du bien-être de ses membres.

Dans un sens plus étroit, l'État social représente une nouvelle forme d'État démocratique qui s'est développée dans divers pays industrialisés après la Seconde Guerre mondiale et qui vise l'intégration sociale, la protection sociale et l'aide sociale à travers la régulation du capitalisme. Selon Gøsta Esping-Andersen, l'État-providence repose sur un petit nombre de décisions politiques centrales prises au milieu du XXe siècle; explicables par les rapports de force politiques et les théories sociales prédominants, les États sociaux se sont développés dans les pays industrialisés comme des variantes de trois idéaux-types différents, dans lesquels prévalent des principes de protection sociale différents. Cependant, la notion d'État social est souvent utilisée de manière plus générale, comme un terme générique désignant la politique sociale d'un pays, pouvant impliquer des interventions étatiques de force variable et apparaître également dans des États non démocratiques.

Lors de la création de l'État fédéral suisse, les compétences législatives de la Confédération dans le domaine de la politique sociale étaient marginales, et les principes de l'État social se limitaient alors aux cantons, chacun ayant ses propres lois en matière d'assistance et de travail. Avec la révision de la Constitution fédérale en 1874, la Confédération est devenue responsable de la législation du droit du travail, et avec la loi sur les fabriques adoptée en 1877, la Suisse a endossé un rôle de pionnier à l'échelle mondiale dans la protection des travailleuses et travailleurs. Ce n'est qu'avec le développement des grandes assurances sociales au cours du XXe siècle que l'État social au sens strict a vu le jour en Suisse. L'élément décisif a été à cet égard la création de l'assurance-vieillesse et survivants (AVS). Depuis 1948, des rentes AVS sont versées en Suisse, qui représentent une couverture universelle - bien que très modeste au départ - des besoins vitaux par l'État.

Les manières de concevoir la politique sociale et les structures de décision politiques, en particulier le fédéralisme et la démocratie directe, ont empêché une extension précoce et rapide de cette couverture. Pour tout domaine de la politique sociale devant être pris en charge par la Confédération, la Constitution devait lui conférer l'autorité législative correspondante. La voie qui a donné naissance à l'État social suisse devait donc passer par une centralisation des compétences législatives en matière de politique sociale. La modification de la Constitution, nécessaire à cette fin, a requis à chaque fois l'approbation de la majorité du peuple et des cantons. En outre, par le référendum facultatif, le peuple disposait également d'un droit de veto sur les lois mettant en œuvre le mandat constitutionnel. Dans certains cas, des délais considérables se sont par conséquent 
écoulés entre l'adoption du mandat constitutionnel et sa mise en œuvre juridique.

$\mathrm{Au}$ moment où, dans la structure institutionnelle suisse, des systèmes d'assurance et des réglementations d'ampleur nationale pouvaient réunir une majorité, des assurances privées ou des solutions cantonales très élaborées (p.ex. des caisses de compensation au sein des entreprises) étaient généralement déjà en place. Celles-ci ont donc préparé le chemin à une assurance sociale obligatoire ou à des prestations sociales harmonisées pour l'ensemble de la Suisse. L'État social suisse se distingue de ce fait par deux caractéristiques centrales: d'une part, le rôle indépendant des cantons et des communes dans de nombreuses questions de politique sociale, et de l'autre, le rôle marqué des organisations privées dans le traitement et le versement des prestations sociales fixées par l'État.

Non seulement les cantons s'occupent de la mise en œuvre des mesures de politique sociale de la Confédération, mais ils assument également un rôle d'États sociaux autonomes dans des domaines clés de la politique sociale. Différents cantons et certaines communes versent des prestations sociales spécifiques sous condition de ressources, notamment des prestations complémentaires pour les familles ou des aides en cas de chômage ou de dépendance. De plus, les cantons prélèvent la majeure partie des impôts directs et peuvent fixer leurs propres priorités en matière de politique sociale lorsqu'ils élaborent la base de calcul de l'impôt cantonal. Dans tous ces domaines, ainsi que dans l'organisation des prestations sociales (p.ex. garde d'enfants, conseil social, institutions sociales résidentielles, mesures du marché du travail, etc.), il existe des différences considérables entre les cantons et parfois aussi entre les communes d'un même canton. Par conséquent, les droits et réglementations peuvent varier en Suisse selon le lieu de résidence.
Outre les cantons et les communes, les organisations privées sont aussi des acteurs centraux de l'État social. Il s'agit d'entreprises privées, dont certaines sont à but lucratif, comme les caisses-maladie ou les caisses de pension, mais aussi de nombreuses fondations et associations comme les sociétés «Pro», qui fournissent des services de conseil social ou versent des aides d'urgence ou des aides sociales sur la base d'un mandat de prestations public. Le rôle des fondations et associations est si important que leurs prestations sont incluses dans les comptes globaux de la protection sociale (CGPS) et dans les statistiques sociales comparatives internationales.

La réorientation de l'État social vers l'activation et les investissements sociaux coïncide avec une importance croissante des prestations et services sociaux relevant de la responsabilité des communes ou des cantons ou délégués à des organisations non étatiques. La coordination des différentes prestations entre les différents niveaux de gouvernement et acteur-trice-s impliqués devient de plus en plus importante, mais aussi de plus en plus complexe. En même temps, il est difficile de doter l'État fédéral de nouvelles compétences dans ces domaines, comme l'a montré le rejet de l'article constitutionnel sur la politique familiale par la majorité des cantons en 2013.

Les traits fondamentaux de l'État social suisse, qui se traduisent au niveau constitutionnel par différents objectifs sociaux et mandats d'encouragement, ne sont guère contestés. Les assurances sociales en particulier bénéficient d'un fort soutien au sein de la population. Mais les changements structurels du marché du travail et les changements sociétaux en général modifient les conditions-cadres de l'État social. Les projets de réforme visant à garantir les rentes de vieillesse dans le sillage des changements démographiques et à assurer de nouveaux risques sociaux comme le divorce ou le chômage résultant de la désindustrialisation et de la pression exercée par la mondialisation 
sur le marché du travail font l'objet de vastes débats sociopolitiques. Il n'est pas toujours aisé de trouver des compromis capables de réunir une majorité. Les groupes sociaux les plus touchés par la restructuration de l'État social sont les plus démuni·e·s, tels les bénéficiaires de l'aide sociale et de rentes d'invalidité ainsi que les chômeurs et chômeuses de longue durée, qui sont confronté.e-s à une baisse des prestations et, en particulier, à un durcissement des conditions d'éligibilité.

\section{Michelle Beyeler}

\section{Références}

Cattacin, S. (2006). Retard, rattrapage, normalisation. L'État social suisse face aux défis de transformation de la sécurité sociale. Études et Sources, 31, 49-78.

Kaufmann, F.-X. (2012). European foundations of the welfare state. New York: Berghahn.

Möckli, S. (2012). Den schweizerischen Sozialstaat verstehen: Sozialgeschichte, Sozialphilosophie, Sozialpolitik. Glarus : Rüegger.

\section{État social actif*}

Hormis la couverture des besoins de base, l'État social actif a pour but d'encourager et de renforcer les ressources et capacités individuelles des personnes pauvres ou menacées de pauvreté. Lorsqu'un risque social ou une situation de détresse survient, il n'accorde pas seulement un soutien financier, mais fournit aussi des prestations immatérielles ou des offres et des mesures en faveur de l'intégration sociale. $\mathrm{Au}$ sens large, les mesures d'activation ne se limitent pas uniquement aux mesures (plus ou moins durables) d'intégration professionnelle, mais touchent d'autres dimensions centrales, souvent interdépendantes, liées à des situations de vie précaires, telles que la formation, les liens sociaux, la santé et le logement. Ainsi, les personnes touchées devraient pouvoir vivre à l'avenir dans l'indépendance le plus longtemps possible, sans avoir besoin de prestations d'assurances sociales ou sous condition de ressources. Dans les discours et la pratique de la politique sociale cependant, les actions de l'État social actif sont souvent réduites à l'encouragement de la capacité de gain (résiduelle) et de la (ré)insertion professionnelle des personnes touchées par la pauvreté. Selon leur conception et leur organisation, les mesures d'activation de l'État social se concentrent davantage sur les efforts des collectivités publiques ou sur la responsabilité individuelle, les droits ou les obligations des personnes concernées, leur autonomisation ou leur déresponsabilisation.

Le développement récent des États-providence a montré que les politiques sociales activantes ne prennent pas forme dans un seul type d'État-providence ou dans un groupe spécifique de pays. Elles représentent plutôt une sorte de leitmotiv dans le développement des sociétés d'abondance dans les pays post-industrialisés. Derrière la transformation de l'État-providence pur en un État social activant se dissimule l'idée fondamentale que l'action étatique est axée sur la mobilisation et le soutien du "potentiel d'auto-assistance», et qu'un lien direct peut être établi entre les mesures sociales de protection et les mesures de participation sociale. Introduit en partie par des réformes explicites, mais aussi engendré par des réajustements plus implicites des mesures de l'État social, le principe de la contre-prestation pour les prestations perçues est mis en place, voire renforcé. En Suisse, la situation sur le marché du travail se présente certes comme confortable en comparaison avec les pays voisins, mais une hausse des rapports de travail précaires et du chômage de longue durée se dessine depuis les années 1990 aussi dans ce pays. Malgré l'élargissement de la politique active du marché de travail, cette tendance n'a, à ce jour, pas été entièrement compensée ou contenue. 
Suivant le principe "encourager et exiger», on attend des bénéficiaires des prestations une contribution active à la résolution de leur problème. Si l'aide n'est pas reçue dans un esprit de coopération, des sanctions peuvent être prises sous la forme de réduction des prestations, les conditions d'octroi des prestations pouvant également être réévaluées. Le droit inconditionnel à la couverture des besoins de base est ainsi restreint, car il est lié à une obligation de participation plus importante de la part des bénéficiaires de prestations. Dans différents sous-systèmes de la sécurité sociale et dans l'aide sociale, ceci engendre un renforcement du principe de subsidiarité et une orientation vers la performance au détriment du principe de finalité et de l'orientation liée aux besoins.

La politique de promotion directe d'un deuxième marché du travail a passé récemment à l'arrière-plan. Les fournisseur.e.s de prestations sont de plus en plus souvent tenu-e-s de proposer des offres plus efficaces en matière de participation professionnelle, et ce, dans des conditions nouvelles ressemblant à la concurrence sur des quasi-marchés créés par l'action publique, et sur lesquels l'État distribue des mandats de prestations de service sociale selon la procédure de l'appel d'offres. Les subventions publiques dépendent alors souvent de la demande effective pour le programme en question et de moins en moins d'un nombre de places convenu au préalable. Le rôle d'avocat des institutions fournissant des prestations, par exemple le lobbying sociopolitique en faveur des intérêts des bénéficiaires de prestations et des participant.e.s aux programmes, semble entravé dans ces conditions de dépendance financière.

L'histoire de la politique d'activation en Suisse a toujours été marquée par les différents intérêts politiques en présence. Selon la position défendue, les deux principes de base ancrés dans la Constitution fédérale de 1999, à savoir la responsabilité individuelle et sociale au sens de l'article 6 et le droit d'obtenir de l'aide dans des situations de détresse au sens de l'article 12, ont été interprétés de différentes façons. Les interventions politiques pour restreindre ou réduire les prestations des assurances sociales et de l'aide sociale ne pouvaient réunir une majorité que si en contrepartie des mesures étaient prises en faveur de l'autodétermination, dans le but de faciliter in fine une réinsertion dans le monde du travail.

Dès le milieu des années 1990, le principe d'activation s'est imposé dans les systèmes de sécurité sociale. Au vu de la hausse du chômage de longue durée, l'assurance-chômage (AC) a été la première à introduire le $1^{\mathrm{er}}$ janvier 1997 des mesures du marché du travail (MMT) dans le cadre de la révision de la LACI. Certains cantons ont suivi avec leurs propres mesures d'activation professionnelle. Par la suite, l'aide sociale a, à son tour, lancé des «mesures favorisant l'intégration sociale et l'insertion professionnelle», mentionnées pour la première fois dans le cadre des normes de la CSIAS de 1998. À l'occasion de la révision partielle de 2005, celles-ci ont été assorties d'un modèle de suppléments ou d'«incitation» conforme au principe du bonus-malus. Il s'agit de récompenser financièrement les personnes bénéficiaires de l'aide sociale qui sont «motivées à travailler et à s'intégrer» ou de punir celles qui ne respectent pas ces conditions. Cela peut aller jusqu'à la suppression totale de l'aide sociale si la personne concernée ne peut pas prouver suffisamment qu'elle n'est pas en mesure de remédier elle-même à la situation de détresse dans laquelle elle se trouve. Lors de la dernière révision partielle de 2016, le concept d'activation est encore renforcé puisque le minimum vital de certains groupes cibles a à nouveau été réduit et le taux maximal de sanction a doublé de $15 \%$ à $30 \%$ du minimum vital. L'assurance-invalidité (AI) introduisait en 1959 déjà des «mesures individuelles de réadaptation». Dans le cadre de la $5^{\mathrm{e}}$ révision de l'AI en 2008, des mesures de détection précoce et d'intégration ont été introduites selon le principe de «la 
réadaptation avant la rente». En 2012, avec la $6^{\mathrm{e}}$ révision de l'AI, ce principe a été complété par de nouvelles mesures de réadaptation pour les personnes bénéficiaires d'une rente AI ( la réadaptation après la rente»).

Le sens et le but ainsi que l'effet des mesures d'activation de l'État social demeurent contestés et font l'objet de discussions controversées, tant dans le monde scientifique que dans le monde politique. À cause d'une conception réductrice de la notion d'activation et des exigences de légitimation, l'accent est toujours mis sur les mesures d'activation professionnelles. Les chances d'intégrer à un poste de travail sur le premier marché du travail après avoir suivi un programme d'activation varient entre $25 \%$ et $50 \%$ en fonction du niveau de qualification, de la branche et des conditions économiques régionales. Il existe souvent une contradiction entre les directives en matière de politique activation et les possibilités réelles des client·e.s de pouvoir mettre leurs capacités à l'épreuve sur le premier marché du travail. Les mesures d'activation réalisées sous la menace de réductions budgétaires n'exercent souvent pas un effet durable, mais peuvent même intensifier la pression subie par les personnes concernées et, partant, favoriser la précarité plutôt que l'autodétermination et l'indépendance. De plus, le concept de l'activation ne semble pas approprié pour repenser l'ensemble des domaines d'action de l'État social. Dans ce contexte, on peut renvoyer aux situations dans lesquelles les gens ont un besoin inconditionnel d'aide, d'assistance et de sécurité sociale ou dans lesquelles une capacité de gain résiduelle ne peut simplement pas être identifiée. Une nouvelle approche est de mise ici pour garantir l'équilibre social.

Rahel Strohmeier Navarro Smith

\section{Références}

Bonvin, J.-M. \& Moachon, E. (2013). Droit au travail et responsabilité individuelle dans les États sociaux contemporains : une analyse en termes de capabilités des politiques d'activation des personnes sans emploi. Revue européenne des droits de l'homme/European Journal of Human Rights, 5, 777-803.

Scherschel, K., Streckeisen, P. \& Krenn, M. (Hrsg.) (2012). Neue Prekarität: Die Folgen aktivierender Arbeitsmarktpolitik - europäische Länder im Vergleich. Frankfurt a.M.: Campus.

Wyer, B. (2014). Der standardisierte Arbeitslose: Langzeitarbeitslose Klienten in der aktivierenden Sozialpolitik. Konstanz: UVK Verlagsgesellschaft.

\section{Exclusion*}

Le terme d'exclusion désigne les tendances sociétales actuelles qui creusent et perpétuent les inégalités sociales, en particulier en lien avec les mutations du monde du travail, la reconfiguration des dispositifs de couverture sociale et le durcissement des politiques dans le domaine des migrations et des frontières. L'exclusion sociale fait référence à l'absence de droits de participation concernant diverses dimensions de la société : marginalisation sur le marché du travail, y compris chômage de longue durée; affaiblissement des liens sociaux, voire isolement social ; privation de la possibilité d'accéder à un certain niveau de vie et de participer à la vie sociale. Depuis les années 1990, la notion d'exclusion se diffuse plus largement dans les analyses sociologiques portant sur l'époque actuelle, et est devenue une «métaphore de la mutation sociale» (Castel) et la «nouvelle désignation» de la «question sociale en Europe» (Kronauer), rapidement reprise dans les débats de politique sociale.

L'exclusion s'articule à différents niveaux (marginalisation économique, politico-institutionnelle, culturelle ou spatiale) et englobe l'accès insuffisant aux ressources sociales comme la formation, la santé, le logement, mais 
aussi aux biens de nature plus abstraite comme les droits, la sécurité ou la reconnaissance. Les exclusions peuvent se renforcer mutuellement et s'imbriquer les unes aux autres (intersectionnalité).

Le terme a été introduit dans les débats scientifiques et politiques en France à partir des années 1980, l'exclusion étant alors étroitement associée aux situations d'éviction du marché du travail. L'exclusion dans le domaine de l'emploi n'entraîne pas seulement une dépendance économique à l'égard de l'État social (partiellement en déclin), elle peut aussi s'accompagner d'un effet d'isolement social et de perte d'insertion dans le tissu social. Par ailleurs, les dynamiques d'exclusion touchent également les personnes (encore) en situation d'inclusion sur le marché du travail : l'insécurité de l'emploi et la crainte du déclassement social sont des réalités au cœur de la société, et deviennent donc le signe distinctif d'une société organisée autour du travail précarisé, avec un effet disciplinaire à la clé.

Depuis les années 1990, l'exclusion est une question discutée également dans le cadre de la politique sociale de l'Union européenne, qui considère l'insertion ou la réinsertion dans le monde du travail comme la principale stratégie de lutte contre l'exclusion. Conformément au nouveau paradigme de la politique sociale d'activation, qui repose sur la formule «encourager et exiger» et sur la «responsabilité personnelle», on exige des personnes au chômage, en contrepartie des prestations sociales, qu'elles fassent la preuve de leur volonté et de leur capacité de travailler.

Dans le domaine du logement, l'exclusion spatiale prend le nom de "gentrification», qui désigne le processus de refoulement des groupes moins favorisés en dehors de l'espace urbain. Ce processus produit des inégalités d'accès aux infrastructures sociales de qualité (écoles, santé) et aux espaces offrant une bonne qualité de vie (pollution atmosphérique, nuisances sonores).
Sur le plan des droits civiques, l'exclusion est aujourd'hui politiquement renforcée par le durcissement des lois sur l'immigration. D'une part, ces lois excluent certains groupes et nationalités du droit de séjour et donc, selon la pensée de Hannah Arendt, d'un droit fondamental qui est le «droit d'avoir des droits». Par ailleurs, on assiste à une stratification des droits sociaux, économiques et politiques à travers la catégorisation des personnes migrantes et réfugiées (ressortissantes UE contre États tiers, à qualification élevée ou basse, personnes requérantes d'asile, sans-papiers) en fonction des conditions fixées pour l'accès au droit de séjour.

En Suisse, le terme d'exclusion est apparu relativement tard dans le débat scientifique et public. Les discussions portent en particulier sur le cas des working poor (travailleur.euse-s pauvres), dont la situation montre que l'insertion dans le monde du travail ne garantit pas nécessairement un niveau de vie socioculturellement décent. Des constats scientifiques importants ont été établis dans le cadre du Programme national de recherche (PNR) 51 «Intégration et exclusion », qui a notamment traité les discours autour de l'inclusion et l'exclusion, les pratiques des institutions publiques et privées (aide sociale, services d'insertion professionnelle, psychiatrie) ou encore les situations et les réactions des personnes visées par les processus d'exclusion.

Depuis le milieu des années 1990, le paradigme de l'activation régit de plus en plus l'évolution de l'assurance-chômage, de l'aide sociale et de l'assurance-invalidité en Suisse. Ce paradigme veut que les bénéficiaires de prestations réintègrent plus rapidement le marché de l'emploi grâce à des mesures et à des formations, tout en les soumettant à des contrôles plus stricts et à des sanctions plus sévères. L’aspect problématique de ce nouveau régime est qu'il produit de nouvelles exclusions et stigmatisations, et qu'il légitime une nouvelle progression des rapports de travail 
précaires. Sous l'angle de la politique d'égalité des sexes, relevons aussi que les obligations qui résultent du travail de care (qui concernent en particulier les femmes) ne sont souvent pas prises en compte ou reconnues dans le cadre des mesures d'activation.

L'exclusion (graduelle) dans le domaine des droits civiques fait qu'environ $25 \%$ de la population sont exclus de la participation politique formelle et privés du droit de vote. En dehors des formes d'exclusion sociale et économique (p.ex. discrimination dans le monde du travail et sur le marché du logement), les personnes migrantes et issues de l'immigration sont aussi affectées par les délimitations symboliques entre le «dedans» et le «dehors». La distinction entre «nous» et «les autres» peut alors être liée à des attributions discriminantes et racistes. Le groupe le plus gravement touché par l'exclusion de la citoyenneté est celui des sans-papiers.

Les critiques adressées à l'utilisation du terme d'exclusion concernent le fait que le concept reste flou et que sa définition est théoriquement peu précise, en particulier par rapport aux concepts classiques de pauvreté et à la théorie des classes traditionnelle. Est également remise en cause la représentation dichotomique opposant le «dedans» au «dehors», et donc l'idée d'une scission au sein de la société. La distinction opérée sur le plan analytique entre les personnes «incluses» ou au contraire «exclues» détournerait le regard des contextes sociaux et des rapports conflictuels et puissants entre l'inclusion et l'exclusion, et n'explorerait pas suffisamment la logique selon laquelle c'est le «dedans» qui produit le «dehors» (Castel). Par ailleurs, l'inclusion deviendrait un idéal normatif exagérément mis en relief par rapport à la situation d'exclusion, occultant le fait que l'inclusion implique souvent, par exemple dans le cas des mesures d'insertion, une assimilation sous contrainte des pratiques et valeurs des groupes inclus. Enfin, la dichotomie entre le «dedans » et le «dehors» focaliserait l'atten- tion sur les groupes sociaux dont on dit qu'ils se trouvent en marge de la société, et qu'on associe à de prétendus facteurs de risque - par exemple des déficits personnels - qui seraient la cause de leur exclusion (l'individu est donc rendu responsable de sa situation). Les populations visées deviennent ainsi le groupe cible d'un travail social de nature généralement technocratique.

La notion d'exclusion doit donc être pensée non pas comme une catégorie statique de l'analyse des structures sociales, mais bien comme un processus graduel et relationnel. Il s'agit de mettre en lumière la dynamique entre l'inclusion et l'exclusion dans divers domaines de la société, et de mieux tenir compte des rapports de pouvoir et des inégalités qui produisent de nouvelles fractures sociales, en privant certains groupes de l'accès aux dispositifs de protection sociale. Au lieu de se concentrer sur l'insertion ou la réinsertion, une société en quête de justice sociale devrait donc tendre à éliminer les rapports sociaux favorisant la discrimination. Les personnes touchées par l'exclusion ne devraient pas être appréhendées comme des victimes passives, mais comme des sujets ayant leur propre pouvoir d'action (agency) et qui, comme le suggérait Bourdieu en 1997 dans La misère du monde, sont capables de lutter de manière autonome et créative contre les formes et les mécanismes d'exclusion sociale.

\section{Sarah Schilliger}

\section{Références}

Castel, R. (1995). Les métamorphoses de la question sociale: une chronique du salariat. Paris : Fayard. Kronauer, M. (2002). Exklusion: Die Gefährdung des Sozialen im hoch entwickelten Kapitalismus. Frankfurt a. M.: Campus.

Kutzner, S., Mäder, U., Knöpfel, C., Heinzmann, C. \& Pakoci, D. (Hrsg.) (2009). Sozialhilfe in der Schweiz: Klassifikation, Integration und Ausschluss von Klienten. Zürich : Rüegger. 


\section{Exécution des peines et des mesures*}

L'exécution des peines et des mesures consiste à mettre en œuvre les sanctions privatives de liberté au moyen de diverses modalités telles que la détention, l'incarcération et le placement de personnes dans des institutions publiques ou privées. L'autorité compétente limite ainsi la zone de mobilité de certaines personnes. De telles sanctions privatives de liberté sont au cœur du contrôle étatique de la criminalité depuis environ 200 ans. Un droit pénal uniforme existe en Suisse depuis 1942. Il incombe aux cantons d'exécuter les jugements et de mettre à disposition et de gérer les établissements idoines. Ces tâches peuvent se réaliser dans le cadre de concordats intercantonaux sur l'exécution des peines et mesures.

En Suisse, les principes suivants s'appliquent à la privation de liberté; ils agissent sur les infrastructures, le personnel, les ressources et les pratiques d'exécution des sanctions pénales :

> Le principe de prévention de la récidive exige d'intervenir, de manière appropriée, sur la personnalité et le comportement du ou de la détenu·e pendant l'exécution de la sanction au moyen du travail obligatoire, de formations, de thérapies, de structures de jour et d'activités de loisirs. Il exige, en outre, de stabiliser l'environnement social futur au travers d'un accompagnement par le travail social (famille, contacts sociaux, travail, assainissement des dettes, médiation entre la victime et le ou la délinquant·e, etc.).

> Le principe de normalisation exige l'alignement le plus global possible des conditions de vie carcérales sur celles en liberté, notamment en posant aux détenu.e.s des exigences conformes à la vie courante ou encore en utilisant les situations de la vie quotidienne en prison comme un terrain d'apprentissage de comportements sociaux (p.ex. exécution en groupe).
> Le principe de prévention des effets nocifs de l'incarcération exige de ne pas isoler les détenu.e.s et de favoriser les contacts sociaux susceptibles de les soutenir (courrier et téléphone, visites, congés spéciaux et relationnels, accès à des journaux, la télévision, des livres et, de manière limitée, à l'Internet).

> Le devoir d'assistance et le principe d'équité exigent de mettre à disposition du ou de la déten·e-u une offre équivalente à celle dont il bénéficierait en liberté en ce qui concerne les soins médicaux et les aides juridique, sociale, religieuse et économique.

, La prévention de la délinquance pendant l'exécution de la sanction vise à garantir la sécurité interne et la protection tant du personnel que des détenu·e.s.

La pratique d'exécution des sanctions pénales varie en fonction de la sanction et de l'âge de la personne condamnée. Ainsi, on distingue les peines et mesures pour adultes et les mesures de protection et les peines pour les jeunes (de 10 à 18 ans), exécutées dans des établissements clairement distincts. Les sanctions privatives de liberté sont prononcées sur la base du délit commis et comprennent une date de fin. Les mesures (de protection) ne se fondent pas sur le délit, mais sur les buts et objectifs des mesures; elles doivent être réexaminées et peuvent être prolongées à plusieurs reprises. Il est en outre possible d'ordonner des mesures ultérieurement, c'est-à-dire après l'exécution de la sanction pénale ou au cours de celle-ci. Une distinction est faite entre les mesures thérapeutiques (p.ex. dans des établissements spécialisés en cas de troubles mentaux ou de problèmes d'addiction) et les mesures de sécurité servant à protéger la société. Ces dernières commencent après que les peines aient été purgées lors de crimes graves et en cas de forte probabilité de récidive.

Dans l'établissement des sanctions pénales, on distingue les établissements ouverts et fermés. Ces derniers sont dotés d'un niveau de 
sécurité plus élevé pour empêcher les fuites ou les évasions. Les 106 établissements suisses disposent, au total, de 7468 places de détention (en 2017). Ils sont petits à très petits en comparaison internationale. Seuls quatre établissements comptent plus de 200 places de détention. Environ la moitié des places de détention sont destinées à la détention préventive (détention avant jugement) et environ deux cinquièmes à la détention ordinaire. Le reste des places est réservé à l'exécution des mesures, à la détention administrative et à des formes alternatives d'exécution des sanctions pénales. Depuis 2003, le taux d'occupation a toujours été supérieur à $80 \%$. L'autorité cantonale d'exécution des peines et des mesures est responsable de l'incarcération et décide, en règle générale, des allégements dans l'exécution des sanctions pénales en prenant en compte la sécurité et en examinant les risques.

Les établissements sont gérés de manière hiérarchique. Ils comprennent différents secteurs avec du personnel spécialisé dans les domaines de la sécurité, de l'encadrement, du travail et de la formation, de la santé et du travail social, de l'administration et de la logistique. En raison de l'obligation de travailler, tous les établissements chargés de l'exécution des sanctions pénales comportent des ateliers de travail. En plus des exigences professionnelles spécifiques (professions soignantes, travail social, diplôme de maîtrise pour les métiers artisanaux, etc.), les futur·e.s employé·e·s de ces établissements doivent disposer d'un diplôme professionnel et d'une formation continue au Centre suisse de formation pour le personnel pénitentiaire à Fribourg.

Outre l'obligation de travailler, la mise sur un pied d'égalité du travail et de la formation ainsi que les mesures thérapeutiques, le plan d'exécution de la peine ou de la mesure est un instrument central. Il est élaboré par la direction de l'établissement et le ou la détenu-e et ajusté périodiquement. Il nomme les objectifs de la peine ou de la mesure, le type de déten- tion, l'emploi, la formation et la formation continue, les mesures thérapeutiques, l'encadrement et les étapes d'allégement.

L'obligation de travailler est considérée comme la pierre angulaire de la réinsertion dans la société, même après l'âge légal de la retraite. Le travail doit être adapté autant que possible aux capacités de la personne. Une partie de la rémunération, fondée sur la performance, est versée sur un compte bloqué pour la période suivant la libération.

Le maintien des relations avec le monde extérieur (téléphone, lecture, lettres, etc.), le droit de visite et la possibilité d'accorder des congés relationnels et spéciaux dans le cadre de la progression et de la préparation à la libération jouent un rôle important. La manière dont les relations avec le monde extérieur peuvent être structurées au cas par cas dépend des réglementations cantonales et spécifiques aux établissements, les décisions étant généralement prises par l'autorité cantonale d'exécution compétente.

L'exécution des peines et des mesures est confrontée à des défis qui trouvent leur origine dans les changements sociaux de ces dernières décennies et qui vont vers une individualisation croissante. Il s'agit notamment des changements dans la population dus aux migrations, du vieillissement de la société ou encore de la prévalence des troubles mentaux.

Les attitudes de la population et du monde politique influencent un autre enjeu, celui qui consiste à trouver un équilibre entre la normalisation et la progression d'un côté et la sécurité de l'autre. Actuellement, on observe une forte tendance à la «sursécurité» qui se traduit par des pratiques restrictives de libération et la remise en cause généralisée, dans les débats publics et politiques, de l'exécution ouverte des sanctions pénales. Un problème de fond caractérise toutes les mesures et interventions de l'État: c'est la difficulté d'atténuer les conséquences négatives de leur segmentation par des formes adéquates de gestion des 
transitions. Dans le contexte de l'exécution des sanctions pénales, cette difficulté s'observe en particulier dans la phase de libération et d'accompagnement par les services de probation. Ces services contribuent à sécuriser l'investissement dans la détention et à prévenir des dommages et coûts futurs causés par un nouvel acte de délinquance.

L'état d'esprit dans la société influence la volonté d'assumer une responsabilité dans la réinsertion des ex-détenu·e-s et contribue à la réussite de la réinsertion. De même, le respect des droits fondamentaux des détenu-e.s est déterminé par l'opinion publique. Deux tendances se dégagent. D’une part, on observe un besoin accru de sécurité qui conduit à prioriser le contrôle et accentue le principe d'exclusion conformément à la théorie punitive de la «neutralisation». D'autre part, on observe des efforts, dans l'optique de la «resocialisation", concernant le sort de la grande majorité des personnes qui ont violé la loi et qui, tôt ou tard, seront libérées. L'accent est alors mis sur les mesures qui favorisent la réinsertion, ce qui réduit les risques de récidive, afin de mieux répondre à l'objectif primordial de la politique de la criminalité, à savoir la protection de la population.

\section{Ueli Hostettler}

\section{Références}

Baechtold, A., Weber, J. \& Hostettler, U. (2016). Strafvollzug: Straf- und Massnahmenvollzug an Erwachsenen in der Schweiz (3., vollst. überarb. und erw. Aufl.). Bern : Stämpfli.

Brägger, B. F. (Hrsg.) (2014). Das schweizerische Vollzugslexikon: Von der vorläufigen Festnahme zur bedingten Entlassung. Basel: Helbing Lichtenhahn.

Office fédéral de la statistique. Thème "Criminalité et droit pénal».https://www.bfs.admin.ch/bfs/fr/ home/statistiques/criminalite-droit-penal.html

\section{Exécution des peines et des mesures pour mineur.e.s}

L'exécution des peines et des mesures de protection pour mineur.e-s correspond à la phase de mise en œuvre de la décision prise par le tribunal des mineur.e.s dans le cadre de la procédure pénale qui suit la commission d'une infraction par une personne mineure (âgée, en Suisse, entre 10 et 18 ans). Les tribunaux des mineur.e.s disposent en Suisse de deux types d'instruments pour répondre à une infraction: les mesures dites de protection (surveillance, assistance personnelle, traitement ambulatoire et placement dans un établissement d'éducation) et les peines (réprimande, prestation personnelle, amende et privation de liberté). Les mesures de protection sont largement minoritaires au regard des peines prononcées. Parmi les peines, la plus utilisée est la prestation personnelle. La peine privative de liberté représente une part très restreinte des peines prononcées. Depuis la moitié du XXe siècle, parmi les mesures de protection, les placements en institution ont progressivement cédé la place aux mesures d'accompagnement en milieu ouvert. Aujourd'hui, l'assistance personnelle est la mesure de protection la plus souvent prononcée.

Jusqu'à la fin du XIXe siècle, un système unique de justice pénale concernait toutes les personnes ayant transgressé la loi pénale, mineur·e·s et majeur·ess confondus. La construction progressive, par les sciences médicales et psychologiques, de la figure de l'enfant comme «être en développement», plus malléable, mais aussi plus vulnérable et moins responsable qu'une personne adulte, a conduit, dès le début du XX $\mathrm{XX}^{\mathrm{e}}$ siècle, à la mise en place, dans la plupart des pays du monde, de systèmes de justice spécifiquement destinés au traitement des mineur·e·s délinquant·e·s. Dès sa création, la justice des mineur·e.s place au cœur de ses objectifs l'éducation et la protection et laisse au second plan - du moins dans 
ses intentions explicites - la punition. Cette orientation éducative donne dès lors un rôle important aux acteur-trice-s et institutions faisant partie de l'État social au sens large (éducateur.trice-s, travailleur.euse-s sociaux, psychologues, maitres socio-professionnels, etc.). Parallèlement, les paniques morales récurrentes associées à la «violence juvénile» ainsi que la demande sociale de maintien de «l'ordre public» ont, elles aussi, contribué à façonner la manière dont la société réagit aux actes de délinquance commis par des mineur.e.s. Par conséquent, la justice des mineur·e-s est le résultat d'une hybridation entre la logique sociale et la logique pénale, entre la visée éducative et la visée punitive, ce qui accroît la complexité de ce champ d'intervention.

Dès la fin du $\mathrm{XX}^{\mathrm{e}}$ siècle, on assiste en Europe à la remise en question progressive de ce modèle protectionnel de justice des mineur.e-s : le seuil de majorité pénale est rabaissé dans certains pays et les impératifs de contrôle et de punition sont remis au centre de la prise en charge des jeunes délinquant.e.s. La réforme de la justice des mineur.e.s en Suisse - engagée avec l'adoption du nouveau Droit pénal des mineurs en 2007 puis avec la mise en œuvre de la Procédure pénale applicable aux mineur·e·s en 2011 - s'inscrit partiellement dans cette tendance sécuritaire, tout en réaffirmant la prédominance de l'objectif éducatif. La lutte contre la délinquance violente et la récidive figure parmi les arguments justifiant les innovations apportées au nouveau texte de loi, notamment la possibilité de cumuler pour un même jeune une mesure de protection et une peine. Néanmoins, la majorité pénale est maintenue à 18 ans sans exception, alors qu'en France par exemple, un. mineur.e âgé·e de plus de 16 ans peut, dans certaines circonstances, être condamné·e à la même peine que celle prévue pour les adultes.

Une des questions centrales concernant l'exécution des peines et des mesures de protection pour mineur.e.s est la déconnexion possible entre le besoin réel de structures de prise en charge des mineur.e.s délinquant $\cdot e \cdot s$ besoin qui découle des jugements prononcés au tribunal - et les logiques politiques qui administrent ces structures. Il peut par exemple arriver, comme c'est le cas en Suisse depuis quelques années, que les institutions fermées pour mineur.e.s délinquant·e.s soient systématiquement sous-occupées, car la délinquance juvénile effective diminue, alors que les élu·e.s politiques, sensibles aux discours sécuritaires, ont promu la construction de nouveaux établissements fermés. Dans d'autres contextes nationaux, on observe à l'inverse que les peines en milieu ouvert sont trop peu souvent prononcées par les juges en raison de la capacité de prise en charge restreinte des dispositifs de milieu ouvert. L'exécution des peines ne relève donc pas de la mise en œuvre mécanique d'une décision judiciaire mais dépend de logiques sociales, politiques et économiques complexes.

Les institutions de prise en charge des mineur.e.s délinquant.e.s doivent également composer, depuis une dizaine d'années, avec la multiplication des types de professionnel-le-s œuvrant en leur sein. Alors que les éducateur-trice-s et autres professionnel-le·s $\mathrm{du}$ travail social occupaient une place quasiment hégémonique, on constate aujourd'hui la présence croissante d'acteur-trice-s du champ médico-thérapeutique, ainsi que l'arrivée de professionnel-le·s de la sécurité. La présence de ces nouveaux.elles acteur-trice-s au sein des institutions pour mineur.e-s induit une redéfinition des territoires de l'action professionnelle, une spécialisation des rôles et la remise en question de la polyvalence du métier d'éducateur.trice. Par ailleurs, la présence de psychologues et psychiatres dans les institutions s'accompagne de nouveaux discours savants sur les causes de la délinquance juvénile, qui pointent davantage les troubles psychiques que les problèmes d'exclusion sociale et professionnelle.

On assiste également à une certaine remise en question du monopole étatique en matière pénale, dont les conséquences sont obser- 
vables à différents niveaux. D'abord, sous la forme d'une injonction à réduire les coûts de la prise en charge des mineur·e·s délinquant·e·s - tout en garantissant son efficacité - qui tend à fragiliser le modèle protectionnel de justice des mineur·e.s, basé sur des interventions longues et individualisées. Par ailleurs, certaines mesures de protection, comme l'assistance personnelle, sont fréquemment exécutées par des organismes privés du secteur associatif; dans un tel contexte, la même mesure peut être exécutée de manières très diverses et l'autonomie des acteur-trice-s d'exécution des mesures par rapport aux institutions judiciaires se voit renforcée. Enfin, on constate l'émergence de nouvelles formes de justice dites «restauratrices » - dont la médiation pénale est la principale expression en Suisse - qui impliquent davantage les acteur.trice-s privé.e-s et notamment la victime du délit.

Finalement, on observe une sorte de polarisation de la réaction sociale à la délinquance juvénile : d'un côté, un durcissement des sanctions pour les cas lourds mais minoritaires; de l'autre, diverses formes de prises en charge en milieu ouvert, basées sur une surveillance souple et promouvant la «prise de conscience» et la «responsabilisation» des jeunes délinquant·e.s, sans toutefois parvenir à offrir les ressources nécessaires à leur réinsertion. L'accroissement des inégalités sociales et la surenchère des diplômes exigés sur le marché de l'emploi combinés au stigmate du ou de la «jeune délinquant.e» constituent en effet souvent des obstacles durables à l'insertion socioprofessionnelle. Face à la multiplication des peines et mesures alternatives à l'enfermement il serait donc erroné de conclure à un adoucissement de la réponse pénale. Il convient plutôt de s'interroger sur les formes singulières de contrôle à l'œuvre dans ces prises en charge en milieu ouvert: celles-ci exigent des jeunes un autocontrôle permanent et une capacité à se montrer autonomes et responsables. Ces compétences - autonomie, responsabilité, autocontrôle - deviennent ainsi paradoxalement des conditions de possibilité de la prise en charge, et non plus des objectifs à atteindre au terme de l'intervention socioéducative.

\section{Géraldine Bugnon}

\section{Références}

Frauenfelder, A., Nada, E. \& Bugnon, G. (2016). Division morale du travail et recompositions du sens de l'enfermement en Centre éducatif fermé. Déviance et société, 39(4), 477-500.

Muncie, J. (2006). Repenalisation and rights : explorations in comparative youth criminology. The Howard Journal of Criminal Justice, 45(1), 42-70.

Viredaz, B. (2005). Le dualisme des peines et des mesures tel que le prévoit la nouvelle Loi fédérale sur la condition pénale des mineurs. Schweizerische Zeitschrift für Strafrecht / Revue pénale suisse, 123(2), 174-186.

\section{Famille}

Le pluralisme actuel des modes de vie familiale s'oppose à la possibilité d'une définition exhaustive de la «bonne» famille. Dès lors, la question de la normativité familiale est devenue un enjeu de lutte parmi une multiplicité d'acteurs et actrices privée-s et institutionnel-le·s.

Au-delà de cet enjeu, le terme famille désigne, d'une part, l'ensemble des individus qui, apparentés par la filiation, l'alliance ou la germanité, et dotés de droits et d'obligations réciproques, sont regroupés soit au sein du groupe nucléaire de père, mère et enfant, soit dans la parenté élargie aux grands-parents, oncles, tantes, cousins et cousines, etc. Cette configuration, cependant, n'est pas la référence de la politique sociale et familiale suisse, qui tend à focaliser son action et ses exigences en direction du groupe nucléaire. Par exemple, le devoir d'assistance de la famille aisée à l'égard d'un.e de ses membres tombé dans le besoin est exigé uniquement en ligne ascendante et 
descendante. Le terme famille désigne, d'autre part, l'institution de reproduction de la vie aux plans symbolique, moral et matériel; elle assigne aux membres des fonctions de soin, d'éducation, de soutien émotionnel et d'intégration qui se perpétuent sur la division sexuelle du travail.

À bien des égards, les dispositifs de soutien aux familles ne corrigent pas fondamentalement les inégalités de genre se (re)produisant dans et par la famille, en partie parce qu'elles sont légitimées par le modèle hérité de la période fordiste, dont la politique familiale peine à s'extraire. Ce modèle, formé par le groupe nucléaire composé du père pourvoyeur unique de revenu, de la mère pourvoyeuse unique de soin, et organisé selon une forte hiérarchisation sexuée des rôles conjugaux et parentaux, est maintenant doublement ébranlé. Sur le plan des valeurs d'abord, l'égalité entre femmes et hommes étant inscrite dans la Constitution fédérale, un modèle de division des responsabilités familiales fondé sur la stricte séparation et hiérarchisation sexuées des rôles familiaux et professionnels ne paraît plus pouvoir répondre aux aspirations de justice et d'autonomie des individus. Sur le plan des pratiques ensuite, l'organisation domestique qui reposait sur la promesse du mariage à vie et sur la possibilité que le seul salaire masculin puisse entretenir la famille n'est plus viable ni fiable dans la société helvétique caractérisée par une forte divortialité, ainsi que par la flexibilité du marché du travail et des modalités atypiques d'emploi. Reste que ce modèle subsiste sous une forme qui se veut une adaptation à ces nouveaux risques : la mère continue de se charger prioritairement du travail domestique, tout en occupant un emploi à temps partiel. C'est aujourd'hui, en Suisse, l'organisation familiale la plus répandue et celle que promeut la politique familiale, tout inégalitaire et créatrice de précarités soit-elle. À la retraite, par exemple, la rente de vieillesse des femmes est, en 2017, inférieure de plus d'un tiers à celle des hommes, en raison de leur moindre insertion dans l'emploi. Par ailleurs, sous le terme de "conciliation» famille - travail, les seules mesures à cet effet se réduisant au temps partiel, visent de fait les mères qui s'adaptent ainsi aux rythmes des membres de la famille et aux horaires des structures scolaires et d'accueil des enfants. Enfin, le droit au congé maternité n'étant accessible qu'aux mères biologiques et en emploi, il naturalise la filiation et contribue à l'absence de reconnaissance du travail domestique. En définitive, la famille nucléaire hétérosexuelle et biparentale, censée trouver dans ses propres rangs féminins des solutions à la prise en charge de ses membres, est le référent des politiques publiques. Référent à l'aune duquel les vulnérabilités spécifiques à d'autres formes de familles - recomposées et homoparentales impliquant la parentalité d'un tiers; parents séparés mobilisant, ou non, différentes formes de départage de l'enfant, etc. - peinent à se voir reconnues et soutenues. Ainsi, la famille homoparentale ne se traduit pas (encore) dans le droit; l'exercice de la pluriparentalité, par les beaux-pères et belles-mères ou par les grands-parents ne bénéficie qu'exceptionnellement d'une reconnaissance; les principes sur lesquels est construit le modèle de filiation occidental (bilatéralité sexuée et exclusivité), s'ils sont contestés dans les pratiques, déterminent le cadre légal de la parenté.

Le fait est que, désormais, les individus vivant dans les collectifs familiaux s'organisent (ou pensent s'organiser) sur la base d'idéaux pluriels forgés en partie par leurs volontés et affects. Un tel fait atteste du rôle actif des individus dans l'invention de leur vie privée et la construction de leur famille, auxquelles les institutions publiques ne s'adaptent qu'en partie. Certes, si l'on constate que des socles jugés inamovibles de l'institution familiale, tels que l'hétérosexualité, sont maintenant questionnés, comme en attestent les pratiques et débats actuels, cela ne va pas sans conflit, discrimina- 
tions et vulnérabilité pour les groupes familiaux qui s'engagent dans ces voies. Faute de protections réelles, ces innovations risquent donc de ne profiter qu'aux groupes les mieux dotés socialement.

C'est dans un équilibre délicat entre innovation et conservatisme que se situe l'enjeu définitionnel de la famille comme objet politique légitime. Étant donné le paysage sociopolitique actuel, dans lequel l'enfant est le centre des attentions, la définition du cadre familial susceptible de répondre au mieux à ses besoins est plus que jamais objet de controverses. Longtemps reléguée hors de la sphère publique, supposée relever d'un soi-disant ordre naturel, fondée sur des représentations différenciées de ce que doivent être un père et une mère, la famille accède difficilement à la délibération politique et à l'égalité réelle. Les recherches récentes témoignent de l'implication comparativement faible et sélective des hommes dans les activités de solidarité, ainsi que de la situation saisissante de la Suisse, qui en matière de congés parental et de paternité, se situe au dernier rang des États de l'Union européenne.

La multiplicité des formes de familles au cours de l'histoire, mais aussi l'orientation des politiques sociales visant à les soutenir, indiquent comment, dans le cadre de quelles configurations et organisations familiales, une société entend répondre aux questions essentielles de la reproduction de la vie et de la prise en charge des individus vulnérables. Ces réponses ne sont pas figées comme en attestent la nouvelle norme d'autorité parentale conjointe au divorce, l'invention du pacte civil de solidarité (PACS) ou l'accession à la filiation par les deux membres d'un couple de même sexe. Il n'en reste pas moins que des résistances demeurent. La famille hétérosexuelle est une institution productrice de discriminations de genre, un espace relationnel marqué par l'antagonisme de sexe. Le refus de reconnaître cet antagonisme, qu'atteste la non-reconnaissance du travail domestique et du travail de care ainsi que de l'inégalité économique au sein du couple qui en résulte, est l'obstacle majeur à toute démarche ambitionnant la définition et la mise en place d'une famille juste.

\section{Marianne Modak}

\section{Références}

Kellerhals, J., Troutot, P.-Y. \& Lazega, E. (1984). Microsociologie de la famille. Paris : Presses Universitaires de France.

Levy, R. \& Le Goff, J.-M. (Éd.) (2016). Devenir parents, devenir inégaux: transition à la parentalité et inégalités de genre. Zürich: Seismo.

Moller Okin, S. (2008). Justice, gender, and the family. New York: Basic Books.

\section{Fédéralisme* $^{*}$}

Le fédéralisme est un système gouvernemental dans lequel la souveraineté des États est partagée entre le gouvernement central et les gouvernements régionaux. Dans un système fédéraliste, les États membres se voient accorder l'autonomie territoriale, c'est-à-dire le pouvoir politique nécessaire à la prise de décision ainsi que la garantie de leur propre identité et de leurs frontières. Les États membres ont également la possibilité de contribuer aux décisions de l'État central. On s'efforcera alors d'obtenir une représentation égale ou équivalente d'États membres ayant un nombre d'habitant-e-s inégal. La répartition des responsabilités entre l'État fédéral et les États membres est réglementée au niveau fédéral, en restant néanmoins sous la codétermination des États membres. La Suisse, l'Allemagne, la Belgique, les États-Unis, le Canada et l'Inde comptent notamment parmi les États fédéralistes.

Même si le fédéralisme va généralement de pair avec la décentralisation des tâches administratives, il n'est toutefois pas synonyme de décentralisation. Des pays comme la Suède 
ou le Danemark, par exemple, délèguent dans une large mesure un vaste éventail de tâches gouvernementales et la perception des impôts nécessaires pour les financer aux collectivités locales décentralisées, sans leur conférer de compétence réglementaire finale et donc de souveraineté étatique.

La Suisse peut être considérée comme le cas paradigmatique d'un État fédéraliste. Aucun autre pays n'a autant d'États membres par rapport à sa taille géographique. Les États membres de la Suisse, les cantons, jouissent de droits d'autodétermination très étendus. La souveraineté et la subsidiarité, les deux plus importants principes du fédéralisme, sont énoncés à l'article 3 de la Constitution fédérale: «Les cantons sont souverains en tant que leur souveraineté n'est pas limitée par la Constitution fédérale et exercent tous les droits qui ne sont pas délégués à la Confédération». Les cantons sont libres de s'organiser en interne, en tenant compte de certains principes fondamentaux, tels que la démocratie, l'État de droit et l'autonomie communale. Ils ont leur propre constitution, leurs propres organes législatifs, exécutifs et judiciaires. Toutes les tâches qui ne sont pas dévolues à l'État fédéral relèvent automatiquement de la compétence des cantons. Même lorsque la Confédération est compétente en matière de réglementation, les cantons sont généralement responsables de l'exécution des activités étatiques.

Outre la démocratie directe, le fédéralisme est coresponsable de la formation tardive de l'État social suisse. Cela s'explique par le fait que l'État fédéral suisse n'a traditionnellement eu de pouvoirs législatifs en matière de politique sociale que lorsqu'il y était autorisé par des dispositions constitutionnelles. À cette fin, il a fallu à chaque fois tout d'abord formuler un mandat constitutionnel, soumis au référendum à la double majorité populaire et cantonale. La Constitution suisse ne peut être modifiée que si l'ensemble de l'électorat (majorité du peuple) et la majorité des cantons sont d'accord. La majo- rité des cantons peut ainsi empêcher un transfert des compétences en matière de politique sociale vers l'État fédéral. Cela s'est produit par exemple en 2013. À cette date, l'article sur la famille, qui aurait autorisé la Confédération à prendre des mesures pour concilier vie professionnelle et vie familiale, a été approuvé par la majorité de l'électorat suisse, dans une faible majorité des cantons néanmoins, la demande n’a pas été acceptée.

Le fédéralisme n'est pas seulement un frein au développement de l'État social, c'est aussi une source d'innovation. Le degré élevé d'autonomie permet aux cantons et aux plus grandes communes et villes de développer leurs propres solutions et innovations. En Suisse, différentes variantes peuvent être mises en œuvre en parallèle, différentes expériences peuvent être réalisées et échangées. Comme les attitudes de la population à l'égard des questions de politique sociale varient considérablement d'une région à l'autre, le fédéralisme permet dans certains cas de s'adapter aux systèmes de valeurs ou aux circonstances régionales. Parmi les innovations cantonales, citons par exemple le régime d'assurance-maternité du canton de Genève, qui a été mis en place avant qu'une solution ait pu être adoptée à la majorité au niveau national, ou encore les prestations complémentaires pour familles, pour lesquelles le canton du Tessin a mis en place un système pionnier.

Les cantons eux-mêmes sont également organisés de manière fédérale et leurs propres «États membres», les communes, peuvent prendre des décisions finales sur un certain nombre de tâches politiques. Ces tâches varient d'un canton à l'autre. Certains cantons ont une organisation interne plus centralisée que d'autres. Dans le domaine de l'aide sociale, par exemple, l'autonomie communale est très prononcée dans les grands cantons de Suisse orientale, tandis qu'en Suisse occidentale, les cantons exercent généralement un pilotage plus marqué et une intervention beaucoup plus 
forte. Dans certains cantons, dont Genève et Glaris, l'aide sociale est prise en charge par le canton.

Dans le système fédéraliste, la coordination et la coopération dans le domaine de la politique sociale sont complexes. Les cantons et les communes ont mis en place des organisations de coordination horizontales afin d'améliorer la coopération et de défendre de manière commune leurs intérêts auprès du niveau gouvernemental supérieur. Au niveau cantonal, l'organe le plus important en matière de politique sociale est la Conférence des directrices et directeurs cantonaux des affaires sociales (CDAS). La CDAS représente les préoccupations sociopolitiques des cantons vis-à-vis de la Confédération et du grand public et assume diverses missions communes et de coordination. Les associations assument également d'importantes fonctions de coordination dans l'État social fédéraliste suisse. Au niveau national, il y a l'Initiative des villes pour la politique sociale, à laquelle participent des communes urbaines de toute la Suisse, ainsi que la Conférence suisse des institutions d'action sociale (CSIAS), l'association professionnelle nationale d'aide sociale.

En plus de l'organisation horizontale, la coordination verticale entre les différents niveaux est également un défi. Avec la réforme de la péréquation financière et de la répartition des tâches entre la Confédération et les cantons (RPT) en 2008, il a été possible de démêler en partie la répartition jusqu'alors peu claire des différentes missions communes. Même si cela a permis d'améliorer la situation, la coordination et la coopération au sein de l'État social fédéraliste restent des questions centrales dans le débat sur la politique sociale. Un reproche fréquent concerne le transfert des coûts d'un niveau gouvernemental à un autre. Par exemple, il est supposé que le durcissement des conditions d'octroi des rentes AI ou des prestations d'assurance-chômage par la Confédération entraînera des frais supplémentaires pour les communes et les cantons. Une autre question qui a été débattue à plusieurs reprises et à différents niveaux concerne la péréquation des charges sociales. Au niveau fédéral, depuis l'entrée en vigueur du nouveau système de péréquation financière, il existe un système de compensation des charges sociales, qui s'appuie sur les contributions de la Confédération mais aussi sur un système de redistribution entre les cantons. Cette tâche est traitée de manière très différente à l'intérieur de chaque canton. Dans certains cantons, il existe des systèmes très étendus pour équilibrer les charges sociales entre les communes, alors que dans d'autres, ce n'est pas le cas. Les deux variantes conduisent régulièrement à des interventions politiques dans les cantons.

\section{Michelle Beyeler}

\section{Références}

Armingeon, K., Bertozzi, F. \& Bonoli, G. (2004). Swiss worlds of welfare. West European Politics, 27(1), 20-44.

Bonoli, G. \& Champion, C. (2015). Federalism and welfare to work in Switzerland : the development of active social policies in a fragmented welfare state. Publius: The Journal of Federalism, 45(1), 77-98.

Vatter, A. (2016). Das politische System der Schweiz (Kapitel zu Föderalismus). Baden Baden : Nomos.

\section{Fin de vie}

La notion de «fin de vie » ne saurait être définie avec précision, ni sur un plan clinique, ni sur un plan social. Une acception restreinte l'assimilera à la période des "soins terminaux», prodigués aux individus dont la probabilité de mourir est élevée, voire imminente ; une acception large la fera correspondre à la période qui s'étend de l'annonce d'une maladie potentiellement mortelle au décès de la personne concernée. Ne pouvant être quantitativement objec- 
tivée, la «fin de vie» désigne par conséquent cette temporalité durant laquelle certains individus ainsi que leurs proches nécessitent une prise en charge médicosociale personnalisée, adaptée à leurs besoins ainsi qu'à ceux de leurs proches, car un pronostic vital est engagé.

C'est à partir du milieu du $\mathrm{XX}^{\mathrm{e}}$ siècle que les individus et les collectivités commencent à percevoir la temporalité de la fin de vie comme «nouvelle» et à l'appréhender en ces termes. Plusieurs facteurs expliquent cet état de fait. Une nouvelle définition de la mort s'est tout d'abord imposée dans la plupart des pays. Il s'agit de la mort «encéphalique» ou mort «cérébrale», fondée sur la perte irréversible de toute activité cérébrale. Cette redéfinition de la mort est étroitement liée aux techniques de réanimation et à la médecine des greffes ; elle soulève des enjeux complexes, notamment juridiques, puisqu'elle inscrit tant la conception de la mort que sa réalité dans un intervalle plus ou moins maîtrisable, susceptible de durer.

Les diagnostics médicaux et les traitements proposés se sont ensuite perfectionnés, rendant plus difficile l'identification de l'approche de la mort, voire de l'agonie. Dans ce contexte, des mouvements associatifs et citoyens sont apparus pour préserver le droit des patient.e.s et promouvoir leur autonomie: faut-il ou non réanimer? Quand convient-il de débrancher les machines? Qui a la légitimité de la décision? Face à ces questions, ces mouvements - qui visent tous à préserver la dignité des patient.e.s - ont pris deux directions différentes. D’un côté celle qui soutient le libre choix individuel face à la mort et la possibilité de recourir à une assistance au suicide; d'un autre côté celle qui vise à soulager la douleur sans hâter la mort, les soins palliatifs.

En un siècle, le profil des défunt-e.s a par ailleurs changé. La mortalité infantile a chuté et la population a vieilli. Dans la plupart des pays, il est attendu que le nombre de décès, surtout ceux d'individus très âgés, augmente considérablement. En Suisse, plus de $85 \%$ des défunt·es ont au moins 65 ans et déjà plus de $60 \%$ ont 80 ans et plus. Démographiquement, la «fin de vie» devient une question de santé publique, cela d'autant plus que les décès surviennent en grande majorité dans les structures socio-hospitalières et non plus au domicile, contrairement à ce que bon nombre de personnes déclarent souhaiter. De ce fait, la prise en charge du mourir, de la mort et du deuil s'est professionnalisée, institutionnalisée, voire médicalisée.

Ces divers changements ont contribué à faire émerger cette nouvelle temporalité de la «fin de vie», temporalité durant laquelle proches et patient·e-s sont de plus en plus amené·e.s à devoir négocier - entre eux et avec divers professionnel-le·s - les décisions qui jalonnent la péjoration d'une grave maladie ou la perte d'autonomie au grand âge. Cela suppose de combiner temporairement aide formelle et aide informelle pour prendre en charge les personnes concernées, en anticipant sur leur qualité de vie en fonction de l'option thérapeutique choisie; en réorganisant les rôles et les dynamiques familiales; en articulant vie privée et accompagnement, et bien souvent encore activité professionnelle.

Ce sont les milieux professionnels et associatifs qui les premiers ont pris la mesure de ces changements. Prenant appui sur des cas singuliers fort complexes, ils ont milité pour l'adoption de nouvelles approches tournées vers des pratiques de care et sensibilisé les pouvoirs publics. Dès les années 1980, les questions de «fin de vie» prennent progressivement place dans les agendas politiques de divers pays, qui mettent en œuvre des dispositions légales relativement au développement des soins palliatifs et parfois aussi à l'aide à mourir. En Suisse, il faut attendre octobre 2009 pour voir le lancement d'une stratégie nationale en la matière, à l'initiative du Département fédéral de l'Intérieur et de la Conférence suisse des directrices et directeurs cantonaux de la santé, après avoir constaté un manque d'ancrage des soins pal- 
liatifs dans le domaine de la santé, l'un des objectifs prioritaires étant de sensibiliser aussi bien les spécialistes que la population à cette question.

Parallèlement à cette action, le Fonds national suisse de la recherche scientifique a lancé un programme national de recherche intitulé «Fin de vie» (PNR 67) afin de mieux connaître les réalités helvétiques sur ce thème. Réalisées entre 2012 et 2017, les études de ce programme documentent de façon interdisciplinaire les principaux enjeux et défis auxquels sont confrontés les individus et les collectivités face à la mort. Elles fournissent les bases empiriques contemporaines à la réflexion et à la prise de décision.

Pour faire face au passage de 60000 décès par année au début du siècle à 90000 décès attendus d'ici 2050, trois domaines méritent d'être considérés en termes de politique sociale. En matière de soins palliatifs premièrement, il s'agit de former un personnel suffisamment qualifié tout en finançant une gamme de prestations à la fois généralistes et spécialisées, à intégrer au système de santé sans créer d'inégalités d'accès. Souvent centrées sur les besoins des patient.e-s et de leurs proches, ces prestations visent à couvrir du mieux possible cette temporalité incertaine de la «fin de vie» que les patient.e-s et les proches identifient rarement comme telle, sinon de manière rétrospective pour mesurer toute l'aide ayant été prodiguée à un individu jusqu'à son décès. Létablissement de directives anticipées est dès lors perçu comme un bon moyen d'y parvenir.

Deuxièmement, face au sentiment de mourir soit trop tôt soit trop tard, la question de l'autodétermination des personnes se pose avec acuité. En Suisse, la pratique du suicide assisté - qui n'est pas un droit - relève d'un modèle unique dans la mesure où la participation des médecins n'est pas obligatoire, si ce n'est pour délivrer la prescription d'un produit létal. Selon l'article 115 du Code pénal, le suicide assisté n'est pas punissable tant qu'aucun mobile égoïste ne le motive. De plus, la personne qui y recourt doit être capable de discernement et effectuer le geste elle-même. Cette pratique ne doit donc être confondue ni avec l'euthanasie, ni avec l'aide médicale à mourir. Ce sont avant tout des associations qui l'encadrent en édictant leurs propres règles de fonctionnement. Dans ce contexte, l'un des enjeux consiste à savoir s'il convient d'autoriser le suicide assisté au sein des établissements financés par les pouvoirs publics comme l'ont déjà fait plusieurs cantons et d'en déterminer les conditions de réalisation.

Une situation de «fin de vie», troisièmement, conduit bon nombre d'individus à revoir l'articulation entre activité professionnelle et accompagnement d'un.e proche gravement atteint·e dans sa santé, en particulier les parents d'enfants malades. À cette fin, de nombreux pays - au tournant du XXI ${ }^{\mathrm{e}}$ siècle - ont adopté des congés dédiés spécifiquement à ces situations ou, plus largement, aux «proches aidants». Au niveau fédéral, la Suisse ne prévoit pour sa part que trois jours de congé pour l'organisation de la garde d'un enfant malade. Depuis une vingtaine d'années, une série de propositions ont néanmoins été et sont encore débattues au parlement en vue d'introduire des mesures de ce type, en les assortissant ou non d'allocations financières. En février 2017, le Conseil fédéral a annoncé vouloir légiférer en la matière. Le cas échéant, il importera de prévenir les biais de genre que d'autres pays ont expérimentés en la matière - ce sont avant tout des femmes qui prennent ces congés - et d'articuler la prise de congés à d'autres solutions pouvant être expérimentées aux interfaces des mondes de la santé publique, des entreprises et des instances politiques afin d'augmenter la flexibilité dont les personnes actives professionnellement souhaitent bénéficier durant l'accompagnement d'un proche en «fin de vie».

Marc-Antoine Berthod 


\section{Références}

Binder, J. \& von Wartburg, L. (2009). Stratégie nationale en matière de soins palliatifs 2010-2012. Berne: Office fédéral de la santé publique \& Conférence suisse des directrices et directeurs cantonaux de la santé.

Comité de direction du PNR 67 Fin de vie (2017). Rapport de synthèse PNR 67, Fin de vie. Berne: Fonds national suisse.

Walter, T. (2017). What death means now: thinking critically about dying and grieving. Bristol: Policy Press.

\section{Financement de l'éducation (contributions à la formation, bourses d'études)*}

L'éducation est une priorité en Suisse et l'objectif politique de l'égalité des chances dans l'accès à l'éducation n'est pas seulement un principe important de la politique de l'éducation, mais aussi une valeur fondamentale de notre société démocratique. Pour permettre aux enfants, aux adolescent·e.s et aux jeunes adultes issus de familles à revenus modestes d'accéder à l'enseignement supérieur, les cantons peuvent octroyer des contributions à la formation sous forme de bourses ou de prêts d'études aux élèves et aux étudiant·e.s.

L'octroi de contributions à la formation fait partie de la politique de l'éducation de la Confédération et des cantons. Il s'agit d'une prestation sous condition de ressources, qui vise à réduire les inégalités sociales en matière d'éducation. En outre, les contributions à la formation ont pour objectif d'aider les individus et la société dans son ensemble à tirer le meilleur parti possible de leur potentiel éducatif.

Les cantons demeurent en principe souverains en ce qui concerne les conditions d'octroi. Toutefois, l'accord intercantonal sur l'harmonisation des contributions à la formation, dans lequel sont définis d'importants principes et un certain nombre de normes minimales, a réduit depuis 2013 les inégalités entre les pra- tiques différentes des cantons en matière d'octroi. Les contributions à la formation existent sous forme de bourses ou de prêts d'études. Les bourses d'études sont des prestations non remboursables accordées à titre unique ou récurrent; les prêts sont également accordés à titre unique ou récurrent, mais ils doivent être remboursés et portent des intérêts. Les contributions à la formation ne sont versées qu'après la scolarité obligatoire et pour les formations initiales (école du degré secondaire II, apprentissage, haute école spécialisée ou université/EPF) ainsi que pour les formations continues basées sur celles-ci. Certains cantons ne connaissent pas de droit à des aides pour une deuxième formation ou octroient seulement des prêts. En Suisse, au même titre qu'en Allemagne, en France ou en Autriche, les bourses d'études sont calculées en fonction des ressources des parents. Le principe de subsidiarité s'applique: l'État n'octroie des aides que si les ressources propres de l'étudiant.e et l'aide financière des parents et d'autres membres de la famille ne suffisent pas. Les contributions sont généralement accordées pour une année de formation. Le cas échéant, elles sont examinées et renouvelées tous les ans.

En règle générale, sont en droit de demander des contributions à la formation les étudianteess qui n'ont pas encore de diplôme professionnel ou d'études et dont le domicile déterminant pour le droit à une bourse se situe dans l'un des 26 cantons. Les étrangères et étrangers ont droit à des aides si leurs parents ou eux-elles-mêmes disposent d'une autorisation d'établissement (permis C) ou s'ils·elles sont autorisé-e-s à résider en Suisse depuis cinq ans et disposent d'une autorisation de séjour (permis B). De même, les réfugié·e·s reconnu·e·s peuvent percevoir des aides. Le critère déterminant pour percevoir une bourse d'études est la situation financière (critère de besoin économique) du·de la requérant·e et de sa famille, autrement dit, ses revenus et son patrimoine (taxation fiscale) de même que la situation de 
l'ensemble de la famille (p.ex. forme familiale, nombre de personnes, état civil, etc.). Le montant des contributions dépend de la situation familiale et de celle du·de la requérant·e, la plupart des cantons définissant des montants minimaux et maximaux selon le type de formation et la situation personnelle.

Le système éducatif suisse est financé dans une large mesure par l'État. En comparaison internationale, la Suisse figure parmi les pays où les dépenses par personne consacrées à l'éducation et à la formation à tous les niveaux sont les plus élevées. Le système suisse des bourses d'études publiques a deux acteurs principaux : la Confédération et les cantons. En outre, de nombreuses fondations et de nombreux fonds privés sont actifs dans la promotion de la formation.

Les bourses et les prêts d'études cantonaux ainsi que les contributions de la Confédération font partie des dépenses publiques d'éducation. Sur les 300 à 350 millions de francs que les cantons et la Confédération y ont consacrés annuellement au cours des 20 dernières années, plus de $90 \%$ ont été versés sous forme de bourses d'études. Ce montant équivaut à environ $1 \%$ des dépenses publiques totales pour l'éducation.

L'engagement financier de la Confédération ayant été sensiblement réduit en 2008 avec la réforme de la péréquation financière et de la répartition des tâches (RPT), les cantons supportent la majeure partie des frais liés aux bourses d'études (plus de 90\%). La Confédération se limite à subventionner les bourses d'études dans l'enseignement tertiaire et n'accorde pas d'aide dans le cadre du degré secondaire II (écoles post-obligatoires et formation professionnelle). Depuis l'introduction de la RPT, la contribution fédérale, qui s'élève à seulement 25 millions de francs, est répartie de manière forfaitaire en fonction du nombre d'habitant.e-s et non plus en fonction des dépenses.
Depuis l'entrée en vigueur de la loi fédérale du 19 mars 1965 sur l'allocation de subventions pour les dépenses des cantons en matière d'aides à la formation, l'harmonisation formelle et matérielle des systèmes cantonaux de bourses d'études, très hétérogènes, est une question importante. La loi fédérale de 1965 peut être considérée comme l'acte de naissance du système moderne de bourses d'État au niveau national. Cette loi a déclenché une vague d'innovations dans les cantons, de sorte que, depuis la fin des années 1960, des services des bourses dotés de leurs propres bases légales et généralement rattachés au Département cantonal de l'éducation existent dans tous les cantons. Pourtant, il existait, notamment dans certains cantons universitaires, un système de bourses d'État relativement efficace bien avant cette loi (p.ex. Bâle-Ville, Berne, Genève ou Zurich).

Créée en 1966, la Conférence intercantonale des préposés aux bourses (à partir de 2001, la Conférence intercantonale des bourses d'études) était l'occasion pour les responsables des bourses des cantons d'échanger entre eux et d'harmoniser la promotion de l'éducation. Le travail de longue date de cette conférence spécialisée a finalement abouti à une avancée historique en 2013 dans le domaine de l'harmonisation des bourses d'études, lorsqu'un concordat intercantonal a été adopté par la Conférence suisse des directeurs cantonaux de l'instruction publique CDIP.

Depuis le $1^{\mathrm{er}}$ mars 2013, la coopération intercantonale dans le domaine des bourses d'études repose sur un accord intercantonal (concordat sur les bourses d'études), qui a déjà été signé par 18 cantons représentant environ $90 \%$ de la population résidente. Les cantons signataires de l'accord ont fixé des normes minimales et des principes pour l'octroi de contributions à la formation. Un secrétariat rattaché à la CDIP coordonne et gère les travaux d'exécution. L’entrée en vigueur de la nouvelle loi fédérale au $1^{\mathrm{er}}$ janvier 2016 a renforcé le concordat, car 
d'importantes spécifications de celui-ci sont désormais considérées comme une condition préalable à l'octroi de subventions.

Il est difficile de situer le système suisse des bourses d'études dans un contexte international, car les particularités des systèmes éducatifs nationaux sont généralement très marquées. En fin de compte, seuls les systèmes où les bourses d'études sont octroyées en fonction des ressources des parents et qui sont intégrés dans un système éducatif qui connaît également la formation professionnelle duale (comme en Allemagne et en Autriche) sont réellement comparables. Finalement, ce n'est pas tant le montant ou le taux de bourses d'études versées qui témoigne de la réussite d'un système éducatif national, mais uniquement la qualité et le succès de l'ensemble du système. À cet égard, le système éducatif suisse offre sans aucun doute d'excellentes performances en termes de qualité et un taux de réussite élevé au niveau post-obligatoire (au moins $95 \%$ d'obtention de diplômes du niveau secondaire II). Cependant, malgré tous les efforts consentis en matière de politique éducative au cours des dernières décennies, l'origine sociale reste de loin le facteur le plus important pour la réussite scolaire de l'individu. Des critères tels que la nationalité, la confession, le lieu de résidence et le sexe jouent également un rôle dans la détermination du niveau de scolarité, mais sont d'une importance secondaire par rapport au statut parental. L'ouverture relative du système éducatif et l'amélioration du niveau de l'éducation au cours des dernières décennies n'ont pas automatiquement conduit à une plus grande équité des chances; elles ont simplement poussé les seuils de sélection à un niveau supérieur. Si l'élargissement de l'accès aux formations supérieures se traduit par une perte d'exclusivité de leurs diplômes (p.ex. l'augmentation des taux de titulaires de la maturité), les inégalités liées à l'origine des étudiant·e·s au niveau de la réussite scolaire persistent dans une large mesure.

Charles Stirnimann

\section{Références}

Arbogast, O., Mühlemann, K., Schöbi, N., Zangger, P. \& Office fédéral de la statistique (2017). Bourses et prêts d'études cantonaux 2016. Neuchâtel: Office fédéral de la statistique.

Institut suisse des médias pour la formation et la culture coopérative sous mandat de la Conférence suisse des directeurs cantonaux de l'instruction publique (Éd.) (s.d.). Bourses d'études. https://boursesdetudes.educa.ch/fr

Stirnimann, C. (2010). Vom Sputnik-Schock zum Stipendienkonkordat: Anmerkungen zur schweizerischen Politik der Ausbildungsförderung. Basel : Historisches Seminar der Universität Basel.

\section{Flexibilisation des rapports de travail ${ }^{*}$}

Selon une ancienne définition de Martinez-Lucio et Blyton (1995), la flexibilité est la liberté de varier la quantité et la qualité de l'input de travail ou de l'adapter à la demande. Outre la flexibilisation dans le sens d'une adaptation de l'input de travail à la demande, il y a également une flexibilisation de l'input en rapport aux besoins des employéee-s. La question de la flexibilité sur le marché du travail se situe à trois niveaux différents. D'une part, le niveau individuel des employé·e·s : c'est là que les exigences et les souhaits de flexibilité sont combinés avec les besoins de sécurité. Les conditions-cadres de la flexibilité et de la sécurité sont définies au niveau macroéconomique ou politique. Les mots clés sont ici les rapports de travail atypiques, l'État social et le droit du travail. Au niveau méso, c'est-à-dire au niveau de l'entreprise, des modèles de flexibilité sont mis en œuvre dans les processus de négociation, qui répondent aux exigences des entreprises et qui devraient également répondre à celles des employé·e.s. Dans ce contexte, il est 
crucial de savoir qui décide quand et comment les employé·e·s doivent travailler. Flexibilité, sécurité et autonomie des employé-e.s sont dès lors étroitement liées. Selon le type de flexibilité choisi, différents degrés d'autonomie et de sécurité peuvent être attestés. La question se pose de savoir s'il n'existe pas des possibilités d'organisation du travail dans les entreprises qui combinent ces objectifs apparemment contradictoires: flexibilité, sécurité et autonomie. Pour répondre à cette question, nous devons examiner les formes de flexibilité qui s'offrent aux entreprises.

Une distinction est faite entre la flexibilité numérique interne (organisation du temps de travail, variation du temps de travail, variation de l'intensité du travail), la flexibilité numérique externe (embauche et licenciement, contrats de travail à durée déterminée, travail temporaire), la flexibilité fonctionnelle interne (reconversion, mutation, qualifications multiples, changement de tâches, délégation et responsabilité) et la flexibilité fonctionnelle externe (externalisation, réseaux d'entreprises, contrats d'entreprise/freelance).

Les formes de flexibilité ont des effets très différents en termes de sécurité et d'autonomie. Le travail temporaire (flexibilité numérique externe) garantit une autonomie nulle et une faible sécurité pour les employé·e·s, mais une grande flexibilité pour l'entreprise. L'embauche et le licenciement (flexibilité numérique externe) garantissent une faible autonomie et une faible sécurité pour les employé·e·s, mais une grande flexibilité pour l'entreprise. Les heures supplémentaires (flexibilité numérique interne) ont pour conséquence une autonomie réduite et une sécurité élevée, mais une flexibilité pour l'entreprise. Toutefois, certaines formes d'organisation du temps de travail, telles que les comptes épargne-temps ou les horaires mobiles (flexibilité numérique interne), sont particulièrement adaptées pour résoudre le dilemme entre la flexibilité, la sécurité et l'autonomie. En effet, une organisation intelligente du temps de travail permet aux entreprises d'adapter le volume de travail à la demande, mais aussi d'assurer un certain degré de sécurité et d'autonomie aux employé·e-s. Des horaires de travail flexibles (flexibilité numérique interne) peuvent ainsi combiner un niveau élevé de flexibilité, d'autonomie et de sécurité. La flexibilisation des horaires de travail est un outil qui peut satisfaire aussi bien les entreprises que les employéee-s. En Suisse, diverses formes d'assouplissement des règles relatives au temps de travail sont actuellement à l'étude, ce qui est interprété notamment comme flexibilisation. Les formes d'autodétermination de la durée et de la situation du temps de travail mises en œuvre pour les employé-e-s seront déterminantes. Celles-ci montreront si la nouvelle réglementation est potentiellement nocive pour ce groupe.

Une forme particulière de flexibilité numérique externe est liée au mot clé de la numérisation en général et de l'économie dite de plate-forme en particulier. Il s'agit d'une forme d'externalisation institutionnalisée (flexibilité fonctionnelle externe) dans laquelle des exploitants de plateformes tels que Booking. com, Amazon ou Uber servent simplement d'intermédiaires entre client.e-s et producteur-trice-s indépendant·e.s. Le lien souple entre le lieu, le rapport de travail et le produit conduit à une flexibilité nettement accrue. Cette forme particulière de flexibilité fonctionnelle externe est problématique du point de vue de la politique sociale, car la réglementation des conditions de travail repose essentiellement sur l'existence d'un lien étroit entre le lieu, le rapport de travail et le produit. Cela est notamment valable pour le recours massif aux travailleur-se-s indépendant.e.s en tant que producteur-trice-s, ce qui rend l'organisation institutionnelle et syndicale particulièrement difficile. En tant que nouvelles formes d'organisation avec un lien souple et une externalisation accrue, quasiment inhérente au modèle d'entreprise, les plateformes accélèrent la ten- 
dance déjà existante à s'écarter des rapports de travail normaux et intensifient ainsi les difficultés sociopolitiques, décrites ci-dessous, de gestion de la couverture sociale des travailleur-se-s précaires. Cette forme de flexibilisation fonctionnelle externe, c'est-à-dire les plateformes, représente la forme d'autonomie et de flexibilité la plus prononcée pour l'entreprise, mais on peut constater empiriquement que l'autonomie, la sécurité et la flexibilité des fournisseur.se's en pâtissent fortement. Une gestion routinière de cette attaque contre les organisations et les régulations du marché n'est pas en vue, alors même que l'idée largement répandue selon laquelle la numérisation est une évolution «naturelle» dont les conséquences doivent être acceptées ne semble pas compréhensible. Il s'agit plutôt de façonner la numérisation afin d'atténuer au moins ses conséquences sociopolitiques. Dans le cas d'Uber en Suisse, cela s'est déjà produit en partie. Dans cette affaire, la SUVA a décidé que les conducteur-trice-s d'Uber n'étaient pas des travailleur.se-s indépendant·e-s, mais qu'ils·elles devaient bénéficier d'une couverture sociale en tant que salarié.e-s. L'affaire est pendante devant le Tribunal fédéral.

Les modèles de flexibilité utilisés par les entreprises dépendent dans une large mesure de leur lieu d'implantation, car les pays et les secteurs économiques ont des cultures et des réglementations très différentes.

D'un point de vue social et sociopolitique, la flexibilisation des rapports de travail revêt une importance considérable pour trois raisons. Premièrement, le nombre de maladies psychiques a fortement augmenté en Suisse, notamment en raison de la surcharge de travail. En décembre 2016, $46 \%$ des rentes versées par l'AI avaient une cause psychologique. Cela peut être la conséquence directe du clivage qui existe entre le manque d'autonomie et une charge de travail élevée, et cela réduit aussi les chances d'atteindre l'âge AVS en bonne santé. Avec la mise en place d'une économie de plateforme plus forte offrant des conditions de travail nettement moins favorables, cette tendance pourrait s'accentuer nettement avec le temps si des réglementations nationales et supranationales ne sont pas introduites. Deuxièmement, la flexibilité axée exclusivement sur les besoins des entreprises n'est pas propice à l'équilibre entre vie professionnelle et vie privée. Les conséquences sociales et sociopolitiques vont de la décision de ne pas avoir d'enfants à la fragmentation des carrières professionnelles qui crée des lacunes dans la prévoyance vieillesse des personnes concernées, principalement des femmes. Ici aussi, les modèles de l'économie de plateforme sont pratiquement exemplaires pour ce qui est d'aggraver ces conséquences sociales et sociopolitiques. Citons par exemple les plateformes qui offrent des services (p.ex. des traductions) décomposés en petites parties aux prix les plus bas possibles. Troisièmement, les évolutions susmentionnées entraînent un ralentissement de l'évolution de la productivité en Suisse, ce qui n'est pas favorable à la prospérité globale de la Confédération. Une numérisation accrue pourrait même exacerber ce problème.

Sebastian Schief

\section{Références}

Kirchner, S. \& Beyer, J. (2016). Die Plattformlogik als digitale Marktordnung: Wie die Digitalisierung Kopplungen von Unternehmen löst und Märkte transformiert (WiSo-HH Working Paper 39). Hamburg: Universität Hamburg.

Martinez-Lucio, M. \& Blyton, P. (1995). Industrial relations and the management of flexibility: factors shaping developments in Spain and the United Kingdom. International Journal of Human Resource Management, 6(2), 271-291.

Schief, S. (2010). Does location matter? An Empirical Investigation of Flexibility Patterns in Foreign and Domestic Companies in Five European Countries. International Journal of Human Resource Management 21(1), 1-16. 


\section{Formation continue*}

La formation continue est le synonyme de formation des adultes, et peut être décrite comme un domaine de formation pluriel aux délimitations imprécises. Les personnes qui, après leur première phase de vie, constituée généralement de la scolarité, de la formation puis des études, participent à des offres de formation ou les organisent elles-mêmes, ont recours à la formation continue. Le domaine pédagogique de la formation continue est défini en Suisse dans la loi fédérale sur la formation continue (LFCo) et est assimilé à la formation non formelle, c'est-à-dire qu'il inclut toutes les offres de formation structurées en dehors du système de formation formel. Cela comprend les offres les plus variées, du cours pluriannuel à l'exposé unique en passant par les mesures du marché du travail et les cours de cadres, avec différentes durées, différents degrés de financement et de capacité de connexion avec le système éducatif public et le marché du travail.

La formation continue a toujours été étroitement liée à l'évolution économique, politique, technique et sociale d'une société. Les nouveautés économiques et techniques posent des exigences nouvelles aux adultes en matière de connaissances et de savoir-faire, ce qui va de pair avec leurs efforts de qualification correspondants. Les inégalités sociales se reflètent en général directement dans la participation à la formation continue. Dans le même temps, l'accès aux possibilités de formation pour les adultes est essentiel pour la cohésion sociale et pour les mouvements politiques. Ces rapports apparaissent à la fois dans la situation actuelle en Suisse et dans la rétrospective historique.

$\mathrm{Au} \mathrm{XVIII}^{\mathrm{e}}$ siècle déjà, la bourgeoisie naissante tentait de renforcer la formation continue sous le signe du patriotisme éclairé, dans le but de renforcer les mœurs et les connaissances de l'ensemble de la population. Avec la fin de l'ancien régime, les associations d'éducation populaire et les sociétés d'utilité publique se sont multipliées avec des projets de réformes économiques et politiques pour devenir des institutions de formation d'adultes. Créé dans le sillage de l'industrialisation, le mouvement ouvrier a aussi renforcé la formation continue grâce à son activité de formation motivée par la politique. Puis, les associations artisanales et commerciales ont commencé à proposer à leurs membres des offres de formation continue spécialisée. Au seuil du XXe siècle - tout comme plus tard dans les années 1970 -, l'étroite implication de la formation continue dans les mouvements politiques et sociaux de l'époque est devenue apparente: les mouvements de femmes et d'ouvriers ainsi que les mouvements chrétiens ont créé leurs propres instituts de formation. Les bouleversements politiques à l'échelle mondiale après la Première Guerre mondiale et la grève générale de 1918 en Suisse ont engendré une forte extension de la formation continue, entre autres parce que les cercles bourgeois espéraient qu'avec la création d'universités populaires, la classe ouvrière renoncerait à ses idées socialistes. Durant la deuxième moitié du XXe siècle, les offres orientées vers l'activité professionnelle ont gagné en importance et justifiaient un développement durable de la formation continue, favorisé notamment par la formation continue des chômeur.euse-s, mais surtout par les formations continues coûteuses destinées aux cadres et les activités déployées par la Confédération sur la base de la loi sur la formation professionnelle, par exemple l'offensive en matière de formation continue dans les années 1990.

La Confédération et les cantons, à quelques exceptions près, ont longtemps traîné les pieds en matière de formation continue. Pendant longtemps, la formation continue n'était pas réglée par une loi propre, mais apparaissait dans différentes lois spéciales. Notamment à la demande des fournisseur-euse-s, une loi fédérale sur la formation continue, réclamée de longue date, a enfin été inscrite dans un article de la nouvelle Constitution de 2006 et 
est entrée en vigueur le $1^{\text {er }}$ janvier 2017. Elle définit les principes de base et règle l'encouragement de l'acquisition et du maintien des compétences de base chez les adultes ainsi que les subventions fédérales allouées aux organisations de formation continue.

Cette loi est avant tout une loi-cadre et laisse à l'avenir aussi le soin à des lois spéciales de définir des réglementations plus approfondies. Ses principes de base renforcent le principe de concurrence marchande entre les fournisseur.euse-s. Comme le suggère le principe de la responsabilité de la formation continue, cette dernière est avant tout considérée comme un investissement professionnel individuel ou une gestion personnelle du temps libre. La loi sur la formation continue stipule en premier lieu la responsabilité individuelle de chaque adulte, puis rappelle aussi la responsabilité de l'employeur-euse, et en dernier lieu seulement la responsabilité de l’État.

Contrairement à d'autres pays, en Suisse la formation des adultes/formation continue ne s'établit que peu à peu comme champ d'études des sciences de l'éducation; de ce fait, il n'existe presque aucune recherche spécifique et continue en la matière, et la professionnalisation académique est encore peu développée. En parallèle à l'extension de l'offre au XX siècle, des structures associatives autour de la formation continue se sont développées. En 1951, la création de la Fédération suisse pour la formation continue (FSEA) réunissant les fournisseur.euse-s de formation continue a été déterminante. L'association s'est engagée fortement pour la création de structures et la professionnalisation de la formation continue, et le fait encore à ce jour.

Bien qu'en comparaison internationale, la Suisse présente dans l'ensemble un taux de participation élevé à la formation continue, cette même participation révèle de nettes différences en fonction de l'origine, du niveau de formation, de la classe sociale et du sexe. L'idée qu'une personne qui, dans son enfance et au début de l'âge adulte, n'a pas obtenu les diplômes nécessaires puisse rattraper ce retard est illusoire, et ce, depuis les débuts de la formation continue structurée. Au contraire, la formation continue tend à accentuer les inégalités sociales, car le niveau de formation formel et la position dans la vie active sont des facteurs centraux pour la participation à une formation continue. Celle-ci est surtout motivée par des raisons professionnelles. En Suisse, les personnes qui ne disposent pas d'une formation post-obligatoire sont fortement désavantagées dans le cadre de la formation continue. En plus de cela, la participation à la formation continue des ressortissants étrangers ayant fréquenté l'école en Suisse est nettement inférieure à celle des Suisses ainsi qu'à celle des ressortissant·e·s étranger-ère·s n'ayant pas fréquenté l'école en Suisse. Comme la formation continue est souvent (co)financée par l'employeur-euse, des différences typiques pour le marché du travail apparaissent aussi dans ce domaine. Ainsi, les employeur.euse-s accordent une participation aux coûts de la formation continue nettement plus élevée pour les hommes que pour les femmes, qui assument souvent elles-mêmes les frais.

Dans l'ensemble, aujourd'hui en Suisse, la formation continue est moins considérée comme un domaine éducatif relevant de la responsabilité publique, que comme un marché. Pourtant, en parallèle avec les formations continues professionnelles et d'entreprise, il a toujours existé des offres de formation citoyenne et politique ainsi que des offres financées par l'État. Dans ce contexte, les politiques sociales ont un lien indirect avec la formation continue. On peut le voir surtout dans les questions relatives à l'encouragement des compétences de base dans le cadre de la lutte contre la pauvreté ainsi que dans l'engagement en faveur d'un accès moins sélectif à la formation continue.

\section{Katrin Kraus}




\section{Références}

Dominicé, P. \& Finger, M. (1990). L'éducation des adultes en Suisse. Zürich : Pro Helvetia.

Kraus, K. (2015). Ein Beitrag zur Geschichte der Erwachsenenbildung in der Schweiz. In K. Kraus \& M. Weil (Hrsg.), Berufliche Bildung: historisch - aktuell - international (S. 76-83). Paderborn : Eusl-Verlagsgesellschaft.

Schläfli, A. \& Sgier, I. (2015). Weiterbildung in der Schweiz: Länderportrait (3., vollst. überarb. Aufl.). Bielefeld : Bertelsmann.

\section{Formation professionnelle*}

En Suisse, environ les deux tiers d'une classe d'âge suivent une formation professionnelle de base de deux à quatre ans. La forme la plus courante de ce type de formation est l'apprentissage «dual» de trois à quatre ans, qui se clôture par un certificat fédéral de capacité (CFC). Une forme réduite à deux ans de la formation professionnelle de base conduit à l'obtention d'une attestation fédérale de formation professionnelle (AFP). Les personnes diplômées porteuses d'un CFC ont accès aux formations dans les hautes écoles spécialisées par le biais de la maturité professionnelle. En outre, elles disposent de nombreuses possibilités de formation continue dans le domaine de la formation professionnelle supérieure.

En Suisse, la formation professionnelle est réglementée au niveau fédéral depuis 1933 par la loi sur la formation professionnelle, révisée à trois reprises (1963, 1978 et 2004). Tandis que la Confédération est responsable de la gestion stratégique et du développement de la formation professionnelle, les cantons et les «organisations du monde du travail» (OrTra: associations professionnelles, de branche, patronales et syndicales) sont, quant à eux, responsables de l'exécution et de la mise en œuvre. Les contenus des formations sont définis par les OrTra et validés par les autorités fédérales sous la forme de règlements et d'ordonnances spécifiques à l'apprentissage.

À l'heure actuelle, des formations professionnelles de base sont dispensées dans environ 230 apprentissages d'une durée de trois à quatre ans, lesquels sont sanctionnés par un certificat fédéral de capacité. Il existe en outre des formations professionnelles de base de deux ans dans une bonne cinquantaine d'apprentissages qui se terminent par une AFP. La forme de formation la plus courante est l'enseignement dit «dual». Ce système est qualifié de dualiste parce qu'il se déroule principalement sur deux lieux d'apprentissage: l'entreprise formatrice (formation pratique) d'une part et l'école professionnelle (formation scolaire) d'autre part. Ces deux lieux d'apprentissage sont complétés par des cours interentreprises (troisième lieu d'apprentissage). Les apprenti.e.s passent en moyenne trois à quatre jours par semaine dans l'entreprise formatrice et un à deux jours dans l'école professionnelle. Le nombre de cours dispensés dans les écoles professionnelles varie considérablement selon l'apprentissage, entre 350 et plus de 800 par an. Les apprenti-e.s concluent généralement un contrat d'apprentissage avec l'entreprise formatrice et perçoivent un salaire («salaire d'apprenti.e») qui varie entre 300 et 2300 francs par mois en fonction de la profession et de l'année de formation. Environ $10 \%$ des apprenti.e.s reçoivent une formation professionnelle de base dans une école professionnelle à temps complet, plus fréquemment en Suisse romande et en Suisse italienne qu'en Suisse alémanique.

Après l'obtention d'un CFC, les diplômé·e-s entrent directement sur le marché du travail ou poursuivent leurs études dans l'enseignement tertiaire. L’accès aux hautes écoles (spécialisées) est accordé par le biais de la maturité professionnelle acquise en parallèle (MP 1) ou à la suite (MP 2) de la formation professionnelle de base. Les diplômé·e·s d'un CFC sont également libres de choisir parmi les programmes de formation professionnelle supérieure. La forme 
la plus répandue de formation professionnelle supérieure consiste dans les brevets fédéraux (examens professionnels), dont environ 14000 sont obtenus chaque année. En règle générale, ils sont acquis après quelques années d'expérience professionnelle afin d'approfondir les connaissances spécialisées dans le domaine concerné et/ou de se préparer aux fonctions de gestion. Les diplômes fédéraux et des écoles supérieures sont d'autres diplômes de la formation professionnelle supérieure.

Les coûts de la formation professionnelle de base sont estimés à environ six milliards de francs par an, soit environ 25000 francs par personne en formation. Les financements publics couvrent un peu plus de la moitié des dépenses (principalement les coûts des écoles de formation professionnelle), $44 \%$ des dépenses étant consacrées à la formation en entreprise selon les estimations. Les salaires des apprenti-e.s sont estimés représenter environ la moitié des dépenses consacrées à la formation en entreprise. D’après des études coûts-bénéfices, la majorité des entreprises formatrices tirent généralement un avantage net de la formation en apprentissage. Cependant, seulement un peu moins d'un cinquième des entreprises en Suisse forment des apprenti.e.s.

La sélection des apprenti-e.s au passage entre le degré secondaire I et II est un processus complexe au cours duquel, outre la situation du marché de l'apprentissage évoquée plus haut, un grand nombre de facteurs de sélection interagissent. La formation professionnelle de base constitue un ensemble extrêmement hétérogène, fortement segmenté et hiérarchisé par profession et par secteur. Les apprentissages exigeants du point de vue scolaire et pratique et offrant de bonnes perspectives d'évolution au niveau tertiaire ou sur le marché du travail se distinguent par des apprentissages avec des exigences plutôt modestes et un faible potentiel de développement. Le degré d'exigence du type d'école fréquentée au niveau secondaire I (exigences élémentaires ou étendues) est l'un des facteurs qui détermine le degré d'exigence des places auxquelles les candidats et les candidates à l'apprentissage peuvent prétendre, indépendamment de la performance scolaire obtenue. En plus des résultats, certains facteurs - par exemple les qualités sur le marché du travail (ponctualité, apparence, caractéristiques «comportementales») - et caractéristiques sociodémographiques - par exemple le statut social, le sexe, le contexte migratoire ou l'âge jouent également un rôle important dans la sélection des apprenti·e·s.

Près d'un quart des candidat·e.s à la formation professionnelle de base ont recours, après leur scolarité obligatoire, à une solution transitoire dans un premier temps. Il s'agit majoritairement d'une offre de passerelle scolaire d'un an. Comme le montre l'étude longitudinale TREE, cette forme de discontinuité lors de la transition vers le niveau secondaire II augmente le risque de rester sans titre de fin de formation post-obligatoire par rapport à une «entrée directe».

Dans le discours de la politique éducative sur la formation professionnelle duale, la proximité de celle-ci avec le marché du travail et la pratique, ainsi que sa capacité à intégrer les jeunes ayant des difficultés scolaires sont toujours soulignées comme des facteurs de réussite. En effet, en comparaison internationale, l'absorption sur le marché du travail des personnes diplômées d'une formation professionnelle est fortement enviable - mesurée, par exemple, en termes de taux d'emploi et de chômage. Cependant, la thèse souvent formulée en politique éducative selon laquelle ce succès est le résultat direct et immédiat de la formation professionnelle duale n'est pas soutenable dans sa forme abrégée. D'une part, la situation exceptionnellement favorable du marché du travail en Suisse est également imputable à des facteurs économiques structurels qui n'ont rien à voir avec la formation professionnelle. D'autre part, il apparaît clairement que la réussite de l'insertion sur le marché du travail 
à la suite d'une formation professionnelle est également largement liée à une forte segmentation professionnelle et sectorielle du marché du travail.

L'un des problèmes structurels permanents de la formation professionnelle duale réside dans sa dépendance au marché et, partant, dans la volatilité de l'offre de formation. La forte influence des facteurs économiques et la volonté d'une minorité relativement petite d'entreprises basées en Suisse d'offrir une formation professionnelle ont pour effet que les possibilités individuelles d'accès à la formation professionnelle de base dépendent fortement des vicissitudes de l'activité économique et de la démographie. En période de pénurie d'offres surtout, cela augmente le risque d'échec à l'entrée ou de sortie précoce du système de formation (professionnelle), en particulier pour les jeunes en difficultés scolaires ou sociales.

Un autre problème est le choix particulièrement genré des parcours professionnels. Selon l'Office fédéral de la statistique, dans sept apprentissages sur huit, il y a moins d'un tiers de jeunes hommes, respectivement de jeunes femmes et dans environ un quart de tous les apprentissages, les femmes et les hommes se retrouvent entre elles ou entre eux.

Dans le segment supérieur de la qualification professionnelle, le déséquilibre entre l'offre et la demande est considérable depuis un certain temps déjà. Dans le contexte de l'accroissement rapide de la participation à la formation au niveau tertiaire, l'accès basé sur la formation professionnelle aux hautes écoles (spécialisées) via la maturité professionnelle reste fortement limité. Le taux de maturité professionnelle est d'environ $15 \%$ et seulement la moitié environ des diplômés et diplômées de la maturité professionnelle obtient un diplôme d'une haute école. Parallèlement, le marché du travail suisse recrute chaque année des dizaines de milliers de personnes actives avec un diplôme étranger de formation supérieure.

Thomas Meyer

\section{Références}

L'étude TREE. Transitions de l'École à l'Emploi. http://www.tree.unibe.ch/ergebnisse/ publikationen/

Maurer, M. \& Gonon, P. (Hrsg.) (2013). Herausforderungen für die Berufsbildung in der Schweiz: Bestandesaufnahme und Perspektiven. Bern: hep. Secrétariat d'État à la formation, à la recherche et à l'innovation (Éd.) (2017). La formation professionnelle en Suisse: faits et données chiffrées. Berne: Secrétariat d'État à la formation, à la recherche et à l'innovation.

\section{Formation professionnelle pour les personnes en situation de handicap*}

La formation professionnelle est une condition essentielle pour participer à la vie active. À cet égard, la loi sur l'égalité pour les handicapés (LHand) apporte une contribution importante en définissant des conditions-cadres élémentaires destinées à aider les personnes handicapées à se former et se perfectionner. L'assurance-invalidité (AI), quant à elle, est l'instance décisive pour financer la formation professionnelle des personnes handicapées. La grande majorité des mesures professionnelles financées par l'AI concerne la formation professionnelle de base, sans toutefois exclure la formation de niveau tertiaire.

L'introduction de la loi fédérale de 1959 sur l'assurance-invalidité constitue un jalon décisif en matière de formation professionnelle des personnes handicapées. Cette loi prescrit la participation financière de l'AI à la formation professionnelle. Une pierre angulaire a ainsi été posée en reconnaissant désormais la capacité des personnes handicapées à se former et en ancrant cette conception dans la loi. Cette conception est en rupture par rapport aux pra- 
tiques du passé, en particulier dans les cas de déficiences cognitives et psychiques graves. Par le passé et selon la tradition, les personnes handicapées suivaient une formation professionnelle initiale dans des centres de formation spécialisés du deuxième marché du travail (ou marché du travail complémentaire) dont les origines remontent à l'entre-deux-guerres. En passant d'un institut versant des rentes à une agence d'insertion, l'assurance-invalidité exige de plus en plus que les personnes handicapées soient formées plus près du (premier) marché du travail afin d'accroître leurs possibilités d'insertion professionnelle au terme de la formation professionnelle. Dans ce contexte, selon l'Office fédéral des assurances sociales (OFAS), le nombre de bénéficiaires de mesures professionnelles pour une formation professionnelle initiale n'a cessé d'augmenter (2010: 8719 personnes, 2015: 11058 personnes). L'orientation accrue vers le marché du travail qui en résulte et la structure duale, caractéristique de la Suisse, de la formation professionnelle, c'est-à-dire la combinaison d'une formation scolaire et d'une formation pratique dans l'entreprise, favorisent la participation dans le monde professionnel. Le changement de paradigme dans la prise en charge des personnes handicapées, formalisé dans la Convention des Nations Unies relative aux droits des personnes handicapées, et le désir des personnes handicapées de participer au marché du travail ordinaire, favorisent l'application de la Supported Education, c'est-à-dire une formation professionnelle accompagnée basée sur le concept d'action du Supported Employment.

En comparaison européenne, on peut dire que la Suisse dispose d'un secteur institutionnel fort et bien développé. Les institutions historiquement responsables de la formation professionnelle des personnes handicapées jouent, encore aujourd'hui, un rôle important. Elles sont de plus en plus orientées vers le marché ordinaire du travail. Cependant, le système de formation structurellement différencié et en même temps très sélectif de la Suisse entraîne des désavantages à différents seuils, ce qui limite la formation professionnelle inclusive. Par contre, la formation professionnelle en alternance (duale) constitue un bon point de départ pour l'insertion professionnelle, y compris pour les personnes en situation de handicap.

La révision de la loi sur la formation professionnelle, en vigueur depuis 2004, touche de manière significative les personnes handicapées: dans le cadre de cette révision, les formations élémentaires cantonales ont été supprimées au profit d'une nouvelle filière de formation professionnelle initiale de deux ans aboutissant à une Attestation fédérale de formation professionnelle (AFP). Les nouvelles formations avec AFP sont un acquis pour certain.e.s jeunes, car elles permettent à ceux et celles qui ne répondent pas (encore) aux exigences de la formation professionnelle avec Certificat fédéral de capacité (CFC) d'obtenir une bonne formation professionnelle de base et une qualification standardisée. D'un autre côté, les jeunes plus faibles échouent en raison des exigences des formations AFP nettement plus élevées que celles des formations élémentaires antérieures. L'association nationale de branche des institutions pour personnes avec handicap, INSOS Suisse, a partiellement comblé cette lacune avec son dispositif de formation pratique (FPr), lancé en 2007 et destiné aux jeunes en situation de handicap. Ce mode de formation flexible est parfaitement adapté à un groupe cible hétérogène. À ce propos, INSOS a élaboré un examen permettant d'attester des compétences des personnes ayant suivi le dispositf FPr ainsi que des jeunes qui ont échoué à la procédure de qualification AFP. Cet instrument est intitulé «Examen des compétences individuelles pour les jeunes sans qualification professionnelle». Le dispositif FPr doit faciliter l'accès au marché du travail. En même temps, il s'agit d'une forme de reconnaissance par les associations professionnelles 
et les employeur·euse-s. Au niveau fédéral, cependant, la formation pratique selon INSOS n'est pas reconnue.

Un acquis majeur est la compensation des désavantages, ancrée dans la LHand et qui s'applique à tous les niveaux de formation. Elle permet d'éliminer un désavantage résultant d'un handicap grâce à des mesures ciblées et individuelles au cours de la formation professionnelle ou lors des examens. D'autres instruments importants existent pour les personnes handicapées: des cours de soutien dans les écoles professionnelles, le soutien individuel et ciblé dans le cadre de la formation AFP ainsi que la possibilité de prolonger une formation professionnelle si nécessaire.

Suite à la réforme de la péréquation financière et de la répartition des tâches entre la Confédération et les cantons (RPT), la responsabilité pour les écoles spécialisées et les ateliers protégés a été transmise, en 2008, de l'Office fédéral des assurances sociales aux administrations cantonales. De nouvelles interfaces ont ainsi été créées, confrontant les jeunes en situation de handicap et leurs parents à de nouveaux défis lors de la transition de l'école à la formation professionnelle. Les difficultés sont particulièrement importantes pour les jeunes ayant des besoins spécifiques qui fréquentent l'école ordinaire. La transition vers une formation professionnelle de ce nouveau groupe cible est complexe: de nombreuses instances sont concernées, et les enseignant·e-s doivent faire en sorte que le choix de la profession soit adapté aux besoins spécifiques de ces jeunes. La situation se complexifie encore davantage si les jeunes ont besoin d'aide mais n'ont pas droit aux prestations de l'assurance-invalidité. Dans le cadre de la $7^{\text {e }}$ révision de l'AI, des mesures sont à l'étude afin d'optimiser la transition de l'école à la formation professionnelle et ceci dans le cadre de la scolarité obligatoire déjà.

Les associations de personnes handicapées critiquent le fait que les jeunes avec un besoin de soutien important soient totalement exclus de la formation professionnelle. Bien que la grande majorité des jeunes aient accès à la formation professionnelle, les évolutions de cette dernière ajoutées aux transformations du marché du travail accroissent les pressions exercées sur les jeunes les plus faibles. La participation professionnelle des personnes handicapées passe par l'accès à la formation professionnelle. Conformément au changement de paradigme dans le domaine de l'assistance aux personnes handicapées, qui ne considère pas le «handicap» comme la caractéristique individuelle d'une personne, mais tient compte des contraintes contextuelles, les mesures de soutien devraient être moins ciblées sur la personne, mais inclure le contexte dans son ensemble et de manière adéquate. Parmi les facteurs importants qui contribuent au succès durable de la participation professionnelle, on peut notamment citer le soutien à long terme adapté aux besoins de l'individu, les adaptations des lieux de formation ou de travail, l'accompagnement de l'employeur.euse et la solidarité des proches.

\section{Susanne Aeschbach}

\section{Références}

Centre suisse de services Formation professionnelle, orientation professionnelle, universitaire et de carrière (Éd.) (2015). Compensation des désavantages pour personnes handicapées dans la formation professionnelle: Rapport. Berne: CSFO.

Egger, T., Stutz, H., Jäggi, J., Bannwart, L., Oesch, T., Naguib, T. \& Pärli, K. (2015). Évaluation des Bundesgesetzes über die Beseitigung von Benachteiligungen von Menschen mit Behinderung - BehiG. Bern : Büro für arbeits- und sozialpolitische Studien BASS.

Sempert, W. \& Kammermann, M. (2010). Evaluation Pilotprojekt Praktische Ausbildung (PrA) INSOS (BSV Forschungsbericht Nr. 7/10). Bern: Bundesamt für Sozialversicherungen. 


\section{Formation tertiaire*}

La formation du degré tertiaire comprend, d'une part, les formations dans les hautes écoles universitaires (HEU) - dont font partie les écoles polytechniques fédérales (EPF) -, les hautes écoles spécialisées (HES) et les hautes écoles pédagogiques (HEP) et, d'autre part, les formations dans les écoles professionnelles supérieures (ES) et celles qui préparent à des examens professionnels et professionnels supérieurs. Le système des hautes écoles au sens strict comprend les universités et les hautes écoles spécialisées et pédagogiques qui, ensemble, réunissent près de $80 \%$ de l'ensemble des étudiant-e-s de l'enseignement tertiaire. Sur ce nombre d'étudiant·e.s, $60 \%$ fréquentent une haute école universitaire, plus de $30 \%$ une haute école spécialisée et un peu moins de $10 \%$ une haute école pédagogique. Les trois types de hautes écoles délivrent des diplômes académiques (Bachelor et Master et, dans le cas des HEU, également le doctorat). Les écoles professionnelles supérieures ainsi que les examens professionnels et professionnels supérieurs font partie de la formation professionnelle supérieure qui représente des filières d'enseignement plus courtes, à vocation professionnelle. Ces filières conduisent à un brevet ou à un diplôme professionnel fédéral et, pour les écoles supérieures, à un diplôme.

Les processus de modernisation et les progrès technologiques ont considérablement accru la demande d'enseignement supérieur. En Suisse, le ratio de l'enseignement tertiaire (y compris la formation professionnelle supérieure) parmi la jeune génération (25-34 ans) est aujourd'hui légèrement inférieur à $50 \%$ (le ratio des hautes écoles est légèrement inférieur à 30\%). Avec le Canada, les États-Unis, la Grande-Bretagne et les pays scandinaves, la Suisse se trouve dans le haut du classement. La différenciation du système tertiaire en un secteur de hautes écoles avec des universités et des hautes écoles spécialisées et un secteur de formation professionnelle supérieure offre de nombreuses options aux personnes ayant suivi une formation duale (un apprentissage). Ce contexte institutionnel explique pourquoi la Suisse atteint, en comparaison internationale, un taux global d'enseignement tertiaire élevé malgré une proportion relativement faible de gymnasien.ne.s.

La tendance à la tertiarisation s'observe dans la plupart des pays de l'OCDE. Cette évolution est interprétée d'une part comme une réponse aux besoins du marché du travail en main-d'œuvre hautement qualifiée, mais aussi comme le résultat d'une dynamique inhérente au système de formation visant des qualifications de plus en plus élevées.

La différenciation du système des hautes écoles a eu lieu relativement tardivement en Suisse. En 1995, les écoles de la formation professionnelle supérieure ont été regroupées en hautes écoles spécialisées régionales de niveau tertiaire, ceci dans le cadre d'un processus de réformes à grande échelle basé sur la nouvelle loi fédérale sur les hautes écoles spécialisées (LHES). C'est à ce moment que les HES ont été dotées d'un mandat de recherche. Cette transformation a été déclenchée, d'une part, par la crainte que les titres de formation professionnelle supérieure ne soient plus reconnus à l'étranger et, d'autre part, par la conviction de pouvoir contrecarrer la pénurie attendue de spécialistes hautement qualifié·e·s en créant des hautes écoles spécialisées à vocation professionnelle. Le développement des hautes écoles spécialisées, intervenu principalement dans le secteur de la formation professionnelle et largement modulé par ces cercles, a finalement conduit à la structure binaire du système des hautes écoles telle qu'on la connaît aujourd'hui : les hautes écoles spécialisées sont formellement égales aux universités en termes de mandat de recherche, de reconnaissance mutuelle ou de titres académiques des deux premiers cycles d'études, sans pour autant se 
situer sur un pied d'égalité avec les universités en termes de statut social et de réputation.

Dans un deuxième temps, avec la révision partielle de la LHES en 2005, les domaines de la santé, du travail social et de l'art sont passés sous compétence fédérale et ont été intégrés dans les hautes écoles spécialisées. Le travail social est aujourd'hui enseigné dans les hautes écoles spécialisées, à l'université de Fribourg et dans les écoles supérieures. Les hautes écoles pédagogiques ont été fondées à la fin des années 1990 sur le même principe que les hautes écoles spécialisées, mais relèvent exclusivement de la compétence des cantons en tant que nouvelles hautes écoles pour la formation du corps enseignant de l'école obligatoire. Un grand nombre de petites écoles normales locales (Lehrerseminar en Suisse germanophone) ont été transférées dans les hautes écoles nouvellement créées. Formellement, les HEP sont affectées au secteur des hautes écoles spécialisées; dans les faits, cependant, elles sont traitées comme une catégorie distincte de haute école spécialisée.

Sur la base du nouvel article constitutionnel qui engage la Confédération et les cantons à assumer conjointement la responsabilité de la qualité et de la perméabilité du paysage de formation et à coopérer dans le domaine des hautes écoles, la loi sur l'encouragement et la coordination des hautes écoles (LEHE) a été créée en 2011 en tant que cadre juridique pour la nouvelle gouvernance des hautes écoles. Cette loi, entrée en vigueur en 2015, régit les objectifs et principes de la coordination assumée conjointement. Elle crée un domaine de hautes écoles homogène au plan national, dans lequel des critères communs (p.ex. les coûts de référence pour le financement de base et les taux de contribution fédérale) s'appliquent, pour la première fois, à tous les types de haute école, tout en conservant une diversité des profils (p.ex. accès différents, cursus différenciés, diplômes spécifiques). En s'appuyant sur la LEHE et sur le concordat intercantonal sur les hautes écoles, la Confédération et les cantons ont réglementé leur coopération et créé de nouveaux organes politiques communs pour les hautes écoles: la Conférence suisse des hautes écoles, la Conférence des recteurs des hautes écoles suisses (avec trois chambres spécifiques pour chaque type, les HEU, les HES et les HEP) et le Conseil suisse d'accréditation.

La création de filières de maturité spécialisée et de maturité professionnelle a diversifié les formations préparant aux études en haute école. L'accès aux hautes écoles est désormais possible avec une maturité professionnelle, ce qui favorise en particulier les diplômé·e·s d'une formation professionnelle initiale. Aujourd'hui, la maturité professionnelle constitue la porte d'entrée ordinaire dans les hautes écoles spécialisées, alors que la maturité gymnasiale permet d'accéder aux hautes écoles universitaires sans examen. L'examen complémentaire «Passerelle maturité professionnelle - haute école universitaire» permet à un petit nombre de titulaires d'une maturité professionnelle d'accéder à l'université. Inversement, un certain nombre de titulaires d'une maturité gymnasiale commence une formation dans une haute école spécialisée après avoir effectué un stage en entreprise. Bien que ces innovations institutionnelles aient rendu le système des hautes écoles plus perméable dans son ensemble, la proportion d'étudiant.e-s qui entrent dans une haute école universitaire par une voie alternative reste très faible (2 à $3 \%$ ).

L'accès à la formation tertiaire et l'obtention d'un diplôme dépendent fortement de l'origine sociale. En Suisse, les enfants issus de familles d'universitaires ont une fois et demie plus de chances d'achever leurs études au niveau tertiaire que le reste de la population. Toutefois, dans la plupart des pays européens, la disparité sociale est nettement plus grande, avec un ratio allant de 2 à 3 . La sélectivité sociale de l'accès aux hautes écoles en Suisse se reflète avant tout dans le choix des types de hautes écoles: les enfants issus de familles d'univer- 
sitaires sont plus de deux fois plus représentés dans les hautes écoles universitaires que les enfants issus de familles non universitaires. Le taux de réussite académique se situe depuis des années à environ $70 \%$; il n'a guère augmenté dans le système de Bologne. Aujourd'hui, les étudiant·e-s sont même moins nombreux à obtenir un diplôme de deuxième cycle (Master) que dans l'ancien système. La proportion d'étudiant.e.s dans les hautes écoles universitaires qui entreprennent de suivre un Master après le Bachelor est de $80 \%$ en moyenne.

Le taux d'emploi des diplômé·e-s d'une haute école se situe entre $85 \%$ et $95 \%$ un an après l'obtention du diplôme. Cependant, toutes les personnes actives n'exercent pas une activité nécessitant un diplôme d'une haute école. Si l'on tient compte du fait que toutes et tous les titulaires d'une maturité ne commencent pas des études dans une haute école et n'obtiennent pas nécessairement leur diplôme, on peut dire que sur la cohorte totale de titulaires d'une maturité, seuls les deux tiers environ trouvent ensuite un emploi en adéquation avec leur formation. La modularisation et les filières d'études en trois cycles du système de Bologne n'ont guère fait évoluer cette situation. Compte tenu du faible taux d'obtention d'une maturité en Suisse, il s'agit là d'un résultat qui donne à réfléchir, et la réduction du nombre d'abandons des études reste un enjeu pour la politique de formation.

\section{Stefan Denzler}

\section{Références}

Becker, R., Der Übergang ins Hochschulstudium Prozesse und Mechanismen am Beispiel der deutschen Schweiz. In M. M. Bergman, S. Hupka-Brunner, T. Meyer \& R. Samuel (Hrsg.), Bildung - Arbeit - Erwachsenwerden: ein interdisziplinärer Blick auf die Transition im Jugend- und Erwachsenenalter (S. 305-331). Wiesbaden: Springer.

Weber, K., Tremel, P. \& Balthasar, A. (2010). Die Fachhochschulen in der Schweiz : Pfadabhängigkeit und Profilbildung. Swiss Political Science Review 16(4), 687-713.
Wolter, S. C., Cattaneo, M. A., Denzler, S., Diem, A., Hof, S., Meier, R. \& Oggenfuss, C. (2018). L'éducation en Suisse: rapport 2018. Aarau: Centre suisse de coordination pour la recherche en éducation.

\section{Genre (inégalité)}

Les études (de) genre se sont développées dans le sillage des mouvements féministes des années 1970 et, plus généralement, dans un contexte de mise en question des inégalités sociales et des systèmes de justifications des différences supposées (de qualités, de rôles, de droits, etc.) référant à la biologie; en déconstruisant les évidences sociales, elles ont notamment permis, et permettent encore, de mettre au jour les biais sexistes et androcentriques des politiques sociales.

L'un des effets des luttes féministes est l'inscription du principe de l'égalité entre les sexes dans la Constitution suisse (1981). Ce principe a conduit à réviser un droit basé sur la différenciation sexuée des droits et des devoirs. C'est désormais le principe d'égalité formelle entre femmes et hommes qui est la règle. Cette égalité formelle ne garantit toutefois pas l'égalité de faits (ou matérielle) qui n'est pas réalisée malgré les dispositifs de la loi fédérale sur l'égalité entre femmes et hommes de 1996. La politique sociale helvétique illustre parfaitement ce hiatus propre aux sociétés professant un discours de l'égalité tout en restant fondées sur une division hiérarchique des sexes.

L'inscription de l'égalité formelle dans la Constitution a obligé le politique à revoir le modèle normatif à la base de plusieurs dispositifs de la sécurité sociale (homme gagne-pain/ femme au foyer), qui ne donnait aux épouses qu'un droit dérivé de celui de leur mari (c'est le cas de l'AVs jusqu'en 1996). Un modèle individualiste tend aujourd'hui à prévaloir dans les régimes de retraites, les cotisations entre époux-épouses étant partagées à parts 
égales durant les années de mariage, et les époux-épouses ayant des droits individuels aux prestations de la sécurité sociale, ce qui semble plus égalitaire. Toutefois, les politiques sociales demeurent androcentriques, car différentes protections sociales se fondent sur l'emploi (qui plus est sur la norme masculine de l'emploi - travail rémunéré, à temps plein et continu entre la fin de la formation et la retraite), défavorisant de fait les personnes soumises à d'autres normes, par exemple liées aux rôles familiaux et domestiques. Cela s'exprime de manière flagrante dans le domaine de la division sexuée du travail. En Suisse, le travail domestique non rémunéré, conséquent et nécessaire à la société, est très majoritairement réalisé par les femmes et très mal reconnu par les politiques sociales: contrairement à l'emploi, il n'est pas spécifiquement protégé. En cas d'accident, par exemple, les personnes s'occupant à temps plein de leur famille sont protégées par l'assurance-maladie et non par l'assurance-accidents, ce qui signifie qu'elles doivent payer une franchise et une quotepart, et qu'elles ne reçoivent pas d'indemnités journalières. Leur droit à l'assurance-chômage n'existe qu'en fonction de l'activité professionnelle exercée avant qu'elles se «consacrent» à l'éducation de leur(s) enfant(s) et, en cas de séparation, de divorce ou de décès du conjoint, elles doivent prouver, pour avoir un droit d'ailleurs très réduit aux indemnités (90 indemnités au maximum), qu'elles sont «contraintes» de reprendre un emploi pour faire face à leur nouvelle situation.

Les inégalités de genre dans l'accès aux assurances sociales ne disparaissent pas totalement lorsque les femmes occupent un emploi rémunéré, et ceci en raison de la configuration même de l'emploi féminin; dans le modèle de genre helvétique en effet, les femmes réduisent fortement leur temps d'emploi lors de la mise en couple et de l'arrivée d'un·e enfant, ce qui a des conséquences sur leur employabilité. L’emploi féminin en Suisse est caractérisé par une forte ségrégation horizontale et verticale, par un très haut taux de temps partiel et par d'autres modalités de travail fortement féminisées comme le travail sur appel ou temporaire. À travail égal, leurs salaires restent inférieurs à ceux des hommes. Or, les indemnités des assurances sociales sont calculées en fonction du salaire, qu'elles visent à remplacer : occuper un emploi à temps partiel, irrégulier, mal payé a dès lors des conséquences négatives sur ces indemnités.

Ces inégalités de genre apparaissent dans toute leur évidence lors de deuils ou de séparations, puisque les femmes se retrouvent beaucoup plus fréquemment que les hommes dans des situations de pauvreté, avec des prestations minimales et socialement stigmatisées (être à l'assistance, ce n'est pas être à l'assurance), et ceci sur le long terme en raison de carrières peu investies (périodes d'emploi entrecoupées, temps partiels, promotions plus difficiles, etc.) et des difficultés qu'elles rencontrent pour se remettre sur le marché du travail. Les inégalités de genre découlant de l'investissement dans l'emploi apparaissent également dans les rentes de vieillesse; à l'AVS s'ajoutent en effet en Suisse, en raison du système des «trois piliers ", des rentes proportionnelles aux cotisations et qui dépendent donc de la carrière. Le genre (comme la classe) rend donc le système de retraite suisse très inégalitaire. Aussi, une analyse de genre des politiques sociales suisses actuelles tend à montrer, pour reprendre une formulation de Christine Delphy, que «dans une situation d'inégalité, un traitement égal est discriminatoire».

Des traitements différenciés en fonction du sexe ont également lieu dans le cadre de la mise en œuvre des dispositifs. Le personnel de l'État social peut en effet être amené à adapter un dispositif à une situation en fonction d'assignations sociales de sexe ou de constats pragmatiques. Par exemple, selon les normes de la Conférence suisse des institutions d'action sociale (CSIAS) l'aide sociale prévoit des excep- 
tions à l'obligation d'emploi dans les cas où le ou la bénéficiaire est en charge d'un·e jeune enfant pour autant que le bien de l'enfant soit en vue. Or, ce droit formellement neutre n'est pas activé ou toléré dans les mêmes proportions lorsque le-la bénéficiaire est un homme ou femme.

L'ancrage idéologique de la différence des sexes dans la biologie organise les droits relatifs à la reproduction, certains droits acquis dans ce domaine étant d'ailleurs régulièrement remis en question (p.ex. l'interruption volontaire de grossesse). De plus, l'absence de certains droits favorise la reconduction des rôles sociaux différenciés, en particulier dans la division sexuelle du travail. La Suisse dispose uniquement d'un congé maternité lié à l'activité professionnelle de la mère (il s'inscrit dans les APG). L'allocation est fixée en fonction du salaire antérieur (ce qui pénalise les faibles rémunérations) et dure 14 semaines. Il n'y a donc pas d'assurance protégeant la maternité de manière universelle et, surtout, il n'existe pas de droits (sous forme de congé, d'allocation, etc.) qui concernent les parents en général (pères, parents adoptifs, conjoint.e dans un couple homoparental, etc.). En l'absence de congé parental - ou, mieux encore, d'une nouvelle organisation du travail dans laquelle pourvoir en revenus et pourvoir en care seraient également valorisés et partagés par les hommes et les femmes - le congé maternité peut avoir pour effet de favoriser l'assignation de la mère au travail domestique. La division des rôles dans le couple qui peut en découler ainsi que, du coup, l'obligation morale faite à la mère de «concilier» travail professionnel et domestique tendent alors à reproduire le modèle androcentrique de l'homme gagne-pain ainsi que le moindre accès des femmes aux dispositifs des politiques sociales.

Les dispositifs des politiques sociales peuvent donc bien être théoriquement neutres du point de vue du sexe de la personne à laquelle ils s'appliquent, ils n'en sont pas moins inscrits dans un contexte social qui en oriente tant le contenu que l'application; inscrits dans une histoire dont ils sont tributaires, ces dispositifs sont également confrontés aux changements sociaux et l'objet de contestations, ce qui les destine à se reconfigurer régulièrement.

Hélène Martin

\section{Références}

Delphy, C. (1991). Penser le genre : problèmes et résistances. Dans C. Delphy (Éd.), L'ennemi principal : penser le genre (vol. 2, pp. 243-260). Paris : Éditions Syllepse.

Fraser, N. (1994). After the family wage. Gender equity and the welfare state. Political Theory, 22(4), 591-618.

Modak, M., Messant, F., Keller, V. \& Girardin, M. (2013). Les normes d'une famille « juste» dans les interventions des assistantes et assistants sociaux de l'aide sociale publique. Nouvelles Questions Féministes, 32(2), 57-72.

\section{Gestion de la qualité**}

Le concept de qualité peut se définir de diverses manières. Selon l'ISO (International Organization for Standardization), celui-ci recouvre «l'ensemble des caractéristiques d'une entité qui lui confèrent l'aptitude à satisfaire des besoins exprimés ou implicites.» Dans chaque organisation, privée ou publique, se pose le problème de la gestion ou de la garantie de la qualité (quality management ou assurance). Dans les grandes organisations cette fonction est prise en charge par un service spécifique qui met en place des systèmes et outils en vue d'atteindre un niveau prédéfini de qualité des produits ou services octroyés aux client·e-s.

Le concept de gestion de la qualité est né au sein de l'industrie, en particulier dans les secteurs où la qualité (et la sécurité) technique du produit était d'une importance fondamentale comme l'aéronautique ou les industries automobile et pharmaceutique. Les principaux instruments et approches ont été développés à 
partir des années 1950 au Japon, aboutissant à l'approche du Total Quality Management (TQM), selon laquelle chaque activité de l'organisation doit être optimisée et, si possible, standardisée afin de garantir un niveau de qualité maximal pour le-la client·e.

En 1987 a été publiée la principale norme internationale sur la gestion de la qualité : ISO 9001. Au cours des années, cette norme a évolué (la dernière mise à jour date de 2015) et elle s'est progressivement détachée de ses racines industrielles en devenant plus «universelle» pour s'appliquer aussi aux organisations actives dans les services et dans le secteur non-profit. Dans sa version la plus récente, la gestion de la qualité correspond à la gestion du processus de travail. L’idée sous-jacente est que seul le contrôle total des processus permet à l'organisation de garantir une qualité constante dans le temps.

À partir des années 1980, les concepts de gestion de la qualité ont été adoptés par les organisations du secteur public: hôpitaux, écoles, administration publique et institutions sociales. Dans la plupart de ces secteurs ont été développés des modèles de référence spécifiques. La gestion de la qualité représente un élément important de la philosophie de la nouvelle gestion publique (NGP) qui détermine l'orientation d'un ensemble de réformes administratives initiées au début des années 1980 dans les principaux pays européens et aux États-Unis. La NGP pousse le secteur public à adopter des techniques managériales qui ont fait leurs preuves dans le secteur privé, notamment la focalisation sur l'efficience et l'efficacité, la gestion des outputs et des outcomes ainsi que l'introduction de mécanismes de marché et de concurrence.

En Suisse, la philosophie de la NGP a été intégrée au niveau fédéral avec la "gestion administrative axée sur résultats» (GAR) qui vise à orienter l'action de l'État vers des prestations (ou niveaux de qualité) mesurables, déléguer de manière adéquate les tâches et respon- sabilités aux unités administratives, améliorer l'économicité et adopter des outils de gestion utilisés dans l'économie privée. Dans le message du 24 novembre 2004 concernant la modification de la loi fédérale sur les finances de la Confédération (LFC), le Conseil fédéral a présenté sa stratégie globale en matière de GAR. Les éléments les plus importants de cette stratégie découlent, directement ou indirectement, de la philosophie de la gestion de la qualité, par exemple l'orientation vers le citoyen-neclient $\cdot e$, le lien entre prestations et ressources (efficience) ou encore la gestion par enveloppe budgétaire et contrats de prestation. Ce dernier outil, crucial pour la mise en œuvre de la GAR, prévoit, outre les aspects financiers, la définition et le respect de niveaux de qualité minimale. À cet effet, chaque organisme public est appelé à se doter d'un système spécifique de gestion de la qualité.

Compte tenu de l'expérience positive des projets-pilotes, de plus en plus d'organismes publics ont adopté une telle approche et introduit des systèmes de gestion de la qualité. Tout d'abord, les hôpitaux où les processus et les niveaux de qualité exigés peuvent être définis et contrôlés avec un certain degré de précision. En dépit du niveau élevé des soins en Suisse, on reconnaît la nécessité d'améliorer leur qualité et de diminuer le nombre d'erreurs de traitement et d'accidents médicaux évitables, tels que les infections nosocomiales, les traitements pharmacologiques erronés, les erreurs de diagnostic ou dans les salles d'opération. À travers la mise en œuvre de la «Stratégie nationale de la qualité», le Conseil fédéral vise à renforcer son rôle de pilote tel que défini dans les priorités de la politique de la santé (Santé2020). Un pilier de cette stratégie est l'adoption de systèmes de gestion de la qualité dans chaque hôpital. Beaucoup d'hôpitaux ont ainsi adopté la norme ISO 9001 ou d'autres modèles généraux (comme le modèle européen développé par l'European Foundation for Quality Manage- 
ment) ou sectoriels (comme le modèle américain de la Joint Commission).

A partir des années 1990, les établissements éducatifs se sont aussi dotés de tels systèmes (à commencer par les universités et les écoles professionnelles), de même que les institutions sociosanitaires. Ainsi, QuaTheDA est un projet de l'Office fédéral de la santé publique pour les domaines des addictions, de la prévention et de la promotion de la santé, dont le but est de renforcer la confiance dans les services des organisations. Il se base sur l'évaluation du niveau de qualité atteint dans le secteur spécifique de la dépendance. Toujours dans le champ de la politique sociale, le $1^{\text {er }}$ janvier 2000 l'Office fédéral des assurances sociales (OFAS) a promulgué la norme «OFAS AI 2000» qui définit les critères pour la création de systèmes de gestion de la qualité dans les institutions de prise en charge des personnes en situation de handicap. La philosophie sous-jacente à ce système s'inspire de la norme ISO 9001. En parallèle ont été adoptés d'autres modèles moins «managériaux», par exemple en Suisse alémanique le modèle Wege zur Qualität promouvant une orientation anthroposophique.

Le transfert dans le secteur public et social de logiques nées dans le monde de l'entreprise suscite à juste titre nombre de questions sur l'adéquation de ces instruments. Le débat est ouvert, mais l'expérience des institutions sociales suggère une réponse contrastée. D’une part, les logiques de la gestion de la qualité sont aussi applicables dans le secteur public (surtout en ce qui concerne les processus d'organisation et de gestion des institutions). D'autre part, une formalisation excessive des activités, notamment dans le domaine de l'accompagnement et des soins aux usager-ère-s, peut conduire à une limitation excessive de la marge de manœuvre et de décision du personnel. À la différence des activités industrielles, les activités des institutions sociales se caractérisent par une haute variabilité des exigences et des situations, où l'importance des aspects émotionnels et relationnels demande une évaluation ad hoc. Le défi est donc de trouver des approches de gestion de la qualité qui tiennent compte de cette complexité au moment de formaliser les processus et mesurer la qualité des prestations.

Une autre grande différence réside dans la difficulté de recueillir le point de vue des usager-ère-s, notamment avec les personnes en situation d'incapacité où il est nécessaire de développer de nouvelles approches pour intégrer et communiquer sur le thème de la qualité. Enfin, les chercheur-euse-s s'accordent pour souligner - dans le secteur social - le primat des relations humaines - entre usager-ère-s, personnel et institution -sur les aspects formels liés au respect des normes et règles.

Alberto Gandolfi

\section{Références}

Broekmate, L., Dahrendorf, K. \& Dunker, K. (2001). Qualitätsmanagement in der öffentlichen Verwaltung. München: Jehle.

Mainardi, M., Gandolfi, A., Parini, C. \& Balerna, C. (2010). Bilancio critico sull'introduzione dei sistemi di gestione della qualità negli istituti per persone adulte con disabilità. Manno: SUPSI.

Peterander, F. \& Speck, O. (2004). Qualitätsmanagement in sozialen Einrichtungen (2., völlig neu bearb. Aufl.). Basel : E. Reinhardt.

\section{Handicap*}

Le handicap est, d'une part, une expérience sociale que tout le monde vit au cours de sa vie. Citons comme exemples caractéristiques les barrières dans le domaine de la mobilité, notamment dans la circulation ou l'utilisation des transports publics, lorsqu'une personne se déplace à l'aide de moyens auxiliaires ou avec une poussette. D'autre part, le handicap est un statut social et juridique attribué à certaines personnes. La loi suisse sur l'égalité 
des personnes handicapées définit le handicap essentiellement à travers les entraves résultant d'une déficience corporelle, mentale ou psychique durable. Dans sa définition du handicap, la Convention des Nations Unies relative aux droits des personnes handicapées insiste sur les interactions entre individu et environnement pouvant conduire à une restriction de la participation sur une base égalitaire.

Le concept actuel du handicap se construit dans le contexte de l'industrialisation et de la formation des États-nations au XIXe siècle. En lien avec la régulation du travail salarié et la question sociale, il joue un rôle important dans l'établissement et le maintien de l'ordre public. Dans les sociétés modernes, on parle de handicap lorsqu'il est question de limitations fonctionnelles, c'est-à-dire d'atteintes aux normes attendues en termes de performance et de comportement. De telles atteintes aux normes sont attribuées à des individus qui sont ensuite qualifiés de «handicapés».

Le concept de handicap fonctionne à deux niveaux. Premièrement, il permet d'imposer des attentes standardisées en matière de performance et de comportement et de traiter comme problématiques la non-réalisation ou le non-respect de ces normes. En fonction du contexte (p.ex. enseignement scolaire, activité professionnelle ou obligations militaires), différents termes et instruments sont créés à cette fin. Il s'agit notamment de la mesure de l'intelligence, des possibilités de classification de la psychiatrie ou du code pénal. Ces approches sous-estiment systématiquement les conditions de la non-réalisation ou du non-respect des attentes, à savoir la répartition inégale des ressources matérielles et culturelles. Deuxièmement, le concept de handicap permet non seulement de gérer les différences des conditions sociales modernes, mais il sert aussi de base pour faire face aux conséquences individuelles des risques collectifs. Citons notamment les maladies chroniques, les conséquences de la guerre ou les accidents de la circulation et du travail. Le concept de handicap sert à évaluer les droits et les prestations dans le domaine de la réhabilitation et des assurances sociales.

Ce n'est qu'après la Seconde Guerre mondiale que les différentes dimensions, définies aujourd'hui comme handicap ou déficience, ont été replacées dans un contexte sociopolitique. Le contexte de ces évolutions est la reconnaissance du fait que les personnes en situation de handicap sont exposées à des risques plus élevés d'être socialement exclues et désavantagées. Ce cadre de référence préconise le fait que les personnes auxquelles est attribué le statut de "personne handicapée» doivent être considérées comme des sujets de droit dans l'ensemble des domaines de la vie en société - travail, éducation, santé, vie sociale et culturelle. Grâce à ce statut, les personnes handicapées peuvent revendiquer les mêmes droits que les personnes sans handicap en termes d'opportunités de participation et de perspectives de vie. L'inégalité de traitement n'est considérée comme légitime que si elle protège contre la discrimination. La reconnaissance des droits fondamentaux indépendamment de ce qu'une personne apporte (ou non) dans une situation spécifique permet d'analyser les sphères sociales et institutionnelles (l'éducation, l'emploi, la consommation, la santé et la vie civile, etc.) à l'aune de pratiques inclusives.

Malgré certaines compétences fédérales dans le domaine des assurances sociales, la politique sociale suisse est structurée de manière fédéraliste et connaît, selon les cantons, une collaboration plus ou moins étroite entre les organisations publiques, privées et écclésiastiques. Cela conduit à des conditions très différentes pour les personnes handicapées, en fonction de la problématique, du canton et de la commune, ainsi que des différents contextes d'expérience du handicap (école, lieu de travail, etc.). Les incidences, positives et négatives, de ces conditions sont par conséquent généralement liées à ces structures spécifiques. Par rap- 
port à d'autres pays, les structures fédéralistes rendent plus difficile la prise en compte au niveau national des préoccupations en matière de handicap. Dans ce contexte, un rôle important incombe aux organisations nationales qui sont en mesure d'initier, mais aussi d'empêcher, des innovations, par exemple les Chemins de fer fédéraux suisses, Suisse Tourisme ou d'autres grandes entreprises actives au niveau national.

Les deux aspects du handicap - une expérience sociale et un statut social avec des conséquences juridiques - constituent les axes de débats controversés dans les sociétés contemporaines. Depuis le tournant du millénaire, une part considérable des débats sociopolitiques et scientifiques s'appuie sur la Classification internationale du fonctionnement, du handicap et de la santé (CIF) de l'Organisation mondiale de la santé (OMS). Cet organisme comprend le handicap comme le résultat des interactions entre la personne et son environnement. En revanche, la discipline Disability Studies se développe à partir des mouvements (inter)nationaux de personnes handicapées. Dans ce contexte, le handicap est compris comme une expérience sociale et culturelle ancrée dans l'économie politique des États nationaux. L'accent n'est donc pas mis sur la personne par rapport à l'environnement, mais sur un ordre social (p.ex. le marché du travail, les établissements d'enseignement) qui empêche les personnes de développer leurs aptitudes.

Malgré la reconnaissance sociale et le respect des droits fondamentaux que les personnes qualifiées de «handicapées » ont obtenu grâce à leurs luttes au cours de ces dernières décennies, les personnes en situation de handicap sont encore exposées à des risques considérables pour leur vie et leur intégrité physique, en particulier en cas de guerre, de pauvreté, de faim et de situations de dépendance à l'égard de tiers. L'un des principaux défis de la communauté mondiale est donc d'analyser la situation des personnes handicapées par rapport à la limitation et à la destruction des perspectives de vie afin de développer des possibilités d'action pour une société inclusive.

\section{Jan Weisser}

\section{Références}

Stiker, H.-J. (1997). Corps infirmes et sociétés. Paris : Dunod.

Watson, N., Roulstone, A. \& Thomas, C. (Eds.) (2014). Routledge handbook of disability studies. London: Routledge.

\section{Hébergement d'urgence}

Des solutions à court terme pour permettre le logement de personnes sans domicile, connues sous le nom de "passade», ont été mises en place par les villes européennes depuis le Moyen-Âge. Aujourd'hui, on peut définir l'hébergement d'urgence comme l'ensemble des structures mises en place par des institutions étatiques ou privées pour permettre aux personnes sans logement d'en trouver un, au moins à court terme. Trois types de structures peuvent être distingués en fonction du public visé: les personnes sans domicile de manière durable ou provisoire, les femmes forcées de quitter leur domicile en raison de violence domestique et les personnes venues demander l'asile.

Selon le Conseil fédéral, 25 lieux d'accueil d'urgence dans 16 villes ou agglomérations sont dénombrés fin 2013 (réponse à l'interpellation parlementaire 14.3770); un nombre inconnu de logements de transition ou de chambres d'hôtel sont utilisés par les services sociaux cantonaux, régionaux ou communaux, par exemple pour résoudre les problèmes des personnes expulsées de leur domicile pour défaut de paiement, pour séparation ou pour non-respect des règles locatives; on dénombre 
18 refuges ouverts pour des femmes victimes de violence conjugale; différents types d'habitat, le plus souvent précaires et collectifs, sont enfin proposés aux personnes dont la procédure d'asile est en cours ou qui en ont été exclues. Leur nombre varie en fonction des arrivées de personnes réfugiées en Suisse.

Selon l'Office fédéral de la statistique, 7\% de la population vit dans un logement surpeuplé en 2014 , et $17 \%$ dans une habitation privée de douche ou de baignoire, sans W.-C., trop sombre ou encore trop humide. Le nombre de personnes ne disposant pas de logement est en revanche inconnu, faute de données statistiques. La question du logement des pauvres n'a en outre guère été thématisée par les politiques sociales, l'étude réalisée en 2015 dans le cadre du Programme suisse de lutte contre la pauvreté étant l'exception. Elle a mis en lumière le fait que les coûts du logement représentent une charge trop élevée pour quatre ménages touchés par la pauvreté sur cinq. Les buts sociaux concernant le logement inscrits à l'article 41, lettre e, de la Constitution fédérale de 1999 ne sont donc pas atteints («La Confédération et les cantons s'engagent, en complément de la responsabilité individuelle et de l'initiative privée, à ce que [...] toute personne en quête d'un logement puisse trouver, pour elle-même et sa famille, un logement approprié à des conditions supportables.»)

Les lieux d'accueil d'urgence hébergent en 2016 des populations très diversifiées: personnes temporairement sans domicile, mendiant.e.s, musicien'ne.s, migrant·e.s, etc., mais la sous-dotation en termes de places reste le point commun de ces structures. Les autorités politiques communales justifient ce rationnement ou même l'absence de lieux d'accueil de nuit en utilisant la rhétorique de l'effet d'attirance. Ces politiques sont en outre le plus souvent basées sur le thermomètre, les places proposées étant plus nombreuses durant les mois d'hiver. Il s'ensuit une politique systématique de pénurie, car il n’y a pas assez de places disponibles, même dans les abris de protection civile (PC), ce qui force de nombreuses personnes à rester dans la rue chaque nuit, comme le documentaire L'Abri de Fernand Melgar s'en est fait le témoin en 2014. Pour cette population, on n'observe guère en Suisse le développement de politiques de type housing first (le logement d'abord) telles qu'elles se déploient au nord de l'Europe ou en Amérique, car on en reste principalement à des modèles d'intervention dits «en escalier» (step to step), basés sur des hébergements de transition, et qui partent de l'idée qu'un individu doit remonter la pente inverse de la désocialisation avant de pouvoir être logé.

La politique concernant l'hébergement d'urgence des femmes victimes de violence domestique est également caractérisée par le manque de places disponibles, signe sans doute de la difficulté à reconnaître socialement les effets de la domination masculine. Selon l'Office fédéral de la statistique, 9381 personnes ont subi des violences domestiques en 2013 : les trois-quarts étaient des femmes ; c'est également la proportion des victimes d'homicide de sexe féminin entre 2009 et $2013(\mathrm{~N}=123)$. Le danger de la vie domestique est donc bien réel pour de nombreuses femmes en Suisse, qui peinent toutefois à trouver un logement d'urgence en cas de menace. La plupart des maisons d'accueil ont adhéré à la Fédération solidarité femmes de Suisse et du Liechtenstein, qui demande le développement d'une politique nettement plus active en la matière.

Enfin, les personnes qui demandent l'asile en Suisse, si elles ne sont pas en mesure de subvenir à leur entretien, reçoivent une aide sociale organisée par les cantons. Pour les loger, plusieurs d'entre eux ont recours à des abris PC, autrement dit aux mêmes types de lieux en sous-sol et sans fenêtre qui sont proposés aux personnes sans-abri, le canton de Vaud étant celui qui a le plus recours à cette "solution». L'Établissement vaudois d'accueil des migrants a ainsi utilisé 10 abris PC en 2014 pour loger 
500 personnes. Le recours aux abris PC est également utilisé par certains cantons depuis 2004 pour les personnes mises au régime de l'aide d'urgence en vue de les inciter à partir, une pratique dénoncée par certaines organisations, mais jugée par le Tribunal fédéral dans son arrêt du 22 novembre 2013 conforme aux exigences concernant le respect de la dignité humaine contenues à l'article 12 de la Constitution fédérale. Malgré la pression que constitue l'arrivée en Suisse de victimes de guerres ou de violences, aucune politique globale d'hébergement n’a été mise en place.

Jean-Pierre Tabin

\section{Références}

Ansermet, C. \& Tabin, J.-P. (2014). Misère de la gestion de la misère. Le Sociographe, 48, 45-55.

Bochsler, Y., Ehrler, F., Fritschi, T., Gasserl, N., Kehrli, C., Knöpfel, C. \& Salzgeber, R. (2016). Wohnversorgung in der Schweiz. Bestandsaufnahme über Haushalte von Menschen in Armut und in prekären Lebenslagen. Bern : Bundesamt für Sozialversicherungen.

Stern, S., Trageser, J., Rüegge, B. \& Iten, R. (2014). Maisons d'accueil pour femmes en Suisse: analyse de la situation et des besoins. Zürich : INFRAS.

\section{Hôpitaux*}

En vertu de l'article 39 de la loi sur l'assurance-maladie (LAMal), les cantons sont responsables de la planification visant à couvrir les besoins en soins hospitaliers. La planification hospitalière se réalise au travers des listes cantonales des hôpitaux. Ces listes précisent les hôpitaux autorisés à facturer les prestations au sens de l'assurance obligatoire des soins (AOS).

Les hôpitaux publics et privés peuvent briguer des mandats de prestations. Selon l'Office fédéral de la statistique, les hôpitaux publics sont des établissements gérés par une collectivité publique. Tous les autres hôpitaux sont considérés comme privés, y compris ceux qui sont de propriété publique, mais disposent de leur forme juridique propre, par exemple une société anonyme (à but lucratif ou non) détenue par une commune, un groupe de communes ou un canton. En raison de la pression sur les coûts et du renforcement de la concurrence, les hôpitaux sont, de plus en plus souvent, contraints de fournir leurs prestations en couvrant au moins les coûts, voire, selon leur statut, en dégageant un bénéfice.

Les hôpitaux existent en Suisse depuis le début du Moyen-Âge. Créés à l'origine par des institutions ecclésiastiques désireuses de proposer des établissements d'assistance aux personnes nécessiteuses, étrangères et lépreuses et financés par des fondations, ils sont devenus au fil des siècles la pierre angulaire des soins de santé pour l'ensemble de la population et, à partir des années 1980, un secteur de plusieurs milliards de francs.

La couverture financière obligatoire en cas de maladie est désormais réglementée par la LAMal pour toutes les couches de la population. Les cantons sont responsables de sa mise en œuvre. Chacun d'eux tient une liste des hôpitaux qui sert à déterminer dans quels hôpitaux, à l'intérieur et à l'extérieur du canton, les habitant·e.s du canton peuvent recourir aux prestations de l'AOS. En cas de maladie, les prestations non couvertes par l'AOS doivent être prises en charge par les patient-e-s eux- ou elles-mêmes ou par leur assurance complémentaire.

Pour obtenir un mandat de prestations, les hôpitaux publics et privés doivent postuler auprès de la direction cantonale de la santé compétente pour le mandat de prestations correspondant. Les mandats de prestations ne sont attribués qu'aux hôpitaux qui remplissent les critères requis, tels que la qualification $d u$ personnel, l'infrastructure spécifique et le nombre minimum de cas pour certains traitements spécialisés. 
Les prestations dispensées en milieu hospitalier sont rémunérées selon un système de forfaits par cas conformément au SwissDRG (Swiss Diagnosis Related Groups). SwissDRG est un modèle qui, comme tous les modèles, ne reflète pas entièrement la réalité. Dans les faits, il existe des cas rentables et des cas déficitaires ; les deux sont censés s'équilibrer selon le principe des moyennes. En réalité, les «cas médicalement complexes» et les «cas socioéconomiquement complexes» ne sont pas suffisamment rémunérés. Cette situation représente une charge particulièrement lourde pour les hôpitaux universitaires et ceux des centres urbains: ils ne peuvent pas transférer les cas complexes et donc coûteux et assument ainsi une fonction de prestataires finaux.

La «complexité médicale» est en partie compensée par des prestations de services publics et des taux de base plus élevés. Mais les dépenses consacrées au traitement, aux soins et au suivi individualisé ne sont pas compensées spécifiquement lorsqu'il s'agit de patient·e.s dans des situations socioéconomiques complexes tels que les personnes âgées multimorbides, celles issu.e.s de la migration, ou ayant des problèmes de dépendance ou de logement ou encore les patient·e-s célibataires très jeunes en détresse financière. En raison de la pression croissante sur les coûts, les hôpitaux publics et privés sont, de plus en plus souvent, amenés à se demander combien le traitement d'un ou d'une patiente peut leur coûter, ou combien de prestations déficitaires ils sont disposés à assumer avec leur organisme responsable.

Le nouveau système de financement hospitalier incite les hôpitaux à travailler le plus efficacement possible, à réduire leurs coûts et à augmenter leurs profits. Outre l'optimisation interne et l'amélioration des processus, le positionnement et la sélection explicite des prestations offertes sont des moyens permettant d'améliorer les résultats. Autrement dit, il s'agit de traiter moins de cas déficitaires et plus de cas lucratifs. Le système de santé, dont l'objectif fondamental consiste à fournir des soins de santé à la population, se transforme ainsi en un marché de plusieurs milliards de francs. Si ses règles sont fixées par le peuple et la politique, elles sont interprétées avec une certaine marge de manœuvre et mises en oeuvre par les différents acteurs (organismes responsables, hôpitaux, assureurs-maladie) en fonction de leur posture et intérêts propres.

L'augmentation des coûts de la santé et la question connexe du rationnement des services de santé sont des préoccupations sur le plan international. La Suisse se distingue des autres pays en cela qu'elle finance les prestations hospitalières stationnaires au moyen d'un système de financement dual : la prestation est prise en charge à environ $45 \%$ par les assureurs-maladie et à environ $55 \%$ par les cantons de résidence. En revanche, les frais des prestations ambulatoires, y compris dans les hôpitaux, sont entièrement à la charge des assureurs-maladie. Dans le passé, l'évolution de la médecine avec ses nouvelles possibilités de traitement a entraîné un transfert des soins stationnaires aux soins ambulatoires. Ce transfert s'est encore accéléré sous l'influence des cantons, à la fois responsables de la planification de la couverture des besoins en soins hospitaliers et de $55 \%$ des coûts des prestations stationnaires. Il en résulte un allègement pour les cantons et les contribuables (coûts de la santé dépendants $\mathrm{du}$ revenu) aux dépens des assureurs-maladie et des payeur.euse-s de primes (coûts de la santé indépendants du revenu). Un tel système de financement est exceptionnel en Europe occidentale. Les modèles de financement basés sur un régime d'assurance sociale dépendant du revenu (Allemagne, Autriche, France, p.ex.) et les systèmes de santé financés uniquement par l'État (Grande-Bretagne, Scandinavie, Italie, p.ex.) sont beaucoup plus courants.

Le nouveau financement hospitalier et l'introduction des listes des hôpitaux a enclenché une consolidation du paysage hospitalier qui 
n'est, aujourd'hui, pas encore achevée. Les coopérations se multiplient. Des hôpitaux ont été fusionnés et certains ont été fermés. De nombreux organismes responsables ont transformé leurs hôpitaux en entités juridiques indépendantes. D'autres hôpitaux sont en passe d'obtenir un nouveau statut juridique; le résultat de la démarche dépendra du climat politique. Les hôpitaux dotés de leur personnalité juridique propre peuvent réagir plus rapidement à un environnement en constante évolution. Ils sont moins soumis aux intérêts politiques, qui ne coïncident pas toujours avec les intérêts de l'établissement. Dans le même temps, la tendance à l'indépendance fait craindre aux partisans de l'État social que la poursuite de la privatisation des hôpitaux conduise à une perte de l'influence directe des acteur.trice-s de la politique sociale. Une influence qui est de toute façon remise en question par des personnes qui pensent que l'État n'a «rien à faire» dans un système de santé, si ce n'est de garantir les soins de base et d'assumer une surveillance efficace.

La question du financement des soins de santé et donc de la qualité et de l'accessibilité des soins de santé pour toutes et tous fait l'objet d'un débat constant dans le champ de tension entre la société, la politique et l'économie. Ce n'est pas la forme juridique ou le statut d'un hôpital, mais bien sa posture et celle de ses bailleurs de fonds (État et assurance-maladie) dans ce champ de tension qui permettront d'offrir des soins médicaux de qualité à l'ensemble de la population. Ce qui est déterminant est la volonté politique d'assumer les coûts de la complexité médicale et socioéconomique.

Erwin Carigiet \& Tom Rezny

\section{Références}

Conférence suisse des directrices et directeurs cantonaux de la santé (2018). Recommandations de la CDS sur la planification hospitalière d'après la révision de la LAMal sur le financement hospitalier du 21.12.2007 et la jurisprudence du 1.1.2012 au1.1.2018 (version rév.). Berne: Conférence suisse des directrices et directeurs cantonaux de la santé.

Schölkopf, M. \& Pressel, H. (2014). Das Gesundheitswesen im internationalen Vergleich: Gesundheitssystemvergleich, Länderberichte und europäische Gesundheitspolitik (3., akt. und erw. Aufl.). Berlin : Medizinisch Wissenschaftliche Verlagsgesellschaft.

\section{Immigration*}

L'immigration désigne un mouvement de population à travers les frontières internationales. Contrairement à l'émigration, qui concerne le départ d'un pays, l'immigration fait référence à l'entrée dans un pays. Elle se distingue des «migrations intérieures» au sein d'un territoire national tel que la Suisse. Le motif et le but de la migration, le fait qu'elle soit volontaire ou forcée, n'entrent pas en considération dans la définition de l'immigration. Il en va d'ailleurs de même pour le statut juridique des personnes concernées. Jusqu'à récemment, la durée de séjour faisait partie de la définition proposée par l'Organisation internationale pour les migrations (OIM), qui associait l'immigration à un changement de domicile durable d'au moins 12 mois. Cependant, au vu des formes de migration temporaire, circulaire et transnationale, la formulation actuelle exclut la durée du séjour de la définition. Actuellement, un quart de la population suisse ne possède pas de passeport suisse, dont un petit nombre de réfugié-e-s.

La Suisse fut pendant longtemps un pays d'émigration. Au milieu du XIX siècle surtout, de nombreuses familles de paysan-ne-s pauvres ont émigré vers l'Amérique du Nord et du Sud pour y prendre un nouveau départ. À la même 
période, l'industrialisation a attiré en Suisse des universitaires et artisan-e-s d'Allemagne, ainsi que des ouvrier ère-s italien·ne-s. Après 1848 , la Suisse a connu une phase d'ouverture, si bien qu'en 1910 la part des étranger-ère-s sur le territoire s'élevait à $14,7 \%$. Cette augmentation a instillé des craintes dans la population et posé pour la première fois la question de la surpopulation étrangère (Überfremdung) sous cette forme. La Première Guerre mondiale mit fin à la politique libérale d'immigration. Dans l'entre-deux guerres, la loi sur le séjour et l'établissement des étrangers (LSEE) de 1931 réglementa pour la première fois l'immigration, l'établissement et l'accès au marché du travail des étranger·ère-s.

Après la Seconde Guerre mondiale, la Suisse a connu une phase d'essor économique qui a conduit à une pénurie de main d'œuvre. L'ouverture du marché du travail fut une des conséquences, tout comme l'introduction du « régime des travailleurs invités». La forme masculine $\mathrm{du}$ terme correspond à l'usage linguistique d'alors, mais aussi à l'idée que l'homme migrait et que la femme et la famille suivaient. Ce qui ne correspondait que partiellement à la réalité. Les travailleur·euse-s invitéee·s, qui provenaient d'Italie, mais aussi d'Espagne et, plus tard, du Portugal, ont été considérés comme une main d'œuvre temporaire. Leur séjour se limitait souvent à une saison ou à quelques années. Ils représentaient une main d'œuvre bon marché qui amortissait les fluctuations conjoncturelles. Dans les baraquements mis à disposition par les entreprises qui les avaient embauchés, leurs conditions de vie étaient souvent précaires et le regroupement familial leur était souvent interdit par la loi. Ils travaillaient généralement dans le bâtiment, l'hôtellerie, les usines et l'agriculture.

Dans les années 1960, la question des étrangers est revenue sur le devant de la scène. L'initiative Schwarzenbach n'a été que la plus célèbre d'une série de votations destinées à lutter contre la surpopulation étrangère. En 1970, l'initiative a certes été rejetée par le peuple, mais elle montre clairement à quel point la crainte de la surpopulation étrangère dominait les débats. En conséquence, le Conseil fédéral a introduit des contingents annuels. Le rôle de «tampon conjoncturel» que jouaient les travailleur-euse-s invité.e-s est clairement apparu, lors de la crise pétrolière de 1973/1974. Bon nombre d'entre eux se sont vus refuser le renouvellement de leur permis de séjour, les contraignant à retourner dans leur pays d'origine. Pour la première fois depuis 1940, la population immigrée diminua. Cependant, ce chômage «exporté» s'est aussi accompagné d'un recul de la consommation d'une ampleur qu'on avait sous-estimée.

Lorsque l'économie s'est redressée au milieu des années 1980, une nouvelle vague d'immigration n'a cessé d'apporter un nombre croissant de personnes immigrées, et ce jusqu'à aujourd'hui. L'ex-Yougoslavie et le Portugal sont venus s'ajouter aux pays d'origine de la main d'œuvre immigrée et des «saisonniers». La crise des Balkans, mais également d'autres conflits politiques, ont fait grossir le flot des personnes ayant accès au pays pour des raisons non pas économiques, mais humanitaires.

En 2002, la politique d'immigration de la Suisse a encore pris un autre tournant. Dans le cadre des accords bilatéraux conclus avec l'UE, garantissant la libre circulation pour les citoyennes et citoyens de l'Union européenne, la Suisse a introduit le "modèle des deux cercles». Les personnes provenant de l'UE ou de l'AELE ont alors le libre accès au marché du travail suisse et le droit à une autorisation de séjour sur présentation d'un contrat de travail. Depuis, l'immigration en provenance de l'UE ou de l'AELE a beaucoup augmenté et se caractérise par une part élevée de personnes hautement qualifiées, issues des pays du Nord, en particulier d'Allemagne. Tandis que l'immigration en provenance des pays du Sud concerne davantage des personnes moyennement ou peu qualifiées. L'accès pour les ressortissant·e·s de 
pays hors UE a été restreint à la main d'œuvre hautement qualifiée, au regroupement familial ou aux réfugié·e·s. Grâce à la diversification de l'immigration, les migrantes et migrants en Suisse travaillent aujourd'hui à différents niveaux de qualification et dans les branches les plus diverses. Le secteur de la santé en est un bon exemple: on y trouve des personnes immigrées à tous les niveaux, de l'aide-soignant·e jusqu'au médecin.

Contrairement à d'autres pays tels que les États-Unis, qui se distinguent par une longue tradition d'immigration, ou la Grande-Bretagne, où l'immigration est marquée par le passé colonial du pays, la population immigrée en Suisse était longtemps issue des pays européens voisins. Ce tableau a commencé à changer il y a quelques années seulement. À quoi s'ajoute encore que l'immigration fut perçue comme temporaire dans le cadre de la politique des travailleur-euse-s invité.e.s et que les questions d'intégration se sont posées relativement tard. Qui plus est, la Suisse se distingue par une politique de naturalisation restrictive. La naturalisation est perçue comme une récompense et non comme un fondement pour une intégration réussie. Et enfin, en Suisse la citoyenneté est transmise par les parents (ius sanguinis) et non par la naissance sur le sol helvétique (ius soli).

Actuellement, la politique migratoire de la Suisse se trouve dans une situation délicate. Depuis que le oui l'a emporté, le 9 février 2014, en faveur de l'initiative populaire contre l'immigration de masse, les accords bilatéraux conclus avec l'UE, et en particulier la libre circulation des personnes, font débat. Dans ce domaine, la Suisse comme de nombreux pays européens est tiraillée. D’un côté, une partie de la population redoute une immigration qu'elle trouve excessive et qu'elle exprime surtout dans la crainte d'une «islamisation» du pays. Une peur attisée avec succès par les politicien-ne-s et partis populistes. De l'autre côté, certains secteurs du marché de l'emploi tels que l'informatique ou les soins manquent de main d'œuvre. Et cette main d'œuvre ne peut être recrutée, du moins rapidement, qu'à l'étranger. Au bas de l'échelle salariale également, de nombreux postes ne peuvent être pourvus que par des immigré.e.s.

La politique migratoire a longtemps été essentiellement menée comme une politique de l'emploi. Désormais, l'immigration est ancrée dans différents domaines de la politique sociale et va bien au-delà du concept d'intégration tel que défini dans la loi sur les étrangers et l'intégration (LEI) de 2018. Elle englobe des thèmes tels que l'égalité des chances dans l'éducation et la formation ou des questions de discrimination institutionnelle. La société d'immigration impose de nouvelles exigences aux institutions publiques, par exemple avec l'offre de services de traduction dans les hôpitaux. La politique d'intégration explicite s'adresse spécifiquement aux immigré.e-s, visant à les aider à s'intégrer par des cours, mais aussi par des outils juridiquement contraignants. En même temps cela comporte le risque d'assimiler la migration à des facteurs socioéconomiques tels que le manque d'éducation ou des ressources économiques limitées.

Marina Richter

\section{Références}

Passagen (Hrsg.) (2017). Vielfältig alltäglich: Migration und Geschlecht in der Schweiz. Zürich: Seismo.

Piguet, E. (2013). L'immigration en Suisse: soixante ans d'entrouverture ( $3^{\mathrm{e}}$ édition entièrement mise à jour). Lausanne: Presses polytechniques et universitaires romandes.

Wicker, H.-R., Fibbi, R. \& Haug, W. (Hrsg.) (2003). Migration und die Schweiz: Ergebnisse des Nationalen Forschungsprogramms „Migration und interkulturelle Beziehungen“. Zürich: Seismo. 


\section{Inclusion*}

Suite aux discussions de la Convention des Nations Unies relative aux droits des personnes handicapées (CDPH), l'inclusion a de plus en plus été évoquée dans le débat général ces dernières années et constitue aujourd'hui le nouveau paradigme de la politique relative aux personnes handicapées. Par le terme d'inclusion, on revendique un droit de l'homme qui garantit la participation et l'autodétermination y compris aux personnes en situation de handicap ou de déficience. En conséquence, le terme est aussi utilisé dans le domaine de l'éducation et désigne la normalisation de l'hétérogénéité dans le système éducatif, ou plus concrètement, l'inclusion des enfants présentant un handicap, quel qu'il soit, dans les écoles ordinaires.

Mais l'inclusion ne concerne pas seulement le domaine du handicap ou de la déficience et doit être comprise dans un sens plus large. Comme son opposé, l'exclusion, elle renvoie à un débat social et politique sur la marginalisation croissante et les expériences de plus en plus nombreuses de marginalisation dans l'État social. C'est ce que révèle clairement l'observation de l'émergence des deux concepts dans les zones franco- et anglophone. Dans les deux débats, il s'agit en fin de compte des questions d'exclusion au sens de mise à l'écart de la société ou de marginalisation de larges franges de la population, considérées comme inutiles et donc fondamentalement non incluses. Naturellement, ces débats ont une influence directe sur l'évolution de la manière dont l'État social et la politique sociale sont appréhendés.

Le terme «inclusion» est utilisé de bien des façons. L'idée théorique fondamentale selon laquelle, dans notre société moderne et différenciée, la participation des individus à la vie de la société peut être décrite par le terme d'inclusion est essentielle. Celui-ci désigne surtout la capacité des humains à participer aux communications de différents systèmes. À ce niveau purement fonctionnel, l'exclusion en tant que contraire de l'inclusion signifie d'abord que les hommes en tant qu'individus ne sont pas tous traités de la même façon et de manière continue, et que, de ce fait, ils ne participent donc pas à tous les systèmes différenciés sur le plan fonctionnel.

L'État social et de droit moderne accorde de la valeur au fait que tous les hommes puissent en principe être inclus dans les prestations de chaque système fonctionnel social. Par conséquent, tous les hommes doivent en principe avoir la possibilité d'être «inclus». C'est pourquoi, par rapport à la société organisée en strates, la société fonctionnellement différenciée déploie un effort de régulation beaucoup plus important sur le plan des pratiques d'inclusion. L'inclusion est la principale idée de régulation qui caractérise la société moderne telle qu'elle se conçoit. C'est la raison pour laquelle la société moderne accorde tant d'importance aux règles d'inclusion institutionnalisées et généralisées: capacité juridique, scolarité obligatoire, accès aux soins de santé, participation au monde du travail, etc., parce que dans nos sociétés modernes, la constitution sociale de la personne passe par son inclusion. Cela signifie que l'absence d'inclusion, autrement dit l'exclusion, empêche les êtres humains de se construire en tant que personne sociale.

Il est donc logique que la question de l'inclusion ait été évoquée dans la CDPH de l'ONU et que dans le cas de la politique en matière de handicap, on ne parle plus en premier lieu d'intégration, mais plutôt d'inclusion. L'inclusion doit être comprise comme un droit de l'homme, car seule l'inclusion permet de mener une vie digne et autodéterminée dans la société moderne. Une société inclusive s'efforce, à l'aide des structures appropriées, de permettre à toutes les personnes, qu'elles soient handicapées ou non, de prendre part à la vie de la société, et de faire tomber les obstacles de toutes sortes. 
Dans cette perspective, le Diversity Management peut aussi être vu comme une politique d'inclusion. D'un point de vue normatif, le Diversity Management s'inscrit dans une optique de droits de l'homme et se met au service de la lutte contre la discrimination. Dans une conception plus globale de l'inclusion, il tente d'établir des conditions-cadres et de modifier en conséquence les structures existantes de manière à ce que chacun·e, dans son individualité, puisse être considéré·e d'emblée comme partie prenante.

Souvent, l'absence d'inclusion ou d'opportunités d'inclusion crée des problèmes existentiels qui vont à l'encontre de la société moderne telle qu'elle se conçoit. Il convient d'accorder à ces cas d'exclusion une place dans le débat sociopolitique, d'empêcher ce type d'exclusion par des réglementations de politique sociale, et d'encourager l'inclusion.

Le fait de ne plus être abordé ou pris en considération est une expérience de l'exclusion tout à fait personnelle. Ici, on peut dire à juste titre que la question n'est pas de savoir qui sont les exclu·e·s ou les marginalisé·e·s, mais plutôt de savoir sous quelles conditions des situations de vie peuvent être qualifiées d'exclues, de superflues ou de marginalisées. Cette autodescription de situations d'exclusion découle d'une série de ruptures de communication et de rejets qui conduisent à un sentiment de perte. De telles expériences d'exclusion se multiplient justement à notre époque et donnent lieu à de nouveaux défis pour les politiques. De toute évidence, la perception de l'adaptation entre les conditions systémiques de l'inclusion et le profil d'inclusion individuel est devenue problématique. Il apparaît que dans les faits, très peu de personnes sont encore marginalisées, mais qu'un nombre croissant de personnes, y compris de la classe moyenne, craignent d'être exclues. Cette crainte d'une possible exclusion peut être décrite comme une attente de l'exclusion. Une attente ou bien une crainte qui conduit en fin de compte à une dégradation de l'évaluation subjective de la sécurité sociale et qui, en tant que telle, peut avoir d'importantes répercussions (socio-)politiques.

C'est à ce moment que la politique sociale doit intervenir. L'inclusion et l'exclusion ne posent pas seulement la question des défaillances du système de l'État social, mais aussi des questions auxquelles il convient de répondre à partir de la perception qu'a l'État de lui-même. Voilà qui interroge les principales valeurs sociales de notre État social: la justice, l'égalité et bien sûr la liberté (au sens de participation). Il convient aussi de se demander comment la politique sociale doit s'adapter pour que ces valeurs sociales se concrétisent. En Suisse, le débat est mené actuellement surtout dans le cadre de la mise en œuvre de la CDPH de l'ONU. Le fait que l'association fédérant les organisations de défense des personnes handicapées s'appelle Inclusion Handicap depuis 2016 témoigne de l'importance du concept d'inclusion.

Sans remettre en question les droits et les besoins des personnes en situation de handicap, il convient de souligner que l'inclusion est un droit fondamental qui s'applique à tous les êtres humains et que l'État doit créer les conditions structurelles (juridiques, politiques et économiques) qui empêchent l'exclusion et rendent possible la participation et l'autodétermination - autrement dit, l'inclusion.

\section{Peter A. Schmid}

\section{Références}

Farzin, S. (2006). Inklusion/Exklusion: Entwicklungen und Probleme einer systemtheoretischen Unterscheidung. Bielefeld: transcript.

Heinrich-Böll-Stiftung (Hrsg.) (2015). Inklusion : Wege in die Teilhabegesellschaft. Frankfurt a.M.: Campus. 


\section{Indicateurs et concurrence artificiellement orchestrée ${ }^{*}$}

Ces dernières décennies les chiffres clés et les indicateurs, portés par une foi croissante dans le marché et la concurrence, sont devenus omniprésents, y compris dans les domaines de l'éducation, de la santé ou de l'action sociale. Ils expriment sous une forme numérique des concepts abstraits socialement valorisés, tels que la performance, l'innovation, l'efficacité ou la qualité. Le principe fondamental étant que la concurrence est mère de l'efficacité, même dans les secteurs où le marché n'existe pas ou n'est pas opérant. Or ce principe est très discutable.

Le marché et la concurrence ne sont pas frère et sœur siamois. Dans de nombreux domaines de la société, il n'existe pas de marchés ou seulement des marchés fonctionnant de manière incomplète. En revanche, il existe une concurrence artificiellement créée ou orchestrée. Cela concerne surtout les domaines de l'éducation, de la santé ou de l'action sociale, prétendument rendus efficaces par la concurrence. L'impression prévaut que de cette façon, des ressources ou des prestations peuvent être allouées de façon efficace. Mais une concurrence artificiellement orchestrée peut finir par fournir des incitations perverses qui, logiquement, débouchent sur des résultats pervers.

Contrairement à un 100 mètres, où c'est le ou la plus rapide qui remporte la compétition, ou à la chaîne de montage d'une usine, où le nombre de pièces traduit la performance, la plupart des performances sont aujourd'hui complexes à évaluer, car la qualité y joue aussi un rôle. On tente par conséquent de rendre les performances mesurables et évaluables à l'aide de chiffres-clés et d'indicateurs. Ce phénomène s'observe dans certains sports où la qualité a son mot à dire, comme le patinage artistique. Il y a dans cette discipline un jury d'experts dont les membres sont capables, souvent de manière mystérieuse, d'attribuer un nombre précis de points au programme libre d'un.e patineur.euse. L'indicateur de qualité est essentiellement le nombre de triples, voire aujourd'hui de quadruples sauts réussis. Ainsi, le patinage artistique est devenu un spectacle étrange, dans lequel un programme libre sert de prétexte à exécuter devant un jury d'expert·e.s en un temps réduit le plus grand nombre possible d'axels, de salchows ou de boucles. En réalité, il ne s'agit plus là de fournir de la qualité, mais d'impressionner le jury par une quantité mesurable. On commence à se concentrer sur les aspects mesurables de la qualité, et l'on néglige d'autres aspects non mesurables, ce dont la qualité dans son ensemble souffre souvent.

Malgré cela, depuis les années 1990, de nouvelles méthodes de management ont orchestré des concurrences artificielles avec des chiffres-clés et des indicateurs, notamment le tableau de bord prospectif et le benchmark. Ces méthodes ont fait, dans le cadre de la nouvelle gestion publique (New Public Management) et de sa variante suisse, la gestion administrative axée sur les résultats, leur entrée également dans les domaines de l'éducation, de la santé et de l'action sociale. Or, ce qui est déjà la plupart du temps problématique au sein de l'entreprise privée devient un véritable village Potemkine dans le cadre de l'administration publique. Derrière la façade des chiffres-clés prétendument objectifs d'un tableau de bord prospectif ou d'un benchmark se cache le plus souvent un non-sens habillé de chiffres.

Les deux méthodes ont pour but d'optimiser autant que possible la performance d'une entreprise ou d'une organisation et de ses services. Le tableau de bord prospectif a vocation à déterminer la situation d'une entreprise ou d'une organisation à l'aide de chiffres-clés quantitatifs, puis à définir les modes de management en fonction de ces chiffres. Il en résulte des orientations stratégiques et politiques que les entreprises ou les administrations publiques se donnent comme objectifs. Dans le 
benchmark, la comparaison entre les coûts, la performance, les effets, les processus, les technologies ou les structures de différentes unités (départements, entreprises, organisations) à l'aide de chiffres-clés prédéfinis ou de normes est fondamentale. Ces derniers sont censés permettre de déterminer ce qu'on appelle les «bonnes pratiques», auxquelles il y a lieu de se conformer en révélant le potentiel d'amélioration et en s'inspirant des «meilleur·e.s ».

Ce type de systèmes, fondés sur des chiffresclés ou des indicateurs, ne garantissent ni la qualité ni l'efficacité d'une offre, mais ils risquent de standardiser la performance et de fournir des incitations perverses. Dans le domaine de l'éducation, l'exemple des études PISA, menées dans la zone de l'Organisation de coopération et de développement économiques (OCDE) depuis 2000, illustre la manière dont les résultats moyens des écolières et écoliers, en tant qu'indicateurs, sont censés rendre compte de l'efficacité du système scolaire sur l'éducation des personnes. Or, ces études se concentrent exclusivement sur les compétences examinées et négligent ainsi d'autres matières au détriment de la culture générale. Partant de l'idée qu'il permettra d'améliorer la performance et la qualité, au moyen des classements (rankings) et des bonnes pratiques, cet «apprentissage sur l'exemple des meilleur.e.s» dégénère en course mondiale dans laquelle toutes et tous courent après «les meilleur.e.s ». Et «les meilleur·ess» sont celles et ceux qui obtiennent les meilleurs résultats en fonction de chiffres-clés fixés de manière arbitraire.

On observe le même phénomène dans le domaine de la santé, où les programmes pay for performance ( $\mathrm{P} 4 \mathrm{P})$ ont trouvé un écho en Suisse aussi. Rémunérer sur la base de leur performance des médecins qui recevront plus ou moins d'argent de la part des caisses-maladie selon la qualité de leurs traitements a pour conséquence qu'ils et elles effectuent de plus en plus d'examens inutiles ou prescrivent hâtivement des médicaments, parce que cela entraîne davantage de "qualité» mesurable. Ce qui débouche non pas sur des économies, mais sur une augmentation des volumes qui contribue largement à la hausse constante des coûts de la santé.

Dans l'action sociale, on trouve une autre incitation potentiellement perverse là où des indicateurs mesurent l'exécution réussie de certaines activités. Si, par exemple, les offices de placement sont jugés en fonction du nombre de chômeuses et de chômeur-euse-s replacé·e·s avec succès, ils ont intérêt à ne plus s'occuper que des chômeuses et des chômeur.euse-s faciles à placer, et à se détourner des cas plus épineux. Dans le jargon technique, on appelle cela le problème de la sélectivité ou de l'écrémage, que l'on retrouve aussi dans l'aide sociale. Lorsque, par exemple, les mesures de réadaptation doivent déboucher sur de l'insertion professionnelle, les entreprises de coaching mandatées sélectionnent de préférence les personnes promettant le plus de succès. Les cas difficiles restent en plan.

Plus les systèmes d'indicateurs sont complexes, plus les incitations générées le sont aussi. En fin de compte, la complexité des indicateurs peut devenir une véritable «boîte noire». Pour les personnes concernées, il devient alors de plus en plus difficile de savoir comment se comporter pour obtenir des résultats aussi bons que possible avec les indicateurs. Les incitations et l'amélioration des performances échouent, mais le développement, l'analyse et l'évaluation des indicateurs entraînent un surcroît très important de travail administratif.

Il existe aujourd'hui une littérature abondante sur la manière dont les gens réagissent, en termes de comportement, lorsqu'on introduit des chiffres-clés pour mesurer leur performance. Cette littérature montre que les gens sont souvent très créatifs lorsqu'il s'agit d'obtenir les meilleurs résultats possibles avec des chiffres-clés, et ce sans nécessairement améliorer la performance réellement perti- 
nente voire en améliorant les chiffres-clés au détriment de cette performance. Le problème réside ici dans le fait que de nombreux·ses spécialistes considèrent de telles réactions comme des exceptions et non comme la règle.

La conclusion qu'il faut en tirer est que la qualité et la performance d'un service ne peuvent que très difficilement être représentées sous une forme numérique. Au contraire, le fait de réduire la qualité et la performance à des indicateurs quantitativement mesurables peut engendrer de nouvelles incitations perverses, qui sont généralement d'autant plus grandes que la corrélation des indicateurs avec la performance qualitative souhaitée est faible et qu'il est possible d'améliorer les indicateurs sans améliorer la performance visée, voire au détriment de celle-ci. C'est ce qu'on appelle le paradoxe de la performance.

Par conséquent, la concurrence artificiellement orchestrée ne constitue pas une solution adéquate pour améliorer la qualité et l'efficacité. Elle risque au contraire de générer de dangereuses incitations, qui poussent à produire du non-sens mesurable, tandis que la qualité réelle reste sur la touche.

\section{Mathias Binswanger}

\section{Références}

Binswanger, M. (2010). Sinnlose Wettbewerbe: Warum wir immer mehr Unsinn produzieren. Freiburg i.B. : Herder.

Binswanger, M. (2013). Künstliche Wettbewerbe im Bildungswesen. Journal für Schulentwicklung, 17, 15-18.

Simon, M. (2001). Die Ökonomisierung des Krankenhauses: Der wachsende Einfluss ökonomischer Ziele auf patientenbezogene Entscheidungen. Berlin : Wissenschaftszentrum Berlin für Sozialforschung.

\section{Inégalités de santé*}

La notion d'inégalités de santé découle du constat qu'il existe des différences sociales pour ce qui est de l'état de santé, du comportement de santé et des soins de santé. Il ressort de l'Enquête suisse sur la santé de l'Office fédéral de la statistique (OFS) que ces différences existent aussi en Suisse: les personnes à bas niveau de formation, bas statut professionnel ou bas revenu sont plus souvent en surpoids, se soucient moins de leur santé (p.ex. examens de dépistage, activité physique) et s'estiment généralement en moins bonne santé que les personnes ayant un statut socioéconomique plus élevé. De telles inégalités de santé s'observent pour pratiquement toutes les maladies, qu'elles soient physiques ou psychiques. En font partie notamment les plus fréquentes, comme les maladies cardiovasculaires, le diabète sucré (diabetes mellitus), le cancer de l'estomac et des poumons, ainsi que la dépression et les troubles de l'anxiété, mais aussi la santé dentaire.

Ces inégalités de santé ne relèvent pas de différences entre les groupes les moins privilégiés de la société et les autres, mais d'un gradient social: plus un individu a une position socioéconomique défavorable, plus sa mortalité est élevée et sa santé mauvaise. Ces corrélations ont été mises en évidence dans de nombreuses études et leur pertinence a été prouvée pour les pays riches industrialisés, et donc aussi pour la Suisse. Le Black Report publié en Grande Bretagne dans les années 1980, et qui fit œuvre de pionnier, a pour la première fois donné des pistes pour expliquer les inégalités face à la santé. Encore débattues aujourd'hui et pour certaines développées, ces explications peuvent être résumées comme suit : l'approche culturelle-comportementale part de l'idée que les personnes à faible niveau de formation et statut professionnel inférieur partagent une «culture» qui favorise un comportement nocif pour la santé, comme la consommation de 
tabac et d'alcool, une mauvaise alimentation et un manque d'activité physique. Des études attestent toutefois que cette approche n'explique pas entièrement le gradient social dans le domaine de la santé. Il importe de considérer également les facteurs matériels et structurels comme la situation financière, les conditions de logement et de travail, ainsi que la situation familiale (approche matérielle). Un statut social inférieur va souvent de pair avec des conditions de vie et de travail préjudiciables à la santé. La recherche plus récente a en outre thématisé les déterminants psychosociaux du gradient social: les individus à bas statut social sont plus souvent exposés à des charges ayant un effet négatif sur la santé. En même temps, ils ont généralement aussi moins de ressources pour atténuer leur impact.

L'approche «parcours de vie» a gagné en importance ces dernières années. Elle analyse les effets des facteurs de stress et des ressources sur la santé d'un individu au cours de sa vie. D'autres déterminants susceptibles de générer des inégalités de santé sont en discussion mais n'ont été que peu étudiés à ce jour, par exemple l'importance de l'accès aux services de santé. À ce propos, on postule que les individus à bas statut social ont moins accès à des soins médicaux de qualité.

Pour les dimensions susmentionnées, on parle d'inégalités verticales. Des données empiriques révèlent également des inégalités horizontales, autrement dit des différences en fonction du sexe et de l'âge. Mentionnons l'espérance de vie plus longue des femmes, ou le risque plus grand pour les femmes que pour les hommes de souffrir de dépression. Inversement, les inégalités sanitaires peuvent induire des inégalités sociales, par exemple lorsqu'un individu ne peut travailler que peu ou pas du tout en raison de son état de santé avec, comme conséquences, un bas revenu, de mauvaises conditions de logement et l'isolement social. Même si les corrélations entre inégalité sociale et santé ne sont pas entièrement élucidées, l'état des connaissances est suffisant pour que l'on puisse dégager des pistes pour réduire les inégalités de santé - un défi aussi bien pour la société que pour le politique. Tous les individus devraient avoir les mêmes chances d'être et de rester en bonne santé, indépendamment de leur niveau de formation, de leur statut professionnel et de leur revenu. Cet objectif peut être atteint par la réduction des inégalités sociales. On pourrait commencer par lever les obstacles financiers et culturels, qui empêchent un accès équitable à la formation. Car sans bonne formation scolaire, sans bonnes qualifications professionnelles, les perspectives sur le marché du travail, partant, les chances de réaliser un revenu suffisant, sont mauvaises. Les inégalités économiques pourraient être réduites par le versement d'un salaire minimum légal et une redistribution financière au moyen d'impôts, de subventions, d'allocations sociales, etc. Les primes toujours plus élevées des caisses-maladie représentent une lourde charge financière, surtout pour les familles à bas revenu. De ce fait, les mesures de prévention ne sont pas assez sollicitées, ou le sont de manière peu ciblée. Il faut donc trouver des solutions pour que ces services demeurent abordables pour les membres plus faibles socialement, par exemple exempter du paiement des primes les enfants de ménages à faible revenu. Hormis ces mesures macrosociales, on pourrait également intervenir au niveau mésosocial, par exemple sur le comportement en matière de santé ou sur les facteurs matériels ou psychosociaux.

Dans son rapport Santé2020, le Conseil fédéral retient comme priorité politique le renforcement des compétences en matière de santé des groupes de population vulnérables, à savoir les personnes ayant un revenu ou un niveau de formation peu élevé, les personnes âgées, les enfants et les jeunes. Ces groupes vulnérables doivent pouvoir mieux s'y retrouver dans le système de santé grâce au renforcement de leurs compétences. Il s'agit non pas d'améliorer leur savoir théorique sur la santé et les mala- 
dies, mais de leur donner un savoir pratique qui leur permette de gérer la santé et la maladie au quotidien. De manière générale, la responsabilité personnelle des assuré·e-s et des patient·e-s doit être renforcée. Il ne faut pas oublier toutefois que le comportement en matière de santé n'est souvent pas, ou pas seulement, librement choisi, mais qu'il est aussi fonction des conditions de vie. Les mesures qui visent un changement de comportement doivent être adaptées aux groupes cibles. Pour que les interventions puissent atteindre leur objectif de réduction des inégalités, il importe d'impliquer activement les représentants des groupes cibles dans toutes les étapes des projets et programmes correspondants, de la planification à la mise en œuvre. Pour les mesures en faveur de personnes d'un certain âge, on tiendra par exemple compte du fait que ces personnes sont peut-être habituées à un style d'éducation et de formation autoritaire et passif-réceptif. Elles doivent donc d'abord apprendre et entraîner l'acquisition active et participative de connaissances - fondement de la compétence interactive en matière de santé. Mentionnons encore l'importance de travailler en intégrant le milieu ou setting. Ainsi, pour atteindre des groupes de population défavorisés au plan économique, qui se concentrent souvent dans des zones de logements à bas loyer, on s'adressera à eux dans le setting de leur quartier.

Julie Page

\section{Références}

Boes, S., Kaufmann, C. \& Marti, J. (2016). Sozioökonomische und kulturelle Ungleichheiten im Gesundheitsverhalten der Schweizer Bevölkerung. Neuchâtel: Schweizerisches Gesundheitsobservatorium.

Cantoreggi, N. (2016). Pondération des déterminants de la santé en Suisse: étude réalisée dans le cadre de l'élaboration d'un modèle de déterminants de la santé pour la Suisse. Genève: Université de Genève.

Wilkinson, R. \& Marmot, M. (2003). Social determinants of health: the solid facts ( $2^{\text {nd }}$ ed.). Copenhagen: WHO Regional Office for Europe.

\section{Inégalités face à l'éducation}

Les inégalités d'éducation désignent l'accès différentiel aux biens éducatifs (scolarisation, savoirs, compétences, diplômes, etc.) en fonction de l'appartenance des individus à un groupe. Il s'agit de comparer les parcours scolaires, l'obtention de diplômes, ou les compétences acquises en fonction du sexe, de l'origine sociale, du parcours migratoire ou ethnique des individus, ou en fonction de toute autre caractéristique jugée pertinente. Une différence d'accès aux biens éducatifs devient une inégalité s’il est démontré que sa source réside dans le fonctionnement de l'école et non pas seulement dans la volonté ou le seul talent des individus.

Les inégalités scolaires deviennent une préoccupation pour les politiques et un objet pour les chercheur·euse·s dès les années 1950 en Europe et aux États-Unis en lien avec le développement puis la massification de l'enseignement obligatoire et post-obligatoire. Dès le début des années 1960, le poids considérable des inégalités scolaires selon l'origine sociale des élèves, leur sexe, ou encore leur groupe ethno-racial est pointé du doigt par le monde de la recherche. Cette attention particulière pour les inégalités scolaires est liée au fait qu'elles sont à la source d'autres inégalités : d'emploi, de parcours professionnel, de niveau de vie, de santé, etc.

Cela occasionne dans beaucoup de pays des réformes des politiques scolaires dans le but de limiter les inégalités d'accès aux diplômes et aux savoirs, perçues comme injustes dans des sociétés démocratiques qui valorisent l'égalité. Dans la plupart des pays du monde, dès l'après Seconde Guerre mondiale, les systèmes éducatifs s'ouvrent pour scolariser l'ensemble d'une classe d'âge. Cette démocratisation de l'enseignement s'accompagne dans beaucoup de pays de réformes portant sur l'allongement de la scolarité obligatoire - aujourd'hui jusqu'à 16 ans dans la plupart des pays, jusqu'à 18 ans 
dans certains systèmes comme dans le canton de Genève -, l'unification du secondaire I sous la forme d'un parcours et de programmes uniques, quel que soit le niveau scolaire des élèves en fin de primaire, et le développement de l'enseignement secondaire post-obligatoire ainsi que de l'enseignement supérieur. Dans un contexte où l'éducation n'est plus pensée comme une simple dépense mais, selon la théorie dite du «capital humain», comme un réel investissement participant à la richesse des nations, les inégalités d'éducation font l'objet d'une attention particulière non seulement au plan des politiques scolaires, mais aussi des politiques de l'emploi, de l'action sociale, de la formation continue, ou encore de la jeunesse. En effet, l'échec scolaire a des conséquences négatives sur l'insertion professionnelle des individus, leur parcours de vie et favorise les situations de vulnérabilité sociale et personnelle.

Cette préoccupation pour les inégalités scolaires s'illustre depuis 2000 par le développement du Programme International pour le Suivi des Acquis des élèves (PISA), conduit par l'Organisation de coopération et de développement économiques (OCDE). Il s'agit d'une enquête répétée tous les trois ans qui compare le niveau de compétence en compréhension de l'écrit, mathématiques et sciences d'un échantillon d'élèves de 15 ans dans plus de 70 pays. L'un des indicateurs majeurs d'évaluation des systèmes éducatifs utilisé dans PISA est l'équité, qui mesure la capacité d'un système éducatif à réduire le plus possible les inégalités de compétences entre élèves en fonction $\mathrm{du}$ niveau socioculturel de leur famille, de leur sexe et de leur parcours migratoire. PISA montre que les inégalités en lien avec l'origine socioéconomique des élèves sont présentes dans tous les pays, mais leur ampleur varie fortement. C'est ainsi qu'en France, en Belgique et en Allemagne ces inégalités d'apprentissage sont très marquées, alors qu'en Finlande, en Corée et au Canada elles sont bien plus faibles.
Pour les inégalités genrées, le constat est plus nuancé. En mathématiques, les filles ont des scores plus faibles que les garçons, et c'est l'inverse en compréhension de l'écrit. En sciences, les résultats montrent un certain équilibre entre filles et garçons au plan des compétences acquises. Enfin au niveau des inégalités liées au parcours migratoire, les comparaisons internationales PISA montrent des acquis significativement plus faibles pour les élèves de première mais aussi de deuxième génération par rapport aux natif·ve.s. Toutefois, ces inégalités sont d'une ampleur très variable d'un pays à l'autre, montrant le poids des politiques scolaires dans la construction des inégalités d'éducation et les marges d'action considérables dont disposent les politiques publiques pour limiter au mieux ces inégalités.

En comparaison internationale, la Suisse est un pays qui se situe dans la moyenne de l'OCDE pour l'équité. Toutefois, l'éducation étant une prérogative des cantons, de très forts contrastes existent entre les 26 systèmes éducatifs cantonaux. Les modes de scolarisation comme l'ampleur des inégalités d'acquis dans le secondaire obligatoire sont très différenciés d'un canton à l'autre. Entre 2000 et 2015, la Suisse a développé un «suréchantillon» de l'enquête PISA de façon à comparer le niveau de compétence moyen et l'ampleur des inégalités à l'intérieur des treize cantons qui ont accepté de participer à cette enquête. Il ressort des analyses que les inégalités scolaires en fonction du niveau socioéconomique et du statut migratoire sont bien plus marquées dans certains cantons. Zurich, Vaud et Saint-Gall sont les cantons les moins équitables au plan éducatif, alors que Fribourg, le Jura et le Valais présentent des cas inverses : les inégalités y sont bien plus faibles que dans la moyenne suisse. Notons que ces contrastes entre cantons ne peuvent être liés à la nature de leur public scolaire (proportion d'élèves défavorisé·ess, migrant·e·s de première génération p.ex.) car les analyses sont 
conduites en maintenant constant l'effet de ces variables contextuelles.

Une question majeure est alors de savoir quels sont les mécanismes qui produisent les inégalités observables entre pays ou, dans le cas suisse, entre cantons. Les travaux sur la question montrent que certains systèmes éducatifs cantonaux séparent très précocement les élèves dans des filières étanches et hiérarchisées, produisant par là même de fortes ségrégations entre élèves de milieux socioéconomiques et de parcours migratoires contrastés. Le risque, dans de tels cas, est de produire des «discriminations systémiques», c'est-àdire d'offrir des scolarités et des programmes d'étude inégaux aux élèves, ainsi qu'un personnel enseignant moins expérimenté dans les filières les moins valorisées. Ces discriminations systémiques ont pour effet de renforcer les inégalités de départ en donnant moins (d'éducation) à ceux qui ont déjà le moins (sur le plan social comme économique et culturel). Cette idée est confirmée par le fait que plus la ségrégation entre filières est marquée dans un canton donné (Zurich et Vaud p.ex.), plus les inégalités d'acquis sont fortes dans ce canton.

Toutefois, les enquêtes PISA ne suffisent pas à comprendre l'ensemble des inégalités d'éducation. Notamment, alors que la comparaison des scolarités en fonction du sexe se fait à l'avantage des filles dans l'enseignement obligatoire (leurs parcours scolaires sont plus linéaires, elles obtiennent de meilleurs résultats aux tests) et post-obligatoire (elles obtiennent plus souvent une maturité et intègrent plus fréquemment que les garçons l'université), les filles restent encore trop absentes des formations scientifiques et techniques en Suisse comme dans beaucoup de pays. Dans l'enseignement professionnel comme dans le secondaire post-obligatoire et le supérieur, les orientations et le choix des spécialités de formation pénalisent les filles en les détournant des filières les plus rentables au plan professionnel.

\section{Georges Felouzis}

\section{Références}

Felouzis, G. (2014). Les inégalités scolaires. Paris : Presses universitaires de France.

Felouzis, G. \& Goastellec, G. (Éd.). (2015). Les inégalités scolaires en Suisse : école, société et politiques éducatives. Bern: Peter Lang.

Nidegger, C. (Éd.). (2014). PISA 2012. Compétences des jeunes romands: résultats de la cinquième enquête PISA auprès des élèves de fin de scolarité obligatoire. Neuchâtel: Institut de recherche et de documentation pédagogique.

\section{Inégalités Nord-Sud*}

Les «inégalités Nord-Sud» désignent la disparité sociale entre les régions riches et les régions pauvres du globe. La notion de «Sud global» a été introduite dans les débats de politique du développement à la fin des années 1980, probablement par la Banque mondiale. Les pays du Sud global se distinguent des pays du Nord, parmi lesquels la Suisse, par un faible PIB par habitant-e, un bas niveau d'industrialisation, une dette élevée, un niveau de formation médiocre, une faible espérance de vie, de fortes inégalités socioéconomiques, une pauvreté importante, peu de démocratie et un passé colonial.

Les inégalités Nord-Sud ont d'importantes répercussions sociopolitiques pour la Suisse. D'une part, elle profite de l'importation d'un capital humain fiscalement imposable et d'un capital économique, ainsi que de produits bon marché en provenance du Sud. D'autre part, des voix critiques s'élèvent face à l'accroissement d'une main d'œuvre migrante moins qualifiée provenant d'horizons culturels lointains qui poserait des problèmes d'intégration et de surcharge financière de ses systèmes sociaux. 
La théorie de la polarité du Nord global versus le Sud est moins connotée normativement que la typologie de la «théorie de la modernisation» qui différencie entre pays développés et pays en développement, la «théorie des systèmes mondiaux», qui différencie entre centre, périphérie et semi-périphérie, et la répartition, obsolète depuis la chute du communisme soviétique, entre premier, deuxième et tiers monde. Cependant, la polarité Nord-Sud est elle aussi controversée, car elle occulterait le fait que le Nord compte aussi des régions pauvres (p.ex. la Moldavie) et le Sud, des régions riches (p.ex. l'Australie).

L'écart entre le Nord et le Sud résulte d'une multiplicité de facteurs endogènes et exogènes qui influencent le développement d'un pays. À l'intérieur d'un pays, ce sont les facteurs politiques, institutionnels et culturels, la formation, mais aussi les facteurs économiques comme la disponibilité de matières premières et les inégalités socioéconomiques. Parmi les facteurs freinant le développement qui ont leur source hors du pays, mentionnons le colonialisme, l'asymétrie des relations commerciales et la fuite de capitaux. Concernant la mondialisation, les avis divergent. Alors que des économistes libéraux mettent en exergue les avantages de l'ouverture des marchés, ses détracteurs dénoncent le fait que ce sont avant tout les grandes entreprises du Nord et les élites politiques du Sud qui profitent du commerce Nord-Sud.

Le Human Development Report, publié chaque année depuis 1990 par le Programme des Nations Unies pour le développement, donne une bonne vue d'ensemble des inégalités Nord-Sud. Cette source de données présente toutefois le désavantage que les indicateurs ne renseignent pas sur les inégalités à l'intérieur des pays ni sur la qualité du régime politique. Elle permet néanmoins de détecter si les États nationaux convergent ou divergent par rapport au développement humain. De facto, les inégalités entre pays riches et pays pauvres ont diminué ces dernières décennies, surtout en ce qui concerne la formation, la santé, le taux d'alphabétisation et l'espérance de vie. L'évolution du Human Development Index - qui indique outre le PIB par habitant·e, l'espérance de vie et le niveau de formation (nombre moyen d'années de scolarité des personnes âgées de 25 ans, durée de formation prévisible pour les enfants) - montre que les pays accusant des valeurs de l'indice faibles à moyennes, notamment la Corée du Sud, l'Iran, la Chine et le Chili, ont le plus progressé depuis 1990. Dans le continent africain par contre les progrès sont faibles. Les pays aux valeurs les plus basses, surtout en Afrique subsaharienne, tendent plutôt à reculer pour ce qui est du revenu et de la pauvreté. Il s'avère en outre que la plupart des régions présentent certes moins d'inégalités au niveau de la formation et de la santé, mais aussi plus d'inégalités au niveau du revenu.

$\mathrm{Au}$ moins en lien avec le revenu et la fortune, il existe des analyses qui tiennent compte des inégalités aussi bien dans les pays qu'entre pays. Selon Milanovic (2016), l'inégalité globale entre les personnes est plus marquée que la plus haute inégalité mesurée à l'intérieur d'un pays. Cela s'explique surtout par le fait qu'au niveau mondial il n'existe pas d'instance qui, comme l'État social national, réduit les inégalités économiques. La propension à l'épargne étant plus grande parmi les personnes disposant d'un revenu élevé, il est évident que la concentration globale de la fortune est plus élevée encore que l'inégalité de revenu. Selon des calculs, le un pour-cent le plus riche de la population mondiale possède plus de $43 \%$ de la fortune globale. À noter que la Suisse fait partie des pays avec les plus fortes concentrations de fortunes.

En termes de produit intérieur brut par habitantee, la Suisse occupe les premiers rangs dans le système de classement international depuis le début du XXe siècle. Comme, en Suisse, l'inégalité de revenu est relativement modeste à la différence de la concentration de fortune, 
même des gens considérés comme pauvres en Suisse font partie de la classe supérieure à l'échelle du globe (après correction du pouvoir d'achat). D'après le Human Development Index, la Suisse fait clairement partie du Nord privilégié. En 2012, elle figurait au $9^{\mathrm{e}}$ rang du classement (sur 187 pays), en 2014 même au $3^{e}$ (sur 188 pays), la Norvège occupant la première place les deux années.

Même si le Sud réduit son écart par rapport au Nord pour de nombreux indicateurs de développement, les inégalités entre le Nord et le Sud demeurent extrêmes pour ce qui est $\mathrm{du}$ revenu et surtout de la concentration des fortunes. On comprend alors aisément que les gens du Sud soient nombreux à vouloir émigrer dans les pays riches du Nord. Pour les pays du Sud, l'émigration est problématique si elle se limite aux travailleur.euse-s hautement qualifié·e-s (brain drain). Mais même alors, les pays pauvres peuvent en principe profiter de l'émigration si les émigré·e.s soutiennent financièrement leurs familles restées au pays (remittances). Pour la population des pays du Nord, les inégalités économiques ne présentent pas de problème tant que des emplois ne sont pas délocalisés dans les pays du Sud, que l'on profite de touristes fortuné-e.s, de migrant.e.s riches et bien formé.e-s, de la fuite de capitaux et, grâce aux bas salaires payés dans le Sud, de produits d'importation bon marché.

Au cas où la migration du Sud vers le Nord continuerait de croître et ne se limiterait plus aux travailleur.euse-s hautement qualifié.e.s et ayant une culture similaire à la nôtre, le climat social en Suisse pourrait se détériorer. Il faudrait alors s'attendre à une attitude de rejet grandissante à l'égard de migrant·e-s qui seront perçu.e.s non pas comme productif.ve.s, mais surtout comme concurrent·e·s sur le marché du travail, difficiles à intégrer et profiteur.e.s $\mathrm{du}$ système social. Les premier.ère-s visé·e-s par ces ressentiments de la part de franges de la population indigène sont les requérant·e-s d'asile peu qualifié·e·s, issu·e·s de contextes culturels complètement différents, que l'on soupçonne d'avoir quitté leur pays non pour des raisons politiques mais pour des motifs économiques. Ce que l'on oublie, c'est que les jeunes migrantee-s qui exercent une activité lucrative participent eux aussi, avec leurs contributions de prévoyance, à la gestion des problèmes financiers de la prévoyance vieillesse dus à la structure d'âge de la population, et que les migrant·e·s, aussi bien légaux-ales que séjournant illégalement en Suisse (sans papiers), déchargent le coûteux système de care.

\section{Michael Nollert}

\section{Références}

Davies, J.B., Sandström, S., Shorrocks, A., Wolff, N. (2011). The level and distribution of global household wealth. The Economic Journal, 121(551), 223-254.

Milanovic, B. (2016). Global inequality: a new approach for the age of globalization. Cambridge : The Belknap Press of Harvard University Press.

Programme des Nations Unies pour le développement (2013). Rapport sur le développement humain 2013. L'essor du Sud: le progrès humain dans un monde diversifié. New York: PNUD.

\section{Inégalités sociales}

Des inégalités sociales marquent toutes les sociétés connues, mais leurs formes et leurs ampleurs varient énormément. Même dans les sociétés les plus égalitaires (chasse et cueillette), l'âge et le sexe au moins donnent lieu à des distinctions qui comportent à la fois des différences (d'identité, d'activités, d'espaces, de références culturelles) et des inégalités (considération sociale, autonomie, pouvoir).

Par inégalités sociales on entend l'organisation hiérarchisée de la société et l'accès inégal des personnes à des biens sociaux importants. Ce qui est un bien social important peut varier entre types de sociétés aussi bien qu'entre les 
sous-ensembles d'une même société. L'importance d'un tel bien découle des valeurs dominantes autant que de l'organisation de la société. Les sociétés contemporaines sont des sociétés marchandes, à économie capitaliste globalisée, d'où l'importance prépondérante de biens comme le revenu, la propriété, la position professionnelle et la formation. Le système des inégalités d'une société forme sa stratification sociale; la pauvreté correspond à une position particulièrement défavorisée (privation de biens essentiels) dans cette stratification.

L'ascension sociale ou au contraire le déclassement, mais aussi la stabilisation d'une position résultent de processus de mobilité sociale. Ils s'appuient notamment sur des pratiques de sélection. Dans les sociétés contemporaines, le système scolaire - qui gère la progression des élèves et étudiant.e.s - tout comme les entreprises avec leurs pratiques d'embauche, de promotion et de licenciement en sont les acteur.trice-s principaux-ales. S'y ajoutent des mécanismes de reproduction entre les générations (transmission du positionnement social - qu'il soit élevé, moyen ou bas) et de discrimination.

On parle de discrimination quand les processus de sélection s'appuient sur des caractéristiques que les personnes concerné·e·s ne peuvent guère changer et qui les classent dans une catégorie sociale inférieure: l'appartenance ethnique («race»), nationale, régionale, le genre, l'origine sociale (statut des parents). La discrimination n'est pas seulement une question de mépris personnel (racisme, sexisme, âgisme, xénophobie etc.), mais aussi de procédures institutionnelles. Les formes de discrimination sont aussi diverses que les catégorisations utilisées et ne sauraient de ce fait être traitées par les mêmes actions (p.ex. dans le cadre de stratégies de diversité ou d'inclusion). Elles ont en commun de consolider, dans le cadre de la stratification, des privilèges pour les gagnant.e-s et des situations défavorables pour les perdant.e.s. Dans son article 8.2, la
Constitution suisse interdit toute discrimination: «Nul ne doit subir de discrimination du fait notamment de son origine, de sa race, de son sexe, de son âge, de sa langue, de sa situation sociale, de son mode de vie, de ses convictions religieuses, philosophiques ou politiques ni du fait d'une déficience corporelle, mentale ou psychique.»

La place qu'une personne occupe dans le système d'inégalités entraîne une série de conséquences concrètes, à commencer par les conditions de vie matérielles, en passant par l'intégration sociale ou le fonctionnement mental jusqu'à la santé et l'espérance de vie. Les inégalités tendent à se cumuler au long du parcours de vie: les privilégié.e.s augmentent leurs privilèges alors que les peu nanti-e.s descendent davantage sur l'échelle sociale.

Les mécanismes de maintien des inégalités, les tentatives de les réduire ou au contraire de les accentuer constituent un enjeu politique majeur. Leur perception est également une cible de tentatives d'influence. Aux yeux du commun des mortels, la société dans sa complexité paraît souvent difficile à appréhender et à influencer. Le caractère construit et non «naturel» des inégalités tend à être occulté de différentes manières, à commencer par l'expérience quotidienne de personnes quand elles vivent des situations qui leur apparaissent comme inébranlables, hors de portée de leurs possibilités d'action. La conscience des inégalités et de leur caractère " produit » est aussi affaiblie par des représentations culturelles, voire des idéologies, par exemple quand celles-ci déthématisent les inégalités («nous sommes tous dans le même bateau»). Des visions qui mettent l'accent sur le mérite individuel («chacun est l'artisan de sa propre fortune») expliquent le monde social avant tout par les valeurs, les intentions et les efforts personnels des acteur-trice-s, niant ainsi l'existence de phénomènes autres qu'individuels. D'autres présentent les inégalités comme «naturelles» (p.ex. découlant «naturellement» du genre 
de la personne ou de talents personnels). Les images qui naturalisent ou essentialisent les inégalités (en les faisant découler de facteurs biologiques ou liés à l'âge, au sexe, voire à la «race» etc.) occultent leur caractère socialement construit. Même l'attribution d'inégalités à des «différences culturelles» (p.ex. entre autochtones et immigré.e.s) peut faire partie de leur essentialisation en les présentant comme impossibles à changer.

Si dans les sociétés contemporaines, la stratification sociale forme un ensemble cohérent d'inégalités, elle est néanmoins multiple: elle est composée de plusieurs dimensions, corrélées entre elles mais bien distinctes les unes des autres (formation, position professionnelle, revenu, fortune, prestige professionnel etc.). Les positions d'une personne par rapport à chacune de ces dimensions constituent donc un profil qui représente son positionnement dans la stratification. Lorsque la corrélation entre les dimensions n'est pas très forte, les individus appartenant à un même positionnement peuvent occuper des profils assez différents. Leurs manières de les vivre sont également différentes, ce qui rend inopérante une analyse en termes d'une dimension hiérarchique simple ou de classes clairement délimitées. Cette diversité de composantes structure des situations de vie concrètes qui se distinguent les unes des autres ce qui soutient l'interprétation individualiste et non collective des situations. Elle rend donc structurellement plus difficile de se reconnaître dans une autre personne et ainsi de former la conscience d'une problématique de positionnement partagée.

Pour ces raisons, les inégalités ne provoquent pas automatiquement des contestations ou des conflits de redistribution, ce qui les consolide tout en favorisant d'autres expressions de malaise (p.ex. maladies ou comportements déviants). S'accordant mal avec des valeurs égalitaires, les inégalités, surtout économiques, peuvent mettre en question la démocratie politique quand leur légitimité fait défaut à long terme.

Les inégalités sont ciblées par une part importante des politiques sociales qui tentent soit de les diminuer (mesures redistributives, p.ex. taux d'impôt progressifs) soit de les aménager pour atténuer leur caractère de privation (p.ex. salaires minimaux). Globalement, les effets redistributifs de l'État social en Suisse sont limités, une grande partie de ses mesures étant subsidiaires ou conditionnées à un constat de nécessité (means tested) et non universalistes (exception la plus importante: l'AVS). Ainsi, plutôt que de diminuer les inégalités, l'État social suisse freine et «organise» la descente sociale des personnes exposées à un risque majeur (âge, monoparentalité, chômage, invalidité etc.).

L'évolution des inégalités à moyen terme, surtout des revenus et des fortunes, tend vers une polarisation (stagnation chez les plus pauvres, augmentation chez les plus riches). Les inégalités de genre, après une première diminution, tendent à stagner, surtout en matière de positionnement professionnel (et par voie de conséquence des revenus, des fortunes et de l'assurance-vieillesse). En comparaison avec les autres pays postindustriels, le degré d'inégalité en Suisse est intermédiaire (plus prononcé qu'en Suède, moins fort qu'aux États-Unis).

\section{René Levy}

\section{Références}

Levy, R. (2009). Die schweizerische Sozialstruktur. Zürich : Rüegger.

Levy, R., Joye, D., Guye, O. \& Kaufmann, V. (1997). Tous égaux? De la stratification aux représentations. Zürich : Seismo.

Nollert, M. \& Budowski, M. (Hrsg.). (2010). Soziale Ungleichheiten. Zürich: Seismo. 


\section{Innovation sociale*}

L'innovation correspond à une forme spécifique de processus de développement et à un certain niveau de qualité des résultats ainsi obtenus, pour lesquels on a recombiné savoirs et expertises de provenances diverses. Ce résultat innovant, qu'il s'agisse d'une offre de services, d'une forme d'organisation ou autre, a une pertinence pratique éprouvée et est capable de faire évoluer la manière de procéder de façon fondamentale, étendue et durable. Les processus issus de l'innovation sociale donnent lieu à des pratiques novatrices, permettant de relever des défis de société. Ces nouvelles pratiques sont acceptées par les personnes et dans les organisations concernées, parce qu'elles sont jugées plus efficaces, performantes, durables et équitables, etc. que les solutions existantes. Les avantages qu'elles apportent peuvent être d'ordre social, politique, culturel ou écologique. Les innovations sociales sont intentionnelles et ont une visée de changement social et de modification de la structure sociale dans ses institutions et modèles culturels, ainsi que dans les actions sociales et contenus de conscience associés. Au sens strict, les innovations sociales sont des nouveautés conçues pour répondre à un besoin socialement justifié, et qui, en tant qu'offres, méthodes, concepts ou formes d'organisation, abordent des problèmes sociaux nouveaux ou traitent des problèmes connus d'une façon innovante. Enfin, elles offrent également une valeur ajoutée, notamment aux bénéficiaires de services sociaux.

À bien des égards, l'innovation est un concept relatif auquel sont aussi liés certains paradoxes: chaque innovation fait appel à des ressources ou à des produits existants et implique en même temps un saut qualitatif du connu vers la nouveauté inattendue. La perception de ce degré d'innovation est liée à un contexte social, spatial et temporel et sa comparaison n'est possible qu'ex post. Outre le côté novateur et relatif, les aspects suivants sont caractéristiques des innovations dans le secteur social:

> Le besoin comme base de légimitation et des composantes essentiellement économiques: la nouveauté de l'innovation ne sert pas à stimuler la demande et à générer des bénéfices, comme dans le contexte de l'entreprise et de l'économie de marché, mais à couvrir un besoin justifié de la manière la plus adaptée et différenciée possible. Comme elle vise souvent les groupes de personnes défavorisées qui ne sont pas des clients souverains dans le contexte de l'État social, le financement public est nécessaire la plupart du temps. En tant qu'investissements, les innovations sociales sont donc associées à des processus et à des conventions dans le domaine des valeurs et normes sociales, ainsi qu'à l'expression d'une volonté politique.

> La plasticité et l'incertitude: plus le potentiel innovant d'une idée pour résoudre un problème d'ordre social est important, plus elle crée d'incertitudes quant à sa mise en œuvre pratique dans un contexte structuré par des processus démocratiques, le rôle de l'État social et la subsidiarité. Les propositions et évolutions moins radicales paraissent souvent plus prometteuses parce que leur «connectivité» augmente leur acceptation.

La manière dont les sciences sociales abordent l'innovation (sociale) peut être imputée à la théorie conjoncturelle proposée en 1912 par Schumpeter, dans laquelle il pose l'hypothèse d'une évolution économique discontinue, au lieu de se baser sur une série uniforme de périodes d'expansion et de ralentissement, comme on le faisait auparavant. Une autre tradition importante dans les sciences sociales est attribuée à la théorie sur le changement social d'Ogburn, qui date de 1923. D'après lui, l'innovation sociale découle du cultural lag, autrement dit du déficit d'adaptation entre la culture matérielle, qui évolue plus vite, et comprend 
aussi les produits technologiques, et la culture non matérielle, plus lente, des pratiques, règles et modes de vie. Des théories plus récentes critiquent la forte intrication de l'innovation technique et sociale et plaident, entre autres, pour un examen isolé des contextes sociaux. Qui plus est, l'innovation sociale figure depuis peu aussi dans les discussions où les exigences sociales sont connectées plus directement aux environnements de production de connaissances. D'ailleurs, une imbrication trop étroite entre le processus de reconnaissance scientifique et la pratique sociale devient à juste titre cible de critique : la science et la recherche en sciences sociales courent le risque d'être envisagées de manière unilatérale, dans une perspective utilitaire, ou en fonction de leur contribution à la résolution de problèmes pratiques. À propos du financement d'offres régulières et des budgets spécialement destinés à l'innovation, il faut justement se poser la question des perdants potentiels de l'innovation. Dans tous les cas, la référence au concept d'innovation sociale à l'interface de la science et de la pratique nécessite autant un positionnement moral qu'une réflexion critique sur les valeurs sociales et les axes d'évolution.

Beaucoup de questions sur le sujet n'ont pas encore de réponse systématique. Certes, depuis le début des années 1980, les sciences sociales étudient l'innovation sociale de manière empirique comme un modèle de résolution au sein des systèmes sociaux. Cependant, comme dans la recherche sur l'innovation en général, elles se focalisent sur les domaines de la technique et de l'économie et s'attachent à décrire et à comprendre les conditions et conséquences sociales générées par l'introduction de nouveaux produits, technologies et modèles commerciaux. Bien que ces dernières années l'intérêt de la recherche se soit de plus en plus diversifié, les sciences sociales n'ont pas encore su avancer une compréhension étendue de l'innovation. Il existe peu de connaissances empiriques sur les facteurs de succès et les aspects méthodologiques du processus de formation des innovations sociales, en particulier pour le contexte suisse. Ces connaissances proviennent essentiellement des hautes écoles spécialisées, plus précisément du travail social, et révèlent une interaction complexe entre les facteurs de contenu technique, sociaux et politiques.

Les innovations sociales sont intégrées à une pratique institutionnelle, à un système de protection sociale régional ou national et à des traditions d'intervention sociopolitique. Elles concernent différents niveaux de la cohabitation sociale: le niveau micro (p.ex. le car sharing, le partage de logement, etc.), le niveau méso (comme l'urban gardening, l'approche de l'environnement social des services sociaux), ou le niveau macro (p.ex. les assurances sociales, le principe des quatre piliers de la politique antidrogue suisse). En Suisse, l'orientation vers le bien-être de toute la population, fixée par la Constitution fédérale a une fonction habilitante et délimitante pour les innovations dans le domaine social. Si la protection sociale est assurée comme c'est le cas en Suisse par l'interaction entre divers systèmes privés et publics, en matière d'innovation et de promotion de l'innovation aussi, les missions et responsabilités se répartissent inégalement entre des acteur-trice-s de la société civile, étatiques et non étatiques. Outre le principe de subsidiarité, il est intéressant d'observer que les nouveaux problèmes de société font souvent d'abord débat dans des sphères informelles (par l'entraide, les mouvements sociaux, les initiatives citoyennes) et dans l'opinion publique. En ce qui concerne la promotion de l'innovation dans les questions sociales, les fondations de droit privé jouent un rôle financier important aux côtés des pouvoirs publics. Il faut souligner encore que l'Agence suisse pour l'encouragement de l'innovation (Innosuisse) s'ouvre toujours plus aux projets d'innovation émanant de domaines cruciaux pour l'économie nationale, comme la pédagogie, la santé ou le travail 
social, et qu'elle inclut donc aussi les innovations sociales. Dans tous les cas, il faut garder à l'esprit que l'innovation sociale naît souvent dans un contexte délicat ou pour des groupes de personnes vulnérables: des analyses approfondies des besoins, des appréciations réalistes des risques et une évaluation concomitante sont nécessaires.

\section{Anne Parpan-Blaser}

\section{Références} \\ Cloutier, J. (2003). Qu'est-ce que l'innovation sociale? \\ Montréal: Centre de recherches sur les innova- \\ tions sociales CRISES. \\ Gillwald, K. (2000). Konzepte sozialer Innovation \\ (WBZ-Schriftenreihe P00-519). Berlin: Wissen- \\ schaftszentrum Berlin für Sozialforschung. \\ Osborne, S. \& Brown, L. (Eds.). (2013). Handbook of \\ innovation in public services. Cheltenham: Elgar.
}

\section{Intégration*}

La compréhension du terme «intégration» est souvent fondée sur des principes normatifs. On y associe par exemple de manière positive une amélioration des possibilités de participation, des droits de protection individuels ou collectifs, ainsi que la garantie de droits sociaux, de possibilités de participation politique ou de droits de vote. Au niveau structurel ou systémique, l'intégration peut également faire référence à un état de stabilité relative, à un rapport d'équilibre ou de cohésion sociale. Inversement, le concept de désintégration renvoie de façon négative aux phénomènes d'effondrement social, aux états indésirables d'absence de normes ou de fragmentation dysfonctionnelle des contextes sociaux. Au niveau des processus, il renvoie également aux tendances à la dissolution des liens sociaux, aux formes de discrimination ou de déviance sociale.

Ces différentes approches se reflètent dans la compréhension sociopolitique du terme «intégration». Fondamentalement, elles peuvent être dérivées du débat socio-théorique dans lequel l'intégration comme concept clé problématise la constitution et le maintien de l'ordre social. Dans le modèle absolutiste de Hobbes, l'intégration est, en tant que garante de la cohésion sociale, uniquement fondée sur l'État. Pour Herbert Spencer, l'intégration fait référence à un processus dans lequel des parties individuelles se transforment en ensembles sociaux. Émile Durkheim, de son côté, a défini l'intégration comme la solidarité organique ou mécanique résultant de la division moderne du travail et des interdépendances, et nécessitant une conscience collective (croyances et attentes communes). Chez Talcott Parsons, le concept d'intégration joue également un rôle central pour que les sociétés puissent être comprises comme des unités malgré leur différenciation fonctionnelle. Enfin, parmi les considérations diverses et variées, on peut également citer Niklas Luhmann, qui ne définit plus l'intégration en référence à un ensemble imaginé (société), mais en lien avec la restriction mutuelle des degrés de liberté de sélection entre sous-systèmes. Du point de vue de sa théorie des systèmes, la distinction entre inclusion/exclusion et donc les formes de multi-inclusion typiques des sociétés modernes dans divers sous-domaines sociaux sont mises en évidence.

Bien que les conceptions socio-théoriques de l'intégration soient multiples, elles font toujours référence à la relation complexe entre l'individu et la société. Dans ce rapport de tension, la politique sociale et l'État social font office de lien. Les institutions de sécurité sociale peuvent donc être comprises comme des instances d'intégration dont les effets concernent tant l'individu (intégration sociale) que la société dans son ensemble (intégration dans le système).

Le concept sociopolitique de l'intégration sociale peut être orienté vers l'inclusion d'un individu dans les contextes de la vie quo- 
tidienne (groupes sociaux, communautés, milieux, etc.) ou dans les contextes fonctionnels d'une société (école, marché du travail, politique, sécurité sociale, etc.). Le principe directeur à ce niveau de référence microsocial est le postulat sociopolitique de la participation des personnes ou des groupes aux possibilités socialement données ou aux formes typiques de satisfaction moderne des besoins, d'articulation des intérêts ou d'orientation culturelle. À cet égard, l'avantage de l'intégration sociopolitique liée aux individus comprend la satisfaction des besoins personnels. L'État-providence, avec sa combinaison de sécurité sociale et de travail social, est considéré ici comme un instrument de prévoyance au service des intérêts propres. Les stratégies sociopolitiques qui en découlent sont à percevoir comme la promotion effective de l'intégration et sont systématisées par Franz-Xaver Kaufmann en quatre formes centrales d'intervention: 1) amélioration du statut juridique des personnes - par exemple égalité de traitement des hommes et des femmes, amélioration de la situation juridique des migrant.e.s; 2) multiplication des ressources disponibles - par exemple redistribution de l'argent par le biais d'impôts progressifs ou de prestations en nature, comme c'est le cas dans certaines assurances sociales en Suisse ; 3) amélioration des structures d'opportunités pour les personnes - par exemple offres d'infrastructure d'insertion professionnelle, logements d'accueil, etc.; 4) amélioration de la capacité d'action des personnes par le biais de services éducatifs (p.ex. offres du travail social, conseils en matière de santé). En outre, dans le cadre d'un processus de soutien axé sur le dialogue et la défense des droits (conseil social au service de la clientèle), l'idée sociopolitique de l'intégration sociale peut avoir une fonction de capacitation - mais elle peut aussi poursuivre des objectifs réglementaires, lui conférant ainsi un caractère disciplinaire ou répressif - notamment lorsque des attentes ou des demandes relatives à une volonté indispensable d'inté- gration ou au manque de cette volonté sont formulées (p.ex. dans le cas de l'aide sociale sous forme de modèles de contre-prestation ou sous forme de conventions d'intégration dans le domaine de la migration). L'intégration peut alors être réalisée comme une demande unilatérale et programmatique d'adaptation/assimilation adressée à des individus ou des groupes. En tant que processus réciproque, elle peut également être conçue comme le moteur d'un changement social s'instaurant entre l'individu et le cadre de vie/sous-système fonctionnel, ou entre les groupes (minoritaires) et la société (majoritaire).

En politique sociale, l'idée de l'intégration dans le système résulte de la prise en compte de larges couches de la population dans les collectifs d'assurance sociale (réciprocité généralisée sous forme de péréquation mutuelle des risques, des dommages et des besoins) et dans les systèmes de prestations fondamentaux d'une société (généralisation du droit de participer aux possibilités de la vie sociale, comme le stipule la Constitution fédérale). La politique sociale a un effet d'intégration dans le système dans la mesure où elle vise, en plus de l'objectif d'inclusion des personnes, aussi la solidarité sociale (cohésion sociale, «ciment social»). L'État-providence compense les risques de la modernisation sociale sans remettre en cause la différenciation structurelle en soi (couches, classes). Par exemple, l'assurance sociale a contribué à pacifier le conflit de classe capitaliste en retirant du contrat de travail un potentiel de conflit considérable. Selon Franz-Xaver Kaufmann, l'effet de la politique sociale en matière d'intégration dans le système peut être compris, premièrement, d'un point de vue culturel, grâce à une réciprocité généralisée, garantie par la politique sociale, qui accroît la légitimité des conditions sociales existantes (comme p.ex. l'économie morale). Deuxièmement, la politique sociale a un effet pacificateur d'un point de vue politique, par exemple sous la forme d'une transformation de la réso- 
lution des conflits (également appelée "paix sociale») qui réduit les conflits de classes ou les conflits d'intérêts. Troisièmement, d'un point de vue économique, elle améliore la formation du capital humain et contribue à l'augmentation globale de la productivité du travail. Enfin, quatrièmement, d'un point de vue social, la politique sociale stabilise le domaine de la vie privée, afin de pouvoir reproduire ou régénérer le capital humain nécessaire à la société.

\section{Esteban Piñeiro}

\section{Références}

Imbusch, P. \& Heitmeyer, W. (Hrsg.) (2008). Integration - Desintegration: Ein Reader zur Ordnungsproblematik moderner Gesellschaften. Wiesbaden: VS.

Kaufmann, F.-X. (2012). European foundations of the welfare state. New York: Berghahn Books.

Peters, B. (1993). Die Integration moderner Gesellschaften. Frankfurt a. M. : Suhrkamp.

\section{Intégration dans le contexte de la migration*}

L'intégration peut se rapporter à différents phénomènes sociaux, à des individus, des groupes, des organisations ou des États-nations. Tandis que le terme d'«intégration systémique» fait référence à l'intégration des institutions dans des réseaux tels que le marché, les médias, la politique, ou désigne la cohésion d'une société dans son ensemble, le terme d'«intégration sociale» (selon Lockwood) renvoie à l'intégration ou à l'insertion d'acteur.trice-s individuel-le·s avec leurs intentions subjectives et leurs relations dans des systèmes existants ou dans des contextes sociaux donnés. Dans le domaine de la migration, on utilise le plus souvent le concept d'intégration sociale. Celle-ci désigne très généralement l'intégration la plus équitable possible des migrant-es dans les sous-systèmes de la société (culture, école, marché du travail, politique, sécurité sociale). Hartmut Esser distingue quatre variantes de l'intégration sociale: la culturation (connaissances et compétences), le positionnement (position sociale ou professionnelle, absence de discrimination), l'interaction (orientation mutuelle des acteur-trice-s, construction de relations par des actions) et l'identification (relations intellectuelles et émotionnelles dans un système ou un collectif, valeurs). La distinction entre intégration et assimilation, proposée par Hans-Joachim Hoffmann-Nowotny, est également très courante. Ce dernier conçoit l'intégration comme une participation aux valeurs, aux biens et aux positions (statutaires) des systèmes sociaux. Les concepts d'assimilation et d'acculturation, qu'il utilise comme des synonymes, se réfèrent par contre à l'adaptation culturelle. Selon lui, l'assimilation exige une intégration réussie. Sont cruciales à cet égard la réceptivité et l'ouverture d'esprit de la société d'accueil.

Depuis le milieu des années 1990, la notion de l'intégration a considérablement gagné en importance dans la recherche et dans les programmes gouvernementaux en matière de migration. Tandis que la question de l'intégration avait été longtemps laissée aux institutions sociales, elle est aujourd'hui considérée comme une tâche essentielle de l'État. Le postulat de l'intégration a d'abord pris de l'ampleur dans les grandes villes suisses en quête de réponses aux crises économiques et aux défis sociétaux. Pour beaucoup de spécialistes, les discussions relatives au choix d'un modèle cantonal amenaient une nouvelle vision. On passait des techniques sociales obsolètes appliquées aux travailleur·euse-s étranger-ère-s immigré·e·s à une politique d'intégration orientée sur l'amélioration de la situation juridique et sociale de la population étrangère. La Confédération a, à son tour, commencé à postuler l'idéal émancipateur d'une participation égale des personnes de nationalité étrangère à la société. 
Alors que, à l'époque de la première loi suisse sur les étrangers (LSEE), la politique visant à empêcher la surpopulation étrangère était encore considérée comme une négation de la population étrangère et l'idée d'intégrer cette population par un ius soli (naturalisation forcée) était conçue comme une stratégie d'absorption nationale de cette même population, la politique d'intégration et d'assimilation des années 1960 et 1970 visait, elle, à réduire la distance culturelle entre la population étrangère et les Suisses. L'insertion et l'assimilation étaient encore conçues comme des stratégies de la police des étrangers visant à combattre «l'emprise étrangère», afin de limiter les contradictions économiques et politiques par un rapprochement entre la population indigène et étrangère. Dans les années 1980, l'idée de la coexistence multiculturelle a atteint son apogée. En effet, la non prise en compte de la diversité culturelle et de la multiplicité des modes de vie est apparue comme problématique. Au lieu de l'assimilation forcée, s'est progressivement imposé un droit à la différence, fondé sur le principe de l'intégration. Ces nouvelles options ont permis une approche pragmatique, fondée sur l'État de droit. Les immigrant.e.s ont commencé à bénéficier de droits civils et, dans certains cas, de droits politiques de plus en plus étendus. Aujourd'hui, le droit de vote et d'éligibilité varie fortement selon le canton et la commune. Les cantons du Jura et de Neuchâtel connaissent le droit de vote au niveau cantonal. Quatre cantons ont introduit le droit de vote et d'éligibilité des personnes étrangères sur le plan communal (NE, JU, VD, FR). Dans le canton de Genève, elles ont le droit de vote mais pas d'éligibilité. Trois cantons alémaniques (AR, GR, BS) ont introduit un droit de vote et d'éligibilité facultatif au niveau communal. Dans le canton de Bâle-Ville, ce droit existe dans les communes de Bettingen et Riehen, mais pas en ville de Bâle.

Avec la loi fédérale sur les étrangers (LEtr) de 2008, l'intégration a été ancrée dans la loi pour la première fois. En tant que l'un des deux principes de la politique migratoire suisse (immigration policy), l'intégration constitue - avec l'admission - une forme de contrôle du séjour (immigrant policy). L'intégration vise, selon la loi suisse sur l'immigration, la «coexistence de la population résidente indigène et étrangère ». Elle est fondée sur la reconnaissance mutuelle et le respect d'une base commune de valeurs fondamentales. D'une part, la Confédération cherche à renforcer la volonté d'accueil de la société majoritaire et à créer des conditions favorables à l'égalité des chances. Il s'agit de promouvoir la participation de la population étrangère à la vie économique, sociale et culturelle. Ces tâches étant conçues comme transversales, tous les niveaux étatiques (Confédération, cantons et communes) sont censés contribuer au processus d'intégration en collaboration avec les partenaires sociaux, les organisations non gouvernementales et les organisations de personnes de nationalité étrangère. D'autre part, on attend de la population étrangère qu'elle respecte l'ordre juridique suisse et les valeurs de la Constitution fédérale, qu'elle apprenne la langue nationale parlée au lieu de résidence, qu'elle tienne compte des conditions de vie en Suisse, qu'elle accepte de participer à la vie économique et qu'elle acquière une formation. L'État peut exiger des efforts d'intégration et menacer les étranger-ère-s de sanctions et de renvoi. Les citoyen·ne-s d' «États tiers» peuvent être soumis·es à un devoir d'intégration sous la forme d'une convention d'intégration. Le principe «encourager et exiger» exprime cette imbrication d'aspects libéraux et restrictifs: si les mesures libérales de soutien visent à favoriser l'engagement individuel en faveur de l'auto-intégration, le principe de l'exigence s'inscrit dans la tradition d'un paternalisme contraignant de l'État activateur. L'intégration n'est plus seulement considérée comme un accompagnement bienveillant vers l'égalité des chances, mais aussi comme un critère de sanctions au regard du droit de séjour. 
Désormais, le concept d'intégration se trouve ainsi souvent sous les feux de la critique.

Tandis que la politique d'intégration de la Confédération est relativement homogène, les mesures d'intégration des cantons et des communes, quant à elles, sont hétérogènes. Chaque canton dispose désormais d'un programme d'intégration cantonal (PIC), regroupant toutes les mesures visant à promouvoir une intégration ciblée. Depuis le $1^{\text {er }}$ janvier 2014, la Confédération et les cantons ont adopté une stratégie commune qui définit les domaines d'encouragement où des mesures d'intégration ciblées sont appliquées dans toute la Suisse. L'actuelle politique d'intégration suisse présente une forme particulière de politique sociale: la connaissance de la langue et celle des conditions de vie locales sont encouragées, voire exigées au regard de l'intégration professionnelle et sociale de la population étrangère. Simultanément, les domaines centraux de la protection sociale telles que la santé et le logement, le soutien précoce aux enfants ou les services sociaux, constituent des points forts des politiques d'intégration.

\section{Esteban Piñeiro}

\section{Références}

Mahnig, H. (1999). La question de «l'intégration» ou comment les immigrés deviennent un enjeu politique : une comparaison entre la France, l'Allemagne, les Pays-Bas et la Suisse. Sociétés Contemporaines, 33-34, 15-38.

Piñeiro, E. (2015). Integration und Abwehr: Genealogie der schweizerischen Ausländerintegration. Zürich : Seismo.

Wicker, H.-R. (2009). Die neue schweizerische Integrationspolitik. In E. Piñeiro, I. Bopp \& G. Kreis (Hrsg.), Fördern und Fordern im Fokus : Leerstellen des Schweizerischen Integrationsdiskurses (S. 23-46). Zürich : Seismo.

\section{Intégration et insertion (sociale et professionnelle)*}

L'intégration est un concept de base dans les sciences sociales. Dans les débats de politique sociale, le terme est aujourd'hui utilisé de manière plus politique et normative qu'analytique. Il désigne le plus souvent un processus unilatéral d'insertion des individus dans une société donnée. Le travail rémunéré est considéré dans ce contexte comme un mode central d'intégration dans la société: l'emploi permet de forger une identité, il promet une reconnaissance sociale, assure la subsistance et ouvre des droits à des prestations d'assurance en cas de préjudice. En règle générale, les personnes intégrées professionnellement le sont aussi socialement.

En Suisse, l'insertion professionnelle comme étalon de l'intégration sociale remonte à l'émergence de l'État social moderne. Au début du XXe siècle, celui-ci a collectivisé la protection contre les risques individuels (aujourd'hui perçus comme des risques sociaux) et intégré les individus assurés dans un collectif d'assurance. Ainsi, les individus sont liés les uns aux autres et à l'État par le biais d'une solidarité démocratiquement légitimée entre personnes qui ne se connaissent pas. Dans la seconde moitié du $\mathrm{XX}^{\mathrm{e}}$ siècle, le mandat d'intégration des assurances sociales et des prestations sous condition de ressources a été développé et concrétisé, en mettant l'accent sur l'insertion professionnelle des personnes en âge de travailler. Dès lors, le mandat d'intégration prend naissance au moment où ces personnes sont exclues du marché du travail. La tâche principale consiste à maintenir ou à rétablir leur employabilité afin qu'elles puissent retrouver rapidement un emploi.

L'assurance-invalidité (AI), introduite en 1960, ouvre le droit à des prestations s'il est attesté que, pour raison de santé, une personne en âge de travailler n'est pas en mesure d'exercer une activité rémunérée, ou seulement de 
manière restreinte. En 2012, dans le cadre de la $6^{\mathrm{e}}$ révision, le principe directeur de l'AI, à savoir «la réadaptation prime la rente», est rappelé. Sa mise en œuvre sera de plus en plus fortement exigée par le monde politique. L'AI considère que son mandat d'intégration consiste à exiger des assuré·e·s n'étant pas en incapacité totale de travailler qu'ils et elles mettent à profit leur capacité de travail résiduelle. Elle leur propose deux types de mesures d'intégration: des mesures de réadaptation socioprofessionnelle et des mesures d'occupation. Les premières visent à maintenir ou à rétablir une capacité d'insertion, alors que les secondes offrent une structuration des journées et visent à maintenir la capacité de travail résiduelle. En ce qui concerne la participation des personnes en situation de handicap à la société au-delà d'une activité professionnelle salariée, elle est généralement désignée par le terme d'inclusion.

Quant à l'assurance-chômage (AC), fondée en 1983, l'un de ses trois principaux objectifs est l'intégration durable au marché du travail. Cette mission est assumée depuis 1997 par les Offices régionaux de placement (ORP). Outre des prestations de conseil et de placement, les ORP appliquent diverses mesures du marché du travail (MMT). Elles sont décidées par les conseillers et conseillères en personnel selon leur appréciation et assignées aux assuré·e-s sous peine de sanctions. Dans le cadre de la $4^{\mathrm{e}}$ révision de l'AC, pour des raisons de coûts, les prestations de base de l'assurance-chômage ont été réduites (plus particulièrement pour les jeunes adultes) à partir d'avril 2011. L'objectif était d'inciter davantage les assuré·e·s à réintégrer rapidement le marché du travail.

Le dispositif de l'aide sociale poursuit également un mandat d'intégration, formalisé lors de la révision des normes de la Conférence suisse des institutions d'action sociale (CSIAS) de 1998. En plus de garantir les moyens d'existence, l'aide sociale vise désormais explicitement à promouvoir l'indépendance financière des ménages assistés. Le nouveau concept dual d'insertion professionnelle et sociale est introduit dans les normes. Diverses mesures d'insertion sont proposées aux niveaux cantonal, régional et, parfois, communal. L'éventail varie considérablement d'un lieu géographique à l'autre. L'attribution est laissée à la discrétion des assistantes et assistants sociaux et peut nécessiter l'approbation des autorités sociales. La révision des normes CSIAS de 2005 lie plus étroitement les prestations d'aide sociale à la volonté d'intégration des bénéficiaires. Le forfait pour l'entretien est réduit, compensé partiellement par un système de suppléments afin d'honorer les efforts d'intégration fournis. De plus, dans certaines régions, des «conventions d'intégration», empruntées au domaine de la migration, sont utilisées dans l'aide sociale. Ces conventions sont conclues entre l'autorité et les bénéficiaires de l'aide sociale. Elles définissent les étapes du processus d'intégration. Si les bénéficiaires refusent de participer à une mesure d'insertion ou l'abandonnent de leur propre initiative, leur forfait pour l'entretien s'en trouve réduit. Enfin, en 2016, dans l'idée de renforcer pour les jeunes adultes le lien entre la garantie de l'existence et l'insertion, leur forfait d'entretien est réduit lorsqu'ils et elles n'exercent pas d'activité rémunérée ou ne suivent pas de formation et vivent seul.e.s.

En résumé, notons que, au sein de la politique sociale suisse, le concept d'intégration s'est modifié au cours des dernières années. Les assurances sociales ne se limitent plus à assurer la sécurité financière des ayants droit, mais soutiennent activement leur (ré)insertion. De leur côté, les ayants droit sont censés jouer un rôle actif dans le processus d'insertion, le mot d'ordre étant : «obligation de réduire les dommages». Selon le principe de la prestation et de la contre-prestation, les efforts individuels d'intégration prennent de plus en plus d'importance, tandis que le mandat d'assurer l'existence est relativisé. 
Dans le contexte d'une répartition toujours plus inégale du travail dans la société, il est nécessaire de considérer d'un œil critique la priorité accordée à l'insertion sur le marché du travail. Les personnes peu qualifiées ne trouvent pratiquement plus d'emploi. Elles sont plus souvent employées sur un deuxième marché du travail (ou marché complémentaire). Dans certains cas, de tels emplois - à salaire partiel ou en programme d'emplois temporaires - peuvent avoir du sens en offrant une structuration des journées voire en ouvrant éventuellement de nouvelles perspectives. Toutefois, de tels emplois dans un marché du travail parallèle et subordonné ne peuvent remplir les fonctions d'une activité rémunérée exercée au sein du premier marché du travail telles qu'énumérées ci-dessus.

Bien que le concept d'intégration se soit élargi depuis le début du siècle et que l'insertion professionnelle et l'insertion sociale soient mieux différenciées, cette dernière continue de jouer un rôle secondaire, étant considérée comme une étape préalable à l'insertion professionnelle ou comme une alternative à une insertion professionnelle ratée ou impossible. Une équivalence des deux objectifs d'insertion - professionnelle et sociale - est actuellement inconcevable. A cela s'ajoutent les aspects de discipline sociale inhérents à la politique d'activation. Concevoir l'intégration comme une simple insertion unilatérale des individus dans une société donnée n'est pas pertinent car l'accent est mis sur les seules prestations à fournir par les «personnes à intégrer». Une telle individualisation ne tient pas compte de la nécessaire réciprocité d'un processus d'intégration réussi. De plus, l'évolution des dispositifs de protection sociale décrite ci-dessus risque de compromettre des acquis et principes centraux, tels le principe de finalité et le droit à la couverture du minimum vital dans l'aide sociale. Les transformations en cours relativisent le droit fondamental à des conditions de vie décentes sur la base d'assignations socio-normatives à la (dés-)intégration. L'État social moderne n'a donc pas seulement un effet intégrateur, mais exclut certaines catégories de personnes, en traçant des frontières entre les personnes éligibles («pauvres dignes») et non éligibles («pauvres indignes»). Ainsi, seules les personnes pauvres jugées aptes à l'emploi ou employables ont pleinement accès aux mesures d'intégration.

\section{Yann Bochsler, Martina Koch \& Christin Kehrli}

\section{Références}

Gallie, D. \& Paugam, S. (2002). Social precarity and social integration: report for the European Commission Directorate-General Employment Eurobarometer 56.1. Luxembourg: Office for official publications of the European Communities.

Kutzner, S., Mäder, U., Knöpfel, C., Heinzmann, C. \& Pakoci, D. (2009). Sozialhilfe in der Schweiz: Klassifikation, Integration und Ausschluss von Klienten. Zürich : Rüegger.

Schallberger, P. \& Wyer, B. (2010). Praxis der Aktivierung: Eine Untersuchung von Programmen zur vorübergehenden Beschäftigung. Konstanz : UVK.

\section{Intersectionnalité}

Les systèmes d'inégalités, fondés notamment sur le genre, la classe, l'ethnicité, l'âge ou la sexualité, participent à créer des catégories de différence évaluées en référence à une norme idéalisée. Le féminin sera ainsi mesuré au regard du masculin, l'enfance et la vieillesse en fonction de l'âge adulte et la couleur de peau à l'aune du solipsisme blanc. L'intersectionnalité postule que ces systèmes d'inégalités s'articulent pour assigner aux personnes des positions sociales hiérarchisées et contextualisées. La perspective scientifique qui en découle cherche à mettre en lumière la diversité des imbrications de ces systèmes d'inégalités en affirmant leur consubstantialité, c'est-à-dire en postulant qu'ils se reproduisent et se coproduisent mutuellement, qu'ils sont interdépen- 
dants. Par conséquent, les identités aussi bien que les catégories ne peuvent être pensées séparément des relations de pouvoir qui les produisent. C'est pourquoi les identités assignées à un individu ou à un groupe social, les catégories de différence, les processus de différenciation et les systèmes d'inégalités constituent les objets de recherche de la perspective intersectionnelle.

Cette perspective est apparue dans les discours du black feminism dans les années 1970 pour dépasser une double invisibilisation des formes spécifiques de domination des femmes noires aux États-Unis. L'article fondateur de Kimberle W. Crenshaw (1991), qui utilise cette perspective dans le monde académique pour la première fois, met en lumière l'effacement des femmes noires aussi bien des discours antiracistes que des discours féministes. Ce constat peut être résumé par le titre d'une anthologie de textes fondateurs des études féministes noires éditée par Gloria T. Hull en 1982: All the Women are White, all the Black are Men, But Some of Us Are Brave. Ce féminisme noir, qui a représenté une révolution sociale et théorique pour les féministes nord-américain·e-s, permet non seulement de saisir la position sociale des femmes noires ou d'autres groupes sociaux mais encore de repenser des notions comme l'emploi, la famille ou le genre. Si la perspective intersectionnelle, qui a vu le jour aux ÉtatsUnis, a d'abord croisé la race avec le genre pour des raisons historiques et politiques contextualisées, la sociologie francophone s'est préalablement intéressée aux intersections des rapports sociaux de classe et de sexe.

Dans leur formulation, les politiques sociales tendent à considérer leurs publics de manière homogène sans prendre en compte la complexité des relations qui les traversent. En Suisse par exemple, il apparaît comme normal que des programmes sociaux proposent un traitement différencié à des groupes sociaux définis sur le seul critère de l'âge. La Conférence suisse des institutions d'action sociale recom- mande ainsi une application spécifique des normes pour les récipiendaires de l'aide sociale de moins de 25 ans, concrétisée par l'octroi de montants financiers inférieurs. Par ailleurs, des politiques de l'emploi proposent la formation aux jeunes adultes sans emploi entre 18 et 25 ans, les NEET (Not in Education, Employment or Training), et une sortie précoce de l'emploi pour la catégorie des chômeurs et chômeuses âgé·e·s à deux ans de l'âge de la retraite. Ces politiques procèdent ainsi à la naturalisation des catégories d'âge en occultant les dissemblances dans des publics pensés comme uniformes. Les catégories définies par l'âge sont pourtant traversées par d'autres rapports sociaux, tels le sexe et la classe notamment. En effet, si l'emploi et la formation sont prescrits autant pour les hommes que les femmes au début de la vie dite «active», le choix de la profession est influencé par la position de classe ainsi que par la division sexuelle du travail qui se calque sur le modèle normatif de l'homme gagne-pain et de la femme au foyer. Des recherches portant sur l'application des politiques sociales ont également montré que, même lorsqu'elles sont dépendantes de l'aide sociale, les mères élevant seules leurs enfants ne sont pas encouragées, par le personnel de travail social qui met en œuvre les politiques, à travailler à plein temps pendant la durée perçue comme légitime pour se consacrer à l'éducation de leurs enfants. À l'opposé, si des mères récipiendaires de l'assistance sociale sont mariées et rattachées à une culture naturalisée perçue comme sexiste, elles seront fortement incitées à trouver un emploi, ceci parce que leur absence d'activité professionnelle sera expliquée par ces normes culturelles différencialisées et non par celles de la «bonne» maternité. Les injonctions à l'emploi diffèrent ainsi selon la position sociale des actrices et des acteur-trice-s, position produite par l'articulation des systèmes d'inégalités et accompagnée de stéréotypes.

L'approche intersectionnelle s'avère être un outil heuristique incontournable dans le 
domaine des politiques sociales. Elle permet non seulement l'analyse critique de ces dernières mais œuvre également à mettre en lumière les effets négatifs de celles-ci sur certaines catégories sociales. Elle est considérée comme une pensée contre-hégémonique. Elle s'attelle à questionner les publics des discours politiques et à saisir des groupes sociaux perçus comme homogènes à la lumière de l'articulation des systèmes d'inégalités: qui sont les «jeunes», cibles des politiques sociales? Quelle est leur position de classe ou leur genre? Peut-on parler des «femmes» comme d'une catégorie unique? Quand la catégorie des «femmes migrantes» est évoquée, s'agit-il de cadres supérieures engagées par des entreprises multinationales ou de mères ethnicisées situées au bas de l'échelle sociale? Quelle est la norme idéalisée qui sert de modèle aux politiques? Les impensés que l'intersectionnalité met au jour permettent de répondre à ces questions afin non seulement de reconnaître la diversité des univers sociaux rattachés à des catégories homogénéisées mais également de déconstruire les stéréotypes qui les constituent.

\section{Anne Perriard}

\section{Références}

Crenshaw, K. W. (1991). Mapping the margins : intersectionality, identity politics, and violence against women of color. Stanford Law Review, 43(6), 1241-1299.

Fassa, F., Lépinard, E. \& Roca i Escoda, M. (2016). L'intersectionnalité: enjeux théoriques et politiques. Paris : La Dispute.

Perriard, A. (2017). La construction de figures de la dépendance problématique par les politiques sociales à l'aune du genre et de l'âge. Enfances, Familles, Générations. Âges de vie, genre et temporalités sociales, 27, http://journals.openedition. org/efg/1439

\section{Investissement social}

Le concept d'investissement social est un paradigme de politique sociale adopté dans une situation politico-historique spécifique afin de réagir au déficit de légitimité de l'État social. Cet article présente brièvement le contexte sociopolitique dans lequel le concept d'investissement social s'est développé, décrit ses caractéristiques et aborde les recherches empiriques réalisées à l'échelon suisse et international.

L'État d'investissement social peut être perçu comme une réponse à la critique néolibérale de l'État-providence des années 1980 qui se répercute tant sur le plan du discours et de la légitimation que dans les programmes politiques concrets. Dans l'État-providence keynésien classique, il existe un consensus sur le fait que les dégâts collatéraux de l'économie capitaliste doivent être atténués par des programmes de démarchandisation et que tous les êtres humains devraient pouvoir mener une vie digne. Les critiques néolibérales mettent à mal cet arrangement: selon leurs arguments, la hausse des dépenses sociales diminue la compétitivité des économies ainsi que les incitations pour les bénéficiaires d'allocations sociales à accepter un emploi. Avec l'État d'investissement social, on assiste par conséquent à un glissement du social vers l'économique: les dégâts collatéraux du système économique et les mesures sociopolitiques visant à y remédier ne figurent plus au centre de l'intérêt. En raison de l'abandon de l'objectif du plein-emploi, de la pression concurrentielle internationale accrue et de la primauté accordée à l'équilibre budgétaire des États, on exige de plus en plus que les dépenses de l'État-providence soient justifiées à l'aune d'un calcul coût-bénéfice de rentabilité. Apparu après la phase de développement keynésienne de l'État-providence dans les années 1950-1960 et dans le sillage des politiques de réduction des dépenses des années 1970-1980, l'État d'investissement 
social est qualifié de «troisième voie». La promesse de l'État d'investissement social consiste à réconcilier les objectifs d'«égalité» et de «performance économique», perçus comme antithétiques dans la théorie néolibérale. Comme l'explique Gøsta Esping-Andersen, un des principaux défenseurs du concept d'investissement social, en se basant sur le modèle de l'État-providence suédois, l'égalité est tout à fait compatible avec la rentabilité économique, elle en représente même la condition: selon lui, la répartition égale du pouvoir d'achat est le prérequis d'une bonne performance macroéconomique, la politique familiale est un investissement dans le capital humain de demain et la politique sociale préventive diminue les coûts économiques. Le concept de «politique sociale productive» est ainsi présenté comme une tentative de défense des mesures de politique sociale et de redistribution.

Le paradigme de l'investissement social s'accompagne d'une redéfinition des objectifs, des principes et des instruments de l'État social. Il vise à adapter la politique sociale à la nouvelle réalité socioéconomique postindustrielle marquée par l'expansion du secteur des services, l'apparition de branches économiques reposant sur le savoir et l'émergence de nouveaux risques sociaux. Cette redéfinition coïncide avec un renversement des relations entre l'économie et le social: les dépenses sociales ne sont plus perçues comme des postes de dépenses passifs dans l'État d'investissement social, mais constituent un facteur productif en tant que tel. Elles visent à «préparer» au lieu de «réparer». La contribution de la politique sociale ne se mesure plus en fonction du degré de réduction des inégalités sociales créées par le marché, mais plutôt en vertu de sa contribution à la croissance économique (p.ex. au moyen d'investissements dans le capital humain, par une meilleure formation des travailleurs et travailleuses, etc.).

Alors que la notion d'investissement social a été mobilisée très tôt pour légitimer le déve- loppement de l'État-providence social-démocrate suédois, elle ne s'est vraiment imposée qu'avec la formulation d'une «troisième voie» (manifeste Blair-Schröder) par les sociaux-démocrates européens, en lien avec l'adoption du traité de Lisbonne (2000) de l'Union européenne. Elle a ainsi été fortement marquée par l'avènement de la nouvelle social-démocratie promue par un groupe de responsables politiques et de scientifiques.

Globalement, le paradigme de l'investissement social diffuse un message ambivalent par rapport à la politique sociale: afin que l'État-providence ne nuise pas à la compétitivité des économies, mais au contraire la favorise, il faut passer d'un État-providence accordant des aides passives à un État social actif et dynamique. Présentée comme une réponse adéquate aux défis posés par le nouvel ordre économique mondial, par la formation d'une économie mondiale de la connaissance, par les changements démographiques qui menacent la viabilité des systèmes de retraite, la politique d'investissement centrée sur l'enfant cherche à réduire les dépenses dites "passives» (notamment les transferts monétaires en faveur des personnes fortement menacées d'exclusion) au profit d'investissements dans le capital humain de demain.

En Suisse, le paradigme de l'investissement social connaît une application limitée. Ainsi, la recherche présente la Suisse comme une version light de l'État d'investissement social. D’une part, les idées liées au paradigme de l'investissement social ont significativement pesé sur la politique sociale suisse au cours des 10 à 15 dernières années, comme le montre la priorité accordée à l'activation et à la réinsertion professionnelle dans les réformes de l'assurance-invalidité, de l'assurance-chômage et des normes de la Conférence suisse des institutions d'action sociale (CSIAS). D'autre part, la portée des mesures de politique familiale et des investissements dans l'éducation de la petite enfance, qui jouent un rôle central dans 
la stratégie d'investissement social axée sur la prévention, est restée relativement limitée en Suisse. Cela s'explique probablement par l'importance des compétences communales et cantonales dans le champ de la famille et de la petite enfance, ainsi que par le manque de consensus politique en faveur d'un élargissement des mesures de politique familiale.

D’un point de vue général, on observe que la promesse de l'État d'investissement social d'améliorer la compétitivité et d'éviter certains coûts en investissant dans le bien commun fait de plus en plus l'objet de critiques. Dans une publication qui résume l'état de la recherche pour la Suisse, Jean-Michel Bonvin et Stephan Dahmen énumèrent comme points de débat fondamentaux la difficulté à définir ce qu'est un investissement social et à calculer avec précision sa rentabilité, ainsi que le risque de réduction des droits sociaux que la focalisation sur les objectifs économiques de la politique sociale peut entraîner. Dans une perspective de genre, l'universalisation du citizen-worker et la dévalorisation des activités de care qui l'accompagne sont aussi problématiques. En outre, les débats internationaux mettent l'accent sur la faible efficacité de l'État d'investissement social pour faire reculer la pauvreté, notamment parce qu'il existe un gradient social dans le recours aux politiques d'investissement social. La recherche révèle que, dans l'aide sociale suisse aussi, une forme de «logique d'investissement» s'est imposée, qui s'accompagne d'une sélectivité renforcée des offres de l'État social, entraînant un effet Matthieu: on tend alors à donner davantage à ceux qui sont plus favorisés ou moins vulnérables, car ils sont susceptibles de générer des retours sur investissement plus élevés. Ainsi, il existe toujours le risque que les perdants de l'État d'investissement social soient ceux dans lesquels il n'est même plus «rentable» d'investir.

Stephan Dahmen \& Jean-Michel Bonvin

\section{Références}

Bonvin, J.-M. \& Dahmen, S. (Hrsg.). (2017). Reformieren durch Investieren? Chancen und Grenzen des Sozialinvestitionsstaats in der Schweiz / Investir dans la protection sociale: atouts et limites pour la Suisse. Zürich : Seismo.

Hemerijck, A. (Ed.). (2017). The uses of social investment. Oxford: Oxford University Press.

Morel, N., Palier, B. \& Palme, J. (2012). Towards a social investment welfare state? Ideas, policies and challenges. Bristol : Policy Press.

\section{Justice restaurative ${ }^{*}$}

La justice restaurative (JR) - le terme original anglais restorative justice est généralement utilisé - est considérée en Suisse comme une réparation ou une médiation en droit pénal. La JR se caractérise en tant que théorie et pratique d'une approche inclusive de la criminalité: d'une part, via une procédure inclusive qui renforce et implique activement les parties prenantes au traitement du délit (parties lésées, délinquant·e·s et communauté concernée); d'autre part, via un résultat inclusif qui vise à restaurer le plus possible l'intégrité des parties. La JR offre ainsi une solution alternative au concept pénal d'exclusion qui prévaut dans la politique criminelle. La JR considère la criminalité moins comme une violation des lois et des États, mais plutôt comme une violation des personnes et des relations. Le (r-)établissement de relations saines est par conséquent un objectif important de la JR.

$\mathrm{Au}$ niveau international, la JR est discutée et pratiquée sous de très nombreuses formes. Cette diversité est l'expression des différents modèles de pensées et traditions qui ont contribué à l'émergence et au développement du mouvement moderne de la JR (qui a débuté dans les années 1970 environ). La JR est d'abord profondément enracinée dans l'héritage culturel d'une justice informelle qui continue d'exister, en particulier dans les pratiques 
de résolution des conflits des peuples autochtones. Les traditions spirituelles des religions du monde comprennent également les modèles de base d'une justice réparatrice, réconciliatrice et curative. La JR s'appuie ensuite sur des approches criminologiques et des mouvements politiques récents, notamment la victimologie et son constat que les intérêts des victimes sont négligés dans la justice pénale traditionnelle, la criminologie critique et sa remise en question fondamentale de la punition étatique, allant jusqu'aux revendications abolitionnistes pour éviter l'emprisonnement, ainsi que les tendances communautaristes et leur souci de revenir au sens et à la valeur de la communauté.

Il existe également de nombreux concepts concernant la relation entre la JR et le système de justice pénale, selon les différentes évaluations du pouvoir formel et informel et du contrôle (social), des garanties procédurales dans le cadre de l'État de droit, et du rôle des expert.e.s et des communautés dans la lutte contre la criminalité (délégation versus participation). D'une part, certain.e.s pensent que la JR est une approche véritablement différente $\mathrm{du}$ concept pénal traditionnel et qu'elle doit donc se situer autant que possible en dehors du système de justice pénale. Les programmes communautaires basés sur le volontariat sont l'expression de cette conception. D'autre part, il y a une demande de faire entrer la JR dans le système de justice pénale autant que possible et donc de le réformer. Les réunions dialogiques entre les personnes accusées et les parties lésées deviennent par exemple un instrument procédural possible et la réparation $d u$ préjudice est envisagée comme une sanction alternative pour les autorités judiciaires et les tribunaux. En tant que voie médiane entre les positions susmentionnées, la JR est une forme de déjudicarisation en marge du système de justice pénale. Par exemple, l'autorité pénale peut confier une affaire à un bureau de médiation externe pour effectuer une médiation entre la victime et l'auteur.e du délit et, si la médiation est couronnée de succès, mettre fin à la procédure pénale.

En Suisse, l'accent est mis sur la conception de la JR comme une forme de déjudiciarisation et en tant qu'instrument de médiation entre la victime et l'auteur.e du délit, la focale étant placée sur la victime individuelle et sa relation avec la personne accusée. Cependant, la JR comprend beaucoup plus d'instruments que le modèle de médiation entre la victime et l'auteur.e du délit. Les modèles qui sortent de ce cadre en intégrant un réseau plus étendu ou la communauté - ce qu'on appelle les circles et les family group conferences - ne sont mis en œuvre en Suisse que dans le cadre de projets isolés. Par contre, des éléments de réparation sont pris en compte à tous les stades de la procédure pénale formelle: lors des procédures préliminaires et d'enquête, des procédures judiciaires, ainsi que dans le cadre de l'exécution des peines.

La JR au sens d'un modèle procédural participatif orienté sur la réparation reste un phénomène marginal en Suisse. La Suisse accuse un retard de deux décennies environ par rapport à ses voisins germanophones en ce qui concerne l'ancrage juridique au niveau fédéral et la mise en œuvre pratique de la JR. Toutefois, l'image globale de la JR en Suisse est essentiellement caractérisée par la diversité fédéraliste de ce pays. Quelques cantons progressistes - à savoir Zurich et Fribourg - mettent en œuvre la JR depuis plus de dix ans avec des projets modèles, des programmes institutionnalisés, des bases juridiques détaillées et une pratique réussie de la médiation en droit pénal. On ne trouve cependant rien de tel dans les autres cantons.

En général, le droit pénal suisse contient un nombre considérable d'éléments d'intégration et de réparation (orientés sur les résultats); leur application dépend cependant principalement des autorités pénales. En revanche, il n'existe que quelques modèles de justice restaurative «à part entière» (orientés vers les processus) qui impliqueraient un traitement 
externe des cas. Le fait que le droit pénal suisse soit relativement modéré et en grande partie inclusif peut entraver la poursuite de la mise en place de la JR, puisque les instruments existants réduisent la pression en faveur de l'utilisation ou l'attrait des solutions alternatives.

Dans le climat actuel de politique pénale, caractérisé par la popularité des approches conservatrices de droite à orientation rétributive et punitive, l'ancrage juridique et l'application pratique d'approches inclusives et axées sur la réparation se trouvent dans une situation difficile. La diffusion ultérieure de la JR devrait donc se poursuivre par le biais de programmes régionaux progressifs spécifiques, d'initiatives pionnières et d'individus engagés. Cependant, la différence de disponibilité de la JR selon les lieux qui en résulte est problématique du point de vue de l'égalité des droits ou de l'égalité d'accès.

La référence au passé contenue dans les adjectifs «restaurative» et «réparatrice» devrait en principe être remise en question de manière critique. Cela pose problème dans la mesure où, dans de nombreux cas, il est nécessaire ou souhaitable que les personnes concernées cherchent à créer une nouvelle réalité au lieu de restaurer un ancien état. Notamment dans le cas des crimes graves, l'idée de réparation est souvent inappropriée ou même présomptueuse; pour les personnes concernées, il faut plutôt jeter les bases d'un nouveau départ, dans la mesure du possible. Par conséquent, la JR ne devrait pas seulement viser la «restauration», mais, autant que possible, également la «transformation». À ce sujet, de nombreuses approches de la JR ont également un grand potentiel au niveau supra-individuel et communautaire: la criminalité est ici comprise comme l'expression d'un besoin de changement social, c'est pourquoi son traitement ne consiste pas simplement à combattre les symptômes et à rétablir les relations dysfonctionnelles préexistantes, mais doit être utilisé comme une impulsion pour la réorganisation des communautés. Ce potentiel transformateur se retrouve de plus en plus dans des approches de JR qui préconisent une participation communautaire élargie (avec des procédures de conferences et circles). De tels modèles inclusifs peuvent être porteurs d'avenir pour l'évolution future de la JR.

\section{Claudio Domenig}

\section{Références}

Domenig, C. (2008). Restorative Justice und integrative Symbolik: Möglichkeiten eines integrativen Umgangs mit Kriminalität und die Bedeutung von Symbolik in dessen Umsetzung. Bern: Haupt.

Perrier, C. (2009). La médiation en droit pénal suisse: étude de la législation suisse relative à la médiation pénale à la lumière des droits français, allemand et belge. Basel : Helbing Lichtenhahn.

Zehr, H. (1990). Changing lenses: a new focus for crime and justice. Scottdale: Herald Press.

\section{Justice (sociale) ${ }^{*}$}

La justice sociale occupe depuis longtemps une place importante dans les débats sociophilosophiques et sociopolitiques. Étalon moral par excellence, la justice désigne d'une part la vertu individuelle d'agir équitablement, mais d'autre part l'idée de justice est aussi un critère de jugement de la légitimité des rapports sociaux et des institutions. Dans le contexte juridique, la justice est surtout synonyme d'égalité et désigne le principe formel de l'égalité des hommes en droits. Dans ce sens, la justice correspond au principe incontesté et raisonnable de la justice procédurale en vertu duquel les cas identiques doivent être traités de la même façon.

Dans notre civilisation moderne, ce principe formel s'accompagne d'un concept matériel, la justice distributive, qui est un principe de base de l'État social de droit tel qu'il s'est développé depuis la fin du XIX siècle. La justice sociale 
en tant que principe constitutionnel rend l'État responsable de la situation et de l'évolution de la société ainsi que de la situation sociale de ses membres. Cette conception de la justice découle de la justice compensatrice (distributive).

Les considérations de justice jouent un rôle essentiel dans les débats sociopolitiques portant sur l'évolution de l'État social, car l'État social moderne peut être compris comme une institution qui compense, par les mécanismes de l'État-providence basés sur des conceptions de justice, les déficits sociaux créés par le système économique. Cette compensation sociale vise non seulement une répartition équitable des biens matériels et immatériels, mais a également pour but de satisfaire les besoins de base et de permettre à la population de mener une vie digne et autodéterminée. Même si la façon de concrétiser cette idée d'une juste répartition fait débat, le concept de justice sert dans une large mesure à mettre en évidence ces aspirations dans le discours de la société sur les questions sociales.

La justice compensatrice, qui part du principe que chaque personne se voit attribuer ce qui lui revient, crée des problèmes immédiats car il n'est pas facile de déterminer en quoi consiste ce qui revient à chacun ou ce qui est raisonnable. Le concept de justice sociale dépend en fin de compte de certaines représentations sociales au sujet de la justice et de considérations théoriques. À cet égard, la justice n'est pas un point de référence fixe, mais plutôt un principe régulateur à partir duquel la répartition concrète des biens et des opportunités dans un État peut être observée de manière critique.

À notre époque, les débats font apparaître de nombreuses conceptions, parfois très différentes, de la justice. Mais c'est certainement John Rawls, en 1971, qui a présenté la théorie de la justice la plus significative dans son œuvre $A$ Theory of Justice. Il y fait la distinction entre deux niveaux d'exigence de justice. Pour lui, le premier et le plus important principe de justice est celui du système le plus étendu de libertés égales pour tou·te-s, selon la philosophie d'Emmanuel Kant. Le premier principe régit l'égale répartition des libertés de base dans la société. Tous les hommes doivent avoir les mêmes droits aux libertés personnelles. Dans le cas de ces libertés de base, la justice fait référence à une répartition égale. Au deuxième niveau, Rawls se demande comment ces mêmes libertés de base peuvent être conciliées avec l'inégalité matérielle qui règne dans la société. Il apparaît alors que les inégalités résultant des divergences entre les situations économiques et sociales des sujets ne sont pas injustes par principe, car la justice comme égalité ou comme répartition égale ne concerne que les libertés de base. L'inégalité est possible dans le domaine économique et social. Mais selon Rawls, cette inégalité doit remplir deux conditions pour être juste. D'une part, l'égalité des chances doit exister malgré l'inégalité, et d'autre part la répartition inégale doit être à l'avantage des plus défavorisés.

Lélément décisif dans cette approche formelle réside dans le fait qu'elle légitime l'inégalité matérielle aussi au prisme de la justice, ce qui lui a valu de nombreuses critiques, notamment de la part d'Amartya Sen et de Martha Nussbaum, qui ont tous deux souligné le fait que la théorie contractuelle de Rawls laisse de côté la question des chances de réalisation effective des droits aux libertés. Avec son approche des possibilités de développement et de réalisation (capabilities), Martha Nussbaum tient compte de la diversité des besoins des hommes, pose la question de la justice distributive au niveau international et évoque la situation particulière des personnes touchées par un handicap. Ce faisant, Nussbaum esquisse un concept de justice orienté sur la couverture des besoins humains dans toute leur diversité, qui joue un rôle majeur dans les débats sociopolitiques portant sur l'organisation des systèmes de protection sociale. 
En ce qui concerne les systèmes de sécurité sociale, de ces considérations sur la justice découlent trois grandes exigences: d'abord, il faut appliquer le principe de la justice procédurale, autrement dit le principe d'égalité de traitement des cas similaires. Ensuite, il faut tenir compte de la justice orientée sur les besoins. Ici, il s'agit de reconnaître et de garantir les besoins des personnes afin que celles-ci puissent vivre dignement. Enfin, il faut aussi tenir compte de manière adéquate de la justice orientée sur la performance. Tandis que la justice procédurale et la justice orientée sur les besoins ne sont pas liées à l'engagement personnel de chaque bénéficiaire de prestations sociales, cet aspect peut être pris en compte par la justice orientée sur la performance, car le droit aux prestations peut être justifié non seulement par l'indigence mais aussi par l'engagement ou l'action réelle.

Dans les débats actuels sur l'État social actif, on assiste de plus en plus en Suisse à un déplacement de la justice orientée sur les besoins vers la justice orientée sur la performance. Le soutien aux démuni-e.s dépend de plus en plus de leur disposition à fournir une contrepartie. D'un point de vue de politique sociale, ce déplacement est fatal dans le sens où le concept de performance remet en question la justice orientée sur les besoins et conditionne l'aide destinée à garantir une existence digne à la docilité des démuni-e.s. On peut craindre que ces effets délétères soient justifiés par des principes dans la mesure où le concept de performance instille dans les débats une distinction et une hiérarchisation des bénéficiaires des prestations de soutien, qui ne sont pas adéquates dans le cadre de l'État social. Si l'on revient au but premier de l'État social, qui consiste à fournir aux personnes le soutien dont elles ont besoin afin de leur permettre de mener une vie digne et autodéterminée, il faut remettre à sa place l'idée de performance. La performance peut et doit jouer un rôle, mais uniquement à titre d'incitation et non comme outil de sanction, et seulement dans le strict respect de la justice orientée sur les besoins.

Peter A. Schmid

\section{Références}

Höffe, O. (2015). Gerechtigkeit: Eine philosophische Einführung (5., durchgesehene Aufl.). München : Beck.

Nussbaum, M. (2006). Frontiers of justice: disability, nationality, species membership. Cambridge: The Belknap Press.

Sen, A. (2009). The idea of justice. Cambridge : Harvard University Press.

\section{Libéralisme}

Nourri de la philosophie de John Locke puis de celle des Lumières, ainsi que d'Adam Smith sur le plan économique, le libéralisme vise la primauté de la liberté de l'individu contre l'arbitraire et l'interventionnisme de l'État. Il revêt sa formulation moderne au tournant des XVIII ${ }^{e}$ et XIX ${ }^{\mathrm{e}}$ siècles avec les déclarations américaine (1776) et française (1789). Une question réside au fondement de sa construction intellectuelle : comment préserver au mieux les acquis de la Révolution, articulés sur la liberté et l'égalité des droits?

Dès les années 1820, les penseurs libéraux se concentrent sur la mise en place d'institutions capables de protéger les droits individuels et de tracer une ligne de démarcation claire entre la sphère privée et la sphère publique, même si l'État n'est pas contesté comme tel. La loi est érigée en garante de la liberté. Le libéralisme se pensera dans le cadre de l'État national.

$\mathrm{Au}$ nom d'une économie organisée autour de la libre entreprise mais sous le contrôle d'un système politique marqué par la séparation des pouvoirs, les libéraux, longtemps attirés par la monarchie constitutionnelle de type britannique, vont progressivement adhérer à l'idéal 
du suffrage universel, au nom de la responsabilité individuelle.

Après la crise de 1929, des libéraux fondent le «néolibéralisme» sous l'impulsion de l'Américain Walter Lippmann, hostile à l'interventionnisme de l'État dans les rouages économiques prôné par John Maynard Keynes. Après-guerre, sous l'influence de l'Ordoliberalismus, théorisé en Allemagne notamment par Walter Eucken et Wilhelm Röpke, une conciliation des principes libéraux avec les exigences d'un État plus providentiel, mais qu'il s'agit de surveiller sur le plan financier, est opérée.

Dès les années 1960 et les crises économiques des années 1970, une césure apparaît à l'intérieur du camp libéral. Une aile s'attache surtout à son versant politique, au nom de la préservation des libertés individuelles, et conservera le nom «libéral»; en Allemagne, elle formera l'aile gauche du parti libéral et, aux États-Unis, elle constituera une composante du parti démocrate. Mais une autre aile, théorisée dans les pays anglo-saxons par Ludwig von Mises ou par le plus modéré Friedrich von Hayek, donne un poids dominant à l'économie de marché, jugée seule à même d'assurer la prospérité générale contre une mainmise excessive de l'État-providence.

Les premiers libéraux suisses prolongent les valeurs des Lumières dans un libéralisme apte à traduire dans des institutions les principales libertés individuelles, notamment celle relative à la presse. Le libéralisme s'impose principalement dans les cantons protestants dès les années 1830.

Favorable à un État doté de finances publiques saines, à un système représentatif, à une économie orientée vers le marché et aux libertés fondamentales, le libéralisme de cette époque n'est pas dépourvu d'une pensée sociale. Si l'individu est responsable de ses actes, on prend conscience des périls d'une liberté sans contrepoids et un intérêt important est porté aux questions éducatives alors que le suffrage universel (masculin) s'impose dans plusieurs cantons.

Fondée en 1810, la Société suisse d'utilité publique s'intéresse au sort des enfants travaillant dans les fabriques ou à celui des prisonnier-ère-s. Si l'esprit d'entreprise doit être valorisé, il s'agit de faire participer le plus grand nombre au progrès général, sous l'égide de la religion, digue morale aux excès d'un marché parfois aveugle. L'éthique du travail est cultivée comme un facteur d'émancipation.

Le mouvement radical émerge sur la gauche du mouvement libéral dès le début des années 1830 et cherche le moyen de concilier les idéaux libéraux et la nécessité désormais avérée d'un État fédéral plus centralisé, capable de construire les infrastructures dont l'économie a besoin. Ce sera le but de la Constitution de 1848. Certains radicaux plaident pour une démocratie plus directe, qui doit promouvoir les changements sociaux.

L'idée d'un État social déployé au niveau national voit le jour dans les années 1860, avec le mouvement démocrate apparu sur l'aile gauche du radicalisme. Le système des coopératives convainc également les libéraux. Charles Secrétan, pionnier de la question féminine, en sera l'un des grands théoriciens.

Les radicaux répondent pragmatiquement à l'évolution de la question sociale. En 1877 est votée une loi sur le travail. Puis, à l'image de l'Allemagne bismarckienne et de son Staatssozialismus, ils élaborent une loi sur l'assurance contre les accidents et la maladie, qui entrera en vigueur après la Première Guerre mondiale. Soucieux d'une bonne gestion financière, les radicaux renoncent à introduire d'autres lois sociales.

Après la Seconde Guerre mondiale, pivots d'un système de gouvernement de type consensuel, les radicaux (PLR depuis 2002) contribuent à l'établissement de l'assurance-vieillesse et survivants (AVS) en 1947, adhérant ainsi au principe de l'État-providence, et acceptent son extension progressive, ainsi que l'adjonction de 
nouvelles assurances comme l'assurance-invalidité ou l'assurance-chômage. Ils refusent toutefois de mettre en danger les finances publiques.

Les libéraux, dès lors qu'ils entendent participer à l'action gouvernementale, ont appris à intégrer dans leur vision du monde un fort pragmatisme. Ils l'ont ainsi adaptée, à travers un marché qui doit rester fondamentalement libre, en y introduisant une dimension démocratique, puis sociale, avec une adhésion à l'État-providence, et, enfin, dans une certaine mesure, environnementale.

Les coûts engendrés par l'État social les ont amenés, à partir des années 1980, à privilégier la croissance économique, l'assainissement des finances publiques et la réforme de l'administration. Alors que les principes directeurs du libéralisme s'étaient diffusés, depuis longtemps, dans les partis conservateurs et, parfois mais plus récemment, dans une partie de la social-démocratie, le débat interne au libéralisme, lié à la prédominance de la liberté politique ou de la liberté économique, s'est avivé.

Fondé sur la synthèse entre l'État et la liberté et sur l'idée d'État de droit, le libéralisme ne se justifie cependant que dans son unité à la fois politique et économique. Néanmoins, avec l'essor technologique dès la fin du $\mathrm{XX}^{\mathrm{e}}$ siècle, le libéralisme, qualifié alors de «néo» ou d'«ultra», s'est engagé en faveur d'une franche ouverture des marchés mondiaux au nom d'un libre échange censé répondre aux besoins de l'humanité. Mais cette évolution s'est réalisée au détriment de son aile plus disposée à accepter une intervention des pouvoirs publics, notamment pour encourager l'égalité des chances ou une ouverture plus large en direction de l'écologie.

Assimilé dans sa dimension «égalitaire» à une tendance proche de la social-démocratie dans sa définition américaine, associé à un capitalisme le moins inhibé possible dans une définition plus européenne, intégré dans le fonctionnement de l'État depuis 1848 par son alliance avec le radicalisme en Suisse, le libéralisme se voit confronté à la nécessité de renégocier en permanence les équilibres internes entre ses différentes composantes.

Les libéraux doivent en outre repenser leur action dans un contexte où se multiplient les appels à un État national à vocation plus protectrice, revendiqué à la fois par ceux et celles qui demandent une intervention étatique plus prononcée et par le courant néoconservateur, centré sur la question nationale. Ils doivent redéfinir leur compréhension d'une liberté dont ils ne peuvent plus, depuis les années 1960, se déclarer les uniques défenseurs.

Olivier Meuwly

\section{Références}

Bessard, P. \& Meuwly, O. (Hrsg.) (2011). Dem Schweizer Liberalismus auf der Spur-Sur les traces du libéralisme suisse. Zürich : Liberales Institut.

Schwarz, G. \& Wenzel, J. (Hrsg.) (2006). Lust und Last des Liberalismus: Philosophische und ökonomische Perspektiven. Zürich : Verlag Neue Zürcher Zeitung.

\section{Logements et contexte spatial ${ }^{*}$}

Le terme «logement» désigne des (unités de) bâtiments utilisés comme des «lieux d'habitation ». Selon la définition de l'Office fédéral de la statistique (OFS), ces derniers comprennent des unités d'habitation bénéficiant d'un accès autonome depuis l'extérieur et d'un équipement de cuisine, dans des maisons à plusieurs logements (immeubles) ou individuelles. Le logement répond aux besoins de base, a un impact sur la santé et le bien-être, illustre le style de vie et la position sociale, et est bien plus qu'un simple toit au-dessus de la tête. La vie quotidienne, les possibilités d'épanouissement ou de socialisation dépendent non seulement de la taille et de l'équipement, mais également de l'emplacement du logement dans 
une commune ou une ville. La répartition inégale des logements dans les agglomérations résulte de l'interaction de leur production (investisseur·e·s), des conditions de propriété, des mécanismes d'insertion sociale (tels que le travail rémunéré) et des réglementations légales.

Durant la période préindustrielle, époque féodale-absolutiste, les gens vivaient dans des conditions de dépendance sociale, dans des bâtiments plus ou moins salubres, le plus souvent dans des lieux fixes. Ils n'ont massivement quitté ces logements - qui leur étaient imposés et qu'ils ne pouvaient pas aménager à leur goût - que grâce à divers développements sociaux (p.ex. le siècle des Lumières, la dissolution des conditions féodales) et technologiques (p.ex. l'industrialisation). Le développement urbain massif qui en a résulté au cours du XIX siècle, en Suisse et dans les pays limitrophes, a entraîné une pénurie et une augmentation du prix des logements, avec des conséquences telles que la sous-location, la location d'un lit pour une nuit, etc. La propriété et l'exercice d'un travail rémunéré déterminaient toujours plus souvent qui pouvait vivre comment et où : les démuni.e.s devaient chaque jour trouver un nouvel abri contre rémunération et en location. Ceux.celels qui n’y parvenaient pas étaient socialement et géographiquement exclu·e.s et dépendaient des prestations de l'aide aux pauvres. Sur le plan socio-spatial, cette ségrégation des groupes de population a conduit au développement de zones résidentielles socioéconomiquement inégales.

À l'échelon politique, ces contextes résidentiels précaires ont été traités depuis le milieu du XIX ${ }^{e}$ siècle comme une «question du logement ouvrier» (classe ouvrière, petite bourgeoisie menacée) et comme une «question du paupérisme» (personnes démunies sans travail): avec leur politique de logement, les élites dirigeantes ont cherché à augmenter les revenus tirés de la propriété et ont misé sur l'implantation et le maintien de leur maind'œuvre par le biais d'une activité de construction ciblée (casernes, logements ouvriers). En vue d'éduquer la classe ouvrière par et pour le logement, les comportements immoraux et malsains (radicalisme politique, changement de partenaires, négligence des enfants) ont été combattus et grâce à des mesures ciblées telles que la promotion de l'art et de la culture ou des associations de construction, un modèle spécifique de logement domestique a été mis en œuvre: la famille de deux générations en tant qu'unité sociale, la séparation des espaces consacrés au logement et au travail rémunéré ainsi que le contraste entre sphère privée et domaine public. En revanche, les plus démuni.e.s économiquement étaient isolé·e-s géographiquement, et recevaient en outre un soutien paternaliste en fonction de leur degré de responsabilité individuelle (établissements de travail, colonies de pauvres en milieu rural).

À l'inverse, la politique de logement de la classe moyenne urbaine a ciblé des réglementations juridiques: des normes pour modifier les méthodes de construction (réforme du logement), municipaliser le terrain et la propriété du logement (réforme agraire) ou modifier l'urbanisme (comme le mouvement des cités-jardins). La classe ouvrière émergente, au bénéfice d'une sécurité précaire et politiquement divisée, a finalement misé sur des salaires sûrs : alors que l'aile antiréformiste, influencée par le marxisme, ne voyait une solution que dans l'élimination des rapports de travail capitalistes, les réformistes prônaient une coopération entre les niveaux national et communal. Ces derniers se sont imposés sur le plan politique, ce qui a conduit en particulier après la Première Guerre mondiale à une politique du logement nationale et à une vague de mesures juridiques (nouveaux règlements de construction, fonds fonciers municipaux, services de logement, etc.) et structurelles (associations de construction, sociétés de construction, coopératives de construction, etc.). D'un point de vue 
marxiste, ces diverses aides au logement n'ont permis que de pacifier la question de la pénurie de logements, mais les rapports de pouvoir et de domination sociaux causant les inégalités n’ont pas été renversés.

Selon l'enquête de l'Office fédéral de la statistique (OFS) de 2014, la Suisse peut aujourd'hui être décrite comme le pays européen des locataires par excellence, avec environ $60 \%$ de la population vivant dans des logements loués. Les défis en termes de politique sociale peuvent être relevés, par exemple en problématisant les modes de propriété des logements: selon l'OFS, plus de $70 \%$ sont des propriétés privées et la tendance est à la hausse. Les biens des investisseurs institutionnels (compagnies d'assurance, caisses de pension) sont en légère baisse (environ $8 \%$ ), alors qu'ils sont en forte baisse pour les sociétés de construction et immobilières (environ $4 \%$ ) et stables pour les coopératives (6\%) et le secteur public ( $2 \%$ pour les communes, les cantons et la Confédération). Au-delà de ces modes de propriété différents, il semble que les inégalités de conditions de logement et de vie s'amplifient et se concentrent sur une base territoriale. Il convient donc de répondre à la question des logements disponibles en fonction du contexte, c'est-à-dire en tenant compte des groupes de population socioéconomiques et du contexte régional.

Le marché du logement est particulièrement tendu dans les régions centrales de la Suisse et ce, en dépit d'une activité de construction forte et soutenue. Cette situation s'explique, d'une part, par un changement dans la pratique du logement, mais aussi par les exigences diverses qui en résultent pour les logements : tendances à l'individualisation et à la pluralisation des modes de vie (nouveaux types de logement), besoins et exigences croissants en matière de mobilité (multi-localité résidentielle), évolution démographique (logement des personnes âgées, logement multigénérationnel) ou mouvements migratoires mondiaux (nouvelles cultures du logement). D'autre part, selon les statistiques sur la charge locative par classe de revenu de l'Office fédéral du logement, le fossé au sein de la population s'est considérablement élargi en termes de situation sociale et économique, ce qui implique qu'aujourd'hui les groupes habituellement défavorisés, à l'instar des personnes à faible revenu, des familles nombreuses, des travailleuses et travailleur.euse-s étranger-ère-s, des chômeuses et chômeurs et des personnes âgées, ne sont pas les seuls à être désavantagés sur le marché du logement. Bien plus, on observe aujourd'hui de nouvelles tendances à l'abandon de références considérées jusqu'alors comme sûres tant au niveau du travail qu'au niveau social - une évolution qui force les gens à assumer davantage de responsabilité individuelle.

$\mathrm{Du}$ point de vue de la politique sociale, il convient de faire avancer concrètement les mesures concernant la sécurité du logement. Les difficultés financières causées par les coûts de location excessifs et les restrictions massives dans le choix du lieu de résidence de certains groupes de personnes âgées et de personnes handicapées illustrent la nécessité d'ajuster les prestations complémentaires à l'AVS/AI. En l'absence de normes, telles que celles fixées par la Conférence suisse des institutions d'action sociale (CSIAS), la contribution d'aide au logement en faveur des bénéficiaires de l'aide sociale risque d'être réduite de manière forfaitaire et leur situation socioéconomique risque de faire l'objet d'une suspicion générale. Cependant, l'importance sociopolitique du logement ne s'arrête pas à la garantie d'avoir un abri pour ces groupes. Il convient davantage d'examiner leur environnement proche, car c'est dans celui-ci que sont supposées se trouver des ressources importantes pour la cohésion sociale (voir p.ex. le programme «Projets Urbains - Intégration sociale dans des zones d'habitation» soutenu par la Confédération). En outre, il s'agit de (re)contextualiser de manière critique les rapports de pouvoir et 
de propriété dominants, ainsi que leurs effets sur l'accès au logement dans les conditions sociales et socio-spatiales actuelles, afin d'en faire une question de politique sociale. En effet, les mesures légales prises jusqu'à présent (p.ex. l'encouragement de la construction de logements d'utilité publique dans les articles 41 ou 108 de la Constitution fédérale), les conditions de propriété prédominantes, les systèmes d'intégration et de sécurité sociales, mais aussi l'idéal historique du logement dépeint ci-dessus sont toujours d'actualité et (re)produisent le logement et les mécanismes d'exclusion de celui-ci.

\section{Christian Reutlinger}

\section{Références}

Engels, F. (1845). La situation des classes laborieuses en Angleterre (2 vols.). Paris: Archives Karéline, 2010.

Frank, H. \& Schubert, D. (Hrsg.) (1983). Lesebuch zur Wohnungsfrage. Köln: Pahl-Rugenstein.

Offices fédéraux du développement territorial, des migrations, du logement \& du sport, Service de lutte contre le racisme \& Commission fédérale pour les questions de migration (Éd.) (2013). Les quartiers en action: une approche plurielle pour un développement partagé. Expériences de développement de quartier issues du Programme «Projets urbains - Intégration sociale dans des zones d'habitation». Berne : OFCL.

\section{Logement pour personnes âgées*}

Dans la phase post-professionnelle, le logement devient pour la plupart des personnes le véritable centre de la vie. Un logement bien équipé et un environnement stimulant augmentent le bien-être, la sécurité et le rayon d'activité des personnes âgées. Les changements du parcours de vie (départ des enfants, décès du ou de la partenaire) conduisent à une réduction de la taille du ménage. Le fait de vivre seul·e est fréquent, en particulier chez les femmes.
En raison de problèmes physiques et de limitations fonctionnelles, les personnes âgées ont davantage besoin d'un logement sans obstacles et d'un environnement qui leur procure un soutien social. L'adéquation entre les besoins individuels et les aspects architecturaux, techniques et sociaux est un facteur décisif pour que les personnes âgées soient satisfaites de leur vie et de leur logement. Inversement, l'absence d'adéquation entre la personne âgée et son environnement entraîne des restrictions et des obstacles quotidiens. Lorsque surviennent des limitations fonctionnelles, sensorielles ou cognitives, de petits désagréments (portes étroites, seuils élevés, accès pentu au logement) peuvent objectivement devenir des obstacles insurmontables.

En général, en Suisse, les personnes âgées bénéficient d'un cadre de vie de haute qualité comparé aux personnes du même âge dans les pays d'Europe de l'Est et du Sud. Cependant, dans de nombreuses régions du pays, on observe un manque croissant de logements bon marché adaptés aux personnes âgées. Cela contribue au fait qu'un trop grand nombre de personnes restent trop longtemps dans des logements non adaptés ou, dans certains cas, déménagent dans un établissement médico-social bien qu'elles n'aient pas besoin de soins.

Trois principes centraux doivent être pris en compte lorsqu'il est question du logement des personnes âgées : premièrement, les processus de vieillissement sont soumis à une hétérogénéité interindividuelle et, dans la mesure où ils ne sont pas standardisés, des termes tels que «logement adapté aux personnes âgées » doivent être utilisés avec modération. Ainsi, un «logement adapté aux personnes âgées» peut signifier des caractéristiques différentes en fonction du processus de vieillissement. Deuxièmement, les besoins d'une personne âgée en matière de logement varient en fonction de la classe sociale, du niveau d'instruction et des revenus. En fonction du montant des rentes de vieillesse et du patrimoine, les personnes âgées 
ont accès à différents types de logement. Les personnes fortunées peuvent s'offrir un logement luxueux dans une résidence pour personnes âgées ou acquérir un appartement coûteux (un nombre croissant de personnes âgées sont propriétaires de leur logement en Suisse). Les personnes moins nanties, en revanche, doivent louer un appartement bon marché ou un logement subventionné pour personnes âgées. Troisièmement, les souhaits relatifs au logement dépendent de l'histoire de chaque personne. Selon les habitudes de vie, la personne préférera certaines formes de logement à d'autres. Les personnes âgées qui ont longtemps habité un logement y associent souvent les souvenirs de leur vie. À un âge avancé, le logement et le lieu de domicile - où la personne a mené sa vie avec ses hauts et ses bas - deviennent souvent des points de repère centraux de sa vie.

Considérant la vieillesse (souvent implicitement assimilée à un déclin de la santé fonctionnelle), deux besoins fondamentaux en matière de logement sont actuellement mis en avant: d'une part, les personnes âgées veulent mener leur vie de manière aussi autonome que possible et continuer à façonner leurs conditions de logement et de vie de manière indépendante. Un habitat autonome n'inclut pas seulement l'aménagement individuel des espaces, mais aussi la possibilité de décider en toute indépendance qui a accès à l'espace privé du logement, et surtout aux pièces intimes (chambre à coucher, salle de bains). D'autre part, un grand besoin de sécurité émerge lorsque des limitations physiques, sensorielles et cognitives surviennent ou sont susceptible de survenir dans un avenir proche. La sécurité n’a pas seulement trait à l'approvisionnement matériel et à l'assistance physique et infirmière, mais aussi au maintien de l'intégration sociale et médico-sociale. Dans ce sens, la sécurité se définit comme la possibilité d'avoir accès à des interlocuteurs sociaux, à des soins médicaux et à un soutien infirmier en cas de besoin.
Ces deux besoins fondamentaux sont susceptibles d'évoluer en fonction des processus de vieillissement. Ainsi, l'importance d'un logement et d'un environnement adaptés, idéalement dénués d'obstacles, va croissante afin de répondre aux besoins d'autonomie des personnes âgées. Quand à la réponse aux besoins de sécurité et de soins, elle dépend de l'existence d'une structure d'aide communale intégrée à mesure que les besoins d'aide et de soins augmentent.

Pour des personnes âgées en bonne santé fonctionnelle, le logement privé n'est pas fondamentalement différent du logement privé occupé au cours des phases antérieures de la vie, et même à un âge avancé, le logement privé normal reste la forme d'habitation la plus courante. Cependant, avec l'augmentation des limitations liées à l'âge, telles que la mobilité réduite, deux facteurs de soutien deviennent plus importants dans le logement privé: premièrement, un logement sans obstacles (une salle de bain facile d'accès, l'absence d'escaliers, etc.) et la possibilité de demander rapidement de l'aide via un système d'appel à domicile ou un bouton d'alarme si nécessaire, peut faciliter la vie en logement privé en cas de limitations physiques. Deuxièmement, une bonne intégration sociale est essentielle au bien-être des personnes âgées. Avoir de bons contacts sociaux (familiaux, amicaux, professionnels et de voisinage) est favorable à la santé dans toutes les phases de la vie, mais avec la diminution de la mobilité, les bons contacts avec le voisinage et des personnes aidantes, la proximité des commerces ou des services médicaux gagnent particulièrement en importance.

Les restrictions en termes de relations sociales et de soins à l'intérieur du logement privé - souvent de vieux appartements non adaptés aux personnes âgées - ont contribué au développement de formes d'habitation alternatives pour les personnes âgées. En ce qui concerne l'intégration sociale, des communautés de personnes âgées ou des maisons 
multigénérationnelles sont encouragées et se créent de plus en plus souvent. Parmi les avantages d'une communauté de personnes âgées ou d'une forme d'habitat intergénérationnel, citons notamment l'entraide mutuelle, les activités communes et un risque moindre de souffrir de solitude. Cependant, l'idée, romantique d'un point de vue social, de vieillir en communauté s'avère problématique, car les logements de type colocation pour les personnes âgées présupposent un niveau de vie social identique pour leurs membres et atteint ses limites lorsque le fardeau des soins devient trop lourd. La plupart des formes de logement communautaire s'adresse, en conséquence, aux personnes âgées en bonne santé.

S'agissant des formes de logement spécialisé pour les personnes âgées ayant besoin d'aide et de soins, la grande majorité d'entre elles sont des formes de logement encadré (ou : logement accompagné, habitat avec services). Le logement encadré combine un logement privé adapté aux personnes âgées ou une unité d'habitation avec cuisine et salle de bain et des prestations de services, d'aide et de soutien spécifiques. L'objectif central est de permettre aux personnes âgées de vivre de manière indépendante, même en cas de problèmes de santé. Comme pour les autres formes de logement pour personnes âgées, les formes de logement encadré ou avec service sont fortement segmentées selon les catégories de revenus (logements de service de luxe pour personnes âgées fortunées, offres limitées avec des standards de logement et de service inférieurs pour personnes âgées à faible revenu).

La Suisse a ceci de particulier que la proportion de personnes de plus de 80 ans vivant dans un établissement médico-social est significativement plus élevée que dans les pays voisins. Cette situation est liée à une longue tradition sociopolitique d'un régime de prise en charge communale (d'abord dans des hospices, puis des maisons de retraite, et aujourd'hui des centres de soins). Ce n'est que durant les dernières decennies que les soins à domicile (Spitex) ont été développés. La proportion des personnes âgées recevant des soins en institution diminue en conséquence. Cependant, le financement public des soins (fortement concentré sur les soins médicaux et non sur l'encadrement médico-social) a pour conséquence, dans certains cantons, que de nombreuses personnes âgées continuent à vivre dans des établissements médico-sociaux alors qu'elles ont de faibles besoins en matière de soins.

\section{François Höpflinger}

\section{Références}

Füglister-Dousse, S., Dutoit, L. \& Pellegrini, S. (2015). Soins de longue durée aux personnes âgées en Suisse: évolutions 2006-2013. Neuchâtel : Observatoire Suisse de la Santé.

Höpflinger, F., Hugentobler, V. \& Spini, D. (2019). Habitat et vieillissement. Réalités et enjeux de la diversité (Age Report IV). Zurich : Seismo.

Jann, A. (2015). Age-Wohnmatrix : Bedürfnisse statt Begriffe ins Zentrum stellen. Zeitschrift für Gerontologie \& Geriatrie, 48, 164-168.

\section{Logement pour personnes en situation de handicap*}

Un logement est bien plus qu'un «toit au-dessus de sa tête». Lors de la $4^{\mathrm{e}}$ Conférence ministérielle sur l'environnement et la santé, l'Organisation mondiale de la santé (OMS) a défini le logement comme impliquant un rapport étroit entre l'hébergement, le domicile, l'environnement immédiat et le voisinage. Une définition aussi complète du logement est particulièrement pertinente dans le contexte du handicap. Elle couvre les préoccupations des personnes handicapées en matière d'égalité et de lutte contre la discrimination, qui ont gagné une nouvelle dimension à la fin du $\mathrm{XX}^{\mathrm{e}}$ siècle et qui concernent également le logement. 
En Suisse, l'égalité entre personnes handicapées et non handicapées est inscrite dans la Constitution fédérale depuis 1999. En outre, la loi fédérale sur l'élimination des inégalités frappant les personnes handicapées (LHand) est entrée en vigueur en 2004. Elle définit les conditions-cadres qui permettent aux personnes handicapées de participer plus facilement à la vie sociale, culturelle et sociétale. Depuis mai 2014 s'applique aussi en Suisse la Convention des Nations Unies relative aux droits des personnes handicapées (Convention sur les droits des personnes handicapées, $\mathrm{CDPH})$, la première convention internationale spéciale visant à assurer aux personnes handicapées la jouissance de tous les droits humains et une participation égale dans la société (inclusion).

L'article 19 de la CDPH sur l'autonomie de vie et l'inclusion dans la société reconnaît à toutes les personnes handicapées le droit de vivre dans la société, avec la même liberté de choix que les autres personnes. Il convient notamment de veiller à ce qu'elles aient la possibilité de choisir leur lieu de résidence et où et avec qui elles vont vivre et qu'elles ne soient pas obligées de vivre dans un milieu de vie particulier. En conséquence, les États parties sont tenues de prendre des mesures efficaces et appropriées pour permettre aux personnes handicapées de vivre de manière indépendante en dehors d'un foyer ou d'une autre institution spéciale.

À l'heure actuelle, toutes les personnes handicapées en Suisse ne sont pas en mesure de choisir librement leur type de logement comme le requiert l'article 19 de la CDPH. Nombre d'entre elles vivent dans des institutions. Selon les chiffres de l'Office fédéral de la statistique, leur nombre n'a cessé d'augmenter depuis le milieu des années 2000. Il est vrai que, depuis l'entrée en vigueur en 2008 de la réforme de la péréquation financière et de la répartition des tâches entre la Confédération et les cantons (RPT), les cantons sont tenus de proposer et de financer des logements adaptés aux personnes handicapées. Toutefois, on entend par «logements adaptés» principalement des logements en institution. La raison en est l'orientation de la loi fédérale sur les institutions destinées à promouvoir l'intégration des personnes invalides (LIPPI) vers le financement obligatoire des logements en institution. Les fonds sont ainsi engagés et le budget des cantons ne leur permet plus de financer des types de logement alternatifs. Les personnes handicapées ont ainsi peu de liberté de choix lors de leurs recherches d'un logement adapté et, en conséquence, ne quittent souvent pas les institutions.

Toutefois, le choix du logement ne dépend pas uniquement de l'offre. Il découle également d'une combinaison des préférences individuelles ainsi que de la santé, de la situation familiale et financière des personnes concernées. Les personnes handicapées en Suisse sont soutenues financièrement dans la réalisation de leur droit à une vie autonome par le biais de l'allocation pour impotent, de la contribution d'assistance, des prestations de l'assurance-maladie versées aux services d'aide et de soins à domicile et/ou des prestations complémentaires (PC). Par exemple, la loi fédérale sur les prestations complémentaires à l'assurance-vieillesse, survivants et invalidité (LPC) prévoit des montants maximaux pour le loyer général imposable (loyer maximal) et le loyer des logements accessibles en fauteuil roulant (forfait pour fauteuil roulant). Pendant longtemps, ceux-ci ne correspondaient plus aux besoins réels, puisque les loyers en Suisse depuis la modification des plafonds en 2001 avaient augmenté de plus de $20 \%$ en moyenne nationale. Suite à de longs débats politiques, un ajustement différencié sur 3 régions du plafond des loyers et du forfait pour les fauteuils roulants en fonction de l'évolution des loyers a finalement été effectué dans la réforme des PC au printemps 2019. 
En vertu de la CDPH et en raison de la situation insatisfaisante dans le contexte de la RPT, un changement de paradigme se dessine dans certains cantons en ce qui concerne la question du financement de l'aide aux personnes handicapées: du financement de l'offre de foyers et autres types de logement, de centres d'accueil et d'ateliers (financement de l'objet) au financement des personnes selon leurs besoins (financement du sujet). Le canton de Berne fait œuvre de pionnier avec un projet pilote lancé en janvier 2016 qui se concentre sur la vie plus libre des personnes handicapées et sur leur besoin personnel d'aide. À partir de 2023 au plus tôt, toutes les personnes handicapées du canton de Berne seront soumises à une évaluation individuelle qui permettra de déterminer leur besoin d'aide en fonction de leur handicap et elles se verront accorder une garantie individuelle de prise en charge des coûts. Le «modèle bernois» a pour but d'offrir aux personnes handicapées les soins et l'assistance dont elles ont besoin personnellement. Elles devraient pouvoir choisir l'assistance avec laquelle elles travaillent et si elles souhaitent vivre dans leur propre logement ou dans une institution. Elles ne devraient plus être désavantagées si elles ont besoin d'une assistance plus large que la moyenne. L'expérience montrera si les conditions-cadres sociales suffiront à permettre aux personnes handicapées de ressentir réellement l'augmentation de leur autodétermination et de leur liberté de choix grâce au changement de système. Le manque de logements abordables et accessibles à tous sur le marché libre du logement pourrait être un obstacle majeur.

Dans le secteur de la construction, les besoins des personnes handicapées ont été pris en compte sous forme de règlements et de normes. C'est ainsi qu'à partir de 1978, les lois cantonales sur la construction contenaient des dispositions relatives au logement adapté aux personnes handicapées. La LHand et l'ordonnance sur l'égalité pour les handicapés n'ont guère fait progresser la construction de logements, si ce n'est l'obligation de mettre un ascenseur dans les immeubles de plus de huit logements. En 2009, la Société suisse des ingénieurs et des architectes (SIA) a introduit la norme SIA 500 Constructions sans obstacles, qui part du principe que l'environnement construit doit être accessible à tous. Il doit donc être aussi accessible de manière autonome aux personnes affectées d'un handicap moteur ou sensoriel, temporairement ou à long terme, depuis la naissance ou par suite d'un accident, d'une maladie ou de l'âge. La norme s'applique à la planification et à la réalisation de constructions uniquement pour des bâtiments pour lesquelles la Confédération, le canton, la commune ou le maître d'ouvrage prescrit une construction sans obstacles ou accessible aux personnes handicapées. En outre, la bonne application de la norme dépend des réglementations cantonales, sachant qu'il existe des différences cantonales considérables et un manque de mécanismes d'informations et de contrôle contraignants.

À l'heure actuelle, de nombreuses personnes handicapées en Suisse ne sont toujours pas vraiment libres de choisir leur lieu de résidence et leur type de logement, en particulier les personnes handicapées ayant des besoins d'assistance élevés. Par conséquent, toutes les conditions-cadres qui permettent l'autodétermination et la participation égale à la vie de la société doivent être améliorées à l'avenir. Par exemple, il faut davantage de services d'assistance communautaires pour les personnes handicapées; un accès plus facile à la contribution d'assistance (de l'assurance-invalidité) et une contribution d'assistance correspondant aux besoins avérés ; le financement des moyens auxiliaires qui ne soient pas basés sur un catalogue restrictif des instruments médicaux mais qui soient adaptés aux besoins de l'individu; la préservation de la liberté d'établissement des personnes handicapées vivant dans une institution; la construction cohérente et généralisée de logements abordables, sans obstacles ou 
pouvant au moins être adaptés au type de handicap et aux besoins individuels des personnes handicapées. En outre, la Confédération et les cantons doivent veiller, dans leurs domaines de compétence respectifs, à ce que les coûts de location des logements accessibles à tous soient abordables pour toutes les personnes handicapées.

\section{Marie-Thérèse Weber-Gobet}

\section{Références}

Billod, M. \& Gazareth, P. (2015). Égalité pour les personnes handicapées: handicap et logement. Neuchâtel: Office fédéral de la statistique.

Fritschi, T., von Bergen, M., Müller, F., Bucher, N., Ostrowski, G., Kraus, S. \& Luchsinger, L. (2019). Bestandesaufnahme des Wohnangebots für Menschen mit Behinderungen (BSV Forschungsbericht Nr. 7/19). Bern : Bundesamt für Sozialversicherungen.

Pro Infirmis \& Institut Architektur der Fachhochschule Nordwestschweiz (Hrsg.) (2017). Zukunftsweisend umbauen: Hindernisfrei wohnen. Basel : Christoph Merian Verlag.

\section{Lutte contre la pauvreté*}

La lutte contre la pauvreté englobe toutes les mesures qui visent à réduire la pauvreté. En font partie aussi bien la garantie des moyens d'existence matériels que la promotion de l'égalité des chances et le renforcement de la résilience (capacité de résistance et d'adaptation).

La couverture des besoins matériels de base est au cœur de la lutte contre la pauvreté. La Constitution suisse en pose le fondement juridique. Dans le préambule, elle retient que la force de la communauté se mesure au bien-être du plus faible de ses membres, et à l'article 12 , que quiconque est dans une situation de détresse et n'est pas en mesure de subvenir à son entretien a le droit d'être aidé et assisté et de recevoir les moyens indispen- sables pour mener une existence conforme à la dignité humaine. À ce jour, il manque toutefois une loi au niveau fédéral qui concrétise ce droit au minimum vital. Les directives élaborées par la Conférence suisse des institutions d'action sociale - les normes CSIAS - servent de référence. En fin de compte, la couverture des besoins de base sous forme d'aide sociale et d'autres prestations sous condition de ressources sont du ressort des cantons et des communes (v. concept «prestations sous condition de ressources).

Hormis la garantie du minimum vital, la lutte contre la pauvreté comprend aussi les mesures de prévention de la pauvreté et celles qui permettent aux personnes touchées de participer à la société. La formation, le logement, la santé, le travail de care, le travail rémunéré et la participation sociale sont les thèmesclés de la prévention de la pauvreté. Hormis la Confédération, les cantons et les communes, les autres acteur-trice-s de la prévention et de la lutte contre la pauvreté sont les partenaires sociaux et les organisations privées, notamment des œuvres d'entraide.

Une bonne formation est une condition préalable afin d'obtenir un travail rémunéré garantissant l'existence. Or, les chances de formation ne sont pas également réparties en Suisse. L'origine sociale est, dès le départ, un facteur d'inégalité des chances qui n'est pas compensée par des réglementations. Un soutien précoce dans ce domaine peut contribuer à la réduction de la pauvreté. Plus tard également, la formation demeure un élément central de la prévention de la pauvreté. Un nombre croissant de travailleurs, hommes et femmes, perdent leur emploi faute de formation continue, deviennent chômeur.euse-s de longue durée, arrivent en fin de droit et tombent dans la pauvreté. La formation continue permet d'adapter les compétences aux exigences du marché du travail. Quant aux personnes non formées, il importe qu'elles aient la possibilité de suivre une formation de rattrapage quali- 
fiante, qui leur permette de sortir durablement de la pauvreté.

Le travail rémunéré offre la meilleure protection contre la pauvreté. C'est pourquoi l'intégration professionnelle dans un emploi qui garantit la couverture du minimum vital est une mesure centrale de la lutte contre la pauvreté. Outre l'offre d'emplois, elle présuppose des salaires convenables, des conditions de travail favorables à la famille, des structures d'accueil extrafamilial et extrascolaire accessibles et abordables, ainsi qu'une répartition équitable du travail de care entre femmes et hommes.

La mise à disposition de logements avantageux permet également de prévenir la pauvreté. Des loyers avantageux déchargent le budget, et la construction de logements d'utilité publique, de par son effet d'inclusion, favorise la participation sociale de personnes touchées par la pauvreté.

La pauvreté peut aussi être causée par des problèmes de santé. C'est le cas notamment lorsqu'un travail rémunéré couvrant le minimum d'existence devient impossible à exercer en raison d'une maladie. Des mesures de promotion de la santé peuvent, à l'inverse, empêcher la pauvreté et stabiliser des situations précaires. La cherté des prestations de santé a également un impact sur les biographies de la pauvreté : on hésite à consulter un médecin par souci d'économie, avec les conséquences négatives que l'on sait en termes de traitement et de guérison. Un accès plus abordable aux prestations médicales contribue à la lutte contre la pauvreté.

La pauvreté va souvent de pair avec la solitude et l'isolement. D'où l'importance de mesures qui encouragent la participation sociale, par exemple des offres de loisirs gratuites pour les enfants et les jeunes ou des entrées au cinéma à prix réduit pour les adultes.

En Suisse, la pauvreté est devenue une thématique au niveau fédéral dans le contexte de l’Année européenne de la lutte contre la pau- vreté et l'exclusion sociale (2010). L'impulsion avait été donnée en 2006 par une motion de la Commission de la sécurité sociale et de la santé publique du Conseil national. Cette intervention déboucha sur une conférence nationale sur la pauvreté et un programme national de lutte contre la pauvreté, élaboré conjointement par l'administration, le politique et la société civile. En mai 2013, le Conseil fédéral lança un programme quinquennal de prévention et de lutte contre la pauvreté, dans le but de définir les bases et les objectifs de ce combat et de mettre en réseau les principaux.pales acteur·trice-s, à savoir les cantons, les villes, les communes, les partenaires sociaux et des organisations non gouvernementales. Cependant, avec la décision du Conseil fédéral en 2018 de réduire considérablement les moyens pour la suite du programme, la nouvelle dynamique positive de la lutte contre la pauvreté subit un dur revers.

La lutte contre la pauvreté est un défi actuel à plus d'un égard. Premièrement, en tant que politique transversale, elle est un sujet complexe qui concerne non seulement la politique sociale, mais aussi les politiques de l'emploi, de la formation, économique, fiscale, de la migration et du logement. Pour réduire durablement la pauvreté, une approche globale s'impose donc. Depuis plusieurs années, les œuvres d'entraide appellent de leurs vœux des stratégies cantonales de lutte contre la précarité, étayées par des rapports, ainsi qu'un monitoring régulier au niveau suisse, pour dresser le bilan de la situation, définir des objectifs, identifier les mesures à prendre et documenter les avancées et les revers. Force est de constater qu'à ce jour seule une petite moitié des cantons rédige de tels rapports sur la pauvreté et le monitoring au niveau fédéral n’a pas été mis en place.

Deuxièmement, depuis plusieurs années, la couverture des besoins vitaux est soumise à une pression politique croissante. On critique les coûts des prestations sous condition de ressources, en négligeant le fait que la politique 
des impôts bas pratiquée par les cantons est coresponsable des caisses vides. Pourtant, les économies se font souvent au détriment des prestations sociales. Quelques cantons seulement connaissent une péréquation entre les communes. Récemment, plusieurs interventions cruciales en faveur de la prévention et de la lutte contre la pauvreté - comme le projet de loi-cadre sur l'aide sociale ou celui sur les prestations complémentaires pour les familles - ont échoué au Parlement. La lutte contre la pauvreté attend encore et toujours d'être institutionnalisée en tant que politique fédérale.

Troisièmement, les nouveaux risques de tomber dans la précarité attendent de nouvelles solutions. Le système de la sécurité sociale devra s'adapter mieux encore aux nouvelles réalités économiques et sociales. L'acception classique de la garantie du minimum vital par le salaire du chef de famille doit être remplacée par celle de la couverture des besoins individuels.

En comparaison internationale, la Suisse investit peu dans la lutte contre la pauvreté. Elle ne dépense que $1,5 \%$ de son produit intérieur brut pour lutter contre la pauvreté des familles et des enfants, alors que les pays de l'OCDE y consacrent en moyenne $2,1 \%$ de leur PIB (2013). Par ailleurs, la structure fédéraliste du pays induit certes ponctuellement de bonnes solutions régionales mais génère aussi des inégalités de traitement des personnes touchées par la pauvreté - un état de fait particulièrement choquant dans le domaine de la garantie du minimum d'existence.

En signant l'Agenda 2030 de l'ONU, la Suisse s'est engagée à réduire de moitié au moins sur son territoire la proportion d'hommes, de femmes et d'enfants de tous âges qui vivent dans la pauvreté dans toutes ses dimensions définies par chaque pays. Les nouveaux objectifs du développement durable créent un cadre de référence international pour la lutte contre la pauvreté dans la décennie à venir, en Suisse aussi.

\section{Bettina Fredrich}

\section{Références}

Almanach social, l'annuaire de Caritas sur la situation sociale en Suisse, publié annuellement depuis 1999.

Assemblé générale des Nations Unies (2015). Transformer notre monde: Le programme de développement durable à l'horizon 2030, Résolution adoptée par l'Assemblée générale le 1er septembre 2015 (A/ $R E S / 70 / 1 *)$. New York : Nations Unies.

Schuwey, C. \& Knöpfel, C. (2014). Neues Handbuch Armut in der Schweiz (völlig neu bearb. Aufl.). Luzern: Caritas-Verlag.

\section{Maltraitance envers les personnes âgées}

Bien qu'il n'existe pas de définition consensuelle de la maltraitance envers les personnes âgées, celle proposée en 2002 par l'Organisation mondiale de la santé (OMS) dans la Toronto Declaration on the Global Prevention of Elder Abuse est la plus fréquemment utilisée. Cette déclaration définit la maltraitance comme: «Un acte unique ou répété, ou un manque d'action appropriée, qui survient dans le cadre d'une relation dans laquelle il y a une attente de confiance et qui cause un dommage ou de la détresse à une personne âgée. La maltraitance peut être de différentes formes : physique, psychologique/émotionnelle, sexuelle, financière ou simplement refléter une négligence intentionnelle ou involontaire.». La maltraitance constitue une atteinte aux droits fondamentaux des aînée-es. Elle s'inscrit à la fois dans les champs de la santé et du social. En Suisse, elle est généralement abordée dans une perspective de santé publique.

Le phénomène de la maltraitance envers les personnes âgées a été décrit pour la première fois en 1975 aux États-Unis. En Suisse, le sujet 
a commencé à être abordé à la fin des années 1990, suite à des scandales dans des établissements médico-sociaux (EMS) et à des reportages télévisés. En 2002, les Nations Unies et l'OMS ont reconnu la maltraitance envers les aîné·e-s comme un problème social, politique et de santé publique prioritaire. Les violences envers les vieux ne constituent pas un fait nouveau, comme en témoignent des écrits datant de l’Antiquité et du Moyen-Âge. La tolérance de la société à leur égard a cependant beaucoup évolué. Ainsi, des actes qui étaient considérés comme normaux par le passé et ne choquaient guère - comme par exemple l'usage de contention physique ou de punitions corporelles sont aujourd'hui considérés comme de la maltraitance. Il en est de même en ce qui concerne les violences envers les enfants. Cette évolution montre que la définition de la maltraitance est toujours relative à des normes et à des valeurs qui diffèrent selon les contextes, les époques, les cultures, les groupes et les individus. Cette caractéristique participe à la complexité de la problématique.

Selon un rapport de l'OMS Région Europe de 2011, un quart des personnes âgées dépendantes d'aide et de soins seraient victimes de mauvais traitements en Europe, ce qui représente plusieurs millions de personnes concernées. Malgré l'hétérogénéité des résultats des études de prévalence, on peut estimer que la maltraitance toucherait entre $10 \%$ et $20 \%$ des personnes de plus de 65 ans, ce qui représenterait pour la Suisse près de 300000 personnes. Contrairement aux idées reçues, plus des trois-quarts des aîné·e·s maltraitéee-s le sont à domicile, généralement par un·e proche. Ces données sont à mettre en perspective avec le fait que la grande majorité des personnes âgées vit à domicile, et non en institution. La maltraitance psychologique (p.ex. menaces, chantage, infantilisation), la maltraitance financière (p.ex. utilisation abusive de fonds ou de biens, captation d'héritage) et les négligences (p.ex. alimentation inadéquate, restriction de l'accès aux soins nécessaires) constituent les formes de maltraitance les plus fréquentes.

Sur le plan socioéconomique, les changements sociétaux, et en particulier le vieillissement de la population et l'augmentation de la prévalence des maladies chroniques, ont un impact important sur le phénomène, notamment une augmentation prévisible du nombre de personnes âgées touchées par la maltraitance. Le vieillissement a également des répercussions significatives sur les relations intrafamiliales, intergénérationnelles et sociétales, avec pour effet de renforcer certains facteurs de risque de maltraitance (épuisement des proches aidants, isolement social, cohabitation enfant adulte/parent âgé et co-dépendance, pressions de rentabilité sur les institutions sociales et de soins, etc.).

Diverses études ont mis en évidence les conséquences à court et long termes de la maltraitance sur la santé physique et mentale des personnes âgées, de même que sur les risques de précarisation. En 2005, le National Committee for the Prevention of Elder Abuse estimait, aux États-Unis, le coût économique de la maltraitance envers les aîné·e-s à plusieurs dizaines de milliards de dollars américains par année.

Sur le plan légal, il n'existe pas en Suisse de dispositions spécifiques relatives à la maltraitance envers les personnes âgées. De manière générale, le signalement des cas de maltraitance n'est pas obligatoire. De nombreuses règles de droit civil, pénal et administratif permettent cependant de prévenir ou de mettre fin à des actes de maltraitance, que ceux-ci aient lieu dans le cadre domestique ou en institution. L'article 28 du Code civil (CC) notamment établit le principe que toute atteinte aux droits de la personnalité est illicite, à moins que la victime ait donné son consentement, qu'il existe un intérêt prépondérant privé ou public, ou qu'il y ait une base légale. Le droit de protection de l'adulte prévoit aux articles 382ss du CC des dispositions particulières dans le but de 
protéger les résidents incapables de discernement au sein d'un établissement médico-social (EMS) pour un séjour de longue durée. Il offre aussi la possibilité à toute personne de signaler à l'Autorité de protection de l'adulte une personne qui semble avoir besoin d'aide (article 443 CC). Il est à noter que les personnes soumises au secret professionnel doivent en être déliés par la personne concernée ou par l'autorité compétente. Depuis 2013, le droit de protection de l'adulte accorde une place importante aux proches dans l'ordre des personnes habilitées à représenter une personne incapable de discernement dans le domaine médical (article $378 \mathrm{CC}$ ). Cette modification vise une meilleure prise en compte de la volonté présumée de la personne. Ce principe peut toutefois s'avérer problématique dans les cas où la maltraitance, notamment financière, émane des proches habilitéee-s (p.ex. le/la conjoint·e ou les descendant.e.s).

Les réponses apportées à la question de la maltraitance varient selon les cantons et les régions. En Suisse romande, alter ego (Association pour la prévention de la maltraitance envers les personnes âgées) a été créée en 2002. Elle est active dans l'information, l'écoute et l'orientation, et la formation. Dans plusieurs cantons de Suisse alémanique, des bureaux indépendants de plaintes pour les questions liées à l'âge (Unabhängige Beschwerdestelle für das Alter UBA) ont été constitués dès la fin des années 1990. Au Tessin, la prévention de la maltraitance envers les personnes âgées est assurée principalement par Pro Senectute Ticino e Moesano. Au niveau fédéral, cette problématique n'est pas considérée comme une priorité. Bien que plusieurs conseiller-ère-s nationaux-ales aient déposé des postulats en ce sens, il n'y a pas de stratégie nationale contre les violences envers les personnes âgées. Par ailleurs, aucune étude nationale de prévalence n'a été réalisée et la recherche dans le domaine reste peu développée, contrairement à d'autres pays comme le Canada ou les États-Unis.
Face au vieillissement de la population et au risque de renforcement des attitudes âgistes, il importe de garder à l'esprit que les droits fondamentaux sont les mêmes à tout âge. Le Centre suisse de compétence pour les droits humains rappelait à ce titre, en 2017, que l'interdiction des traitements inhumains ou dégradants est absolue et qu'elle ne peut être assouplie en aucune circonstance. Dans cette perspective, les Nations Unies ont nommé en 2014 une Experte indépendante chargée de promouvoir l'exercice par les personnes âgées de tous les droits de l'homme. L'établissement d'une Convention des droits des personnes âgées fait également l'objet de travaux. Le respect des droits fondamentaux des personnes âgées et la prévention de la maltraitance représentent des enjeux majeurs dans une société vieillissante, qui tend à porter un regard négatif sur le vieillissement et les individus âgés.

\section{Delphine Roulet Schwab}

\section{Références}

Beaulieu, M. \& Bergeron-Patenaude, J. (2017). La maltraitance envers les aînés: changer le regard. Laval: Presses de l'Université de Laval.

Belser, E.M., Kaufmann, C., Egbuna, A. \& Ghielmini, S. (2017). Différents en âge, égaux en droits : catalogue des droits fondamentaux des personnes âgées en Suisse. Berne: Centre suisse de compétences pour les droits humains.

Sethi, D., Wood, S., Mitis, F., Bellis, M., Penhale, B., Iborra Marmolejo, I.... Ulvestad Kärki, F. (Eds.) (2011). European report on preventing elder maltreatment. Copenhagen: WHO Regional Office for Europe.

\section{Maltraitance infantile}

Apparaissant pour la première fois au début des années 1990, le terme «maltraitance infantile» a depuis fait l'objet d'un travail continu de tentative de définition conceptuelle par le corps médical et les sciences psychologiques 
ou de l'éducation. Au-delà des différences disciplinaires, les auteur·e·s s'accordent à dire que la notion est floue et «fourre-tout». Pourtant, une définition commune s'est stabilisée dans les manuels. Inspirée de la définition de l'Organisation mondiale de la santé (OMS), elle sert de guide aux professionnel-le-s des différents secteurs confronté-e-s au dépistage des cas d'enfants maltraités et en charge de les protéger: elle comprend les violences physiques, psychologiques, ainsi que les négligences et abus sexuels dans le cadre familial «entraînant un préjudice réel ou potentiel pour la santé de l'enfant, sa survie, son développement, sa dignité».

S'il est difficile de dénombrer les cas d'enfants maltraités - différents travaux de coordination sont en cours en Suisse - on sait que de 1990 à 2015, le nombre d'enfants signalés aux services de protection de l'enfance a fortement augmenté. À Genève, le nombre de cas de maltraitance signalés par le Service Santé Jeunesse est passé de 12 en 1989 à 300 en 2000. De telles augmentations s'observent également en France.

La protection de l'enfance, l'une des missions les plus anciennes de l'État social et qui s'est intensifiée ces dernières décennies, n'a rien d'un phénomène naturel. Elle trouve son origine en Suisse (et en Europe) dans l'adoption de lois inédites et convergentes. À Genève, la loi du 20 mai 1891 permet de priver les parents «indignes» de la puissance parentale. Dès lors, l'État devient, selon Durkheim, «un facteur de la vie domestique» et l'usage de «mauvais traitements à l'encontre des enfants» une déviance. Cette mission sera inscrite dans le Code civil suisse en 1907 (article 307). Elle constitue jusqu'à ce jour le cadre juridique que les professionnels chargés de protéger les enfants sont tenus de rappeler aux familles.

Jusqu'en 1960 pourtant, les «cas d'enfants maltraités » ne font pas l'objet d'une attention publique, cette dernière se concentrant sur la délinquance juvénile. La maltraitance apparaît en 1962 aux États-Unis en tant que «manière de décrire et classifier des actes» lors d'observations de pédiatres comme Henry Kempe qui attirent l'attention sur des blessures infligées de façon répétée à de petits enfants. Rapidement, la préoccupation s'exporte en Europe puis vers l'hémisphère Sud par le biais de conférences internationales. La «cause» gagne encore en visibilité en 1989, lors de l'adoption par les Nations Unies de la Convention internationale relative aux droits de l'enfant. Elle reconnaît ce dernier comme sujet de droits particuliers dans une étape spécifique de la vie: notamment celui d'être protégé de toute forme de violence et celui de ne pas être maltraité, mais aussi celui d'être entendu et celui de donner son opinion sur toute question le concernant durant sa minorité, en regard de son intérêt supérieur.

La cause s'institutionnalise progressivement en Suisse : en 1992 paraît un rapport sur l'enfance maltraitée, soulignant pour la première fois «l'ampleur du problème des sévices envers les mineur.e.s», ainsi que «le retard des détections et la faiblesse des interventions». En 1995, le Conseil fédéral reconnaît la maltraitance comme «thème de politique nationale» et ratifie, en 1997, la Convention des Nations Unies relative aux droits de l'enfant. Cependant, la demande des experts du rapport de 1992 visant à introduire dans la Constitution fédérale l'interdiction des châtiments corporels ne sera pas suivie. À l'instar de la France ou de l'Italie, et à l'opposé de la majorité des pays européens qui ont fait entrer dans la loi l'éducation non violente, en Suisse les autorités politiques n'ont, à ce jour, pas voulu prohiber le châtiment corporel.

Suite à la Convention des droits de l'enfant émerge, dès 1990, une nouvelle sensibilité collective visant à «lutter contre la maltraitance». De multiples acteur-trice-s participent à la création d'un nouvel intolérable: les politicien-ne-s votent des motions et officialisent ce problème social, les médecins organisent des réunions 
pour mettre en œuvre de nouvelles procédures en matière de détection, des formations visant à sensibiliser le personnel d'enseignement sont mises en place et de nouvelles méthodes facilitées de signalement, sans «besoin de certitude», sont proposées par les juges aux travailleur-euse-s sociaux·ales. Parallèlement, la définition de la maltraitance évolue, signe de son caractère construit. Dès 1999, la prise en compte des facteurs de risque de maltraitance (à savoir un enfant qui «connaît des conditions d'existence risquant de mettre en danger sa santé») donne au concept une signification beaucoup plus large. En conséquence, le regard des professionnel-le·s en charge de protéger les enfants s'est aiguisé durant ces dernières décennies, ce qui explique pourquoi le nombre de signalements de cas d'enfants maltraités a explosé dans les cantons suisses.

Ainsi, en se focalisant sur le repérage, la politique de lutte contre la maltraitance a placé au cœur du mandat de protection des travailleur·euse-s sociaux-ales la surveillance accrue des familles. Pourtant, loin de renvoyer uniquement à une dimension morale ou pénale, la maltraitance renvoie aussi - dans une perspective sociologique - à une dimension sociale souvent déniée par les professionnel-le·s euxet elles-mêmes : celle des inégalités en matière de ressources matérielles et culturelles permettant l'accès au nouveau modèle légitime du savoir-éduquer. Selon les enquêtes, les familles étiquetées maltraitantes appartiennent très majoritairement aux fractions les plus démunies de capital culturel des classes populaires. Ces dernières continuent à privilégier - effet des conditions d'existence qui sont les leurs des modèles éducatifs plus «autoritaires», à distance du modèle d'autorité négociée et d'autonomie encadrée, promu par les travailleur-euse-s sociaux-ales et qui se trouve en affinité élective avec les valeurs éducatives et les modes de vie des nouvelles fractions des classes moyennes auxquelles ils se rattachent objectivement. En effet, la structuration des méthodes éducatives est d'autant plus rigide que l'on trouve davantage de personnes par pièce habitée. Comportant un caractère de nécessité, ces méthodes permettent alors d'organiser l'existence des familles: l'accent porté sur l'obéissance rend possible la cohabitation entre les générations dans des espaces partagés. Dès lors, les interactions aux guichets des services de la protection de l'enfance ont toutes les chances d'être source d'incompréhensions. Selon les historien·ne·s, l'avènement d'un nouveau modèle éducatif plus permissif et moins autoritaire - qui s'impose en Europe de manière concomitante dès le début des Trente Glorieuses - s'est diffusé inégalement des professions libérales vers les ouvrier`ère-s, ces dernier`ère-s manifestant le plus de difficultés à s'adapter à ces nouvelles normes. Et si, aujourd'hui, les normes éducatives des classes populaires tendent à se rapprocher de celles des classes moyennes, cela tient vraisemblablement au contact prolongé avec les travailleur.euse-s sociaux-ales dont le travail quotidien renforce le processus d'acculturation aux normes dominantes. Il convient toutefois de souligner que cette question des normes éducatives, plus ou moins permissives ou autoritaires, ne s'applique sans doute pas de la même façon à toutes les formes de maltraitance et notamment aux abus sexuels. Quoi qu'il en soit, la perspective sociologique permet de rappeler utilement que toute politique de lutte contre la maltraitance ne peut uniquement agir au niveau des facteurs intra-familiaux de la mise en danger des enfants, mais doit aussi intégrer des politiques de soutien aux familles (crèches, accès au logement, fiscalité) et de lutte contre la précarité économique.

\section{Christophe Delay \& Eric Paulus}

\section{Références}

Groupe de travail enfance maltraitée (1992). Enfance maltraitée en Suisse: rapport final. Berne : Département fédéral de l'intérieur. 
Hacking, I. (2001). La fabrication d'un genre: le cas de l'enfance maltraitée. In I. Hacking, Entre science et réalité: la construction sociale de quoi? (pp. 171-221). Paris : La Découverte.

Schultheis, F., Frauenfelder, A. \& Delay, C. (2007). Maltraitance: contribution à une sociologie de l'intolérable. Paris : L'Harmattan.

\section{Marché du travail*}

Dans les économies de marché, le marché du travail fonctionne sur le modèle de la négociation entre l'offre de travail et la demande de main d'œuvre. Les individus louent leur force de travail contre rémunération à des employeur.euse-s pour effectuer des tâches productives. Selon la théorie économique néoclassique, le marché du travail équivaut à un marché de biens. Sur un tel marché, l'équilibre peut être obtenu par des ajustements au niveau de la rémunération (le prix de la force de travail). Dans une situation d'équilibre entre demande de main d'œuvre et offre de travail, il n'existe pas de chômage involontaire. Vu sous l'angle néoclassique, le chômage est donc occasionné en premier lieu par des interventions sur le marché du travail, qui entravent la variation des taux de rémunération et induisent une rigidification des salaires. Pour donner un exemple: des salaires minimaux peuvent avoir pour effet que le niveau de rémunération demeure au-delà du niveau d'équilibre. Dans ce cas de figure, l'offre de travail excède la demande de main d'œuvre. Un faible chômage ne doit pas être assimilé au plein emploi. Dans une économie nationale, une situation de plein emploi veut dire que pratiquement toutes les personnes en âge de travailler ont une activité rémunérée. Par conséquent, l'effectif des personnes qui ne travaillent pas est plus grand que celui des personnes prises en compte dans le taux de chômage. Mentionnons à ce propos par exemple les personnes investies de tâches de care, qui n'ont souvent pas la possibilité de participer au marché du travail ; elles n'ont pas d'activité rémunérée, mais ne sont pas pour autant au chômage.

D’un point de vue socioéconomique et politico-institutionnel, l'assimilation du marché du travail au marché de biens est hasardeuse, car le premier marché est fondamentalement différent du deuxième. Le politologue allemand Günther Schmid donne quatre raisons à cela. Premièrement, la prestation de travail négociée sur le marché du travail est invariablement liée à un individu dont la dignité humaine doit être respectée, ce qui a pour effet de restreindre le droit de l'acheteur de disposer de lui. De cette contingence, ainsi que de l'asymétrie du pouvoir entre les personnes qui offrent des prestations de travail et celles qui les achètent, il découle le droit, pour les premières, de s'organiser collectivement et d'influer en tant que collectif sur le mécanisme de formation des prix du marché du travail. Deuxièmement, ce qui est négocié sur le marché du travail n'est pas une prestation de travail finie, mais le potentiel d'une prestation. Il s'ensuit, troisièmement, que la qualité du bien «force de travail» a une influence bien plus déterminante sur le marché du travail que la qualité des biens sur le marché des biens. Et enfin, le marché du travail présente la particularité que les fournisseur.euse-s d'un travail sont en même temps les consommateur-trice-s des produits qui résultent de ce travail.

Bien qu'il soit question le plus souvent «du» marché du travail, il serait plus juste de parler de marchés segmentés ou de marchés partiels, qui sont en partie très différents les uns des autres pour ce qui concerne les conditions de travail, la rémunération et les possibilités de carrière. D'après le concept du marché du travail segmenté de Peter B. Doeringer et Michael Piore, le marché du travail est en réalité articulé en plusieurs marchés partiels, qui se distinguent par divers critères comme la profession, le sexe ou la nationalité. La mobilité entre ces marchés partiels est faible en raison 
de seuils élevés : le passage à un autre marché du travail partiel présuppose des diplômes, des qualifications et des compétences que les travailleur-euse-s actif·ive-s dans des marchés partiels moins attractifs n'ont généralement pas. La littérature scientifique met en exergue plusieurs mécanismes qui ont pour effet une segmentation du marché du travail. En Suisse, mentionnons par exemple la politique des travailleur·euse-s étranger·ère-s, qui a systématiquement exclu la main d'œuvre étrangère de certaines activités et l'a discriminée au plan sociopolitique. Cependant, la segmentation du marché du travail n'est pas due seulement à des interventions du législateur. Les conventions et les attentes de la société peuvent également en être la cause. Le marché suisse du travail est ainsi typiquement subdivisé en un marché de plein emploi dominé par les hommes et un marché d'emploi partiel dominé par les femmes. Comme le travail à temps partiel va souvent de pair avec un moindre salaire et des perspectives professionnelles réduites, il en découle une différence significative entre les sexes, aussi en termes sociopolitiques.

Dans la littérature internationale plus récente, on observe une segmentation croissante du marché du travail due à des réformes du droit du travail. Il s'agit de mesures politiques qui visent à flexibiliser davantage les rapports de travail, mais qui, en raison de fortes résistances politiques, se limitent à certains groupes de travailleur-euse-s et formes de travail. Mentionnons à ce propos les tentatives entreprises dans la plupart des pays industrialisés de réduire la protection contre le licenciement des travailleur·euse-s engagé·ess pour une durée indéterminée, tentatives qui ont toutefois souvent échoué en raison de l'opposition de syndicats bien organisés. Au lieu de cela, les pays industrialisés ont fortement assoupli les restrictions afférentes à la conclusion de contrats de travail de durée déterminée ou de travail partiel. En outre, ils ont instauré de nouvelles formes de travail qui ne donnent plus guère aux travailleur-euse-s de protection sociopolitique et de droit du travail, mais qui exigent d'eux une grande flexibilité. Appelée «dualisation» dans la littérature spécialisée, cette évolution s'observe aussi en Suisse, même si la protection contre le licenciement relativement faible y a pour effet que ladite dualisation des rapports de travail est plutôt peu marquée. Globalement, le marché suisse du travail a connu des développements contradictoires ces dernières décennies. Alors que certains paramètres ont été fortement flexibilisés (p.ex. le temps de travail, les horaires de travail), les mesures d'accompagnement aux accords bilatéraux avec l'UE ont à nouveau renforcé le rôle des conventions collectives de travail.

Les interventions étatiques ou syndicales sur le marché du travail ne se traduisent évidemment pas toujours par une plus forte segmentation du marché du travail. De nombreuses mesures visent plutôt à éliminer des désavantages structurels et à soutenir les travailleur·euse-s. Mentionnons par exemple le développement de l'accueil extrafamilial, pour permettre tout spécialement aux femmes de mieux concilier famille et profession. Dans le domaine de la formation également, des mesures ont été prises pour augmenter l'employabilité de personnes ayant des difficultés. Un rôle très important revient dans ce contexte au marché de l'emploi complémentaire, ou «second marché du travail », qui englobe toutes les mesures étatiques visant l'intégration sociale et professionnelle, indépendamment du statut de chômage. Le marché du travail complémentaire couvre en premier lieu des activités encouragées par les pouvoirs publics, complémentaires au marché primaire et qui ne sont pas censées lui faire concurrence. En Suisse, des mesures d'intégration sociale et professionnelle ont été développées plus spécialement en réaction à la hausse du chômage, pendant la première moitié des années 1990. Aujourd'hui, le second marché du travail s'adresse surtout aux personnes en fin de droit, qui ne reçoivent 
plus d'indemnités de l'assurance-chômage et qui sont tributaires de l'aide sociale.

\section{Patrick Emmenegger}

\author{
Références \\ Doeringer, P. B. \& Piore, M. J. (1971). Internal Labor \\ Markets and Manpower Analysis. Lexington: \\ Heath Lexington Books. \\ Grawehr, A. \& Knöpfel, C. (2001). Ergänzender \\ Arbeitsmarkt: Ein erfolgreiches Konzept zur sozi- \\ alen und beruflichen Integration? Luzern : Cari- \\ tas-Verlag. \\ Schmid, G. (1987). Zur politisch-institutionellen \\ Theorie des Arbeitsmarkts : Die Rolle der Arbeits \\ marktpolitik bei der Wiederherstellung der \\ Vollbeschäftigung. Politische Vierteljahresschrift, \\ 28(2), 133-161.
}

\section{Médecine préventive}

La médecine préventive est un domaine de la médecine qui vise à éviter l'apparition d'une maladie ou d'un accident chez un individu ou dans une population, ou d'en réduire le nombre de cas et la gravité. En pratique, la prévention est catégorisée par l'Organisation mondiale de la santé (OMS) selon trois niveaux: la prévention primaire vise à diminuer la survenue dans une population de nouveaux cas (on parle d'incidence) d'une maladie ou d'un accident au travers de mesures individuelles ou collectives (p.ex. au moyen de la vaccination); la prévention secondaire a pour but de réduire dans une population le nombre de cas présents (on parle alors de prévalence) d'une maladie ou d'un accident à un instant donné au travers de mesures de dépistage précoce ou d'initiation d'un traitement (p.ex. par le dépistage du cancer du côlon); la prévention tertiaire a pour objectif de réduire au maximum les handicaps et incapacités consécutifs à une maladie ou un accident (p.ex. par des mesures de reconditionnement physique après un évènement cardiaque).
Les concepts de base de la médecine préventive ne datent pas de l'ère moderne. Initialement, les mesures de prévention visaient essentiellement à exclure ou à isoler les personnes porteuses d'une maladie infectieuse ou suspectes de l'être, afin de protéger la population saine. Ainsi, des conseils d'hygiène personnelle visant à réduire le risque de transmission de maladies de personne à personne figurent dans les écrits de l'Ancien Testament. Lors de l'épidémie de la peste noire, une maladie contagieuse causée par une bactérie, en Europe au XIVe siècle, des mesures de mises en quarantaine furent entreprises pour isoler les cas confirmés ou suspects de la maladie, alors que son mode de transmission était encore inconnu. Les connaissances scientifiques en matière de prévention de la maladie connurent un essor majeur vers le milieu du XIX ${ }^{\mathrm{e}}$ siècle et le début du XX $\mathrm{XX}^{\mathrm{e}}$ siècle, en particulier grâce au progrès réalisé dans les domaines de la microbiologie et de la nutrition. C'est à cette période que furent développés de nombreux vaccins (p.ex. le vaccin contre la poliomyélite, le tétanos, la fièvre typhoïde) qui visent à stimuler le système immunitaire des individus, permettant secondairement de protéger la collectivité grâce au développement d'une immunité de groupe. Sous l'impulsion de l'OMS, de vastes campagnes de vaccination internationales furent organisées depuis la Seconde Guerre mondiale, permettant notamment l'éradication de la variole au niveau mondial en 1980.

C'est également au XIX ${ }^{e}$ siècle que furent créées les prémices de ce qui deviendra plus tard la médecine du travail, avec pour but de promouvoir les mesures préventives et la législation sociale des maladies professionnelles et des accidents du travail. La médecine préventive de la fin du XXe siècle fut marquée notamment par la survenue de l'épidémie mondiale du virus d'immunodéficience humaine (VIH), ainsi que par des avancées médicales et scientifiques significatives en particulier pour les maladies cardiovasculaires et cancéreuses. Les 
études scientifiques entreprises depuis lors ont permis d'élaborer par étapes des stratégies et recommandations nationales et internationales en matière de prévention au travers du dépistage de ces maladies (p.ex. le dépistage du cancer du sein). À noter qu'en matière de prévention, d'importantes avancées ont également été réalisées dans le domaine des addictions et de la santé mentale (p.ex. prévention des addictions au tabac, à l'alcool, aux drogues ; prévention du suicide), ainsi que dans d'autres domaines de soins visant à réduire les comportements délétères (p.ex. par la diffusion de conseils hygiéno-diététiques ou de conseils en matière de comportements sexuels à risques).

De nos jours, les mesures préventives telles que la vaccination et le dépistage de certaines maladies sont progressivement entrées dans les mœurs de la population générale et dans la pratique médicale dans les pays occidentaux. Développé depuis le début du XX $\mathrm{XX}^{\mathrm{e}}$ siècle dans le domaine de la prévention primaire, le bilan de santé (check-up) d'un individu réalisé à intervalles réguliers chez sa/son médecin de famille est devenu emblématique de l'évolution de la médecine préventive contemporaine. $\mathrm{Au}$ niveau international, les recommandations pour les interventions préconisées lors du bilan de santé sont basées primairement sur le travail du groupe d'expert·e-s américain·e-s de médecine préventive (US Preventive Services Task Force - USPSTF), une organisation à but non-lucratif et indépendante qui évalue et propose les recommandations selon leur niveau de preuve d'efficacité. En Suisse, ces recommandations sont adaptées au contexte helvétique sur la base du travail de plusieurs sociétés et groupes spécialisés, dont le Swiss Medical Board, l'Office fédéral de la Santé Publique, l'initiative Smarter Medicine et le programme national de prévention clinique EviPrev.

Le processus d'élaboration des recommandations en matière de prévention doit pouvoir répondre de manière indépendante à plusieurs questions essentielles telles que retenues dans les recommandations suisses pour le bilan de santé au cabinet médical: «Dispose-t-on de données démontrant qu'une intervention précoce est efficace? Quels sont l'efficacité et les effets indésirables de l'intervention? Quelle est l'efficience de l'intervention, c'està-dire le rapport entre le coût et l'efficacité? Quelles sont les préférences du patient quant à l'intervention et aux conséquences de l'intervention?» À titre illustratif, le dépistage du cancer du côlon est recommandé et remboursé depuis juillet 2013 par l'assurance obligatoire des soins en Suisse pour toute personne âgée de 50 à 69 ans. D'autres recommandations de dépistage ont fait l'objet de vifs débats dans la communauté médicale et scientifique en raison du risque de surdiagnostic d'une maladie, c'est-à-dire de diagnostiquer une maladie qui n'aurait jamais été perçue au cours de la vie du·de la patient·e et qui n'aurait modifié ni sa qualité de vie ni sa durée de vie, ou de déduire à tort que la maladie existe, alors que la personne n'est pas malade (risque de faux-positif). Ce fut le cas lors de la remise en question par certains médecins de l'efficacité de la mammographie pour le dépistage du cancer du sein. Pour le médecin et son-sa patient·e, la conduite d'un dialogue ouvert, informé et constructif peut faciliter la prise d'une décision partagée entre les deux parties en matière de prévention, ceci pour autant que le médecin reste attentif au degré de littératie en santé de son patient, c'est-à-dire la mesure dans laquelle le patient a la capacité d'obtenir, de traiter et de comprendre des informations de base en matière de santé et le fonctionnement des services nécessaires lui permettant de prendre une décision importante pour sa santé.

Étant donné que le degré de littératie est lié aux inégalités sociales, celles-ci attirent une attention particulière en matière de médecine préventive. Les déterminants sociaux des inégalités de santé sont nombreux et relèvent non seulement de la précarité matérielle, mais aussi de mécanismes psychologiques en lien avec des 
difficultés sociales et relationnelles. Ainsi, il importe d'assurer l'accès au système de santé en mettant en place des dispositifs de soins de proximité tels qu'ils apparaissent en Suisse, à Lausanne ou à Genève, destinés spécifiquement aux populations vulnérables. Au-delà du renoncement aux soins pour des questions financières, dont plusieurs études estiment l'étendu en Suisse à une proportion de 10 à $15 \%$ de population, la médecine préventive se doit aussi d'amener les patients à investir le champ de leur santé et d'encourager le développement de compétences cliniques transculturelles pour mieux prendre en compte, justement, le niveau de littératie en santé.

En Suisse, la majorité des pathologies qui surviennent de nos jours sont liées à des maladies non transmissibles, telles que les maladies cardiovasculaires ou le diabète, offrant un rôle de choix, dans les soins médicaux, aux interventions de prévention des comportements à risques pour la santé. Bien que la qualité du système de santé suisse soit unanimement reconnue, la Suisse se place paradoxalement parmi les pays qui investissent le moins dans la prévention. Au niveau national, la médecine préventive du pays a fait et continue de faire l'objet de débats et de controverses entre les milieux médicaux, scientifiques, assécurologiques, politiques, financiers et les associations de patients, en particulier au sujet du remboursement des prestations médicales dans le domaine de la prévention. Au niveau international, la Suisse a pris un retard relatif par rapport à d'autres pays pour des actions préventives dans le domaine de la santé publique (p.ex. le retard dans la ratification de la convention-cadre de l'OMS pour la lutte antitabac - Framework Convention on Tobacco Control - FCTC).

Francis Vu \& Patrick Bodenmann

\section{Références}

Becker, D. M. \& Gardner, L. B. (Eds.) (1988). Prevention in clinical practice. New York: Plenum.

Bodenmann, P. Jackson, Y. \& Wolff, H. (2018). Vulnérabilités, équité et santé. Chêne-Bourg: RMS, Médecine et hygiène.

Cornuz, J., Auer, R., Neuner-Jehle, S., Humair, J. P., Jacot-Sadowski, I., Cardinaux, R., ... Rodondi, N. (2015). Recommandations suisses pour le bilan de santé au cabinet médical. Swiss Medical Forum, 15, 974-980.

\section{Mesures d'incitation}

Sous le terme «mesures d'incitation» peuvent être regroupées toutes les mesures qui visent, principalement par des incitations financières, à stimuler l'activité des bénéficiaires de prestations sociales, que ce soit au niveau de certaines assurances sociales ou prestations sociales sous condition de ressources. L'objectif est double: d'une part, influencer le comportement des individus en les incitant à chercher, trouver et rester en emploi afin de tendre vers l'autonomie financière sans l'aide de prestations de l'État et, d'autre part, éviter des effets de dépendance aux prestations ou des phénomènes de «trappe de pauvreté», c'est-à-dire des effets de dissuasion à rejoindre le marché du travail.

Ces mesures sont prioritairement d'ordre financier. Elles s'adressent pour la plupart directement aux bénéficiaires. Par exemple, dans le cadre de l'aide sociale, le supplément d'intégration encourage les personnes à faire des efforts particuliers en faveur de leur insertion (formation, participation à des programmes d'insertion socioprofessionnelle, etc.). D'autres mesures s'adressent aux employeur.euse-s (l'allocation d'initiation au travail qui est une participation de l'assurance-chômage au paiement de l'employé durant sa période d'initiation ou encore le placement à l'essai dans le cadre de l'assurance-invalidité). 
Les mesures d'incitation sont progressivement apparues à partir des années 1990 pour se renforcer dans les années 2000. Cette progression est à mettre en lien avec la montée de la théorie économique néoclassique dans le domaine social. Les politiques sociales sont pensées et orientées selon des modes de raisonnements économiques et des objectifs marchands. Même si la logique d'un État social solidariste basé sur la dette sociale et la responsabilité collective qui indemnise et protège dans une logique réparatrice est encore très présente, un nouveau modèle basé sur un État social activateur s'est progressivement développé en mettant l'accent sur la réciprocité, la contrepartie et la responsabilité individuelle. Ce dernier modèle se veut accompagnateur dans une logique incitatrice. Il gère des individus qui doivent prendre une place contributive dans la société et non pas rester à la marge sous les figures légitimes de l'inadaptation ou du handicap. En suivant cette logique, la protection et l'indemnisation sont des mesures «passives » qui déresponsabilisent les gens et ne les incitent pas à trouver des solutions autres que les prestations sociales.

La logique d'incitation n'a pas pour autant remplacé celle de la protection, mais s'est petit à petit installée dans certaines politiques sociales. L'assurance-invalidité en est un bon exemple avec l'évolution de la réadaptation. Si celle-ci a toujours été de mise, elle s'est transformée d'une réadaptation vue comme une réparation en une réadaptation plus focalisée sur l'incitation et la responsabilisation des personnes assurées devant fournir des efforts et mobiliser leurs capacités de travail. Dans l'assurance-chômage, l'introduction des mesures relatives au marché du travail puis la réduction de la durée d'indemnisation pour certains publics, notamment les jeunes, illustrent également cette tendance à tout mettre en œuvre pour que les bénéficiaires restent le moins longtemps possible dans une prestation d'indemnisation et soient incités à tout faire pour trouver une solution d'insertion. Enfin, l'aide sociale a elle aussi introduit différentes mesures dans le but d'inciter les bénéficiaires à s'engager dans une démarche d'insertion socioprofessionnelle, comme le supplément d'intégration mentionné précédemment ou encore la franchise sur le revenu provenant d'une activité sur le premier marché du travail.

Les mesures d'incitation sont souvent discutées et ceci tant au niveau du terrain de l'action sociale que du politique. Tout d'abord, cette logique incitatrice pose la question du mérite. La montée de la responsabilité individuelle dans les prestations sociales interroge la solidarité et ses fondements. De plus en plus de contre-prestations sont attendues de la part des bénéficiaires, c'est-à-dire que l'octroi des prestations est conditionné par des obligations en matière de recherche d'emploi ou d'amélioration de l'employabilité. Le contrat d'insertion est également employé pour fixer des objectifs d'évolution afin d'améliorer et stabiliser la situation personnelle du bénéficiaire en vue de son insertion. Les mesures peuvent également être négatives et donc utilisées comme des instruments de sanction (réduction des prestations pour augmenter le caractère contraignant de la contre-prestation). Ainsi, les questions de conditionnalité des prestations, de pénalisation ou encore d'astreinte à l'emploi sont soulevées. Se pose également la question de la marge d'appréciation des intervenants dans l'octroi ou non de ce type de mesures.

De plus, la logique d'incitation interroge la notion de faute comme celle de bonne foi des personnes aidées et met en évidence l'importance de la responsabilité ainsi que de l'initiative privée pour trouver des solutions d'insertion. Des bénéficiaires peuvent être suspectés de profiter des prestations. Abuse celui qui est passif, qui ne fait pas, ou pas suffisamment, d'efforts pour subvenir à ses besoins de manière autonome. L'incitation peut alors être ambivalente entre contrôle et aide. Ces mesures orientent le comportement individuel, 
mais plus largement le normalisent en définissant ce qui est souhaitable et acceptable.

Enfin, l'efficacité des mesures d'incitation est parfois contestée et les coûts mis en lien prioritairement avec la réussite en termes de sorties des prestations. Pourtant, les effets sont difficiles à mesurer, à chiffrer, à isoler d'autres facteurs d'insertion. Souvent, la focalisation sur la logique d'incitation se fait au détriment d'éléments constituant des obstacles déterminants au retour à l'emploi comme la montée des exigences sur le marché du travail ou encore la discordance entre l'offre d'emploi et la demande. La non-insertion est attribuée aux caractéristiques personnelles du bénéficiaire. Le contexte et les conditions de vie sont rarement pris en compte dans la compréhension de la situation face à l'emploi, ce qui accentue le poids de l'individu comme facteur causal. De plus, comme le souligne le bureau BASS, les analyses des effets incitatifs dans l'aide sociale ne tiennent que rarement compte du fait que les incitations financières interagissent avec des motivations non financières et que leurs effets dépendent fortement des modèles de perception des bénéficiaires, ces derniers n'agissant pas de manière aussi rationnelle que l'orthodoxie libérale le revendique.

Aujourd'hui, les enjeux de l'incitation s'étendent encore, notamment avec les défis pour les professionnels et les politiques de prendre en charge des individus qui ne trouvent pas de solution malgré l'incitation. Le postulat du «tout le monde est intégrable» est de plus en plus mis en doute, l'intégration devenant plus un état qu'un processus (Castel). Certains bénéficiaires restent durablement en insertion, non car ils n'ont pas de ressources et n'agissent pas, mais car leurs actions restent insignifiantes dans un contexte uniquement orienté vers l'insertion professionnelle. Cela demande alors de réfléchir non pas uniquement à l'intégration des individus à la société par l'emploi, mais aussi à la capacité d'intégration de la société, à la définition de la solidarité envers les individus en difficulté, à la place et la valeur accordées à l'emploi. Pour les politiques sociales, cela implique de continuer à développer l'incitation et la motivation des bénéficiaires à trouver rapidement un emploi. Mais, comme le mentionne l'OCDE, l'accompagnement et les débouchés sont également à renforcer. Les bénéficiaires, même motivés, peuvent rencontrer des difficultés à trouver un emploi s'ils ne sont pas guidés dans leur démarche. L'amélioration des débouchés est aussi nécessaire, notamment par une augmentation de la diversité des offres d'emploi. Ces dimensions étant interdépendantes, elles appellent à un renforcement de la collaboration entre les différent·e-s acteur.trice-s des politiques sociales et économiques.

\section{Martine Zwick Monney}

\section{Références}

Castel, R. (2009). La montée des incertitudes: travail, protection, statut des individus. Paris: Seuil.

Dubach, P., Rudin, M., Bannwart, L., Dutoit, L. \& Bischof, S. (2015). Évaluation des normes à caractère incitatif selon les normes CSIAS. Berne : Büro für Arbeits- und Sozialpolitische Studien (BASS). Organisation for Economic Cooperation and Development (Ed.) (2016). OECD Employment Outlook 2016. Paris : OECD Publishing.

\section{Migrant·e·s sans statut de séjour*}

De nos jours, il est communément sous-entendu que les «sans-papiers» font référence à des requérant.e-s d'asile qui sont arrivé-e.s en Suisse sans documents de voyage ou à des personnes qui ne peuvent être expulsées par les autorités par manque de documents d'identité. Parfois, il est aussi fait allusion à des personnes qui sont entrées sur le territoire suisse de manière illégale ou à des personnes qui travaillent au noir. Toutefois, face à la définition juridique du terme, toutes ces références sont 
inadéquates. Du point de vue du droit suisse, une personne sans-papiers est à une personne étrangère qui au regard de la loi sur les étrangers et l'intégration ne dispose pas de l'autorisation nécessaire à son séjour dans le pays. Les sans-papiers ne font donc pas référence à l'absence de documents d'identité ni à l'absence de permis de travail, mais plutôt à l'absence d'une autorisation de séjour valide en Suisse.

Plusieurs situations mènent au statut de sans-papiers: 1) lorsqu'une personne étrangère entre sur le territoire sans visa et séjourne ensuite en Suisse illégalement, c'est-à-dire sans l'autorisation migratoire correspondante; 2) lorsqu'une personne entre sur le territoire légalement, c'est-à-dire avec le visa requis, et qu'elle reste en Suisse après la fin de son droit de séjour ; 3 ) lorsque les personnes étrangères étaient en possession d'une autorisation de séjour mais celle-ci est périmée; et 4) quand les personnes pour lesquelles la demande d'asile a été refusée restent en Suisse sans être admises provisoirement.

Comme les personnes sans-papiers ne sont enregistrées nulle part, il est difficile d'en évaluer le nombre. La dernière estimation (qui date de 2015) table sur environ 76000 personnes. $86 \%$ des sans-papiers adultes exercent une activité lucrative. Plus de la moitié travaille dans des ménages privés, $18 \%$ dans le bâtiment, $16 \%$ dans l'hôtellerie et la restauration et $5 \%$ dans l'agriculture.

Les débats sur les sans-papiers mettent en présence des idéaux, des valeurs et des convictions politiques et économiques qui poursuivent des objectifs différents, voire contradictoires. D'un point de vue politique, la fermeture du marché du travail aux États tiers liée au système dual d'admission est au premier plan: tandis que les personnes provenant de l'espace UE/AELE ont le droit de travailler en Suisse presque sans restrictions, en ce qui concerne les personnes en provenance de tous les autres États, seuls les spécialistes, professions cadres et autre professions quali- fiées peuvent être recrutés. Le monde politique oublie ainsi que les mouvements migratoires actuels, du moins ceux qui ne résultent pas de conflits ou de catastrophes naturelles, ne sont pas conditionnés par l'État, mais par le marché et les besoins de l'économie. Les divers secteurs d'activité recrutent leur personnel là où il est disponible et non là où ils ont le droit de le faire. Les sans-papiers satisfont le besoin de main-d'œuvre de certains secteurs qui ne peuvent le satisfaire légalement.

$\mathrm{Si}$ les personnes sans-papiers ne disposent d'aucun statut de séjour légal, elles ne sont pas sans droits, car les droits humains et les droits fondamentaux inscrits dans les conventions internationales et dans la Constitution fédérale suisse s'appliquent à toute personne sur le territoire suisse, quelle que soit sa nationalité et indépendamment de l'existence d'une autorisation de séjour nécessaire le cas échéant. Les sans-papiers ont donc assurément des droits et peuvent les faire valoir si les conditions y relatives sont remplies. Faire respecter ces droits est cependant difficile à cause de la peur d'être découvert par les autorités. En raison de ce risque, les sans-papiers évitent autant que possible de recourir aux services des organismes et institutions pour faire valoir leurs droits, notamment dans le domaine des assurances sociales. L'assurance-maladie obligatoire, par exemple, doit couvrir toute personne résidant en Suisse, y compris les sans-papiers. Cependant, pour nombreux sans-papiers l'affiliation à l'assurance-maladie est trop risquée - souvent d'ailleurs les caisses-maladie ne sont pas prêtes à les accepter. C'est pourquoi, en 2002, l'Office fédéral des assurances sociales s'est vu contraint d'exiger, dans une circulaire adressée aux assureurs, qu'ils affilient les sans-papiers domiciliés en Suisse au même titre que toutes les autres personnes soumises à l'obligation de s'assurer. L'Office fédéral a en outre rappelé aux assureurs l'obligation de garder le secret vis-à-vis de tiers et les possibles conséquences pénales d'une violation de cette obligation. 
Malgré tout, dans certaines régions de Suisse, les sans-papiers éprouvent encore des difficultés à s'affilier à une caisse maladie. À cela s'ajoute le fait que les primes d'assurance-maladie sont trop élevées pour la plupart des sans-papiers, qui gagnent en règle générale de bas salaires. Certes, ces personnes auraient droit à une réduction de prime dans les mêmes conditions que les personnes vivant légalement en Suisse. Mais la soumission d'une demande de réduction de prime est tout aussi risquée. C'est la raison pour laquelle certains cantons prévoient des processus particuliers pour aller au-devant de ces demandes et les traiter.

Le fait que de nombreuses personnes sans-papiers ne soient couvertes ni pour la maladie, ni pour les accidents, et qu'elles disposent de moyens financiers très limités complique leur accès aux services de santé. Ainsi, par exemple, il existe depuis 1996 à Genève une Unité de soins communautaires qui prodigue des soins médicaux aux personnes démunies et surtout aux personnes sans assurance-maladie. Dans cette unité, les sans-papiers aussi peuvent se faire aider sans avoir à craindre d'obstacle administratif insurmontable. Dans d'autres cantons également, il existe maintenant des réseaux auxquels les sans-papiers peuvent s'adresser en cas de problème de santé.

Les autorités ayant pour politique de ne pas encourager ni récompenser l'illégalité, dans la problématique régularisation ou expulsion, l'expulsion prime. La légalisation est rare et ne se produit que de manière exceptionnelle. Les régularisations collectives telles qu'elles se pratiquaient au début des années 2000 hors de Suisse en Europe, ou encore aujourd'hui aux États-Unis, font l'objet d'un refus catégorique en Suisse.

Les rares légalisations de séjour de sans-papiers sont possibles uniquement par le biais de la «clause de rigueur» de la loi sur les étrangers et l'intégration. Celle-ci stipule que dans les cas individuels d'une extrême gravité, les autorités cantonales de migration peuvent délivrer aux sans-papiers un permis de séjour, à condition que le Secrétariat d'État aux migrations (SEM) ait donné son approbation. Les autorités cantonales se voient donc attribuer un rôle décisif dans la légalisation, car elles doivent par principe être disposées à délivrer un permis au sans-papiers. Cette volonté varie cependant beaucoup d'un canton à l'autre. Ainsi, en 2015 par exemple, neuf cantons seulement ont transmis au SEM un total de 318 demandes pour cas de rigueur. Sur ces 318 demandes, 220 provenaient du seul canton de Genève. De février 2017 à fin 2018, dans le cadre de l'Opération Papyrus, ce dernier canton a notamment aussi mené une campagne spécifique pour légaliser plusieurs centaines de sans-papiers.

Depuis quelques années seulement, dans certaines conditions, il est possible de délivrer un permis de séjour aux jeunes personnes sans papiers ayant fréquenté l'école obligatoire en Suisse pendant au moins cinq ans sans interruption, afin qu'ils puissent faire un apprentissage. Les parents et frères et sœurs de ces jeunes personnes en situation de légalisation peuvent aussi obtenir un permis pourvu qu'elles remplissent les conditions déjà mentionnées du cas individuel de rigueur. Au vu des chances de réussite limitées d'une demande et $\mathrm{du}$ risque d'expulsion qu'elle peut entraîner, il n'est pas étonnant que le nombre de demandes de jeunes sans-papiers pour cas de rigueur est bas, lui aussi.

\section{Martina Caroni}

\section{Références}

Morlok, M., Meier, H., Oswald, A., Efionayi-Mäder, D., Ruedin, D., Bader, D. \& Wanner, P. (2015) Sans-Papiers in der Schweiz 2015: Schlussbericht zuhanden des Staatssekretariats für Migration (SEM). Basel : B,S,S. Volkswirtschaftliche Beratung AG. 
Niederöst, P. (2009). Sans-Papiers in der Schweiz. In P. Uebersax, B. Rudin, T. Hugi Yar \& T. Geiser (Hrsg.), Ausländerrecht: Eine umfassende Darstellung der Rechtsstellung von Ausländerinnen und Ausländern in der Schweiz (S. 373-415). Basel : Helbing Lichtenhahn.

Petry, R. (2013). La situation juridique des migrants sans statut légal: entre droit international des droits de l'homme et droit suisse des migrations. Genève : Schulthess.

\section{Migration et formation}

Toute immigration, qu'elle soit économique ou politique, conduit tôt ou tard à l'insertion d'une nouvelle population dans la structure économique du pays de réception: la formation et l'éducation sont cruciales à cet égard. Se pencher sur le lien entre migration et formation revient à analyser le profil scolaire et professionnel des immigré.e.s: le type de sélectivité des politiques d'admission des immigré·e-s est la clef d'explication. La Suisse a conçu l'immigration comme une politique de marché du travail. Depuis la fin de la Seconde Guerre mondiale jusqu'à il y a une vingtaine d'années, elle a choisi d'accorder la priorité à l'immigration de personnes faiblement scolarisées, pour qu'elles occupent les emplois les moins convoités et qualifiés dans la stratification de la société suisse. Vers la fin des années 1990, dans le contexte de la nouvelle poussée de globalisation, les autorités ont en revanche favorisé l'immigration de personnes hautement qualifiées. Ces deux politiques d'admission expliquent pourquoi, en comparant immigré·e-s de la première génération et Suisses, on observe dans le premier groupe une surreprésentation à la fois des personnes sans formation post-obligatoire ( $28 \%$ vs. $14,8 \%$ ) et des personnes avec une formation de niveau tertiaire (36\% vs. $32,2 \%$ en 2015 ).

S'interroger sur le rapport entre migration et formation requiert aussi d'analyser com- ment la population descendante d'immigré·e·s réussit sur le plan scolaire dans le nouveau pays de résidence: la politique scolaire et les opportunités offertes par le système scolaire jouent un rôle clef à cet égard. Le sort de ces jeunes personnes - qu'elles restent confinées aux emplois tout en bas de l'échelle sociale ou qu'elles s'en affranchissent - a un impact tant sur la performance économique du pays, que sur la cohésion sociale. L'impératif de l'intégration passe par l'accès équitable aux qualifications scolaires et professionnelles. Alors, quelles sont les performances scolaires des enfants de migrant·e.s en Suisse?

Des indicateurs permettent de se faire une idée des écarts de scolarisation entre les personnes jeunes nées en Suisse (deuxième génération) et les jeunes personnes non issues de la migration. L'absence d'un diplôme post-obligatoire réduit les chances d'insertion sur le marché du travail et augmente les probabilités de futurs problèmes (chômage, risque de pauvreté). En 2015, les jeunes personnes de la deuxième génération, âgées de 25 à 34 ans, sont deux fois plus nombreuses que celles et ceux non issu.e.s de la migration dans cette situation. Ce taux est parmi les plus bas observés dans les pays de l'OCDE.

Par ailleurs, les jeunes personnes d'origine migrante se retrouvent plus souvent dans la filière à exigences élémentaires du secondaire I. Si une jeune personne suisse sur cinq fréquente le secondaire I, c'est le cas d'environ deux jeunes originaires d'Italie, d'Espagne, du Portugal ou de Turquie sur cinq et de plus de trois jeunes d'ex-Yougoslavie et d'Albanie sur cinq. L'obtention d'un diplôme d'études de niveau tertiaire couronne un parcours de réussite scolaire qui confère de bonnes chances d'insertion professionnelle et sociale. En 2015, un peu plus du tiers des enfants de migrant.e.s (37\%) âgés de 25 à 34 ans atteint une formation de niveau tertiaire, contre la moitié chez les jeunes non-issu.e.s de la migration. 
Ces données expriment des moyennes combinant les migrations hautement et faiblement qualifiées; or, les trajectoires scolaires des jeunes sont fortement influencées par l'origine sociale des parents. Parmi les pays de l'OCDE, le système scolaire suisse figure parmi les plus inégalitaires en raison d'un fort lien entre performance scolaire et origine sociale qui est le signe de la reproduction sociale. Ainsi les enjeux sociaux majeurs concernent la scolarisation et les performances des enfants de migrant·e·s faiblement qualifié·e·s. En effet, en comparaison avec des enfants suisses de milieu modeste, la proportion d'élèves de milieu modeste qui parvient à obtenir de très bons résultats scolaires est deux fois inférieure chez les enfants d'immigré·e-s né·e.s en Suisse et quatre fois inférieure chez les enfants immigrés.

Le passage de l'école obligatoire aux formations du secondaire II est crucial pour l'insertion sociale des jeunes. La transition entre la scolarité obligatoire et le post-obligatoire s'avère difficile: une jeune personne étrangère sur quatre doit recourir à des «solutions » transitoires (10 année de secondaire I, école préparatoire ou préapprentissage) alors que ceci n'est le cas que pour une jeune personne suisse sur dix. Les chances de maîtriser ce passage dépendent plus de l'origine sociale et de l'origine migratoire que des performances scolaires, comme le démontrent les analyses des premières données longitudinales sur le secondaire II.

Si l'on prend en compte les trajectoires scolaires de l'école primaire jusqu'à l'insertion professionnelle, on observe que les jeunes personnes de la deuxième génération turque et balkanique sont moins nombreuses que leurs ceux et celles d'origine suisse ( $16 \%$ vs. $28 \%$ ) à inscrire systématiquement leurs parcours dans les filières de formation les plus qualifiantes et à obtenir des postes de travail élevés. Ceci conforte l'image dominante des moindres performances scolaires des enfants de migrant $\cdot e \cdot s$, notamment à cause de leur origine sociale défavorisée. L'autre face de la médaille est moins connue: ces jeunes personnes connaissent un parcours de formation et d'insertion professionnelle ascendant, quoique quelque peu accidenté, plus souvent que ceux et celles d'origine suisse ( $60 \%$ vs. $40 \%$ ). Elles ont fréquenté les filières les moins exigeantes du secondaire I, sont peut-être passées par une dixième année scolaire et un apprentissage, mais parviennent à une position professionnelle de niveau intermédiaire, grâce notamment à la formation continue.

Par ailleurs, une fois terminées les filières gymnasiales du secondaire II, les jeunes de la deuxième génération ne semblent pas être désavantagé·e-s lors du passage aux formations tertiaires. Au contraire, si l'on contrôle l'origine socioéconomique et les résultats scolaires, les hommes de deuxième génération originaires d'ex-Yougoslavie, d'Albanie/Kosovo, de Turquie ou du Portugal ont même une plus grande probabilité de commencer une formation supérieure.

De ces diverses analyses, il ressort que les obstacles les plus redoutables pour les jeunes personnes issues de la migration, venant de familles au faible capital scolaire, semblent se concentrer dans la première partie du parcours éducatif.

Pour expliquer les écarts des performances scolaires des enfants de migrant.e.s, l'attention s'est d'abord portée sur les facteurs qui caractérisent les migrant-e.s: la condition sociale et les compétences linguistiques. La culture d'origine est également convoquée pour rendre compte des réussites et des échecs au sein des divers groupes immigrés. Ces explications différentialistes présentent le défaut de reposer sur une vision des cultures figée dans le temps et sur une représentation homogène des groupes d'origine, alors que le fait d'émigrer, les processus d'adaptation associés à la migration et le passage des générations produisent 
des changements majeurs dans les horizons culturels des migrant·e-s et leurs familles.

Plus récemment la recherche visant à expliquer ces différences de performances scolaires des enfants de migrant.e-s dans divers pays, a porté le regard non pas sur les migrant·e.s, mais prioritairement sur les caractéristiques des systèmes scolaires des pays d'immigration. Comparant la population descendante de l'immigration turque dans plusieurs pays européens, l'étude TIES (The Integration of the European Second Generation) démontre comment les structures scolaires différentes des pays d'immigration ont des répercussions sur les inégalités scolaires et la mobilité intergénérationnelle des descendants d'immigrés. Les systèmes scolaires où le début de la scolarité est tardif et la sélection précoce (à l'instar de l'Allemagne, l'Autriche et de la Suisse) offrent moins de temps aux enfants de migrant·e-s issu-e.s de familles faiblement scolarisées, pour les apprentissages nécessaires à une réussite scolaire, que les systèmes privilégiant une scolarité précoce et une sélection tardive (tels que la France et la Suède).

\section{Rosita Fibbi}

\section{Réferences}

Gomensoro, A. \& Bolzman, C. (2016). Les trajectoires éducatives de la seconde génération : quel déterminisme des filières du secondaire I et comment certains jeunes le surmontent. Schweizerische Zeitschrift für Soziologie, 42(2), 289-308.

Sacchi, S., Hupka-Brunner, S., Stalder, B. E. \& Gangl, M. (2011). Die Bedeutung von sozialer Herkunft und Migrationshintergrund für den Übertritt in anerkannte nachobligatorische Ausbildungen in der Schweiz. In M.M. Bergman, S. Hupka-Brunner, A. Keller, T. Meyer \& B.E. Stalder (Hrsg.), Transitionen im Jugendalter: Ergebnisse der Schweizer Längsschnittstudie TREE (S. 120-156). Zürich : Seismo.

Schnell, P. \& Fibbi, R. (2016). Getting ahead : educational and occupational trajectories of the 'new' second-generation in Switzerland. Journal of International Migration and Integration, 17(4), 1085-1107.

\section{Migration et vieillesse}

La migration et la vieillesse sont deux thématiques importantes pour la société suisse dans un contexte démographique d'augmentation de la population venue d'ailleurs et de la population âgée. Cependant pendant longtemps elles ont été traitées de manière indépendante. L'intérêt pour la migration s'est focalisé sur la population adulte étrangère active. Quant à la vieillesse, la question ne semblait concerner que la population d'origine suisse. Lorsqu'on faisait le lien entre les deux thématiques, on avait tendance à confirmer ces représentations dominantes puisqu'on évoquait la migration comme l'une des manières de rajeunir la population ou de financer les retraites de la population suisse vieillissante.

Ainsi, la notion de personne âgée migrante ne faisait pas partie de l'imaginaire collectif. La migration était associée à l'idée de productivité et l'image la plus répandue était celle des migrant-e.s retournant dans leurs pays d'origine une fois l'âge de la retraite atteint. Ce n'est qu'à partir de la seconde moitié des années 1990 que des recherches vont commencer à sensibiliser l'opinion au phénomène du vieillissement sur place de la population migrante. En 2001, une enquête pionnière de Claudio Bolzman, Rosita Fibbi et Marie Vial met en évidence que seule une minorité des personnes recrutées pour travailler en Suisse dans les années 1950 et 1960, venues principalement d'Italie et d'Espagne, retournerait au pays d'origine au moment de la retraite.

Le passage à la retraite joue pour les migrant.e.s surtout le rôle d'une frontière socio-institutionnelle (passage du statut de la personne salariée à celui de la rentière) et, dans une moindre mesure, le rôle d'une frontière spatiale (à savoir le moment du retour au pays d'origine ou surtout de mobilité géographique plus fluide entre les deux pays). Tout comme la population née suisse, la population migrante devient ainsi «vieille» vis-à-vis des 
institutions sociales lorsqu'elle atteint l'âge de recevoir une pension de vieillesse (AVS) et/ou de retraite (deuxième pilier).

L'étude pionnière a pourtant montré que l'âge réel de sortie du monde du travail ne coïncide pas nécessairement avec les âges socialement définis comme ceux à partir desquelles on peut toucher une rente. En effet, les types de métiers exercés ont une influence sur l'usure prématurée des salarié·e·s par rapport à ce que les institutions sociales définissent comme les âges pivot de passage. Dans la mesure où la grande majorité des travailleur-euse-s venu.e.s du sud de l'Europe a exercé des métiers manuels et/ou peu qualifiés, les chances de sortie précoce du monde du travail en raison d'un accident ou d'une maladie sont plus élevées que pour la moyenne de la population. Ce phénomène a été défini par Paola Bollini et Harald Siem comme un exhausted migrant effect. Ces populations dont le corps a été usé de manière prématurée ne bénéficient donc pas des mesures de politique sociale destinées à la vieillesse, mais des mesures destinées à la population «active» (assurances accidents ou invalidité), voire de l'assistance sociale. Elles doivent ainsi attendre parfois plusieurs années avant de pouvoir bénéficier des mesures destinées aux personnes aînées.

Une fois à la retraite, ces migrant·e-s peuvent rencontrer des difficultés particulières liées à leur parcours de vie précédent. Ayant souvent commencé à travailler tôt dans leurs vies, leurs pensions de vieillesse peuvent être faibles par manque d'années de cotisation. Le fait d'avoir exercé une activité professionnelle dans au moins deux pays avec des systèmes différents de retraite peut nuire à la continuité de leurs versements, même si l'existence d'accords bilatéraux de sécurité sociale peut limiter ce problème. Par ailleurs, une partie des femmes migrantes seules (divorcées ou veuves) et avec un faible niveau de qualification) bénéficie moins souvent des prestations du deuxième pilier du fait d'avoir travaillé à temps partiel et pour des salaires trop bas, dans des branches de l'économie où les conventions collectives sont peu respectées. Ces femmes auraient droit à des prestations complémentaires de l'AVS, mais ne sont pas toujours bien informées sur cette possibilité.

Si une partie considérable des personnes âgées migrantes relèvent du type de parcours et situations décrits ci-dessus, il y a également des migrant·e.s âgé-e·s d'autres origines et avec d'autres types de trajectoires migratoires et professionnelles, ainsi que vivant des situations variées après la retraite. Certain·e-s migrant·e.s ont fait la plupart de leur vie professionnelle en Suisse, mais ont exercé plutôt des métiers qualifiés. C'est le cas notamment des ressortissant.e.s d'Allemagne ou de France, ainsi que de l'Europe du Nord ou de l'Amérique du Nord. Pour la plupart, ces personnes ne connaissent pas des difficultés économiques ou sanitaires particulières après la fin de la vie active. D'autres migrant.e-s encore sont venu.e.s comme jeunes adultes dans le cadre de l'asile ou du regroupement familial. Si une partie de ces personnes a pu travailler dans leur domaine d'expertise, d'autres personnes ont connu une déqualification durable importante ou une insertion instable sur le marché du travail. Pour ces deux derniers cas, la période de la retraite peut s'avérer compliquée du point de vue financier et/ou psychosocial.

Certain.e.s migrant·e.s arrivent en Suisse vers la fin de leur vie professionnelle, d'autres arrivent après leur retraite dans leur pays d'origine dans le cadre du regroupement familial. Ce type de déplacement «tardif», limité en nombre, est généralement envisagé que suite à une modification importante du mode de vie de ces personnes et de leurs liens transnationaux avec leurs familles. C'est souvent un événement contextuel (violences politiques ou crise économique au pays d'origine, introduction de visas par le pays où réside leur famille, etc.), un événement qui affecte directement la personne âgée (veuvage, accident, maladie, dépendance, 
perte d'autonomie, etc.), ou un événement qui affecte ses enfants (naissance, divorce, maladie, dépression, etc.) qui déclenche le processus. Selon les situations, la migration peut être envisagée par la personne et sa famille comme provisoire, comme part d'un mode de vie itinérant ou comme permanente. Dans ce dernier cas de figure, la personne va vivre les dernières années de sa vie dans un pays inconnu. De plus, divers problèmes de prise en charge financière, sociale ou sanitaire peuvent surgir. En effet, le regroupement familial d'un·e ascendant.e n'est accepté par les autorités helvétiques que si sa famille s'engage à assumer tous les frais découlant du soutien à la personne âgée. Dans ce cas, la solidarité est déléguée strictement à la sphère privée.

Par ailleurs, ce genre de migration «tardive» est également pratiqué par un nombre croissant de la population suisse qui s'expatrie vers d'autres destinations, notamment vers le Sud de l'Europe, mais aussi vers des pays comme la Thaillande ou le Maroc, autour du moment de la retraite. Elle cherche surtout une meilleure qualité de vie (climat plus chaud p.ex.), mais aussi parfois une nouvelle vie suite à un divorce et/ou à éviter une situation de précarité liée à la faiblesse de la rente AVS et l'absence d'un deuxième pilier. Ces personnes espèrent que le différentiel du coût de la vie entre la Suisse et ces pays leur permettra d'améliorer leur pouvoir d'achat. Cependant, elles peuvent être confrontées à certains problèmes, tels que l'impossibilité de s'affilier à une assurance-maladie à un coût raisonnable.

Ce dernier exemple, et d'autres évoqués plus haut montrent que l'une des difficultés majeures auxquelles sont confrontées les personnes âgées immigrées est le décalage entre leurs trajectoires et modes de vie transnationaux et des politiques sociales nationales. La plupart des politiques sociales sont pensées pour des citoyen-ne.s vivant toute leur vie dans un même État. Étant donné que les politiques sociales jouent un rôle grandissant à l'âge avancé, les effets négatifs de ce décalage apparaissent avec plus de visibilité lors de cette étape de l'existence.

\section{Claudio Bolzman}

\section{Références}

Bollini, P. \& Siem, H. (1995). No real progress towards equity: health of migrants and ethnic minorities on the eve of the year 2000. Social Science and Medicine, 41(6), 819-828.

Bolzman, C., Fibbi, R. \& Vial, M. (2001). La famille : une source de légitimité pour les immigrés âgés après la retraite? Revue européenne des migrations internationales, 17(1), 55-78.

Hungerbühler, H. \& Bisegger, C. (2012). «Alors nous sommes restés...» : les migrantes et les migrants âgés en Suisse. Berne : Commission fédérale pour les questions de migration et Forum national «Âge et migration».

\section{Mineur·e·s requérant·e·s d'asile non accompagné·e·s}

Il existe une tension entre deux principes dans les sociétés contemporaines : d'une part le souci universel de protéger l'enfance qui se cristallise dans la Convention internationale des droits de l'enfant (CIDE), et d'autre part la délégation de la gouvernance des migrations internationales aux États, lesquels définissent, selon leurs propres critères, qui a la légitimité d'entrer et de séjourner dans le cadre des frontières qu'ils contrôlent. Les mineur·e·s non accompagné·e·s symbolisent cette contradiction puisqu'il s'agit à la fois d'enfants en situation de vulnérabilité qui doivent être l'objet de protection selon la CIDE, et d'étranger-ère-s qui doivent avoir de «bonnes» raisons pour pouvoir séjourner de manière légitime dans un autre État que le leur.

En Suisse, les personnes mineures qui demandent l'asile sont considérées comme non accompagnées lorsqu'elles ne voyagent ni avec leurs parents, ni sous la responsabilité d'un autre adulte. La loi sur l'asile (LAsi) défi- 
nit principalement les conditions d'admission, d'accueil et de séjour de ces personnes. Lorsqu'elles déposent une demande d'asile, elles sont désignées comme requérantes d'asile mineures non accompagnées (RAMNA). C'est à partir du début des années 1990 que la problématique des RAMNA émerge dans le discours public. Malgré une première directive, sommaire, en 1989 les organismes d'aide aux réfugiéee-s soulignaient les carences de leur prise en charge institutionnelle et juridique, contribuant par la même occasion à donner une certaine visibilité à cette catégorie d'exilé.e-s et à la constituer en "problème social» spécifique. La dénonciation d'octobre 1991 au Conseil fédéral, suite à la décision de renvoi de deux mineurs hébergés dans le canton de Vaud, révélait les principales lacunes du traitement des RAMNA. Ces lacunes ont constitué - avec d'autres par la suite - les pierres d'achoppement majeures entre les institutions de défense du droit d'asile et les autorités compétentes. De manière générale, les discussions se sont concentrées sur l'opposition entre la protection des mineur.e-s et le droit d'asile, puisque les autorités doivent notamment tenir compte de la CIDE de 1989, signée par la Suisse en 1991 et entrée en vigueur en 1997.

Considéré·e·s comme requérant·e·s d'asile, les RAMNA suivent en gros la même procédure d'accueil que les adultes. Quelques différences peuvent être signalées: traitement prioritaire de sa demande dans l'un des Centres d'enregistrement pour requérant.e-s d'asile; adaptation $\mathrm{du}$ déroulement des auditions; examen de sa capacité de discernement et éventuellement de son âge réel ; nomination d'une représentation légale au moment de son affectation à un canton; et prise en compte de motifs spécifiques susceptibles de rendre inexigible l'exécution de son renvoi. Notons toutefois que tous ces éléments ne sont pas appliqués de manière systématique, alors que d'autres posent problème du point de vue de la protection de l'enfance.
Les conditions d'octroi du statut de réfugié.e pour les personnes mineures et adultes sont identiques. Ainsi, les requérant·e-s doivent rendre vraisemblable l'existence de persécutions ciblées contre leur personne par un État, ou tout au moins démontrer que l'État qui régit leur région de provenance ne peut ou ne souhaite pas les protéger des menaces qui les concernent. Ceci implique donc généralement que la personne qui demande l'asile fasse partie d'un mouvement politique et y mène une activité telle qu'elle la met en danger de manière individuelle. Or, il arrive rarement qu'une personne mineure puisse avancer de tels motifs de sorte qu'en Suisse le taux des RAMNA qui obtiennent chaque année le statut de réfugié·e est très bas et souvent inférieur à $1 \%$.

Les mineur·e's non accompagné·e·s qui se présentent dans les centres d'enregistrement sont automatiquement mis·es dans la procédure d'asile. La capacité de discernement pour toutes personnes mineures et le droit à une représentation tutélaire qui en découle sont ainsi ignorés par les autorités suisses. Par ailleurs, une fois attribuées aux cantons, ces derniers omettent souvent la nomination d'une représentation tutélaire ou d'une personne de confiance qualifiée. Ce non-respect de la loi qui bloque toutes les démarches ultérieures n'est pourtant pas conforme à la CIDE qui exige que toutes mesures prises fassent prévaloir le bienêtre de l'enfant.

Si la loi exclue la mise en détention d'enfants de moins de 15 ans, celle notamment de requérant·e.s d'asile débouté·e·s, âgé·e·s de moins de 18 ans est possible pour une durée renouvelable - de trois mois en vue de leur renvoi du territoire suisse. En effet, sous certaines conditions, par exemple par manque de coopération avec les autorités, les RAMNA ne sont pas exempté-e.s d'expulsion et sujet à la détention malgré une base légale qui peut paraître douteuse. Cependant, en termes de détention la législation suisse est comparable à celle 
d'autres pays européens, en dehors des variations dans la durée possible d'internement.

La vérification de l'âge des requérant·e-s constitue un autre point sensible de la procédure appliquée aux mineur·e·s. La minorité d'une personne requérante donnant droit à une meilleure protection en ce qui concerne l'exécution du renvoi, on considère que des jeunes adultes avancent un âge inférieur afin de maximiser leurs chances de rester en Suisse, ou tout au moins de prolonger leur séjour. Dès lors, les autorités peuvent procéder à des examens osseux visant à déterminer l'âge biologique de requérant·e.s se prétendant mineur·e.s. D’après le Conseil fédéral, ces vérifications ont pour but d'assurer au mieux le principe de l'intérêt supérieur des enfants, de garantir un encadrement adéquat aux requérant·e-s d'asile effectivement mineur.e.s et de lutter contre les abus fréquents constatés dans ce domaine. Toutefois, la marge d'erreur des examens osseux est de plus ou moins deux ans, ce qui rend difficile, dans de nombreux cas, la détermination de l'âge exact de la personne.

On constate donc que les mineur.e.s exilé·e·s sont considéré·e·s comme des requérant.e-s avant d'être pris en compte dans leur spécificité liée à leur condition d'enfant. Les concessions accordées à leur statut d'enfant, progressivement élargies mais parfois ambivalentes (représentation tutélaire, placement, formation, etc.), sont censées ne bénéficier qu'à un minimum d'individus - d'où l'importance de la détermination de l'âge - étant donné qu'elles constitueraient un avantage pour les personnes concernées. De fait, depuis 2004 il s'agit de moins de 200 à 800 RAMNA par année (à l'exception de 2015 et 2016 avec 2000 et plus), soit de moins de $3 \%$ des requérant.e.s d'asile en Suisse.

Qui plus est, ne permettant pas de viser le long terme, le dispositif mis en place entraîne une importante déperdition dans la construction d'une future insertion sociale des RAMNA, soit en Suisse, soit dans leur pays d'origine, soit encore dans un pays tiers. Ainsi, aussi bien les efforts de ces jeunes personnes que ceux des professionnel-le-s peuvent-ils être court-circuités à tout moment par les décisions administratives prises par les autorités lors du passage à la majorité. Le manque de coordination entre les autorités chargées de statuer sur l'asile et les professionnel-le·s qui suivent les jeunes, avec la prédominance des critères juridiques sur les considérations sociales ou éducatives, est un des problèmes majeurs dans ce domaine.

Les RAMNA voudraient se construire progressivement un futur en tant qu'adultes, mais le poids de l'étiquette «requérant·e d'asile» qu'ils portent sur leurs épaules rend difficile ce travail de construction. Ces personnes souhaiteraient être comme les autres jeunes, mais elles se rendent compte qu'elles ne sont pas considérées comme les autres jeunes.

\section{Claudio Bolzman}

\section{Références}

ADEM, Alliance pour les droits des enfants migrants. http://www.enfants-migrants.ch

Bolzman, C. (2011). Les mineurs non accompagnés en Suisse : demandeurs d'asile ou enfants exilés? Les politiques sociales, 3-4, 104-117.

Lachat Clerc, M. (2007). Les mineurs non-accompagnés en Suisse: exposé du cadre légal et analyse de la situation sur le terrain. Le Mont-sur-Lausanne: Terre des hommes.

\section{Minimum vital*}

Des minimums vitaux sont définis en vue de mesurer la pauvreté, de déterminer un droit à des prestations sociales ou de préserver une assistance sociale minimale. La garantie d'une assistance minimale assure l'existence des intéressé·e.s. Cette notion peut toutefois être interprétée de deux manières différentes. Le minimum vital absolu est ce dont un individu a besoin pour survivre physiquement. Ce besoin 
varie cependant en fonction de facteurs individuels et des conditions climatiques. En Suisse, le minimum vital repose sur la nourriture, mais aussi le logement, les vêtements et l'accès aux soins de santé. Le minimum vital social est le montant financier minimal qui, au-delà de l'existence, permet aussi d'être partie prenante de la société. Ce concept revêt donc une dimension relative, dans la mesure où il se base sur les normes en vigueur dans une société donnée. Le montant du minimum vital absolu, et surtout du minimum vital social, est étroitement lié aux conditions économiques et sociales, ainsi qu'aux normes sociales d'une société. Si l'accès aux soins médicaux exige la présentation d'une carte d'assurance-maladie, il faut prendre en compte le coût d'une telle assurance lors du processus de fixation du minimum vital absolu. Si la communication entre les membres d'une société se fait essentiellement par téléphone ou Internet, le minimum vital social doit englober le coût des appareils et des accès nécessaires. Ces composantes relatives entraînent une augmentation du minimum vital social proportionnelle à celle de la prospérité d'une société.

En Suisse, le minimum vital est protégé par les articles 12 et 41 de la Constitution fédérale. L'État s'engage à permettre à toute personne vivant en Suisse de mener une existence conforme à la dignité humaine. Déterminer dans quelle mesure ces articles donnent droit au minimum vital social, qui va au-delà du minimum vital absolu, est une question controversée. La validité de ces droits ne peut être déduite d'un simple article constitutionnel ; bien plus, elle est liée à l'interprétation de l'ensemble des buts sociaux et des droits fondamentaux, qui sont protégés non seulement par la Constitution fédérale, mais aussi par les constitutions cantonales et le droit international.

Le minimum vital est habituellement exprimé en montants monétaires, généralement calculés sur la base de déductions pro- fessionnelles ou scientifiques. Toutefois, aucun minimum vital, qu'il soit absolu ou social, ne peut être défini de manière purement scientifique. Tout minimum vital présente une composante politique reflétant l'équilibre entre les ressources qu'un individu peut estimer nécessaires et celles qui sont considérées comme possibles d'un point de vue sociétal ou budgétaire. Par exemple, le minimum vital est habituellement fixé pour une personne seule, puis recalculé à l'aide d'une échelle d'équivalence pour les ménages de plus grande taille. Ces échelles, qui se basent aussi sur l'observation que les besoins individuels diminuent au fur et à mesure que la taille du ménage augmente, ne sont jamais le fruit de considérations purement scientifiques. Elles relèvent elles aussi, à un moment précis, d'une décision normative ou politique.

En Suisse, il n'existe pas de minimum vital uniforme. Trois minimums vitaux sociaux se sont constitués au cours de la deuxième moitié du XXe siècle. L'un servant à calculer le droit à des prestations complémentaires de l'AVS/AI et réglé dans la loi fédérale sur les prestations complémentaires à l'AVS/AI (LPC); un autre destiné à protéger les créanciers en cas de dettes, réglementé par la loi sur les poursuites et faillites (LP). Le troisième, enfin, permet de calculer le droit à l'aide sociale et est décrit au chapitre A.6. des normes CSIAS. Ce dernier est généralement adopté dans les législations cantonales en matière d'aide sociale ou, du moins, sert de cadre de référence étroit. C'est sur ce minimum vital, largement accepté, que se basent les statistiques nationales en matière de pauvreté initiées au début du XXe siècle.

Bien que les trois méthodes soient axées sur une participation sociale minimale, elles aboutissent à des minimums vitaux distincts. Chacune se base sur différents montants forfaitaires destinés à couvrir les besoins matériels fondamentaux, calcule différemment les dépenses de santé et les coûts du logement, et prend différemment en compte les prestations 
circonstancielles. On observe généralement que les calculs réalisés selon les principes de la LPC aboutissent au minimum vital le plus élevé, tandis que ceux s'orientant aux normes CSIAS donnent le montant le plus faible. Un autre tableau peut cependant être dressé en fonction de la composition et de la situation du ménage, qui peuvent éventuellement donner lieu à des compléments d'allocations.

Les forfaits destinés à couvrir les besoins matériels fondamentaux se basent déjà sur un minimum vital social, dans la mesure où ils sont établis de manière à permettre à leurs bénéficiaires de participer un minimum à la vie sociale. Les besoins de base tels que les envisage la CSIAS reflètent par exemple le comportement de consommation des $7 \%$ de la population aux revenus les plus faibles. Leur «panier» contient aussi des dépenses telles que les cotisations à des associations, l'achat de quotidiens ou encore un repas occasionnel au restaurant.

Les prestations circonstancielles (PCi) tiennent compte de la situation de santé, économique, personnelle et familiale des personnes et des ménages aidés. Elles permettent d'une part d'octroyer l'aide sociale de manière individuelle et en fonction des besoins et, d'autre part, de lier l'octroi de moyens particuliers à certains objectifs comportementaux chez le bénéficiaire. Les PCi font partie du minimum vital social et peuvent être aisément prises en compte lors de l'évaluation individuelle des besoins. Il est plus difficile de les prendre en considération dans les analyses statistiques. Dès lors, l'Office fédéral de la statistique (OFS) base ses calculs sur des PCi forfaitaires et compte un complément de 100 francs par personne de plus de 16 ans.

D'un point de vue sociopolitique, le concept de minimum vital tel qu'appliqué en Suisse présente trois points faibles majeurs: sa dépendance du niveau de solidarité sociale, la nécessité d'en interpréter la base légale et la coexistence de minimums vitaux distincts.
Le choix et le montant des minimums vitaux dans une société donnée reflètent non seulement la prospérité de cette société, mais expriment aussi le niveau de solidarité qui y règne. La multiplication des attaques politiques contre l'aide sociale au début du $\mathrm{XX}^{\mathrm{e}}$ siècle témoigne d'une solidarité en berne. Lors de la révision de ses normes en 2015, la CSIAS s'est vue contrainte, sous la pression politique, de diminuer les besoins de base des ménages de grande taille et de renoncer à l'augmentation des prestations octroyées aux ménages plus petits, pourtant préconisée par les spécialistes - le tout en dépit d'une prospérité générale croissante. La dépendance à la solidarité sociétale transparaît également dans le cas des minimums vitaux sociaux accordés aux demandeurs et demandeuses d'asile, qui sont nettement inférieurs à ceux de l'aide sociale «normale».

L'ancrage légal du concept est un autre point faible. À ce niveau, la législation qui devrait constituer un outil de clarification direct ne tient pas ses promesses. L'existence d'un minimum vital social ne peut pas découler d'un simple article de loi, mais doit être le fruit de toute une réflexion juridique. Le montant de chaque minimum vital est une question encore plus complexe. Il serait donc urgent de définir une base légale claire et moins sujette aux interprétations afin de protéger les plus démunis.

À une logique fédérale omniprésente en Suisse vient s'ajouter une forte tendance à penser le système de sécurité sociale uniquement en termes de finances et de risques. Les règles changent en fonction des causes de la pauvreté et du domicile des personnes concernées. On peine ainsi à expliquer pourquoi les critères d'octroi des prestations sociales seraient différents pour une personne devenue pauvre suite à une maladie et une autre ayant perdu son emploi à un âge avancé. Cette hétérogénéité fait qu'il est difficile pour les personnes tributaires de la solidarité sociale de parler d'une 
seule voix, au-delà des différences de caisses d'allocations et de cantons. Par conséquent, leur voix est moins bien entendue que celle des membres de la société, bien plus nombreux, qui financent cette solidarité sociale.

\section{Christin Kehrli}

\section{Références}

Bollhalder, F. (2014). Vereinheitlichung bzw. Harmonisierung der verschiedenen Existenzminima in der Schweiz. Jahrbuch zum Sozialversicherungsrecht, 3, 95-105.

Conférence suisse des institutions d'action sociale. Concepts et normes de calcul de l'aide sociale. https://normes.csias.ch/

Office fédéral de la statistique (2014). Forfait CSIAS pour l'entretien: calcul actualisé par l'OFS. Neuchâtel: Office fédéral de la statistique.

\section{Mobilité résidentielle et quotidienne}

La mobilité résidentielle désigne le changement de lieu de domicile, tandis que la mobilité quotidienne renvoie aux déplacements réalisés à l'échelle de la journée, par exemple entre le domicile et le lieu de travail. Les ménages opèrent des arbitrages plus ou moins conscients entre ces deux formes de mobilité, entre déménagement et pendularités, selon leur lieu de travail. Ces arbitrages tendent à favoriser les mobilités quotidiennes sous l'effet combiné de la globalisation de l'économie, de l'amélioration des réseaux de transports (développement de l'offre et vitesse de déplacement) et des télécommunications qui rendent possibles le télétravail.

Les spécificités historiques, politiques et urbaines de la Suisse tendent à renforcer les mobilités réversibles, telles que les pendularités. Premièrement, la Suisse bénéficie d'un territoire extrêmement bien desservi par les réseaux de transports routiers, ferroviaires et urbains. Le cadencement des horaires et la desserte en transports publics très étendue y compris dans les régions rurales et montagneuses - la Suisse est souvent citée comme un modèle en matière de politique de transports en Europe - offrent des conditions propices à la réalisation de trajets pendulaires. Deuxièmement, bénéficiant d'une situation économique particulièrement florissante, la Suisse fait face à un flux important de migrations pour le travail qui contraignent encore davantage un marché du logement déjà tendu, en particulier dans les agglomérations et l'arc lémanique. La prospérité favorise la recherche de surfaces habitables toujours plus grandes, tandis que les évolutions sociétales (mise en couple et parentalité plus tardives, séparations, augmentation des familles monoparentales) entraînent un accroissement du nombre de ménages. Ainsi, et il s'agit là de la troisième spécificité, un marché du logement très tendu, avec peu de vacance de logement et des coûts en hausse, favorise les pendularités plutôt que le déménagement, même si un changement professionnel de l'un ou l'autre membre du ménage implique des trajets plus longs. Enfin, les particularités institutionnelles et culturelles que sont l'autonomie des cantons et les différences linguistiques encouragent peu les ménages à déménager d'un canton à l'autre. Face à la faible vacance des logements et à leur coût croissant, le déménagement des ménages les plus pauvres apparaît peu stratégique. D'autant plus que le choix d'un lieu de vie n'est jamais le résultat d'un simple calcul stratégique. Il s'agit toujours d'un choix sous contrainte dans lequel se mêlent les aspirations des ménages, la réalité du marché $\mathrm{du}$ logement et les contraintes, notamment financières, des ménages. D’autres éléments plus sensibles ou affectifs jouent également, tels que l'attachement au lieu de vie, que ce soit le logement lui-même, la ville ou la région mais aussi les ancrages relationnels, amicaux et familiaux des individus qui composent le ménage. L'ensemble de ces ancrages constituent des freins à la mobilité résidentielle. 
Les transformations du travail participent également au développement des pendularités. Les déplacements dans le cadre de l'activité professionnelle deviennent monnaie courante. Le télétravail, s'il permet d'éviter des déplacements, peut s'accompagner d'effets pervers dans la mesure où il rend possible l'acceptation d'un emploi très éloigné du lieu de vie; si les pendularités sont moins fréquentes, elles seront néanmoins plus coûteuses en temps. Le développement des télécommunications ne vient pas remplacer les déplacements géographiques mais les deux dynamiques s'alimentent l'une l'autre vers toujours plus de mobilité et d'échanges.

La croissance des pendularités est l'un des aspects les plus spectaculaires du développement des mobilités quotidiennes en Suisse. Ainsi, en 2000 , près de $60 \%$ des personnes actives travaillaient hors de leur commune de domicile. Cette forte croissance des mobilités quotidiennes entraîne une saturation des réseaux de transports que même un cadencement au quart d'heure ne suffit pas à endiguer. Une série de mesures visant à réguler la saturation des réseaux de transports par les pendulaires a été annoncée début 2011 prévoyant entre autres l'augmentation du tarif annuel de la vignette autoroutière ainsi qu'une adaptation des tarifs ferroviaires pour les personnes voyageant durant les heures de pointe. Basées sur la contrainte économique, ces mesures apparaissent d'une part discriminatoires et d'autre part relativement limitées pour faire face au phénomène. Discriminatoires, tout d'abord, pour toutes les personnes qui n'ont pas le choix de leurs horaires de travail, ni de leurs horaires familiaux. Limitées, ensuite, car les pendularités renvoient plus largement aux temporalités sociales et urbaines, aux choix résidentiels et familiaux des ménages, à la transformation des manières de travailler, autant de dimensions complexes et intriquées qu'un seul ajustement par les prix ne saurait résoudre.
Derrière ces pendularités intensives par leur durée et leur fréquence, se cachent les arrangements complexes des ménages, pris dans l'accélération et l'intensification des modes de vie. Les pendularités constituent bien souvent des stratégies de conciliation pour les couples bi-actifs qui, tout en conservant un logement commun, pendulent le plus souvent à la journée, plus rarement à la semaine entre le logement familial et un second logement proche $\mathrm{du}$ lieu de travail. De multiples contraintes horaires rythment alors les déplacements des pendulaires : celles liées aux horaires de travail, mais aussi aux horaires privés tels que ceux des garderies, des écoles ou les horaires des magasins et ceux de la mobilité elle-même, créant des emplois du temps minutés qui laissent peu de place à l'improvisation et affectent la qualité de vie des personnes. En effet, les temps de déplacements quotidiens impliquent des temps d'absence du domicile qui réduisent les possibilités de subvenir aux soins des proches, que ce soient les enfants dont la prise en charge doit se faire par des tiers - membres de la famille, structures de garde publiques ou privées coûteuses pour les familles et la collectivité - ou les personnes proches malades ou vieillissantes. La croissance des pendularités limite alors l'entraide familiale entre générations et constitue un enjeu majeur pour l'avenir des politiques sociales.

Ainsi, l'articulation entre mobilités résidentielles et quotidiennes constitue un enjeu social et politique fort qui dépasse largement le strict domaine du transport et implique l'ensemble des politiques qui gèrent les espaces mais aussi les temps sociaux tant dans le domaine du travail que du hors travail. Le rythme effréné des modes de vie pendulaires interpelle directement les politiques sociales en faveur d'un meilleur accompagnement des ménages dans l'articulation entre mobilités, travail et vie personnelle et familiale. 


\section{Références}

Beige, S. \& Axhausen, K. W. (2017). The dynamics of commuting over the life course: Swiss experiences. Transportation Research Part A: Policy and Practice, 104, 179-194.

Rérat, P. \& Bierlaire, M. (2016). Les déplacements pendulaires font-ils partie du choix d'un lieu d'habitation? In M. Bierlaire, V. Kaufmann \& P. Rérat (Éd.), La mobilité en questions (pp. 141156). Lausanne: Presses polytechniques et universitaires romandes.

Vincent-Geslin, S. \& Kaufmann, V. (Éd.) (2012). Mobilité sans racine: plus vite, plus loin, plus mobiles? Paris: Descartes \& Cie.

\section{Mobilité sociale*}

Par la notion de mobilité sociale, on entend les changements de statut social d'un individu ou d'un groupe d'individus dans le système de la stratification sociale, autrement dit des mouvements vers le haut ou vers le bas de la position socioéconomique, celle-ci étant déterminée par le statut social, le revenu, le prestige professionnel et le niveau de formation. Outre les cas de mobilité ascendante et descendante, le champ de la mobilité sociale inclut également la non-mobilité qui implique, dans une perspective de position sociale, l'idée de la reproduction d'inégalités sociales. La mobilité sociale est importante du fait qu'elle est liée à des opportunités biographiques. L'héritage social de la pauvreté, la sortie de la pauvreté ou la chute dans la pauvreté relèvent tous de cette thématique.

Dans la recherche sur la mobilité, une distinction est faite entre la mobilité intergénérationnelle et la mobilité intragénérationnelle. La mobilité intergénérationnelle (ascendante ou descendante) désigne le rapport entre la position sociale des parents et celle des enfants, autrement dit, l'évolution positive ou négative de la position sociale atteinte par les descendants par rapport à celle qu'ont atteinte les parents. La mobilité intragénérationnelle, elle, se réfère aux mouvements ascendants ou descendants dans le parcours individuel, qui se traduisent par un changement de la position sociale. Un exemple pour le premier type pourrait être celui de la fille d'une famille de bûcherons, qui entreprend des études et devient enseignante secondaire, et pour le deuxième, celui d'un électricien formé qui, après avoir suivi une formation spéciale pour accéder à une école supérieure, devient assistant en soins diplômé. Le rêve américain du «plongeur devenu millionnaire» fait partie de ce deuxième type.

La formation est un facteur-clé de la mobilité sociale car elle joue un grand rôle dans la reproduction d'inégalités sociales. Selon l'idéal des sociétés industrialisées, devenues depuis une centaine d'années des «sociétés du savoir», la répartition des positions et des biens doit se faire selon des critères de performance. Le potentiel d'un être humain se trouve ainsi mesuré à ses diplômes qui indiquent qualifications et compétences. Des modèles d'attribution de statut qui mettent en évidence l'étroitesse du rapport entre l'origine sociale (le statut professionnel des parents), la formation, le statut en début de carrière et le statut au moment d'une carrière avancée, donnent à voir une situation relativement stable pour les pays industrialisés occidentaux tels que la Suisse. D'une part, si l'on observe des cohortes de naissance, on note, durant le siècle dernier, une légère baisse du rapport entre l'origine sociale et la formation, ce qui signifie une légère augmentation de la mobilité, mais au final surtout une persistance des inégalités (de formation). D'autre part, l'importance de la formation et des diplômes demeure relativement stable pour le positionnement dans la vie professionnelle (statut professionnel).

Le degré de mobilité sociale dépend des conditions-cadre institutionnelles mises en place par la politique sociale. En raison de l'importance primordiale de la formation pour la mobilité sociale, le système de formation et la 
politique de formation jouent eux aussi un rôle essentiel. Ce sont donc les politiques sociales et de la formation qui définissent le contexte de la mobilité individuelle vers le haut ou vers le bas, partant, de la reproduction des inégalités.

Le classement de politiques sociales nationales à l'aide d'une catégorisation abstraite comme la typologie des États-providence d'Esping-Andersen permet d'en faire ressortir les implications en termes d'inégalités sociales et, à l'inverse, d'opportunités de mobilité sociale. Les États-providence qui parviennent à réduire les inégalités au travers de redistributions, de prestations sociales et d'autres mesures (encouragement de l'emploi, aide à la reconversion, etc.) favorisent la mobilité sociale (modèle socio-démocrate ou nordique, p.ex. la Norvège). À l'opposé, il y a les États-providence conservateurs qui tendent à reproduire les inégalités (p.ex. l'Autriche). Quant aux État-providence libéraux (p.ex. les États-Unis), ils sont souvent présentés dans le discours public comme un modèle offrant un haut degré de mobilité (ascendante). Toutefois, étant donné ses perspectives de mobilité sociale de facto limitées, des études empiriques les situent plus près du type d'État-providence conservateur que du type socio-démocrate.

Parmi les facteurs-clé de la mobilité, on compte l'étendue du système de formation, c.-à-d. le degré de développement du niveau secondaire supérieur (p.ex. écoles de maturité) ou du système tertiaire (p.ex. universités), et le degré de stratification, qui indique avec quelle précocité les élèves sont sélectionnés dans le système du degré supérieur pour l'une ou l'autre voies de formation parallèle (tracks). Le développement du système de formation a nourri l'espoir qu'en particulier les couches sociales inférieures, auparavant exclues des études supérieures (p.ex. les ouvriers), profitent des chances offertes et que la mobilité sociale s'en trouve accrue. Or, des recherches empiriques démontrent que l'expansion de la formation n'a conduit qu'à une hausse modérée de la mobilité sociale et que le degré d'inégalité est demeuré élevé. La stratification du système de formation, avec des filières distinctes, semble entraver la mobilité sociale, car la sélection pour les différentes filières est socialement sélective: les enfants d'ouvriers se retrouvent plutôt dans des filières de formation professionnelle, tandis que les enfants de familles d'universitaires suivent davantage la voie des hautes études. À l'inverse, dans des systèmes de formation peu stratifiés (p.ex. en Finlande), où des élèves de différents niveaux de compétence et d'origines différentes fréquentent les mêmes classes sur une durée plus longue, des inégalités de formation moins importantes (cf. études PISA) et un niveau de mobilité légèrement plus élevé ont pu être démontrés de manière empirique.

En comparaison internationale, la Suisse présente une mobilité sociale plutôt faible, partant, un degré d'inégalité important, ce qui n'a pas lieu d'étonner si l'on considère son système social et ses systèmes scolaires cantonaux. L'État-providence présente bien des caractéristiques libérales, et dans une certaine mesure sociodémocrates, mais il est en fait conservateur et peu favorable à la mobilité, surtout en ce qui concerne la couverture matérielle des besoins, basée sur le système assurantiel, jusqu'à l'âge de la retraite et l'importance de la famille comme unité. La majorité de systèmes scolaires cantonaux, plus exactement ceux des cantons alémaniques, ont une longue tradition de voies séparées au niveau secondaire, une stratification qui ne se perméabilise que progressivement depuis quelques d'années. Cette constellation favorise plutôt la reproduction des inégalités au lieu d'assurer la mobilité sociale: les enfants d'ouvriers continuent de s'engager plutôt dans des formations de niveau inférieur, tandis que les enfants d'universitaires continuent le plus souvent de suivre des études supérieures, gage d'emplois mieux payés et de meilleures perspectives de vie. 
En termes de mobilité sociale, la lutte contre les inégalités demeure un défi majeur. Il en va de même de la question de savoir dans quelle mesure les migrant·e-s peuvent bénéficier des chances de la mobilité ascendante, et - étant donné le vieillissement de la population et la situation tendue des systèmes de pension comment éviter, à la retraite, une mobilité vers le bas? Pour ce qui est de la promotion de la mobilité sociale par la formation, on constate une tendance à «déstratifier» les systèmes de formation, c'est-à-dire à éviter de cimenter de manière précoce des voies scolaires et des biographiques distinctes et à donner une chance aux élèves défavorisés grâce à des classes intégratives. Un nombre plus élevé d'enfants d'ouvriers pourrait ainsi accéder à une formation supérieure et connaître une mobilité sociale ascendante.

\section{Andreas Hadjar}

\section{Références}

Hadjar, A. \& Gross, C. (2016). Education systems and inequalities : international comparisons. Bristol: Policy Press.

Hadjar, A. \& Samuel, R. (2014). Does upward social mobility increase life satisfaction? A longitudinal analysis using British and Swiss panel data. Research in Social Stratification and Mobility, 39(1), 48-58.

Levy, R. (2010). La structure sociale suisse: radiographie d'une société. Lausanne: Presses polytechniques et universitaires romandes.

\section{Mouvement des femmes*}

Le mouvement des femmes renvoie à un ensemble d'actions collectives menées par des groupes, des organisations et des individus qui s'engagent pour l'égalité et la reconnaissance des femmes dans tous les domaines de la société.

Il relève d'une importante dimension historique. En Suisse, l'essor du mouvement fémi- niste au cours des deux dernières décennies du XIX siècle s'inscrit dans le contexte du développement étatique suite aux révisions de la Constitution fédérale de 1874 et 1891 . La Confédération et les cantons assument depuis lors davantage de tâches dans les domaines social et de la formation, ce qui nécessite des relais locaux. La période est donc favorable à des ouvertures sur des questions sociales qui touchent directement les femmes, telles que l'introduction d'une assurance-maladie et accident. Rapidement, de multiples sociétés féminines consacrées à diverses thématiques s'établissent: des associations pour le relèvement moral œuvrent pour l'abolition de la prostitution et la protection des mineur.e.s; des sociétés d'éducation et de bienfaisance engagées pour la formation des jeunes femmes visent à développer la capacité des femmes de toutes couches sociales à subvenir à leurs besoins; des associations professionnelles (p.ex. d'ouvrières ou d'institutrices) se créent ainsi que des associations féminines confessionnelles et des organisations pour le suffrage féminin. En 1900, une organisation faîtière nationale l'Alliance de sociétés féminines suisses (ASF) - voit le jour.

Ce qu'on appellera par la suite la «première vague» du mouvement des femmes se tasse pendant la période des guerres mondiales. Cependant, dès les années 1970, de nouveaux mouvements féministes se forment dans la plupart des pays occidentaux et dans d'autres régions du monde. C'est la «deuxième vague» qui soulève des questions d'équité sociale, d'épanouissement des femmes et de reconnaissance de la différence. En Suisse aussi, la revendication de la dépénalisation de l'avortement est au premier rang. S'y ajoutent d'autres sujets tels que la sanction pénale du viol et de la violence au sein du couple, le congé maternité ou encore l'égalité salariale entre femmes et hommes dans les faits («à travail égal, salaire égal»). Par ailleurs, le mouvement crée des lieux qui permettent aux femmes de discuter, 
entre elles, de sexualité et de solidarité, de critiquer le patriarcat et le capitalisme et de développer toutes formes de Self-Help et de conscience de soi.

La «troisième vague » correspond à l'entrée du féminisme dans la sphère virtuelle (cyberféminisme) ainsi qu'à l'ancrage des revendications féministes dans les structures juridiques et les institutions nationales et internationales, ceci dès le milieu des années 1980. En parallèle se développent de multiples groupements et réseaux permettant d'expérimenter de nouveaux modes de vie et de nouvelles formes de protestation. Leurs dénominateurs communs sont la reconnaissance de la diversité, l'égalité et la justice sociale ainsi que la solidarité transnationale.

L'histoire du mouvement des femmes est marquée par plusieurs questions clés. Parmi celles-ci figure, tout d'abord, la question litigieuse de savoir si le combat contre la discrimination des femmes doit être mené sur la base du postulat d'une similitude de principe entre hommes et femmes, ou, au contraire, au nom d'une spécificité féminine. À titre d'exemple, $\mathrm{au}$ début du $\mathrm{XX}^{\mathrm{e}}$ siècle, certaines tendances $\mathrm{du}$ mouvement pour le suffrage féminin soutiennent le principe d'égalité entre toutes les personnes humaines, alors que d'autres soulignent les capacités spécifiques et les contributions propres des femmes et en particulier des mères. Dans les années 1970, ce débat se poursuit sous forme d'une controverse entre les concepts d'«égalité» et de «différence».

Ensuite, la question de l'alliance avec d'autres groupes sociaux se pose constamment aux militantes du mouvement des femmes. En 1900, lors de la fondation de l'ASF, l'adhésion des associations ouvrières ne se réalise pas sans oppositions. Par la suite, les rapports de sexe et de classe comme fondements de la solidarité féminine sont discutés à maintes reprises. Dès les années 1970, les catégories de race et d'ethnie font l'objet de débats. On reproche en effet aux militantes du mouvement féministe amé- ricain de se cantonner dans une organisation de femmes blanches de classe moyenne tout en ignorant les besoins d'autres femmes, notamment celles des femmes immigrées ou noires. Les études de genre analysent aujourd'hui l'imbrication des différentes formes de discrimination à travers la notion d'intersectionnalité.

Enfin, la thématique de la coopération avec le système institutionnel revient régulièrement dans les débats. Elle touche les positionnements stratégiques et le choix des formes d'intervention politique entre les pôles «révolution» et «réforme». Durant les années 1970, lorsque le mouvement des femmes milite principalement pour une révision légale en revendiquant la légalisation de l'avortement, la voie parlementaire et des alliances y relatives sont privilégiées. De même, les votations sur l'inscription de l'égalité des sexes dans la Constitution («Égalité des droits entre hommes et femmes», votée en 1981) tout comme le congé maternité sous la forme d'une allocation pour perte de gain («assurance-maternité», rejetée en 1984, 1987 et 1999 et votée en 2004) sont le résultat de campagnes à grande échelle dans lesquelles le mouvement des femmes a dû s'adapter aux règles du jeu politique. Se développe dès lors une stratégie à deux axes prévoyant, d'un côté, le développement de contre-institutions féministes les plus autonomes possible, et de l'autre, la «marche à travers les institutions». Les bureaux de l'égalité en sont le meilleur exemple: sanctionnés par les autorités et tentant de traduire les revendications féministes dans l'action publique, y travaillent généralement des personnes issues du mouvement des femmes ceci tout au moins dans leur phase de création à la fin des années 1970 et dans les années 1980 .

Après la Seconde Guerre mondiale, la Suisse occupe une position particulière en matière de droit de vote des femmes. Si la situation politique des femmes avant la Première Guerre mondiale ne diffère guère de celle des autres pays, l'interprétation du droit de vote géné- 
ral en tant que droit de vote des hommes est une caractéristique unique de la Suisse parmi les États démocratiques dans les décennies d'après-guerre. Ce n'est qu'en 1990 que sera réglée la revendication pour le droit de vote des femmes, lorsque le dernier canton, celui d'Appenzell Rhodes-Intérieures, introduise enfin, sur son territoire, le droit de vote des femmes et ceci sur ordre du Tribunal fédéral. En raison du système politique suisse axé sur la négociation et le compromis, diverses revendications du mouvement des femmes suisse ont pris du retard en comparaison européenne (assurance-maternité, dépénalisation de l'avortement). D'autres problématiques ne sont pas encore réglées, en particulier en matière de sécurité sociale (droits à la retraite, p.ex.) ou de droit fiscal.

Les revendications $\mathrm{du}$ mouvement des femmes ne sont aujourd'hui pas satisfaites. Des militantes féministes continuent à s'engager, d'autant plus que les lieux de réflexion et d'action féministes pour la transformation de la société se multiplient. Un réel défi consiste à coordonner les actrices hétéroclites tant en termes d'expérience générationnelle, de situation de vie et d'emploi, d'orientation sexuelle, de degré de professionnalisation et d'orientation politique que d'approches et d'objectifs $\mathrm{du}$ changement social. Le féminisme est aussi mis au défi sur ses fondements théoriques et doit se repositionner dans les débats actuels de politique sociale. Dans un contexte de réorganisation néolibérale et d'une division du travail à l'échelle globale, les revendications autrefois progressistes prennent aujourd'hui une nouvelle dimension. Ainsi, contre l'autodétermination reproductive - jadis une revendication féministe incontestée («un enfant si je veux, quand je veux!») - s'élèvent aujourd'hui, au vue des nouvelles possibilités offertes par la procréation médicalement assistée, notamment la gestation pour autrui, des voix cri- tiques dans les propres rangs du mouvement des femmes.

\section{Kristina Schulz}

\section{Références}

Schulz, K. (Ed.) (2017). The women's liberation movement: impacts and outcomes. New York: Berghahn.

Schulz, K., Schmitter, L. \& Kiani, S. (2014). Frauenbewegung. Die Schweiz seit 1968: Analysen, Dokumente, Archive. Baden: Hier und Jetzt.

Villiger, C. (2009). «Notre ventre, leur loi !» : Le mouvement de libération des femmes de Genève. Neuchâtel: Alphil.

\section{Mouvements sociaux ${ }^{*}$}

Les mouvements sociaux sont des acteurs collectifs qui s'engagent pour ou contre le changement social et politique. Pour ce faire, ils recourent à un répertoire caractéristique d'actions, dont font plus particulièrement partie les contestations de tous types. On ne parle de mouvement social que lorsque plusieurs actions de contestation collectives, par exemple des rassemblements, des manifestations, des veillées, des occupations et des blocus, sont organisées sur une période prolongée dans un but partagé. Les campagnes menées dans le cadre de mouvements, qui consistent en des actions de contestation présentant un lien entre elles, visent à influencer les décideurs, qu'ils soient publics ou privés, ainsi que l'opinion publique. La mobilisation de camarades de combat nécessaire pour y parvenir, étendue et prolongée dans le temps, nécessite la formation d'organisations formelles comme des associations, des groupes d'intérêt, des plateformes d'action ou des groupes d'entraide actifs sur le plan politique. Ces organisations visent aussi à institutionnaliser l'objet et les revendications du mouvement social. Les nou- 
velles campagnes peuvent recourir aux organisations et aux réseaux existants.

Les mouvements sociaux s'emparent de préoccupations et de thèmes sociaux, mobilisent autour d'eux et les organisent. En critiquant les normes politiques et sociales, ils cherchent à susciter le débat et à attirer d'autres milieux ainsi que les décideurs politiques dans un conflit public. Toutefois, il faut garder à l'esprit que les insiders ont beaucoup plus de facilités à mobiliser l'opinion autour de problèmes et de préoccupations que les outsiders. Par exemple, les personnes touchées par la pauvreté, les SDF et les chômeur-euse's rencontrent beaucoup de difficultés à s'organiser. Les ressources telles que l'éducation et les revenus ne constituent pas seulement des conditions essentielles à une participation individuelle, elles sont également nécessaires pour l'organisation en groupes. Afin de s'organiser collectivement, certaines infrastructures sont nécessaires, comme des locaux pour les réunions et les tâches administratives. L'auto-organisation nécessite toutefois l'existence d'une conscience de groupe, d'une identité commune ainsi que de membres prêts à diriger l'organisation et disposant des connaissances et du réseau nécessaires pour mener à bien cette mission. Plus un groupe social est marginalisé, moins ces conditions sont présentes.

Dans le domaine de la politique sociale, divers mouvements ont régulièrement mis en avant de nouvelles préoccupations, contribuant parfois aussi à leur réalisation. Comme dans tous les pays d'Europe de l'Ouest, la Suisse a eu aussi son mouvement ouvrier, qui se portait garant de l'avènement et du développement de l'État social. Si on le compare à celui d'autres pays, ce mouvement était toutefois moins militant. Après que la question sociale a dégénéré en grève générale en 1918, les conflits de classe qui ont suivi se sont généralement résolus de manière pacifique. Pendant longtemps, les syndicats, qui constituent la forme organisationnelle de base des travailleurs et travailleuses, ne prônaient pas les instruments de l'État, mais privilégiaient leur propre caisse ou des solutions partenariales avec les employeur.euse-s. Ce n'est que récemment que les réglementations sociales de l'État sont devenues l'objectif principal des syndicats, qui misent de plus en plus sur les instruments de démocratie directe, comme les initiatives et les référendums, pour atteindre leur but.

Dans les années 1970 et 1980, le mouvement féministe a également fortement influencé l'État social suisse. Quand, en 1981, l'électorat suisse a adopté l'article constitutionnel sur l'égalité entre hommes et femmes, il s'agissait en réalité d'une contre-proposition à une initiative populaire des organisations de femmes, qui étaient fortement mobilisées à l'époque. Cet article a déclenché toute une série de réformes visant à réduire les inégalités entre les sexes dans les assurances sociales, qui étaient jusque-là fortement orientées sur un modèle de soutien familial masculin en ménage commun. Par exemple, un système dit de splitting ainsi que des bonifications pour tâches éducatives ont été introduits dans les rentes de vieillesse de l'AVS. Aux côtés du nouveau mouvement féministe, ceux qu'on appelle les nouveaux mouvements sociaux, issus des secteurs de la protection de l'environnement et du tiers monde ont participé à cette transformation du système social. En plus de la question de l'égalité des sexes, qui en Suisse resurgît depuis la grève des femmes en 2019, ces mouvements ont davantage soulevé des questions telles que l'égalité des chances, l'intégration et la redistribution des ressources.

À la fin des années 1990, l'interdépendance croissante de l'économie a suscité de fortes réactions. Unis pour critiquer la mondialisation, les groupements anticapitalistes, les syndicats et diverses organisations non gouvernementales (ONG) issues des nouveaux mouvements sociaux ont lutté pour plus de justice sociale, mais aussi contre le libre-échange ou les multinationales. Enfin, l'occupation de 
lieux publics par le mouvement de contestation Occupy de 2011 à 2013 a représenté un moment fort, inspirant dès 2018 le mouvement Extinction Rebellion. Parallèlement aux critiques de la mondialisation des mouvements orientés à gauche de l'échiquier politique, les mouvements nationalistes de droite ont également critiqué la mondialisation et reçu un soutien croissant. Dans de nombreux pays européens, les partis populistes de droite se sont emparés $\mathrm{du}$ potentiel contestataire de ce mouvement, qui se positionne contre la libre circulation des personnes et le libre-échange, et pour le protectionnisme national.

Le système politique suisse est réputé être ouvert aux mouvements sociaux et aux initiatives venant «du bas», car le fédéralisme crée de nombreuses possibilités d'accès différentes et les instruments de la démocratie directe offrent la possibilité d'influencer directement la politique institutionnelle. L'initiative populaire permet d'apporter de nouvelles propositions politiques, parfois radicales, au débat public. Ainsi, en 2016, un comité a soumis au vote l'introduction d'un revenu de base inconditionnel, proposition qui a recueilli le soutien de près d'un quart de l'électorat. En revanche, les mouvements qui recourent à des formes de contestation plus radicales et donc souvent illégales pour faire valoir leurs revendications rencontrent plus de difficultés en Suisse: la culture politique de la concordance exige une approche modérée afin de pouvoir participer, en tant que pouvoir légitime, à l'élaboration des politiques. De même, le multilinguisme et la petite échelle de la structure politique du système fédéral rendent plus difficile la mobilisation de mouvements plus importants et à l'échelon du pays.

La manière dont les mouvements sociaux se mobilisent et font avancer leurs revendications dépend également des technologies de communication existantes et des médias. La transformation actuelle rapide du paysage médiatique entraînée par l'essor de la commu- nication en ligne, et en particulier des réseaux sociaux comme Facebook, Twitter ou Whatsapp, a également un impact important sur les mouvements sociaux et leurs formes de contestation. Les médias sociaux permettent une mobilisation plus efficace et plus rapide, le recours à de nouvelles formes de contestation (p.ex. les flashmobs, les shitstorms) et une communication, plus directe et non dénaturée par les sélections des journalistes, avec les sympathisant $\cdot e \cdot s$ et le groupe cible de la contestation. Toutefois, cette mutation de la communication médiatique présente aussi des risques. La communication en ligne basée sur des algorithmes risque en effet de créer des bulles de communication autoréférentielles et d'empêcher toute confrontation avec des opinions différentes et de nouvelles préoccupations. Ainsi, la perte de contrôle des médias traditionnels et des élites due aux nouvelles technologies de communication participatives ne mènera pas nécessairement à une renaissance des nouveaux mouvements sociaux et de leurs revendications en matière de participation et d'intégration, mais risque d'entraîner une plus grande segmentation, une hausse de l'extrémisme ainsi que l'apparition de tendances centrifuges dans la société.

\section{Michelle Beyeler}

\section{Références}

Beyeler, M. (2013). Was bewirkt Globalisierungskritik? Protestkampagnen gegen die Welthandelsorganisation und das Weltwirtschaftsforum. Frankfurt a.M.: Campus.

Giugni, M. (1995). Entre stratégie et opportunité: les nouveaux mouvements sociaux en Suisse. Zürich : Seismo.

Levy, R. \& Duvanal, L. (1984). Politik von unten: Bürgerprotest in der Nachkriegsschweiz. Basel : Lenos. 


\section{Naturalisation}

La naturalisation est l'octroi par un État de la nationalité de cet État à un·e étranger-ère qui la demande. Ce rapport volontaire à la nationalité demeure en réalité une exception: d'ordinaire, la nationalité ne se choisit pas, elle relève d'un statut attribué par l'État à la naissance; la majorité des gens étant ainsi inscrits comme citoyen-ne·s malgré eux. Les règles gouvernant la naturalisation peuvent être plus ou moins restrictives selon les lois sur la nationalité que les États préconisent compte tenu de leur histoire. En Suisse, l'accès à la nationalité demeure restrictif, il est fondé sur le droit du sang et confère à l'échelon local (communal et cantonal) une importance décisive de l'octroi du droit de cité (par rapport à l'échelon fédéral). Les politiques de la nationalité apparaissent indissociables de la construction et de la légitimation de l'État moderne et agissent (in) directement dans l'établissement des frontières de l'État social. Ces mécanismes découlent du fait que l'État est un État-nation, au sens minimal, dans la mesure où il proclame (et est cru) être l'État d'une nation: l'État «de» et «pour» une nation particulière, distincte, délimitée se devant de procurer certains «avantages» à ses citoyen-ne-s. De ce point de vue, la naturalisation représente pour un·e étranger-ére un moyen d'être pleinement reconnu.e comme membre du groupe national et de pouvoir bénéficier ainsi d'un plein accès aux droits civils, sociaux et politiques.

Les pays traditionnellement les plus ouvert à l'immigration attribuent en général la nationalité à tous les individus nés sur leur territoire (principe du ius solis). Dans ce contexte, la naturalisation est alors activement recommandée par l'État via des procédures simples et des critères clairement spécifiés, la non-naturalisation devenant presque une anomalie. À l'autre extrémité, c'est uniquement la nationalité des parents qui compte, la naissance sur le territoire n'a guère d'influence, même dans le cas de générations successives (principe du ius sanguinis): dans ce contexte, au contraire, la naturalisation représente une forme d'anomalie, un privilège accordé - via une procédure souvent complexe et longue - à certains individus méritants.

En Suisse, sur le plan idéologique, les politiques de naturalisation connaîtront un tournant décisif à partir de la Première Guerre mondiale. L'idéologie de l'«emprise étrangère» (Überfremdung) façonnée à cette époque constitue le substrat symbolique de l'exclusion juridico-politique des étranger-ére-s qui se soldera par un durcissement des règles de naturalisation prévalant jusque-là. La naturalisation ne sera dès lors plus vue comme un moyen d'intégrer les immigrant·e-s mais plutôt comme un outil permettant de protéger l'«identité suisse» face au danger externe, l'immigration excessive et anormale des étranger·ère-s et les naturalisations «opportunistes». L'«assimilation réussie» deviendra une condition préalable à la naturalisation. Ce durcissement de l'accès à la nationalité se manifestera par une extension progressive du délai de séjour requis pour pouvoir déposer une demande: dès 1917, le délai de séjour passera à 4 ans (contre 2 auparavant); en 1920, six ans seront demandés, puis 12 ans en 1952.

La construction de l'État social contribuera, en creux, pour sa part également à la construction de la saillance du référant national. Pourtant, à la fin du XIX ${ }^{\mathrm{e}}$ siècle, un contexte où la responsabilité de l'assistance relève en Suisse majoritairement de la commune d'origine (ou «bourgeoisie»), il n'y a pas encore de distinction entre non bourgeois et personnes de nationalité étrangère au niveau de l'assistance sociale. L'étranger-ère, c'est aussi bien la personne originaire d'un autre canton que celle venue d'un autre pays. Or, progressivement, l'expérimentation de différents concordats intercantonaux en matière d'assistance (une pratique qui sera généralisée à l'ensemble des cantons en 1967) permettra de différencier 
nettement la situation des Confédéré-e-s indigent.e.s des autres, en d'autres termes de «produire l'étranger» au sens moderne du terme, c'est-à-dire sur la base d'une appartenance nationale et non plus communale ou cantonale. Ceci étant dit, l'octroi du droit de cité helvétique demeure largement structuré en Suisse par les instances politiques locales.

En Suisse comme dans certains autres pays, le fait d'être à l'aide sociale agit négativement sur les chances à devenir suisse. Dans l'ordonnance sur la nationalité du 17 juin 2016, cette appréciation de la situation sociale est objectivée dans un contexte où les autorités sont obligées désormais - suite à deux arrêts du Tribunal fédéral prononcés en 2003 - de motiver de plus en plus leur décision (notamment de refus). La prise en compte de «circonstances personnelles» est toutefois prévue et peut légitimer certaines dérogations. L'inactivité du candidat·e nécessite d'être légitimée pour ne pas porter préjudice à sa demande. Selon l'ordonnance sur la nationalité, le législateur prévoit trois cas de figure à cet égard: «un handicap physique, mental psychique; en raison d'une maladie grave ou de longue durée; pour des raisons personnelles majeures telles que de grandes difficultés à apprendre, à lire et à écrire, un état de pauvreté malgré un emploi, des charges d'assistance familiales à assumer, une dépendance à l'aide sociale résultant d'une première formation formelle en Suisse, pour autant que la dépendance n'est pas été causée par le comportement du requérant». Malgré la reconnaissance de certaines garanties juridiques, l'accès à la nationalité ne relève pas d'un droit, toute demande de naturalisation reste soumise à un examen, de telle sorte que le candidat ne saurait avoir d'avance l'assurance de son «élection»; la naturalisation demeure vécue comme une épreuve.

Depuis les années 1990, le nombre de naturalisation a augmenté en Suisse comme dans d'autres pays d'Europe. En chiffre absolu, ce taux - qui s'élève en 2014 à un peu moins de
$2 \%$ par rapport à la population étrangère permanente - a un peu plus que doublé depuis 1992. Toutefois, en comparaison internationale, ce taux demeure l'un des plus bas d'Europe dans un contexte où le droit de cité suisse est souvent instrumentalisé en fonction d'intérêts politiques visant à préserver - via l'appel à l'émotion - une mythique «identité nationale» souvent ethnicisée. Les effets associés à la nouvelle loi sur la nationalité (adoptée en 2014, entrée en vigueur en 2018) se caractérisent par un renforcement de la sélectivité. Si depuis 1952, la détention d'un titre de séjour (valable) depuis 12 ans était exigée, la nouvelle loi exige du·de la candidat.e désormais la détention d'une «autorisation d'établissement» et cela depuis 10 ans. Compte tenu du temps de séjour requis à l'obtention de ce titre (permis C), exigences temporelles variant selon l'origine extra/communautaire des personnes, la durée de séjour minimale sur le territoire suisse pour pouvoir déposer une demande de naturalisation s'élève au minimum à 15 ans pour un citoyen de l'UE des quinze et de l'AELE et à 20 ans pour les ressortissants des États tiers.

Ainsi les transformations en cours de la politique de la naturalisation tendent à hiérarchiser et diviser encore davantage les différents statuts d'étranger. D’un côté, la voie de la naturalisation restera barrée aux requérant.e-s d'asile et aux personnes admises provisoirement (permis $\mathrm{N}$ et $\mathrm{F}$ ), de l'autre, les descendant·e.s de troisième génération pourront bénéficier d'une naturalisation facilitée. Cette sélectivité sociale en amont de l'accès à la nationalité s'accompagne d'une prolongation de la période «probatoire» en aval (l'«annulation» de la naturalisation était possible dans un délai maximum de 5 ans, la nouvelle loi prolonge cette période "probatoire» à 8 ans). Toute la question est alors de savoir, si un groupe national et «étatisé» "pourra un jour se passer de cette croyance en l'homogénéité nationale et maintenir une certaine cohésion 
sans avoir recours notamment à des considérations « raciales» ou «culturelles».

\section{Arnaud Frauenfelder}

\section{Références}

Argast, R., Arlettaz, G. \& Studer, B. (2013). Le droit d'être Suisse: acquisition, perte et retrait de la nationalité de 1848 à nos jours. Lausanne: Antipodes.

Frauenfelder, A. (2007). Les paradoxes de la naturalisation: enquête auprès des jeunes issus de l'immigration (préface de Claudio Bolzman). Paris : L'Harmattan.

Gutzwiller, C. (2008). Droit de la nationalité et fédéralisme en Suisse: acquisition, perte et perspectives. Genève: Schulthess.

\section{New Public Management*}

La notion de New Public Management fait référence, dans la littérature internationale, à différentes approches visant, depuis les années 1980, à réformer l'administration publique. Les gouvernements dirigés par Margaret Thatcher au Royaume-Uni et Ronald Reagan aux ÉtatsUnis ont ainsi réformé les administrations de leurs pays respectifs dans un esprit néoconservateur, ce que l'on a qualifié de New Public Management. En Europe et dans le reste du monde, c'était le «modèle de Tilburg» qui prévalait. Basé sur des réformes mises en œuvre à partir du milieu des années 1980 dans la ville néerlandaise de Tilburg, il consiste à confier l'exécution de tâches de l'État à des organisations autonomes et privées. Les activités d'une administration publique étant largement liées à des bases juridiques, il existe de nombreuses formes d'administrations publiques et, donc, tout autant de manières de les réformer. C'est la raison pour laquelle les réformes menées en Scandinavie sont différentes de celles appliquées aux administrations française, allemande ou britannique, bien qu'elles portent toutes le nom de New Public Management.
Bien souvent, les méthodes de New Public Management prévoient, à l'instar du modèle de Tilburg, l'externalisation et l'autonomie de certains domaines de l'administration (les pompiers, les hôpitaux ou les services de secours, les services d'approvisionnement et d'assainissement de l'eau, etc.) afin que ceux-ci puissent fonctionner en-dehors de toute influence politique et avec des budgets plus souples (en constituant des réserves, p.ex.). D'un point de vue international, un autre but fréquent consiste à réduire le nombre de postes de travail avec un statut de fonctionnaire public pour privilégier des statuts d'employé·e·s privé·e·s.

L'approche suisse du New Public Management est fréquemment appelée gestion administrative axée sur les résultats ou, en allemand, Wirkungsorientierte Verwaltungsführung (WoV). Depuis plus de 20 ans, la Confédération, les cantons et les grandes communes développent des projets qui (parfois sous d'autres dénominations) ont pour but de réformer la gestion ou les activités administratives. Contrairement aux approches adoptées dans de nombreux autres pays, les réformes qu'entraîne la WoV touchent aussi les organes législatifs (parlements).

La plupart des projets de réforme menés en Suisse ont trois objectifs principaux. Tout d'abord, passer d'une gestion déterminée par l'input à une culture du résultat. Auparavant, le mandant (le Parlement, le Conseil d'État pour les prestataires hors administration) gérait les moyens financiers disponibles (via un budget détaillé). Désormais, un budget global est fixé en partant des résultats visés. Dans un système de WoV, l'utilisation des moyens n'est plus jugée selon le type ou l'ampleur des mesures prises mais selon leur effet. Ensuite, il s'agit de distinguer clairement la responsabilité stratégique de la responsabilité opérationnelle. Les organes législatifs doivent développer des actions plus stratégiques et céder à d'autres entités la responsabilité des tâches de gestion. Ainsi, par exemple, un parlement se limiterait 
à exiger le respect de la protection des données, tandis qu'il reviendrait au gouvernement ou au conseil municipal de décider du nombre et du type de destructeurs de documents à acquérir. Enfin, un maximum de responsabilité est attribué aux organes opérationnels en matière de mise en œuvre. Les approches de gestion contemporaines délèguent un maximum de compétences aux organes chargés de la mise en œuvre opérationnelle. Dans le cadre de la WoV, cela se fait via un mandat de prestation et un budget global grâce auxquels les organes chargés de la mise en œuvre savent quels effets les mesures prises doivent produire pour la société. Ces organes reçoivent un montant forfaitaire pour y parvenir. Il leur revient ensuite de décider comment utiliser ces moyens financiers au mieux (p.ex. en engageant du personnel ou en faisant appel à un sous-traitant).

De nombreuses évaluations ont montré que les projets de WoV ne comportaient pas que des avantages, mais créaient aussi de nouveaux défis. Pour un parlement de milice, la gestion stratégique représente un défi majeur et la charge des parlementaires s'est plutôt alourdie avec la WoV. De plus, il est illusoire de penser que le Parlement puisse élaborer une stratégie partagée par tout le monde. La liberté entrepreneuriale de même que la responsabilité ne peuvent pas être déléguées simplement vers le bas dans l'administration. En effet, les représentant·e-s élu·e·s ne peuvent pas déléguer la responsabilité qui leur est confiée par le peuple. Par conséquent, de nombreuses décisions opérationnelles continuent d'être prises à un niveau de gestion trop élevé. L'évaluation probante des objectifs d'efficacité est extrêmement exigeante et donc coûteuse. Dans de nombreux cas, aucun instrument approprié n'a encore été trouvé pour définir et vérifier ces objectifs. Ainsi, généralement, une mesure de protection de l'enfant décidée par l'Autorité de protection de l'enfant et de l'adulte (APEA) ne produit son effet qu'après 10 ou 15 ans évaluer s'il correspond à l'effet désiré est une entreprise délicate. De même, le succès de mesures de formation ne peuvent être démontrés qu'après des décennies. La charge administrative liée aux processus de planification et de reporting a augmenté de manière significative. L'introduction de la WoV exige beaucoup de ressources. Il n'a pas encore été possible de prouver que l'administration est plus efficace voire moins chère avec la WoV.

Dans l'action sociale et son éventail de services, cette nouvelle forme de gestion a un impact colossal. Dans ce secteur, le principal effet de la gestion administrative axée sur les résultats consiste en la focalisation sur l'impact des activités déployées. Les contrats de prestation axés sur l'efficacité sont utilisés par l'État dans l'idée d'employer l'argent des contribuables de manière plus ciblée. Souvent, ce changement de système est lié à un plan d'austérité concomitant, de sorte que la gestion administrative axée sur les résultats devient un instrument d'économie (et non pas, comme prévu à l'origine, de majoration de l'efficacité). Dans de nombreux cas, il est nécessaire de réorgansier entièrement la comptabilité : pour être en mesure d'informer sur les montants dépensés pour un effet donné, les données financières de chaque activité et domaine doivent pouvoir être fournies. Outre l'introduction de la comptabilité analytique, il est souvent nécessaire de passer au plan comptable selon la norme «SWISS GAAP RPC $21 »$. Dans l'action sociale plus particulièrement, l'obtention d'un effet s'inscrit dans une perspective à long terme. Il est donc particulièrement difficile et souvent très coûteux de documenter l'atteinte d'un effet désiré. Une évaluation d'impact sérieuse sera facilement plus coûteuse que les prestations sociales fournies. En outre, l'accent mis sur les résultats peut conduire au développement d'offres pour des «cas faciles». De telles offres permettent de bons résultats à moindre effort et faciles à documenter. In fine et à l'extrême, les situations plus complexes (qui ont davantage besoin de l'aide de l'État) ne trou- 
veront plus d'aide. Enfin, divers auteur.e.s du travail social doutent que le concept New Public Management convienne au domaine social ou vont jusqu'à le déclarer inopérant.

En résumé, on peut dire que le New Public Management - ou la gestion administrative orientée sur les résultats en version suisse entraîne sans doute une plus grande complexité pour les parties concernées. Dans le même temps, il favorise une réflexion sur les effets visés et les résultats obtenus, ce qui augmente la professionnalité. Toutefois, réduire le financement tout en introduisant une WoV n'est pas constitutif de la WoV - il s'agit du résultat d'un plan d'austérité concomitant dans le secteur public.

\section{Matthias Meyer}

\section{Références}

Giauque, D. \& Emery, Y. (2008). Repenser la gestion publique: bilan et perspectives en Suisse. Lausanne: Presses polytechniques et universitaires romandes.

Heimgartner, M. \& Dietrich, A. (2008). Wirkungsorientierte Verwaltungsführung in den Schweizer Kantonen. Bern: Eidgenössisches Finanzdepartement.

Schedler, K. \& Proeller, I. (2011). New Public Management (5., korr. Aufl.) Bern : Haupt.

\section{Non-recours}

Le concept de non-recours évoque le fait de ne pas faire valoir ses droits. Dans le domaine des politiques sociales, il a donné lieu à deux définitions. Selon la première, le non-recours renvoie à toute personne éligible à une prestation sociale financière et qui - en tout état de cause - ne la reçoit pas. Dans une perspective plus large, incluant les prestations non financières, le non-recours fait référence à toute personne qui ne bénéficie pas d'une offre de droits et de services à laquelle elle pourrait prétendre.
On distingue quatre catégories de non-recours. La non-connaissance renvoie au fait d'ignorer l'existence d'une prestation ou de se méprendre sur les critères d'éligibilité. Lorsque la prestation n'est pas demandée alors qu'elle est connue, on parle de non-demande. Celle-ci peut être subie (crainte d'être stigmatisé p.ex.) ou choisie (préférences pour d'autres solutions). La troisième catégorie est la non-réception. Dans ce cas, la prestation est connue et demandée, mais elle n'est pas reçue ou seulement partiellement, parce que l'ayant droit se décourage ou suite à des blocages administratifs. Enfin, la non-proposition renvoie aux cas où les agent·e-s des services sociaux omettent de proposer une prestation, volontairement ou par ignorance.

Les premières enquêtes sur le non-recours remontent aux années 1960 en Grande-Bretagne et aux États-Unis. Des travaux sont ensuite menés en Europe continentale, durant les années 1970 et 1980 en Allemagne et aux Pays-Bas, puis, dès les années 1990, en France. Les recherches confirment l'ampleur et l'étendue de ce phénomène qui concerne des pays aux systèmes de protection sociale différents. Ainsi, les taux de non-recours aux aides financières estimés dans 16 pays européens se révèlent pour la plupart supérieurs à $40 \%$ et concernent une grande variété de prestations (aides sociales, allocations familiales, subsides au logement, etc.).

Les principales raisons du non-recours renvoient au manque d'information, aux coûts ou à la complexité des démarches administratives, ainsi qu'aux barrières sociales. Le non-recours apparaît cependant comme un phénomène très hétérogène, qui concerne de multiples groupes sociaux dans toutes les couches socioéconomiques et résulte d'une combinaison de facteurs. Certaines caractéristiques, comme le fait de vivre dans l'isolement ou d'avoir migré récemment, accroissent la probabilité de ne pas recourir aux prestations. 
Par contraste avec celle de ses voisins européens, la littérature sur le non-recours en Suisse est limitée et ce n'est que depuis quelques années qu'une dynamique de recherche se dessine. Les rares données disponibles à l'échelle nationale laissent supposer un phénomène d'ampleur significative. Ainsi, l'OFS estimait en 2009 qu'un bon quart des personnes pauvres ne recevaient aucune aide. Les chiffres les plus précis concernent le canton de Berne, où le taux de non-recours à l'aide sociale atteindrait $26,3 \%$. Le non-recours se révèle plus faible en milieu urbain que dans les régions rurales, un phénomène attribué à l'anonymat que procurent les villes.

Plusieurs caractéristiques du système helvétique sont susceptibles d'influer sur les formes et l'ampleur du non-recours. Du point de vue politique et institutionnel, l'extrême complexité du régime de protection sociale (fédéralisme, segmentation des domaines de sécurité sociale notamment) représente une entrave à l'accès aux droits. Le manque d'information sur les offres et les procédures, ainsi que le manque de coordination entre les prestataires sont les principaux obstacles identifiés de ce point de vue. Par ailleurs, la protection sociale est marquée par le principe de subsidiarité, selon lequel l'octroi d'une prestation ne se justifie qu'en dernière instance. Dans cet esprit, les prestations ne sont pour la plupart pas versées automatiquement et doivent être demandées, parfois suivant un ordre hiérarchique précis. De même, l'aide sociale n'intervient que lorsque les autres sources d'aide disponibles - famille et prestations sociales - s'avèrent insuffisantes. Enfin, la loi fédérale sur les étrangers contribue à produire du non-recours chez les personnes qui n'ont pas la nationalité suisse, en conditionnant le regroupement familial et le renouvellement des autorisations de séjour ou d'établissement au fait de ne pas dépendre durablement de l'aide sociale. Dans ce contexte marqué par la complexité et la conditionnalité des prestations, les associations jouent un rôle important pour aider les personnes en situation précaire à faire valoir leurs droits.

$\mathrm{Au}$ sein des administrations, la lourdeur de la gestion et des contrôles associés aux nombreuses prestations sous conditions de ressources représente une cause possible de découragement pour les ayants droit. De plus, l'organisation locale du système d'aide sociale en Suisse, qui ne favorise pas l'anonymat des démarches, peut se révéler dissuasive et brouille la lisibilité du système, suscitant des craintes, comme celle d'être obligé de rembourser l'aide financière - une obligation dans de nombreux cantons -, ou que les parents, tenus d'aider financièrement leurs proches, soient contactés et appelés à contribuer. Du fait de la grande marge de manœuvre des institutions locales, le type de non-recours varie selon les procédures adoptées. Ainsi, certains services sociaux de Suisse alémanique rencontrent plus d'abandons dès l'accueil, alors que d'autres enregistrent plus de non-réception en fin de parcours.

Du point de vue des normes sociales, le fait d'être dépendant de l'État est en général mal vu dans un pays dominé par les idéologies libérales et conservatrices. Des travaux reportent un sentiment de honte associé à cette perspective. Par ailleurs, un fort stigmate s'attache au fait d'être à l'assistance publique, renforcé par la prégnance du discours sur les «abus». De ce point de vue, une enquête menée à Berne associe le non-recours à l'importance locale des partis de droite conservatrice ouvertement opposés à l'aide sociale. Ces différents éléments, ainsi que la force de valeurs comme la responsabilité individuelle poussent des personnes dans le besoin à favoriser des solutions alternatives (comme l'endettement).

Enfin, le régime de genre traditionnellement inégalitaire en Suisse pourrait contribuer à l'expression de formes genrées de non-recours. Des entretiens menés auprès de familles à Genève alimentent cette hypothèse, resituant le non-recours dans le cadre d'une expérience 
genrée de la précarité. Ainsi, la réticence des hommes à demander des aides financières vise d'abord à préserver leur statut symbolique de pourvoyeur de revenu. Par contraste, les femmes relient le non-recours à une inadéquation de l'offre à leur besoin de qualification sociale et d'émancipation.

Dans ce contexte, la question du non-recours a atteint l'agenda politique fédéral au début des années 2000 par l'entremise du problème de l'accès aux droits lié à la complexité du système. En 2004, une étude mandatée par l'Office fédéral des assurances sociales préconise la création de guichets sociaux sur la base des rares expériences cantonales ou communales existantes. Cette orientation s'est poursuivie dans le cadre du Plan national de lutte contre la pauvreté 2014-2018, qui encourage, en plus des guichets sociaux, une information de qualité «en ligne». La priorité donnée aux problèmes d'accessibilité, aux dépens d'autres grilles de lectures du non-recours, se retrouve à l'échelle des cantons et communes.

Champ de recherche en expansion, le non-recours contribue à alimenter une analyse critique des politiques sociales, selon des perspectives différentes. Du point de vue de l'équité, il révèle les capacités inégales des individus ou groupes sociaux à faire valoir leurs droits tout comme les capacités inégales des dispositifs sociaux à lutter contre ces inégalités. Du point de vue de l'efficience, il questionne la capacité des politiques à atteindre leurs objectifs. En lien avec le développement des politiques d'activation en Europe, l'attention se déplace sur le contenu de l'offre, ses présupposés et ses conditions de réalisation, alimentant une critique plus radicale de la pertinence comme de l'acceptabilité des politiques sociales. Au final, la problématisation du non-recours se révèle éminemment politique, en ce qu'elle convoque des visions différentes de l'État et de l'intervention sociale, mais aussi des publics concernés.

\section{Barbara Lucas}

\section{Références}

Hümbelin, O. (2016). Nichtbezug von Sozialhilfe: Regionale Unterschiede und die Bedeutung von sozialen Normen. University of Bern Social Sciences Working Papers, 21, online. https://boris. unibe.ch/94881/

Lucas, B., Ludwig, C., Chapuis, J. \& Crettaz, E. (2019). Le non-recours aux prestations sociales à Genève: quelles adaptations de la protection sociale aux attentes des familles en situations de précarité? Genève: Haute École de Travail Social et Haute École de Santé.

Warin, P. (2016). Le non-recours aux politiques sociales. Grenoble: Presses universitaires de Grenoble.

\section{Organisation du territoire*}

La notion d'organisation du territorial désigne l'ensemble des activités de planification territoriale publique. En Suisse, l'organisation du territoire est une tâche conjointe de la Confédération, des cantons et des communes. Le terme est souvent utilisé comme synonyme d'aménagement du territoire, mais il est plus large, car il englobe tous les domaines politiques liés à l'organisation du territoire y compris, par exemple, les politiques économique, environnementale et des transports. Les objectifs de l'organisation du territoire consistent à adapter les différents besoins de la société à l'espace, influençant ainsi l'organisation du territoire de manière ciblée et protégeant la ressource rare qu'est le sol. Dans sa législation sur l'aménagement du territoire, la Suisse s'est fixée pour objectif de politique sociale «de favoriser la vie sociale, économique et culturelle des diverses régions du pays et de promouvoir une décentralisation judicieuse de l'urbanisation et de l'économie». Cet objectif tient compte du fait 
que l'organisation du territoire - en particulier via le marché du logement - exerce une influence significative sur la composition de la population dans une zone donnée.

L'urbanisation s'est fortement développée en Suisse au cours du XX $\mathrm{XX}^{\mathrm{e}}$ siècle. Avec cette expansion, la nécessité de planifier l'urbanisation s'est d'abord faite sentir dans les villes, puis dans les autres régions du pays. Les premiers plans d'affectation, qui régissent le type et l'étendue de l'utilisation du territoire dans une zone donnée, ont été élaborés au niveau communal dans les années 1930. En 1969, un article a été ajouté dans la Constitution fédérale, attribuant à la Confédération la compétence d'édicter la législation de base en matière d'aménagement du territoire. La loi fédérale sur l'aménagement du territoire est entrée en vigueur en 1980.

En Suisse, l'aménagement du territoire est marqué par le système d'État fédéral. Dans toute la mesure du possible, les décisions sont prises au niveau politique le plus bas, c'està-dire au niveau de la commune. La tâche est déléguée au niveau politique supérieur approprié si le niveau inférieur est dépassé, par exemple lorsque les effets de la planification dépassent les frontières communales.

La Confédération limite sa législation sur l'aménagement du territoire à quelques domaines seulement: la loi sur l'aménagement $\mathrm{du}$ territoire contient des prescriptions relatives aux instruments d'aménagement à utiliser par les cantons et les communes, des règles de coordination pour les mesures ayant une influence sur le territoire, ainsi que des règles de base centrales d'aménagement du territoire, telles que la délimitation des zones à bâtir ou leur étendue admissible. En plus de ce rôle limité dans l'aménagement du territoire dans un sens restreint, la Confédération exerce son influence sur l'organisation du territoire dans d'autres domaines politiques. C'est notamment le cas de la politique des transports, par exemple l'aviation, les infrastructures ferro- viaires et les routes nationales, la politique agricole, la politique régionale ainsi que la politique financière et fiscale.

Les cantons sont responsables de l'établissement de plans d'aménagement. D'une part, ils édictent une législation d'application cantonale sur l'aménagement du territoire. Ces lois cantonales sur l'aménagement du territoire et la construction définissent les instruments de planification, les termes, les procédures et les prescriptions en matière de construction et de conception des bâtiments. D'autre part, les cantons élaborent des plans directeurs dans lesquels ils précisent la coordination des activités ayant une influence sur l'aménagement du territoire cantonal. Les plans directeurs sont souvent fondés sur des objectifs de politique sociale, tels que la promotion d'un certain degré de mixité sociale. Ils sont approuvés par le Conseil fédéral et sont contraignants pour les autorités de la Confédération, des cantons et des communes.

Dans la plupart des cantons suisses, ce sont les communes qui sont responsables des plans d'affectation. Ces plans, détaillés et obligatoires pour les propriétaires fonciers, délimitent les zones à bâtir et les zones non constructibles. Ils définissent le type d'utilisation ainsi que l'étendue constructible dans les zones à bâtir. Les plans d'affectation comprennent habituellement un règlement et un plan de zones. C'est sur la base de ces plans d'affectation que les communes, la plupart du temps, octroient des permis de construction pour chaque projet.

La politique d'organisation du territoire et l'aménagement du territoire influencent la composition socioéconomique de la population dans l'espace, notamment par le biais du marché immobilier et du logement. Avec leurs instruments d'aménagement du territoire, les cantons et les communes fixent les conditions-cadres du développement du territoire. Ils déterminent la densité de construction autorisée dans une zone donnée ainsi que l'utilisation autorisée. Ils influencent ainsi l'offre 
de terrains à bâtir et, indirectement, la disponibilité de logements dans une zone donnée. La demande de logements est actuellement très forte dans les villes suisses. Les prix des logements y sont plus élevés qu'en zone périurbaine. Les ménages à faible revenu se déplacent en conséquence vers ces régions.

Les offres de transport mises à disposition par le secteur public influencent également la mixité sociale des villes et des agglomérations. L'extension du réseau routier et de l'offre de RER au XXe siècle a permis la séparation spatiale des lieux de vie et de travail et de formation. De grandes agglomérations urbaines se sont formées en Suisse. Grâce aux facilités d'accès, les ménages à revenus élevés peuvent choisir des lieux de résidence de haut standard mais éloignés des lieux de travail au centreville.

Le 3 mars 2013, l'électorat suisse a approuvé à plus de $60 \%$ des suffrages exprimés une modification de la loi sur l'aménagement du territoire. Cet amendement vise notamment à limiter l'expansion urbaine et à stopper le mitage du territoire. La loi exige des cantons de prouver que les zones à bâtir se limitent aux besoins prévisibles sur quinze ans. En parallèle, ils sont tenus de renforcer l'urbanisation dans les zones à bâtir existantes. Ces dernières années, ce principe, appelé développement interne, est devenu la logique prépondérante de l'aménagement du territoire en Suisse. L'espace est limité, en particulier dans les centres économiques, et il doit être utilisé le plus efficacement possible compte tenu de la croissance démographique continue. Limiter l'urbanisation peut produire des conflits d'intérêts notamment en vue d'objectifs de politique sociale: une pénurie de terrains à bâtir entraîne une augmentation des loyers, ce qui rend la recherche d'un logement de plus en plus difficile pour les ménages à faible revenu.

La raréfaction croissante du sol en tant que ressource et la hausse des prix du logement qui en découle constituent de véritables défis sociaux. Il existe une volonté de promouvoir ou de préserver la mixité sociale dans diverses villes et agglomérations. Afin de permettre aux ménages moins aisés de vivre dans les centres urbains, les grandes villes, en particulier, ont pris diverses mesures au cours des dernières décennies. De nombreuses villes et communes construisent elles-mêmes des logements à loyer modéré ou cèdent des terrains à des promoteurs immobiliers d'utilité publique. Ces derniers y construisent du logement abordable. Cependant, l'accent est de plus en plus mis sur l'aménagement du territoire: la valeur ajoutée que les propriétaires fonciers retirent de l'aménagement du territoire peut être utilisée pour la construction de logements à loyer modéré. Certaines communes lient l'urbanisation, dans certaines zones, à la construction de logements à loyer modéré. Reste à voir si ces mesures d'organisation du territoire en particulier et d'autres, plus générales, suffiront à promouvoir l'habitat à loyer modéré.

\section{Lukas Beck}

\section{Références}

Association suisse pour l'aménagement national VLP-ASPAN (Éd.) (2012). Aménagement du territoire en Suisse : introduction. Berne : VLP-ASPAN.

Beck, L., Diggelmann, H., Eugster, C., Haase, R. \& Thoma, M. (2012). Logements à prix modérés à l'aide de mesures d'aménagement du territoire? Analyse d'impact et recommandations [sur mandat de l'Office fédéral du logement] - résumé. Zurich : Ernst Basler + Partner.

Häussermann, H., Siebel, W. \& Wurtzbacher, J. (2004). Stadtsoziologie: Eine Einführung. Frankfurt a.M.: Campus.

\section{Organisation du travail ${ }^{*}$}

Selon la définition donnée dans le lexique de l'économie de Gabler (Wirtschaftslexikon), l'organisation du travail vise à réduire les charges et à augmenter la satisfaction et la perfor- 
mance des travailleur-euse-s. Les éléments principaux en sont l'aménagement de la place du travail et l'organisation du travail, les deux ayant une influence centrale sur la productivité des travailleur-euse-s. Dans les sociétés modernes, le travail rémunéré s'effectue le plus souvent dans le cadre d'une organisation. La forme de l'organisation peut être hiérarchisée ou bureaucratique, participative ou hybride, autrement dit présenter des caractéristiques du marché à l'intérieur de l'organisation.

L'organisation du travail intervient à différents niveaux. Au niveau de l'État, celui-ci délimite le cadre légal du travail avec, notamment, une législation sur le travail. Au niveau des branches, mais aussi à celui de grandes entreprises, les conditions-cadre sont négociées dans des conventions collectives de travail - ainsi les temps de travail dans le secteur des banques et des assurances par exemple ne sont pas les mêmes que dans le commerce de détail. Finalement, les conditions de travail sont réglées concrètement au niveau des entreprises, avec l'aménagement de conditions de travail à la place de travail. Pour la Suisse, le niveau «entreprises » est décisif, surtout depuis les deux dernières décennies.

Le concept de l'organisation du travail s'est d'abord développé dans le monde des affaires militaires et administratives. Jusqu'au XVIII ${ }^{\mathrm{e}}$ siècle, on travaillait le plus souvent dans de très petites unités, organisées dans le cadre familial. Avec l'industrialisation, qui prend ses débuts en Grande Bretagne, dans les manufactures et les fabriques, des conditions avant tout techniques sont mises en place, pour obtenir des gains de productivité élevés moyennant une organisation rigoureuse du travail, avec une assignation précise des rôles et des tâches et un système élaboré de sanctions. Les pionniers de la production industrielle de masse ont été Frederick Taylor (organisation scientifique du travail) et Henry Ford (travail à la chaîne, modèle de rémunération). La rationalisation induite par la production industrielle de masse liée au Taylorisme et au Fordisme au début $\mathrm{du} \mathrm{XX}^{\mathrm{e}}$ siècle fut immense. Le modèle fordien combinait une organisation centralisée du travail, dans laquelle les travailleur·euse-s étaient les exécutant·e·s de tâches mécaniques simplifiées mais hautement spécialisées, avec des salaires plus élevés («les voitures n’achètent pas des voitures»). Le rythme de travail pouvait être dicté par le réglage de la chaîne. Le fabricant de chaussures Bally, à Schönenwerd dans le canton Soleure, fut le précurseur des principes fordiens en Suisse.

Dans les années 1930, le mouvement des relations humaines (human relations movement) intégra la question des répercussions des conditions de travail sur les travailleur.euse-s. Mentionnons à ce propos les expériences de Hawthorne, qui analysaient l'importance de structures de groupes formelles et informelles, tant pour le bien-être individuel que pour la productivité. Depuis, des concepts «postfordiens» se sont répandus, avec, entre autres, le modèle de la lean production (Toyotisme) et bien d'autres tentatives encore pour améliorer l'efficience de la production, comme la production just in time, le management reengineering, le total quality management, etc.

Plus récemment, le pilotage du marché, l'informatisation, le télétravail, l'ubérisation, la work-life balance et, de manière générale, les ressources humaines, sont des facteurs qui ont une influence considérable sur l'organisation moderne du travail. Contrairement à l'organisation d'une entreprise de production de masse traditionnelle, le pilotage du marché intègre les fluctuations du marché dans l'organisation du travail au travers de chiffres clés et d'informations sur la concurrence et la clientèle. Les fluctuations du marché sont aussi de plus en plus en souvent compensées par une division de l'effectif entre le personnel de base ou «nucléaire» et le personnel accessoire ou «périphérique»; le premier travaille dans de meilleures conditions et gagne souvent davantage, alors que le deuxième est engagé comme 
intérimaire ou sur appel. Le terme de l'informatisation décrit l'influence des nouveaux moyens de communication et des ordinateurs. Des formes virtuelles d'organisation du travail, c'est-à-dire sans ancrage géographique, sans effectif fixe ni attribution définie des rôles, sont aujourd'hui envisageables, voire existent déjà. Seul l'avenir nous dira dans quelle mesure ces nouveaux modèles pourront s'imposer. Pour l'heure, on en est à l'analyse des effets du télétravail, autrement dit le travail effectué à domicile à l'aide de moyens de communication modernes, sur l'organisation du travail. Cette formule pourrait gagner du terrain avec l'avancée du numérique.

Sous le nom d'économie du partage (share economy), aussi appelée ubérisation ou gig economy, une autre tendance se dessine dans l'organisation du travail. De nouvelles entreprises comme Uber et AirBnB, qui offrent des prestations de transport de personnes pour l'une, d'hébergement pour l'autre, sont des plateformes en ligne sur lesquelles des prestataires indépendants peuvent proposer leurs services. Cependant, la plupart des prestataires vont se retrouver dans une situation de dépendance vis-à-vis de la plateforme de mise en contact qui détient les atouts. Résultat final: une relation asymétrique d'employé-e-employeur-euse, mais sans les avantages sociaux offerts par l'intégration dans une entreprise moyennant un contrat de travail (salaires et temps de travail réglementés, assurances sociales, etc.). Pour les syndicats, ces formes d'organisation du travail soulèvent le problème de l'organisation du personnel.

L'organisation du travail a également pour objectif de réaliser un équilibre entre sécurité, autonomie et flexibilité pour les travailleur-euse-s et les entreprises - c'est bien ici que l'on conçoit son importance pour l'emploi et la protection des ressources humaines. Comme le montrent les exemples de temps de travail trop longs ou incompatibles avec une vie sociale, l'organisation du travail peut avoir des effets directs sur la santé et la productivité du personnel. Une mauvaise organisation du travail peut se solder par une baisse de productivité et de motivation, alors qu'une bonne organisation du travail aura l'effet contraire. La Caisse nationale suisse d'assurance en cas d'accidents (SUVA) est d'ailleurs un partenaire important dans l'aménagement des places de travail en Suisse.

\section{Sebastian Schief}

\section{Références}

Hielscher, V. (2000). Entgrenzung von Arbeit und Leben? Die Flexibilisierung von Arbeitszeiten und ihre Folgewirkungen für die Beschäftigten: Eine Literaturstudie. Berlin: WZB.

Lehndorff, S. (2005). Widersprüche der «Vermarktlichung»: Marktsteuerung in der Arbeitsorganisation von Dienstleistungen. Forum Wissenschaft, 22(1), 10-14.

Schief, S. (2010). Does location matter? An empirical investigation of flexibility patterns in foreign and domestic companies in five European Countries. International Journal of Human Resource Management, 21(1), 1-16.

\section{Organisation sans but lucratif*}

Les non-profit organisations (NPO) ou organismes sans but lucratif (OSBL) dans le domaine social sont des organisations de la société civile, et donc privées, qui ne poursuivent pas de but lucratif. Elles complètent les moyens de subsistance individuels du système de sécurité sociale suisse, soit les prestations des assurances sociales publiques. Il s'agit d'organisations caritatives ou faîtières ou de groupes d'entraide. Leurs statuts juridiques sont principalement ceux de l'association ou de la fondation. Le spectre s'étend des nombreuses petites entités hautement spécialisées à un nombre relativement restreint de grands organismes dont certains opèrent au niveau international. Leur offre de services comprend, d'une part, des 
prestations de soutien, de conseils, de formations initiales et continues ainsi que des tâches de coordination et, d'autre part, des prestations matérielles et financières. Un certain nombre d'OSBL du domaine social entretiennent des relations d'échange avec l'État; elles remplissant des tâches spécifiques pour lesquelles elles sont rémunérées, le plus souvent sous forme de mandat de prestation. De plus, elles se financent par des dons et des revenus propres.

Si les OSBL dans le domaine social fournissent des services (objectif de résultat), leur mandat inclut également la représentation au niveau politique des intérêts de leurs groupes cibles ainsi que les relations publiques (objectif d'influence). De plus, de nombreuses OSBL dans le domaine social permettent un engagement valorisé de bénévoles et de proches dans leur domaine.

Historiquement, les OSBL dans le domaine social sont adossées, en Suisse, au rôle majeur des communes, détenu depuis des siècles, et des églises, dans la lutte contre la pauvreté. Si depuis le XIX ${ }^{\mathrm{e}}$ siècle une tradition coopérative solide ainsi qu'une vie associative très développée jouent un rôle important dans les décisions et changements politiques, ces deux éléments favorisent également les OSBL. En Suisse, en comparaison européenne, ce n'est que tardivement que la question sociale a été débattue politiquement et a débouché sur des réponses d'État social. Plus d'un dispositif public fut alors fondé sur l'expérience d'institutions privées antérieures qui, en tant qu'OSBL, servaient de pionnières et de modèles.

L'Office fédéral de la statistique estime le nombre d'OSBL dans le domaine de la protection sociale à environ 1400, avec une dépense totale de 2,9 milliards de francs (2010), sans compter l'apport non négligeable de travail bénévol dont le volume ne peut que faire l'objet d'estimations. $57 \%$ des dépenses encourues par ces OSBL concernent leurs prestations directes, tandis que les autres dépenses concernent l'organisation et la gestion des activités. Dans ces OSBL, environ 36000 personnes occupent quelque 24000 postes à plein temps. Le nombre de bénévoles est estimé à 160000 . En ce sens, les OSBL dans le domaine de la protection sociale représentent un facteur économique significatif et croissant.

Toujours selon l'Office fédéral de la statistique, en 2010, les prestations des OSBL dans le domaine de la protection sociale s'effectuent principalement dans les deux domaines de l'invalidité ( $25 \%$ ) et de la maladie/soins de santé (21\%). Suivent les domaines de l'exclusion sociale $(17 \%)$ et de la vieillesse ( $15 \%)$, alors que les domaines famille/enfants, logement, chômage et survivants représentent des parts respectives de $10 \%$ ou moins pour un total de $22 \%$.

La plus grande part des prestations consiste en des prestations en nature: des conseils, des traitements, du transports etc. (70\%) ou des biens (19\%). Seulement $11 \%$ des prestations sont des prestations en espèces. $55 \%$ des prestations sont fournies sous condition de ressource, une part bien plus importante que les prestations de l'État, ceci pour des raisons systémiques. En 2010, ces OSBL ont versé des prestations en espèces à environ 180000 ménages ou à 290000 personnes, alors que les prestations en nature concernaient environ 1,1 million de ménages.

Les OSBL suisses dans le domaine de la protection sociale sont financées à $58 \%$ par des dons, des cotisations de membres et des revenus propres, alors que $42 \%$ le sont par des financements publics sous forme d'apports et de compensations de prestations de la Confédération, des cantons et des communes. En 2010, le total des Comptes de la sécurité sociale s'est élevé à 153 milliards de francs. La part des OSBL du domaine en représentait 0,8\%. Si l'on fait abstraction des grandes assurances sociales, on obtient une part des OSBL d'environ un tiers de l'ensemble des prestations sous condition de ressource (2010: 2 milliards), sans compter le travail des bénévoles. 
Une particularité suisse est la fonction complémentaire précitée des OSBL du domaine social. Elle contraste avec la situation à l'étranger, par exemple en Allemagne, où une grande partie des tâches et des prestations sociales est déléguée à des organisations caritatives. Dans d'autres pays, par exemple en Europe du Sud ou de l'Est, les prestations étatiques sont insuffisantes et les OSBL sont actives à titre compensatoire. Le fédéralisme et le principe de subsidiarité sont en outre propres à la Suisse ; selon ces logiques, la responsabilité sociale incombe d'abord à l'individu et à sa famille. Le contexte social (connaissances, voisinage, associations et, en partie aussi, organisations d'entraide), suivi par les niveaux étatiques: communes, cantons, Confédération. Le fédéralisme suisse contribue sans doute à la grande diversité des OSBL du domaine social. D'un côté, il garantit une proximité sociale et un haut niveau d'acceptation, mais, de l'autre, il fait obstacle à la comparaison et à la coopération, ceci d'autant plus que la perception des questions de politique sociale varie considérablement d'une région du pays à l'autre.

L'un des défis pour de nombreuses OSBL du domaine social consiste dans le fait qu'une part substantielle de leur financement provient de contributions publiques ou de compensations pour des mandats de prestations. Ces OSBL courent donc le risque d'être impliquées dans les planifications et les objectifs de l'État de manière plus étroite que souhaité. Elles perdent ainsi leur orientation stratégique et leur marge de manœuvre tant dans le travail opérationnel que dans les relations publiques. En outre, un financement public massif peut représenter un risque économique.

Par ailleurs, la reconnaissance et l'importance des OSBL du domaine social ne sont plus aussi incontestées que dans leur phase prospère entre 1980 et 2000 . Selon certain.e-s chercheur·e.s, l'efficience et l'efficacité les OSBL en tant que service providers seraient globalement limitées et leur rôle consisterait davan- tage à asseoir leur situation de pionnière et à influencer les débats politiques. Cette logique appelle à une implication accrue d'entreprises privées dans ces «domaines d'activité». De fait, des entreprises privées sont déjà présentes dans le domaine social, qu'il s'agisse de la gestion de l'aide sociale communale, de l'accueil de demandeurs d'asile ou de la prise en charge de personnes âgées dépendantes. De même, de nombreux bailleurs de fonds, notamment l'État, introduisent des éléments d'économie de marché dans l'exécution des tâches sociales : ils lancent des appels d'offres, définissent des exigences en matière de gestion et de comptabilité et fixent des normes pour les prestations de soins. Ces logiques peuvent aboutir au fait que les OSBL n'offrent plus que des prestations dites rentables et assurées financièrement, tandis que - d'un autre point de vue - leur tâche consisterait à fournir aide et soutien précisément dans les domaines où l'État et l'économie privée n'offrent rien et où l'aide individuelle ou familiale atteint ses limites.

Les institutions sociales suisses ont toujours fait l'objet de débats publics auxquels les OSBL ont participé intensément. Au début du $\mathrm{XXI}^{\mathrm{e}}$ siècle, il apparaît que les grandes assurances sociales, créées dans les années d'aprèsguerre sur fond de foi en l'avenir, sont désormais sous pression en raison de l'évolution démographique, d'une part, et de l'évolution du climat économique, d'autre part. Les effets de ce nouveau contexte sur les organisations privées actives dans le domaine social et de la lutte contre la pauvreté n'apparaissent pas encore clairement.

\section{Albert Schnyder}

\section{Références}

Anheier, H. K. (2014). Nonprofit organizations : theory, management, policy ( $2^{\text {nd }}$ ed.). Abingdon : Routledge. 
Gysin, B. \& Adamoli, M. (2013). Les organisations sans but lucratif dans le domaine de la protection sociale: situation et développement entre 1990 et 2010 dans le cadre des comptes globaux de la protection sociale. Neuchâtel: Office fédéral de la statistique.

Helmig, B., Lichtsteiner, H. \& Gmür, M. (Hrsg.) (2010). Der Dritte Sektor der Schweiz: Länderstudie zum Johns Hopkins Comparative Nonprofit Sector Project (CNP). Bern : Haupt.

\section{Orientation scolaire et professionnelle}

Les premières formes d'une pratique organisée de l'Orientation scolaire et professionnelle (OSP) en Suisse virent le jour au début du XX $\mathrm{X}^{\mathrm{e}}$ siècle avec la création, en 1916, de l'Association suisse pour l'orientation professionnelle. Dès la fin de la Première Guerre mondiale, des offices d'orientation publics ou privés, apparaissent dans les différents cantons avec une première harmonisation fédérale sous l'égide de la loi fédérale sur la formation professionnelle en 1930. Leurs objectifs explicites et concrets furent alors de répondre au besoin grandissant de l'industrie en matière de maind'œuvre qualifiée et de combattre le chômage tout en soutenant une visée éducative ancrée dans le système de valeurs morales et sociales de l'époque: la transmission du goût et de la valeur du travail aux jeunes afin de combattre l'oisiveté et les errements stériles résultant de choix hasardeux et insuffisamment documentés.

Dès leur création, les OSP visent donc avant tout l'insertion professionnelle des jeunes à l'issue de la scolarité obligatoire. Pour ce faire, les premier-ère-s professionnel-le-s du domaine, les conseiller-ère·s de vocation, cherchent à identifier la «vocation professionnelle», qui présuppose une voie idéale - voire sacrée, si l'on se réfère à l'origine judéo-chrétienne du terme - résultant d'un appariement optimal entre un métier (avec ses exigences en termes d'aptitudes requises et sa culture professionnelle sous-jacente) et un individu (dont les aptitudes, habiletés et autres traits caractéristiques sont mesurés à travers une batterie de tests médicaux et psychométriques). L’approche ici est positiviste, mettant la méthode scientifique au service des problématiques sociales, et déterministe, puisque le choix formulé va permettre l'insertion stable et la progression professionnelle linéaire de l'individu qui n'aura plus à le remettre en question.

À partir des années 1960, avec les mouvements sociaux d'émancipation et de défense des droits individuels et l'émergence de la psychologie humaniste et existentielle, on observe un virage progressif dans la visée et les pratiques de l'OSP. Quittant une posture prescriptive, les spécialistes du domaine œuvrent à développer une conception de l'orientation en tant que prestation d'accompagnement au service de la personne considérée comme une actrice autonome et responsable de son projet professionnel. Les conseiller-ère-s en OSP offrent donc à leurs « consultant $\cdot e \cdot s$ » un espace de réflexion sur soi et d'expression de soi, les soutenant dans une démarche d'explicitation des objectifs, d'identification des compétences et de développement de carrière dans un contexte de croissance économique et de plein-emploi.

Face aux changements significatifs du marché de l'emploi à partir du milieu des années 1990 (globalisation, flexibilisation du travail, nouvelles technologies de l'information etc.), l'OSP se transforme. Les parcours professionnels deviennent plus imprévisibles et obéissent moins à une logique de planification à long terme. Une première orientation n'est plus définitive, puisque chaque individu aura à formuler une série de choix et à négocier, de gré ou de force, de multiples périodes de transition et de réorientation à travers son parcours. Ces choix et ces transitions ne sont plus vus comme totalement sous le contrôle de la personne puisque le contexte, avec ses exigences grandissantes et 
ses changements rapides, lui impose un certain nombre de ruptures et de réajustements et l'expose à des risques d'exclusion. Cette nouvelle réalité mène les conseiller·ère-s à soutenir des interventions qui visent à l'accompagnement des personnes dans leurs efforts pour faire face à l'incertitude ambiante, créer du sens et remanier leur identité à travers les transitions, et développer des capacités d'adaptation pour maintenir leur employabilité.

L'OSP est fortement liée à certains éléments constitutifs du système de formation. En Suisse, ils induisent l'émergence précoce et récurrente des questions d'orientation. À la différence du système à filière unique en vigueur dans la majorité des pays de l'OCDE, le système scolaire suisse est organisé par filières différenciées. Ainsi, au passage du cycle primaire au cycle secondaire, les élèves sont évalué.e-s et orientée-e-s en fonction de leurs performances scolaires vers une filière qui aura des conséquences sur leur parcours à venir, puisque certaines filières ouvrent l'accès à une voie académique continue jusqu'aux études supérieures, alors que d'autres visent l'entrée en formation professionnelle à l'issue de la scolarité obligatoire. Or la forte tradition de la formation professionnelle (près de $60 \%$ des jeunes suisses optent pour la voie de l'apprentissage), dont l'un des avantages est sans doute une insertion par paliers sur le marché de l'emploi, fait des futur.e.s apprenti.e.s le principal public cible de l'OSP: les conseiller-ère-s en orientation sont présent·e·s au sein même de l'école pour soutenir de jeunes élèves, encore aux prises avec les défis de l'adolescence et les exigences de la scolarité, dans l'élaboration d'un choix professionnel et les accompagner vers une première forme d'insertion professionnelle sur un marché de l'apprentissage qui, de par ses exigences et sa compétitivité, ressemble en bien des points au marché de l'emploi. Par ailleurs, l'avènement précoce de ce premier choix professionnel le rend particulièrement perméable à l'influence du genre, du statut social ou de l'origine culturelle (ce qui amène les filles à se projeter vers des occupations ou des professions traditionnellement perçues comme féminines, p.ex.). De ce fait, les conseiller-ère-s doivent œuvrer à dénoncer et combattre ces inégalités afin de garantir un accès équitable - basé sur les préférences et les capacités plutôt que sur les caractéristiques sociodémographiques - à la formation et à l'emploi.

Porté par une économie solide et dynamique, le marché de l'emploi suisse présente un taux de chômage particulièrement bas au regard de la moyenne des pays de l'OCDE. Toutefois, les nouvelles exigences d'un marché du travail profondément transformé par des phénomènes tels que la mondialisation des marchés, la digitalisation du travail, la tertiarisation des métiers ou encore le vieillissement démographique mettent à mal, également en Suisse, certains groupes de la population active qui se retrouvent en position de vulnérabilité à différents moments de leur parcours professionnel. C'est le cas des jeunes adultes sans qualification qui, en cumulant deux facteurs de risque essentiels que sont le manque d'expérience et l'absence de formation, connaissent de grandes difficultés d'insertion professionnelle et courent le risque d'une exclusion et d'une dépendance de l'aide sociale à long terme. Ici s'ouvre l'un des grands chantiers de l'OSP suisse qui, depuis une dizaine d'années et dans différents cantons, développe des mesures d'accompagnement des transitions, de préparation à l'entrée en formation et d'aide à l'insertion. Citons également certains groupes de travailleur.euse-s «seniors» (55 ans et plus) qui, fortement sollicités par les exigences de formation continue et de flexibilité, et menacés par une compétition intense, courent le risque d'une perte d'emploi et d'un chômage de longue durée. Enfin, des efforts sont également consentis pour combattre les inégalités et la précarité, en aidant par exemple les travail-

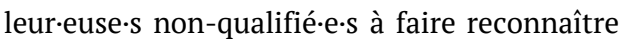
leurs acquis, valider leurs compétences par un 
diplôme officiel et accéder ainsi à un statut moins précaire.

\section{Koorosh Massoudi}

\author{
Références \\ Masdonati, J., Massoudi, K. \& Rossier, J. (Éd.) (2012). \\ L'orientation scolaire et professionnelle en \\ Suisse. O.S.P. L'Orientation scolaire et profession- \\ nelle, 41(2), en ligne. https://journals.openedi- \\ tion.org/osp/3764 \\ Masdonati, J., Massoudi, K. \& Rossier, J. (Éd.) (2019). \\ Repères pour l'orientation. Lausanne: Antipodes.
}

\section{Parent non statutaire}

Emprunté à Virginie Descoutures qui l'applique aux mères lesbiennes, le terme parent non statutaire définit la situation d'une personne qui, dans un couple élevant l'enfant de l'un des deux, assume une parentalité sans disposer des droits de parenté découlant de la filiation, hormis ceux que veulent bien lui concéder informellement le ou les parents légaux, ainsi que l'enfant. Cette situation qu'ont rendue publique les associations de défense des familles homoparentales les touche particulièrement, mais elle ne leur est pas spécifique et concerne également les compagnons ou compagnes des pères ou mères vivant en famille hétérosexuelle recomposée.

$\mathrm{Du}$ fait de ce vide juridique, que le droit comble en partie depuis fort récemment, le parent non statutaire souffre d'un déficit de reconnaissance publique, qu'il compense partiellement par différentes stratégies privées: soutenir financièrement l'enfant, participer au travail éducatif le concernant, s'appuyer sur des ressources symboliques, construire un entourage relationnel bienveillant à l'égard de son rôle parental et surtout s'assurer de l'appui de sa ou son conjoint. Réciproquement, les enfants conçus et nés au sein d'un couple homoparental étaient privés de leur droit fon- damental à la double filiation. Leurs parents n’ont pas accès au mariage, mais depuis peu à l'adoption, qui est autorisée, comme pour les couples hétérosexuels, sous certaines conditions. En effet, le processus de «modernisation » du droit de la famille en cours actuellement, bien que lent et relativement timide, évolue en faveur de la reconnaissance du parent non statutaire. L'entrée en vigueur du nouveau droit de l'adoption, le $1^{\text {er }}$ janvier 2018, d'une part étend celle-ci aux couples homosexuels unis par un partenariat enregistré, ainsi qu'aux concubins hétérosexuels, et d'autre part, ouvrir un droit aux relations personnelles non lié à la filiation, avec l'accord de l'autorité de protection de l'adulte et de l'enfant. Auparavant, et cela reste vrai pour bien des situations, au regard du droit helvétique, et malgré une marge d'interprétation possible du bien de l'enfant par les juges, le parent non statutaire ne disposait formellement d'aucun droit de parenté et donc d'aucune des protections sociales découlant de ce droit. Mais il avait, et a, des obligations : partageant le quotidien d'un enfant, marié ou concubin, il est soumis à l'obligation d'entretien.

Questionnant l'institution de l'hétérosexualité en tant que socle naturel de la famille, heurtant de front des croyances profondément ancrées concernant la filiation (biparentale et bisexuée), la révision du droit de l'adoption constitue un ébranlement institutionnel majeur, mais qui semble inéluctable. Premièrement, elle aligne le droit helvétique sur nombre de législations européennes et extra-européennes. Deuxièmement, elle corrige une double inégalité - entre les enfants possédant leur double filiation et ceux qui ne la possèdent pas, et entre les sexualités-correction qui à ce jour est inachevée, puisque le mariage reste interdit aux couples homosexuels, de même que l'accès à la reconnaissance de l'enfant sur le modèle de la reconnaissance en paternité. Troisièmement, cette révision entérine l'autonomie des individus dans la construction de leur vie privée, légitimant ainsi des familles qui 
de fait existent, et protégeant les parents non statutaires dans la séparation. Par conséquent, quatrièmement, le travail de soin et d'éducation de l'enfant par le parent non statutaire, autrement dit sa parentalité, pourrait se voir mieux reconnue et protégée.

Actuellement c'est loin d'être le cas. Alors qu'un parent légal conserve son statut même s'il n'exerce pas son rôle parental, le parent non statutaire doit apporter la preuve de son implication et de ses compétences. En effet, l'absence des supports institutionnels ordinaires de la famille hétérosexuelle que sont par exemple le droit, les identités de genre et la division sexuée du travail, renforce chez le parent non statutaire la nécessité d'inventer de tels supports et, sur cette base, de faire valider le fait qu'il ne forme pas seulement un couple conjugal avec le parent légal de l'enfant, mais aussi, à certains égards, un couple parental. Si les couples homosexuels qui ont réalisé en commun leur projet d'enfant parviennent, avec beaucoup d'efforts et sans garantie d'une protection, à imposer leur position, les études montrent que la situation est plus difficile pour les parents non statutaires dont la parentalité s'exerce en présence des deux parents légaux de l'enfant. Les belles-mères dans les familles hétérosexuelles recomposées, notamment, déplorent leur mise à l'écart des décisions en matière scolaire ou médicale par exemple, décisions dont elles ont généralement à assumer les conséquences au quotidien. Le non-partage absolu de l'autorité parentale entre les trois parents qui de fait s'occupent de l'enfant atteste ainsi de la force de notre modèle de filiation, biocentré et biparental. Or les situations de pluriparentalité, dans les familles hétérosexuelles recomposées et homoparentales (recomposées ou non), ébranlent la règle d'exclusivité du statut de mère ou de père, qui ne peut être occupé par deux personnes à la fois.

Tout ceci n'offre guère de marge de manœuvre pour l'intervention sociale auprès de ces familles. Les professionnel-le-s - travailleurs et travailleuses sociales, personnels de santé ou psychologues - sont certes formé·e-s à s'adapter au pluralisme familial actuel, quoique dans les limites liées à l'hétérocentrisme des institutions de soutien à la parentalité et à la famille. En effet, selon certaines études, si les professionnel-le-s reconnaissent être assez fréquemment en contact avec des parents non statutaires, c'est en montrant une indécision à leur égard: d'un côté, ces parents font partie des adultes pris en compte dans le système familial - l'intervention sociale en Suisse romande en particulier est largement fondée sur la théorie systémique -; mais de l'autre, ce ne sont pas des parents comme les autres puisque la loi interdit cette assimilation, ils sont donc écartés de toutes les décisions concernant l'enfant ayant une portée légale. Ainsi, aux yeux des professionnel-le·s, le parent non statutaire est à la fois dedans et dehors de la famille - dedans, car on compte sur son travail de parentalité; dehors, car il ne dispose d'aucun droit, de par son «non-statut », à prendre des décisions et/ou à bénéficier des prestations sociales protectrices destinées aux parents légaux - ce qui le fragilise.

\section{Marianne Modak}

\section{Références}

Ansermet, C., Ben Hounet, Y., Gaberel, P. \& Modak, M. (2014). Le «parent non statutaire» face aux cadres institutionnels suisses : entre espoirs et angoisses. In A. Fine \& J. Courduriès, (Éd.), Homosexualité et parenté (pp. 189-203). Paris : Armand Colin.

Nay, Y. E. (2013). Queering citizenship? Processes of normalisation of same-sex and transgender parents in law - Qu(e)er zum Recht? Normalisierungsprozesse gleich- und transgeschlechtlicher Elternschaft durch Recht. FamPra.ch, 13(2), 366394.

Odier, L. (2018). Les métamorphoses de la figure parentale: analyse des discours de l'Ecole des parents de Genève, 1950 à 2010. Lausanne: Antipodes. 


\section{Parentalité}

Le terme parentalité, souvent utilisé dans divers registres, recouvre plusieurs significations. Les spécialistes en isolent trois principales. Dans les champs psychanalytique ou psychologique, la parentalité renvoie généralement aux processus psychiques ou psychoaffectifs que vivent les individus lorsqu'ils deviennent «parent». Dans le champ de l'anthropologie, se distinguant de la parenté, elle désigne la position sociale et les responsabilités qui définissent celles et ceux que l'on nomme parent dans divers contextes sociohistoriques. Enfin, dans le champ juridique, ou celui des politiques sociales, la parentalité sert plus généralement à qualifier les compétences et l'exercice des tâches qui incombent à la position parentale légale. Elle tend, dans ce champ, à une non-reconnaissance légale des tâches parentales assumées par des conjoints ou partenaires de parents légaux et à l'exclusion de certains droits. Par exemple, les parents «non-statutaires» (dans des familles recomposées non-mariées ou homoparentales) sont soumis à l'obligation d'entretien s'ils vivent avec les enfants, mais ne peuvent obtenir le droit de garde en cas de décès du parent légal ou de séparation qu'à condition qu'un magistrat considère que c'est important pour le développement de l'enfant.

$\mathrm{Si}$ ces trois définitions diffèrent, elles ont pour point commun de désigner un processus individuel ou social et dénaturaliser les liens parent-enfant. Leur émergence a ainsi permis de nommer et de penser la fonction ou le rôle parental en dehors du lien biologique et de la distinction entre maternité et paternité. Elles apportent une complexification à la notion de famille comme en témoignent les exemples historiques d'utilisation du terme évoqués ci-dessous.

C'est autour de revendications visant à obtenir une reconnaissance de la pluralité des modes de «faire famille» et à les rendre visibles que la notion de parentalité s'est en effet popularisée et propagée. Dans l'espace francophone, c'est d'abord dans les années 1970 autour du combat pour la déstigmatisation de celles que l'on nommait les «filles-mères» que le terme parentalité associé à la particule «mono»a émergé dans l'espace public. Plus récemment, les expressions «homoparentalité» et "pluriparentalité»ont aussi été revendiquées pour une reconnaissance de l'exercice parental des parents de même sexe, ou des beaux-parents dans le cadre de familles dites recomposées.

Si l'histoire de l'utilisation de cette notion révèle des enjeux de reconnaissance de la pluralité des situations d'éducation des enfants dans la sphère privée et une volonté de dénaturaliser la position parentale, et plus particulièrement maternelle, l'histoire des politiques sociales se référant aux pratiques parentales montre les ambiguïtés du terme et les enjeux sociaux qui s'y rapportent.

Historiquement, en Suisse, on peut identifier l'une des premières formes d'intervention dans la parentalité, entendue comme «pratiques parentales», dans des programmes d'eugénisme «positifs » des années 1920, ayant pour objectifs de renforcer la reproduction des «bons» éléments de la population. Par exemple, les «bureaux de conseil sur le mariage», dont celui de Zurich fondé en 1932, réunissaient des groupes de jeunes femmes pour leur adresser des conseils sur le choix d'un bon mari et sur la bonne tenue du foyer en vue de favoriser une éducation appropriée des générations à venir. Par ailleurs, comme l'a révélé le scandale des enfants de la "Grande route», des parents considérés comme inadéquats, généralement en raison de leur appartenance de race ou ethnique, de leur niveau de vie ou de leur écart avec les normes conjugales pouvaient être internés et se voyaient retirer leurs enfants de force. Ceux-ci étaient alors placés en institutions étatiques ou religieuses ou encore dans des familles d'accueil, généralement paysannes et preneuses d'une nouvelle main-d'œuvre, 
sur la base des mesures de protection de l'enfance du Code civil entré en vigueur en 1912 et des internements à fin d'assistance. Alors que ces placements de force se perpétuent jusque dans les années 1980, plusieurs initiatives privées cherchent à les éviter en intervenant sur les pratiques et les compétences parentales en vue de les renforcer ou de les normaliser. Dès les années 1950, des Écoles de Parents, par exemple, émergent dans les cantons romands et à Winterthour. À travers leurs cours et leurs groupes de parole animés par des professionnel-le·s de l'enfance, elles soulignent le processus d'apprentissage des tâches et responsabilités parentales. Les mères, premières destinataires de ces programmes, sont dès lors valorisées dans l'exercice des tâches parentales reconnues comme n'étant pas «naturelles» mais acquises et complexes. Dans ce même mouvement, la position maternelle est l'objet de nouvelles normes auxquelles les mères sont confrontées. Cette tension entre valorisation et surveillance traverse toute l'histoire des politiques sociales visant la parentalité.

Depuis la fin des années 1990, cette tension se construit autour de la prolifération d'expert.e.s qui interviennent sur la parentalité et développent toujours plus de savoirs à son sujet - notamment sur les relations affectives entre parents et enfants ou sur les «limites à poser aux enfants». Si ces savoirs ont l'avantage de rendre visibles des pratiques jusque-là peu valorisées et de proposer des outils aux personnes (principalement des femmes) qui les assument, ils conduisent également à produire des normes et à élargir le spectre des pratiques considérées comme problématiques.

Par ailleurs, les programmes étatiques et para-étatiques de soutien à la parentalité par exemple le programme Positive Parenting Program dans plusieurs cantons, Elternbildung à Zurich, le programme national «l'Education donne la force» mené entre 2006-2010, ou encore les programmes de soutien aux familles monoparentales - continuent généralement de viser des populations très spécifiques: «les familles migrantes» ou les «jeunes mères». Sous un vocable d'aide et de soutien, on assiste à une sorte d'euphémisation de la stigmatisation de certaines pratiques parentales et des rapports sociaux qui s'y articulent, notamment les rapports sociaux de sexe.

En Suisse, comme dans de nombreux pays européens et plus largement occidentaux, les dispositifs et les politiques publiques visant la parentalité tendent à s'intensifier depuis la fin du XXe siècle. Cependant, comme pour les politiques familiales, ils sont souvent pris en charge par des organismes privés et ne font pas l'objet d'une politique nationale coordonnée.

Au-delà d'une action publique visant plus spécifiquement les mères, la responsabilité et l'exercice des pratiques parentales restent fortement assumés par les mères et les femmes, malgré un investissement accru des hommes. Si les conséquences de l'inégal partage des tâches sont déjà connues, des travaux récents montrent comment l'entrée en parentalité constitue un moment clé dans la sexuation des trajectoires professionnelles. Les carrières masculines étant favorisées par l'arrivée d'un enfant (augmentation des responsabilités et du salaire) alors que les trajectoires féminines sont freinées. Tout en permettant de nommer et valoriser des tâches et une implication longtemps considérées comme «naturelles» et «féminines», les programmes visant la parentalité tendent à occulter la dimension fortement sexuée de l'exercice parental et de l'intervention des expert.e.s.

\section{Lorraine Odier}

\section{Références}

Bachmann, L., Gaberel, P. \& Modak, M. (2016). La parentalité: perspectives critiques. Lausanne: Éditions ÉÉSP.

Furrer, M., Heiniger, K., Huonker, T., Jenzer, S. \& Praz, A.-F. (Hrsg.) (2014). Fürsorge und Zwang: Fremdplatzierung von Kindern und Jugendlichen in der Schweiz 1850-1980. Basel: Schwabe. 
Odier, L. (2018). Métamorphoses de la figure parentale: analyse des discours de l'École des parents de Genève, 1950 à 2010. Lausanne: Antipodes.

\section{Participation*}

La notion de participation (Teilhabe en allemand) est régulièrement utilisée dans des débats scientifiques, politiques et journalistiques sur la justice, l'intégration et l'inclusion, mais généralement sans référence à une définition précise. On ne peut toutefois pas considérer cette notion comme un terme fondamental de la philosophie, des sciences politiques, de la sociologie, de la pédagogie spécialisée, de l'éducation sociale ou du droit. Néanmoins, le terme est de plus en plus utilisé. Il a un sens plus strict et un sens plus large. Le sens plus strict découle de l'emploi fréquent des termes de Teilnahme et de Teilhabe, signifiant tous deux "participation» en français. Tandis que Teilnahme renvoie à la pratique sociale, à un contexte d'action auquel il est possible de participer, Teilhabe se rapporte à la possession, à un avoir, à un bien qui découle de ladite participation. En participant, un individu reçoit et a (haben) une part (Teil) de ce qui est distribué. Si l'individu a une part importante, il ou elle peut a fortiori prendre part (teilnehmen). Le sens plus large de Teilhabe, quant à lui, englobe les deux aspects, la participation en tant que telle et la possession ultérieure. Il correspond en grande partie au concept d'inclusion, à condition que son sens ne se limite pas à Teilnahme (participation stricto sensu). Teilnahme est la traduction littérale de participation. Toutefois, Teilhabe signifie aussi participation en anglais et en français.

Le double sens du terme Teilhabe reflète aussi bien l'acte que le résultat de la distribution. Par conséquent, dans la conception de l'équité de distribution, une distinction est établie entre l'équité des règles et celle des résul- tats. La participation (Teilhabe), qu'elle soit entendue dans un sens plus strict ou plus large, laisse ouverte la question des objets de la distribution. Il s'agit donc de déterminer les biens (capitaux, ressources, moyens) dont la répartition différenciée entre les personnes constitue la structure sociale d'une société, en répondant aux questions suivantes: Quels sont les biens que les personnes souhaitent posséder? Qui a accès à ces biens et dans quelle mesure ? Pierre Bourdieu distingue les capitaux économique, culturel, social et symbolique, c'est-à-dire le revenu et le patrimoine, la formation, le réseau de relations et le prestige. Une discrimination (négative) peut être fondée sur l'absence de biens. Permettre la participation (au sens de Teilnahme et de Teilhabe) satisfaisante de tous les membres de la société est donc lié à la politique de lutte contre les discriminations.

La philosophie établit les origines de sa réflexion sur la participation aux théories platoniciennes. Le terme en grec ancien methexis est généralement traduit en latin par participatio et en allemand par Teilhabe et décrit le rapport entre les objets concrets et les idées ainsi que le rapport des idées entre elles. Cependant, l'intérêt philosophique pour la participation comprise dans ce sens a presque entièrement disparu. Dans le même temps, la philosophie moderne traite très souvent de questions concernant la participation (aux sens de Teilnahme et de Teilhabe) dans le contexte de l'équité, mais pas sous cette dénomination.

En droit, ce sont les droits de participation (Teilhabe) qui sont abordés. La genèse historique élaborée par Thomas $H$. Marshall est, dans ce contexte, souvent invoquée: les droits à la liberté individuelle du XVIII ${ }^{\mathrm{e}}$ siècle, les droits de participation politique du XIX ${ }^{\mathrm{e}}$ siècle, les droits aux prestations sociales du XXe siècle. Dans la littérature spécialisée sont qualifiés de droits de participation parfois les droits politiques, parfois les droits sociaux.

Dans la science émergente qu'est le travail social, une attention croissante est portée à la 
participation (Teilhabe), bien que les théories $\mathrm{du}$ travail social n'incluent guère la participation comme un concept de base. Toutefois, Tilly Miller intègre la participation dans la définition de l'objet même du travail social. Dans sa publication Inklusion - Teilhabe - Lebensqualität (Inclusion - Participation - Qualité de vie), publiée en 2012, elle note que la participation aux ressources matérielles et immatérielles présuppose l'inclusion dans des systèmes. Selon elle, l'inclusion et la participation sont des conditions préalables à la qualité de vie fondée sur la dignité humaine et la prise en compte des besoins.

La plus grande attention portée à la question de la participation concerne celle des personnes en situation de handicap. Or le concept de participation (Teilhabe) n'est utilisé ni dans la Déclaration universelle des droits de l'Homme de 1948 ni dans la Convention européenne des droits de l'Homme de 1950. Aussi la référence à la participation dans la Convention relative aux droits des personnes handicapées (Convention on the rights of persons with disabilities) est-elle d'autant plus importante. Cette Convention a été adoptée par l'Assemblée générale des Nations Unies fin 2006 pour entrer en vigueur en mai 2008. Elle précise, d'entrée de jeu, au paragraphe e), que le handicap résulte «de l'interaction entre des personnes présentant des incapacités et les barrières comportementales et environnementales qui font obstacle à leur pleine et effective participation à la société sur la base de l'égalité avec les autres». À la lettre y) est stipulé l'objectif de vouloir contribuer «à remédier au profond désavantage social que connaissent les personnes handicapées» et de vouloir «[favoriser] leur participation, sur la base de l'égalité des chances, à tous les domaines de la vie civile, politique, économique, sociale et culturelle, dans les pays développés comme dans les pays en développement». L'un des principes fondamentaux est «la participation et l'intégration pleines et effectives à la société» et ceci «dans tous les domaines ».

Le gouvernement fédéral allemand donne le titre de Teilhabebericht (rapport de participation) à son étude approfondie de la «situation des personnes handicapées». Le concept de participation est tout aussi central dans le «rapport général sur la pauvreté et la richesse ». La loi fondamentale de la République fédérale d'Allemagne (la Constitution allemande) ne connaît cependant pas la notion de Teilhabe, pas plus que la Constitution fédérale suisse. L'administration fédérale suisse distingue néanmoins la participation politique, économique, sociale et culturelle.

La notion de participation constitue, en outre, une base normative à de nouvelles conceptions de la société. Gerd Grözinger, Michael Maschke et Claus Offe appellent leur modèle d'un nouvel État-providence une «société participative» (Teilhabegesellschaft). Ce modèle prévoit que les citoyennes et citoyens reçoivent, à leurs 18 ans, un capital de départ de 60000 euros, un héritage social financé par l'impôt sur la fortune et les successions. Sur un plan déontologique, les auteurs légitiment ce modèle par le fait que dans une société libérale fondée sur le principe de l'égale liberté réelle, l'introduction d'un revenu de base s'impose dans les conditions économiques actuelles. Par conséquent, écrivent-ils, l'introduction de droits civiques économiques est souhaitable car ils contribueraient à résoudre des problèmes sociaux majeurs (accès inégal à la formation, chômage, criminalité, etc.). Le livre Wege in die Teilhabegesellschaft publie, quant à lui, une quarantaine de contributions collectées en 2015 par la Fondation allemande Heinrich Böll sous le mot-clé de l'inclusion. Ces contributions explorent les «Voies vers une société participative». Ces voies ne sont, de loin, pas limitées à une dimension matérielle. Par exemple, la distinction faite par Iris M. Young entre external et internal inclusion est traduite par participation d'accès 
et participation de cogestion (Zugangs- und Mitwirkungsteilhabe). Enfin, le modèle d'une société de la participation ou de l'engagement (Beteiligungsgesellschaft) de Gregor Husi, proposé dans le sillon de cette discussion, entend la participation à la fois comme l'acte de "prendre part» (Teilnahme) et d' "avoir sa part» (Teilhabe). Sa définition de la participation englobe l'empathie (Anteilnahme) vécue dans l'expérience ainsi que l'appartenance (Teilsein) en tant qu'interaction réuissie du juste et du bien, des valeurs personnelles et des normes sociales. Conformément à ce modèle philosophique et sociologique, dont les normes se fondent sur la Déclaration du Millénaire des Nations Unies, les sociétés modernes se sont donnés pour tâche de concrétiser les valeurs fondamentales de liberté, d'égalité, de sécurité, de tolérance, de solidarité et de paix.

\section{Gregor Husi}

\section{Références}

Grözinger, G., Maschke, M. \& Offe, C. (2006). Die Teilhabegesellschaft: Modell eines neuen Wohlfahrtsstaates. Frankfurt a.M.: Campus.

Heinrich-Böll-Stiftung (Hrsg.) (2015). Inklusion: Wege in die Teilhabegesellschaft. Frankfurt a.M. : Campus.

Husi, G. (2012). Auf dem Weg zur Beteiligungsgesellschaft. In M. Lindenau \& M. Meier Kressig (Hrsg.), Zwischen Sicherheitserwartung und Risikoerfahrung: Vom Umgang mit einem gesellschaftlichen Paradoxon in der Sozialen Arbeit (S. 75-119). Bielefeld : transcript.

\section{Participation des enfants et des jeunes}

La participation des enfants et des jeunes fait référence aux droits d'exprimer librement son opinion et à la liberté d'expression, tels qu'ils sont stipulés dans les articles 12 et 13 de la Convention internationale relative aux droits de l'enfant (CIDE). Ces droits supposent que le point de vue des enfants soit pris en consi- dération dans les décisions qui les concernent. Dans cette perspective, la participation est considérée comme une dimension fondamentale dans la formation des enfants et des jeunes à l'échelle tant individuelle que collective, dans la mesure où elle soutient l'actualisation des droits de l'enfant. Si la dimension politique de la participation des enfants est particulièrement intéressante à aborder, c'est parce qu'elle rend compte de leur capacité d'agir sur l'environnement par des engagements collectifs dans des dispositifs soutenant et incitant à l'expression, à la délibération et à la prise de décision.

La ratification par la Suisse de la Convention Internationale relative aux Droits de l'Enfant en 1997 a obligé l'État à reprendre et réviser son appareil législatif (l'ensemble des lois touchant aux conditions de vie et au bienêtre des mineur.e-s) afin de le rendre compatible avec les articles de la CIDE. Si la Suisse n’a pas encore levé toutes les réserves émises au moment de la ratification, la signature du traité a cependant permis et soutenu la mise en œuvre d'une politique de l'enfance et de la jeunesse à l'échelle du pays axée sur la protection, l'encouragement et la participation.

La Suisse distingue, relativement à l'enfance et la jeunesse, une politique large et transversale, d'une politique ciblée sur l'enfance et la jeunesse au sens strict. La première n'est pas spécifique aux enfants et touche aux conditions de vie de la population en général et des mineur.e.s en particulier alors que la seconde est orientée sur des lois, des programmes et des mesures directement ciblées sur les enfants et les jeunes, telle que la loi sur l'encouragement de l'enfance et de la jeunesse (LEEJ). Sachant que la mise en œuvre des politiques ainsi que l'application des lois y relatives dépendent des cantons et des communes, le paysage suisse en matière de lois et de mesures spécifiquement adressées aux enfants et aux jeunes est très diversifié. Cependant, tous les cantons se préoccupent de la protection des mineur·e·s 
et tendent à accroître les mesures d'encouragement et de participation des enfants et des jeunes à la vie sociale en général.

Ce contexte politique de soutien et d'encouragement à la participation a favorisé l'émergence d'initiatives locales, qu'elles relèvent de dispositifs institutionnalisés (conseils d'enfants ou de jeunes, soutien à la mise en œuvre de projets individuels, entre autres) ou de projets ponctuels rattachés aux associations actives dans le domaine des activités extrascolaires (associations de quartier, centres d'animation, centres aérés, clubs, etc.).

Ainsi le principe de subsidiarité, tel qu'il se donne à voir en Suisse, promeut le développement de dispositifs adaptés aux « cultures institutionnelles » locales. Cette spécificité du fonctionnement des organisations favorise la mise en œuvre de solutions à l'échelle communale et cantonale dont la teneur dépend des associations, des administrations publiques, ainsi que de l'orientation politique des gouvernements. Notons, à ce propos, que les conseils d'enfants et/ou de jeunes constituent l'instrument privilégié par les villes en matière de promotion de la participation décisionnelle et/ou consultative des jeunes habitant·e.s. Cette apparente homogénéité dans le choix de l'instrument laisse pourtant entrevoir une grande diversité dans la mise en œuvre concrète des dispositifs. Ainsi, en ce qui concerne les enfants plus particulièrement, Berne et Bâle ont opté pour des «bureaux» centralisés - un dans chacune des deux villes -, alors que Lausanne et Genève ont privilégié une approche décentralisée en liant les «conseils» aux quartiers.

Néanmoins et malgré la diversité des projets locaux et des objectifs qu'ils poursuivent, l'analyse des dispositifs institutionnalisés met en évidence des points communs. Tous sont dégagés d'une appartenance politique et sont par définition non partisans. De plus, ils sont non représentatifs au sens où les enfants et les jeunes qui s'y engagent ne sont pas élus démocratiquement. De ce fait, les enfants et les jeunes - les durées d'engagement peuvent être très variables - ne sont pas porteurs d'une délégation politique et ne défendent pas forcément les intérêts de l'ensemble de la population enfantine ou juvénile d'une ville ou d'un quartier. Ce détachement des espaces participatifs adressés aux enfants et aux jeunes par rapport aux institutions politiques locales leur permet de bénéficier d'une relative indépendance, notamment du point de vue des projets qui y sont réalisés, mais nuit parfois à leur visibilité.

Se pose donc la question de la place occupée par ces dispositifs encourageant la participation dans le tissu associatif et politique local et, par conséquent également, de la reconnaissance des enfants et des jeunes en qualité d'interlocuteurs valables. Un premier constat réside dans l'ambiguïté du positionnement institutionnel de ces dispositifs. Adressés à une classe d'âge - les enfants ou les jeunes les projets rattachés au secteur associatif et les conseils sont tout à la fois un soutien à la prise de parole de celles et ceux qui sont généralement absent·e.s ou exclu·e.s des débats publics, et une limitation des prérogatives des participant.e.s à des objets strictement liés à leurs spécificités d'enfants ou de jeunes. Le risque d'essentialisation de l'enfance ou de la jeunesse comme catégorie homogène, «qui va de soi », est grand, tout comme celui de ne pas les considérer comme des pairs au sens de Fraser. Selon la philosophe, être pair, suivant le principe de parité, signifie que les individus sont reconnus, à égalité, dans leur diversité et dans leur complexité. Dans ce sens, elles et ils ne sont pas les représentant·e·s d'une seule catégorie sociale. Le deuxième constat, découlant du premier, est que la reconnaissance des enfants et des jeunes dans leur diversité soulève la question de la redistribution des ressources et des capacités à s'exprimer, d'autant plus si l'on tient compte des inégalités sociales et de genre qui traversent les publics juvéniles 
constituant ou appelés à faire partie des dispositifs participatifs.

\section{Dominique Malatesta \& Dominique Golay}

\section{Références}

Fraser, N. (2005). Qu'est-ce que la justice sociale? Reconnaissance et redistribution. Paris : La Découverte.

Golay, D. \& Malatesta, D. (2014). From formal rights to living rights : potentialities and limits of children's councils in terms of children's recognition as social actors. Global Studies of Childhood, 4(2), 89-100.

Office fédéral des assurances sociales (Éd.) (2014). État actuel de la politique de l'enfance et de la jeunesse en Suisse. Berne: Office fédéral des assurances sociales.

\section{Pauvreté*}

Il existe plusieurs définitions de la pauvreté. La définition de la pauvreté et la méthode utilisée pour la mesurer déterminent le seuil de pauvreté et l'ampleur de celle-ci. La pauvreté est définie de manière absolue (besoin minimum) et relative (en comparaison sociale). La pauvreté absolue se rapporte au panier-type d'un pays donné couvrant le minimum vital; l'élargissement de la définition absolue au minimum vital social inclut des aspects de la participation sociale. La pauvreté relative dépend de facteurs temporels et contextuels. Elle est définie par un pourcentage de la médiane nationale du revenu disponible équivalent et fait donc référence à la situation économique des autres membres de la société. Elle permet d'établir des comparaisons internationales indépendamment du niveau de vie dans chaque société. Outre ces définitions unidimensionnelles, il existe également des définitions multidimensionnelles. Ces définitions mesurent la pauvreté à l'aune des privations et du manque de ressources dans des sphères importantes de la vie, sur une certaine durée et à une période historique donnée, selon des critères qui sont spécifiques à chaque société. Si la pauvreté est souvent réduite à la dimension du revenu, il est généralement admis qu'elle dépend de multiples facteurs. D'un point de vue scientifique, la pauvreté est une construction sociale qui s'inscrit dans des rapports de pouvoir et d'inégalité et qui est connotée normativement. La pauvreté intergénérationnelle, souvent mise en relation avec le concept biologique controversé d'hérédité, renvoie à l'inégalité des perspectives biographiques due à la pauvreté de la famille d'origine, conjuguée à l'imperméabilité de positions socioéconomiques et au manque de mobilité sociale. La pauvreté est associée à des concepts tels que le besoin, la précarité, le niveau de vie, la participation, l'inégalité, la sécurité, l'exclusion et la dignité humaine.

La Suisse ne connaît pas de définition officielle de la pauvreté ni de législation en la matière. Dans le temps, communes et cantons étaient responsables de l'aide aux personnes nécessiteuses conformément au principe de la subsidiarité. Aujourd'hui, la compétence en incombe aux cantons. Une loi fédérale règle la compétence en matière d'assistance aux personnes dans le besoin depuis 1977 (LAS). L'aide sociale, le dernier filet de sécurité et subsidiaire à tous les revenus de transfert des assurances sociales, n'est pas réglée au niveau constitutionnel. Pour le calcul des prestations d'aide, on distingue entre individus pauvres et ménages pauvres.

$\mathrm{Au}$ début du XX siècle, l'assistance aux pauvres «méritants» était régie par des lois cantonales d'aide, alors que le traitement de pauvres «indignes» ou «tombés dans la pauvreté par leur propre faute» relevait de la police des pauvres. Dans les années 1950 et 1960, l'aide matérielle aux pauvres fut complétée par des prestations de conseil et de prise en charge. Depuis les années 1990, cette aide est subordonnée aux efforts d'intégration sociale et professionnelle («activation») des allocataires. 
Le développement historique de l'aide sociale se reflète aujourd'hui encore dans sa structure fédéraliste. L'aide aux personnes touchées par la pauvreté est fournie par l'État et le marché, mais aussi par le troisième secteur et de manière informelle par les familles et les ménages respectivement. Dans les années 1990, par exemple, des sociétés d'utilité publique, des églises et des œuvres caritatives étaient présentes dans $60 \%$ de toutes les communes et contribuaient, par une aide essentiellement financière, à hauteur d'un tiers de la charge de l'aide sociale publique.

Aujourd'hui, la Conférence suisse des institutions d'action sociale (CSIAS), en tant que faîtière nationale spécialisée dans le domaine, assume une fonction centrale dans le calcul et la coordination de l'aide sociale dans les cantons et les communes. Les bases légales sont les articles constitutionnels 7 («Dignité humaine») et 12 («Droit d'obtenir de l'aide dans des situations de détresse»). Toutefois, les recommandations de la CSIAS ne sont exécutoires que si les cantons les inscrivent dans leur législation. La Conférence des directrices et directeurs cantonaux des affaires sociales (CDAS) plaide pour des normes CSIAS harmonisées et à caractère plus contraignant, et contre une loi-cadre sur l'aide sociale.

En Suisse, la pauvreté est définie comme une insuffisance de ressources matérielles, culturelles et/ou sociales dans des domaines essentiels comme la santé, l'alimentation, le logement le travail, la sécurité sociale et les contacts sociaux. Selon la valeur seuil du minimum vital social utilisé par la CSIAS, 5,9\% à 9,3\% de la population résidante suisse était pauvre entre 2007 et 2014 . Les taux relatifs de pauvreté comparables au niveau international (60\% de la médiane du revenu équivalent disponible) étaient de $13,3 \%$ à $15,5 \%$ pour la même période.

En comparaison internationale, la Suisse a un faible taux de pauvreté. Ce taux évolue tendanciellement de manière inversement pro- portionnelle au développement économique et suit le taux de chômage avec un retard temporel. Indépendamment des conjonctures, un socle relativement persistant de pauvres s'est mis en place depuis les années 1990. Il s'agit en premier lieu de jeunes adultes, de mères élevant seules leurs enfants, de personnes retraitées d'un certain âge (surtout des femmes), de personnes à bas niveau de formation et de personnes de nationalité étrangère.

Les mesures politiques de réduction de la pauvreté se distinguent entre celles qui visent à l'égalité des chances par rapport à l'accès à des biens sociaux prisés, et celles qui visent à la redistribution de ces biens afin de réduire les inégalités. La politique de la Suisse comprend les deux types de mesures, mais avec un accent sur les premières. Un système d'éducation public de qualité, une formation professionnelle différenciée, un système de santé accessible à tous et un système de sécurité sociale nuancé favorisent la perméabilité des positions socioéconomiques et la mobilité sociale et réduisent les risques sociaux de tomber dans la pauvreté. Toutefois, comme il ressort de la situation des personnes à l'âge de la retraite, la réduction de la pauvreté ne va pas forcément de pair avec une plus grande égalité des revenus.

Différentes réformes dans le système de la sécurité sociale (p.ex. de l'assurance-invalidité, de l'assurance-chômage, de l'aide sociale) ainsi que les débats sur la légitimité des recommandations de la CSIAS concernant le seuil de la pauvreté absolue montrent que les mesures structurelles prises à ce jour pour réduire la pauvreté, bien que probantes, sont remises en question. L'attention se concentre actuellement sur des mesures individualisées.

Dans le sillage de la polarisation politique accrue et du diktat de finances publiques durables et de budgets serrés, la politique en matière de pauvreté reprend, depuis les années 1990, certains traits «disciplinaires», avec la distinction entre pauvres «méritants» 
et pauvres «non méritants» et une focalisation sur les abus. En atteste l'approche welfare to workfare: les personnes touchées doivent faire des efforts pour trouver un travail ou s'intégrer, à défaut de quoi leurs prestations sont réduites. Par ailleurs, l'égalité de traitement de personnes avec différents statuts de séjour ou présentant certaines caractéristiques sociodémographiques (jeune adultes, familles nombreuses) a du plomb dans l'aile en Suisse. La politique suisse en matière de pauvreté demeure fragmentée, même dans le cadre du «Programme national contre la pauvreté» (2014-2019) de l’Office fédéral des assurances sociales (OFAS).

Il convient de développer surtout les mesures de prévention et de réduction de la pauvreté susceptibles d'améliorer les perspectives socioéconomiques et la mobilité sociale. Mentionnons en particulier les défis suivants : l'évolution démographique; le développement de structures d'accueil de qualité pour les enfants et les personnes (âgées) nécessitant un encadrement; les "grandes solidarités » en rapport avec l'égalité et la dignité de tous les êtres humains; les conditions de travail et les possibilités alternatives d'assurer une existence digne; la qualité de systèmes sociaux universels de prévention de la pauvreté, ainsi que des visions pour la Suisse en tant que membre d'une communauté mondiale sans pauvreté.

\section{Monica Budowski}

\section{Références}

Epple, R. \& Schär, E. (2010). Stifter, Städte, Staat: Zur Geschichte der Armut und Unterstützung in der Schweiz. Zürich : Seismo.

Gordon, D. (2006). The concept and measurement of poverty. In C. Pantazis, D. Gordon \& R. Levitas (Eds.), Poverty and social exclusion in Britain : the millennium survey (pp. 29-69). Bristol: Policy Press.

Schuwey, C. \& Knöpfel, C. (2014). Neues Handbuch Armut in der Schweiz (völlig neu bearb. Aufl.). Luzern: Caritas-Verlag.

\section{Pauvreté et population âgée}

Dans les sociétés occidentales, l'allongement de la durée de vie durant le $\mathrm{XX}^{\mathrm{e}}$ siècle a conduit à une rapide progression de la population atteignant les âges de la vieillesse. Ces âges sont caractérisés entre autres par une fragilité accrue et une baisse des capacités fonctionnelles. Les transitions démographiques des deux siècles écoulés ont aussi conduit à une diminution de la natalité qui, conjointement à la mobilité spatiale, à la divortialité, et à l'individualisme croissant, a fragilisé les solidarités familiales. Ainsi, de plus en plus d'aîné·e·s, principalement des femmes, finissent leur vie dans un ménage individuel. La part des personnes restant définitivement sans enfant augmente régulièrement et la présence de proches à proximité immédiate du ménage âgé, susceptibles de fournir de l'aide pratique ou financière, est de moins en moins fréquente.

Ces évolutions ont précarisé la situation économique de la population âgée au cours de la première moitié du $\mathrm{XX}^{\mathrm{e}}$ siècle, ceci d'autant plus que les transformations du marché $\mathrm{du}$ travail ont rendu difficile l'exercice d'une activité rémunérée en période de post-retraite. Par ailleurs, les inégalités salariales croissantes se répercutent sur la situation économique au moment de la retraite et conduisent à la formation de groupes précarisés qui côtoient d'autres groupes privilégiés.

En Europe, la mise en place de systèmes de retraite a tenté de répondre à ces tendances et représente un substitut à la solidarité intergénérationnelle et intrafamiliale. En Suisse, le $1^{\text {er }}$ pilier a été instauré en 1948, mais les prestations complémentaires n'ont été introduites qu'en 1966, alors que la loi fédérale sur la prévoyance professionnelle rendant obligatoire le $2^{\mathrm{e}}$ pilier date de 1985 . Ainsi, les personnes nées avant la Seconde Guerre mondiale ont souvent une prévoyance vieillesse partielle. Parallèlement, alors que la population active bénéficiait directement de la prospérité économique 
d'après-guerre pour accroître ses revenus, les retraité·e·s ont observé une très lente adaptation de leur pouvoir d'achat, Pour ces raisons, jusqu'à la fin du XX $\mathrm{XX}^{\mathrm{e}}$ siècle, on a jugé la situation économique des personnes âgées comme précaire, comparativement aux actifs. Des données empiriques plus récentes nuancent cependant l'hypothèse d'une précarité accrue des retraité-e-s comparativement aux actifs et actives.

Des difficultés entachent la mesure de la pauvreté, qui est définie par l'Office fédéral de la statistique (OFS) comme une insuffisance de ressources (matérielles, culturelles et sociales) telle que les personnes sont exclues du niveau de vie minimal reconnu comme acceptable dans le pays où elles vivent. Deux approches sont généralement utilisées pour identifier les ménages pauvres. La première vise à comparer le revenu déclaré par les ménages au moment d'enquêtes par rapport à un seuil. Celui-ci peut être défini de manière absolue: les normes de la Conférence suisse des institutions d'action sociale (CSIAS) servent alors généralement de seuil de référence (2 200 francs par mois pour un adulte, 3050 francs pour deux adultes sans enfant en 2012), mais il peut aussi être défini de manière relative. La seconde approche repose sur le taux de privation matérielle, qui fait référence à l'incapacité auto-déclarée lors d'enquêtes de faire face à différents types de dépenses (alimentation, santé, chauffage, loisirs, etc.).

Selon le critère du taux pauvreté absolue, les personnes âgées de 65 ans et plus présentent en 2012 un taux de pauvreté de 16,4\%, contre $7,7 \%$ pour l'ensemble de la population. Selon celui du risque de pauvreté relatif (50\% de la médiane), le taux est de $12,8 \%$ pour les retraité.e-s contre $7,2 \%$ pour l'ensemble de la population. Le taux de privation matériel est par contre inférieur pour les retraité-e·s $(2,1 \%)$ comparativement à la population totale $(3,6 \%)$. Ainsi, même si la proportion des retraité.e.s présentant un revenu faible est plus élevée que la moyenne, cette situation ne produit pas une privation matérielle.

Parmi les facteurs expliquant le paradoxe entre une pauvreté mesurée en des termes financiers relativement importante et une pauvreté subjective plutôt faible figurent les sources de revenus prises en compte dans le calcul. Alors que les personnes actives tirent essentiellement profit de l'activité professionnelle pour constituer leur revenu total, les retraité·e·s présentent des ressources financières plus diverses provenant de la prévoyance vieillesse, de la prévoyance professionnelle, dans quelques cas de l'exercice d'une activité rémunérée en post-retraite, mais aussi de l'épargne. Une étude de Wanner et Gabadinho reposant sur des données fiscales a ainsi montré qu'un couple retraité moyen présente un revenu issu pour $10 \%$ de l'activité professionnelle en post-retraite, $40 \%$ des rentes du $1^{\text {er }}$ pilier, $20 \%$ des rentes du second pilier, $30 \%$ des revenus de la fortune, le solde étant constitué d'autres sources. Or le revenu de la fortune et l'utilisation de l'épargne (parmi laquelle figurent les éventuelles prestations du $2^{\mathrm{e}}$ pilier en capital) ne sont pas prises en compte dans les enquêtes. En y intégrant ces deux éléments, la situation financière des retraité·e.s est alors en moyenne meilleure que celle des actives et actifs, en particulier des jeunes.

Le système suisse de retraite favorise la redistribution de la fortune des personnes riches vers les revenus moyens et diminue la dispersion du revenu: en effet, la rente du $1^{\text {er }}$ pilier est la même quel que soit le revenu professionnel et le $2^{\mathrm{e}}$ pilier est plafonné $(84600$ francs annuels). Par contre, les caractéristiques du système de prévoyance sociale conduisent à la précarisation des personnes ayant eu un parcours professionnel accidenté ou n'ayant pas exercé d'activité durant l'ensemble de leur vie (la rente AVS étant calculé en tenant compte du nombre d'années de cotisation). Les interruptions de carrière professionnelle en raison du chômage, d'invalidité, des tâches éducation- 
nelles précarisent la constitution du $2^{\mathrm{e}}$ pilier, alors qu'un revenu inférieur à la déduction de coordination (21150 francs) ne rend pas obligatoire la cotisation. En outre, les populations migrantes arrivées tardivement sur le marché du travail suisse et n'ayant pas cotisé durant l'ensemble de leur vie courent un risque évident de pauvreté, surtout s'ils sont originaires de pays à faible couverture sociale. Ces éléments sont susceptibles de conduire à une très grande diversité de situations financières au sein de la population retraitée, caractérisée par une hétérogénéité croissante. Notons que si le système du $1^{\text {er }}$ pilier prévoit d'assurer le minimum vital à chaque personne, en particulier grâce aux prestations complémentaires, celles-ci ne sont pas toujours utilisées, le non-recours étant fréquent.

En définitive, le système suisse de retraite joue son rôle et protège les retraité-e.s d'un niveau de précarité aigue. Cependant, les revenus des retraité.e-s dépendent étroitement du vécu professionnel. Les retraité·e-s actuels âgés de moins de 80 ans ont été actifs durant les Trente Glorieuses, ont eu des comportements de consommation et d'épargne considérés comme sages et ont bénéficié de la prévoyance professionnelle. Leur situation est favorable par rapport à leurs aîné·e·s. Les retraité·e·s futurs, qui ont vécu dans un contexte économique plus discriminant, se sont parfois endettés et présentent un profil professionnel et de vie plus accidenté, courent pour leur part un risque accru de précarité au moment de leur retraite. Les migrant·e-s arrivés en deuxième moitié de vie active en Suisse et les personnes s'étant retirées du marché du travail pour plusieurs années, quelle qu'en soit la raison, présentent également un risque de précarité important en fin de vie.

\section{Références}

Guggisberg, M. \& Häni, S. (2014). La pauvreté des personnes âgées. Neuchâtel: Office fédéral de la statistique.

Leu, R. E., Burri, S. \& Priester, T. (1997). Lebensqualität und Armut in der Schweiz. Bern: Haupt.

Wanner, P. \& Gabadinho, A. (2008). La situation économique des actifs et des retraités. Berne: Office fédéral des assurances sociales.

\section{Pauvreté invisible}

Le sociologue Georg Simmel a montré en 1906, dans son ouvrage consacré aux pauvres, que la pauvreté n'existe qu'en fonction de la réaction sociale qu'elle provoque. Selon lui, ne sont pauvres que les personnes qui reçoivent des prestations sociales de l'État. Cela signifie a contrario que les personnes démunies mais sans accès aux droits sociaux, ou qui ne font pas recours aux allocations sociales qui leur sont destinées, ne sont pas socialement considérées comme pauvres. Suivant cette acception, la pauvreté invisible est donc celle qui n'est pas prise en charge par l'État social.

L'histoire du traitement de la pauvreté montre que les dispositifs déployés rendent invisibles certaines situations de pauvreté lorsqu'ils ne prennent pas en compte certaines catégories de personnes. Par exemple, l'ampleur du problème du chômage féminin est sous-estimée à cause du droit de l'assurance-chômage et insolvabilité (LACI). Il faut en effet avoir occupé régulièrement un emploi d'une certaine importance pour recevoir des prestations de cette assurance : sont exclues du droit les personnes qui travaillent de manière irrégulière ou à des pourcentages trop faibles. Les femmes de ménage, les «mamans de jour», les travailleuses sur appel ne sont pas dénombrées comme chômeuses à cause de cette exclusion du droit qui ne concerne pas des professions intermittentes masculines comme le travail du bâtiment. L'invisibilité de l'ampleur 
du chômage féminin est également renforcée par le fait qu'une personne qui cesse son activité professionnelle pour se consacrer durant plus de 4 ans au travail domestique perd ses droits LACI pour ne conserver qu'un droit à l'assistance, sous conditions de ressources. La répartition sexuée des rôles en Suisse implique que ce retrait du marché du travail concerne principalement les femmes: en effet, selon l'Office fédéral de la statistique, 23,3\% des ménages ayant un enfant de moins de 4 ans en 2016 suivent le modèle de l'homme gagne-pain à $100 \%$ et de la femme à plein temps au foyer. La situation inverse est statistiquement insignifiante.

L'ampleur des problèmes que rencontrent les femmes est également sous-estimée dans d'autres domaines que le chômage. Ainsi, les personnes sans emploi, de même que les personnes qui travaillent moins de 8 heures par semaine chez le même employeur.euse sont assurées contre les accidents non-professionnels auprès de l'assurance-maladie (LAMal), et non auprès de l'assurance-accident (LAA). Cette répartition a pour conséquence de rendre invisibles les accidents domestiques qui ne sont pas recensés par la LAMal. De ce fait, ils ne sont pas pensés comme un problème social et peuvent générer de la pauvreté invisible.

Les politiques sociales rendent également invisible l'ampleur des problèmes sociaux que rencontrent les personnes de nationalité étrangère, parce que leur accès aux droits est souvent lié à un permis de séjour ou à une durée de résidence dans le pays. Le statut de saisonnier contenait ainsi des obligations de cotiser à l'assurance-chômage sans ouvrir aucun droit à cette dernière. Jusqu'à l'abolition de ce statut en 2002, les dizaines de milliers de saisonnier-ère-s étaient pour cette raison les grands invisibles de la statistique du chômage helvétique. On peut aussi citer les «fonds en déshérence» de la prévoyance professionnelle, soit des prestations non versées à des personnes de nationalité étrangère, qui avaient fait grand bruit dans les pays limitrophes de la Suisse au milieu des années 1990, alors même que la pauvreté susceptible de résulter de cette absence de versement restait invisible en Suisse. L'exportation des problèmes sociaux des migrant·e·s venu·e.s d'Europe a caractérisé le système social helvétique jusqu'à l'entrée en vigueur des accords bilatéraux avec l'Union européenne.

Aujourd'hui encore, les situations de pauvreté affectant les personnes de nationalité étrangère restent largement invisibles dans les dispositifs sociaux. La cinquième révision de l'assurance-invalidité en 2008 a par exemple porté d'un à trois ans la durée minimale de cotisation requise pour ouvrir un droit, ce qui fait que les immigré·e-s récent.e-s devenu·e-s invalides n'ont pas accès aux prestations de l'AI. De même, les personnes originaires d'un pays extra-européen sont soumises à la condition d'un séjour minimum de 5 à 10 ans (ininterrompu) pour pouvoir obtenir un droit aux prestations complémentaires (PC) à l'AVS/AI. À cause de cette exigence, elles n'apparaissent pas dans la statistique des PC, ce qui fait que leur pauvreté est sous-évaluée.

Trois autres raisons expliquent qu'une partie des situations de pauvreté ne bénéficie pas d'une prise en charge de l'État social et reste invisible socialement.

Dans toute une série de circonstances, les droits sociaux ne sont pas réclamés, comme le montrent les travaux de l'Odenore (Observatoire des non-recours aux droits et services) en France. L'étude d'Oliver Hümbelin publiée en 2016 évalue le taux de non-recours à l'assistance dans le canton de Berne à 26,3\%, tandis que l'Office fédéral de la statistique, dans son rapport social 2015, estime qu'en 2012 plus d'une personne pauvre sur deux ne reçoit pas de prestations d'aide sociale. Toutes ces formes de pauvreté restent invisibles au sens de la définition de Simmel.

La législation sur les étranger-ère-s est une seconde raison de l'invisibilité sociale de cer- 
taines situations de pauvreté. D’abord, parce que recourir durablement à l'assistance pour soi-même ou pour une personne dont on a la charge peut être un motif de renvoi du territoire helvétique. Ensuite, parce que suivant le permis de séjour octroyé, le fait de demander l'aide sociale peut conduire au non-renouvellement de ce dernier, y compris s'il s'agit d'un permis $\mathrm{B}$ CE/AELE, et à la révocation du permis L en cas d'absence d'emploi. Enfin, parce que les personnes qui arriventen Suisse pour y chercher de l'emploi ou pour y passer leur retraite, y compris si elles viennent d'un des pays de l'UE ou de l'AELE, sont exclues du droit à l'aide sociale. Le dilemme posé aux personnes de nationalité étrangère démunies qui vivent en Suisse est: se faire aider financièrement, et courir le risque d'être renvoyé, ou ne pas se faire assister, et vivre de manière indigne. Dans les deux cas, renvoi ou non-recours, leur pauvreté sera invisible sur le territoire national.

Enfin, toute une série de personnes sont exclues de la sécurité sociale ordinaire: ce sont les personnes déboutées de la procédure d'asile, qui n'ont droit qu'à une aide d'urgence très inférieure aux seuils de pauvreté reconnus par la Suisse, et celles qui sont sans papier ou sans autorisation de travail, qui n'ont presque aucun droit social. Nous remarquons la trace de cette pauvreté, par exemple les mendiant·e.s dans les rues, mais du point de vue de la protection sociale cette pauvreté n'existe pas, puisque ces personnes sont exclues du droit à l'assistance. La statistique ne les dénombre pas non plus.

\section{Jean-Pierre Tabin}

\section{Références}

Hümbelin, O. (2016). Nichtbezug von Sozialhilfe : Regionale Unterschiede und die Bedeutung von sozialen Normen. University of Bern Social Sciences Working Papers, 21, online. https://boris. unibe.ch/94881/
Probst, I., Tabin, J.-P. \& Waardenburg, G. (2012). Les atteintes à la santé dues au travail : du visible à l'invisible. In A. Mias \& F. Aballéa (Éd.), Organisation, gestion productive et santé au travail (pp. 293-303). Toulouse: Octarès.

Togni, C. (2015). Le genre du chômage: assurance chômage et division sexuée du travail en Suisse (1924-1982). Lausanne: Antipodes.

\section{Péréquation*}

Le système étatique fédéral de la Suisse vise à garantir l'autonomie politique et financière à tous les niveaux de l'État. À cet égard, il convient de clarifier les compétences et responsabilités pour la mise en œuvre des missions de l'État d'un côté et leur financement de l'autre. La Constitution fédérale attribue les responsabilités selon le principe de subsidiarité, tandis que le financement repose sur le principe économique «L'utilisateur paie et ordonne» (principe d'équivalence). La Constitution lie la responsabilité d'une tâche à la souveraineté financière (principe de connexité). L'autorité locale responsable d'une tâche a donc le droit de percevoir des redevances pour financer sa mise en œuvre : l'objectif d'autonomie est ainsi atteint. Dans une perspective économique, les conditions sont ainsi réunies pour produire efficacement des biens et des services publics et permettre la concurrence fiscale et territoriale entre les collectivités.

Cependant, toutes les collectivités territoriales n'ont pas les mêmes ressources et ne sont pas confrontées aux mêmes défis. Réduire les conséquences financières de ces déséquilibres tout en maintenant l'autonomie et la compétitivité dans le but de préserver l'unité de la Confédération, tel est le contexte politique de la péréquation. En matière de politique sociale, elle contribue à l'harmonisation des performances des collectivités territoriales et à la cohésion sociale. 
La Suisse dispose d'un système de péréquation au niveau Confédération - cantons et de 26 systèmes cantonaux de péréquation. En 2008, la Réforme de la péréquation et de la répartition des tâches entre la Confédération et les cantons (RPT) est entrée en vigueur. Elle a remplacé la péréquation de 1959 en s'imposant contre les alternatives de réforme territoriale et d'harmonisation fiscale matérielle. La RPT, pour sa part, a permis de poursuivre le développement des 26 systèmes intercommunaux de péréquation.

Avec la RPT, une distinction est établie entre une péréquation au sens large et au sens étroit. La première comprend les trois éléments décrits ci-dessous: desenchevêtrement des tâches et du financement, nouvelles formes de coopération et de financement entre la Confédération et les cantons pour des tâches communes, et coopération intercantonale avec partage des charges.

Le desenchevêtrement des tâches et du financement vise à garantir qu'un seul niveau étatique, dans la mesure du possible, soit responsable d'une tâche et de son financement. Cela renforce l'autonomie des collectivités territoriales et réduit les transferts financiers complexes. Avec la RPT, la Confédération s'est vue transférer la compétence exclusive pour sept tâches (p.ex. prestations individuelles de l'AVS et de l'AI) et les cantons pour dix tâches (p.ex. écoles spécialisées, construction et exploitation d'institutions pour personnes en situation de handicap).

Quant aux tâches communes, elles peuvent être réparties entre la Confédération et les cantons (p.ex. les caisses d'assurance-maladie, les prestations complémentaires) ou entre cantons et communes (fédéralisme coopératif). En règle générale, le niveau supérieur de l'État est responsable de la gestion stratégique et de la législation, tandis que le niveau inférieur est responsable de la mise en œuvre. Le financement est partagé et il est orienté autant que possible vers le résultat et l'output (au lieu des coûts et de l'input). C'est ce qui caractérise les nouvelles formes de coopération et de financement entre la Confédération et les cantons, destinées à étendre la marge de manœuvre des cantons et à permettre un pilotage par les résultats.

Le troisième élément - la coopération intercantonale avec partage des charges - est la réponse aux défis qui transcendent les frontières cantonales. Afin de centraliser les tâches de la Confédération et éviter tout resquillage, les cantons concluent entre eux des conventions, incluant des dispositions de financement. En outre, à la demande des cantons, la Confédération peut déclarer des accords intercantonaux contraignants pour tous les cantons dans neuf domaines (dont l'exécution des peines et des mesures, les institutions pour l'intégration et la prise en charge des personnes invalides).

Les trois éléments de la péréquation au sens large ont été partiellement intégrés dans le développement continu des systèmes de péréquation intercommunaux. Le concept, expliqué ci-après, de la péréquation au sens étroit, avec répartition des ressources et des charges, sera bientôt intégré dans l'ensemble des législations cantonales.

Selon la Constitution, la péréquation au sens étroit du terme vise à ce que, en dépit des disparités, les collectivités territoriales «disposent des moyens financiers nécessaires pour accomplir leurs tâches». La péréquation est limitée aux recettes et aux dépenses qui échappent à l'influence des collectivités territoriales. Afin d'éviter les incitations négatives et les conflits d'intérêts, le transfert financier n'est pas lié à des tâches spécifiques - il n'est pas affecté dans le but de préserver la concurrence fiscale et l'autonomie. La prise en compte séparée des recettes (ressources) et des dépenses (charges) favorise la transparence des flux financiers. Lors du passage d'anciennes à de nouvelles dispositions de péréquation, il est également possible de prévoir une compensation des cas de rigueur pour l'atténuation de certaines 
charges particulières. Au total, les versements dans le cadre de la RPT se sont élevés à 4,1 milliards francs en 2008 et à plus de 5 milliards en 2018. En moyenne, $78 \%$ de ces montants ont été affectés à la compensation des ressources, $15 \%$ à celle des charges (par moitié au niveau géo-topographique et sociodémographique) et $7 \%$ à celle des cas de rigueur.

La compensation des ressources vise à harmoniser la capacité contributive. Elle repose sur la valeur fiscale potentielle d'une collectivité territoriale («rendement fiscal harmonisé», "potentiel de ressources») et non sur les recettes fiscales effectives. Au travers de la notion de capacité contributive, indexée conformément aux prescriptions juridiques, les collectivités territoriales peuvent être classées selon leur fort ou faible potentiel de ressources. Quant à l'intensité de la compensation, elle dépend, entre autres, des décisions politiques sur les moyens mis en œuvre.

Les systèmes de péréquation distinguent, en Suisse, entre divers types de charges: des charges géo-topographiques (p.ex. emplacement escarpé, densité de la population), des charges sociodémographiques (p.ex. taux d'enfants et de jeunes, de personnes âgées, de personnes pauvres), des charges de centre (p.ex. offres culturelles et sportives) et des charges extraordinaires (p.ex. catastrophes naturelles). Il existe de nombreuses modalités de déterminer ce qui relève d'une charge et de déterminer son poids; ces modalités dépendent des situations des collectivités territoriales. Ainsi, certains cantons pratiquent une franchise pour la compensation sociodémographique des charges dans l'idée d'une mesure d'incitation à la prise de conscience des coûts, bien que le bénéficiaire, par définition, ne puisse guère influencer ce type de charges. L'exemple illustre l'influence de considérations de politique sociale sur la péréquation motivée, quant à elle, par une logique de politique et de cohésion étatiques. D’une manière générale, la conception de la répartition sociodémogra- phique des charges s'avère délicate en raison de la complexité du système de sécurité sociale, de la traçabilité des interdépendances et de la mesurabilité des charges.

Les fonds de péréquation proviennent soit de la collectivité territoriale supérieure (compensation verticale) soit des collectivités territoriales de même niveau (compensation horizontale). Dans le cas des systèmes suisses de péréquation, la première modalité s'applique plus généralement à la répartition des charges tandis que la seconde se pratique pour la répartition des ressources. La recherche souligne les avantages de la compensation horizontale: les donneurs constituent un contrepoids aux receveurs car ils ne sont pas intéressés à étendre les critères d'éligibilité de réception. Le transfert financier horizontal renforce l'autonomie du niveau étatique inférieur et permet de réduire les différences difficilement influençables, ceci de manière plus efficacement que le transfert vertical. Ce constat se trouve confirmé empiriquement par les rapports d'évaluation de l'efficacité de la Confédération et de plus en plus de cantons, visant à évaluer la capacité de contrôle de leurs systèmes de péréquation.

Les évolutions de ces dernières années sont les suivantes: les dispositions légales sur la péréquation sont régulièrement débattues et révisées. Cela montre clairement que les systèmes de péréquation font partie et sont le résultat de processus de négociations politiques. La diversité des systèmes suisses de péréquation offre des suggestions et des incitations pour leur développement ultérieur.

\section{Daniela Tschudi}

\section{Références}

Mischler, P. \& Moser, W. (2011). Neugestaltung des Finanzausgleichs und der Aufgabenteilung zwischen und Kantonen (NFA). In A. Lienhard (Hrsg.), Finanzrecht (S. 259-341). Basel : Helbing Lichtenhahn. 
Rühli, L. (2013). Irrgarten Finanzausgleich: Wege zu mehr Effizienz in der interkommunalen Solidarität. Zürich: Avenir Suisse.

Tschudi, D. (2015). Ausgleich oder Wettbewerb? Die Sozialhilfe im interkommunalen Soziallastenausgleich: Ein systematisierter Überblick über die interkommunalen Soziallastenausgleichssysteme in der Schweiz und Überlegungen zum Kanton Zürich (Masterarbeit Executive Master of Public Administration MPA). Bern : Universität Bern.

\section{Placement à des fins d'assistance (PLAFA)*}

«Une personne peut être placée dans une institution appropriée lorsque, en raison de troubles psychiques, d'une déficience mentale ou d'un grave état d'abandon, l'assistance ou le traitement nécessaires ne peuvent lui être fournis d'une autre manière ». C'est ainsi que le Code civil suisse définit depuis le $1^{\text {er }}$ janvier 2013 la notion de placement à des fins d'assistance ou PLAFA. Il prévoit qu'un médecin désigné par les autorités cantonales, mais aussi les autorités de protection de l'adulte et de l'enfant (APEA), peuvent, si les conditions requises sont réunies, ordonner un placement à des fins d'assistance de personnes physiques sans leur consentement ou contre leur gré (des dispositions en partie divergentes s'appliquent aux personnes mineures). Le placement prend fin au plus tard six semaines après avoir été prononcé par un médecin, à moins que l'APEA ne décide de prolonger le PLAFA. Un placement peut être décidé par l'APEA pour une durée illimitée, il doit toutefois être régulièrement contrôlé.

Les conditions nécessaires à un placement sont un état de faiblesse (déficience mentale, troubles psychiques ou état grave d'abandon), une nécessité de traitement médical ou de prise en charge (besoin de protection), ainsi que la disponibilité d'un établissement adéquat. De plus, le PLAFA doit respecter la règle de pro- portionnalité, à savoir être vraiment indispensable: lorsque des mesures moins radicales, c'est-à-dire ambulatoires, ont échoué ou ne peuvent pas être envisagées. En cas de décision de placement, il est possible de prendre en compte la charge pour les proches et pour des tiers tels que des voisins ou voisines ou des professionnel-le-s, notamment d'un organisme de soins à domicile, ainsi que leur protection. Une simple «mise en danger d'autrui» ne suffit toutefois pas pour un PLAFA: les personnes affectées doivent souffrir d'un état de faiblesse ou avoir elles-mêmes besoin de protection. En cas de PLAFA prononcé par un médecin, c'est l'institution qui décide de la sortie de la personne concernée. En cas de placement prononcé par l'APEA, c'est à celle-ci que revient le pouvoir de décision d'une sortie, à moins qu'elle ne le délègue à l'institution. Un PLAFA est assorti d'une protection juridique étendue. Cela signifie que les personnes affectées peuvent contester au tribunal une décision de placement, une prolongation du placement ainsi que des mesures médicales ou limitant leur liberté de mouvement prises pendant leur placement.

Le placement à des fins d'assistance est un sujet sensible et polémique, tant sur le plan historique qu'éthique et juridique. Sur le plan historique car il n'existait pas de base juridique unique au niveau fédéral régissant l'hospitalisation forcée avant l'introduction en 1981 dans le Code civil suisse des anciennes dispositions légales relatives à la "privation de liberté à des fins d'assistance». Par conséquent, il n'est pas rare de voir, aujourd'hui encore, des personnes «internées administrativement» suite à des décisions arbitraires des autorités. Sur le plan éthique, car un PLAFA viole la liberté de la personne concernée et son droit à l'autodétermination. Ceci pose la question de l'attitude qu'une société devrait adopter vis-à-vis des personnes déviant d'une certaine norme. Sur le plan juridique, enfin, car des notions telles que l'«adéquation» ne sont pas précisément défi- 
nies et laissent de ce fait une certaine marge d'appréciation. Même si les personnes et autorités chargées d'appliquer le droit se basent sur la loi, la jurisprudence, la doctrine et la pratique juridique, on ne peut pas exclure que des valeurs et des appréciations personnelles interviennent dans l'utilisation de notions juridiques, ce qui peut jouer un rôle lors de décisions ayant des conséquences considérables pour les individus concernés.

On ne dispose pas en Suisse de données fiables sur le taux de placements, ce qui rend toute comparaison au niveau européen peu probante. Il n'existe pas non plus de système de monitoring, appliqué à l'ensemble de la Suisse. Les pratiques de placement appliquées dans les différents cantons peuvent être très différentes. Par exemple, le fait qu'un canton autorise tous les médecins agréés du territoire cantonal ou uniquement des médecins spécialisés à décider d'un placement a une influence sur la pratique. Un médecin ayant peu ou pas d'expérience avec des personnes atteintes de troubles psychiques aura éventuellement plus tendance à prescrire un placement en institution. Les structures de prise en charge ont aussi toute leur importance: les spécialistes s'accordent aujourd'hui à dire que les taux de placement pourraient diminuer s'il existait davantage de structures ambulatoires, telles des équipes d'intervention de crise, susceptibles de prendre plus tôt en charge les personnes concernées. Les systèmes de financement nécessaires à la mise sur pied de telles structures font toutefois souvent défaut. Des mesures ambulatoires relevant des APEA, telles que des visites médicales régulières imposées, peuvent néanmoins prévenir des crises. Ces dispositions ne peuvent cependant pas être mises en place sans l'accord de l'intéressé.

La révision du droit à la protection de l'adulte a donné lieu pour le placement à des fins d'assistance à des adaptations terminologiques ainsi qu'à de nouvelles dispositions au sujet de la compétence de placement des médecins, du droit du patient à recourir à une personne de confiance et des conditions régissant le traitement médical forcé. La pratique juridique, la jurisprudence et le législateur devront encore régler divers points juridiques dans le cadre d'une révision. Est-il ainsi justifié, dans le cadre d'un placement à des fins d'assistance, de "se contenter de tenir compte» de l'avis du patient quant aux traitements de troubles psychiques et, ce faisant, de négliger le droit de représentation légale dans les situations médicales, alors que ces éléments jouent un rôle clé sur le plan somatique? Distinguer le psychisme et la somatisation est-elle encore une approche pertinente à notre époque? Quelles appréciations sont susceptibles d'en découler et quelles en sont les conséquences pour les personnes concernées? Comment cette philosophie interagit-elle sur les deux régimes juridiques différents $\mathrm{du}$ «traitement sans consentement» et des «mesures limitant la liberté de mouvement»? Dans les établissements psychiatriques, la médication forcée et des mesures limitant la liberté de mouvement sont souvent combinées, ce qui pose la question de la praticabilité des réglementations existantes. Les aspects juridiques ne sont pas clairs non plus quand une personne est par exemple forcée de prendre des médicaments pour traiter ses troubles psychiques tout en étant alimentée de force, ce qui signifie qu'elle subit à la fois un traitement psychique et un traitement somatique. Dans ce cas, qui dispose de quelles compétences et de quels droits? Il reste des zones d'ombres en dehors des cliniques psychiatriques aussi. Ainsi, si une personne incapable de discernement doit être admise dans un établissement de soins ou un home, faut-il recourir à un PLAFA quand son consentement à cet égard n'est pas clair? Que faut-il faire lorsque cette personne refuse de prendre des médicaments lors de son séjour dans l'institution? Un PLAFA doit-il être envisagé dans ce cas? 
Même si de nombreux points finissent par être éclaircis, le placement à des fins d'assistance reste un point de tension sur le plan des politiques sociales et sociétales. Il est le reflet de la manière dont une société traite les personnes qui, pour quelque raison que ce soit, sont différentes de la majorité et ont besoin d'une protection spécifique.

\section{Simone Münger}

\section{Références}

Geiser, T. \& Etzensberger, M. (2012). Kommentar zu Art. 426-439 ZGB. In T. Geiser \& R. Reusser (Hrsg.), Basler Kommentar Erwachsenenschutz, Art. 360-456 ZGB, Art. 14, 14a SchlT ZGB (S. 444-530). Basel: Helbing Lichtenhahn.

Rosch, D. (2014). Medizinische Massnahmen im Rahmen einer fürsorgerischen Unterbringung: Schnitt und Nahtstellen. AJP / PJA Aktuelle Juristische Praxis / Pratique Juridique Actuelle, 1, 3-10. Vaerini, M. (2015). Guide pratique du droit de la protection de l'adulte et de l'enfant. Berne: Stämpfli.

\section{Planification sociale*}

Par planification sociale, on entend le processus qui consiste à planifier, à concevoir et à piloter l'infrastructure sociale dans son ensemble. Elle ne doit pas être confondue avec le «plan social», qui désigne le dispositif mis en place en cas de changements prévus dans une entreprise (réduction de postes). La planification sociale englobe tout l'inventaire social avec sa multiplicité d'institutions et d'offres de protection sociale, qu'elles soient publiques ou privées. Elle se fait pour l'essentiel dans les administrations communales et cantonales. En effet, comme l'exécution des lois (sociales) relève de leur compétence, les administrations portent une responsabilité particulière dans la réalisation des objectifs de l'État social. De nombreuses institutions non étatiques - fondations, œuvres caritatives, entreprises, organisations d'entraide, etc. - font elles aussi de la planification sociale. La planification sociale s'effectue dans différents domaines politiques où elle est aménagée en fonction de la zone de planification (p.ex. quartier, commune, canton), de la thématique (p.ex. pauvreté, santé) et du groupe cible (p.ex. enfants, familles, personnes âgées). En tant que «moteur» de la planification et du développement de l'infrastructure sociale, la politique sociale joue un rôle déterminant à l'égard d'autres politiques (p.ex. de la formation, de la famille, de la migration). Les débuts de la planification sociale sont associés, d'une part, à l'instauration d'un système de protection sociale en Europe, à la fin du XIX ${ }^{\mathrm{e}}$ siècle, et d'autre part à l'émergence du travail social communautaire. Ces deux contextes ont mis en lumière les finalités à donner aux prestations sociales et mesures émergeantes pour permettre une gestion prévoyante, clairvoyante et ciblée des conditions de vie et des risques sociaux comme la maladie, l'accident, l'invalidité et l'âge.

Le concept même de «planification sociale» ne s'est pas établi en Suisse de la même manière qu'en Allemagne, ou encore au Danemark, en Suède, en Grande Bretagne et en Amérique du Nord. Malgré ce manque de visibilité, les acteur-trice-s public-que-s et privéee-s de la sécurité sociale de notre pays procèdent eux aussi de manière planifiée. En attestent des «rapports sociaux» qui sont de plus en plus souvent utilisés pour la planification sociale au niveau cantonal. Dans le canton de Soleure, par exemple, le Conseil d'État a l'obligation légale d'informer régulièrement le Grand Conseil dans un rapport social «si et dans quelle mesure les objectifs, les résultats et les effets ont été atteints et quels points de la planification sociale doivent être adaptés, le cas échéant » (§ 20, al. 5, SG).

Dans son acception scientifique actuelle, la planification sociale comporte deux volets: le volet infrastructurel et le volet programmatique. La planification infrastructurelle se rapporte aux besoins en matière d'offres et 
d'institutions sociales et se concentre sur le processus d'identification des besoins, alors que la planification programmatique se rapporte à la conception prévisionnelle de mesures concrètes ainsi qu'à l'aménagement des offres et des prestations.

Les rapports sociaux livrent des informations importantes pour le relevé des besoins, plus spécialement pour la planification infrastructurelle. À l'aide de données tirées de statistiques officielles, comme la statistique de l'aide sociale par exemple, les conditions de vie, les problèmes et les situations de différents groupes cibles sont décrits et comparés entre eux sur la durée. De plus en plus, la planification sociale inclut des analyses sociospatiales qualitatives pour tenir compte de la validité empirique et de la sensitivité des données par rapport aux conditions et spécificités du milieu social.

La planification programmatique a pour objet le design des produits et des processus. Dans ce contexte, la planification sociale se penche sur les objectifs et les résultats de produits et leur opérationnalisation, ainsi que sur le développement des structures professionnelles d'accompagnement et d'assurance de qualité.

Les deux volets, infrastructurel et programmatique, sont étroitement liés. En effet, pour être efficaces, les offres d'aide doivent se traduire en mesures concrètes et en fin de compte aussi en actions quotidiennes. Une planification orientée sur les services favorise la fourniture de prestations sociales adaptées aux besoins et aux situations de vie, ce que la création d'offres infrastructurelles ne garantit pas forcément per se. Se borner à planifier des infrastructures (p.ex. prévoir un nombre $\mathrm{X}$ de centres de consultation, de points de rencontre ou de places dans des foyers) ne suffit pas. La planification sociale ne consiste pas uniquement à élaborer des bases de décisions, ni ne s'achève avec la réalisation d'une analyse ou d'un plan. Au-delà des phases de préparation des décisions et de définition des objectifs, elle intervient également dans la phase de mise en œuvre. Les processus de décision sont considérés comme inhérents à la planification. Cette conception de la planification sociale en tant que partie intégrante du processus de production de prestations sociales marque une rupture avec la vision antérieure, purement quantitative, de la protection sociale et de la planification correspondante d'offres institutionnelles.

En politique sociale et dans le travail social, la planification sociale a un caractère fortement normatif. Selon une lecture répandue, une protection sociale appropriée consiste à compenser les désavantages ou à améliorer les chances de participation de groupes de population donnés, dans une région donnée, dans différentes sphères de la vie en société. L’objectif idéal de planification, l'aide à la maîtrise de la vie en vue de la justice sociale, sert encore aujourd'hui de référence. Il en découle que le développement d'offres sociales et la fourniture de prestations d'aide doivent partir des situations de vie et des besoins des personnes concernées. Une telle planification «responsive » est axée sur les conditions de vie, les situations et les besoins de groupes de population ou de milieux, et conçoit la structure et l'organisation des offres et mesures en conséquence. La production de prestations sociales sera d'autant plus efficace qu'elle ajustera l'offre à la demande des groupes cibles et veillera à ce que ceux-ci puissent y accéder. La pratique de la planification sociale suit sans doute encore d'autres directions que celle, esquissée, de la planification «responsive». L'instauration dans l'administration publique suisse, à la fin des années 1990, des principes de la nouvelle gestion publique et de la gestion administrative axée sur les résultats a eu pour effet une économicisation du travail de planification et généré d'autres lectures des notions d'efficacité et d'efficience, qui pourraient se solder par un démantèlement social. 
La mise en pratique des données et des résultats tirés de rapports sociaux passe par l'interprétation ou la pondération des situations de vie recensées afin de déterminer les situations de besoins qui s'avèrent importants pour la politique et le travail social et pédagogique. Pour que l'évaluation professionnelle des situations de vie ne conduise pas à une planification inadéquate des offres et des mesures, et pour réduire à un minimum le risque d'une mauvaise interprétation lors de la conception de prestations d'aide et de soutien, la planification doit se faire sur le mode du dialogue et impliquer les personnes concernées (approche participative). Comprise ainsi, la planification sociale inclut les acteur.trice-s et les prestataires de services sociaux, ainsi que des groupements sociétaux et politiques. La participation précoce et durable de toutes les personnes intéressées et concernées est une condition essentielle pour le développement d'une offre de prestations sociales qui soit un véritable service social à la communauté, apte à réagir à toute situation problématique de manière situative, flexible et adaptée à la demande.

\section{Jörg Dittmann \& Esteban Piñeiro}

\section{Références}

Brülle, H. \& Hock, B. (2010). Dimensionen von Sozialplanung in den Kommunen und der Stellenwert von Jugendhilfeplanung. In S. Maykus \& R. Schone (Hrsg.), Handbuch Jugendhilfeplanung: Grundlagen, Anforderungen und Perspektiven (3., vollst. überarb. und aktual. Aufl., S. 67-90). Wiesbaden: VS.

Dittmann, J. \& Tappert, S. (2014). Sozialplanung aus Sicht von Planungsträgern : Eine Standortbestimmung der Schweiz am Beispiel der Region Basel. Bern: Soziothek.

Merten, R. \& Olk, T. (2018). Sozialpädagogik als Profession: Historische Entwicklungen und künftige Perspektiven. In A. Combe \& W. Helsper (Hrsg.), Pädagogische Professionalität: Untersuchungen zum Typus pädagogischen Handelns (8. Aufl., S. 570-582). Frankfurt a.M.: Suhrkamp.

\section{Politique budgétaire}

La politique budgétaire est une politique publique consistant à moduler le volume et la composition des dépenses et des recettes des collectivités publiques afin d'atteindre divers objectifs. L'objectif peut être une allocation plus efficace et efficiente des ressources (travail, capital, environnement) à des fins de consommation ou de production. Il peut être une distribution plus équitable des richesses financières et matérielles. Il peut finalement être la régulation de l'économie dans sa globalité (croissance, chômage, inflation). La politique budgétaire est donc largement une politique publique institutionnelle au service des politiques publiques substantielles touchant directement les ménages, en particulier la politique sociale.

En pratique, on tend à associer la politique budgétaire surtout à l'objectif de régulation macroéconomique. Cet objectif est double. Il s'agit d'atténuer les fluctuations conjoncturelles, en particulier, les perturbations majeures du cycle conjoncturel. Et il s'agit aussi de favoriser la croissance à long terme, dans une perspective structurelle. Pour atteindre l'objectif de régulation, la politique budgétaire est, avec la politique monétaire, le principal instrument à disposition de l'État.

Conjoncture et structure sont liées: en effet, les économies de marché tendent à osciller autour d'une tendance structurelle. Sur le long terme, la richesse produite par une économie comme celle de la Suisse - généralement mesurée par le produit intérieur brut réel (PIB) - tend à croître. Toutefois, à court terme, le PIB peut régresser: les capacités de production ne sont plus totalement utilisées (sous-emploi); on parle de basse conjoncture ou d'écart de production négatif (negative output gap). Mais le PIB peut aussi surpasser le rythme de croissance à long terme : les capacités de production sont alors surutilisées (impliquant notamment des heures supplémentaires); on parle de haute 
conjoncture ou d'écart de production positif (positive output gap).

Les théories économiques sont partagées sur les causes des fluctuations conjoncturelles et sur les remèdes à y apporter. Pour la théorie classique $\left(\mathrm{XVIII}^{\mathrm{e}}-\mathrm{XIX}^{\mathrm{e}}\right.$ siècle), les cycles économiques sont des processus naturels qui se résorbent grâce à la flexibilité des prix et des salaires. Par conséquent, aucune action de la part de l'État n'est requise. Pour la théorie keynésienne (dès les années 1930), prix et salaires peuvent s'avérer rigides, provoquant des périodes de sous-emploi et de chômage importants, donc des périodes au cours desquelles la demande globale de biens et services se contracte. L'État doit alors intervenir pour stimuler la demande, en augmentant ses dépenses et/ou en baissant la fiscalité. Cette théorie et ses développements ultérieurs ont popularisé l'idée selon laquelle la politique budgétaire doit poursuivre un objectif de stabilisation macroéconomique. La théorie néolibérale (dès les années 1970) se développe en réaction aux idées keynésiennes et, plus généralement, à l'intervention de l'État. En matière de politique budgétaire, elle soutient que les déficits publics n'ont d'effets positifs qu'à court terme sur le PIB et l'emploi et qu'ils seront un fardeau pour les générations futures. En matière structurelle, les dépenses publiques doivent se concentrer sur les domaines clés pour la croissance et la redistribution (éducation, santé publique, infrastructures, etc.).

En pratique, pour atténuer les fluctuations conjoncturelles, la politique budgétaire agit à travers deux mécanismes. Le premier est celui des stabilisateurs automatiques qui lient certaines dépenses et recettes publiques à la conjoncture. Ainsi, en matière d'assurance-chômage, les prestations sont définies dans la législation. Lorsque le nombre de personnes au chômage s'accroît, le montant total des indemnités de chômage augmente automatiquement. En matière fiscale, les modalités d'imposition sont aussi ancrées dans la légis- lation. Lorsqu'une basse conjoncture réduit le revenu ou le bénéfice imposable, les recettes prélevées par l'État se réduisent spontanément. Ces automatismes creusent les déficits publics lorsque la conjoncture est basse et les résorbent en phase de boom. À son tour, le développement des déficits stimule automatiquement la demande globale et la conjoncture, tandis que leur résorption a une action modératrice. Le second mécanisme est celui des impulsions discrétionnaires données à la demande globale par des décisions spécifiques des pouvoirs publics. Citons les divers programmes fédéraux pour atténuer les effets d'une forte déprime conjoncturelle ou d'une accélération prononcée du renchérissement en période de surchauffe. Dans ces cas, l'État utilise son pouvoir discrétionnaire pour influencer la conjoncture à travers les budgets publics. On voudrait évidemment que les interventions soient anticycliques, autrement dit qu'elles stimulent la demande globale en cas de basse conjoncture et la modère en cas de haute conjoncture. Toutefois pour des raisons techniques (p.ex. délais de mise en œuvre, erreurs de prévisions) ou politiques (notamment clientélistes), les interventions peuvent être procycliques, c'est-à-dire stimuler la demande en haute conjoncture ou la freiner en phase de basse conjoncture.

La Constitution fixe les principes généraux pour conduire la politique budgétaire. En matière de régulation macroéconomique, suivant la théorie keynésienne, la Constitution fédérale, à son article 100, dispose que «La Confédération, les cantons et les communes fixent leur politique budgétaire en prenant en considération la situation conjoncturelle». Elle prévoit que «La Confédération prend des mesures afin d'assurer une évolution régulière de la conjoncture et, en particulier, de prévenir et combattre le chômage et le renchérissement». Les constitutions cantonales ne comprennent généralement pas de dispositions aussi développées. 
Constitution fédérale et constitutions cantonales fixent également des exigences visant à limiter les déficits ou l'endettement, suivant en cela d'une certaine manière la théorie néolibérale. L'article 126 de la Constitution fédérale dicte que «La Confédération équilibre à terme ses dépenses et ses recettes » et règle les grandes lignes du frein à l'endettement de la Confédération.

La loi sur les finances, qu'elle soit fédérale ou cantonale, concrétise les dispositions constitutionnelles liées spécifiquement à la gestion des finances. D'autres lois encadrent et contraignent la politique budgétaire. Mentionnons les lois sur le régime financier qui règlent les modalités fiscales et para-fiscales suivant lesquelles les collectivités perçoivent leurs recettes. Dans le contexte suisse, il est également nécessaire de mentionner les dispositions légales qui régissent la péréquation financière et la répartition des tâches entre les échelons institutionnels (Confédération-cantons; respectivement canton-communes).

Le système de démocratie directe suisse limite la marge de manœuvre de la politique budgétaire. En effet, modifier les lois et en particulier les lois fiscales demande davantage d'efforts et de temps. Il est techniquement impossible de les amender dans le cadre de l'élaboration du budget, par exemple. Le risque est donc accru que les interventions discrétionnaires soient procycliques parce qu'elles exercent leurs effets trop tardivement, alors que le déséquilibre conjoncturel s'est déjà résorbé. C'est la raison pour laquelle la tendance, à l'échelon fédéral, est plutôt de laisser agir les stabilisateurs automatiques. Le frein à l'endettement de la Confédération concrétise cette volonté. L'expérience réalisée depuis son introduction montre qu'il contraint effectivement les dépenses fédérales à s'ajuster à la conjoncture de manière anticyclique. Par contre, il n'empêche pas une hausse structurelle des dépenses dès lors que cette augmentation s'accompagne d'une élévation - elle aussi structurelle - des recettes (notamment sur la période récente obtenue par une augmentation du taux de TVA). De leur côté, les cantons ont récemment introduit des règles contraignantes visant à équilibrer les budgets et les comptes, sans faire grand cas de la situation conjoncturelle. En phase d'écart de production négatif, de telles dispositions peuvent obliger à des programmes d'austérité qui, du coup, ont des effets procycliques. Du point de vue de la cohérence de la politique budgétaire d'un État fédéraliste comme la Suisse, les règles actuellement en vigueur dans les cantons nécessiteraient donc de voir leur formulation revue.

Nils Soguel

\section{Références}

Administration fédérale des finances (Éd.) (2016). Principes économiques juridiques et organisationnels applicables à la gestion des finances. Berne : Administration fédérale des finances.

Soguel, N. (Éd.) (2011). Des politiques au chevet de la conjoncture - Die Politiken als Retterinnen der Konjunktur. Lausanne: Presses polytechniques et universitaires romandes.

\section{Politiques de la dépendance}

La dépendance renvoie au besoin d'une aide régulière de tiers dans l'accomplissement des activités de la vie quotidienne (AVQ), comme se lever, s'habiller, se laver, aller aux toilettes, manger ou se déplacer. Les politiques de la dépendance (ou politiques du care) s'adressent donc en théorie à toute personne nécessitant des soins ou un accompagnement régulier, comme les enfants, les personnes handicapées ou les personnes âgées en perte d'autonomie. En Suisse, la dépendance est ancrée dans la législation fédérale à travers le concept d'impotence, qui se décline selon trois degrés de gravité. Ce concept, en usage dans l'assurance-invalidité (AI), l'assurance-accident 
(LAA) et l'assurance-vieillesse et survivants (AVS), permet notamment de distinguer la dépendance de la maladie, qui relève de la loi sur l'assurance-maladie (LAMal).

Historiquement, la prise en charge des «vieillards» a longtemps été considérée en Suisse comme relevant de la sphère privée. Les soins étaient prodigués par les familles ou, pour les plus démunis, dans des «asiles» tenus par des organisations religieuses. C'est durant les années 1960 que la dépendance des personnes âgées est problématisée comme un enjeu public au niveau fédéral. Les allocations pour impotents sont introduites dans l'AVS et la Confédération soutient financièrement la construction de foyers et de homes médicalisés, afin de décharger les familles.

$\mathrm{Au}$ milieu des années 1990, la politique fédérale amorce un tournant vers le maintien à domicile. L'objectif est désormais d'éviter une institutionnalisation des personnes âgées dépendantes. De nombreux cantons optent pour un moratoire en matière de construction de homes médicalisés et misent sur le développement des services d'aide et des soins à domicile. Simultanément, l'augmentation des cas de démences s'impose comme un défi politique majeur, auquel la Suisse répond depuis 2014 à travers sa «Stratégie nationale en matière de démences».

Le virage politique des années 1990 s'accompagne d'une refamilialisation du care. En effet, les services d'aide et de soin à domicile, comme les offres dites «de répit», sont appelés à favoriser l'implication des aidant·e-s informel·le-s au service de politiques de maintien à domicile. À l'articulation des sphères publique et privée, une nouvelle catégorie d'action publique émerge : les proches aidant.e-s. À ce jour pourtant, et contrairement à plusieurs pays européens comme l'Allemagne ou la Finlande, la Suisse n'a pas adopté de mesure permettant de soutenir financièrement les proches aidant $\cdot e \cdot s$ (à l'exception des bonifications pour tâches d'assistance qui se répercutent sur le mon- tant de la rente vieillesse). Malgré une récente volonté fédérale de mieux reconnaître le travail informel des proches, aucun congé rémunéré n'est prévu pour les aidant·e.s en emploi et seuls quelques communes ou cantons (comme Fribourg ou le Tessin) proposent des allocations financières. Enfin, employer les proches aidant $\cdot e \cdot s$, sur le modèle de certaines municipalités danoises ou françaises par exemple, n'est pas une pratique diffusée en Suisse.

Contrairement à l'Allemagne, la Suisse n'a pas non plus adopté d'assurance sociale obligatoire de soins de longue durée pour les personnes âgées. Dans ce contexte, les coûts de la prise en charge de la dépendance, en home médicalisé ou à domicile, sont financés principalement à travers les allocations d'impotence de l'AVS et certaines prestations de la LAMal, à l'exclusion toutefois des prestations d'aide qui ne relèvent pas du soin. L'entretien du ménage ou l'accompagnement social par exemple sont à charge des personnes concernées. Les prestations complémentaires aux rentes AVS complètent le dispositif pour les retraitéee-s ayant un faible revenu.

En 2011, ce système de financement a fait l'objet d'une réforme globale («Nouveau régime de financement des soins»), visant à maîtriser les coûts de la LAMal. Le nouveau régime répartit les coûts entre les assuré·e·s, les cantons et les assurances-maladies. S'il introduit une allocation pour impotence faible pour les personnes âgées résidant à leur domicile (AVS), il marque surtout un désengagement partiel des assureurs maladie et un report de charge sur les bénéficiaires de soin à domicile, qui peuvent être amené·e-s désormais à participer aux frais jusqu'à hauteur de $20 \%$. Ce sont les cantons qui assument le financement résiduel, avec la possibilité de réduire la participation des assuré·e·s.

En comparaison européenne, la politique de la dépendance en Suisse se caractérise par l'importance du niveau infranational dans le financement et l'organisation des prestations et par 
l'importance des acteur·trice-s privé·e·s dans la mise en œuvre des dispositifs, d'où une grande diversité locale des prestations. Trois types de politiques de la dépendance des personnes âgées sont discernables à l'échelle des cantons. Dans le modèle du partenariat (illustré en partie par le cas de Genève), le canton soutient financièrement un réseau principalement associatif, qu'il gouverne par le biais de contrats de prestations. L'objectif est la diversification des prestations, l'autonomie des personnes âgées et la lutte contre les inégalités d'accès et de genre. Dans le modèle de la responsabilisation (dont le canton de Thurgovie partage certaines pratiques), le canton limite son financement au domaine de la prise en charge de la dépendance. Il édicte des normes et délègue la régulation de ces enjeux aux communes et au marché, encourageant le développement de structures privées marchandes. L'objectif est le «libre choix» des services et la responsabilisation individuelle. Dans le modèle du secours (en partie appliqué en Valais), le canton gouverne à travers la planification sanitaire, déléguant la gestion concrète des soins aux régions et à quelques grandes associations. Dans le but de secourir les personnes dépendantes sans les stigmatiser, l'État promeut une approche communautaire, valorisant les solidarités informelles, les rôles genrés traditionnels et les services de proximité.

En dépit de la qualité générale des prestations dispensées et d'importantes mesures sociales (notamment les prestations complémentaires fédérales et cantonales), la prise en charge de la dépendance en Suisse souffre de plusieurs faiblesses. En premier lieu, l'ancrage institutionnel de l'organisation et du financement du care apparaît particulièrement fragile, dans un système de santé centré sur la dimension curative. De plus, ce régime tend à renforcer les inégalités sociales. En effet, le care reste considéré comme une prérogative féminine de nature informelle et, en conséquence, les prestations de soins non médicaux ne sont que faiblement ou pas rémunérées. Cela génère des inégalités de genre, dans la mesure où les femmes restent les principales pourvoyeuses de care, formel ou informel, mais aussi des inégalités de classe et d'origine: les ménages qui en ont les moyens se tournent vers les services privés tandis que le travail informel de care est souvent confié à des femmes migrantes, avec ou sans statut légal. Enfin, la fragmentation du système de soin limite la capacité de gouvernance fédérale à réformer le domaine de manière globale et peut générer des inégalités de traitement selon les régions, cantons ou communes.

En conclusion, les politiques de la dépendance en Suisse sont aujourd'hui mises en œuvre dans un contexte social et politique en tension. D’un côté, la critique néo-libérale des dépenses sociales met les budgets publics sous pression; de l'autre, les attentes sociales à l'égard des soins de longue durée sont toujours plus fortes. Par ailleurs, alors que les besoins de prise en charge s'accroissent et se complexifient, particulièrement dans les cas de démences, la disponibilité des aidant.e.s proches - notamment des femmes - diminue et les institutions font face à une pénurie de personnel qualifié. Ces éléments laissent présager que le modèle du maintien à domicile, objet d'un discours politique consensuel, pourrait bien atteindre ses limites prochainement.

\section{Barbara Lucas}

\section{Références}

Colombo, F., Llena-Nozal, A., Mercier, J. \& Tjadens, F. (Éd.). (2011). Besoin d'aide? La prestation de services et le financement de la dépendance. Paris : OECD Publishing.

Höpflinger, F., Bayer-Oglesby, L. \& Zumbrunn, A. (2011). Pflegebedürftigkeit und Langzeitpflege im Alter: Aktualisierte Szenarien für die Schweiz. Bern: Huber.

Lucas, B. (2011). Trois gouvernements des démences: les biopolitiques à l'épreuve des réseaux d'action publique locaux. Revue internationale de politique comparée, 18(4), 61-75. 


\section{Politique de la famille}

La politique familiale comprend l'ensemble des mesures et des dispositifs visant à soutenir et à promouvoir la famille: 1) Les mesures monétaires, telles que les allocations familiales, l'assurance-maternité, les bourses d'études, ainsi que la fiscalité des familles et les prestations complémentaires. 2) Les services aux familles, tels que l'accueil extrafamilial, le système scolaire et de formation et les services de conseil et de formation aux parents. 3) Les dispositions juridiques qui déterminent le cadre légal de la famille, ainsi que les droits et obligations de chacun des membres, par exemple en cas de mariage, divorce, séparation et de partenariat enregistré.

Au-delà de ces domaines spécifiques, les familles sont concernées par une multitude de politiques, notamment économique, de formation, de l'emploi, de retraite, de l'égalité, de l'enfance, de migration, de logement, de transports et de santé. Dans ce sens la politique familiale est transversale.

Le contexte institutionnel, politique et culturel suisse a induit un développement tardif et modeste de la politique familiale. Le facteur principal est la structure fédéraliste et le principe de subsidiarité. Tout domaine qui n'est pas de la juridiction de la Confédération tombe sous la responsabilité des niveaux inférieurs (cantons et communes). La subsidiarité implique aussi que la priorité soit donnée à l'initiative privée. D'une part, la famille est vue comme étant avant tout responsable du bienêtre de ses membres. D'autre part, des organismes privés et sans but lucratif sont encouragés à fournir des services aux familles, ce qui dilue les responsabilités. Par ailleurs, d'autres facteurs ont également freiné l'essor de la politique familiale: la démocratie directe et le lent développement de l'État social; l'équilibre des forces au Parlement en faveur de la droite; l'adoption tardive du suffrage féminin; ainsi que le pluralisme culturel et religieux.
On peut identifier six étapes de développement de la politique familiale au niveau fédéral. La première étape concerne la période préindustrielle où la politique familiale se résume aux aides éparses fournies par les églises et sociétés philanthropiques, notamment aux orphelin·e-s et mères célibataires.

Lors de la deuxième étape, avec l'industrialisation de la Suisse et les phénomènes d'urbanisation et de paupérisation qui l'accompagnent, émergent les premières mesures (étatiques mais aussi de la part des entreprises elles-mêmes) visant à réglementer le travail et à couvrir certains risques sociaux.

La troisième étape englobe les deux guerres mondiales et se conclut par l'adoption en 1945 d'un article constitutionnel sur la famille (article 34 quinquies, puis article 116 dans la Constitution de 1999). Cet article pose les fondements de la politique familiale fédérale. Il stipule un objectif général - prise en considération des besoins de la famille - et attribue des domaines de compétences spécifiques à la Confédération, notamment les allocations familiales, l'assurance-maternité et la construction de logements. Pour autant, à l'exception des allocations familiales dans le domaine agricole introduites en 1952, la plupart de ces mandats ne seront réalisés que bien plus tard.

Lors de la quatrième étape (1950-1980), ce sont les assurances sociales qui connaissent des avancées alors que la politique familiale est quasiment absente de l'agenda politique.

La cinquième étape (1980-2000) se déroule sur fond de changements sociaux importants, notamment la pluralisation des formes de vie familiales et l'augmentation de l'activité salariée des mères. La politique familiale devient plus visible dans l'administration fédérale, avec par exemple la création d'un service de coordination pour les questions familiales (1984) et l'institution d'une commission fédérale de coordination pour les questions familiales (1995) en tant qu'organe consultatif du Conseil 
fédéral. D'autre part, le dispositif juridique qui touche à la famille et ses membres est substantiellement modifié. Un article constitutionnel qui stipule l'égalité de droit et de fait entre l'homme et la femme, notamment dans le domaine de la famille, est adopté (1981). Le droit des enfants nés hors mariage est révisé (1979). Le droit du mariage institue l'égalité des conjoints (1988). La 10évision de l'AVS introduit une bonification pour tâches éducatives dans le calcul de la rente qui valorise le travail familial (1997). Finalement, le droit du divorce est complètement révisé (1998). Par contre, des disparités régionales dans le domaine des allocations familiales continuent à exister et l'introduction d'une assurance-maternité fédérale rencontre des obstacles importants. Entre 1974 et 1999 , quatre projets de loi sont rejetés en votation populaire.

La sixième étape commence dès les années 2000. C'est une période de modernisation durant laquelle les principales mesures de politique familiale fédérale (monétaires et de services) sont introduites. L'avancée la plus marquante a lieu en 2004, avec l'adoption d'une assurance-maternité de 14 semaines pour salariées et indépendantes (loi sur les allocations pour pertes de gain). En 2003, un crédit temporaire pour la création de places d'accueil extrafamilial pour enfants est adopté au parlement. Il fut renouvelé trois fois depuis lors. En 2006, une loi fédérale qui harmonise et augmente le montant des allocations familiales est acceptée en votation populaire. Des accords intercantonaux sont également conclus sur l'âge de la scolarité obligatoire (2009) et sur les bourses d'études (2013). Finalement plusieurs changements législatifs sont à relever: adoption du partenariat enregistré entre personnes de même sexe (2004), révision du droit du nom des époux (2011), introduction de l'autorité parentale conjointe (2014) et révision du droit d'entretien de l'enfant (2015).

Mis à part ce développement au niveau fédéral, un grand nombre de mesures qui touchent directement les familles restent de la compétence des cantons et/ou des communes. Il s'agit notamment de l'instruction publique, des structures d'accueil extrafamilial ainsi que des prestations complémentaires pour les familles à bas revenus.

Dans l'ensemble la politique familiale suisse reste comparativement modeste. Elle suit plutôt une approche dite «individualiste» où la famille est considérée comme une affaire privée: c'est à la famille d'assurer la prise en charge et le bien-être de ses membres. L'État ne doit intervenir qu'en dernier recours lorsque la famille ou le marché ont échoué. La Suisse consacre un pourcentage de son PIB à la politique familiale qui est inférieur à la moyenne des pays de l'OCDE ( $1,9 \%$ contre $2,5 \%$ en 2011 ). Le taux de fréquentation des services de garde pour enfants en âge préscolaire est également en dessous de la moyenne alors que le coût de ces services pour les parents est significativement plus élevé que dans les pays voisins. La Suisse est également le seul pays européen à ne pas avoir de congé parental ni de congé d'adoption.

Un enjeu essentiel de la politique familiale concerne son influence sur les rapports de genre. Historiquement, la politique familiale s'est développée en prenant pour référence le modèle traditionnel de l'homme pourvoyeur de ressources et de la femme au foyer. Plusieurs dispositions de la politique familiale avaient pour effet de dissuader l'activité professionnelle des femmes. La taxation commune des couples mariés illustre bien ce phénomène. S'il est vrai que l'adoption récente de mesures de conciliation soutient l'activité professionnelle des mères, le temps partiel prévaut et le partage des tâches familiales et domestiques reste très genré. Parmi les mesures débattues actuellement qui comportent des enjeux importants pour l'égalité, on peut citer la fiscalité de la famille, le droit de la famille, le congé paternité et parental, le soutien aux familles à faibles revenus et la prise en compte des relations 
entre adultes et leurs parents âgés dans une politique des générations.

Un autre enjeu concerne le développement futur de la politique familiale. En effet, le partage des responsabilités entre différents niveaux politiques aboutit, en l'absence d'un concept global, à un manque de cohérence des mesures et à un problème de coordination des acteur.trice-s. Pourtant la centralisation de la politique familiale ne fait pas l'unanimité. Preuve en est l'échec en 2013 d'un article constitutionnel qui aurait étendu les compétences de la Confédération dans le domaine de la conciliation du travail et de la famille.

\section{Isabel Valarino}

\section{Références}

Conseil Fédéral. (2015). Rapport du Conseil Fédéral sur la politique familiale: état des lieux et possibilités d'action de la Confédération. Berne: Office fédéral des assurances sociales.

Mätzke, M. \& Ostner, I. (2010). Introduction: Change and Continuity in Recent Family Policies. Journal of European Social Policy, 20(5), 387-398.

Stutz, H., Mäder, U., Schassmann, H., Binder, H.-M., Kübler, D., Gerlach, I ... Wetzorke, P. (2004). Rapport sur les familles 2004: structures nécessaires pour une politique familiale qui réponde aux besoins. Berne: Département fédéral de l'intérieur.

\section{Politique de la reproduction}

La politique de la reproduction comprend une série d'enjeux relatifs au contrôle des naissances et à la contraception, à l'avortement et plus récemment aux nouvelles technologies de reproduction communément appelées procréation médicalement assistée (PMA) et à la gestation pour autrui (GPA). Si la contraception et l'avortement, aussi appelés interruption de grossesse (IG) pour sa forme sanctionnée par la loi, s'attachent au contrôle des naissances, la PMA et la GPA portent, quant à elles, sur la sti- mulation de la reproduction. C'est l'invention de la fécondation in vitro en 1978 qui, en permettant la fécondation d'un ovule en dehors du corps de la femme, a marqué le début d'un fertile développement en matière de PMA. Les avancées technologiques se sont rapidement enchaînées pour permettre notamment la congélation des ovules et des embryons ainsi que le diagnostic préimplantatoire qui permet d'examiner génétiquement les embryons avant leur implantation, afin de ne sélectionner que ceux qui ne seraient pas, par exemple, porteurs d'une prédisposition génétique à une maladie grave. Avec le développement de la PMA est apparue la pratique sociale de la GPA où une femme tierce assure la gestation pour autrui. Cette gestation est dite altruiste lorsqu'elle ne comprend pas de rémunération financière.

Alors que la contraception n'est que peu régulée en Suisse, l'IG et la PMA sont eux fortement encadrés légalement. L'accès à l'IG est réglé par le modèle dit du régime du délai depuis 2002. Les articles 118 et 119 du Code pénal différencient l'IG non punissable sur requête de la femme qui doit invoquer un état de détresse durant les 12 premières semaines suivant ses dernières menstruations, l'IG non punissable pour indication médicale grave relative à la préservation de l'intégrité physique et psychique de la femme à partir de la $13^{\text {e }}$ semaine sur avis médical uniquement, et l'IG punissable qui comprend toutes autres circonstances. Ce dernier cas de figure est lourdement sanctionné pour la personne ayant pratiqué l'IG et la femme qui a consenti à l'IG illégale. En cas d'IG non punissable, le corps médical doit recueillir le consentement écrit de la femme, informer cette dernière des risques médicaux de l'intervention et des possibilités d'adoption ainsi que lui remettre un dossier comprenant les listes des centres de consultation et des associations susceptibles d'apporter une aide morale ou matérielle.

L'accès à la PMA est sévèrement restreint en Suisse par l'article 119 de la Constitution 
fédérale sur la procréation médicalement assistée et le génie génétique dans le domaine humain et la loi sur la procréation médicalement assistée entrée en vigueur en janvier 2001 (LPMA). Ce cadre légal pose de strictes conditions de recours à la PMA pour raisons médicales uniquement et interdit la congélation des embryons, le don d'embryon ou d'ovule et jusqu'à récemment le développement de plus de trois embryons in vitro et le diagnostic préimplantatoire. Les couples de même sexe et les femmes célibataires sont interdits d'accès à la PMA tandis que seuls les couples mariés peuvent accéder aux techniques nécessitant un don de sperme. Quant à la gestation pour autrui, elle a été interdite sous toutes ses formes dès 1992.

La politique suisse de la reproduction est relativement restrictive en comparaison européenne. L'accès à l'IG durant les premières semaines de grossesse n'est pas un droit inconditionnel en Suisse, mais une exception à sa pénalisation et ceci uniquement à condition que la femme fasse valoir un état de détresse, condition qui a été abolie dans la plupart des pays européens. Le délai de 12 semaines est également un des plus courts d'Europe. La régulation de la PMA et de la GPA se distingue également par son caractère restrictif. La majorité des pays européens autorise la congélation des embryons in vitro et le don d'ovule; un nombre croissant de pays ont ouvert l'accès à la PMA aux couples de même sexe et permettent certaines formes non commerciales de GPA. La politique suisse en matière de reproduction ne figure pas non plus parmi les plus libérales d'Europe en matière de financement public. La contraception n'est pas remboursée par l'assurance de base, l'IG n'est, elle, remboursée que depuis 1982 et uniquement après déduction de la quote-part et de la franchise alors que d'autres pays européens garantissent un accès $100 \%$ gratuit. Une IG se situant entre 400 et 3500 francs, la quote-part de $10 \%$ n'est pas négligeable pour les femmes, et plus particuliè- rement pour celles dotées de faibles ressources économiques. Quant à la PMA, elle n'est que partiellement couverte par l'assurance-maladie et reste en grande partie du ressort financier des couples, ce qui accentue les inégalités socioéconomiques face à la reproduction, le seul coût d'un cycle de fécondation in vitro étant estimé à 6000 francs.

L'IG et la PMA ont connu un débat public particulièrement vif en Suisse. La question de la libéralisation de l'IG a occupé la scène fédérale dès le début des années 1970 par l'entremise d'une initiative visant à la décriminalisation de l'avortement déposée par Anne-Marie Rey et les futur.e.s membres fondateur.trice-s de l'Union suisse pour décriminaliser l'avortement. De multiples solutions, allant de l'interdiction totale à la délégation fédéraliste aux cantons ou à l'entière décriminalisation, ont été soumises pas moins de cinq fois à la décision populaire jusqu'à l'acceptation du régime du délai le 2 juin 2002 par $72,2 \%$ de oui et le rejet à $81,7 \%$ de l'initiative concurrente «pour la mère et l'enfant» qui visait à son interdiction. Le régime du délai représente en Suisse un compromis politique obtenu de haute lutte au bout de plus de 30 ans de tergiversations entre les partis laïcs et le mouvement en faveur de la décriminalisation, le Parti démocrate-chrétien qui favorisait un accès plus restrictif centré sur l'obligation de la consultation et les mobilisations évangélique et pro-vie qui militaient en faveur de la protection de l'embryon.

La PMA est arrivée plus tardivement en Suisse mais n'en a pas moins suscité controverse. La première initiative lancée par Der Schweizerische Beobachter en 1985 et soutenue par l'organisation Feministischer Frauen gegen Gen- und Reproduktionstechnologie a cadré le débat politique de manière instrumentale sur la protection contre les abus en matière de PMA et les risques de futures pratiques eugénistes. Le peuple suisse a approuvé à une large majorité en 1992 un contre-projet à l'initiative qui reprenait le principe de la protection de l'être 
humain et de son milieu naturel contre l'utilisation abusive des techniques de procréation et de génie génétique. Malgré les demandes du corps médical en faveur d'un assouplissement, la loi sur la PMA de 2001 suivra largement la ligne restrictive de l'article constitutionnel et rajoutera des contraintes et interdictions supplémentaires.

La politique de la reproduction est récemment réapparue sur la scène fédérale par le biais de deux votations populaires. L'initiative populaire «Financer l'avortement est une affaire privée» avait été lancée en 2010 par un comité interpartis et soutenue par l'Union démocratique du centre et le mouvement pro-vie avec pour objectif de radier l'IG de la liste des actes médicaux couverts par l'assurance de base sous réserve de rares exceptions. Constituant une remise indirecte de la libéralisation de l'accès à l'avortement, elle a été rejetée par une large majorité de votant·e.s en janvier 2014. Du côté de la PMA, alors que la réouverture du débat sur la GPA ne semble pas être à l'ordre du jour, le peuple suisse a voté en juin 2016 en faveur d'un assouplissement de l'interdiction du diagnostic préimplantatoire qui pourra désormais être pratiqué sous condition d'existence d'un risque sérieux de prédisposition héréditaire à une maladie grave qui se déclarerait avant l'âge de 50 ans et pour laquelle il n'existe aucune thérapie efficace et appropriée.

Isabelle Engeli

\section{Références}

Engeli, I. (2010). Les politiques de la reproduction: les politiques d'avortement et de procréation médicalement assistée en France et en Suisse. Paris : L'Harmattan.

Rey, A.-M. (2007). Die Erzengelmacherin: Das 30-jährige Ringen um die Fristenregelung. Zürich: Xanthippe Verlag.

Rothmayr, C. (2006). Explaining restrictive ART policies in Switzerland and Germany: similar processes - similar results? German Policy Studies, 3(4), 595-647.

\section{Politique de la santé*}

La politique de la santé caractérise l'ensemble des mesures destinées au maintien et à l'amélioration de l'état de santé de la population. Le bien-être (physique, psychique et social) en constitue l'essence. Plusieurs champs constituent ses axes d'intervention. Ceux en lien direct avec l'état de santé et son rétablissement, à savoir la lutte contre les maladies, la prévention, les soins, la sécurité sociale et l'industrie pharmaceutique. Ceux qui déterminent de manière générale l'environnement sanitaire, par exemple l'égalité des chances, l'emploi et le monde du travail, la formation, l'environnement, l'habitat et la mobilité ou la sécurité des denrées alimentaires et la nutrition. Ces domaines s'appréhendent du point de vue de la santé dans une double perspective: l'amélioration du cadre de vie et des comportements et l'instauration de régimes de sécurité sociale déterminant l'offre, l'accès, la qualité et le financement des prestations de politique sanitaire.

En Suisse, les politiques de santé trouvent leurs origines vers le milieu du $\mathrm{XIX}^{\mathrm{e}}$ siècle. Dominées par la médecine curative, elles privilégient la protection de la santé et l'accès aux soins, subissant l'influence de la médecine hospitalière. Les hôpitaux jouent en effet un rôle significatif dans le rétablissement de l'état de santé de la population jusqu'aux années 1980. Reconnus d'intérêt général, ils sont le cœur des politiques de santé, quand bien même les médecins «de campagne » s'activent avec beaucoup d'engagement mais avec des moyens limités pour soigner les populations. Apparaissent alors également les services de santé publique et les premières règles de police sanitaire. $\mathrm{Au}$ rang des préoccupations principales, on trouve l'hygiène publique (état sanitaire des eaux et des viandes), la santé du bétail et les professions médicales (médecins, sages-femmes, apothicaires). L'histoire de la médecine et celle des hôpitaux détermineront donc les contours 
des politiques publiques de santé. Plus tard, le développement de la chirurgie (anesthésie et antisepsie), les connaissances anatomiques et physiologiques, l'apparition des vaccins et des antibiotiques, puis de la psychanalyse ou l'essor de la profession d'infirmière marquent d'autres étapes dans la prise en charge des souffrances et des maladies.

Du point de vue institutionnel, depuis les années 1890, l'assurance-maladie sociale est constamment au cœur des développements de la politique de santé. Acceptée en 1911, elle ne cesse de faire débat, devenant obligatoire avec la loi de 1994 (LAMal). Au long du $\mathrm{XX}^{\mathrm{e}}$ siècle, d'autres législations compléteront l'appareil normatif. Il s'agit des lois fédérales sur les assurances accidents et militaire, les épidémies, les produits thérapeutiques, les transplantations, les denrées alimentaires, les stupéfiants, la recherche sur l'être humain, les professions médicales. Les lois cantonales sur les institutions sanitaires, les soins à domicile, la prévention ou le droit des patients complètent cet arsenal législatif.

Six problématiques récurrentes animent le débat sur la politique de santé et l'assurance-maladie. 1) La Solidarité. La justice sociale et l'égalité de traitement sont les principes qui concrétisent la dimension sociale du système. 2) La régulation. La loi confère une obligation de bonne gouvernance. La Confédération et les cantons édictent ainsi les instruments déterminant le niveau de l'offre de prestations (la planification hospitalière, p.ex.). 3) La qualité des prestations, indépendamment de la couverture d'assurance ou du domicile. 4) La réduction des multiples inégalités découlant du fédéralisme (offre et niveau des prestations, primes). 5) L'innovation. La rareté des moyens ne doit ni freiner le progrès, ni générer une médecine de riches et une de pauvres. 6) L'allocation optimale des ressources comme condition de bonne gouvernance: rationaliser avant de rationner.
Fédéralisme, libéralisme, subsidiarité, décentralisation, démocratie semi-directe et quête de consensus caractérisent le fonctionnement des politiques de santé. Si le fédéralisme attribue aux cantons un rôle central en matière de mise en œuvre des prestations, en vertu du libéralisme et de la subsidiarité, les acteur-trice-s privé.e-s ont une place prépondérante dans son organisation.

Parmi les compétences fédérales, mentionnons: la définition des règles de transparence et la surveillance des caisses maladie; la définition des modalités d'application des normes de qualité ; la surveillance des médicaments et des dispositifs médicaux; la procréation médicalement assistée et le génie génétique; la transplantation d'organes et la biomédecine; la sécurité au travail; la formation et les professions de la santé; la production d'informations statistiques et d'indicateurs; partiellement la promotion, la prévention, protection de la santé (SUVA, p.ex.). Pour accomplir ses tâches, la Confédération s'est dotée de trois offices principaux: de la santé publique, des assurances sociales et de la statistique (de qui dépend l'observatoire national de la santé).

Les cantons sont principalement chargés de l'application du droit fédéral des assurances sociales et de l'organisation et la coordination du système de soins : hôpitaux, établissements médicosociaux, soins à domicile, médecine scolaire, services psychosociaux, services d'urgence et de sauvetage. De plus, ils délivrent les autorisations de pratiquer les professions de la santé, assurent la surveillance des établissements de soins et le contrôle des denrées alimentaires. Ils participent à la fixation des tarifs et au financement des prestations, ils assurent la production d'informations statistiques et d'indicateurs. Pour coordonner leurs activités et parler d'une voix unie face à la Confédération, les cantons sont organisés au sein d'une conférence suisse des directrices et directeurs cantonaux de la santé (CDS). 
L'évolution des politiques de santé s'inscrit au centre de plusieurs champs de tensions qui sont, en soi, des défis à relever. 1) Les attentes quasi infinies des individus alors que les ressources disponibles, publiques et collectives, sont limitées. 2) La dimension sociale et sanitaire des soins et les multiples intérêts économiques qui caractérise ce secteur. 3) Les mécanismes de régulation auxquels s'opposent les velléités d'une "privatisation» accrue du système. 4) L'exigence de solidarité et celle d'un renforcement de la responsabilité individuelle. 5) L'intégration des développements technologiques et les conséquences en termes de coûts et de gains effectifs pour l'état de santé de la population. 6) La rationalisation du système et le rationnement des soins.

Plus fondamentalement, la gouvernance des politiques suisses de santé pose problème. Complexité, compétences éclatées, pluralité des acteur-trice-s, incohérences, diversités et inégalités caractérisent un ensemble devenu inefficient, car sans pilote, sans objectifs explicites et partagés, sans vision globale uniforme. La perspective de gouvernance est donc désormais cruciale. Après le temps des combats sociaux, qui ont abouti à la reconnaissance politique des enjeux de politique sanitaire; après celui de la structuration des organes d'application; après celui du développement et des réformes, toujours en cours, des institutions sanitaires; après celui de l'évaluation et de la qualité; après celui des fulgurants progrès technologiques, le temps est venu du bilan structurel et systémique. C'est une étape cruciale et le moment de dépasser les rapports de force, les blocages idéologiques et les intérêts particuliers (de pouvoir et financiers) pour qu'au centre de l'action publique l'intérêt général retrouve sa juste place.

Stéphane Rossini

\section{Références}

Achtermann, W. \& Berset, C. (2006). Les politiques suisses de santé: potentiel pour une politique nationale. Bern: Office fédéral de la santé publique.

Organisation de coopération et de développement économiques et Organisation mondiale de la santé (Éd.) (2012). Examen de l'OCDE des systèmes de santé: Suisse 2011. Paris: OECD Publishing.

Rossini, S. (Éd.) (2014). La gouvernance des politiques suisses de santé. Lausanne: Réalités sociales.

\section{Politique de la vieillesse}

La politique de la vieillesse englobe l'ensemble des interventions publiques visant à agir sur, ou à influencer la situation des personnes catégorisées comme «âgées» ou «vieilles», leur place et statut dans la société et leurs rapports avec ses autres composantes.

Si ces interventions relèvent toujours, à un titre ou à un autre, d'une légitimité et d'un pouvoir d'imposition ou d'incitation conférés par l'État et sont donc «publiques», la place et le rôle des acteur-trice-s y sont particulièrement importants, plus que dans d'autres secteurs de l'action publique. Ainsi, la prévoyance vieillesse, son passé et son actualité, est le produit de l'action d'une pluralité d'acteur-trice-s - milieux associatifs, œuvres privées et associations philanthropiques, assurances - en interaction avec l'action de l'État fédéral, ses lois et programmes, et l'a aussi précédé historiquement. Le poids des acteur.trice-s non étatiques dans la politique de la vieillesse et son caractère pour ainsi dire inhérent est bien illustré par l'association Pro Senectute, fondée en 1917 en tant qu'organisme charitable, qui intervient, en partie sur mandat de la Confédération, sur une vaste gamme de problématique et «besoins » des personnes âgées, promouvant leur participation et qualité de vie. Dans une veine plus militante, l'AVIVO (Association des vieillards, invalides, veuves et orphelins), s'engage depuis sa création en 1949 pour le déve- 
loppement de l'AVS et des prestations en faveur des personnes âgées. Les dernières décennies ont vu éclore divers groupements attachés à promouvoir les droits des retraité-e.s et leurs revendications. Le Conseil suisse des aîné·e·s, créé en 2001, a pour but de fédérer au niveau national les efforts et les intérêts des différents groupes et associations et de faire entendre une parole commune sur la scène fédérale. En dépit de ces développements, la voix propre des personnes âgées et de leurs organisations est globalement encore peu prise en compte et exerce une influence limitée sur la production et mise en œuvre au niveau national de la politique de la vieillesse.

Cette dernière est pour une large part une réalité cantonale et communale, que ce soit au travers de la mise en œuvre des législations et programmes fédéraux ou comme relevant de domaines de compétence propre; la présence et le poids des acteur-trice-s non étatiques y sont d'autant plus prononcés. Il existe de fortes variations infra-nationales et locales des politiques de la vieillesse, ce qui ne va pas sans générer des inégalités parmi leurs destinataires.

Un autre trait de la politique de la vieillesse est le rôle important joué par la circulation des idées et des savoirs et les réseaux d'acteur-trice-s actif·ive·s au niveau européen et des organisations internationales, que ce soit historiquement (comme l'influence du Bureau international du travail sur la constitution des systèmes nationaux de pension de retraite et plus largement de sécurité sociale) ou dans les reconfigurations actuelles, par exemple au travers de l'élaboration et diffusion du référentiel $\mathrm{du}$ «vieillissement actif».

$\mathrm{Au}$ fil des décennies, la politique de la vieillesse a connu des évolutions majeures: extension des domaines d'intervention bien au-delà des secteurs classiques (eux-mêmes redéfinis) de la prévoyance vieillesse financière et assistance à la vieillesse indigente d'une part, de la protection sanitaire et des soins d'autre part; reformulation des conceptions et visées, «l'ancien» n'étant pas abandonné mais plutôt réélaboré et repositionné dans de nouvelles configurations plus englobantes. Les rapports des trois Commissions fédérales consultatives publiés respectivement en 1966, 1979 et 1995, et la Stratégie en matière de politique de la vieillesse publiée par le Conseil fédéral en 2007 en témoignent. Le premier des rapports porte le triple souci de répondre aux besoins fondamentaux des personnes âgées (déclinés en revenu, état de santé, logement), de la solidarité qu'il s'agit de manifester à leur encontre et du partage avec elles des bénéfices apportés par la nouvelle prospérité (les fameuses Trente Glorieuse). Le deuxième rapport y adjoint une «politique du mode de vie» (Anne-Marie Guillemard), qui pose la nécessité d'adapter l'organisation de la société au vieillissement démographique, d'articuler vie professionnelle et vie de temps libre à la retraite, de prendre en compte et d'encourager les formes de participation des aîné·e·s, de développer les dispositifs d'hébergement et d'équipement sanitaires, et en particulier les services sociaux et médicosociaux en milieux ouvert; les enjeux liés aux professions gérontologiques et à la formation faisant également leur apparition. Le troisième rapport y ajoute les enjeux liés à la fin de vie ; il consacre par ailleurs une large place à l'hétérogénéité de la population âgée et aux inégalités qui la traversent (notamment du point de vue du genre), ainsi qu'à la distinction entre troisième et quatrième âge, vue comme un produit sociohistorique et donc contingent; il défend enfin l'idée d'un «nouveau pacte intergénérationnel», dans lequel seraient également reconnues, prises en compte et promues les contributions des personnes retraitées au bien commun, élargissant ainsi le domaine d'application du principe de réciprocité au fondement de «l'ancien pacte». Quant à la Stratégie en matière de politique de la vieillesse du Conseil fédéral de 2007, elle reprend les thèmes déjà évoqués avec quelques ajouts (l'égalité des 
chances dans l'accès à la société de l'information p.ex.) mais se signale surtout par les deux grandes orientations assignées à la politique de la vieillesse. Si celle "vers les besoins et les risques» est classique, celle «vers les ressources et les potentiels» l'est moins, notamment le triple accent mis (selon page $44 \mathrm{du}$ rapport) sur «la reconnaissance de ce que les personnes âgées sont, ont et font pour ellesmêmes, leurs proches et la société, ainsi que le développement de leurs potentiels ", la participation à la vie économique et sociale ainsi que l'engagement et solidarité à l'encontre des générations à venir et des proches, «l'autonomie, la possibilité de se prendre en charge et l'autodétermination ».

Depuis lors, la question de l'âge de la retraite a acquis une place prééminente sur la scène publique, sans que les «diagnostics» et «solutions» prennent toujours suffisamment en compte l'hétérogénéité et inégalités des (futur·e.s) retraitée.e.s, ni les discriminations dont sont victimes nombre de travailleur.euse-s âgé·e·s.

En même temps qu'ils y contribuent, les reconfigurations et réaménagements de la politique de la vieillesse sont le produit des changements dans ce qui constitue matériellement et symboliquement la «vieillesse» ou la «retraite», dans les expériences objectives et subjectives qu'en font les cohortes successives, dans les catégories cognitives, évaluatives et normatives permettant de les penser et qualifier (des catégories elles-mêmes influencées par les savoirs experts, notamment médicaux), tout en étant également influencés par les transformations de la société dans son ensemble.

L'évocation de l'évolution de la politique de la vieillesse rappelle aussi que celle-ci ne vise pas seulement à agir sur ou à influencer les ressources et supports des destinataires, mais aussi leurs comportements et leurs représentations. Ce qui ne veut pas dire qu'elle parvienne nécessairement aux objectifs visés: ses effets sur les destinataires peuvent être autres que ceux attendus ou n'être effectifs que pour une partie d'entre eux·elles. Par ailleurs, les personnes vieillissantes ne sont pas passives mais interprètent et font usage, de manière différenciée et souvent marquée par les inégalités sociales, des dispositifs et mesures mises en place.

Signalons pour conclure deux caractéristiques qui distinguent la politique vieillesse de la Suisse par rapport à celles des pays voisins : l'architecture de la prévoyance vieillesse, non pas l'existence en soi de plusieurs «piliers» mais le poids comparativement plus faible du premier d'entre eux (système public de pension); le dispositif d'aide et de soin et son financement, marqués par la part comparativement élevée reposant sur les ménages, en l'absence d'une assurance sociale «dépendance», et le faible soutien institutionnel apporté pour les aides et soins informels.

\section{Jean-François Bickel}

\section{Références}

Conseil fédéral (2007). Stratégie en matière de politique de la vieillesse: Rapport du Conseil fédéral donnant suite au postulat 03.3541 Leutenegger Oberholzer du 3 octobre 2003. Berne : Chancellerie fédérale.

Martin, M., Moor, C., Sutter, C. (2010). Kantonale Alterspolitiken in der Schweiz. Bern: Bundesamt für Sozialversicherungen.

Repetti, M. (2018). Les bonnes figures de la vieillesse: regard rétrospectif sur la politique de la vieillesse en Suisse. Lausanne: Antipodes.

\section{Politique de l'éducation*}

Le système d'éducation suisse est largement soumis à la souveraineté cantonale. Bien que le droit à la formation élémentaire soit inscrit dans la Constitution fédérale depuis 1874 , l'influence de la Confédération dans les écoles est restée modérée jusqu'à l'intégration des nou- 
veaux articles sur la formation dans la Constitution fédérale en 2006. L'article 62 révisé de la Constitution fédérale a introduit une nouvelle compétence subsidiaire de législation de la Confédération pour le cas où les efforts de coordination entre les cantons n'aboutiraient pas à une harmonisation de l'instruction publique concernant la scolarité obligatoire, l'âge de l'entrée à l'école, la durée et les objectifs des niveaux d'enseignement et le passage de l'un à l'autre, ainsi que la reconnaissance des diplômes. Dans ce contexte, l'accord intercantonal sur l'harmonisation de la scolarité obligatoire (concordat HarmoS) est entré en vigueur en 2009.

Au niveau du degré secondaire II, la Confédération et les cantons engagent une coopération traditionnelle. Depuis 1906, la Confédération édicte une réglementation de la maturité pour les gymnases et, dans le domaine de la formation professionnelle, elle définit conjointement avec les organisations du monde du travail les conditions-cadres de l'apprentissage. En contrepartie, les cantons dirigent les centres de formation et déterminent les conditions de l'offre cantonale de formation générale (gymnase, école de culture générale) et de formation professionnelle. De manière analogue, les hautes écoles spécialisées ayant ouvert leurs portes dans les années 1990 sont soumises à la législation fédérale, alors qu'elles sont dirigées soit de manière individuelle par un seul canton, soit de manière régionale par plusieurs cantons réunis. Initialement, dans le domaine traditionnel des hautes écoles, les cantons étaient seuls responsables des universités, tandis que la Confédération était responsable des écoles polytechniques fédérales ainsi que de la recherche. Depuis des décennies, la Confédération exerce une certaine influence dans le domaine des hautes écoles cantonales par le biais du soutien financier qu'elle accorde.

Les nouveaux articles de la Constitution fédérale consacrés à l'éducation exigent non seulement une reconnaissance sociale équi- valente de la formation générale et de la formation professionnelle, mais aussi la qualité et la perméabilité de l'espace suisse de formation. Parmi les instruments de pilotage visant à contrôler la qualité, il existe, entre autres, des standards d'enseignement définis au niveau national, des plans d'études coordonnés par région linguistique et un monitorage de l'éducation au niveau national. Parmi les objectifs de politique éducative définis conjointement par la Confédération et les cantons depuis 2011 figurent l'harmonisation de l'école obligatoire, notamment la hausse du taux de réussite à $95 \%$ dans le degré secondaire II, la diminution des changements et des abandons d'études aux universités et la garantie des offres d'accueil extrafamilial, par exemple grâce aux horaires scolaires continus. Du point de vue de la politique sociale, les crèches et les écoles à plein temps subventionnées par l'État, actuellement un enjeu politique, ont une double importance. D’une part, les ménages défavorisés sur le plan socioéconomique, dont les deux parents doivent travailler, ont besoin d'un encadrement externe pour leurs enfants. D'autre part, les offres d'accueil extrafamilial permettent aux femmes autant qu'aux hommes de participer au marché du travail et soulagent les femmes du travail familial non rémunéré (égalité des sexes).

Enfin, la ratification par la Suisse en 2014 de la Convention de l'ONU relative aux droits des personnes handicapées requiert une meilleure perméabilité du système d'éducation afin de favoriser un accès inclusif à la formation. Cela signifie que le système d'éducation officiel, dès la formation précoce jusqu'à la formation tertiaire, doit être remodelé de façon à permettre à toutes et tous, indépendamment de leur origine ou de leur handicap, d'accéder à la formation et au soutien avec des opportunités équitables.

Une meilleure perméabilité du système d'éducation est visée à plusieurs niveaux. Dans ce contexte, on distingue la perméabilité hori- 
zontale (changement de type d'école au même niveau) de la perméabilité verticale (changement possible de niveau scolaire ou de formation). Dans le degré secondaire I, une meilleure perméabilité signifie la suppression de la stricte séparation entre les types d'écoles du cycle secondaire. L'objectif des réformes scolaires cantonales ayant lieu au niveau décentralisé depuis les années 1960 est d'exploiter le réservoir de talents et d'assurer l'égalité des chances en assouplissant la hiérarchisation des types d'écoles. Pour ce faire, le canton du Tessin a créé la scuola media, un cycle secondaire général sans différenciation, et les cantons francophones, tout comme le canton de BâleVille, ont ensuite introduit les cycles d'orientation à la suite du degré primaire. Dans les cantons alémaniques, de plus en plus de modèles d'écoles coopératives et intégratives sont implémentés. Les cantons qui préfèrent un système d'écoles plus intégré à la sélection réduite offrent aux élèves de toute origine sociale de meilleures perspectives de formation. Inversement, les systèmes d'écoles séparés accentuent les inégalités sociales.

$\mathrm{Au}$ degré secondaire II, la perméabilité signifie un assouplissement des limites entre la formation professionnelle élémentaire essentiellement organisée de manière duale et la formation générale, par exemple avec l'introduction d'écoles de culture générale qui offrent à la fois des cours d'enseignement général et spécialisé. De surcroît, la validation cantonale des performances de formation constitue une nouvelle forme de perméabilité du système d'éducation. Elle permet de prendre en compte les acquis sur une base procédurale, d'attester les compétences opérationnelles et d'obtenir un titre formel. Cette validation des acquis permet notamment aux personnes ne disposant pas d'un diplôme de formation postobligatoire (p.ex. après un abandon d'apprentissage) d'obtenir des qualifications professionnelles. À cela s'ajoute la validation des professions et diplômes étrangers.
En ce qui concerne le degré tertiaire, la perméabilité permet le passage après la formation professionnelle avec maturité professionnelle aux hautes écoles spécialisées ou, en passant un examen supplémentaire, à une université, ou le passage entre différentes types d'hautes écoles (p.ex. de la haute école spécialisée à l'université) dans le cadre d'une même formation. Ainsi, l'ouverture sociale de la formation supérieure progresse. Ceci suppose toutefois aussi des réformes et l'élimination d'inégalités d'éducation dans l'école obligatoire, car celles-ci engendrent de manière déterminante l'inégalité sociale d'accès aux hautes écoles.

La politique d'éducation devra relever le défi d'assumer une position intermédiaire des écoles suisses visant la conciliation et la cohésion entre la famille, l'économie et la société. Lorsque des parents aisés peuvent imposer leurs intérêts particuliers pour le bien-être de leur enfant (p.ex. en l'envoyant dans une école privée ou alternative), cela favorise les inégalités sociales. Par contre, si l'école est soumise aux besoins de l'économie et est essentiellement conçue selon des catégories économiques (pilotage de l'output grâce aux standards de formation, investissement dans le capital humain, etc.), cela ternit l'influence publique sur les écoles et sa contribution à la solidarité sociale. Enfin, l'économicisation de l'école résulte de la mondialisation de la politique d'éducation suisse par l'influence croissante des organisations internationales telles que l'OCDE, qui impose les thèmes de la politique d'éducation sur la base d'études de comparaison internationales (p.ex. PISA) et de classements, sans prendre en compte les processus démographiques de formation d'opinions et de prise de décisions.

\section{Christian Imdorf}




\section{Références}

Herzog, W. (2013). Aussichten der freien Schulwahl : Die globale pädagogische Reformbewegung im Härtetest der direkten Demokratie. Zeitschrift für Erziehungswissenschaft, 16(3), 579-597.

Rosenmund, M. (2011). Bildungsföderalismus in der globalisierten Bildungsinstitution: Das Schulsystem der Schweiz. In K. Kansteiner-Schänzlin (Hrsg.), Schule im gesellschaftlichen Spannungsfeld (S. 33-46). Baltmannsweiler : Verl. Pestalozzianum.

Wolter, S. C., Cattaneo, M. A., Denzler, S., Diem, A., Hof, S., Meier, R. \& Oggenfuss, C. (2018). L'éducation en Suisse: rapport 2018. Aarau: Centre suisse de coordination pour la recherche en éducation.

\section{Politique de l'égalité*}

La démocratie suisse est jeune, tout comme sa politique de l'égalité. En effet, ce n'est qu'en 1971 que les femmes ont obtenu le droit de vote et d'éligibilité au plan fédéral. Depuis, diverses dispositions ont été adoptées suite à des débats nourris. Ainsi, la Constitution fédérale contient, depuis 1981, une disposition consacrée spécifiquement à l'égalité des sexes, en particulier dans les domaines de la famille, de la formation et du travail ainsi qu'en matière de salaire. Depuis 2000, ce qui est devenu l'article 8 alinéa 3 exige explicitement une égalité non seulement de droit mais de fait.

L'objectif ultime de la politique de l'égalité est qu'il n'existe plus de barrières fondées sur le sexe faisant obstacle à une participation pleine et entière à la vie économique, politique et sociale. Cela signifie que tous les êtres humains doivent avoir la possibilité de développer librement leurs capacités individuelles et de prendre des décisions, sans être limités par des stéréotypes de genre. Enfin, il s'agit que les éventuelles différences de comportement, d'intérêts et de besoins des femmes et des hommes soient prises en compte, reconnues et promues de façon égale.
La politique de l'égalité recouvre l'ensemble des institutions, des bases légales, des objectifs et des mesures soutenus par les pouvoirs publics pour concrétiser le mandat constitutionnel et remplir les obligations contractées à travers divers engagements internationaux, en particulier celles issues de la Convention sur l'élimination des discriminations envers les femmes (CEDEF), ratifiée par la Suisse en 1997. La CEDEF traite d'une vaste palette de thèmes : droit, structures et financement pour l'égalité, mesures de discrimination positive, stéréotypes et pratiques préjudiciables, violence à l'égard des femmes, traite des êtres humains et exploitation de la prostitution, positions de pouvoir et de décision dans le domaine politique ou économique, éducation, emploi et sécurité sociale, santé, femmes rurales, réfugiées, requérantes d'asile et autres groupes défavorisés, mariage et relations familiales.

Pour réaliser l'égalité de droit et de fait, la Suisse a institué, en 1988, un Bureau fédéral de l'égalité entre femmes et hommes (BFEG), dont le mandat est de faire avancer l'égalité entre les sexes dans tous les domaines de la vie et d'éliminer toutes formes de discrimination directe et indirecte. Sur le plan thématique, le BFEG met l'accent sur l'égalité dans la vie professionnelle - et plus spécifiquement sur l'égalité salariale -, sur la conciliation entre les vies professionnelle et familiale, sur l'égalité juridique et enfin sur la lutte contre la violence dans les relations de couple. Ses modes d'intervention vont de l'information de la population aux études et conseils pour les autorités, en passant par le développement d'outils et les contrôles de l'égalité salariale dans les entreprises ayant obtenu un marché public. Le BFEG peut par ailleurs accorder des aides financières à des organisations à but non lucratif pour mener des projets visant à encourager l'égalité dans la vie professionnelle.

Parmi les autres instances chargées de l'égalité au niveau fédéral, se trouve la Commission fédérale pour les questions féminines (CFQF), 
commission extraparlementaire permanente, dont la mission est de conseiller le Conseil fédéral et qui dispose d'une large autonomie quant aux sujets à traiter.

Les questions d'égalité sont un élément important non seulement de la politique intérieure, mais aussi de la politique extérieure. Les inégalités entre les sexes constituent en effet l'un des principaux obstacles à la croissance économique et à la réduction de la pauvreté. C'est pourquoi la Direction du développement et de la coopération (DDC) intègre une perspective de genre dans l'ensemble de ses activités et projets. De façon plus générale, dans sa politique extérieure des droits humains, la Suisse s'engage résolument pour les droits des femmes et leur autonomisation, ceci au niveau bilatéral comme au niveau multilatéral. Concernant la nouvelle feuille de route mondiale du développement durable pour 2030, adoptée par les États membres des Nations Unies en 2015, la Suisse a participé activement à ce que l'égalité des sexes figure non seulement comme un thème transversal se reflétant dans tous les objectifs, mais aussi comme un objectif spécifique.

Dix-neuf cantons et cinq villes possèdent au moins une institution, bureau ou commission, chargée des questions d'égalité, avec des ressources et des mandats très variables : personnel administratif, famille, diversité, intégration, éducation, violence. Les bureaux sont réunis en une Conférence suisse des délégué·e·s à l'égalité, qui assure l'échange de bonnes pratiques et coordonne des projets d'importance nationale. En outre, les universités et les hautes écoles spécialisées disposent de leurs propres bureaux de promotion de l'égalité des chances, qui possèdent, eux aussi, leurs propres structures de coordination.

Malgré ce maillage en apparence dense, les moyens financiers et humains de ces structures sont souvent modestes et une demi-douzaine de cantons, tous situés en Suisse alémanique, ne disposent pas de mécanisme institutionnel, alors même que le Tribunal fédéral a stipulé, dans un jugement décisif datant de 2011, que tous les cantons devaient se doter des mesures institutionnelles et organisationnelles pour l'accomplissement du mandat constitutionnel.

$\mathrm{Au}$ cours des deux dernières décennies, des changements importants ont pu être apportés, parmi lesquels on citera le nouveau droit du mariage (1988), la nouvelle loi sur la nationalité (1992), la loi sur l'égalité (1996), la 10e révision de l'AVS (1997), le nouveau droit du divorce (2000), la dépénalisation de l'interruption volontaire de grossesse (2002), la poursuite d'office des délits de violence dans le couple (2004), l'allocation de maternité (2005), l'instauration dans le droit civil d'une protection contre les violences, menaces et harcèlement (2007), l'instauration dans le Code pénal d'une interdiction des mutilations génitales féminines (2012) et du mariage forcé (2013), le nouveau droit de nom et de cité (2013) ou encore l'autorité parentale conjointe comme règle générale (2014).

En dépit de ces avancées majeures, il reste du chemin à faire sur la voie de l'égalité. Les femmes continuent d'être moins bien rémunérées que les hommes. La conciliation entre le travail et la famille demeure difficile pour les deux parents : il y a trop peu de places d'accueil extrafamilial pour les enfants. La proportion de femmes élues dans le Parlement fédéral demeure encore faible. Filles et garçons sont toujours fortement influencés par des stéréotypes dans le choix de leur formation, de leur profession et de leur mode de vie. Enfin la violence domestique est un fléau répandu: en moyenne, elle tue environ une personne toutes les deux semaines, ce qui signifie que près de la moitié des homicides sont commis dans ce contexte.

La politique de l'égalité figure donc encore dans le programme de législature de la Confédération, où l'on peut observer une double approche, d'un côté sectorielle et spécifique, et de l'autre, transversale et intégrée (gender 
mainstreaming). À cet égard, il ne faudrait pas oublier que, si la politique de l'égalité peut contribuer substantiellement aux politiques familiale, sociale et économique, l'égalité est d'abord et avant tout une question de droit.

\section{Sylvie Durrer}

\section{Références}

Bureau fédéral de l'égalité entre femmes et hommes (Éd.) (2014). Quatrième et cinquième rapport de la Suisse sur la mise en œuvre de la Convention sur l'élimination de toutes les formes de discrimination à l'égard des femmes (CEDEF). Berne: Confédération suisse.

Derungs, F., Lüthi, J., Schnegg, B., Wenger, N. \& Ganzfried, M. (2014). Égalité entre femmes et hommes - Plan d'action de la Suisse : bilan 19992014. Berne: Bureau fédéral de l'égalité entre femmes et hommes.

Liebig, B., Gottschall, K. \& Sauer, B. (Éd.) (2016). Gender equality in context: theories, practices, and perspectives in Switzerland. Opladen: Barbara Budrich.

\section{Politique de l'emploi*}

La politique de l'emploi est la branche de la politique économique qui vise à maximiser la participation à l'emploi de la population en âge de travailler. Elle peut se déployer de diverses manières allant de l'intervention directe de l'État en faveur de la création d'emplois (approche keynésienne) à la mise en place de conditions favorables à la création d'emplois par les acteur.trice-s du marché eux- et ellesmêmes (ce qu'on appelle la supply-side economics). En Suisse, la politique de l'emploi renvoie à l'objectif implicite de la politique sociale bourgeoise qui vise l'intégration sociale sans mettre en cause l'économie capitaliste.

Contrairement à d'autres pays européens, où les approches keynésiennes ont pris pied après la Seconde Guerre mondiale, la conviction économique libérale prédominante, celle des partis de droite, est que la Suisse poursuit la meilleure politique de l'emploi si elle renonce à des mesures visant directement la promotion de l'emploi. Suivant la conception mainstream de l'économie, les mesures cherchant directement à augmenter l'emploi rémunéré, ou à atténuer sa réduction, telles que l'école (néo-)keynésienne les proposent, sont considérées comme des efforts bien intentionnés mais naïfs. Un tel dirigisme n'aboutirait qu'à conserver les structures existantes et serait donc contre-productif. Il est vu d'un mauvais œil par les tenant·e.s de l'approche mainstream qui lui préfèrent les mots d'ordre suivants : pas de politique de l'emploi directe via un renforcement du service public, pas de nationalisations en cas de faillites imminentes de grandes entreprises privées, pas de subventions dans le cadre d'une politique industrielle ou sectorielle active, pas de protection tarifaire ni de barrières commerciales (sauf pour l'agriculture), pas de protection contre le licenciement ni de salaire minimum, pas d'utilisation discrétionnaire du mécanisme de la dette publique dans la politique économique en dehors du cadre étroit défini par le frein à l'endettement. Le soutien quasi unanime des associations patronales de branche et des syndicats en faveur du chômage partiel est une position qui déroge partiellement à ces principes, alors même que de nombreuses études ont montré que cet instrument ne produit pour ainsi dire que des effets d'aubaine. En d'autres termes: des suppressions d'emplois déjà décidées sont au mieux un peu retardées par le chômage partiel.

En raison de leurs convictions (ordo)libérales, les partis de droite sont fondamentalement opposés à toutes les mesures de politique économique visant à influencer directement le nombre d'emplois. Pourtant, la finalité implicite de la politique de l'emploi fait l'objet d'un très large consensus social qui s'étend de l'extrême gauche à l'extrême droite. Par conséquent, l'objectif politique consistant à maintenir la participation la plus élevée possible de tous les groupes sociaux de personnes en âge de 
travailler (actuellement : entre 18 et 65 ans) au marché du travail capitaliste ne semble même pas nécessiter de débat. Cet objectif semble si évident que la nécessité de le légitimer ne s'est jamais imposée. Dans ce contexte, désigner la participation maximale au marché du travail comme un objectif politique semble trivial tellement cela va de soi. Le rapport 2012-2015, adopté par le Conseil fédéral, énumère les six domaines d'action de la politique de croissance. Le troisième de ces domaines préconise le maintien d'un niveau élevé de participation au marché du travail comme un objectif de la politique du marché du travail. Bien que cet objectif ne soit mentionné que dans ce troisième domaine, l'ensemble des six points du rapport vise, implicitement, à créer more and better jobs. De fait, la Suisse détient l'une des premières places en matière de participation au marché du travail de la population en âge de travailler. Elle connaît depuis la fin des années 1990 une forte augmentation tant du travail frontalier que de l'immigration.

C'est par le renforcement direct des facteurs permettant la croissance des entreprises que la politique de l'emploi indirecte est censé agir indirectement. L'État doit donc promouvoir ces facteurs. Dans cette logique, on espère que l'expansion des entreprises créera de nouveaux emplois qui viendront compenser voire dépasser ceux qui sont supprimés à l'occasion des transformations structurelles. Une telle politique de croissance se situe dans la droit ligne de la supply side economics. L'État est censé utiliser les ressources fiscales pour financer les biens publics de manière efficace, sans chercher à concurrencer les entreprises en proposant ses propres services publics. Ainsi, l'État fournit au secteur privé des «conditions-cadres attractives » : 1) Les charges financières découlant des activités étatiques seront réduites au minimum pour les entreprises en diminuant la taille de l'État social autant que possible et, surtout, en taxant les salaires et non les profits et bénéfices. De plus, les salaires sont imposés non pas de manière progressive, mais proportionnelle afin de ne pas décourager l'emploi. 2) Une sécurité juridique, immunisée contre toute forme de corruption, garantira les droits de propriété des biens matériels et intellectuels. 3) L'État finance des infrastructures fiables et modernes. 4) Le système de formation, apparemment pensé comme détaché du système économique, financé par des fonds publics mais mis en œuvre par des acteur-trice-s privé·e-s, fourni une relève appliquée, performante et motivée. 5) La fonction principale de ce système de formation, financé uniquement par l'État dans toute la mesure du possible, consiste aussi à fournir la relève performante nécessaire. 6) En plus de la promotion classique de la place économique suisse et de l'exportation, le soutien de l'État à la recherche et à l'innovation garanti le leadership technologique de la Suisse en tant que site de production (p.ex. par le financement des écoles polytechniques qui assurent le transfert de technologies au moyen de public private partnerships, ou par des fonds de lancement en faveur des start-ups). L'agence de promotion Innosuisse, soutenue par la Confédération, dispose d'un fonds de subvention que le Conseil fédéral exploite avec souplesse. Ce fonds peut aussi être utilisé officieusement, au cas par cas, dans le cadre d'une politique conjoncturelle axée sur la demande (comme ce fut le cas lors de la crise financière de 2008/2009).

En Suisse, une politique de croissance explicite coïncide donc avec une politique de l'emploi implicite ou indirecte, laquelle se présente comme le seul type de politique sociale compatible avec l'impératif capitaliste de maximisation de la croissance économique. La condition de réussite sine qua non d'une telle politique de croissance est la mise en concurrence globale des sites économiques. Cette concurrence est dès lors perçue comme un fait de nature darwinien qui ne peut pas être aménagé et dont la pertinence ne peut pas être remise en ques- 
tion. On ne peut que se soumettre à ce fait de nature ou, à défaut, sombrer.

Lorsqu'on la compare avec l'Europe et le reste du monde, la Suisse est confrontée à un autre type de problème. En effet, tandis que la plupart des autres pays, du moins depuis la crise financière de 2008/2009 sont affectés par un chômage élevé des jeunes, une augmentation des contrats précaires, une généralisation des bas salaires et une augmentation de la dette publique, la Suisse s'est préoccupée, quant à elle, d'exploiter au mieux le potentiel de main-d'œuvre domestique et d'améliorer l'efficience de ses agences publiques pour l'emploi, ceci dans le but d'endiguer l'immigration de masse et de maintenir les accords bilatéraux I et II avec l'Uunion européenne.

\section{Thomas Ragni}

\section{Références}

Conseil fédéral (2012). Politique de croissance 20122015: rapport du Conseil fédéral. Berne : Confédération suisse.

Organisation for Economic Co-operation and Development (Ed.) (2003). OECD Employment Outlook 2003: towards more and better jobs. Paris : OECD Publishing.

Zimmerli, W., Malaguerra, C., Künzli, R. \& Fischer, M. (2009). Zukunft Bildung Schweiz: Anforderungen an das schweizerische Bildungssystem 2030. Bern: Akademien der Wissenschaften Schweiz.

\section{Politique des addictions*}

La politique des addictions a pour tâche de régler la production, le commerce et la consommation de substances légales et illégales, ainsi que d'offres susceptibles d'induire une dépendance (jeux d'argent, offres en ligne, jeux) dans le but de minimiser les risques pour les consommateur-trice-s, leur entourage, l'économie et la société. Une politique étatique des addictions peut aller d'une interdiction totale de la production, du commerce et de la consommation (prohibition) à une libéralisation totale (libre marché), en passant par des formes intermédiaires, par exemple la dépénalisation de certains domaines ou leur réglementation étatique (régulation du marché).

La politique de la Suisse en matière d'alcool, de tabac, de drogues et de jeux d'argent s'est développée dans des contextes sociopolitiques, économiques, de santé publique et de sécurité différents. Une politique globale des addictions, indépendante du genre de substance et d'offre et incluant toutes les substances psychoactives et toutes les offres, n'existe pas; aujourd'hui encore, la politique suisse des addictions est une politique différenciée par substance. La production, le commerce et la consommation d'alcool, de tabac, de drogues illégales et de jeux d'argent sont réglés dans des lois spécifiques. Depuis quelques années toutefois, plusieurs acteur-trice-s travaillent ensemble dans l'optique d'une approche globale: la Commission fédérale pour les problèmes liés aux addictions avec son «modèle du cube» (2007), les trois commissions extraparlementaires du domaine des addictions avec le rapport «Défi addictions» (2010) et l'Office fédéral de la santé publique avec la «Stratégie nationale addictions 2017-2024» (2015).

Politique drogues: suite à l'augmentation de la consommation en Suisse vers la fin des années 1960, la loi sur les stupéfiants fut révisée et les tâches répressives de la police et de la justice furent complétées avec des offres de prévention et de traitement. À la fin des années 1980 , les scènes ouvertes et la forte hausse du nombre de victimes d'overdose et des infections VIH conduisirent au réexamen de la politique dite des trois piliers (prévention, traitement et répression) et à son élargissement au volet réduction des risques et aide à la survie. Même si l'initiative fédérale sur la légalisation des drogues fut rejetée en votation populaire, en 1998, elle n'en a pas moins débouché sur l'approvisionnement médical des personnes touchées, la distribution de matériel d'injec- 
tion stérile et de préservatifs, ainsi que l'administration contrôlée d'héroöne et de méthadone. Ce fut la politique des quatre piliers, valable encore aujourd'hui, qui a été pendant longtemps unique au monde et dont de nombreux autres pays se sont inspirés. Sur le continuum entre prohibition et libre marché, la politique suisse des drogues est plus proche de la prohibition. La prohibition n'est pas toutefois pas totale pour deux raisons : la consommation de cannabis par des adultes n'est pas forcément poursuivie pénalement (modèle des amendes d'ordre) et la distribution contrôlée d'héroïne est autorisée.

Politique alcool: la politique suisse dans ce domaine découle des problèmes graves liés à l'alcool dans les années 1880 («peste de la gnôle») et 1930 («pléthore d'alcool»). En 1932, le gouvernement suisse promulgua la première loi anti-alcool pour juguler l'abus répandu d'alcool à pourcentage élevé. La politique en matière d'alcool est fortement influencée par des intérêts économiques (producteur-trice-s de fruits et viticulteur-trice-s, brasseurs, distillateur-trice-s, commerce de détail, gastronomie, publicité), ce qui explique le succès mitigé de la régulation du marché de l'alcool pour réduire les risques liés à l'alcool. La révision totale de la loi sur l'alcool (2012-2015), qui visait à réduire la consommation problématique d'alcool dût être suspendue en raison de divergences inconciliables entre les défenseur·e·s des intérêts économiques et partisan·e-s de la prévention. Entre prohibition et libre marché, la politique de la Suisse relève de la forme intermédiaire de la régulation du marché : la production et le commerce de boissons alcoolisées sont réglementés par l'État (exigences de qualité, impôt, interdictions de vente aux enfants et jeunes, etc.).

Politique tabac: comme la politique alcool, la politique tabac est liée à des intérêts économiques. La production de tabac est cependant strictement réglementée et d'importantes mesures de prévention du tabac ont été ins- crites dans la législation au tournant du dernier millénaire (interdiction de la publicité pour les produits du tabac en 2006 ; loi sur la protection contre la fumée passive en 2010). Concernant le commerce et la publicité, la Suisse fait partie des pays les plus libéraux d'Europe. Elle est le seul pays européen à ne pas avoir ratifié la Convention du tabac de l'Organisation mondiale de la santé. La politique tabac est elle aussi une politique de régulation du marché, avec des prescriptions relatives à la production, le commerce et la consommation (exigences de qualité, impôt, interdiction de fumer dans l'espace public, etc.).

À la différence des politiques alcool et tabac, la politique des jeux d'argent a été prohibitive pendant tout le $\mathrm{XX}^{\mathrm{e}}$ siècle, avec l'interdiction des banques de jeux (casinos) et des jeux de loterie par la vox populi, en 1920 en 1923 respectivement. On assiste à un changement d'orientation à la fin du $\mathrm{XX}^{\mathrm{e}}$ siècle pour des motifs économiques. En raison de la crise économique des années 1990 et au vieillissement de la population, l'interdiction des casinos est levée en 1993 afin de renflouer les caisses de l'AVS et de l'AI. En plus des recettes fiscales de l'impôt sur le tabac et sur l'alcool, qui servent à alimenter l'AVS/AI, 60 à $80 \%$ des gains des casinos sont reversés à cette institution de prévoyance fondée en 1948. Les loteries sont interdites aujourd'hui encore, à l'exception des loteries qui servent à des fins d'utilité publique ou de bienfaisance. La politique des jeux d'argent est une politique de régulation du marché. Les casinos et les loteries sont soumis à des réglementations étatiques, notamment sur la protection des joueur-euse-s. Il n'existe pas de politique à proprement parler concernant les offres en ligne et les jeux d'argent. Cette politique est proche du marché libre.

En Suisse, l'aménagement et la mise en œuvre de la politique des addictions relèvent de tous les échelons de l'État fédéral, avec une législation nationale, cantonale et communale. L'avantage de cette décentralisation est qu'elle 
permet de tenir compte des réalités locales et de mener des projets pilotes à un niveau local/régional, qui pourront être repris ailleurs comme bonne pratique; mentionnons à titre d'exemple la distribution contrôlée d'héroïne, testée en ville de Zurich, reprise par d'autres villes et qui a finalement été ancrée dans la législation nationale. Son désavantage : le foisonnement des bases légales, qui rend difficile le développement cohérent et lié aux besoins de l'offre globale. La prévention, le traitement et la réduction des risques dépendent en outre grandement des politiques cantonales et locales et des capacités financières, ce qui se traduit in fine par de grandes différences entre les cantons.

La politique répressive des drogues illégales, qui a prédominé dans le monde entier depuis les années 1970, n’a pas produit les effets souhaités. Elle n'a pas permis de réduire notablement la consommation de drogues illégales ni de juguler la criminalité liée à la drogue. Face à ce résultat, plusieurs États ont commencé à repenser leur politique de drogues et à chercher de nouvelles solutions, notamment pour le cannabis. Par analogie aux drogues légales, le cannabis est légalisé et sa production, son commerce et sa consommation sont réglementés. Ce modèle de la régulation du marché est en principe applicable à toutes les drogues illégales, les drogues dangereuses devant toutefois demeurer soumises à des règles plus sévères que celles qui le sont moins. Le développement de la politique drogues en direction d'une régulation du marché s'avère difficile, car cette politique est empreinte de valeurs et de débats moralisateurs qui freinent le mouvement. Ceci est valable aussi bien pour la politique des drogues illégales que pour celles de l'alcool, du tabac et des jeux d'argent.

Petra Baumberger

\section{Références}

Coordination politique des addictions (2013). Régulation du marché en matière de politique des drogues. Zofingue : Coordination NAS-CPA.

Groupe de pilotage des commissions fédérales pour les problèmes liés à l'alcool, les questions liées aux drogues et la prévention du tabagisme (Éd.) (2010). Défi addictions: fondements d'une approche durable de la politique des addictions en Suisse. Berne: Groupe de pilotage Défi addictions.

Nutt, D. J., King, L. A. \& Phillips, L. D. (2010). Drug harms in the UK : a multicriteria decision analysis. The Lancet, 376(9752), 1558-1565.

\section{Politique du handicap*}

La politique en faveur des personnes en situation de handicap est un domaine dont les contours ne sont pas clairement délimités. Elle est constituée de plusieurs champs politiques et d'une tâche sociale commune. La politique du handicap comprend des domaines tels que l'égalité et la lutte contre la discrimination, le droit au minimum d'existence, l'insertion sur le marché du travail, la formation et l'éducation, les barrières architecturales et dans les transports, le développement de technologies adaptées aux besoins des personnes handicapées, les soins et l'assistance, etc. Par conséquent, de nombreux champs politiques sont concernés: droits de l'homme, affaires sociales, économie, système éducatif, technologie et innovation, santé.

Lors de l'élaboration d'une politique du handicap, tout dépend de la définition donnée au terme «handicap». La définition du handicap a des conséquences directes sur la conception et la mise en œuvre des différents axes de cette politique. Le regard exclusivement médical porté aux handicaps pendant des décennies ne suffit plus. L'accent doit plutôt être mis sur les personnes qui, en raison d'obstacles infrastructurels et liés au marché du travail, ne sont pas en mesure de prendre part à la société, ou seulement de manière limitée. Le 
modèle médical doit donc être complété par le modèle social dans le but de permettre aux personnes en situation de handicap de choisir librement, comme toutes les autres personnes, leurs conditions de vie.

La littérature spécialisée internationale cite généralement trois axes constitutifs d'une politique du handicap: 1) une orientation de compensation qui prône la compensation et la ségrégation selon un principe d'assistance; 2) une orientation de réhabilitation qui prône la prévention et la réhabilitation selon un principe d'assurance; 3) une orientation de participation qui prône la participation et l'égalité selon le principe de la garantie des droits fondamentaux.

Plus simplement, l'orientation de compensation consiste à offrir une indemnisation ou un soutien en cas de handicap. Cela peut se faire au travers de moyen auxilaires, de solutions techniques, de soins, de l'enseignement d'aptitudes utiles à la vie de tous les jours, etc. Les personnes sans handicap restent la référence de cette orientation. L'orientation de réhabilitation cherche à éliminer ou à atténuer les handicaps ou leurs conséquences. Elle vise à aider les personnes en situation de handicap à s'intégrer. Dans cette orientation également, les personnes sans handicap servent de référence. L'orientation de participation, quant à elle, place la participation aux décisions qui les concernent au centre. La Convention de l'ONU relative aux droits des personnes handicapées se fonde sur cette orientation.

Cependant, d'un point de vue critique, même une orientation fondée sur la participation ne suffit pas. Elle ne constitue que le point de départ et la condition préalable indispensable à l'inclusion, c'est-à-dire à une société qui traite les personnes en situation de handicap comme l'une de ses composantes évidentes, une société dans laquelle leur présence est «normale».

Tandis que la plupart des États membres de l'Union européenne ont commencé, dans les années 1990, à réformer fondamentalement leur politique du handicap, la Suisse n'a pas encore construit de politique nationale en la matière. Au cours des dernières décennies, les débats politiques ont surtout porté sur l'assainissement de l'assurance-invalidité. Les autorités politiques et administratives se sont limitées à lancer de nouvelles révisions de la loi fédérale sur l'assurance-invalidité. La Confédération, les cantons, les communes, les assurances sociales et d'autres acteur.trice-s ont fonctionné de manière non coordonnée voire contradictoire. La loi sur l'égalité pour les handicapés (LHand), entrée en vigueur en 2004, et la ratification de la Convention des Nations Unies relative aux droits des personnes handicapées par la Suisse en 2014, n'ont guère contribué à renverser cette tendance. Néanmoins, certains cantons, comme Berne et Bâle-Ville, disposent désormais de leur propre politique du handicap. Le rapport de 2016 sur cette politique dans le canton de Berne est explicite : il précise que les exigences centrales de la Convention des Nations Unies relative aux droits des personnes handicapées, telles que le renforcement de l'autodétermination et la participation à la société, ne sont pas ou que partiellement réalisées. Selon ce rapport, un changement d'attitude est nécessaire et les structures et processus qui se sont imposés au long de l'histoire doivent être adaptés.

Fin 2015, le Conseil fédéral a chargé le Département fédéral de l'intérieur (DFI) d'élaborer avant la fin de l'année 2016 des propositions en vue d'une meilleure coordination des mesures de la Confédération et des cantons. Il a également mandaté un rapport sur la manière dont les principaux champs politiques - l'éducation et l'emploi - pourraient être mieux intégrés dans la politique du handicap. Le rapport devait proposer un monitoring de l'égalité des personnes en situation de handicap. À la mi-janvier 2017, le Département fédéral de l'intérieur (DFI) a publié le «Rapport sur le développement de la politique en faveur des 
personnes handicapées». Il définit 8 objectifs et 15 mesures visant à améliorer l'égalité, la mise en réseau, le pilotage et la transparence de la politique en faveur des personnes en situation de handicap. Son objectif principal est de favoriser l'insertion professionnelle. Toutefois, ce rapport n'est qu'une étape préliminaire; le Conseil fédéral a chargé le DFI de présenter un nouveau rapport pour la fin de l'année 2017. Les organisations d'aide aux personnes handicapées critiquent le fait que le rapport ne contienne ni mesures concrètes pour améliorer les conditions de vie des personnes handicapées ni stratégie et qu'il s'agisse avant tout d'une déclaration de bonnes intentions.

$\mathrm{Du}$ point de vue des personnes handicapées, il est clair que la Suisse doit adopter une nouvelle approche pour élaborer une politique nationale en faveur des personnes en situation de handicap en se référant à une orientation inclusive. Elles demandent qu'une politique nationale dans le domaine du handicap vise clairement l'inclusion. En outre, une telle politique doit couvrir tous les aspects de la vie, inclure toutes les formes de handicap et tenir en particulier compte des intérêts spécifiques des femmes, des enfants, des personnes âgées, des migrantes et des migrants en situation de handicap. Elle doit contenir un plan d'action permettant de concrétiser l'égalité et la participation dans tous les aspects de la vie. Il est essentiel d'associer l'ensemble des acteurs et actrices - notamment les personnes handicapées - à l'élaboration d'une politique nationale et d'un plan d'action en faveur des personnes en situation de handicap.

Suzanne Auer

\section{Références}

Département fédéral de l'intérieur (2017). Rapport sur le développement de la politique en faveur des personnes handicapées. Berne: Confédération suisse.
Detreköy, C., Steiner, E. \& Zürcher, T. (2016). Politique du handicap du canton de Berne 2016: rapport du Conseil-exécutif au Grand Conseil. Berne: Direction de la santé publique et de la prévoyance sociale du canton de Berne.

Maschke, M. (2007). Behindertenpolitik in der Europäischen Union: Ein Vergleich der Lebenssituation behinderter Menschen und der nationalen Behindertenpolitik in 15 Mitgliedstaaten. Wiesbaden: VS.

\section{Politique du logement}

Il n'existe pas de «droit au logement» en Suisse, mais la Constitution fédérale prévoit parmi ses buts sociaux que «la Confédération et les cantons s'engagent, en complément de la responsabilité individuelle et de l'initiative privée, à ce que [...] toute personne en quête d'un logement puisse trouver, pour elle-même et sa famille, un logement approprié à des conditions supportables» (article $41 \mathrm{ch} .1$ ). Cet article est complété par les articles 108 et 109, dont on peut extraire les principes directeurs de la politique suisse du logement:

> sa subsidiarité par rapport à l'initiative privée et aux marchés

> la collaboration de la Confédération avec, voire la délégation aux cantons

> le traitement égal du logement locatif et du logement en propriété

> la priorité donnée à certaines catégories «fragiles» de la population: les familles, les personnes âgées, handicapées ou dans le besoin

> la protection des locataires dans le droit du bail

On distingue dans la Constitution les deux piliers principaux de la politique du logement: l'aide au logement et le droit du bail. Ce dernier, qui est un chapitre du Code des obligations (CO), pourrait se limiter à préciser les éléments obligatoires et compléter les points manquants des contrats entre parties, comme 
le font d'autres chapitres du CO. En réalité et en application de l'article 109 de la Constitution fédérale, le droit du bail prévoit une série de dispositions protégeant les locataires contre les loyers élevés et les hausses de loyer non justifiés, ainsi que contre les congés qui les exposent à des conséquences pénibles. On trouve d'ailleurs des dispositions similaires dans pratiquement tous les appareils législatifs nationaux, mais le droit du bail suisse revêt une importance particulière puisqu'il concerne plus de six ménages sur dix. Il fait donc partie intégrante de la politique du logement.

Avec une proportion de logements locatifs dépassant $60 \%$, la Suisse vient en tête de tous les pays comparables. On pourrait y voir l'échec du pan de l'aide au logement visant à encourager l'acquisition de son propre logement. Il est vrai que les mesures mises en place à cette fin, principalement un avantage fiscal et des aides au financement, sont bien moins généreuses que dans d'autres pays. En même temps, on peut voir dans la proportion élevée de ménages locataires, qui en grande majorité se déclarent satisfaits de leur situation, une marque de succès du droit du bail helvétique, qui parvient à équilibrer tant bien que mal les intérêts des bailleurs et bailleresses et des locataires.

L'autre pan de l'aide au logement, qui vise à encourager la construction de logements, n'est pas bien mieux doté, ni au niveau fédéral, ni dans les cantons. La volonté est clairement de laisser l'initiative privée répondre aux besoins. Les logements en mains de collectivités publiques ne représentaient que $4,3 \%$ de tous les logements locatifs en 2017. Depuis 2003, la Confédération ne soutient plus que les maîtres d'ouvrage d'utilité publique, et ceci très modérément. Ceux-ci construisent et possèdent des logements à prix avantageux, dont les loyers ne dépassent pas les coûts, pour toutes les couches sociales de la population. Ils étaient propriétaires de $7 \%$ des logements locatifs en 2017. Les aides directes et ciblées pour la construction et la rénovation de logements sociaux prévues par la nouvelle loi d'application de l'article constitutionnel n'ont jamais été mises en œuvre, victimes des programmes d'allègement du budget fédéral.

Même au début des années 1990, quand l'aide au logement atteignait un pic, la proportion des logements construits avec cette aide ne dépassait pas $10 \%$, une sorte de plafond informel concrétisant le principe de la subsidiarité. L'aide a pu être plus importante antérieurement, mais cela répondait alors à une volonté de soutenir la conjoncture qui n'existe plus aujourd'hui. Dorénavant, au vu des moyens limités, la Confédération entend concentrer son soutien sur les ménages défavorisés, les personnes ayant des besoins spécifiques peu pris en compte par le marché, les quartiers en difficultés et les économies d'énergie.

Ceci requiert des interventions différenciées dans le territoire et une collaboration avec les autorités locales, généralement en charge de ces missions. Elles connaissent mieux les besoins et peuvent coordonner les mesures avec d'autres instruments de la politique sociale. Elles vont donc privilégier ce qu'on appelle l'aide à la personne, soit un soutien direct aux personnes visées, visant à abaisser leur taux d'effort ou charge locative, c'est-àdire la part de leur revenu qu'elles doivent consacrer aux frais du logement. Là où l'offre de logements est insuffisante, les autorités recourent aussi à ce qu'on appelle l'aide à la pierre, soit un soutien à la construction ou la rénovation de logements permettant d'aboutir à des loyers abaissés. Parfois elles construisent elles-mêmes ou à travers des fondations ou sociétés immobilières de droit public. Enfin, les communes possèdent souvent encore des réserves foncières qu'elles peuvent engager pour du logement destiné à certains groupes désavantagés sur le marché. On voit que l'aide au logement peut prendre une grande variété de formes.

Malgré la multitude des instruments à disposition, la situation reste difficile pour de 
nombreux ménages. Les cantons et les communes utilisent ces instruments à des degrés très divers, selon les équilibres politiques davantage que les besoins reconnus. Environ un ménage locataire sur quatre supporte une charge locative dépassant $25 \%$, un plafond usuellement jugé supportable mais qui est en fait trop élevé pour les ménages vraiment modestes. La proportion des ménages supportant une charge locative excessive est d'ailleurs bien plus élevée (plus de $80 \%$ ) parmi les ménages touchés par la pauvreté, un problème plus important pour eux que des conditions de logement inappropriées. L'analyse de leur situation montre qu'ils ne paient pas des loyers particulièrement élevés, donc ce sont bien leurs revenus trop faibles qui conduisent à une charge locative excessive.

Un des effets indésirables du droit du bail est l'existence de différences prononcées de loyer pour des logements similaires selon qu'ils sont occupés depuis longtemps par les mêmes locataires ou proposés sur le marché. De plus, la construction de logements peine à suivre la demande pour diverses raisons ne relevant pas que de la politique du logement. L'ouverture complète à la libre circulation des personnes en 2007 n'a apparemment pas été anticipée, si bien que le parc immobilier n'était pas prêt pour le doublement de la croissance démographique qui en a résulté. Le taux de logements vacants, un indicateur de la disponibilité, était à un niveau bien trop faible, soit autour de $1 \%$, de 2002 à 2014. La conséquence de tout ceci est que les ménages à revenus modestes qui doivent déménager ou s'installer dans une commune urbaine rencontrent encore de grandes difficultés à trouver un logement abordable adapté à leurs besoins. Cela touche aussi les personnes du troisième âge, qui sont particulièrement concernées par les résiliations de bail et par les rénovations qui conduisent à des hausses de loyers alors que leurs revenus sont constants.

\section{Philippe Thalmann}

\section{Références}

Cuennet, S., P. Favarger \& Thalmann, P. (2002). $L a$ politique du logement. Lausanne: Presses polytechniques et universitaires romande.

Hauri, E. (2009). Quelle politique pour le logement social? Dans L. Pattaroni, V. Kaufmann \& A. Rabinovich (Éd.), Habitat en devenir: enjeux territoriaux, politiques et sociaux du logement en Suisse (pp. 299-321). Lausanne: Presses polytechniques et universitaires romandes.

Office fédéral du logement (Éd.) (2016). Dialogue en matière de politique du logement entre la Confédération, les cantons et les villes: rapport du groupe de travail, 12 décembre 2016. Granches : Confédération suisse.

\section{Politique économique}

La politique économique est un champ particulier de la politique qui s'intéresse aux interventions des pouvoirs publics (État, administrations, banque centrale, entités territoriales) sur l'activité économique au sens large, afin de favoriser la croissance économique, le plein emploi, mais également la justice sociale. La perspective poursuivie lors de ces interventions consiste à corriger les déséquilibres macroéconomiques que sont le chômage, l'inflation ou le déficit des finances publiques.

Selon Richard Musgrave, l'intervention des pouvoirs publics dans l'économie devrait poursuivre trois objectifs primordiaux. À savoir: l'allocation des ressources, la stabilisation de l'activité économique et la redistribution des revenus. Ces trois objectifs sont mis en œuvre par la politique économique qui veille à assurer le meilleur état possible de l'économie en utilisant principalement les instruments budgétaires et monétaires. 
Cette vision interventionniste de la politique économique, mettant en évidence l'importance de l'État central et des pouvoirs publics dans l'atteinte d'une meilleure allocation des ressources, d'une redistribution plus équitable des richesses, ainsi que dans l'atténuation des déséquilibres macro-économiques, rompt définitivement avec le courant de pensée antérieur, porté par David Ricardo et Adam Smith et sa célèbre main-invisible.

Dès la première moitié du XIX ${ }^{e}$ siècle, on assiste au développement des politiques économiques susceptibles de corriger un ordre économique qui n'est plus, comme par le passé, pensé comme naturellement équilibré. En Suisse, du fait de son attachement au libéralisme, l'organisation des compétences étatiques entre l'État fédéral et les vingt-deux cantons souverains, telle que prévu par la 1ère constitution fédérale de 1848, privilégie largement la politique d'ordonnancement (définition de conditions-cadres) et la politique structurelle dans le secteur agricole pour en améliorer son fonctionnement à moyen et long terme. Cette vision libérale est renforcée par les spécificités du système politique suisse, à savoir son fédéralisme et ses influentes fédérations nationales que sont l'Union suisse du commerce et de l'industrie (USCI) et l'Union suisse des arts et métiers (USAM), qui restreignent fortement la marge de manœuvre des autorités fédérales.

L'industrialisation de la Suisse et l'intégration au marché mondial, facilitée par l'essor des chemins de fer dans la deuxième moitié du XIX ${ }^{\mathrm{e}}$ siècle, ouvrent une nouvelle étape interventionniste pour la politique économique suisse, visant à réduire les obstacles à l'exportation tout en protégeant le marché intérieur contre la concurrence internationale. C'est durant cette période de croissance économique et démographique que de nouvelles formes de pauvreté jugées particulièrement graves voient le jour et que progresse l'idée selon laquelle l'État, en tant que représentant des intérêts généraux, doit intervenir dans la vie économique en faveur des groupes socialement défavorisés.

À la fin du XIXe siècle, la Suisse compte plus d'un millier de caisses de secours mutuels qui offrent, en échange d'une prime, une protection modeste contre les conséquences d'un accident ou d'une maladie. Dans le même temps, l'État fédéral impose des directives spécifiques en matière de protection des travailleurs et travailleuses en limitant la durée légale du travail et en protégeant les enfants. Ces deux points constituent des précurseurs importants des assurances sociales modernes avec l'adoption de la loi sur l'assurance-maladie et accidents en 1912, la création de l'Office fédéral des assurances sociales en 1913 et de la Caisse nationale suisse d'assurance en cas d'accidents (SUVA) en 1918.

Lors du premier conflit mondial, les interventions étatiques, sous forme de mesures protectionnistes (taxes douanières, limitations d'importation), se multiplient en faveur du marché intérieur et demeurent nombreuses durant l'entre-deux-guerres en raison d'une conjoncture très instable et d'une croissance intérieure erratique. Sur le plan social, la faiblesse de l'assistance, la pénurie alimentaire et la hausse des prix aggravent les difficultés sociales et préparent le terrain de réformes sociales d'envergure.

$\mathrm{Au}$ début de la grande dépression des années 1930, diverses mesures de politiques économiques sont décidées - les unes durables comme l'introduction du secret bancaire (loi de 1934 sur les banques), les autres plus éphémères, comme l'interdiction d'ouvrir ou d'agrandir des succursales et des grands magasins (1933-1945). C'est dans ce climat de difficultés sociales induit par la grande dépression que s'organisent également les caisses de pension, l'assurance-chômage et la prévoyance vieillesse.

Dès 1939, l'économie de guerre implique un interventionnisme assez poussé de l'État dans 
les domaines de l'alimentation, des transports, du travail et de la prévoyance. Les problèmes dans le domaine des assurances sociales, la santé et l'assistance aux réfugié-e.s sont ainsi pris en charge par l'Office de guerre pour la prévoyance. Cette période est également marquée par des développements de la sécurité sociale au plan fédéral, l'introduction d'un régime d'allocations pour perte de salaire et de gain en étant le signe le plus visible. C'est en 1947 que la loi sur l'AVS - $1^{\text {er }}$ pilier de la prévoyance vieillesse et pièce maîtresse de la sécurité sociale - est votée.

Conséquence directe de la reconstruction d'après-guerre, les années 1950 et 1960 connaissent une conjoncture exceptionnellement dynamique caractérisée par un développement massif des infrastructures. La Suisse adopte progressivement le principe du libre-échange à travers son adhésion à plusieurs organisations telles que l'Organisation de coopération et de développement économiques (OCDE), l'Association européenne de libre-échange (AELE) et l'Accord général sur les tarifs douaniers et le commerce (GATT).

La crise des années 1970 frappe plus durement la Suisse que les autres pays membres de l'OCDE et ouvre la voie aux partisan.e.s de la politique économique néolibérale, notamment en raison de l'inefficacité des politiques monétaires et budgétaires interventionnistes inspirées par l'économiste britannique John Maynard Keynes et ses disciples, qui visaient à stabiliser l'activité économique. Des réformes de la politique économique suisse dans le sens d'une large dérèglementation du marché et une limitation des compétences de l'État sont ainsi proposées. On relève en particulier la limitation des dépenses de l'État, un système fiscal qui favorise la croissance, ainsi qu'une politique sociale mieux ciblée en raison de mécanismes de redistribution jugés trop larges. Une révision des dispositifs des assurances sociales est ainsi préconisée et toute couverture dépassant le minimum vital est renvoyée au domaine de la prévoyance privée. C'est également à cette période que la fondation Avenir Suisse, think tank largement soutenu par les entreprises suisses, développe les idées pour le futur de la Suisse.

Les enjeux actuels et futurs de la politique économique suisse sont décrits dans le Livre blanc Suisse d'Avenir Suisse, paru en 2018 sous forme de six esquisses d'avenir en prise directe avec les préférences du peuple suisse en matière, d'une part, de centralisation de l'activité économique suisse (interventionnisme étatique versus libre fonctionnement du marché) et, d'autre part, d'intégration de la Suisse dans les instances supranationales (intégration faible et autonomie accrue versus intégration forte et autonomie réduite). Dans les années à venir, ces préférences auront des répercussions sur toute une série de domaines tels que, par exemple, la politique migratoire, la politique financière et monétaire, la règlementation du marché intérieur, la souveraineté, la politique du marché du travail ou encore les politiques sociales et de redistribution des richesses.

En privilégiant la voie de la centralisation et de l'intégration, en particulier en regard de l'Union européenne, ce qu'on appelle également la voie «scandinave», on assisterait vraisemblablement à un développement important des politiques sociales et de redistribution ainsi qu'à un retour de l'État-providence par rapport à la situation actuelle. À l'inverse, en privilégiant la voie de la décentralisation et de l'autonomie, voie également appelée de «l'Oasis globale», on assisterait à une politique sociale et de redistribution des richesses réduite à sa plus simple expression.

Entre ces deux extrêmes, la voie appelée de «normalité européenne», qui privilégie la décentralisation et l'intégration au sein de l'Union européenne, serait neutre du point de vue de la politique sociale et de la redistribu- 
tion et resterait sensiblement identique à celle qui prévaut actuellement en Suisse.

\section{Yves Flückiger \& Pierre Kempeneers}

\author{
Références \\ Bonoli, G. \& Bertozzi, F. (Éd.) (2018). Les nouveaux \\ défis de l'État social - Neue Herausforderungen für \\ den Sozialstaat. Lausanne, Bern: Presses poly- \\ techniques et universitaires romandes, Haupt. \\ Deiss, J. \& Gugler, P. (2012). Politique économique et \\ sociale. Bruxelles : De Boeck. \\ Grünenfelder, P. \& Schellenbauer, P. (Éd.) (2018). \\ Livre blanc Suisse, six esquisses d'avenir. Zurich: \\ Avenir Suisse.
}

\section{Politique financière}

La politique financière désigne toute action visant à gérer efficacement le budget de l'État. Pour les un·e·s, il s'agit d'équilibrer le budget, pour les autres de le réduire ou de l'optimiser dans le sens d'une allocation optimale des ressources. Ces objectifs se servent de critères peu clairs: de quelle efficacité et de quelle optimisation s'agit-il au juste? De surcroît, il n'est guère possible de parler d'une seule politique financière, tant les outils de gestion peuvent varier entre communes, cantons et Confédération. La politique financière pratiquée en Suisse cherche donc sans cesse à concilier la logique économique avec la logique politique. Elle s'appuie sur la structure des comptes publics dont voici les principaux éléments.

Entre 1990 et 2014, les dépenses publiques de la Confédération en termes nominaux ont plus que doublé. Ce fort accroissement est avant tout imputable à la sécurité sociale, dont les dépenses ont triplé durant la même période. Ce poste représente environ un tiers des dépenses de la Confédération. Il sert d'indice pour mesurer l'ampleur de la politique de redistribution, et indirectement, l'effort consenti par les citoyen-ne.s pour assurer la cohésion sociale. Cependant, la quote-part des cotisations sociales par rapport au produit intérieur brut (PIB), environ $7 \%$, est restée assez stable durant ces dernières années. Cette observation vaut également pour les dépenses sociales en général évaluées dans une perspective historique récente. La Suisse se situe tout proche de la moyenne des pays membres de l'Organisation de coopération et de développement économiques (OCDE), mais bien derrière ses voisins directs, notamment la France.

Les autres grandes catégories de dépenses de la Confédération sont, par ordre décroissant: les finances et les impôts, le trafic et les télécommunications, la formation, l'administration générale, l'ordre et la sécurité publics ainsi que la défense, l'économie publique, notamment le soutien à l'agriculture, et la protection de l'environnement et l'aménagement du territoire.

La politique financière reflète des choix idéologiques quant à la place de l'État dans une économie, délimite le marché par rapport au secteur public, et sert d'indice du degré de solidarité par l'importance accordée aux transferts sociaux. Elle est régie par les principes suivants.

Toute dépense publique doit être financée, soit par l'impôt, soit par l'emprunt. Du point de vue macroéconomique, seule la fiscalité est pertinente pour la politique financière. Comme à tout emprunt correspond une créance, les deux s'annulent dans la comptabilité nationale. Des recettes fiscales supérieures aux dépenses publiques rend les comptes publics excédentaires et contribuent ainsi à augmenter l'épargne nationale. Des recettes fiscales inférieures, par contre, conduisent à un déficit public, ce qui ponctionne l'épargne privée et réduit ainsi le financement des investissements. Comme ces derniers sont le moteur de la croissance, un déficit public aujourd'hui entrave la croissance dans le futur.

Un excédent du solde budgétaire de l'État, par contre, constitue une épargne publique, 
qui contribue à son tour à financer les investissements. La croissance économique se trouve stimulée et entraîne à son tour des dépenses et des recettes publiques supplémentaires.

Quant à l'affectation des recettes fiscales, le financement des dépenses publiques par l'impôt est alimenté par des sources très variables. En principe, l'impôt sur les revenus finance les dépenses cantonales et communales et l'impôt indirect sur la valeur ajoutée celles de la Confédération. En pratique, cette distinction ne s'applique pas, car la Confédération prélève également un impôt direct. En outre, un réseau complexe de transferts financiers entre communes, cantons et Confédération rend toute classification des sources de financement aléatoire. Pourtant, un principe de financement devrait s'appliquer: moins les recettes fiscales sont affectées à des tâches spécifiques, plus la gestion publique est flexible et l'allocation des ressources optimale. Or, en pratique, le parlement lie souvent les recettes fiscales à des dépenses spécifiques.

Il n'y a pas de règles théoriques selon lesquelles le niveau et le montant des budgets publics peuvent être déterminés. Cependant, il est généralement admis qu'ils ne doivent pas évoluer plus fortement que la croissance économique. En Suisse, ce principe est respecté, car leur quote-part est restée assez stable durant les dernières années et s'élève en moyenne annuelle à environ $28 \%$ du PIB. De même, le degré d'endettement en Suisse est resté faible en comparaison internationale. Les critères de Maastricht, d'ailleurs rarement atteints par les pays membres de l'Union européenne, prévoient un plafonnement de la dette publique à $60 \%$ du PIB. La Suisse reste bien en dessous de cette norme avec environ $35 \%$ pour l'endettement de l'ensemble des administrations publiques. Cette évolution favorable est sans aucun doute le résultat d'efforts répétés visant à limiter l'expansion du secteur public et à garder son financement sous contrôle.
Ce contrôle est exercé par des politiques de stabilisation qui s'appuient sur un ensemble de mesures, parmi lesquelles figurent le modèle des trois comptes, le frein à l'endettement, et un programme de stabilisation proprement dit.

Le modèle des trois comptes, appliqué au niveau cantonal seulement, part du principe que le premier compte, comptabilisant les dépenses publiques courantes, vise l'équilibre, alors que le deuxième compte, concernant les investissements publics, peut être déficitaire, car ces dépenses sont également utiles pour les générations futures. Enfin, le troisième compte doit faire clairement apparaître la source du financement.

Quant au frein à l'endettement, il est ancré dans la Constitution fédérale depuis 2001. Il s'agit d'un mécanisme qui assure que les dépenses ne dépassent pas les recettes publiques durant la période d'un cycle conjoncturel complet.

Enfin, pour ce qui est du programme de stabilisation proprement dit, le Conseil fédéral a prévu 24 mesures d'économie pour 2017-2019 de près d'un milliard de francs par année.

La politique de stabilisation est tributaire de la santé économique du pays, elle-même fortement dépendante du contexte international. En périodes de haute conjoncture les recettes fiscales augmentent souvent plus fortement que les dépenses publiques. De surcroît, l'inflation gonfle l'assiette fiscale en termes nominaux. Un excédent budgétaire est dès lors probable. En périodes de basse conjoncture, l'inverse peut être observé: les recettes fiscales diminuent, tandis que les dépenses publiques décidées par voie législative, souvent lente et sinueuse, ne se réduisent pas si mécaniquement. Un déficit de l'État en est la conséquence.

Comme le développement économique des cantons se poursuit à des vitesses et des trajectoires différentes, la politique fiscale a été également mise au service de la convergence et de la réduction des inégalités, ce qui entre en tension avec la règle, la politique financière doit 
être affectée strictement à l'objectif de gestion efficace des comptes publics, tandis que la péréquation financière doit viser séparément l'objectif de convergence du développement économique entre cantons.

La politique financière est un chantier permanent. Elle fait l'objet de nombreux projets de réformes, notamment sur de nouvelles bases fiscales, dans des domaines variés allant de l'environnement naturel et social, jusqu'à la redéfinition de la charge fiscale des entreprises, discutée notamment dans le cadre de la troisième réforme après qu'un projet largement adopté par les Chambres a été refusé en votation populaire en 2017. La tendance vers une harmonisation fiscale au sein de l'Union européenne façonnera à l'avenir la politique financière qui se définira de moins en moins en termes purement nationaux.

\section{Beat Bürgenmeier}

\section{Références}

Administration fédérale des finances. Indicateurs des finances publiques. https://www.bfs.admin.ch/

Dafflon, B. (2014). Panorama des impôts en Suisse, du local au fédéral, entre équité et concurrence: quels enjeux? Lausanne: Domaine public.

Longchamp, O. (2014). La politique financière fédérale (1945-1958). Lausanne: Antipodes.

\section{Politique monétaire}

La politique monétaire consiste à utiliser les instruments dont dispose la Banque centrale pour atteindre un certain nombre d'objectifs de politique économique. Parmi ceux-ci se trouvent surtout la stabilité des prix à la consommation et la stabilité du système financier, qui est formé par les banques et les institutions financières non bancaires, comme les caisses d'épargne et les compagnies d'assurance. Ces deux objectifs sont aussi importants pour les politiques sociales dans la mesure où ils contribuent à préserver la capacité d'achat de la classe moyenne. La stabilité des prix sur le marché des biens et services est mesurée à l'aide d'un indice des prix à la consommation, qui repose sur un panier de produits achetés par un échantillon représentatif de ménages et qui est utilisé pour calculer le taux d'inflation. La stabilité financière, par contre, est un objectif dont la mesure reste à déterminer car, en l'état, il n'y a pas d'indicateurs clairement établis pour ce faire.

Historiquement, la Banque centrale avait une multiplicité d'objectifs concernant l'ensemble du système économique. En plus des objectifs de stabilité des prix et des taux de change de la monnaie nationale, elle était censée contribuer à la stabilisation de la conjoncture et, par là, du marché du travail, en particulier à travers le financement des dépenses publiques au niveau national. De cette manière, l'État pouvait soutenir l'activité économique afin de réduire le taux de chômage lors des périodes de fort ralentissement conjoncturel, voire de crise économique, sans devoir nécessairement s'endetter sur les marchés financiers à des taux d'intérêt évoluant à la hausse au fur et à mesure que la situation des finances publiques se dégrade. Si la conjoncture est mauvaise, en effet, les dépenses publiques pour les politiques sociales augmentent, alors que les recettes fiscales peuvent diminuer de manière importante, creusant ainsi de plus en plus les déficits publics. Le financement des déficits budgétaires par la Banque centrale permettait à l'État d'atteindre ses propres objectifs de politique économique à des taux d'intérêt bas et stables à long terme, lui laissant également davantage de temps pour rembourser la dette publique, qui d'ailleurs pouvait facilement être rééchelonnée par la Banque centrale en cas de problèmes majeurs affectant les finances publiques.

Cette collaboration étroite entre la Banque centrale et le gouvernement national a bien fonctionné du temps des Trente Glorieuse 
(1946-1973), caractérisées par la stabilité des taux de change (sous le régime de Bretton Woods) et par des politiques économiques d'inspiration keynésienne, qui visaient la stabilisation conjoncturelle à travers l'intervention de l'État et de la Banque centrale - qui à l'époque était soumise aux autorités politiques et dès lors ne pouvait pas définir ses propres objectifs indépendamment du gouvernement national. Ce fut ainsi une période de prospérité croissante et de bien-être pour l'ensemble de la population des pays occidentaux, qui prit fin avec l'abandon du régime de changes fixes au début des années 1970 et les deux crises pétrolières intervenues durant la même décennie. La deuxième moitié de celle-ci fut alors caractérisée par le phénomène de la stagflation, à savoir, une période où le taux d'inflation augmente malgré un taux de chômage élevé (ou qui augmente). Face à l'impuissance des politiques keynésiennes pour réduire le chômage avec des dépenses publiques accrues, dans un contexte de forte augmentation des prix à la consommation, un courant de pensée alternatif a émergé dans le monde occidental, à commencer par les États-Unis et le RoyaumeUni. S'inspirant des économistes prônant la non-intervention de l'État dans le système économique, ce courant de pensée (néolibéral) a amené au découplage entre la politique monétaire de la Banque centrale et la politique budgétaire du gouvernement. Désormais, la première ne doit se focaliser que sur la stabilité des prix à la consommation, alors que la seconde doit assurer l'équilibre des finances publiques, si possible de manière annuelle ou, en tous cas, au terme de la législature. Il serait en effet impossible pour une banque centrale de contribuer à la stabilisation conjoncturelle et, de là, à la maximisation du niveau d'emploi par les instruments de politique monétaire, comme les taux d'intérêt directeurs ou les interventions sur les marchés financiers. Depuis les années 1980, les banques centrales des pays occidentaux visent donc tout d'abord, voire uniquement, la stabilité des prix sur le marché des biens et services, imaginant que cet objectif contribue efficacement à la réalisation des objectifs de politique économique du gouvernement.

La Banque nationale suisse s'inscrit dans cette perspective car elle assure la stabilité des prix sur le marché des biens et services tenant compte de l'évolution de la conjoncture comme l'exige l'article 5 de la loi fédérale sur la Banque nationale suisse. Cela lui laisse une certaine marge de manœuvre lors de périodes conjoncturelles difficiles, parce qu'elle peut alors utiliser la politique monétaire pour aider à résorber le chômage et à relancer les activités économiques, pour autant que cela n'empiète pas, à terme, sur la stabilité des prix (définie par un taux d'inflation en dessous mais proche de $2 \%$ sur base annuelle). Or, la flexibilité implicite dans le mandat attribué à la Banque nationale suisse à l'égard de l'évolution conjoncturelle n'a souvent pas été utilisée pour le bien commun, étant donné que le directoire de cette institution s'inspire, en général, de la pensée monétariste, qui refuse toute possibilité d'influencer la conjoncture, donc le niveau d'emploi, avec les interventions de politique monétaire. Lors de l'abandon des objectifs de croissance monétaire en 1999 - qu'elle avait introduits juste après la fin du régime de Bretton Woods -, la Banque nationale suisse a adopté une stratégie de politique monétaire axée sur les prévisions d'inflation, visant à faire en sorte que l'augmentation des prix à la consommation soit positive mais proche de $1 \%$ sur base annuelle durant l'horizon temporel de ses prévisions (qui est de trois années). En principe, elle augmente le taux d'intérêt directeur lorsque sa prévision d'inflation montre que la hausse des prix sur le marché des produits dépasse $2 \%$ par année et réduit ce taux si elle prévoit que les prix des biens et services diminuent ou n'augmentent pas durant son horizon prévisionnel. 
Les enjeux actuels de cette stratégie de politique monétaire sont au nombre de deux. D'une part, la Banque nationale suisse a dû renoncer à sa stratégie du taux plancher (face à la monnaie européenne) et fait appel aux taux d'intérêt négatifs, afin de déprécier le taux de change du franc suisse. Cela induit des coûts pour les épargnant·e-s de la classe moyenne, les poussant à prendre davantage de risques sur les marchés financiers pour augmenter le rendement de leurs avoirs. D'autre part, le volume exorbitant de liquidités que les banques ont sur leurs comptes de virement auprès de la Banque nationale suisse suite à ses achats de devises pousse ces banques à octroyer des prêts hypothécaires qui font enfler les prix immobiliers de manière préoccupante pour assurer la stabilité financière. Une crise immobilière pourrait alors se produire en Suisse, bien avant que la Banque nationale suisse commence à «normaliser» sa politique des taux d'intérêt, après que la zone euro aura su surmonter sa propre crise.

\section{Sergio Rossi}

\section{Références}

Friedman, M. (1968). The role of monetary policy. American Economic Review, 58(1), 1-17.

Rossi, S. (2008). Macroéconomie monétaire: théories et politiques. Genève : Schulthess.

Rossi, S. (2015). Considerazioni su „Le franc suisse. L'histoire d'un succès“ di Ernst Baltensperger. Archivio Storico Ticinese, 52(158), 128-135.

\section{Politiques et pratiques policières}

La police a pour mandat le «maintien de la sécurité » et de «l'ordre public », si l'on se réfère aux diverses lois cantonales la régissant. Elle dispose pour cela d'une habilitation à faire usage de la violence physique de manière légale. Évoquer ces objectifs généraux et ce moyen particulier cache cependant le fait que, dans la réalité, les politiques et les pratiques policières sont diverses. Les tâches policières - et donc les compétences des professionnel-le·s - sont en effet particulièrement variées. Elles consistent en partie à détecter et sanctionner des infractions, une activité qui n'occupe cependant pas la majorité du temps des policières et des policiers de terrain. Les arrestations, ainsi que l'usage de la contrainte physique, sont bien plus rares que ne le laisse penser l'image publique de cette profession. L'essentiel de l'activité policière consiste à gérer des conflits et des incidents, à garantir ce que la loi qualifie parfois de «tranquillité publique». Le métier confronte dès lors ces professionnel-le-s à des situations et des problèmes sociaux complexes, souvent chargés émotionnellement, auxquels ils et elles doivent apporter des solutions dans l'urgence. La prise en charge ou les contacts avec des personnes vivant dans un contexte de précarité, ou sujettes à des problèmes psychiques ou de dépendance, sont fréquents. Par ailleurs, l'intervention de la police a la plupart du temps lieu au moment de crises ou lors de conflits, notamment domestiques ou de voisinage. Ces situations impliquant souvent des personnes démunies ou en souffrance, elles peuvent nécessiter l'accomplissement de tâches relevant de l'accompagnement social ou psychologique.

La prise en compte de la variété des publics, des tâches et des problématiques prises en charge par la police incite à considérer les politiques policières et de sécurité comme un sous-ensemble des politiques sociales. Elles concernent certes la régulation et le contrôle social, mais la police n'a pas le monopole de ces activités. En outre, une partie du travail policier peut viser à nourrir la cohésion sociale, notamment au travers de la résolution de conflits. Les débats sur la manière dont la police doit remplir son mandat public et s'acquitter de ses tâches portent, comme dans d'autres domaines des politiques sociales, sur la place à accorder aux mesures répressives et aux sanctions négatives dans la régulation des 
rapports sociaux. Celle-ci fait débat également dans le travail social, sanitaire ou éducatif, où se posent les questions du degré d'autonomie alloué aux bénéficiaires, du respect de leurs singularités et de la protection de leur dignité. Catégoriser les politiques policières de manière distinctive des politiques sociales vise le plus souvent à défendre une approche strictement répressive des problèmes sociaux ou à réduire les mesures de prévention à de la dissuasion au travers d'une menace de sanction.

Les réformes inspirées du community policing étatsunien, souvent traduit par l'expression «police de proximité», s'inscrivent dans une critique de la légitimité et de l'efficacité des approches policières centrées uniquement sur la répression. Elles pensent la police non comme le «bras armé de l'État», mais comme un service social visant principalement à lutter contre les causes de la délinquance, en partenariat avec d'autres services de l'État. Selon cette perspective, l'objectif principal de la police consiste à éviter que des infractions soient commises plutôt qu'à les détecter ensuite. Son activité ne devrait pas se concentrer sur les «belles affaires», mais sur les infractions considérées comme les plus dérangeantes par les usagères et les usagers (la «petite délinquance»). Les auteur-trice-s d'infractions ne sont pas désigné.e.s comme étant les destinataires principaux-ales du travail policier, celui-ci s'adressant à la population en général. L'un des objectifs de la police de proximité est donc de partir du «terrain» et de développer une action localisée au niveau des quartiers et de leurs habitant-e-s. Cette conception de la police valorise la résolution des problèmes de manière proactive (et non pas la réaction aux appels d'urgence), les services rendus aux usagères et usagers, ainsi que les partenariats établis avec d'autres institutions et associations. Cette perspective considère que les outils coercitifs sont inefficaces pour régler les problèmes sur le long terme et pour combattre le sentiment d'insécurité de la population. Elle promeut donc des compétences alternatives, telles que les techniques de gestion des conflits et des émotions, ou celles relevant de la communication, de la persuasion, de la négociation ou de la médiation. Cette vision hétérodoxe du métier s'inscrit donc contre la représentation traditionnelle des policières et des policiers comme étant des agent.e.s de «lutte contre le crime» voué.e.s à la détection des infractions grâce à l'usage de la contrainte, dont l'objectif de «faire du chiffre» (nombre d'arrestations p.ex.) serait la meilleure manière d'en mesurer l'efficacité. Par ailleurs, elle est davantage compatible avec une conception de la délinquance comme un phénomène complexe trouvant ses causes dans le contexte social et économique.

Si ce modèle a pu inspirer des réformes dans différents pays, sa radicalité est restée un frein à une mise en œuvre effective. Ces modèles critiques ont ainsi eu un impact sur les politiques et les organisations policières suisses, sans que cela ne débouche néanmoins sur des réformes de grande envergure. Il existe certes au sein des corps de police helvétiques des courants critiques. Certaines policières et certains policiers relativisent l'importance de la coercition et défendent une vision du métier comme étant avant tout relationnel. Ces perspectives hétérodoxes ne cherchent pas pour autant à ôter l'usage de la force des prérogatives policières. Elles visent plutôt à élargir la définition du métier en intégrant sa dimension «sociale» et, de ce fait, à mieux correspondre à la réalité du terrain. Même si des mouvements réformateurs ont pu, dans certains cantons, infléchir en partie les politiques et les pratiques policières en Suisse, une perspective plus orthodoxe continue cependant à les dominer. La dénonciation des infractions reste au centre de la manière dont est défini le métier, et nombreux sont les policiers et les policières possédant des visions négatives des tâches et compétences non coercitives, souvent qualifiées de «sociales» ou de «faire du social», bien souvent considérées comme étant du «sale boulot». Les conce- 
voir comme des tâches pleinement policières reviendrait à rapprocher la profession du travail social, ce qui peut être perçu par certain.e.s comme une atteinte à leur identité de policière ou de policier et comme une dévalorisation de leur métier. Les résistances aux tentatives de rendre les tâches et compétences non coercitives plus légitimes sont particulièrement grandes parmi les professionnel-le·s dont l'identité ou le statut repose sur l'aspect moral du métier et sur le pouvoir que l'État lui délègue, ainsi que parmi ceux et celles adhérant aux modèles virils de la masculinité.

\section{David Pichonnaz}

\section{Références}

Brodeur, J.-P. (2003). Les visages de la police: pratiques et perceptions. Montréal : Les Presses de l'Université de Montréal, 2003.

Jobard, F. \& de Maillard, J. (2015). Sociologie de la police: politiques, organisations, réformes. Paris : Armand Colin.

Pichonnaz, D. (2017). Devenirs policiers : une socialisation professionnelle en contrastes. Lausanne: Antipodes.

\section{Politique sociale}

Nous pouvons distinguer trois composantes principales de la politique sociale: un premier cercle englobe les transferts de revenu en faveur des personnes affectées par un risque social ce sont les assurances sociales - ou en situation de pauvreté - c'est l'assistance sociale ; un deuxième cercle comporte toutes les interventions liées au besoin de soutien des personnes en fonction de leurs situations de vie spécifiques, il inclut les politiques de formation, de santé et de logement, ainsi que les politiques du marché du travail et de la famille ou encore la politique fiscale; un troisième niveau envisage la politique sociale comme une politique transversale à l'ensemble des champs de l'action publique, dans la mesure où les questions de justice sociale sont partout présentes (on peut penser p.ex. à la politique de l'environnement, des transports, à la politique monétaire ou encore la politique de la recherche).

On le voit, la politique sociale peut poursuivre une diversité très grande d'objectifs allant du soutien aux populations démunies avec un double souci d'aide et de contrôle - à la volonté de promouvoir leur insertion sociale et professionnelle dans les meilleures conditions, tout cela dans un cadre où les questions d'équilibre budgétaire et de cohésion sociale jouent un rôle souvent important. Par ailleurs, l'élaboration et la mise en œuvre de la politique sociale peuvent impliquer de nombreux acteur-trice-s public-que-s et privé'e-s (État, entreprises, partenaires sociaux, ONG au service d'une cause sociale ou environnementale, etc.), que ce soit aux échelons national, cantonal ou local: elle peut ainsi être considérée comme une prérogative de l'État ou, au contraire, faire l'objet de discussions et compromis entre acteur-trice-s public-que-s et partenaires sociaux -ales; dans le même esprit elle peut donner une place plus ou moins importante aux acteur-trice-s locaux-ales ou encore viser à une centralisation en vue de garantir une uniformité de traitement sur tout le territoire national. Cette pluralité des acteur-trice-s débouche sur une très grande diversité des moyens d'action mobilisés (où l'État joue un rôle plus ou moins grand, à côté du marché, de la famille et des associations). La politique sociale se caractérise ainsi par une très grande diversité des régimes ou configurations d'État social, qui a donné lieu à de nombreux travaux de recherche visant à ordonner cette diversité au travers de l'élaboration de typologies dont la plus connue est sans doute celle d'Esping-Andersen (voir concept Régimes d'État-providence [de Protection sociale]).

En Suisse, la politique sociale s'est mise en place avec l'appui indispensable des partenaires sociaux, ce qui s'est notamment concrétisé à travers le rôle charnière joué par la grève 
générale de 1918. Ce vaste mouvement social qui a ses origines dans la question et les luttes sociales des décennies précédentes a en effet permis de donner une priorité au développement des politiques sociales. Cependant, le système institutionnel helvétique et la nécessité d'inscrire dans la Constitution le principe d'une intervention fédérale avant de pouvoir la concrétiser par l'adoption d'une loi ad hoc, ont considérablement retardé ce processus de développement. Le rôle des partenaires sociaux dans le déploiement de l'État social suisse a été crucial à toutes les étapes, ainsi que l'illustre leur implication étroite dans le cycle d'élaboration des politiques publiques, où la menace du référendum a constamment agi comme un aiguillon puissant en faveur de l'adoption de compromis. Ainsi, le temps du compromis a souvent imposé son rythme comme en témoigne la mise en œuvre tardive de l'assurance-chômage (seulement en 1984) ou de l'assurance-maternité (2005). L'importance des acteur.trice-s syndicaux-ales et patronaux-ales et des acteur-trice-s de l'économie privée se traduit aussi dans leur participation active à la gestion des assurances sociales, notamment en lien avec le chômage, la retraite et la santé. Le système suisse se présente comme une combinaison entre institutions publiques et privées, avec des modalités de financement également plurielles. Cette caractéristique ne favorise pas sa cohérence d'ensemble.

La politique sociale suisse contemporaine se caractérise par un certain nombre de spécificités. Tout d'abord la volonté de réintégrer les personnes sur le marché du travail a toujours été un objectif central, soulignant par là le rôle secondaire de la politique sociale de compensation financière. Le vecteur d'intégration premier est en effet le marché du travail et la politique sociale doit préparer l'intégration professionnelle des publics n'ayant jamais exercé d'emploi ou faciliter voire accélérer le retour sur le marché du travail de ses bénéficiaires. Ce n'est que lorsque la capacité de travail est absente, en raison d'une invalidité durable ou d'un âge trop avancé par exemple, qu'un soutien financier à long terme peut être envisagé. Ce primat de la réintégration professionnelle sur le soutien du revenu est une constante de la politique sociale suisse. Cet objectif est d'ailleurs largement partagé par les associations d'employeur-euse-s et les syndicats de travailleur-euse-s qui tous deux apportent leur soutien aux mesures d'insertion et d'activation des bénéficiaires de l'assurance-chômage, l'assurance-invalidité et l'aide sociale notamment. Dans ce cadre l'intervention sur l'offre de main-d'œuvre est privilégiée, dans la mesure où la Suisse affiche une réticence forte à toute action keynésienne de soutien à la demande d'emplois. Sur le versant de la demande, l'action de l'État doit viser à assurer les conditions-cadres de la compétitivité de l'économie et des entreprises tandis que, sur le versant de l'offre, la politique sociale est conçue comme un instrument d'incitation, voire de contrainte si nécessaire, à reprendre un emploi.

Ensuite, la politique sociale suisse affiche constamment son souci de l'équilibre des finances publiques. La plupart des réformes récentes des assurances sociales sont ainsi justifiées par la nécessité d'assainir leurs comptes en vue de garantir leur viabilité à long terme. Cette spécificité rend difficile la mise sur pied d'un État social qui investirait massivement dans le développement de certaines prestations. Ainsi, la Suisse s'est longtemps caractérisée par un sous-développement des politiques familiales, notamment dans le domaine des crèches et jardins d'enfants où le nombre de places est notoirement insuffisant. Depuis le début des années 2000, une politique d'impulsion a été mise en place, mais en raison de cette prudence budgétaire elle reste d'ampleur modeste et le rattrapage se fait à petits pas. De même, les politiques d'activation mises en place depuis les années 1990 privilégient le plus souvent des mesures peu coûteuses et de 
court terme, ainsi qu'en témoigne le pourcentage du PIB consacré à ces dépenses qui est peu élevé en comparaison des pays scandinaves par exemple. Le soutien à l'insertion professionnelle passe donc surtout par la confiance placée dans la capacité des acteur-trice-s du marché à créer des emplois en suffisance plus que par un investissement massif dans le développement du capital humain.

En troisième lieu, la politique sociale suisse tend à privilégier les solutions locales, qu'elles soient privées ou publiques. L'importance accordée au principe de subsidiarité, qui veut qu'une intervention plus proche des personnes concernées soit aussi plus efficace, ainsi que le souci d'équilibrer les finances publiques, qui se caractérise souvent par des transferts de charge aux niveaux inférieurs, renforcent cette tendance. On voit ainsi que les réformes des assurances sociales se traduisent souvent par des reports de dépenses à l'échelon des cantons et des communes, lesquels à leur tour tentent d'impliquer la Confédération plus largement afin de contenir le niveau de leurs propres dépenses. Les débats actuels autour de l'assurance-invalidité ou des régimes de prestations complémentaires illustrent ce phénomène. Dans le même sens, certaines réformes récentes impliquent une forme de familialisation de la politique sociale, dans la mesure où les tâches qui ne sont plus assumées par l'État doivent dès lors être prises en charge par la famille ou les proches, à l'image des processus de désinstitutionnalisation que l'on peut observer dans le domaine de la prise en charge des personnes âgées par exemple.

Enfin, la politique sociale suisse s'est construite autour d'une vision standardisée du parcours de vie caractérisée par la tripartition école (jusqu'à 20 ans), emploi (de 20 à 65 ans), retraite (au-delà de 65 ans) et par la division sexuelle du travail, laquelle se traduit par exemple par un accès plus difficile aux droits sociaux pour les personnes travaillant à temps partiel, le plus souvent des femmes, ou encore la non-reconnaissance du travail domestique comme source de droits sociaux. Dans le contexte actuel, ces deux éléments structurants de la politique sociale sont largement remis en question. D'une part, la durée des études s'allonge, la transition école/emploi se complexifie, la linéarité des parcours professionnels est remise en question (donnant lieu à des trajectoires de plus en plus souvent discontinues), le passage à la retraite doit parfois être anticipé, etc. Ainsi, la politique sociale suisse est appelée à donner une importance croissante à la question des transitions ainsi qu'en témoigne l'accroissement actuel des mesures dites de transition I et II en faveur des jeunes sans formation certifiée. D'autre part, la remise en question de la division sexuelle du travail (homme gagnepain, femme en charge des tâches familiales), qui était sous-jacente à la construction d'un État social octroyant des droits propres aux hommes et des droits dérivés aux femmes, ainsi que la fragilisation de la cellule familiale, questionnent la vision genrée traditionnelle de l'État social suisse. Des réformes telles que l'adoption du splitting ou encore du bonus éducatif dans l'AVS témoignent d'une prise de conscience à cet égard, mais elles restent d'ampleur limitée.

Confrontée à ces divers défis (insertion sur le marché du travail, équilibre des finances publiques, souci de subsidiarité, prise en compte de parcours de vie pluriels), la politique sociale suisse se situe à un tournant qui peut la mener aussi bien à des solutions de repli (réduction des prestations en vue de préserver l'équilibre des finances publiques) ou à des visions plus innovantes et porteuses de progrès. Comme l'illustre la diversité des réformes récemment adoptées en Suisse, si la politique sociale peut être un vecteur de progrès via le développement de la politique de la petite enfance par exemple, elle peut aussi contribuer à renforcer la vulnérabilité des personnes en réduisant les prestations et services rendus et en les soumettant à des conditionnalités qui 
peuvent redoubler le sentiment de stigmatisation et de honte de ses bénéficiaires.

\section{Jean-Michel Bonvin \& Pascal Maeder}

\section{Références}

Bonoli, G. (2014). Politiques sociales. In P. Knoepfel, Y. Papdopoulos, P. Sciarini, A. Vatter \& S. Häusermann (Éd.), Handbuch der Schweizer Politik / Manuel de politique suisse (5., völlig überarb. und erw. Aufl., S. 805-826). Zürich : Verlag Neue Zürcher Zeitung.

Bonvin, J.-M., Gobet, P., Rossini, S. \& Tabin, J.-P. (2015). Manuel de politique sociale ( $2^{\mathrm{e}}$ éd.). Lausanne : Éd. ÉÉSP.

Knöpfel, C. (2015). Sozialstaatliche Rahmenbedingungen in der Schweiz. In B. Wüthrich, J. Amstutz \& A. Fritze (Hrsg.), Soziale Versorgung zukunftsfähig gestalten (S. 23-35). Wiesbaden: Springer VS.

\section{Précarité $^{*}$}

Depuis plus de vingt ans, le noyau dur de l'emploi dit «normal à plein temps » se rétrécit lentement mais inéluctablement dans la plupart des économies nationales européennes. À ce type d'emplois se confronte un nombre considérable de chômeur-euse-s de longue durée et d'autres personnes soutenues par l'État social. Entre ces deux types se développe une zone grise de relations de travail atypiques, telles que le travail temporaire, l'emploi à durée déterminée ou mineur et le travail indépendant fictif. Selon l'Organisation internationale du travail (OIT), de telles relations de travail sont qualifiées de précaires si elles se caractérisent par une absence de couverture sociale et de droit du travail, des moyens de subsistance insuffisants et de faibles revenus. Cette définition, qui repose sur des critères objectifs, est généralement complétée par des aspects subjectifs. Par conséquent, les relations de travail sont précaires si elles impliquent des risques à court terme pour les employé-e-s et des incertitudes à long terme pour la planifi- cation de leurs projets de vie personnels. Ces risques et incertitudes ne permettent guère aux employéee-s de maîtriser leur situation d'emploi. Par ailleurs, le concept de précarité a été utilisé dans des recherches récentes en sciences sociales en dehors du contexte du marché du travail pour désigner des conditions de vie fondamentalement précaires (prospérité précaire des ménages, conditions de vie précaires des jeunes, etc.).

Toutefois, la précarité n'est pas un phénomène nouveau. Une grande partie de l'emploi rémunéré, en particulier celui des femmes et des migrant·e.s, a toujours été exclue du modèle des rapports de travail dits normaux masculins. Pour appréhender les nouveaux aspects de la précarité, il est nécessaire de prendre en compte les différentes dynamiques politiques et économiques. Depuis les années 1990, ces dynamiques soumettent plus étroitement le travail salarié aux risques entrepreneuriaux du marché à court terme. Les stratégies des entrepreneur-euse-s pour exploiter les qualifications et le potentiel de leur main-d'œuvre se sont développées différemment en fonction de chaque secteur du marché de l'emploi. Les stratégies de flexibilité opérationnelle avec recours au travail intérimaire peuvent être utilisées, par exemple, dans les industries orientées vers l'export; elles permettent de réagir rapidement aux fluctuations des commandes. Dans les secteurs hautement réglementés comme la construction, les stratégies des entrepreneur.euse-s visent plus souvent à contourner les normes salariales générales et les normes minimales du travail (sous-traitant·e.s, indépendant.e.s fictif-ive.s). Dans d'autres cas encore, elles servent tout simplement à réduire les coûts, par exemple dans les branches peu qualifiées du secteur des services (travail sur appel, temps partiel non choisi). En outre, l'introduction du principe dit d'activation dans les dispositifs de politique sociale et du chômage a contribué à une réforme profonde du marché du travail en augmentant la pression pour 
réintégrer le marché du travail (mini-emplois, entreprises uninominales). Enfin, l'augmentation de l'emploi féminin et les évolutions des régimes migratoires ont contribué, à leur tour, à exacerber la situation concurrentielle des groupes peu qualifiés sur les marchés du travail précaires. Il en résulte une forte segmentation du marché du travail.

Bien que diverses études aient tenté de quantifier les relations de travail précaires en Suisse, les résultats ne sont guère fiables. Selon les définition et les méthode utilisées, le taux d'emplois précaires se situe entre $2 \%$ et $10 \%$ de la population active. Toutefois, il ne fait aucun doute que le nombre de relations de travail précaires augmente également en Suisse. On constate surtout une augmentation du nombre de personnes pauvres depuis les années 1990, principalement dû à l'accroissement de la pauvreté parmi les travailleurs et travailleuses (working poor). La raison du nombre croissant de faibles revenus ne réside pas tant dans une diminution relative des rémunérations horaires, mais surtout dans la multiplication des emplois précaires. En comparaison internationale, cet aspect est remarquable en ce sens qu'une forte proportion d'emplois précaires est généralement corrélée à une forte protection contre le licenciement. La Suisse dispose d'un marché du travail traditionnellement libéral avec des droits peu étendus pour les travailleurs et les travailleuses et, pourtant, les relations de travail continuent à se précariser. Toutefois, cette précarisation ne transparaît que partiellement dans les statistiques, puisque l'incertitude est également liée, dans une large mesure, à la perception subjective des travailleurs et des travailleuses. Ils et elles réagissent à l'évolution du marché du travail par diverses stratégies d'adaptation.

La précarisation du marché de l'emploi représente un nouveau défi, en particulier pour les politiques sociales et pour le travail syndical. En raison de leur temps de présence en moyenne court dans l'entreprise et des rap- ports de dépendance accrus, non seulement les employé·e-s précaires sont plus difficiles à mobiliser, mais l'expérience montre aussi que les conditions générales objectives de même que la perception subjective de la précarisation dissimulent des différences sociales et des hiérarchies considérables. Il en résulte des attentes et exigences différentes face aux relations de travail, ce qui limite les stratégies collectives. Tandis que certain.e.s n'ont aucune perspective d'une relation de travail sûre, d'autres considèrent, au contraire, le travail précaire comme une période de transition vers une consolidation professionnelle et en acceptent les inconvénients pendant un certain temps. Si pour des intellectuel-le-s jeunes et très qualifiéee-s, le développement de relations de travail flexibles peut correspondre à une perspective émancipatrice, l'intérêt d'une vendeuse précarisée se concentre sur l'horizon d'un emploi permanent assorti d'un salaire minimum garanti, soit sur une approche réglementaire relativement traditionnelle. La précarité conduit à une intensification des luttes de positionnement et s'inscrit, comme l'a observé Pierre Bourdieu à la fin des années 1990, dans une nouvelle forme de pouvoir basé sur l'incertitude devenue permanente.

Bien que, dans les pays du nord de l'Europe, les syndicats aient pu obtenir des concessions (réglementation du chômage partiel, protection du personnel permanent) de la part de l'État et des organisations patronales, ce «corporatisme de crise» accentue les clivages sur le marché du travail. Contrairement au capitalisme d'après-guerre, ce type de corporatisme n'atteint plus aujourd'hui qu'une partie de la population active. L'émergence d'un secteur à bas salaires, aux conditions de travail précaires et avec une protection sociale défaillante, se répercute inévitablement sur les segments du marché du travail caractérisés par des emplois relativement stables.

Le débat plus récent sur la «déprécarisation» est une tentative de combiner des stra- 
tégies d'adaptation s'opposant aux exigences inacceptables de précarisation et les formes organisationnelles du mouvement ouvrier traditionnel. Ce débat prend place dans une situation caractérisée par une fragmentation extrême des parcours professionnels et des luttes individuelles de positionnement. Il s'agit, premièrement, de protéger - de manière essentiellement défensive - les relations dites normales de travail contre les nombreuses remises en question des dispositions de protection. Deuxièmement, de renforcer - de manière offensive - les droits pour les formes d'emploi non garanties par l'État social ni par la réglementation tarifaire (salaire minimum légal, régularisation des travailleurs et travailleuses sans statut de séjour). De tels droits doivent aussi être renforcés pour les groupes de population exclus des différentes prestations de l'État social (revenu de base, etc.). Enfin, troisièmement, il s'agit de développer des mesures organisationnelles spécifiques permettant d'intégrer les personnes précaires dans les organisations de travailleurs et de travailleuses.

\section{Alessandro Pelizzari}

\section{Références}

Bourdieu, P. (1998). La précarité est aujourd'hui partout. In P. Bourdieu, Contre-feux: propos pour servir à la résistance contre l'invasion néo-libérale (pp. 95-101). Paris : Éditions Raisons d'Agir.

Pelizzari, A. (2009). Dynamiken der Prekarisierung: atypische Erwerbsverhältnisse und milieuspezifische Unsicherheitsbewältigung. Konstanz : UVK Universitätsverlag.

Rodgers, G. \& Rodgers, J. (1989). Precarious jobs in labour market regulation: the growth of atypical employment in Western Europe. Geneva: International Institute for Labour Studies.

\section{Prestations complémentaires à l'AVS et à l'AI*}

Les prestations complémentaires à l'AVS et à l'AI (PC) constituent une prestation d'assurance sociale fédérale qui garantit la subsistance des bénéficiaires de rentes AVS et AI à faible revenu. De plus, elles forment un pilier central du financement des séjours dans les homes et épargnent en règle générale aux bénéficiaires de rentes de devoir frapper à la porte de l'aide sociale. Elles constituent un système social d'indemnisation conçu sur la base du principe de provision et l'une des principales caractéristiques des PC est la normalisation du droit aux prestations et du cadre des prestations. Les prestations sont déterminées selon un procédé similaire à la procédure fiscale. Elles sont de deux types: les prestations complémentaires annuelles versées sous forme de mensualités et le remboursement des frais de maladie et d'invalidité. Le montant des prestations complémentaires annuelles correspond à la somme des dépenses reconnues dépassant les revenus déterminants.

À leur introduction, les prestations de l'AVS et de l'AI étaient insuffisantes pour mettre en œuvre le mandat constitutionnel garantissant la couverture des besoins vitaux de manière appropriée. Après six révisions de l'AVS et malgré une nette augmentation des rentes, il s'avérait que les classes de revenus inférieures avaient besoin de revenus supplémentaires pour assurer leur survie économique. Le nombre de bénéficiaires de rente à faible revenu était estimé à 200000 au milieu des années 1960. Lors des travaux préparatoires pour des prestations complémentaires à l'AVS et à l'AI, la discussion portait sur la manière de combiner le principe du besoin et le principe d'assurance. Les discussions ont abouti à une solution basée sur des subventions qui laissaient le choix aux cantons d'allouer des PC ou non. Dans le vote final du 19 mars 1965, les deux chambres fédérales ont approuvé à l'unanimité la loi sur les 
prestations complémentaires à l'AVS et à l'AI (LPC), qui est entrée en vigueur le $1^{\text {er }}$ janvier 1966. Les caractéristiques principales de cette loi étaient le principe d'assurance, le droit clair et exécutoire à une rente et l'absence d'éléments d'assistance tels que l'obligation de remboursement et l'obligation d'entretien en vertu du droit de la famille. Conçues initialement comme une solution transitoire, les PC ont été inscrites dans la Constitution fédérale le $1^{\text {er }}$ janvier 2008 et ont ainsi été reconnues au niveau constitutionnel, comme elles l'étaient déjà dans la pratique, en vue de garantir l'existence en cas de vieillesse, de statut de survivant et d'invalidité. Outre garantir l'existence, les PC ont aussi progressivement garanti le financement des soins. Environ la moitié des résident·e.s de homes ont aujourd'hui besoin des PC pour assumer les coûts croissants. Près d'un bénéficiaire d'une rente AVS sur dix et presque un bénéficiaire d'une rente d'invalidité sur deux perçoivent des PC.

Contrairement aux prestations de l'AVS et de l'AI, les PC ne sont pas financées par le biais des cotisations prélevées sur les salaires, mais intégralement par les recettes fiscales fédérales (environ $30 \%$ ), cantonales et en général aussi communales. Le montant des PC correspondant au minimum vital se base dans l'ensemble sur les conditions socioéconomiques du pays et sur le niveau de vie minimal adapté aux conditions culturelles et sociales. Ce revenu minimal standardisé est le plus élevé parmi les systèmes en vigueur en Suisse.

Dans la LPC, le cercle des ayants droit potentiels est étroit et clairement défini : ont droit aux PC les personnes pouvant prétendre à une rente AVS, à une rente AI ou à une allocation pour impotent.e.s de l'AI ou percevant depuis au moins six mois des indemnités journalières de l'AI, qui sont domiciliées en Suisse et y résident habituellement, qui possèdent la citoyenneté suisse ou qui, en tant que ressortissant·e·s étranger·ère·s, remplissent certains délais de carence. Les ressortissant·e.s de l'UE sont mis·es sur pied d'égalité avec les Suisses.

Du point de vue économique, il est entendu que la somme des dépenses reconnues par la loi dépasse les revenus déterminants. Les principales dépenses des bénéficiaires d'une rente AVS et AI vivant à domicile sont celles destinées à la couverture des besoins vitaux et le loyer. Pour ceux et celles qui résident dans un home ou à l'hôpital de manière permanente ou à long terme, les dépenses les plus importantes sont les coûts du home et les frais personnels. Dans le cadre des PC, les primes de caisse maladie sont remboursées jusqu'à concurrence de la prime de référence de chaque canton.

En Suisse, contrairement à d'autres pays, la lutte contre la pauvreté chez les personnes âgées n'est pas assurée par l'aide sociale, mais par une véritable provision. Bien que le modèle des trois piliers de la prévoyance vieillesse et survivants soit considéré comme exemplaire à l'échelle internationale et que plus de la moitié des dépenses d'assurances sociales soient attribuées à la prévoyance vieillesse, l'OCDE constate que la Suisse occupe la quatrième place derrière le Mexique, l'Australie et la Corée dans le classement des taux de pauvreté les plus élevés. Les PC assument certes une fonction centrale dans la lutte contre la pauvreté chez les personnes âgées, mais le montant des prestations est considéré comme relativement bas, et il est avéré que tous et toutes les ayant $\cdot e \cdot s$ droit ne réclament pas les prestations. Puisque l'OCDE, dans sa comparaison internationale, base ses estimations sur une définition relative de la pauvreté, il convient de préciser qu'en Suisse, une personne bénéficiaire d'une rente AVS touchée par la pauvreté dispose d'un revenu plus élevé que dans la plupart des autres pays. Néanmoins, une augmentation du niveau des prestations devrait être débattue.

Le nombre de personnes bénéficiant des PC ainsi que les coûts y afférents n'ont cessé d'augmenter au cours des dernières années. En ce qui concerne les prestations complémen- 
taires à l'AVS, l'augmentation est surtout due à l'évolution démographique et à la hausse des coûts pour les résident·e·s des homes. Pour les prestations complémentaires à l'AI, la hausse constante du nombre de nouveaux bénéficiaires de rente a entraîné pendant longtemps une forte augmentation des dépenses. S'y ajoutent plusieurs révisions de lois, dans le cadre et en dehors de la législation sur les PC. Il convient de mentionner à cet égard la $5^{\mathrm{e}}$ révision de l'AI en 2008, qui inclut la suppression des rentes supplémentaires et du supplément de carrière, ainsi que la révision de la LPG en 2019 avec la hausse des montants maximaux reconnus au titre du loyer, l'abaissement des franchises sur la fortune et la fixation du droit aux prestations à moins de 100000 francs de fortune. À l'avenir, il faudra s'attendre à de nouvelles hausses annuelles des coûts, avec des coûts des PC à l'AVS qui seront supérieurs à ceux des PC à l'AI.

En raison de l'augmentation de leurs coûts, les PC sont de plus en plus au cœur du débat politique et des mesures d'économies sont fréquemment. Dans le cadre de ces discussions, il faut toutefois prendre en compte que les principaux facteurs de coûts se situent en dehors des dispositions légales relatives aux PC et qu'il ne s'agit pas de remettre en question le système en soi. De plus, il ne faut pas perdre de vue la mission principale des prestations complémentaires, à savoir lutter contre la pauvreté chez les bénéficiaires de rente vivant chez eux·elles et prévenir la dépendance de l'aide sociale des résident·e.s de homes. Les contrôles du mode de vie, les réductions du niveau de prestations pour atteindre le niveau de l'aide sociale en raison d'une prise en compte insuffisante des dépenses réelles, telles que les frais réels des taxes de home et de logement, s'opposent au principe de provision et au mandat constitutionnel des prestations complémentaires.

Uwe Koch

\section{Références}

Carigiet, E. (2001). Gesellschaftliche Solidarität: Prinzipien, Perspektiven und Weiterentwicklung der sozialen Sicherheit. Basel: Helbing Lichtenhahn.

Carigiet, E. \& Koch, U. (2009). Ergänzungsleistungen zur AHV/IV: Darstellung, Charakterisierung und Wirkungsweise. Zürich: Schulthess.

Organisation for Economic Co-operation and Development (2015). Pensions at a glance 2015: OECD and G20 indicators. Paris : OECD Publishing.

\section{Prestations complémentaires pour familles}

Les prestations complémentaires pour familles (PC Familles) sont considérées comme un complément de revenu permettant de garantir la sécurité matérielle des familles disposant de faibles ressources financières malgré une activité professionnelle. Ces PC Familles sont ainsi destinées à venir en aide aux familles de working poor - catégorie de la population au sein de laquelle les familles sont surreprésentées en raison de charges familiales. Le concept de ces prestations se fonde sur le postulat selon lequel l'aide sociale n'est pas adaptée à une population devant faire face à une problématique principalement structurelle, liée à la présence d'enfant(s).

Le modèle des prestations complémentaires pour familles est calqué sur celui, éprouvé, des PC à l'assurance-vieillesse et invalidité (AVS/ $\mathrm{AI})$, qui permet déjà de réduire la pauvreté des personnes âgées. Il s'agit ici d'apporter un complément au revenu d'activité, permettant de couvrir les besoins vitaux des membres de la famille. Une allocation, dont le montant est calculé en tenant compte de l'ensemble des revenus et des dépenses reconnues de la famille, est versée sur une base mensuelle. Elle peut s'accompagner du remboursement de frais de santé, ainsi que de frais de garde.

Ces prestations se différencient des allocations familiales aux personnes salariées ou 
indépendantes, servant à compenser partiellement les charges liées aux enfants, sans tenir compte du niveau de revenu. Les PC Familles, destinées à des familles qui travaillent, poursuivent d'une part un objectif de politique familiale, en permettant de concilier activités familiales et travail, et d'autre part un objectif de politique sociale, dans le sens où l'on souhaite éviter que la naissance d'un enfant constitue une cause de pauvreté.

$\mathrm{Au}$ début des années 2000 en Suisse, les questions de politique familiale ont suscité un vif intérêt et des débats politiques nourris. Faisant suite aux résultats d'études portant sur le risque de pauvreté des familles et sur les coûts directs et indirects liés à l'arrivée d'un enfant, de nombreuses interventions parlementaires ont été déposées au niveau fédéral et une activité de lobbying a été lancée par des organisations actives au niveau national sur les questions familiales. Ces interventions concernaient principalement trois domaines : la compensation des charges familiales, la conciliation entre vie familiale et vie professionnelle et la protection de la maternité. Dans ce cadre, la lutte contre la pauvreté des familles a retenu une attention particulière.

Dans le système suisse, la compensation des charges familiales est basée principalement sur les allocations familiales et les déductions fiscales pour enfants, avec des écarts très importants d'un système cantonal à un autre. Les travaux fédéraux ont donc porté sur la réalisation du principe «un enfant - une allocation», avec l'adoption en votation populaire en 2006 d'une loi fédérale sur les allocations familiales, fixant les conditions d'octroi et des montants minimums au niveau suisse. La révision de l'imposition du couple et de la famille, quant à elle, a échoué en votation populaire en 2004 .

Ces mesures (allocations familiales et déductions fiscales) ne permettent que dans une faible mesure de compenser les charges familiales. C'est pourquoi, en 1999, la Commission fédérale de coordination pour les questions familiales (COFF) demandait l'introduction au niveau national du modèle des prestations complémentaires pour familles, à l'exemple du canton du Tessin qui appliquait déjà ce dispositif depuis 1997. La Conférence des directeurs cantonaux des affaires sociales (CDAS) s'est également saisie du dossier en 2000 et recommandait aux cantons d'examiner la création de PC Familles. La même année, le Conseil national adoptait deux initiatives parlementaires en faveur d'un système de PC Familles pour les familles disposant de faibles revenus du travail, calqué sur le modèle tessinois. En 2004, sa Commission de la sécurité sociale et de la santé (CSSS-N) mettait en consultation un projet de loi, accompagné de plusieurs variantes. La consultation montra qu'une réglementation de droit fédéral, ainsi qu'un financement des PC Familles par la Confédération et les cantons, était majoritairement approuvé. Différentes questions devaient cependant encore être examinées, dont notamment l'exportation vers l'étranger et les coûts effectifs du dispositif, particulièrement au regard du transfert de charges de l'aide sociale. Le délai de traitement des deux initiatives fut prolongé à deux reprises, en raison de la priorité donnée au projet de loi fédérale sur les allocations familiales, puis des décisions attendues sur la répartition des charges entre la Confédération et les cantons ( $3^{\text {e }}$ volet RPT). En février 2009, la CSSS-N décida de prolonger une nouvelle fois le délai de traitement et chargea l'administration d'élaborer une solution alternative visant à alléger les conditions de vie des travailleur.euse-s pauvres, à garantir que les prestations ne soient pas exportables et à laisser aux cantons la compétence d'introduire des PC Familles. Les travaux autour de deux interventions parlementaires adoptées par le Conseil national ont duré dix ans, avant leur classement en 2011. En effet, la majorité de la Commission estima qu'il était inutile de poursuivre les travaux, étant donné qu'aucun projet d'acte n'était parvenu à rallier une majorité après dix 
ans de discussion. En outre, elle considérait que le soutien aux familles à revenu modeste devait être du ressort des cantons aptes à trouver des solutions adéquates. Pour une minorité de la Commission, il s'agissait d'éviter que les cantons continuent de développer des systèmes différents qu'il faudrait par la suite harmoniser, et elle a demandé au minimum la création de directives fédérales. Mais la politique familiale en Suisse étant structurée selon les principes du fédéralisme et de subsidiarité, la Confédération ne dispose pas de compétence claire pour légiférer dans ce domaine.

En raison de cette évolution, la CDAS décida en 2009 d'élaborer des recommandations à l'attention des cantons, visant à contribuer à l'harmonisation de solutions cantonales et à la coordination en vue d'une future solution fédérale. Parallèlement, la Conférence suisse des institutions d'action sociale (CSIAS) développa son modèle de PC Familles, afin de conseiller les cantons en la matière.

Avec un certain pragmatisme, après le canton $\mathrm{du}$ Tessin, pionnier en la matière, trois autres cantons ont mis en place des dispositifs de PC Familles: Soleure, Vaud et Genève. Plusieurs autres cantons ont entamé des réflexions ou ont élaboré des projets, qui ont toutefois échoué en votation populaire ou lors des travaux parlementaires. Le canton du Tessin a mis en œuvre les prestations complémentaires pour familles en 1997. Axées sur deux volets, couvrant toute la famille durant les trois premières années de l'enfant, ainsi qu'une allocation dite «intégrative», destinée à couvrir les besoins vitaux des enfants uniquement, jusqu'à 15 ans, le dispositif a été adapté au début des années 2000. Cela afin d'introduire des mesures visant à faciliter le maintien de l'activité lucrative des parents. Le canton de Soleure a mis en place son dispositif de PC Familles en 2010 pour une période d'essai, après son adoption en votation populaire. En 2016, le parlement soleurois a décidé de les maintenir définitivement dès 2018. Le dispositif cantonal est destiné aux familles avec enfants de moins de 6 ans qui disposent d'un revenu minimum d'activité selon le barème. Dans le canton de Vaud, le dispositif des PC Familles est entré en vigueur en 2011. Il est destiné aux familles avec enfants de moins de 16 ans et, comme le modèle tessinois, il prévoit des prestations dégressives en fonction de l'âge des enfants. Enfin, Genève a introduit ses PC Familles en 2012, pour les familles avec enfants de moins de 25 ans, disposant d'une activité minimale de $90 \%$ pour les couples et de $40 \%$ pour les familles monoparentales.

Afin d'inciter au maintien ou à l'augmentation de l'activité lucrative, trois de ces cantons tiennent compte dans tous les cas d'un revenu minimum fixe (revenu hypothétique), pris en compte lors du calcul des revenus déterminants de la famille. Et deux cantons prévoient en sus une franchise sur le revenu d'activité lucrative. De plus, tous ces cantons prévoient le remboursement de frais de garde ou en tiennent compte dans le calcul des dépenses. Cependant, les barèmes pour besoins vitaux sont différents d'un canton à l'autre.

Chaque dispositif cantonal prévoit une durée de résidence minimale dans le canton. Les systèmes de financement des dispositifs tessinois et vaudois ont intégré une participation des employeur.euse-s, des salariés et des personnes indépendantes (ainsi que les personnes sans activité lucrative au Tessin), en complément du financement cantonal et communal.

Les évaluations ont démontré que les PC Familles se révèlent efficaces pour assurer la couverture des besoins vitaux des familles et réduire ainsi le recours à l'aide sociale, tout en favorisant le maintien d'une activité lucrative. Ces prestations doivent cependant aller de pair avec d'autres mesures en faveur des familles, dont principalement le développement de l'accueil de jour des enfants.

Anouk Friedmann 


\section{Références}

Abrassart, A., Guggenbühl, T. \& Stutz, H. (2015). Évaluation des effets de la loi sur les prestations complémentaires cantonales pour les familles et les prestations cantonales de la Rente-pont (LPCFam): rapport final mandaté par le Département de la santé et de l'action sociale du canton de Vaud. Berne: BASS.

Bauer, T., Streuli, E. \& Bureau d'études de politique du travail et de politique sociale BASS (2000). Modèles de compensation des charges familiales: une analyse chiffrée pour la Suisse. Berne: Commission fédérale de coordination pour les questions familiales.

Conférence suisse des institutions d'action sociale (2011). Prestations complémentaires pour familles - modèle CSIAS: discussion détaillée des pointsclés. Berne: Conférence suisse des institutions d'action sociale.

\section{Prestations sociales sous condition de ressources}

Les prestations sociales sous condition de ressources constituent le dernier maillon de la protection sociale: de nature subsidiaire, elles sont allouées selon le principe du besoin et selon la situation financière du ou de la bénéficiaire. Elles visent particulièrement à 1) assurer l'accès aux prestations publiques de base (subsides à l'assurance-maladie, bourses d'études, assistance judiciaire) ; 2) compléter des prestations d'assurances sociales (prestations complémentaires AVS/AI, aides aux familles); et 3) garantir l'atteinte du minimum vital aux personnes dont les ressources privées sont insuffisantes (avances sur pension alimentaire, aides au logement, aide sociale). Composant l'assistance au sens large, elles se situent en amont de l'assistance au sens étroit, l'aide sociale. Cette dernière, elle-même subsidiaire à toutes les autres prestations sous condition de ressources, est allouée lorsque la totalité des autres possibilités sont épuisées ou insuffisantes pour atteindre le minimum vital.
La plupart des prestations sous condition de ressources des trois ensembles cités sont de la compétence des cantons et communes, d'autres encore relèvent de la solidarité privée (aides de fondations p.ex.). Elles peuvent être financières ou en nature. Seules celles qui sont de ressort cantonal et communal ont un financement public, par la fiscalité, et constituent des transferts sociaux. Bien que constituant une dimension importante de la protection sociale, ces prestations ne font pas système. Certaines d'entre elles ont un caractère obligatoire découlant de dispositions fédérales: notamment celles qui permettent d'assurer l'accès aux prestations publiques de base (subsides à l'assurance-maladie, et bourses d'études et d'apprentissage), les prestations complémentaires AVS/AI qui complètent des prestations assurantielles, ainsi que les avances sur pension alimentaire et l'aide sociale. Celles qui n'ont pas ce caractère obligatoire n'existent que dans une partie des cantons. Bien que leur finalité soit la même, c'est-à-dire remédier au manque de ressources pour atteindre le minimum vital, toutes sans exception dépendent de cadres légaux, de réglementations et de modes d'application propres et différents, ce qui produit une grande hétérogénéité des aides elles-mêmes, comme de leurs conditions d'octroi. Pour ces raisons, mais aussi du fait de leur grand nombre, il est extrêmement difficile non seulement de les recenser exhaustivement, mais aussi de les comparer sur le plan national.

Une partie des prestations sous condition de ressources sont inventoriées depuis la fin des années 1990 par l'OFS. L'inventaire se concentre particulièrement sur les prestations de niveau cantonal, financières (en espèces), individuelles (se rapportant aux personnes), et régies par des cadres légaux permettant d'étudier leurs spécificités. Malgré ces précautions, le constat reste identique au fil des inventaires réalisés. De très nombreuses prestations existent dans les cantons en amont de l'aide sociale, et la disparité est très marquée entre 
les cantons. Notons d'une part la grande diversité dans l'existence même des prestations, et d'autre part s'agissant de celles qui existent dans plusieurs ou tous les cantons, de grandes variations du montant de l'aide, ainsi que des critères appliqués pour déterminer le droit à l'aide: diversité des seuils d'accès (limites de revenus), différences dans la prise en compte du revenu et de la fortune, différences de bases légales et de lisibilité de ces dernières, et enfin de grandes différences également dans la latitude laissée dans l'application des dispositions (stricte subsidiarité, ou prise en compte de cas de rigueur p.ex.).

Ces différences découlent du système fédéraliste helvétique, dans lequel les cantons, les communes, voire des instances privées, possèdent la compétence d'organiser des mesures assistancielles propres, pour lesquelles l'État fédéral se contente au mieux d'édicter le cadre des compétences ou des recommandations. Ainsi bon nombre de prestations sociales sous condition de ressources ont été créées et mises en œuvre selon la volonté des entités cantonales ou communales qui s'en sont saisies, et reflètent ainsi non seulement le contexte historique dans lequel elles ont été instaurées, les rapports de force politiques du moment, mais aussi une certaine vision de la protection sociale et de la solidarité. Il découle de cette situation que la garantie du minimum vital n'est pas assurée de manière uniforme en Suisse. Ce système continue à générer des différences au fur et à mesure du développement de nouvelles prestations sociales sous condition de ressources: c'est le cas, par exemple, avec les prestations complémentaires pour les familles, qui n'existent actuellement que dans certains cantons, et dont il n'existe pas de modèle unique.

Les prestations sociales sous condition de ressources sont une composante importante de la complexité et de l'opacité du système de protection sociale suisse. Si leur fonction ne pose guère question, leur organisation est source de grandes difficultés, et génère des différences voire des inégalités de traitement à différents niveaux entre des personnes qui ont des besoins analogues: en fonction du ciblage des aides, des critères appliqués et de la multiplicité des minima vitaux notamment, entre les habitant·e.s des communes d'un même canton, entre les habitant.e.s des différents cantons, etc. Plusieurs études successives de la CSIAS ont démontré des inégalités intercantonales sur le plan de la couverture du minimum vital des ménages menacés de pauvreté, en mettant en évidence les grandes différences pouvant en résulter pour un même ménage selon sa domiciliation, les aides à disposition et leur ordonnancement, ainsi qu'en fonction du système fiscal s'appliquant. Des dysfonctionnements, qui contreviennent à la justice sociale, sont mis en évidence: effets de seuils, reports de charges, effets pervers sur l'activité et pertes financières. Ces problèmes découlent notamment des grandes disparités des aides à disposition, mais encore plus de leur juxtaposition, de leur absence de coordination et du manque de prise en compte de leur implication notamment en matière d'imposition. Cette complexité est aussi source de non-recours à des prestations, par méconnaissance et/ou par la nécessité, pour pouvoir y accéder, de les demander et de prouver l'état de besoin.

D'un point de vue de politique sociale, le manque de coordination et d'harmonisation des prestations se révèle particulièrement problématique sur deux plans : sur le plan horizontal d'une part, c'est-à-dire entre les prestations (de même nature) mises en œuvre par les cantons ; sur le plan vertical d'autre part, soit entre les prestations sous condition de ressources et l'aide sociale, ainsi qu'avec la fiscalité, au sein d'un même canton. Cela a notamment conduit quelques cantons à aménager leur offre dans l'objectif de mieux agencer et coordonner leurs prestations sous conditions de ressources. Cet objectif nécessite d'intervenir sur différents éléments pris en compte pour obtenir ces 
prestations: harmoniser et unifier le revenu déterminant pris en compte, définir de façon uniforme l'unité d'assistance (ou unité économique de référence), et enfin hiérarchiser l'accès aux prestations sociales en définissant l'ordre de priorité dans lequel les prestations doivent être demandées.

Sur le plan national, de multiples interventions de milieux concernés et d'acteur-trice-s politiques plaident pour une révision en profondeur de l'organisation de l'aide sociale au sens large, qui permettrait de dépasser les dysfonctionnements et effets pervers de la juxtaposition de prestations qui prévaut, et d'assurer la garantie d'une couverture uniforme du minimum vital en Suisse. Une telle réforme, qui nécessiterait de renoncer en partie aux particularités du fédéralisme, passerait par l'harmonisation et la coordination, voire une intégration de toutes les prestations sociales sous condition de ressources, aide sociale comprise.

\section{Caroline Regamey}

\section{Références}

Conseil fédéral (2015). Aménagement de l'aide sociale et des prestations cantonales sous condition de ressources: besoins et possibilités d'intervention. Rapport du Conseil fédéral donnant suite au postulat 13.4010 Commission de la sécurité sociale et de la santé publique du Conseil national «Loi-cadre relative à l'aide sociale» du 6 novembre 2013. Berne: Office fédéral des assurances sociales.

Office fédéral de la statistique (Éd.) (s.d.). Aide sociale [Inventaire de l'aide sociale au sens large]. https://www.bfs.admin.ch/bfs/fr/home/statistiques/securite-sociale/aide-sociale.html

\section{Prévention de la criminalité ${ }^{*}$}

La prévention de la criminalité englobe toutes les mesures visant à prévenir les actes relevant du droit pénal. Les mesures de prévention des actes criminels relèvent traditionnellement $d u$ droit pénal et de la justice pénale. Les objec- tifs préventifs du droit pénal sont la prévention générale et la prévention spécialisée. D'une part, les menaces de poursuites pénales et les sanctions ont pour but de dissuader les membres de la société de commettre des délits (prévention générale négative). D’autre part, les normes établies doivent être expliquées afin de sensibiliser le public aux aspects juridiques de la criminalité et de l'inciter à respecter la loi (prévention générale positive). La prévention spécialisée s'adresse à certain·e-s délinquant.e.s afin de les dissuader, de manière positive, de commettre de nouveaux délits, ceci par le biais de mesures de resocialisation, ou alors de manière négative par l'emprisonnement. La prévention de la criminalité au sens large comprend, quant à elle, des mesures préventives dans les domaines de la famille, de l'école et de l'espace public.

Compte tenu du fait qu'une mesure pénale suite à un comportement criminel n'a qu'une faible influence sur l'ampleur de la criminalité, il paraît aujourd'hui évident que la criminalité doit se combattre de manière préventive. Depuis les années 1990, de multiples études démontrent le succès de la prévention en dehors du système de justice pénale et de la prévention de la récidive en milieu carcéral. La question de l'efficacité des mesures de prévention de la criminalité a soulevé un intérêt croissant. Sur la base de l'influent Rapport Sherman, la prévention de la criminalité fondée sur des preuves scientifiques a grandement gagné en importance dans les pays européens.

En ce qui concerne les mesures de prévention de la criminalité en dehors du secteur judiciaire, des interventions se sont développées dans trois domaines. La prévention de la criminalité axée sur le développement est centrée sur les individus et comprend des interventions visant à favoriser le développement des enfants et des jeunes afin de les empêcher de se livrer à des comportements criminels. Les mesures efficaces dans ce domaine comprennent des programmes préscolaires dont l'objectif est 
promouvoir le développement cognitif et socio-émotionnel en développant les compétences sociales (notamment l'apprentissage de l'autorégulation et de l'empathie) ainsi que des programmes familiaux visant à améliorer les compétences éducatives et à réduire le risque de maltraitance des enfants. Ensuite, dans le secteur scolaire, les programmes de lutte contre le harcèlement et de gestion des conflits peuvent être considérés comme efficaces. La prévention de la criminalité axée sur la communauté, enfin, comprend des programmes et des stratégies qui améliorent les conditions sociales et développent les institutions susceptibles d'avoir une influence positive en termes de criminalité. Il a été démontré que des programmes de mentorat pour des jeunes à risque et des contrôles de voisinage, répandus dans de nombreux pays, réduisent la criminalité. Les activités de loisirs après l'école, comme les centres de loisirs et de jeunesse, semblent également efficaces. Quant à la prévention de la criminalité contextuelle, elle consiste en des stratégies visant à réduire les opportunités de criminalité en modifiant l'environnement physique, les produits (protection contre le vol) ou les systèmes. Il existe, par exemple, diverses méthodes pour protéger les propriétés privées contre les cambriolages. Un meilleur éclairage public s'est également avéré efficace, de même que l'utilisation de la vidéosurveillance (CCTV) en particulier sur les parkings. Seul bémol: la criminalité se déplace vers des zones non surveillées.

Les analyses coûts-avantages des mesures de prévention montrent que celles-ci sont souvent rentables sur le plan financier (si elles sont bien mises en œuvre et sur une longue période), principalement en raison des coûts évités de poursuite et d'exécution des peines, mais aussi des coûts intangibles tels les souffrances évitées aux victimes.

À l'instar d'autres pays européens, en Suisse, le débat des questions de la prévention de la criminalité s'est intensifié au cours des dernières décennies, souvent sur des sujets identiques. Dans les années 1990, la prévention de la criminalité des toxicomanes était au premier plan. Le modèle réussi de la politique des quatre piliers (intervention, prévention, thérapie et aide à la survie) ainsi que les programmes de distribution d'héroïne ont conduit à une réduction massive et durable de la criminalité motivée par la recherche d'argent.

Depuis la fin des années 1990 environ, la prévention de la criminalité s'est considérablement développée en Suisse. Depuis lors, une priorité a été accordée à la violence des jeunes et diverses mesures préventives ont vu le jour. $\mathrm{Au}$ plan national, la Confédération a lancé, en 2011, deux grands programmes visant à une meilleure coordination des acteur.trice-s. L'un était consacré à la violence des jeunes et l'autre, à la protection des jeunes face aux médias.

Avec la désapprobation sociale croissante de la violence sexuelle dans les relations intimes, de la violence à l'égard d'enfants et de personnes dépendantes, le thème de la violence domestique a gagné en importance, phénomène accompagné par le développement des services d'aide aux victimes et le renforcement des poursuites pénales contre les auteur·e.s.

Au cours des dernières décennies, c'est aussi du côté de la police que les actions de prévention de la criminalité ont été intensifiées, que ce soit par le biais de campagnes, d'interventions dans les écoles ou de services spécialisés auprès de la jeunesse. En 1995, la Prévention Suisse de la Criminalité a été mise sur pied, un centre de compétence qui gère, pour le compte de la Conférence des directrices et directeurs des départements cantonaux de justice et police, une vaste plateforme en ligne pour la prévention de la criminalité.

Par ailleurs, on observe, depuis une vingtaine d'années, des changements importants dans le domaine de l'exécution des peines. En particulier, l'accent a été mis davantage sur le délit et le risque en se focalisant sur les besoins et les risques des criminel-le-s. Cette orienta- 
tion fournit une meilleure base pour une réinsertion réussie.

Les défis actuels en matière de prévention de la criminalité concernent plusieurs domaines. Mentionnons tout d'abord Internet et les médias sociaux qui recèlent de nombreux dangers tels que le cyberharcèlement, l'addiction, la pédocriminalité ou la fraude. En outre, des efforts supplémentaires sont nécessaires pour protéger les victimes de violences sexuelles dans les relations intimes. Il s'agit, également, de mieux protéger les enfants et les victimes de la traite des êtres humains par la prévention et la poursuite pénale des auteur-trice-s. Par ailleurs, la prévention de l'extrémisme politique, incluant l'extrémisme de droite et de gauche et, actuellement, l'extrémisme islamique, représente un autre défi. Les actes extrémistes sont rares, mais lorsqu'ils se produisent, ils impliquent généralement de nombreux dommages. Il en va de même pour les tueries - les folies meurtrières - perpétrées dans les écoles, les familles ou les entreprises. Dans ce domaine, on tente de détecter les premiers signes par un système de gestion précoce des menaces. De manière générale, la création d'une base de connaissances approfondie sur l'efficacité des offres de prévention par le biais d'évaluations de haute qualité est souhaitable.

Les relations entre la politique sociale et la prévention de la criminalité sont complexes et controversées. Les institutions et pratiques sociales visant à améliorer les perspectives de réussite et les opportunités d'action des personnes ont un effet fonctionnel de prévention de la criminalité, même si tel n'est pas leur but premier. À cet égard, il est justifié d'adopter une approche sociale globale et coordonnée de la prévention de la criminalité, approche qui englobe des mesures de politique sociale dans les domaines de la famille, de la jeunesse, de la formation et de la lutte contre la pauvreté. Certain-e-s sont d'un autre avis; ils et elles admettent comme mesures de prévention de la criminalité uniquement celles axées directe- ment sur la prévention de comportements criminels que ce soit de la part de groupes à risque ou de délinquant.e.s identifié.e.s.

La présence croissante de la prévention fait l'objet d'un débat critique. L'augmentation du recours à des mesures de surveillance policière (téléphonie, Internet) qui ne reposent sur aucune suspicion concrète d'une personne est considérée comme problématique par beaucoup. Il existe une zone de tension entre les droits à la liberté personnelle et la garantie optimale de la sécurité.

\section{Patrik Manzoni}

\section{Références}

Averdijk, M. \& Eisner, M. (2014). Wirksame Gewaltprävention: Eine Übersicht zum internationalen Wissensstand. Bern: BBL, Bundespublikationen. Sherman, L.W., Farrington, D., Welsh, B. C. \& MacKenzie, D. L. (Eds.) (2006). Evidence-based crime prevention (rev. ed.). London: Routledge. Welsh, B.C. (2011). Crime Prevention. In M. Tonry (Ed.), The Oxford handbook of crime and criminal justice (pp. 126-155). Oxford: Oxford University Press.

\section{Prévention des addictions*}

La prévention des addictions peut viser, selon la substance considérée, la problématique d'addiction et le groupe cible, soit la non-entrée en consommation, soit la prévention de la consommation précoce, ou de la consommation excessive, ou des conséquences négatives de la consommation, ou de la consommation chronique à risque ou de la dépendance. Ces objectifs sont pertinents pour les problèmes en lien avec une substance psychoactive ou avec certains comportements (utilisation d'Internet, jeux d'argent, etc.).

Une distinction est faite entre la prévention universelle, sélective et indiquée. La prévention universelle s'adresse à l'ensemble de la popula- 
tion ou à toutes les personnes de certains segments (p.ex. toutes les personnes retraitées). Elle fait sens lorsque les risques sont largement répartis au sein d'un groupe. Cette catégorie de prévention inclut des mesures légales, des campagnes médiatiques ou encore le travail dans les écoles. La prévention sélective vise des groupes à risque définis. Les personnes appartenant à de tels groupes sont généralement en bonne santé et ne présentent pas de signes particuliers, mais une probabilité plus élevée de développer une addiction en raison de facteurs de risque confirmés empiriquement (p.ex. des enfants d'une famille touchée par des problèmes d'addiction). La prévention indiquée s'adresse, quant à elle, à des personnes présentant des comportements à risque manifestes mais qui ne répondent pas (encore) aux critères de diagnostic d'une addiction (p.ex. de jeunes adultes avec une consommation excessive d'alcool en fin de semaine). Les stratégies sélectives et indiquées sont complexes à appliquer et demeurent peu développées et peu étudiées en Suisse.

Les problèmes liés aux substances psychoactives se situent dans un triangle formé par les trois dimensions que sont le produit, la personne et la société ou l'environnement. L’objectif de la prévention des addictions est de réduire les facteurs de risque (p.ex. un environnement familial défavorable) et de renforcer les facteurs de protection (p.ex. la confiance en soi) en tenant compte de ce triangle. La plupart des problèmes d'addiction repose sur de nombreux facteurs de risque et de protection, ce qui complexifie l'action préventive. En fonction des besoins identifiés et de l'efficacité des mesures préventives, elles peuvent agir sur les trois dimensions. Les interventions visant à influencer les connaissances, l'attitude, la motivation ou le comportement d'une personne ou d'un groupe cible déterminé font partie de ce qu'on appelle la prévention centrée sur le comportement. Elle se distingue des mesures de prévention structurelles qui, quant à elles, relèvent d'une approche centrée sur les conditions-cadres et visent à réduire les risques liés aux conditions de vie, de travail et d'environnement et de renforcer les facteurs de protection correspondants.

Les réglementations légales visant à réduire la disponibilité et la demande font partie des approches les plus efficaces et à la portée la plus large en matière de prévention des addictions aux substances légales et aux jeux d'argent. Les mesures tarifaires, telles que la réglementation des offres à bas prix - mesures qui agissent principalement sur le comportement des jeunes et des personnes dont la consommation est forte et fréquente - sont particulièrement efficaces et peu coûteuses. Une autre façon de réduire la demande est de limiter la publicité sur les substances addictives, y compris en adoptant des stratégies publicitaires de substitution telles que le parrainage d'événements sportifs ou culturels. En ce qui concerne les restrictions d'accès, les mesures qui se sont avérées efficaces sur la base de données probantes comprennent, par exemple, l'application de dispositions relatives à la protection des mineur.e.s et la réduction des heures de vente de l'alcool ou l'interdiction totale ou partielle de la vente lors de manifestations sportives ou de loisirs. En comparaison européenne, la Suisse se situe à cet égard en milieu de classement. Dans les domaines de la restriction des ventes et dans celui des taxes (pas de taxe sur le vin, taxation faible sur la bière) plus particulièrement, il existe un potentiel d'amélioration considérable.

Outre ces approches universelles, il est important d'élaborer des mesures spécifiques pour des groupes cibles, car les grands groupes de population comme les jeunes ne forment pas un ensemble homogène. L'expérience, le risque en matière de consommation de substances addictives et d'autres comportements à risque varient fortement d'un ou d'une jeune à l'autre. Les mesures structurelles ne peuvent influencer que de manière limitée le compor- 
tement de jeunes avec un comportement à risque supérieur à la moyenne. Les mesures structurelles doivent être complétées par une prévention centrée sur le comportement, ceci par exemple dans le contexte familial ou scolaire où s'acquièrent les compétences de base essentielles en matière de prévention (p.ex. la promotion de la santé, la capacité à gérer les conflits, les capacités relationnelles). On peut considérer que les effets de la prévention des addictions sont d'autant plus importants qu'elle est vaste et complète : les projets impliquant tout autant les écoles, les familles et l'environnement social produisent les résultats les plus prometteurs.

En Suisse, de nombreux acteur-trice-s étatiques et non étatiques sont impliqués, aux niveaux cantonal et régional, dans la prévention des addictions. La structure fédérale de la prévention des addictions (et des offres d'aide en cas d'addiction en général) a donné lieu à une multitude de mesures et de projets. D'une part, ceux-ci tiennent compte des différents besoins des communes et des cantons, mais d'autre part, ils sont souvent peu coordonnés. Depuis les années 1990, on a tenté de créer au niveau national un cadre favorisant la coordination et la coopération en lançant des programmes nationaux tels que le Programme national alcool, le Programme national tabac ou le Plan de mesures de la Confédération de la Stratégie nationale Addictions. Par ailleurs, la Confédération participe à la recherche et au financement de projets pilotes de prévention des addictions.

Il existe désormais de nombreuses preuves scientifiques de l'efficacité de la prévention des addictions (bien qu'encore peu nombreuses en Suisse). L'un des problèmes est que, pour l'heure, les priorités de la politique en matière d'addiction en Suisse ne tiennent pas compte de l'état actuel de la recherche ni davantage à l'étendue réelle du problème. Ainsi, des intérêts économiques puissants compromettent la mise en œuvre de mesures préventives structu- relles pourtant efficaces. L'exemple de l'échec de la révision de la loi sur l'alcool en 2015 le démontre. En dépit de la volonté du Conseil fédéral, presque toutes les mesures préventives efficaces, telles que les mesures tarifaires, ont finalement été abandonnées sous la forte pression de l'industrie de l'alcool.

À cela s'ajoute la tendance politique actuelle qui met l'accent sur la responsabilité individuelle des consommateurs et des consommatrices, tandis que la responsabilité de la société et de la politique passe au second plan malgré la déréglementation croissante du marché. Cette vision restrictive devrait être élargie et la prévention des addictions davantage comprise comme une mission relevant de la société dans son ensemble dont tous les acteur.trice-s, les consommateur·trice·s, l'État et l'économie, portent la responsabilité. Dans ce contexte, il convient de maintenir l'objectif visant à réduire les grandes inégalités persistantes dans l'accès aux offres de prévention et d'améliorer l'égalité des chances en matière de santé. Cet objectif est désormais fixé dans les nouvelles stratégies du Conseil fédéral, la Stratégie Santé 2020, la Stratégie nationale Prévention des maladies non transmissibles et la Stratégie nationale Addictions. Ces stratégies ont en outre en commun le fait qu'elles visent à renforcer la prévention et la protection de la santé en Suisse et à les aborder de manière transversale. Alors que les programmes de prévention des addictions et la politique d'addiction de la Confédération se sont principalement concentrés ces dernières années sur les trois domaines que sont l'alcool, le tabac et les drogues illégales avec, jusqu'à présent, peu de points communs, ces programmes tiendront à l'avenir davantage compte de plusieurs facteurs de risque, de différentes dimensions des addictions ainsi que de plusieurs aspects de la santé psychique.

Irène Abderhalden 


\section{Références}

Addiction Suisse. https://www.addictionsuisse.ch/

Bühler, A. \& Thrul, J. (2013). Expertise zur Suchtprävention. Köln : Bundeszentrale für Gesundheitliche Aufklärung.

Conseil fédéral. (2015). Stratégie nationale et plan de mesures addictions 2017-2024. Berne: Office fédéral de la santé publique.

\section{Prévention et promotion de la santé}

Jusqu'à l'avènement de la médecine moderne et de ses traitements d'une efficacité redoutable, le salut (salve) et la longue vie passaient par le «prévenir» plutôt que par le «guérir». Ainsi les mesures d'hygiène à partir de la fin du XIX ${ }^{e}$ siècle ont-elles permis de réduire de manière spectaculaire la mortalité infantile, contribuant de la sorte à l'augmentation non moins spectaculaire de l'espérance de vie à la naissance au cours du XXe siècle. Il est vrai qu'à partir du milieu du siècle dernier l'impact des mesures d'hygiène a été renforcé, notamment par le développement de vaccins contre de nombreuses maladies, permettant d'en réduire l'incidence en sus de la mortalité.

Une nouvelle étape a été franchie dans le «prévenir » par l'adoption, en 1986, de la Charte d'Ottawa pour la promotion de la santé par l'Organisation mondiale de la santé (OMS), qui stipule que «la promotion de la santé a pour but de donner aux individus davantage de maîtrise de leur propre santé et davantage de moyens de l'améliorer. Pour parvenir à un état de complet bien-être physique, mental et social, l'individu, ou le groupe, doit pouvoir identifier et réaliser ses ambitions, satisfaire ses besoins et évoluer avec son milieu ou s'y adapter». La Charte d'Ottawa définit trois stratégies en vue du maintien de la santé des individus et des populations. La première vise à créer les conditions-cadres nécessaire à la santé : c'est la notion de plaidoyer ou advocacy. La seconde entend permettre à tout un chacun d'assurer son potentiel de santé : c'est la notion d'autonomisation ou empowerment. La troisième se base sur la notion de médiation entre les divers acteur.trice-s, afin de s'engager ensemble pour la santé. Ces stratégies impliquent un ensemble d'actions en faveur de la promotion de la santé, résumées ainsi dans la Charte: «Elaborer une Politique publique saine; Créer un environnement favorable; Renforcer l'action communautaire; Développer les compétences personnelles; Réorienter les services de santé vers la prévention et promotion de la santé».

De fait, en matière de prévention et de promotion de la santé, il apparaît comme crucial de comprendre les éléments qui déterminent la santé des individus et des populations. Au fil du temps, trois grands champs se sont avérés comme jouant un rôle clé en matière de santé et de maladies. Il s'agit d'une part de l'environnement social et économique des communautés et des individus, de leur environnement physique et enfin des caractéristiques biologiques et des comportements de tout un chacun. Depuis une vingtaine d'années l'OMS s'est fait un devoir de souligner l'effet majeur qu'ont les déterminants sociaux sur l'état de santé des individus et des populations et sur lesquels devraient porter prioritairement les interventions en matière de prévention et de promotion de la santé. En résumé, citons les déterminants sociaux suivants: le niveau de revenu et le statut social, le niveau d'éducation, l'emploi et plus particulièrement l'autonomie dans le cadre de son travail, la qualité du réseau social, l'organisation des services de santé, et des moyens qui y sont affectés, y compris en matière de prévention et de promotion de la santé.

Nous sommes actuellement confrontés à l'explosion des maladies chroniques non transmissibles (MNT) et ce pas qu'en Suisse, mais dans le monde entier: le problème est suffisamment grave pour que les Nations Unies en aient fait une priorité absolue, puisque les MNT engendrent beaucoup de souffrances pour les 
personnes concernées et leurs proches, ainsi que $80 \%$ des coûts de la santé. Et l'action passe en grande partie par la prévention et la promotion de la santé, telles que définies plus haut. En effet, les recommandations internationales préconisent une approche en cinq points, à savoir : leadership, prévention / promotion de la santé, traitement, coopération internationale, suivi. Le leadership doit être assuré par les autorités politiques. Cela implique de mettre la lutte contre les maladies non transmissibles au sommet de l'agenda politique, ainsi que d'adopter une approche multisectorielle face aux problèmes générés par les MNT. En termes de prévention/promotion de la santé, la priorité devrait être donnée au contrôle des principaux facteurs de risque responsables de maladies non transmissibles, les best buy interventions, c'est-à-dire les interventions les plus efficaces et les plus efficientes. La première en est la lutte contre le tabagisme à travers la mise en œuvre de la Convention cadre de l'OMS pour la lutte antitabac, dont le but ultime est un monde sans tabac en 2040. Les autres priorités comprennent la réduction de la consommation quotidienne de sel à moins de $5 \mathrm{~g}$ par personne en 2025, la réduction de la consommation d'alcool et la promotion de l'accès à une alimentation saine et à une activité physique quotidienne dès le plus jeune âge. Cela peut être réalisé à un coût relativement faible (les estimations vont de 0,5 à 4 \$ US par personne et par an, selon le pays). Quant au traitement, cela implique le renforcement des soins de base, afin de faciliter l'accès aux soins médicaux de qualité à un coût raisonnable à toute personne à risque de maladies non transmissibles. La notion de Coopération internationale sous-entend la nécessité d'accorder la priorité à la lutte contre les MNT dans l'agenda mondial, en veillant à l'allocation des ressources appropriées et à l'établissement de synergies avec d'autres priorités en matière de santé globale, tel que l'impact du changement climatique sur la santé. Enfin, la notion de suivi comprend l'éva- luation de l'atteinte des objectifs fixés, impliquant la mise en place d'un monitoring sérieux et l'allocation des ressources appropriées.

L'engagement en termes de prévention et de promotion de la santé en Suisse a contribué à l'amélioration de l'état de santé de la population au cours du siècle passé. Citons à ce propos le taux de mortalité infantile en Suisse, qui a passé de $15 \%$ en 1900 à $33 \%$ en 2018. Mentionnons aussi l'espérance de vie à la naissance, qui, de 46 ans pour les hommes et 49 ans pour les femmes en 1900, a augmenté 115 ans plus tard à respectivement 82 et 85 ans.

Comme au niveau mondial, la Suisse est confrontée à des défis majeurs de santé publique, liés notamment au fardeau croissant que représentent les MNT mais aussi par l'apparition de nouvelles maladies. C'est dans ce contexte que s'inscrivent les orientations politiques en matière de santé de la Confédération Santé2030 et Stratégie MNT - prévenir les maladies non transmissibles. Santé 2030 se concentre sur les quatre défis les plus urgents la transformation technologique et numérique, les changements démographiques et sociétaux, le maintien de soins de qualité et abordables, et l'opportunité de vivre en bonne santé - et définit 8 objectifs et 16 principaux axes politiques pour la mise en œuvre. La Stratégie MNT, elle, accorde la priorité à la prévention et la promotion de la santé et vise en particulier les MNT les plus répandues, à savoir les maladies cardiovasculaires, les cancers, le diabète, les affections chroniques des voies respiratoires et les atteintes musculo-squelettiques. Ces deux stratégies ont été adoptées avant le début de la pandémie du coronavirus. Dans ce contexte, elles ne perdent pas leur validité, bien au contraire: les patient-e-s souffrant de maladies non transmissibles telles que l'hypertension, le diabète ou les maladies coronariennes, dont les vaisseaux sanguins sont déjà endommagés, doivent s'attendre à une évolution particulièrement grave de la maladie du Covid-19 et à des dommages à long terme aux organes. La pandé- 
mie du coronavirus met clairement à l'évidence l'importance de la promotion de la santé et de la prévention.

\section{Philippe Chastonay, Corina Wirth, Ursula Zybach \& Thomas Mattig}

\author{
Références \\ Chastonay, P., Zybach, U. \& Mattig, T. (2016). Pro- \\ motion de la santé et prévention des maladies \\ et leurs acteurs. Dans W. Oggier (Éd.), Système \\ de santé suisse 2015-2017: survol de la situation \\ actuelle ( $5^{\mathrm{e}}$ éd. entièrement rév., pp. 337-352). \\ Berne: Huber. \\ International Conference on Health Promotion \\ (1986) \& World Health Organization. Division of \\ Health Education and Health Promotion (1995). \\ Health promotion: Ottawa Charter $=$ Promotion \\ santé, Charte d'Ottawa. Geneva: WHO. \\ Organisation mondiale de la santé. Déterminants \\ sociaux de la santé. https://www.who.int/social_ \\ determinants/fr/
}

\section{Prévoyance professionnelle}

La prévoyance professionnelle est le régime professionnel des pensions en Suisse, dont elle représente le deuxième pilier. À ce titre, elle complète le revenu de substitution garanti par l'assurance-vieillesse et survivants (AVS) et par l'assurance-invalidité (AI) en cas de réalisation des risques vieillesse, décès ou invalidité. Son but est de permettre aux personnes assurées de maintenir le niveau de vie qui était le leur avant la réalisation du risque assuré. Elle est basée sur un mécanisme de capitalisation, le premier pilier reposant pour sa part sur un modèle de répartition.

Apparue ponctuellement et de manière

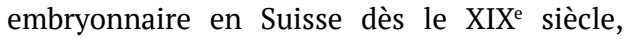
essentiellement à l'initiative de collectivités publiques soucieuses de la protection sociale de leurs employé·e·s, la prévoyance professionnelle voit son rôle se renforcer au début des années 1970, lorsque le modèle de pensions en trois piliers, incluant le développement d'un deuxième pilier obligatoire, est privilégié en votation populaire, au détriment des projets de pensions populaires défendus par les partis de gauche. Elle devient une assurance sociale obligatoire le $1^{\text {er }}$ janvier 1985, date de l'entrée en vigueur de la loi sur la prévoyance professionnelle du 25 juin 1982 (LPP).

La prévoyance professionnelle obligatoire protège les travailleuses et travailleurs salarié·e.s réalisant auprès du·de la même employeur.euse un salaire minimum défini par la loi. Les personnes actives à titre indépendant ou cumulant auprès de plusieurs employeur.euse-s des salaires moindres dont le total atteint pourtant le salaire minimum permettant l'accès à la prévoyance professionnelle ont la possibilité de s'assurer à titre facultatif. Les personnes sans activité lucrative n'ont pas accès à la prévoyance professionnelle.

Pour les personnes assurées, seule une partie de leur salaire AVS, le salaire coordonné, est prise en considération dans le cadre de la prévoyance professionnelle obligatoire. Le salaire coordonné s'obtient en principe en déduisant du salaire AVS le montant de coordination, qui équivaut aux $7^{\text {e }}$ et $8^{\text {e }}$ de la rente AVS annuelle maximale. Le but de cette déduction est d'assurer la coordination entre les rentes du premier et du deuxième pilier. À l'origine, le montant de coordination correspondait à celui de la rente AVS annuelle maximale. Il a été abaissé à l'occasion de la première révision de la LPP, entrée en vigueur au $1^{\text {er }}$ janvier 2005, pour favoriser la prévoyance des personnes ayant un faible revenu. La déduction de coordination qui, dans la LPP, ne dépend pas du taux d'activité, a pour effet de pénaliser les salarié·e·s à temps partiel, dont le revenu est moindre. Malgré plusieurs interventions politiques, le législateur a jusqu'ici toujours refusé de régler cette question dans la loi. Certaines caisses de pension, principalement des caisses publiques, prévoient dans leurs règlements de prévoyance 
une adaptation de la déduction de coordination en fonction du taux d'activité.

La prévoyance professionnelle obligatoire verse des prestations sous forme de rentes, exceptionnellement de prestations en capital. La rente de vieillesse correspond à un pourcentage du capital de prévoyance constitué tout au long de la carrière professionnelle (taux de conversion). Le taux de conversion dépend de différents facteurs, notamment de l'âge de la retraite et de l'espérance de vie des bénéficiaires de rentes. L'allongement de l'espérance de vie est ainsi une des raisons pour lesquelles ce taux a aujourd'hui tendance à baisser. Dans le cadre de la prévoyance obligatoire, la LPP fixe un taux de conversion minimal, qui est aujourd'hui le même pour les femmes et les hommes, à savoir 6,8\%.

Les employeur-euse-s ont la liberté d'affilier leurs employé·e.s auprès d'institutions de prévoyance pratiquant la prévoyance dite surobligatoire (ou étendue), c'est-à-dire offrant des conditions d'assurance plus avantageuses que les minima imposés par la LPP. Il est ainsi possible, par exemple, d'assurer une part plus importante du salaire, de prévoir des possibilités de retraite anticipée ou encore d'autres bénéficiaires des prestations versées en cas de décès. En pratique, seul un quart des personnes assurées ne bénéficie que d'une protection minimale selon la LPP, la majorité d'entre elles bénéficiant d'un plan de prévoyance plus avantageux, ce qui entraîne, de fait, une inégalité de traitement entre les personnes assurées.

Tant dans la prévoyance professionnelle obligatoire que surobligatoire, les cotisations doivent être financées paritairement par la personne assurée et par son employeur-euse, ce-cette dernier-ère étant libre cependant de prévoir une solution plus favorable pour son personnel.

La prévoyance professionnelle est gérée de manière décentralisée, par un peu plus de 1500 institutions de prévoyance, qui peuvent relever du droit public lorsqu'elles sont créées par une collectivité publique, ou du droit privé. Elles prennent alors obligatoirement la forme d'une fondation ou, plus rarement, d'une société coopérative.

À l'échelle helvétique, la particularité de la prévoyance professionnelle est d'être gérée paritairement. L'organe dirigeant des institutions de prévoyance doit ainsi comprendre un nombre égal de représentants des milieux patronaux et des travailleuses et travailleurs. Lorsque l'entreprise comprend plusieurs catégories de travailleuses et travailleurs, chacune doit en principe être représentée. Par exemple, si l'entreprise emploie des travailleuses et travailleurs syndiqué.e-s et d'autres qui ne le sont pas, il n'est pas conforme au principe de la parité que seules des personnes syndiquées siègent au sein de l'organe dirigeant.

Depuis le $1^{\text {er }}$ janvier 1995, la LPP est complétée par la loi fédérale du 17 décembre 1993 sur le libre passage (LFLP). Cette loi a pour effet de garantir le maintien de la prévoyance tout au long de la carrière professionnelle de la personne assurée. Ainsi, le fait de quitter son institution de prévoyance alors qu'aucun risque ne s'est réalisé lui donne droit de prendre avec elle le capital accumulé jusque-là (prestation de sortie), qui sera en principe versé à sa nouvelle institution de prévoyance. On évite ainsi qu'un, voire plusieurs changements d'employeur-euse ne prétéritent la constitution de la prévoyance.

Le financement de la prévoyance professionnelle dépendant largement du rendement des capitaux placés par les institutions de prévoyance, une baisse à long terme des performances des marchés financiers est de nature à mettre en danger le paiement des prestations convenues. Il est ainsi régulièrement question de baisser le niveau des rentes afin d'en assurer la pérennité, en particulier depuis la crise financière mondiale de 2007. Une première révision de la LPP, entrée en vigueur en 2005, avait déjà entraîné une baisse du taux de conversion, et donc du niveau des rentes. Un autre ajustement a été sèchement rejeté 
par le peuple suisse en 2010. La question de la baisse du taux de conversion s'est à nouveau posée dans le cadre d'une réforme générale des retraites proposées par les autorités fédérales en 2017 (Prévoyance 2020), et également rejetée en votation populaire. Le débat n'est pas clos dans la mesure où, malgré une forte opposition de principe, parmi la population, à toute baisse des rentes du deuxième pilier, il semble bel et bien acquis que le financement de cette branche de la protection sociale n'est désormais plus garanti à long terme.

La possibilité qu'ont actuellement les personnes assurées, au moment de la retraite, de retirer tout ou partie des avoirs acquis dans le cadre de la prévoyance professionnelle sous forme de capital fait également l'objet de discussions. En effet, le risque existe que les personnes bénéficiant de cette possibilité dépensent rapidement ce capital, et, n'ayant alors plus les moyens de subvenir à leurs besoins, dépendent des pouvoirs publics. La même critique est émise à l'encontre de la possibilité qu'ont les personnes assurées de retirer leurs avoirs de prévoyance en espèces lorsqu'elles quittent la Suisse pour s'établir dans un pays hors de l'Union européenne et de l'AELE, ou encore lorsqu'elles optent pour l'exercice d'une profession indépendante. Dans ce second cas, il est en particulier problématique qu'aucun contrôle ne soit effectué pour savoir si les avoirs de prévoyance sont effectivement affectés au lancement de l'activité indépendante. En outre, la faillite de cette nouvelle activité réduit à néant les efforts de prévoyance, contraignant alors le plus souvent la personne concernée à dépendre, là encore, des pouvoirs publics.

En revanche, la possibilité d'utiliser une partie des avoirs de prévoyance pour accéder à la propriété du logement principal n'est pas, sur le principe, remise en cause. Le risque de voir ces avoirs disparaître est moins grand dès lors qu'ils sont investis dans un bien immobi- lier et doivent être restitués à l'institution de prévoyance si ce dernier est vendu.

Anne-Sylvie Dupont

\section{Références}

Oberson, F. (2013). La prévoyance professionnelle: principe et fondements. Genève: Schulthess.

Schneider, J.-A., Geiser, T. \& Gächter, T. (Éd.) (2017). LPP et LFLP: lois fédérales sur la prévoyance professionnelle vieillesse, survivants et invalidité et sur le libre passage dans la prévoyance professionnelle vieillesse, survivants et invalidité ( $2^{\mathrm{e}}$ éd.). Berne: Stämpfli.

Stauffer, H.-U. (2012). Berufliche Vorsorge (2. Aufl.). Zürich: Schulthess.

\section{Prix $^{*}$}

Le prix est la valeur d'un bien ou d'un service réalisée en échange de celui-ci. On parle de prix lorsque la transaction d'achat/de vente est effectivement effectuée. Il est généralement défini ou convenu en unités monétaires nationales (francs, euros, dollars, etc.) par pièce, par unité de mesure ou par unité de service définie. Dans le commerce de détail, le prix inclut l'emballage et la taxe sur la valeur ajoutée (impôt indirect). Selon l'ordonance suisse sur l'indication des prix, le prix de détail d'un bien doit être indiqué dans le commerce de détail. Dans les magasins en libre-service, l'impression n'est plus obligatoire, mais le prix doit être inscrit sur le présentoir, dans les rayons du magasin. Les prix de vente indiqués par le-la vendeur.euse sont fermes. Dans le commerce de gros et le commerce de business-to-business (B2B), d'autres définitions de prix usuelles dans le secteur concerné peuvent également être pratiquées, par exemple des prix au catalogue pour un service défini, y compris les taxes, la livraison, le montage et la garantie de service. L'État recense périodiquement les prix dans le commerce de détail (dans l'optique des 
consommateur-trice-s privé-e-s) et ceux dans le commerce de gros (dans l'optique des revendeur.euse-s, des fabricant.e-s ou des importateur·trice-s). En Suisse, l'Office fédéral de la statistique est responsable des enquêtes sur les prix, du traitement des données, de la pondération et de la publication.

L'indice suisse des prix à la consommation (IPC) recense les prix de vente finaux des biens de consommation durables et non durables pour les ménages privés. Les prix relevés sur une base mensuelle (environ 70000 biens de consommation) sont indexés à partir d'une date de base. Les prix de location (y compris les coûts énergétiques) sont également inclus dans l'IPC, mais ils ne sont pas mis à jour mensuellement. Les primes d'assurance-maladie ne sont pas intégrées à l'IPC, mais les prix des composants sont indiqués sous forme de prix individuels dans le secteur de la santé (médicaments, tarifs des médecins, tarifs hospitaliers, etc.). L'IPC dans son ensemble (pondéré par les prix des différents composants) montre de quel pourcentage les biens de consommation ont augmenté ou diminué par rapport au mois précédent ou à l'année précédente pour un ménage moyen. Lorsque les prix à la consommation (IPC) augmentent, on parle de renchérissement ou d'inflation. Lorsqu'ils baissent temporairement, on parle de renchérissement négatif ou de déflation. Si les prix très volatiles des produits pétroliers et des légumes saisonniers sont exclus de l'indice, on parle de renchérissement de base ou d'inflation de base.

En termes de politique sociale, les prix et l'IPC sont pertinents à bien des égards. Ils sont en lien avec les coûts de la vie et le pouvoir d'achat général. Plus la vie est chère, plus les prix touchent le pouvoir d'achat de la population. Considéré comme un «indice d'entente», c'est-à-dire accepté par les partenaires sociaux, l'IPC a une fonction sociopolitique importante en matière d'ajustement des salaires au renchérissement des prix (indexation). Pour de nombreuses relations de travail individuelles et collectives, l'ajustement annuel des salaires aux prix est garanti de manière à préserver le pouvoir d'achat des salaires (c'est-à-dire la valeur de l'argent mesurée en biens). La doctrine de l'indexation automatique des salaires, c'est-à-dire l'ajustement total et permanent à l'évolution des prix, a été fortement affaiblie ces dernières années sous la pression des rapports de concurrence.

L'IPC est également un paramètre important dans l'ajustement des prestations sociales, des rentes AVS et des prestations complémentaires (PC) notamment. Les rentes AVS et les PC doivent être périodiquement ajustées à l'évolution des prix et des salaires dans l'ensemble de l'économie (selon la formule: évolution de l'IPC plus évolution des salaires divisées par deux). Cette formule à vocation sociale sert à maintenir le pouvoir d'achat des rentes de vieillesse. La Conférence suisse des institutions d'action sociale (CSIAS) recommande que les prestations de l'aide sociale soient également ajustées en fonction de l'AVS et des PC. Tous les cantons ne se conforment pas à cette exigence.

Lévolution des prix a également un effet distributif indirect. Si les prix augmentent fortement (inflation), les épargnant·e.s perdent leur pouvoir d'achat réel sur leur épargne, tandis que les débiteur.trice-s peuvent tirer les avantages correspondants du renchérissement. En termes de politique économique, l'autorité la plus importante pour influencer les prix, en particulier dans la lutte contre le renchérissement, est la Banque nationale suisse (BNS). Avec sa politique monétaire, elle peut lutter contre le renchérissement élevé, selon la doctrine actuelle, surtout lorsque l'IPC dépasse $2 \%$ par an.

Selon le modèle de marché présenté dans les manuels d'économie les prix sont basés sur le libre jeu de l'offre et de la demande. Les courbes de l'offre et de la demande y sont présentées par paires prix-quantités. Le prix réel du marché devrait alors se situer à l'intersection des courbes de l'offre et de la demande. 
Dans la réalité économique, rares sont les prix de marché totalement libres qui remplissent ces conditions. C'est le cas, par exemple, dans le commerce des matières premières, c'està-dire avec des marchandises homogènes et comparables. Un grand nombre de prix sont des prix administrés. Ceux-ci sont influencés par le contrôle de l'État ou la taxation, par exemple les prix des lettres postales, de l'électricité, de l'eau, des eaux usées, des chemins de fer, des médicaments, de l'utilisation des cimetières, des produits agricoles. De nombreux prix sont fixés unilatéralement par des fournisseur.euse-s en situation de monopole, par exemple pour la fourniture liée à la prestation d'eau, d'électricité, de transport ferroviaire et de télécommunications fixes. Ils sont aussi souvent déterminés par des entreprises puissantes ou par des accords entre fournisseur-euse-s privéee-s, tels que les prix du chauffage et du carburant, les produits de marque, les produits importés dans le cadre d'accords d'importation exclusifs (dits ententes verticales). Par ailleurs, les accords sur les prix et sur la concurrence entre fournisseur-euse-s ou entre client.e.s peuvent être combattus en vertu de la législation sur la concurrence. En Suisse, la Commission de la concurrence (COMCO) est chargée de cette tâche, en vertu de la loi sur les cartels. En revanche, dans le cas des prix administrés par l'État et des fournisseur·e-s lié·e.s à des prestations de services (appelés monopoles techniques), la surveillance des prix est prévue par la loi.

Il existe aussi de très graves distorsions de prix dans la réalité économique. En particulier, les prix de livraison de certains biens de consommation importés sont excessifs en comparaison internationale et ce, en raison d'une «surtaxe suisse» appliquée par les fournisseur·e·s étranger·ère·s. On parle de «l'îlot de cherté suisse». Les détaillant·e-s et grossistes suisses ne peuvent pas acheter certains produits de marque directement auprès du-de la fabricant·e à l'étranger, mais seulement indi- rectement par l'intermédiaire d'un·e importateur-trice exclusif-ve en Suisse, qui facture des prix d'achat plus élevés. Le problème des prix élevés peut alors être attribué à une restriction de concurrence au niveau des importations (organisations de distribution sélectives). La conséquence en est que la population (surtout à proximité de la frontière) se livre au tourisme d'achat à l'étranger, ce qui est un problème sociopolitique car les consommateur.trice-s profitent différemment de cet avantage en fonction de la distance qui les sépare de la frontière.

$\mathrm{Au}$ cours des dernières années, le modèle de la libre fixation des prix en fonction de l'offre et de la demande a été de plus en plus remis en question. Tout d'abord, les prix du marché ne reflètent souvent pas la vérité écologique parce qu'ils ne rendent pas compte des coûts engendrés auprès de personnes externes (ce que l'on appelle les coûts externes), par exemple les coûts de la pollution atmosphérique ou de l'empoisonnement de l'eau. Le débat de plus en plus important sur la durabilité se focalise notamment sur ces coûts, portés principalement par la collectivité, et l'on voit émerger un nombre croissant d'appels en faveur de méthodes de production plus durables, par exemple dans l'agriculture ou l'industrie.

Ensuite, l'économie comportementale (behavioural economics) remet en question, même au niveau théorique, le modèle de concurrence de la libre fixation des prix. Elle tient compte du comportement irrationnel des consommateur·trice-s dû à la publicité sophistiquée, la manipulation, les comportements grégaires, les réactions de panique, les achats impulsifs, et met en doute la prévalence du comportement rationnel des acheteur-euse-s, comme le suppose le modèle abstrait de l'homo œconomicus dans les manuels.

Rudolf Strahm 


\section{Références}

Kutzner, S., Mäder, U., Knöpfel, C., Heinzmann, C. \& Pakoci, D. (2009). Sozialhilfe in der Schweiz: Klassifikation, Integration und Ausschluss von Klienten. Zürich : Rüegger.

Office fédéral de la statistique. Prix, https://www.bfs. admin.ch

Office fédéral de la statistique (Éd.) (2018). Indice suisse des prix à la consommation - Pondération 2018. Neuchâtel: Office fédéral de la statistique.

\section{Procédure pénale}

Lorsqu'une infraction pénale parvient à la connaissance de l'autorité, celle-ci engage une action pénale. Les États modernes ont dès lors mis en place des structures permettant d'assurer le bon déroulement de ces actions pénales. C'est ainsi que nous connaissons aujourd'hui des institutions, telles que la police, le ministère public (composé de procureur.e-s), les tribunaux (composés de juges), les autorités d'exécution des peines, etc., qui participent toutes à ce que l'on appelle la lutte contre la criminalité.

La procédure pénale consiste en un corpus de normes destinées à réglementer cette action pénale et à donner un cadre légal aux différentes institutions qui y interviennent. Il s'agit en effet de savoir quand et comment les forces de l'ordre peuvent agir, ce qu'elles ont le droit de faire, quels sont les droits des personnes qui sont suspectées par la police ou par la justice d'avoir commis une infraction, quelles sont les autorités qui dirigent l'action pénale - et qui peuvent interroger des suspectee-s ou des témoins, effectuer des perquisitions, séquestrer des objets, ordonner des écoutes téléphoniques, relever des empreintes digitales, prélever un échantillon d'ADN, etc. -, quelles sont les différentes instances judiciaires devant lesquelles une affaire pénale peut être traitée, comment se déroule le jugement et quelles sont les voies de recours de la personne condamnée et de la personne lésée lorsque cette dernière s'est constituée partie plaignante.

La procédure pénale apporte donc la garantie que toute personne sera traitée de la même manière lorsqu'elle sera suspectée d'avoir commis une infraction ou lorsqu'elle en aura été la victime. C'est ainsi qu'elle nous concerne tou.te-s, puisque nous sommes tou.te-s susceptibles d'être un jour suspectée.es, témoins ou victimes d'une infraction et, de ce fait, de nous poser des questions quant au droit que nous aurions alors de consulter le dossier, de refuser de témoigner contre un-e proche ou de participer à une audience en tant que lésée. La procédure pénale permet dès lors non seulement d'inculper des auteur.e.s d'infractions, mais également de disculper des personnes suspectées à tort, de régler le déroulement d'une audition et de prévoir le rôle que peuvent jouer les lésé-e-s, les parties plaignantes et les victimes dans le processus pénal qui devrait mener la justice à condamner la personne coupable. En résumé, le Code de procédure pénale est le code qui contient les garanties octroyées à l'ensemble des justiciables qui pourraient être impliquéees - à un titre ou à un autre et à tort ou à raison - dans une procédure pénale.

En Suisse, depuis l'unification du droit pénal en 1942 et jusqu'en 2010, nous connaissions 25, puis 26 (depuis la fondation du canton du Jura) codes cantonaux de procédure pénale différents. L'unification de la procédure est interve-

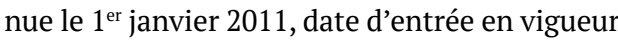
du Code de procédure pénale suisse.

Préalablement à toute action pénale, la société doit avoir défini les actes qu'elle désire ériger en infractions. C'est ainsi que le-la législateur-trice - c'est-à-dire nous tous, puisque nous vivons dans un État démocratique édicte régulièrement de nouvelles lois pénales en pensant ainsi régler des problèmes sociaux dont on ignore souvent la source, mais dont on croit savoir comment les combattre efficacement. Criminaliser de nouveaux comportements procure en effet le sentiment de s'atta- 
quer à un phénomène et donne surtout bonne conscience, alors qu'en réalité, toute criminalisation pourrait être considérée comme un aveu d'échec d'une politique sociale. Ce n'est en effet que parce que d'autres moyens de résoudre un problème échouent que l'on criminalise. C'est ainsi notamment que la consommation de stupéfiants n'est pas un problème pénal, mais bien un problème de santé publique géré de façon désastreuse par le politique, et qu'il ne serait pas nécessaire de criminaliser la circulation routière si des politiques de préventions adéquates (empêchant par exemple tout excès de vitesse ou toute ivresse au volant par l'intermédiaire de mesures techniques) étaient enfin mises en œuvre.

L'évolution du droit pénal est ainsi faite d'une multitude d'abolitions d'interdits «désuets» (tels de la fornication, le concubinage, l'homosexualité, l'avortement, la prostitution, etc.) et d'un nombre non moins considérable de nouvelles criminalisations (telles que l'abus de carte bancaire, la soustraction ou la détérioration de données informatiques, l'utilisation frauduleuse d'un ordinateur, le blanchiment d'argent, etc.). La question de savoir laquelle de ces deux tendances prédomine n'est pas simple à résoudre. Dans la littérature, il est pourtant fait mention du fait que la plupart des modifications de la législation pénale concernent l'adoption de nouveaux interdits plutôt que la suppression d'incriminations existantes. Il semble d'ailleurs s'agir du résultat d'une longue évolution qui, depuis plusieurs siècles, fait continuellement émerger de nouvelles situations mettant en danger les biens juridiques d'autrui. C'est ainsi qu'avant l'existence du papier, il n'y avait pas lieu de légiférer sur le faux dans les titres et qu'avant l'existence des nouvelles technologies, il ne serait venu à l'idée de personne de criminaliser certains comportements découlant de leur usage. De manière similaire, les infractions de mise en danger (c'est-à-dire créant un risque de lésion, risque qui peut être concret, voire abs- trait) étaient inconnues il y a quelques siècles en arrière et se sont développées ces dernières décennies sous l'effet de la multiplication des situations «dangereuses» post révolution industrielle.

Nous vivons dès lors plutôt dans un temps d'accroissement du nombre d'actions pénales engagées. Le-la législateur-trice a ainsi dû trouver un moyen de faire face à cet afflux de dossier à traiter. Il a de ce fait créé - à côté de la procédure pénale ordinaire qui débute par la découverte d'une infraction et qui se termine par l'entrée en force d'un jugement exécutoire en passant par une phase d'instruction, une phase de jugement et éventuellement une série de recours à des instances judiciaires supérieures - une procédure spéciale dite de l'ordonnance pénale. Celle-ci permet au ministère public de faire une proposition de jugement à une personne prévenue qui, si elle n'y fait pas opposition dans un délai de dix jours, accepte sa culpabilité et la sanction ainsi proposée. À l'inverse, si la personne prévenue fait opposition à l'ordonnance pénale, le processus pénal reprend là où il en était resté et sera, le cas échéant, mené jusqu'à son terme, soit un jugement par une autorité judiciaire indépendante. Aujourd'hui, la procédure de l'ordonnance pénale est appliquée dans plus de $90 \%$ des affaires pénales, la procédure dite «ordinaire» s'appliquant donc dans moins de $10 \%$ des cas. Bien que nécessaire face à l'afflux des dossiers, ce traitement de masse implique néanmoins souvent une certaine dépersonnalisation de la procédure pénale en opposition avec le principe de l'individualisation des peines (soit la prise en compte de la singularité des affaires et des circonstances de l'infraction, ainsi que de la trajectoire et la personnalité du délinquant). De plus, le délai étant relativement bref, l'opposition à l'ordonnance pénale peut poser problème surtout pour des personnes vulnérables 
qui ne comprennent pas nécessairement les conséquences de ce processus.

\section{André Kuhn}

\section{Références}

Jeanneret, Y. \& Kuhn, A. (2018). Précis de procédure pénale ( $2^{2}$ éd.). Berne : Stämpfli.

Kuhn, A. (2008). Procédure pénale unifiée: reformatio in pejus aut in melius? Charmey: Les Éditions de l'Hèbe.

Piquerez, G. \& Macaluso, A. (2011). Procédure pénale suisse ( $3^{e}$ éd. entièrement refondue et mise à jour en référence au CPP suisse). Genève: Schulthess.

\section{Processus décisionnels en politique sociale*}

Sont qualifiés de processus décisionnels en politique sociale les procédures par le biais desquelles des normes contraignantes sont définies dans le domaine de la politique sociale. Dans le sens plus strict, il s'agit du processus législatif. Celui-ci ne comporte pas uniquement les lois (règles de procédure), mais aussi les acteur·trice-s impliqué·e-s et leurs interactions. Il est important de relever que les processus décisionnels en politique sociale ne concernent pas uniquement les normes formelles (lois, ordonnances, règlements) mais aussi les règles informelles qui guident l'action (corporatisme, consultations, etc.). Bien entendu, ces processus décisionnels, qui définissent de manière contraignante la politique sociale en Suisse, ont lieu à tous les niveaux de l'État, à savoir communal, cantonal, intercantonal, national et international. De surcroît, ils peuvent être de la compétence exclusive de l'autorité exécutive (gouvernement) ou inclure la compétence de l'autorité législative (Parlements, cas échéant, le peuple). Il en résulte une multitude de processus qui ne peuvent être présentés ici de manière exhaustive. Néanmoins, il existe des caractéristiques fonda- mentales des processus décisionnels en Suisse (p.ex. la redondance institutionnelle, le corporatisme, la concordance, l'intervention populaire) qui sont similaires dans leur tendance et s'appliquent à toutes les décisions importantes en politique sociale. C'est pourquoi cet article est consacré aux processus législatifs au niveau fédéral dans la politique sociale, mais ils sont en général valables en dehors de ce cadre.

Les processus décisionnels politiques en Suisse, particulièrement dans le domaine de la politique sociale, se distinguent par leur ouverture et leur redondance institutionnelle (selon Pascal Sciarini). Ouverture signifie que les différents stakeholders (partis, associations, organisations, personnes concerné·e-s, fournisseur-euse-s, etc.) ont des possibilités multiples d'apporter leur préoccupations et points de vue dans la prise de décision. L'ouverture est notamment garantie par les procédures de consultation, les commissions d'expert.e.s et les décisions populaires, rendues possibles par la démocratie directe. Redondance institutionnelle signifie que les décisions en politique sociale sont prises en plusieurs étapes consécutives séquentielles formant le processus décisionnel, et les décisions sont réévaluées en intégralité à chaque étape. Étant donné que les processus décisionnels en politique sociale revêtent en générale une grande importance et qu'un nombre considérable d'intérêts bien organisés sont présents dans ce domaine politique, ils équivalent aux étapes usuelles du processus législatif suisse: un avant-projet d'une décision est établi au sein de l'administration, puis soumis à consultation interdépartementale. Une fois finalisé, le projet est examiné par une commission d'expert.e.s qui, le cas échéant, peut modifier entièrement le projet. Les commissions d'expert·e-s sont constituées dans les processus décisionnels importants et se composent de représentant·e-s d'associations (en particulier les acteur.trice-s corporatistes des syndicats et des employeur-euse-s) et de représentant·e.s du pouvoir exécutif (admi- 
nistration) ainsi qu'éventuellement de représentant.e.s issus du monde scientifique. Le projet de la commission d'expert·e-s est ensuite soumis à une consultation ouverte, dans laquelle toutes les parties prenantes (individuelles et collectives) peuvent s'exprimer. La consultation délivre une première estimation sur l'éventuel succès de la procédure législative. Ensuite, le pouvoir exécutif (Conseil fédéral, Conseil d'État, etc.) adopte le projet qui sera remis au pouvoir législatif. Ainsi, la phase préparlementaire se termine et la phase parlementaire commence: le projet est discuté de manière alternée par les deux Chambres (niveau fédéral), d'abord par la commission compétente (en règle générale la commission de la sécurité sociale et de la santé publique), puis en séance plénière. Lorsque la procédure d'élimination des divergences entre les deux Chambres est terminée, le délai référendaire de 90 jours commence. Si aucun référendum n'a été lancé, le processus de mise en œuvre commence. Si au moins 50000 signatures valides ont été collectées, le projet est soumis en votation populaire. Le processus est largement similaire à celui des initiatives populaires (qui requièrent 100000 signatures) et des initiatives parlementaires (avec une phase préparlementaire plus courte).

Il est important de noter que, jusqu'à la fin des années 1990, la phase préparlementaire était de loin l'étape la plus longue, la plus importante et la plus influente de l'ensemble du processus décisionnel. Cela a été confirmé par de nombreuses études citées par P. Sciarini dans son ouvrage publié en 2014. En d'autres termes, seuls quelques rares aspects de projets en politique sociale ont été modifiés de façon significative au Parlement. Par conséquent, les associations (syndicats, employeur-euse-s) et l'administration étaient considérées comme les plus puissant.e-s acteur-trice-s de la politique sociale en Suisse, car ils influençaient les projets de manière déterminante. Durant les années 1990, un changement important a com- mencé dans les processus décisionnels en politique sociale: le Parlement a endossé un rôle de plus en plus actif et initiatique, par exemple en lançant ses propres projets de loi (comme les initiatives parlementaires qui ont mené à l'introduction de l'assurance-maternité en 2004 ou des aides financières fédérales pour les crèches en 2003), en modifiant radicalement des projets de réforme (comme lors de la $10^{\mathrm{e}}$ et la $11^{\mathrm{e}}$ (échouée) révisions de l'AVS en 1995 et 2004, dans le projet de «Prévoyance vieillesse 2020 » échoué en 2017, lors de la deuxième révision de l'assurance-chômage en 1995 ou lors de la $1^{\mathrm{er}}$ révision de la prévoyance professionnelle en 2003). Depuis la fin des années 1990, la politique sociale en Suisse est davantage dirigée par les partis politiques que par les associations et l'administration.

La recherche a constaté les motifs suivants pour expliquer ce changement: du côté des processus préparlementaires, on constate l'affaiblissement des associations (diminution $\mathrm{du}$ nombre de membres des syndicats, fragmentation des associations d'employeur.euse-s) et l'escalade des conflits dans les relations corporatistes. À cela s'ajoute le fait qu'après la «modernisation» de la politique sociale (individualisation, adaptation au divorce, structures instables du marché du travail et de la famille, etc.), les associations ont perdu des compétences parce que la politique sociale ne fait plus partie de leurs thèmes centraux. L'influence grandissante des parlementaires s'explique toutefois aussi par des facteurs issus du Parlement et des partis eux-mêmes : d'une part, le Parlement dispose d'une plus grande capacité d'agir grâce à des ressources renforcées (des commissions); d'autre part, la polarisation drastiquement intensifiée des partis politiques en Suisse a pour conséquence que les parlementaires sont moins consensuel-le-s et veulent se profiler sur leurs thèmes clés. L'activité accrue du Parlement est suivie de deux scénarios possibles, qui semblent se suivre du point de vue chronologique: jusqu'au début 
des années 2000, le Parlement était en mesure d'atténuer les conflits survenus durant la phase préparlementaire et de compléter le projet avec des compromis. Cette capacité à trouver des compromis a fortement faibli depuis le début des années 2000, raison pour laquelle de plus en plus de processus décisionnels en politique sociale ont échoué pendant la phase de référendum. Une chose est certaine: les processus décisionnels en politique sociale en Suisse sont aujourd'hui davantage marqués par la concurrence qui règne entre les partis politiques qu'il y a 10 ou 20 ans.

\section{Silja Häusermann}

\section{Références}

Afonso, A. \& Papadopoulos, Y. (2015). How the populist radical right transformed Swiss welfare politics : from compromises to polarization. Swiss Political Science Review, 21(4), 617-635.

Bonoli, G. (2014). Politiques sociales. In P. Knoepfel, Y. Papadopoulos, P. Sciarini, A. Vatter \& S. Häusermann (Hrsg.), Handbuch der Schweizer Politik (S. 805-826). Zürich: NZZ Libro.

Sciarini, P. (2014). Processus législatif. In P. Knoepfel, Y. Papadopoulos, P. Sciarini, A. Vatter \& S. Häusermann (Hrsg.), Handbuch der Schweizer Politik (S. 527-562). Zürich: NZZ Libro.

\section{Professions de la santé*}

Les professionnel-le-s de la santé disposent des compétences nécessaires pour prodiguer des soins à des personnes malades, handicapées ou âgées, ainsi qu'à des personnes en bonne santé (p.ex. à des femmes avant, pendant et après l'accouchement). Ils diagnostiquent, préviennent, soignent et soulagent les problèmes de santé, promeuvent le bien-être des patient.e-s et leurs compétences en matière de santé, et s'engagent en faveur d'une coordination efficace entre prestataires.

Dans les années 1960 à 2000, c'est la CroixRouge suisse (CRS) qui, sur mandat de la Confé- rence des directrices et directeurs cantonaux de la santé, assurait la surveillance des professions de santé non médicales (soins infirmiers, physiothérapie, ergothérapie, sages-femmes, conseil en diététique, etc.) ainsi que des professions médicotechniques et d'assistance (infirmières auxiliaires). En janvier 2005, avec l'entrée en vigueur de la loi sur la formation professionnelle et de la loi sur les hautes écoles spécialisées, cette tâche de surveillance est passée dans le domaine de compétence de la Confédération. Les professions médicales (médecine humaine, médecine dentaire, médecine vétérinaire, pharmacie, chiropraxie), étaient déjà réglementées par la Confédération; elles sont réglées depuis 2007 dans la loi fédérale sur les professions médicales (LPMéd).

Parallèlement à la réforme des anciennes professions CRS, les professions du niveau secondaire II ont été elles aussi remodelées ou créées, les professions de assistant·e/ en soins et santé communautaire (ASSC), et d'aide en soins et accompagnement (ASA) notamment. Combinées à une maturité professionnelle, ces filières ouvrent la voie à une formation HES. Dans les cantons romands, les formations en professions de la santé sont dispensées exclusivement dans des HES, alors qu'en Suisse alémanique, elles le sont dans des écoles supérieures (ES) et des HES. Globalement, la systématique de formation des métiers de la santé suit la devise «aucun diplôme sans connexion ». Ainsi, dans le domaine des professions de la santé, une personne qui commence son parcours de formation avec un CFC de niveau secondaire II, par exemple, peut aller jusqu'au doctorat en sciences infirmières.

Les offres de formation continue au niveau secondaire II, des ES, des HES et celles d'autres prestataires (associations professionnelles) sont nombreuses. Certaines sont proposées sur le marché libre, d'autres sont réglementées au niveau fédéral, comme les examens professionnels (EP) et les examens professionnels supérieurs (EPS). Diverses filières de formation 
continue du niveau tertiaire permettent des approfondissements spécifiques. Si les nombreux nouveaux diplômes sont un enrichissement pour le domaine des soins de santé, ils mettent les établissements au défi d'accorder au mieux les tâches et les compétences entre les différents professionnels de la santé et les différents niveaux de formation (skill and grade mix).

Le Parlement a adopté la loi sur les professions de la santé en 2016. Cette loi, qui vise à promouvoir la qualité des professions de la santé dans l'intérêt de la santé publique, règle les compétences finales au niveau du bachelor des professions suivantes: infirmier-ère-s, physiothérapeutes, ergothérapeutes, sagesfemmes, diététicien·ne·s, optométristes et ostéopathes. Elle règle en outre l'exercice de ces professions, ainsi que de celles issues d'une formation de niveau ES. Un registre national informe sur les diplômes, les autorisations de pratiquer et les mesures disciplinaires éventuellement prononcées. Pour des raisons de protection de la santé de la population, la nouvelle législation prévoit l'accréditation obligatoire des filières d'études. Au niveau du master consécutif, les compétences et les diplômes sont réglés pour l'heure uniquement pour l'ostéopathie.

Comme pour les professions médicales, les compétences finales générales et spécifiques des professionnel-le·s de la santé sont évaluées sur la base des sept rôles du référentiel de compétences contenus dans le modèle canadien CanMEDS: expert.e (médical), communicateur-trice, collaborateur.trice, leader, promoteur-trice de la santé, apprenant·e et enseignant·e, professionnel-le. Au terme de leur formation, les professionnels de la santé, en tant que spécialistes, sont capables de fournir des services de santé à des personnes malades, à des personnes nécessitant des soins et à leurs proches. Elles savent évaluer les données issues de la recherche et les mettre en pratique dans leur travail quotidien (pratiques fondées sur des preuves scientifiques). Elles connaissent les processus de réflexion, de décision et d'action dans le système de la santé, ainsi que les interactions entre les différentes professions de la santé, et sont ainsi préparées à une collaboration interprofessionnelle.

Dans le domaine du diagnostic et du traitement, ces professionnel-le-s travaillent sur délégation conformément à la loi sur l'assurance-maladie (LAMal); ils-elles facturent les prestations ambulatoires et domiciliaires fournies sur mandat médical à la charge de l'assurance-maladie, conformément à l'ordonnance sur les prestations de l'assurance des soins (OPAS). Ils-elles exercent sous leur propre responsabilité professionnelle.

Malgré le fait que le niveau master n'est pas réglementé, les diplômé·e.s MSc jouent un rôle d'expert-e.s cliniques au service des patient·e-s, des équipes de soins et des établissements. Ils·elles veillent à une durée de maintien maximale et une qualité de vie optimale dans un setting non stationnaire pour les cas complexes. Le master est considéré comme la qualification standard au niveau international pour la prise en charge ambulatoire et stationnaire de personnes présentant plusieurs pathologies et nécessitant donc différents traitements, souvent très âgées et/ou ne disposant que de ressources sociales limitées (niveau de formation, moyens financiers, réseau d'aide). Les associations professionnelles et les hautes écoles appellent de leurs vœux une réglementation fédérale des compétences au niveau du master, afin de renforcer encore la sécurité des patient-e.s et la coopération interprofessionnelle.

Pour relever de manière proactive les défis actuels et à venir (forte augmentation des maladies dégénératives/chroniques, de la multimorbidité et des problèmes liés au grand âge), des mesures s'imposent afin de pallier la pénurie de personnel qualifié et mettre en place des modèles innovants en matière de partage des tâches, de collaboration et de financement. 
L'Observatoire suisse de la santé prévoit qu'à l'horizon 2025 il faudra 40000 professionnel-le·s supplémentaires, dont $70 \%$ dans le domaine des soins de longue durée. Fort de ce constat, le Conseil fédéral a décidé fin 2016 de promouvoir l'image des soins de longue durée ainsi que de soutenir financièrement des cours de réentrée professionnelle et des améliorations concrètes des conditions de travail. Le taux élevé de départs dans ledit domaine s'explique, d'après les syndicats, par la pression du temps, le stress, une mauvaise organisation du travail par équipe, les bas salaires et la difficulté de concilier travail et famille, avec, en corollaire, des absences pour maladie et des reconversions professionnelles. Les syndicats demandent que l'État social s'engage davantage pour de bonnes conventions collectives afin d'améliorer les conditions de travail.

Le succès de la collaboration interprofessionnelle dans la pratique clinique passe par des offres de formation interprofessionnelle. Parmi les premiers projets réussis, mentionnons des entraînements de compétences dans des situations d'urgence avec des étudiant-e.s en soins et en médecine. De telles formations communes sont nécessaires pour préparer les professionnel-le·s de la santé à une pratique collaborative, qui couvre les besoins de santé au niveau local de manière optimale. La collaboration dans une équipe interprofessionnelle présuppose que chaque membre de l'équipe acquière au préalable des compétences interdisciplinaires clés et ajuste son activité professionnelle à la fonction qui contribue le mieux à la résolution du problème. Pour cela, il faut des conditions-cadres appropriées, au niveau politique, dans les établissements et dans la législation. En font partie l'acceptation d'une académisation des professions de la santé, le soutien de l'administration et des cadres, ainsi qu'une plus grande responsabilité dans le décompte des prestations sous la propre responsabilité professionnelle.

\section{Ursina Baumgartner \& Iren Bischofberger}

\section{Références}

Académie suisse des sciences médicales (2014). Charte: collaboration entre les professionnels de la santé. https://www.samw.ch/fr/Projets/Interprofessionnalite.html

Office fédéral de la santé publique (2013). Rapport $d u$ groupe thématique «Interprofessionnalité». Berne : Office de la santé publique.

\section{Prostitution}

La prostitution est communément considérée comme une transaction marchande impliquant deux catégories d'acteur-trice-s: les travailleuses et travailleurs du sexe et leurs client·e.s. Le travail du sexe est exercé (du moins dans le contexte suisse) majoritairement par des femmes ou des personnes d'apparence féminine, d'origine migrante, souvent stigmatisées en raison de leur activité. Outre l’opprobre moral qui la frappe, cette activité est aussi caractérisée par des gains imprévisibles et fluctuants, ainsi que par la confrontation à des formes multiples de violence. La clientèle est majoritairement masculine. La prostitution ou le travail du sexe met en évidence une série d'enjeux particuliers: sanitaires (telle la prévention des risques pour la santé publique), sécuritaires (telle la répression de la criminalité liée à la traite des migrant·e-s), moraux (telle la protection des mineur.e.s et des risques d'obscénité), économiques (tel l'établissement d'une taxation sur les gains), ou encore territoriaux (telle la planification urbaine).

En raison de la controverse morale qui entoure l'activité prostitutionnelle, l'analyse de la prostitution en termes de rapports sociaux de domination se divise en deux courants majeurs: l'un dénonçant l'ultime forme d'ex- 
ploitation que subissent les femmes de la part des hommes, l'autre mettant en avant l'autonomie potentielle des travailleuses et travailleurs du sexe. Ces deux courants influencent aussi la manière dont s'organise la prise en charge de la prostitution par les politiques sociales.

Trois modèles de prise en charge se distinguent: le régime prohibitionniste (qui pénalise l'ensemble des acteur.trice-s: personnes prostituées, client·ess et proxénètes), le régime abolitionniste (qui vise l'abolition de la prostitution, car il considère les personnes prostituées comme des victimes) et le régime réglementariste (qui postule que la régulation par l'État de l'activité prostitutionnelle permet de réprimer la criminalité et de garantir de meilleures conditions pour l'activité prostitutionnelle). Dans ce dernier contexte, la prostitution, tout en étant légale, fait l'objet de restrictions, notamment par des contrôles (y compris via la tenue de registres par la police) ou encore par l'imposition d'une délimitation géographique. La Suisse est caractérisée par le régime réglementariste; ainsi, l'exercice de la prostitution y est licite. Elle est considérée comme une activité lucrative privée qui relève du principe de la liberté économique, à condition qu'elle soit effectuée de manière indépendante, c'est-àdire non salariée.

Le contexte légal au niveau fédéral est fixé (de manière succincte) par le Code pénal suisse. L’article 199 du Code pénal stipule que celui ou celle qui enfreint les dispositions cantonales réglementant l'exercice de la prostitution est puni d'une amende. Ainsi la définition spécifique de l'encadrement de l'activité prostitutionnelle est du ressort des cantons. Ces derniers disposent d'une certaine liberté dans la définition des cadres qui règlementent l'activité de la prostitution sur leur territoire (par des lois ou par des règlements cantonaux). On observe, depuis les années 2000, une tendance des cantons à légiférer, en visant une régulation plus contraignante de la prostitution, sou- vent au nom de la protection des personnes qui l'exercent.

Il est difficile de trouver des chiffres fiables concernant l'ampleur du phénomène prostitutionnel en Suisse, puisque l'organisation même des contrôles diffère considérablement selon les cantons, et il n'existe aucune statistique couvrant la Confédération. De plus, la frontière poreuse entre prostitution officielle et non officielle rend difficile une cartographie précise de l'activité prostitutionnelle. Ainsi, bon nombre de personnes peuvent exercer la prostitution de manière occasionnelle sans apparaître dans les recensements. Seule une estimation (entre 4000 et 8000 ) du nombre de travailleuses et travailleurs du sexe est donc possible. Toutefois, les observations de la police des mœurs ainsi que des associations de soutien aux personnes pratiquant la prostitution permettent de constater une augmentation du nombre de personnes qui exercent cette activité, ce qui contribue à créer une offre plus grande que la demande et détériore les conditions de travail (baisse du prix des prestations ou acceptation de pratiques à risque, p.ex.).

En Suisse, l'encadrement de l'activité prostitutionnelle est caractérisé par une collaboration (plus ou moins étroite) entre l'ensemble des acteur-trice-s concerné-e·s: les services cantonaux de santé publique et de police, ainsi que les associations de soutien représentant les travailleuses et travailleurs du sexe. L'efficacité de cette collaboration assure une (relative) prise en compte des besoins des personnes prostituées dans l'élaboration de mesures de prise en charge, de sorte qu'elle facilite la mise sur pied de programmes de réduction de risques pour la santé publique. Par ailleurs, cette même collaboration permet de chercher des réponses aux violences multiples que peuvent subir les personnes pratiquant la prostitution : violences tant politiques (contraintes administratives), économiques (exploitations professionnelles), physiques (agressions physiques ou sexuelles) que psychiques (insultes, humiliations). 
Un changement juridique en 2014 concerne l'inscription explicite d'une limite d'âge (minimum 18 ans) dans le Code pénal, qui engage la Suisse à se conformer à la Convention du Conseil de l'Europe pour une protection accrue des mineur.e.s contre l'exploitation et les abus sexuels. Lutter contre les diverses formes d'exploitation est aussi la préoccupation centrale des associations qui soutiennent les travailleuses et travailleurs du sexe ou encore des syndicats qui représentent l'intérêt de leurs membres dans un important travail de lobbying (le plus souvent au niveau cantonal, notamment dans les processus de légifération). Ce tissu associatif bien développé et diversifié reflète la multiplicité des contextes d'exercice et le degré varié d'appartenance à une identité professionnelle.

Un enjeu actuel est la pénalisation des client.e.s, une mesure qui vise à faire disparaître la prostitution en réprimant non pas l'offre mais la demande. Depuis l'introduction de cette mesure - pour la première fois en Suède en 2000 et notamment votée en France en 2016 - l'attention accordée aux client·e-s est bien présente, tant dans les médias que dans l'arène politique, et ceci y compris en Suisse. Toutefois, nombreuses voix (dont celle des représentant·e-s des travailleuses et travailleurs du sexe) dénoncent cette mesure comme étant contreproductive du point de vue de la réduction des risques (particulièrement en repoussant l'activité prostitutionnelle dans la clandestinité), et également comme étant contraire au droit de disposer librement de son corps.

Un autre enjeu actuel concerne le risque d'un amalgame entre «traite des femmes» et prostitution, cette dernière étant considérée par certain'e-s comme une violence faite aux femmes. En effet, certains aspects de l'expérience migratoire de travailleuses du sexe en situation de séjour provisoire ou irrégulière peuvent rappeler la définition de la traite d'êtres humains et constituer un facteur par- ticulièrement fragilisant pour les personnes concernées. Ces femmes ne peuvent pas s'adresser à la police en raison de leur statut illicite de séjour; certaines d'entre elles ont dû s'endetter pour effectuer le voyage vers l'Europe, ont subi des violences (dont des séquestrations) ou encore sont venues attirées par de fausses promesses (p.ex. un poste de travail dans la restauration). Toutefois, malgré ces constats, le Conseil fédéral dans son rapport sur la prostitution et la traite d'êtres humains en juin 2015 se prononce contre l'interdiction de la prostitution et estime que la lutte contre la traite doit notamment passer par la sensibilisation des acteur-trice-s concerné·e-s, par exemple une formation spécifique destinée au corps de la police et aux magistrat.e.s.

Agnes Földhazi

\section{Références}

Bugnon, G., Chimienti, M. \& Chiquet, L. (2009). Marché du sexe en Suisse: état des connaissances, best practices et recommandations. Genève: Université de Genève.

Conseil fédéral (2015). Rapport du Conseil fédéral sur la prostitution et traite d'êtres humains à des fins d'exportation: rapport du Conseil fédéral en réponse aux postulats 12.4162 Streiff-Feller, 13.3332 Caroni, 13.4033 Feri et 13.4045 Fehr. Berne: Département fédéral de justice et police.

Földhazi, A. \& Chimienti, M. (2007). Marché du sexe et violences à Genève. Genève: Université de Genève.

\section{Protection contre la discrimination*}

La protection contre la discrimination comprend le cadre effectif et juridique/éthique de la lutte contre la discrimination ainsi que l'ensemble des approches disponibles pour agir. La discrimination est considérée comme une forme de désavantage particulièrement injuste et puissante qui s'est développée sur une longue période et qui se caractérise par le 
fait que des personnes sont systématiquement désavantagées et soumises à la stigmatisation et à l'exclusion en raison de leur appartenance réelle ou attribuée à un groupe ou sous-groupe particulier. L'objectif de la protection contre la discrimination est de réduire les formes de préjudice dans l'accès aux ressources via des réglementations juridiques et éthiques ainsi que des stratégies, programmes et mesures. Tandis que la conception philosophique place notamment la dignité humaine au premier plan en tant que bien à protéger, du point de vue des sciences sociales, il s'agit d'éliminer les rapports hiérarchiques et de domination structurellement consolidés.

Parmi les principales inégalités structurelles auxquelles la protection contre la discrimination doit s'attaquer figurent l'âgisme, l'abléisme (handicap), le sexisme et l'hétérosexisme ou l'hétéronormativité (discrimination fondée sur le sexe biologique et social, l'identité sexuelle et le désir sexuel), le racisme (discrimination fondée sur la couleur de peau, la religion et les attributions ethniques ainsi que les processus de construction de l'altérité) et le classisme (ou discrimination fondée sur le statut social et la pauvreté). Dans la pratique, il s'agit souvent de discriminations multiples/ intersectionnelles, c'est-à-dire de formes de marquage des différences qui se caractérisent par l'interaction de plusieurs catégories de discrimination.

La protection contre la discrimination est fondée, d'une part, sur un concept des droits de l'homme qui était déjà établi dans l'Antiquité, les écrits religieux et les Lumières, et qui a été développé dans le cadre des Nations Unies au lendemain de la Seconde Guerre mondiale. D'autre part, le concept a été fortement influencé par les luttes émancipatoires pour les droits fondamentaux, surtout par le mouvement des droits civiques des années 1960 aux États-Unis et les mouvements transnationaux de décolonisation. Au début du débat conceptuel, des concepts principalement libéraux étaient au premier plan. Ces derniers postulaient des interdictions légales de discrimination et exigeaient des droits correspondants à l'égard des États et des entreprises.

À partir des années 1970, de plus en plus de dispositions institutionnelles ont été mises en place pour soutenir l'application des interdictions de discrimination par des structures étatiques. De plus, il a été reconnu à un stade précoce que, outre les interdictions formelles de discrimination et les mécanismes institutionnels, des mesures visant à promouvoir de manière ciblée les groupes structurellement défavorisés sont également nécessaires, mesures qui ont été connues dans des pays tels que les États-Unis, l'Afrique du Sud et l'Inde notamment sous le nom affirmative action et en Europe comme des mesures positives. Le développement des différentes approches a été soutenu en particulier par les mouvements théoriques des legal gender studies et de la critical race theory, mais aussi des disability legal studies, des theories on law and ageing et du néomatérialisme.

Ces évolutions historiques ont donné lieu à une protection juridique contre la discrimination qui englobe, à un premier niveau fondamental, l'ensemble des dispositions constitutionnelles, législatives et réglementaires en vigueur, ou proposées sur la base de la théorie des droits de l'homme, relatives à la gestion des programmes et des politiques, la prévention, l'intervention, la restitution, la compensation et la sanction de la discrimination. La mise en œuvre et l'application des interdictions légales de discrimination, y compris des mesures dites appropriées pour supprimer les désavantages individuels, revêtent une importance cruciale. Il s'agit notamment de dispositions organisationnelles prises par les entités administratives, telles que des mesures de sensibilisation, de prévention et de mise en réseau. L'accompagnement politique critique par des organisations publiques indépendantes, telles que des commissions parlementaires, une commission 
des droits de l'homme et des médiateur.e.s indépendant·e·s, ainsi que le contrôle et la supervision par des organes publics de suivi font par ailleurs partie de la protection juridique contre la discrimination. Il est également important que les acteur-trice-s de la société civile mobilisent des avocat-e-s pour des procédures judiciaires en droit privé, pénal, administratif et constitutionnel.

Une pratique transdisciplinaire de la protection contre la discrimination est ce que l'on appelle le contentieux stratégique (également appelé strategic human rights litigation), dont le but est d'élargir les possibilités d'action afin que les personnes touchées par la discrimination puissent se défendre conjointement dans le cadre d'alliances et de mouvements collectifs organisés. Les éléments non juridiques de la protection contre la discrimination comprennent également le travail communautaire, les activités artistiques engagées sur le plan social, le conseil psychosocial, les mesures dans le domaine du développement organisationnel - telles que l'intégration et la gestion de la diversité, les conseils en matière de politique et les interventions discursives par les sciences.

Les niveaux dépendent du problème concret posé, des objectifs et des méthodes : les mesures d'autonomisation des personnes concernées visent à soutenir les personnes touchées par la discrimination, par exemple avec des services de conseil et des projets dans le domaine du réseautage, de l'autonomisation et de l'intervention tactique autodéterminée. Les mesures visant à former les décisions se concentrent sur des instruments qui ont un effet dissuasif et éliminent la discrimination tout en favorisant la confrontation avec les stéréotypes discriminatoires et leurs impacts sur les préjugés et les barrières structurelles. De plus, des mesures dites positives sont également nécessaires pour amener à des postes de décision des personnes qui ont l'expérience correspondante de la discrimination. Les mesures visant à réaliser la diversité sont, par exemple, des règlements en matière de quotas. Cela comprend également des mesures douces visant à une sensibilisation systématique et orientée vers les processus, la prévention, la participation et d'autres mesures visant à améliorer durablement la qualité de vie avec des exigences particulières et à créer des conditions favorables pour la reconnaissance sociale, la participation, l'implication et l'inclusion.

En ce qui concerne la Suisse, on peut constater d'une part que le concept de protection contre la discrimination a pris une importance croissante dans les discours scientifiques et, parfois, dans les débats publics et pratiques, notamment en ce qui concerne la question des discriminations multiples. D'autre part, il est également clair, en théorie et dans la pratique, que le concept de discrimination est très général afin de traiter efficacement des problèmes spécifiques tels que la situation des femmes réfugiées. Les différences entre les standards de protection des différents groupes touchés par la discrimination constituent donc également l'un des plus grands défis actuels de la protection contre la discrimination.

Tarek Naguib

\section{Références}

Borillo, D. (2002). Les instruments juridiques français et européens dans la mise en place du principe d'égalité et de non-discrimination. Revue française des affaires sociales, 1, 113-125.

Naguib, T., Pärli, K., Copur, E. \& Studer, M. (2014). Diskriminierungsrecht: Handbuch für Jurist_innen, Berater_innen und Diversity-Expert_innen. Bern: Stämpfli.

The right to equality and non-discrimination in the administration of justice (2003). In Office of the High Commissioner for Human Rights in coop. with the International Bar Association (Eds.), Human Rights in the Administration of Justice: A Manual on Human Rights for Judges, Prosecutors and Lawyers (pp. 631-679). New York: United Nations Publications. 


\section{Protection de l'adulte*}

La protection de l'adulte intervient lorsqu'une personne est incapable ou insuffisamment capable de gérer ses affaires en raison d'un état de faiblesse (incapacité mentale, troubles mentaux ou autres causes) et qui a ainsi besoin de protection. La loi sur la protection de l'adulte, qui est régie par le Code civil et a fait l'objet d'une révision complète en 2013, prévoit différents instruments pour remédier au besoin de protection et sauvegarder les intérêts: outre ses propres mesures de précaution (mandat pour cause d'inaptitude et directives anticipées du patient ou de la patiente) et les droits de représentation des proches, des mesures officielles sont également envisagées. Cet article se concentre sur les mesures prises par les autorités.

Les principaux objectifs de la révision en 2013 étaient de professionnaliser l'organisation des autorités, de promouvoir l'autodétermination, de renforcer la solidarité familiale et d'introduire des mesures taillées sur mesure. Les trois derniers points correspondent aux orientations des pays voisins. La professionnalisation de l'organisation des autorités était une particularité de la Suisse (dans les pays voisins, les autorités ont toujours été professionnalisées). Le fait qu'en Suisse, les mêmes services et personnes sont généralement responsables de la protection des mineur.e.s et de la protection de l'adulte est également une particularité (en règle générale, ces tâches sont séparées à l'étranger).

Le groupe cible de la protection de l'adulte comprend les personnes atteintes de troubles mentaux, de vieillesse ou d'invalidité ainsi que les jeunes adultes inexpérimenté·e·s, mais aussi les personnes qui ont soudainement besoin de protection à la suite d'un accident ou d'une maladie. Fin 2016, environ 90000 adultes dans toute la Suisse (hors placement à des fins d'assistance) étaient concerné·e-s par des mesures de protection (soit $1,3 \%$ de la population adulte en Suisse). Le nombre de cas n'a cessé d'augmenter depuis les années 1990, même en comparaison internationale. Cela s'explique principalement par l'évolution démographique de la population et la judiciarisation croissante de la société.

Les mesures de protection de l'adulte sont des interventions officielles dans le domaine de la liberté individuelle. Elles garantissent la protection et le bien-être des personnes ayant besoin d'assistance et veillent au maintien et à la promotion de leur autodétermination dans la mesure du possible. C'est une question de conseil et de soutien, souvent aussi de représentation. Les mesures sont généralement prises en accord avec la personne concernée, si nécessaire elles peuvent également être ordonnées contre son gré. La protection de l'adulte se situe dans la zone conflictuelle entre un mode de vie autodéterminé et la sauvegarde des intérêts déterminée par d'autres.

En matière de protection de l'adulte, les valeurs importantes sont l'autodétermination, l'individualisation et l'approche de l'espace social, tandis que les principes importants sont la subsidiarité (le soutien de la famille, des proches parents ou les services privés et publics sont prioritaires), la complémentarité (les possibilités d'action de la personne concernée ne sont pas remplacées mais complétées et renforcées) et la proportionnalité (appropriée et requise, autant que nécessaire et aussi peu que possible).

Les acteur-trice-s centraux-ales sont les autorités de protection de l'enfant et de l'adulte (APEA) ainsi que les curateurs et curatrices. L'APEA ordonne une mesure et désigne une personne curatrice pour la mettre en œuvre. L'APEA est une autorité interdisciplinaire qui, selon le canton, est conçue comme une autorité administrative ou judiciaire, respectivement une autorité cantonale ou (inter)communale (en Suisse romande, l'APEA est généralement une juridiction; en Suisse alémanique, elle est généralement une autorité administrative). 
En Suisse, il y a 142 APEA (janvier 2017) qui emploient au total près de 2000 personnes (environ 1300 spécialistes dans les domaines du droit, du travail social et de la psychologie et environ 700 personnes dans le domaine de l'administration/révisorat). En ce qui concerne les personnes curatrices, une distinction est opérée entre les personnes curatrices professionnelles (près de 5000 professionnel-le-s employée-e.s par un service de curatelle professionnel ou un service social, qui détiennent en moyenne de 10 à 80 mandats et qui ont généralement un diplôme en travail social) et les personnes curatrices privées (quelque 28000 personnes en Suisse qui sont des proches ou des particuliers et qui détiennent en moyenne 1 à 3 mandats). Les décisions de l'APEA peuvent être soumises à un tribunal par voie de recours et les personnes concernées peuvent s'adresser à l'APEA pour contester les actes de la personne curatrice. Il n’y a pas de surveillance fédérale. La Conférence en matière de protection des mineur.e.s et des adultes (COPMA) coordonne les cantons, recueille des statistiques, donne l'impulsion et est responsable de la coopération avec la Confédération.

Les mesures officielles les plus importantes sont la curatelle et le placement à des fins d'assistance. Il existe différents types de curatelles. Les tâches de la personne curatrice sont déterminées individuellement par l'APEA en fonction des besoins de la personne concernée (p.ex. logement, santé, administration, finances, etc.). Selon le type de mesure, la personne curatrice a des compétences différentes. Dans le cas d'une curatelle d'accompagnement, ce n'est qu'une fonction consultative. Dans le cas d'une curatelle de représentation, la personne curatrice peut agir en qualité de représentant ou représentante, éventuellement aussi contre la volonté de la personne concernée. Dans le cas d'une curatelle de coopération, la personne curatrice et la personne concernée ont besoin d'un consentement mutuel. Dans le cas d'une curatelle de portée générale, la per- sonne curatrice dispose d'un droit de représentation complet et la personne concernée n'est plus en mesure de conclure elle-même des transactions juridiques (cela exclut les droits strictement personnels). La mesure la plus courante est la curatelle de représentation (environ $75 \%$ de toutes les mesures). La curatelle de portée générale représente environ $18 \%$ de toutes les mesures. En comparaison à long terme, les mesures plus douces tendent à augmenter et les plus strictes à diminuer.

Dans le domaine de la protection de l'adulte, l'État agit dans un domaine sensible: l'État contrôle les capacités des personnes ayant potentiellement besoin de protection et intervient dans leurs droits personnels, le cas échéant. L'engagement du·de la législateur trice en faveur de la subsidiarité et de l'autodétermination et l'accent mis sur les intérêts et les besoins de la personne concernée sont des réalisations importantes d'un État libéral. Dans la pratique, il existe des frictions dans des cas isolés parce que les proches parents ou la société demandent une intervention plus répressive. Les attentes concernant les possibilités d'influencer de la protection de l'adulte sont parfois exagérées: seuls des droits de représentation peuvent être accordés et des intérêts garantis, mais les processus de changement ne peuvent être forcés. La protection de la société contre les personnes dangereuses ne fait pas non plus partie du mandat de l'APEA. Selon le point de vue, l'APEA intervient trop tôt ou trop tard, trop fortement ou trop faiblement.

D’autres défis sont identifiés dans l'action méthodologique (diagnostic, clarification et planification/contrôle des interventions), l'assurance qualité (qu'est-ce qu'une bonne protection de l'adulte?), l'amélioration de la coopération avec les systèmes de prévoyance (case management) et le profil affiné de groupes cibles spécifiques (quel groupe cible reçoit quelle prestation avec quel objectif et quelle utilisation des ressources?). La coopération interprofessionnelle reste dominée par 
les juristes. Pour que la protection de l'adulte puisse mieux répondre à ses objectifs, les professions non juridiques, en particulier le travail social, doivent s'impliquer davantage.

L'évolution démographique liée à l'augmentation du nombre de personnes âgées remettra quantitativement en question la protection de l'adulte, mais aussi qualitativement en raison de l'augmentation des problèmes multiples. Des solutions doivent être trouvées pour le nombre croissant de cas, en particulier les prestations des systèmes sociaux en amont (p.ex. le conseil ou l'administration des salaires par les services sociaux communaux) ainsi que des réseaux familiaux doivent être étendus et mieux utilisés ou revus et, le cas échéant, activés. La question de savoir comment l'autodétermination, l'autonomie et l'auto-assistance peuvent être rendues possibles malgré la maladie mentale ou le handicap mental doit également être abordée, afin que les prestations psychosociales aient davantage de poids à l'avenir.

\section{Diana Wider}

\section{Références}

Affolter, K., Biderbost, Y., Häfeli, C., Langenegger, E., Meier, P., Rosch, D.... Zingaro, M. (2012). Droit de la protection de l'adulte - Guide pratique (avec modèles) (Conférence en matière de protection des mineurs et des adultes COPMA, Éd.). Zürich : Dike.

Conférence en matière de protection des mineurs et des adultes COPMA. www.copma.ch

Meier, P. (2016). Droit de la protection de l'adulte. Genève: Schulthess.

\section{Protection des consommateurs et des consommatrices}

Inscrite dans la Constitution fédérale suite à la votation populaire du 14 juin 1981 et reprise à l'article 97 de la révision de la Constitution de
1999, la protection des consommateurs et des consommatrices connaît son application à travers une série de lois et d'ordonnances fédérales. Ensemble, elles couvrent divers domaines du droit de la consommation, comme par exemple la sécurité des produits et des services ou l'information des consommatrices et des consommateurs, qui y sont généralement considérés des acteur-trice-s faibles sur le marché, vu le déséquilibre informationnel et structurel entre ces dernier-ère-s et les professionnel-le-s. Ces actes législatifs concernent directement les intérêts des consommateur-trice-s, sans pour autant oublier ceux des producteur-trice-s et des distributeur-trice-s à travers la législation sur la concurrence déloyale ou les entraves techniques au commerce. Le Code de procédure civile, qui a remplacé en 2011 les 26 lois de procédure cantonale, a lui aussi favorisé l'accès à la justice pour les consommateur.trice-s.

La protection de la consommation devient un thème politique au début des années 1930 aux États-Unis (lutte contre les corporations) et se développe avec les campagnes contre l'industrie automobile américaine, lancées par Ralph Nader à la fin des années 1950. C'est dans ce cadre que John F. Kennedy énoncera devant le Congrès, le 15 mars 1962, quatre droits fondamentaux des consommateur-trice-s : le droit à la sécurité, le droit à l'information, le droit de choisir et le droit d'être entendu. À la même époque naissent en Europe les premières coopératives d'achat qui entendent défendre les intérêts des classes populaires face à l'explosion de la production de masse, en particulier dans les domaines du contrôle des prix, de la qualité et de la sécurité des produits alimentaires.

En Suisse aussi, les femmes se mobilisent et, dès les années 1960 - avant même d'avoir obtenu le droit de vote (1971) - transforment les coopératives de consommation créées le siècle précédent en associations de défense des consommateur-trice-s, qui voient alors le jour en 1959 en Suisse romande, en 1961 en Suisse 
alémanique et en 1974 en Suisse italienne. Suite à une initiative populaire pour instaurer la surveillance des prix en 1978 et à l'entrée de la protection des consommateur.trice-s et des consommatrices dans la Constitution suisse en 1981, l'information aux consommateur-trice-s est formalisée dans la loi en 1986. En 2010, la Fédération romande des consommateur-trice-s (FRC), l'Associazione consumatrici e consumatori della Svizzera italiana (ACSI) et la Stiftung für Konsumentenschutz (SKS) ont décidé de développer ensemble un Agenda des consommateur-trice-s pour défendre d'une seule voix les intérêts des consommateur-trice-s au niveau national, sous le nom d'Alliance des organisations de consommateur.trice-s. Dans le but d'entretenir le dialogue avec la politique et l'économie, par-delà même les frontières linguistiques et nationales, l'Alliance est membre du Bureau européen des unions de consommateurs (BEUC).

Dès 1975, la prédécesseuse de Union européenne, la Communauté économique européenne, a adopté un programme pour une politique de protection et d'information des consommateur-trice-s liée, selon les expertes Astrid Epiney et Florence Rivière, essentiellement à la réalisation de deux objectifs : d'une part, amortir les effets de la libéralisation de la circulation transfrontalière des marchandises et des services et prendre des mesures de protection des consommateur-trice-s, afin d'éviter que la réalisation des libertés fondamentales ne remette en cause les intérêts des consommateur.trice-s. D'autre part, il s'agit de favoriser l'élimination des distorsions de concurrence et des obstacles au commerce, et donc également la réalisation du marché intérieur, par une certaine harmonisation. Depuis, la Suisse adapte régulièrement son droit national en suivant les grandes lignes tracées par Bruxelles.

En effet, bien que la Suisse ne soit pas membre de l'Union européenne, la majeure partie des textes consacrés à la protection des consommateur-trice-s reprennent, sou- vent mot à mot, le contenu de directives européennes. Ainsi les règles du droit européen de la consommation concrétisent des objectifs, qui sont identiques à ceux de l'article $97 \mathrm{de}$ la Constitution (protection de la santé, de la sécurité, les intérêts économiques et procéduraux des consommateur.trice-s). Comme le relève la Commission fédérale de la consommation (2016), en Suisse comme dans l'UE, le droit de la consommation ne relève pas du droit social (avec le consommateur comme partie faible à protéger), mais du droit économique. Dès lors, le droit de la consommation complète le droit de la concurrence, car il vise à corriger des déficits structurels, pour permettre au consommateur d'arbitrer le jeu économique, en faisant pression par ses choix sur les offres des professionnel.le's.

Cette caractéristique du droit suisse de la consommation s'explique par le principe de l'adaptation autonome du droit suisse au droit européen, qui doit essentiellement servir à préserver et améliorer les chances des entreprises suisses d'accéder sans trop d'entraves au marché européen. Il en résulte une capacité contractuelle généralement plus faible des consommateur-trice-s et de leurs organisations - que ne peut compenser l'aide financière limitée du Bureau fédéral de la consommation ou l'action mesurée du Surveillant des prix - par rapport aux lobbies de l'économie privée.

Les marchés se sont profondément transformés au cours des 20 dernières années. La réglementation, l'ouverture des marchés mondiaux, les nouvelles technologies et la multiplication des services aux consommateur-trice-s ont été les facteurs principaux du changement. Ces évolutions n'apportent pas que des avantages aux consommateur.trice-s. Les marchés proposent aujourd'hui un plus grand choix de produits d'une complexité croissante, rendant plus difficile aux consommateur.trice-s de comparer et de juger la valeur de ce qui leur est offert, surtout si l'on pense à l'explosion du commerce online qu'accompagne la disparition des maga- 
sins de proximité et la diffusion des services de l'économie de plateforme (sharing economy).

Les consommateur-trice-s aussi ont changé. Un nombre croissant d'enfants et de jeunes adultes ont maintenant accès aux marchés, ainsi qu'une multitude d'adultes âgé-e·s, qui s'y heurtent toutefois à des difficultés spécifiques. Cette segmentation du marché accentue les problèmes d'information aux consommateur-trice-s, car s'il est vrai que ces dernier·ère-s sont dans l'ensemble mieux éduqué-e-s et plus sensibles aux problèmes de durabilité de la consommation, beaucoup n'ont pas les compétences requises sur un marché devenu plus complexe et plus riche en informations.

La théorie économique dominante part du principe que le libre fonctionnement des marchés donnerait habituellement les meilleurs résultats pour les consommateur.trice-s. En réalité, le marché ne peut produire des résultats optimaux en l'absence de réels concurrents ou lorsque les consommateur-trice-s ne disposent pas d'informations suffisantes sur les produits et les prix disponibles ou si les informations sont incomplètes, trompeuses, excessivement complexes ou trop nombreuses et qu'il n'existe pas de réponse collective possible (class action).

Il s'agit alors de déterminer si le niveau de préjudice subi par les consommateur-trice-s doit déclencher l'intervention de l'État: réglementer pour protéger le-la citoyen-ne-consommateur-trice ou laisser faire le marché est le dilemme habituel des politiques nationales, avec une forte pression de la part des multinationales et des trusts pour le laissez-faire et pour l'abolition du protectionnisme - sauf celui de leurs intérêts - comme le démontrent les discussions sur TTIP/TISA, qui prévoient la suppression systématique de normes de qualité, de sécurité ou de santé, gênantes pour le commerce, et la privatisation de services publics.

Antoine Casabianca

\section{Références}

Bureau fédéral de la consommation (Éd.) (2016). 30 ans: article constitutionnel sur la protection des consommatrices et consommateurs. Berne : Eidgenössisches Büro für Konsumentenfragen.

Epiney, A. \& Rivière, F. (2003). La protection du consommateur. Genève: F.J.S.

Marchand, S. (2012). Droit de la consommation: le droit suisse à l'épreuve du droit européen. Genève : Schulthess.

\section{Protection des mineur $\cdot e \cdot \mathbf{s}^{*}$}

La protection des mineur.e.s est une tâche réglementée par l'État qui comprend aussi bien des mesures juridiques qu'institutionnalisées. $\mathrm{Au}$ sens strict, elle vise à protéger les enfants et les jeunes dans leur bien-être et à éviter les mises en danger du bien de l'enfant. Les formes typiques de menaces pour le bien de l'enfant sont la violence physique, psychologique et sexuelle contre les enfants ainsi que la négligence. L'État peut intervenir dans la liberté et le statut juridique des titulaires de la garde parentale si le bien-être de l'enfant est en danger et que les parents ne veulent et/ou ne peuvent pas éviter ce risque. L'objectif de la protection des mineur.e.s au sens large est de prévenir le développement de menaces pour le bien de l'enfant dans les familles et les institutions par le biais des services de l'aide aux enfants et à la jeunesse et de créer des conditions pour qu'ils-elles grandissent dans une relation intergénérationnelle.

Pendant longtemps en Suisse, la protection des mineur·e·s n’a pas été considérée comme une mission de l'État. Ce n'est qu'avec l'émergence d'un système de production capitaliste, la montée de la question sociale et l'évolution des attitudes envers la famille et l'enfance, que la protection des enfants a été considérée non plus seulement comme une affaire privée mais comme une affaire publique aussi. À la fin du $\mathrm{XIX}^{\mathrm{e}}$ siècle, dans un contexte de baisse de la 
mortalité infantile et du taux de natalité, un modèle familial bourgeois a commencé à s'établir, lequel considérait l'enfance et la jeunesse comme une période préservée pour l'éducation, la formation et le développement personnel. Bien que ce modèle familial bourgeois ne pût s'imposer durant une longue période, il a servi de légitimation pour les interventions sociales de l'État dans les familles. Orientée vers le concept de «déchéance» et des perspectives moralisatrices, les placements selon la loi sur les pauvres cèdent de plus en plus la place à des mesures préventives de retrait d'enfants. Elles ont été soutenues par des processus de judiciarisation, de rationalisation, de scientifisation et de professionnalisation de la tutelle. Les dispositions du Code civil relatives à la protection des mineur·es, qui ont été introduites en 1907, ont ainsi établi la responsabilité de l'État pour le bien-être des enfants et des jeunes. Cela a permis à l'État d'intervenir plus qu'auparavant dans les familles. Les interprétations et les pratiques eugéniques et médicopsychiatriques, de plus en plus répandues dans la première moitié du XXe siècle, soutenaient des approches sociodisciplinaires et abusives. Aujourd'hui, elles sont résumées sous le terme de «mesures coercitives à des fins d'assistance ", dans le contexte duquel des dizaines de milliers d'enfants de familles pauvres (Verdingkinder) ou de familles ayant un mode de vie itinérant ou une origine yéniche («les enfants de la grande-route») ont été placé-e·s dans des fermes ou dans des foyers, ont dû travailler dur et ont parfois subi de graves abus (sexuels) durant une bonne partie du XX $\mathrm{X}^{\mathrm{e}}$ siècle.

Après la Seconde Guerre mondiale, l'acceptation de modèles de vie et de famille pluralisés s'est progressivement accrue suite à l'essor économique, la prospérité sociale et l'ouverture culturelle. Ces processus de libéralisation se sont accompagnés d'une révision complète du droit des enfants en 1976. Elle a englobé une série de nouvelles mesures de protection de l'enfance et introduit le concept de «bien de l'enfant» en tant que principe directeur du droit de l'enfance. En 1995, le Conseil fédéral a commenté le rapport «Enfance maltraitée en Suisse » publié trois ans plus tôt, sensibilisé à l'ampleur des abus envers les enfants et cherché à améliorer l'application de la loi et des conventions internationales. Avec la ratification de la Convention des Nations Unies relative aux droits de l'enfant en 1997, la position juridique des enfants dans la société, leur protection contre les menaces qui visent leur bienêtre et ainsi l'importance sociopolitique de la protection des mineur·e-s ont été renforcées. Le rapport du Conseil fédéral de 2012 intitulé «Violence et négligence envers les enfants et les jeunes au sein de la famille» attribue pour la première fois un rôle clé à l'aide aux enfants et à la jeunesse et souligne l'importance d'une offre nationale de services d'aide aux enfants et à la jeunesse. Le rapport contient une déclaration de l'Office fédéral de la justice sur l'interdiction des châtiments corporels, selon laquelle l'interprétation du terme «bien de l'enfant» interdit aujourd'hui la violence dans le cadre des méthodes d'éducation des parents. Cependant, il n'existe actuellement en Suisse aucune loi interdisant expressément les châtiments corporels dans l'éducation.

La protection des mineur.e.s en Suisse est assurée par des interventions de l'État, qui sont principalement régies par le Code civil suisse (CC). Le CC contient des conditions relatives à l'ingérence légitime dans le droit des parents afin de protéger les enfants et les jeunes contre les menaces pour leur bien-être, qui sont appliquées par 146 autorités de protection de l'enfant et de l'adulte (APEA).

En 2013, les APEA ont remplacé, en tant qu'autorités spécialisées, les 1420 autorités tutélaires, dont la plupart étaient dirigées par des laïcs. En plus d'assurer la protection des adultes incapables de jugement et d'action, leur tâche est de clarifier les cas de mise en danger du bien de l'enfant et, le cas échéant, d'ordonner, de superviser et d'abroger les mesures de 
protection des mineur.e-s en droit civil. Elles prennent leurs décisions dans un organe tripartite qui, selon les recommandations de la Conférence des autorités cantonales de tutelle, devrait être composé de manière aussi interdisciplinaire que possible (voir l'entrée «Protection des adultes » pour une discussion détaillée sur l'APEA et d'autres organes dans le domaine de la protection des mineur.e-s).

Le système suisse de protection des mineur·e-s est unique à l'échelle internationale. Sa structure et son organisation varient d'un canton à l'autre. Il ne dispose pas de suffisamment d'accès légaux et institutionnels aux services de l'aide aux enfants et à la jeunesse, qui ne sont pas liés à l'adoption de mesures de protection de l'enfance en vertu du droit civil. Dans de nombreux autres pays, la protection des mineur·e.s est principalement assurée par des services consensuels d'aide aux enfants et à la jeunesse. En Suisse, par contre, bien que la législation renforce le consensus, elle est mise en œuvre dans la pratique principalement selon la logique de «l'assistance par l'intervention» et garantie par des mesures et des sanctions étatiques dans les domaines du droit civil et pénal.

Le remplacement des autorités de tutelle organisées dans le système de milice par les APEA en 2013 a constitué une étape importante pour la protection des mineur.e-s. Les spécialistes formé·e-s qui travaillent actuellement veillent à rendre leurs décisions bien fondées et compréhensibles. Pourtant, ils font face à des critiques massives de la part du public et des médias, lesquelles ont été exacerbées par des cas individuels tragiques de protection des mineur.e-s. Le financement des décisions arrêtées par les APEA est également controversé, puisqu'avec l'introduction des APEA, certains cantons ont adopté des règlements selon lesquels les APEA sont devenues partie intégrante de l'administration cantonale, tandis que la responsabilité des coûts incombe aux com- munes de résidence des personnes concernées par les décisions.

Compte tenu de ce contexte problématique, il y a actuellement le risque que la réorganisation de la protection des mineur.e.s perde de son élan et que l'APEA ne dépasse pas sa réputation d'organisme d'enregistrement et d'intervention. Il est donc nécessaire d'examiner de manière critique les conditions-cadres sociopolitiques nécessaires pour répondre aux exigences et attentes en matière de protection des mineur·e.s tournée vers l'avenir. Il serait souhaitable de renforcer une protection des mineur.e.s davantage orientée vers le principe directeur de «l'assistance au lieu de l'intervention» et exploitant de manière plus offensive les possibilités existantes en matière d'aide aux enfants et à la jeunesse dans le contexte du traitement des mises en danger du bien de l'enfant.

\section{Kay Biesel \& Clarissa Schär}

\section{Références}

Rosch, D., Fountoulakis, C. \& Heck, C. (Hrsg.) (2015). Handbuch Kindes- und Erwachsenenschutz: Recht und Methodik für Fachleute. Bern: Haupt.

Vaerini, M. (2015). Guide pratique du droit de protection de l'adulte et de l'enfant. Berne: Stämpfli.

Voll, P., Jud, A., Mey, E., Häfeli, C. \& Stettler, M. (Hrsg.) (2008). Zivilrechtlicher Kindesschutz. Akteure, Prozesse, Strukturen: Eine empirische Studie mit Kommentaren aus der Praxis. Luzern : Interact.

\section{Protection des travailleur-euse- $\mathbf{s}^{*}$}

La Constitution fédérale suisse dispose que la Confédération peut légiférer sur la protection des travailleur.euse-s. Cette protection consiste à écarter les risques pour la santé ainsi qu'à protéger la sphère personnelle des travailleur-euse-s. En signant le Pacte I de l'ONU, la Suisse s'est engagée à offrir «des conditions de 
travail justes et favorables ». Elle a également ratifié plusieurs accords de l'Organisation internationale du travail (OIT). La prévention des accidents est réglée dans la loi sur l'assurance-accidents, la prévention d'autres risques sanitaires dans la loi sur le travail (LAA). La loi sur l'égalité entre femmes et hommes prévoit des dispositions spéciales en cas de discrimination à raison du sexe et de harcèlement sexuel. Conformément au droit du contrat de travail, les travailleur-euse-s ont droit à la protection de leur intégrité physique et psychique. La durée minimum des vacances est également réglée dans le droit des obligations. Des salaires minimaux peuvent être fixés dans des contratstypes et des conventions collectives. À ce jour, les prescriptions légales ne fixent aucun salaire minimum.

$\mathrm{Au}$ XIX ${ }^{\mathrm{e}}$ siècle déjà, on assiste à des initiatives de réduction du temps de travail journalier pour des motifs sociaux et de protection de la santé des travailleur·euse-s. Les réglementations cantonales concernant le temps de travail maximum furent relayées en 1877 par la loi fédérale sur les fabriques. Cette loi, considérée alors comme la plus progressiste du continent européen, réglait notamment la durée du travail et du repos, la protection des enfants, ainsi que la protection contre les accidents, les maladies professionnelles et le surmenage. La loi sur le travail entrée en vigueur en 1966 étendit cette protection aux domaines de l'artisanat et du commerce. En 1993, en lien avec l'adaptation au droit de l'Union européenne (UE), le champ d'application des principales dispositions de protection de la santé fut encore élargi aux employéee-s de l'administration publique. Avec l'introduction d'une assurance-accidents obligatoire (LAA), en 1984, les dispositions sur la prévention des accidents furent transférées dans la loi sur l'assurance-accidents, ce qui conduisit malheureusement à un dualisme dans l'exécution.

Les dispositions sur la protection des travailleur·euse-s délèguent aux entreprises la responsabilité de protéger les employé·e·s contre les risques professionnels. Les employeur-euse-s doivent veiller au respect des prescriptions concernant la durée du travail et du repos et prendre toutes les mesures nécessaires et raisonnablement exigibles afin de protéger la santé et l'intégrité des travailleur-euse-s contre des atteintes nuisibles ou incommodantes au lieu de travail. Ils doivent en outre aménager leurs installations et régler la marche du travail de manière à préserver autant que possible les travailleur.euse-s des dangers menaçant leur santé et du surmenage. De leur côté, les employée-e·s doivent seconder l'employeur-euse dans ce domaine et ont un droit de regard sur ces questions dans le cadre de l'entreprise. La loi sur l'assurance-accidents et la loi sur le travail règlent les principes de la prévention des accidents et de la protection de la santé. Les autres aspects afférents à la protection de la santé des travailleur.euse-s sont réglés au niveau d'ordonnances et concrétisés par des directives et des instructions, le but étant de valoriser rapidement les nouvelles connaissances scientifiques sous forme de mesures efficaces. Le contrôle incombe à la Suva et aux inspectorats du travail. Le travailleur individuel ou la travailleuse individuelle peuvent également se prévaloir des dispositions de protection de la santé. Des règles spéciales concernant la durée de travail et de repos s'appliquent aux jeunes, aux femmes enceintes et aux mères qui allaitent, et des mesures spécifiques sont prévues pour protéger l'enfant à naître. En complément à ce dispositif, la loi sur les allocations pour perte de gain règle le droit à une allocation de maternité les 14 semaines suivant la naissance de l'enfant.

Dans les contrats de travail de droit privé, les travailleur.euse-s ont droit à quatre semaines de vacances au minimum (5 semaines pour les moins de 20 ans). Les contrats de travail de droit public sont en partie plus généreux.

Contrairement à ce qui est le cas dans le droit de l'Union européenne (UE), la protec- 
tion de la santé et la prévention des accidents reposent en Suisse sur deux bases légales différentes et relèvent de deux organes d'exécution. Si des efforts sont faits pour coordonner les deux systèmes, il manque une connexion plus étroite entre santé et sécurité comme elle est d'usage ailleurs. Dans l'UE, les entreprises doivent présenter régulièrement une évaluation détaillée de tous «leurs» dangers professionnels. En Suisse, de telles évaluations de risques sont exigées uniquement pour l'environnement de travail des femmes enceintes et pour la prévention d'accidents et de maladies professionnels dans des entreprises présentant un haut potentiel de dangerosité. Les autres risques pour la santé physique et psychique ne sont pas relevés systématiquement.

Le fait que certains aspects de la protection des travailleur·euse-s soient délégués aux partenaires sociaux est un autre particularisme suisse. Ainsi, depuis 2016, des exceptions dans la saisie et le décompte du temps de travail peuvent être convenues contractuellement entre eux. La législation suisse sur la protection de la santé est peu détaillée et contient de nombreux principes qui doivent être interprétés. Une des raisons pour cela pourrait être que les partenaires sociaux sont impliqués en amont du processus législatif déjà, ce qui rend la révision de lois difficile et laborieuse.

Les dispositions légales relatives à la protection du travail sont toujours en conflit avec la liberté économique qui, en Suisse, est elle aussi garantie par la Constitution. Cet antagonisme s'exprime tout spécialement dans la grande réticence face à l'intervention de l'État à propos des règlementations sur les salaires. La protection contre les discriminations dans le domaine de l'emploi se limite aux discriminations en raison du sexe. Il manque une protection générale contre d'autres types de discrimination. La loi sur l'égalité des personnes handicapées, par exemple, s'applique uniquement aux rapports de travail régis par la loi sur le personnel de la Confédération. Des observateurs étran- gers peuvent difficilement comprendre que le peuple a rejeté à plusieurs reprises (la dernière fois en 2012) des initiatives visant à augmenter la durée minimale des vacances.

Une part croissante de l'activité professionnelle se flexibilise aux niveaux temporel et spatial. La question de l'impact de cette évolution sur la protection des travailleur-euse-s n'est encore que peu débattue. En Suisse aussi, on observe que le cadre légal de la protection des travailleur·euse-s tend à être perçu comme une entrave, et partant, que des travaux sont délégués à du personnel freelance. Mais la jurisprudence est (encore) sévère et ne tolère pas l'indépendance fictive, qu'il s'agisse de contourner les dispositions du droit du travail ou celles du droit des assurances sociales. Dans le contexte de la migration du travail, il importe d'améliorer encore la protection des travailleur.euse-s dans l'agriculture et dans les ménages privés. Ces emplois devraient être soumis à la législation du travail et mieux contrôlés.

Les cadres occupant une fonction dirigeante élevée ne sont pas soumis aux règles sur le temps de travail. Dans les entreprises de services surtout, on assiste à une hausse de la demande d'exceptions pour d'autres travailleur.euse-s ayant une grande autonomie dans l'organisation de leur travail. Cette demande semble toutefois en contradiction avec le constat qu'un nombre croissant de travailleur.euse-s, aussi de ceux qui occupent des postes à responsabilité, souffrent physiquement et surtout psychiquement des exigences toujours plus élevées de leur travail. Les conséquences financières et sociales de maladies et d'accidents professionnels sont portées par les assurances sociales, par les personnes touchées et leurs familles, et par la collectivité. Il apparaît dès lors problématique de réduire la protection des travailleur.euse-s sans, en contrepartie, renforcer le principe de "pollueur - payeur» voulant que les entreprises participent davantage aux conséquences financières d'une prévention et protection insuffisantes. 
La législation et la jurisprudence prêtent encore peu d'attention au fait que les atteintes à l'intégrité de la personne (p.ex. harcèlement, discrimination en raison de l'âge, de l'origine, de la religion) doivent être empêchées et sanctionnées. L’efficacité de dispositions salariales légales est, elle aussi, sujette à controverse.

Sabine Steiger-Sackmann

\section{Références \\ Steiger-Sackmann, S. (2013). Schutz vor psychischen Gesundheitsrisiken am Arbeitsplatz: Rechtliche Möglichkeiten zur Verbesserung der Prävention. Zürich: Schulthess. \\ Witzig, A. (2018). Droit du travail. Genève : Schulthess.}

\section{Rationnement dans le secteur de la santé*}

La notion de rationnement est comprise de différentes manières en fonction du contexte sociopolitique et de la perspective scientifique. Utilisé à l'origine pour signifier une distribution équitable de ressources devenues rares en temps de guerre, le terme s'emploie depuis quelques années dans le domaine de la santé pour parler de la limitation de prestations de soins. En politique, une interprétation exclusivement négative prédomine généralement, le rationnement des soins étant perçu comme une privation non justifiée de prestations utiles. En économie de la santé, on entend en règle générale par rationnement l'allocation de prestations de soins dont les prix ne sont pas formés par le marché, en raison de leur financement par la collectivité. Par rapport à la définition politique, une définition plus large s'est entretemps établie en éthique de la santé : le rationnement y désigne tout mécanisme ou décision ayant pour effet de priver une personne ayant besoin d'un traitement d'une prestation utile. À la différence de la définition politique toujours, cette définition tient pour acquis l'inéluctabilité de limitations dans le domaine des prestations utiles. Elle permet en outre de différencier entre formes justes et injustes de rationnement et est donc plus neutre. Une autre distinction est faite entre le rationnement implicite ou non réglementé de prestations au chevet du patient (muddling through elegantly) et le rationnement explicite, dicté par une instance supérieure. Mentionnons encore la distinction, importante elle aussi, entre la rareté de biens à distribuer qui se produit par sa nature (p.ex. la rareté d'organes à transplanter) et la rareté de biens à distribuer, qui résulte de décisions politiques (p.ex. dans le domaine du financement, du personnel ou des infrastructures). Le terme phonétiquement proche de rationalisation renvoie quant à lui à une amélioration de l'efficience sans limitation de prestations utiles et ne donne dès lors pas lieu à controverse sur le plan éthique. La priorisation et la postériorisation de prestations médicales signifient le classement de prestations de santé en fonction de leur importance. Ce classement peut, mais ne doit pas, servir de critère de décision pour le rationnement de soins.

Jusqu'à des années récentes, les discussions sur le rationnement des soins furent relativement unilatérales dans un sens franchement négatif. On parla de médecine à deux vitesses, dénoncée comme discriminatoire du point de vue sociopolitique et, de ce fait, rejetée. Mais avec l'évolution démographique, l'augmentation continue des coûts de la santé, le changement des attentes et des exigences des patients et, surtout, les progrès très coûteux de la médecine, le débat est devenu plus nuancé. Une première impulsion donnée à la réorientation du débat fut la décision prise à Bâle en 1999, et controversée par la suite, de refuser un traitement très coûteux (Novo Seven) à un patient au prétexte de son âge avancé. Un rapport publié en 2007 par l'Académie Suisse des Sciences Médicales (ASSM) «Rationnement 
au sein du système de santé suisse: analyse et recommandations » et un jugement du Tribunal fédéral (TF) marquèrent d'autres jalons importants. Dans son arrêt rendu en novembre 2010, le TF invoque pour la première fois l'argument d'économicité; il arrive à la conclusion que l'assurance-maladie n'est pas obligée de rembourser le Myozyme, un médicament très coûteux contre la maladie de Pompe, l'utilité thérapeutique du médicament étant jugée trop faible par rapport à son coût élevé. La discussion politique qui suivit démontra que, du point de vue juridique, l'égalité devant la loi et la sécurité juridique étaient mises en cause : Combien une «année de vie gagnée, pondérée par la qualité » peut-elle coûter au maximum pour que les caisses-maladie soient obligées de rembourser le traitement? La question demeure posée. Le fait est que la maladie de Pompe est une maladie rarissime et que, par conséquent, le prix du traitement est très élevé. Cependant, comme le Conseil fédéral ne voit pas actuellement la nécessité d'agir dans ce domaine, un débat politique et des décisions concrètes portant sur la prise en compte du rapport coût-efficacité de prestations médicales se font encore attendre.

La décision de l'Office fédéral de la santé publique (OFSP), prise en 2015, de limiter à certaines catégories de patient.e-s seulement l'accès au Sofusbuvir (noms commerciaux: Solvadi, Harvoni) - un médicament très coûteux mais efficace contre l'hépatite $C$ et répondant donc au critère d'économicité - suscita une fois encore la controverse. Dans la motivation de cette limitatio, l'OFSP renvoie d'une part à la loi sur l'assurance-maladie, en vertu de laquelle une prestation médicale doit être efficace, adéquate et économique pour être prise en charge, d'autre part aux coûts très élevés qu'occasionnerait le libre accès au traitement de toutes les personnes atteintes d'une hépatite $\mathrm{C}$. Le cas est intéressant dans la mesure où l'argument porte cette fois non pas sur le rapport coût-efficacité, qui est incontesté (le coût du traitement est très élevé, mais son efficacité par rapport aux traitements conventionnels l'est également), mais sur le très grand nombre de patient.e.s qui, s'ils avaient tous droit au traitement, provoquerait une nette hausse des primes d'assurance-maladie. Reste la question, controversée elle aussi, de la justification du prix élevé de ce traitement, au vu de son retour sur investissement extrêmement élevé, l'hépatite $C$ étant une maladie infectieuse répandue dans le monde entier.

Ces dernières années, ces développements ont conduit à la prise de diverses initiatives pour fonder une institution HTA (health technology assessment). La mission d'institutions HTA consiste justement à évaluer le rapport coûts-efficacité de prestations médicales. Le Swiss Medical Board, fruit d'une initiative privée, réalise de telles évaluations et peut compter aujourd'hui sur le soutien d'importantes institutions politiques dans le domaine de la santé. L'introduction en Suisse, en 2012, du nouveau système de remboursement des prestations stationnaires avec des forfaits par cas au lieu de forfaits journaliers a eu pour effet de renforcer encore la concurrence pour les "patients avantageux». Ces changements et d'autres similaires, qui visent dans un premier temps et pour l'essentiel une amélioration de l'efficience, font actuellement l'objet de discussions que l'on pourrait résumer sous l'étiquette d'«économisation» du secteur de la santé.

En Suisse, la situation est caractérisée en particulier par la forte influence politique de l'industrie pharmaceutique et par l'offre très étendue des prestations médicales, alors que les réglementations limitatives (limitationes) sont rares. Corollaire: une augmentation du rationnement implicite et une pression accrue sur le personnel traitant de rationner les soins au chevet des patients individuels. D'un point de vue d'éthique médicale, cette situation n'est ni juste ni satisfaisante, car elle ouvre la porte à de grandes inégalités de traitement. Depuis plusieurs années, c'est le rationnement gériatrique, qui risque d'augmenter la pression 
sociale sur les personnes âgées, qui domine dans les débats éthiques. La forte hausse des coûts de la santé met en péril l'acceptation par la population d'une prise en charge sociale de ces frais et augure de vifs débats pour les années à venir. Une véritable discussion publique à ce sujet n'a pas encore commencé en Suisse, contrairement à ce qui est le cas dans d'autres pays, par exemple la Suède.

Markus Zimmermann

\section{Références}

Daniels, J. \& Sabin, J. (2002). Setting limits fairly: can we learn to share medical resources? Oxford: Oxford University Press.

Lindroth, K. (2008). Resolving health care's difficult choices: survey of priority setting in Sweden and an analysis of principles and guidelines on priorities in health care. Linköping : Linköping University Electronic Press.

Zimmermann-Acklin, M. (2011). Die Rationierungsdiskussion in der Schweiz: Beobachtungen aus ethischer Perspektive. In V. Wild, E. Pfister \& N. Biller-Andorno (Hrsg.), DRG und Ethik: Ethische Auswirkungen von ökonomischen Steuerungselementen im Gesundheitswesen (S. 127-139). Basel : EMH, Schweizerischer Ärzteverlag.

\section{Réadaptation*}

Selon la définition actuelle de l'OMS, la réadaptation désigne un processus permettant aux personnes avec des handicaps de développer et de maintenir, de manière optimale, leurs potentialités fonctionnelles physique, sensoriel, intellectuel, psychologique et social. La réadaptation crée la base pour que les personnes handicapées acquièrent la meilleure autonomie et autodétermination possible.

Le principe directeur de la réadaptation (en français aussi : réhabilitation) consiste à rétablir l'indépendance et l'autodétermination dans l'environnement préexistant de la personne dans toute la mesure du possible. Si le processus de réadaptation met en évi- dence que ce n'est pas possible, il convient alors d'ajuster les objectifs ou d'apporter des modifications à l'environnement. La réadaptation d'aujourd'hui est basée sur le modèle de la CIF (Classification internationale du fonctionnement, de l'invalidité et de la santé, ICF en anglais pour International Classification of Functioning, Disability and Health).

En principe, on distingue la réadaptation médicale (généralement assurée par du personnel médical, soignant et thérapeutique), les mesures de réadaptation sociale (toujours réalisées en complément de la réadaptation médicale ou professionnelle) et les mesures de réadaptation et de réinsertion professionnelle proprement dites. La réadaptation peut se dérouler selon un mode stationnaire ou ambulatoire. La collaboration interdisciplinaire est aujourd'hui considérée comme la condition la plus importante pour une réadaptation orientée vers des résultats.

C'est dans le domaine de l'orthopédie que la médecine de réadaptation a fait ses débuts en Suisse. Les racines morales de l'orthopédie et de l'assistance aux personnes handicapées physiques remontent au siècle des Lumières. C'est le médecin et professeur français Nicolas Andry (1658-1742) qui a créé le terme «orthopédie» à Paris. Il l'a popularisé avec son ouvrage L'orthopédie ou l'art de prévenir et de corriger dans les enfants les difformités $d u$ corps, publié en 1741. Dans ce livre se trouve l'image du célèbre et hautement symbolique «arbre orthopédique». Ce dernier ne vise pas à corriger une difformité existante, mais à prévenir son aggravation qui pourrait handicaper un organisme en croissance de manière irréversible. Aujourd'hui encore, nous comprenons la réadaptation orthopédique en ce sens. Jean André Venel (1740-1791) partageait ce point de vue. En 1780, il a fondé à Orbe, dans le canton de Vaud, le premier hôpital orthopédique du monde, dans lequel a été mis en œuvre, pour la première fois, le principe, encore valable aujourd'hui, consistant à offrir une éducation 
et une formation professionnelle aux enfants handicapés physiques en plus des soins et des traitements médicaux. L'accueil positif des efforts d'André Venel en Suisse romande a conduit à la fondation de l'Hospice orthopédique de la Suisse romande à Lausanne en 1876.

La loi fédérale de 1913 sur la tuberculose encouragea la construction et l'exploitation de cliniques d'altitude, qui furent transformées par la suite, après la découverte de médicaments antituberculeux, en cliniques de réadaptation pour les maladies pulmonaires, cardiaques et d'autres maladies relevant de la médecine interne. Tandis que la réadaptation cardiaque est une prestation obligatoire des caisses-maladie depuis 1977 grâce aux décisions du Département fédéral de l'intérieur et du Tribunal fédéral des assurances, la réadaptation en tant que telle et dans son ensemble ne fut définitivement inscrite dans la loi en tant que prestation de base que lors de la révision de la loi sur l'assurance-maladie (LAMal) en 1994.

$\mathrm{Au}$ cours des dernières décennies, la neuroréadaptation s'est imposée à côté des secteurs classiques de la réadaptation de médecine physique, orthopédique, cardiaque et pulmonaire. Cette évolution résulte, aussi, de la consolidation d'une chaîne de traitements de plus en plus efficace comprenant les soins aigus notamment de traumatismes neurologiques sévères et d'accidents vasculaires cérébraux graves. Elle a considérablement modifié l'image des cliniques de réadaptation perpétrée par le sens commun. Quant à la réadaptation gériatrique et paraplégique, organisée selon des normes internationalement reconnues, elle a également connu un développement important.

La Suisse compte dix branches d'assurances sociales qui se complètent. Les quatre assurances sociales importantes en matière de réadaptation socioprofessionnelle sont l'assurance-invalidité (AI), l'assurance-maladie (AMal), l'assurance-accidents (AA) et la pré- voyance professionnelle (PP). L'AI est principalement responsable des mesures de réintégration professionnelle (outre les prestations financières).

Le législateur ordonne la prochaine introduction d'un système tarifaire national unique en matière de compensation des prestations stationnaires en Suisse, et ceci également dans le domaine de la réadaptation. Dans ce cadre, le développement d'un système tarifaire dans le domaine de la réadaptation stationnaire est en cours depuis quelques années déjà, ceci sous l'égide de la SwissDRG SA (responsable du développement du système forfaitaire par cas en soins aigus) et sur la base de projets élaborés par $\mathrm{H}+$ (association faîtière des hôpitaux publics et privés) et la CTM (Commission des tarifs médicaux) entre 2011 et 2015 . Le système tarifaire ST-Reha consiste principalement à attribuer les patient·e-s à une catégorie de réadaptation donnée et en tenant compte de la gravité. Ce système fait actuellement l'objet d'une évaluation intensive. Son introduction ne devrait pas intervenir avant 2022 .

Le mandat légal des assureurs dans le domaine des prestations de l'assurance-accidents englobe la prise en charge des coûts des soins aigus aux victimes d'accidents jusqu'au versement d'une rente d'invalidité. Les problèmes de coordination entre l'hôpital de soins aigus et la clinique de réadaptation ainsi qu'entre la clinique de réadaptation et la réadaptation ambulatoire jusqu'à la réinsertion professionnelle vont en augmentant. L'académisation des professions thérapeutiques et soignantes développera la tendance à des offres thérapeutiques novatrices et fondées sur des données probantes. Cette évolution exige du personnel qualifié et qui continue à se perfectionner. Parallèlement, la pénurie déjà existante de personnel soignant et de médecins aura un impact croissant sur le recrutement de personnel dans l'ensemble du secteur de la réadaptation. 
En raison de l'impact négatif de facteurs économiques et démographiques, les mesures de réadaptation et de réinsertion sociales et professionnelles, qui complètent la réadaptation médicale très performante, sont de plus en plus difficiles à mettre en œuvre en Suisse. Souvent, les exigences professionnelles du marché de l'emploi ordinaire sont trop élevées pour les personnes dont la capacité de travail est partiellement limitée. Dans ce contexte, le rôle des cliniques de réadaptation, très pointues, gagne encore en importance, en particulier en matière de suivi post-hospitalisation. Ce suivi doit se mettre en oeuvre en collaboration avec les assureurs et les institutions de rentes afin d'assurer la pérennité d'un processus de réadaptation efficace et la mise en œuvre cohérente de mesures de réinsertion professionnelle efficaces à long terme.

\section{Stephanie Garlepp \& Christian Kätterer}

\section{Références}

Organisation mondiale de la santé (2001). CIF : classification internationale du fonctionnement, du handicap et de la santé. Genève: Organisation mondiale de la santé.

Zäch, G. \& Koch, H. (Hrsg.) (2005). Paraplegie: Ganzheitliche Rehabilitation. Basel: Karger.

\section{Recherche en politique sociale*}

La recherche en politique sociale vise à générer des connaissances sur l'État social, et ce de trois façons: premièrement, elle sert à informer et à mettre en lumière. Elle explique l'origine, le rôle et le fonctionnement de l'État social dans ses différents aspects partiels et dans sa globalité, et regroupe des informations à ce sujet. Ces informations sont censées servir de base à des décisions politiques fondées sur des données probantes et être mises à la disposition d'un large public afin de promouvoir la compréhension des contextes sociopolitiques. Ce dernier point s'applique en particulier aux étudiant·e-s et aux stagiaires qui acquièrent des connaissances fondées sur la recherche en vue d'une pratique professionnelle ultérieure. D'une part, ils/elles prennent ainsi connaissances des dernières découvertes scientifiques, d'autre part, ils/elles sont confronté·e-s à des questions et des problèmes fondamentaux, dont la solution peut varier selon l'approche et la perspective.

Deuxièmement, la recherche en politique sociale sert à élaborer des analyses scientifiques d'impact. Les changements sociétaux et économiques ont un impact sur l'État social; à son tour, l'État social, avec ses différents instruments, influence les conditions de vie de la population, que ce soit dans son ensemble ou pour certains groupes de personnes ou situations de vie particulières. Les analyses scientifiquement fondées de la recherche en politique sociale ont pour but d'identifier d'éventuels besoins d'action ou d'aménagement actuels ou prévisibles concernant l'État social et ses divers instruments.

Troisièmement, l'objet de la recherche en politique sociale est également de formuler des propositions d'amélioration. La recherche en politique sociale est supposée mettre en évidence des options, avec leurs points forts et leurs points faibles respectifs, ou leurs opportunités et leurs risques, qui permettraient de répondre aux éventuels besoins d'action et d'aménagement. La recherche en politique sociale doit contribuer à ce que les instruments de politique sociale soient conçus de manière à obtenir l'effet escompté (effet visé) du mieux possible et à réduire au minimum les effets non escomptés (effet involontaire). Les effets des instruments et mesures mis au point doivent être socialement équitables, efficients et efficaces (impact maximal avec un minimum de moyens) et compatibles avec le droit supérieur (conformité avec les droits fondamentaux). 
La politique sociale de l'État fédéral suisse étant définie comme une tâche commune de la Confédération et des cantons, le secteur public joue un rôle de premier plan également dans la recherche en politique sociale aux côtés des acteur.trice-s privé·e-s (comme les fondations privées ou les groupes de réflexion d'orientation sociopolitique): citons notamment la recherche de l'administration fédérale, dont l'objectif est de produire les connaissances scientifiques dont l'administration fédérale et la politique fédérale ont besoin pour remplir leurs missions. Dans le domaine de la politique sociale, il existe des bases juridiques particulières, comme dans la loi sur l'assurance-invalidité, qui obligent expressément la Confédération à entreprendre des «études scientifiques» sur la mise en œuvre des réglementations de l'assurance-invalidité. À côté de cette recherche sous mandat de l'administration fédérale, le secteur public accorde des subventions à la recherche indépendante, notamment dans le cadre du Fonds national suisse de la recherche scientifique, avec ses programmes et ses accents particuliers. Dans le secteur de l'enseignement supérieur, la recherche en politique sociale est de plus en plus souvent pratiquée non seulement dans les universités, mais aussi dans les hautes écoles spécialisées.

Les questions de la recherche en politique sociale sont le plus souvent formulées de manière interdisciplinaire: des méthodes et des questions issues de l'anthropologie, du droit, de l'économie, de l'éthique, de l'histoire, de la psychologie, des sciences politiques et de la sociologie sont utilisées pour analyser et présenter la situation sociale et économique de la population dans tous les domaines de la vie de manière fondée et dans la perspective de chacune de ces disciplines.

La science politique, par exemple, met l'accent sur l'émergence de réglementations politico-sociales en tant que résultats de l'interaction de forces politiques et de leurs solutions, sur la mise en œuvre de politiques (en tant qu'interaction entre réglementation, contexte et exploitation de marges de manœuvre dans la mise en œuvre) et sur les impacts de la politique dans ses effets visés et involontaires.

La recherche économique en politique sociale étudie quant à elle notamment les effets de redistribution qui peuvent se déployer horizontalement, c'est-à-dire en considérant différentes phases de la vie ou générations (bilans générationnels), ou verticalement, soit mesurés à l'aune de la performance économique. L'étude des rapports coûts-avantages de services sociopolitiques (p.ex. des services de prise en charge extrafamiliaux des enfants) peut également faire partie de la recherche économique en politique sociale.

En guise de troisième exemple, citons le droit, qui utilise de plus en plus l'instrument de l'analyse prospective de l'impact de la législation, généralement sous une forme virtuelle, dans laquelle on développe un modèle pour simuler la façon dont les normes prévues sont susceptibles d'être mises en œuvre aux divers niveaux administratifs, et les effets concrets qu'elles pourraient avoir.

Ces différentes branches de la science disposent d'une grande variété de méthodes scientifiques qui, selon l'objet de la recherche, sont davantage axées sur la quantité ou la qualité: analyse de données et de documents, enquêtes, études de cas, expériences, comparaisons, expériences pilotes, groupes de réflexion, interviews écrites ou téléphoniques, observations et analyses de réseaux. Cette pluralité de méthodes permet de recenser les effets des mesures de politique sociale de manière différenciée et à l'aide de l'instrument optimal, de les évaluer en fonction de leur capacité à atteindre les objectifs et d'identifier les besoins d'ajustement (amélioration de l'efficience ou de l'efficacité).

L'objet de la recherche en politique sociale peut être très varié: celle-ci peut porter sur des instruments et mesures précis (niveau micro, p.ex. la question de savoir comment 
une prestation financière influence le comportement de son bénéficiaire), ou examiner tel ou tel impact au niveau du système global (niveau macro, p.ex. l'effet de l'aménagement de la prévoyance vieillesse sur les rentes des hommes et des femmes). La recherche en politique sociale peut aussi délaisser la perspective purement nationale pour comparer l'organisation de l'État social de son pays avec les solutions d'autres pays, ce qui peut apporter des connaissances à plusieurs égards: la comparaison internationale peut montrer si d'autres instruments et mesures que ceux utilisés au niveau national offrent une solution plus efficiente et plus efficace pour certaines situations problématiques, mais elle peut aussi aider à mettre en lumière des liens de cause à effet ou contribuer à la théorisation.

Le discours sociopolitique public et la politique ont besoin d'analyses et d'interprétations fondées et théoriquement justifiées concernant les problèmes des citoyen'ne-s. La science engagée et indépendante doit contribuer à identifier des problèmes émergents à un stade précoce grâce à une analyse approfondie, et proposer des mesures appropriées et ciblées aux décideurs politiques. La recherche en politique sociale possède à cet égard une valeur intrinsèque, que ses résultats soient mis en œuvre ou non par la politique qui suit ses propres logiques et ses propres lois.

\section{Renate Salzgeber et Pascal Coullery}

\section{Références}

Bundesamt für Sozialversicherungen (2017). Forschungskonzept 2017-2020: Soziale Sicherheit. Bern: Bundesamt für Sozialversicherungen.

Busemeyer, M. (Hrsg.) (2013). Wohlfahrtspolitik im 21. Jahrhundert: Neue Wege der Forschung. Frankfurt a.M.: Campus.

Stoker, G. \& Evans, M. (Eds.) (2016). Evidence-based policy making in the social sciences: methods that matter. Bristol : Policy Press.

\section{Redistribution*}

Le terme de redistribution renvoie aux processus et aux résultats des mesures de politique financière et sociale qui influent sur la distribution primaire des revenus et de la fortune. La distribution primaire désigne la distribution des revenus et des produits du capital générés dans les processus du marché. La distribution secondaire, quant à elle, renvoie à la distribution des revenus après l'intervention de l'État, bien qu'il soit admis que la distribution primaire est également structurée politiquement. L'État social moderne doit fonder ses activités sur le principe de solidarité et contribuer ainsi à réduire les inégalités économiques, tant sur le plan interpersonnel qu'intergénérationnel. En principe, l'État dispose de deux instruments principaux pour réduire les inégalités primaires en matière de revenus et de fortune, à savoir les transferts sociaux (dépenses) et les impôts (recettes). Dans la plupart des pays de l'OCDE, les transferts sociaux et les assurances sociales sont conçus de manière à ce que les quantiles de revenu faibles en touchent davantage que les riches. Le seul point controversé est de savoir si le régime universel de sécurité sociale basé sur le modèle scandinave implique une plus grande redistribution du haut vers le bas que les transferts ciblés en faveur des pauvres. De la même manière que les transferts sociaux, l'imposition progressive des revenus et de la fortune garantit que les quantiles de revenu supérieurs paient plus d'impôts non seulement en termes absolus, mais aussi en termes relatifs. Idéalement, les deux processus aboutissent à une réduction des inégalités. C'est ce que montre la courbe de Lorenz: le graphique indique combien la part $\mathrm{x}$ d'une population détient de part y d'une ressource, et constitue ainsi la base de calcul du coefficient de Gini.

Dans différents contextes, par exemple en Amérique latine, mais aussi dans des secteurs qui défendent leurs intérêts particuliers de manière forte (p.ex. les agricultrices et agri- 
culteurs, les retraité·e·s), l'État redistribue les ressources cependant trop souvent $d u$ «bas vers le haut». En d'autres termes, les inégalités s'accroissent lorsque les prestations de transfert n'atteignent pas les groupes les moins privilégiés ou, au contraire, favorisent les groupes professionnels privilégiés. De même, les inégalités augmentent lorsque l'imposition est dégressive, c'est-à-dire que les quantiles de revenu supérieurs sont proportionnellement moins imposés que les moins privilégiés. Cependant, les impôts sur la consommation, les impôts personnels, les taxes et les déductions fiscales fixes sont également dégressifs. Du fait de la progressivité de l'impôt, ils sont d'autant plus avantageux que les revenus sont élevés (p.ex. déductions pour enfants, cotisations à la prévoyance vieillesse). Outre les deux effets de redistribution verticale (de haut en bas, de bas en haut), des effets horizontaux sont également envisageables. C'est le cas, par exemple, des assurances sociales où les cotisations et les prestations sont corrélées de manière linéaire.

Bien que le discours sur la redistribution se concentre généralement sur l'État social, on ne peut négliger le fait que d'autres domaines étatiques procèdent également à la redistribution. Il suffit de penser au subventionnement des entreprises privées ou de l'agriculture. Onéreuse en tant qu'institutions, mais quasiment gratuite pour les étudiant·e.s, la formation tertiaire tend, elle aussi, à créer une redistribution du bas vers le haut, contrairement à la formation primaire, en raison des faibles possibilités de mobilité scolaire des enfants issus des classes de revenus inférieures. En outre, des processus de redistribution existent également entre les sous-unités politiques. Dans de nombreux pays de même que dans l'Union européenne, il est prévu que des entités financièrement solides, comme le canton de Zoug ou l'Allemagne, soutiennent des entités plus faibles, comme le canton du Jura ou la Grèce, réduisant ainsi les inégalités interpersonnelles. Des œuvres d'entraide privées pratiquent éga- lement la redistribution, mais leurs transferts sociaux n'entraînent pas de redistribution verticale.

En Suisse, d'une part, les transferts sociaux ont un effet égalitaire, surtout en ce qui concerne l'AVS et l'aide sociale. D'autre part, l'imposition des revenus (gains, capitaux) dans la Confédération et dans la plupart des cantons est progressive, tant en matière de revenus, de fortune ou de succession. Quant aux péréquations financières entre les cantons et les communes, elles contribuent également à une redistribution, car elles réduisent la charge fiscale pesant sur les habitant·e-s des régions à fiscalité élevée.

Notons cependant que de nombreux cantons ont réduit ou supprimé la progressivité, ou l'envisagent, en particulier dans les quantiles de revenu supérieurs. Certains cantons ont introduit ou ont l'intention d'introduire une flat tax neutre en matière de distribution (taux d'imposition sur le revenu constant et donc non progressif) selon le modèle de l'Europe de l'Est. De nombreux cantons ont par ailleurs supprimé les impôts sur les successions. N'oublions pas, en outre, que de nombreuses déductions fiscales ont un effet dégressif, en particulier les déductions pour enfants et le troisième pilier. S'ajoutent à ces aspects les variations considérables de la charge fiscale, du taux de progressivité et des taxes non seulement entre cantons, mais également entre communes. Par conséquent, la liberté d'établissement présente une extraordinaire possibilité pour les personnes à revenu élevé de se protéger contre la redistribution par l'État: elles sont libres de choisir leur résidence dans une commune à faible charge fiscale.

Ainsi, la Suisse se distingue des autres pays notamment à travers trois particularités. Premièrement, les transferts sociaux, à l'exception de l'AVS et de l'aide sociale, ne contribuent que modestement à la réduction des inégalités primaires. Deuxièmement, il existe des disparités régionales extrèmes en matière de fiscalité. 
Troisièmement, l'impôt sur la consommation est relativement modéré, bien que les primes d'assurance-maladie indépendantes du revenu et certaines déductions fiscales produisent des effets dégressifs.

La Suisse fait donc partie des pays de l'OCDE dont la redistribution est relativement faible. L'AVS et l'aide sociale sont les principaux facteurs de redistribution dans le domaine des transferts sociaux, tandis que les impôts progressifs sur le revenu et sur la fortune opèrent dans le domaine fiscal. En ce qui concerne l'aide sociale, il convient toutefois de noter que les effets de seuil sont problématiques en termes de politique de distribution. Ainsi, il se peut qu'un ménage au revenu brut juste en dessus du seuil dispose d'un revenu moindre qu'un ménage avec un revenu inférieur au seuil.

Plaider en faveur d'une restructuration politique des inégalités de revenus primaires ou d'efforts supplémentaires de redistribution verticale ne fait clairement pas partie de l'agenda politique actuel. Des opposants à la redistribution se trouvent à la fois chez les néolibéraux (p.ex. Avenir Suisse) et chez les sociaux-démocrates (Schröder-Blair 1999). En Suisse, l'aide sociale semble perdre le soutien de la population active, contrairement aux assurances sociales dont les effets sont plus horizontales. Une réduction de la redistribution s'annonce également dans la politique fiscale. Il suffit de penser à la concurrence fiscale intercommunale et intercantonale qui accélère la réduction des taux d'imposition et la progressivité, tout comme à l'introduction d'un impôt à taux unique (flat tax) dans certains cantons ou encore au passage rampant de l'imposition directe, principalement progressive, à une imposition indirecte, principalement dégressive. En outre, les cantons plus riches remettent désormais la péréquation fiscale intercantonale en question. Ainsi, la ségrégation sociale de l'espace entre les régions à fiscalité élevée respectivement basse risque de s'accentuer. En fin de compte, cette tendance à la désolidarisation menace non seulement la cohésion sociale de la Suisse en général, mais aussi et surtout la capacité de l'État social à réduire les inégalités créées par le capitalisme.

Michael Nollert

\section{Références}

Caminada, K., Goudswaard, K., Wang, C., Wang, J. (2019). Has the redistributive rffect of social transfers and taxes changed over time across countries? International Social Security Review, 72, 3-31.

Goudswaard, K., Caminada, K. (2010). The redistributive effect of public and private social programmes: a cross-country analysis, International Social Security Review, 63, 1-19.

Kenworthy, L. (2011). Progress for the poor. Oxford: Oxford University Press.

\section{Réforme de la sécurité sociale}

Le système actuel de sécurité sociale suisse est le produit des propositions de réformes, acceptées ou refusées, effectuées depuis l'inscription dans la Constitution en 1890 de compétences fédérales en matière d'assurances sociales. Les propositions officielles au niveau fédéral font l'objet de cette contribution et peuvent émaner du gouvernement ou des chambres fédérales.

Une caractéristique importante du processus décisionnel est sa longueur et la recherche de compromis, notamment parce que les acteur-trice-s capables d'organiser un referendum sont intégrés au processus de décision. Les referendums facultatifs et obligatoires peuvent considérablement retarder la mise en œuvre des propositions de réformes, comme en témoigne par exemple le refus à trois reprises (1984, 1987, 1999) de l'assurance-maternité avant son acceptation en 2004. Même si les initiatives populaires sont souvent refusées par le peuple en matière de politique sociale, les propositions officielles de l'État fédéral sont parfois liées à ces initiatives puisqu'elles prennent 
parfois la forme de contre-projets. Cela a par exemple été le cas avec le projet des trois piliers de la politique des retraites en 1972 .

Les propositions de réformes au niveau fédéral sont fortement marquées par le principe de la subsidiarité et la structure fédérale des institutions. En effet, de nombreuses politiques sociales échappent à la Confédération et sont de la compétence des cantons ou communes. C'est le cas notamment de la politique familiale, de l'aide sociale (sauf en ce qui concerne les réfugiés), ou encore des politiques de l'enfance et de la jeunesse. Lorsque les compétences sont cantonales, l'État fédéral peut jouer un rôle subsidiaire, en intervenant par exemple au moyen d'incitations visant à développer les politiques cantonales ou communales. Le programme d'impulsion visant à encourager la création de places d'accueil pour les enfants, entré en vigueur en 2003, est l'archétype d'une telle politique fédérale incitative et subsidiaire: à travers le subventionnement de la mise en place de nouvelles places d'accueil sur une durée limitée, la Confédération a atteint son objectif de multiplication pérenne des structures d'accueil. Le rôle subsidiaire de l'État fédéral se voit par ailleurs dans les modalités des réformes mises en place, qui se sont souvent appuyées sur des pratiques existantes. Ainsi, les caisses de pension et caisses de chômage ont toutes deux été mises en place dans les entreprises, branches, communes ou syndicats avant d'être rendues obligatoires au niveau fédéral.

Le contenu des propositions de réformes est d'abord, de manière évidente, influencé par le contexte (économique, social, démographique, politique etc.). L'introduction de l'assurance-chômage a eu lieu dans le contexte d'une perte massive d'emplois dans les années 1970. Les réformes récentes de l'assurance-vieillesse et survivants (AVS) ou de la prévoyance professionnelle (LPP) ne peuvent pas être comprises en dehors du contexte démographique. Trois autres caractéristiques peuvent être mention- nées concernant les propositions de réformes: leur caractère incrémental, sectoriel, et le fait qu'elles sont souvent soumises à une tension entre réduction de prestations et compensations. Afin de favoriser leur acceptation dans le cadre d'un système consensuel et avec de multiples points de vetos, les réformes sont généralement incrémentales, c'est-à-dire qu'elles constituent souvent des ajustements progressifs qui doivent être reconsidérés après une période relativement courte. Le caractère sectoriel des réformes est également caractéristique. Chaque dispositif de la sécurité sociale est né et s'est développé séparément, pour répondre à des risques qui lui sont propres et en suivant une logique de financement et d'organisation propre. Des caisses et prestations distinctes font alors l'objet de propositions de réformes distinctes, même si elles sont parfois confrontées à des problèmes (financiers, démographiques etc.) ou buts (l'intégration professionnelle) communs. Enfin, les propositions de réformes visant à réduire le niveau des protections sociales semblent être acceptées en référendum seulement lorsqu'elles s'accompagnent de compensations. Le contenu des propositions en tient souvent compte. Il s'agit d'une condition nécessaire mais pas suffisante puisqu'elle ne garantit pas automatiquement le succès politique.

Les principales réformes en cours ou récentes (état: décembre 2017) peuvent illustrer ces trois caractéristiques. En ce qui concerne la réforme Prévoyance vieillesse 2020 refusée de justesse par le peuple en septembre 2017, l'objectif principal était le maintien des prestations et l'équilibre financier de l'AVS et du $2^{\mathrm{e}}$ pilier. Elle prévoyait notamment d'harmoniser l'âge de référence de la retraite des hommes et des femmes à 65 ans tout en flexibilisant l'âge du départ à la retraite. Le taux de conversion minimal dans la prévoyance professionnelle devait être abaissé progressivement, mais les rentes de la prévoyance professionnelle obligatoire ne devaient pas 
diminuer en raison notamment de l'abaissement de la déduction de coordination. La réforme prévoyait également la réduction des prestations pour les veuves et veufs ainsi que l'abaissement du seuil d'accès à la prévoyance professionnelle obligatoire devant permettre d'améliorer la protection des personnes à faible revenu. Enfin, un financement supplémentaire devait être assuré par une hausse de la TVA, et un mécanisme d'intervention devait permettre de prendre à temps des mesures garantissant l'équilibre financier de l'AVS. Cette tentative de réforme est exemplaire du caractère incrémental des propositions de réformes, puisqu'elle ne prévoyait une solution au problème de financement que jusqu'en 2030. En liant l'AVS et la LPP (option qui a fait en soi l'objet de débats), elle constituait en même temps un des uniques contre-exemples concernant le caractère sectoriel des réformes. Elle reflète également le souci de lier les priorités financières avec des mesures de compensation. Par exemple, l'augmentation de l'âge de référence à 65 ans pour les femmes devait être compensée par des mesures favorables aux femmes ayant des bas revenus (abaissement du seuil d'accès au $2^{\mathrm{e}}$ pilier). Des projets de réformes antérieurs visant l'augmentation de l'âge de la retraite ou la baisse du taux de conversion sans compensations claires ont subi un échec beaucoup plus net que la réforme Prévoyance vieillesse 2020 au cours des dernières années. Il reste à voir si, à moyen terme, de nouvelles initiatives allant dans ce sens seront rejetées. Pour lors, l'acceptation du projet Réforme fiscale et financement de l'AVS (RFFA) lors des votations fédérales au mois de mai 2019 apporte à l'AVS une nouvelle source de financement.

Concernant l'assurance-invalidité, les réformes récentes et en cours («Développement continu de l'AI») sont incrémentales dans le sens où elles approfondissent une logique préexistante, celle de la réadaptation qui était déjà un objectif central de l'AI lors de son introduction en 1960. La proposition de réforme actuelle vise les enfants (révision de la liste des maladies congénitales), les jeunes (mesures de transitions entre école, formation professionnelle et monde du travail) et les assuré·e·s atteint·e·s dans leur santé psychique (extension ou mise en place de mesures). Un système linéaire pour les nouvelles rentes doit aussi renforcer le système d'incitations au retour à l'emploi, et la collaboration avec les employeur-euse-s et les médecins doit être consolidée. Le caractère sectoriel des réformes récentes et en cours de l'AI est perceptible dans le sens où l'importance accrue de l'objectif de l'insertion professionnelle a été repensé dans le cadre de l'assurance, et non dans un cadre plus large englobant les autres acteur.trice-s de la sécurité sociale centrés sur le même objectif (assurance-chômage, aide sociale, domaine de la migration et de la formation). La recherche de compensations se reflète dans l'augmentation conséquente des moyens financiers à disposition pour la réadaptation des assuré·e·s, notamment dans le cadre de la $5^{\mathrm{e}}$ révision et de la révision 6a LAI, combinée à l'objectif de réduction du nombre des rentes. La réduction des rentes doit ainsi aller de pair avec de meilleures chances d'insertion dans le marché du travail. En ce qui concerne spécifiquement la proposition de réforme en cours, elle s'est donnée pour objectif d'être neutre d'un point de vue financier et peut ainsi difficilement être soupçonnée de s'assainir sur le dos d'éventuels «perdants».

Les caractéristiques mentionnées (incrémental, sectoriel, compensations) sont marquées par la recherche d'équilibres et les ajustements progressifs. Illustrant la stabilité plus générale du système politique suisse, elles le rendent vulnérables à d'éventuels chocs qui exigeraient des innovations rapides et radicales. Ces chocs peuvent être de nature économique, démographique et sociale, mais aussi technologique ou sanitaire comme en témoignent les discussions en cours sur la digitalisation ou la pandémie du coronavirus. En 
dehors des organes officiels, l'innovation radicale peut cependant émerger par le biais de la démocratie directe, la proposition rejetée d'un revenu de base inconditionnel constituant un exemple récent.

\section{Frédéric Widmer}

\section{Références \\ Bonoli, G. (1999). La réforme de l’État social Suisse : contraintes institutionnelles et opportunités de changement. Swiss Political Science Review, 5(3), 57-78. \\ Kriesi, H. \& Trechsel, A. H. (2008). The politics of Switzerland: continuity and change in a consensus democracy. Cambridge : Cambridge University Press.}

\section{Régime fiscal ${ }^{* *}$}

Une première et importante justification de l'impôt réside dans la nécessité pour l'État de financer la dépense publique. Selon la Constitution fédérale, tous les êtres humains sont égaux devant la loi. En matière fiscale, cette disposition se concrétise par le principe de l'imposition selon la capacité contributive qui intègre les principes de généralité et d'uniformité de l'impôt. Ainsi, dans le but d'éviter discriminations et privilèges, toute personne et tout groupe de personnes doivent être imposés selon les mêmes dispositions légales (principe de généralité); de plus, toute personne ou groupe qui se trouve dans la même situation doivent être imposé·e-s de la même manière, alors que celles et ceux qui se trouvent dans des situations différentes doivent être imposé·e·s de manière différente (principe d'uniformité). Quant au principe de la capacité contributive, il est respecté lorsque chaque personne ou groupe de personnes contribue à la couverture des dépenses publiques selon «ses forces» et donc sur la base de sa situation personnelle et à proportion de ses moyens. En Suisse, ce prin- cipe s'applique aux impôts directs, prélevés par la Confédération et les cantons.

En droit fiscal, le revenu constitue l'indice par excellence de la capacité contributive. Outre le revenu, le patrimoine et les augmentations de la valeur du patrimoine sont aussi considérés comme des indices directs de la capacité contributive. Par contre il convient de signaler qu'un revenu minimum ne constitue pas un indice de capacité contributive car ce serait en contradiction avec les dispositions de la Constitution selon lesquelles quiconque est dans une situation de détresse et n'est pas en mesure de subvenir à son entretien a le droit d'être aidé.e et assisté·e et de recevoir les moyens indispensables pour mener une existence conforme à la dignité humaine. Selon le Tribunal fédéral, le législateur n'est toutefois pas contraint d'exonérer d'impôt les revenus qui équivalent au minimum vital, mais il doit garantir que chaque contribuable ne soit pas lésé.e dans son droit à assurer sa survie. À cette fin, il peut mobiliser divers outils tels que la fixation des taux d'imposition, l'exemption de certains montants et les déductions fiscales, ou encore en octroyant ponctuellement l'exonération de l'impôt aux personnes en situation de besoin.

En matière d'impôts directs, le Tribunal fédéral relève que l'évolution des taux d'imposition ne doit pas seulement respecter les droits fondamentaux de la garantie de la propriété et de la liberté économique, mais, conformément à la justice distributive, satisfaire aussi des exigences sociales. Cette considération correspond à une conception dominante de l'ordre juridique, selon laquelle le principe de l'imposition selon la capacité contributive s'inscrit au croisement de considérations juridiques, sociales et économiques. Selon le Tribunal fédéral, la justice fiscale est avant tout une question de justice distributive et implique une juste répartition des dépenses et des besoins entre les membres de la communauté. La promotion de la prospérité commune ainsi 
que la garantie, dans la limite du possible, de l'égalité des chances pour tous les citoyen-ne-s constituent des objectifs sociaux qui engagent la responsabilité de l'État. Pour cette raison, la Constitution fédérale a opté pour une conception de l'impôt favorable à la redistribution.

Afin de pouvoir comparer les capacités contributives des citoyen-ne-s, une base de comparaison objective est nécessaire. En introduisant un impôt sur le revenu global net, le législateur fédéral a opté pour le revenu et le patrimoine en tant que critères d'imposition des individus. Comme toute personne est imposée en fonction de ces deux critères, l'égalité de traitement est formellement respectée. Il faut cependant aussi tenir compte de la situation économique subjective du contribuable. En effet, des revenus égaux ne doivent pas être imposés de manière égale si la situation personnelle et sociale des contribuables est différente. Les déductions sociales (déductions pour personnes à charge du ou de la contribuable: enfants mineur.e.s, enfants aux études, personnes dans le besoin, etc.) et les taux d'imposition différenciés (époux vivant en ménage commun, familles monoparentales, contribuables vivant seul.e.s, etc.) visent à adapter autant que possible la charge fiscale selon la situation subjective du ou de la contribuable, conformément au principe de l'imposition selon la capacité contributive. L'utilisation de tels paramètres catégoriels et déductions forfaitaires est inévitable, car pour des raisons pragmatiques il n'est évidemment pas possible de considérer chaque situation de manière individuelle.

Enfin, la progression des taux d'imposition ne doit pas conduire à une charge fiscale excessive. Le principe de l'imposition selon la capacité contributive pose une limite d'imposition maximale au législateur qui s'élève théoriquement à $100 \%$, mais l'interdiction de l'impôt confiscatoire aboutit inévitablement à une limite bien au-dessous de $100 \%$. En effet, à un seuil déterminé, il faut interrompre la progres- sion des taux d'imposition, en fixant une valeur maximale pour le taux marginal et pour le taux moyen. La fixation de cette limite relève d'une décision purement politique.

En matière d'impôts directs sur le revenu et sur la fortune des personnes physiques, ainsi que sur le bénéfice et le capital des personnes morales, les législateurs cantonaux sont tenus d'harmoniser leurs lois fiscales sur différents points (sujets soumis à l'impôt, période de calcul, procédure, dispositions pénales, etc.); ils sont toutefois libres de choisir les barèmes, les taux et les montants exonérés de l'impôt, en veillant toutefois à respecter les droits fondamentaux, en particulier le principe de l'égalité de traitement et ses corollaires en matière fiscale, notamment le principe de l'imposition selon la capacité contributive. En raison de cette marge de manœuvre, découlant du fédéralisme qui caractérise le système suisse, on observe une concurrence fiscale entre les cantons qui tentent d'attirer de riches contribuables et de nouvelles entreprises sur leur territoire à travers des taux ou barèmes plus avantageux.

À titre d'exemple, certains cantons suisses ont opté pour la flat rate tax qui, au lieu d'un taux d'imposition progressif, prévoit un taux marginal unique combiné à une importante déduction fiscale. Bien que la plupart des expert.e-s considèrent la flat rate tax conforme au principe de l'imposition selon la capacité contributive, dès lors que la charge fiscale augmente de manière plus que proportionnelle à l'augmentation du revenu, celle-ci pose quand même question en termes de justice fiscale. En effet, cette tax se caractérise par une progression «freinée» qui favorise les classes les plus riches et nuit au principe de la redistribution de la richesse.

Il faut souligner aussi que les 26 cantons disposent de ressources financières inégales en raison de leur position géographique, du développement économique inégal et d'autres facteurs engendrant des différences au niveau 
du tissu fiscal. Dans le but de réduire ces disparités et créer un mécanisme de solidarité, des systèmes de péréquation financière et de compensation des charges ont été développés. La péréquation des ressources distingue les cantons à fort et à faible potentiel; les cantons faibles reçoivent, de la part des cantons forts (péréquation horizontale) et de la Confédération (péréquation verticale), une contribution financière dont ils peuvent disposer librement. En outre, la Confédération octroie une compensation aux cantons qui doivent supporter des coûts plus élevés en raison de leurs caractéristiques géographiques et sociodémographiques.

\section{Samuele Vorpe \& Kelly Scapozza}

\section{Références}

Oberson, X. (2012). Droit fiscal suisse (4 éd. entièrement rev. et augm.). Bâle: Helbing Lichtenhahn.

Pedroli, A. (2008). Non solo aliquote: le imposte fra etica, giustizia e concorrenza fiscale. Rivista ticinese di diritto, 1, 11-53.

Yersin, D. (1992). L'égalité de traitement en droit fiscal. Revue de droit suisse, 111(2), 145-297.

\section{Régimes d'État-providence (de protection sociale)*}

Les théories des régimes voient les domaines politiques comme des réseaux d'institutions interdépendants capables de s'autostabiliser par différentes mesures. Dans le domaine de la politique sociale, on appelle ces réseaux institutionnels des régimes d'État-providence (de protection sociale). Contrairement au concept d'«État social», le régime de protection sociale ne concerne pas seulement les politiques et les institutions réelles, mais aussi leurs interactions entre elles et avec l'économie et la société. Les régimes sont des outils heuristiques: ils présupposent une série de configurations typiques idéales sur la base desquelles des politiques sociales réelles peuvent être comparées. Dans la recherche en la politique sociale, la notion des régimes d'État-providence a été lancée par Gøsta Esping-Andersen dans son ouvrage publié en 1990 et intitulé Les trois mondes de l'État-providence. Essai sur le capitalisme moderne. Les trois régimes typiques idéaux de G. Esping-Andersen se distinguent par leurs origines idéologiques et politiques et les caractéristiques institutionnelles qui en résultent. À juste titre, sa conceptualisation est considérée comme la contribution la plus importante et la plus citée dans la recherche en politique sociale et conserve sa pertinence et sa validité empirique et analytique malgré des points critiques spécifiques. Ses successeurs ont notamment introduit un autre type caractéristique d'Europe du Sud ou critiqué à raison l'absence d'une perspective de genre explicite chez G. Esping-Andersen. Ce dernier avance que les États sociaux occidentaux se différencient systématiquement selon deux dimensions: le degré d'indépendance des personnes actives vis-à-vis du marché du travail comme source de subsistance («décommodification») et le degré d'inégalité sociale engendrée ou atténuée par les prestations sociales («stratification»). Les États sociaux-démocrates d'Europe du Nord ont tendance à se distinguer, selon G. Esping-Andersen, par un profil généreux (ou décommodifié), universel et égalitaire de la sécurité sociale, tandis que les États sociaux libéraux anglo-saxons présentent aussi un profil égalitaire, mais focalisent sur des politiques sociales en fonction des besoins, privilégiant la lutte contre la pauvreté (stratifiante); enfin, les États sociaux continentaux démocrates-chrétiens ont créé des systèmes d'assurance sociale certes généreux, mais fortement stratifiés, qui entraînent la décommodification sélective des personnes occupées sous contrats d'emploi standards tout en créant des lacunes de couverture pour les carrières professionnelles atypiques. 
Les régimes sociaux sont étroitement liés à leurs origines historiques et sociales. Du point de vue historique, les régimes d'État-providence se sont constitués dans des contextes de structures de division sociale spécifiques et de la répartition du pouvoir des forces politiques qui en résulte: le régime continental démocrate-chrétien existe uniquement dans les pays dont l'histoire politique a été fortement marquée par la mobilisation de la démocratie chrétienne et où l'État social représentait un compromis entre la classe ouvrière et l'Église. Dans les pays qui n'ont pas connu la mobilisation démocrate-chrétienne se sont établis des régimes libéraux ou sociaux-démocrates. Quant aux régimes sociaux-démocrates égalitaires, ils sont issus d'un compromis historique entre la social-démocratie et les partis politiques des paysans et des petits propriétaires fonciers. Enfin, les régimes libéraux se sont implantés dans les pays qui ont connu une faible mobilisation ouvrière et où la démocratie chrétienne n'existait pas. Le retour aux origines historiques et politiques souligne le caractère structurel durable des régimes de protection sociale dont les changements restent limités dans le cadre de réformes politiques. Chaque régime d'État-providence génère des coalitions de soutien politiques spécifiques qui le stabilisent à l'aide de mécanismes institutionnels de feedback.

Dans la littérature comparée, la Suisse est en général assimilée au régime continental démocrate-chrétien, car elle met l'accent sur le principe d'assurance et finance l'État social essentiellement avec les cotisations salariales et les droits sociaux visent (en partie encore) la sécurité matérielle du pourvoyeur financier de la famille. Dans ce sens, la Suisse entretient un lien très étroit entre l'activité lucrative et les droits sociaux, un critère typique de ce genre de régime. Toutefois, en matière de configuration des différentes assurances sociales, la Suisse constitue bien plus un hybride des trois régimes de protection sociale. En effet, le premier pilier de l'assurance-vieillesse (AVS) correspond à une logique sociale-démocrate (égalitaire/universelle/redistributive), alors que le deuxième pilier équivaut à une logique continentale démocrate-chrétienne (préservation du statut/ financement par des cotisations/régression) et la forte position des assureurs privés de l'assurance-maladie et de la prévoyance vieillesse cadre avec la logique libérale. Herbert Obinger établit une localisation très détaillée des différents éléments qui constituent l'État social suisse dans son œuvre de référence consacrée à la politique sociale en Suisse. Ces «incohérences» institutionnelles s'expliquent par la forte fragmentation territoriale et temporelle dans la mise en place de l'État social suisse. La fragmentation fédéraliste de la Suisse a eu pour effet que les politiques sociales nationales constituaient souvent des agrégations de solutions cantonales préalables. En ce qui concerne les lignes de fracture historiques politiques et les systèmes de partis, les cantons constituent des contextes hétérogènes qui donnent naissance à différentes logiques de régime. De plus, sur le plan national, l'État social suisse n'est arrivé que très tard «à maturité», car certains éléments importants (tels que l'assurance-chômage obligatoire, le deuxième pilier, l'assurance-maladie obligatoire et l'assurance-maternité) n’ont été introduits que dans les années 1980 à 2000. À cette époque, la plupart des États sociaux se trouvaient déjà en phase de consolidation, ce qui a favorisé la création d'un hybride vu les tendances internationales de réforme et l'intensité des problèmes.

Dans le débat actuel, on ne constate pas seulement une tendance hybride en Suisse, mais dans tous les régimes de protection sociale européens continentaux. Ceci concerne en particulier le renforcement de la politique sociale «d'activation» (surtout dans la politique de chômage et dans la politique familiale), de l'individualisation (dans le cadre des droits sociaux équitables entre hommes et femmes) et des systèmes de garantie du minimum vital 
(en tant que réponse à des marchés de travail de plus en plus instables). Ces éléments de réforme ne suivent pas la logique traditionnelle du régime continental démocrate-chrétien, mais sont empruntés à la fois à la logique libérale et à la logique sociale-démocrate. Ils répondent néanmoins de manière ciblée aux besoins engendrés par de "nouveaux risques sociaux», qui n'avaient pas été anticipés dans ce régime de protection sociale continental (et qui résultent des lacunes de couverture de ces régimes). La signification empirique des réseaux institutionnels que représentent les régimes s'illustre justement par la lenteur et la lourdeur avec laquelle les régimes continentaux démocrates-chrétiens réorientent leur politique sociale. Non seulement les structures de pouvoir institutionnellement renforcées, mais aussi les normes et les attentes de l'opinion publique consolident et stabilisent les régimes d'État-providence.

\section{Silja Häusermann}

\section{Références}

Esping-Andersen, G. (1990). The three worlds of welfare capitalism. Princeton: Princeton University Press.

Häusermann, S. (2010). Reform opportunities in a Bismarckian latecomer: restructuring the Swiss welfare state. In B. Palier \& T. Alti (Eds.), $A$ long good-bye to Bismarck? The politics of welfare reform in continental Europe (pp. 207-232). Amsterdam: Amsterdam University Press.

Obinger, H. (1998). Politische Institutionen und Sozialpolitik in der Schweiz: der Einfluss von Nebenregierungen auf Struktur und Entwicklungsdynamik des schweizerischen Sozialstaates. Frankfurt a.M.: Peter Lang.

\section{Regroupement familial}

Le regroupement familial est un dispositif légal qui offre la possibilité à une personne étrangère de faire venir en Suisse les membres de sa famille en vue d'y poursuivre une vie commune. Le droit au respect de la vie familiale est garanti par l'article 8 de la Convention européenne des droits de l'homme et les articles 13 et 14 de la Constitution fédérale. La Suisse est donc tenue de le respecter. Si la Convention européenne des droits de l'homme ne garantit pas le droit d'entrer ni de séjourner dans un pays particulier, le droit à la vie familiale est toutefois touché lorsqu'un État impose une séparation de la famille ou lorsqu'il empêche celle-ci d'établir une vie commune, par exemple en cas de refus de prolongation d'une autorisation de séjour. Le droit à la vie familiale peut également être invoqué en cas de mariage ou pour l'octroi d'un visa. En cas de dissolution, le regroupement familial inversé peut être invoqué, s'il y a des enfants de nationalité suisse dont le parent exerçant l'autorité parentale est confronté au renvoi. Bien que le droit au respect de la vie familiale soit inscrit dans les bases légales internationales, européennes et nationales, la Suisse ne le garantit pas dans son intégralité à toutes les personnes étrangères.

La Suisse a commencé à réguler la question du regroupement familial au niveau législatif dès les années 1980, sa réglementation ayant été jusque-là très peu développée. Auparavant, le statut de saisonnier ne donnait pas droit au regroupement familial, ce qui avait pour conséquence que les parents proches séjournaient souvent illégalement. Ce thème est aujourd'hui traité dans différentes lois, en particulier la loi sur l'asile, la loi sur les étrangers et l'accord sur la libre circulation des personnes entre la Confédération suisse et la Communauté européenne et ses États membres.

La Suisse étant un État fédéral, la compétence en matière d'application des normes et des régimes du regroupement familial appartient aux cantons. Le droit fédéral prévoit des droits, respectivement des possibilités, de regroupements familiaux différents en fonction des statuts juridiques. Cependant, dans tous les cas, le respect d'un certain nombre de 
critères est nécessaire, par exemple un séjour régulier, un logement approprié ou des ressources financières suffisantes. La pratique des cantons révèle une grande diversité notamment dans l'utilisation et l'interprétation de concepts tels que «l'intérêt de l'enfant», les «raisons familiales majeures» ou encore les «besoins financiers». Ce dernier critère a pour conséquence l'exclusion des bénéficiaires de l'aide sociale ou des personnes risquant de devenir dépendantes de l'aide sociale du droit au regroupement familial.

Une des particularités du régime suisse concernant le regroupement familial est qu'il contient une discrimination des citoyen.ne-s suisses par rapport aux ressortissant·e.s des États membres de l'Union européenne (discrimination à rebours). En effet, lorsqu'une personne suisse demande le regroupement familial en faveur d'un·e ressortissant·e d'État tiers, des conditions strictes s'appliquent (regroupement familial des enfants jusqu'à 18 ans uniquement, pas de regroupement des ascendants) alors que les ressortissant $\cdot e \cdot s$ de l'Union européenne bénéficient d'un droit au regroupement plus large (enfants jusqu'à 21 ans ainsi que beaux-enfants et beaux-parents). Cette discrimination a pour conséquence des pratiques différentes suivant les normes juridiques qui s'appliquent.

Autre aspect essentiel développé par la jurisprudence et en particulier celle de la Cour de justice de l'Union européenne: le regroupement familial inversé. La question ici est de savoir si un parent étranger (regroupé) peut se baser sur le droit de séjour de son enfant mineur.e (regroupant) pour demander une autorisation de séjour. Durant plusieurs années, les autorités suisses ont refusé d'accepter cette possibilité mais, en 2009, le Tribunal fédéral a repris l'interprétation du regroupement familial inversé de la Cour de justice de l'Union européenne et a autorisé dans deux cas la délivrance d'un titre de séjour à des parents ressortissants de pays tiers dont l'enfant pos- sédait la nationalité suisse. Dans ces décisions, les juges fédéraux ont surtout mis l'accent sur l'intérêt supérieur de l'enfant selon la Convention relative aux droits de l'enfant et sa nationalité suisse qui lui permet de partir et revenir en Suisse.

Les débats autour du regroupement familial se focalisent sur deux questions. Tout d'abord celle de l'interprétation de la notion de famille et son traitement dans notre société. Cette question sensible se répercute sur l'interprétation du terme d'unité de la famille. Il s'ensuit que certaines réglementations prévoyant une définition stricte de la famille ont pour effet de laisser certains liens personnels sans protection. Un exemple actuel est la mise en œuvre de l'initiative populaire sur le renvoi des étranger-ère·s criminel·le·s, qui prévoit en général l'automaticité du renvoi avec des exceptions pour les cas de rigueur. Une telle pratique peut avoir de lourdes conséquences sur la vie familiale. La protection de la vie familiale, inscrite dans le droit international, est également remise en question par l'initiative populaire pour la primauté du droit national sur le droit international. Une dernière question est liée à l'augmentation des flux migratoires et à la séparation des familles pendant leur fuite. Le regroupement familial est d'une grande importance pour ces nouveaux.elles migrant·ess et devient, de ce fait, une «cible» des partisans d'une politique migratoire restrictive.

Cesla Amarelle \& Stefanie Kurt

\section{Références}

Amarelle, C., Christen, N. \& Nguyen, M. S. (Éd.) (2012). Migrations et regroupement familial. Berne: Stämpfli.

Amarelle, C. \& Nguyen, M. S. (Éd.). Code annoté en droit des migrations (vol. II, Loi sur les étrangers LEtr). Berne: Stämpfli.

Dubacher, C. \& Reusser, L. (2012). Le regroupement familial et les limitations au droit à la vie familiale. Berne: Observatoire suisse du droit d'asile et des étrangers. 


\section{Relations de travail (atypiques) ${ }^{*}$}

On appelle «relation de travail atypique» les formes d'activité qui sortent du cadre d'un «contrat de travail normal». Par «contrat de travail normal», on entend un engagement à durée indéterminée et à temps plein pendant la semaine, aux heures de bureau, sur un lieu de travail situé hors du domicile. Parmi les relations d'emploi atypiques figurent: le temps partiel, les engagements de durée déterminée, le (faux) travail indépendant, le travail à la maison, le travail de nuit ou le week-end, et le travail sur appel. Ces formes d'emploi, qui diffèrent du contrat de travail normal, se sont développées depuis les années 1980 dans toute l'Europe et sont devenues, en Suisse également, un phénomène relativement répandu (notamment le travail à temps partiel des femmes). On assimile parfois les relations d'emploi atypiques à des situations précaires : lorsqu'ils ne sont pas volontaires, lorsqu'ils restreignent la participation sociale, lorsqu'il en résulte des prestations sociales désavantageuses pour les personnes concernées ou lorsqu'ils s'accompagnent d'un bas salaire.

La période de prospérité inédite de l'aprèsguerre a conduit, en particulier pour les hommes, à une standardisation du parcours de vie, et par conséquent, à une standardisation des relations d'emploi. Dans la plupart des pays d'Europe, une grande partie des hommes en âge de travailler est employée à temps plein et pour une durée indéterminée, suivant des horaires réglementés et réguliers. Lorsque le moteur économique a commencé à se gripper dans les années 1970 et que la mondialisation a accentué la pression concurrentielle, de nombreuses entreprises ont tenté d'augmenter leur productivité par de nouveaux modèles de travail plus flexibles. Ces mesures, combinées à l'arrivée de plus en plus massive des femmes sur le marché du travail, ont entraîné un développement des relations d'emploi atypiques depuis les années 1980.
Le travail à temps partiel se décline en plusieurs variantes. Les emplois avec un taux d'occupation de 90 à $100 \%$ sont considérés comme du temps plein, les emplois à un taux inférieur à $10 \%$ comme un emploi minimal. On peut donc en déduire que le temps partiel désigne les taux d'occupation compris entre 10 et $90 \%$. Le temps partiel est particulièrement répandu chez les femmes et recèle des risques, surtout lorsque le taux d'occupation est inférieur à $50 \%$, par exemple lorsque ce taux est combiné à un engagement à durée déterminée, lorsqu'il réduit les opportunités de carrière ou lorsqu'il empêche d'accéder à certaines prestations sociales.

Les engagements à durée déterminée recouvrent tous les contrats de travail à durée limitée tels que les contrats d'apprentissage, les stages, les emplois de location de service et les contrats de travail limités dans le temps. Les employeur.euse-s ont recours aux contrats de travail à durée déterminée pour faire face aux fluctuations saisonnières et conjoncturelles de leurs activités; c'est la raison pour laquelle ils sont très répandus dans des secteurs tels que le bâtiment, l'hôtellerie et la restauration ou le tourisme. Mais on fait aussi appel aux engagements à durée déterminée dans les pays où les contrats à durée indéterminée sont associés à une protection particulièrement généreuse des employéee-s. Les entreprises y ont recours pour pouvoir réagir en souplesse aux fluctuations de la conjoncture et pour faire des économies à long terme. Souvent, ces relations d'emploi à durée déterminée concernent surtout les jeunes actifs. En particulier dans les pays où les personnes employées pour une durée indéterminée sont protégées, un fossé s'ouvre entre le noyau dur du marché, bien protégé, et le marché périphérique des personnes qui travaillent à durée déterminée.

Le travail indépendant et le faux travail indépendant font partie des formes de travail atypique qui font souvent débat. Il s'agit ici de freelancers, d'entrepreneur-euse-s indépen- 
dant.e.s ou de personnes participant à la sharing economy, qui n'ont pas d'autre employé qu'euxmêmes. Les indépendants sont seuls responsables de leur couverture sociale et ne peuvent compter sur les contributions paritaires des employeur-euse-s pour leur protection contre le chômage ou la maladie ou pour leur retraite. Dans certains cas bien précis, les faux indépendants ne travaillent que pour un seul client ou une seule cliente (ou quelques-uns seulement) et sont considérés par ces entreprises comme une solution alternative peu coûteuse à un emploi (parce que les charges sociales sont assumées par le·la travailleur·euse).

D'autres formes de relation d'emploi atypique reposent sur l'organisation temporelle $\mathrm{du}$ travail et sur l'autonomie du.de la travailleur·euse. Le travail régulier de nuit, le weekend ou en soirée sont des formes de travail atypique qui, en raison du décalage avec le contexte de vie des personnes concernées, peuvent avoir des répercussions négatives sur leur vie familiale et sociale. Outre le travail en équipe dans l'industrie et les métiers de ser-

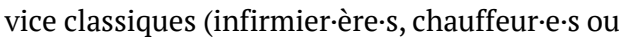
vendeur-euse-s), le travail de nuit et le weekend fait partie des quelques formes de travail atypique qui concernent également les cadres et les professions libérales (milieu médical, judiciaire, etc.). En général, ceux-ci bénéficient cependant d'une plus grande liberté pour l'organisation de leurs horaires irréguliers. Il reste enfin à mentionner le travail sur appel : dans ce cas, les travailleur.euse-s apprennent semaine par semaine ou dans des délais très courts s'ils vont travailler (heure par heure). Les entreprises ont recours à ce type de contrat pour faire face à des pics imprévus d'activité hebdomadaires ou quotidiens. Dans le travail sur appel, il convient de noter si le temps d'attente est rémunéré.

En Suisse, on observe deux particularités. D’une part, la Suisse présente, avec les PaysBas, le pourcentage de travail à temps partiel des femmes le plus élevé. Après la naissance $\mathrm{du}$ premier enfant, notamment, de nombreuses femmes passent au temps partiel ou reprennent un emploi à temps partiel après plusieurs années de pause familiale. Le temps partiel limite les opportunités de promotion et, dans le cas d'un emploi minimal (et donc de salaire minimal), peut empêcher les personnes concernées de se créer une prévoyance professionnelle.

Qui plus est, en raison de la réglementation relativement libérale du marché du travail, la différence entre contrats à durée déterminée et contrats à durée indéterminée est moins marquée en Suisse que, par exemple, dans les pays voisins que sont l'Allemagne, la France ou l'Italie. Comme les employé·e-s titulaires d'un contrat à durée indéterminée peuvent être assez facilement licenciés, les emplois à durée déterminée en Suisse ne sont pas forcément plus précaires que les autres. Par rapport aux autres pays européens, la Suisse se situe dans la moyenne pour la part des travailleur-euse-s sous contrat à durée déterminée ou des faux indépendants (l'Irlande, la Grèce et l'Espagne se classant en tête).

Les réformes sociales de ces dernières années, qui ont donné naissance à un État social activant, n'ont probablement pas été sans conséquences sur les franges atypiques et précaires du marché du travail. Reste à savoir si ces politiques donneront lieu, à moyen terme, à une nouvelle augmentation des relations d'emploi atypiques dont l'État social sera partiellement responsable. C'est sans compter l'évolution démographique, qui représente un deuxième défi de taille: la réforme du système de retraite suisse fera très probablement reculer l'âge du départ à la retraite et redéfinira aussi les contours de ce processus de transition. C'est pourquoi le recours aux formes de travail atypiques se multipliera sans doute à l'aube de la retraite. Pour cette période de la vie, il faudra donc trouver des solutions à moyen et long termes pour que «travail atypique» ne rime pas forcément avec «précarité» pour les travail- 
leur·euse-s d'un certain âge. Il convient enfin de noter dans quelle mesure la sharing economy (Uber, AirBnB, etc.) est devenue un défi, surtout en ce qui concerne la fausse indépendance. L'avenir nous montrera si ces nouvelles formes atypiques de travail peuvent être réglementées.

\section{Felix Bühlmann}

\section{Références}

Kalleberg, A. L. (2000). Nonstandard employment relations : part-time, temporary and contract work. Annual Review of Sociology, 26, 341-365.

Pelizzari, A. (2009). Dynamiken der Prekarisierung: atypische Erwerbsverhältnisse und milieuspezifische Unsicherheitsbewältigung. Konstanz : UVK Verlagsgesellschaft.

Rodgers, G. (1989). Precarious work in Western Europe: the state of the debate. In G. Rodgers \& J. Rodgers (Eds.), Precarious jobs in labour market regulation: the growth of atypical employment in Western Europe (pp. 1-16). Geneva: International Institute for Labour Studies.

\section{Relations de travail}

Les relations de travail (ou relations professionnelles) renvoient aux liens contractuels

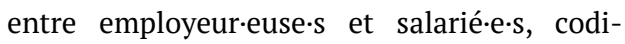
fiant les prestations fournies par la personne salariée en échange d'une rémunération. Ils en résultent des droits et des obligations réciproques pour les deux parties. Les relations de travail sont codifiées dans le droit du travail (code des obligations, loi fédérale sur le travail, conventions collectives de travail principalement) englobant à la fois la législation publique, mais aussi les accords privés négociés par les syndicats ouvriers et les organisations patronales. Les relations de travail peuvent être individuelles ou collectives : alors que les premières renvoient aux négociations entre une personne individuelle et l'entité qui l'emploie, les secondes se déroulent entre des organisations de salarié.e's et une entreprise ou une organisation patronale. La codification des relations de travail se joue ainsi à différents niveaux, de l'échelon national jusqu'au lieu de production.

Avec l'adoption de la loi fédérale sur les fabriques en 1877, la Suisse fait figure de précurseur sur le plan européen en matière de protection des travailleur-euse-s, en limitant la durée du travail et en édictant des mesures protégeant les femmes et les enfants. Cependant, en raison d'un État fédéral faible et d'une forte tradition d'autorégulation par les acteur-trice-s privé.e-s, la législation publique sur le travail est restée flexible et peu contraignante, tout en étant complétée par des conventions collectives de travail (CCT) adoptées par les organisations syndicales et patronales. Les négociations collectives, principalement au niveau des branches, représentent le fondement du partenariat social helvétique. Les CCT ont une grande importance en Suisse pour compléter la législation publique, en matière de salaires (en particulier des salaires minimaux), de temps de travail, de protection contre les licenciements, de certaines prestations sociales ou en matière de règlement des conflits. Outre leur rôle de partenaire social sur le marché du travail, les principaux syndicats et organisations patronales sont également étroitement impliqués dans les processus politiques, en particulier dans l'élaboration et la mise en œuvre des principales politiques et assurances sociales. Celles-ci furent dans un premier temps organisées sur une base purement privée et ne furent qu'ultérieurement et partiellement transférées à l'État fédéral (assurance-chômage, assurance-vieillesse et maladie notamment).

Même si les premières conventions collectives datent déjà du XIX siècle dans certaines branches bien précises de l'artisanat et de la petite industrie, ce n'est qu'au $\mathrm{XX}^{\mathrm{e}}$ siècle que les négociations collectives entre syndicats et associations patronales prennent leur essor et s'institutionnalisent. Jusqu'aux années 1930, les principales associations patronales refusent 
de négocier avec les syndicats et de signer des CCT. Le début du XX $\mathrm{X}^{\mathrm{e}}$ siècle est marqué par de nombreux conflits de travail, qui atteignent leur apogée avec la grève générale de 1918 . On assiste ensuite à une pacification progressive des relations de travail. En 1937, dans les deux principales branches industrielles de l'horlogerie et de la métallurgie et des machines, les organisations syndicales et patronales signent les fameux accords de paix du travail. Toutefois, l'immédiat après-guerre est encore marqué par de nombreuses grèves; ce n'est qu'au début des années 1950 que les conflits de travail diminuent fortement pour quasiment disparaître dans les décennies suivantes. Les CCT comportent très fréquemment des clauses de paix du travail, interdisant le recours aux mesures de luttes (grève pour les syndicats et lock out pour le patronat) durant la validité de la CCT. On distingue deux types de clauses de paix du travail, absolue ou relative, la première interdisant toute mesure de lutte alors que la seconde interdit les mesures de lutte portant sur des objets codifiés dans la CCT.

Les relations de travail se sont ainsi progressivement institutionnalisées et pacifiées durant la première moitié du $\mathrm{XX}^{\mathrm{e}}$ siècle. En raison de la centralité des organisations syndicales et patronales à la fois comme partenaires sociaux, mais aussi comme acteur-trice-s politiques en matière de politiques sociales et économiques, la Suisse a souvent été classée parmi les pays néo-corporatistes, comme l’Autriche ou les pays scandinaves. Toutefois, le taux de couverture par les CCT des salarié·e-s du secteur privé n’a jamais dépassé les $50 \%$, ce qui reste une proportion faible en comparaison internationale, notamment avec les pays scandinaves, mais aussi avec la France ou l'Allemagne. Beaucoup de secteurs économiques ne sont ainsi pas couverts par une CCT, principalement dans les services. Dans une perspective comparative, les relations de travail en Suisse se distinguent par leur décentralisation au niveau des branches, voire des entreprises ainsi que par leur stabi- lité et leur caractère pacifique. Les collectivités publiques n'interviennent pas (sauf exception en cas de conflits importants) dans le déroulement des négociations collectives des syndicats et des organisations patronales, qui disposent d'une très large autonomie dans ce domaine.

A partir des années 1990, dans un contexte de stagnation économique, on assiste à une certaine remise en cause du contenu normatif des CCT (salaires et temps de travail) sous l'impulsion des milieux patronaux, qui revendiquent une plus grande flexibilité des réglementations du marché du travail. Ces changements suscitent l'opposition et la mobilisation des syndicats, mais sans grand succès. Cette période est marquée par un durcissement des relations entre syndicats et associations patronales. La flexibilisation des relations de travail se traduit par une décentralisation des négociations collectives, de la branche vers les entreprises individuelles. Cependant, le taux de couverture par les CCT des salarié.e.s du secteur privé reste stable, voire progresse légèrement. Dans ce contexte plus difficile, les syndicats recourent plus fréquemment à l'initiative populaire pour essayer de faire aboutir leurs revendications (réduction de la durée du travail, introduction d'un salaire minimum, augmentation de la durée des vacances), sans toutefois obtenir de majorités populaires.

L'entrée en vigueur en 2002 des Accords bilatéraux avec l'Union européenne sur la libre-circulation des personnes s'est combinée avec l'adoption de mesures d'accompagnement visant à lutter contre les risques de sous-enchère salariale et des conditions de travail suisses. Ces mesures (extension facilitée du caractère obligatoire des CCT, loi sur les travailleur·euse-s détaché·e·s, édiction de contrats-types de travail) ont partiellement contrebalancé les tendances à la flexibilisation des relations de travail telles qu'amorcées durant les années 1990. Les syndicats revendiquent de plus nombreuses extensions du 
caractère obligatoire des CCT afin de limiter les risques de dumping salarial.

\section{André Mach}

\section{Références}

Aubert, G. (1989). Les conventions collectives et la paix du travail en Suisse. Revue internationale $d u$ travail, 128(3), 411-426.

Fluder, R. \& Hotz-Hart, B. (1998). Switzerland : still as smooth as clock work? In A. Ferner \& R. Hyman (Eds.), Changing industrial relations in Europe (pp. 262-282). Oxford: Blackwell.

Oesch, D. (2007). Weniger Koordination, mehr Markt? Kollektive Arbeitsbeziehungen und Neokorporatismus in der Schweiz seit 1990. Schweizerische Zeitschrift für Politikwissenschaft, 13(3), 337-368.

\section{Répartition de la fortune*}

La répartition de la fortune décrit la forme de distribution des fortunes - avant tout des biens matériels, des valeurs pécuniaires et des participations - entre des individus, des ménages, des groupes de population et des secteurs économiques, aux niveaux régional, national et mondial.

L'inégalité documentée de la répartition de la fortune est nettement plus grande que celle des revenus. Et elle l'est sans doute de facto plus grande encore. En effet, de nombreuses grandes fortunes sont pratiquement impossibles à cerner. La richesse est également un potentiel de pouvoir, qui permet d'imposer des intérêts particuliers en dépit de résistances. Des réseaux et des connaissances sont utiles. Le capital économique est primordial.

Par fortune économique, on entend l'ensemble des moyens et des biens dont des individus ou des groupes sociaux disposent. Des méthodes de calcul plus récentes incluent les avoirs de caisses de pension étatiques et privées. Cette approche est toutefois controversée, car ces avoirs sont principalement des salaires différés. La valeur réelle d'avoirs immobiliers est souvent négligée et leur valeur fiscale généralement inférieure à la valeur vénale.

Après la Seconde Guerre mondiale, le compromis politique libéral recherché entre capital et travail, qui visait entre autres objectifs la cohésion sociale, a amené un certain équilibre social. De larges couches de population ont pu améliorer leur quotidien matériel et s'employer à consommer davantage. L'heure étant à la prospérité, le capital et le travail étaient considérés plus ou moins d'égale valeur. Cependant, depuis la fin des années 1970, on assiste au développement d'un libéralisme économique d'inspiration anglo-saxonne, avec l'argent comme moteur, qui tente de justifier la répartition unilatérale de la richesse.

Le nouveau capitalisme financier vise la valorisation optimale du capital, en partant du credo que c'est le marché qui détermine la valeur du travail. Depuis, on observe le renforcement de quatre tendances. Premièrement, le chômage structurel augmente. Lorsque des machines remplacent le travail manuel, il en résulte en principe plus de temps et d'argent, et la productivité augmente. C'est dans la répartition que le bât blesse. Deuxièmement, les salaires, même s'ils augmentent en partie en valeur nominale ne suivent pas l'évolution des coûts de la vie. Corollaire : un nombre grandissant de travailleur.euse-s pauvres (working poor) et une précarisation des conditions de travail. Troisièmement, le système de la sécurité sociale est tout axé sur le travail rémunéré et ignore les nouvelles situations de vie. Nombre de personnes vivant seules, de familles monoparentales et de familles avec enfants se retrouvent en difficulté, aussi parce que les taux de la charge sociale et des prestations sociales n'ont pratiquement pas changé depuis le début XXI ${ }^{\mathrm{e}}$ siècle, alors que les valeurs patrimoniales ont plus que doublé. Quatrièmement, la fracture sociale tend à s'élargir au niveau des fortunes privées. Celles-ci continuent à se concentrer et le correctif politique démocra- 
tique ne peut empêcher la polarisation sociale que jusqu'à un certain point.

Le libéralisme politique antérieur voulait équilibrer les gains en capitaux extrêmes et les disparités sociales que le libéralisme financier accepte et privatise. Cette évolution caractérise le changement de paradigme actuel. Il y a disparité lorsque des individus ou des groupes sociaux sont très inégalement dotés de moyens et de biens convoités. En font partie, outre l'argent, le prestige, la prospérité et l'influence.

Les actifs financiers sont fortement concentrés et unilatéralement répartis dans le monde entier. Le coefficient de Gini est une mesure statistique de distribution qui varie de 0 à 1,0 signifiant l'égalité parfaite (tous possèdent la même chose) et 1 l'inégalité parfaite (un individu possède tout). En Suisse, le coefficient de Gini est de plus de 0,8 selon les statistiques officielles, ce qui place la Suisse aux derniers rangs pour ce qui est de l'égalité. En Namibie, en Afrique du Sud, en Russie et aux États-Unis les fortunes sont réparties de manière encore plus inégale. L'écart devrait néanmoins être plus marqué dans la plupart des pays, car les grosses fortunes sont souvent placées dans des oasis fiscales où il est encore et toujours possible de les cacher.

D'après les chiffres de l'organisation d'aide au développement Oxfam, en 2017, moins d'une douzaine de personnes possédaient plus de fortune que la moitié de la population mondiale réunie. Depuis les années 1980, cette inégalité de répartition s'est renforcée, tant au niveau mondial qu'au sein de nombreux pays. En Suisse, le plus riche 0,1\% de la population a nettement accru ses parts au volume total des actifs ces trente dernières années. Ainsi, les 300 personnes les plus riches ont sextuplé leur fortune nette imposable à plus de 600 milliards de francs, comme il ressort de l'édition $2017 \mathrm{du}$ traditionnel numéro spécial du magazine économique Bilan Les 300 plus riches de Suisse.

Selon le Rapport 2018 de l'Union syndicale suisse sur la répartition des salaires, des reve- nus et de la fortune en Suisse, $1,9 \%$ des contribuables les plus riches ont, en Suisse, autant de fortune nette à eux seuls que les autres $98,1 \%$, et le un pour-cent le plus riche détient plus de $42 \%$ de la fortune nette, incluant tous les actifs moins les dettes. Les $10 \%$ les plus riches possèdent trois quarts des richesses, les autres $90 \%$ se partageant le quatrième quart. Près d'un quart des contribuables n'a pas de fortune nette imposable du tout - un paramètre important du point de vue sociopolitique. À noter également la disparité par rapport à la moyenne: selon le Global Wealth Report 2017, publié par le Crédit Suisse, la fortune moyenne des Helvètes s'élève à plus d'un demi-million de francs.

La forte concentration de richesse en Suisse s'explique notamment par la faible taxation fiscale des fortunes et des successions. Les fortunes demeurent pour ainsi dire intactes du vivant de leurs détenteurs et passent aux générations suivantes pratiquement sans être entamées. $10 \%$ des héritier·ère-s reçoivent trois quarts du volume total des successions, alors qu'un tiers de la population n'hérite de rien. Autrement dit, celui qui a déjà reçoit encore plus. Les inégalités se trouvent ainsi cimentées, aussi parce que les baisses d'impôts favorisent les hauts revenus et les grandes fortunes. S’y ajoutent trois autres éléments: le fait que des salaires élevés génèrent plus de fortune, la hausse des gains privatisés et les paradis fiscaux internes qui profitent de l'afflux d'étranger·ère.s fortuné·e.s.

La densité de millionnaires est un bon indicateur de l'inégalité de répartition. En 2015, d'après les chiffres de l'OCDE, c'est en Suisse qu'elle est la plus élevée. Idem pour la densité des milliardaires. Sur les 300 personnes les plus riches de Suisse, plus d'un tiers sont milliardaire, et sur tous les milliardaires du monde, un sur quatorze vit en Suisse. Seuls $13 \%$ des Ultra High Net Worth Individuals, soit les individus qui détiennent une fortune d'au moins 30 millions de dollars, sont des femmes. De manière 
générale, les femmes sont nettement sous-représentées dans les segments supérieurs des revenus et des fortunes. En Suisse, les femmes gagnent en moyenne $25 \%$ de moins que les hommes. Et leur fortune privée est d'un tiers environ inférieur à celui des hommes, aussi si elles vivent en partenariat. Une fois de plus, les critères du genre et de la classe sociale s'additionnent. La répartition des richesses touche ainsi aux fondements mêmes de la démocratie.

Dans son livre Le Capital au XXI siècle, publié en 2014, Thomas Piketty décrit l'impossibilité d'équilibrer les inégalités en matière de richesse par la croissance économique après les années prospères d'après-guerre dans de nombreux pays. Le fait que le taux de rémunération du capital soit supérieur au taux de croissance de l'économie est à son avis le principal moteur de l'inégalité, une inégalité qui sape la paix sociale. Pour Oliver Nachtwey, les inégalités croissantes marquent aussi la «société des relégués» (Abstiegsgesellschaft). Une telle société est susceptible de favoriser des courants autoritaires qui font fi des fondements libéraux. Si cette évolution se poursuit, l'inégalité renforcera les antagonismes de classe et restreindra les droits sociaux - la répartition de la fortune est donc un enjeu sociopolitique majeur.

\section{Ueli Mäder}

\section{Références}

Mäder, U. (2015). Macht.ch: Geld und Macht in der Schweiz. Zürich : Rotpunktverlag.

Nachtwey, O. (2016). Die Abstiegsgesellschaft: Über das Aufbegehren in der repressiven Moderne. Berlin : Suhrkamp.

Piketty, T. (2013). Le capital au XXI ${ }^{e}$ siècle. Paris : Seuil.

\section{Répartition du revenu*}

La notion de répartition du revenu décrit comment, au cours d'une année, le revenu produit par l'ensemble de l'économie se répartit entre les différents membres de la société (individus, ménages) et facteurs de production (capital, travail). On distingue la répartition personnelle de la répartition factorielle du revenu: la répartition personnelle du revenu correspond à la répartition du produit (national) parmi les ménages privés et les individus, alors que la répartition factorielle (ou fonctionnelle) du revenu est la répartition entre les facteurs de production que sont le capital (part des profits) et le travail (part salariale). Habituellement, la répartition du revenu est observée au niveau national, parfois cantonal. Ce n'est que depuis peu que la répartition du revenu est étudiée au niveau mondial, c'est-à-dire sous l'angle de la répartition du revenu mondial parmi les individus et les ménages de la société-monde.

La répartition personnelle du revenu décrit les (différentes) conditions de vie matérielles des ménages ainsi que des citoyennes et citoyens au sein d'une société, fournissant ainsi des indications sur les inégalités de revenu existantes et les potentielles inégalités des chances. Cela vaut en particulier pour la répartition du revenu disponible d'équivalence des ménages, qui est le volume de revenus le plus pertinent pour la mesure des différences en matière de prospérité et de bien-être. On obtient le revenu d'équivalence des ménages en additionnant toutes les sources de revenu de l'ensemble des membres d'un ménage (revenu du travail, revenu du capital, transferts publics et privés), puis en déduisant les dépenses obligatoires (impôts, cotisations aux assurances sociales, primes d'assurance-maladie), et enfin en procédant à une pondération en fonction de la taille du ménage, selon des échelles d'équivalence. L'échelle d'équivalence la plus utilisée, l'échelle d'équivalence «modifiée» de l'OCDE, assigne la pondération 1 au premier adulte du ménage, puis la pondération 0,5 à chaque adulte suivant du ménage, et la pondération 0,3 aux enfants. La problématique de la mesure du revenu revêt une grande importance pour 
la question de la répartition du revenu (mais aussi de la mesure de la pauvreté) parce que les différentes méthodes de mesure, définitions du revenu et échelles d'équivalence influent notablement sur la répartition du revenu. Par exemple, les revenus des ménages sont répartis de manière plus équilibrée que ceux des individus. Les revenus disponibles oscillent aussi à l'intérieur d'une marge plus étroite que ce qu'on appelle les revenus primaires (revenus d'une activité lucrative et revenus du capital, sans prestations de transfert). En Suisse, le coefficient de Gini, qui est l'indice peut-être le plus connu pour mesurer les inégalités de revenu et présente une valeur comprise entre 0 (égalité parfaite) et 1 (inégalité maximale), oscille selon les sources de données et les années entre 0,26 et 0,30 en ce qui concerne le revenu disponible d'équivalence des ménages de ces dernières années (2010-2014), et entre 0,40 et 0,44 pour le revenu primaire. L'effet de la redistribution par l'État (par le biais de la politique sociale et de la progressivité de l'impôt) est donc considérable et se situe entre 0,10 et 0,18 point de coefficient de Gini. En comparaison internationale, la Suisse fait partie des pays présentant une inégalité de revenus plus faible que la moyenne : le coefficient de Gini du revenu disponible d'équivalence des ménages de tous les pays de l'OCDE est actuellement (2013) de $0,31$.

La répartition du revenu disponible a-telle changé ces dernières années? Les différences en matière de prospérité se sont-elles accentuées en raison de la mondialisation et de la mutation technologique? Pour la Suisse, on constate globalement que les inégalités du revenu des ménages sont actuellement à peu près égales à celles du début des années 1990. Toutefois, l'inégalité croît dans les périodes d'essor économique (1998-2001, 2003-2007) et reste stable ou connaît un léger recul lors des récessions (début des années 1990, 20022003, 2008-2009). Cet impact de la conjoncture tient d'une part à l'effet régulateur de la politique sociale, qui stabilise les revenus des ménages les plus modestes durant les années de crise (grâce à l'assurance-chômage, aux aides sociales et aux rentes de vieillesse dont le montant est en grande partie indépendant de la croissance économique); d'autre part, les revenus très élevés réagissent de manière plus sensible que les revenus moyens et faibles à la croissance économique parce qu'ils sont davantage déterminés par les revenus du capital et les bonus, eux-mêmes étroitement liés aux cycles boursiers. Toutefois, l'image de globale stabilité du revenu des ménages disponible est tempérée si l'on considère les revenus du travail individuels. Ainsi, les écarts salariaux se sont accentués ces dix dernières années en Suisse. Alors que les revenus faibles et moyens n'ont que légèrement progressé, les salaires les plus élevés, qui ont connu une augmentation supérieure à la moyenne, ont été le moteur de cette évolution. Mais la progression du travail à temps partiel et l'accroissement des inégalités des salaires horaires jouent également un rôle dans ce changement.

Plusieurs facteurs ont contribué au fait qu'en Suisse, les écarts salariaux des ménages se sont moins creusés que dans de nombreux autres pays ces dernières années. D'abord, l'augmentation du nombre de femmes exerçant une activité lucrative a réduit l'inégalité des revenus des ménages en Suisse. Ensuite, la proportion de ménages de petite taille (qui tendent à accroître l'inégalité des revenus des ménages) a augmenté moins rapidement en Suisse que dans d'autres pays. Enfin, la redistribution étatique par les rentes, les transferts publics et les impôts a légèrement progressé au fil du temps.

Dans presque tous les pays d'Europe, Suisse incluse, la répartition factorielle du revenu a évolué ces dernières décennies en faveur des détenteurs de capitaux. Selon plusieurs études, les détenteurs de capitaux des pays riches ont vu leur part au revenu global progresser de 15-25\% à 25-30\% entre les années 
1970 et 2010. Comme la précision des mesures varie, les données changent sensiblement en fonction de la source, du pays et des modalités d'ajustement. Il semble toutefois que la Suisse fasse partie d'un groupe de pays dans lequel la part salariale (part du revenu salarial au revenu global) a reculé plutôt faiblement, au contraire par exemple de l'Autriche, de la Norvège et de la Finlande. Les raisons invoquées pour ces changements à long terme de la répartition factorielle du revenu sont la mutation technologique, l'automatisation et la globalisation de la production. Cependant, l'évolution des rapports de force entre employeur.euse-s et employéee-s pourrait également avoir joué un rôle non négligeable.

La structure et l'évolution de la répartition du revenu ont des répercussions sociales et politiques immédiates: des différences de revenu trop importantes et en augmentation peuvent engendrer des fossés en matière de prospérité, des fractures sociales et des préjudices pour des groupes entiers de la population, et menacer durablement la cohésion sociale d'un pays. D'un point de vue de la politique sociale, la grande stabilité de la répartition du revenu des ménages disponible est donc une bonne nouvelle. Elle signifie qu'en Suisse, les tendances structurelles aux fractures et à l'exclusion et leurs conséquences sociopolitiques sont moins manifestes actuellement que dans d'autres pays. Mais cette situation sociopolitique favorable pourrait changer ces prochaines années, soit à court terme en raison de réformes politiques qui entraveraient des mécanismes ayant eu jusque-là un effet stabilisateur, soit à long terme en raison par exemple d'un recul persistant et accru de la part salariale. Enfin, il faut tenir compte, sur le long terme, de l'évolution technologique et démographique, propice au creusement des inégalités. Les effets régulateurs de la fiscalité et des transferts étatiques (jusqu'ici) considérables seront particulièrement importants à court et moyen termes. Ils pourraient se voir réduits notablement par des réformes fiscales (régressives) ou certains changements dans les prestations de politique sociale (p.ex. suppression de l'indexation des rentes AVS).

\section{Christian Suter}

\section{Références}

Modetta, C. \& Müller, B. (2012). Inégalité des revenus et redistribution par l'État: composition, répartition et redistribution des revenus des ménages privés. Neuchâtel: Office fédéral de la statistique.

Salverda, W., Nolan, B., Checchi, D., Marx, I., McKnight, A., Tóth, I. \& van de Werfhorst, H. (2014). Changing inequalities in rich countries: analytical and comparative perspectives. Oxford : Oxford University Press.

Suter, C., Kuhn, U., Gazareth, P., Crettaz, E. \& Ravazzini, L. (2016). Considering the various data sources, survey types and indicators: To what extent do conclusions regarding the evolution of income inequality in Switzerland since the early 1990s converge? In A. Franzen, B. Jann, C. Joppke \& E. Widmer (Eds.), Essays on Inequality and Integration (pp. 153-183). Zürich: Seismo.

\section{Resocialisation*}

La resocialisation fait partie des missions que le législateur a attribuées à la peine privative de liberté sans sursis. Malgré l'ambiguïté de ce terme, l'intention politique sous-jacente est suffisamment claire: l'emprisonnement ne doit pas être seulement une punition, il doit aussi aider le·la délinquant $\cdot e$ à adopter, après sa libération, un comportement socialement conforme et à s'intégrer dans le tissu social. Il faut donc agir sur le-la délinquant·e de façon à éliminer les déficits de socialisation ayant pu contribuer aux délits qu'il a commis. Le terme de resocialisation va donc plus loin que le simple respect de la loi ou que le fait de renoncer à commettre de nouveaux délits. Par des mesures appropriées, le-la délinquant·e doit assimiler et s'approprier les normes sociales existantes et apprendre à s'y plier. D’un point 
de vue historique et sociopolitique, la resocialisation s'oppose d'une part à la vengeance et à la dissuasion, et se distingue d'autre part du concept actuellement à la mode de désistance (la sortie consciente ou inconsciente d'une carrière criminelle) dans le sens où l'abandon d'un comportement criminel peut se produire en dehors ou en marge de la normalisation sociale. Comme la resocialisation fait référence à l'importance des processus sociaux comme source potentielle de criminalité, ce concept représente une alternative à l'idéologie du traitement surtout répandue dans les pays anglosaxons et aux modèles qui considèrent le comportement criminel comme l'expression d'une maladie.

L'idée, si non le terme, de resocialisation est aussi vieille que la peine privative de liberté elle-même: seuls les moyens employés pour atteindre cet objectif ont changé avec le temps. Depuis le siècle des Lumières et l'émergence de la philosophie utilitariste la prison est conçue comme une institution devant poursuivre des objectifs profitables pour la société, ce qui fait de l'enfermement une punition à la fois plus humaine et plus judicieuse. L'idée de resocialisation est revenue au premier plan après la Seconde Guerre mondiale, en particulier grâce aux initiatives de réformes déclenchées par les mouvements sociaux des années 1970 et sous l'effet des critiques émises à l'égard de l'exécution des peines. On a alors formulé l'hypothèse que les conditions d'emprisonnement étaient contre-productives : autrement dit, que la privation de liberté contribuait à reproduire la criminalité au lieu de resocialiser la personne. En même temps, des voix se sont élevées pour remettre en question l'efficacité des programmes de prévention pour les délinquants incarcérés, sous la devise de nothing works. Depuis, la resocialisation, en tant qu'objectif de la peine privative de la liberté, est repassée au second plan, sous la pression de l'opinion publique, et le besoin accru de sécurité dans la société. On réclame désormais une exécution des sanctions orientées vers les risques, ce qui permettrait de réduire la probabilité de récidive chez les personnes libérées de prison.

Dans le Code pénal entré en vigueur au $1^{\mathrm{er}}$ décembre 1942, l'objectif de la peine privative de liberté est décrit dans l'article 37. Conformément à cet article, l'application de la peine doit avoir un «effet éducatif sur le détenu et le préparer à son retour à la vie de citoyen », principalement en le guidant vers un travail correspondant à ses capacités. Ce qu'il faut comprendre par «effet éducatif» de l'exécution de la peine est laissé à l'appréciation de chacun. Le droit de l'exécution des peines a été largement remanié le $1^{\text {er }}$ janvier 2007, avec l'entrée en vigueur de la révision de la partie générale du Code pénal. L'article 75 stipule que désormais, l'application des peines privatives de liberté repose sur cinq principes: la prévention des récidives après exécution de la peine, la normalisation des conditions d'emprisonnement, la lutte contre les conséquences néfastes de la privation de liberté, le devoir d'assistance et la prévention des récidives pendant la période de privation de liberté. Certes, la privation de liberté est censée «améliorer le comportement social du détenu », mais cet objectif désigne moins la resocialisation du détenu que son adaptation aux normes pénales existantes dans le sens du respect de la loi. Au-delà de la redéfinition des objectifs poursuivis par l'exécution de la peine, cette révision laisse entrevoir un scepticisme à peine voilé quant à l'effet resocialisant de la privation de liberté. Cela apparaît clairement dans l'article 75, où l'on attend paradoxalement de l'emprisonnement qu'il répare les dommages qu'il cause, et surtout dans les arguments qui ont conduit à l'abolition des courtes peines privatives de liberté sans sursis. Dans le rapport de la commission d'experts comme dans le message accompagnant la révision, on souligne avec insistance le fait que les peines privatives de liberté de moins de six mois n'ont pas de sens, notamment «en raison de leurs répercussions sociales souvent négatives et de 
l'absence de possibilité d'effet resocialisant». En outre, il est précisé à juste titre que « tous les détenus n'ont pas besoin d'être resocialisés ».

Le scepticisme que suscite la mission de resocialisation semble justifié à différents égards. Premièrement, la part des délinquant·e·s qui récidivent après avoir purgé leur peine privative de liberté est relativement élevée. Selon les données de l'Office fédéral de la statistique, environ $50 \%$ des personnes libérées en 2008 ont été à nouveau condamnés dans les cinq ans suivant leur libération, et $20 \%$ ont de nouveau été incarcérées. Deuxièmement, la part des peines privatives de liberté de moins de six mois, qui laissaient peu de temps pour mettre en œuvre des mesures de resocialisation, reste très élevée en Suisse. Chaque année, 7360 détenu·e.s sur un total de 9224 (soit 80\%) restent incarcérés six mois ou moins. Environ 6000 délinquant.e.s (64\%) quittent l'établissement pénitentiaire après avoir purgé une peine de trois mois ou moins. Troisièmement, on peut se demander combien de délinquant.e.s présentent réellement des déficits de socialisation et sont accessibles aux efforts entrepris dans ce domaine. Cela pose surtout problème dans le cas des délinquant·e·s étranger-ère-s sans domicile en Suisse. $69 \%$ des incarcérations concernent des étranger-ère-s. Pour une population carcérale moyenne de 4583 détenu.e-s, $45 \%$ sont des étranger-ère-s sans domicile ou des demandeur.euse-s d'asile. Quatrièmement, on peut aussi se demander si la société postmoderne, caractérisée par une individualisation croissante et un assouplissement des normes sociales, est capable de définir des standards sociaux pouvant servir de référence à tout type de resocialisation. Enfin, il semble justifié de s'interroger sur la disposition d'une société qui poursuit l'idéal du risque zéro à accueillir de manière bienveillante les délinquant·e·s ouvert·e.s à la resocialisation.

On ne peut exiger de l'exécution d'une peine qu'elle résolve les problèmes que d'autres institutions (famille, école) ne sont pas parvenues à résoudre. Si l'on veut donner un sens à l'idée de resocialisation, il faut aussi tenir compte du fait qu'il faut accorder aux personnes concernées la liberté de réagir à la peine qui leur est infligée, et ce, même si cette réaction va à l'encontre des intentions du législateur.

\section{Claudio Besozzi}

\section{Références}

Laub, J.H. \& Sampson, R.J. (2001). Understanding desistance from crime. Crime and Justice, 28, 1-69.

Queloz, N., Luginbühl, U., Senn, A. \& Magri, S. (Éd.) (2009). L'objectif de resocialisation est-il toujours d'actualité? Berne: Stampfli.

\section{Responsabilité}

La notion de «responsabilité» est l'un des piliers de la politique sociale. Elle est étroitement liée à l'idéal de liberté qui fonde les droits aussi bien politiques (droit de vote, de référendum, etc.), civils (droit de conclure des contrats, etc.) que sociaux (droit à l'assurance-chômage, à l'aide sociale, etc.) des individus. C'est parce que nous sommes des êtres pourvus d'une certaine liberté que nous pouvons agir (nous mouvoir, donner notre avis, acheter des biens, etc.). Or, cet agir produit des effets qui impactent notre environnement et dont nous sommes (pour une part du moins) tenus pour responsables. Dit autrement, notre liberté et les droits censés la garantir impliquent une certaine forme de responsabilité.

Si tout le monde s'accorde généralement sur ce point, les avis divergent par contre fortement dès lors qu'il s'agit de définir plus précisément les contours de cette responsabilité.

Ainsi, la responsabilité peut être comprise aussi bien comme une mission à accomplir que comme une réponse à apporter à une situation donnée. Dans le premier cas, elle est tournée vers l'avenir. Il est alors attendu de la 
personne ou de l'institution responsable une contribution positive aux tâches ou devoirs qui lui incombent. Il peut s'agir ici aussi bien de préserver et de protéger (l'environnement, les personnes vulnérables, etc.) que d'innover (en proposant des solutions inédites à des défis sociaux majeurs p.ex.). Dans le second cas, c'est le passé qui prédomine, et la responsabilité est alors renvoyée à son origine étymologique (être responsable signifie littéralement «répondre de»). S'appuyant sur cette définition, certain.e-s estiment que chacun'e doit avant tout répondre de ses propres actes, assumer ce que il ou elle a fait ou omis de faire. Cette compréhension de la responsabilité, associée à des actes jugés moralement ou juridiquement condamnables, tend aisément à être assimilée à la culpabilité. Mais il est aussi possible d'envisager la responsabilité vis-à-vis du passé de manière plus large, en y intégrant les faits et gestes des autres individus. Ainsi comprise, la responsabilité se comprend comme la réponse que nous apportons au monde dont nous héritons : être responsable, c'est prendre en charge le système politique, social et économique qui nous est légué et que nous n'avons pas nécessairement contribué à forger.

La question de savoir si la responsabilité doit être assumée individuellement ou collectivement fait également souvent débat. La solution au problème du chômage par exemple doit-elle venir des individus concernés ou de la collectivité? Et s'il s'agit d'une responsabilité non pas seulement individuelle mais collective et partagée, quelle place et quel statut convient-il de donner à chacun des acteur-trice-s institutionnel-le·s? Faut-il faire une différence entre la responsabilité des organismes privés (entreprises, ONG, etc.) et la responsabilité publique et politique de l'État? Faut-il exiger de ces deux types d'institution le même degré d'engagement pour répondre aux défis de la politique sociale?

En lien étroit avec ces deux premiers points se pose la question de savoir sur quel objet pré- cisément se porte notre responsabilité. D'aucun'e-s soutiendront qu'il s'agit avant tout, voire même exclusivement, d'être responsable de soi-même (comme individu ou comme collectivité) et de veiller en l'occurrence à ce que les actions que nous menons assurent notre survie et notre bien-être. Pour d'autres, la responsabilité portera également sur autrui. Un «autre» dont les pourtours sont susceptibles de grandes variations, aussi bien spatiales que temporelles. Selon les approches, la responsabilité pour autrui pourra s'étendre à la terre toute entière, voire même aux personnes qui ne sont pas encore nées, ou s'arrêter aux frontières de la cellule familiale. Certain·e-s se sentiront ainsi responsables des conditions de vie des «leurs» (de leurs enfants, de leurs parents, etc.), mais pas de celles et ceux qui vivent à l'autre bout de la planète ni des générations futures.

Enfin, le rapport entre responsabilité, violence et moralité est également sujet à controverse. De l'avis de certain-e-s (qui trouveront dans les écrits de Machiavel et de Max Weber un appui), il semble évident que le fait d'endosser une responsabilité, et notamment une responsabilité politique, peut légitimer l'usage de la contrainte et de moyens moralement douteux. Ils estimeront ainsi par exemple que les membres d'un gouvernement sont en droit, en vertu de leur responsabilité, de faire appel à la force pour contrer des manifestant.e.s qui menaceraient l'ordre public ou d'utiliser le mensonge pour protéger la nation. D'autres, au contraire, défendront l'idée que la responsabilité est indissociable de la moralité et que l'on ne peut admettre qu'une personne responsable use de moyens immoraux pour parvenir à ses fins.

Ces diverses compréhensions de la responsabilité sous-tendent les différents modèles de politique sociale et les discours qui les accompagnent. Tous les partis en appellent à la responsabilité, mais tous ne partagent pas la même vision de cette dernière. Ainsi, selon 
les époques et les orientations politiques du moment, c'est plutôt l'une ou l'autre conception de la responsabilité qui tendra à s'imposer.

Qu'en est-il de la politique sociale aujourd'hui en Suisse? De manière générale, deux grandes tendances semblent se dessiner.

On observe tout d'abord une privatisation de la responsabilité ou, pour le dire autrement, un déplacement progressif de la charge sociale allant de l'État vers le domaine privé. Ce déplacement se manifeste dans le corps même de la Constitution fédérale: la notion de «responsabilité individuelle» y fait son apparition en 1999, au moment de la révision totale du texte. À sa lecture, il en ressort assez clairement que l'État assume un rôle subsidiaire à celui de l'individu qui, le premier, est responsable de luimême et de la société à laquelle il appartient.

L'examen des discours politiques et de l'évolution des lois permet par ailleurs de mettre en évidence le développement de toute une série de déclarations (publiques ou privées) et de modifications légales faisant appel à la responsabilité sociale (ou sociétale) des entreprises. Il est de plus en plus attendu que les employeurs et employeuses assument tout ou partie des coûts sociaux et environnementaux engendrés par leur activité économique. Ce phénomène s'observe dans le domaine de l'assurance-invalidité notamment, où les entreprises sont appelées à jouer un rôle toujours plus actif pour assurer le maintien en emploi et la réinsertion professionnelle des personnes affectées dans leur santé. C'est également dans cette perspective par exemple que s'inscrivent les « Principes directeurs relatifs aux entreprises et aux droits de l'homme» adoptés en 2011 par le Conseil des droits de l'homme de l'ONU et soutenus par la Suisse.

La privatisation de la responsabilité se manifeste enfin par la mise en place de mesures visant à inciter les individus à se prendre en charge et assumer eux-mêmes les risques économiques et sociaux (chômage, accident, etc.) auxquels ils pourraient être confrontés. C'est ainsi que se développent toutes sortes de discours invitant tout un chacun à contracter des assurances complémentaires (maladie, $3^{\mathrm{e}}$ pilier, etc.) ou des propositions visant à faire payer davantage celles et ceux qui, par leur comportement (alcool, fumée, nourriture, etc.), mettraient à mal les finances du système social. Cet accent mis sur la responsabilité individuelle (plutôt que collective) a pour corollaire une culpabilisation des personnes en situation d'échec (économique ou social) et induit une forme de désolidarisation à l'égard d'autrui et de l'espace public.

La seconde grande tendance que l'on peut observer est un élargissement de la portée à la fois géographique et temporelle de la responsabilité. Le développement des nouvelles technologies (génie génétique, nanotechnologies, informatique ubiquitaire, etc.) et la mondialisation, entre autres, font qu'il nous est de plus en plus demandé d'assumer les conséquences de nos actions au-delà des frontières et des époques. Cette tendance se traduit par exemple par des invitations de plus en plus pressantes à appliquer le principe de précaution ou à prendre en compte les générations futures dans les réflexions qui portent sur le financement des assurances sociales.

Cet élargissement de la portée de notre responsabilité est parfaitement cohérent avec l'idée qui veut que cette dernière soit intimement liée à notre liberté. L'amplification de notre pouvoir d'action sur l'environnement (naturel et humain) qui nous entoure et nous constitue fait d'une certaine manière de nous des êtres de plus en plus assignés à responsabilité.

\section{Céline Ehrwein}

\section{Références}

Arendt, H. (2005). La responsabilité collective [1968]. In H. Arendt, Responsabilité et jugement (pp. 173183). Paris : Payot. 
Ricœur, P. (1991). Postface. In P. Ricœur, Temps de la responsabilité: Lectures 1 (pp. 272-289). Paris : Seuil.

Weber, M. (1963). Le métier et la vocation d'homme politique [1919]. In M. Weber, Le savant et le politique (pp. 123-222). Paris : Plon.

\section{Responsabilité sociale des entreprises*}

Le concept de responsabilité sociale des entreprises, appelé aussi responsabilité des entreprises ou encore Corporate Social Responsibility (CSR), décrit l'intégration d'aspects sociaux et écologiques dans les activités entrepreneuriales ainsi que la responsabilité à assumer l'impact de ces activités sur la société. Il est essentiel que cette responsabilité s'inscrive dans une logique d'intégration au sein du cœur de métier de l'entreprise. Cela signifie que la CSR regarde comment les entreprises génèrent leurs bénéfices et non comment elles les utilisent au sens d'une «éthique de don».

La discussion autour de la responsabilité des entreprises s'est intensifiée et a gagné en maturité depuis les années 1980 en parallèle à la montée en puissance de la société civile, dans un contexte de mondialisation croissante et à l'occasion de conférences majeures qui se sont traduites par le rapport Brundtland (1987) ou d'autres documents liés à la Conférence de Rio (1992). Plusieurs scandales impliquant des entreprises durant ces trente dernières années ainsi que la crise financière mondiale à la fin de la dernière décennie alimentent et font progresser le débat.

Le monde politique, le monde économique et la société reconnaissent toujours plus souvent que, dans une économie mondiale, le développement durable ne peut plus relever uniquement de réglementations étatiques (règles du jeu) car celles-ci sont (à de rares exceptions près) généralement liées à la notion
d'État-nation et du droit national. La capacité limitée d'action des pouvoirs politiques et juridiques entraîne ainsi un déplacement partiel du niveau de responsabilité : au-delà des règles du jeu édictées par le monde politique, l'attention se porte toujours plus souvent sur la responsabilité des entreprises. Il faut y ajouter la notion de soft law qui recouvre toute une série d'initiatives générales ou sectorielles, visant à développer des solutions collectives à un échelon situé entre le politique et l'entreprise. Ces initiatives, qui ont tendance à impliquer moult acteur-trice-s différent·e-s, sont activées en partie par des entreprises et en partie par la société civile. Elles sont aussi appelées «initiatives multipartites» (multi stakeholder initiative).

La notion de Corporate Social Responsibility englobe une vaste palette de thèmes sociaux et écologiques, dont les conditions de travail, les droits humains, la protection de l'environnement, la prévention de la corruption, la concurrence loyale, la protection des consommateur-trice-s, les taxes et impôts, la transparence.

$\mathrm{Si}$, il y a encore quelques années, la responsabilité de l'entreprise était un concept totalement volontaire, comme le prévoyait notamment le Livre vert de la Commission européenne de 2001, la Commission européenne a retravaillé dix ans plus tard sa définition du concept en supprimant cette notion de démarche volontaire. Cela a constitué dès cette époque un signe avant-coureur de ce qu'allait devenir la pratique au sein de l'Union européenne (UE), à savoir l'obligation de rédiger depuis 2017 des rapports sur la CSR pour les entreprises d'importance publique majeure et comptant plus de 500 employé·e.s.

En comparaison avec la situation internationale et surtout en Europe, les débats politiques et médiatiques en Suisse sont caractérisés par une forte polarisation entre la «droite» et la «gauche» qui considèrent la thématique de manière critique, pour des raisons bien différentes toutefois. Les uns craignent qu'une CSR nuise à la politique économique libérale. 
Les autres y voient une tentative d'assouplir les réglementations et exigent des mesures juridiquement contraignantes. Dans sa prise de position officielle sur la CSR (2015), le Conseil fédéral a élevé la question de la responsabilité des entreprises à un échelon politique en Suisse aussi, embrayant ainsi le pas aux autres pays européens qui ont adopté cette logique depuis les années 2000. Si cette prise de position prévoit différentes mesures favorisant la responsabilité des entreprises en Suisse, elle n'exige toutefois aucun rapport obligatoire sur la CSR. Il faut désormais attendre de voir comment les différents projets se concrétiseront en pratique. Au-delà de cette initiative de Berne, toute une série de normes et d'orientations internationales revêtent également de l'importance pour les entreprises suisses: comme les normes d'élaboration des rapports de la Global Reporting Initiative, le Pacte mondial des Nations unies, la norme ISO 26000 , les recommandations de l'OCDE pour les entreprises multinationales, le cadre Ruggie en matière de droits humains ou encore les Sustainable Development Goals, pour ne citer que quelques exemples.

Volkswagen falsifie ses mesures d'émissions polluantes, les banques manipulent les indices financiers et la FIFA fait davantage penser à une organisation mafieuse qu'à une fédération sportive. Ce ne sont certes que quelques exemples des délits commis par des entreprises, mais ils placent la responsabilité d'entreprise en mauvaise position dans le débat public.

Pour faire avancer les choses de manière productive, il conviendrait dans un premier temps d'observer les pratiques entrepreneuriales de manière nuancée. Elles sont en effet extrêmement variées. Ainsi, certaines entreprises prennent la CSR au sérieux, l'intègrent efficacement dans leur organisation et appliquent aussi des critères sociaux et écologiques à leurs stratégies. D'autres confondent la CSR avec une posture de marketing et communiquent beaucoup à ce sujet, sans pour autant agir pro- portionnellement en interne. Enfin, il existe aussi des entreprises qui méprisent purement et simplement les questions sociales et écologiques, quand elles ne piétinent pas la notion même de responsabilité.

Il conviendrait par ailleurs de définir de manière adéquate le terme de responsabilité d'entreprise, afin qu'il ait un sens sur le plan normatif prenant son essence éthique au sérieux. Les débats académiques et publics tendent à envisager la CSR uniquement comme des options win-win, devant autant servir à la société qu'à l'entreprise. Cette approche en elle-même est irrecevable, dans la mesure où elle mélange les questions du «bien faire» avec celles de l'implémentation.

Troisièmement, tant les débats académiques que les pratiques des entreprises devraient davantage adopter une position proactive plutôt que défensive ou réactive vis-à-vis de la CSR. La responsabilité d'entreprise ne consiste en effet pas seulement à éviter des pratiques immorales (telles que la corruption, la falsification de bilans, etc.), mais aussi à se demander plus particulièrement quelle contribution les entreprises peuvent apporter à la société via de bonnes pratiques commerciales. Envisager la responsabilité des entreprises de manière proactive revient aussi à considérer les entreprises comme des acteur.trice-s politiques qui participent au processus de gouvernance ou Governance sociétale et contribuent à développer une politique (sociale) d'intérêt général.

Enfin, il serait bon de réfléchir plus en profondeur au rôle de la politique (et du droit) dans le contexte de la responsabilité d'entreprise. Des programmes d'action nationaux comme la prise de position du Conseil fédéral suisse sont un bon point de départ. Ils doivent toutefois être mis en pratique. Mais la politique (et le droit) ne doivent pas se limiter à des mesures d'encouragement de ce type, mais aussi appliquer les lois contraignantes ou hard law classiques via des mécanismes de pilotage. L'Allemagne a entamé des discussions au sujet 
du droit pénal des entreprises, la Suisses et d'autres pays européens auraient tout intérêt à faire de même. L'initiative multinationales responsables ouvrira peut-être cette voie.

Thomas Beschorner

\section{Références}

Beschorner, T. (2006). Social Responsibility of Firms. In J. Beckert \& M. Zafirovski (Eds.). International encyclopedia of economic sociology (pp. 618-622). London: Routledge.

Conseil fédéral. (2015). La responsabilité sociétale des entreprises: position et plan d'action du Conseil fédéral concernant la responsabilité des entreprises à l'égard de la société et de l'environnement. Berne: Confédération suisse.

Schneider, A. \& Schmidpeter, R. (Hrsg.) (2015). Corporate social responsibility: Verantwortungsvolle Unternehmensführung in Theorie und Praxis (2., erg. und erw. Aufl.). Berlin: Springer Gabler.

\section{Retraite}

La retraite décrit un mécanisme aujourd'hui généralisé régulant la sortie, partielle ou complète, du marché de l'emploi à un âge donné, plus ou moins flexible et précis, et ouvrant les droits à des prestations minimales de revenu. À l'origine, le terme a signifié "se retirer», tout en désignant le lieu dans lequel se faisait le retrait pour un court terme (lieu d'aisance) ou un temps plus long (quitter la Cour). Le terme recouvre des champs et des acceptions variables relevant autant du droit, des politiques publiques que de la pratique quotidienne. Le sens dominant actuellement prend ses racines dans le monde militaire et administratif, avec des expressions telles que «battre en retraite». Les représentations de la retraite ont varié dans le temps : durant les dernières décennies du $\mathrm{XX}^{\mathrm{e}}$ siècle, prendre sa retraite était un aboutissement, un objectif désirable et pour certains un refuge. Les traductions du terme en allemand (Ruhestand) ou en espagnol (jubilación) soulignent cette idée dominante de repos et de calme. À partir du début du XXI siècle, être retraitée a pris une signification plus dynamique que l'on dénomme communément, vieillissement actif.

Le droit à la retraite a constitué une des revendications clé des mouvements ouvriers avec la protection contre les accidents et la maladie durant la seconde partie du XIX ${ }^{e}$ siècle. Sa mise en place se fera toutefois par étapes, avec un premier pas franchi sous Otto von Bismarck en Prusse en 1883, qui instaure un régime de retraite obligatoire. Cette utopie ouvrière du XIX ${ }^{\mathrm{e}}$ se généralisera dans les pays occidentaux à partir des années 1945-1950. Une des idées qui préside alors à ce développement social est de permettre aux personnes âgées de vivre une fin de vie dans la dignité, en leur offrant un peu de repos. En Suisse, à cette période, l'espérance de vie moyenne à la naissance se situe alors aux alentours de 65 ans, légèrement plus pour les femmes, un peu moins pour les hommes. La durée de vie passée à la retraite est courte, moins de dix ans, lors de la mise en place du régime de l'assurance-vieillesse et survivants (AVS), en 1948.

Le changement essentiel, qui interviendra durant la seconde partie du XX $\mathrm{XX}^{\mathrm{e}}$ siècle, concerne la durée de vie à la retraite, laquelle a plus que doublé depuis sa mise en place. En sortant du marché de l'emploi, un·e salarié·e peut espérer une carrière de plus d'une quinzaine d'années dans son statut de retraitée.e. L'adaptation prendra cependant du temps et les taux d'activité demeureront élevés après l'âge de la retraite. D’un côté, les montants versés ne permettent pas un retrait total et immédiat du marché du travail. De l'autre, habiter ce droit prendra du temps. En 1970, un homme sur deux travaille encore à l'âge de 70 ans. Les rentes AVS ne couvrent que les besoins vitaux et cela insuffisamment. Pour un·e salarié.e qui n'est pas au bénéfice des prestations d'une caisse de pension, ne pas travailler après l'âge de la retraite signifie une chute brutale de son niveau de vie. 
Mais l'insuffisance des revenus versés n'explique pas à elle seule la longue phase d'adaptation nécessaire à la généralisation du régime de retraite. Une retenue sociale générale s'exprime face aux «risques» sociaux que présente le temps libéré de toute obligation de travailler. Les dangers de l'oisiveté liés à une vie sans activités rémunérées ont été maintes fois soulignés dans les débats parlementaires qui ont précédé l'adoption de l'AVS dans les années 1940 déjà. Le passage brutal d'une existence où le travail est omniprésent à une vie sans attache à l'emploi est thématisé comme présentant des risques tant pour la santé physique que psychique des travailleurs et travailleuses. Les dépressions et les addictions diverses sont largement évoquées. Le besoin de préparer la transition à la retraite pour organiser une existence libérée des obligations du travail généralise les cours de préparation à la retraite. Ce soin à anticiper les problèmes susceptibles de se poser aux futur.e.s retraité.e.s se justifie d'autant plus que la durée de vie post-retraite tend à s'allonger dès les années 1940. Il s'agit d'éviter la retraite-retrait et de favoriser l'intégration des retraité.e.s, d'abord par la consommation de loisirs, ensuite par la diversification des activités au service de la communauté, globalement qualifiée de vieillissement actif. Le maintien du lien social les encourage à favoriser les contacts intergénérationnels, spécialement en faveur des petits-enfants.

La crise des années 1970 a eu, entre autres, pour conséquence l'encouragement des retraites anticipées, faisant passer l'âge réel d'entrée en retraite en dessous de l'âge légal. La Suisse a été confrontée à ce phénomène plus tardivement et dans une moindre mesure que des pays comme la France ou la Belgique, et le phénomène a fortement régressé au tournant du XXI ${ }^{\mathrm{e}}$ siècle. Depuis, la transition à la retraite s'est complexifiée. Les sorties précoces du marché de l'emploi se sont maintenues, mais leur forme s'est diversifiée. Il faut ainsi distinguer les départs anticipés volontaires des retraites prématurées involontaires, des formes de retraites flexibles ou encore des carrières d'indépendant·e tardives. Par ailleurs, le nombre de départs à la retraite anticipée a fléchi, mais celui des travailleurs et travailleuses âgées au chômage s'est accru surtout parmi les chômeurs et chômeuses de longue durée. Elles et ils sont aussi plus nombreux à se retrouver à l'assurance-invalidité (AI) ou encore à l'aide sociale. On enregistre également moins de retraites anticipées, mais plus de licenciements: une partie croissante des travailleurs et travailleuses âgées peinent à se maintenir en emploi en fin de carrière professionnelle. Et pourtant, avec les années 2000, les autorités suisses comme les organisations d'employeur.euse-s ont multiplié les encouragements au maintien des employé·e·s âgé-e·s au sein des entreprises. L'objectif avoué est de valoriser une main-d'œuvre de qualité, l'or gris dont l'économie a besoin pour anticiper la pénurie qui semble menacer avec le départ à la retraite de la génération des baby-boomers. Comme ailleurs en Europe, il s'agit en particulier de lutter contre les représentations négatives envers les seniors au travail, l'âgisme qui marque fréquemment leur identité.

Pour les tenants du maintien des seniors en emploi, les personnes en fin de carrière professionnelle devraient rester plus longtemps au travail, entre autres pour favoriser le transfert des connaissances et pour mettre leurs compétences spécifiques à disposition des entreprises.

Dans ou hors du champ professionnel, les retraité.e-s sont très sollicité-e.s. Avec l'allongement de l'espérance de vie, elles et ils sont appelés à demeurer actifs, essentiellement pour rester intégrés et bénéficier d'un statut social. Le changement de paradigme est important puisqu'au repos, objectif primitif de la retraite, se sont substitués les multiples appels à un engagement en faveur de la famille ou du bénévolat. 
La problématique de la retraite s'impose comme une donnée majeure et complexe, d'une part parce qu'elle concerne un nombre grandissant de personnes et d'autre part parce que l'augmentation du nombre de bénéficiaires est essentiellement abordée en termes de charges socioéconomiques.

La situation financière des retraité.e.s pourrait ainsi constituer une source de préoccupation à l'avenir. Bon nombre d'entre elles et eux seront sans doute contraints de se maintenir en emploi, pour compenser les insuffisances de leur prévoyance professionnelle. Elles et ils pourraient être amenés à accepter des postes de travail instables, à temps partiel, assurer des remplacements, etc. voire des conditions de travail peu favorables ou adaptées à leur âge. Leur situation pourrait encore se péjorer si des propositions telles que l'élévation généralisée de l'âge donnant droit à la retraite devaient s'imposer. Les premières idées concrètes dans cette direction ont été avancées dans le cadre du projet Prévoyance vieillesse 2020, rejeté par le peuple en 2017.

\section{René Knüsel}

\section{Références}

Guillemard, A.-M. (2010). Les défis du vieillissement: âge, emploi, retraite - perspectives internationales. Paris : Armand Colin.

Knüsel, R., Bickel, J.-F., Steiner, B. \& Höpflinger, F. (Éd.) (2015). Transformation des politiques de retraite. Revue suisse de sociologie, 41(3), 341-515. Settersten, Jr., R. \& Angel, J. (Eds.) (2010). Handbook of sociology of aging. New York: Springer.

\section{Risques sociaux}

Les risques sociaux renvoient aux aléas de la vie qui rendent les individus vulnérables en réduisant leur capacité à travailler et en limitant ainsi leur intégration dans la société. On y a traditionnellement inclus les accidents du travail, la maladie, le chômage, le handicap ou encore la vieillesse. Les mesures de sécurité sociale mises en place dès la fin du $\mathrm{XIX}^{\mathrm{e}}$ siècle avaient ainsi pour ambition de protéger les individus des conséquences néfastes de ces risques. La notion de «nouveaux risques sociaux» est quant à elle associée aux changements socioéconomiques et démographiques des dernières décennies, l'instabilité du marché du travail et de la famille générant en effet de nouvelles formes de vulnérabilité. On y associe plus largement les difficultés liées à la conciliation entre travail et famille, particulièrement marquées dans les familles monoparentales, l'insécurité liée au travail, les risques de déclassement social, les problèmes de logement, ou encore l'exclusion sociale. Ces nouveaux risques sociaux qui se déclinent tout au long du parcours de vie sont au cœur des débats relatifs aux réformes de la sécurité sociale en Suisse et en Europe.

L'émergence de l'État social, telle qu'analysée par François Ewald dans son ouvrage L'État-providence, aujourd'hui classique, repose notamment sur une approche rationnelle du risque, rendue possible par l'accumulation de données relative à la vie collective. Au moment où les risques professionnels augmentaient en raison des développements de la société industrielle, le calcul des probabilités a permis de montrer que leur occurrence et conséquences étaient calculables à l'échelle d'une population. Cette approche a conduit à la mise en place en Suisse et ailleurs d'assurances sociales fondées sur le partage de la compensation du risque entre différents groupes sociaux, contribuant à un fonds commun permettant d'indemniser les victimes. L'analyse systématique des observations récoltées a ainsi transformé différents aléas en des faits objectivés pouvant être gérés à l'aide d'une règle de répartition de la charge et des dommages. Ces mécanismes d'assurance, reflétant une responsabilisation collective face aux problèmes sociaux, ont conduit à la reconnaissance des droits sociaux de différentes 
catégories de la population (les salarié·e·s, les personnes âgées, les personnes en situation de handicap, les chômeur·euse·s, etc.).

Cependant, dès les années 1970 cette appréciation rationnelle des risques sociaux s'ébranle. Tout d'abord, les conséquences négatives associées aux changements technologiques et socioéconomiques de la société industrielle sont dénoncées comme risque sans aucune possibilité de couverture. La «société du risque», telle que décrite en 1986 par Ulrich Beck, produit des risques (p.ex. le réchauffement climatique, un «accident» nucléaire, etc.) dont l'ampleur globale et le caractère imprévisible dépassent largement la capacité des régimes assurantiels à indemniser les victimes d'éventuels dommages.

D'autres transformations affectant les sociétés occidentales depuis la fin des Trente Glorieuse mettent directement en cause la logique de prévoyance du système de protection sociale. On citera ici certaines de ces transformations. Le vieillissement démographique crée de forts besoins en matière de régimes de retraite, mais aussi en matière de dépendance liée au maintien à domicile. Les transformations économiques ont été caractérisées par une plus forte implication des femmes dans le marché du travail, une plus grande instabilité des trajectoires professionnelles et une flexibilisation des conditions de travail. Le modèle de la famille nucléaire organisée autour de la division genrée des tâches professionnelles et domestiques a également évolué, en raison notamment de l'augmentation des divorces. Dans ce contexte, il est constaté que les mères qui élèvent seules leurs enfants sont particulièrement exposées aux risques de pauvreté, en raison de la difficile conciliation entre activité professionnelle et tâches domestiques. Enfin, l'allongement de la jeunesse est associé à une plus longue dépendance des jeunes envers leurs parents, renforcée par des parcours prolongés de formation, des seuils plus élevés pour l'entrée au marché du travail ainsi que pour certains jeunes par la non-obtention de diplômes scolaires qui affectera durablement leur trajectoire.

Associés à diverses formes de vulnérabilité qui concernent l'ensemble des parcours de vie, ces changements ont généré de «nouveaux risques sociaux». Ils fragilisent la capacité de prévoyance des personnes les plus vulnérables (chômeur-euse-s en fin de droit, parents célibataires, working poors, etc.) et posent un défi aux mécanismes traditionnels d'intégration sociale par l'emploi. En même temps, il y a un report de la responsabilité collective, inhérente aux régimes assurantiels, vers une individualisation du risque et de l'accompagnement social, basée sur des principes de rationalité économique et soutenue par des appels récurrents à la responsabilité individuelle.

Si depuis 1970 les dépenses sociales en Suisse ont été multipliées par cinq - avec une augmentation plus forte que la croissance économique et en 2012 des recettes supérieures aux dépenses - le système de protection sociale en Suisse demeure centré sur les risques sociaux traditionnels. Ainsi, les comptes globaux de la protection sociale confirment l'importance des dépenses liées à la vieillesse, la maladie et l'invalidité. La faible part des dépenses consacrées aux familles (moins de 10\% des dépenses) reflète, à titre d'exemple, le faible engagement de l'État helvétique par rapport aux défis posés par les transformations sociales des dernières décennies. Il convient de constater que les autorités fédérales oscillent, au détriment de politiques sociales plus égalitaires, entre une approche néolibérale, mettant en avant les limites de la responsabilité de l'État, et le maintien des acquis établis.

Les débats relatifs aux nouveaux risques sociaux doivent être situés dans l'inflation générale du recours à l'idée de risque au cours du XXe siècle. Cette inflation reflète la volonté de maîtriser les aléas futurs, évalués à travers l'analyse systématique des données du passé. Cette démarche initiée autour des mécanismes 
d'assurances sociales a soutenu la mise en place de dispositifs de gestion des risques dans de nombreux domaines (industries, catastrophes naturelles, transports, médecine...). Associés à une amélioration constante des conditions de vie et du bien-être, ces dispositifs ont influencé les attentes du public envers les institutions et les expert·e.s. C'est ainsi que l'on constate un décalage constant entre la réduction effective des menaces et une croissance exponentielle de la demande de sécurité.

Les sciences sociales ont par ailleurs souligné combien la gestion des risques dépend de l'acceptabilité sociale des risques, qui est définie par des acteur·trice-s sociaux-ales dans un contexte spécifique. Autrement dit, la définition des risques à prévenir et à compenser est contingente, amenant à des débats entre visions antagonistes. La question des «nouveaux risques sociaux» renvoie à des approches normatives définissant ce que l'État devrait faire ou ne pas faire pour assurer la protection des citoyens et citoyennes. Ainsi, la dénonciation des abus à certaines assurances sociales (chômage, invalidité et aide sociale) rend compte de ces valeurs, associées à des visions différentes de la responsabilité individuelle et collective. Le contrat social qui se met en place autour de la gestion des risques ne résulte donc pas simplement de la capacité à prédire les aléas du futur, mais d'un choix de société qui parvient à s'imposer à un moment donné.

\section{Claudine Burton-Jeangros}

\section{Références}

Bertozzi, F., Bonoli, G. \& Gay-des-Combes, B. (2005). La réforme de l'État social en Suisse: vieillissement, emploi, conflit travail-famille ( $2^{\mathrm{e}}$ éd. mise à jour). Lausanne: Presses polytechniques et universitaires romandes.

Office fédéral de la statistique (2015). Rapport social statistique 2015. Neuchâtel: Office fédéral de la statistique.

Ranci, C. (Ed.) (2010). Social vulnerability in Europe: the new configuration of social risks. Basingstoke Palgrave Macmillan.

\section{Salaire*}

Le salaire est l'indemnisation financière que les travailleurs et les travailleuses obtiennent pour leur travail. On distingue entre le salaire brut et le salaire net (après déduction des charges sociales) et entre le salaire nominal et le salaire réel (après ajustement à l'évolution des prix). En Suisse, les revenus salariaux représentent deux tiers du produit intérieur brut et sont la principale source de financement des assurances sociales.

Dans la théorie économique néoclassique, le salaire correspond à la productivité marginale du-de la salarié.e et donc à la valeur ajoutée supplémentaire réalisée à l'engagement d'un·e travailleur·euse supplémentaire. Cette théorie explique en partie pourquoi les ingénieurs reçoivent un salaire plus élevé que les machinistes. En réalité, des conceptions culturelles et le pouvoir de négociation jouent également un rôle dans la fixation des salaires. Dans les pays industrialisés, les hommes, les indigènes et les travailleur.euse-s organisé-e·s en syndicats ont généralement plus de pouvoir de négociation que les femmes, les étranger-ère-s et les travailleur.euse-s non syndiquéee-s.

En Suisse, l'avantage salarial en faveur des hommes vis-à-vis des femmes est tenace, même si l'article 8 de la Constitution retient l'égalité salariale des hommes et des femmes pour un travail de valeur égale. Alors que l'inégalité salariale entre les genres diminue lentement depuis les années 1990, l'écart entre les salaires les plus bas et les plus hauts s'est encore creusé entre 1994 et 2012. La raison de cette évolution est la forte croissance des salaires très élevés, plus spécialement dans les 1 et $10 \%$ les plus élevés. Pourtant, la Suisse fait partie des pays plutôt égalitaires d'Europe en matière de répartition des salaires, contrairement à ce qui est le cas pour la répartition des fortunes.

Dans la plupart des pays industrialisés, l’inégalité des salaires a fortement progressé 
depuis les années 1990 et la part des salaires $\mathrm{au}$ produit intérieur brut (PIB) a baissé au profit des revenus du capital. En Suisse en revanche, la quote-part des salaires n'a guère changé. Entre 1991 et 2010, elle est demeurée stable à $62-64 \%$ du PIB. Les considérations sur l'inégalité des salaires et la quote-part des salaires sont toutefois entachées d'incertitude sur le plan statistique, même si la situation en matière de données sur les salaires s'est améliorée depuis les années 1990, grâce surtout à l'enquête sur la structure des salaires menée tous les deux ans depuis 1994 par l'Office fédéral de la statistique auprès d'un vaste échantillon d'entreprises.

La Suisse est un des rares pays d'Europe occidentale à ne pas connaître de salaire minimum légal. Depuis les années 1990, un tel salaire minimum a été introduit en Allemagne (2015), en Grande Bretagne (1999) et en Irlande (2000). Entretemps, 22 des 28 pays membres de l'UE connaissent un salaire minimum légal. En Suisse, une initiative populaire sur l'introduction d'un salaire minimum de 4000 francs par mois a été rejetée en 2014.

Quoiqu'il en soit, la Suisse connaît elle aussi des règles de protection salariale. La grande majorité des conventions collectives de travail passées entre les organisations d'employeur-euse-s et les syndicats fixent des salaires minimum. Certaines de ces conventions prévoient des salaires minimum différenciés en fonction des qualifications et des régions, par exemple dans la construction, alors que d'autres n'en ont qu'un seul, par exemple dans le secteur bancaire. Environ $40 \%$ des personnes actives travaillent dans des branches et des entreprises qui connaissent un salaire minimum convenu par contrats collectif. Dans quelques branches, comme la construction, l'hôtellerie, le placement de personnel ou le nettoyage, les contrats collectifs sont déclarés de force obligatoire par le Conseil fédéral; dans ces branches, les salaires minimum s'appliquent aux employé·ess de toutes les entre- prises du pays ainsi qu'aux travailleur-euse-s détaché·e·s de l'étranger.

La protection des salaires a gagné en importance avec l'introduction, en 2002, de la libre circulation des personnes entre la Suisse et l'UE. Suite à la suppression des contingents, du contrôle administratif des salaires et de la priorité nationale, la notion de «salaire usuel » a été introduite dans le cadre des mesures d'accompagnement à la libre circulation des personnes. La loi sur les travailleur·euse-s détaché·e·s met les commissions tripartites nationale et cantonales engagées en 2002 en devoir d'intervenir si «au sein d'une branche économique, les salaires usuels dans la localité, la branche ou la profession font l'objet d'une sous-enchère abusive et répétée».

Dans les cas de sous-enchère systématique par rapport au salaire usuel, les commissions tripartites peuvent proposer deux mesures aux exécutifs national et cantonaux: déclarer de force obligatoire une convention collective de travail existante ou adopter un contrat-type de travail avec fixation d'un salaire minimal obligatoire. Un tel contrat existe au niveau national pour l'économie domestique ainsi que, dans quelques cantons frontaliers, pour des branches sans partenaires sociaux. Mentionnons à titre d'exemple le contrat-type pour cosméticiennes et cosméticiens en vigueur dans les cantons de Genève et du Tessin.

Les salaires usuels pour des profils de qualification spécifiques peuvent être déterminés avec les calculateurs de salaires interactifs de l'Union syndicale suisse ou de l'Office fédéral de la statistique. Le catalogue salarial du canton de Zürich (Lohnbuch des Kantons Zürich) donne une vue d'ensemble des salaires minimum et usuels pour les différentes professions et branches en Suisse.

Daniel Oesch 


\section{Références}

Amt für Wirtschaft und Arbeit des Kantons Zürich (Hrsg.) (2016). Das Lohnbuch 2016. Zürich : Orell Füssli.

Kuhn, U. \& Suter, C. (2015). L'évolution des inégalités de revenus en Suisse. Social Change in Switzerland, 2, en ligne. https://www.socialchangeswitzerland.ch

\section{Sanctions pénales}

Le système pénal, tel que nous le connaissons aujourd'hui, est fondé sur l'idée que la sanction pénale - qui représente l'aboutissement d'un processus judiciaire inventé par l'être humain en guise de réaction sociale à des comportements considérés comme inadéquats et érigés en crimes - devrait être propre à contrer la crimilité. Les buts de la sanction pénale peuvent ainsi être subdivisés en deux grandes catégories, à savoir les fonctions morales et les fonctions utilitaires. Parmi les premières, on trouve l'expiation (c'est-à-dire la purification de l'âme souillée par la commission d'une infraction) et la rétribution (soit la punition vengeresse faisant suite à une mauvaise conduite). Ces fonctions morales n'ont toutefois aucune utilité sociale. Ainsi, considérant que toute sanction pénale devrait être profitable à la société et/ ou exécutée de manière à servir de «leçon », on lui attribue également d'autres buts, plus utilitaires. Parmi ceux-ci, on trouve le maintien de la cohésion sociale et de la conscience commune (notion durkheimienne qui fait référence au fait de marquer, par la sanction, le pouvoir de l'État sur ses justiciables), la resocialisation (soit la réintégration sociale à la suite d'une prise en charge destinée à améliorer les compétences sociales d'un individu), l'intimidation (par l'effet dissuasif de la sanction sur la personne coupable - pour qu'elle ne soit pas tentée de recommencer - et sur les auteurs potentiels d'infractions que nous sommes tous - en nous insufflant une certaine «peur du gendarme »-), l'élimination (par l'infliction de la mort, par l'expulsion ou par l'enfermement à très long terme), la réparation (par l'obligation ou l'incitation à la réparation du dommage causé par l'auteur) et la réconciliation entre la victime et l'auteur (par l'intermédiaire d'un processus de conciliation ou de médiation, processus qui ressortent bien davantage de la justice dite restaurative que de notre justice rétributive).

Il existe deux catégories de sanctions pénales: les peines d'une part et les mesures d'autre part. Les premières ont pour vocation de «punir» l'acte commis dans le passé et sont donc généralement à quantum déterminé, alors que les secondes sont destinées à prendre en charge de manière particulière un délinquant·e particulier et sont dès lors à durée indéterminée, puisqu'elles seront maintenues aussi longtemps que nécessaire. C'est ainsi que si la peine ne suffit pas (notamment par ses effets intimidateurs et resocialisant) à écarter le danger qu'une personne ne recommette une infraction grave, et qu'elle nécessite un traitement ou qu'elle représente un risque trop important pour la société, les juges prononceront, en plus de la peine, une mesure thérapeutique institutionnelle ou un internement. Contrairement à ce que semble souvent croire le public, ces mesures n'ont dès lors aucun caractère punitif, puisqu'elles ne se centrent pas sur le passé de la personne et sur l'infraction qu'elle a commise, mais sur son avenir et celui de la société.

En matière de peines, la Suisse connaît, depuis le $1^{\mathrm{er}}$ janvier 2018, des peines pécuniaires (prononcées en jours-amende, soit un nombre de jours correspondant au degré de culpabilité de l'individu, chaque jour correspondant à un certain montant d'argent qui dépend de la situation financière de cet individu), des peines privatives de liberté (dont la durée est également fonction du degré de culpabilité et dont l'exécution peut s'effectuer sous la forme d'un enfermement en établissement pénitentiaire, sous la forme d'arrêts domiciliaires sous 
surveillance électronique ou sous la forme de travaux d'intérêt général) et des amendes (dont l'unité est le franc et dont le montant dépend de la faute commise et de la situation personnelle du·de la condamné·e). Par ailleurs, les peines pécuniaires et les peines privatives de liberté peuvent, si les conditions en sont réalisées, être assorties d'un sursis ou - mais pour les peines privatives de liberté seulement d'un sursis partiel, soit d'une suspension totale ou partielle sous condition de ne pas recommettre une nouvelle infraction durant un certain délai d'épreuve. Le sursis est dès lors une institution - dont le rôle premier est la dissuasion - consistant à placer au-dessus de la tête de la personne condamnée une épée de Damoclès, épée qui tombera à la moindre incartade de celle-ci.

En matière de mesures, la Suisse connaît aujourd'hui les mesures dites thérapeutiques institutionnelles (traitement des troubles mentaux, traitement des addictions, mesures applicables aux jeunes adultes), les mesures d'internement (ordinaire ou à vie), les traitements ambulatoires (soit l'équivalent du traitement des troubles mentaux et du traitement des addictions, mais sous la forme d'un traitement non-institutionnel) et les «autres mesures» (dont font notamment partie la confiscation, l'expulsion, l'interdiction d'exercer une activité, l'interdiction de contact et l'interdiction géographique).

L'une des questions les plus intéressantes, en matière de sanctions pénales, est de savoir si le but principal assigné à ces sanctions - soit le fait de juguler la criminalité - est atteint ou non. Les recherches criminologiques montrent, d'une part, que les effets d'une politique d'élimination (expulsion, peine de mort ou neutralisation par des enfermements à vie) sont extrêmement modestes, puisque la très large majorité des infractions sont commises par des délinquant·e-s primaires - qui n'auraient donc pas pu faire préalablement l'objet d'une élimination - et que, pour certaines infractions (dont font partie le trafic de stupéfiants, les homicides par des tueur-euse-s à gages, voire les actes dits «terroristes»), les criminel-le·s éliminé·e·s sont immédiatement remplacé·e·s sur le marché du crime par d'autres personnes. D'autre part, il a pu être démontré que des sanctions pénales démesurées peuvent conduire à une augmentation de la criminalité, plutôt qu'à la diminution logiquement attendue selon l'idée de l'effet dissuasif; c'est ce que l'on appelle le phénomène de brutalisation, soit l'exemple négatif montré par l'État qui désinhibe les citoyen·ne-s. C'est ainsi que l'on a pu observer que lorsque l'État procède lui-même à des exécutions capitales, il désinhibe les justiciables en les confortant dans l'idée que la violence est une manière adéquate de résoudre les conflits, accroissant par là le nombre de crimes violents; les homicides ont ainsi augmenté après la réintroduction de la peine de mort dans certains États américains, alors qu'ils n'ont pas évolué dans les États voisins n'ayant pas retouché leur système de sanctions. De la même manière, il n'est pas impossible que dans les États connaissant la prison comme peine centrale de leur système pénal, certains parents reproduisent le système étatique et enferment leurs enfants dans leur chambre lorsque ceux-ci ou celles-ci font des bêtises, commettant ainsi des crimes de séquestration...

C'est ainsi que s'il peut être démontré qu'au bas de l'échelle des sanctions l'effet dissuasif semble bel et bien exister (p.ex. en matière de circulation routière où les conducteur.trice-s respectent largement les limitations de vitesse et l'obligation de porter la ceinture de sécurité), il en va tout différemment au haut de cette échelle où l'effet dissuasif fait place à un effet inverse d'incitation au crime appelé brutalisation.

André Kuhn 


\section{Références}

Killias, M., Kuhn, A. \& Dongois, N. (2016). Précis de droit pénal général (4 éd.). Berne: Stämpfli.

Kuhn, A. (2009). Peut-on se passer de la peine pénale? Un abolitionnisme à la hauteur des défis contemporains. Revue de Théologie et de Philosophie, 14(2), 179-192.

Kuhn, A. (2010). Sanctions pénales : est-ce bien la peine? Et dans quelle mesure? Charmey: Les Éditions de l'Hèbe.

\section{Sans-abrisme ${ }^{*}$}

Sont considérées comme sans-abri les personnes vivant dans la rue, dans des lieux publics ou sans logement pouvant être qualifié comme tel. Les personnes accueillies dans des hébergements d'urgence et qui n'ont donc pas de domicile fixe et passent la nuit dans des foyers d'urgence ou dans des structures à bas-seuil, sont également considérées comme sans-abri. Cette définition est basée sur la typologie européenne de l'exclusion liée au logement (ETHOS, European Typology on Homelessness and housing exclusion). La typologie sensibilise au lien entre le sans-abrisme et la situation du logement et distingue donc les types suivants : «sans-abri», «sans logement», «en logement précaire» et «en logement inadéquat». Une personne est considérée comme sans logement lorsqu'elle a un abri dans des foyers d'hébergement temporaires ou permanents pour personnes sans domicile, pour femmes, pour étranger-ère-s (p.ex. des logements provisoires) ou lorsqu'elle n'est pas libérée d'une institution pénale, d'une institution médicale ou d'une institution pour enfants (homes) par manque de logement. Une personne est considérée en logement précaire lorsque, par exemple, elle est hébergée temporairement dans sa famille, chez des amis ou des connaissances, lorsqu'elle doit vivre avec son partenaire ou sa famille après s'être séparée de son-sa partenaire par manque de possibilités de logement, ou lorsqu'elle est menacée d'expul- sion. Une personne est en logement inadéquat lorsqu'elle vit dans des structures provisoires, dans des conditions de surpeuplement ou inappropriées.

Historiquement parlant, il existe plusieurs manières de désigner les personnes menacées ou touchées par le sans-abrisme. Et chaque désignation est étroitement liée à la compréhension de l'engagement social de l'État. Dans le mercantilisme, par exemple, on parlait de «mendiants» ou de «vagabonds» et on encourageait la mise en place d'un programme public qui, après un examen individuel, accordait des droits sous forme d'insignes de mendicité; quiconque mendiait ou vagabondait sans permission était passible d'emprisonnement ou de travail forcé. L'image pré-moderne des sans-abri en tant que «clochards» ou «vagabonds » est liée à la thèse que l'errance est une décision volontaire. Des thèses scientifiques comme celle de l'instinct migrateur génétique ont légitimé une attitude sociopolitique de ne pas devoir aider ces personnes. Le settlement movement avec ses maisons de quartier des années 1930 aux États-Unis, la désignation des sans-abri comme «frères de la grand-route» (Friedrich von Bodelschwingh) ou la Fondation Emmaüs du prêtre français Abbé Pierre après la Seconde Guerre mondiale ont fait figure d'offres compensatoires d'un État social émergent: les sans-abri étaient pris en charge, conseillés ou accompagnés dans leur réinsertion sociale par philanthropie ou compassion.

Ce n'est qu'avec l'apparition d'organisations intermédiaires dans l'État social moderne que la vision du sans-abrisme s'est élargie en faveur de la compréhension d'une situation de vie qui n'est pas simplement auto-infligée ou choisie, mais qui est aussi le résultat de conditions contextuelles. Le sans-abrisme est considéré ici comme une forme extrême de pauvreté et d'exclusion sociale. Le problème découlerait de toute une série de décisions sociopolitiques qui s'appliquent également à la Suisse: une politique du logement sans accompagnement 
social suffisant, une transformation radicale en un État social activant avec des programmes correspondants de segmentation et de réduction des prestations (p.ex. aide au logement), une gouvernance de la sécurité sociale dans laquelle les organes étatiques gouvernent par le biais de subventions jusqu'au niveau local (financement d'hébergements d'urgence, de soupes populaires, etc.); une précarisation des personnes peu qualifiées sur le marché du travail. Les sans-abri sont ensuite interprétés comme des groupes particulièrement vulnérables qui ont peu ou pas d'options d'action ou qui y ont accès difficilement.

Contrairement à la plupart des pays européens, le sans-abrisme est peu étudié en Suisse. Les quelques études menées sur le sujet établissent un lien entre des aspects liés à la santé et le sans-abrisme (toxicomanie, maladies mentales) ou mettent l'accent sur les compétences inadéquates en matière de logement des personnes touchées. Seules quelques problématiques sociopolitiques sont soulevées, par exemple dans les travaux qui se basent sur des parcours biographiques pour illustrer les processus d'exclusion sociale vécus par les sansabri ; ces travaux abordent, au moins en partie, les conflits sur l'espace public où vivent les sans-abri. Dans l'ensemble, les connaissances sur le sans-abrisme en Suisse sont mal structurées et peu différenciées. En ce sens, les estimations régulièrement publiées sur le nombre de sans-abri dans les centres urbains sont difficilement vérifiables.

La situation juridique actuelle de la protection des personnes sans abri montre clairement le faible niveau de prise de responsabilité de l'État social: la Suisse n'a pas ratifié la Charte sociale européenne, dont l'article 31 oblige les États à prévenir et à réduire l'état de sans-abri en vue de son élimination progressive. Dans l'article 41 de la Constitution fédérale (Cst.), la Confédération et les cantons s'engagent toutefois à ce que toute personne en quête d'un logement puisse trouver un logement approprié à des conditions supportables. Toutefois, on ne saurait en déduire l'existence d'un droit direct à une aide de l'État. À cet égard, les mesures de lutte contre le sans-abrisme se concentrent en particulier sur les instruments cantonaux et communaux d'aide en situation de détresse au sens de l'article 12 de la Constitution: les logements d'accueil et les foyers d'urgence. Les stratégies européennes telles que le programme social housing first, qui offre aux sansabri un logement sûr comme condition de base pour toutes les mesures d'aide ultérieures, ne se sont pas établies en Suisse.

La pénurie de logements et la hausse des prix, la fuite et les déplacements forcés, la migration de main-d'œuvre et le travail migrant, ainsi que les migrant.e-s sans papiers : tels sont les défis actuels qui interagissent directement avec le sans-abrisme et remettent cette question à l'ordre du jour de la politique sociale européenne. Les estimations d'Eurostat pour 2014 indiquent que sur les quelque 218 millions de ménages en Europe, environ $11 \%$ dépensent plus d'argent pour leur logement qu'ils ne peuvent se le permettre (Suisse: 10,6\%), qu'environ $17 \%$ des ménages vivent dans des conditions de logement inappropriées (valeurs limites: taille, qualité et sécurité du logement), que $14 \%$ des ménages sont situés dans des zones à risque sanitaire (valeurs limites: pollution atmosphérique, accès insuffisant ou nul à l'eau potable).

L'étude réalisée en 2015 par Bochsler et al. montre le lien étroit qui existe en Suisse entre la pauvreté et le logement: $82 \%$ des ménages en situation de pauvreté et $48,9 \%$ des ménages en situation de précarité vivaient dans un logement trop cher pour leur revenu en 2012 ; $12,6 \%$ des ménages en situation de pauvreté et $8 \%$ des ménages en situation de précarité vivent dans un logement trop petit.

Ces chiffres illustrent la vulnérabilité des personnes due aux formes de logement inadéquat en Europe. Le manque parallèle de données européennes sur l'ampleur quantitative 
et la structure du sans-abrisme est considéré comme grave.

Sur la base des rapports nationaux, la Fédération européenne des associations nationales travaillant avec les sans-abri (FEANTSA) et l'Observatoire européen sur le sans-abrisme ont, premièrement, observé de nouvelles formes de sans-abrisme, telles que l'hébergement à court terme et forcé chez des connaissances et des amis, notamment chez des jeunes (sofa surfing, hidden homelessness), deuxièmement, constaté le changement notable de la cause du sans-abrisme de même que le passage de causes individuelles à des causes structurelles (personnes en fuite, manque de logements abordables), et troisièmement, reconnu un vide juridique concernant les sans-papiers, qui ne peuvent pas se rendre dans un hébergement d'urgence de peur d'être signalés aux autorités compétentes en matière de migration et menacés d'expulsion.

Du point de vue de la recherche, on s'intéresse de plus en plus aux raisons pour lesquelles la plupart des États sociaux européens, y compris la Suisse, mais aussi la politique sociale européenne ne cherchent pas à obtenir des chiffres sur le sans-abrisme et pourquoi ils basent leurs mesures sur des estimations plus ou moins vagues. Des voix critiques pensent que ce manque d'intérêt pour la question est intentionnel: parce que les chiffres concrets sont des instruments puissants pour une politique de (d'in)justice sociale. En l'absence de chiffres ou de comparaisons possibles, l'État social peut avancer des arguments autres que les causes structurelles (ignorance ontologique).

\section{Matthias Drilling et Jörg Dittmann}

\section{Références}

Aldanas, M.-J., Coupechoux, S., Domergue, M., Owen, R., Spinnewijn, F. \& Uhry, M. (2017). Second overview of housing exclusion in Europe. Brussels: The Foundation Abbé Pierre \& FEANTSA.
Bochsler, Y., Ehrler, F., Fritschi, T., Gasserl, N., Kehrli, C., Knöpfel, C. \& Salzgeber, R. (2016). Wohnversorgung in der Schweiz: Bestandsaufnahme über Haushalte von Menschen in Armut und in prekären Lebenslagen. Bern: Bundesamt für Sozialversicherungen.

Marquardt, N. (2015). Counting the countless : statistics on homelessness and the spatial ontology of political numbers. Environment and Planning D: Society and Space, 34(2), 301-318.

\section{Santé}

La santé est une notion plurielle, aux contours multiples, associée étroitement à la représentation qu'on en a et au contenu qu'on lui attribue, à un moment donné et dans une société déterminée. Formellement, en 1948, l'Organisation mondiale de la santé (OMS) la définit comme un état de complet de bien-être physique, mental et social. Considérée jusque-là comme l'absence de maladie, elle est appréhendée désormais dans une acception large et évolutive. Ainsi, en 1986, la Charte d'Ottawa pour la promotion de la santé lui reconnait une nouvelle dimension: la capacité de l'être humain d'améliorer son état de santé. La santé se comprend dès lors non seulement en regard des systèmes organisés de dispensation des soins, des facteurs biologiques ou génétiques, mais aussi du cadre et des conditions de vie, qui influencent l'état de santé et le bien-être des individus. Parmi ces facteurs contextuels, on trouve la paix ou les situations de guerre, le statut social, le niveau d'éducation, l'activité professionnelle, le niveau de revenu, le logement ou la qualité de l'environnement.

Historiquement, la santé est longtemps appréhendée en regard de la pratique des soins. La relation médecin - patient y est prédominante, privilégiant l'approche curative au détriment d'une perspective de santé publique imposant d'accorder une importance prépondérante aux mesures préventives, donc à l'en- 
vironnement sociétal. Conséquence, dans la conception de la protection sociale relevant des normes de l'Organisation internationale du travail en matière de sécurité sociale (OIT 102, 1952), la santé renvoie d'abord aux soins, à l'organisation de la prise en charge des malades, accidentés ou invalides. Pour la population, les réponses médicales et techniques, allouées dans le cadre d'assurances sociales réglant les conditions d'accès aux soins et les coûts vont de soi.

Les choix politiques et les bases légales qui en découlent définissent la géométrie et l'intensité de la solidarité, les dimensions publique ou privée de l'organisation, les modalités et critères d'allocation des ressources (adéquation, économicité, efficacité, qualité, évaluation, planification). Schématiquement, la configuration des systèmes de santé peut se résumer en trois catégories. 1) Le système national caractérisé par un accès de l'ensemble de la population à des soins financés exclusivement par les pouvoirs publics et l'impôt (Grande-Bretagne, Italie, Danemark). 2) Le système d'assurance-maladie régi par une législation définissant une offre mixte de prestations, publique et privée. Le financement des organes d'assurance-maladie y est basé sur des primes et des compléments publics ou patronaux (Allemagne, France, Pays-Bas). 3) Le système libéral : l'offre de prestations et la couverture d'assurance sont d'abord du ressort d'organismes privés, des régimes spécifiques pouvant couvrir des catégories particulières de la population (États-Unis).

Pourtant, depuis la fin des années 1980, l'évidence scientifique démontre les limites du seul système de soins à l'amélioration de l'état de santé de la population. Alors que les facteurs environnementaux contribuent pour beaucoup à l'état de santé de la population (hygiène, prévention, etc.), les soins absorbent toujours la quasi-totalité des ressources affectées à la politique de santé. Une prise de conscience émerge cependant pour repenser l'alloca- tion des ressources du domaine de la santé de manière plus globale et cohérente. Il est désormais admis que tant le contexte au sein duquel vit l'individu que son statut socioéconomique ont un impact déterminant sur son état de santé. Les faits sont clairs : plus la position sociale d'une personne est élevée, meilleur sera son état de santé; moins le statut socioéconomique est favorable, plus les indicateurs de santé sont mauvais: espérance de vie plus courte, plus petite taille à la naissance, davantage de mortalité infantile, plus de tabagisme et d'alcoolisme, moins d'exercice physique et plus de surcharge pondérale, plus de maladies cardio-vasculaires et chroniques (diabète, arthrite, hypertension, maladies du foie, des reins, maladies respiratoires), plus de maladies mentales et de suicides, moins d'accès aux prestations préventives.

La santé et les politiques qui s'y rapportent s'articulent autour d'un certain nombre de législations, qui expriment la reconnaissance des problématiques, traduisent les types d'actions menées et déterminent les objectifs et les moyens disponibles. La Suisse ne se distingue guère des autres pays développés par les champs d'intervention qu'elle privilégie et les lois fédérales qui s'y réfèrent: pensions aux personnes blessées ou mutilées au service militaire (1852); professions de médecin, de pharmacien et de vétérinaire (1877); travail dans les fabriques (1877); épidémies (1886); denrées alimentaires (1905); assurance-maladie et accidents (1911, puis LAMal, 1994); stupéfiants (1951); assurance-invalidité (1959); subventions pour la lutte contre les maladies rhumatismales (1962); commerce des toxiques (1969); imposition du tabac (1969); protection de l'environnement (1983); protection de l'air (1985); protection des eaux (1991); produits thérapeutiques (2000); transplantations (2004). De plus, des législations cantonales régissent la prévention et la promotion de la santé, le droit des patients, l'organisation des 
institutions et des acteur-trice-s sanitaires, ainsi que les modalités de gouvernance.

Le domaine de la santé est ancré dans les principes institutionnels que sont le fédéralisme, le libéralisme, la subsidiarité, la décentralisation et la démocratie semi-directe. Ainsi, par exemple, la législation sur l'assurance-maladie comporte une double dimension. La première se fonde sur une législation sociale obligatoire pour l'ensemble de la population (LAMal). La seconde octroie aux assureurs la possibilité de proposer des assurances complémentaires privées. Particularité helvétique, l'assurance sociale est financée par des primes par tête, ne tenant pas compte de la capacité économique de l'assuré.e ou du ménage. Des subventions sous condition de ressources viennent en aide aux assuré-e-s économiquement modestes qui en font la demande. Les compétences opérationnelles se situant essentiellement au niveau cantonal, la Suisse ne dispose pas d'«une» politique nationale de santé, globale et cohérente. Les cantons disposent d'une marge de manœuvre importante dans l'application des législations fédérales. En découlent des pratiques diverses, tant en ce qui concerne la philosophie d'intervention que l'offre et le niveau des prestations.

L'ampleur et la diversité du champ de la santé induisent des défis nombreux et complexes. Garantir à long terme la protection et la prise en charge de la santé par des mesures accessibles à tou-te-s et répondant au principe d'allocation optimale des ressources suppose une modernisation des mécanismes d'organisation et de gouvernance de la politique sanitaire. Ce défi de l'innovation, auquel est associé celui du renforcement de la solidarité, devra par ailleurs tenir compte des intérêts contradictoires qui caractérisent la posture et les attentes des acteur.trice-s concerné-e.s. Pensons au désir de l'individu d'obtenir les meilleurs soins possibles dans un secteur aux ressources limitées ou à la maîtrise des coûts et des primes d'assurance alors que les intérêts financiers des professionnel-le·s de la santé, des cliniques privées ou de l'industrie pharmaceutique peuvent induire une augmentation des coûts.

Plusieurs problématiques constituent aujourd'hui des enjeux majeurs pour, d'une part, réduire les impacts négatifs sur l'état de santé de la population et, d'autre part, garantir une prise en charge de soins de qualité et financièrement supportable, tant pour les personnes que pour les autorités publiques. Mentionnons, par exemple, la protection de la santé (physique et psychique) dans le domaine de l'emploi, le vieillissement démographique, les maladies chroniques, le travail en réseau et l'interdisciplinarité, l'amélioration des modes de vie (hygiène, pratiques alimentaires, activité physique et lutte contre l'obésité) ou l'accroissement des symptômes psychiques chez les adolescents et les jeunes adultes. Enfin, l'essor des technologies médicales et des technologies de l'information (cybersanté) contribuera également au développement des systèmes de santé.

\section{Stéphane Rossini}

\section{Références}

Martin, J. (2014). Prendre soin: un médecin engagé dans le monde. Bâle: EMH Éditions médicales suisses.

Observatoire national de la santé (Éd.) (2015). La Santé en Suisse. Le point sur les maladies chroniques: rapport national sur la santé 2015 . Neuchâtel: Observatoire Suisse de la Santé.

Rossini, S. \& Legrand-Germanier, V. (2010). Le système de santé: politiques, assurances, médecine, soins et prévention. Lausanne: Presses polytechniques et universitaires romandes.

\section{Santé des personnes âgées}

Selon Le Grand Robert, la vieillesse est «caractérisée par un affaiblissement global des fonctions physiologiques et des facultés mentales ». Le risque d'incapacités ou de souffrir de mala- 
dies chroniques croit avec l'âge. La santé, par ses ruptures et défaillances, s'impose comme la source principale de changements de vie, elle est au cœur des préoccupations des personnes âgées. Mais ses manifestations et son évolution varient largement selon les individus et la dimension considérée (physique, fonctionnelle, cognitive, etc.). La santé est aussi une condition importante du bien-être, notion qui renvoie à une réalité plus large impliquant les conditions matérielles, l'environnement ou les liens sociaux.

Dans la seconde moitié du XXe siècle, l'évolution des sociétés occidentales a produit une embellie significative de l'état de santé, et plus en général des conditions de vie, de la population âgée. En même temps on a assisté à l'émergence du «troisième âge », fruit d'une dissociation progressive entre le moment de la retraite et celui de la sénescence. Le troisième âge s'offre aux individus comme une nouvelle étape du parcours de vie riche de potentialités, un cadeau dont on souhaite profiter, alors que la véritable vieillesse (le «quatrième âge») est repoussée vers un âge toujours plus avancé. Il faut cependant récuser l'opposition entre un troisième âge de tous les possibles et un quatrième âge plombé par tous les maux.

Dans les années 1970 et 1980, la vieillesse était le plus souvent vue comme un poids, aussi bien pour les personnes concernées elle rimait avec dépendance, mise à l'écart, voire «mort sociale» - que pour la collectivité. Dans les décennies suivantes, suite à l'émergence d'une vision plus positive, sont établies des politiques promouvant le vieillissement «réussi », actif, en bonne santé. Ceci se traduit en un discours préventif et dans la mise en place de stratégies qui valorisent l'activité physique et le bénévolat, le maintien d'une bonne santé ou encore l'alimentation saine, le tout dans le but de favoriser le bien-être des individus et réduire les effets du vieillissement (ou «vieillir sans devenir vieux», comme on peut lire dans un document de l'Organisation mondiale de la santé de 2002). Cette perspective, dans sa version plus radicale, fait l'objet de plusieurs critiques: d'une part, le «bien vieillir» risque de se transformer en une obligation et l'individu de devenir le seul maître de son propre vieillissement, en déresponsabilisant l'État; d'autre part, l'impression est que ces politiques prennent comme modèle le troisième âge mais montrent leurs limites en ce qui concerne le quatrième âge.

Depuis les années 1990, de nouveaux concepts ont surgi pour rendre compte de la condition des personnes très âgées. Le grand âge se caractérise par un processus de fragilisation qui très souvent déclenche un état de fragilité. La fragilisation correspond à une altération, progressive ou par à coup, mais inévitable avec l'avance en âge, des réserves de divers ordres: physiologiques, sensori-motrices, cognitives, etc. La fragilité, quant à elle, apparaît à partir d'un certain seuil d'insuffisance et affecte la résilience d'une personne, c'est-à-dire sa capacité à préserver un équilibre avec son environnement ou à le récréer à la suite d'événements perturbateurs. De nos jours, le trait commun du quatrième âge n'est ni la maladie ni la dépendance, mais une fragilité dont l'expérience peut prendre un caractère durable, a des implications importantes dans plusieurs aspects de la vie quotidienne et requiert la mobilisation de différents types de ressources: des savoirs faire et capacités d'adaptation de l'individu, aux aides de son entourage familial et amical, jusqu'aux apports de professionnels (services d'aides et de soins à domicile, foyers et hôpitaux de jour, EMS, etc.).

En comparaison internationale, en Suisse l'état de santé des personnes âgées est plus que satisfaisant. Selon une enquête sur la santé, le vieillissement et la retraite en Europe (SHARE), la Suisse présente des meilleurs scores par rapport au reste de l'Europe, avec un moindre pourcentage de personnes qui se disent en mauvaise santé ou qui ont des limitations dans les activités de la vie quotidienne, 
et une prévalence de la fragilité inférieure à la moyenne. Dans notre pays, une forte majorité des personnes de 65 à 80 ans jouissent d'une santé relativement bonne et mènent une vie indépendante; même au-delà, le fait de souffrir de dépendance chronique aux soins reste minoritaire. Et l'amélioration du bilan de santé au fil des décennies se poursuit en ce début de $\mathrm{XXI}^{\mathrm{e}}$ siècle, tandis que l'évolution est moins claire dans d'autres régions du monde: aux États-Unis, seuls les cas de handicap sévère ont connu une (légère) diminution au cours des années 1990, et la situation semble s'être stabilisée depuis 2000; dans certains pays d'Europe latine s'observent les effets néfastes de la Grande Récession.

Au-delà des tendances générales, il importe de souligner la grande hétérogénéité des situations de vie chez les personnes âgées. Tous ne vieillissent pas de la même manière et, même à âge semblable, les différences de santé entre les individus sont extrêmes (notamment selon genre et le statut socioéconomique). Elles résultent des parcours de vie distincts ainsi que des environnements physiques et sociaux traversés. Répondre aux besoins d'une population si diversifiée est loin d'être aisé et peut entraîner des politiques décousues.

Un autre enjeu des politiques sociosanitaires est représenté par la prise en charge de la fragilité. Notion par définition multidimensionnelle, elle appelle des réponses globales plutôt que de considérer chaque besoin séparément. Il convient également d'examiner les liens entre la fragilité et d'autres types de vulnérabilité, comme la précarité économique et la faible insertion relationnelle. Par exemple, la combinaison d'isolement social et fragilité peut se traduire en un fort sentiment de solitude et une grande anxiété. Mais si un réseau complexe de services est à disposition des personnes âgées pour faire face aux problèmes de santé, les réponses institutionnelles à la vulnérabilité relationnelle demeurent rares.
Enfin, il faut concevoir la santé des personnes âgées dans toute sa complexité, sans se limiter à la présence ou l'absence de maladie et incapacités, et en intégrant des dimensions plus subjectives. Les résultats de plusieurs études, transversales et longitudinales, menées en Suisse ont mis en évidence une aptitude remarquable des personnes du grand âge à réguler subjectivement l'impact de pertes liées à la santé, à rebondir malgré des ressources diminuées. Alors que l'état de santé tend à se dégrader au fil des ans, et cela presque toujours de manière irréversible, l'évaluation subjective que les individus portent sur leur santé reste étonnamment stable. Cette capacité d'adaptation a un impact positif sur le bien-être des personnes âgées. Les politiques publiques doivent donc envisager des mesures qui aident les personnes fragiles à faire face aux déclins associés au vieillissement, à reconstruire une vie quotidienne qui fasse sens.

Stefano Cavalli

\section{Références}

Höpflinger, F., Bayer-Oglesby, L. \& Zumbrunn, A. (Éd.) (2011). La dépendance des personnes âgées et les soins de longue durée scénarios actualisés pour la Suisse. Berne: H. Huber.

Lalive d'Epinay, C. \& Cavalli, S. (2013). Le quatrième âge ou la dernière étape de la vie. Lausanne: Presses polytechniques et universitaires romandes.

World Health Organization (2015). World report on ageing and health. Geneva : WHO.

\section{Santé mentale}

Selon l'Organisation mondiale de la santé (OMS), la santé mentale est un état de bienêtre dans lequel une personne peut se réaliser, surmonter les tensions normales de la vie, accomplir un travail productif et contribuer à la vie de sa communauté. 
La santé mentale (ou santé psychique) est un processus qui résulte d'interactions complexes entre différents types de facteurs:

> biologiques : facteurs génétiques ou physiologiques

> psychologiques: aspects cognitifs et affectifs

> socioculturels: relations au sein de la famille, à l'école, au travail, rapports de pouvoir au sein de la société, soutien social

> socioéconomiques: conditions de vie, revenu, formation, emploi, conditions de travail

> politiques et institutionnels: possibilité d'exercer ou de voir respectés ses droits fondamentaux, d'avoir accès aux ressources et aux dispositifs de soutien.

> L'ensemble de ces facteurs touche plusieurs secteurs pouvant influencer la santé mentale: la santé somatique, mais aussi le social (politiques sociales dont la politique de la jeunesse, de la vieillesse, familiale), l'économie et l'emploi, ou encore l'habitat, pour n'en citer que quelques-uns.

En effet, si la majorité de la population résidant en Suisse se sent en bonne santé psychique, selon les estimations, au moins une fois dans sa vie, chaque individu traversera une crise psychique, donnant lieu parfois à des troubles de santé mentale. Ceux-ci sont susceptibles d'affecter non seulement la sphère intime et quotidienne des personnes concernées et de leurs proches, mais aussi leur formation et leur vie sociale et professionnelle. Les conséquences peuvent aller jusqu'à l'invalidité ou au suicide. Les implications sont également importantes pour la société en termes de coûts directs et indirects (soins, assurances sociales, aide sociale, perte de productivité), Par exemple, les troubles de santé mentale représentent le motif d'invalidité le plus fréquent en Suisse. Dès lors, la santé mentale représente un enjeu et une priorité de santé publique. Le constat qu'il ne peut y avoir de santé sans santé psychique a infléchi et fait évoluer les conceptions de la santé ainsi que les politiques de santé publique, donnant naissance à une nouvelle branche, la santé mentale publique (Public Mental Health). Celle-ci, à partir des années 1990, a connu un nouvel élan à la suite d'un changement significatif de paradigme. Les interventions de l'État ont dès lors dépassé le champ traditionnel de l'hygiène mentale ou du champ psychiatrique, envisageant ainsi la santé mentale sous un double aspect: la santé psychique positive, c'est-à-dire l'autonomie, le bien-être, l'épanouissement personnel, et la santé mentale négative, c'est-à-dire la détresse psychologique suite à des événements de vie ainsi que les troubles de santé mentale. Par conséquent, la santé mentale publique articule :

> la promotion de la santé mentale, soit le renforcement des ressources personnelles et la création de conditions favorables à leur acquisition ou déploiement

> la prévention, c'est-à-dire la réduction des facteurs de risque et de l'incidence des troubles mentaux

> la planification, l'organisation et la gestion des structures et procédures de soins généraux et spécifiques ainsi que les dispositifs de réadaptation ou de (ré)intégration sociale pour les personnes souffrant de troubles de santé mentale

> la sensibilisation de la population et la formation des divers corps de métiers ainsi que la production de données étayées.

La mise en œuvre de ces composantes nécessite l'élaboration de programmes, dispositifs et mesures adaptés aux divers groupes de la population, aux différentes phases de vie et aux possibles événements critiques de vie. Le plan mondial d'action pour la santé mentale 2013-2020 vise, entre autres, à renforcer le leadership et la gouvernance en matière de santé mentale publique et à promouvoir des services de santé mentale et de protection sociale complets. Ces objectifs nécessitent l'engagement, l'action concertée et la collaboration étroite et coordonnée d'une multitude d'acteurs et d'ac- 
trices à différents niveaux (national, régional, cantonal, local) et dans des domaines ou secteurs variés (santé, social, formation, économie, urbanisme, mobilité, participation citoyenne).

En Suisse, faute de base légale, la Confédération ne mène que peu d'actions et la responsabilité d'œuvrer dans ce domaine revient principalement aux cantons. La moitié de ces derniers disposait en 2014 d'un programme de santé mentale, alors que 9 autres proposaient des actions sans programme spécifique. La Confédération intervient toutefois dans la statistique, via la production de données et le monitorage, dans l'assurance-invalidité qui octroi des rentes et soutient des mesures de réinsertion, dans l'assurance obligatoire des soins qui rembourse des prestations en cas de maladie psychique ou encore dans le droit du travail par le biais de la protection des travailleurs et travailleuses ou l'intégration des personnes concernées dans la politique de l'emploi. Le rapport du «Projet-dialogue sur la santé psychique» réunissant l'Office fédéral de la santé publique (OFSP), la Conférence suisse des directrices et directeurs cantonaux de la santé (CDS) ainsi que Promotion Santé Suisse (PS-CH) a identifié les besoins et les champs d'actions prioritaires suivants pour la Suisse :

> la sensibilisation, la déstigmatisation et l'information

> la réalisation d'actions de promotion de la santé, de prévention et de détection précoce

, la sensibilisation et la diffusion des bases scientifiques

> les structures et les ressources.

Le plan d'action pourra s'appuyer sur le Réseau Santé Psychique Suisse.

Plusieurs enjeux traversent la santé mentale publique dont la mise en place d'un système de pilotage intégré, susceptible d'anticiper les évolutions et de maximiser les ressources allouées en fonction des besoins et des réalités de différents types de bénéficiaires. L’amélioration de la coordination et des synergies entre acteurs et actrices impliquées dans le domaine de la santé mentale permettra d'assurer une meilleure prise en soin et un soutien adéquat des personnes concernées. L'intégration de celles-ci et de leur famille dans la planification et l'organisation des services contribuera à assurer la pertinence et la qualité des prestations offertes. Enfin, la poursuite des activités de sensibilisation du grand public et de formation de professionnel-le-s de champs divers, tout comme le transfert des connaissances, représenteront également des enjeux de taille.

Deux défis majeurs attendent la santé mentale publique en Suisse et les politiques pouvant contribuer à la promouvoir: d'une part, la mise à disposition sur la durée de ressources susceptibles de soutenir la santé psychique positive ou le dépistage précoce, tout en maintenant les politiques de psychiatrie intégrée; d'autre part, l'inclusion de la santé mentale dans l'ensemble des politiques sociales, de santé, de l'emploi, de la formation, de l'habitat, de la mobilité et, de manière plus large, dans tout dispositif susceptible d'influer sur la santé mentale d'une population (Mental Health in All Policies). Vaste programme, à l'heure où la prise en compte intégrale des dimensions psychiques de la santé est encore largement insuffisante aussi bien dans la recherche, la pratique, la formation que dans la politique et où les personnes souffrant de troubles psychiques sont encore stigmatisées et discriminées.

\section{Dolores Angela Castelli Dransart}

\section{Références}

Bürli, Ch., Amstad, F., Duetz Schmucki, M. \& Schibli, D. (2015). Santé psychique en Suisse: état des lieux et champs d'action. Bern: Office fédéral de la santé publique.

Mütsch, M., Schmid, H., Wettstein, F. \& Weil, B. (2014). Manifeste suisse relatif à la Public Mental Health. Olten: Santé publique Suisse.

Réseau Santé Psychique Suisse. http://www.npg-rsp. $\mathrm{ch} /$ 


\section{Santé sexuelle}

La santé sexuelle est un concept qui apparaît dans les années 1970 dans les travaux de l'Organisation mondiale de la santé (OMS). Il s'est depuis développé au niveau international à la croisée des champs de la médecine, de la sexologie, de la santé publique et des droits humains. La plupart des acteur.trice-s actuel-le-s s'appuient sur la définition de la santé sexuelle issue du Report of a Technical Consultation on Sexual Health de l'OMS de 2002 et 2006 pour développer des programmes d'éducation, de conseil, de prévention et de soins en matière de santé sexuelle.

Cette définition relaie une vision positive de la sexualité. Elle la considère comme une composante importante du bien-être et de l'épanouissement individuel qui a le droit d'être vécue sans contrainte ni discrimination et qui concerne à la fois les sphères individuelle et sociale. En tant qu'aspect central de l'être humain, la sexualité est présente tout au long de la vie. Elle ne se limite pas à la reproduction mais comprend le sexe biologique, l'identité et les rôles sexuels, l'orientation sexuelle, l'érotisme, le plaisir, l'intimité et la reproduction. Elle peut être vécue sous forme de pensées, fantasmes, désirs, de croyances, attitudes, valeurs, de comportements, pratiques, rôles et relations. Elle est influencée par des facteurs biologiques, psychologiques, sociaux, économiques, politiques, culturels, éthiques, juridiques, historiques, religieux et spirituels.

La santé sexuelle est dès lors un état d'équilibre dynamique en lien avec la sexualité et la reproduction. Pour être atteinte, maintenue et développée, elle doit être soutenue par des mesures qui agissent à la fois sur le renforcement des connaissances et compétences des individus (information, éducation sexuelle, conseil psychosocial, prévention, etc.) et sur le développement de conditions cadre sociales, économiques et juridiques favorables (accès aux prestations, défense des droits humains, mesures et législation de protection, etc.). La santé sexuelle est indissociable des droits sexuels. Ces derniers sont les droits humains liés à la sexualité et à la reproduction. Ils émanent des droits à la liberté, à la sécurité, à l'égalité, au respect de la vie privée, à l'autodétermination, à l'intégrité et à la dignité de tout individu. Les droits sexuels ne sont pas formalisés dans une déclaration politique mais ont été explicités par différentes organisations internationales comme en 2008 par la Fédération internationale de planification familiale (IPPF) ou en 2014 par l'Association mondiale pour la santé sexuelle (WAS). En tant que droits humains, ils sont des droits fondamentaux, universels, inaliénables et indivisibles qui doivent être respectés, protégés et garantis.

Si le droit à la santé sexuelle et reproductive fait partie intégrante du droit à la santé, il est indissociable d'autres droits humains (Comité des droits économiques, sociaux et culturels $2016 \mathrm{n}^{\circ} 22$, art.12). Il se traduit par le droit à vivre une vie sexuelle satisfaisante et agréable, exempte de toute forme de coercition, de discrimination et de violence, le droit à l'intégrité corporelle, le droit de choisir un.e partenaire, le droit aux relations sexuelles et au mariage consensuels, le droit à l'information et à l'éducation sexuelle, le droit de décider librement et de façon responsable du nombre d'enfants, de l'intervalle, du moment pour en avoir et des moyens pour y arriver, le droit d'accès aux services de santé sexuelle et reproductive. Au niveau international, depuis la Conférence sur la population et le développement du Caire en 1994, la santé sexuelle et reproductive ainsi que les droits ont été introduits dans différents accords ou programmes tels que le Programme d'action de l'ONU en faveur du développement durable à l'horizon 2030, la Stratégie 20162021 de l'ONUSIDA ou les Standards de l'OMS Europe pour l'éducation sexuelle en Europe (2010). Les droits sexuels sont aussi régulièrement utilisés comme outils de référence dans les processus d'évaluation des droits humains 
de l'ONU et la Suisse a ratifié différentes conventions, notamment celle sur l'élimination de toute forme de discrimination à l'égard des femmes (1979) et celle des droits de l'enfant (1989).

En Suisse, les prestations publiques de santé sexuelle se sont développées à partir de deux principales thématiques: la santé reproductive et la lutte contre le VIH/sida. Les mesures actuelles découlent essentiellement de la loi sur les épidémies du 28.09.2012 (LEp) sur laquelle repose le Programme national VIH/IST (PNVI), et de la loi fédérale sur les centres de consultation en matière de grossesse du 9 octobre 1981, base aux prestations en santé sexuelle, planning familial et éducation sexuelle. La santé sexuelle et les droits ne sont pas régis par une loi fédérale spécifique. Ils sont codifiés dans différents articles de la Constitution, du Code civil, du Code pénal ou encore dans des lois et directives d'application nationales ou cantonales. L'assurance-maladie obligatoire permet de couvrir une large gamme de soins médicaux incluant l'interruption de grossesse (article 119 - 120 du Code pénal) et tous les cantons offrent $\mathrm{du}$ conseil gratuit et confidentiel en lien avec la grossesse, la contraception et le planning familial ainsi que des prestations de prévention, dépistage et soins liés au VIH et autres infections sexuellement transmissibles. Ce dispositif est complété par des mesures liées au domaine de la violence, notamment sexuelle, essentiellement régi par le Code pénal suisse et la loi fédérale sur l'aide aux victimes d'infractions (LAVI) du 23 mars 2007. Existent aussi des programmes nationaux de lutte contre les mariages forcés ou de prévention de la violence chez les jeunes.

De manière générale, la population suisse bénéficie de prestations de bonne qualité en matière de santé sexuelle. Cependant, en raison de barrières linguistiques, de situations sociales défavorisées, de stéréotypes, de handicaps ou de lacunes législatives, les requérant·e·s d'asile, les personnes homosexuelles, trans* ou intersexuelles (LGBTI), celles vivant avec le VIH ou un handicap, les professionnel-le.s du sexe, ou certain.e.s migrant.e.s subissent des discriminations et ne bénéficient pas du même accès aux prestations que la majeure partie de la population suisse. Les personnes homosexuelles, trans* ou intersexuelles sont par exemple victimes de discriminations liées à des lacunes juridiques, notamment dans le droit privé, qui aboutissent à des traitements différents de celui des personnes hétérosexuelles. L'accès à certaines prestations, notamment à la contraception et à l'interruption de grossesse, reste précaire pour les femmes requérantes d'asile en raison du manque de prise en compte de la santé sexuelle dans les procédures d'accueil et de systèmes de financement souvent insatisfaisants. L'égalité d'accès aux prestations n'est pas garantie non plus en matière d'éducation sexuelle, dont la responsabilité incombe aux cantons. La lutte contre toute forme de discrimination liée au genre, à la sexualité ou à l'orientation sexuelle et la défense de l'égalité d'accès aux prestations pour tous les groupes de la population restent donc des priorités en Suisse.

Pour répondre aux défis actuels, les cadres existants ne sont toutefois pas suffisants. Le manque d'investissements dans la prévention, la promotion de la santé et le dépistage précoce, l'application différente des lois en fonction des cantons et l'absence d'une vision globale en matière de santé sexuelle amènent aujourd'hui la Suisse à réfléchir à l'opportunité de développer une stratégie nationale basée sur les droits. En ce sens, l'ancienne «Commission fédérale pour les questions de sida » a été renommée en 2012 «Commission fédérale pour la santé sexuelle». Dans la même année, elle a officialisé une première définition de la santé sexuelle pour la Suisse qui définit cinq domaines d'action prioritaires: santé sexuelle et santé psychique, santé reproductive, VIH et autres IST, violences sexuelles et éducation à la santé sexuelle. 
Cette compréhension de la santé sexuelle ouvre de nouvelles perspectives en vue d'une approche coordonnée et transversale aux politiques sanitaires, sociales, éducatives, d'égalité et d'intégration. Dans l'attente d'une stratégie nationale les cantons se mobilisent pour répondre adéquatement aux besoins. Preuve en est la publication Stratégie globale de promotion de la santé sexuelle. Guide pour une politique cantonale, éditée en 2016 par la Conférence latine des Affaires sanitaires et sociales (CLASS) en collaboration avec SANTÉ SEXUELLE Suisse, la Fondation qui promeut en Suisse la santé sexuelle et reproductive ainsi que les droits qui lui sont liés.

\section{Gilberte Voide Crettenand}

\section{Références}

Commission fédérale pour la santé sexuelle (2015). Santé sexuelle: une définition pour la Suisse. Berne: Commission fédérale pour la santé sexuelle.

Fédération internationale de planification familiale (2008). Déclaration des droits sexuels. London: Fédération internationale de planification familiale.

Tshibangu, N. \& Voide Crettenand, G. (2016). Stratégie globale de promotion de la santé sexuelle: guide pour une politique cantonale. Lausanne: Conférence latine des affaires sanitaires et sociales, SANTÉ SEXUELLE Suisse.

\section{Sécurité sociale}

On peut attribuer au gouvernement étasunien du président Franklin D. Roosevelt la popularisation du terme «sécurité sociale» suite à la promulgation du Social Security Act en 1935. Il renvoie à la fois à une institution (la «Sécu » en France, p.ex.) et à une conception du monde. Selon cette dernière, la compensation d'un risque, ou d'une éventualité dans le vocabulaire des juristes, ne ressort pas toujours de la responsabilité individuelle. Il y a une insé- curité liée à la vie en société et la protection contre les conséquences de la réalisation de ces risques sociaux est envisagée commeune des tâches de l'État.

Cette conception du monde n'a pas toujours dominé. Son origine remonte en Europe $\mathrm{au}$ «siècle des Lumières », durant lequel s'est répandue l'idée que des causes naturelles, génétiques, biologiques, épidémiologiques ou sociales expliquent la réalisation de certains risques. Ce processus de désenchantement du monde, comme l'a nommé Max Weber, a eu pour conséquence de rendre la compensation d'un risque social pensable en Occident: ce n'est pas aller à l'encontre d'une décision divine que de réparer les conséquences de la réalisation d'un risque en mettant en place une assurance. C'était un premier pas.

Mais pour que se développe une sécurité sociale, encore fallait-il, comme l'écrit Robert Castel, que le patronat accepte que le temps de la domination sans partage était révolu et que les organisations ouvrières renoncent au principe de la révolution anticapitaliste comme unique solution. L'État, qui entre la fin du $\mathrm{XIX}^{\mathrm{e}}$ siècle et la première partie du $\mathrm{XX}^{\mathrm{e}}$ siècle est devenu le mode légitime de gouvernement en Occident, a été appelé à jouer un rôle de tiers entre des intérêts de classes opposés en développant la sécurité sociale. Cela signifie que la sécurité sociale peut être analysée comme le résultat d'un compromis politique, comme une voie moyenne entre libéralisme et socialisme.

L'Organisation internationale de travail (OIT) est une illustration de ce compromis. Cette institution de l'ONU, qui regroupe depuis 1919 des représentant·e·s du patronat, du salariat et des États, a promulgué en 1944 une recommandation $\left(\mathrm{N}^{\circ} 67\right)$ demandant à ses membres de garantir de manière universelle les moyens d'existence. En 1952, elle a édicté une norme minimale de sécurité sociale $\left(\mathrm{N}^{\circ} 102\right)$ qui liste les 9 types de prestations constitutives de la sécurité sociale, soit les prestations médicales, les indemnités en cas de maladie, les 
prestations de chômage, de vieillesse, en cas d'accidents du travail et de maladies professionnelles, aux familles, de maternité, d'invalidité et de survivant.e.s. En 2018, 55 pays ont ratifié cette convention (surtout d'Europe).

Souvent présentée comme un «système», la sécurité sociale est d'abord un empilement de dispositifs hétéroclites développés pour des groupes spécifiques de population. Ils sont définis par leur rapport à l'emploi, comme les salarié.e.s ou certaines corporations professionnelles, par leur autorisation de séjour sur le territoire, par leur âge, comme les enfants et les personnes âgées, par leur statut matrimonial, comme les veufs et les veuves, par leur atteinte à la santé, comme les personnes malades, accidentées, et/ou invalides, etc.

La Suisse est un bon exemple de cet empilement de dispositifs. La première protection sociale de la Confédération helvétique, outre l'assistance publique organisée au plan communal ou cantonal, est la protection des militaires en 1901. En 1911, c'est l'assurance-maladie (facultative) et accidents (obligatoire pour certaines catégories de salarié·e-s) qui est acceptée. Des allocations pour perte de gain (APG) en cas de service militaire sont mises en place dès 1940, puis l'assurance-vieillesse et survivants (AVS) est édictée en 1946. Des allocations familiales pour la paysannerie sont introduites en 1952, l'assurance-invalidité (AI) en 1959, les prestations complémentaires à l'AVS/AI (une forme d'assistance) en 1965. Au début des années 1980, ce sont successivement l'assurance-accidents (1981), l'assurance-chômage et insolvabilité de l'entreprise (LACI) (1982) et prévoyance professionnelle (LPP) (1982) qui sont introduites. Le congé maternité voit le jour en 2004 et les allocations familiales fédérales en 2006. L'assistance publique est interprétée de manière très différente suivant les époques, les régions et les populations (résident·e-s régulier-ère-s, personnes dans ou hors du processus d'asile, personnes âgées, etc.), ce qui en fait une institution dont les contours sont flous. L'empilement de tous ces dispositifs n'est pas optimal et un des risques sociaux reconnus par l'OIT, la perte de revenu en cas de maladie, ne fait pas l'objet d'une assurance sociale fédérale.

Ajoutons que des révisions multiples de ces dispositifs ont eu lieu, qui ont parfois modifié profondément leurs populations cibles: par exemple en 1994 l'assurance-maladie est devenue obligatoire, ou en 2008 la nouvelle définition de l'invalidité a exclu de l'AI des personnes qui auparavant pouvaient prétendre à des pensions. Après plus d'une décennie de débats sous la coupole fédérale, le Parlement a renoncé en 2000 à une systématique pour se limiter, avec la loi sur la partie générale des assurances sociales, à les harmoniser sur le plan formel, à l'exception toutefois de la LPP. Le développement de la sécurité sociale en Suisse a ainsi suivi, dès l'échec de la loi Forrer en 1900, une logique plus politique que systématique, le possible dictant le champ du pensable.

La sécurité sociale helvétique est complexe, car un même risque, par exemple une atteinte à la santé, va être compensé, selon le statut de la personne touchée, par l'assurance-maladie, l'assurance-accident ou la protection des miliaires, l'assurance-invalidité, les prestations complémentaires et l'assistance publique pouvant également intervenir de cas en cas. La protection sociale est financée parfois par l'impôt (assistance publique ou protection des militaires, p.ex.), parfois par des cotisations sur les salaires qui peuvent donner l'impression d'une coopération entre patronat et salariat dans le financement de protection sociale (alors que les cotisations sont parties du salaire), parfois par des primes par tête (comme dans la LAMal). Des établissements différents gèrent la sécurité sociale: caisses de compensation dans l'AVS, institutions de prévoyance dans la LPP, caisses privées dans la LAMal, caisses publiques, patronales ou syndicales dans la LACI, etc. et les prestations financières ne sont pas identiques d'un dispositif à l'autre, y com- 
pris pour un même risque, par exemple l'accident ou l'invalidité. Cela va à l'encontre d'un des principes posés par William H. Beveridge dans son rapport de 1944, celui de l'uniformité des prestations de la sécurité sociale.

Outre sa complexité, la sécurité sociale protège de manière inégale les personnes qui résident en Suisse. Le personnel stable et salarié de manière régulière est le mieux couvert, tandis que les personnes au foyer et les travail-

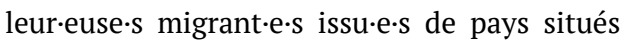
en dehors de l'UE sont globalement les grands perdants de cette organisation. De la sorte, la métaphore de la sécurité sociale fait globalement l'impasse sur les asymétries sociales à l'origine des problèmes sociaux pour mettre en scène une communauté de risques auxquels elle prétend répondre.

\section{Jean-Pierre Tabin}

\section{Références}

Castel, R. (1995). Les métamorphoses de la question sociale: une chronique du salariat. Paris: Fayard.

Esping-Andersen, G. (1999). Social foundations of postindustrial economies. Oxford: Oxford University Press.

Weber, M. (1967). L'éthique protestante et l'esprit du capitalisme. Paris: Plon.

\section{Sécurité sociale des enfants et des jeunes*}

Les enfants et les jeunes bénéficient d'une protection particulière dans la législation sociale, découlant de la législation sur la protection des travailleur.euse-s du XIX ${ }^{\text {e }}$ siècle et conforme aux obligations internationales et constitutionnelles. Les assurances sociales et, au niveau cantonal, l'aide sociale jouent un rôle important pour tout ce qui concerne leur santé et leur développement physique ainsi que leur éducation et leur formation professionnelle.
Ils sont tous assujettis à l'assurance-vieillesse, survivants, invalidité et maladie, pour autant qu'ils remplissent les conditions d'assurance déterminantes et ont droit, en situation de détresse, aux prestations sociales cantonales. Si un jeune travaille ou reçoit un salaire d'apprenti ou de stagiaire, il bénéficie également d'une protection en vertu de la loi sur l'assurance-accident et de la loi sur l'assurance-chômage. À partir d'un certain niveau de revenu, il est également assuré à titre obligatoire auprès de la prévoyance professionnelle. En outre, les parents qui touchent une rente de vieillesse ou d'invalidité perçoivent une rente pour enfant dans certaines branches des assurances sociales.

En cas de maladie, d'accident et d'infirmités congénitales mineures, les mesures médicales (traitements ambulatoire et stationnaire, médicaments, mesures thérapeutiques reconnues diverses, moyens et appareils, transport) sont remboursées en nature principalement par l'assurance-maladie (AMal). Si une atteinte à la santé est liée à une infirmité congénitale grave figurant sur la liste des infirmités congénitales, ou s'il s'agit d'une maladie à stabiliser qui a des répercussions sur la capacité de réinsertion professionnelle, l'assurance-invalidité (AI) couvre les frais médicaux jusqu'à un certain âge (20 ans révolus), à la suite de quoi c'est l'assurance-maladie qui s'en charge. Si un jeune qui travaille est victime d'un accident ou d'une maladie professionnelle, l'assurance-accidents (AA) s'en charge en tant qu'assurance des employéee-s. Pendant la durée du service obligatoire, l'assurance-militaire couvre tous les frais médicaux occasionnés par une maladie ou un accident.

En ce qui concerne les mesures professionnelles, l'AI soutient les enfants et les jeunes souffrant d'une atteinte à la santé en les accompagnant lors de leur entrée dans la vie active et en prenant en charge les coûts de leur formation professionnelle initiale ou de leur reconversion. En cas de chômage dû à la situation sur 
le marché du travail, l'assurance-chômage offre aux jeunes qui sortent de l'école ou sont au chômage un accès à des mesures du marché du travail (mesures de formation et programmes d'occupation) et couvre les coûts des cours et de la formation continue; en revanche, elle ne prend pas en charge les frais liés à l'absence de formation initiale ou de base.

Les enfants ont droit à des prestations en espèces s'ils ont constamment besoin de l'aide supplémentaire d'autres personnes pour accomplir les tâches quotidiennes, comme s'habiller, manger, se laver, se déplacer et entretenir des contacts sociaux avec des enfants de leur âge. Selon le degré d'impotence (faible, moyen ou grave), l'AI verse une allocation pour impotent, ainsi qu'un supplément pour soins intenses en cas de soins permanents et/ou de surveillance personnelle de mineur.e-s à domicile. Dans certaines circonstances, les enfants mineur.e.s en formation peuvent également demander une contribution d'assistance. Pendant la mise en œuvre des mesures d'insertion médicales ou professionnelles de l'AI, les assuré·e·s ont droit à une indemnité journalière au plus tôt à partir du premier jour du mois suivant leur $18^{\mathrm{e}}$ anniversaire s'ils perdent entièrement ou partiellement leur capacité de gain. Des indemnités journalières sont également versées en cas d'incapacité de travail totale ou partielle consécutive à un accident (ou au service militaire), le salaire déterminant pour les jeunes en formation n'étant cependant pas fixé selon la méthode d'évaluation habituelle.

Les indemnités de chômage versées aux jeunes après la scolarité obligatoire sont soumises à des règles particulières, par exemple en ce qui concerne la période de cotisation, qui ne peuvent être satisfaites en raison d'une formation. Les jeunes ayant résidé en Suisse pendant au moins dix ans sont libérés des conditions relatives à la période de cotisation, mais doivent observer un délai d'attente spécial de 120 jours et l'indemnité est fixée selon des taux forfaitaires en fonction du niveau de formation. La durée d'indemnisation maximale est de 90 jours.

Les enfants dont le père ou la mère est décédé.e perçoivent une rente d'orphelin de l'assurance-vieillesse et survivants (AVS), dans certaines circonstances de la prévoyance professionnelle et, en cas de décès accidentel de parents de condition dépendante, de l'AA, jusqu'à l'âge de la majorité ou jusqu'à la fin de leurs études, mais au plus tard jusqu'à l'âge de 25 ans révolus, à condition que les défunts remplissaient les conditions de prestation prévues par les lois en vigueur.

Les rentes d'invalidité pour les jeunes ne sont accordées par l'AI, sur la base du principe «la réadaptation prime la rente», que si les mesures de réadaptation ont été menées à terme ou se sont révélées impossibles ou inutiles et si le taux d'invalidité est au minimum de $40 \%$. Le droit à la rente prend naissance au plus tôt à l'échéance d'une période de six mois à compter de la date à laquelle l'assuré.e a fait valoir son droit aux prestations, mais pas avant le mois qui suit le $18^{\mathrm{e}}$ anniversaire de l'assuré.e. Étant donné qu'une rente ordinaire exige une période de cotisation de trois ans, les jeunes invalides ou les invalides précoces et les personnes présentant une infirmité congénitale ne peuvent prétendre qu'à une rente extraordinaire. Le choix de la méthode d'évaluation de l'invalidité (comparaison des revenus, comparaison des activités) pour les enfants et les jeunes qui n'ont pas encore eu d'activité lucrative dépend de leur âge et de l'exigibilité d'une activité lucrative et varie suivant qu'ils ont commencé une formation ou n'ont pas pu acquérir des connaissances professionnelles suffisantes pour des raisons de santé.

Dans la mesure où l'AI verse une rente d'invalidité, la prévoyance professionnelle est également tenue à prestations, à condition que le-la jeune salarié·e gagnant un salaire suffisamment élevé lui soit assujetti. Les jeunes nés avec une infirmité congénitale et les mineur·e·s invalides qui étaient déjà partiellement inca- 
pables de travailler au moment de leur affiliation à l'institution de prévoyance sont néanmoins assuré·e·s au titre de la prévoyance professionnelle contre l'aggravation de leurs souffrances, sous certaines conditions. En ce qui concerne le calcul du montant de la rente, la prévoyance professionnelle ne prévoit pas de disposition spéciale pour les jeunes invalides, il est basé sur les conditions de rémunération effective conformément au principe de capitalisation, de sorte que le montant de la rente est modeste.

Le droit à une rente d'invalidité de l'AA prend naissance dès lors qu'une invalidité due à un accident de $10 \%$ au moins est attestée, que la continuation du traitement médical ne permet pas d'espérer une amélioration sensible de l'état de santé et que les éventuelles mesures de réadaptation de l'AI ont été menées à terme. Dans le cas des apprenti.e.s, stagiaires, assistant-e.s et volontaires, les revenus déterminants pour l'évaluation du degré d'invalidité et le montant de la rente sont définis conformément à des dispositions particulières. Les limitations idéelles liées à des dommages corporels subis et ayant des conséquences pour toute la vie sont compensées dans l'AA par une indemnité pour atteinte à l'intégrité déterminée de manière abstraite en fonction du degré de l'atteinte (entre 5 et $100 \%$ ).

Les jeunes ayant leur domicile et leur résidence habituelle en Suisse et percevant des prestations de l'AVS et de l'AI peuvent également demander des prestations complémentaires après l'âge de 18 ans révolus si leurs revenus annuels ne couvrent pas les dépenses reconnues.

\section{Gabriela Riemer-Kafka}

\section{Références}

Riemer-Kafka, G. (2011). Soziale Sicherheit von Kindern und Jugendlichen: Ihre Rechte insbesondere gegenüber Arbeitgeber, Schule, Eltern, Sozialversicherungen, Sozialhilfe und Opferhilfe. Bern: Stämpfli.

\section{Sécurité sociale (financement) ${ }^{*}$}

Les instruments de la sécurité sociale en Suisse ont pour objectif constitutionnel de protéger l'individu contre les effets économiques des risques sociaux que sont l'âge, l'invalidité, la maladie, l'accident, le chômage, la maternité, la condition d'orphelin et le veuvage. En 2014, le total des dépenses afférentes à la protection sociale, $y$ inclus les prestations cantonales sous conditions de ressources, s'est élevé à 157 milliards de francs, soit l'équivalent de $25 \%$ environ du PIB. Comme dans d'autres pays développés, la prévoyance vieillesse et santé absorbe la majeure partie de ces moyens.

Premier pilier de la prévoyance vieillesse, l'assurance-vieillesse et survivants (AVS ; 26\% du total des dépenses pour la sécurité sociale) a une forte composante d'équilibre social car elle couvre toute la population, y inclus les personnes sans activité lucrative. L'AVS fonctionne selon le système de la répartition: les cotisations perçues pendant une période servent à payer les rentes pendant la même période. Les prestations AVS sont financées pour trois quarts par les cotisations salariales et pour un quart par des contributions des pouvoirs publics. Les rentes AVS ne couvrant pas les besoins vitaux, elles sont complétées par des prestations complémentaires (PCAVS). Les PC sont financées exclusivement avec les recettes fiscales de la Confédération, des cantons et des communes. Environ $58 \%$ des PC sont versées en complément à des rentes AVS et $42 \%$ en complément à des rentes de l'assurance-invalidité (AI). Les PC représentent une petite branche de la sécurité sociale (3\% du total des dépenses).

La prévoyance professionnelle (PP ; 33\% du total des dépenses) est le deuxième pilier de la prévoyance vieillesse. Elle fonctionne selon le système de la capitalisation. La PP est financée par des cotisations salariales et par les rendements des placements de capitaux, qui sont portés au crédit des assurés individuels. La PP est gérée par des assureurs privés qui doivent 
respecter des règles définies dans la loi (taux d'intérêt minimal, taux de conversion du capital). À la différence du $1^{\text {er }}$ pilier, le $2^{\mathrm{e}}$ pilier est cofinancé indirectement seulement par les pouvoirs publics, par exemple moyennant des déductions fiscales accordées sur des contributions volontaires à la PP (comme aussi, d'ailleurs, à la PP privée ou pilier 3a).

L'assurance obligatoire des soins (AMal), elle aussi gérée par des assureurs privée, absorbe $17 \%$ du total des dépenses pour la sécurité sociale. Elle est financée principalement par les primes des assuré·e·s, qui sont indépendantes du revenu (prime par tête). Pour des motifs de justice sociale, les assureurs n'ont pas le droit de faire de grandes différences de primes selon les caractéristiques personnelles des assuré·e-s. Il est difficile de déterminer les parts des différents acteur-trice-s au financement de l'AMal. Les pouvoirs publics accordent des réductions de primes aux assuré-e-s à bas revenu et financent directement certains prestataires, plus spécialement dans le domaine hospitalier. D'autres assurances, notamment des assurances complémentaires privées, l'assurance-accidents (AA), l'AI, les PC à l'AVS (pour les soins de longue durée) et l'assurance-militaire (AM), prennent également en charge des prestations de santé. En outre, les prestations dans le domaine des soins de longue durée ne sont pas toutes couvertes. L'AMal est financée selon le système de la répartition, ce qui explique que les recettes et les dépenses se développent grosso modo en parallèle.

Hormis les assurances susmentionnées, il existe des assurances-risques qui couvrent des pertes de gains pour différents motifs (la PP contient également une part risque). L'assurance-invalidité (AI ; $6 \%$ du total des dépenses) est, comme l'AVS, financée pour moitié par des cotisations salariales et pour moitié par des contributions de la Confédération. L'assurance-accidents (AA; 4\% du total des dépenses), qui est centrée sur l'évitement de coûts sociaux ultérieurs, couvre aussi bien des traitements médicaux que la perte de gain. À la différence des primes AMal, les primes AA sont fixées en fonction de classes de risques. L'assurance-chômage (AC ; $4 \%$ du total des dépenses) est financée en majeure partie par les cotisations salariales des assuré.e-s. Les cantons contribuent aux mesures de marché du travail, qui visent la réinsertion dans le marché de l'emploi. Les allocations pour pertes de gains (APG) couvrent une partie de la perte de gain en cas de service militaire, de service de protection civile et de service civil. Depuis 2005, l'APG finance également le congé maternité des femmes qui travaillent. Hormis la PP, l'APG est la seule assurance financée uniquement avec les cotisations des assuré.e-s et les revenus de placements (1\%). Financée avec les recettes fiscales générales de la Confédération, l'assurance militaire (AM), qui couvre les risques de santé des militaires, est de loin la plus petite branche de la sécurité sociale.

Pendant des années, les prestations destinées à compenser les charges de famille (frais d'entretien et de formation des enfants) étaient fort différentes, d'un canton à un autre, quant aux types d'allocations, aux montants versés et aux conditions d'octroi. Entrée en vigueur en 2009, la loi fédérale sur les allocations familiales (LAFam) définit des montants minimaux. Les AFam (4\% du total des dépenses) sont financées pour ainsi dire exclusivement par les contributions des employeur.euse-s et des indépendants. Des réglementations spéciales s'appliquent pour les AFam dans l'agriculture.

Dernier filet de la sécurité sociale, les prestations sociales sous conditions de ressources cantonales sont financées par les impôts généraux, principalement par les cantons et les communes. En 2014, les prestations nettes des différentes branches de l'aide sociale aide sociale économique, aide sociale dans le domaine de l'asile/des réfugiés refinancée par la Confédération, avances sur pensions alimentaires, aide aux personnes âgées/aux soins, aide 
au logement, etc. - se sont élevées à 3 milliards de francs ( $2 \%$ du total des dépenses).

L'évolution démographique est un des grands défis actuels pour le financement de la sécurité sociale. L'AVS, qui a clôturé dans le rouge en 2015, se bat avec le rapport toujours plus désavantageux entre le nombre de cotisant $\cdot e \cdot s$ et le nombre de rentier $\cdot$ ière $\cdot s$. Pour la PP (régime obligatoire depuis 1985), encore en développement, une baisse des taux de conversion et des taux d'intérêt minimaux est à prévoir en raison de l'augmentation de l'espérance de vie et du contexte des taux d'intérêt difficile sur le marché des capitaux. Dès le milieu des années 1990, l'AI a dû faire face à un déficit croissant. En recentrant ses efforts sur la détection précoce et la réintégration, elle a réussi à stabiliser le niveau des dépenses. Autre défi de taille: le financement socialement supportable de l'assurance-maladie. Cette branche connaît une croissance supérieure à la moyenne depuis des années (+ $4 \%$ par année) et met les ménages privés en raison de la hauteur des primes à rude épreuve. Si les $\mathrm{PC}$, avec $3 \%$ du total des dépenses, ne représentent qu'une petite branche de la sécurité sociale, leur progression de près de $5 \%$ par année pendant la dernière décennie, due notamment à des changements dans le financement des soins, ne manque pas d'inquiéter.

La part des dépenses sociales financée par l'impôt est faible en Suisse par rapport à des pays comme l'Allemagne, la France, l'Italie, les Pays-Bas ou la Suède. Chez nous, les assurances financées par des cotisations salariales et des primes par tête (assurance-maladie uniquement) prédominent. Par ailleurs, la Suisse dépense relativement peu pour la protection sociale mesuré au PIB, soit $25 \%$ comparé à $33 \%$ en France. Ce plus faible pourcentage s'explique en partie par le fait que certaines assurances sociales - assurance perte de gain en cas de maladie, assurance des soins de longue durée, congé paternité et parental - n'existent pas en Suisse.

\section{Kilian Künzi}

\section{Références}

Künzi, K. \& Schärrer, M. (2004). Wer zahlt für die Soziale Sicherheit und wer profitiert davon: Eine Analyse der Sozialtransfers in der Schweiz. Zürich: Rüegger.

Office fédéral des assurances sociales (Éd.). Statistiques des assurances sociales suisses, données et publications les plus récentes. http://www.bsv. admin.ch

Office fédéral de la statistique (2015). Rapport social statistique suisse 2015. Neuchâtel : Office fédéral de la statistique.

\section{Sécurité sociale (propositions d'alternatives)}

Il existe de nombreuses propositions d'alternatives à la sécurité sociale telle qu'elle est envisagée aujourd'hui. Elles sont souvent conçues, théorisées ou soutenues par des personnalités issues de milieux politiques ou scientifiques, à l'image de l'écrivain et philosophe André Gorz qui a consacré de nombreux travaux à cette thématique dont l'ouvrage intitulé Métamorphoses du travail (1988). À travers le monde, diverses formations politiques - allant de l'extrême gauche aux libertariens, en passant par les sociaux-démocrates et les verts - ou des organes de la société civile, tels que des ONG, syndicats, think tank nationaux ou transnationaux, peuvent également être à l'origine de l'une ou l'autre de ces contributions ou en débattre. Parmi les propositions énumérées ici, motivées en totalité ou en partie par les déficits d'adaptation des structures existantes de la protection sociale aux mutations socioéconomiques, certaines vont dans le sens de l'instauration d'un revenu garanti alors que d'autres recommandent le partage du travail rémunéré. Plutôt que la réforme du système de sécurité 
sociale, c'est donc l'adoption d'un système alternatif qui est mise en avant.

L'alternative la plus connue et probablement la plus controversée est celle du revenu garanti. Elle fait l'objet de différentes déclinaisons: allocation universelle, dividende universel, revenu de base inconditionnel (RBI) ou imposition négative. L'allocation universelle consiste à assurer à tout individu, indépendamment de son statut ou de son état, dès sa naissance et jusqu'à sa mort, un revenu suffisant pour couvrir ses besoins et lui permettre de participer à la vie sociale. La paternité de cette notion peut être attribuée à l'humaniste Thomas More au début du $X{ }^{e}$ siècle. Elle a été reprise au XVIII ${ }^{e}$ siècle et aux débuts de l'industrialisation, puis a régulièrement été remise au goût du jour sous des formes diverses et en réponse à des contextes particuliers. Par exemple, Philippe Van Parijs, économiste et philosophe belge, soutient dans un article de 1986 un déplacement de la division marxiste classique entre propriétaires des moyens de production et travailleurs, vers une division entre celles et ceux qui disposent d'un travail salarié et celles et ceux qui en sont privés. De là, il défend l'idée de l'octroi d'une allocation universelle (universal grant) ou d'un revenu de base (basic income) qui doit permettre de neutraliser ces inégalités face à l'emploi. Ce modèle a fait l'objet de diverses expérimentations à travers le monde, à l'exemple de la Finlande qui a initié début 2017 un tel programme pilote s'adressant à un échantillon de personnes sans emploi. À noter que le peuple suisse a refusé en juin 2016 une initiative fédérale visant à instaurer un régime similaire, initiative lancée à l'origine par un groupe bâlois et à laquelle s'est ensuite jointe l'association Basic Income Earth Network (BIEN) Suisse. Une autre déclinaison du revenu garanti, distincte du RBI par son caractère non universel, est l'imposition ou fiscalité négative prônée par l'économiste libéral Milton Friedman. Ce dernier, visant à venir en aide aux personnes économiquement faibles, imagina dans
Capitalisme et liberté au début des années 1960 ce mécanisme d'imposition conditionné aux ressources matérielles.

Une autre piste de réflexion a été suggérée par l'essayiste américain Jeremy Rifkin. Dans son ouvrage La fin du travail (1996), dont le titre se réfère au postulat qu'il soutient concernant la raréfaction de l'emploi, il évoque son possible partage par la réduction de l'horaire hebdomadaire. Toutefois, il pousse plus loin son analyse: si les individus ne trouvent pas un travail rémunéré, ils doivent assumer une autre fonction au sein de la société. Ainsi, il encourage le développement du tiers secteur, lequel devrait être soutenu par l'État et offrir aux individus non insérés dans l'emploi une alternative, par la valorisation de leur engagement dans des activités associatives d'intérêt général. Ainsi, les individus actifs hors de l'économie classique devraient bénéficier d'un salaire social.

Dans l'esprit de cette orientation visant à réduire le temps de travail, il est possible de mentionner aussi la proposition de Congé sabbatique inconditionnel (CSI) émanant du réseau de réflexion suisse Denknetz. L'idée consiste à offrir la possibilité à toute personne, entre le début de sa carrière professionnelle et son départ à la retraite, de prendre des congés payés ou, si elle privilégie cette option, d'anticiper son départ à la retraite. Le droit à ce congé sabbatique est inconditionnel et vise à permettre de nouer un autre rapport au travail en pouvant être dédié à toutes formes d'activité (formation, développement personnel, loisirs, etc.). Partant du constat que le système helvétique de protection sociale est très fragmenté et que des doublons entre les divers dispositifs de ce système pourraient être évités, tout en souhaitant répondre aux difficultés liées à l'augmentation des inégalités face à l'emploi, ce même réseau de réflexion a développé le concept d'une assurance générale du revenu (AGR). L'objectif d'une telle assurance, qui viendrait se substituer aux principales assu- 
rances sociales et à l'aide sociale, consisterait à garantir un revenu suffisant à tout individu, lui permettant de subvenir à ses besoins tout en ayant accès à la participation sociale, pour pallier la perte d'un emploi ou une incapacité de travail. Les bénéficiaires de l'AGR aptes à travailler seraient tenu.e.s de réintégrer le marché de l'emploi, mais les conditions prévues par les auteurs de ce projet seraient plus favorables que dans le régime en vigueur dans les assurances sociales existantes.

Chacune de ces propositions, si elle venait à être mise en œuvre, se substituerait partiellement aux régimes actuels de la sécurité sociale. En conséquence, les modalités de financement et par là les règles de redistribution des richesses devraient être réformées et de nouveaux critères d'éligibilité définis. Toutes ces contributions sont motivées par la recherche de réponses aux difficultés auxquelles fait face notre société dans son rapport au travail salarié, elles impliquent une remise en cause des conceptions traditionnelles de la sécurité sociale en vue d'une plus grande justice distributive.

\section{Olivier Grand}

\section{Références}

Gurny, R. \& Ringger, B. (2009). Die grosse Reform: Die Schaffung einer Allgemeinen Erwerbsversicherung $A E V$. Zürich: Edition 8.

Rifkin, J. (1996). La fin du travail. Paris : La Découverte.

Van Parijs, P. (1986). A revolution in class theory. Politics and Society, 15, 453-482.

\section{Sexualité(s)}

La sexualité est un vaste domaine constitué de normes, de valeurs ainsi que de lois qui historiquement définissent une morale sexuelle. Cette morale est encadrée par des agents dont le pouvoir de contrôle et de définition quant à la «bonne sexualité » varie au cours de l'histoire et prend différents sens selon les contextes: les instances religieuses, le corps médical, les politiques économiques ou culturelles. La sexualité est également une question identitaire. Ce champ de l'intime embrasse l'identité de genre, l'orientation sexuelle, les différences corporelles, les capacités reproductives, les besoins, les désirs, les fantasmes, les pratiques sexuelles et érotiques. Mais la sexualité subit un contrôle par l'État à travers le droit qui fixe la limite du normal et du pathologique, comme le sens normatif du mariage, de la reproduction ou de la majorité sexuelle. Ce va-et-vient entre l'intime et le social forme, selon le sociologue Jeffrey Weeks, la boîte noire de la sexualité.

Concernant les droits sexués, en Suisse comme ailleurs, l'on verra inscrites dans le Code pénal et civil ainsi que dans la Constitution des lois encadrant la sexualité et les sexualités. $\mathrm{Au}$ cours du $\mathrm{XX}^{\mathrm{e}}$ siècle, tant la médecine que le droit ce sont affairés à réguler le domaine de la sexualité, allant de l'eugénisme promu par le sexologue Auguste Forel, en promulguant des lois qui interdisent la reproduction à certaines catégories de la population, aux débats interminables autour des droits reproductifs. Citons à ce titre les trente ans du processus législatif de l'avortement avec l'entrée en vigueur du modèle du régime du délai en 2002. Plus récemment la libéralisation de l'accès à l'avortement a été remise en question avec l'initiative populaire «Financer l'avortement est une affaire privée », lancée en 2010, rejetée par une majorité du souverain en janvier 2014. Du côté de la Procréation médicalement assistée (PMA), le peuple suisse a voté en juin 2016 en faveur d'un assouplissement de l'interdiction du diagnostic préimplantatoire qui pourra désormais être pratiqué sous condition d'existence d'un risque sérieux de prédisposition héréditaire à une maladie grave qui se déclarerait avant l'âge de 50 ans et pour laquelle il n'existe aucune thérapie efficace et appropriée. Ce débat toujours d'actualité croise 
de nos jours trois phénomènes: le développement des nouvelles technologies utilisées dans les processus de reproduction humaine; leur encadrement juridique et normatif ; l'ouverture des droits aux minorités sexuelles.

Dès les années 1950 avec les études de Kinsey, en passant par les réflexions de Foucault, la sexualité contemporaine a été un sujet de conceptualisations, un terrain de revendications portées par les mouvements féministes et LGBT ; mais aussi un terrain de contre-mobilisations, comme c'est le cas des mouvements pro-vie ou anti-mariage homosexuels. Ces contre-mobilisations ont fait l'objet d'initiatives populaires récentes, sous forme de comités référendaires tant au niveau fédéral que cantonal.

A côté des mobilisations et contre-mobilisations, le domaine de la sexualité s'est vu affecté d'une suite d'événements; citons notamment l'épidémie du sida. Cette crise sanitaire révélera des enjeux sociaux et politiques liés à la sexualité. On parlera des droits humains sexuels, on assistera à une visibilisation des pratiques et des sexualités minoritaires. En Suisse, à la fin des années 1980, une nouvelle santé publique va se profiler pour faire face à cette épidémie. Il faudra nommer et montrer des actes sexuels dans une pédagogie préventive. La solidarité et la lutte contre les exclusions sociales seront les piliers de la politique de prévention. De ce fait, deux des populations les plus affectées par l'épidémie, les homosexuels et les prostituées, seront appréhendées dans une logique de reconnaissance et donc d'intégration des droits sexuels dans l'espace politique. La question homosexuelle et la prostitution montrent comment dans le domaine de la sexualité il y a bel et bien des basculements de qualification importants allant d'une question de la morale à une question de droits.

Le Code pénal suisse de 1942 dépénalise les relations homosexuelles entre adultes consentants. Cependant, la loi condamne encore toujours les actes commis par un majeur sur un mineur, les abus de détresse et la prostitution. Cette dépénalisation se caractérisera par une pathologisation de l'homosexualité, car les homosexuels sont considérés comme des malades mentaux jusqu'aux années 1990. Les pathologies sexuelles changent au cours de l'histoire et selon les institutions. Dans la classification internationale des maladies de l'OMS (CIM), le transsexualisme fait toujours partie de la liste des maladies mentales, au titre des «troubles de la personnalité et du comportement chez l'adulte». Par contraste, la récente mouture du DSM-5 (Diagnostic and Statistical Manual of Mental Disorders), la «bible» américaine adoptée par les médecins-psychiatres du monde entier, ne considère plus le transsexualisme comme un trouble.

Dans le même registre, on peut penser à la lutte historique des féministes dénonçant les violences envers les femmes, où la question du viol a été centrale. Tant la pédophilie que le viol, par exemple, sont des phénomènes dont la une qualification morale basculera du tabou social et de l'impensable juridique à la condamnation pour immoralité. Concernant les violences envers les femmes, ce qui était à une époque perçu comme un devoir conjugal sera inscrit dans le Code pénal, en 1992 comme viol conjugal, en tant qu'infraction contre l'intégrité sexuelle; et par la suite, en 2004, poursuivi d'office. Cette inscription pénale n'a pas été exempte de débats entre expert·e-s et parlementaires. La question des agressions sexuelles faites aux mineur.e.s et par corollaire la majorité sexuelle (qui en Suisse est fixée à 16 ans) a aussi été l'objet de débats politiques et législatifs en Suisse, dès les travaux autour du Code pénal de 1942.

Toutefois, la logique des droits sexuels propulsée par les organismes internationaux a été adoptée par la Confédération dès les années 2000. De ce fait, la santé publique suisse travaille sur la mise en place d'une perspective de santé sexuelle. Dans cette démarche, la Commission fédérale pour les questions de sida 
s'est transformée en 2012 en Commission fédérale pour la santé sexuelle.

Citons également les controverses historiques au sein du féminisme quant à la prostitution ou la pornographie. La prostitution féminine a toujours été admise dans le droit suisse comme relevant du libre arbitre des femmes s'y livrant, mais réglementée au cas par cas par les cantons. Dans cet esprit libéral, en droit suisse, seuls certains aspects de la pornographie sont réprimés. Mais depuis le $1^{\text {er }}$ juillet 2014, consommer de la pornographie dure est punissable de 1 à 3 ans de prison, selon la nouvelle réglementation entrée en vigueur. Et l'âge de protection des enfants passe de 16 à 18 ans.

Enfin, ce vaste domaine de la sexualité et sa dimension sociohistorique doivent aussi être pensés comme lieu de conflits, de controverse de luttes morales et politiques. Quelle est la bonne sexualité? Quelle est la bonne attitude sexuelle? Quelle est l'identité sexuelle normée?

\section{Marta Roca i Escoda}

\section{Références}

Giami, A. \& Spencer, B. (2004). Les objets techniques de la sexualité et l'organisation des rapports de genre dans l'activité sexuelle: contraceptifs oraux, préservatifs et traitement des troubles sexuels. Revue d'épidémiologie et de santé publique, 52(4), 377-387.

Mottier, V. (2012). État et contrôle de la sexualité reproductive : l'exemple des politiques eugénistes dans les démocraties libérales (Suisse, Suède et Royaume-Uni). Politique et sociétés, 31(2), 31-50.

Weeks, J. (2014). Sexualité. Lyon : Presses universitaires de Lyon.

\section{Socialisme*}

Le socialisme (dérivé du latin socialis: social, sociable) peut être compris comme une idéologie politique, un mouvement et une forme d'organisation sociale. En tant qu'idéologie, il fait partie - à côté du libéralisme et du conservatisme - des trois grands courants de pensée relatifs à la vie en société nés au XIX ${ }^{\mathrm{e}}$ siècle. En tant que mouvement, il est étroitement lié aux formes d'organisation des travailleuses et travailleurs apparues au cours de ce même XIX ${ }^{\text {e }}$ siècle. En tant qu'organisation sociale, il s'inscrit dans une séquence historique qui a débuté avec la Révolution russe de 1917 et pris fin (peut-être qu'à titre provisoire) au moment de la chute de l'Union soviétique, en 1991. Une question reste ouverte: les États qui se disent aujourd'hui encore «socialistes» - la République populaire de Chine, la Corée du Nord, le Vietnam ou Cuba - méritent-ils cet attribut?

La définition du socialisme est large et variée. Le socialisme peut être compris comme une idéologie politique qui se donne pour mission de transformer la société existante dans le but d'atteindre l'égalité et la justice sociales. Il s'oppose ainsi à une forme de société façonnée par la contrainte à l'accumulation du capital. En 1918, dans Que veut la ligue spartakiste?, la marxiste Rosa Luxemburg définissait le socialisme comme formation politique dans les termes suivants : «L'essence de la société socialiste réside en ceci : la masse laborieuse cesse d'être une masse que l'on gouverne, pour vivre elle-même la vie politique et économique dans sa totalité et pour l'orienter par une détermination consciente et libre.»

De façon sommaire, on peut distinguer entre orientations communistes, sociales-démocrates et anarchistes du socialisme. L'orientation communiste souligne la nécessité de la lutte des classes et de la récupération du pouvoir politique par la classe des travailleuses et travailleurs et de leurs allié-e-s (paysans, paysannes et autres classes moyennes). Dans le marxisme-léninisme traditionnel, le prolétariat est compris comme le vecteur de la révolution. Toutefois, afin de pouvoir renverser effectivement l'ordre ancien, on considère qu'il 
a besoin d'une avant-garde résolue, le Parti communiste.

L'orientation sociale-démocrate insiste sur l'importance d'une transition progressive vers une nouvelle société, transition pouvant être mise en œuvre en particulier par des réformes sociales. Elle parle du «socialisme démocratique» qui est censé se distinguer des caractéristiques totalitaires d'un communisme marxiste-léniniste.

L'orientation anarchiste revendique la rupture totale avec le capitalisme. Elle vise une société sans pouvoir dominant, dont l'organisation s'appuierait sur l'autogestion collective.

La plus grande fracture au sein du mouvement socialiste a résulté des divergences qui se sont faites jour au sein du mouvement des travailleuses et travailleurs face à la guerre : la majorité des sociaux-démocrates et des sociales-démocrates des pays européens, décrit.e.s par leurs adversaires comme des «réformateurs/réformatrices» ou des «révisionnistes», voyaient dans la guerre mondiale de 1914 un événement qui rendait nécessaire la défense de leur «propre» patrie contre les puissances ennemies. Celles et ceux qui refusaient la guerre, comme Rosa Luxemburg et Karl Liebknecht en Allemagne, restèrent minoritaires. En Russie, en revanche, les bolcheviks parvinrent, sous la conduite de V. I. Lénine, à s'emparer du pouvoir politique en faisant propagande contre la guerre. Le combat remporté contre le fascisme allemand et japonais en Europe et en Asie permit l'avènement d'un camp socialiste qui contribua largement à «neutraliser» temporairement le capitalisme dans ses régions clés et à favoriser les mouvements anticoloniaux dans les régions périphériques. De fait, le conflit entre l'Union soviétique et la Chine fit cependant exploser ce camp depuis les années 1960 .

Après la Seconde Guerre mondiale, c'est essentiellement grâce à l'initiative de la social-démocratie d'Europe de l'Ouest que l'on a pu bâtir des États sociaux au sein de régimes capitalistes et améliorer ainsi notablement la situation sociale des travailleuses et travailleurs et d'autres cercles de la population. Dans la bataille que se livraient les systèmes capitaliste et socialiste, le «socialisme réellement existant» ou «socialisme réel» conçu sur le modèle soviétique resta finalement en plan, parce qu'il ne parvint pas à développer dans les faits un véritable contre-modèle. Il s'avéra, à quelques exceptions près - comme le Printemps de Prague de 1968 en Tchécoslovaquie, qui fut finalement écrasé par les chars soviétiques -, largement incapable de tirer un enseignement de ses propres erreurs et de créer les conditions nécessaires à l'émergence d'une société différente, dans laquelle «le libre développement de chacun est la condition du libre développement de tous», comme le formulaient Karl Marx et Friedrich Engels en 1848 dans leur Manifeste du parti communiste.

Dans ce sens, le dissident de la RDA Rudolf Bahro critiqua lui aussi ledit socialisme réellement existant et examina le potentiel d'une refonte fondamentale de la société. Il plaida pour une reformulation radicale de la «notion de progrès» et rejeta l'idée selon laquelle le capitalisme pourrait un jour être «dépassé » grâce à une croissance massive de la production. Il pensait au contraire qu'il était nécessaire de rompre avec une dynamique économique extensive et de «réinsérer l'être humain dans l'équilibre de la nature». Il ouvrit ainsi la pensée socialiste à la question écologique.

Avec la fin du «socialisme réellement existant» se pose aussi la question de l'avenir de la social-démocratie. Le mouvement socialiste, influencé par des visions d'une «troisième voie» comme les défendaient l'ancien Premier ministre britannique Tony Blair et l'ancien chancelier fédéral allemand Gerhard Schröder, s'est teinté d'idéologie néolibérale. Ceci a contribué à émousser les différences entre politique de gauche et politique bourgeoise et à réduire l'influence politique de la social-démocratie, en particulier en Europe. Aujourd'hui, 
on observe un renouveau de la pensée socialiste aux États-Unis surtout.

Le socialisme en tant qu'idéologie politique et en tant que mouvement est fortement marqué par la pensée marxiste. Il existe cependant d'autres courants en son sein qui se distinguent du marxisme ou vont au-delà de la pensée marxiste traditionnelle. Citons notamment le socialisme religieux et le féminisme socialiste.

Le socialisme religieux a d'abord été un courant apparu à l'intérieur du protestantisme germanophone vers 1900. Les socialistes religieuses et religieux, comme le théologien réformé Leonhard Ragaz et l'écrivaine juive Margarete Susman, se référaient à la critique du pouvoir formulée par les prophètes et prophétesses de la Bible hébraïque ainsi qu'à l'option christique pour les pauvres. Des groupements socialistes religieux, qui se démarquaient pour partie de la social-démocratie majoritairement athée, apparurent entre la fin du XIX et le début du XXe siècle. Aujourd'hui, il existe des groupes généralement peu importants de socialistes religieuses et religieux dans différents pays d'Europe et d'Amérique du Nord. Le socialisme religieux est aussi étroitement lié à la théologie de la libération telle qu'elle est apparue depuis les années 1960, essentiellement en Amérique latine. Celle-ci associe une critique radicale de la société avec le message biblique d'un nouveau paradis et d'un nouveau monde, dans lesquels les puissants seront détrônés et les pauvres s'élèveront.

Le féminisme socialiste se réfère au marxisme tout en adoptant un point de vue critique à son égard, surtout dans les questions liées à la reproduction et au travail de care, souvent reléguées au rang de «contradictions accessoires » dans la conception marxiste traditionnelle. Le féminisme socialiste insiste pour que le patriarcat, l'oppression des femmes et le capitalisme soient vus comme faisant partie d'un seul et même ensemble. La sociologue et philosophe Frigga Haug, considérée comme l'inspiratrice du féminisme socialiste, souligne que le développement rapide de la mondialisation néolibérale, qui a des conséquences désastreuses pour une majorité de femmes, est la meilleure des preuves «que le féminisme socialiste n'est pas à remiser dans le vieux placard des erreurs passées ».

\section{Kurt Seifert}

\section{Références}

Badiou, A. (2010). The communist hypothesis. London: Verso.

Bahro, R. (1977). Die Alternative: Zur Kritik des real existierenden Sozialismus. Köln : Europ. Verlagsanstalt.

Haug, F. (2008). Die Vier-in-einem-Perspektive: Politik von Frauen für eine neue Linke. Hamburg: Argument-Verlag.

\section{Soins de longue durée*}

Les soins de longue durée (SLD) comprennent le soutien social et sanitaire au quotidien de personnes malades, handicapées et âgées pendant des mois, des années ou des décennies. La population âgée de plus de 80 ans a les plus forts besoins dans ce domaine. Mais les adultes en âge de travailler et les enfants souffrant de maladies mentales ou somatiques peuvent aussi en dépendre. Les SLD s'effectuent dans les ménages privés et des logements avec encadrement (prestations à domicile, Spitex en allemand), des établissements médicaux-sociaux et des institutions pour personnes handicapées (prestations stationnaires) ou encore dans des centres de jour et d'accueil de nuit (prestations intermédiaires). Les prestations à domicile et intermédiaires gagnent en importance du fait de la politique de santé et des préférences individuelles. Les SLD sont réalisés par des proches, des bénévoles et des professionnel-le·s de la santé. À l'heure actuelle, les proches et l'environnement social fournissent un volume 
de services nettement supérieur à celui des prestataires professionnels.

Les SLD sont marqués par les normes sociales et les transformations au sein de la famille, du monde du travail, de la santé et de l'action sociale. L'importance de l'engagement privé - assumé majoritairement par les femmes et généralement gratuit - reflète la division sexuée des tâches ainsi qu'une orientation familialiste des SLD. En raison de l'individualisation, de la mondialisation et de la numérisation, les rôles traditionnels de genre perdent leur prédominance, de multiples formes familiales se développent, de nouveaux modèles de travail s'établissent et les relations sociales s'organisent de plus en plus souvent à distance. Dans l'ensemble, les proches sont moins disponibles en termes temporel et de proximité géographique. Dans le même temps, la demande en SLD augmente en raison de l'évolution démographique ainsi que des progrès pharmaceutiques et techniques.

Le nouveau régime de financement des soins est entré en vigueur en 2011. Il réglemente le financement des établissements médico-sociaux et des soins à domicile et sa répartition entre l'assurance-maladie, les assuréee-s et les contributions étatiques. Désormais, les contributions de l'assurance-maladie obligatoire sont accordées selon un système tarifaire unique dans toute la Suisse et ceci en fonction du temps consacré ; la participation maximale des assuré-e.s aux coûts des soins est déterminée et, enfin, une nouvelle catégorie de soins - les soins aigus et de transition (SAT) pendant deux semaines - a été introduite. Les cantons doivent réglementer le financement restant.

Le financement des soins fait partie d'un système de sécurité sociale différencié et élaboré au fil du temps pour la maladie et le handicap. Il comprend la prise en charge des coûts des soins sur la base de la loi sur l'assurance-maladie (LAMal) et de l'ordonnance sur les prestations de l'assurance des soins (OPAS). L'AVS/AI offre aux assuré-e-s des allo- cations pour impotent (API, sans condition de ressource) et des prestations complémentaires (PC, sous condition de ressource). La loi sur les prestations complémentaires (LPC) prévoit le remboursement des frais de maladie et d'invalidité, y compris une compensation de la perte de revenu des proches aidant.e.s. La réforme de la péréquation et de la répartition des tâches entre la Confédération et les cantons (RPT) a conduit à 26 réglementations cantonales de PC différentes. Selon la loi sur l'AVS, les proches avec une activité lucrative faible ou inexistante peuvent demander, depuis 1997 et sous certaines conditions, des bonifications pour tâches d'assistance. Certains cantons et communes accordent, sur demande, des contributions financières aux proches qui assument des soins à domicile.

La responsabilité des SLD est de compétence cantonale. Les cantons peuvent déléguer l'organisation des prestations aux communes. Par conséquent, il existe une multitude de structures locales des SLD. La Suisse alémanique compte beaucoup plus de lits en EMS que la Suisse romande, tandis que cette dernière a un taux d'emploi plus élevé dans l'aide et les soins à domicile. La structure fragmentée de l'offre en SLD crée un besoin élevé de coordination du coté des assuré-e.s, des proches et des professionnel-le·s. Depuis 2012, l'OPAS préconise que la coordination puisse être assumée par les organismes d'aide à domicile et remboursée par les caisses maladie. Certains organismes d'aide à domicile engagent les proches qui prennent en charge un parent afin de les soumettre, grâce au statut de salarié·e, aux protections du droit du travail.

La Suisse dispose d'une vaste offre d'institutions de SLD. En comparaison européenne, le financement public est élevé dans les domaines hospitalier et intermédiaire, alors qu'il reste faible dans le domaine de l'aide et des soins à domicile. En Suisse, les ménages privés contribuent au financement des SLD à hauteur d'un quart du coût total des dépenses. Le coût des 
prestations d'accompagnement et de soutien social leur incombe plus particulièrement.

Les SLD relèvent du travail de care qui se prête mal à une augmentation de l'efficacité et à la rationalisation. Trois axes favorisent des SLD accessibles sur l'ensemble du territoire et abordables.

Premièrement, des ressources en personnel suffisantes pour répondre à la demande croissante de SLD, rémunérés et non rémunérés. Ce sont surtout les femmes qui travaillent dans les SLD, bénévolement ou pour de bas salaires, alors que ces prestations impliquent un travail intense soumis à une sollicitation psychologique et physique élevée. Dans le même temps, les femmes actives manquent dans les SLD assumés dans les familles. Certains prestataires transnationaux comblent des lacunes en important du personnel (généralement féminin) (migration du personnel de care, soins à domicile $24 \mathrm{~h} / 24 \mathrm{~h})$. Ces évolutions soulèvent des questions d'éthique, de droit du travail et de qualité. Des efforts accrus s'imposent pour permettre la conciliation entre vie professionnelle et familiale et pour répartir plus équitablement le travail de care entre les hommes et les femmes.

Deuxièmement, la création de structures et d'offres coordonnées. L'individualisation et l'autodétermination sont primordiales pour une qualité de vie optimale dans les SLD. $\mathrm{Au}$ lieu de la dichotomie "ménage privé» et «EMS», des offres intermédiaires doivent être développées, à savoir des organismes flexibles, localisés dans les quartiers et offrant des services payants et d'autres gratuits. Si l'on veut garantir des prises en charge durables et stables, l'information quant aux offres, aux coûts et au financement est centrale; elle doit être conviviale et facilement accessible. De plus, les SLD doivent articuler des prestations d'accompagnement et de suivi social au même titre que des prestations de santé. Pourront y contribuer des professionnel-le-s de la coordination tels des case-managers (ou care-mana- gers) issus des services d'aide à domicile, des assurances-maladies, du travail social communal ou encore des ligues de la santé.

Troisièmement, le développement de modèles de financement intégrés et forfaitaires dans l'ensemble du périmètre des prestations sociales et de santé des SLD. Tant que l'augmentation des coûts des soins aigus stationnaires ne ralentit pas, le développement et le financement des SLD se heurtent à des limites certaines. Les coûts des SLD sont assumés par l'assurance-maladie, les contributions étatiques et les ménages privés. Ces derniers supportent des coûts deux fois plus élevés que dans les autres pays de l'OCDE. Il s'ensuit que, en Suisse, les SLD sont considérés comme un secteur insignifiant du point de vue de l'économie de la santé. Ils jouent pourtant un rôle économique important. L'orientation familiale conduit à une réduction des salaires et des pensions (surtout pour les femmes). De nouveaux modèles de financement sont nécessaires pour couvrir les prestations de soins, d'aide et d'accompagnement social à la fois au domicilie et sous les formes intermédiaire et stationnaire. Ce que l'on appelle les modèles de financement forfaitaire (managed long-term care), négociés entre prestataires et financeurs, favorisent une collaboration intégrée, interprofessionnelle et interinstitutionnelle.

Les SLD affectent non seulement les systèmes de santé et de sécurité sociale, mais aussi la politique familiale et celle de l'égalité entre les sexes. En fin de compte, la question relève de la politique sociale et de l'éthique : comment la responsabilité du travail de care nécessaire dans le domaine des SLD sera-t-elle organisée et financée à l'avenir, et de quelles options et possibilités de financement la population dispose-t-elle?

\section{Karin van Holten \& Iren Bischofsberger}




\section{Références}

Colombo, F., Llena-Nozal, A., Mercier, J. \& Tjadens, F. (2011). Help wanted? Providing and paying for long-term care. Paris: OECD Publishing.

Dutoit, L., Füglister-Dousse, S. \& Pellegrini, S. (2016). Soins de longue durée dans les cantons: un même défi, différentes solutions - évolutions 20062013. Neuchâtel: Observatoire suisse de la santé. Werner, S., Kraft, E., Mohagheghi, R., Meuli, N. \& Egli, F. (2016). Angebot und Inanspruchnahme von intermediären Strukturen für ältere Menschen in der Schweiz: Ergebnisse einer Kantonsbefragung und einer Auswertung der Statistik der sozialmedizinischen Institutionen. Neuchâtel: Schweizerisches Gesundheitsobservatorium.

\section{Soins de santé aux personnes âgées*}

Compte tenu de l'évolution démographique très rapide que connaît actuellement la Suisse, où l'on s'attend à ce que le nombre de personnes âgées de 65 ans et plus double entre 2015 et 2030 , et compte tenu de la stagnation, voire de la diminution, du segment le plus jeune de la population, les soins de santé aux personnes âgées gagnent une importance sociale décisive sur trois plans. Sur le plan individuel, les personnes âgées de 65 ans et plus désirent une qualité de vie élevée et une autonomie assurée jusqu'à un âge avancé. Sur le plan sociétal, l'évolution démographique signifie que la réussite économique de la Suisse dépendra de plus en plus des personnes âgées, car les jeunes adultes ne seront pas assez nombreux. Sur le plan de la politique de santé, le doublement attendu du nombre de personnes âgées représente un défi pour assurer le financement de soins médicaux de haute qualité, d'autant plus qu'il faut s'attendre à une augmentation des maladies liées à l'âge telles que la démence, les fractures osseuses et les accidents cardiovasculaires. Envisager la santé des personnes âgées en misant sur un allongement de l'espérance de vie en bonne santé et sans incapacité constitue une approche centrale pour les trois plans.
L'adoption de cette approche repose sur une nouvelle compréhension de la santé des personnes âgées. Notons que notre biologie est limitée, et que la vieillesse est fondamentalement liée à l'apparition de maladies chroniques. Si leur apparition ne peut être évitée, il est néanmoins possible de retarder les maladies liées à l'âge, et donc de maintenir plus longtemps la qualité de vie, la mobilité et l'autonomie, en promouvant la santé par une approche préventive. Cette approche de santé publique est également appelée «allongement de l'espérance de vie en bonne santé » ou, comme l'a formulé l'Organisation mondiale de la santé (OMS) en 2016, «maintien de la capacité intrinsèque», ou «maintien de la capacité fonctionnelle». Atteindre cet objectif nécessite une nouvelle approche de recherche visant à tester des mesures efficaces, bien tolérées et abordables, pouvant être appliquées au niveau de la population et capables d'améliorer simultanément plusieurs fonctions organiques. Cette approche de recherche est aussi appelée «Delayed Aging - vieillissement retardé» et constitue l'objectif central de la recherche moderne sur le vieillissement. Elle diffère complètement du modèle de recherche classique, qui se concentre sur une fonction organique ou une maladie. L'allongement de l'espérance de vie en bonne santé et le maintien de la capacité fonctionnelle nécessitent de stimuler toutes les fonctions organiques importantes et d'envisager la personne dans sa globalité.

Dans cette optique, le lancement de l'étude DO-HEALTH en Suisse a constitué un jalon important dans la gérontologie moderne. Réalisée auprès de plus de 2000 femmes et hommes en bonne santé, âgé·e·s de 70 ans et plus, dans cinq pays (Allemagne, Autriche, France, Portugal et Suisse), l'étude montre en quoi trois mesures simples (prise quotidienne de vitamine $\mathrm{D}$, oméga-3 et programme simple d'exercices à domicile) peuvent retarder le processus de vieillissement et réduire le risque de maladies chroniques importantes liées à l'âge 
et prolonger ainsi l'espérance de vie en bonne santé. Au début de l'étude DO-HEALTH, $42 \%$ de tou.te-s les participant.e-s dans tous les pays étaient des Healthy Agers, c'est-à-dire des personnes exemptes de maladies chroniques et jouissant d'une bonne santé physique et mentale. En Suisse, cette proportion atteignait même $51 \%$. L'objectif est que les interventions DO-HEALTH aient un impact à l'avenir et fassent augmenter encore la proportion de personnes de 70 ans et plus qui sont actives et en bonne santé.

Par ailleurs, la prise en charge globale du nombre croissant de patient.e.s âgé-e·s dans les hôpitaux de soins aigus reste un champ d'action important. Compte tenu de l'évolution démographique, une personne sur dix devant être traitée dans un hôpital de soins aigus est aujourd'hui âgée de 80 ans ou plus. Ces patient·e-s sont traité·e-s dans toutes les spécialités, bien qu'elles ou soient généralement hospitalisé·e-s pour un problème majeur (p.ex. une crise cardiaque). Le rétablissement optimal d'un·e patient·e âgé·e requiert la prise en compte de toutes ses maladies chroniques, de l'interaction des médicaments - sachant que les fonctions organiques changent avec l'âge -, de la fonction de la mémoire, des capacités fonctionnelles, de la mobilité et de l'alimentation, ainsi que des ressources multidimensionnelles (du/de la patient·e et de son environnement). Cette dimension supplémentaire nécessite idéalement l'intégration de compétences en gériatrie. La création de centres de traumatologie gériatrique est un concept qui a déjà fait ses preuves. Dans ces centres, des chirurgien.ne.s traumatologues travaillent en étroite collaboration avec les gériatres dès l'admission $\mathrm{du} / \mathrm{de}$ la patient $\cdot e$, dans le but de remettre sur pied le plus rapidement possible les patient.e.s âgé·e-s de 70 ans et plus souffrant de blessures suite à une chute (fractures osseuses, traumatisme crânien). Il convient de noter que l'âge des patient·ess pose des exigences spécifiques en matière de traitement médical. Chez les patient·e·s âgé·e.s souffrant d'une fracture, il convient de stabiliser celle-ci d'un point de vue chirurgical de manière à ce que le/la patient·e puisse se remettre debout dès le lendemain de l'opération et à éviter ainsi le risque élevé de diminution des forces et des capacités fonctionnelles lié à l'alitement prolongé.

Parallèlement aux soins médicaux aigus, la rééducation (précoce) immédiate revêt donc une grande importance dans les soins de santé aux personnes âgées. Des séances d'entraînement quotidiennes et des soins actifs (traitement gériatrique complexe) chez les personnes âgées immobilisées (30\% de diminution des forces en une semaine d'alitement) préviennent la dégradation fonctionnelle rapide et permettent ainsi une récupération durable de l'autonomie. De tels concepts ciblés innovants sont envisageables pour de nombreuses spécialités médicales et susceptibles de renforcer durablement la qualité des soins médicaux de pointe en Suisse pour les patient·e.s de 70 à 80 ans et plus, ainsi que de réduire certains risques importants comme le délire (état de confusion aigu) et certaines complications comme les chutes, les effets secondaires des médicaments et la perte d'autonomie.

Outre la promotion de la santé des personnes âgées par la prévention et une prise en charge médicale aiguë globale, l'amélioration des interfaces entre les services ambulatoires, la médecine aiguë et le suivi des patient·e-s âgé-e.s est un domaine d'action important pour l'avenir. L'objectif est de mettre sur pied un concept de soins intégré avec une circulation optimale des informations et des connaissances entre tous les partenaires du système de santé, afin d'assurer conjointement le rétablissement des patient·e.s âgé·e-s et le maintien de leur autonomie. On note un besoin important de recherches complémentaires, d'une part pour pouvoir examiner et établir durablement de nouveaux concepts de soins en intégrant toutes les interfaces, d'autre part pour pouvoir 
offrir un soutien personnalisé aux personnes âgées nécessitant des soins.

Enfin, il convient de tenir compte des déterminants sociaux de la santé. Les conditions de vie, l'origine, le mode de vie, les activités professionnelles, mais aussi l'accès aux soins de santé et la nature de ceux-ci influencent le développement humain au fur et à mesure que l'âge augmente. La recherche en sciences sociales a permis de mettre en évidence les inégalités en matière de santé. Ces déterminants de la santé, qui sont particulièrement pertinents du point de vue de la politique sociale, doivent également être pris en considération dans les soins de santé aux personnes âgées.

En résumé, il convient de souligner que la santé des personnes âgées offre une stratégie pour garantir les meilleurs soins médicaux possibles face au défi de l'évolution démographique. La prévention et les concepts novateurs de cogestion dans les hôpitaux de soins aigus sont des approches importantes à cet égard. Ils peuvent avoir une influence positive sur l'évolution démographique rapide de la Suisse et permettre au système de santé de réaliser des économies grâce au maintien prolongé d'une bonne santé et à des soins médicaux aigus durables.

Heike A. Bischoff-Ferrari

\section{Références}

Etude DO-HEALTH. https://www.media.uzh.ch/en/ Press-Releases/2017/DO-HEALTH.html Organisation mondiale de la santé (Éd.). Stratégie et plan d'action mondiaux sur le vieillissement et la santé. Genève: Organisation mondiale de la santé.

\section{Soins médicaux}

La notion de soin médical renvoie à l'ensemble des prestations fournies par le système de santé à l'exclusion des traitements à vocation esthétique. Toute personne soignante, quelles que soient ses qualifications professionnelles, apporte un soin médical dès lors que ses prestations ont la prévention, le traitement, la réhabilitation, le soulagement ou le soutien pour objectif. Ainsi, seule une partie des soins médicaux est livrée par le corps médical. De plus, la fourniture de soins médicaux n'est pas réservée aux professionnel-le·s de la santé. Les proches aidant.e-s, mais aussi la patiente ou le patient sont des fournisseur.euse-s important·e.s de soins médicaux.

Parmi les soins médicaux, on distingue usuellement les soins primaires, secondaires et tertiaires. Les soins primaires désignent les interventions préventives et le traitement des affections bénignes. Ils sont généralement fournis par les médecins de premier recours ou par l'infirmier-ère-s de pratique avancé·e (advanced practice nurse, APN) dans les pays où la fonction est reconnue. Au cœur du système de santé, les soins secondaires mettent l'ensemble des ressources du plateau hospitalier à la disposition des patient·e.s. Ils sont destinés au traitement des maladies aiguës et des maladies chroniques en phase aiguë. Finalement, le secteur des soins tertiaires comprend les soins de réhabilitation, les soins et l'aide à domicile, ainsi que les prestations des établissements médicaux-sociaux (EMS). En assurant des congés d'hôpitaux sans délai et une prise en charge post-hospitalière adéquate, le secteur des soins tertiaires permet de réduire le temps de séjour hospitalier et le taux de réhospitalisation, tandis que par le maintien à domicile, il contribue à différer, et parfois à éviter l'institutionnalisation.

Toutefois les interfaces entre les secteurs sont trop souvent des obstacles à une prise en charge continue et cohérente, la culture professionnelle ne favorise pas la collaboration entre les différents corps de métier et aucun acteur ou actrice n'est explicitement chargé·e de garder une vue d'ensemble sur la situation de soin. 
Le système de prise en charge est morcelé. Le problème est structurel. Il trouve ses origines dans le profond mouvement de spécialisation professionnelle, la diversification de l'offre et l'intensification progressive de la concurrence qui ont marqué le développement du système sanitaire dans la période de forte croissance économique de l'après-guerre.

Ce déficit est particulièrement manifeste dans la prise en charge au long cours de la maladie chronique. En 2015, l'Observatoire suisse de la santé estime à plus de 2,2 millions le nombre personnes dans le pays souffrant d'une maladie chronique. Cela représente approximativement un tiers de la population de 15 ans et plus. Plus l'âge avance, plus le risque de morbidité est grand. Parmi les personnes de plus de 50 ans, la moité souffre d'une maladie chronique et dans le groupe des personnes de 80 ans ou plus, $40 \%$ sont atteints par au moins deux maladies chroniques simultanément. En 2011, les coûts de traitement des maladies chroniques non-transmissibles étaient estimés à 52 milliards de francs, soit $80 \%$ environ du coût global de la santé. C'est pourquoi, le développement de la coordination et de l'intégration des soins est un axe prioritaire de la politique de la santé présentée en 2013 sous le titre «Santé2020» par le Conseil fédéral.

Les modèles de soins intégrés sont des entités développées pragmatiquement et ancrées historiquement. Il n'est par conséquent pas aisé d'en produire une typologie systématique et exhaustive. Djalali et Rosemann proposent 13 critères susceptibles à la fois de les catégoriser et d'en évaluer la puissance intégrative. Parmi les modèles qui peuvent ainsi être esquissés, le managed care et le réseau de soins intégrés (RSI) véhiculent une conception globale du système de santé.

Le managed care consiste à instaurer un jeu d'incitations d'ordre économique et financier qui tracent la voie d'un comportement économiquement rationnel des acteur.trice-s impliqué·e·s. Développé initialement aux États-Unis, il repose essentiellement sur les principes d'une concurrence régulée et du payement prospectif des prestations. Il est également lié au développement des Caisses de santé (Health Maintenance Organisations, HMO) et des réseaux de médecins. Dans leur forme la plus aboutie, les Caisses de santé sont des vecteurs d'intégration puissants, dont l'efficacité économique, en termes de calcul coût-bénéfice, reste toutefois discutable. Combinant les rôles d'assureur.e et de fournisseur.e de prestations, elles ambitionnent d'offrir une palette aussi complète que possible de services dans les trois secteurs des soins médicaux. L'assurance-maladie (LAMal), qui entre en vigueur en 1996, confère au managed care les bases légales d'un développement durable. Renforçant considérablement le poids des agents payeurs, il ne rencontre toutefois pas le succès escompté auprès de la population. Appelée à se prononcer par les urnes, celle-ci rejette le projet en 2012. Cette opposition au managed care n'est pourtant pas interprétée par les expert·e·s de la santé comme un rejet des soins intégrés, mais comme une invitation à considérer d'autres modèles d'intégration.

Le RSI se présente comme alternative possible au managed care. Il apparaît au Canada dans le cadre de la réforme de la prise en charge gérontologique et psychiatrique du tournant des années 2000. La coordination entre les fournisseur-euse-s de prestations et la planification de leurs interventions est assurée par des instruments comme le case management, l'assessment pluriprofessionnel, le guichet unique ou encore les protocoles et les algorithmes de traitement qui sont les leviers de l'intégration dans ce modèle. Le RSI est une entité organisationnelle propre - généralement une association à but non lucratif - dont les membres sont les fournisseur.euse-s de prestations, publics et privés. Le financement du fonctionnement du réseau, ainsi que des projets que celui-ci conduit, est en principe assuré par les cotisa- 
tions des institutions membres. Mais il peut aussi être couvert par les pouvoirs publics.

Alors que le managed care s'inspire du marché pour concevoir et structurer la prise en charge sanitaire, le RSI est pensé comme un instrument de santé publique. C'est pourquoi les requérant-e-s de prestations sont considéré.e-s dans ce modèle comme des bénéficiaires, ou encore des ayants droit, avant d'être client.e.s ou consommateur.trice-s. Toutefois, la mise sur pied des RSI implique la création d'une strate organisationnelle supplémentaire qui surplombe les organismes pourvoyeurs de prestations existants. Il est permis de penser que celle-ci réduise l'efficience et la flexibilité du dispositif. En outre, avec la mise en place de directives et d'algorithmes d'intervention, l'accompagnement, fortement standardisé, est construit comme un processus fondamentalement linéaire et planifiable. Cette approche rend le RSI particulièrement sensible aux contingences de l'accompagnement qui apparaissent comme des éléments essentiellement dysfonctionnels, susceptibles d'en perturber la marche. Enfin, si le RSI ne fait pas appel à la métaphore du client, il reste attaché à la conception bio-psycho-sociale du patient. Dans ce cadre, la maladie est construite comme une altération des fonctionnalités somatiques ou psychiques qui trouve sa signification dans les besoins qu'elle engendre. Pourtant, l'affection a une autre teneur lorsque ses conséquences sont définitives puisque la patiente ou le patient, qui n'a plus la perspective de guérir, doit apprendre à vivre avec elle. Dans ce cas, ce ne sont pas les déficits qui sont déterminants pour la prise en charge, mais les richesses et les réserves qui peuvent effectivement être mobilisées pour faire face dans la durée. Pour permettre une prise en charge adéquate de la maladie chronique, le RSI doit pouvoir s'appuyer sur une image constructive de la patiente ou du patient qui met en exergue ses ressources et ses potentiels, ainsi que ceux de son entou- rage et du réseau institutionnel associé à l'accompagnement.

\section{Pierre Gobet}

\section{Références}

Djalali, S. \& Rosemann, T. (2015). Neue Versorgungsmodelle für chronisch Kranke: Hintergründe und Schlüsselelemente. Neuchâtel: Schweizerisches Gesundheitsobservatorium.

Fleury, M.-J. (2002). Émergence des réseaux intégrés de services comme modèle d'organisation et de transformation du système sociosanitaire. Santé mentale au Québec, 27(2), 7-15.

Observatoire suisse de la santé (Éd.) (2015). La santé en Suisse - le point sur les maladies chroniques: rapport national sur la santé 2015. Berne: Hogrefe.

\section{Solidarité}

La solidarité désigne une doctrine, des actions, une posture éthique ou un idéal. Fondée sur la justice et l'égalité, elle renvoie à la relation entre personnes ou entre groupes sociaux partageant une communauté d'intérêts. Elle se comprend comme une préoccupation de réciprocité entre les acteur-trice-s sociaux·ales qui composent la collectivité. La solidarité se rapporte ainsi au vivre ensemble et aux politiques publiques qui l'organisent. Ses formes institutionnalisées les plus connues sont les assurances sociales et l'aide sociale. En relèvent également les politiques fiscales, les mesures étatiques de redistribution des richesses, les actions des organismes sans but lucratif ou les relations entre les générations.

En Suisse, trois niveaux de solidarité sont identifiés. 1) La solidarité verticale. De nature économique, elle régit les relations entre riches et pauvres. Cela sous-tend le principe de progressivité de l'impôt ou le prélèvement de cotisations sociales relatives au revenu ou à la capacité économique des personnes ou des ménages. 2) La solidarité horizontale exprime la relation entre certaines catégories de la 
population, à savoir celles qui contribuent au financement des prestations sociales et celles qui bénéficient des mesures de solidarité. Pensons à la solidarité entre les bien-portants et les malades, les actif.ve's et les inactif.ve's ou les rentier·ère-s, les jeunes et les vieux, les hommes et les femmes, les consommateur-trice-s ou non. 3) La péréquation (financière) scelle la solidarité entre les différents niveaux institutionnels, la Confédération et les cantons, d'une part, les cantons et les communes, d'autre part. Elle a pour ambition d'atténuer les disparités géo-topographiques, sociodémographiques, économiques ou financières entre les composantes territoriales pour garantir leur cohésion, qu'elle soit nationale, cantonale ou sociale.

L'idée de solidarité est récente. Le philosophe Pierre Leroux semble être le premier, en 1839, à penser la notion de solidarité sur un plan philosophique, tout en l'associant à un autre principe: l'égalité. Cette idée émergera dans la sphère politique à la fin du XIX $\mathrm{X}^{\mathrm{e}}$ siècle avec Léon Bourgeois, prix Nobel de la paix, dans l'ouvrage intitulé Solidarité publié en 1896. Sa vision de la solidarité entend concilier liberté individuelle et justice sociale. Chaque être humain retire en effet des bienfaits de la vie sociale et a de ce fait des obligations envers ses contemporains et ses successeurs. Les sociologues Alfred Fouillée (La Science sociale contemporaine, 1880) ou Émile Durkheim (De la division du travail social, 1893) soulignent que dans des sociétés contractuelles les individus sont à la fois de plus en plus autonomes et de plus en plus dépendants les uns des autres. Cette solidarité de type organique, contractuelle et coopérative, nécessite l'intervention de la puissance publique pour en garantir la juste exécution. La solidarité constitue donc l'essence des systèmes de protection sociale qui se mettent en place à partir de la fin du XIXe siècle. De la création des mutualités régionales ou professionnelles aux fondations de prévoyance des entreprises ou aux assurances sociales, elle se conjugue au gré des revendi- cations, des catégories de population protégées, des prestations allouées, des modalités de financement.

En 1942, William Beveridge voit la sécurité sociale comme un compromis entre la préservation des libertés individuelles et l'existence d'un État bienveillant, chargé de promouvoir la solidarité sociale et civique. Cette conception ancre le noyau structurel et le fondement moral sur lesquels se construit l'État social tout au long du XXe siècle. L'extension des assurances sociales et des mesures d'aide sociale, la redistribution des richesses au moyen de l'impôt ou l'intervention de l'État dans les domaines de la scolarisation des enfants, de l'accès aux soins médicaux, des retraites, de la prévention du chômage ou du soutien aux familles illustrent la concrétisation des politiques de solidarité.

Parallèlement, on assiste à l'émergence d'initiatives visant à aider autrui sans forcément recourir aux politiques publiques institutionnalisées. Des engagements sociaux pragmatiques émanent de la société civile. L'action vise la solution immédiate de problèmes rencontrés souvent par les parents de personnes en situation de handicap. Elle donne naissance à d'innombrables fondations, associations et institutions privées assumant des missions d'action sociale. Avec les années 1990, un processus d'individuation de la solidarité prend forme. Elle tend à valoriser les êtres dans leur singularité plutôt que dans leurs rôles et leurs statuts de patient, d'élève ou de membre d'une famille. Cela se traduit, à la fois, par une prise en charge personnalisée (case management) au sein des régimes sociaux et par de nouvelles formes d'engagement, notamment bénévole et humanitaire.

La solidarité par les politiques publiques et sociales se caractérise par différentes spécificités, qui en déterminent les contours et l'intensité. 1) La dimension politique: elle légitime par une décision démocratique un cadre d'intervention. On y reconnaît l'intérêt général de répondre à des problèmes spécifiques par des 
prestations sociales en nature ou en espèce. Cela concerne la couverture de la population en soins médicaux; l'accueil extrafamilial des enfants ; la garantie d'un revenu de substitution en cas de maladie, d'accident, de perte d'emploi ou de retraite; ou par un revenu de compensation (allocations familiales). 2) Le principe de protection: assurance ou sous condition de ressources (assistance). Le principe d'assurance se fonde sur un droit aux prestations découlant de l'affiliation à un régime particulier (maladie, accident, retraite, chômage, invalidité, etc.). Le principe d'assistance conditionne l'octroi et le niveau des prestations à la situation particulière de la personne (ressources financières, situation familiale, etc.). 3) Le choix des populations protégées, du type et du niveau des prestations. Il détermine le contenu de la politique et l'intensité de la solidarité. On peut $\mathrm{y}$ assurer toute la population (régime universel, par exemple pour le premier pilier AVS, l'invalidité ou la maladie) ou certaines catégories seulement (les salariés en matière de chômage, de prévoyance professionnelle ou d'accident; les personnes en situation économique défavorable: subventionnement des primes d'assurance-maladie). 4) L'organisation du financement: elle structure les modalités de prélèvement des ressources, par l'impôt ordinaire, par des cotisations sociales sur les salaires, par des contributions sur la consommation (TVA, impôt sur le tabac et l'alcool).

La géométrie de la solidarité varie selon les régimes. Elle est le fruit d'un processus de décision politique, qui exprime à la fois la nécessité d'une solidarité, tout en fixant ses limites. En Suisse, la solidarité s'inscrit dans une conception libérale de l'État et est indissociable de la responsabilité individuelle.

Plusieurs enjeux sous-tendent les concrétisations politiques de la solidarité. La durabilité des régimes de protection sociale renvoie à la légitimité de l'intervention et à la garantie des financements à long terme. En matière de gouvernance, une meilleure coordination des régimes contribuera à une allocation optimale des ressources et à une organisation plus cohérente des mesures en vigueur. L'innovation de la prise en charge devra permettre de répondre aux besoins accrus de soutien liés au vieillissement démographique (prestations de retraite et de soins). Les synergies et collaborations avec l'économie devront optimiser la participation et l'intégration de la population au monde du travail, dans un contexte marqué par de fulgurants progrès technologiques. Enfin, les relations intergénérationnelles seront de plus en plus l'expression des diverses formes de solidarité qui interviennent tant au sein des familles (travail de care plus ou moins spontané et reconnu) que des politiques publiques (allocation des ressources de protection sociale).

Stéphane Rossini

\section{Références}

Bonvin, J.-M., Gobet, P., Rossini, S. \& Tabin, J.-P. (2015). Manuel de politique sociale (2e éd.). Lausanne : Éd. ÉÉSP.

Merrien, F.-X., Parchet, R. \& Kernen, A. (2005). L'État social: une perspective internationale. Paris : A. Colin.

Rossini, S. \& Fischer, A. (2015). Les jeunes et la solidarité: enjeux et défis de la mémoire sociale. Saarbrücken: Éditions universitaires européennes.

\section{Statistique sociale*}

On entend par statistique sociale les données et indicateurs servant à décrire la situation sociale et en particulier le bien-être social d'un pays. La finalité de la statistique sociale est de fournir une description de la situation socioéconomique des différents groupes de population et une analyse des problèmes sociaux.

L'administration et les autorités se servent de ces données et indicateurs de la statistique sociale afin de déterminer les situations socio- 
politiques problématiques, planifier la politique sociale et les mesures de gouvernance sociopolitique, et analyser l'efficacité des mesures sociopolitiques. La statistique sociale est également très importante pour les associations et les autres acteur.trice-s sociopolitiques. Les données sociostatistiques permettent de décrire l'état et le fonctionnement de l'État social, d'évaluer l'efficacité des actions gouvernementales et d'identifier les lacunes dans la protection sociale.

La première statistique suisse sur la pauvreté a été établie dès 1872 . En raison du fédéralisme marqué de la Suisse, son élaboration était déjà une tâche complexe et fastidieuse et prenait plusieurs années. Le développement socioéconomique qui a eu lieu au tournant du $\mathrm{XX}^{\mathrm{e}}$ siècle et la précarisation de larges couches de la population qu'il a entraînée ont donné une grande importance à la «question sociale», suscitant un véritable besoin d'informations sur le marché du travail, les prix et les comportements des consommateurs. Par la suite, un service «Statistique sociale» a été créé dans l'ancien Office fédéral de l'industrie, des arts et métiers et du travail (OFIAMT), qui établissait l'indice des prix à la consommation ainsi que les statistiques relatives aux salaires, à la production et à l'emploi, et qui a été transféré à la fin des années 1980 à l'Office fédéral de la statistique (OFS). En 1992, la loi sur la statistique fédérale a créé une base légale unique pour l'établissement des différentes statistiques. Depuis 2000, la statistique fédérale est également inscrite dans la Constitution fédérale (révision totale, article $65 \mathrm{CF}$ ) et doit répondre aux directives relatives à la protection des données (loi fédérale sur la protection des données du 19 juin 1992).

Aujourd'hui, les enquêtes mentionnées sur les prix à la consommation, ainsi que sur les salaires, la production et l'emploi font partie des statistiques économiques. Le changement social et économique qui a commencé dans les années 1970 a entraîné une hausse des problèmes et des risques sociaux, ce qui a fait naître un besoin beaucoup plus important en informations sur la situation sociale de la population et sur les effets des prestations de l'État social. Les informations recueillies servent de bases décisionnelles indispensables aux adaptations du système de sécurité sociale, ce qui a entraîné un accroissement des activités de recherche sur les problèmes sociaux. Des rapports sur la pauvreté ont été établis pour différents cantons. Grâce à ces connaissances, une série de nouvelles enquêtes et statistiques ont été menées depuis les années 1990 dans le cadre de la Statistique fédérale, ce qui a permis de combler les déficits d'informations par rapport à d'autres pays européens.

Sur la base de ces nouvelles données et indicateurs sociostatistiques, la Suisse ambitionne depuis les années 1990 d'établir des rapports sociaux continus. Les développements sociaux, l'apparition de nouveaux problèmes et la répartition des chances de vie dans les principaux domaines de la vie, comme le revenu, l'éducation, le logement, la santé et le travail font l'objet d'un monitoring régulier (p.ex. dans les rapports sociaux de l'OFS et du Swiss Centre of Expertise in the Social Sciences FORS ou dans les almanachs sociaux publiés chaque année par Caritas depuis 1999, qui sont axés sur la politique sociale).

Les recensements qui, jusqu'en 2000, ont été réalisés tous les 10 ans auprès de la totalité de la population (recensement complet), constituent une base importante de la statistique sociale. À compter de 2010, les données reposent sur les données de registre des services du contrôle des habitants harmonisées chaque année. Les informations relatives au recensement de la population qui ne figurent pas dans les registres du contrôle des habitants sont complétées par le relevé structurel annuel (consultation d'environ 200000 personnes) avec des données relatives à l'éducation, à la langue, à la religion et aux comportements en matière de mobilité sont collectées. 
À l'exception de quelques enquêtes ponctuelles, on manquait jusqu'aux années 2000 de données fiables et à l'échelle de toute la Suisse sur l'aide sociale et la pauvreté. Avec l'établissement de la statistique de l'aide sociale au début des années 2000, cette lacune a été comblée en partie. Outre les données sur les bénéficiaires de l'aide sociale, qui sont recueillies chaque année pour toute la Suisse depuis 2005 par les communes et les cantons, l'inventaire des prestations sociales sous condition de ressources (aide sociale au sens large) donne des renseignements sur toutes les prestations liées aux besoins dans les cantons. La statistique financière fait état des dépenses cantonales dans le domaine de l'aide sociale au sens large.

Pour tenir lieu de statistique intégrale sur les aspects financiers de la sécurité sociale, les comptes globaux de la protection sociale ont été développés à la fin des années 1990 . Cette synthèse statistique repose sur plusieurs sources différentes et renseigne de manière globale sur les finances de la sécurité sociale. Elle se base sur une méthode alignée sur EUROSTAT (Office statistique de l'Union européenne) du Système européen de statistiques intégrées de la protection sociale (SESPROS), ce qui permet une comparaison avec tous les pays de l'Union européenne. Le taux de prestations sociales (dépenses totales consacrées aux prestations sociales en pourcentage du PIB), qui mesure le niveau des prestations sociales d'une nation, représente un indicateur central. En 2017, il s'élevait en Suisse à 26,1\%. Ainsi, notre pays se situe légèrement en deçà de la moyenne de l'UE.

Les grandes enquêtes primaires représentatives menées dans le cadre des statistiques publiques constituent également des données de base importantes de la statistique sociale. En effet, elles fournissent des informations sur la répartition sociale des chances de vie en se basant sur la disponibilité des ressources telles que le revenu, l'éducation, la santé et le logement. Mentionnons notamment l'enquête suisse sur la population active (ESPA) qui, chaque année depuis 1991 et tous les trimestres depuis 2010, est effectuée auprès d'un grand nombre de répondant.e.s. Une autre source remarquable pour les questions sociopolitiques est le projet SILC (Statistics on Income and Living Conditions), un ensemble de données établi en Suisse depuis 2007 et harmonisé à l'échelon européen reposant sur un échantillon d'environ 8000 ménages, soit 18000 personnes. Sur la base de cet ensemble de données, l'OFS présente régulièrement des indicateurs de pauvreté comparables à l'échelon international. Le panel suisse des ménages établi par FORS revêt également une grande importance. Il se base sur un échantillon de ménages représentatif de la population suisse et interrogé chaque année. Ainsi, des informations sur les parcours de vie, le changement social et les conditions de vie de la population sont générées.

Ces dernières années, les données administratives (provenant notamment des assurances sociales) ont davantage été utilisées pour la statistique sociale. En reliant différents ensembles de données, on peut générer des données riches en contenu. En raison de la forte complexité du système de prestations de la sécurité sociale, il est devenu nécessaire de disposer d'une vue d'ensemble des principaux systèmes de prestations. Ainsi, les données issues des trois grands domaines de la sécurité sociale (AC, AI et aide sociale) sont associées pour former l'ensemble de données AS-AI-AC et servent de base à un monitorage ainsi qu'à des recherches régulières. Lors du croisement des données, le numéro AVS constitue un identificateur fondamental. Par ailleurs, les statistiques utilisent de plus en plus des données issues des registres fiscaux et sur les revenus.

La statistique sociale doit relever le défi qui consiste à s'adapter en permanence aux changements socioéconomiques (nouveaux groupes à risque) et aux modifications des besoins en informations tout en garantissant une constance élevée. Différentes lacunes 
informationnelles persistent. Par exemple, il n'existe toujours pas de rapports nationaux sur la pauvreté. La structure fédérale de l'État social suisse rend coûteuse la collecte des informations dans les différents domaines de l'existence tout en rendant nécessaire l'exécution d'analyses à l'échelle locale.

\section{Robert Fluder}

\section{Références \\ Caritas Suisse (Éd.) (annuellement depuis 1999). L'Almanach social: l'annuaire de Caritas sur la situation sociale en Suisse. Tendances, analyses et faits. Lucerne: Éditions Caritas. \\ Office fédéral de la statistique (Éd.) (tous les 4 ans depuis 2011). Rapport social statistique suisse. Neuchâtel: Office fédéral de la statistique. Rapport social 2004, Rapport social 2008, Rapport social 2012, Rapport social 2016. Zurich: Seismo [voir aussi www.socialreport.ch]}

\section{Statut d'étranger et aide sociale}

L’aide sociale étant toujours réservée en priorité à celles et à ceux qu'une société considère comme «siens", il n'est guère étonnant que la question des destinataires soit au cœur des débats sur l'aide sociale depuis les origines de l'État helvétique. Hier, on excluait de l'aide sociale les «étrangers» d'autres communes ou d'autres cantons, aujourd'hui ce sont surtout les personnes de nationalité étrangère qui sont les victimes de cette exclusion.

La relation entre aide sociale et statut d'étranger peut a priori paraître paradoxale. En effet, d'une part la législation sociale est censée protéger toute personne se trouvant dans le besoin. L'article 12 de la Constitution fédérale de 1999 stipule que «quiconque est dans une situation de détresse [...] a le droit d'être aidé et assisté et de recevoir les moyens indispensables pour mener une existence conforme à la dignité humaine». L'assistance publique ou l'aide sociale est le dispositif mis en place pour répondre à cette exigence constitutionnelle. Mais, au contraire de ce que l'on aurait pu attendre, tout le monde n'a pas droit à l'aide sociale ordinaire. Ce droit résulte en effet de l'autorisation de séjour, ce qui signifie que l'autorité d'assistance n'intervient qu'en aval des autorités compétentes en matière de migration. L'universalité du droit à l'aide sociale est donc très relative puisque certaines personnes en sont exclues. Le paradoxe n'est qu'apparent: la citoyenneté sociale étant le privilège des autochtones, elle est ouverte de manière restrictive aux personnes qui n'ont pas la nationalité du pays dans lequel elles vivent. La Suisse, comme de nombreux États, a introduit des conditions, par exemple de domicile sur le territoire, de durée de résidence ou de type d'autorisation de séjour pour l'accès aux prestations de l'État social.

Trois catégories de personnes qui vivent en Suisse sont exclues de l'aide sociale ordinaire. D'une part, les personnes de nationalité étrangère sans autorisation de travail qui n'ont droit qu'à l'aide d'urgence généralement remise sous forme de bons ou en nature (p.ex. hébergement et repas dans des structures collectives), et encore dans le cas des personnes déboutées du droit d'asile à condition qu'elles coopèrent à leur retour au pays d'origine. D'autre part, les personnes qui sont dans le processus d'asile, qui reçoivent des cantons une aide sociale spécifique dont le montant s'élève le plus souvent à environ la moitié de l'aide sociale destinée à la population résidante. Enfin, les migrant·ess qui viennent chercher de l'emploi en Suisse, car c'est le statut de travailleur qui ouvre un éventuel droit à l'aide sociale, y compris pour les ressortissant·e.s de l'Union européenne (UE) et de l'Association européenne de libre-échange (AELE). Se retrouver sans emploi en Suisse peut faire perdre ce statut - et donc le droit à l'aide sociale. En effet, selon la jurisprudence du Tribunal fédéral les ressortissant·e-s de l'UE et de l'AELE perdent leur statut de travailleur 
si elles se trouvent au chômage de manière volontaire, ou si, se trouvant au chômage de manière involontaire, on peut déduire de leur comportement qu'il n'existe plus aucune perspective qu'elles soient engagées à nouveau dans un laps de temps raisonnable, ou encore si elles adoptent un comportement «abusif»: le flou de l'énoncé ouvre la porte à diverses interprétations. La question du droit à l'aide sociale des personnes de nationalité étrangère est d'ailleurs une thématique récurrente au sein des États européens, avec une pression pour le restreindre comme ce fut le cas au RoyaumeUni en 2016 lors du vote sur le Brexit.

Les autres personnes de nationalité étrangère vivant en Suisse ont accès à l'aide sociale ordinaire, mais cet accès peut leur faire perdre leur droit de séjour en Suisse, car la législation suisse sur les étrangers s'appuie sur une conception utilitaire de la migration. La présence de personnes de nationalité étrangère n'est admise qu'à condition qu'elle coûte le moins possible à la collectivité, et le fait de se trouver à la charge de l'assistance publique est considéré par la loi comme un facteur similaire à un délit, puisque dans les deux cas la sanction de l'expulsion est prévue.

L'article 62 al. 2 lit. de la loi sur les étrangers entrée en vigueur en 2008 (qui ne s'applique pas aux ressortissant.e.s de l'UE et de l'AELE) prévoit que le titre de séjour (permis B) d'une personne de nationalité étrangère peut être révoqué si «lui-même ou une personne dont il a la charge dépend de l'aide sociale». Pour les personnes titulaires d'une autorisation d'établissement (permis C), donc en principe d'un droit de séjour à long terme, ce droit peut être révoqué si la personne de nationalité étrangère «ou une personne dont [elle] a la charge dépend durablement et dans une large mesure de l'aide sociale» (article 63, al. 1 lit. c). Seules les personnes de nationalité étrangère titulaires d'une autorisation d'établissement et résidant en Suisse depuis plus de 15 ans échappent à cette mesure (article 63, al. 2). Mais dans son
Message relatif à la modification de la loi fédérale sur les étrangers du 4 mars 2016, le Conseil fédéral a prévu de durcir ces dispositions, et notamment de supprimer la limite de 15 ans.

Concernant le sens des notions de «dépendance durable» et dans «une large mesure» de l'aide sociale, le Tribunal fédéral a rendu différents arrêts : selon cette jurisprudence, résumée dans un dossier de veille de l'Association romande et tessinoise des institutions d'action sociale (ARTIAS), ces conditions sont réunies avec 210000 francs d'aide sociale sur environ 11 ans pour une famille de 5 personnes, avec 96000 francs en 9 ans et avec 143361 francs en 12 ans pour une personne seule, avec 80000 francs en 5 ans et demi ou avec 50000 francs en 2 ans pour un couple. Les directives du Secrétariat d'État aux migrations d'octobre 2013 prévoient qu'il y a une dépendance durable et marquée à l'aide sociale lorsqu'une personne de nationalité étrangère a touché des montants dépassant 80000 francs en deux à trois ans.

Il n'existe pas de statistique fédérale sur l'application de ces articles, qui est du ressort cantonal. Pour les personnes de nationalité étrangère séjournant à l'année, il n’y a en général pas expulsion, mais le permis de séjour n'est pas prolongé. Cet article est aussi appliqué pour justifier la non-transformation du permis $B$ (de séjour) en permis C (d'établissement) et pour limiter le regroupement familial. Les autorités nient parfois le droit de vivre en famille au nom du risque potentiel de dépendre de l'aide sociale et des personnes renoncent à faire valoir leur droit à l'aide sociale pour éviter de perdre leur droit de séjour. Pour continuer de résider en Suisse, les personnes de nationalité étrangère doivent donc parfois renoncer à une partie de leurs droits.

C'est parce que la protection sociale est un privilège de la citoyenneté que des personnes définies comme étrangères par la législation sont souvent soupçonnées, notamment dans les campagnes politiques, de vouloir faire un usage injustifié ou excessif de celle-ci. Le débat 
comme les dispositions prévues rappellent que leur présence, toujours considérée comme provisoire et conditionnelle, est à tout moment révocable. La condition d'étranger fait que ces personnes se trouvent fréquemment amenées à devoir prouver que leur séjour est légitime et le droit des étrangers leur rappelle régulièrement le prix à payer du fait de leur migration internationale, ou de celle de leurs parents.

\section{Claudio Bolzman \& Jean-Pierre Tabin}

\section{Références}

Bolzman, C., Poncioni-Derigo, R., Rodari, S. \& Tabin, J.-P. (2002). La Précarité contagieuse. Les conséquences de l'aide sociale sur le statut de séjour des personnes de nationalité étrangère: l'exemple des cantons de Genève et Vaud. Lausanne/Genève : Genève, Éditions IES/Éditions ÉÉSP.

Fauchère, Y. (2016). Aide sociale et fin du droit au séjour. Yverdon: ARTIAS.

Tabin, J.-P., Frauenfelder, A., Togni, C. \& Keller, V. (2010). Temps d'assistance: le gouvernement des pauvres en Suisse romande depuis la fin du XIX ${ }^{e}$ siècle (nouvelle éd. revue). Lausanne: Antipodes.

\section{Subsidiarité*}

Le terme de subsidiarité désigne un principe structurel qui affecte la relation entre l'État et l'individu ainsi que la relation entre la Confédération, le canton et la commune. La question est de savoir quelle unité d'organisation (étatique ou individuelle; fédérale, cantonale ou communale) est responsable d'une tâche. Le principe de subsidiarité stipule que l'entité supérieure ne doit entrer en jeu que si l'unité inférieure n'est pas en mesure d'assumer une tâche (du mieux possible). Le principe de subsidiarité comporte une dimension fédéraliste et une dimension sociopolitique.

Le principe fédéraliste de subsidiarité signifie que la Confédération ne doit pas s'attribuer des tâches ou des responsabilités que les cantons, ou les cantons et les communes conjoin- tement, peuvent assumer aussi bien ou mieux. Depuis 2008, ce principe fédéraliste de subsidiarité est nommé dans les articles $5 \mathrm{a}$ et $43 \mathrm{a}$ de la Constitution fédérale. Avant même cette formalisation, la subsidiarité comme principe de base était incontestée. Elle figure également à l'article 3 de la Constitution qui stipule une compétence subsidiaire générale des cantons. C'est sur la base du principe de subsidiarité qu'il sera décidé quelle unité d'organisation sera chargée de la prise en compte d'un problème (sociopolitique). Dans le domaine des assurances sociales, la subsidiarité fédéraliste se traduit notamment dans l'application cantonale des lois fédérales et dans la création d'importantes institutions d'assurance au niveau cantonal (p.ex. Offices AI). L'aide sociale est un autre exemple de la compétence cantonale et, parfois, communale.

Le principe sociopolitique de subsidiarité, quant à lui, traite de la question de savoir si un dommage ou les conséquences d'un risque social doivent être assumés par les personnes concernées en responsabilité individuelle, ou si une communauté solidaire (p.ex. la famille, une assurance ou l'aide sociale) en est responsable. La subsidiarité est souvent perçue à cet égard comme une mise en cause de la solidarité. Toutefois, cela n'est pas exact car le principe de subsidiarité contribue à éviter une surcharge de la solidarité. Dans le domaine de la sécurité sociale, le principe de subsidiarité signifie qu'il n'existe un droit au soutien étatique que pour les personnes incapables de subvenir à leurs besoins. Le principe de subsidiarité en tant qu'il permet de distinguer la responsabilité étatique de la responsabilité individuelle est inscrit dans plusieurs articles de la Constitution. Il est appliqué à des degrés divers dans les différentes branches de la sécurité sociale.

Larticle 6 de la Constitution stipule que toute personne est responsable d'elle-même. Il exprime le postulat libéral selon lequel des prestations d'État ne seront accordées qu'à titre subsidiaire à la responsabilité individuelle. 
Cette disposition acquiert de l'importance lors de l'interprétation et l'application d'autres dispositions (notamment dans le domaine de l'aide dans des situations de détresse). Il n'en découle toutefois pas de devoirs directement exécutoires pour l'individu.

Les buts sociaux, énoncés à l'article 41 de la Constitution, constituent l'un des instruments juridiques permettant la mise en œuvre du principe de l'État social. La subsidiarité de l'action étatique face à la responsabilité individuelle est clairement exprimée : l'engagement de la Confédération et des cantons en faveur des buts sociaux est prévu comme complémentaire à la responsabilité individuelle et à l'initiative privée.

Les assurances sociales échappent au principe de subsidiarité stipulé dans les buts sociaux. Un droit à des prestations d'assurance existe même si un ou une assurée serait en mesure de subvenir à ses besoins sans de telles prestations. Néanmoins, dans certains cas, la responsabilité individuelle prime sur les prestations d'assurance. Tant le $1^{\mathrm{er}}$ pilier que l'assurance-chômage n'offrent qu'une compensation «appropriée » pour les besoins vitaux ou la perte du revenu. Il appartient aux individus, en responsabilité propre, de pallier la différence d'avec leur niveau de vie antérieur (p.ex. par le biais d'assurances privées). En outre, une évolution s'observe dans les assurances sociales: l'obligation de diminuer le dommage s'accentue et les contributions personnelles exigées des assuréee-s sont en augmentation. Ainsi, le droit aux prestations de l'AI est subordonné à la participation active à des mesures de réadaptation raisonnablement exigibles (principe: la réinsertion prime sur la rente).

Il en va autrement de l'aide dans des situations de détresse garantie par la Constitution et mise en œuvre notamment dans le cadre de l'aide sociale cantonale. Cette aide a un caractère subsidiaire qui découle directement de l'article 12 de la Constitution: seul «celui qui est dans une situation de détresse et n'est pas en mesure de subvenir à son entretien » a le droit d'être aidé et assisté et de recevoir les moyens indispensables pour mener une existence conforme à la dignité humaine. Le droit à l'aide dans des situations de détresse n'est donc pas inconditionnel, mais soumis à la subsidiarité, qui est considérée comme une condition préalable (négative) à l'octroi du droit. La précision «n'est pas en mesure de subvenir à son entretien » n'a été incluse dans le texte que lors des délibérations parlementaires sur la nouvelle Constitution. Il est donc particulièrement important de connaître les prestations en amont de l'aide dans des situations de détresse. Il s'agit notamment, d'une part, de prestations de tiers telles des prestations d'assurances sociales, de membres de la famille ou même de prestations volontaires de tiers. La subsidiarité implique, d'autre part, des contributions et efforts raisonnablement exigibles de la part de la personne concernée, tel que notamment l'acceptation d'un travail convenable. Le Tribunal fédéral estime qu'il n'y a pas de situation de détresse tant que l'intéressé est en mesure d'occuper un emploi et de gagner un salaire (ATF 139 I 218).

Dans l'aide sociale, le principe de subsidiarité, inscrit dans toutes les lois cantonales sur l'aide sociale, n'est pas seulement une condition préalable à l'octroi du droit. Ce principe impose aussi certains comportements, notamment le devoir de réduire le dommage plus particulièrement en cherchant un travail convenable et en l'acceptant. Les prestations de tiers, dont celles d'assurances sociales, et les prestations propres (raisonnablement exigibles) priment sur l'aide sociale. En cas de manquement à ces obligations, les prestations d'aide peuvent être réduites ou suspendues.

Ce fort accent sociopolitique de la subsidiarité dans le domaine des prestations de protection sociale, fondé sur la Constitution, est une particularité de la politique sociale suisse. Il ne se retrouve guère dans les textes constitutionnels étrangers. 
La question de la subsidiarité sociopolitique relève d'une question de société fondamentale et cruciale. Les affrontements portant sur l'étendue de la responsabilité individuelle par opposition à la responsabilité de l'État continueront dans le cadre des processus législatifs, mais aussi dans la jurisprudence. Il convient d'accorder une attention particulière et critique à la question de la subsidiarité dans le domaine de l'aide sociale. Le principe de subsidiarité fonde de nouveaux modèles d'aide (prestation - contre-prestation), ce qui impacte considérablement la garantie d'existence des individus.

Melanie Studer

\section{Références \\ Gächter, T. (2014). Grundstrukturen des schweizeri- schen Rechts der Sozialen Sicherheit: Charakte- risierung des schweizerischen Modells. Zeitschrift für Schweizerisches Recht, 133(2), 5-111. \\ Mäder, U. (2000). Subsidiarität und Solidarität. Bern : Peter Lang.}

\section{Surendettement}

En droit, le surendettement se définit comme l'incapacité durable de faire face à ses obligations financières et de rembourser ses dettes. L'image de la spirale ou du cercle vicieux rendent compte de ce processus en chaîne qui conduit inexorablement à une dégradation financière. C'est dans ce contexte que prend place le désendettement qui a pour objectif l'assainissement de dettes, partiel ou complet. Dans les services sociaux, le terme de désendettement qualifie à la fois la démarche processuelle d'accompagnement et les procédures administratives, comptables et juridiques qui la sous-tendent. Dans ce domaine, l'aide apportée est conçue comme une réponse réparatrice. En 1996, pour coordonner leurs pratiques et développer des principes éthiques communs, les services sociaux spécialisés dans l'assainissement de dettes se sont regroupés au sein de l'association Dettes conseil suisse. Cette faîtière rassemble les voix des services sociaux dans les débats législatifs relatifs à la protection des consommateur-trice-s et à la prévention du surendettement.

Concrètement, la personne endettée cumule la plupart du temps diverses formes d'emprunts : un ou plusieurs petits crédits, leasing des biens de consommation, découverts sur des cartes de crédits ou sur des cartes clients de grandes enseignes commerciales. À cela s'ajoute les possibilités de découvert sur les comptes bancaires ou postaux, les avances sur salaire, des prêts et des emprunts effectués parmi les proches. Il est à noter que tous ces emprunts obéissent à des règles contractuelles différentes qui font varier le niveau des ressources et des dépenses, ainsi que les échéances des remboursements, ce qui complexifie la gestion de dettes. De par la multiplicité des formes et des modalités de paiement des emprunts, la personne endettée ne dispose pas d'une vue d'ensemble de sa situation financière.

La question du surendettement des ménages doit toutefois s'apprécier en regard du contexte sociétal. Si le surendettement constitue un des révélateurs des formes actuelles de consommation véhiculées par la publicité, incitant à consommer tout en banalisant le crédit et ses effets, c'est également un révélateur de la pauvreté persistante qui caractérise nos sociétés développées. Statistiquement, les groupes de population les plus menacés de pauvreté sont également les plus exposées au risque d'endettement. S'acquitter de son loyer, de ses primes d'assurance-maladie, des frais de garde des enfants, des coûts de transports et des frais liés à l'activité professionnelle sont les charges qui grèvent le plus les ménages des classes populaires et moyennes en Suisse. Le besoin financier demeure en raison des effets conjugués des bas salaires pratiqués dans certains secteurs économiques et de l'expansion des emplois 
atypiques. L'emprunt permet donc de disposer d'une marge de manœuvre en fin de mois pour faire face aux obligations financières ou de jongler avec ses paiements en attendant le versement du prochain salaire.

Le surendettement est un sujet régulièrement débattu : la Suisse doit-elle se doter d'une politique de prévention dans ce domaine et son application dépend-elle de la Confédération ou des cantons? Pour les milieux économiques, cette question relève de la responsabilité individuelle privée alors que pour les organismes de défense des consommateur-trice-s, les services spécialisés dans l'assainissement et les collectivités publiques, elle découle également de la responsabilité de l'État car les conséquences individuelles $\mathrm{du}$ surendettement affectent les finances publiques des cantons et des communes, tout autant que les perspectives de vie des personnes concernées. En effet, celles qui se trouvent en situation de détresse diffèrent leurs paiements voire ne paient plus leurs impôts et leurs assurances pour continuer à honorer leurs emprunts. Par ailleurs, pour vivre et se désendetter, elles doivent recourir aux aides de l'État (subsides, avances sur prestations des assurances sociales, aide sociale) financées en grande partie par l'impôt. L'État est alors le créancier de ces citoyen·ne-s débiteurs et bénéficiaires de ses prestations.

Cinq types d'interventions sont proposés aux personnes surendettées en fonction de leur solvabilité et de leur degré d'endettement:

> L'échelonnement des remboursements, si aucune poursuite n'est en cours.

> La gestion des dettes et du budget pour préserver le minimum vital et éviter la constitution de nouvelles dettes pour les personnes ne pouvant actuellement épurer leurs dettes.

> Le rachat des dettes par concordat extra-judiciaire pour désendetter en partie ou en totalité les personnes en soldant d'anciennes dettes pour une valeur inférieure à leur valeur initiale, avec l'accord d'une par- tie des créanciers et l'intervention d'un·e juge et d'un-e commissaire. Il s'agit cependant d'une procédure juridique lourde et coûteuse, peu utilisée pour résorber les dettes privées des ménages.

> Le règlement à l'amiable des dettes pour désendetter en partie ou en totalité les personnes avec l'accord de toutes les parties à la solution proposée.

> La faillite personnelle pour des personnes durablement surendettées. Cette mesure est prononcée par un·e juge. Cependant, elle ne constitue pas un désendettement : les créanciers reçoivent un document dénommé acte de défaut de biens, qui leur donne la possibilité de réclamer leur dû, si la situation de la personne surendettée devait s'améliorer. Le droit suisse des poursuites et faillites ne prévoit pas la possibilité d'annuler les dettes des personnes surendettées, alors que de telles procédures ont été introduites en Europe. Toutefois, les services sociaux peuvent recourir aux fonds de désendettement existants dans les cantons pour faciliter le désendettement de leurs usager-ère·s.

Dans tous les cas, un désendettement même partiel implique de se restreindre financièrement, afin de réserver une somme d'argent, appelée quotité disponible, au remboursement des dettes. Tel qu'énoncé, il représente une épreuve économique et sociale. Pour parvenir à l'assainissement, les services sociaux établissent des budgets mensuels standardisés à partir de l'ensemble des ressources et des dépenses des ménages. Les catégories comptables et budgétaires employées requièrent la prévisibilité et la stabilité des ressources, ainsi que la possibilité d'épargner, alors que la majorité des personnes surendettées qui font appel aux services sociaux sont dans une situation économique précaire, caractérisée par la variabilité et l'instabilité des ressources à moyen et à long terme. L'emploi de l'argent repose ainsi sur un processus de catégorisation des comportements économiques empruntés aux 
comportements majoritaires des classes supérieures plus épargnées par les crises économiques successives que les classes populaires et moyennes. De plus, cette analyse comptable fait abstraction de la composition des ménages et de la provenance des ressources, alors que ces éléments sont essentiels aux yeux des personnes concernées dans la définition de leurs moyens d'existence et des critères d'affectation de l'argent utilisé à leur désendettement. Dans le cadre légal actuel, où le traitement égal des intérêts des créanciers et des personnes débitrices prévaut, la gestion administrative, juridique et financière des dettes prend le pas sur la résolution des effets sociaux du surendettement.

\section{Sophie Rodari}

\section{Références}

Cambier, E., Perler-Isaaz, F. \& Reusse, I. (2005). Le désendettement: une pratique proposée par des services spécialisés pour lutter contre un fléau socio-économique inquiétant, le surendettement des ménages (Dossier de l'ARTIAS, septembre octobre). Yverdon: Artias.

Dettes et État social (2014). Sécurité sociale CHSS, 1, 6-28.

Perrin-Heredia, A. (2016). L'accompagnement budgétaire, un instrument ambivalent des conduites économiques domestiques. Dans S. Dubuisson-Quellier (Éd.), Gouverner les conduites (pp. 365-398). Paris : Presses de Sciences Po.

\section{Temps de travail*}

Selon les dispositions suisses et de l'UE, le temps de travail au sens strict est n'importe quel laps de temps pendant lequel un travailleur.euse se tient à disposition d'un employeur-euse pour effectuer des activités ou des tâches. Au sens large, on peut distinguer entre le temps de travail rémunéré et le temps réservé à des tâches domestiques et familiales ou encore à un travail bénévole. Cette définition élargie a l'avan- tage de mettre en lumière la relation entre les différentes sphères du travail.

Le temps de travail accompli dans le cadre d'un travail rémunéré est réglé par la loi et par contrat. En Suisse, les modalités relatives au temps de travail peuvent être réglées au niveau des branches et des entreprises, mais aussi individuellement, pour autant qu'elles soient conformes aux dispositions légales. La répartition du temps de travail (travail de jour, de nuit, par équipes, etc.), ses modalités d'horaire (horaire fixe ou mobile, comptes de temps de travail, temps de travail fondé sur la confiance, etc.) et sa durée sont, avec le salaire et les conditions de travail, les éléments-clés des conventions collectives de travail.

On part généralement de l'idée que le temps de travail a progressivement diminué au fil des siècles. En vérité, on travaillait nettement moins au Moyen-Âge qu'au début de l'ère industrielle, d'une part à cause des conditions techniques de l'époque (p.ex. le travail devait se faire à la lumière du jour), d'autre part, en raison du nombre alors nettement plus élevé de jours fériés. Au début de l'industrialisation, le temps de travail en Suisse a passé à plus de 65 heures par semaine. En dehors de l'économie corporatiste, le temps de travail n'était guère réglementé. Des mouvements ouvriers se formèrent bientôt pour militer en faveur d'une réduction des horaires de travail démesurés. En 1877, la journée de 11 heures fut inscrite dans la loi fédérale sur les fabriques. Suite à la grève nationale de novembre 1918 , la semaine de 48 heures s'imposa progressivement; elle fut adoptée en 1920 dans la révision de la loi sur les fabriques et dans plusieurs autres réglementations contractuelles. Dès les années 1930, on assista à des tentatives d'abaisser le temps de travail à 40 heures par semaine, mais la mobilisation faiblit dans les années 1970, comme aussi dans une bonne partie de l'Europe. En 1976 et 1988, des initiatives populaires visant une réduction du temps de travail, la dernière lancée avec le soutien des 
syndicats, furent rejetées. Depuis, le temps de travail effectif des personnes employées à plein temps en Suisse stagne à environ 42 heures par semaine.

Tandis que la réduction générale du temps de travail marquait un arrêt, le temps partiel a continuellement augmenté en Suisse et en Europe. Comparée à l'Autriche et à l'Allemagne, la Suisse compte les taux de temps partiels les plus élevés pour la période 1995-2015, aussi bien globalement (2015: $26,8 \%$ ), que pour les hommes (2015 : 10,9\%) et les femmes (2015: $45 \%)$. L'analyse diachronique révèle que le temps partiel des hommes a le plus augmenté dans les trois pays: la part des hommes travaillant à temps partiel a pratiquement triplé en Allemagne $(1995: 3,4 \% ; 2015: 9,3 \%)$ et en Autriche $(3,1 \% ; 8,6 \%)$, alors qu'il n'a que peu progressé en Suisse (1995 : 7,9\% ; 2015 : 10,9\%). L'évolution est similaire pour la proportion de femmes travaillant à temps partiel. En Suisse, cette proportion stagne à $45 \%$ depuis 20 ans, alors qu'en Autriche, elle a passé de 21,6\% en 1995 à $35 \%$ en 2015, et en Allemagne, de 29,1\% à $37,4 \%$ pendant la même période, même si, dans ce pays, on observe un net fléchissement de la tendance depuis 2005.

Officiellement, le temps partiel est considéré comme une réduction (individuelle) du temps de travail ordinaire, mais les conditions de travail et les répercussions sociopolitiques du temps partiel sont très différentes de celles d'une réduction générale du temps de travail. L'aménagement des assurances sociales en Suisse est fortement axé sur le modèle du travail rémunéré à plein temps sur une longue période. Des interruptions de travail et le temps partiel se soldent par des lacunes dans la couverture d'assurance, plus spécialement dans la prévoyance vieillesse. En outre, le temps partiel se décline encore le plus souvent au féminin, ce qui renforce l'inégalité sur le marché de l'emploi en termes de carrière professionnelle, de revenu et de prévoyance vieillesse. Finalement, l'aspect de la répartition de productivité entre capital et travail est complètement négligé dans le travail à temps partiel individuel, autrement dit, la réduction du revenu s'aligne sur la réduction du temps de travail.

Jusqu'à la fin de la Seconde Guerre mondiale, seuls les fonctionnaires avaient droit à des vacances. Les vacances font leur entrée dans l'économie privée en 1946, d'abord au niveau cantonal et dans quelques conventions collectives privées. Dans les années 1950, les travailleur-euse-s en Suisse bénéficiaient en règle générale de deux semaines de vacances. Les années 1960 marquent le passage au droit à trois semaines de vacances, droit qui sera réglé directement dans les contrats de travail. Dans les années 1970 et 1980, le droit aux vacances augmente à quatre, voire cinq semaines. En 1983, un minimum de quatre semaines de vacances par année (5 semaines pour les jeunes jusqu'à 20 ans) est fixé dans le droit des obligations. Il y eut par la suite deux tentatives visant à obtenir, par la vox populi, une cinquième semaine (1985) et une sixième semaine de vacances (2012), mais ces deux initiatives populaires furent rejetées.

Actuellement, la discussion sur le temps de travail porte principalement sur quatre aspects : travail et santé, flexibilisation, réduction du temps de travail et égalité entre femmes et hommes. De manière générale, un lien a pu être établi entre la productivité du travail et la durée du temps de travail, de longs temps de travail diminuant le plus souvent la productivité. Les temps de travaux «antisociaux» (la nuit, le week-end) ont eux aussi des répercussions: travailler de nuit sur une plus longue durée en particulier peut nuire à la santé et à la vie sociale, la situation personnelle des travailleur·euse-s jouant évidemment aussi un rôle.

Pour ce qui est de la flexibilisation du temps de travail, les débats portent sur la question de savoir dans quelle mesure le temps de travail est adaptable aux besoins des entreprises et des travailleur·euse-s - qui peut décider de la durée et de la répartition du temps de travail? 
Une autre question clé est celle de la saisie $\mathrm{du}$ temps de travail. La flexibilisation croissante du temps de travail, notamment avec des comptes de temps de travail, rend la saisie de temps de travail supplémentaire toujours plus difficile. Une modification de la loi sur le travail est entrée en vigueur au $1^{\text {er }}$ janvier 2016, qui prévoit des dérogations à l'obligation de tenir un compte détaillé des heures de travail. Flexibilisation nécessaire ou dilution de la protection du travail? Les réponses à la question divergent.

Le temps de travail en Suisse, plus précisément la réduction de sa durée, suscite le débat surtout par rapport au temps de travail d'usage à l'étranger. En comparaison européenne, la durée du temps de travail des personnes employées à plein temps en Suisse est extraordinairement longue. Cependant, à la différence de ce qui s'est passé en France, les initiatives visant à la réduire légalement ont été rejetées en votation populaire. L'égalité entre hommes et femmes est elle aussi un défi pour la régulation du temps de travail. Afin d'arriver à de réels progrès en la matière, aussi bien dans le domaine professionnel que dans le domaine domestique et familial, les voix se multiplient pour demander une réduction du temps de travail salarié. Les partisans d'une telle réforme estiment qu'une diminution du temps de travail à 32 heures par semaine permettrait plus spécialement aux hommes de s'investir davantage dans les tâches domestiques et familiales - ce qui va tout à fait dans le sens de l'égalité des sexes.

\section{Sebastian Schief}

\section{Références}

Allmendinger, J., Haarbrücker, J. \& Fliegner, F. (2013). Lebensentwürfe heute: Wie junge Frauen und Männer in Deutschland leben wollen. Kommentierte Ergebnisse der Befragung 2012 (Discussion Paper P 2013-002). Berlin: Wissenschaftszentrum Berlin für Sozialforschung.
Lehndorff, S. (2006). Sicherheit anbieten, Vielfalt ermöglichen : Über Krise und Reformen der Arbeitszeitregulierung. In S. Lehndorff (Hrsg.), Das Politische in der Arbeitspolitik: Ansatzpunkte für eine nachhaltige Arbeits- und Arbeitszeitgestaltung (S. 157-194). Berlin: edition sigma.

Schempp, D., Schief, S. \& Wagner, A. (2015). Determinants of detraditionalization of the division of house and family work in Swiss couple households. Schweizerische Zeitschrift für Soziologie, 41(1), 33-57.

\section{Travail*}

Le terme «travail» renvoie à des activités fort différentes mais qui, toutes, servent à la survie de l'être humain sur les plans matériel et culturel. Le travail s'accomplit par la confrontation, aussi l'appropriation, de la nature. On distingue entre travail rémunéré et activités non rémunérées, comme par exemple le travail artistique ou politique. Le travail rémunéré désigne les activités qui génèrent un revenu sur le marché du travail et qui servent à la subsistance. Les activités fournies dans le cadre de la famille (travail de care), d'un engagement bénévole en politique ou dans la société civile (p.ex. aide de voisinage) ne sont au contraire pas monétarisées. Le système politique de la Suisse, qui est une démocratie semi-directe axée sur une très large participation au niveau local, est tributaire de la bonne volonté des citoyen-ne-s d'assumer des tâches et des mandats politiques sans indemnisation financière. Le travail rémunéré pour sa part contribue à la création de la valeur économique et à la formation de capital économique dans la société. L'économie suisse est réputée très compétitive et innovante. Les avis divergent sur les raisons pour lesquelles la productivité économique du travail en Suisse est néanmoins plutôt faible en comparaison internationale (p.ex. taux d'activité élevé, grand nombre d'heures de travail, degré d'automatisation relativement bas). 
En ancien français «travail» est synonyme de tourment (du latin tripalium, un instrument de torture); les verbes travailler et faire souffrir s'utilisaient indifféremment. Les premiers «travaux» de la chasse et de la cueillette sont relayés par ceux de l'agriculture et l'élevage. Tôt déjà, on pratique également les échanges commerciaux de produits à l'échelle mondiale. Les professions qui se spécialisent progressivement permettent la réalisation d'un revenu en dehors de l'agriculture. Les professions sont aussi à l'origine du corporatisme. Les corporations jouent un rôle important dans la régulation de l'accès au marché, la formation, l'éthique professionnelle et l'entraide déjà dans les villes du Moyen-Âge, comme le font encore aujourd'hui les associations professionnelles. Ce n'est toutefois qu'à l'ère industrielle que le travail salarié dit libre, c'est-à-dire négocié sur le marché du travail, se généralise en tant que source de revenu. La force de travail est désormais louée indépendamment de relations communautaires, en échange d'un salaire et sur la base d'une convention contractuelle.

Vers 1900, la Suisse compte parmi les pays les plus industrialisés d'Europe. La discipline de la fabrique, les étapes de travail mécanisées ainsi que la mobilité sociale et géographique accrue marquent le mode de vie de la classe ouvrière émergente. Le besoin de forces de travail dans l'industrie textile et alimentaire, plus tard dans le secteur de la construction, ne pourra bientôt plus être couvert avec les travailleur.euse-s domiciliéee-s en Suisse. Dans le sillage de l'industrialisation, la Suisse se transforme de terre d'émigration en pays d'immigration. Les individus rompent avec leur mode de vie traditionnel et les relations de solidarité s'effritent. En même temps, les inégalités sociales se renforcent. La distribution inéquitable du capital économique permet aux grands propriétaires d'exploiter des individus obligés de vendre leur force de travail pour assurer leur subsistance. Les problèmes sociaux qui résultent de cette évolution posent les fondements du mouve- ment ouvrier syndicalisé et atteignent leur paroxysme en Suisse avec la grève nationale de novembre 1918. La semaine de 48 heures et l'introduction d'une assurance-vieillesse et invalidité figurent parmi les neuf revendications des grévistes.

Avec l'exploitation de la main d'œuvre et le délitement du lien social (Karl Polany), le risque était grand que le capitalisme sape les bases mêmes dont il était en fin de compte tributaire. C'est sur cette toile de fond que se développe l'État-providence moderne et avec lui, la mise en place de «droits sociaux» (Thomas H. Marshall), au travers d'institutions de politique de travail et sociopolitiques d'une part, et de conditions de travail négociées entre partenaires sociaux d'autre part (en Suisse, par l'instrument de la convention collective de travail). La protection des travailleur-euse-s trouve sa concrétisation également dans les dispositions en matière de droit du travail de la loi fédérale sur les fabriques de 1877 . Le système de sécurité sociale créé ultérieurement visait à réduire les risques sociaux découlant du mode de vie financé par le travail salarié. Le sociologue français Robert Castel voit dans l'actuelle précarisation du travail salarié dans différents pays européens, en liaison avec le démantèlement partiel de la sécurité sociale, la recrudescence de problèmes sociaux liés au capitalisme, que la société avait un temps réussi à maîtriser. Dans quelques pays, on observe aujourd'hui une augmentation des inégalités sociales.

Moins bien positionnées sur le marché du travail que les hommes pour des raisons historiques, les femmes sont davantage menacées de paupérisation, à commencer par les mères élevant seules leurs enfants. Longtemps, les femmes n'ont eu accès qu'à des activités professionnelles subalternes. La protection spéciale des femmes prévue dans la loi sur les fabriques et l'aménagement d'institutions sociales avaient cimenté la division du travail en fonction du sexe, dans la famille et dans le monde du travail. Aujourd'hui encore, les 
femmes gagnent moins que les hommes, alors même que le principe du salaire égal à travail égal est inscrit dans la constitution. Si les femmes sont certes plus nombreuses à occuper des postes qualifiés grâce à leur formation, le choix de la profession dépend encore et toujours fortement du sexe. Par ailleurs, par rapport à d'autres pays en Suisse le travail à temps partiel demeure particulièrement genré.

Si par le passé le secteur industriel gagnait en poids économique au détriment de l'agriculture, aujourd'hui le secteur des services domine. Les compétences individuelles, les savoirs et les réseaux gagnent en importance. En raison de la globalisation et de la flexibilisation des rapports de travail, les personnes actives misent sur la formation continue, voire se préparent à la vie professionnelle en suivant plusieurs formations. Les développements susmentionnés vont de pair avec une insécurité croissante et une mobilité élevée. Les entreprises, quant à elles, intensifient leurs efforts pour trouver des forces de travail appropriées. De nouvelles formes d'organisation du travail - hiérarchies horizontales, possibilités de participation visent à améliorer la satisfaction des employé·e·s, mais aussi la capacité d'innovation des entreprises et d'autres organisations. L'accélération des processus de travail confronte les employéee-s au stress et à la gestion du stress, et les nouvelles technologies de la communication numérique augmentent leur disponibilité. Il devient toujours plus difficile de séparer vie professionnelle et vie privée. S'y ajoute que de nouvelles formes de travail numériques collaboratives ne sont encore guère réglementées par l'État sur le plan de la sécurité sociale. La mondialisation et les grands groupes internationaux commandent eux aussi un besoin de réglementation au niveau international.

L'«industrie 4.0 » ou «industrie du futur» désigne la quatrième étape d'industrialisation rendue possible par l'Internet des objets et dont on attend de profondes mutations du monde du travail. Cette nouvelle ère, qui semble correspondre à la vieille utopie du travail accompli par des robots, devient progressivement réalité avec le développement des possibilités technologiques. Pour les humains, elle n'est pas a fortiori seulement synonyme de gain de liberté; pour certains groupes professionnels, elle diminue les chances de trouver un emploi sur le marché du travail ordinaire. Avec l'industrie 4.0, la flexibilisation des activités professionnelles induite par la globalisation et le changement des profils d'exigences - pas forcément dans le sens de nouvelles spécialisations mais aussi, par exemple, par la combinaison de plusieurs profils existants passent à une vitesse supérieure. Désormais, la coïncidence entre l'offre et la demande de travail devient un cas exceptionnel, ce qui signifie un grand défi aussi bien pour le système de la formation professionnelle que pour les entreprises à la recherche de main d'œuvre appropriée. Ces changements ont des effets plus particulièrement pour les institutions sociales dont le financement et les prestations sont fonction du travail salarié. Une assurance complémentaire de risques sociaux découplée du travail rémunéré, par exemple sous la forme d'un revenu minimum de base inconditionnel, va sans doute à l'avenir figurer en bonne place dans les discussions sociopolitiques.

\section{Chantal Magnin}

\section{Références}

Bernet, B. \& Tanner, J. (Hrsg.) (2015). Ausser Betrieb: Metamorphosen der Arbeit in der Schweiz. Zürich : Limmat-Verlag.

Boillat, V., Degen, B., Joris, E., Keller, S., Tanner, A. \& Zimmermann, R. (Éd.) (2006). La valeur du travail: Histoire et histoires des syndicats suisses. Lausanne: Antipodes.

Castel, R. (1995). Les métamorphoses de la question sociale: une chronique du salariat. Paris : Fayard. 


\section{Travail « au noir»}

Le travail «au noir» est une activité professionnelle à caractère licite, rémunérée, non déclarée ou dissimulée, en ce sens qu'elle échappe au contrôle de l'État. On le différencie du travail «au gris », activité rémunérée non entièrement déclarée, par exemple des heures supplémentaires ou des pourboires. En Suisse, cette distinction n'est pas toujours faite. Le travail au noir entre dans la catégorie de l'économie souterraine ou informelle licite. Les activités illicites telles que les trafics d'armes, de drogues ou le proxénétisme n'entrent pas dans cette définition.

Le travail au noir (ou au gris) est illégal dans la mesure où il échappe à la fiscalisation et aux cotisations patronales et salariales des assurances sociales (AVS et chômage notamment). Bien que l'ampleur du phénomène soit très difficile à évaluer précisément, il est avéré qu'il constitue un gros manque à gagner dans les revenus de l'État. Pour 2001, en Suisse, le Conseil fédéral l'estimait à environ 37 milliards de francs, soit 9,3\% du PIB, ce qui place ce pays en queue de peloton des pays de l'OCDE. Le travail au noir touche de très nombreuses activités économiques. Les branches de la construction apparaissent souvent en première ligne, suivies de la restauration, de l'hébergement, du nettoyage et de l'artisanat. Mais d'autres secteurs d'activités connaissent aussi des pratiques économiques non déclarées, en particulier certains services tels que la finance ou la location immobilière. Elles peuvent aussi concerner les activités d'avocats, de dentistes ou d'architectes. À noter que les nouvelles technologies de communication contribuent au développement de certaines activités non déclarées dans la mesure où le contrôle est difficile à mettre en œuvre, par exemple le e-commerce et de multiples autres prestations de services par internet (traduction, mise à disposition de logiciels, tenue de comptabilités, construction de sites web, placements boursiers et autres).
En Suisse le travail au noir semble être moins pratiqué à plein temps, à l'exception de courtes périodes (durant les vacances ou entre deux emplois). Il consiste plutôt en des activités rémunérées «à côté» d'une activité officielle (le soir ou en fin de semaine). Il faut dire que ces dernières années, sans doute en raison de la flexibilisation croissante du marché de l'emploi, le nombre de travaux atypiques (travail à temps partiel, à durée limitée, sur appel, temporaire, en pseudo-indépendance, etc.) a considérablement augmenté en Suisse. Or ce sont ces populations malmenées et ballottées selon les conjonctures ou les bons vouloirs des employeur-euse-s qui constituent une part non négligeable des personnes qui travaillent au noir.

Si les raisons de travailler au noir s'expliquent souvent par les absences ou les carences de formation, et donc l'impossibilité pour la personne qui demande de l'emploi d'être au bénéfice de formations reconnues et légitimées, l'étude de Heim, Ischer et Hainard effectuée en Suisse romande souligne la grande diversité des motivations à recourir au travail au noir. Signalons en premier lieu et de manière non exhaustive, les motivations économiques, certes les plus importantes, qui renvoient au souci de compléter son revenu à améliorer sa condition de vie, à la difficulté de trouver un emploi dans sa branche et à la volonté de certains employeur.euse-s d'éviter les effets de seuils (certaines petites entreprises artisanales ou de services évitent ainsi de dépasser un chiffre d'affaires supérieur à 100000 pour ne pas avoir à payer de TVA) Puis sont évoquées les motivations de type «administratif», telles que la méconnaissance des lois et des risques courus, l'évitement de lourdes démarches administratives (pour l'employeur.euse) ou encore l'alternative aux contraintes de l'assurance-chômage. Enfin, pour certaines personnes sans emploi, sont mentionnées les motivations psychosociologiques comme l'envie de se sentir valorisé, 
ou la volonté d'échapper à l'inactivité et aux stigmates de l'aide sociale, ou encore le refus de toute forme de dépendance et le besoin de démontrer sa capacité à se débrouiller par soimême. De manière plus générale, il convient de préciser que certaines formes de travail au noir découlent de contraintes économiques et financières fortes alors que dans d'autres cas, les personnes concernées tentent d'améliorer leur quotidien au travers d'un complément de revenu. Cette distinction a bien sûr des implications en matière de politique sociale.

En Suisse (comme ailleurs) la lutte contre le travail au noir est difficile à conduire: les moyens disponibles font souvent défaut pour détecter les faux indépendants, les abus de sous-traitances ou les faillites à répétition. Il semble qu'un nombre toujours croissant d'entreprises emploient des personnes non déclarées aux assurances sociales ou ne respectent pas les salaires définis par les conventions collectives. Les commissions paritaires (associations patronales et syndicales) sont insuffisamment équipées pour faire respecter une législation jugée trop bureaucratique et complexe à mettre en œuvre, surveiller efficacement la régularité des permis de travail, contrôler les chantiers, instruire les dossiers à charge et contraindre au paiement d'amendes, par ailleurs souvent considérées peu dissuasives.

Dans un autre domaine, tout aussi significatif, certain·e-s soulignent les carences des assurances sociales et leur lien avec le développement du travail au noir: les indépendant·e·s ne peuvent pas cotiser à l'assurance-chômage et donc ne peuvent pas bénéficier de ses prestations; certaines personnes en âge de retraite peuvent être contraintes de travailler pour des raisons alimentaires, leurs revenus étant insuffisants; les rentes des caisses de pension peuvent être très modestes, pour autant qu'il y ait eu la possibilité de cotiser (ce qui n'est pas le cas si les personnes n'atteignent pas un seuil minimal de revenu chez un même employeur-euse). Fait aussi problème l'absence d'assurance obligatoire pour des indemnités journalières en cas de maladie de longue durée. D’une manière générale, toute longue période sans revenu est propice à la prise d'emplois à temps partiel non déclarés. Un autre aspect important à signaler est que par le biais du travail au noir il y a la possibilité d'améliorer ou d'entretenir une employabilité exigée par des employeur·euse-s toujours plus sélectif·ive·s et à la recherche de performances optimales de rendement. Aujourd'hui se retrouver sans activité professionnelle équivaut à une autoexclusion et incite dès lors à détourner les règles lorsqu'il n'y a pas d'alternative.

Il est manifeste que c'est dans les contextes où les fluctuations de marché sont marquées, où les emplois sont précaires, et où les fragilités humaines sont fortes que la débrouille sous forme de travail au noir prend le dessus.

\section{François Hainard}

\section{Références}

Conseil fédéral (2002). Message concernant la loi fédérale contre le travail au noir du 16 janvier 2002. Feuille fédérale, 3371-3437.

Fontaine, L. \& Weber, F. (2011). Les paradoxes de l'économie informelle: à qui profitent les règles? Paris : Karthala.

Heim, J., Ischer, P. \& Hainard, F. (2011). Le travail au noir: pourquoi on y entre, comment on en sort? Paris : L'Harmattan.

\section{Travail de care (care work)*}

Par travail de care (care work), on entend le travail de prise en charge d'enfants, d'assistance et de soins aux personnes malades, handicapées et âgées, ainsi que tout autre activité de soutien dont l'être humain est tributaire à une période ou l'autre de sa vie. Dans la littérature spécialisée, le care work - le terme francisé de «travail de care» est entré dans le vocabulaire 
courant - a plusieurs définitions plus ou moins larges. Au sens étroit, tel qu'il est utilisé dans le Rapport du Bureau fédéral de l'égalité entre femmes et hommes (BFEG) de 2010, le travail de care désigne d'une part des tâches d'assistance directe, par exemple laver et habiller une personne qui ne peut pas ou plus le faire ellemême, mais aussi surveiller la prise en charge de la personne assistée, et d'autre part des tâches d'aide indirecte, comme faire le ménage et la cuisine. Au sens large, il englobe en sus des prestations d'aide, rémunérées ou non, à des adultes qui seraient capables de les fournir elles-mêmes, ainsi qu'à soi-même. Tout travail de care présente un certain nombre de caractéristiques qui le distinguent d'autres types de travail, à savoir principalement la relation à la personne, la nécessité vitale, la responsabilité vis-à-vis du bien-être corporel et psychique d'autrui, une logique et une motivation particulières, ainsi que, souvent, une asymétrie et inégalité de pouvoir entre prestataire de care et bénéficiaire.

Rémunéré ou non, le travail de care s'inscrit dans un contexte politique et sociétal que l'on peut appeler le système de care. Dans chaque système de care, on distingue quatre secteurs (avec leurs institutions correspondantes): le secteur public (État), le secteur du marché (entreprises), le troisième secteur (organisations à but non lucratif) et le secteur des ménages (ménages privés). Partant de la situation en Suisse, nous esquissons ci-après les principales composantes du système de care, à savoir les systèmes de prise en charge et des soins.

Le système de prise en charge: Les enfants sont le plus souvent pris en charge gratuitement dans des ménages privés, en majeure partie par les parents, avec l'aide des grands-parents ou d'autres proches, d'ami-e.s, de voisin.ine-s et de connaissances. On fait appel à l'occasion, contre rémunération, à des mamans (papas) de jour, des baby-sitters, des personnes «au pair», etc. En dehors du secteur des ménages, l’offre de prise en charge payante des enfants (de 0 -3 ans, de 3-6 ans, écoliers) est fort diversifiée dans les trois autres secteurs : crèches, jardins d'enfants, écoles primaires et secondaires, écoles à temps plein, garderies scolaires, structures d'accueil parascolaires, internats, foyers pour enfants, encadrement pour les devoirs et pendant les vacances, etc. - avec, parfois, l'appui de bénévoles non rémunérés.

Le système des soins: Aujourd'hui encore, une majeure partie du travail des soins en faveur de personnes malades, handicapées et âgées est assurée gratuitement par le ou la partenaire, des enfants adultes (le plus souvent les filles ou les belles-filles), d'autres membres de la famille, des ami-e.s et des connaissances. Les hôpitaux et les EMS fournissent le travail de care rémunéré dans le domaine des soins. Ces établissements, qui sont toujours plus gérés comme des entreprises privées, doivent faire face à une concurrence accrue et satisfaire à des critères d'efficience. Dans bon nombre d'entre eux, des bénévoles complètent l'offre de prestations payantes. Les organisations de soins extrahospitaliers (Spitex), en majorité des organismes d'utilité publique, prennent en charge l'aide et les soins à domicile. Les personnes qui en ont les moyens peuvent recourir en sus à un large éventail d'autres prestations payantes à domicile - aide au ménage, accompagnement de jour, entraînement de la mobilité, etc. - dont l'organisation et la coordination sont toutefois généralement assurées par des bénévoles.

L'aménagement et le financement des systèmes de prise en charge et des soins et d'autres offres de care relèvent de décisions politiques qui se fondent sur des normes sociétales (de genre). Chaque société doit savoir qui fournit quelles prestations de care nécessaires, quelles prestations devraient être fournies contre rémunération et lesquelles gratuitement. Un certain nombre de défis socioéconomiques se posent dans ce contexte, dont plusieurs sont décrits ci-après. 
Division du travail entre les femmes et les hommes: Il est indéniable que les hommes s'investissent de nos jours davantage dans le travail de care, notamment dans la prise en charge des enfants. Toujours est-il que la division entre les sexes du travail de care, qu'il soit rémunéré ou non, demeure très marquée: les femmes en assument la majeure partie, avec des conséquences financières considérables, la vie durant. Des approches égalitaires visent un partage des tâches qui réduise les inégalités en rapport avec le genre, la classe sociale et l'origine, au lieu de les renforcer et de les cimenter.

Couverture sociale et décompte du travail de care: Le travail de care, surtout s'il est fourni gratuitement, n'est guère protégé socialement (travail de care informel). Certes, depuis la $10^{\mathrm{e}}$ révision de l'AVS (1997), les années consacrées à l'éducation des enfants et à la prise en charge d'adultes nécessitant des soins sont prises en compte dans le calcul de la rente AVS, mais cela ne suffit pas à compenser les désavantages financiers. Une autre méthode radicalement différente consisterait à prendre en compte des crédits de temps pour des soins et des prises en charge auxquels, plus tard, on pourrait recourir soi-même en cas de besoin (projets pilotes : ville de St-Gall et association KISS).

Financement du travail de care: En cas de coupes budgétaires et de réduction et privatisation de prestations de l'État social, le travail de care rémunéré est souvent (re-)délégué aux ménages privés. Il peut en résulter un renforcement d'inégalités sociales. En effet, si les ménages qui en ont les moyens peuvent employer des aides ménagères et du personnel soignant, les ménages à bas revenus en sont réduits à recourir à des prestations publiques sous-financées ou à des réseaux familiaux sur-sollicités.

Soins intensifs de longue durée et care migration: Comme la plupart des personnes âgées veulent rester à la maison le plus longtemps possible, la demande en soins de longue durée et en accompagnement 24 heures sur
24 augmente. Si ce travail de care intensif ne peut plus être accompli bénévolement et/ou que les services d'aide et soins à domicile ne suffisent plus, une lacune apparaît, surtout dans le domaine des soins intensifs de longue durée. Pour assurer ce travail, on embauche des femmes de pays à bas salaire (Europe de l'Est, Amérique du Sud, Asie, etc.). Une «solution» qui n'est guère durable car elle néglige la dimension globale du problème - même les pays de provenance des migrantes soignantes connaissent une pénurie de personnel dans ledit domaine.

Le travail de care en tant que secteur de croissance : Le nombre de personnes employées dans le care a constamment progressé ces dernières années. Cependant, si l'on transpose le travail de care non rémunéré dans le secteur rémunéré (commodification), le produit intérieur brut (PIB) augmente sans croissance concomitante du volume de prestations (pseudo-croissance). En outre, il est pratiquement impossible d'améliorer la productivité du travail de care sans que la qualité en souffre. La rationalisation dans ce domaine est donc fortement limitée comparé à d'autres domaines économiques.

Mouvement en faveur du travail de care: Des manifestes, des appels à la révolution du care, des grèves et autres phénomènes de mobilisation attestent de l'émergence d'un mouvement mondial qui vise à sensibiliser l'opinion aux problèmes, aux déficiences, aux conditions de travail (souvent mauvaises), à la faible rémunération et à la couverture sociale insuffisante du travail de care, et qui revendique des améliorations urgentes.

\section{Ulrike Knobloch}

\section{Références}

Bureau fédéral de l'égalité entre femmes et hommes (Éd.) (2010). Reconnaissance et revalorisation $d u$ travail de care: agir pour l'égalité. Berne. Confédération suisse. 
Modak, M. \& Bonvin, J.-M. (Éd.) (2013). Reconnaître le care: un enjeu pour les pratiques professionnelles. Lausanne: ÉÉSP.

Razavi, S. \& Staab, S. (Hrsg.) (2012). Global variations in the political and social economy of care: worlds apart. London: Routledge.

\section{Travail domestique}

Pour recenser les heures de travail domestique (qui inclut tâches ménagères et familiales) effectuées au sein du ménage, les études de budget-temps définissent le travail domestique comme un ensemble de tâches effectuées gratuitement à l'intérieur de la maison et nécessaires à l'entretien du ménage et de ses membres : cuisine, lavage, repassage, courses, nettoyage, entretien, soins aux enfants et aux proches, etc. Les femmes assument la grande majorité de ces tâches. Les féministes matérialistes contestent la définition empirique du travail domestique. Dans Travail ménager ou travail domestique? publié en 1978, Christine Delphy montre que les tâches qui constituent le travail domestique n'existent pas uniquement dans la sphère privée, mais sont effectuées, contre rémunération, dans des contextes professionnels. Elle avance que la spécificité du travail domestique réside dans le fait qu'il s'agit d'un travail gratuit réalisé majoritairement par les femmes au service d'autrui, en particulier des hommes. Résultat du rapport particulier liant la travailleuse - l'épouse ou la compagne - à son conjoint ou compagnon, le travail domestique est donc le travail gratuit réalisé par les femmes et approprié par les hommes au sein du ménage.

Historiquement, le travail domestique est le produit de la séparation des sphères privée, considérée comme non-productive, et publique et productive, survenue avec la révolution industrielle. La construction de l'opposition entre travail domestique, assigné aux femmes, et travail salarié, assigné aux hommes, va de pair avec l'émergence de la figure de la femme au foyer et de l'homme pourvoyeur principal de la famille. L'«inactivité» (au sens de non-participation au travail productif) des femmes (bourgeoises) leur permet de se consacrer entièrement aux responsabilités domestiques, et notamment, à l'éducation des enfants laquelle constitue désormais le cœur des obligations des mères. L'idéal de la femme au foyer «inactive» ne correspond plus aujourd'hui à la réalité de la majorité des femmes, y compris les mères. Néanmoins, l'emploi stable et à plein temps qui sert de base à la protection sociale, reste l'apanage des hommes. Résultat du modèle fordiste de production industriel, il s'est diffusé en Europe au lendemain de la Seconde Guerre mondiale jusqu'aux années 1970. Les forts gains de productivité découlant de l'organisation scientifique du travail et soutenus par la demande née des besoins de la reconstruction permettaient une redistribution partielle des gains aux salariés de l'industrie sous forme d'augmentation des salaires et d'institutionnalisation des assurances sociales.

Toute personne a besoin de travail domestique pour (sur-)vivre. Soit elle l'effectue ellemême, quand elle est adulte, comme c'est le cas des femmes et des hommes vivant seul.e.s ; soit quelqu'un d'autre le fait pour elle, totalement ou en partite. En Suisse, près de $80 \%$ du travail domestique est assumé par les femmes dans les couples hétérosexuels ayant des enfants. Le mariage renforce la division sexuée du travail au sein du couple, les femmes mariées effectuant plus d'heures de travail domestique que les femmes non mariées vivant en couple. L'entrée massive des femmes sur le marché de l'emploi depuis les années 1970 n'a pas produit une répartition plus égalitaire du travail domestique et salarial entre les sexes. À un taux d'activité professionnelle égal, les femmes assument plus de travail domestique que leur partenaire. Dans huit sur dix ménages constitués d'un couple avec enfants en dessous de 
15 ans, les femmes sont les responsables principales du travail domestique. En 2015, 80,6\% des mères travaillent à temps partiel en Suisse (contre $11,4 \%$ des pères), ce qui renforce à la fois leur dépendance vis-à-vis du (salaire du) conjoint et la légitimité du travail domestique. L'accès contingent des femmes à l'emploi se traduit par une protection sociale limitée en matière d'AVS et de prévoyance professionnelle notamment et un risque de pauvreté élevé.

Depuis 1981, le principe de l'égalité entre femmes et hommes est inscrit dans la Constitution fédérale laquelle stipule à l'article 8 lit. 3 Cts. «l'égalité de droit et de fait, en particulier dans les domaines de la famille, de la formation et du travail». Pour encourager «la réalisation de l'égalité entre les sexes dans tous les domaines [...]» (article 16 de la loi fédérale sur l'égalité entre femmes et hommes du 24 mars 1995), le Conseil fédéral a institué, en 1988, le Bureau fédérale de l'égalité entre femmes et hommes. Le 14 juin 1991, lors de la "grève des femmes» initiée par l'Union syndicale suisse, des milliers de femmes ont dénoncé la persistance des inégalités dans les sphères privée et professionnelle. Aujourd'hui, la participation des hommes au travail domestique reste cependant marginale et la revendication d'un partage égalitaire au sein du couple a disparu des débats publics, la division sexuée du travail étant désormais considérée comme relevant du «choix» des deux partenaires. Pour les couples des classes moyennes et supérieures, ce «choix» se traduit souvent par l'externalisation, contre rémunération, d'une partie des tâches ménagères et familiales à du personnel domestique. Cette «solution» privée au problème du non-partage du travail domestique reste l'apanage des classes aisées. Elle marque le retour de la domesticité, c'est-à-dire la réintroduction des rapports de classe et de race dans la sphère privée, les emplois domestiques, souvent précaires et mal payés, étant largement occupés par des personnes immigrées.
Depuis les années 2000, les milieux féministes, politiques et économiques mettent l'accent sur l'accès inégal des femmes à l'emploi. Des politiques sociales sont mises en œuvre au niveau fédéral pour encourager une participation accrue des femmes au marché du travail: introduction d'une allocation de maternité pour les mères exerçant une activité lucrative pendant les 14 premières semaines suivant l'accouchement; augmentation des subventions en vue de l'extension des structures d'accueil extrafamilial des enfants; déduction pour les frais de garde des enfants par des tiers au niveau de l'impôt fédéral direct (loi fédérale sur les allègements fiscaux en faveur des famille avec enfants du 25 septembre 2009). Lancée en 2011 par le Conseil fédéral, l'initiative visant à combattre la pénurie de personnel qualifié en Suisse fait de la conciliation entre vie professionnelle et familiale un des piliers pour une meilleure exploitation du potentiel de la maind'œuvre indigène. Toutefois, les mesures prises par les milieux politiques et économiques en faveur de l'emploi des femmes sont marginales et se limitent souvent aux femmes qualifiées. Ainsi, l'offre en structures d'accueil pour enfants reste insuffisante, surtout pour les familles disposant d'un bas revenu. En outre, la Suisse est, à ce jour, un des rares pays en Europe qui ne connaît pas de congé paternité ou parental au niveau fédéral.

Si les politiques de conciliation travail-famille permettent à certaines femmes de mener une carrière professionnelle, elles ne touchent pas au problème du non-partage du travail domestique. Au contraire, elles risquent d'augmenter la charge de travail des femmes, notamment lorsque celles-ci sont responsables d'organiser et de gérer l'externalisation de la garde des enfants.

Natalie Benelli 


\section{Références}

Devetter, F.-X. \& Rousseau, S. (2011). Du balai: essai sur le ménage à domicile et le retour à la domesticité. Ivry-sur-Seine : Raisons d'agir éd.

Kersten, S. (2016). Individuelle und kantonale Bestimmungsgründe des Zeitaufwands für Hausarbeit von erwerbstätigen Frauen und Männern in der Schweiz. Schweizerische Zeitschrift für Soziologie, 42(1), 85-107.

Lanfranconi, L. M., Valarino, I. (2014). Gender equality and parental leave policies in Switzerland: a discursive and feminist perspective. Critical Social Policy, 34(4), 1-23.

\section{Travail frontalier}

Le travail frontalier est une activité professionnelle rémunérée et habituelle exercée dans un pays par un non-résident qui retourne chaque jour ou au moins chaque semaine dans son pays de domicile. De ce fait, cette activité expose les frontalier·ère-s à des difficultés particulières notamment en termes de droits d'entrée et de travail, d'imposition fiscale, de taux de change et de sécurité sociale. En Suisse, les personnes actives étrangères doivent obligatoirement obtenir le livret $\mathrm{G}$ si elles souhaitent résider hors de Suisse tout en y occupant légalement un emploi. Selon les cas, cette autorisation est limitée pour une période spécifique et renouvelable. Elle n'est pas requise pour les citoyen-ne-s suisses qui vivent à l'étranger et travaillent en Suisse. Il y a donc une asymétrie juridique entre les différentes sous-populations de travailleur·euse $\cdot s$ frontalier-ère-s.

Deux facteurs expliquent en grande partie le travail frontalier. D'une part, suite à la transformation des États en État-nations au cours des derniers siècles, les sociétés sont aujourd'hui organisées socialement, juridiquement, politiquement et culturellement sur des territoires nationaux. Cet état de fait a entrainé l'institution de contrôles pour "sécuriser» les frontières et réguler le passage des biens et des personnes telles que les frontalier·ère-s.
D'autre part, les transformations économiques et sociales des deux derniers siècles ont fait naître des sociétés modernes fortement urbanisées et mobiles mais aussi hautement différenciées et inégales en termes de conditions de vie. Certaines régions frontalières (en Europe et ailleurs) vivent de manière plus exacerbée que d'autres l'influence de ces facteurs politiques et économiques (différentiels territoriaux de niveau de vie et d'activité) mais aussi d'un troisième facteur géographique (distance et coûts de déplacement dans la région), de sorte que se créent des systèmes organisant les flux transfrontaliers entre localités.

En Suisse, c'est dans la région du Haut-Rhin qu'apparaît dès les années 1880 le travail frontalier. Les restrictions tarifaires imposées par l'Empire allemand forcent les industries suisses en plein essor à installer des succursales sur le territoire allemand proche de la frontière. On y engage avant tout de la main-d'œuvre suisse qui, moins chère, tire pleinement avantage du régime de libre passage en vigueur jusqu'à la Première Guerre mondiale. Malgré l'introduction d'importantes restrictions d'entrée due au conflit armé, ce n'est que les crises économiques de l'entre-deux-guerres qui sonnent le glas de cette activité. Notons que ces frontalier-ère-s bénéficiaient du régime obligatoire d'assurances sociales introduit par Bismarck dès 1883 alors qu'en Suisse les salarié.e-s doivent attendre encore plus d'un demi-siècle pour voir des prestations sociales similaires se concrétiser.

La croissance économique après 1945 fait revivre le flux de frontalier.ère-s mais dès lors principalement dans le sens inverse, provenant d'Allemagne, de France ou d'Italie, et reflétant ainsi la prospérité croissante en Suisse. À l'instar de l'immigration, le travail frontalier est régi dès 1931 par la loi sur le séjour et l'établissement des étrangers (LSEE) et dès 2004 par les Accords bilatéraux sur la libre circulation des personnes (ALCP) entre la Suisse et l'Union européenne (UE). La part du travail frontalier 
étranger dans la population active fluctue en fonction de la demande sur le marché du travail suisse et, en période de baisse de l'activité économique, elle sert d'«amortisseur conjoncturel» comme dans les années 1970, le début des années 1990 ou, plus brièvement, après la crise financière de 2008.

Par ailleurs, jusqu'à l'entrée en vigueur de l'ALCP, des «zones frontalières", d'étendue variable selon les pays et les années, circonscrivent le lieu de domicile et de travail des frontalier·ère·s. Aujourd'hui, cette «zone» s'étend sur tout le territoire de l'UE et de l'Association européenne de libre-échange (AELE) ayant auparavant jamais excédé plus de 60 $\mathrm{km}$ de part et d'autre de la frontière suisse. En tant que ressortissant.e-s de l'UE, depuis 2004 il est désormais possible, sous statut de frontalier-ère-s, d'avoir par exemple son domicile principal à Berlin et de travailler à Zurich en semaine.

Durant les années 2000 et 2010 le nombre de frontalier·ère-s a considérablement augmenté tout comme celui des immigré.e-s, reflétant l'importante croissance économique de la Suisse pendant cette période. En 2018 la Suisse compte près de 320000 frontalier-ère-s dont $80 \%$ reste concentré dans les trois principales régions frontalières (l'Arc lémanique, la Suisse du Nord-Ouest et le Tessin). Alors que la main-d'œuvre frontalière ne représente qu'un peu plus de $6 \%$ de la population active suisse, au Tessin, à Bâle-Ville et dans le Canton de Genève ce taux s'élève à plus de $25 \%$.

Dans le même temps, les profils socioéconomiques des frontalier-ère-s se diversifient et se rapprochent de la population active suisse. Certaines personnes actives à la frontière n'accèdent plus au marché du travail suisse par manque de formation - et de niveau d'allemand pour les frontalier.ère-s alsacien.ne.s. À Genève, le nombre important de frontalier-ère-s suisses (env. 20000 ou un quart du nombre de frontalier·ère-s en 2016) met en exergue des dynamiques de développement urbain qui vont de pair avec une stratification sociale selon le revenu plutôt que selon le statut de frontalier.

Le travail frontalier met à l'épreuve l'État social tant sur le plan de la sécurité sociale que de la fiscalité, la santé, la reconnaissance des qualifications et diplômes, l'épargne pour la retraite ou encore le droit du travail. Si le principe de départage fiscal (afin d'éviter la «double imposition») s'établit à travers des conventions bilatérales dès le début du XXe siècle, les modalités de l'imposition continuent à faire débat comme l'illustre le récent protocole de modification de 2015 entre l'Italie et la Suisse. Le traitement fiscal des frontalier.ère-s varie selon le pays de résidence, le canton de travail ou encore le taux d'emploi. Quant aux assurances sociales, essentiellement construites à l'échelle nationale en Suisse ou ailleurs en Europe, elles suivent le principe de l'assujettissement aux cotisations sociales sur le lieu de travail. Depuis 2012 les dispositions de l'Union européenne posent la base légale pour coordonner les différents régimes nationaux de sécurité sociale sans pour autant éliminer les inégalités de traitement. À titre d'exemple, en cas de chômage ou d'invalidité les prestations des assurances sociales, pourtant basées sur le prélèvement de cotisations à des pourcentages identiques en Suisse, seront différentes pour les frontalier-ère-s car perçues dans le pays de résidence selon des critères d'indemnités spécifiques. Un nombre croissant d'organisations de défense d'intérêts dénoncent ces disparités tout comme la complexité à laquelle les frontalier-ère-s doivent faire face au croisement de plusieurs systèmes de sécurité sociale.

Ces difficultés sont le fruit des discontinuités des régimes sociaux et de migration entre la Suisse et les pays de résidence des frontalier·ère-s. Elles se sont atténuées mais restent importantes. De nombreuses études montrent que la présence des frontalier-ère-s est une nécessité et un enrichissement économique pour les cantons limitrophes et que leur nombre n'a pas d'influence sur le niveau 
d'embauche de la population active suisse. Or, les frontalier·ère-s sont vu·e.s par une partie de la population comme une menace ou comme des «pique-assiettes». Des débordements xénophobes se poursuivront tant que les frontalier.ère-s (quelle que soit leur nationalité) seront vus comme les boucs-émissaires d'autres problèmes sociaux. La «préférence indigène» peut rassurer. Depuis le $1^{\text {er }}$ juillet 2018, suite à l'adoption de l'initiative contre l'immigration de masse en 2014, les nouvelles offres d'emploi dans les branches où le taux de chômage dépasse un certain seuil, sont réservées pour un temps donné aux personnes résidentes en Suisse. Toutefois les besoins de main-d'œuvre mais aussi de justice sociale nationale et transfrontalière continueront de peser sur les modalités d'accès au marché de travail et aux prestations de sécurité sociale.

\section{Cédric Duchêne-Lacroix \& Pascal Maeder}

\section{Références}

Bolzman, C. \& Vial, M. (2007). Migrants au quotidien, les frontaliers : pratiques, représentations et identités collectives. Zurich: Seismo.

Duchêne-Lacroix, C. (2016). Les habitants suisses des régions françaises limitrophes de la Suisse. Politorbis, 3, 17-20.

Usinger-Egger, P. (2016). Die Verordnung (EG) Nr. 883/2004 und deren Durchführungsverordnung. Jahrbuch zum Sozialversicherungsrecht, 81-93.

\section{Travail social*}

Le travail social traite les problèmes d'intégration, constitutifs des sociétés capitalistes modernes, démocratiques et fonctionnellement différenciées. Ces problèmes se matérialisent dans des situations défavorisées et des modes de vie marginaux et psycho-socialement problématiques en termes de participation et de ressources.
Dans ses différents domaines d'intervention, le travail social intervient là où de tels problèmes d'intégration se transforment en problèmes de mode de vie des individus - traditionnellement autour de comportements déviants, du handicap et de la pauvreté, mais aussi de la migration, domaine qui accentue encore la question sociale de l'intégration. Parmi les domaines d'intervention du travail social, citons notamment l'éducation spécialisée ou sociale avec hébergement, le travail social en milieu scolaire, le travail social en milieu ouvert auprès de l'enfance et de la jeunesse, le conseil éducatif et l'aide à la famille, la protection de l'adulte et de l'enfance, l'assistance de probation et le régime pénitentiaire, l'aide aux personnes en situation de handicap, l'aide aux victimes d'infractions, l'aide aux personnes dépendantes, le service social en milieu hospitalier, l'aide sociale, l'aide aux réfugié·e·s, le service social d'entreprise, le travail communautaire et l'animation socioculturelle.

Une autre définition répandue, et à première vue évidente, serait que le travail social traite les problèmes sociaux. Cela est vrai, car les problèmes de mode de vie liés aux problèmes d'intégration sont essentiellement des problèmes sociaux. Cependant, cette définition n'est pas suffisante, car tous les problèmes sociaux ne relèvent pas de la compétence du travail social et tous les problèmes de mode de vie ne sont pas des problèmes sociaux. Les problèmes psychologiques, par exemple, peuvent être à la fois cause et conséquence d'un problème d'intégration individuel et, à ce titre, ils peuvent faire l'objet d'une intervention du travail social. De plus, des problèmes sociaux existent depuis que les humains existent. Cependant, le travail social est un phénomène relativement récent qui n'est pas apparu par hasard dans la forme de société contemporaine.

Ce sont diverses évolutions sociales (p.ex. le siècle des Lumières et la modernisation et donc la dé-traditionalisation et l'individualisation, le passage à un mode de production capi- 
taliste) qui, articulées entre elles, ont transformé la structure de la société pour lui donner sa forme actuelle et qui ont créé, en conséquence, le problème de l'intégration. Au fond, le problème vient du fait que les individus sont «libérés». Concrètement, cette liberté signifie que chaque individu n'a plus simplement une position donnée par sa naissance, mais doit acquérir sa position au cours de sa vie (généralement par le travail). Cette forme dynamique de socialisation s'accompagne de tâches de développement exigeantes. Elle peut échouer pour diverses raisons. En outre, les possibilités et les ressources nécessaires pour faire face à ces tâches de développement sont inégalement réparties à et dès la naissance. Malgré la libération et donc l'égalité de principe de tous les individus, une économie capitaliste génère systématiquement des inégalités et des exclusions sociales. Ces dernières s'ancrent structurellement dans la différenciation verticale de la société: elles produisent des groupes de populations défavorisés. Ce n'est pas un problème en soi, mais c'en est un dans une société civile «bourgeoise» d'aspiration démocratique. Car la consolidation et l'ampleur des discriminations entrent en contradiction fondamentale avec les valeurs démocratiques que l'on peut exprimer par les principes fondamentaux de la liberté, de l'égalité et de la fraternité.

Cette contradiction engendre la «question sociale», la question de la justice sociale. Dans une démocratie, la question de la justice sociale doit être traitée politiquement sur la base des valeurs démocratiques notamment ancrées dans les constitutions démocratiques. Historiquement, deux formes de politique sont significatives pour le développement du travail social: d'une part, la politique d'État et l'émergence de l'assistance publique ou, plus généralement, l'action sociale et l'État-providence. D'autre part, les mouvements sociaux lesquels, à partir de la contradiction fondamentale, transforment les expressions du problème d'intégration en des problèmes sociaux dans les discours publics et dans les processus législatifs. Ces processus politiques progressifs dans le contexte des sociétés modernes, qui tendent vers une résolution rationnelle des problèmes, ont permis l'émergence de la profession et, dans son sillage, de la science du travail social.

Le travail social se forme donc en rapport avec les valeurs démocratiques. Le fait qu'il se réfère fondamentalement aux principes fondateurs de la démocratie n'est donc pas une coïncidence. En tant que système social fonctionnel, il est chargé du traitement pratique des conséquences des inégalités sociales. À un autre niveau, basé sur les mêmes valeurs fondamentales de la démocratie, le travail social est pensé comme une "profession des droits humains ». Les droits humains constituent une référence possible pour le développement des objectifs professionnels du travail social si l'on envisage les droits humains comme une forme juridiquement codifiée de protection de personnes potentiellement vulnérables mais dotées d'une dignité inviolable, et qu'il s'agit de protéger les personnes contre les conditions structurelles de la société. Une autre approche qui nourrit actuellement le travail social est l'approche par les capabilités (capabilities approach en anglais). Dans cette logique, l'objectif reste celui de développer des repères en matière de politique sociale et de travail social permettant de mettre en œuvre le concept abstrait de justice social. Ainsi, la politique et le travail social pourront viser le développement humain des individus et des communautés.

Les références aux valeurs démocratiques et à la politique sociale montrent clairement que le travail social dépend plus directement des évolutions politiques que d'autres professions. $\mathrm{Au}$ fond, les valeurs démocratiques constituent le cadre normatif pour l'ensemble de la société démocratique. Le débat sur la question sociale constitue donc une «zone de combat» constante dans la société et en particulier dans le système politique. Le travail social doit ainsi développer et affirmer en permanence sa com- 
pétence et la technicité qui en découle. Dans le même temps, son autonomie professionnelle est fortement marquée par les rapports de force politiques et leurs réponses à la question sociale, à savoir favoriser un certain équilibrage social et réduire les inégalités sociales ou vice versa.

La tâche consistant à développer une péréquation sociale, c'est-à-dire d'aider ses semblables et (sauf dans le domaine de la migration) ses concitoyen-ne-s à faire face aux problèmes liés à leur mode de vie et au moins partiellement causé par la société, est extrêmement exigeante. Comme pour toutes les activités complexes qui exigent du professionnalisme, l'élargissement des connaissances spécifiques est un facteur décisif pour le développement présent et futur du travail social. En Suisse, la discipline du travail social a trouvé une place structurelle avec l'introduction des hautes écoles spécialisées. Grâce aux personnes qui y travaillent ainsi qu'aux titulaires des chaires de travail social à l'Université de Fribourg et de pédagogie sociale à l'Université de Zurich, la discipline du travail social a dépassé une «masse critique» et il lui sera désormais possible de faire progresser le développement des connaissances. Au cours des quinze dernières années, la science du travail social en Suisse a connu un véritable boom dans le domaine de la recherche et du développement et des publications qui en découlent. La fondation de la Société suisse de travail social et la création de sa Revue suisse de travail social sont deux éléments constitutifs d'un processus de développement rapide, qui a permis l'admission du travail social à l'Académie suisse des sciences humaines et sociales.

Afin d'assurer, en Suisse, un travail social de qualité orienté sur l'intégration sociale et la résolution des problèmes, le développement continu des connaissances sera décisif. Les connaissances doivent être liées à l'évolution de la pratique du travail social, de sorte qu'une aide appropriée et efficace puisse être apportée dans des situations problématiques toujours plus complexes en matière d'intégration sociale, marquées par des développements transnationaux et globaux, qui constituent un point de référence supplémentaire pour le travail social d'aujourd'hui.

\section{Peter Sommerfeld}

\section{Références}

Nussbaum, M. (2012). Capabilités: comment créer les conditions d'un monde plus juste? Paris : Flammorion.

Sommerfeld, P., Hollenstein, L. \& Calzaferri, R. (2011). Integration und Lebensführung: Ein forschungsgestützter Beitrag zur Theoriebildung der Sozialen Arbeit. Wiesbaden: VS.

Staub-Bernasconi, S. (2018). Soziale Arbeit und Menschenrechte: Vom beruflichen Doppelmandat zum professionellen Tripelmandat. Leverkusen: Barbara Budrich.

\section{Travail social (histoire)*}

L'industrialisation, au XIX ${ }^{\mathrm{e}}$ siècle, fut productrice d'inégalité sociale. Depuis, la politique sociale suisse s'est employée à établir l'équilibre selon des principes de justice sociale âprement débattus dans l'arène politique. Pour le travail social, en tant que profession, un lien s'avère alors comme particulièrement important: Vers 1900, le développement du système de sécurité sociale au niveau fédéral marquant un ralentissement, les acteur.trice-s du travail social émergent se tournent alors vers les communes. Elles et ils professionnalisent l'assistance sociale, jusqu'alors organisée par le privé, et mettent en place des offres publiques, d'abord dans les villes industrielles. Dans le cadre de l'aide sociale communale, les travailleur-euse-s sociaux-ales sont en contact direct avec les bénéficiaires. D'un côté, en tant qu'ils agissent sur mandat d'une institution qui exige un engagement efficient des moyens, ils sont censés, implicitement, contrôler le comporte- 
ment des bénéficiaires, de l'autre, ils doivent aider ceux-ci à vivre de manière autodéterminée.

D'un point de vue historique, le champ d'action du travail social est caractérisé par ce rapport tendu entre aide et contrôle. En Suisse, jusqu'aux bouleversements de 1968, le travail social accordait généralement plus de poids au mandat institutionnel qu'à l'objectif d'autodétermination des client.e-s. Ce fut le cas tout spécialement pour l'aide aux pauvres, l'éducation en foyer et le système des tutelles, domaines situés dans un contexte de contrainte, réglementé par la loi. Un travail social critique, politiquement engagé, soucieux de faire pencher les conditions-cadre sociétales vers une plus grande justice sociale, était alors marginal en Suisse, et donc marginale aussi l'idée d'une relation à pied d'égalité entre travailleur·euse-s sociaux-ales et personnes concernées.

Le thème de la relation entre les personnes qui donnent et celles qui reçoivent a une longue tradition. Au Moyen-Âge, l'assistance relève de l'église et des évêques. Les hôpitaux et les hospices bénéficient de donations et de legs de fidèles qui, à l'occasion de leurs funérailles ou de messes d'anniversaires, font distribuer de l'argent aux pauvres. Thomas d'Aquin (12241274) est le plus célèbre représentant d'une théorie théologique de l'assistance. Pour lui, l'amour du prochain et l'aumône sont des préceptes religieux et un devoir moral contraignants. Le mouvement piétiste du XIX siècle, arguant lui aussi de l'amour du prochain, prône une intériorisation individuelle de la vie chrétienne et tire de cette conviction religieuse des principes éducatifs qu'il met en œuvre dans des asiles.

Des philanthropes de la veine d'un Henri Pestalozzi, ancrés dans la tradition des Lumières, appellent, eux, à une réforme de la société par l'éducation. Ils sont généralement issus de la bourgeoisie détentrice de biens et savante, produits de l'industrialisation. Le grand nombre de sociétés fondées à cette époque reflète l'importance de la philanthropie au XIX siècle. Mentionnons la Société suisse d'utilité publique, fondée en 1810 à Zurich dans le but de promouvoir le bien commun spirituel et matériel, et la Société d'utilité publique des femmes suisses, créée en 1888. Au niveau local, des sociétés de secours et des associations de femmes s'attaquent à ce qu'elles appellent la «question sociale», à savoir les problèmes de la classe ouvrière générés par l'industrialisation fulgurante. Les associations de femmes bourgeoises défendent une répartition traditionnelle des rôles - l'homme au travail, la femme au foyer - dans une action philanthropique à caractère moralisateur.

Sur toile de fond de l'idéal bourgeois de la distribution des rôles entre femmes et hommes, les premières travailleuses sociales après 1900 donnent une nouvelle clé de lecture de l'assistance avec l'idée de la «maternité sociale». Les femmes, tel leur argument, sont empathiques de nature et donc bien disposées envers autrui. À cette idée de «maternité sociale», elles associent une stratégie d'émancipation. L'effet est ambivalent: si des femmes bourgeoises célibataires peuvent désormais exercer une activité professionnelle, leur champ d'action demeure limité à des domaines réputés correspondre à leur nature de femme, comme la protection de l'enfance. Les postes prestigieux et mieux payés, par exemple celui de secrétaire de la jeunesse ou de tuteur officiel, sont réservés à des juristes masculins, alors que les premières travailleuses sociales occupent des emplois subalternes. En outre, l'attachement à la représentation bourgeoise des rôles masculin et féminin a des effets normatifs sur les client·e-s, $\mathrm{du}$ fait que les mères ouvrières et les pères ouvriers de la classe inférieure ne peuvent ou ne veulent pas correspondre aux impératifs comportementaux liés au modèle de l'homme nourricier et de la femme au foyer. Les femmes bourgeoises ne sont guère capables, à l'époque, de réagir aux réalités des personnes concernées avec des méthodes professionnelles adéquates 
et se rabattent sur leurs valeurs morales dans le traitement des cas sociaux.

Par voie de conséquence, la génération de savoir dans le travail social en Suisse en est restée à un stade préscientifique jusque dans un $\mathrm{XX}^{\mathrm{e}}$ siècle bien avancé. La pratique demeure empreinte de paternalisme et centré sur le contrôle de comportement des clients. Dans les écoles de travail social aussi, la proximité à la pratique est, au début, davantage considérée que le savoir théorique. Ajoutons à cela que les travailleuses et travailleurs sociaux-ales ne participent guère aux débats de fond menés lors de congrès de politique sociale et relayés dans la presse spécialisée - la parole est aux juristes, aux médecins et aux pédagogues.

Après 1945, la conviction fait son chemin dans les pays d'Europe occidentale que l'État social doit jouer un rôle de pacificateur. On problématise la mainmise disciplinaire sur les clients. En postulant le respect de la dignité humaine dans le domaine du travail social, l'ONU lance une réflexion sur des interventions fondées sur la théorie et sur des valeurs éthiques. Dans le cadre de cette réflexion, la méthode du casework, développée aux ÉtatsUnis par Mary Richmond, est progressivement adoptée en Suisse. Le casework réforme l'aide individuelle classique en combinant le processus d'évaluation avec un plan d'intervention conçu, dans l'idéal, en collaboration avec les client·e.s. Pour la première fois, des représentantes des écoles de travail social participent à des débats sur la politique sociale.

Depuis les années 1960, la formation et la pratique dans le domaine du travail social adoptent de manière accrue des éléments du travail communautaire, avec un accent fort sur l'intégration culturelle - méthodes prônées et pratiquées des décennies auparavant déjà dans l'espace anglophone, notamment dans le settlement movement. Plus récemment, l'activité de conseil a augmenté dans de nouveaux lieux d'intervention, par exemple l'école. L'autocompréhension du travail social a également changé : d'abord compris comme expression de l'amour du prochain, puis au sens de la maternité sociale, le travail social se charge bientôt d'une fonction normalisante, fonction qu'il cherche à dépasser depuis les années 1980 en axant ses interventions sur les réalités, les droits de la personne et les droits sociaux, au travers de théories d'émancipation.

\section{Nadja Ramsauer}

\section{Références}

Hering, S. \& Waaldijk, B. (Eds.) (2003). History of social work in Europe (1900-1960): female pioneers and their influence on the development of international social organizations. Opladen: Leske + Budrich.

Matter, S. (2011). Der Armut auf den Leib rücken: Die Professionalisierung der Sozialen Arbeit in der Schweiz, 1900-1960. Zürich: Chronos.

\section{Travail social en milieu scolaire*}

En Suisse, le travail social en milieu scolaire désigne une forme d'aide aux enfants et à la jeunesse offerte directement dans les établissements scolaires. Selon les principes de la justice sociale, des professionnel-le-s du secteur social offrent des services d'assistance et d'éducation (notamment, par des conseils, des projets, des travaux de groupe) pour aider les enfants et les jeunes en ce qui concerne leur vécu et qui rencontrent des problèmes psychosociaux. En outre, ils participent activement aux processus de développement scolaire (p.ex. création d'un parlement des élèves; mesures d'amélioration de la culture de dialogue des établissements). Les prestations de travail social en milieu scolaire reposent généralement sur la coopération avec les professionnel-le.s et les services scolaires et extrascolaires.

En Suisse, le travail social en milieu scolaire peut prendre des formes très variées. Le volontariat, l'accessibilité, la discrétion, la 
confidentialité, le travail relationnel, les activités de plaidoyer ainsi que le sens du service et orienté sur le sujet constituent en de nombreux endroits des règles de conduite essentielles et sont considérés dans le discours spécialisé comme des conditions d'efficacité importantes pour le travail social en milieu scolaire. Le travail social en milieu scolaire joue un rôle particulier dans le domaine de l'aide aux enfants et à la jeunesse, car il fait partie non seulement des champs de compétences qui croissent le plus rapidement, mais il constitue aussi la prestation sociale les plus facilement accessible à la plupart des adolescent·e.s en Suisse, qui peuvent y recourir sans devoir passer par des tiers (p.ex. les parents, les services spécialisés), de surcroît gratuitement.

Des années 1960 à la fin des années 1990, le travail social en milieu scolaire était peu répandu. Mais, par la suite, l'offre s'est rapidement développée. La partie francophone du canton du Valais et le Tessin font exception : à la place du travail social en milieu scolaire, on y trouve des possibilités de médiation scolaire ou un système de professeur.e-s de confiance (docente mediatore). Les circonstances dans lesquelles on a introduit le travail social en milieu scolaire varient. Ainsi, selon les endroits, celui-ci a été introduit afin de répondre aux situations difficiles en salle de classe causées par les élèves présentant des troubles de comportement, mais il a parfois aussi été lancé par l'aide aux enfants et à la jeunesse afin de fournir aux écoles des solutions de soutien à bas seuil plus nombreuses. Sous l'influence des structures fédérales, diverses implantations de travail social en milieu scolaire se sont développées indépendamment les unes des autres et de manière non systématique, la plupart du temps en ne suivant aucune stratégie cantonale. Si l'on compare les différentes régions, on peut constater que le travail social en milieu scolaire est plus répandu en Suisse alémanique. En fonction de la région (linguistique, rurale, urbaine) dans laquelle ils gran- dissent, les enfants et les adolescent.e-s disposent de possibilités d'accès différentes, tant au niveau qualitatif que quantitatif, au travail social en milieu scolaire. Depuis 2005 environ, on entend de plus en plus de discours de spécialistes du travail social en milieu scolaire qui, en fonction de la région et de la langue, favorisent des conceptions parfois très contrastées de ce qu'est le travail social en milieu scolaire et donnent des réponses tout à fait différentes à certaines questions techniques. Ces dernières années, on assiste à une mise en réseau interrégionale de plus en plus importante entre les différents acteurs et actrices issus de la pratique, d'associations professionnelles et des hautes écoles, qui fait avancer le développement d'une pratique basée sur la recherche en Suisse ainsi que l'élaboration d'une théorie sur le travail social en milieu scolaire dans l'espace germanophone. En mai 2016, afin de compléter les recommandations-cadres (2004; 2007 et 2010) ainsi que les directives de qualité sur le travail social en milieu scolaire (2010), des lignes directrices du travail social en milieu scolaire ont été publiées en deux langues, grâce à la collaboration d'AvenirSocial et de l'Association du travail social en milieu scolaire (SSAV).

Au niveau du droit, le travail social en milieu scolaire est principalement régi par la législation sociale ou scolaire des cantons, mais il existe dans certains cas des réglementations au niveau des communes. Cependant, parfois, il n'existe tout simplement pas de cadre légal. Sur le plan administratif, le travail social en milieu scolaire est soumis à l'administration scolaire ou à l'administration sociale. Le pouvoir décisionnel et financier repose entre les mains tant des communes que des cantons. Cet état de fait entraîne des différences structurelles importantes entre les cantons, mais aussi au sein de certains d'entre eux, d'une part en ce qui concerne la conception et l'orientation du travail social en milieu scolaire, et d'autre part au niveau des conditions-cadres, notamment 
les ressources humaines, les compétences et les infrastructures.

Dans les milieux spécialisés, il est incontestable que les professionnel-le-s du travail social en milieu scolaire devraient disposer d'une formation initiale tertiaire en travail social (université, haute école spécialisée ou formation comparable), éventuellement complétée par des formations continues dans leur domaine de compétences ou spécifiques à l'offre.

Les particularités nationales sont imputables à la structure spécifique ainsi qu'au profil de l'aide aux enfants et à la jeunesse en Suisse qui n'est régie par aucune législation nationale et donc contraignante. En outre, les différences linguistiques compliquent la compréhension entre professionnel-le-s et cultures ainsi que la mise en réseau suprarégionale du travail social en milieu scolaire suisse. Bien que le Conseil fédéral ait expressément recommandé de développer le travail social en milieu scolaire dans le cadre de sa stratégie globale de lutte contre la pauvreté de 2010, le fédéralisme a eu pour conséquence de créer des structures de pilotage et d'offres de travail social en milieu scolaire différentes dans les 26 cantons, tant sur le plan horizontal que vertical. De ce fait, l'organisation est par exemple différente de ce qui existe en France, où le travail social en milieu scolaire est défini et géré par une autorité centrale. En outre, les organismes responsables privés du secteur, qui sont par exemple courantes en Allemagne, sont rares chez nous. D'autres particularités nationales concernent les missions du travail social en milieu scolaire. La spécificité de celui-ci en Suisse est sa fonction de tri (servir d'intermédiaire, mise en réseau) ainsi que le fait qu'il consiste souvent en des tâches de conseil et de soutien individuel. Les approches qui accordent la priorité au travail social en milieu scolaire ciblé sur l'éducation et les processus de développement de l'école, comme c'est par exemple le cas aux Pays-Bas, sont peu présentes en Suisse, tout comme les méthodes sociospatiales et récréa- tives ou axées sur certains groupes, qui sont par exemple appliquées en Allemagne.

Les défis liés à la consolidation du travail social en milieu scolaire concernent notamment les débats politiques et professionnels relatifs au caractère fondamentalement nécessaire du travail social en milieu scolaire, à la nécessité de conditions-cadres adaptées et à l'orientation du contenu de l'offre. Actuellement, on cherche dans beaucoup d'endroits à régler la question des organismes responsables et du financement, à intégrer le travail social en milieu scolaire (p.ex. dans le cadre des écoles à horaire continu et dans le paysage éducatif) à l'éventail d'offres locales et à concevoir et proposer le travail social en milieu scolaire aux enfants de tous les âges (du jardin d'enfants aux écoles de l'enseignement post-obligatoire) en fonction de leurs besoins. Certains aspirent également à favoriser des mises en réseau professionnels au-delà des régions linguistiques, à étendre le travail social en milieu scolaire et le rendre plus visible, notamment en Suisse romande. En outre, le domaine de travail se caractérise par les évaluations comparativement plus nombreuses de la pratique $\mathrm{du}$ travail social en milieu scolaire. Certain.e.s acteurs et actrices professionnels et politiques critiquent le fait que la diversité du domaine professionnel soulève régulièrement des questions concernant l'existence d'un profil de pratique commun pour le travail social en milieu scolaire et plaident en faveur de la création de critères de qualité différenciés, spécialisés et pertinents.

\section{Sarina Ahmed \& Martina Fischer}

\section{Références}

Avenir Social et l'Association du travail social en milieu scolaire (Éd.) (2016). Lignes directrices $d u$ travail social en milieu scolaire. Berne/Lucerne : AvenirSocial, SSAV. 
Baier, F. \& Deinet, U. (Hrsg.) (2011). Praxisbuch Schulsozialarbeit: Methoden, Haltungen und Handlungsorientierungen für eine professionelle Praxis. Opladen: Verlag Barbara Budrich.

Kottelat, J. (2015). Tournée romande: les travailleurs sociaux sont de plus en plus nombreux en milieu scolaire. ActualitéSociale, 55, 7-8.

\section{Travailleur-euse pauvre}

Il n'y a pas de consensus concernant la définition du phénomène de travailleur.euse pauvre ou de working poor. D’une part se pose la question de définir qui est pauvre dans un pays riche, et de fixer un seuil de pauvreté monétaire. De plus, la pauvreté peut aussi se définir en termes de conditions de vie matérielles, sur la base d'une liste de biens et services, ou sur la base des dépenses de consommation. La deuxième dimension est encore plus problématique, à savoir définir qui est un·e «travailleur.euse». La plupart des définitions fixent un nombre minimal d'heures par semaine, ou de mois par année, ce qui implique que certaines catégories de travailleur.euse-s sont exclu·ess d'emblée de l'analyse, notamment des femmes et des jeunes adultes. Il y a toutefois un point sur lequel ces définitions s'accordent: les working poor sont des individus qui travaillent et qui vivent dans un ménage pauvre.

Alors qu'aux États-Unis la prise de conscience d'une forte augmentation de la pauvreté parmi les personnes actives se fit rapidement dès les années 1980, la recherche européenne continua à se focaliser sur les taux de chômage élevés dans nombre de pays d'Europe continentale jusque dans les années 1990. De fait, il fallut attendre la fin de cette décennie pour que les premières études se focalisant sur les working poor soient publiées. La Suisse n'a pas connu de chômage de masse dans les années 1980, mais plutôt un pic au début des années 1990 qui s'est résorbé dans la deu- xième moitié de la décennie, et le chômage n'a jamais atteint un niveau comparable aux autres pays européens. Cela explique probablement pourquoi les chercheur-euse-s et les autorités suisses ont été parmi les premiers en Europe à aborder explicitement la question des travailleur.euse-s pauvres.

L'outil classique de lutte contre la pauvreté laborieuse est le salaire minimum, qu'il soit fixé dans la loi ou dans le cadre de conventions collectives de travail. En termes de politiques sociales, les premières mesures ciblant spécifiquement les working poor furent développées aux États-Unis et au Royaume-Uni dès les années 1970, sous forme de crédits d'impôts pour travailleur-euse-s. Ces mesures reposent sur la déclaration d'impôts des personnes actives: si le revenu est faible, le-la contribuable est non seulement exonéré.e de payer l'impôt sur le revenu, mais il ou elle peut même recevoir de l'argent des autorités fiscales. Ces crédits d'impôts ont gagné du terrain depuis les années 2000 et ont été introduits en Nouvelle-Zélande, Irlande, Suède, France, Finlande, et dans certaines provinces canadiennes. D’autres pays connaissent différents types de prestations sous conditions d'emploi, comme l'Australie, l'Autriche, le Danemark, le Japon, la Corée du Sud, le Portugal, la Belgique, l'Allemagne, la Finlande et les Pays-Bas. Dans les quatre derniers pays, ces prestations prennent la forme de réduction des cotisations salariales ou d'allègements fiscaux pour personnes actives.

Comme les personnes concernées vivent dans des ménages pauvres, et qu'une partie d'entre elles a des enfants, les politiques familiales peuvent contribuer à réduire le taux de working poor, mais ce ne sont pas des politiques ciblant spécifiquement ce groupe de la population. De même, toute mesure politique soutenant les partenaires non-actifs de working poor peut contribuer à faire diminuer ce risque (assurance-chômage, assurance-invalidité, etc.). 
En termes de politiques sociales, force est de constater que les politiques existantes ne sont guère adaptées à la situation des travailleur-euse pauvres en Suisse. En effet, la plupart des mesures de lutte contre la pauvreté (aide sociale, prestations complémentaires, et diverses autres prestations «sous condition de ressources ») ont surtout été conçues pour soutenir des personnes ne travaillant pas. En particulier, l'aide sociale n'a pas été conçue et n'est pas équipée pour faire face au phénomène de la pauvreté laborieuse. En Suisse, il n'y a pas vraiment de politiques comparables aux prestations sous conditions d'emploi décrites ci-dessus, ni d'ailleurs de salaire minimum légal au niveau national. Une exception notable concerne les prestations complémentaires (PC) pour les familles ciblant explicitement les ménages avec enfants dont les membres travaillent, qui ont été introduites dans les cantons de Genève, Vaud et Soleure. D'autres PC familles existent, mais n'ont pas de condition d'emploi. On pourrait s'étonner du fait que la recherche suisse ait été pionnière au niveau européen, mais que la politique sociale soit si peu adaptée; l'explication se trouve probablement dans le fait que les politiques de lutte contre la pauvreté sont de la responsabilité des cantons ; en outre, il est possible que nombre de responsables politiques locaux ne soient pas informére-s des résultats des recherches effectuées dans ce domaine.

Le principal débat oppose diverses visions de ce qu'une activité salariée doit permettre d'atteindre. Pour certain·e.s, exercer une activité professionnelle doit générer un revenu qui soit suffisant pour ne pas avoir à recevoir d'aides pour boucler ses fins de mois; cela implique aussi que les emplois mal rémunérés ne sont pas souhaitables. En outre, les prestations sous conditions d'emploi décrites plus haut sont perçues comme une subvention publique aux secteurs économiques à bas salaires. L'attrait d'une telle approche est évident puisque le revenu professionnel du ménage est suffisant pour dépasser le seuil de pauvreté. La critique est qu'une telle approche pourrait éliminer beaucoup d'emplois non qualifiés et·ou à faible productivité, ce qui pourrait augmenter le chômage parmi les personnes peu ou pas qualifiées.

D'un autre côté, on trouve l'argument, plus économique, selon lequel une partie des personnes peu ou pas qualifiées et cherchant un emploi ne peuvent guère prétendre à des salaires permettant de boucler les fins de mois aisément, notamment si elles exercent des activités à faible productivité. Ainsi il pourrait être préférable que ces personnes perçoivent un bas salaire complété par des prestations sociales spécialement conçues pour elles, plutôt que d'être sans emploi. Un argument similaire se focalise sur les mouvements migratoires très importants enregistrés dans un passé récent. Une partie de cette population a un faible niveau de formation et une maîtrise limitée des langues parlées en Europe de l'Ouest, et leur intégration sur les marchés du travail européens pourrait passer par des emplois peu rémunérés. On a reproché à ce genre d'approche d'inciter les employeur-euse-s à proposer des salaires toujours plus bas ; par contre, la plupart de ces mesures sous conditions d'emploi ont le mérite de permettre à des personnes mal rémunérées de boucler leurs fins de mois sans devoir se rendre aux services sociaux.

\section{Eric Crettaz}

\section{Références}

Crettaz, E. (2011). Fighting working poverty in post-industrial economies: causes, trade-offs, and policy solutions. Cheltenham: Edward Elgar Publishing.

Crettaz, E. (2013). A state-of-the-art review of working poverty in advanced economies : theoretical models, measurement issues and risk groups. Journal of European Social Policy, 23(4), 347-362.

Kenworthy, L. (2015). Do employment-conditional earnings subsidies work? ImPRovE Working Paper, 15(10), online. http://improve-research.eu/ 


\section{Trois piliers (principe des)}

Le principe des «trois piliers» décrit les trois composantes du système de prévoyance vieillesse suisse, à savoir l'assurance-vieillesse et survivants (AVS, $1^{\text {er }}$ pilier) introduite en 1947, la prévoyance professionnelle organisée par les caisses de pensions et régie par une loi entrée en vigueur en 1985 (LPP, $2^{\mathrm{e}}$ pilier) et, enfin, l'épargne retraite individuelle ( $3^{e}$ pilier) qui a été formalisée à la fin des années 1980 . Chacun des «piliers» repose sur un mode de financement qui lui est propre: si l'AVS est basée sur le principe de la répartition des charges, la LPP et le $3^{\text {e }}$ pilier sont financés par capitalisation. Le poids de chacun des piliers dans les prestations vieillesse est également très différent: $s i$ l'AVS offre des prestations de base à l'ensemble des personnes retraitées, actuellement seuls 4 hommes sur 5, respectivement 2 femmes sur 3 , touchent une rente complémentaire LPP. Enfin, environ un tiers des retraité.e-s touchent une prestation du $3^{\text {e }}$ pilier.

L'AVS organisée par l'État fédéral est introduite en 1947, après plus de trois décennies de controverses politiques autour de sa forme et de son financement. Cet accouchement difficile met en lumière la force des «vétos » institutionnels tels que le fédéralisme ou encore les mécanismes de la démocratie directe (en particulier le référendum) qui ont permis de freiner le développement de la sécurité sociale en Suisse. En parallèle aux controverses relatives à l'AVS, de nombreuses caisses de pension sont créées par des entreprises du secteur public et privé et les grandes compagnies d'assurance vie organisent des contrats d'assurance de groupe. Les institutions de prévoyance qui se développent dès la fin de la Première Guerre mondiale couvrent $22 \%$ de la main-d'œuvre en 1941 (40\% en 1970 et plus de $85 \%$ après 1985 ) et accumulent des réserves considérables (ces dernières représentent déjà $29 \%$ du produit intérieur brut en 1941, $41 \%$ en 1970, plus de $100 \%$ au début du XXI ${ }^{\mathrm{e}}$ siècle). Depuis les années 1920, la définition des frontières et des rôles respectifs dévolus à l'AVS et aux caisses de pension constitue un enjeu central de la politique des retraites et de la structuration du marché de la prévoyance vieillesse.

Après cette période d'émergence, le principe des «trois piliers» s'affirme en Suisse à la fin des années 1960. Cette métaphore ternaire, au cœur de laquelle on retrouve l'idée d'une affiliation obligatoire aux caisses de pension, est défendue en premier lieu par les partis bourgeois, les associations d'employeur-euse-s et les compagnies d'assurance vie. Le principe des «trois piliers» peut être interprété comme une stratégie de ces milieux visant à défendre les caisses de pension, freiner l'expansion de l'AVS, qui ne connaît pas moins de huit révisions entre 1947 et 1973, et contrecarrer les «pensions populaires», projet proposé par l'extrême gauche et visant à étendre le domaine de la répartition au détriment des caisses de pension par capitalisation. De nombreux syndicats ainsi que la direction du Parti socialiste suisse refusent le projet des pensions populaires et proposent à sa place des réformes en profondeur des caisses de pension. À l'issue d'un débat politique passionné, les pensions populaires sont balayées en votation populaire en décembre 1972. Face à l'opposition farouche du patronat, le projet d'une réforme en profondeur des caisses de pension fait long feu.

Inscrit dans la Constitution fédérale en 1972 et réalisé en 1985 par le biais de la LPP, le principe des «trois piliers» introduit l'affiliation obligatoire des personnes salariées aux caisses de pensions existantes. Cet ancrage législatif $\mathrm{du} 2^{\mathrm{e}}$ pilier renforce durablement le poids de la capitalisation comme mode de financement de la prévoyance vieillesse. Par contraste, le niveau des cotisations et des prestations de l'AVS, financée par le système de répartition, est gelé. En complément à la LPP, plusieurs ordonnances introduisent des mesures d'encouragement fiscal pour l'épargne retraite individuelle, le $3^{\text {e }}$ pilier. Ces développements ouvrent la voie 
pour la consolidation des différentes composantes du système des «trois piliers», enjeu central des débats sur les retraites depuis le début du XXI ${ }^{e}$ siècle.

Avant de présenter ces développements, il faut souligner les spécificités du système suisse de prévoyance vieillesse en comparaison internationale. Dans les pays voisins (France, Allemagne, Italie, Autriche), le principe de la répartition joue un rôle prépondérant et les caisses de pension par capitalisation sont soit peu développées ou n'ont connu qu'un développement récent. Par contre, le cas suisse présente des similarités avec les Pays-Bas, les États-Unis ou encore la Grande-Bretagne, pays dans lesquels la retraite par capitalisation joue un rôle important. À l'instar de la situation prévalant en Suisse, l'immense majorité des salarié.e.s néerlandais·es est ainsi affiliée à une caisse de pension. Toutefois, alors que le $2^{\mathrm{e}}$ pilier néerlandais est composé avant tout de quelques douzaines de caisses couvrant des secteurs entiers de l'économie, les caisses de branche jouent un rôle marginal en Suisse en comparaison avec les caisses d'entreprises et les contrats de groupe gérés par les compagnies d'assurance. Cette place centrale des assureurs vie dans la gestion du $2^{\mathrm{e}}$ pilier suisse se retrouve également au Royaume-Uni ou aux États-Unis. Cependant, le cas suisse se démarque de ces deux cas par le caractère obligatoire de la LPP. La doctrine des «piliers» de la retraite désigne également un horizon réformateur popularisé par la Banque mondiale, l'Organisation pour la co-opération et le développement économiques (OCDE) ou encore l'Union européenne, et visant à développer les systèmes professionnels et individuels reposant sur la capitalisation au détriment de la retraite par répartition. Le principe des «trois piliers » de la retraite fait désormais partie du vocabulaire des politiques sociales comparées, domaine de recherche en forte expansion.

Une génération après l'entrée en vigueur de la LPP, l'impact du système des «trois piliers » sur la situation socioéconomique des personnes retraitées fait l'objet d'études encore disparates. Si l'AVS représente une source primordiale de revenus pour plus de la moitié des ménages de retraité·e·s, le taux de remplacement des rentes AVS tourne autour de $35 \%$ des revenus antérieurs. Les prestations de la LPP jouent par conséquent un rôle fondamental, notamment pour les revenus moyens à élevés, afin d'atteindre l'objectif d'un taux de remplacement d'environ $60 \%$. La contribution du $3^{\mathrm{e}}$ pilier à la prévoyance vieillesse demeure marginale : cette épargne individuelle joue avant tout un rôle d'allégement fiscal pour les personnes aisées. Les travaux disponibles soulignent que les personnes âgées disposent en Suisse d'un niveau moyen de revenu élevé. Toutefois, ces moyennes cachent de fortes disparités: les bas salaires, et en particulier les femmes, sont ainsi nettement moins bien couverts par la LPP. Les rentes de l'AVS étant plafonnées, de nombreuses personnes doivent également faire appel aux prestations complémentaires (PC AVS). Au final, le poids grandissant de la capitalisation dans les $2^{\text {e }}$ et $3^{\text {e }}$ piliers réduit les dimensions potentiellement redistributives du système de répartition. Depuis le début du $\mathrm{XXI}^{\mathrm{e}}$ siècle, le vieillissement démographique, les incertitudes de la conjoncture économique, les mutations du monde du travail et l'instabilité financière mettent sous pression l'AVS et la LPP. Les rejets successifs de la $11^{\mathrm{e}}$ révision AVS en 2004, de la baisse du taux de conversion permettant de calculer les rentes LPP en 2010, et d'une réforme combinée des deux premiers piliers en 2017 («Prévoyance $2020 »$ ) soulignent la difficulté structurelle à réformer ce système complexe.

\section{Matthieu Leimgruber}




\section{Références}

Leimgruber, M. (2008). Solidarity without the state: business and the shaping of the Swiss welfare state, 1890-2000. Cambridge : Cambridge University Press.

Leimgruber, M. (2011). The historical roots of a diffusion process : the three-pillar doctrine and European pension debates, 1972-1994. Global Social Policy, 12 (1), 24-44.

Office fédéral des assurances sociales (Éd.) (s.d.). Histoire de la sécurité sociale en Suisse. www. histoiredelasecuritesociale.ch

\section{Vieillissement de la population}

La conscience que les êtres humains vieillissent est aussi ancienne que l'humanité mais l'idée qu'une population puisse vieillir est jeune. Le concept de vieillissement démographique a pris sa forme actuelle en 1928 seulement, élaboré par le démographe français Alfred Sauvy. Il se mesure à travers plusieurs indicateurs, le plus commun étant la proportion des personnes âgées de 65 ans et plus, parfois 60 ans et plus, au sein de l'ensemble de la population. Ceci implique donc l'existence d'un âge à partir duquel les individus sont considérés comme vieux, un tel seuil ne faisant pas consensus, étant par ailleurs susceptible de fluctuer dans le temps et dans l'espace, sans même évoquer la variabilité interindividuelle. Ces débats affectent l'ensemble des mesures: l'indice de renouvellement, qui dans les statistiques officielles suisses est le nombre des 0-19 ans divisé par les 65 ans ou plus, ou le rapport de dépendance qui est un ratio entre les adultes d'âges actifs au dénominateur, les jeunes et les vieux au numérateur. Lorsque seules les personnes âgées sont prises en comptes, on parle de taux de dépendance des âgés. Tous ces indicateurs impliquent de définir un âge à l'entrée et à la sortie de l'âge «adulte» ou «actif». Suite aux changements démographiques récents, de nouveaux indices sont apparus, centrés sur les très vieux: l'indice de grand vieillissement, qui est le ratio entre les 80 ans et plus et les 65-79 ans, ou le taux de sénilité qui correspond au pourcentage des 80 ans et plus. À nouveau, les recherches gérontologiques indiquent que considérer 80 ans comme le seuil d'entrée dans ce qui serait un quatrième âge est une approximation discutable mais l'approche populationnelle passe par le choix de tels seuils.

Le concept de vieillissement démographique a pris forme dans l'entre-deux-guerres dans un contexte de recul de la natalité. De fait, en Suisse comme ailleurs en Europe, le vieillissement de la population a d'abord eu lieu «par le bas », à travers un recul des jeunes situés au bas de la pyramide des âges, entraînant une augmentation uniquement proportionnelle des aîné·e·s. Ce n'est que depuis les années 1970 que s'observe un vieillissement "par le haut», directement attribuable aux progrès de l'espérance de vie. Cette dernière se situait vers 65 ans au milieu des années 1940 et a désormais dépassé les 80 ans (80,8 pour les hommes, 84,9 pour les femmes en 2015). Il en résulte désormais un vieillissement dans le vieillissement, qui se traduit par la progression spectaculaire des octogénaires, nonagénaires et centenaires.

Mais le défi qui se présente à nos portes relève quant à lui d'un effet de structure. En effet, depuis 2005 les premiers baby-boomers atteignent l'âge de la retraite. Ces générations nées entre 1940 et 1964, renforcées par les vagues de migrant·e.s arrivé.e.s après la guerre, forment les classes d'âges les plus nombreuses au sein de la pyramide des âges. Elles accélèrent et vont accélérer le vieillissement de la population. En 2015, 18\% des habitant.e.s du pays ont 65 et plus; le scénario de référence de l'Office fédéral de statistique prévoit $24,5 \%$ en 2035, puis une continuation plus modérée de cette tendance, pour arriver à $26,4 \%$ en 2045. Alors que les 80 ans et plus représentent en $201528 \%$ des retraité-e·s, ils devraient être près de $40 \%$ en 2045.

Si l'on considère les spécificités suisses, elles sont peu apparentes. En termes d'espérance de 
vie, les valeurs helvétiques sont parmi les plus hautes au monde, à peine inférieures à celles du Japon, mais cette position avantageuse ne doit pas être surestimée : tous les pays développés sont proches les uns des autres. Les écarts actuels et à venir sont déterminés avant tout par l'histoire de la fécondité et des migrations au cours des dernières décennies. En considérant les pays voisins de la Confédération, le baby-boom a été général, mais à partir du milieu des années 1960 le nombre d'enfants par femme a profondément chuté en Allemagne et en Italie alors que la France restait proche du seuil de renouvellement des générations (classiquement fixé à 2,1). La Suisse a tenu une position intermédiaire avec bon an mal an 1,5 enfants par femme, mais aussi de forts flux d'immigration qui ont renforcé la population active et dans une certaine mesure la natalité, réduisant de la sorte le vieillissement démographique. L'inscription de cette histoire dans la pyramide des âges de la population résidente en Suisse suggère qu'à l'avenir, elle vieillira plus lentement et moins intensément que ses voisins, sauf la France.

La discussion critique a été entamée dès le début de cette notice en notant la validité toute relative des seuils utilisés pour définir les âges de la vie et délimiter les sous-populations réputées jeunes, adultes, vieilles ou très vieilles. Ils font cependant écho à l'institutionnalisation du parcours de vie, avec en particulier pour ce qui nous concerne ici, l'âge officiel de la retraite à 65 ans. En raison de la montée de l'espérance de vie en bonne santé (ou sans handicap), la question de sa pertinence est de plus en plus posée, un recul de cette transition étant à l'agenda politique en Suisse et déjà décidé par certains de ses voisins. Ces discussions assument que les retraité·e-s sont une charge improductive, une idée qui nous ramène une fois encore au début de cette notice. La formation du concept de vieillissement démographique dans l'entre-deux-guerres a d'emblée été associée à une vision négative de la vieillesse, la déclinant sous les atours de la sénilité et de la dépendance. De manière symptomatique, un indicateur usuel se nomme le taux de dépendance, et son mode de calcul considère que les vieux sont dépendants des adultes et «pèsent» sur eux; cette idée d'être un poids a acquis une valeur commune au point d'être intériorisée par les aîné·e·s eux- et elles-mêmes. Pourtant, le même raisonnement pourrait s'appliquer aux jeunes et que cela n'ait guère été le cas illustre à quel point nos représentations des âges de la vie sont affectées par une tendance à «l'âgisme», un terme apparu en 1968 pour, à l'instar du racisme ou du sexisme, dénoncer la discrimination d'un groupe, ici en fonction de son âge.

Une analyse historique aide à prendre de la distance. Une comparaison de la situation suisse en 1900 et en 2014 montre que le rapport de dépendance des vieux a nettement crû, de 11 à 29. Mais sur la même période, la charge des jeunes est passée de 79 individus de moins de 20 ans pour 100 adultes de 20 à 64 ans, à 33. En termes démo-économiques simples, la structure des âges est aujourd'hui plus favorable, malgré le vieillissement. Mais en 1900, les enfants n'étaient pas une charge puisqu'ils allaient travailler dès 12 ans ou moins, et les pensionné·e-s étaient une petite minorité privilégiée. Les mutations institutionnelles, en particulier dans le système éducatif et celui des assurances sociales, ont construit les enjeux contemporains bien plus que les changements démographiques. Ces derniers apparaissent cependant comme menaçant l'État social en raison du passage à la retraite des générations du baby-boom, qui sera suivie dans quelques années par leur transition vers le grand âge, avec son lot de difficultés. Il ne faut pour autant pas oublier que les vagues massives des baby-boomers ont d'abord envahi un système scolaire qui, loin de craquer, s'est à l'époque étendu et même démocratisé jusqu'à un certain point ; puis ils ont afflué sur le marché de l'emploi, qui les a absorbés sans coup férir. Ce rap- 
pel ne doit pas conduire à nier les défis actuels et futurs pour financer les pensions et assurer à tous et toutes une vieillesse dans la dignité. Cela implique, justement, de considérer la réalité des inégalités sociales à la retraite et dans la vieillesse, inégalités de genre, de statut socioéconomique ou d'origine nationale, que les recherches récentes ont mises en évidence.

\section{Michel Oris}

\section{Références}

Kohli, R. (2015). Les scénarios de l'évolution de la population de la Suisse 2015-2045. Neuchâtel : Office fédéral de la statistique.

Oris, M. \& Remund, A. (2012). Les conditions socioéconomiques et culturelles du vieillissement en Suisse. Sécurité sociale CHSS, 20(4), 203-209.

Wanner, P. (2014). Une Suisse à 10 millions d'habitants: enjeux et débats. Lausanne: Presses polytechniques et universitaires romandes.

\section{Vieillissement des publics vulnérables}

La vulnérabilité s'est imposée comme un terme générique pour désigner une vaste gamme de situations; un certain nombre d'entre elles et les personnes qui en font l'expérience sont l'objet d'un travail de catégorisation et constitués en différents «publics» de politiques et interventions sociales à chaque fois spécifiques: "personnes en situation de handicap », «migrant·e.s», «personnes toxicodépendantes», etc. Or, et c'est une des facettes du vieillissement de la population, pas nécessairement la plus médiatisée ou celle à laquelle on pense en premier, ces publics vieillissent, non sans que cela donne prise, parfois, à la formation de nouvelles catégories spécifiques de l'action publique.

Une première composante de ce vieillissement est l'allongement de la durée de vie, autrefois limitée, de certains de ces publics. Les personnes atteintes d'une incapacité d'ori- gine intellectuelle illustrent particulièrement bien cette évolution: alors que par le passé elles décédaient la plupart du temps jeunes, elles ont aujourd'hui une espérance de vie qui se situe globalement au-delà de l'âge AVS; et s'il faut tenir compte des écarts importants qui existent selon le type de syndromes, le degré de sévérité et l'unicité ou multiplicité de ceux-ci, les personnes présentant un déficit léger ou modéré ont de nos jours une espérance de vie qui se rapproche de celle de l'ensemble de la population. Autre composante, les effectifs des personnes en situation de vulnérabilité qui atteignent l'étape de la «retraite» ou de la «vieillesse» sont en augmentation et constituent une part croissante de la population âgée. Deux exemples: en une trentaine d'années, l'effectif de la population étrangère âgée de 65 ans et plus a été multiplié par quatre, alors que celui pour l'ensemble de la population résidente ne l'a été «que» par un et demi, et aujourd'hui plus d'une personne âgée de 65 ans et plus sur dix est de nationalité étrangère ; durant le même laps de temps, le nombre de personnes soumises à une exécution de peines ou mesures a été multiplié par un facteur de 1,5 , alors que celui des personnes âgées de 65 ans et plus dans le même cas a quintuplé. Cet accroissement quantitatif s'accompagne d'une diversification interne: par exemple, la population migrante vieillissante est de plus en plus composée de personnes venues en Suisse par d'autres canaux (asile, regroupement familial) que celui de la migration de travail «classique»; elle est aussi de plus en plus originaire d'autres régions européennes et du monde que les pays traditionnels de provenance (pays limitrophes et d'Europe du Sud); quant à son arrivée et son installation en Suisse, elles peuvent intervenir à un âge déjà avancé dans le parcours de vie, voire au-delà de l'âge de la retraite; des cas de figure qui se distinguent ainsi de celui plus «traditionnel» des personnes migrantes arrivées jeunes adultes dans le pays «d'accueil» 
et qui poursuivent leur parcours de vie et vieillissent dans celui-ci.

Le vieillissement des publics vulnérables pose de sérieux défis à la politique et action sociales. D'une part, les dispositifs orientés vers ces publics et les professionnel-le-s qui les mettent en œuvre sont confrontés à des «problèmes» et enjeux inédits. Ainsi, la survenue de morbidités associées au vieillissement qui interagissent avec les déficiences ou troubles de santé à l'origine de la situation de vulnérabilité ou découlant de comportements addictifs complexifie tant le diagnostic et les soins à prodiguer que l'accompagnement social ; autre exemple, la retraite des travailleur.euse-s handicapé·e-s a des implications et des significations qui vont au-delà du seul domaine professionnel et constitue une rupture et une épreuve singulière pour les publics concernés, tout en obligeant à repenser des interventions et projets de vie largement orientés vers l'intégration par le travail. Les passages d'un dispositif à l'autre, par exemple entre assurance-invalidité et assurance-vieillesse et survivants, posent aussi de sérieux et délicats problèmes de par les changements de statuts qu'ils impliquent et des modes de prises en charge, types et niveaux de prestations différents selon les dispositifs et qui ne permettent pas toujours, ni automatiquement le maintien des acquis (cas des prestations d'assistance p.ex.). D’autre part, les politiques, dispositifs, procédures et manière de faire «standards » mis en place pour la population âgée «ordinaire» peuvent se révéler en décalage par rapport à ces «nouveaux» publics vieillissants, dont les expériences, les ressources et les besoins sont au moins en partie spécifiques et qui requièrent des interventions adaptées à ces spécificités: ainsi, en va-t-il d'un certain nombre de personnes issues de la migration dont le statut précaire et/ou l'arrivée récente ou encore les difficultés ou manque de compréhension de la langue font obstacle ou rendent plus difficile la connaissance et l'accès aux prestations et droits «ordinaires».
Au cours de la période récente, de très nombreuses initiatives ont vu le jour pour répondre aux défis posés par le vieillissement des publics vulnérables. Deux illustrations: des EMS ont introduit des dispositifs en vue de l'accueil et prise en charge des seniors migrant.e-s; de nouvelles formes d'hébergement et d'accompagnement pour les personnes handicapées retraitées ont vu le jour. Mais relever les défis posés implique aussi un affaiblissement et réaménagement des frontières entre secteurs de l'action publique dans le domaine social et sanitaire, celle-ci s'étant constituée et restant encore largement composées de «mondes sociaux» (Anselm Strauss) plus ou moins autonomes les uns des autres, chacun avec ses professionnel-le-s, ses institutions, ses techniques, ses usager-ère-s, ses savoirs experts (y compris sur le plan académique et scientifique), ainsi que ses cursus et contenus de formation. Initiatives et projets se multiplient dans cette direction. Elles s'accompagnent du développement de collaborations et coopérations entre les professionnel-le-s impliqués; comme de la création d'interfaces professionnelles, capables de soutenir et d'orienter les publics vulnérables vieillissants vis-à-vis des dispositifs et services actifs dans le champ de la vieillesse, ainsi que de permettre à ces derniers de mieux prendre en compte et répondre aux spécificités des publics concernés. Ce mouvement et les innovations qui l'alimentent sont appelés à se développer, ce qui aura aussi des implications pour la formation des (futur.e-s) professionnel-le·s et acteur.trice-s de l'action publique.

$\mathrm{Au}$ niveau de la conception générale de la politique sociale, de sa philosophie pourrait-on dire, les dynamiques évoquées invitent à une convergence au moins partielle des politiques et à coordonner leurs dispositifs, ici ceux de la «vieillesse» avec ceux du «handicap», de la «migration et intégration», des «addictions », etc. Cette convergence et coordination devraient permettre d'assurer un traitement égal selon la situation de vulnérabilité ou le 
besoin à satisfaire, indépendamment de l'âge, de l'origine, du statut ou du parcours des personnes, ainsi que la continuité de l'intervention dans le temps et l'avancée en âge. Une piste pourrait par exemple être de généraliser les mécanismes et prestations des Prestations complémentaires et de ne plus les limiter à certains âges ou situations de vie. Cette exigence d'égalité et de continuité et les dispositifs qui la rendent effectives devraient aller de pair avec l'élaboration de réponses et interventions adaptées et évolutives, en adéquation avec la diversité (croissante) des situations et des parcours.

\section{Jean-François Bickel}

\section{Références}

Delporte, M. (2016). L'épreuve de la retraite en milieu protégé: les travailleurs handicapés dans la fabrique du vieillissement (thèse de doctorat). Université de Lille 3, Lille.

Hungerbühler, H. \& Bisegger, C. (2012). «Alors nous sommes restés...»: les migrantes et les migrants âgés en Suisse. Berne : Commission fédérale pour les questions de migration et Forum national "Âge et migration».

Pilgram, A. \& Seifert, K. (2009). Vivre avec peu de moyens: la pauvreté des personnes âgées en Suisse. Berne: Pro Senectute.

\section{Violences de genre}

Les violences de genre recouvrent une pluralité d'actes, de nature psychologiques, physiques ou sexuels, qui viennent sanctionner des transgressions de l'ordre sexué et permettent de réaffirmer la dimension structurelle des rapports de pouvoir que sont les rapports de genre. Dans cette perspective, les violences de genre recouvrent non seulement les violences faites aux femmes, mais également celles faites aux personnes LBGT ou aux hommes qui ne se conforment pas aux attendus sexués. Inversement, ces mêmes normes engagent à considé- rer que les hommes sont davantage capables de violences, rendant l'usage de la force ou de la contrainte par les femmes à la fois moins tolérable et moins visible.

$\mathrm{Si}$ ces formes de violences ont toujours existé, ce sont les mouvements féministes qui ont contribué à leur reconnaissance et à leur théorisation, en soulignant la large proportion des femmes qui les subissent de la part d'un proche, d'un parent, d'un conjoint ou d'un collègue. Dès les années 1970, les mouvements des femmes ont ainsi imposé le débat sur la scène publique en dénonçant la dimension privée ou individuelle qui était encore trop souvent associée à ce type de brutalités. Ce faisant, ils ont contribué à théoriser les liens qui existent entre les violences conjugales, le harcèlement sexuel au travail, les viols et les agressions sexuelles, en insistant sur la notion de continuum. Cette perspective permet aujourd'hui d'élargir l'analyse à l'exercice des pouvoirs politiques et militaires, où les guerres civiles et les interventions internationales s'accompagnent des violences spécifiques: viols massifs, prostitution forcée, grossesses forcées, stérilisations forcées, etc.

Toutes ces mobilisations féministes ont permis aux «violences faites aux femmes » d'apparaître comme une catégorie d'action publique et ont donné lieu à des formes d'institutionnalisation de la prévention et de la sanction, qui se circonscrivent principalement autour de la notion de protection des femmes, les études quantitatives en population générale venant confirmer les analyses des militantes féministes et souligner la forte propension pour les femmes d'être victimes d'hommes qu'elles connaissent. Ainsi, en Suisse comme ailleurs, ce sont les violences dans le couple qui font avant tout l'objet de l'attention publique - la Suisse ayant pour spécificité sans doute de favoriser davantage l'équilibre familial, et ce de façon différente selon les cantons.

Le plan d'action de la Suisse pour la mise en œuvre du programme d'action de la quatrième conférence mondiale sur les femmes de Beijing 
(1999) propose toute une gamme de mesures institutionnelles, législatives et préventives, dont la création, en 2003, d'un service "violences domestiques » rattaché au Bureau fédéral de l'égalité, désormais intitulé "domaine violences domestiques». Chargé d'informer le public, il défend une vision centrée sur la prévention (coordination de la prévention entre services sociaux, écoles, police, hôpitaux et administrations) et la qualité de l'accueil. Il coordonne également les services cantonaux d'intervention, regroupés depuis 2008 dans la Conférence latine sur les violences domestiques pour la Romandie et le Tessin, dans la Konferenz der Interventionsstellen, Interventionsprojekte und Fachstellen gegen häusliche Gewalt Schweiz pour la Suisse alémanique et la Zentralschweizer Fachgruppe häusliche Gewalt pour la Suisse centrale. Le paysage institutionnel suisse est ainsi relativement complexe, puisque plusieurs instances cohabitent, engageant une certaine fatigue pour les victimes qui se voient confrontées à une multitude d'acteur-trice-s institutionnel-le·s. Citons pêle-mêle également, la Conférence suisse des déléguées à l'égalité, la Conférence suisse des Offices de liaison de la loi fédérale sur l'aide aux victimes d'infractions centres LAVI, la Fédération Solidarité Femmes de Suisse et du Liechtenstein, les associations de victimes, celles pour les femmes ou les hommes violents, le corps médical, le personnel de la justice, les formateurs et les personnes du monde de l'éducation.

Aujourd'hui, la requalification des violences conjugales en «violence domestique» tend à l'emporter à tous les échelons, malgré les amalgames que cela peut entraîner entre les divers types de violences (entre adultes, envers les enfants, les jeunes, les grands-parents, les personnes handicapées, etc.) et d'auteurs (conjoints, parents, enfants). Ces processus de requalification sont entourés de controverses et de débats, et soulignent la propension familialiste qui distingue la Suisse des autres pays. Une partie des milieux associatifs résistent à cette requalification qui, à leurs yeux, efface la dimension de genre.

En termes législatifs, les violences de genre font l'objet de législations diverses en fonction du cadre dans lequel elles sont perpétrées. Dans la famille, les violences conjugales sont réglementés par le Code pénal suisse (article 123 pour la poursuite des lésions corporelles, article 126 pour les voies de faits réitérés et article 180 pour les menaces), et depuis 2004, elles sont poursuivies d'office et concernent l'ensemble des partenaires, qu'ils et elles soient hétéro- ou homosexuels, marié·e·s, enregistré·e·s ou en simples relations affectives. En outre, depuis 2007 et l'entrée en vigueur d'une norme de protection contre la violence (article $28 \mathrm{~b}$ du Code civil), les tribunaux civils peuvent ordonner l'éloignement du domicile pour le conjoint violent et lui interdire de s'approcher ou de contacter la victime. La pénalisation du viol conjugal (article 190) est effective, quant à elle, depuis 1992. Si dans la première version, le viol entre conjoint n'était poursuivi que sur dépôt de plainte, il est depuis 2004 poursuivi d'office, et ce malgré de nombreuses résistances parmi les parlementaires, révélant un souci profond de ne pas mettre en péril les liens sacrés du mariage. Parallèlement à ces réformes importantes au niveau fédéral, plusieurs cantons ont promulgué des lois et des politiques spécifiques contre les violences domestiques (notamment Genève en 2005, Zurich en 2007 ou encore Vaud en 2009).

En ce qui concerne l'espace public, le viol et l'agression sexuelle font également l'objet de deux articles séparés du Code pénal, qui distingue, spécificité suisse, le viol avec pénétration vaginale (ne concernant donc que les femmes) (article 190) de l'agression sexuelle (article 189). Dans le monde du travail, le harcèlement sexuel est réglementé par le Code des obligations, avec la notion de protection de la personnalité (article 328) et est défini comme une discrimination depuis 1995 par la loi sur l'égalité (article 4). Depuis les années 
1990, le respect des normes européennes et mondiales occasionnera également plusieurs changements législatifs, dont notamment la loi sur l'aide aux victimes d'infractions (LAVI) en 1993, qui protège juridiquement les victimes et impose la mise en place de centres de consultation dans les cantons. Récemment, le champ des personnes protégées par la loi fédérale s'est également élargi à de nouvelles formes de violences, avec la loi interdisant les mutilations génitales (2011) et celle interdisant le mariage forcé (2012).

Ce tournant législatif vers des pratiques considérées comme culturelles est patent du fait que les violences de genre sont au croisement d'une pluralité de rapports de pouvoir. Si la prise en compte des violences envers les femmes a indubitablement contribué à une meilleure reconnaissance de formes de discriminations sexuées, et permis de qualifier comme politiques des pratiques et des logiques trop longtemps considérées comme privées, les critiques post-coloniales viennent aujourd'hui remettre en cause la vision universaliste au cœur du projet féministe occidental. Non seulement, les revendications et les politiques autour de la question des violences participent d'une forme de naturalisation des femmes, comme étant des sujets vulnérables nécessitant davantage de protection, elles tendent surtout à homogénéiser une grande variété d'expériences féminines, pourtant constituées par différents rapports de pouvoir.

\section{Marylène Lieber}

\section{Références}

Abu-Lughod, L. (2013). Do muslim women need saving. Cambridge : Havard University Press.

Gillioz, L., De Puy, J. \& Ducret, V. (1997). Domination et violence envers la femme dans le couple. Lausanne: Payot.

Hanmer, J. \& Maynard, M. (Eds.) (1987). Women, violence and social control. Basingstoke : Macmillan Press.

\section{Vulnérabilité}

En Suisse comme dans les autres pays développés, la lame de fond de l'individualisation, l'accent mis sur la réalisation de soi et la responsabilité personnelle, ont transformé les politiques sociales qui entendent de plus en plus activer, renforcer ou restaurer les ressources des vulnérables pour qu'ils soient aptes à vivre dignement de manière autonome. Cette «psychologisation du social» a fait débat et c'est dans ce cadre que certains auteurs ont violemment dénoncé le concept de vulnérabilité comme déresponsabilisant le collectif et culpabilisant les vulnérables, renvoyés à leurs déficits. Cette discussion est utile, mais elle reste stérile si les termes n'en sont pas dépassés. Le fait est qu'au cours des 20 dernières années, l'intérêt des praticien·ne-s comme des académiques pour la vulnérabilité a explosé, reflétant une montée de la demande sociale pour la comprendre et l'atténuer. Pour y répondre, nous posons deux prémisses. D’abord, la vulnérabilité est intrinsèque au genre humain puisque nous sommes tous et toutes mortel-le.s. La conscience de cette évidence devrait permettre d'utiliser le mot sans stigmatiser des individus ou des groupes. Pour autant, et c'est le deuxième point, il y a différentes formes (p.ex. pauvreté, maladies chroniques, etc.) et degrés (p.ex. pauvreté, précarité, etc.) de vulnérabilité, qui s'inscrivent dans les relations des individus à leur environnement social et institutionnel.

Sur ces bases, nous prônons une approche originale de la vulnérabilité comme un processus dynamique et systémique de ressources accumulées et de stress au cours de la vie. La vulnérabilité est ainsi définie comme un processus de fragilisation et comme un manque de ressources dans un ou plusieurs domaines de vie qui, dans des contextes spécifiques, exposent les individus ou certains groupes à : 1) des conséquences négatives liées à des sources de stress ; 2) une incapacité à faire face de manière efficace à ces stress ; 3) une réduc- 
tion de l'aptitude à récupérer des effets négatifs des stress ou à saisir de nouvelles opportunités dans un délai de temps donné. Cette vision de la vulnérabilité ouvre ce concept à trois perspectives complémentaires dont la pertinence pour les politiques sociales est brièvement discutée ci-après.

La première considère que la vulnérabilité est multidimensionnelle dans le sens où elle est ancrée dans différentes sphères de vie et dans leurs interactions systémiques: biologique (i.e. le bagage génétique, les handicaps, la fragilité des personnes âgées), psychologique (i.e. adaptabilité apprise, quotient intellectuel ou affectif, dépression, identité), sociale (i.e. capital social, accessibilité d'aides et soutiens, conflits). Une telle conception multidimensionnelle systémique et dynamique de la vulnérabilité a des implications pratiques sur l'action des institutions. Elle implique la nécessité de l'interdisciplinarité et de la coordination entre différent.e.s intervenant.e.s pour comprendre et agir sur une vulnérabilité donnée. Une perte d'emploi est ainsi souvent associée à des problèmes de santé, à des origines sociales défavorisées, à leur tour en lien avec une formation insuffisante, voire des problèmes relationnels. Agir uniquement sur une seule sphère risque dès lors de se révéler inefficace ou même parfois contreproductif. L'enjeu pour les politiques cantonales et fédérales est de développer une réflexion inter-départements et interprofessions. Trop souvent, le département des affaires sociales d'un canton travaille de manière indépendante de celui de l'économie ou de la santé. De même, les professionnel-le-s du social sont insuffisamment intégrés en tant que partenaires à pied d'égalité dans des équipes pluridisciplinaires avec des spécialistes de la santé ou de l'emploi. Pour s'en tenir à un exemple: combien de personnes vont régulièrement aux urgences hospitalières alors que leurs besoins sont avant tout sociaux?

La seconde perspective affirme que la vulnérabilité s'ancre à différents niveaux; elle n'est pas qu'une problématique individuelle. Dans son essence, elle se réfère à la relation de l'individu avec son environnement. Les individus vivent dans des groupes (famille, ami-e-s, collègues, etc.) avec qui ils interagissent et sont liés à des institutions (l'État, l'entreprise, etc.) dans une relation d'imbrication systémique. La vulnérabilité est toujours relative à des normes sociales et institutionnelles. Ainsi, être malade et non hypocondriaque, pauvre et non profiteur de l'aide sociale, isolé en souffrance et non misanthrope, tout cela sont des états au sein de processus imbriqués dans des contextes institutionnels et sociaux situés spatialement et temporellement. Dès lors, la définition des ayants droit à une prestation en raison d'une vulnérabilité donnée est toujours relative à un cadre légal et politique. Lorsque les niveaux sont en conflit, typiquement lorsque l'individu s'estime vulnérable et que ses proches et/ou les institutions lui récusent ce statut, cette exclusion peut produire une désaffiliation, l'une comme l'autre étant des formes de vulnérabilité, inscrites dans ce schéma relationnel. La problématique du non-recours à des prestations sociales montre bien que les logiques institutionnelles et individuelles ne se rencontrent pas toujours, notamment par peur de la stigmatisation liée au statut de bénéficiaire de mesure sociale, par les incohérences internes au système des prestations qui mettent en conflit le recours aux aides dans une sphère de vie avec la possibilité de bénéficier de soutien dans un autre domaine, ou par des pratiques plus ou moins assumées par les institutions sociales elles-mêmes pour limiter l'accès à certains droits.

Dans la troisième perspective, la vulnérabilité d'un individu ou d'un groupe n'est pas un état nécessairement donné et défini une fois pour toutes. La vulnérabilité est davantage le résultat dynamique d'un processus qui est susceptible de varier dans le cours de la vie, qui peut être infléchi par l'action des personnes concernées et/ou par le cadre institutionnel 
et socioéconomique qui leur offrira (ou non) des opportunités, qui induira plus ou moins de contraintes et de stress affectant les individus au fil de leurs trajectoires. L'étude des parcours de vie montre que les inégalités entre individus, qu'elles soient d'ordre biologique, psychologique ou social, apparaissent très tôt, parfois dès la conception, et qu'elles ont potentiellement des effets à très long terme, jusque tard dans le parcours de vie. L'épidémiologie a montré par exemple que le poids à la naissance, fortement corrélé avec le statut social de la mère, a des répercussions fortes sur la santé de l'adulte. De même, le niveau d'éducation a des répercussions sur les processus de vieillissement au grand âge. Mais malgré la puissance des effets d'origine (stratification sociale, génétique) et la fréquence de l'héritabilité des statuts sociaux, il ne s'agit pas pour autant de déterminants absolus des parcours de vie qui seraient écrits dès le berceau. Des interventions en milieu scolaire peuvent ainsi partiellement gommer les inégalités sociales, même si la durabilité de leur impact reste à prouver. De même, aider un.e jeune à finir une formation lui assurera des ressources qui vont faire croître ses chances d'insertion professionnelle. Les individu·e-s eux- et elles-mêmes peuvent également, à travers leurs capacités d'agir, créer ou saisir des opportunités pour contrecarrer les effets négatifs d'un départ pénalisé par des déficits de ressources. Les trajectoires complexes de gains et pertes qui s'observent au fil du temps, les cas où les désavantages (ou vulnérabilités) ne s'accumulent pas, où les cercles vicieux sont brisés, documentent le principe de multidirectionnalité des trajectoires de vie. L’observer nécessite souvent mettre en place des dispositifs de suivi long qui restent trop rares, ou à défaut d'évaluer les effets des investissements sociaux à différentes phases de la vie. Par exemple, parmi les chômeur-euse-s qui ont obtenu un travail en passant par un office de l'emploi, combien l'ont gardé 5 ans plus tard? Est-ce que les investissements sociaux doivent être faits le plus vite possible dans le parcours de vie (enfants et jeunes) comme le défendent des expert·ess ou est-ce que certaines interventions sociales, par exemple communautaires, peuvent être bénéfiques à toutes les générations?

En conclusion, la vulnérabilité définie comme une dynamique individuelle et relationnelle inscrite dans le parcours de vie et la trame historique renvoie à des processus multidimensionnels, multiniveaux et multidirectionnels dont la prise en compte est vitale pour une action sociale efficiente. L'exploration de chacune de ces trois perspectives enrichit de jour en jour de nouvelles recherches et applications dans le domaine des politiques sociales. Leur intégration invite à considérer la vulnérabilité comme un processus sur lequel on peut agir à différents moments du parcours de vie, à différents niveaux et dans différents domaines selon des logiques innovantes.

\section{Dario Spini, Laura Bernardi \& Michel Oris}

\section{Références}

Brodiez-Dolino, A. (2015). La vulnérabilité, nouvelle catégorie de l'action publique. Informations sociales, 188, 10-18.

Châtel, V. \& Roy, S. (Éd.) (2008). Penser la vulnérabilité: visages de la fragilisation du social. Québec: Presses de l'Université du Québec.

Spini, D., Bernardi, L. \& Oris, M. (2017). Toward a life course framework for studying vulnerability. Research in Human Development, 14(1), 5-25.

\section{Xénophobie}

Du point de vue étymologique on peut définir la xénophobie comme l'aversion de l'étranger·ère, la peur de l'étranger-ère. Du point de vue des sciences sociales, la xénophobie peut être caractérisée comme le rejet de l'Autre $\mathrm{du}$ fait de sa condition, réelle ou imaginaire, d'étranger-ère, de personne non-nationale. La non-appartenance de l'Autre à la communauté 
politique, justifie ainsi une attitude hostile à son égard et un traitement inégal par rapport à la population nationale.

La logique xénophobe veut faire de la différence national-e/étranger-ère une opposition centrale dans la vie d'une société. Il s'agit d'une logique simpliste et réductrice qui présente de nombreuses similitudes avec le racisme. Dans les deux cas, on dénigre certaines catégories de la population: on considère comme normal de les exclure, de les disqualifier au nom des différences supposées irréductibles. Une différence entre le racisme et la xénophobie réside dans les caractéristiques de celles et ceux qui sont désigné·e-s comme des boucs émissaires : immigré·e-s et «étranger·ère-s » qui, dans le cas du racisme, se réfère à une palette plus large de minorités, y compris des personnes «naturalisées» ou ayant la même nationalité. Une autre différence fondamentale réside dans la légitimité sociale de ces deux phénomènes: alors que les expressions ouvertes de racisme sont condamnées le plus souvent par l'opinion publique et la législation, la xénophobie, du moins dans certaines de ses manifestations, est tolérée, voire accepté par de larges secteurs de la population. Ainsi, par exemple les partis et mouvements qui construisent leur action autour de l'hostilité à l'égard des étranger-ère-s, jouissent d'une large liberté d'expression et sont représentés dans la plupart des parlements européens. Dans certains cas, leurs idées sont reprises, du moins en partie, par d'autres forces du spectre politique et même par les institutions de l'État. Ce phénomène existe dans tous les États européens et aussi ailleurs. Il se manifeste à des degrés divers et avec une intensité variable selon les contextes sociohistoriques et politiques. En Suisse, du fait de ses institutions démocratiques spécifiques (initiative populaire, référendum), la xénophobie peut connaître des expressions publiques plus manifestes mais cela ne signifie pas qu'elle soit nécessairement plus intense qu'ailleurs.
D'un point de vue historique, dans le cas suisse, les tendances xénophobes commencent à s'exprimer de manière plus visible vers la fin du XIX ${ }^{\mathrm{e}}$ siècle. C'est la période de montée des nationalismes et, dans l'espace public, la violence populaire à l'égard des ressortissant·e-s étranger-ère-s se manifeste de manière ouverte, tout comme dans des textes et des discours qui émanent des milieux dirigeants. La Première Guerre mondiale conduit à une centralisation de la politique d'immigration et à une fermeture des frontières vis-à-vis de la population étrangère. Ainsi, en 1917 est créé l'Office central de police des étranger-ère·s qui mène son action restrictive dans un contexte d'hostilité croissante à l'égard de personnes étrangères «perturbatrices ». Dans ce contexte de méfiance à l'égard de la population étrangère sera élaborée la loi sur le séjour et l'établissement des étrangers de 1931 (LSEE). Cette loi légitime la politique restrictive suivie dans les années précédentes et introduit la notion d'Überfremdung comme dimension importante de la politique d'immigration. Il est notamment stipulé dans l'article 16 de la LSEE que le nombre d'étranger-ère-s que la Suisse peut accueillir dépend des intérêts moraux et économiques du pays ainsi que du degré d'Überfremdung. Ce terme, traduit tour à tour en français comme «envahissement par les étranger·ère·s», "altération excessive de l'identité nationale», «emprise étrangère » ou « surpopulation étrangère » marquera l'attitude officielle à l'égard de la population étrangère tout au long du $\mathrm{XX}^{\mathrm{e}}$ siècle, tout d'abord dans l'attitude vis-à-vis des réfugié-e-s lors de la Seconde Guerre mondiale, puis pendant la longue phase d'expansion économique de l'après-guerre et lors des crises successives. La population étrangère apparaît ainsi comme une menace à la stabilité du pays et au consensus national.

Des mouvements xénophobes vont utiliser cet espace politique pour lancer leurs propres initiatives populaires visant à limiter ou à réduire la population étrangère. C'est ainsi que 
de 1965 à nos jours divers mouvements et partis vont lancer plusieurs initiatives qui estiment qu'il y a trop d'immigration ou trop de personnes étrangères en Suisse et visent donc une restriction de leur nombre. La plus connue de ces initiatives a été lancée par l'Action nationale et son seul conseiller national, James Schwarzenbach, en 1967. Elle visait à réduire à $10 \%$ le nombre d'étranger-ère·s par canton, à l'exception de Genève avec $25 \%$. Elle a été rejetée en 1970 par $54 \%$ du suffrage.

D'un point de vue institutionnel, en 1991, dans le but de se rapprocher de l'Union européenne (UE), les autorités vont élaborer une distinction entre les étranger·ère-s «intégrables» sur le marché du travail et les «non intégrables ", à travers le modèle dit des «trois cercles». Celui-ci différencie la main-d'œuvre potentielle en fonction de leur région de provenance. Le premier cercle est composé des ressortissant.e.s de l'UE et de l'Association européenne de libre-échange (AELE) qui pourront bénéficier de la libre circulation des personnes. Le deuxième est intégré par des ressortissant·e-s des États industrialisés tels que le Canada, les États Unis, le Japon qui pourront venir travailler en Suisse selon les besoins de l'économie. Enfin, le troisième cercle, à savoir les ressortissants du reste du monde, qui ne pourront venir travailler en Suisse que de manière exceptionnelle. Ce modèle a été fortement critiqué par la Commission fédérale contre le racisme (CFR), qui a estimé en 1996 dans sa prise de position que «le modèle de trois cercles, avec ses prémisses ethnocentriques exerce un effet discriminatoire à l'égard de certains groupes d'habitants étrangers en Suisse et encourage les préjugés fondés sur l'hostilité à l'étranger et le racisme culturel à l'encontre des personnes appartenant au troisième cercle ou supposées telles». Suite à ces critiques, ce modèle a été remplacé en 1998, par un modèle de deux cercles. En effet, les deuxième et troisième cercles ont été regroupés dans un seul cercle extérieur. La CFR peut ainsi jouer par- fois un rôle modérateur par rapport à certaines mesures institutionnelles, dans les limites du cadre légal et politique helvétique.

Plus récemment, l'hostilité ne se focalise plus exclusivement sur les ressortissant-e-s des pays dits «éloignés», mais également sur les ressortissant.e.s européens. En effet, l'Union démocratique du centre (UDC) a lancé l'initiative «Contre l'immigration de masse» qui vise à gérer de manière autonome la migration, en marge des Accords bilatéraux signés avec l'UE. Il s'agit de fixer des quotas annuels selon les besoins de l'économie «dans le respect du principe de la préférence nationale». Cette initiative a été votée le 9 février 2014 et acceptée par $50,3 \%$ du suffrage et a ouvert une période de relations tendues entre la Suisse et l'UE. Suite à l'interprétation légale de l'initiative faite par le parlement en 2017, ce parti a lancé une nouvelle initiative visant à supprimer la libre circulation en janvier 2018.

En fait, dans le cadre de l'histoire récente de la Suisse, la population étrangère est accusée tour à tour d'être trop nombreuse, de venir prendre le travail aux indigènes, d'être trop différente du point de vue culturel et donc «inassimilable» ou encore de vouloir «abuser» du système social helvétique. Ainsi, la présence des étranger-ère-s pose problème quoi que fassent les personnes en question : tantôt c'est leur nombre, tantôt leur différence, tantôt le fait qu'elles travaillent ou tantôt le fait qu'elles ne travaillent pas et coûtent trop cher à la collectivité. Leur présence est ainsi perçue comme foncièrement illégitime.

Selon le sociologue et anthropologue Andreas Wimmer, il y a un lien entre la constitution de l'État moderne (achevée au début du $\mathrm{XX}^{\mathrm{e}}$ siècle), la solidarité nationale et l'exclusion des Autres. En effet, l'État moderne combine trois dimensions: une communauté imaginaire, une communauté d'intérêts, une bureaucratie nationalisée. Le résultat est que l'État, le territoire, la culture, mais aussi la sécurité sociale apparaissent comme la propriété d'une 
communauté imaginaire rassemblée dans une nation et soutenue par une bureaucratie nationalisée. Si le pacte entre ces acteurs et actrices entre en crise, la xénophobie apparaît comme un appel pour le rétablissement du pacte de solidarité entre la communauté populaire imaginaire et la bureaucratie nationale qui menace de se briser et de conduire certains groupes vers une pente sociale descendante.

Dans ce contexte, le discours anti-étranger n'est pas uniquement un discours psychosocial destiné à conjurer le sort et à se sentir un peu moins impuissant face aux menaces qui pointent à l'horizon. C'est aussi une lutte pour l'obtention de la protection sociale de l'État et la propriété du territoire. Ce qui est en jeu, ce sont des processus qui touchent à la fois à l'identité collective et aux intérêts collectifs. Dès lors, une information précise et des arguments logiques ne suffisent pas à modifier les mentalités. Les enjeux portent sur qui est membre légitime de la communauté, sur qui a des droits et mérite le soutien de la collectivité.

\section{Claudio Bolzman}

\section{Références}

Bolzman, C. (2004). Migration et xénophobie : thèses explicatives et réalité empirique. Dans M. Eckmann \& M. Fleury (Éd.), Racisme(s) et citoyenneté: un outil pour la réflexion et l'action (pp. 25-32). Genève/Zurich : Éditions IES/Fondation pour l'éducation à la tolérance.

Perrenoud, M. (2004). La «surpopulation étrangère», une longue histoire suisse. Dans M. Eckmann \& M. Fleury (Éd.), Racisme(s) et citoyenneté: un outil pour la réflexion et l'action (pp. 85-100). Genève/ Zurich: Éditions IES/Fondation pour l'éducation à la tolérance.

Wimmer, A. (1996). Der Appell an die Nation. Kritische Bemerkungen zu vier Erklärungen von Xenophobie und Rassismus. In H.R. Wicker, J.L. Alber \& C. Bolzman, R. Fibbi, K. Imhof \& A. Wimmer (Hrsg.), Das Fremde in der Gesellschaft: Migration, Ethnizität, Staat (S. 173-198). Zürich: Seismo. 



\section{Thèmes et responsables de rubriques}



Action sociale, Carlo Knöpfel

Addiction, Urs Gerber

Connaissances en matière de politique sociale, Jörg Dittmann

Délinquance, Arnaud Frauenfelder

Droits et lois, Hans-Jakob Mosimann

Éducation, Christian Imdorf

Enfance et jeunesse, Stefan Schnurr

Famille, Marianne Modak

Genre et sexualité, Hélène Martin \& Marta Roca i Escoda

Handicap, Andreas Dummermuth

Logement et territoire, Doris Sfar

Migration, Claudio Bolzman

Pauvreté et inégalités, Michael Nollert

Politique, Silja Häusermann

Politique économique et financière, Spartaco Greppi

Santé et soins, Anna Sax

Sécurité sociale, Jean-Pierre Tabin

Travail, Patrick Emmenegger

Valeurs et idées, Urs Marti

Vieillesse, Jean-François Bickel 



\section{Liste des auteur.e·s}



Abderhalden, Irene, Professeure, Institut de travail social et de santé, Haute école de travail social, FHNW

Achermann, Christin, Professeure en migration, droit et société, Centre de droit des migrations et Laboratoire d'études des processus sociaux, Université de Neuchâtel

Adam, Stefan, Professeur et directeur de l'Institut conseil, coaching et gestion sociale, Haute école de travail social, FHNW

Aeschbach, Susanne, Travailleuse sociale diplômée, prorectrice et directrice de l’École supérieure santé et social, Aarau

Afonso, Alexandre, Professeur de politiques publiques, Université de Leyde, Pays-Bas

Ahmed, Sarina, Collaboratrice scientifique, Institut Aide à l'enfance et à la jeunesse, Haute école de travail social, FHNW

Amarelle, Cesla, Conseillère d'État du Canton de Vaud, professeure de droit public à l’Université de Neuchâtel

Armingeon, Klaus, Professeur, titulaire de la chaire de politique comparée et de politique européenne, Institut de science politique, Université de Berne

Auer, Suzanne, Secrétaire générale, AGILE. $\mathrm{CH}$ - Les organisations de personnes avec handicap

Baumann, Holger, Chercheur-enseignant, Centre de recherche sur l'éthique, Université de Zurich

Baumberger, Petra, Linguiste et médiologue, ancienne secrétaire générale Fachverband Sucht
Baumgartner, Ursina, Infirmière diplômée, professeure en sciences infirmières, rectrice, Careum Département de la santé, membre de la Haute école spécialisée Kalaidos

Beck, Lukas, Urbaniste FSU, responsable de l'aménagement du territoire et de l'urbanisme à l'EBP Zurich

Benelli, Natalie, Collaboratrice scientifique, Haute école de travail social et de la santé Lausanne, HES-SO

Bernardi, Laura, Professeure en sociologie des parcours de vie et en démographie sociale, membre du Conseil de la recherche du Fonds national suisse

Berthod, Marc-Antoine, Professeur et co-doyen, responsable du Laboratoire de recherche santé-social (LaReSS), Haute école de travail social et de la santé Lausanne, HES-SO

Beschorner, Thomas, Professeur et directeur, Institut d'éthique des affaires, Université de Saint-Gall

Besozzi, Claudio, Sociologue, chargé de cours, Institut de droit pénal et de criminologie, Université de Berne

Beyeler, Michelle, Professeure de politique sociale, Département de travail social, Haute école spécialisée bernoise BFH, private-docente, Institut d'études politiques, Université de Zurich

Bickel, Jean-François, Professeur, Haute école de travail social Fribourg, HES-SO 
Biesel, Kay, Professeur en aide à l'enfance et à la jeunesse avec un accent particulier sur la protection de l'enfance, Haute école de travail social, FHNW

Binswanger, Mathias, Professeur d'économie, Haute école de gestion, FHNW

Bischoff, Heike, Directrice de la clinique gériatrique, Hôpital universitaire de Zurich, médecin-cheffe, Clinique universitaire de gériatrie Hôpital Waid Zurich, professeure de gériatrie et de recherche sur le vieillissement, Université de Zurich

Bischofsberger, Iren, Professeure de sciences infirmières et de la gestion des soins, membre de la direction, Careum Département de la santé, membre de la Haute école spécialisée Kalaidos

Bochsler, Yann, Collaborateur scientifique, Haute école de travail social, FHNW

Bodenmann, Patrick, Professeur, médecin chef du département vulnérabilités et médecine sociale, Unisanté, Centre universitaire de médecine générale et santé publique, Lausanne

Bohnet, François, Professeur ordinaire, Faculté de droit, Université de Neuchâtel

Bolzman, Claudio, Professeur honoraire, Haute école de travail social Genève, HES-SO

Bonvin, Jean-Michel, Professeur en politiques sociales et vulnérabilités, Université de Genève

Budowski, Monica, Professeure de sociologie, de politique sociale et de travail social, Université de Fribourg
Bugnon, Géraldine, Sociologue, chercheuse postdoc, Haute école de travail social Genève, HES-SO

Bühlmann, Felix, Professeur en sociologie des parcours de vie, Université de Lausanne

Bürgenmeier, Beat, Professeur honoraire d'économie politique, Université de Genève

Burton-Jeangros, Claudine, Professeure de sociologie, Université de Genève

Caplazi, Alexandra, Professeure, responsable du MAS droit social, Institut pour l'intégration et la participation, Haute école de travail social, FHNW

Carigiet, Erwin, Docteur en droit, expert en droit social, politique sociale et direction d'organisations expertes, ancien directeur du Stadtspital Triemli à Zurich

Caroni, Martina, Professeure de droit public, de droit international et de droit comparé, Université de Lucerne, membre de la Commission fédérale suisse des migrations

Casabianca, Antoine, Economiste, ancien président, Associazione Consumatrici e consumatori della Svizzera Italiana ACSI

Castelli Dransart Dolores, Angela, Professeure, Haute école de travail social Fribourg, HES-SO

Cavalli, Stefano, Professeur, Centre de compétence sur le vieillissement, SUPSI

Champion, Cyrielle, Cheffe de projet et consultante, socialdesign SA

Chastonay, Philippe, Professeur titulaire, Université de Fribourg 
Chollet, Antoine, Maître d'enseignement et de recherche, Institut études politiques, Université de Lausanne

Coullery, Pascal, Professeur de politique sociale et de droit social, Département de travail social, Haute école spécialisée bernoise BFH

Crettaz, Eric, Docteur en administration publique, professeur de politiques sociales, Haute école de travail social Genève, HES-SO

Dahmen, Stephan, Chargé de recherche, Centre de recherche sur l'enfance et la jeunesse, Université de Bielefeld

Degen, Bernard, Historien, collaborateur scientifique, Département d'histoire, Université de Bâle

Delay, Christophe, Professeur de sociologie, Haute école de travail social et de la santé Lausanne, HES-SO

Dembinski, Paul H., Professeur titulaire de la chaire de stratégie et de concurrence internationales, Université de Fribourg, directeur de la Fondation Observatoire de la finance, Genève

Denzler, Stefan, Politologue, directeur adjoint du Centre suisse de coordination pour la recherche en éducation (CSRE), Aarau

Despland, Béatrice, Professeure honoraire, Haute école de travail social et de la santé Lausanne, HES-SO

Dittmann, Jörg, Docteur en sociologie, professeur, Institut pour la planification sociale, le changement organisationnel et le développement urbain, Haute école de travail social, FHNW
Domenig, Claudio, Docteur en droit, médiateur FSM, vice-président APEA du Mittelland méridional

Drilling, Matthias, Géographe, urbaniste MAS EPF, professeur et directeur de l'Institut pour la planification sociale, le changement organisationnel et le développement urbain, Haute école de travail social, FHNW

Duchene-Lacroix, Cédric, Docteur en sociologie, enseignant-chercheur, Université de Bâle

Dupont, Anne-Sylvie, Professeure ordinaire aux Facultés de droit des Universités de Genève et de Neuchâtel

Durrer, Sylvie, Directrice, Bureau fédéral de l'égalité entre femmes et hommes, Département fédéral de l'intérieur

Eckmann, Franziska, Directrice, Infodrog, Centrale nationale de coordination des addictions

Ehrler, Franziska, Rédactrice scientifique, Centre de compétences suisse en sciences sociales FORS

Ehrwein, Céline, Docteure en théologie, professeure d'éthique, Haute École d'Ingénierie et de Gestion du Canton de Vaud, HES-SO, et responsable de formation, ARPIH - École supérieure du domaine social

Emmenegger, Patrick, Professeur d'économie politique comparée et de politique publique, Université de Saint-Gall

Engeli, Isabelle, Professeure de politiques publiques, Université d'Exeter, RoyaumeUni 
Felder, Maxime, Collaborateur scientifique, Laboratoire de sociologie urbaine, EPFL

Felli, Romain, Politologue, Collaborateur personnel de la cheffe du Département des infrastructures et des ressources humaines du Canton de Vaud

Fellmann, Lukas, Collaborateur scientifique, Institut Aide à l'enfance et à la jeunesse, Haute école de travail social, FHNW

Felouzis, Georges, Professeur en sciences de l'éducation, Université de Genève

Ferreira, Cristina, Sociologue, professeure, Haute École de santé Vaud (HESAV), HES-SO

Fibbi, Rosita, Sociologue, senior researcher, Forum suisse pour l'étude des migrations et de la population, Université de Neuchâtel

Fischer, Martina, Collaboratrice scientifique, Institut Aide à l'enfance et à la jeunesse, Haute école de travail social, FHNW

Flückiger, Yves, Professeur d'économie, recteur de l’Université de Genève

Fluder, Robert, Professeur, Département de travail social, Haute École spécialisée bernoise $\mathrm{BFH}$

Földhazi, Agnès, Docteure en sociologie, maîtresse d'enseignement HES, Haute école de travail social Genève, HES-SO

Frauenfelder, Arnaud, Professeur, Haute école de travail social Genève, HES-SO

Fredrich, Bettina, Docteure en géographie, secrétaire exécutive de la Commission fédérale pour les questions féminines
Friedmann, Anouk, Directrice, Direction générale de la cohésion sociale, Direction des aides et assurances sociales, Département de la santé et de l'action sociale du Canton de Vaud

Fuchs, Manuel, Collaborateur scientifique, Institut Aide à l'enfance et à la jeunesse, Haute école de travail social, FHNW

Gandolfi, Alberto, Professeur de gestion et d'organisation, Centre de compétences en management et entrepreneuriat, SUPSI

Garlepp, Stephanie, Médecin, présidente Swiss Association of Rehabilitation SAR

Gerber, Urs, Psychothérapeute, professeur, Institut de travail social et de santé, Haute école de travail social, FHNW

Gerodetti, Julia, Collaboratrice scientifique, Institut Aide à l'enfance et à la jeunesse, Haute École de travail social, FHNW

Gianni, Matteo, Professeur, Département de science politique et relations internationales, Université de Genève

Giauque, David, Professeur de sociologie des organisations et des administrations publiques, Institut d'études politiques, historiques et internationales (IEPHI), Université de Lausanne

Glaser, Marie, Ethnologue, directrice ETH Wohnforum, ETH CASE Centre for Research on Architecture, Society \& the Built Environment, Département d'architecture, EPFZ

Gobet, Pierre, Sociologue, professeur, Haute école de travail social et de la santé Lausanne, HES-SO 
Golay, Dominique, Professeure, Haute école de travail social et de la santé Lausanne, HES-SO

Grand, Olivier, Responsable du domaine travail social, HES-SO, ancien secrétaire général d'Avenir Social

Greppi, Spartaco, Professeur et responsable du Centre de compétences travail, welfare et société, SUPSI

Hadjar, Andreas, Professeur en sociologie de l'éducation, Institute of Education and Society, Université de Luxembourg

Haefeli, Bettina, Cheffe de projet, Info-Entraide Suisse

Hainard, François, Professeur honoraire de sociologie, Université de Neuchâtel

Häusermann, Silja, Professeure, titulaire de la chaire de politique suisse et d'économie politique comparée, Institut d'études politiques, Université de Zurich

Heeg, Rahel, Docteure en sociologie, collaboratrice scientifique, Institut Aide à l'enfance et à la jeunesse, Haute école de travail social, FHNW

Hess-Klein, Caroline, Responsable de l'égalité, Inclusion Handicap, chargée de cours, Faculté de droit, Université de Bâle

Holten, Karin von, Chercheuse senior, Careum Département de la santé, membre de la Haute école spécialisée Kalaidos

Höpflinger, François, Professeur titulaire émérite de sociologie, Centre de gérontologie, Université de Zurich
Hostettler, Ueli, Anthropologue social, privat-docent, directeur du Prison Research Group, Institut de droit pénal et de criminologie, Université de Berne

Husi, Gregor, Docteur en sociologie, professeur, Haute école de Lucerne, Travail social

Imdorf, Christian, Professeur en sociologie de l'éducation, Université Leibniz de Hanovre, Allemagne

Jaquier, Véronique, Cheffe de projet et chargée de cours, Universités de Neuchâtel et de Lausanne

Jeannin, Pascal, Avocat et doctorant en droit, Université de Neuchâtel

Juelich, Tanja, Assistante de recherche, Centre de droit social, ZHAW School of Management and Law

Kätterer, Christian, Médecin-chef neurologie, ancien président de la Société suisse neurorééducation, Rehab Bâle SA

Kehrli, Christin, Directrice Freiraum Rifferswil, ancienne responsable secteur études, Conférence suisse des institutions d'action sociale

Keller, Véréna, Professeure honoraire, Haute école de travail social et de la santé Lausanne, HES-SO

Kempeneers, Pierre, Adjoint scientifique, Institut de démographie et socioéconomie, Université de Genève

Knobloch, Ulrike, Professeure d'économie et de genre, Université de Vechta, Allemagne 
Knöpfel, Carlo, Professeur de politique sociale et travail social, Haute école de travail social, FHNW

Knupfer, Caroline, Sociologue, adjointe à la politique sociale et à la formation, Direction générale de la cohésion sociale, Département de la santé et de l'action sociale du Canton de Vaud

Knüsel, René, Professeur honoraire de politique sociale, Université de Lausanne

Koch, Martina, Docteure en sociologie, collaboratrice scientifique, Haute école de travail social, FHNW

Koch, Uwe, Avocat, professeur en assurances sociales et politique sociale, Institut pour la diversité et la participation sociale, ZHAW Travail social

Kraus, Karin, Professeure et directrice, Institut de formation continue et de conseil, Haute école pédagogique FHNW

Krebs, Marcel, Sociologue, travailleur social, collaborateur scientifique, Institut de travail social et de santé FHNW, collaborateur scientifique chez Infodrog, Centrale nationale de coordination des addictions

Kuhn, André, Professeur de droit pénal et de criminologie aux Universités de Neuchâtel et de Genève

Kunz, Karl-Ludwig, Professeur émérite de droit pénal et de criminologie, Université de Berne

Künzi, Kilian, Sociologue/historien économique, membre de la direction et associé du Büro für arbeits- und sozialpolitische Studien BASS, Berne
Kurt, Stefanie, Docteure en droit, professeure, HES-SO / Valais-Wallis, Haute école de travail social

Le Goff, Jean-Marie, Sociodémographe, maitre d'enseignement et de recherche, Centre de recherche sur les parcours de vie et les inégalités sociales, Université de Lausanne

Leemann, Regula, Professeure, titulaire de la chaire de sociologie de l'éducation, Haute école pédagogique $\mathrm{FHNW}$

Leimgruber, Matthieu, Professeur d'histoire contemporaine et d'histoire suisse, Université de Zurich

Lengwiler, Martin, Professeur d'histoire générale contemporaine, Université de Bâle

Leuenberger, Simone, Collaboratrice scientifique politique sociale, AGILE.CH, vit depuis 1997 avec une assistance personnelle

Levy, René, Professeur honoraire de sociologie, Université de Lausanne

Licci, Sara, Docteure en droit, professeure, Centre de droit social, ZHAW School of Management and Law

Lieber, Marylène, Professeure en études genre, Université de Genève

Liebig, Brigitte, Professeure de psychologie appliquée, Haute école de psychologie appliquée, FHNW

Losa, Fabio, Development Coordination Officer, Nations-Unies, auparavant chercheur-enseignant, Centre de compétence travail, welfare et société, SUPSI 
Lucas, Barbara, Professeure, Haute école de travail social Genève, HES-SO

Mach, André, Professeur, Institut d'études politiques, historiques et internationales, Université de Lausanne

Mäder, Ueli, Professeur de sociologie émérite, Université de Bâle, Haute école de travail social, FHNW

Maeder, Pascal, Responsable de projet scientifique, HES-SO, domaine travail social, responsable du transfert des connaissances au Pôle de recherche national LIVES

Maggiori, Christian, Professeur, Haute école de travail social Fribourg, HES-SO

Magnin, Chantal, Chercheuse-enseignante et cheffe de projets, Institut d'économie d'entreprise et régionale, Haute école de Lucerne, Economie

Mainardi, Michele, Docteur en pédagogie spéciale et inclusive, professeur et responsable du Centre de compétences besoins éducatifs, école et société, SUPSI

Malatesta, Dominique, Professeure, Haute école de travail social et de la santé Lausanne, HES-SO

Manzoni, Patrik, Docteur en sociologie, professeur pour l'étude de la délinquance et de la prévention de la criminalité, ZHAW Travail social

Marazzi, Christian, Professeur, Centre de compétence travail, welfare et société, SUPSI

Martin, Hélène, Professeure, Haute école de travail social et de la santé Lausanne, HES-SO
Martinoni, Mauro, Docteur, expert en éducation spécialisée en Suisse

Massoudi, Koorosh, Maître d'enseignement et de recherche, Institut de psychologie, Université de Lausanne

Mattig, Thomas, Directeur, Promotion Santé Suisse, professeur titulaire, Faculté de médecine, Université de Genève

Messmer, Heinz, Professeur habilité, Institut Aide à l'enfance et à la jeunesse, Haute école de travail social, FHNW

Meuwly, Olivier, Juriste et historien, chef de projet, Statistique Vaud

Meyer, Gil, Professeur honoraire, Haute école de travail social et de la santé Lausanne, HES-SO

Meyer, Matthias, Professeur, responsable du MAS NPPM, Institut de gestion publique et non-profit, Haute école d'économie, FHNW

Meyer, Thomas, Docteur en sociologie, codirecteur de l'étude TREE (Transition de la formation initiale à la vie active), Université de Berne

Modak, Marianne, Professeure honoraire, Haute école de travail social et de la santé Lausanne, HES-SO

Mösch Payot, Peter, Professeur de droit social, Haute école de Lucerne, Travail social

Muders, Sebastian, Collaborateur scientifique, Centre de recherche sur l'éthique, Université de Zurich 
Münger, Simone, Professeure de droit, Haute école spécialisée bernoise $\mathrm{BFH}$, juge à temps partiel, tribunal pour enfants et adultes du canton de Berne

Nadai, Eva, Sociologue, professeure, Institut de recherche et de développement de la profession, Haute école de travail social, FHNW

Naguib, Tarek, Avocat spécialisé dans la protection transdisciplinaire contre la discrimination, chercheur associé au Centre de droit social, ZHAW School of Management and Law

Neumann, Sacha, Professeur d'éducation de la petite enfance et d'études sur l'enfance, Integrative Research Unit on Social and Individual Development, Université du Luxembourg

Nielen Garmwisch, Susanne, Travailleuse sociale, directrice du Centre de conseil pour l'aide aux victimes Argovie Soleure

Nollert, Michael, Sociologue, professeur au Département Travail social, politique sociale et développement global, Université de Fribourg

Noti, Odilo, Docteur en théologie, ancien responsable de la communication et du marketing et membre de la direction générale de Caritas Suisse

Odier, Lorraine, Docteure en sciences sociales

Oehler, Patrick, Pédagogue social et docteur en sociologie, professeur, Institut pour la planification sociale, le changement organisationnel et le développement urbain, Haute école de travail social, FHNW
Oesch, Daniel, Professeur de sociologie, Université de Lausanne

Oris, Michel, Professeur de socioéconomie et démographie, Université de Genève

Page, Julie, Professeure, Institut des sciences de la santé, ZHAW Santé

Palazzo, Clothilde, Professeure, HES-SO / Valais-Wallis, Haute école de travail social

Parpan-Blaser, Anne, Travailleuse sociale diplômée, docteure et professeure, Institut pour l'intégration et la participation, Haute école de travail social, FHNW

Paulus, Eric, Professeur honoraire, Haute école de travail social et de la santé Lausanne, HES-SO

Pelizzari, Alessandro, Docteur en sociologie, Directeur de la Haute école de travail social et de santé Lausanne, HES-SO

Perrenoud, Stéphanie, Docteure en droit, chargée d'enseignement, Université de Neuchâtel

Perriard, Anne, Chercheuse postdoc, Haute école de travail social Genève, HES-SO

Pfaffinger, Monika, Professeure de droit privé, de droit des nouvelles technologies et de droit de l'information, Kalaidos Law School, ancienne vice-présidente de la Commission fédérale de coordination des affaires familiales (COFF)

Pfister, Pascal, Chargé de communication, Info-Entraide Suisse

Pichonnaz, David, Docteur en sociologie, professeur, HES-SO / Valais-Wallis, Haute école de travail social 
Piñeiro, Esteban, Docteur en sociologie, professeur, Institut pour la planification sociale, le changement organisationnel et le développement urbain, Haute école de travail social, FHNW

Queloz, Nicolas, Juriste et sociologue, professeur de droit pénal et de criminologie, Faculté de droit, Université de Fribourg

Ragni, Thomas, Économiste, Secrétariat d'État à l'économie

Ramirez, José, Professeur, Haute école de gestion de Genève, HES-SO

Ramsauer, Nadja, Historienne, professeure, Institut pour l'enfance, la jeunesse et la famille, ZHAW Travail social

Regamey, Caroline, Sociologue, chargée de politique et recherche sociales, Centre social protestant Vaud

Rérat, Patrick, Professeur, Institut de géographie et durabilité, Université de Lausanne

Reutlinger, Christian, Géographe social et pédagogue, professeur habilité et directeur de l'Institut pour le travail social et les espaces sociaux (IFSAR), FHS Saint-Gall

Rezny, Tom, Collaborateur de direction Stadtspital Triemli

Richter, Marina, Professeure, HES-SO / Valais-Wallis, Haute école de travail social

Riemer Kafka, Gabriela, Professeure émérite de sécurité sociale et de droit du travail, chargée de cours pour le droit du travail, conseillère juridique, Université de Lucerne
Roca i Escoda, Marta, Maître d'enseignement et de recherche, Faculté des sciences sociales, Université de Lausanne

Rodari, Sophie, Professeure, Haute école en travail social Genève, HES-SO

Rosenstein, Emilie, Maître-assistante, Département de sociologie, Université de Genève

Rossi, Sergio, Professeur de macroéconomie et d'économie monétaire, Université de Fribourg

Rossini, Stéphane, Docteur en sciences sociales, Directeur de l'Office fédéral des assurances sociales

Roulet Schwab, Delphine, Docteure en psychologie, professeure, Haute école de la santé La Source, Lausanne, HES-SO

Salzgeber, Renate, Professeure honoraire, Département travail social, Haute école spécialisée bernoise BFH

Sanchez-Mazas, Margarita, Professeure, Faculté de psychologie et des sciences de l'éducation, Université de Genève

Sax, Anna, Economiste de la santé, Directrice du Département de la santé du Canton de Schaffhouse

Scapozza, Kelly, Assistante, Centre de compétence sur la fiscalité, SUPSI

Schär, Clarissa, Master en sciences de l'éducation et géographie, collaboratrice, Institut Aide à l'enfance et à la jeunesse, Haute école de travail social, FHNW 
Schief, Sebastian, Maitre d'enseignement et de recherche, domaine sociologie, politique sociale, travail social, Université de Fribourg

Schilliger, Sarah, Docteure en sociologie, chargée de cours, Centre études genre, Université de Bâle et Master Social Work, Berlin

Schmid, Peter A., Philosophe, professeur et responsable de filière du Master en travail social, Haute école de Lucerne, Travail social

Schmid, Walter, Avocat, professeur et ancien directeur de la Haute école de Lucerne, Travail social, ancien président de la Conférence suisse des institutions d'action sociale (CSIAS)

Schnurr, Stefan, Pédagogue, professeur et directeur de l'Institut Aide à l'enfance et à la jeunesse, Haute école de travail social, FHNW

Schnyder, Albert, Historien, professeur, Haute école de Lucerne, Economie (auparavant cadre auprès de Caritas Suisse)

Schulz, Kristina, Professeure en histoire contemporaine, Université de Neuchâtel

Seifert, Kurt, Journaliste indépendant

Slavik, Eva, Docteure en droit, professeure en droit social, Centre de droit social, ZHAW School of Management and Law et juge suppléante au Tribunal des assurances sociales du Canton de Zurich

Soguel, Nils, Professeur, titulaire de la chaire de finances publiques, Institut de hautes études en administration publique, Université de Lausanne
Sommerfeld, Peter, Professeur de travail social, Institut de travail social et de santé, Haute école de travail social, FHNW

Spack, Annelyse, Professeure, Haute école de travail social et de la santé Lausanne, HES-SO

Spini, Dario, Professeur en psychologie sociale, directeur du Pôle de recherche national LIVES, Université de Lausanne

Sprumont, Dominique, Professeur, titulaire de la chaire de droit de la santé, Université de Neuchâtel

Stadelmann-Steffen, Isabelle, Professeure de politique comparée, Institut de sciences politiques, Université de Berne

Steiger-Sackmann, Sabine, Avocate, docteure en droit, professeure en droit du travail et des assurances sociales, Centre de droit social, ZHAW School of Management and Law

Steiner, Olivier, Doctorat en sociologie, professeur, Institut Aide à l'enfance et à la jeunesse, Haute école de travail social, FHNW

Stirnimann, Charles, Historien, ancien chef de l'Office des contributions à l'éducation Bâle-Ville, président de la Conférence intercantonale des bourses d'études 20012016 (Concordat des bourses d'études)

Stoecklin, Daniel, Sociologue, professeur, Centre interfacultaire en droits de l'enfant, Université de Genève

Strahm, Rudolf, Dr. h.c., ancien contrôleur fédéral des prix, ancien conseiller national, chargé de cours, Universités de Berne et de Fribourg 
Streckeisen, Peter, Enseignant et chercheur, Institut pour la diversité et la participation sociale, ZHAW Travail social

Strohmeier Navarro Smith, Rahel, Docteure en sciences sociales, professeure, Institut pour la diversité et la participation sociale, ZHAW Travail social

Studer, Annina, Responsable du domaine travail, INSOS Suisse

Studer, Melanie, Avocate, doctorante à la chaire de droit social privé, Université de Bâle

Stüdli, Beat, Doctorant, Département d'histoire, Université de Bâle

Suter, Christian, Professeur de sociologie, Université de Neuchâtel

Tabin, Jean-Pierre, Professeur, Haute école de travail social et de la santé Lausanne, HES-SO

Tanner, Jakob, Professeur émérite d'histoire contemporaine et d'histoire suisse, Université de Zurich

Tecklenburg, Ueli, Sociologue, ancien secrétaire général de la Conférence suisse des institutions d'action sociale, cadre dans les administrations cantonales de Genève et Vaud, retraité

Thalmann, Philippe, Professeur d'économie, directeur du Laboratoire d'économie urbaine et de l'environnement, EPFL

Thomas, Marie-Paule, Sociologue-urbaniste, titulaire d'un doctorat de l'EPFL, directrice de projet senior chez iConsulting
Togni, Carola, Historienne, professeure, Haute école de travail social et de la santé Lausanne, HES-SO

Traub, Andreas, Docteur en droit, greffier du Tribunal fédéral et juge à la Cour d'appel de Bâle-Ville

Tschudi, Daniela, Cheffe adjoint des services sociaux de la ville de Saint-Gall

Valarino, Isabel, Docteure en sciences sociales, collaboratrice de recherche au Service de la recherche en éducation (SRED), Département de l'instruction publique, de la formation et de la jeunesse du Canton de Genève

Vincent Geslin, Stéphanie, Maitresse de conférence, Université Lyon 2, LAET

Voide Crettenand, Gilberte, Responsable du secteur promotion et qualité, SANTÉ SEXUELLE (2009-2019)

Vorpe, Samuele, Enseignant-chercheur, responsable, Centre de compétence sur la fiscalité, SUPSI

Vu, Francis, Docteur en médecine, chef de clinique, Unisanté, Centre universitaire de médecine générale et santé publique, Lausanne

Wanner, Philippe, Professeur de démographie, Institut de démographie et socioéconomie, Université de Genève

Weber-Gobet, Marie-Thérèse, Ancienne conseillère nationale, responsable de la politique sociale de Procap Suisse jusqu'en mai 2017 
Weisser, Jan, Professeur et directeur de l'Institut pour l'éducation spécialisée, Haute école pédagogique, FHNW

Wetzel, Marina, Collaboratrice scientifique, Institut Aide à l'enfance et à la jeunesse, Haute école de travail social, FHNW

Wider, Diana, Juriste et assistante sociale diplômée, professeure à la Haute école de Lucerne, Travail social, secrétaire générale de la Conférence en matière de protection des mineurs et des adultes COPMA

Widmer, Eric D., Professeur de sociologie, Université de Genève, co-directeur du Pôle de recherche national LIVES

Widmer, Frédéric, Docteur en science politique, chef de projet dans l'Administration fédérale

Wirth, Corina, Docteure en neurophysiologie, directrice, Santé publique Suisse

Wüthrich, Bernadette, Collaboratrice scientifique, Institut de conseil, de coaching et de gestion sociale, Haute école de travail social, FHNW

Wyss, Sarah, Directrice Info-Entraide Suisse

Zimmermann, Markus, Professeur titulaire, maître d'enseignement et de recherche en éthique sociale chrétienne, Département de théologie morale et d'éthique, Université de Fribourg

Zimmermann, Nadine, Juriste, Cheffe du Département aide sociale publique du Canton de Zurich
Zwick Monney, Martine, Collaboratrice scientifique, Office fédéral des assurances sociales

Zybach, Ursula, Ingénieure en alimentation, présidente Santé Publique Suisse 


\section{Liste d'institutions en lien avec les politiques sociales (sélection)}





\section{Addictions}

\section{Addiction Suisse}

Avenue Louis-Ruchonnet 14

Case postale 870

1001 Lausanne

https://www.addictionsuisse.ch/

Commission fédérale pour les questions liées aux addictions (CFLA)

Schwarzenburgstrasse 157

3003 Berne

Coordination politique des addictions

c/o polsan

Effingerstrasse 2

3011 Berne

https://www.nas-cpa.ch/

Fachverband Sucht

Weberstrasse 10

8004 Zurich

https://fachverbandsucht.ch/

Groupement romand d'études des addictions (GREA)

Rue Saint-Pierre 3

Case Postale 6319

1002 Lausanne

https://www.grea.ch/

Infodrog

Centrale nationale de coordination

des addictions

Eigerplatz 5

Case postale 460

3000 Berne 14

https://www.infodrog.ch/
Intergroupe parlementaire Politique des addictions, prévention et protection de la jeunesse

c/o GREA - Groupement romand d'études des addictions

Rue St-Pierre 3

Case postale 6319

1003 Lausanne

Intergroupe parlementaire Politique des drogues

GOAL AG für Werbung und Public Relations

Case postale

8450 Andelfingen

\section{Stratégie nationale Addictions}

Division Prévention des maladies non transmissibles (OFSP)

Schwarzenburgstrasse 157

3003 Berne

https://www.bag.admin.ch/bag/fr/home/strategie -und-politik/nationale-gesundheitsstrategien/ strategie-sucht.html

\section{Délinquance}

Commissions des affaires juridiques (CAJ) de l’Assemblée fédérale

Palais du Parlement

3003 Berne

https://www.parlament.ch/fr/organe/commissions/commissions-thematiques/commissions-caj

Conférence des directrices et directeurs des départements cantonaux de justice et police (CCDJP)

Maison des cantons

Speichergasse 6

Case postale

3001 Berne

https://www.kkjpd.ch/ 
Office fédéral de la justice

Bundesrain 20

3003 Berne

https://www.bj.admin.ch/

\section{Swiss RJ Forum}

Forum suisse de justice restaurative

https://www.swissrjforum.ch/

Tribunal fédéral

Cour de droit pénal

Avenue du Tribunal-Fédéral 29

1005 Lausanne

https://www.bger.ch/

\section{Éducation}

Académies suisses des sciences

Maison des Académies

Laupenstrasse 7

Case postale

3001 Berne

http://www.akademien-schweiz.ch/

Centre suisse de coordination pour la recherche en éducation (CSRE)

Entfelderstrasse 61

5000 Aarau

https://www.skbf-csre.ch/

Conférence suisse des directeurs cantonaux

de l'instruction publique (CDIP)

Maison des cantons

Speichergasse 6

Case postale

CH-3001 Berne

http://www.edk.ch/

Éducation privée suisse

Hotelgasse 1

Case postale

3001 Berne

http://www.privateEducation/formationschweiz.

$\mathrm{ch} /$
Fédération des associations de parents

d'élèves du cycle d'orientation (FAPEO)

Rue de Saint-Jean 12

Case postale 708

1211 Genève

https://www.fapeo.ch/

Fédération suisse pour la formation continue (FSEA)

Rue de Genève 88

1004 Lausanne

https://alice.ch/

Intergroupe parlementaire Formation professionnelle (GFP)

Altendorferstrasse 19

9470 Buchs

Intergroupe parlementaire Formation, recherche et innovation

c/o scienceindustries

Case postale

Nordstrasse 15

8021 Zurich

Orientation.ch

Centre suisse de services Formation professionnelle sur mandat des cantons

https://www.orientation.ch/

profunda suisse

Association des professionnels en orientation professionnelle

Burstwiesenstrasse 57

8606 Greifensee

https://www.profunda-suisse.ch/

Secrétariat d'État à la formation, à la recherche et à l'innovation (SEFRI)

Einsteinstrasse 2

3003 Berne

https://www.sbfi.admin.ch/ 
swissuniversities

Secrétariat général

Effingerstrasse 15

Case postale

3001 Berne

https://www.swissuniversities.ch/

Syndicat des enseignants romands (SER)

Avenue de la Gare 40

1920 Martigny

http://www.le-ser.ch/

\section{Famille / enfance et jeunesse}

Association faîtière Familles arc-en-ciel

Rue de la Navigation 36

1201 Genève

https://www.regenbogenfamilien.ch/

Association faîtière suisse pour l'animation (AFAJ)

Enfance et jeunesse en milieu ouvert

Pavillonweg 3

3012 Berne

https://doj.ch/

Association suisse pour la coparentalité

GeCoBi

3000 Berne

https://gecobi.ch/

Commission fédérale pour l'enfance et la jeunesse (CFEJ)

Effingerstrasse 20

3003 Berne

https://www.ekkj.admin.ch/

Commission fédérale pour les questions familiales (COFF)

c/o Office fédéral des assurances sociales (OFAS)

Effingerstrasse 20

3003 Berne

https://www.ekff.admin.ch/
Conférence des cantons en matière de protection des mineurs et des adultes (COPMA)

Secrétariat général

c/o Haute école spécialisée de Lucerne - travail

social

Werftestrasse 1

Case postale 2945

6002 Lucerne

https://www.copma.ch/

Conseil suisse des activités de jeunesse (CSAJ)

Avenue de Beaulieu 9

1004 Lausanne

http://www.sajv.ch/

Fédération suisse des familles monoparen-

tales (FSFM)

Case postale 334

3000 Berne 6

https://svamv.ch/

Formation des Parents Suisse

Steinwiesstrasse 2

8032 Zurich

https://www.formation-des-parents.ch/

Intergroupe parlementaire enfance

et jeunesse

c/o Conseil Suisse des Activités de jeunesse

(CSAJ)

Gerberngasse 39

Case postale 292

3000 Berne

Intergroupe parlementaire Politique familiale c/o Pro Familia Suisse

Marktgasse 36

3011 Berne

Jeune et Médias

Plateforme nationale de promotion des compé-

tences médiatiques

https://www.jeunesetmedias.ch/ 
kibesuisse

Fédération suisse pour l'accueil de jour de l'enfant

Siège central

Josefstrasse 53

8005 Zurich

https://www.kibesuisse.ch/

\author{
Office fédéral du sport OFSPO \\ Jeunesse+Sport \\ Route principale 247 \\ CH-2532 Macolin \\ https://www.jugendundsport.ch/ \\ PACH Pflege- und Adoptivkinder Schweiz \\ Pfingstweidstrasse 16 \\ 8005 Zurich \\ https://pa-ch.ch/
}

Plateforme électronique consacrée à la politique de l'enfance et de la jeunesse

https://www.politiqueenfancejeunesse.ch/

\section{Pro Familia Suisse}

Marktgasse 36

3011 Berne

http://www.profamilia.ch/

Pro Juventute Suisse

Bureau Suisse romande

Place Chauderon 24

1003 Lausanne

https://www.projuventute.ch/

\section{Protection de l'enfance Suisse}

Schlösslistrasse 9a

3008 Berne

https://www.kinderschutz.ch/

Terre des hommes Suisse

Laufenstrasse 12

4018 Bâle

https://www.terredeshommesschweiz.ch/

\section{Finances, argent et impôts}

\author{
Administration fédérale des contributions \\ Eigerstrasse 65 \\ 3003 Berne \\ https://www.estv.admin.ch/
}

\author{
Administration fédérale des finances AFF \\ Bundesgasse 3 \\ 3003 Berne \\ https://www.efv.admin.ch/ \\ Banque nationale suisse \\ Börsenstrasse 15 \\ Case postale \\ 8022 Zurich \\ https://www.snb.ch/
}

Conférence des directrices et directeurs cantonaux des finances

Maison des cantons

Speichergasse 6

Postfach

3001 Berne

https://www.fdk-cdf.ch/

Office fédéral de la statistique (OFS)

Comptes globaux de la protection sociale

Section Analyses sociales

Espace de l'Europe 10

CH-2010 Neuchâtel

https://www.bfs.admin.ch/

\section{Genre et sexualités}

alliance $\mathbf{F}$

Alliance de sociétés féminines suisses

Herrengasse 24

3011 Berne

https://www.alliancef.ch/ 
Bureau fédéral de l'égalité entre femmes et hommes (BFEG)

Schwarztorstrasse 51

3003 Berne

https://www.ebg.admin.ch/

Commission fédérale pour les questions féminines (CFQF)

Schwarztorstrasse 51

3003 Berne

https://www.ekf.admin.ch/

\section{Conférence suisse des délégué·e·s à l'égalité}

Organisation des services et bureaux de l'égalité de la Confédération, des cantons et des villes https://www.equality.ch/

Fédération solidarité femmes de Suisse

Case postale 1357

8031 Zurich

https://www.frauenhaus-schweiz.ch/

\section{GENRE ET SEXUALITÉS CAMPUS Suisse}

Etudes genre, égalité des chances et diversité dans les hautes écoles suisses

https://www.Genre et sexualitéscampus.ch/

\section{Intergroupe parlementaire Femmes}

Waldackerweg 11

8604 Volketswil

\section{MenCare Suisse}

Programme national pour la promotion de l'engagement des pères et de la participation des hommes

Bahnhofstrasse 16

3400 Burgdorf

http://www.mencare.swiss/

\section{Organisation suisse des lesbiennes}

Monbijoustrasse 73

3007 Berne

http://www.organisationlesbienne.ch/

\section{Pink Cross}

Fédération suisse des hommes* gais et bi

Monbijoustrasse 73

Case postale

3001 Berne

https://www.pinkcross.ch/

\section{TransGenre et sexualités Network Switzerland Monbijoustrasse 73 \\ 3007 Berne \\ https://www.tgns.ch/}

\section{Handicap}

AGILE.CH

Les organisations de personnes avec handicap

Effingerstrasse 55

3008 Berne

https://www.agile.ch/

Association Cérébral Suisse

Zuchwilerstrasse 43

4500 Soleure

https://www.vereinigung-cerebral.ch/

Bureau fédéral de l'égalité pour les personnes handicapées (BFEH)

Inselgasse 1

3003 Berne

https://www.edi.admin.ch/

Inclusion Handicap

Association faîtière des organisations suisses de personnes handicapées

Muehlemattstrasse 14a

3007 Berne

https://www.inclusion-handicap.ch/

insieme Suisse

Aarbergergasse 33

Case postale

3001 Berne

https://insieme.ch/ 


\section{INSOS Suisse}

Association de branche nationale des institutions

pour personnes avec handicap

Zieglerstrasse 53

3000 Berne

https://www.insos.ch/

Intergroupe parlementaire pour les questions relatives aux personnes handicapées

c/o Inclusion Handicap

Mühlemattstrasse 14a

3007 Berne

Pro Infirmis

Feldeggstrasse 71

Case postale 1332

8032 Zurich

https://www.proinfirmis.ch/

\section{Pro Mente Sana}

Association romande

Rue des Vollandes 40

1207 Genève

http://www.promentesana.org/

\section{Procap}

Association de et pour personnes avec handicap en Suisse

Frohburgstrasse. 4

Case postale

4601 Olten

https://www.procap.ch/

\section{Laboratoire d'idées}

Avenir Suisse

Chemin de Beau-Rivage 7

1006 Lausanne

https://www.avenir-suisse.ch/

\section{Réseau de réflexion}

Le Thinktank gauche de la Suisse

Case postale

8036 Zurich

http://www.denknetz.ch/

\section{Logement et territoire}

\author{
Association HabitatDurable \\ Bollwerk 35 \\ Case postale 2464 \\ 3001 Berne \\ https://habitatdurable.ch
}

\author{
Association suisse des locataires (ASLOCA) \\ Rue Jean-Jacques-Cart 8 \\ 1006 Lausanne \\ https://www.asloca.ch/
}

\section{Commission fédérale du logement (CFL) \\ Storchengasse 6 \\ 2540 Granges \\ https://www.bwo.admin.ch/bwo/fr/home/ \\ wohnungspolitik/wohnungspolitik-bund/ \\ ekw.html}

\section{Coopératives d'habitation Suisse}

Association romande des maitres d'ouvrage

d'utilité publique

Rte des Plaines-du-Loup 32

Case postale 227

1000 Lausanne 22

www.armoup.ch/

Fédération romande immobilière

Rue du Midi 15

Case postale 5607

1002 Lausanne

https://www.fri.ch/

\author{
Intergroupe parlementaire Développement \\ territorial \\ c/o Schweizerische Vereinigung für Landespla- \\ nung (VLP-ASPAN) \\ Sulgenrain 20 \\ 3007 Berne
}

Intergroupe parlementaire Politique du logement et de l'immobilier

Thurwiesenstrasse 3

8037 Zurich 
Intergroupe parlementaire Propriété immobilière et foncière

Hauseigentümerverband Schweiz Parlamenta-

riergruppe

Seefeldstrasse 60

Postfach

8032 Zurich

\section{LOGEMENT SUISSE}

Association des coopératives de construction

Obergrundstrasse 70

6002 Lucerne

http://www.wohnen-schweiz.ch/

Office fédéral du développement territorial (ARE)

\section{Worblentalstrasse 66}

3063 Ittigen

https://www.are.admin.ch/

Office fédéral du logement (OFL)

Storchengasse 6

2540 Grenchen

https://www.bwo.admin.ch/

Union des villes suisses

Monbijoustrasse 8

Case postale

3001 Berne

https://uniondesvilles.ch/

\section{Médias}

faktuell.ch - Fakten zur schweizerischen

Sozialpolitik

https://www.faktuell.ch/

\section{PANORAMA}

Informations spécialisées pour la formation, l'orientation et le marché du travail

Maison des cantons

Speichergasse 6

Case postale

3001 Berne

https://www.panorama.ch/
Rapport social statistique suisse

Office fédéral de la statistique

Section Analyses sociales

Espace de l'Europe 10

CH-2010 Neuchâtel

https://www.bfs.admin.ch/

\section{REISO}

Revue d'information sociale

Chemin du Cerisier 1

1004 Lausanne

https://www.reiso.org/

\section{Sécurité sociale CHSS}

Plate-forme journalistique de l'Office fédéral des assurances sociales (OFAS)

Effingerstrasse 20

3003 Berne

https://soziale-sicherheit-chss.ch/

sozialinfo.ch

Schwarztorstrasse 26

3007 Berne

https://www.sozialinfo.ch/

SPECTRA - Prévention et promotion de la santé

Office fédéral de la santé publique OFSP

Schwarzenburgstrasse 157

3003 Berne

http://www.spectra-online.ch/

La Vie économique - plateforme de politique économique

Département fédéral de l'économie, de la

formation et de la recherche (DEFR)

Secrétariat d'État à l'économie (SECO)

Holzikofenweg 36

3003 Berne

https://dievolkswirtschaft.ch/ 


\section{Migrations et droits humains}

\author{
Amnesty International \\ Speichergasse 33 \\ 3001 Berne \\ https://www.amnesty.ch/ \\ Centre suisse de compétence pour les droits \\ humains (CSDH) \\ Schanzeneckstrasse 1 \\ Case postale \\ 3001 Berne \\ https://www.skmr.ch/ \\ Commission fédérale contre le racisme (CFR) \\ Inselgasse 1 \\ 3003 Berne \\ http://www.ekr.admin.ch/
}

\section{FIMM Suisse}

Forum pour l'Intégration des Migrantes et des

Migrants (FIMM)

Speichergasse 39

3011 Berne

\section{Humanrights.ch / MERS}

Plateforme d'informations

Hallerstrasse 23

3012 Berne

https://www.humanrights.ch/

Intergroupe parlementaire migrations

Institut für Öffentliches Recht

Schanzeneckstrasse 1

3001 Berne

Intergroupe parlementaire Suisses

de l'étranger

c/o Auslandschweizer-Organisation

Alpenstrasse 26

3006 Berne
Organisation des Suisses de l'étranger (OSE)

Alpenstrasse 26

3006 Berne

https://www.aso.ch/

Organisation suisse d'aide aux réfugiés

(OSAR)

Weyermannsstrasse 10

Case postale

3001 Berne

https://www.osar.ch/

Schweizerischen Konferenz der Fachstellen

für Integration (KoFI)

Geschäftsstelle

Tribschenstrasse 78

6005 Lucerne

http://www.kofi-cosi.ch/

Secrétariat d'État aux migrations (SEM)

Quellenweg 6

3003 Berne-Wabern

https://www.sem.admin.ch/

\section{Pauvreté}

Association romande et tessinoise des institutions d'action sociale (ARTIAS)

Rue des Pêcheurs 8

1400 Yverdon-les-Bains

http://www.artias.ch/

\section{Association Surprise}

Münzgasse 16, 4051 Bâle

Scheibenstrasse 41, 3014 Berne

Kanzleistrasse 107, 8004 Zurich

https://surprise.ngo

\section{ATD Quart Monde}

Centre national

Case postale 16

La Crausa 3

1733 Treyvaux

http://www.quart-monde.ch/ 
Commission fédérale en matière de poursuite et de faillite (CFPF)

Bundesrain 20

3003 Berne

https://www.bj.admin.ch/bj/fr/home/wirtschaft/ schkg/kommission.html

\section{Dettes Conseils Suisse}

Association faîtière des membres des services de conseils en désendettements

Kirchstrasse 11

2540 Grenchen

http://www.schulden.ch/

\section{IG-Sozialhilfe}

Verein zur Verwirklichung der Menschenrechte für Armutsbetroffene in der Schweiz

Gutstrasse 162

8055 Zurich

https://ig-sozialhilfe.ch/

KABBA « Komitee der Arbeitslosen und

Armutsbetroffenen »

Postfach 2584

3001 Berne

https://kabba.ch

Pain pour le prochain

Secrétariat romand

Avenue du Grammont 9

1007 Lausanne

https://painpourleprochain.ch/

\section{Planet 13}

Internetcafé

Klybeckstrasse 60

4057 Bâle

https://planet13.ch

\section{Plateforme contre la pauvreté}

Effingerstrasse 20

3003 Berne

http://www.contre-la-pauvrete.ch/
Table Suisse

Bahnhofplatz 20

3210 Chiètres

https://www.schweizertafel.ch/

\section{Santé et soins}

Aide et soins à domicile Suisse

Effingerstrasse 33

3008 Berne

https://www.spitex.ch/

Association Spitex privée Suisse ASPS

Uferweg 15

3000 Berne

https://www.spitexprivee.swiss/

Association suisse des infirmiers

et infirmières (ASI)

Choisystrasse 1

Case postale 8124

3008 Berne

https://www.sbk.ch/

Conférence nationale suisse des ligues

de la santé

GELIKO

Josefstrasse 92

8005 Zurich

https://www.geliko.ch/

Conférence suisse des directrices et directeurs cantonaux de la santé (CDS)

Maison des Cantons

Speichergasse 6

Case postale

3001 Berne

https://www.gdk-cds.ch/

Croix-Bleue romande

Avenue Gare 31

1022 Chavannes-Renens

http://www.croix-bleue.ch/ 
Croix-Rouge suisse

Case postale

3001 Berne

https://www.redcross.ch/
Office fédéral de la santé publique (OFSP)

Schwarzenburgstrasse 157

3003 Berne

https://www.bag.admin.ch/

\section{CURAVIVA Suisse}

Association de branche des institutions au service des personnes ayant besoin de soutien

Zieglerstrasse 53

Case postale 1003

3000 Berne 4

https://www.curaviva.ch

Dialogue «Politique nationale de la santé» plateforme de la Confédération et des cantons Schwarzenburgstrasse 157

3003 Berne

https://www.bag.admin.ch/bag/fr/home/

strategie-und-politik/nationale-

gesundheitspolitik.html

Fédération suisse des associations professionnelles du domaine de la santé (FSAS)

Secrétariat général

Altenbergstrasse 29

Case postale 686

3000 Berne

https://www.svbg-fsas.ch/

Fédération suisse des psychologues (FSP)

Effingerstrasse 15

3008 Berne

https://www.psychologie.ch/

\section{H+ Les Hôpitaux de Suisse}

Sécrétariat central

Lorrainestrasse $4 \mathrm{~A}$

3013 Berne

https://www.hplus.ch/

\section{Intergroupe parlementaire Soins}

c/o Association Spitex privée Suisse (ASPS)

Uferweg 15

3000 Berne

\section{Santé et soins}

Organisation nationale faîtière du monde du travail en santé (OdASanté)

Secrétariat général

Seilerstrasse 22

3011 Berne

https://www.odasante.ch/

Organisation professionnelle du corps médical suisse FMH

Secrétariat général

Elfenstrasse 18

Case postale 300

3000 Berne

https://www.fmh.ch/

\section{Promotion Santé Suisse}

Avenue de la Gare 52

1003 Lausanne

https://promotionsante.ch

\section{Reha Suisse}

Société suisse de médecine physique et réadaptation (SSMPR)

Sennweidstrasse 46

6312 Steinhausen

https://www.reha-schweiz.ch/

\section{Réseau Santé Psychique Suisse}

Bureau de coordination

c/o Promotion Santé Suisse

Wankdorfallee 5

3014 Berne

https://www.npg-rsp.ch/ 
Santé publique Suisse

Organisation indépendante nationale qui défend le point de vue de la santé publique

Dufourstrasse 30

3005 Berne

https://www.public-health.ch/

\section{SANTÉ SEXUELLE SuisSe}

Rue St-Pierre 2

Case postale 1229

1001 Lausanne

https://www.sante-sexuelle.ch/

\section{santésuisse}

Organisation de la branche de l'assurance-maladie sociale

Römerstrasse 20

4502 Soleure

https://www.santesuisse.ch/

Stiftung Kifa Schweiz

Im Römerquartier 4a

4800 Zofingen

https://www.stiftung-kifa.ch/

\section{Sécurite sociale / Action sociale}

Armée du Salut

Suisse, Autriche \& Hongrie

Laupenstrasse 5

Case postale

3001 Berne

https://www.armeedusalut.ch/

Association suisse de politique sociale (ASPS)

Monbijoustrasse 22

Case postale

3000 Berne

https://www.svsp.ch/

\section{AvenirSocial}

Association professionnelle suisse

du travail social

Geschäftsstelle Schweiz

Schwarztorstrasse 22

Case postale

CH-3001 Berne

https://avenirsocial.ch/

\section{Caritas Suisse}

Adligenswilerstrasse 15

Case postale

CH-6002 Lucerne

https://www.caritas.ch/

Commissions de la sécurité sociale et de la santé publique (CSSS) de l'Assemblé fédérale

Palais du Parlement

3003 Berne

https://www.parlament.ch/fr/organe/com-

missions/commissions-thematiques/commis-

sions-csss

Conférence des directrices et directeurs cantonaux des affaires sociales (CDAS)

Secrétariat général

Speichergasse 6

Case postale

3001 Berne

http://www.sodk.ch

Conférence suisse des institutions d'action sociale (CSIAS)

Monbijoustrasse 22

Case postale

3000 Berne

https://skos.ch/

EPER

Entraide protestante Suisse

Siège romand

Chemin de Bérée $4 \mathrm{~A}$

Case Postale 536

1001 Lausanne

https://www.eper.ch/ 
Initiative des villes pour la politique sociale

c/o Ville de Winterthour, Département des

affaires sociales

Pionierstrasse 7

CH-8403 Winterthour

https://staedteinitiative.ch/

\section{Oeuvre suisse d'entraide ouvrière}

Secrétariat national

Schwarztorstrasse 18

3007 Berne

http://www.sah-schweiz.ch/

Office fédéral des assurances sociales

Effingerstrasse 20

3003 Berne

https://www.bsv.admin.ch/

\section{Secours d'hiver Suisse}

Secrétariat central

Clausiusstrasse 45

8006 Zurich

https://www.winterhilfe.ch/

Société suisse d'utilité publique (SSUP)

Schaffhauserstrasse 7

8042 Zurich

https://www.sgg-ssup.ch/

\section{Tribunal fédéral}

Première et deuxième Cour de droit social

Schweizerhofquai 6

6004 Lucerne

https://www.bger.ch/

Unabhängige Fachstelle für Sozialhilferecht (UFS)

Pflanzschulstrasse 56

8004 Zurich

https://www.sozialhilfeberatung.ch/

\section{Travail}

\author{
Association Workfair 50+ \\ 4000 Bâle \\ http://www.workfair50plus.ch/
}

\author{
Avenir50Plus \\ Verband für Menschen mit und ohne Arbeit \\ Geschäftsstelle Schweiz \\ Hirschmattstrasse 13 \\ 6003 Luzern \\ https://avenir50plus.ch
}

\section{Centre patronal}

Route du Lac 2

1094 Paudex

https://www.centrepatronal.ch/

Conférence des Chefs des départements cantonaux de l'économie publique (CDEP)

Maison des cantons

Speichergasse 6

Case postale

3001 Berne

https://www.vdk.ch/

\section{economiesuisse}

Fédération des entreprises suisses

Carrefour de Rive 1

Case postale 3684

1211 Genève

https://www.economiesuisse.ch/

\section{Employés Suisse}

Organisation faîtière d'employés

Grand-Rue 26

1630 Bulle

https://employes.ch/

Fédération des entreprises romandes

Rue de Saint-Jean 98

Case postale 5278

1211 Genève

http://www.fer-sr.ch/ 


\section{Insertion Suisse}

Antenne en Suisse romande

Rue du Lion d'Or 4

1003 Lausanne

http://www.arbeitsintegrationschweiz.ch/

\section{Intergroupe parlementaire Travail}

Kulturpark

Pfingstweidstrasse 16

8005 Zurich

Secrétariat d'État à l'économie (SECO)

Hozikofenweg 36

3003 Berne

https://www.seco.admin.ch/

SUVA

Fluhmattstrasse 1

6004 Lucerne

https://www.suva.ch/

Travail.Suisse

Hopfenweg 21

Case postale 3119

3001 Berne

https://www.travailsuisse.ch/

Union patronale suisse

Hegibachstrasse 47

Case postale

8032 Zurich

https://www.arbeitgeber.ch/

Union suisse des arts et métiers (USAM)

Schwarztorstrasse 26

Case postale

3001 Berne

https://www.sgv-usam.ch/

Union syndicale suisse (USS)

Monbijoustrasse 61

3007 Berne

https://www.uss.ch/

\section{Vieillesse}

\section{Alzheimer Suisse}

Gurtengasse 3

3011 Berne

https://www.alzheimer-schweiz.ch/

\author{
Association Dignitas \\ Case postale 17 \\ 8127 Forch \\ http://www.dignitas.ch/
}

Conseil suisse des aînés

Hopfenweg 21

3007 Berne

https://ssr-csa.ch/

\section{Exit Suisse romande}

Association suisse pour le Droit de Mourir dans

la Dignité

Rue de Lausanne 56

1202 Genève

https://exit-romandie.ch

Fédération des Associations des retraités et de l'entraide en Suisse (FARES)

3000 Berne

https://vasos.ch/

Fédération suisse des retraités

Route de Lully 73

1470 Lully

http://www.fsr-srv.ch

Forum national «âge et migration »

c/o Croix-Rouge suisse

Werkstrasse 18

3084 Wabern

http://www.alter-migration.ch/

\section{GERONTOLOGIE.CH}

Réseau pour la qualité de vie des personnes âgées

Kirchstrasse 24

3097 Liebefeld

https://www.gerontologie.ch/ 
Intergroupe parlementaire pour les questions

relatives à la vieillesse

c/o Pro Senectute Schweiz

Lavaterstrasse 60

8027 Zurich

Office fédéral des assurances sociales (OFAS)

Domaine de Famille, générations et société

Effingerstrasse 20

3003 Berne

https://www.bsv.admin.ch/bsv/fr/home/ofas/

organisation/fgg.html

\section{Pro Senectute Suisse}

Rue du Simplon 23

1800 Vevey

https://www.prosenectute.ch

Association d'établissements économiquement indépendants pour personnes âgées

Case postale

3001 Berne

http://www.senesuisse.ch/

Unabhängige Beschwerdestelle für das Alter (UBA)

Geschäftsstelle

Malzstrasse 10

8045 Zurich

http://www.uba.ch 
La politique sociale est d'une importance capitale pour la prospérité de la Suisse. Elle façonne les parcours de vie et influence significativement la qualité de vie de la population. La nouvelle édition du Dictionnaire de politique sociale suisse, entièrement revue, apporte un éclairage sur la mise en œuvre, les objectifs et les effets de la politique sociale en Suisse, ainsi que sur son contexte historique, socioéconomique et juridique. Réunissant plus de 250 articles, le dictionnaire porte un regard analytique et critique sur les diverses composantes de la politique sociale, mettant en lumière les spécificités de la politique sociale suisse, ainsi que les besoins d'action et les défis actuels et futurs. Cette vue d'ensemble inédite des politiques sociales suisses fortement marquées par le fédéralisme est dressée par des expert·ess provenant de trois des quatre régions linguistiques du pays, actifs dans la recherche, l'administration publique et la société civile. Rédigé dans une langue accessible et basé sur des constats étayés par la recherche et la pratique, le dictionnaire fournit tant aux spécialistes qu'au grand public des connaissances de base en matière de politique sociale.

Jean-Michel Bonvin, professeur en politique sociale à l'Université de Genève (UNIGE). Valérie Hugentobler, professeure à la Haute école de travail social et de santé (HETSL) à Lausanne. Carlo Knöpfel, professeur en politique sociale et travail social à la Haute école spécialisée du nord-ouest de la Suisse (FHNW). Pascal Maeder, responsable de projet scientifique à la Haute école spécialisée de Suisse occidentale (HES-SO) et responsable du transfert de connaissances au Pôle de recherche national LIVES. Ueli Tecklenburg, ancien secrétaire général de la Conférence suisse des institutions d'action sociale (CSIAS). 